P U B L I CATION S R O M N E S E F R A N ÇA I S E fondées par Mario Roques, aujourd'hui dirigées par JeAn-René Valette

CCLXXIII

GÉRALDINE TONIUTTI

\title{
LES DERNIERS VERS \\ DU ROMAN ARTHURIEN
}

Trajectoire d'un genre,

anachronisme d'une forme

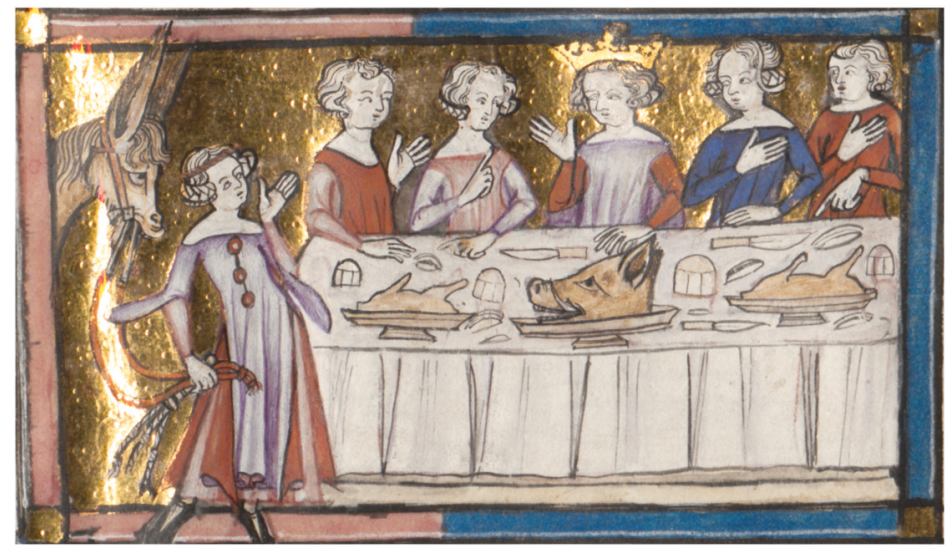

D R O Z 


\section{LIBRAIRIE DROZ}

Tous droits réservés par la Librairie Droz SA en vertu des règles de propriété intellectuelle applicables. Sans autorisation écrite de l'éditeur ou d'un organisme de gestion des droits d'auteur dûment habilité et sauf dans les cas prévus par la loi, l'œuvre ne peut être, en entier ou en partie, reproduite sous quelque forme que ce soit, ni adaptée, représentée, transférée ou cédée à des tiers.

Ce travail est sous licence Creative Commons Attribution - pas d'utilisation commerciale - pas de modification 2.5 Suisse License. Pour obtenir une copie de la licence visitez http://creativecommons.org/licenses/ by-nc-nd/2.5/ch/ ou envoyez une lettre à Creative Commons, PO Box 1866, Mountain View, CA 94042, USA.

Pour toutes informations supplémentaires, merci de contacter l'éditeur : droits@droz.org
All rights reserved by Librairie Droz SA as proscribed by applicable intellectual property laws. Works may not, fully or in part, be reproduced in any form, nor adapted, represented, transferred or ceded to third parties without the written authorization of the publisher or a duly empowered organization of authors' rights management and except in instances provided for by law.

This work is licensed under the Creative Commons Attribution - No commercial use - No modification 2.5 Suisse License. To view a copy of this license, visit http://creativecommons.org/ licenses/by-nc-nd/2.5/ch/ or send a letter to Creative Commons, PO Box 1866, Mountain View, CA 94042, USA.

For any additional information, please contact the publisher : rights@droz.org

11, rue Firmin Massot |1206 Genève-GE|0041 (0)22 3466666 (t)|0041(0)22 34723 91(f)| droz@droz.org - www.droz.org 


\section{Les derniers vers du roman arthurien}


$\frac{\tilde{N}}{\frac{0}{J}}$

ᄃ

픅

픔

들

(1)

풀

ฮํ

(1)

다

ข)

듬

이

ฮิ

브

능 
P U B L I CATION S R O M A N E E T F R A N ÇA I S ES fondées par Mario Roques, aujourd'hui dirigées par Jean-René Valette

CCLXXIII-

GÉRALDINE TONIUTTI

\section{LES DERNIERS VERS \\ DU ROMAN ARTHURIEN}

Trajectoire d'un genre,
anachronisme d'une forme

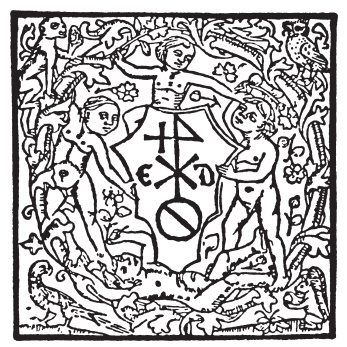

DROZ 
L'étape de la prépresse de cette publication a été soutenue par le Fonds national suisse de la recherche scientifique.

\section{FNSWF \\ FONDS NATIONAL SUISSE \\ DE LA RECHERCHE SCIENTIFIQUE}

www.droz.org

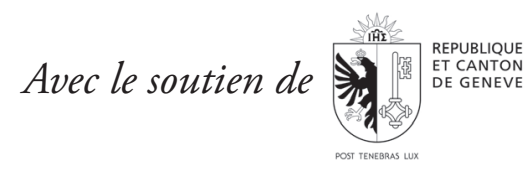

ISBN : 978-2-600-06223-7

ISBN PDF : 978-2-600-16223-4

DOI : $10.47421 /$ droz62237

ISSN : 0079-7812

(C) 2021 by Librairie Droz S.A., 11, rue Firmin-Massot, Genève.

All rights reserved. No part of this book may be reproduced, translated, stored or transmitted in any form or by any means, electronic, mechanical, photo copying or otherwise without written permission from the publisher. 


\title{
INTRODUCTION
}

\author{
Quel est celui de nous qui n'a pas, dans ses jours \\ d'ambition, rêvé le miracle d'une prose poétique, \\ musicale sans rythme et sans rime, assez souple \\ et assez heurtée pour s'adapter aux mouvements \\ lyriques de l'âme, aux ondulations de la rêverie, \\ aux soubresauts de la conscience? \\ Charles Baudelaire, "À Arsène Houssaye», in \\ Euvres complètes, éd. Claude Pichois, t. 1, Paris, \\ Gallimard, 1975, p. 275-276.
}

Lorsque, dans les années 1860, Baudelaire présente ses poèmes en prose à Arsène Houssaye, il a conscience d'offrir un type de production innovant, en phase de création, par la conjonction originale d'une forme et d'un genre. Jusque-là, la poésie française privilégie la forme fixe en vers, comme s'il existait une incompatibilité entre prose et poésie ${ }^{1}$. Appliquer

\footnotetext{
Le rapport entre prose et poésie est déjà exploré par certains auteurs du XVIII siècle, qui préparent la dissociation entre poésie et versification. Sans doute pourrait-on trouver plusieurs exemples de prose poétique avant la tentative de Baudelaire, que l'on pense notamment à la chantefable qu'est Aucassin et Nicolette (XII ${ }^{\mathrm{e}}$ siècle). Il faut néanmoins admettre que ce que propose Baudelaire est reçu comme une innovation, vécu comme un moment de rupture. Il ne s'agit pas seulement de la composition et de la reconnaissance d'une prose poétique, mais de la construction d'un nouveau genre appelé au succès, le poème en prose. On ne peut nier l'existence d'une prose poétique avant Baudelaire, mais pour faire poème, il faut encore qu'y préside un geste de transformation, l'élaboration d'une nouvelle forme. Baudelaire imite en cela Aloysius Bertrand, dont le recueil Gaspard de la nuit (composé dans les années 1830, publié à titre posthume en 1842), offre la première véritable attestation de poèmes en prose en tant qu'entreprise concertée. Jean-Pierre Bertrand opère en ce sens une distinction: Baudelaire serait le promoteur du poème en prose, et non son inventeur ( Poème en prose, in Le dictionnaire du littéraire, Paris, PUF ("Quadrige»), 2010, p. 579). Sur l'histoire du poème en prose, voir Pierre Moreau, La Tradition française du poème en prose avant
} 
la prose à la poésie revient dès lors à infléchir l'imaginaire qui lui est attaché, à en justifier l'emploi, à réinventer ses effets. Le poème en prose induit «une autre conception de la poésie, définie comme une attitude et non plus comme un genre codifié de règles» ${ }^{2}$. Ce choix est concerté par Baudelaire; il résulte d'une expérimentation poétique, celle d'atteindre la poésie par une autre forme que celle privilégiée jusque-là, expérimentation dans laquelle le poète se lance avec précaution, comme le laisse transparaître sa lettre à Arsène Houssaye. L'invention de la prose poétique nourrit l'ambition d'une communication directe au lecteur de la rêverie du poète; la prose se fait "volontaire effacement de la forme»" Baudelaire, dont Marcel Ruff traduit les intentions, la conçoit comme un medium à même de transcrire sans obstacles les mouvements de l'âme:

Bien plus, alors que dans la poésie en vers, il nous fait parvenir la voix de l'auteur à travers un instrument qui l'amplifie, mais aussi la modifie, l'art du poème en prose, tel que Baudelaire le comprend, a pour effet de supprimer les obstacles qui, dans le langage direct, arrêtent les aveux les plus intimes ${ }^{4}$.

Sous cet angle, la prose dispose d'un potentiel poétique plus important que le vers, qualité qu'exploiteront abondamment les poètes à la suite de Baudelaires.

Le choix d'une forme, inévitablement, contraint et transforme le genre et sa définition, touche à la notion même de poésie, au point que les auteurs du tournant des $\mathrm{XIX}^{\mathrm{e}}$ et $\mathrm{XX}^{\mathrm{e}}$ siècles s'efforcent de tracer les

Baudelaire, Paris, Lettres modernes ("Archives des Lettres modernes", 19-20), 1959, et Suzanne Bernard, Le Poème en prose de Baudelaire jusqu'à nos jours, Paris, Nizet, 1959. Les titres de ces deux ouvrages rendent compte en eux-mêmes de l'importance de l'entreprise de Baudelaire et du tournant que représentent ses poèmes en prose. Comme tout avènement, il est préparé par divers prémices que ces deux études retracent.

2 Claude Pichon, "Notice du Spleen de Paris», in Charles Baudelaire, Euvres complètes, Paris, Gallimard ("Pléiade»), 1975 [1869, posthume], tome 1, p. 1304.

3 Robert Guiette, "Baudelaire et le poème en prose», Revue belge de philologie et d'histoire, 42/3, 1964, p. 851.

4 Marcel A. Ruff, "Baudelaire et le poème en prose», Zeitschrift für französische Sprache und Literatur, 77, 1967, p. 122.

5 Voir Michel Murat, "Le dernier livre de la bibliothèque. Une histoire du poème en prose», Fabula, Atelier de théorie littéraire, https://www.fabula.org/atelier. php?Histoire_du_poeme_en_prose\#_ednref27 
contours de ce nouveau genre: le poème en prose doit à tout prix se distinguer d'une simple page écrite en prose ${ }^{6}$. La nécessité de préciser l'emploi de la prose en poésie témoigne de l'influence de la forme sur le genre littéraire. Les poèmes en prose de Baudelaire et sa propre description de la prose poétique citée en épigraphe invitent à réfléchir au profil générique et fluctuant de chaque forme. C'est à l'origine de cette spécialisation générique des formes qui perdure jusqu'au $\mathrm{XIX}^{\mathrm{e}}$ siècle que nous souhaitons nous intéresser en traitant le problème inverse que posent les poèmes en prose de Baudelaire: qu'implique le choix du vers dans le genre romanesque ?7 La prose s'impose dès le début du XIII ${ }^{\mathrm{e}}$ siècle dans le roman, en particulier à travers les proses du Graal. Avant cela, tout texte narratif s'écrit en vers. Le vers n'est pour autant pas subitement abandonné, mais coexiste largement dans le roman avec la prose dans la première moitié du XIII ${ }^{\mathrm{e}}$ siècle. La fin du $\mathrm{XIII}^{\mathrm{e}}$ siècle est en revanche une période de mutation; l'écriture en vers résiste, mais est en décalage avec la forme irrémédiablement privilégiée.

La question des conséquences génériques qu'engendre le choix d'une forme se pose avec acuité dans les romans en vers de cette période, dans la mesure où leur forme est anachronique, et qu'elle engendre une façon particulière de traiter la matière. Ce rapport entre forme et genre est

6 Ainsi de Max Jacob critiquant les poèmes en prose de Rimbaud: "Une page en prose n'est pas un poème en prose, quand bien même elle encadrerait deux ou trois trouvailles. [...] Le poème en prose est un objet construit et non la devanture d'un bijoutier. Rimbaud, c'est la devanture du bijoutier, ce n'est pas le bijou: le poème en prose est un bijou.»(Le Cornet à dés, Paris, Gallimard («Poésie»), 2003, p. 23-24)

7 Nous nous référons à l'ouvrage de Francis Gingras, Le Bâtard conquérant: essor et expansion du genre romanesque au Moyen Âge, Paris, Champion, 2011, pour une définition et une contextualisation du genre "roman». Si le roman résiste à tout classement, Francis Gingras dégage des critères stables dans toutes les langues: il s'agit d'une forme narrative plutôt longue et généralement en prose (p. 17). Les romans médiévaux étant aux XII ${ }^{\mathrm{e}}$ et $\mathrm{XIII}^{\mathrm{e}}$ siècles massivement en vers, on peut parler plutôt de neutralité formelle, qui oppose le genre à celui de la poésie lyrique et de la chanson de geste. Nous reprenons cette définition minimale lorsque nous employons les expressions "genre romanesque» ou "roman"sans autre précision. Le roman est une catégorie qui englobe des genres qui lui sont subordonnés: le roman arthurien, mais aussi le roman antique, le roman dit "réaliste» ou le roman courtois. Mikhaïl Bakhtine a posé les bases d'une esthétique du roman, qui se définit par son hétérogénéité, son dialogisme, son perpétuel devenir. Voir Esthétique et théorie du roman, Paris, Gallimard, 1978. 
particulièrement clair dans le roman arthurien, dont la formalisation en vers ou en prose implique des perspectives différentes sur le monde raconté, sur la temporalité, sur les valeurs: on ne présente pas le mythe arthurien de façon identique selon la forme employée. Si la prose a pour horizon la fin des temps arthuriens, le vers se concentre sur l'apogée du règne d'Arthur et place ses récits dans une atemporalité qui empêche toute perspective eschatologique sur le monde fictif. Dans les romans arthuriens en vers de la fin du XIII ${ }^{\mathrm{e}}$ siècle, l'anachronisme de la forme choisie est conjoint à un mode de présentation de l'univers déjà supplanté par celui de la prose. Les auteurs doivent tenir compte des innovations diégétiques de la prose, tout en respectant les codes du roman arthurien en vers dans lequel ils inscrivent leurs œuvres. Létude des derniers romans en vers doit ainsi rendre compte de certaines contaminations de la prose au vers, mais aussi des différences entre vers et prose, voire des incompatibilités profondes entre ces deux façons de représenter en roman la matière arthurienne. Ces relations entre vers et prose informent l'épuisement de la production arthurienne en vers du XIII ${ }^{\mathrm{e}}$ au XIV ${ }^{e}$ siècle, qui illustre plus généralement l'abandon du vers au profit de la prose dans le genre romanesque français. Étudier les derniers représentants du roman arthurien en vers invite à historiciser les emplois attribués au vers et à la prose au cours des siècles. Contrairement aux poèmes en prose de Baudelaire, les derniers romans arthuriens en vers sont les témoins de la fin d'une conjonction désuète entre une forme et un genre.

Cet énoncé suppose que le roman arthurien en vers est un genre littéraire à part entière. Admettre ce présupposé revient à reconnaître que la notion de genre est applicable à la littérature du Moyen Âge, ce qui ne va pas de soi pour tous les critiques, et que le roman arthurien peut être considéré comme tel, ce qui, là encore, pose plusieurs questions. Si le roman arthurien est étudié depuis plus d'un siècle, la Société internationale arthurienne clarifie pourtant peu les bornes de son champ de recherche et laisse le chercheur libre de faire entrer sous l'étiquette «domaine arthurien» ce que bon lui semble ${ }^{8}$. Quant à l'avant-propos au Bulletin bibliographique de la Société internationale arthurienne, il précise que sont recensés les articles qui traitent de la «matière de Bretagne». Sont exclues en revanche les études sur des textes postérieurs au Xvi ${ }^{\mathrm{e}}$ siècle. Le roman arthurien et la matière de Bretagne auraient donc une réalisation

8 Voir le site internet de la SIA, http:/www.internationalarthuriansociety.com/ about. 
bornée dans le temps. Faut-il faire une distinction entre roman arthurien et matière de Bretagne? Le roman arthurien est-il un genre ou plutôt une matière? La question suppose encore de bien comprendre la différence entre ces deux notions, celle de "matière» étant déterminante pour la poétique médiévale et sans cesse problématique.

On associe volontiers le roman arthurien à une matière? ${ }^{9}$, véritable concept poétique utilisé par les auteurs du Moyen Âge et que l'on peut définir temporairement par «ce qui est non encore organisé par une forme et à partir de quoi, grâce à quoi, dans le domaine de la création littéraire, on écrit ${ }^{10}$. La matière désigne donc un contenu brut, qui, dans le cas du roman arthurien, englobe des personnages spécifiques et un cadre spatiotemporel: pour entrer dans la catégorie, il faut que le récit mette en scène le roi Arthur, Guenièvre ou Gauvain, et que l'histoire prenne place pendant le règne de celui-là, au royaume de Logres. Néanmoins, on rencontre des textes qui adoptent une structure, des motifs, une idéologie communs au corpus reconnu comme arthurien, sans reconduire son univers. Il en est ainsi de Cristal et Clarie, roman en vers composé aux alentours de 1268, régulièrement assimilé à un roman arthurien en vers malgré l'absence flagrante d'Arthur, de sa cour et des objets qui lui sont rattachés. Les éléments qui évoquent le roman arthurien dans ce texte ne relèvent donc pas de la matière. Il faut admettre qu'il existe d'autres paramètres qui donnent l'idée de l'arthurien: peut-on dès lors parler de "genre», entendu comme regroupement d'œuvres qui présentent des caractéristiques structurelles, formelles, idéologiques, stylistiques ou sémantiques communes ? $^{11}$

9 Richard Trachsler souligne par exemple dans son article, "Genres und matières. Überlegungen zum Erbe Jean Bodels", in Gattungen mittelalterlicher Schriftlichkeit, éd. Barbara Frank, Thomas Haye et Doris Tophinke, Tübingen, Narr, 1997, p. 201-219, que la SIA fonde son objet d'étude sur une matière alors que la Société Rencevals étudie un genre. Nous reviendrons sur la définition du terme «matière» et ses implications pour la poétique médiévale. Signalons pour l'instant les actes du colloque de Rennes, Poitiers et Bucarest dirigés par Catalina Girbea et Christine Ferlampin-Acher, Matières à débat. La notion de matiere littéraire dans la littérature médiévale, Rennes, PUR («Interférences»), 2017.

10 Jacqueline Cerquiglini, "Littérature médiévale?», in La Littérature française: dynamique et histoire, dir. Jean-Yves Tadié, Paris, Gallimard («Folio essais»), 2007, p. 111.

11 C'est la définition que donne Wolfgang V. Ruttkowski, Die literarischen Gattungen, Bern-München, Francke, 1968, p. 15: "Gattungen sind Gruppierungen von Dichtungen, die sich in entscheidenden Strukturmerkmalen ähneln.»; "Les 
Le fait même que l'on puisse différencier sur plusieurs plans le roman arthurien en vers et celui en prose, comme nous entendons le faire au cours de l'étude, prouve qu'il s'agit de catégories distinctes, et, partant, que le domaine arthurien est soumis aux lois de la généricité. Le critère de la forme ne suffit pas à lui seul à opposer roman arthurien en vers et roman arthurien en prose; d'autres éléments fondamentaux de distinction interviennent, conditionnés par le choix de la forme, et qui relèvent de la généricité. Le corpus des derniers romans arthuriens en vers se révèle un terrain propice à l'étude du concept de genre littéraire pour la période médiévale: il permet de réfléchir aux conséquences de la forme sur le genre, par les relations entretenues avec les romans en prose qui précèdent. Ces relations concernent à la fois l'importation de procédés narratifs, car les derniers romans arthuriens en vers s'inspirent des structures que privilégie la prose, mais aussi l'impossibilité de transposer tel quel le récit arthurien d'une forme à l'autre. L'effet de la forme sur le genre explique en dernier lieu le tournant historique que représente la spécialisation lyrique du vers et l'abandon du vers narratif dans le roman. Notre recherche adopte donc la double perspective de l'histoire et de la théorie littéraires: que fait le choix anachronique de la forme du vers au genre du roman arthurien, à une époque où la prose s'est déjà imposée dans le genre ${ }^{12}$ romanesque français?

Historiciser les derniers romans arthuriens en vers revient à les confronter aux romans en prose, mais aussi à la tradition dont ils sont les successeurs. Si le roman arthurien en vers est un genre, il est bien souvent évalué à l'aune des compositions de Chrétien de Troyes, reconnu comme fondateur de ce type de productions. Les œuvres arthuriennes versifiées postérieures à l'écrivain champenois du XII ${ }^{\mathrm{e}}$ siècle sont traitées comme des épigones, de piètres imitateurs d'un maître indépassable. Les derniers romans arthuriens en vers font particulièrement l'objet de telles critiques, à l'exemple de Claris et Laris (1270) et Escanor (1281) dont rend

genres sont des groupements d'œuvres qui présentent des caractéristiques structurelles différentielles communes.» (nous traduisons)

12 Il nous faut préciser ici que nous employons le terme de "genre» à la fois pour désigner le roman mais aussi ses "sous-genres», dont fait partie le roman arthurien, tout comme le roman policier, le roman pastoral, le roman courtois, etc. Le genre du roman se scinde en différentes catégories qui relèvent de la généricité. Le chapitre premier précisera notre définition du genre. 
compte Beate Schmolke-Haßelmann, auteure d'une étude pionnière sur les romans arthuriens en vers:

Zwar scheint ein Werkumfang von 30'000 Versen dem Publikum der Prosazyklen zumutbar gewesen zu sein, aber die Überdehnung, Zergliederung und endliche Auflösung des Erzählzusammenhangs zeugt von einem inhärenten Missverstehen arthurischer Gattungsmerkmale, die den Versroman charakterisieren. Die Verwendung der beliebten arthurischen Gestalten und Stoffe tritt dem langsamen Sterben der Gattung nicht mehr wirksam entgegen ${ }^{13}$.

Malgré la réhabilitation des romans arthuriens en vers que son étude offrait dans les années quatre-vingts et l'intérêt indéniable de cet ouvrage pour l'histoire du roman médiéval, Beate Schmolke-Haßelmann perpétue un jugement de valeur négatif sur les derniers représentants du genre dont nous entendons nous distancier. Ces critiques résultent de l'érection de Chrétien de Troyes en norme absolue. Il semble que plus le temps avance,

13 Beate-Schmolke Haßelmann, Der arthurische Versroman, von Chrestien bis Froissart: Zur Geschichte einer Gattung, Tübingen, Max Niemeyer Verlag, 1980, p. 19. "Certes, l'ampleur d'une œuvre de 30000 vers a pu paraitre raisonnable au public des cycles en prose, mais l'extension excessive, la destructuration et la dissolution finale du cadre narratif témoignent d'une incompréhension profonde des repères du genre arthurien qui caractérisent le roman en vers. Le recours à la matière arthurienne et à ses figures, tant appréciées, ne suffit plus à empêcher efficacement la lente agonie du genre.» (nous traduisons). Bien que de tels avis négatifs soient partagés par plusieurs critiques, il faut toutefois noter que l'intérêt pour ces textes est grandissant. Plusieurs travaux tendent à tirer les romans tardifs de l'ombre: Richard Trachsler, Les Romans Arthuriens en vers après Chrétien de Troyes, Paris; Roma, Memini («Bibliographie des Ecrivains Français» 11), 1997, "Héritiers et épigones. Les auteurs des romans arthuriens en vers après Chrétien de Troyes", in Les Héritiers littéraires dans la littérature française (XVI'-XX" siècle), éd. Franziska Meier, Brigitte Diaz et Francine Wild, Paris, Garnier, 2014, p. 181-196, "De la Prose au Vers. Le cas de Dynadan dans l'Escanor de Girart d'Amiens", in Actes du XX Congrès de la Société Internationale de Linguistique et Philologie Romanes, Université de Zurich, 6-11 avril 1992, Tübingen; Basel, Francke, 1993, p. 401-412, «Chrétien de Troyes, créateur. De l'inventeur d'un genre au statut de maitre", in Chrétien de Troyes et la tradition du roman arthurien en vers, éd. Annie Combes, Patrizia Serra, Richard Trachsler, Maurizio Virdis, Paris, Garnier, 2013, p. 13-25, Corinne Pierreville, Claris et Laris, somme romanesque du XIII siècle, Paris, Champion, 2008, Norris Lacy, «Les Merveilles de Rigomer and the Esthetics of "Post-Chrétien" Romance", Arthurian Yearbook, 1993, 3, p. 77-90, ou Adeline Latimier-Ionoff, Lire le nom propre dans le roman médiéval, Paris, Garnier, 2019. 
plus les auteurs se départissent du modèle de Chrétien de Troyes: si les romans arthuriens en vers de deuxième génération, ceux de Renaut de Beaujeu, de Raoul de Houdenc ou les anonymes Hunbaut, Fergus, L'Âtre Périlleux par exemple, ont des liens forts avec l'esthétique de Chrétien de Troyes, le constat est beaucoup moins valable pour les textes plus tardifs. À l'aune des compositions novatrices de Chrétien de Troyes, les auteurs de textes de la fin du XIII ${ }^{\mathrm{e}}$ siècle sont réduits à de piètres épigones ayant mal compris la catégorie narrative dans laquelle ils entendaient s'inscrire. La suprématie établie du Champenois sur le roman arthurien en vers engendre des avis négatifs sur les représentants postérieurs du genre, mais occulte aussi les autres influences dont profitent les œuvres qui feront l'objet de la présente recherche. Le canon, en ce contexte, se révèle en définitive peu applicable à la réalité des textes, en particulier pour les derniers représentants du genre, qui opèrent un profond remaniement de l'esthétique arthurienne.

Sera comprise dans cette catégorie toute ouvre arthurienne en vers depuis le dernier tiers du XIII ${ }^{\mathrm{e}}$ siècle. Sans qu'il s'agisse d'un véritable moment de rupture, il nous semble percevoir un changement lors de cette période, un glissement progressif qui se précise tout au long de la fin du XIII ${ }^{\mathrm{e}}$ siècle: les romans arthuriens en vers développent une esthétique commune que l'on pourrait qualifier de «tardive ${ }^{14}$. La notion de tardivité inscrit historiquement les textes par rapport aux romans arthuriens en vers qui les précèdent. Les œuvres tardives ne sont pas seulement celles qui continuent un genre à succès, mais celles qui terminent le genre, sont les témoins de son achèvement. Leur intérêt est dès lors symétrique à celui que l'on peut porter aux précurseurs, car leur étude permet de retracer

14 Sur la notion de tardivité, voir les travaux de Christine Ferlampin-Acher: "Introduction. Après Arthur?", in Arthur après Arthur. La matière arthurienne tardive en dehors du roman arthurien (1270-1530), Rennes, PUR ("Interférences»), 2017, p. 7-21, le projet européen LATE (Littérature arthurienne tardive en Europe), qu'elle dirige, paru en 2020 aux Presses universitaires de Rennes, et «La matière arthurienne en langue d'oïl à la fin du Moyen Âge: épuisement ou renouveau, automne ou été indien?", Bulletin bibliographique de la Société Internationale Arthurienne, vol. LXIII, 2011, p. 258-294. La critique considère que les romans arthuriens tardifs, aussi bien en vers qu'en prose, constituent "des tentatives originales, souvent isolées, différentes les unes des autres» («Introduction. Après Arthur?", p. 10). Malgré l'originalité et l'individualité forte de chaque œuvre, qui chacune à sa manière transforme l'usage de la matière arthurienne, il nous semble pouvoir dégager des liens de parenté entre les derniers romans arthuriens en vers. 
l'histoire d'une réception, le début et la fin d'un genre. Judith Schlanger, qui s'emploie à définir la notion de "précurseur", souligne qu'il n'y a pas d'antonyme à ce terme, pour désigner «l'accomplisseur ou l'épanouisseur, bref l'absolu dont le précurseur est le relatif ${ }^{15}$. C'est par opposition à la notion de précurseur que nous conceptualisons celle de tardivité, non pas pour qualifier l'"épanouisseur", mais le "finisseur», celui qui serait l'inverse du pionnier, une sorte de retardataire. Judith Schlanger utilise le mot d' "attardés» pour rendre compte des représentations habituelles de l'histoire littéraire:

L'histoire culturelle du changement parle de pionniers et d'attardés: de pionniers qui ont le mérite d'ouvrir, d'initier, de dégager un nouvel espace, et d'attardés ou d'épigones qui continuent par inertie à produire des œuvres qui convenaient autrefois, mais qui ne correspondent plus désormais à l'esprit de l'époque (car les attardés sont devenus inadéquats et rétrogrades non pas parce que ce qu'ils font est mauvais en soi, mais parce que ce n'est plus le juste moment de le faire) ${ }^{16}$.

Cette définition s'applique à la façon dont ont été abordés les derniers romans arthuriens en vers. À Chrétien de Troyes, tout comme à Baudelaire pour le poème en prose, revient le statut de précurseur, à Escanor et Melyador, celui d'attardés. En introduisant la notion de tardivité, nous entendons relativiser l'idée d'inertie qui irait de pair avec la reproduction du modèle précurseur: les textes tardifs interviennent bien à la fin d'une tradition, au contraire du précurseur qui annonce, anticipe et prépare, mais la redynamisent pas divers moyens narratifs. Leur statut relève de la contingence: au fond, leurs innovations auraient très bien pu donner lieu à une nouvelle tradition qui aurait pu les faire passer de tardifs à précurseurs.

En l'état, le caractère rétrograde des textes tardifs dont parle Judith Schlanger convient bien aux derniers romans arthuriens en vers. La tardivité a partie liée avec l'anachronisme, entendu comme un "état de décalage entre le moment où un événement se produit et celui où il aurait dû

\footnotetext{
15 Judith Schlanger, "Le précurseur", in Le Temps des auvres. Mémoire et préfiguration, dir. Jacques Neefs, Saint-Denis, PUV, 2001, p. 21.

16 Ibid., p. 17-18.
} 
se produire ${ }^{17}$ : le choix formel du vers est déphasé, il ne convient plus aux nouvelles tendances du roman qui favorise la prose. Le vers, dès la fin du XIII ${ }^{e}$ siècle, est anachronique, dans la mesure où il est déjà en passe d'obsolescence. Cet anachronisme fait des œuvres tardives des survivances, voire des résurgences, dont il s'agit de décrire les mécanismes communs et les enjeux pour l'histoire littéraire et culturelle. Le choix de la forme entraîne d'autres choix, génériques, qui définissent le roman arthurien en vers par rapport à celui en prose. C'est cette conjonction entre une forme et une façon de représenter l'univers arthurien qui s'éteint progressivement, extinction que permettent de retracer les romans en vers tardifs, corpus entre mutation et survivance. Partant de ce rapport historique entre précurseur et tardif, nous soutenons que l'extinction n'est pas moins intéressante que le commencement ${ }^{18}$.

La période du dernier tiers du XIII ${ }^{\mathrm{e}}$ siècle ne doit pas être appréhendée comme un tournant ferme qui assurerait la transition d'un état du roman arthurien à un autre, mais plutôt comme une époque de fluctuation: les liens avec la tradition sont encore fermes, en même temps que les œuvres proposent des innovations fondamentales. Le choix de cette période s'affermit encore si l'on considère la fin du XIII ${ }^{\mathrm{e}}$ siècle comme un moment de changements esthétiques qui touchent l'ensemble de la production narrative: le tournant des $\mathrm{XIII}^{\mathrm{e}}$ et $\mathrm{XIV}^{\mathrm{e}}$ siècles voit aussi s'amenuiser progressivement puis s'éteindre la production de fabliaux, preuve que le rapport du lecteur à la narration versifiée est en mutation. Le genre du fabliau est en effet datable, de la fin du XII ${ }^{\mathrm{e}}$ siècle au premier tiers du XIV ${ }^{\mathrm{e}}$ siècle $^{19}$. Après ces années, les auteurs cessent d'en produire. Sans doute

17 Frédérique Fleck, «Anachroni(sm)e: mise au point sur les notions d'anachronisme et d'anachronie", Fabula, Atelier Fabula, 2011, http://www.fabula.org/atelier. php?Anachronisme_et_anachronie. Nous ne retenons pas le sème d' "erreur» ni le sens péjoratif que peut prendre ce terme.

18 Notre démarche est dès lors semblable à celle des auteurs du Dictionnaire raisonné de la caducité des genres littéraires, dir. Saulo Neiva et Alain Montandon, Genève, Droz, 2014. La caducité ne recoupe pas une dégénérescence, mais atteint un stade de mutation, d'infléchissement, composé à la fois de pertes et de gains (voir l'«Introduction» de Saulo Neiva, p. 15). Voir l'article de Francis Gingras dans ce recueil, qui retrace l'histoire du roman courtois: "Roman courtois", p. 795-805.

19 Dominique Boutet, "Les formes de la dérision: le fabliau", in Histoire de la France littéraire, vol. 1, dir. Frank Lestringant et Michel Zink, Paris, PUF, 2006, p. 501-505, et Magali Lachaud, "Fabliau», in Dictionnaire raisonné de la caducité 
faut-il envisager que le fabliau est remplacé par la nouvelle en prose: les Cent nouvelles nouvelles offrent par exemple des récits brefs dont le comique, le cadre et le registre sont proches de ceux des fabliaux. À l'aune de cette comparaison, il devient clair que la fin du XIII ${ }^{\mathrm{e}}$ est une époque qui voit divers enjeux esthétiques se transformer et qui signe la fin progressive d'une forme littéraire.

La période retenue, celle du dernier tiers du XIII ${ }^{\mathrm{e}}$ siècle, garantit encore la possibilité d'une influence des textes en prose, y compris le Tristan en prose et le cycle de Guiron le courtois, dont la composition intervient à peu près au milieu du siècle. Cette influence qui concerne les romans en prose que nous dénommons de deuxième et troisième générations (voir plus loin) est déterminante dans la définition de l'esthétique tardive, comme nous aurons l'occasion de le montrer au cours de l'étude. Il importe donc que les textes du corpus soient postérieurs à leur composition.

Les romans arthuriens en vers qui nous sont parvenus depuis la fin du XIII ${ }^{\mathrm{e}}$ siècle sont au nombre de six $^{20}$, présentés ci-après. Il est difficile d'être tout à fait sûr de la date d'écriture de ces textes; nous proposons des datations qui nous semblent convaincantes, à partir des hypothèses critiques. Le choix de créer un corpus qui rassemble des œuvres composées depuis le dernier tiers du XIII ${ }^{\mathrm{e}}$ siècle n'exclut pas des similitudes entre les textes de notre corpus et d'autres romans arthuriens en vers à peine plus anciens.

des genres littéraires, dir. Saulo Neiva et Alain Montandon, Genève, Droz, 2014, p. 307-325.

20 Nous excluons ici le Chevalier au lion de Pierre Sala (1522), qui représente un cas de réécriture et non une production originale. Pierre Sala entend simplifier et moderniser le texte de Chrétien de Troyes, agissant ainsi comme un copiste, ou peut-être plutôt comme un philologue, désireux de rendre le texte ancien accessible au public du Xvi ${ }^{\mathrm{e}}$ siècle. Voir l'introduction à l'édition de Pierre Servet, Pierre Sala, Le chevalier au lion, Paris, Champion ("Bibliothèque du $\mathrm{Xv}^{\mathrm{e}}$ siècle», 56), 1996, p. 9-95, Jean-Claude Mühlethaler, «Défense et illustration du vers dans les récits du Moyen Âge tardif: du règne de Philippe le Bel au règne de Charles VI", in Rencontres du vers et de la prose: conscience théorique et mise en page, dir. Catherine Croizy-Naquet et Michelle Szkilnik, Turnout, Brepols, 2015, p. 121-122, Elizabeth Burin, "Pierre Sala's Manuscript of Le Chevalier au lion", in Les manuscrits de Chrétien de Troyes, éd. Keith Busby, Terry Nixon, Alison Stones et Lori Walters, Amsterdam; Atlanta, Rodopi, 1993, tome 2, p. 323-330, et Jane H. M. Taylor, "Pierre Sala, poacher", in Rewriting Arthurian Romance in Renaissance France. From Manuscript to Printed Book, Cambridge, Brewer, 2014, p. 11-37. 
Il s'agit toutefois de rendre compte de phénomènes et non d'analyser en détail cette production de manière exhaustive.

Les éditions, aussi bien que les manuscrits qui ont transmis ces textes, sont rares: nous prendrons les plus récentes comme éditions de référence, excepté pour Rigomer, puisqu'il s'agit d'une anthologie partielle, et pour Biaudouz, dont nous préférons souvent citer directement le manuscrit. Parallèment au nombre d'éditions, les études critiques ne foisonnent pas sur ce corpus. Beate Schmolke-Haßelmann aborde l'ensemble des romans arthuriens en vers dans son travail de 1980 dont nous entendons réviser certaines thèses. Les derniers romans arthuriens en vers ont depuis surtout fait l'objet d'articles consacrés à une voire deux œuvres à la fois ${ }^{21}$. Christine Ferlampin-Acher est la première à grouper ces textes en corpus ${ }^{22}$ : elle envisage que la tardivité, en littérature arthurienne, intervient à des périodes différentes pour le vers et la prose. Si elle souligne l'intérêt d'études sur ce corpus, elle annonce se concentrer plus amplement sur la prose tardive. C'est à Adeline Latimier qu'il revient pour la première fois en 2019 de proposer une recherche d'ensemble sur certains textes communs à notre propre corpus, qu'elle soumet à la question de l'onomastique ${ }^{23}$. Notre corpus - semblable à trois textes près du sien - est donc l'objet d'un nouvel intérêt et mérite d'être actualisé par de nouvelles études.

Notre corpus se compose des œuvres suivantes (voir aussi l'annexe A):

- Claris et Laris, daté avec assez de certitude des environs de 1270 par l'éditrice Corinne Pierreville, le prologue renvoyant à des événements contemporains $^{24}$. Ce roman anonyme, édité en 1884 puis en 2008, n'est conservé que dans un manuscrit, le BnF fr. 1447, daté du début du XIV ${ }^{\mathrm{e}}$ siècle $^{25}$.

21 Nous renvoyons aux quelques ouvrages importants sélectionnés note 13, page 13. Voir aussi les regroupements par textes dans la bibliographie.

22 Christine Ferlampin-Acher, "La matière arthurienne en langue d'oïl à la fin du Moyen Âge: épuisement ou renouveau, automne ou été indien?», art. cit.

23 Voir Lire le nom propre. Adeline Latimier-Ionoff prend en considération Claris et Laris, Floriant et Florete, Rigomer et Melyador, ainsi que Cristal et Clarie qu'elle aborde comme un roman arthurien.

24 Voir l'introduction à l'édition, Claris et Laris, éd. Corinne Pierreville, Paris, Champion, (“CFMA»), 2008, p. 9-10.

25 Selon Albert Henry, Les auvres d'Adenet le roi, Brugge, De Tempel, 1951, t. 1, p. 119-120. Le critique se fonde sur l'illustration et la graphie pour avancer cette datation. 
- Le lien intertextuel ${ }^{26}$ que le roman de Floriant et Florete entretient avec Claris et Laris, dont il cite plusieurs passages, et les allusions au contexte politique sicilien de l'époque autorisent une datation aux alentours de $1280^{27}$. Ce roman anonyme est lui aussi un unicum, conservé dans le manuscrit de la bibliothèque de New York, Public Library, De Ricci 122, daté du tournant entre les XIII ${ }^{\mathrm{e}}$ et XIv ${ }^{\mathrm{e}}$ siècles par Richard Trachsler et Annie Combes ${ }^{28}$.

- La datation de Rigomer ${ }^{29}$, composé par un certain Jehan ${ }^{30}$, est plus controversée: les critiques disposent de peu d'indices concrets et se fondent sur des critères stylistiques et structurels. Lori Walters propose

26 Selon la définition que donne Tiphaine Samoyault, qui préconise de parler d'intertextualité lorsque «le texte réfère directement à des textes antérieurs, selon des modes d'intégration bien visibles". L'intertextualité. Mémoire de la littérature, Paris, Armand Colin, 2005, p. 31. C'est cette définition que nous sous-entendons lorsque nous employons le terme d'«intertextualité».

27 Voir l'introduction à l'édition Floriant et Florete, éd. et trad. Richard Trachsler et Annie Combes, Paris, Champion, («CCMA»), 2003, p. XxiII-XxxI. Il s'agit de la troisième édition de Floriant et Florete: Floriant et Florete: a metrical romance of the fourteenth century edited from a unique manuscript at Newcastle Abbey by Francisque-Michel, Edinburgh, Clark for the Roxburghe Club, 1873; Floriant et Florete, éd. Harry F. Williams, Ann Arbor, University of Michigan Press; London, Oxford University Press ( University of Michigan Publication in Language and Literature», 23), 1947.

28 Les éditeurs signalent que la décoration est typique d'un atelier d'T̂le de France de la fin du XIII ${ }^{\mathrm{e}}$ siècle, tout en évoquant un copiste du début du XIV ${ }^{\mathrm{e}}$ siècle (éd. cit., p. XVII et note 20, p. Xxi).

29 Nous suivons l'avis de Francesco Carapezza au sujet du titre de ce roman: la marge supérieure du manuscrit Chantilly, Condé 472, partiellement tronquée, laisse apparaître ce que l'on peut interpréter comme " $\mathrm{Ci}$ comence Rigomer". L'éditeur Wendelin Foerster (Les Merveilles de Rigomer, éd. Wendelin Foerster et Hermann Breuer, Dresde, Gesellschaft für romanische Literatur, 1908 et 1915) allonge le titre sur la base du vers 16, qui déclare traiter des «merveilles de Rigomer». Notre choix se justifie également par un souci de simplification. Voir Francesco Carapezza, «Le Fragment de Turin de Rigomer: Nouvelles perspectives", Romania, 119:1-2 [473-474], 2001, p. 85, note 30.

30 Ce nom apparaît tout du moins à plusieurs reprises dans les commentaires métanarratifs. Richard Trachsler souligne que «le statut de ce personnage est toutefois loin d'être clair, car il peut s'agir de l'auteur comme de la personne qui a fourni une partie de la matière à l'écrivain, et l'on tient là sans doute un autre indice d'une certaine hétérogénéité de l'œuvre." (Les romans arthuriens en vers après Chrétien de Troyes, p. 189). Francesco Carapezza («Le fragment de Turin», 
les environs des années 1268-1275, le roman étant probablement quasi contemporain du manuscrit qui l'a transmis, le ms. Chantilly, Condé $472^{31}$. Nous possédons encore un fragment endommagé, conservé à la bibliothèque de Turin, BN L.IV.33 ${ }^{32}$, qui transmet l'épisode final de la Quintefeuille, isolé du reste du roman. Nous devons pour ce texte nous contenter de l'édition de Wendelin Foerster de 1908 et de la traduction partielle de Margherita Lecco en $2013^{33}$.

- Biaudouz n'a lui aussi que peu suscité l'enthousiasme auprès de la critique et n'a été édité que deux fois, à la fin du XIX ${ }^{\mathrm{e}}$ siècle par Jacob Ulrich et en 2008 par Jacques-Charles Lemaire ${ }^{34}$. Ce roman de Robert

art. cit.) suppose quant à lui que Jehan est l'auteur de la source principale de Rigomer, qui aurait composé la partie qui traite de Gauvain.

31 Voir notamment Lori Walters, "The formation of a Gauvain cycle in Chantilly manuscript 472», Neophilologus, ${ }^{\circ} 78: 1,1994$, p. 29-43. Francis Gingras partage l'hypothèse de la contemporanéité de Rigomer et du ms. Chantilly, Condé 472. "La triste figure des chevaliers dans un codex du XIII ${ }^{\mathrm{e}}$ siècle (Chantilly, Condé 472)", Revue des langues romanes, $\mathrm{n}^{\circ} 110: 1,2006$, p. 77-97. Au sujet de la datation de ce manuscrit, voir Terry Nixon, "Catalogue of Manuscripts", in Les Manuscrits de Chrétien de Troyes, vol. 2, p. 39-41.

32 Voir l'article de Francesco Carapezza, «Le fragment de Turin», art. cit., et Keith Busby, Codex and Context. Reading Old French Narrative in Manuscript, Amsterdam, Rodopi, 2002, vol. 1, p. 87-93. Ce fragment fait partie d'un manuscrit papier daté de la fin du XIV siècle ou du début du Xv siècle. Comme il a brûlé lors de l'incendie de la bibliothèque de Turin en 1904, nous n'avons que peu d'informations sur ce document. Il semble manifestement avoir été copié à partir du manuscrit de Chantilly: les deux versions de l'épisode de la Quintefeuille se terminent notamment sur les mêmes vers, qui occupent la fin d'un verso dans Chantilly.

33 Le Meraviglie di Rigomer (Les Merveilles de Rigomer). Tradizione manoscritta et tradizione narrativa, éd. Margherita Lecco, Alessandria, Edizioni dell'Orso, 2013. Nous utiliserons l'édition de Foerster et Breuer, éd. cit. Une thèse soutenue à l'université de Harvard se consacre entièrement à ce texte: Matthieu William Boyd, The Source of Enchantment: "The Marvels of Rigomer" ("Les Merveilles de Rigomer") and the Evolution of Celtic Influence on Medieval Francophone Storytelling, PhD thesis, Harvard University, 2011.

34 Milena Mikhaïlova-Makarius prépare une nouvelle édition de ce texte, qui entend se conformer à la présentation spécifique au ms. BnF fr. 24301 : l'édition présentera les œuvres de Robert de Blois dans leur ensemble, telles qu'elles sont transmises dans ce manuscrit. Biaudouz apparaîtra ainsi tout à fait pertinemment comme un roman-recueil. Nous reviendrons sur les spécificités de ce roman, qui nous semble composé pour l'occasion de la mise en recueil de l'œuvre complet au 
de Blois, auteur du milieu du XIII ${ }^{\mathrm{e}}$ siècle, a dû être composé dans le but d'enchâsser les œuvres de l'écrivain et de créer ainsi un œuvre complet. Il nous est parvenu dans le ms. BnF fr. 24301, dans lequel il a fonction de récit encadrant, aux côtés des autres œuvres du poète ${ }^{35}$. Il est probable que l'auteur ait présidé lui-même à cette mise en recueil

chapitre III, «Un récit encadrant: Biaudouz et le didactisme», p. 617-629. Notons déjà que l'édition de l'ensemble, et non du seul roman recomposé et coupé des œuvres didactiques et courtoises qu'il contient, permet d'éviter les problèmes inhérents aux bornes de l'œuvre: où commence et où finit la première partie de Biaudouz? On consultera à ce sujet Milena Mikhaïlova-Makarius, L'École du roman. Robert de Blois dans le manuscrit BNF fr. 24301, Paris, Champion, 2010, p. 297-298. Lorsque nous évoquerons le prologue général à la compilation des œuvres de Robert de Blois telle qu'elle se présente dans le ms. BnF fr. 24301, nous citerons d'après sa transcription, p. 365-374. Ce prologue comporte des parties communes à celui que l'on trouve dans d'autres recueils dédiés à Robert de Blois. Elles figurent en vis-à-vis dans cette transcription.

35 Sur l'œuvre de Robert de Blois, on consultera John Howard Fox, Robert de Blois, son ouvre didactique et narrative: étude linguistique et littéraire, suivie d'une édition critique avec commentaire et glossaire de l'Enseignement des princes" et du "Chastoiement des dames", Paris, Nizet, 1950. La mise en recueil particulière de ce roman a été étudiée par Francis Gingras, "Le Biausdous de Robert de Blois: la nature du roman et l'art de la digression", in La digression dans la littérature et l'art du Moyen Âge. Actes du $29^{\circ}$ colloque du CUER-MA, février 2004, éd. Chantal Connochie-Bourgne, Aix-en-Provence, Publications de l'Université de Provence, 2005, p. 187-199, "Mise en recueil et typologie des genres aux XIII ${ }^{\mathrm{e}}$ et XIV ${ }^{\mathrm{e}}$ siècles: romans atypiques et recueils polygénériques (Biaudous, Cristal et Clarie, Durmart le Gallois et Mériadeuc)", in Le Recueil au Moyen Âge, dir. Yasmina Foehr-Janssens et Olivier Collet, Turnhout, Brepols, 2010, vol. 1, p. 91-111, "Récriture, collages et bricolages dans Cristal et Clarie et Biausdous de Robert de Blois", in Chrétien de Troyes et la tradition du roman arthurien en vers, éd. Annie Combes, Patrizia Serra, Richard Trachsler et Maurizio Virdis, Paris, Garnier, 2013, p. 93-106, Sylvie Lefèvre, "Prologues de recueils et mise en œuvre des textes. Robert de Blois, Christine de Pizan et Antoine de la Sale», in Seuils de l'ouvre dans le texte médiéval, éd. Emmanuèle Baumgartner et Laurence Harf-Lancner, Paris, Presses de la Sorbonne, 2002, p. 89-125, et Lori Walters, "Manuscript Context of the Beaudous of Robert de Blois", Manuscripta, 37:2, 1993, p. 179-192. Nous proposons à l'annexe $\mathrm{D}$ un tableau résumant l'ordre d'apparition des œuvres dans le ms. BnF fr. 24301. Pour plus de détails sur les autres recueils de Robert de Blois et pour une comparaison entre ces différents manuscrits, nous renvoyons aux tableaux élaborés par Milena Mikhaïlova-Makarius, L'École du roman. Dans le ms. BnFr fr. 24301, on trouve également, dans cet ordre, une Vie des Pères, une chronique des rois de France, une Passion de Jésus Christ en vers, et le Dolopathos de Jean de Haute Seille. 
particulière: Milena Mikhaïlova-Makarius souligne que les nombreux ajouts et remaniements que comportent les textes de Robert de Blois, de même que la cohérence du projet d'ensemble, orientent vers cette hypothèse. Selon la critique, le ms. BnF fr. 24301 n'est néanmoins pas un manuscrit autographe, car cette copie contient trop de fautes que l'auteur n'aurait pu commettre et qu'on y perçoit des traits lorrains qu'on ne peut attribuer à l'auteur ${ }^{36}$. Il peut toutefois s'agir d'un manuscrit apographe, c'est-à-dire copié depuis l'original. On peut vraisemblablement dater cette copie de la fin des années 1260: les initiales parties, prolongées de bandes d'I - fréquentes dès le milieu du XIII ${ }^{\mathrm{e}}$ siècle ${ }^{37}$ - et décorées d'arabesques à la plume, de même que l'écriture ${ }^{38}$, orientent la datation vers le dernier tiers du XIII ${ }^{\mathrm{e}}$ siècle. Néanmoins, la Petite chronique des rois de France contenue aux pages 263-264 liste les rois "qi de France trespassé sont» (page 264b) jusqu'à Louis VIII, mort en 1226. Comme il manque saint Louis, mort en 1270, on peut supposer que le recueil a été copié juste avant la mort du $\operatorname{roi}^{39}$. Si l'on

36 Voir Milena Mikhaïlova-Makarius, L'École du roman, p. 353. L'édition de Jacques Lemaire souligne également les nombreuses entorses à la rime ou au mètre dans son édition, Biaudouz, éd. cit.

37 "La décoration du manuscrit», ressource de l'IRHT: https://irht.hypotheses. org/751

38 En comparant cette écriture aux exemples du Catalogue des manuscrits en écriture latine portant des indications de date, de lieux ou de copistes, éd. Charles Samaran et Robert Marichal, Paris, Éditions CNRS, t. 3, en ligne: http://gallica.bnf.fr/ ark:/12148/bpt6k4830j/f2.item.zoom, il nous a semblé voir plusieurs similitudes avec les modèles de textes datés entre 1256 et 1300 . On remarque notamment le $\mathrm{D}$ oncial, le $\mathrm{O}$ presque rond, de même que les panses des $\mathrm{D}, \mathrm{P}$ et $\mathrm{B}$, le $\mathrm{M}$ gothique tracé par jambages. On note également la séparation nette des mots et des lettres. Selon la base de données de l'IRHT «Jonas», il s'agit d'une gothique textuelle bâtarde. http://jonas.irht.cnrs.fr/consulter/manuscrit/detail_manuscrit. php?projet $=45906$

39 Il faut au moins supposer que la copie de cette Petite chronique est antérieure à 1270 : la copie du reste du manuscrit pourrait avoir eu lieu juste après cette date. L'École du roman, Milena Mikhaïlova-Makarius date la composition du recueil du dernier tiers du XIII ${ }^{\mathrm{e}}$ siècle, probablement après 1262, voire après 1272 . Notons encore que, selon Felix Lecoy, ce manuscrit est copié d'une seule main: "L'écriture, très régulière, quelque peu anguleuse, reste la même d'un bout à l'autre de la copie.» (La Vie des Pères, éd. Felix Lecoy, Paris, Société des Anciens Textes français, 1987, t. 1, p. xx). Milena Mikhaïlova-Makarius fait la même hypothèse, L'École du roman, p. 337. 
admet que Biaudouz est la dernière œuvre de Robert de Blois et a été composé pour l'occasion de la mise en recueil que l'on retrouve dans BnF fr. 24301, il semble raisonnable de situer l'écriture du roman entre 1260 et 1269 . Même si nous disposons de peu d'indices sur la vie du poète et la date de sa mort, la dédicace présente dans le manuscrit BnF fr. 2236 n'exclut pas qu'il ait vécu jusqu'en 1269, date de la mort du dédicataire Thierry de Forbach ${ }^{40}$.

- Escanor de Girart d'Amiens est le dernier roman arthurien en vers du XIII ${ }^{\mathrm{e}}$ siècle: la commanditaire, Aliénor de Castille, et l'armorial mènent Gérald Brault à dater le roman de $1281^{41}$. S'il ne nous reste aujourd'hui que le ms. BnF fr. 24374 (fin du XIII ${ }^{e}$ siècle ${ }^{42}$ ), auquel il manque plusieurs feuillets, deux fragments perdus qui servaient de reliure ainsi que la mention dans l'inventaire de la bibliothèque de Charles $\mathrm{V}$ laissent penser à une diffusion plus importante de ce roman que celle des autres ouvres tardives. Linventaire de Charles V mentionne son prêt à la reine en 1390, preuve qu'il était encore lu à cette date. Escanor a été édité une première fois par Michelant en 1886 et une seconde par Richard Trachsler en $1994^{43}$. Girart d'Amiens est l'auteur de deux autres textes narratifs: un roman oriental, Meliacin ou le cheval du fust $(1285)^{44}$, et une chanson de geste,

40 Voir John Howard Fox, Robert de Blois, son auvre didactique et narrative, p. 45-46.

41 Il s'agit des armes du roi d'Écosse et du roi de Galles. Ce dernier s'étant opposé à la couronne anglaise, sauf pendant les années 1277 à 1286, il semble légitime de postuler qu'il fut mis en scène pendant ces années de soumission, afin de complaire au roi anglais. Gérald Brault, "Arthurian heraldry and the date of Escanor", Bulletin bibliographique de la Société internationale arthurienne, 11, 1959, p. 81-88.

42 Selon la datation de Richard Trachsler, dans son introduction à l'édition Girart d'Amiens, Escanor, Genève, Droz ("Textes littéraires français»), 1994, p. 11. Le BnF fr. 24374 ne contient aujourd'hui qu'Escanor, mais peut-être faut-il considérer qu'il transmettait à l'origine plusieurs textes: les cahiers perdus attestent de son dépeçage et sa présence sous le titre «vieux romans des Chevaliers de la Table ronde», au pluriel, dans le catalogue du Collège de Navarre établi par Masson en 1741 (BnF, lat. 9371, voir Richard Trachsler, Escanor, éd. cit., p. 22), laisse envisager la possibilité que notre roman figurait côte à côte avec d'autres romans arthuriens. Il provient d'un atelier parisien.

43 Richard Trachsler traite de la transmission manuscrite aux pages 11 à 21 de son édition.

44 Voir l'édition d'Antoinette Saly, Girart d'Amiens, Meliacin ou le Cheval de fust, Aix-en-Provence, Publications du CUER-MA («Senefiance», 27), 1990. Ce texte, 
L'Istoire le roy Charlemaine (1300-1308) ${ }^{45}$. L'œuvre de l'écrivain est donc issue de traditions variées.

- Enfin, Melyador est composé par un autre poète polygraphe, Jean Froissart. Héritier de la littérature du début du XIv ${ }^{\mathrm{e}}$ siècle, il est écrit selon l'éditrice Nathalie Bragantini-Maillard entre 1362 et 1369 dans sa première version, pour la cour d'Édouard III et Philippa de Hainaut, et entre 1381 et 1383 pour la seconde, qui constitue un remaniement auquel sont intégrées les compositions poétiques du duc Wenceslas de Brabant ${ }^{46}$. Il nous est transmis par un manuscrit, le ms. BnF fr. 12557 (tournant du XIv ${ }^{\mathrm{e}}$ ), et quelques fragments, réunis dans BnF nouv. acqu. lat. 2374 (fin $\mathrm{XIV}^{\mathrm{e}}$-début $\left.\mathrm{Xv}^{\mathrm{e}}\right)^{47}$. Comme pour Escanor, on peut supposer une diffusion plus large, quoique loin d'égaler celle des Chroniques de Jean Froissart: l'inventaire de 1466 de la bibliothèque de Charles d'Orléans mentionne Melyador.

Ce texte est le dernier roman arthurien en vers du Moyen Âge français: le retour du genre près d'un siècle après son prétendu épuisement ne laisse pas d'étonner. L'étude de Melyador permettra d'esquisser l'orientation d'une esthétique qui se dessine à la fin du XIII ${ }^{\mathrm{e}}$ siècle et se précise au XIV siècle tout en s'enrichissant d'autres éléments. Elle répond parfaitement à notre objectif, car elle met en perspective les

adaptation d'un conte des Mille et une Nuits et donc ancré en Orient, a connu un plus grand succès qu'Escanor, puisqu'il est transmis par cinq manuscrits.

45 Critical Edition of Girart d'Amiens' "L'Istoire le roy Charlemaine”, poème épique du $X I V^{e}$ siècle, éd. Daniel Métraux, Lewiston, Queenston et Lampeter, Edwin Mellen Press («Studies in French Literature», 72), 2003.

46 On consultera l'introduction à l'édition de Nathalie Braganini-Maillard pour des détails sur la datation et les manuscrits, Jean Froissart, Melyador, éd. Nathalie Bragantini-Maillard, Genève, Droz («Textes littéraires français»), 2012, p. 25-69. L'évocation de Melyador au Livre III, $\$ 13$ des Chroniques ainsi que dans Le Dit dou Florin éclairent cette datation et fournissent quelques informations sur la rédaction et la diffusion du roman. Celui-ci a été édité pour la première fois par Auguste Longnon: Méliador par Jean Froissart, roman comprenant les poésies lyriques de Wenceslas de Bohême, duc de Luxembourg et de Brabant, éd. Auguste Longnon, Paris, Firmin Didot ("Société des anciens textes français», 35), 18951899,3 t.

47 La datation des manuscrits nous est fournie par l'édition de Nathalie BragantiniMaillard, éd. cit., p. 25-30. 
mutations littéraires effectives au $\mathrm{XIV}^{\mathrm{e}}$ siècle, dont la tendance est perceptible dans le reste du corpus ${ }^{48}$.

En suivant l'idée d'une dérivation progressive de la littérature arthurienne en vers, ce corpus peut faire l'objet d'une hiérarchisation: plus le temps avance, plus les textes produits relèvent de cette esthétique de la tardivité que nous entendons définir. Malgré les innovations notables qu'elles instaurent, les trois premières œuvres se distinguent par une parenté plus importante avec les romans du début du XIII ${ }^{\mathrm{e}}$ siècle, notamment par leur pratique de l'intertextualité et de la parodie. Les deux dernières, Escanor et Melyador, sont au contraire de véritables résurgences qui rompent plus fermement avec le roman arthurien en vers tel qu'inventé par Chrétien de Troyes. La tardivité s'exprime en termes de secondarité dans Claris et Laris, Floriant et Florete et Rigomer, et en termes de résurgence dans les deux derniers textes de l'histoire du roman arthurien en vers, selon la rupture que chacun opère plus ou moins par rapport à la tradition et aux techniques de l'écriture arthurienne versifiée; nous admettons ainsi l'idée qu'il existe des degrés de tardivité et qu'un texte peut être plus ou moins tardif. Le roman de Biaudouz est quant à lui un témoin à part qui démontre le caractère protéiforme de l'écriture tardive, capable de soumettre le roman arthurien en vers à toutes les expérimentations littéraires. L'étude s'emploiera à préciser les spécificités de chaque roman.

La production de textes en prose peut, tout comme celle en vers, être envisagée en termes de générations: par «romans en prose de première génération", nous entendons le cycle ${ }^{49} \mathrm{du}$ Lancelot-Graal, qui comprend le

48 Michel Zink traite de ces changements qui affectent la littérature du XIV ${ }^{e}$ siècle dans "XIII. Le Roman", in Grundriß der romanischen Literaturen des Mittelalters. La littérature française aux XIV et XV siècles, vol. VIII/I, Heidelberg, Carl Winter, 1988, p. 197-218. Nous renvoyons à l'annexe A pour une présentation synoptique des textes de notre corpus et des manuscrits qui les conservent.

49 Annie Combes définit la notion de cycle comme suit: "un cycle est formé d'une série d'œuvres autonomes reliées par une unité thématique et une successivité chronologique." (Les voies de l'aventure. Réécritures et composition romanesque dans le Lancelot en prose, Paris, Champion, 2001, p. 55). Le Lancelot en prose est un cycle, car il raconte la vie de Lancelot depuis la naissance jusqu'à la mort; le Cycle de Guillaume est un cycle, car plusieurs chansons autonomes se succèdent chronologiquement pour raconter les enfances et les péripéties de Guillaume, de son neveu Vivien et de personnages de leur entourage. On consultera surtout l'ouvrage de Patrick Moran, Lectures cycliques. Le réseau inter-romanesque dans les cycles $d u$ 
Lancelot propre, la Queste del saint Graal, la Mort Artu et les ajouts tardifs de l'Estoire del saint Graal et du Merlin en prose. Ces œuvres sont composées dans le premier tiers du XIII $^{\mathrm{e}}$ siècle. Les romans en prose de deuxième génération comprennent le Tristan en prose dans ses deux versions (1230 et 1250) et la Suite du Roman de Merlin (vers 1240). Enfin, la troisième génération regroupe Meliadus (1235-1240), le Roman de Guiron (12351240), la Suite Guiron (1230-12340) ${ }^{50}$ et le Livre d'Artus (milieu du XIII ${ }^{\mathrm{e}}$ siècle) ${ }^{51}$. Toutes ces œuvres informent peu ou prou l'esthétique des textes de notre corpus. Nous tiendrons également compte du cas particulier que représente le Conte du Papegau (tournant des $\mathrm{XIV}^{\mathrm{e}}-\mathrm{XV}^{\mathrm{e}}$ siècles), roman arthurien en prose dont la structure ressemble à celle des romans arthuriens en vers, à tel point qu'on a pu le prendre pour un dérimage ${ }^{52}$.

Graal du XIIt siècle, Paris, Champion, 2014, pour une étude du fonctionnement des cycles. Considérant qu'un cycle désigne une architecture complexe formée de plusieurs textes autonomes, dont la combinaison est modulable au gré des manuscrits et des lectures offertes, le Lancelot-Graal est selon lui le seul véritable cycle arthurien du Moyen Âge. Le Tristan en prose doit quant à lui être appréhendé comme une somme romanesque. La somme et le cycle partagent la même visée totalisante que définit Emmanuèle Baumgartner à propos du cycle: l'un des enjeux de la prose est de "créer un cycle, c'est-à-dire un univers romanesque à la recherche de son origine et de sa clôture, et éventuellement capable d'absorber tous les récits préexistants, tous les récits à venir; bref, configurer globalement non pas le temps humain - c'est là l'enjeu propre des histoires, universelles ou non, du récit historique - mais un temps romanesque, un temps fictionnel qui en soit le plus parfait, le plus achevé des simulacres» ("Les techniques narratives dans le roman en prose», in The Legacy of Chrétien de Troyes, éd. Norris J. Lacy, Douglas Kelly et Keith Busby, Amsterdam, Rodopi, 1987-1988, p. 170).

50 Sur la datation retenue pour le cycle de Guiron le courtois, voir Nicola Morato, "Formation et fortune du cycle de Guiron le courtois", in Le Cycle de Guiron le courtois. Prolégomènes à l'édition intégrale du corpus, dir. Lino Leonardi et Richard Trachsler, Paris, Garnier, 2018, p. 179-247.

51 L'étude de Patrick Moran éclaire les rapports entre les différents romans en prose: le cycle Vulgate est un noyau et les autres romans se construisent «au second degré à partir de l'univers de fiction que ce cycle fonde. Les romans suivants vont s'élaborer dans les interstices de la Vulgate, en parallèle comme le Tristan, dans des zones plus faiblement définies comme Guiron le courtois (qui se construit au troisième degré en référence à la fois à la Vulgate et au Tristan), ou dans l'amont et l'aval informulés, comme le Perceforest et Ysä̈e le Triste» (Patrick Moran, Lectures cycliques, p. 596-597).

52 Voir les pages 12-14 de l'édition d'Hélène Charpentier et Patricia Victorin, Le Conte du Papegau, Paris, Champion (“CCMA»), 2004. 
Les romans arthuriens en prose postérieurs à 1300 ne seront pris en considération que ponctuellement, pour pointer tantôt des similitudes, tantôt des différences avec notre corpus. Cette production, qui comprend Perceforest ${ }^{53}$, Artus de Bretagne (1296-130554) et Ysä̈e le Triste (fin du XIV ${ }^{\mathrm{e}}$ début du $\mathrm{Xv}^{\mathrm{e}}$ siècle), tente elle aussi un renouvellement des pratiques arthuriennes en s'intéressant à la préhistoire du monde arthurien (Perceforest) ou à ses descendants (Ysä̈e le Triste, Artus de Bretagne). Tout comme les textes de notre corpus, ces œuvres ne sont jamais mises en cycle, malgré leur construction en suite ou en prequel (chapitre III, «Structures arthuriennes: imiter la prose», p. 493-554). La tardivité, en vers et en prose, s'homogénéise surtout par l'adjonction d'histoires au monde arthurien qui ne viennent pas contredire ce qu'en ont déjà dit les cycles en prose du XIII ${ }^{\mathrm{e}}$ siècle; la façon de réaliser ces adjonctions est toutefois toujours modulée par le choix du vers ou de la prose, même dans les œuvres tardives. Sans avoir l'ambition de proposer une étude parallèle de ce que serait la tardivité en prose et en vers, nous nous contenterons de suggérer ici et là des points communs.

Afin de confronter les deux corpus du roman arthurien tardif en vers et des romans en prose $\mathrm{du} \mathrm{XIII}^{\mathrm{e}}$ siècle en envisageant leurs oppositions génériques, il s'agira de problématiser le concept théorique de genre littéraire et de définir le genre du roman arthurien en vers, ceci dans le but aussi de nuancer les critiques à l'égard de ce corpus de «mauvais romans arthuriens». D'autres œuvres, convoquées plus ponctuellement, mèneront à approfondir la généricité arthurienne et la nécessité ou non des critères génériques que nous pourrons établir. Il s'agit de textes en vers où l'influence du roman arthurien est manifeste, mais auxquels il manque plusieurs critères pour être pleinement rattachés au canon du genre. Beate Schmolke-Haßelmann les exclut d'ailleurs de son corpus de romans arthuriens en vers. Nous les présentons ici dans l'ordre dans lequel ils apparaîtront au cours de l'étude:

53 La datation de Perceforest divise la critique. Gilles Roussineau estime qu'une première version des années 1340 aurait donné lieu à un remaniement au milieu $\mathrm{du} \mathrm{Xv}^{\mathrm{e}}$ siècle. Voir notamment "Réflexions sur la genèse du Perceforest", in Perceforest. Un roman arthurien et sa réception, dir. Christine Ferlampin-Acher, Rennes, PUR, 2012, p. 255-267. Christine Ferlampin-Acher estime quant à elle que Perceforest aurait été terminé en 1460 par David Aubert. Perceforest et Zéphir. Propositions autour d'un récit arthurien bourguignon, Genève, Droz, 2010.

54 Artus de Bretagne. Roman en prose de la fin du XIII siècle, éd. Christine FerlampinAcher, Paris, Champion ("CFMA»), 2017, p. XxIII-XXXvI. 
- Brun de la Montagne (entre 1295 et 1320), texte en laisses d'alexandrins monorimes dont les thèmes sont plus romanesques (éducation par les fées, errance aventureuse) qu'épiques. Le protagoniste rencontre le roi Arthur sur son chemin. Ce texte pose la question de l'influence de la forme sur le genre avec acuités5;

- Le Tournoi de l'Antéchrist de Huon de Méry (après 1236), qui exploite des motifs arthuriens et propose un Arthur allégorique ${ }^{56}$;

- La Bataille Loquifer (fin XII ${ }^{\mathrm{e}}$-début XIII ${ }^{\mathrm{e}}$ siècle), exemple de séjour avalonien épique ${ }^{57}$;

- Le Roman du Hem de Sarrasin (1278), reportage du tournoi historique de 1278 au hameau du Hem dont les participants se muent en personnages arthuriens ${ }^{58}$;

- Blandin de Cornouailles (XIv ${ }^{\mathrm{e}}$ siècle), roman occitan du Sud de la France qui ressemble en tous points à un roman arthurien: l'action se déroule en Cornouailles, où l'on suit les aventures de deux chevaliers errants jusqu’à leurs mariages. Mais, à nouveau, il n'est fait aucune mention d'Arthur ${ }^{59}$.

Ce corpus secondaire sera abordé comme un groupe "para-arthurien", qui donnera l'occasion de traiter de la généricité arthurienne dans des œuvres qu'on ne reconnait habituellement pas comme des romans arthuriens. Leur étude donnera corps à notre réflexion sur la solidarité ou non des rapports entre les différents critères génériques.

La question des conséquences génériques et esthétiques d'un choix formel que nous posons au corpus des romans arthuriens en vers tardifs sera traitée en trois temps. Nous fixerons d'abord le cadre théorique de

55 Nous recourons à l'édition de Charles Louis Janssens, An Annotated Edition of Brun de la Montaigne, thèse de l'Université d'Arizona, 1967. Nous donnons également la datation de l'éditeur.

56 Huon de Méry, Le Tournoi de l'Antéchrist, éd. Georg Wimmer, prés. Stéphanie Orgeur, Orléans, Paradigme ("Medievalia», 13), 1995.

57 La Bataille Loquifer, éd Monica Barnett, Oxford, Society for the Study of Medieval Languages and Literature ("Medium Aevum»), 1975.

58 Sarrasin, Le roman du Hem, éd. Albert Henry, Bruxelles, Éditions de la Revue de l'Université de Bruxelles; Paris, Belles Lettres («Travaux de la Faculté de philosophie et lettres de l'Université de Bruxelles", 9), 1939.

59 Blandin di Cornovaglia, éd. Sabrina Galano, Alessandria, Edizioni dell'Orso, 2004. 
notre recherche en élaborant une théorie du genre valable pour la littérature du Moyen Âge. Un genre littéraire se reconnaît sur la base de différents critères que nous entendons définir dans ce premier chapitre, qui conduira finalement à préciser l'articulation entre genre et matière. La hiérarchisation des différents postes génériques constituera un premier jalon de la réflexion sur les interactions entre genre et forme. Ce cadre théorique mènera à une définition du roman arthurien en vers classique, dans le but de la confronter à l'esthétique des textes de notre corpus, dont le caractère paralittéraire ou décadent sera également interrogé dans ce chapitre. Les critères relevés seront mis en parallèle avec quelques textes para-arthuriens qui en problématiseront la portée et montreront qu'aucun critère n'est indispensable pour engager une réflexion de type générique. Cette étude approfondira celle des romans tardifs et de leur rapport au genre arthurien. La fin du genre étant à comprendre en lien avec la forme versifiée qu'il choisit, le deuxième chapitre envisagera les enjeux que revêt l'écriture en vers après le milieu du XIII ${ }^{\mathrm{e}}$ siècle: la distinction entre vers et prose, l'extinction du vers comme forme privilégiée du genre romanesque et quelques cas de survivance du genre versifié, sous la forme de la mise en prose et de l'hapax du Conte du Papegau. Une fois clarifié le choix du vers dans notre corpus, nous pourrons caractériser la nouvelle esthétique induite par la tardivité de ces textes lors du troisième chapitre, à partir des critères génériques repérés. Nous considérerons le statut des personnages, le cadre spatio-temporel et la structure. Finalement, l'ouverture des romans tardifs sur d'autres types de discours sera problématisée sous l'angle de la confluence générique.

Ces pistes successives permettront d'envisager l'évolution du roman arthurien en vers comme une trajectoire ${ }^{60}$ non pas linéaire (apogéedéclin), mais dynamisée par les multiples influences qui le nourrissent. L'extinction ne s'explique pas en ce sens par l'incompétence des auteurs,

60 Nous donnons à la notion de trajectoire la définition suivante: «L'étude d'une trajectoire, c'est l'étude des positions successives occupées par un agent au cours du temps (Bourdieu, 1986), des choix qui ont été faits parmi l'univers des possibles (Gingras, 2000). Comprise entre un début et une fin, reconnaissant les sinuosités, les incurvations, les ruptures imposées à l'individu par les contingences du quotidien, les hasards ou les déterminismes sociaux." Anne-Sophie FournierPlamondon et Jules Racine-Saint-Jacques, "(Re)Constituer la trajectoire», Conserveries mémorielles, 15, 2014, en ligne: http://journals.openedition.org/ $\mathrm{cm} / 1740$ 
la reproduction sèche de structures narratives éculées ou le désintérêt du public pour la veine arthurienne. L'étude montrera qu'il faut plutôt la comprendre comme la rencontre de conjonctures défavorables au roman arthurien en vers, le rapport de moins en moins intuitif à la forme versifiée en premier lieu. La trajectoire du roman arthurien en vers, à l'aune de ses derniers représentants, est indissociable de l'essor des œuvres en prose, si bien que l'on peut dire, avec Richard Trachsler, que les romans tardifs «obéissent sans doute aussi à une autre esthétique, qui n'est ni celle des écrits en prose, ni certainement celle des récits en vers, mais qui se situe, comme celle d'Escanor, quelque part à cheval entre les deux et qui reste à définir ${ }^{61}$. C'est à cette tâche que nous aimerions nous atteler.

${ }^{61}$ Richard Trachsler, «De la Prose au Vers. Le cas de Dynadan dans l'Escanor de Girart d'Amiens", art. cit., p. 410. 


\section{CHOIX DE FORME, CONSÉQUENCES GÉNÉRIQUES}

Concevoir l'influence de la forme sur le genre impose de définir l'acception et l'utilisation de cette notion théorique. Ce premier chapitre se veut une mise au point nécessaire à la perspective générique qui est la nôtre sur notre corpus, envisagé à travers le dialogue que les œuvres établissent avec la littérature. Nous utilisons le terme de "généricité» pour désigner les rapports qu'entretiennent les œuvres entre elles, rapports qui relèvent d'une réflexion sur le genre: il permet de penser «la participation d'un texte à plusieurs genres ${ }^{1}$ et de considérer la théorie du genre comme un dialogue entre des textes qui ont des points communs. Adopter une perspective générique, c'est donc percevoir des ressemblances entre des textes, que l'on peut regrouper en ensembles cohérents. Le genre est alors envisagé, pour suivre Patrick Moran, comme un outil communicationnel et non taxinomique: telle manifestation littéraire relève $d u$ genre, mais ne rend pas compte d'une appartenance à un genre ${ }^{2}$. Cela présume d'abord que la notion de genre est applicable à la littérature médiévale, malgré l'absence à cette époque de véritable théorisation littéraire. L'objet de la première partie de ce chapitre sera de démontrer la pertinence de cet outil et de dégager les critères opérants de la généricité médiévale, la forme étant un critère déterminant qu'il faudra situer hiérarchiquement

Jean-Michel Adam et Ute Heidmann, «Six propositions pour l'étude de la généricité», in Le Savoir des genres, dir. Raphaël Baroni et Marielle Macé, Rennes, PUR («La licorne», 79), 2006, p. 25.

2 Nous reprenons ici la réflexion de Patrick Moran, "Genres médiévaux et genres médiévistes: l'exemple des termes chanson de geste et épopée», Romania, 541-542, 2018, p. 38-60. 
par rapport aux autres. Notre perspective sur les romans arthuriens tardifs suppose ensuite que le roman arthurien peut être considéré comme un genre, dont il faut définir les modalités et le canon virtuel; ce sera l'objet de la seconde partie.

\section{UNE THÉORIE DES GENRES POUR LE MOYEN ÂGE?}

\section{Pertinence de la notion de genre}

L'applicabilité des concepts de genre et de littérature au Moyen Âge n'est pas toujours allée de soi. La réticence à utiliser la notion de "genre", partagée d'ailleurs par plusieurs critiques dont notamment Paul Zumthor ${ }^{3}$, est liée à la modernité de son élaboration: peut-on dès lors l'appliquer au Moyen Âge ?4 Les objections qui en découlent s'expliquent par plusieurs facteurs: d'abord, la littérature étant en construction au Moyen Âge, elle ignore les distinctions poétologiques qui concernent la modernité et n'a pas engendré de règles rigoureuses ni de traités. Or, il est difficile de classer ce qui est à peine défini. Le mot "genre» n'est d'ailleurs pas employé à cette époque, au contraire de celui de "matière», qu'il ne faut pas appréhender comme un concept équivalent. Hélène Naïs traite de l'apparition progressive de termes liés à la généricité, comme maniere ou taille. Elle souligne que si le mot «genre» est totalement absent, la notion est néanmoins implicite. Divers indices permettent justement d'affirmer que les érudits des $\mathrm{XII}^{\mathrm{e}}$ et XIII ${ }^{\mathrm{e}}$ siècles opéraient des groupements textuels cohérents et conscients: nous verrons que la mise en recueil, l'existence de traités

3 Paul Zumthor, Essai de poétique médiévale, Paris, Seuil, 2000.

4 Il faut noter que le Moyen Âge est souvent occulté dans les histoires de la notion théorique: Dominique Combe, Les Genres littéraires, Paris, Hachette, 1992, passe par exemple de l'Antiquité au XvII siècle sans transition.

5 Hélène Naïs, "La notion de genre en poésie au XvI ${ }^{\mathrm{e}}$ siècle: étude lexicologique et sémantique», in La notion de genre à la Renaissance, dir. Guy Demerson, Genève, Slatkine, 1984, p. 103-127. Le terme "genre» est bien présent au Moyen Âge, mais il ne prend le sens de "catégorie d'œuvres définie par des caractères communs (sujet, style, etc.)" (Dictionnaire historique de la langue française, dir. Alain Rey, tome 1, Paris, le Robert, 1992, p. 882) qu'au XviI siècle. Avant cela, il désigne une catégorie, un type, une espèce, applicable à l'humanité: le "genre humain ", attesté dès le début du XIII ${ }^{\mathrm{e}}$ siècle, désigne un groupement d'êtres ayant des ressemblances naturelles (p. 881-882). 
poétiques pour la production en latin et quelques témoignages individuels signalent la possibilité cognitive pour les médiévaux de hiérarchiser le champ poétique.

En plus d'être un concept contextuel lié à la modernité, la théorie du genre s'appuie encore sur la triade aristotélicienne, qui peine à s'appliquer à la période médiévale, en raison de l'absence de normes institutionnelles et des problèmes théoriques qu'elle pose: la théorie d'Aristote entend édicter des prescriptions d'écriture et hiérarchiser axiologiquement le champ poétique, le drame étant le mode de référence par lequel sont jugés les autres. La différenciation repose sur trois critères: les moyens (les formes), les objets (les personnages sont meilleurs ou pires que nous) et les modes (les objets sont représentés par un narrateur ou par des acteurs). Se dessine ainsi une opposition: celle qui distingue le drame de la narration, ce qui exclut la lyrique du système. Ce n'est qu'au XviII ${ }^{\mathrm{e}}$ siècle qu'une lecture romantique d'Aristote poussera à reformer la théorie pour y insérer la lyrique ${ }^{6}$.

Il faut donc renoncer tout du moins à cette triade pseudo-aristotélicienne (drame - narration - poésie lyrique), de même qu'au caractère prescriptif que peut avoir cette théorie générique. Notre proposition s'avérera toutefois proche de la lecture que Gérard Genette opère de La Poétique: le critique en retient plutôt l'idée d'une conjonction entre différents éléments que l'érection d'archigenres. Si la théorie communément admise du genre ne fonctionne pas pour la période qui nous intéresse, c'est qu'elle mérite d'être révisée. Au lieu d'exclure le Moyen Âge de la théorie du genre, nous préfèrerons adapter celle-ci, une théorie ne faisant sens que lorsqu'elle englobe un maximum de phénomènes, pour suivre l'avis de Patrick Moran:

La validité d'une théorie se vérifie au nombre de phénomènes dont elle permet de rendre compte. Si la théorie littéraire ne parvient pas à rendre compte de la littérature médiévale, ce n'est peut-être pas tant parce que celle-ci est intrinsèquement rétive que parce que celle-là n'est pas encore au point: en ce sens les textes médiévaux sont moins un défi à la théorie qu'un défi pour la théorie; ils doivent la pousser à

6 Au sujet de cette triade - drame, épopée, lyrique -, on consultera Gérard Genette, "Introduction à l'architexte», in Théorie des genres, dir. Gérard Genette et al., Paris, Seuil, 1986, p. 89-159, Jean-Marie Schaeffer, Qu'est-ce qu'un genre littéraire?, Paris, Seuil, 1989, et Marielle Macé, Le genre littéraire, Paris, Flammarion ("GF corpus»), 2004, ainsi que notre article, "Triade aristotélicienne, matières bodéliennes, genres médiévaux: dépasser les apories génériques avec Gérard Genette", Perspectives médiévales, à paraître. 
se repenser, s'élargir et se corriger, si elle ne souhaite pas renoncer à ses prétentions généralisantes ${ }^{7}$.

En incluant la littérature médiévale dans une réflexion théorique sur le genre, on renforce le constat que les genres ne sont pas des essences qui préexistent aux textes, qu'ils ne s'élaborent pas en dehors d'eux et ne sont pas des catégories biologiques ${ }^{8}$. L'existence de groupements poétiques en dépit de l'absence de norme et d'institutionnalisation du champ littéraire démontre que celui-ci s'organise par lui-même et qu'il se crée des rapports entre ses représentants sans l'intervention d'une pensée critique préalable.

Travailler avec la notion de genre littéraire implique encore qu'il existe une littérature médiévale. Cela ne va pas de soi: Paul Zumthor remet aussi en cause la pertinence du terme pour notre période, en raison d'abord de la diffusion massivement orale de la poésie, ensuite pour le caractère institutionnel et contextuel du concept de «littérature»; celui-ci naît de la société bourgeoise et trace une hiérarchie du champ textuel sur le mode de l'exclusion (être littéraire, ne pas l'être, être "paralittéraire») ${ }^{9}$. Au Moyen

7 Patrick Moran, Lectures cycliques, p. 641. Catherine Croizy-Naquet, dans sa contribution au colloque "Littérature": où allons-nous, du 3 au 5 octobre 2012», "Dislocation de la discipline "Littérature" ?", souligne les divers problèmes que pose la littérature médiévale à la théorie littéraire: la dimension philologique et linguistique, nécessaire à son abord, et l'idée selon laquelle elle représente les balbutiements de la littérature expliquent la mise à l'écart dont elle fait l'objet. Voir la synthèse sur le site de Transitions: http://www.mouvement-transitions.fr/ index.php?option $=$ com_content $\&$ view $=$ article $\&$ id $=565$ : civilites-qlitterature-ouallons-nousq-dislocation-de-la-discipline\&catid=29\&Itemid=101.

8 Voir Marielle Macé, Le genre littéraire.

9 Le colloque international " "Littérature" : où allons-nous?", organisé par François Cornilliat et Hélène Merlin-Kajman à Paris du 3 au 5 octobre 2012, a interrogé la pertinence du mot "littérature» pour désigner les textes sur lesquels les «littéraires» travaillent. Les participants soulèvent le problème de l'anachronisme de la notion: ce qui définit un texte littéraire $a u x I^{\mathrm{e}}$ siècle ne définit pas forcément un texte littéraire du $\mathrm{XIX}^{\mathrm{e}}$ siècle. La synthèse du colloque fait apparaître le difficile cadrage de la notion, si ce n'est l'impossibilité d'une définition valable pour toutes les périodes. Nous nous bornons ici à citer quelques remarques du débat qui nous paraissent aller dans notre sens. Peut-être faut-il se résigner à adopter une acception différente selon les époques. Il faudrait ainsi parler de «littérarités " au pluriel. Voir la synthèse du colloque, en ligne, http:/www.mouvement-transitions.fr/ index.php/litterarite/colloques/3-5-octobre-2012-litterature-ou-allons-nous, et la synthèse de Hélène Merlin-Kajman parue dans Versants, 62, 2015, "Retour sur le colloque "Littérature: où allons-nous?" : synthèse et débat", p. 171-194. 
Âge en revanche, il n'y a pas d'instance surplombante; la production ne se nomme pas, il n'existe pas de terme désignant un ensemble formant un tout ${ }^{10}$. L'absence de mot ne signifie pas pour autant l'inexistence du phénomène littéraire ${ }^{11}$ : la conscience littéraire s'exprime par divers moyens, notamment la reconnaissance de maîtres en matière d'écriture, Chrétien de Troyes en chef de file, dont on loue les "bons dis» ${ }^{12}$ et dont on dit qu'il «trova si bel de Perceval» (Sarrasin, Roman du Hem, v. 477). L'auteur est celui qui trouve $e^{13}$, c'est-à-dire qu'il compose une œuvre en

10 Voir Paul Zumthor, La lettre et la voix: de la "littérature» médiévale, Paris, Seuil («Poétique»), 1987. Sur ces questions, nous renvoyons aux réflexions de Patrick Moran, "Deux questions de théorie littéraire», in Lectures cycliques, p. 609-647: «Ce que nous appelons littérature médiévale est une pratique sans autorité, qui ne se confere pas de statut surplombant et ne se construit pas un domaine éminent au sein des divers exercices culturels de l'époque.» (p. 616)

11 Au sujet du sens du mot «littérature» au Moyen Âge, voir Jacqueline CerquigliniToulet, "Littérature médiévale? », art. cit., et "Littérature», conférence au colloque " "Littérature": où allons-nous, du 3 au 5 octobre 2012 », dir. François Cornilliat et Hélène Merlin-Kajman, Paris, en ligne: http://www.mouvement-transitions. fr/index.php/litterarite/colloques/3-5-octobre-2012-litterature-ou-allons-nous. Alors que litteratura désigne d'abord la lecture commentée des auteurs, le fait de tracer des lettres et non les ouvres elles-mêmes (Michel Zink, "Littérature(s)», in Dictionnaire raisonné de l'Occident médiéval, dir. Jacques Le Goff et JeanClaude Schmitt, Paris, Fayard («Pluriel»), p. 611), au XiI ${ }^{\mathrm{e}}$ siècle, sa transposition en langue vernaculaire (lettreüre) renvoie à ce qui est écrit, à la connaissance de l'écrit et des livres faisant autorité (Joëlle Ducos, Olivier Soutet et Jean-René Valette, Le français médiéval par les textes: anthologie commentée, Paris, Champion ("Références et Dictionnaires»), 2015, p. 50-52). Ce n’est qu'au Xviri ${ }^{\mathrm{e}}$ siècle qu’il faut comprendre par «littérature" l'"ensemble des œuvres, des textes relevant des belles-lettres" (Dictionnaire historique de la langue française, tome 1, p. 1137) et que se précise le sens institutionnel et exclusif.

12 The Romance of Hunbaut: An Arthurian Poem of the Thirteenth Century, ed. Margaret Winters, Leiden, Brill ("Davis Medieval Texts and Studies», 4), 1984, v. 187. Voir Colette-Anne Van Coolput, «Appendice: Références, adaptations et emprunts directs", in The Legacy of Chrétien de Troyes, dir. Norris J. Lacy, Douglas Kelly et Keith Busby, Amsterdam, Rodopi, 1987-1988, vol. 1, p. 333-342, qui recense les mentions directes de Chrétien de Troyes dans la littérature médiévale.

13 Sur la notion d'auteur et la façon dont les écrivains caractérisent leur travail, on consultera Emmanuèle Baumgartner, "Sur quelques constantes et variations de l'image de l'écrivain (XII ${ }^{\mathrm{e}}-\mathrm{XIII}{ }^{\mathrm{e}}$ siècle)", in Auctor et auctoritas. Invention et conformisme dans l'écriture médiévale. Actes du colloque de Versailles-Saint-Quentinen-Yvelines (14-16 juin 1999), dir. Michel Zimmermann, Paris, École des Chartes, 2001, p. 391-400, Jean-Claude Mühlethaler, Delphine Burghgraeve et 
agençant habilement le langage à partir de sources éparses qu'il combine. Écrire requiert un savoir-faire, il faut y mettre «sa painne et s'antancïon $»^{14}$, même si, on le sait, la notion d'auteur est en construction et que la création est toujours avant tout une recréation. L'inscription des auteurs dans un champ fondé sur des autorités, animé par une activité singulière, celle de l'écriture artistique, démontre l'appréhension cognitive par les médiévaux d'un domaine littéraire.

L'établissement de critères de définition de la littérarité reste néanmoins complexe, d'autant plus si l'on veut trouver une acception du terme qui fonctionne pour toutes les époques: reconnaître un effort esthétique ${ }^{15}$ dans l'écriture exclut par exemple les sources documentaires, les livres de comptes ou rapports juridiques. En revanche, doivent être tenues pour littéraires les encyclopédies en vers du type de celle de Gossuin de Metz, L'image du monde, puisque la rhétorique y guide l'écriture. Le critère du plaisir procuré au lecteur par le texte, indépendamment de toute portée utilitaire $^{16}$, ne peut pas non plus être pertinent dans la mesure où l'écriture médiévale est aussi une éthique: on écrit avant tout pour être utile ${ }^{17}$.

Claire-Marie Schertz, "Introduction. Figure, posture, ethos à l'épreuve de la littérature médiévale», in Un territoire à géographie variable. La communication littéraire au temps de Charles VI, Paris, Garnier ("Classiques Garnier»), 2017, p. 9-51, et Delphine Burghgraeve, Jérôme Meizoz, Jean-Claude Mühlethaler, Postures d'auteurs: du Moyen Âge à la modernité, Fabula / Les colloques, 2014, http://www. fabula.org/colloques/sommaire2341.php. On consultera également la base de données Clerc6, qui recense les substantifs se référant à l'auteur sous l'époque de Charles VI. http://wp.unil.ch/clerc6/.

14 Chrétien de Troyes, Le Chevalier de la Charrette, éd. Catherine Croizy-Naquet, Paris, Champion ("CCMA»), 2006, v. 29.

15 Nous entendons par "esthétique» la recherche du beau, d'une harmonie, liée à l'expérience sensible. L'esthétique suppose une relation de contemplation posée envers un objet et une source de plaisir. Écrire en vers traduit notamment la recherche d'un effet, euphorique ou dysphorique. Pour une définition de l'esthétique, voir Gérard Dessons, "Esthétique», in Le dictionnaire du littéraire, Paris, PUF ("Quadrige»), 2010, p. 253-255 et Jean-Marie Schaeffer, Adieu à l'esthétique, Paris, PUF, 2000.

16 Jean-Marie Schaeffer, Adieu à l'esthétique, considère le plaisir comme une donnée inhérente à la conduite et au jugement esthétique, c'est-à-dire à l'élaboration et à la réception de l'objet esthétique.

17 Voir Judson Boyce Allen, The Ethical Poetic of the Later Middle Ages: a decorum of convenient distinction, Toronto, University of Toronto Press, 1982, chapitre 1 "Ethical poetry, poetic ethics, and the sentence of poetry», et Florence Bouchet, 
Les médiévaux perçoivent la dimension plaisante et gratuite des textes, mais cela ne constitue pas un critère pertinent d'opposition sur le plan rhétorique, la pédagogie étant partie prenante de la littérarité médiévale. Michel Zink souligne que si, dans notre esprit, la littérature s'oppose à d'autres disciplines comme la science ou l'histoire, le Moyen Âge n'opère pas de telles distinctions: "L'art de l'expression et de l'écriture s'applique également à tous les contenus. ${ }^{18}$ Les miroirs des princes, les bestiaires ou l'historiographie peuvent en ce sens être appréhendés comme littéraires. On pourrait s'en sortir en recourant au couple "fiction" et "diction" de Gérard Genette, en s'y référant comme les deux uniques critères de littérarité: "un roman est littéraire parce qu'il est fictionnel, alors que des Mémoires ne sont littéraires que si on les trouve bien écrites. ${ }^{19}$ Le problème demeure néanmoins que la fiction est une catégorie ambiguë, à plus forte raison au Moyen Âge: nous y reviendrons. Ces impasses théoriques font dire à Patrick Moran que «la littérature, s'il fallait choisir un critère, se définit peut-être par l'incomplétude, le manque, par l'impossibilité de fixer, précisément, un critère. $»^{20}$

Il faut en tout cas renoncer à la dimension institutionnelle de la littérarité, qui ne fonctionne pas pour le Moyen Âge, en l'absence d'académies habilitées à décider ce qui est ou n'est pas littéraire. La littérarité est surtout concevable dans l'optique de la lecture: elle implique dans tous les cas un choix et une prise de position de la part du critique pour déterminer ce qui entre dans son champ ou non. La littérarité dépend alors d'une perspective sur les textes, d'une relation particulière élaborée autour des textes. Nous proposons quant à nous de considérer comme littéraire tout texte destiné à une diffusion, ayant pour but de toucher le récepteur, que ce soit de manière esthétique, plaisante, didactique ou morale. Le rapport établi entre destinateur et destinataire nous paraît constituer un critère opérant pour former un corpus littéraire. La remarque de Sarah Nancy

Le Discours sur la lecture en France aux XIV et XV siècles: pratiques, poétique, imaginaire, Paris, Champion, 2008, p. 64-78. C'est un topos bien connu des romans, que celui de l'utilitas et de la delectatio, inspiré de l'Art poétique d'Horace.

18 Michel Zink, «Littérature(s)», art. cit., p. 611.

19 Marielle Macé, Le genre littéraire, p. 227. Voir Fiction et diction, Paris, Seuil, 1991.

20 Patrick Moran, Lectures cycliques, p. 632. C'est également la conclusion que l'on peut tirer du colloque "Littérature": où allons-nous, du 3 au 5 octobre 2012». 
lors du colloque "'Littérature": où allons-nous?» nous laisse penser que cette définition pourrait être valable pour d'autres siècles:

Nous devons avoir la force de parier qu'on puisse appeler «littérature» des textes destinés à être interprétés, qui supposent une adresse, qui appellent quelque chose: une lecture, une interprétation, un devoir de s'en saisir ${ }^{21}$.

S'il faut adapter la définition de la littérarité à chaque époque, le point de contact entre les littérarités réside peut-être dans le degré d'interprétation que le texte littéraire permet et les réseaux de sens que l'on peut en dégager. Le texte littéraire ne se réduit pas à la simple transmission d'informations; sa complexité en fait un représentant de la littérature. En ce sens, que la lecture soit naïve ou spécialiste, le texte littéraire donne au lecteur une expérience identique, car elle suscite l'interrogation ${ }^{22}$. Ainsi, dans le cas médiéval, la reproduction en série manuscrite, l'enluminure, la mise en représentation - chantée par exemple - d'un texte peuvent être des indices - non exclusifs - de littérarité.

La dimension orale de la production poétique médiévale, qui constitue un autre facteur de résistance pour Paul Zumthor, ne change selon nous rien à sa littérarité, d'autant qu'il n'est plus à prouver que l'écrit est bien présent au Moyen Âge; en témoignent les nombreux manuscrits qui nous sont encore conservés et qui ne dévoilent qu'une petite partie de la production réelle. Divers indices démontrent la tendance de plus en plus importante à une réception textuelle des œuvres, comme l'essor au $\mathrm{XIII}^{\mathrm{e}}$ siècle de la décoration dans les manuscrits, destinée à agrémenter visuellement la lecture, ou les tables de rubriques, qui facilitent le repérage dans l'ensemble textuel ${ }^{23}$. Florence Bouchet analyse cette transition

21 Sarah Nancy, colloque "Littérature": où allons-nous?", Débat de la séance du 5 décembre 2012, http://www.mouvement-transitions.fr/index. php?option $=$ com_content $\&$ view $=$ article $\&$ id $=542$ : civilites-qlitteratureq-ouallons-nous\&catid=27: hospitalites-effervescence\&Itemid $=213$.

22 Ces réflexions nous sont inspirées des discussions qui ont suivi la première session du colloque " "Littérature": où allons-nous?». Voir en particulier l'intervention de Jean-Paul Sermain.

23 Florence Bouchet, Le Discours sur la lecture en France aux XIV et XVe siècles, p. 23-55, Guglielmo Cavallo et Roger Chartier, "Introduction", in Histoire de la lecture dans le monde occidental, dir. Guglielmo Cavallo et Roger Chartier, Paris, Seuil, 1995, p. 23-28, Malcolm Parkes, «Lire, écrire, interpréter le texte. Pratiques 
vers la lecture personnelle et visuelle et donne l'exemple du personnage de Cleriadus dans Cleriadus et Meliadice, roman en prose du début du $\mathrm{Xv}^{\mathrm{e}}$ siècle, surpris en pleine lecture assis sur un lit, lecture qu'il ne semble pas partager à voix haute avec les autres personnes de la pièce. Elle note également que les verbes «lire» ou "veoir» interviennent souvent en complémentarité de "ouïr» ou "ouïr lire», témoignant ainsi de la conception d'une réception double, auditive et visuelle ${ }^{24}$.

Le développement d'une réception visuelle et individuelle des œuvres n'empêche pas le recours à des formules stéréotypées suggérant une communication orale du texte, peut-être fictive. On en trouve des exemples dans notre corpus, dans Floriant et Florete: "Si comm'orrez / Se vous entendre me voulez» (Floriant et Florete, v. 1193-1194). Dans Rigomer, le narrateur interpelle sans cesse son auditoire: "Or escoutés, signor baron" (v. 6379), "Qui velt oïr et escouter / Des merveilles de Rigomer, / Or en pora asés oïr» (v. 6103-6105), «Entendu avons et oï / De Rigomer dont jo vos dit.» (v. 6403-6404) Même au milieu du $\mathrm{XIV}^{\mathrm{e}}$ siècle, l'imbrication de la narration et de l'oralité reste marquée, Jean Froissart y recourant très fréquemment dans Melyador en usant de formules comme «si com vous orés» (v. 870), «je vous voi disant» (v. 937) ou «or l'entendés» (v. 20344) 25 $^{2}$ Le lien entre récit, narration d'une part, et communication, oralité de l'autre, demeure cognitivement ancré; dans les mentalités, une histoire se raconte oralement. La transition, si elle s'est opérée dans les pratiques, ne parvient pas tout de suite à supprimer dans les esprits l'ancrage de l'oralité, qui se traduit par une habitude rhétorique dans les écrits ${ }^{26}$. Cela ne vient en rien mettre en doute l'existence d'une littérature médiévale: au contraire, l'écriture s'affirme par l'oralité.

monastiques dans le Haut Moyen Âge", in Histoire de la lecture dans le monde occidental, p. 109-123, Jacqueline Hamesse, "Le modèle scolastique de la lecture", in Histoire de la lecture dans le monde occidental, p. 125-145, et Michel Zink, Littérature française du Moyen Âge, Paris, PUF ("Quadrige»), 1992, p. 14-18.

24 Florence Bouchet, Le Discours sur la lecture en France aux XIV et XV siècles, p. 23-55. Voir les pages 50-54 sur l'importance que prend l'idée d'entendement, en lien avec la lecture privée, qui exprime l'intériorisation du texte.

25 Voir l'article de Nathalie Bragantini-Maillard, "L'écriture des interventions narratoriales dans Melyador", CRMH, 19, 2010, p. 423-464.

26 Voir Florence Bouchet, Le Discours sur la lecture en France aux XIV et XV siècles, p. 36-47, sur cette habitude rhétorique. 


\section{Témoignages individuels et traités latins}

Le concept de genre littéraire peut donc s'appliquer théoriquement aux $\mathrm{XII}^{\mathrm{e}}$ et $\mathrm{XIII}^{\mathrm{e}}$ siècles, étant admis que cette période produit une littérature et que toute littérature s'organise génériquement, c'est-à-dire que toute littérature pense les rapports entre ses textes de manière générique, sans toutefois forcément établir de classes hermétiques. La pertinence d'une telle réflexion est confirmée par divers éléments attestant une conscience médiévale des genres: l'auto-désignation des œuvres par une étiquette générique, la mise en recueil des manuscrits, l'existence de traités poétiques en latin et divers témoignages individuel ${ }^{27}$. Bertrand de Bar-sur-Aube distingue par exemple au tournant des $\mathrm{XII}^{\mathrm{e}}$ et $\mathrm{XIII}^{\mathrm{e}}$ siècles trois types de chanson de geste:

N'ot que trois gestes en France la garnie;

Ne cuit que ja nus de ce me desdie.

Des rois de France est la plus seignorie,

Et l'autre aprés, bien est droit que jeu die,

Fu de Doon a la barbe florie,

Cil de Maience qui molt ot baronnie. [...]

La tierce geste, qui molt fist a prisier,

Fu de Garin de Monglenne au vis fier ${ }^{28}$.

Cette époque perçoit donc des similitudes entre les textes, qui permettent de les regrouper en types ou en classes ${ }^{29}$. Le témoignage de Bertrand de Bar-sur-Aube signale une conscience des différences de contenu, tandis

27 Plusieurs publications confirment la conscience médiévale des genres: Danièle James-Raoul (dir.), Les Genres littéraires en question au Moyen Âge, Bordeaux, Presses universitaires ("Eidôlon», 97), 2011, Florence Bouchet (dir.), La mouvance des genres littéraires au Moyen Âge, CRM, 18, 2009, p. 179-261, Hélène Charpentier et Valérie Fasseur (dir.), Les Genres au Moyen Âge: la question de l'hétérogénéité, Bandol, Vallongues ("Méthode!», 17), 2010.

28 Bertrand de Bar-sur-Aube, Girart de Vienne, éd. Wolfgang van Emden, Paris, SATF, 1970, v. 11-47.

29 Nous ne convoquons par le sens que Paul Zumthor donne au mot "classe»: réticent à employer le concept de genre, il préfère développer celui de "classe», défini par des traits pertinents non interchangeables d'une classe à l'autre et organisé autour d'une dominante. Essai de poétique médiévale, p. 194-221. Nous lui donnons simplement la définition de "catégorie regroupant des objets présentant des similitudes". 
que la forme, identique, n'est pas mentionnée: chaque type de geste est déterminé par un type de personnage. Il s'agit ici moins d'un classement générique que d'une hiérarchisation de chansons groupées autour d'une diégèse ${ }^{30}$ propre à chaque figure.

Néanmoins, la forme n'est pas occultée dans tous les cas: les traités de rhétorique en latin considèrent des critères moins sémantiques pour classer les œuvres. Il en est ainsi chez Jean de Garlande, qui, dans la Parisiana Poetria (début du $\mathrm{XIII}^{\mathrm{e}}$ siècle), propose uniquement une distinction de forme pour les genres dramatiques qu'il envisage: 1 . Forme verbale, prose ou vers; 2 . Forme de la représentation, place de l'auteur dans son œuvre; 3. Degré de réalité: historia, fabula, argumentum; 4. Sentiments exprimés dans les récits: ironique, satirique, tragique, élégiaque, comique; 5. Style: haut, moyen, bas ${ }^{31}$. La fameuse roue de Virgile, que reprennent Jean de Garlande et Geoffroi de Vinsauf par exemple, prend elle aussi en considération le style élevé, moyen ou simple pour différencier les genres à côté d'autres critères; le type de personnage, le lieu ou l'animal emblématique $^{32}$. S'il ne s'agit pas, dans le cas de la roue de Virgile en particulier, de véritables systèmes de genres tels qu'on les élabore aujourd'hui, les distinctions de styles proposées résultent d'un point de vue générique. Ces traités en latin n'influencent que peu la production vernaculaire, mais ils prouvent que la mentalité médiévale agence le champ littéraire en groupements.

30 Nous définissons le mot "diégèse" à partir de son sens étymologique, diegesis, chez Aristote; l'histoire racontée par le récit, les données sélectionnées par ce récit. Ce n'est dès lors pas le sens qu'Étienne Souriau donne au mot «diégèse» ( La structure de l'univers filmique et le vocabulaire de la filmologie", Revue internationale de filmologie, 7-8, 1951, p. 231-240) que nous entendons convoquer, ni celui que Gérard Genette précisera dans Nouveau discours du récit, Paris, Seuil, 1983: les deux critiques définissent la diégèse comme un concept proche, si ce n'est équivalent, à celui d'univers de fiction.

31 Pour un développement de ces critères, voir l'article de Danièle James-Raoul, "La poétique des genres dans les arts poétiques médiolatins ( $\mathrm{XII}^{\mathrm{e}}-\mathrm{XIII}{ }^{\mathrm{e}}$ siècles) », in Les genres littéraires en question au Moyen Âge, p. 169-186, et Hans Robert Jauss, "Littérature médiévale et théorie des genres», "Littérature médiévale et théorie des genres", in Théorie des genres, Paris, Seuil, 1986.

32 Voir Edmond Faral, Les Arts poétiques du XII et du XIII siècle: recherches et documents sur la technique littéraire du Moyen Âge, Paris, Champion, 1924, p. 86-89. 


\section{Désignations - Autodésignations}

D'autres éléments viennent corroborer ce constat: on trouve fréquemment des étiquettes génériques au sein des textes, c'est-à-dire des expressions qui réfèrent à des types de productions spécifiques. Ainsi, les noms "chanson de geste», «roman», «lai», «fable», «fablel», apparaissent régulièrement comme autodésignations ${ }^{33}$. On pourrait objecter qu'il n'est pas certain que ces mots aient été utilisés de la même manière que nous les entendons aujourd'hui et qu'ils n'ont pas partie liée avec une désignation générique. Néanmoins, la spécialisation du mot «roman», qui signifie d'abord "romain", puis «langue vernaculaire» et finit par désigner une matière mise en forme par un procédé poétique, illustre la perspective générique que les médiévaux peuvent adopter sur la production littéraire. C'est ce qu'exprime Francis Gingras:

On note, entre le $\mathrm{XII}^{\mathrm{e}}$ et le $\mathrm{XIII}^{\mathrm{e}}$ siècle, une extension sémantique du terme roman très large qui, à côté du sens primitif de «traduction en langue vernaculaire", va du sens très général de "discours, conversation" à celui, particulier, de "récit fictif» qui conduit à l'inscription du terme dans la typologie des genres ${ }^{34}$.

Dès la fin $\mathrm{du} \mathrm{xII}^{\mathrm{e}}$ siècle, plusieurs exemples démontrent que le mot «roman» est utilisé dans une acception générique et désigne une forme poétique spécifique. Guillaume le clerc recourt à ce sens dans l'épilogue de Fergus:

Ici met la bonne et l'estace;

Ici est la fins del roumans.

Grans joie viegne as escoutans (v. 7010-7012) $)^{35}$

Le terme n'a pas ici le sens de traduction du latin au français, mais désigne un type de composition narrative; il qualifie l'œuvre que vient d'écrire et d'achever l'auteur.

33 La base de données Clerc6 recense les substantifs se référant à l'œuvre sous l'époque de Charles VI. On trouve par exemple «dit», "ditié», «escript», «livre», «matiere». http://wp.unil.ch/clerc6/.

34 Francis Gingras, Le Bâtard conquérant, p. 81. Voir l'ensemble du chapitre «Roman et romain".

35 Guillaume le Clerc, The Romance of Fergus, éd. Wilson Frescoln, Philadelphia, Allen, 1983. 
Le roman est donc une forme poétique reconnue dès la fin $\mathrm{du} \mathrm{XII}^{\mathrm{e}}$ siècle, la meilleure preuve en est sans doute les nombreuses condamnations dont il fait l'objet dans le milieu clérical. Le Cartulaire général de l'Ordre des Hospitaliers de Saint-Jean de Jérusalem, écrit vers 1262, dicte les règles à suivre par les frères de l'Ordre. La lecture de romans est réprouvée au même titre que le jeu d'échec:

Item il est establi as freres qui sont en l'enfermarie et jueuront as eschaes ou liront romans, ou mangeront viandes defendues, qui li freres ne leur doine riens de l'enfermerie d'en qui en avant, et autre peine n'en doivent avoir ${ }^{36}$.

Ce type de jugement négatif institue paradoxalement l'autonomie du genre critiqué $^{37}$. Les rivalités exprimées fréquemment dans les écrits religieux utilisent le terme "roman" pour stigmatiser des textes narratifs et plaisants, appréhendés comme un tissu de mensonges par rapport aux écrits moraux et chrétiens, délaissés malgré l'élévation de l'âme qu'ils promettent. L'exemple de l'Évangile de l'enfance, texte en vers relatant les enfances de Dieu et composé vers 1250, est particulièrement éloquent à cet égard:

S’avez oï aséz souvent

Les romans de diverses gent

Et des mençongez de ce monde,

E de la grant Table Roonde

Que li rois Artus maintenoit,

Ou point de verité n'avoit,

Qui vous venoient a talent. (Évangile de l'enfance, v. 13-19) $)^{38}$

36 Cartulaire général de l'Ordre des Hospitaliers de Saint-Jean de Jérusalem, éd. Joseph Delaville, Paris, Leroux, 1894, vol. 3, p. 52.

37 Comme l'exprime Jacqueline Cerquiglini-Toulet: «La taxinomie négative, en revanche, des matières que proposent les auteurs moralistes - ce qu'il ne faut pas lire - confirme les grands champs dégagés par les médiévaux eux-mêmes: chansons de geste, romans arthuriens, lyrisme, à travers le genre tout particulièrement de la pastourelle.» («Littérature médiévale?», art. cit., p. 128) Sur les critiques dont le roman fait l'objet au Moyen Âge, voir l'article de Michel Stanesco et Michel Zink, "Critiques du roman", in Histoire européenne du roman médiéval, dir. Michel Stanesco et Michel Zink, Paris, PUF, 1992, p. 175-189, Florence Bouchet, Le discours sur la lecture en France au XIV et XV siècles, p. 262-275, et Francis Gingras, Le Bâtard conquérant, notamment p. 164-189 et 331-337.

38 The old French Evangile de l'Enfance, éd. Maureen Barry McCann Boulton, Toronto, Pontifical Institute of Mediaeval Studies, 1984. 
On constate d'abord que le terme «roman" est ici clairement employé dans un sens générique et non linguistique; il s'associe au mensonge, puis aux récits sur Arthur et sa Table Ronde. Les condamnations dont cette catégorie fait l'objet sont le fruit de rapports concurrentiels entre des genres différents et ne sauraient être appréhendées comme des jugements d'autorité semblables à ceux de l'Académie dès le XVII ${ }^{e}$ siècle: au Moyen Âge, l'absence de normes esthétiques théoriques et d'institution habilitée à évaluer la production littéraire donne aux auteurs une liberté totale sur leurs compositions. Les critiques émises par les acteurs du champ, copistes ou auteurs concurrents, sont le fait d'avis individuels de lecteurs.

Le deuxième constat qui s'impose concerne l'esquisse de l'expression «romans de la Table Roonde»: il ne s'agit pas d'une formule fréquente, mais elle témoigne tout de même de la conceptualisation d'une homogénéité entre plusieurs textes traitant de la même matière. Gerbert de Montreuil, dans le Roman de la Violette, confirme la conception d'une catégorie liée au monde arthurien, en affirmant que son œuvre «N'est pas de la Reonde Table / Dou roi Artu ne de ses gens» dans le but de démarquer la matière de son "conte biel et delitable»" ${ }^{39}$. Le groupe "contes de la Table Ronde et d'Arthur" semble donc exister en tant que tel dans les consciences médiévales. D'autres exemples attestent la perception d'une classe de textes apparentés. Au début du XIII ${ }^{\mathrm{e}}$ siècle, un auteur anonyme champenois dédie une Vie des Pères en prose à Blanche de Navarre, comtesse de Champagne, et l'exhorte à vivre loyalement tout en évitant les péchés du siècle. Il consacre quelques vers de ces recommandations à distinguer son œuvre moralisatrice des «romans de vanité», prisés par les «autres dames» dont doit se distancier la dédicataire:

Les autres dames de cest mont,

Qui plus pensent aval qu'amont,

Si font les mençonges rimer

Et les paroles alimer

Pour les cuers mielz enrooillier

Et pour honesté avillier.

Dame, de ce n'avez vos cure:

De mençonge qui cuers oscure,

Et corrompt la clarté de l'ame,

39 Gerbert de Montreuil, Le Roman de la Violette ou de Gerart de Nevers, éd. Douglas Labaree Buffum, Paris, Champion, 1925, v. 33-35. 
Nen aiez cure, douce dame.

Leissiez Cligès et Perceval,

Qui les cuers perce et trait aval,

Et les romanz de vanité,

Assez troveret veritéét

La lecture fait donc partie intégrante de l'éducation d'une noble: elle affecte l'honnêteté, l'âme et le cœur, lorsqu'elle prend le chemin du mensonge et de la vanité. Ce prologue identifie deux classes de productions narratives: celle des récits fictifs, qui corrompent les lectrices, et celle des textes édificateurs, véritables purificateurs des âmes capables de «cuers de crestïens esmeuvre / A bien penser et a bien faire, / Et pour eus de pechié retraire» (v. 20-22). Ce témoignage reproduit une condamnation fréquente du roman dans certains milieux littéraires du Moyen Âge, destinée à mettre en valeur les écrits didactiques, religieux ou scientifiques.

La légende arthurienne est en ce contexte particulièrement associée à la fable et au mensonge romanesque, qui détourne le chrétien de ses devoirs religieux, comme l'illustre l'évocation de Perceval par l'anonyme champenois. Elle est donnée en exemple de récits corrupteurs par Philippe de Mézières également, dans son Songe du vieil Pèlerin, dédié à Charles VI en 1389:

Tu te dois garder de trop deliter es livres qui sont appelé apocrifes, et par especial des livres et des romans qui sont remplis de bourdes qui atraient le lisant souvant a imposibilité, a folie, vanité et pechié, si come le livre des bourdes de Lancelot ${ }^{41}$.

Le «Livre de Lancelot» est fallacieux, mensonger («apocrife», «bourdes»), et encourage son lecteur au péché: il convient de ne pas trop s'y plonger, malgré le plaisir ("deliter») qu'il procure. Philippe de Mézières insiste à plusieurs reprises sur le caractère mensonger des récits sur Arthur, dont

40 Prologue au manuscrit Lyon, BM 868 de la Vie des Pères dédiée à Blanche de Navarre, v. 23-36, édité dans Grégoire le Grand, Le Pastoralet. Traduction médiévale française de la Regula Pastoralis, éd. Martine Pagan, Paris, Champion, 2007, p. 29-33.

41 Philippe de Mézières, Songe du viel pelerin, éd. Joël Blanchard, Genève, Droz, 2015, Livre III, chap. 52, p. 948. Voir Florence Bouchet, Le Discours sur la lecture en France aux XIV et XV siècles, p. 262-265. La suite de la citation dénonce le caractère luxurieux de cette littérature. 
le nom apparaît également dans son texte ${ }^{42}$. L'association entre les récits arthuriens et la futilité du divertissement parcourt tout le Moyen Âge: l'exemple de Philippe de Mézières démontre qu'à la fin du XIV siècle, l'engouement pour cette matière est toujours assez vivace pour susciter un tel commentaire. Charles VI possède malgré tout plusieurs manuscrits du Lancelot en prose, du Tristan en prose et du Conte du Graal hérités de Charles $\mathrm{V}^{43}$, rendant ainsi effectifs les paradoxes qui entourent les récits arthuriens: condamnés par les moralisateurs, ils demeurent au centre de la culture curiale. Charles VI emprunte d'ailleurs en 1381 un texte intitulé «Du Saint Graal et de Meliagant, de Lancelot du Lac» ${ }^{44}$, preuve que les romans arthuriens ne se résument pas à des possessions, mais font effectivement partie de ses lectures.

Il est notable que les deux auteurs cités fassent allusion à un ensemble de textes en mentionnant simplement un nom ("Lancelot», "Cliges», «Perceval»): c'est bien l'entier des œuvres qui se rapprochent du «livre de Lancelot» que le destinataire doit percevoir comme représentants des

42 Sur le programme éducatif proposé au roi par Philippe de Mézières, voir Stefan Vander Elst, "Literature and chivalric education in Philippe de Mézières' Le Songe du Vieil Pelerin", in Philippe de Mézières and His Age. Piety and Politics in the Fourteenth Century, dir. Renate Blumenfeld-Kosinski et Kiril Petkov, Leiden; Boston, Brill, 2012, p. 189-206. Le roman arthurien est condamné non seulement pour son caractère mensonger, mais aussi parce qu'il pousse à l'outrecuidance par l'exemple de la vaillance mondaine de Gauvain et Lancelot. Enfin, c'est aussi la fin'amor qui fait l'objet des réserves de l'auteur: elle conduit au péché de luxure.

43 Voir l'article de Sarah Fourcade, «Les lecteurs nobles de la littérature arthurienne à la fin du Moyen Âge", in Arthur après Arthur. La matière arthurienne tardive en dehors du roman arthurien (1270-1530), dir. Christine Ferlampin-Acher, Rennes, PUR («Interférences»), 2017, p. 429-442. Les inventaires de la bibliothèque de Charles V et Charles VI recensent plusieurs Lancelot en prose, plusieurs Guiron le courtois, plusieurs cycles composés du Conte du graal et des Continuations, un Méraugis, un Atre Périlleux parmi d'autres textes arthuriens. Voir Leopold Delisle, Recherches sur la librairie de Charles V, roi de France (1337-1380), Paris, Champion, 1907, 2 vol., et Inventaire de la bibliothèque du roi Charles VI fait au Louvre en 1432, éd. Louis Douët-D’Arcq, Paris, Imprimerie Charles Lahure, Société des Bibliophiles, 1867. Selon Cedric E. Pickford, la librairie de Charles VI contenait entre trente et trente-cinq œuvres arthuriennes en prose. L'évolution $d u$ roman arthurien en prose vers la fin du Moyen Âge: d'après le manuscrit 112 du fonds français de la Bibliothèque nationale, Paris, Nizet, 1960, p. 281-282.

44 Selon Marie-Hélène Tesnière, «Les romans de la Table Ronde dans la Librairie royale de Charles V et Charles VI", in La Légende du Roi Arthur, dir. Thierry Delcourt, Paris, BnF; Seuil, 2009, p. 51. 
«livres de bourdes» et qu’il doit éviter. Aux yeux du lecteur médiéval, il existe bien une classe de production homogène qui se construit autour des personnages de la cour d'Arthur, que l'auteur de la Vie des Pères dédiée à Blanche de Navarre intitule «roman de vanité».

C'est le cas aussi dans les Dialogues de Saint Grégoire et dans le Roman du comte d'Anjou de Jean Maillart, qui évoquent Gauvain, Tristan, Perceval et Lancelot comme figures de proue de récits condamnables: on en raconte des "fables» et des "aventures" ${ }^{45}$. La traduction des Dialogues de Saint Grégoire précise la nature des récits:

Les fables d'Arthur de Bretaigne

Et les chançons de Charlemagne

Plus sont cheries e meins viles

Que ne soient les Evangiles ${ }^{46}$.

La classe est désignée "fables d'Arthur» et se distingue des "chansons de Charlemagne ${ }^{47}$ : l'emploi des substantifs "fables" et "chansons" souligne que la différence est d'ordre générique, ou tout du moins formel.

45 Jean Maillart, Roman du comte d'Anjou, éd. Mario Roques, Paris, Champion, 1931 , v. 2. "Maint ont mis leur temps et leurs cures / En fables dire et aventures; / Li uns dit bourdes, l'autre voir, / Si com il sevent concevoir; / Li uns de Gauvain nous raconte, / L'autre de Tristan fet son conte; / Li uns d'Yaumont et d'Agoulant, / L'autre d'Olivier, de Rollant, / De Perceval, de Lancelot; / De Robichon et d'Amelot / Li auquant chantent pastourelles; / Li autre dient en vïelles / Chançons royaus et estempies, / Dances, noctes et baleriez, / En leüst, en psalterion, / Chascun selonc s'entencion, / Lais d'amours, descors et balades, / Pour esbatre ces genz malades. / En tiex trufles leur temps despendent, / Qu'a nule autre chose n'entendent; Et non pour quant sont apeléz, / Es grans liex, et bien ostelés, / Comment qu'a l'ame rienz ne facent / Fors que l'anui des cuers enchacent / Par leurs contes et par leurs fables; / Mez en doit chosez pourfitables, / Et qui les cuers des genz esmuevent / A bien fere, quant il lez truevent, / Plus deligemment escouter / Pour soi en bonnes meurs monter; / Quer, avec le bon examplaire / Qu'en i ot, doit miex aussi plaire / Chose qui est vraie prouvee / C’unne mençonge controuvee.» (v. 1-34)

46 Le Dyalogue Saint Gregore: les dialogues de Saint Grégoire le Grand traduits en vers français à rimes léonines par un Normand anonyme du XIV siècle, éd. et trad. Sven Sandqvist, Lund, Lund University Press («Études romanes de Lund», 42), 1989, v. $1-4$.

47 Voir Francis Gingras, Le Bâtard conquérant, p. 171. Francis Gingras s'intéresse aux désignations génériques, qui prouvent bien l'existence d'une conscience générique. Voir notamment les pages 164-189. 
Un consensus se dessine pour définir les textes qui nous intéressent, du point de vue de certains auteurs médiévaux en concurrence: il s'agit de romans vains, mensongers, qui détournent le chrétien de ses devoirs moraux. L'autre élément remarquable dans ces exemples est la prégnance du nom propre dans l'évocation de cette catégorie de production: le genre à proscrire se reconnaît par les personnages dont on raconte les aventures.

L'étiquette "roman arthurien", développée par la critique, ne se rencontre pas dans les œuvres. Point de «roman d'Arthur» ni de «roman de la Table Ronde»; les auteurs de romans arthuriens parlent plutôt de "conte», d'"aventure», de «roman», parfois accompagnés d'une caractérisation plus précise. L'expression «conte d'aventure" se trouve dans trois textes: elle désigne la source de l'histoire dans le Bel Inconnu (v. 5) ${ }^{48}$ et Erec et Enide (v. 13) ${ }^{49}$, et l'œuvre en présence dans Durmart (v. 14) ${ }^{50}$. Le terme «aventure» a en ce sens une portée générique: même s'il n'est pas réservé aux textes arthuriens, il y apparait assez fréquemment comme autodésignatif pour que l'on puisse y concevoir des enjeux spécifiques à la catégorie. C'est le cas dans Rigomer, lorsque, dans un prologue intermédiaire, le narrateur veut "acointier / Une aventure sans tencier, / Qui mout est plaisans et mignote. / Cançonete, fablia ne note / N'est si plaisans» (v. 1095710961). Le mot "aventure", défini par sa propension à plaire, s'oppose à d'autres catégories de récit et se propose donc comme une classe narrative. Beate Schmolke-Haßelmann relève quinze occurrences du substantif dans les prologues et épilogues et souligne qu'il faut le considérer comme un terme littéraire, voire une forme de récit («literarische Erzählform») ${ }^{51}$ : il suppose un contenu spécifique et une manière de le disposer.

Le syntagme «aventures de Bretaigne» que l'on rencontre dans Rigomer (v. 5) et dans Claris et Laris (v. 88) en précise encore l'acception: l'aventure est consubstantielle à la Bretagne et traite «Del roi Artu et de ses houmes" comme le suggère le narrateur de Rigomer (v. 7):

48 Renaut de Beaujeu, Le Bel Inconnu, éd. Michèle Perret et Isabelle Weil, Paris, Champion ("CCMA»), 2003.

49 Chrétien de Troyes, Erec et Enide, éd. Jean-Marie Fritz, Paris, Le Livre de Poche («Lettres gothiques»), 2013.

50 Durmart le Galois, roman arthurien du treizième siècle, éd. Joseph Gildea, Villanova, Villanova Press, 1965-1966.

51 Beate Schmolke-Haßelmann, Der arthurische Versroman, p. 21-25. Nous reviendrons au chapitre I, «L'errance aventureuse», p. 205-230, sur l'importance de l'aventure dans la définition du genre. 
Jehans qui en maint bien s'afaite

Et pluisor bele rime a faite,

Nos a un romanç commenchié.

Assés briément l'a romanchié

Des aventures de Bretaigne.

Bien cuic que des mellors ataingne.

Del roi Artu et de ses houmes

Est cis roumans que nos lisoumes

$[\ldots]$

Or ai talent que je vos die

De Lanselot del Lac partie,

Et si vos voel dire et conter

Les Merveilles de Rigomer,

Dont cis romanç muet et commence. (Rigomer, v. 1-17)

L'auteur souligne encore que les aventures de Bretagne sont «romanchié[e]» (v. 4) et inscrit l'œuvre dans le genre romanesque à quatre reprises dans cette introduction. Si l'on devait résumer ce prologue, on pourrait sans trop d'impertinence affirmer qu'il présente le texte à suivre comme un roman des aventures de Bretagne, c'est-à-dire du roi Arthur et de ses chevaliers ${ }^{52}$. Cette désignation n'est pas si différente que cela de notre propre définition du roman arthurien.

Ces étiquettes arthuriennes sont d'autant plus signifiantes que les auto-désignatifs répondent à des emplois bien circonscrits; c'est l'étude que mène Francis Gingras. Il démontre que la plupart des chansons de geste $^{53}$ s'autodésignent "chanson", tandis qu'aucun texte en décasyllabe

52 Nous reviendrons plus loin sur la distinction entre l'auteur Jehan et le narrateur dans ce texte, qui explique que le roman soit traité comme une sorte de source. Nous étudierons aussi les implications de la revendication de brièveté (exprimée au v. 4) dans les romans tardifs.

53 Pour une problématisation de la définition de la chanson de geste, voir Carlos Clamote Carreto, "Rainouart au pays des fées. Interchangeabilité des personnages et dialogisme dans La Bataille Loquifer», in Façonner son personnage au Moyen Âge, éd. Chantal Connochie-Bourgne, Aix-en-Provence, Presses universitaires de Provence, 2007, p. 99-122, William Kibler, "La "chanson d'aventures" ", in Essor et fortune de la chanson de geste dans l'Europe et l'Orient latin. Actes du IX Congrès international de la Société Rencesvals, vol. 2 "Rapports entre chanson de geste et roman au XIII ${ }^{e}$ siècle", Modena, Mucchi, 1984, p. 509-515, et François Suard, "La chanson de geste française: une forme littéraire évolutive», in Épopées $d u$ monde. Pour un panorama (presque) général, dir. Ève Feuillebois-Pierunek, Paris, Garnier, 2011, p. 331-350. 
ne s'appelle "roman " ${ }^{54}$, ce qui prouve l'appréhension d'une différence d'ordre générique entre les textes. Le prologue à l'épisode de Chantecler du Roman de Renart confirme la conceptualisation de différentes classes narratives:

Signor, oï avez maint conte,

Que maint conteor vous raconte

Coment Paris ravi Helainne,

Le mal qu'il en ot et le painne;

De Tristan que La Chievre fist,

Qui assés belement en dist,

Et faubliaus et cançons de jeste;

Romans de li et de la beste ${ }^{55}$

Maint autre conte par la terre ${ }^{56}$.

Les trois expressions "fabliaus", "chançons de geste» et "romanz» se réfèrent à des textes narratifs, qui tous entrent dans l' "hypercatégorie ${ }^{57}$ "conte». Dans son acception médiévale, ce dernier $\operatorname{mot}^{58}$ désigne tout récit, toute narration, orale ou écrite, indépendamment de sa matière et de sa forme, comme le prouve encore son emploi dans le prologue de la Chanson des Saxons, qui nomme indifféremment les productions des matières de Bretagne, de Rome et de France "conte ${ }^{59}$.

54 Francis Gingras, Le Bâtard conquérant, p. 175-181.

55 Le vers 8 est énigmatique et varie beaucoup selon les manuscrits. Il a pu être interprété comme une transcription erronée de "Romanz d'Yvain et de sa beste», mais aucune version ne donne cette leçon. Voir le commentaire qu'en donne Armand Strubel, Le Roman de Renart, éd. dirigée par Armand Strubel, Paris, Gallimard («Pléiade»), 1998, p. 1088-1089 et 1104. Voir aussi François Bérier, "Étude rhétorique et stylistique du prologue de la branche II-Va du Roman de Renart», Bulletin de la Faculté des Lettres de Mulhouse, IX, 1978, p. 9-14, et Anthony Lodge, "De Tristan que la chievre fist», Romania, CIV, 1983, p. 524-533.

56 Le Roman de Renart, éd. cit., branche VIIa, v. 1-9.

57 Par «hypercatégorie», nous désignons une catégorie englobante, qui surplombe d'autres formes plus spécifiques.

58 Étymologiquement, le mot «conte» (aussi orthographié «compte»), vient du latin computare, "compter»: employé au sens figuré, il désigne le fait d' "énumérer des événements». Voir "compter», Oscar Bloch et Walther Von Wartburg (dir.), Dictionnaire étymologique de la langue française, Paris, PUF ("Quadrige»), 1932.

59 Jean Bodel, La Chanson des Saxons, éd. Annette Brasseur, Genève, Droz ( TLF»), 1989, v. 9. Nous citons l'extrait infra, p. 169. 
Si ces noms doivent être appréhendés comme le résultat d'un regard générique porté sur les œuvres, le lecteur moderne est parfois perplexe face à certaines désignations. Il est notamment confronté à un certain flottement entre les termes "fabliau» et «lai», récits dont le trait formel commun est leur brièveté. Le lai se définit d'abord comme une forme narrative chantée, dont le but est de garder en mémoire un événement. L'expression, dans les textes, renvoie initialement au chant, source de la mise par écrit, ainsi que l'expliquent Nathalie Koble et Mireille Séguy dans l'introduction à leur édition de lais bretons: "le terme de lai ne désigne presque jamais le texte en cours, mais fait référence à une pièce lyrique dont le récit entend préserver la mémoire, et qui constitue sa source première. ${ }^{60}$ Les éditrices reconnaissent comme traits définitoires la remembrance visée par le lai, sa brièveté, son inspiration amoureuse, sa structure fondée sur l'aventure, teintée de merveilleux. Monique Léonard esquisse une définition qui nous parait regrouper les éléments traditionnellement attribués aux lais, présentés comme des

œuvres narratives plutôt brèves composées en octosyllabes à rimes plates. Les lais se caractérisent le plus souvent par une thématique amoureuse et courtoise, par un goût prononcé, mais non exclusif, pour les atmosphères surnaturelles, probablement en rapport avec leur origine celtique, et par un style généralement soigné ${ }^{61}$.

Alors qu'une unité générique se dégage particulièrement des lais sélectionnés par Mireille Séguy et Nathalie Koble pour leur édition, d'autres textes brefs autodésignés «lais» n'ont que peu en commun avec le corpus proposé. Ainsi, le lecteur moderne peine à percevoir l'ensemble

60 Nathalie Koble et Mireille Séguy, "Introduction", in Lais bretons (XII'-XIII siècles): Marie de France et ses contemporains, éd. N. Koble et M. Séguy, Paris, Champion, ("CCMA»), 2011, p. 18. On lira l'introduction dans son intégralité pour une définition et des précisions sur le genre du lai.

61 Monique Léonard, "L'hybridation générique dans le domaine du dit narratif: le cas du Lai de l'Oiselet", in Fiction narrative et hybridation générique dans la littérature française, dir. Hélène Baby, Paris, L'Harmattan, 2006, p. 38. Voir aussi Jean Frappier, "Remarques sur la structure du lai. Essai de définition et de classement», in La Littérature narrative d'imagination, Paris, PUF, 1961, p. 23-39, qui singularise les lais par le rôle de l'aventure, de l'événement merveilleux et la superposition de deux mondes (monde quotidien / monde féerique ou sentimental). 
que pourraient former le Lai de Narcisse ${ }^{62}$, le Lai d'Aristote et des lais bretons comme Yonec ou Tydorel. Le premier est une adaptation courtoise du Narcisse des Métamorphoses d'Ovide, tandis que le second adopte un ton grivois: Aristote, figure du savoir, est ridiculisé par la maîtresse d'Alexandre, vexée qu'il ait détourné son amant d'elle. La jeune femme fait en sorte qu'il tombe amoureux d'elle puis l'encourage à porter une selle et à se laisser chevaucher. Les allusions scabreuses et l'intrigue de base, qui propose un maitre épris d'un amour qu'il interdisait à son élève, en font un récit comique dont on tire une morale: il ne faut pas blâmer les amants. La grivoiserie, la ruse féminine et le comique sont justement des traits caractéristiques du fabliau. Le Lai d'Aristote s'en démarque toutefois par son ancrage antique, et non dans la vie quotidienne, comme c'est le propre du genre ${ }^{63}$. On a coutume depuis Joseph Bédier de définir le genre du fabliau comme des "contes à rire en vers ${ }^{64}$. Il est possible d'en préciser la nature en le désignant avec Denis Hüe et Hélène Gallé comme

une forme narrative brève, de 250 vers en moyenne, dépassant très rarement 600 vers, qui a pour fonction de déclencher le rire ou le sourire en rapportant une histoire qui se veut réaliste, et tourne autour des éléments fondateurs du rire: bas corporel, sexualité, adultère, avarice, etc. ${ }^{65}$

62 Au sujet du genre du Lai de Narcisse, voir l'article de Stéphanie Le Briz-Orgeur, "Le Narcisse anonyme du XII ${ }^{\text {e }}$ siècle: une histoire de roman", in Fiction narrative et hybridation générique dans la littérature française, dir. Hélène Baby, Paris, L'Harmattan, 2006, p. 19-33. Jean Frappier, "Remarques sur la structure du lai», art. cit., traite de la différence entre fabliau et lai.

63 C'est en tout cas une caractéristique que lui attribue Dominique Boutet, «Les formes de la dérision: le fabliau", art. cit., p. 502. Le critique souligne encore que «le fabliau n'est concevable que dans une société en mutation, dont les valeurs anciennes, féodalo-chrétiennes, fondées sur le dynamisme de la défense de la terre et de la foi, commencent à fléchir devant le principe de plaisir, et devant un plaisir qui est conçu comme celui du corps.» (p. 502)

64 Joseph Bédier, Les Fabliaux, Paris, E. Bouillon, 1895, p. 30.

65 Denis Hüe et Hélène Gallé, Rutebeuf, Neuilly, Atlande ( Clefs concours - Lettres médiévales"), 2006, p. 79. Voir aussi les études d'Alain Corbellari, Des fabliaux et des hommes. Narration brève et matérialisme au Moyen Âge, Genève, Droz, 2015, Per Nykrog, Les fabliaux, Copenhague, Ejnar Munksgaard, 1957, Jean Rychner, "Les fabliaux: genre, styles, publics", in La Littérature narrative d'imagination, Paris, PUF, 1961, p. 41-54, Dominique Boutet «Les formes de la dérision: le fabliau», art. cit., Magali Lachaud, "Fabliau», art. cit., et Francis Gingras, "La 
Ainsi, l'autodésignation ne renvoie pas à un système fixe et le substantif «lai » peut bien, dans certains cas, s'appliquer à des textes que l'on qualifierait aujourd'hui plutôt de fabliau ou de récit bref antique ${ }^{66}$. L'étiquette choisie par le copiste ou l'auteur médiéval, si elle prouve la conscience d'une hiérarchisation du champ poétique, n'est pas soumise à une codification et ne saurait servir de classement strict: l'étiquette générique varie d'ailleurs pour un même texte selon les manuscrits, signe que le genre dépend de l'interprétation de chacun ${ }^{67}$. Chaque acteur de la sphère littéraire, que ce soit l'auteur ou les différents copistes, retient un aspect saillant de tel genre et y est plus sensible à la lecture de tel texte. Ainsi, le copiste qui classe le Lai de Narcisse dans la catégorie des lais est probablement marqué par divers liens de communauté entre le genre et l'œuvre: la brièveté, la fiction narrative, l'octosyllabe et surtout l'atmosphère courtoise $^{68}$. L'étiquette générique n'est donc pas employée sans discernement et parait finalement renvoyer, aux yeux des médiévaux, à des réalités assez stables $^{69}$, comme en témoigne encore l'exemple du prologue d'un dit attribué à Raoul de Houdenc, qui interroge clairement la généricité de son texte:

Encontre le dolc tans qui vient

Me plaist, por ce qu'il m'en souvient,

Que je die un fablel novel.

part du vers dans la définition médiévale des fabliaux", in Rencontres du vers et de la prose: conscience théorique et mise en page, éd. Catherine Croizy-Naquet et Michelle Szkilnik, Turnout, Brepols, 2015, p. 61-74. Pour une analyse thématique et sociale des fabliaux dans leur ensemble, on consultera les travaux de Marie-Thérèse Lorcin, en particulier Façons de sentir et de penser: les fabliaux français, Paris, Champion ("Essais sur le Moyen Âge», 6), 1979.

66 Le problème du nom est développé par Per Nykrog au sujet des fabliaux: il évoque les cas où le mot "fabliau» désigne un texte d'un autre genre et les cas où un autre mot désigne un texte qui appartient au genre. Voir Les fabliaux, p. 3-14.

67 Ainsi, le Lai de l'Oiselet ne s'appelle «lai» que dans un manuscrit, de même que le Lai de Narcisse.

68 C'est la conclusion de Stéphanie Le Briz-Orgeur, "Le Narcisse anonyme du XII siècle», art. cit.

69 Francis Gingras souligne d'ailleurs qu'il y a finalement assez peu de confusion entre l'utilisation des termes "fabliau», "lai» et «fable». Voir Le Bâtard conquérant, chap. "Roman et narration longue», et «La part du vers dans la définition médiévale du fabliau», art. cit. 
J'ai tort quant je fablel l'apel,

Car ce n'est me fabiliaus: non,

Il n'a de fablel fors le non,

Car li dit en sont veritable;

Por tant l'apel fablel sans fable

Que Raols de Hosdaing commence ${ }^{70}$.

L'appellation «fabliau» se justifie par la dimension satirique du dit, composé comme le fabliau en couplets d'octosyllabes. Mais le sème «mensonge» contenu dans le mot «fabliau» gêne l'auteur, qui ne trouve pas de dénomination plus satisfaisante que «fablel sans fable»" Cet exemple démontre sans doute possible la réflexion menée par les auteurs médiévaux sur des groupements génériques et les implications des noms: le mot «fablel» est lié au mensonge mais contient d'autres sèmes génériques, assez pertinents pour qualifier le poème de Raoul de Houdenc. On en conclura avec Francis Gingras que, bien que

les contours de certains genres littéraires soient un peu flous [, cela] ne les prive pas pour autant de traits définitoires, fussent-ils minimaux. Au reste, l'imprécision et le caractère nébuleux sont sans doute moins le fait des usages médiévaux que de notre incapacité à bien les cerner ${ }^{72}$.

Dans notre corpus, l'autodésignation présente aussi une certaine cohérence: le narrateur de Rigomer qualifie à plusieurs reprises son texte de «romanç» (v. 3, 8, 17, 6421, 6431, etc.), hormis une occurrence du terme «fable» ("Lor vos acontera la fable » ${ }^{73}$, v. 6443); le narrateur assume peutêtre ici la part plaisante («Biaus et plaisans», v. 6434) et fictionnelle liée à la fabula, comme c'est d'ailleurs de plus en plus le cas dans le roman tardif - nous y renviendrons au chapitre I, "Historia et fabula», p. 112-142. L'explicit de Claris et Laris le désigne aussi comme un roman («Explicit le

70 Raoul de Houdenc, Dits, v. 1-9, édité par Lewis Thorpe d'après le manuscrit de Nottingham, University Library, Mi Lm 6. Lewis Thorpe, «Raoul de Houdenc: a possible new poem", The Modern Language Review, 47/4, 1952, p. 512-515.

71 Voir Francis Gingras, qui traite de cet exemple: Le Bâtard conquérant, p. 345-346.

72 Francis Gingras, Le Bâtard conquérant, p. 331.

73 Wendelin Foerster et Hermann Breuer notent qu'il pourrait s'agir d'une erreur du copiste, le vers attendu étant plutôt «Ne vos aconterai ja fable». Rigomer, éd. cit., vol. 2, p. 198. 
roumanz de Claris et Laris»), ce qui correspond à la catégorie à laquelle le lecteur rattache ces œuvres. Deux occurrences étonnent néanmoins dans ce texte: il s'agit de l'emploi du terme «laisse»;

Ore est droiz que de ceus vous laisse,

$\mathrm{Si}$ vous redirai une laisse

Des compaignons qui chevauchoient. (Claris, v. 4999-5001)

Atant l'estoire de lui laisse

Si vous redirai une laisse

De Gaherïez [...] (Claris, v. 11665-11666)

On connaît l'usage poétique de ce terme pour désigner la forme du couplet spécifique à la chanson de geste, attesté dès le XIII ${ }^{\mathrm{e}}$ siècle. De manière plus large, le mot réfère à une partie de chanson, une pièce de vers, selon le dictionnaire de Frédéric Godefroy ${ }^{74}$, ou un "texte, couplet, tirade chanté ou dit sans interruption ${ }^{75}$. Des attestations que mentionne le dictionnaire, on retient en particulier l'idée d'unité narrative et de morceau chanté. Le recours à cette désignation par l'auteur de Claris et Laris peut être interprété différemment: en dehors des nécessités de la rime, il peut être compris dans le sens de "micro-récit mené de son commencement à son terme", ce qui ferait écho à la structure entrelacée pratiquée dans le roman (infra, chapitre III, "Structures arthuriennes: imiter la prose», p. 493-554); le substantif «laisse» renvoie finalement à l'esthétique de la chanson de geste, avec laquelle l'œuvre entretient plusieurs liens de parenté (infra, chapitre III, "Adoption de "patrons génériques exportables": l'épopée arthurienne», p. 572-595).

L'appellation de «dit» pour l'œuvre complet de Robert de Blois dans le ms. BnF fr. 24301 interpelle elle aussi: «Mais tel dit doit on bien oïr / Dont tuit ce pueent esjoïr.» (v. 21-22, prologue général du recueil) ${ }^{76}$, «Car je vuel por toz chastoier / Un novial dit encomencier» (v. 209-210, prologue général), «Et mout doit on prisier tel dit / Qui fait solas et grant

74 "Laisse», in Dictionnaire de l'ancienne langue française et de tous ses dialectes du $I X^{e}$ au XV siècle, Paris, Librairie des sciences et des arts, 1937-1938, vol. 4, p. 703.

75 "Laisse", Dictionnaire historique de la langue française, vol. 1. Ce sens provient de l'expression "d'une laisse», qui signifie "d'un trait», en laissant libre cours à la voix.

76 Ce prologue est transcrit par Milena Mikhaillova, L'École du roman, p. 365-374. 
profit» (v. 299-300, prologue exclusif à Biaudouz). Le genre du dit se définit bien moins par son contenu, largement diversifié, que par la situation d'énonciation. Il est destiné à être récité et restitue le point de vue personnel d'un énonciateur, comme l'écrivent Denis Hüe et Hélène Gallé:

Ce qui le caractérisera, ce sera bien une situation de performance [...], où c'est à un public que s'adresse un personnage qui est censé, dans la fiction de l'énonciation, tenir un discours personnel et sincère ${ }^{77}$.

Le dit exploite la subjectivité du je en tant qu'elle permet l'introduction d'une discursivité et l'établissement d'un contact avec le public. Les renvois au genre du «dit» dans la compilation des œuvres de Robert de Blois encadrées par Biaudouz visent une proximité entre le narrateur et les destinataires à instruire: la mise en scène de la figure de la mère de Biaudouz, qui endosse le rôle du narrateur à la première personne pour transmettre l'enseignement, renforce ce lien discursif avec le narrataire ${ }^{78}$. L'autodésignation "dit» pour l'œuvre de Robert de Blois confirme sa dimension didactique, comme le relève Jacqueline Cerquiglini-Toulet:

Le «je» du dit donne à découvrir le clerc: «je» aux traits individués mais qui ne sont pas individuels, «je» marqué, typé, ce «je» qui mime la parole dans une écriture est un "je» qui enseigne: c'est la position du clerc. Ce n'est donc pas le didactisme qui fonde le dit (et on explique alors le flou de toutes les définitions essayant de s'appuyer sur ce critère), c'est l'énonciation du dit qui permet le didactisme ${ }^{79}$.

Le choix du terme "dit» semble donc délibéré de la part de l'auteur et illustre son possible rejet de la veine romanesque, dans laquelle Biaudouz

77 Denis Hüe et Hélène Gallé, Rutebeuf, p. 93. Au sujet du dit, voir la définition qu'en donne Jacqueline Cerquiglini-Toulet, "Le dit», in Grundriß der romanischen Literaturen des Mittelalters. La littérature française aux XIV et XV siècles, vol. VIII/I, Heidelberg, Carl Winter, 1988, p. 86-94, et Monique Léonard, Le "dit» et sa technique narrative des origines à 1340, Paris, Champion, 1996.

78 Nous reviendrons sur le rôle particulier de la mère de Biaudouz et de sa confusion avec le je du narrateur au chapitre III, «Un récit encadrant: Biaudouz et le didactisme», p. 617-630.

79 Jacqueline Cerquiglini-Toulet, "Le clerc et l'écriture: le Voir dit de Guillaume de Machaut et la définition du dit ", in Grundriß der romanischen Literaturen des Mittelalters, "Literatur in der Gesellschaft des Spätmittelalters, I, dir. Hans Robert Jauss, Heidelberg, Carl Winter, 1980, p. 161. 
pourrait être rangé: cela confirme peut-être que l'œuvre arthurienne fut composée dès le départ pour enchâsser les textes didactiques de Robert de Blois et qu'elle forme un tout avec ceux-ci, s'inscrivant en continuité parfaite du prologue général dans sa désignation générique (voir infra, chapitre III, "Un récit encadrant: Biaudouz et le didactisme», p. 617-630.)

\section{Mises en recueil}

Par l'enchâssement des œuvres didactiques de l'auteur, la mise en recueil du manuscrit de Biaudouz est cohérente génériquement: l'œuvre de Robert de Blois s'ajoute à la suite d'une Vie des Pères et du Dolopathos, confirmant ainsi l'orientation didactique et morale du volume. La conscience générique des contemporains du XIII ${ }^{\mathrm{e}}$ 'exprime aussi dans les recueils manuscrits, qui présentent des regroupements de textes aux caractéristiques semblables ${ }^{80}$. Bien sûr, plusieurs manuscrits résistent à toute interprétation et il faut admettre parfois que «l'organisation d'un manuscrit et son contenu dépendent moins d'une réflexion sur la littérature que des désirs d'un commanditaire ${ }^{81}$. Néanmoins, des critères génériques président souvent à la mise en recueil ${ }^{82}$ : il en va ainsi du recueil de la $\mathrm{BnF}$, nouv. acq. fr. 1104, qui transmet exclusivement des textes brefs, intitulés "lais", mais au contenu hétérogène - ainsi les lais bretons côtoient le Lai de l'ombre, le Lai du Conseil ou le Lai d'Aristote, toutefois relégués à la fin du manuscrit. Il semble dans ce cas que le critère de la brièveté soit génériquement signifiant du point de vue médiéval, comme l'est aussi celui du contenu: il existe ainsi des recueils exclusivement dédiés au Roman

80 Keith Busby souligne la dimension générique qui préside à la mise en recueil, dans "Narrative genres", in The Cambridge Companion to Medieval French Literature, éd. S. Gaunt et S. Kay, Cambridge, Cambridge University Press, 2008, p. 139-152.

81 Dominique Boutet, Poétiques médiévales de l'entre-deux, ou le désir d'ambiguïté, Paris, Champion, 2017, p. 19.

82 Voir les travaux de Francis Gingras à ce sujet: Le Bâtard conquérant, "Mise en recueil et typologie des genres aux XIII ${ }^{\mathrm{e}}$ et XIV ${ }^{\mathrm{e}}$ siècles", art. cit., et "Roman contre roman dans l'organisation du manuscrit du Vatican, Regina Latina 1725", in La mise en recueil des textes médiévaux, dir. Xavier Leroux, La Garde, Université du Sud Toulon-Var («Babel», 16), 2007, p. 61-80. Le critique soulève la rareté des manuscrits polygénériques et mène une enquête sur quelques-uns d'entre eux. 
de Renart ${ }^{83}$ ou au Graal ${ }^{84}$. C'est également une perception générique qui semble motiver le regroupement opéré dans le manuscrit Chantilly, Condé 472: à l'exception du Perlesvaus, roman arthurien en prose, et de six branches du Roman de Renart, relégués en fin de volume, ce recueil ne transmet que des romans arthuriens en vers. Il comporte, dans l'ordre: Rigomer, L'Âtre Périlleux, Erec et Enide, Fergus, Hunbaut, Le Bel Inconnu, La Vengeance Raguidel, Le Chevalier au lion, Le Chevalier de la Charrette, Perlesvaus et le Roman de Renart. Ce témoignage prouve que la catégorie "romans arthuriens» existe pour les médiévaux: le compilateur est sensible à une ressemblance de type générique entre ces textes, regroupés en un tout homogène autour d'une matière et de la forme versifiée.

La mise en recueil n'est pas le fruit du hasard dans ce manuscrit : l'ordre dans lequel apparaissent les textes révèle des intentions parodiques et met à mal l'idéal, représenté par les œuvres arthuriennes de Chrétien de Troyes, toutes présentes, à l'exception du Conte du graal. Ce dernier est remplacé par Fergus, réécriture comique du parcours de Perceval, et par Perlesvaus, composé en prose, qui fournit une sorte de continuation-réécriture de la quête du graal sur un ton moins spirituel que la Queste del saint Graal ${ }^{85}$,

83 Comme les mss BnF fr. 3334, 3335 et 12583 par exemple. Dominique Boutet suggère de considérer les branches du Roman de Renart plus comme un genre que comme une œuvre. Voir les pages 159 à 231 de Poétiques médiévales de l'entre-deux, ou le désir d'ambiguïté.

84 Plusieurs manuscrits regroupent ainsi le Conte du graal et ses continuations: Londres, British Library, Add. 36614; Edinburgh, National Library, Advocates 19.1.5; BnF, fr 12576; BnF n.a.fr. 6614; Montpellier, Bibliothèque interuniversiatire, section médecine $\mathrm{H}$ 249; Mons, Bibliothèque de l'Université de Mons-Hainaut 331/206; BnF fr. 1429; BnF fr. 12576; BnF fr. 12577; BnF fr. 1453; BnF fr. 794; BnF fr. 1450. Voir l'article de Terry Nixon, "Catalogue of Manuscripts ", in Les Manuscrits de Chrétien de Troyes, dir. Keith Busby, Terry Nixon, Alison Stones et Lori Walters, Amsterdam; Atlanta, Rodopi, 1993, tome 2, p. 17-85, et The Continuations of the old French Perceval of Chrétien de Troyes, éd. William Roach, Philadelphia, University of Pennsylvania Press, 1949, p. XVI-XXXIII. Seul le manuscrit de Berne, Stadtbibliothek 113, transmet la Deuxième Continuation sans le Conte du graal.

85 Sa mise en scène d'un christianisme sauvage et violent, parsemé de merveilleux folklorique, fait de Perlesvaus un roman bien différent de la Queste del saint Graal. Voir à ce sujet l'introduction d'Armand Strubel, Le Haut Livre du Graal, Paris, Le Livre de Poche («Lettres gothiques»), 2007, Francis Dubost, "Le Perlesvaus, livre de haute violence», in La Violence dans le monde médiéval, Aix-en-Provence, CUERMA ("Senefiance», 36), 1994, p. 181-199, et Anne Berthelot, «Violence et 
surtout que la version du manuscrit de Chantilly s'arrête à la branche VIII et ne voit pas s'achever la quête de Perlesvaus. On s'éloigne de cette façon de toute lecture eschatologique du monde arthurien pour se concentrer sur un jeu littéraire avec l'écriture romanesque, nourri d'échos intertextuels, favorisé par l'esthétique du roman arthurien en vers. Ainsi, Lancelot est pour une fois moqué dans Rigomer, avant même de se montrer en amant parfait dans Le Chevalier de la Charrette qui intervient plus tard dans le manuscrit. Ce dernier texte est en plus tronqué de sa fin : il manque donc le tournoi au mieux, pendant au tournoi au Noauz qui devait réhabiliter Lancelot dans l'exercice armé. L'image que la mise en recueil privilégie demeure celle qui s'impose en premier lieu: un chevalier qui se gave dans les cuisines de Rigomer, délaisse une jeune fille qu'il a pourtant mise enceinte (épisode de Marte, v. 4580-4586) et remporte un défi en retenant son adversaire par le bras puis en tuant son cheval lors de la course qui les oppose (Rigomer, v. 5143-5157). Deux versions contradictoires du même personnage coexistent donc au sein du même ensemble ${ }^{86}$. Gauvain fait aussi les frais de la parodie dans L'Âtre Périlleux et Hunbaut, tandis qu'Erec fait partie des chevaliers qui échouent à retrouver Fergus, puis Gauvain dans Hunbaut. Quant à Yvain, s'il n'est jamais ridiculisé, il est toujours le second à se confronter à ses propres aventures, puisque celles-ci ont déjà été vécues par d'autres chevaliers que lui: Fergus se mue l'espace d'un instant en homme sauvage, Gauvain demande son chemin à un vacher dans La Vengeance Raguidel, l'aventure de la fontaine

passion, ou le christianisme sauvage de Perlesvaus: Le Haut Livre du Graal", in La Violence dans le monde médiéval, Aix-en-Provence, CUERMA ("Senefiance», 36), 1994, p. 21-36. Anne Berthelot souligne que «la lecture chrétienne est toujours seconde, et secondaire, par rapport à l'imaginaire romanesque» (p. 35).

86 Nous reviendrons sur la question des univers de fiction, qui éclaire de manière intéressante la contradiction au sein d'un même monde fictionnel. Signalons pour l'instant que chaque texte propose sa version du monde arthurien qui entre plus ou moins en contradiction avec les données connues de l'univers. Le lecteur accepte cette concurrence, qu'il faut appréhender comme un jeu littéraire et qui témoigne de l'absence de sacralisation d'une version. Au sujet de Lancelot dans Chantilly, Condé 472, on consultera Douglas Kelly, «Chretien's Lancelot Rewritten: From the Charrette to Rigomer in Manuscript and Narrative Cycle", in Dame Philology's Charrette. Approaching Medieval Textuality through Chrétien's Lancelot. Essays in Memory of Karl D. Uitti, dir. Gina L. Greco et Ellen M. Thorington, Tempe, ACMRS, 2012, p. 77-96. 
a déjà eu lieu dans Rigomer. Le chevalier au lion pâtit donc de sa position dans le recueil ${ }^{87}$.

Par son parti pris générique, le manuscrit se propose comme catalogue de motifs arthuriens. Celui de la chasse au cerf est par exemple développé dans plusieurs textes (Rigomer, Atre Périlleux, Erec, Hunbaut, Fergus, Raguidel, Bel Inconnu), ce qui donne lieu à une mise en perspective avec sa première occurrence littéraire chez Chrétien de Troyes, le motif étant détourné dans un but parodique ${ }^{88}$. La crainte de l'absence d'aventures parcourt également le recueil (Perlesvaus, Raguidel, Rigomer), de même que l'aventure du cimetière (Perlesvaus, Rigomer, Atre Périlleux) et le danger de la recreantise (Erec, Bel Inconnu). Les romans se font écho, ils se répondent entre eux. La mise en recueil du manuscrit Chantilly, Condé 472 met en avant une composante essentielle du genre arthurien: la construction fondamentalement intertextuelle et autoparodique des romans arthuriens en vers.

Ce cas se révèle fort intéressant dans la perspective qui est la nôtre: le geste de compilation, qui assemble romanesque et anti-romanesque, le canon et sa subversion, témoigne d'une attention générique aux textes et à ce qui crée leur cohérence d'ensemble. Francis Gingras souligne en ce sens que «la veine parodique que révèlent les mises en recueil suppose des conventions génériques bien connues et bien intégrées ${ }^{89}$. Pour que le canon soit parodié, il doit nécessairement d'abord être communément admis. En élargissant cette réflexion à l'ensemble de la littérature des $\mathrm{XII}^{\mathrm{e}}$ et XIII ${ }^{\mathrm{e}}$ siècles, il faut concevoir la mise en recueil comme le résultat d'un regroupement qui illustre les analogies établies par les médiévaux, comme l'explique Keith Busby:

I take the grouping of texts according to generic resemblance as evidence of an awareness among compilers and planners that texts

87 Francis Gingras, «Décaper les vieux romans: voisinages corrosifs dans un manuscrit du XIII ${ }^{\mathrm{e}}$ siècle (Chantilly, Condé 472)", in De l'usage des vieux romans, éd. Ugo Dionne et Francis Gingras, Études françaises, 42:1, 2006, p. 13-38. On consultera aussi Keith Busby, Codex and Context. Reading Old French Narrative in Manuscript, vol. 1, p. 405-413, et «Post-Chrétien verse romance: the manuscript context», CRM, 14, 2007, p. 11-24.

88 Francis Gingras, "Décaper les vieux romans», art. cit., p. 25-27.

89 Ibid., p. 36. 
could be categorized as belonging to types, even if these types were not susceptible of definition in the strict sense of the word ${ }^{90}$.

La mise en recueil révèle quels critères sont perçus comme génériquement pertinents par les commanditaires ou compilateurs médiévaux, qui sont autant de figures de lecteur ${ }^{91}$.

Il faut toutefois nuancer les constats auxquels amène le manuscrit de Chantilly: de tels regroupements de romans arthuriens en vers sont rares, pour ne pas dire qu'il s'agit du seul représentant à en offrir une concentration aussi importante ${ }^{92}$. Les romans arthuriens en vers figurent en effet souvent avec des textes d'autres genres. La présence de plusieurs romans arthuriens en vers dans le même ensemble s'explique d'ailleurs souvent par d'autres perspectives que celle du genre: il peut s'agir de proposer une petite anthologie des textes de Chrétien de Troyes ( $\mathrm{BnF}$ fr. $794 ; \mathrm{BnF}$ fr. $1450 ; \mathrm{BnF}$ fr. 12560) ou d'opérer un regroupement du Conte du graal et de ses continuations ${ }^{93}$. Seuls quatre autres recueils présentent plus d'un roman arthurien en vers: le BnF fr. 1433, où figurent l'Âtre Périlleux et le Chevalier au lion; Turin, L IV 33, manuscrit perdu qui contenait une partie de Rigomer, le Lai de Mélion ${ }^{94}$, Gliglois et Mérangis, entourés entre autres du Roman de Troie en prose et du Roman de Thèbes en prose; Vatican, Regina latina 1725, dans lequel on trouve dans l'ordre le Chevalier de la Charrette, le Chevalier au lion, le Roman de la Rose et Mérangis; BnF fr. 12603, qui s'ouvre sur le Chevalier aux deux épées et le

90 Keith Busby, Codex and Context. Reading Old French Narrative in Manuscript, vol. 1, p. 465. Voir aussi les pages 437 à 463.

91 Le rôle du lecteur est déterminant dans le cadrage générique et doit être considéré pour toute réflexion sur le genre. Nous développerons plus loin l'étendue de son importance.

92 À moins que l'on imagine qu'Escanor figurait initialement avec d'autres romans arthuriens, comme le laisse penser l'inventaire du Collège de Navarre établi par Masson en 1741 (BnF, lat. 9371, voir Richard Trachsler, Escanor, éd. cit., p. 22): il figure sous le titre "vieux romans des Chevaliers de la Table ronde", au pluriel, dans ce catalogue. Les cahiers perdus du ms. BnF fr. 24374 attestent de son dépeçage et rendent l'hypothèse d'une mise en recueil originelle plus étendue tout à fait vraisemblable.

93 Nous citions ces manuscrits à la note 84 , page 58 .

94 Même s'il s'agit d'un lai et non d'un roman, le Lai de Mélion s'intègre bien aux textes qui l'entourent par son contexte arthurien. 
Chevalier au lion et se poursuit avec le Roman d'Eneas, le Roman de Brut, les Enfances Ogier le Danois, Fierabras, des fabliaux et les Fables de Marie de France ${ }^{95}$. Le groupement de romans arthuriens en vers n'est donc pas systématique ni vraiment significatif, ceux-ci étant dans trois cas accompagnés de textes aux genres divers.

L'étude des manuscrits de ce corpus force tout de même à admettre que les romans arthuriens en vers ne figurent presque jamais avec des romans arthuriens en prose. Le Conte du graal lui-même ne se couple pas aux romans du graal en prose qu'il a pourtant inspirés. Il semble dès lors pertinent d'affirmer qu'il existe une distinction nette entre ces deux formalisations d'un même univers de fiction ${ }^{96}$ et que le récepteur médiéval était sensible aux différences qui les opposent. La mise en recueil éclaire ces incompatibilités: le manuscrit de romans en prose offre une expérience de lecture distincte de celle du recueil de romans en vers. Emmanuèle Baumgartner explique que la prose se présente linéairement sur la page, sans beaucoup marquer les intervalles des unités narratives: "Le lecteur doit donc procéder lui-même au découpage du texte, au repérage de ses articulations essentielles. ${ }^{97}$ Le rythme de lecture se réinvente à chaque fois. La mise en page influe sur la réception et va de pair avec les ambitions totalisantes de la prose, comme l'écrit encore Emmanuèle Baumgartner:

[Le roman en prose] propose surtout dans sa matérialité même une vision nouvelle, totalisante, des récits qu'il réunit, vision qui s'oppose à la vision fragmentaire, discontinue et dans une certaine mesure prédécoupée que donne le recueil de récits narratifs en vers ${ }^{98}$.

La transmission matérielle éclaire en partie la rareté de la coprésence de romans arthuriens en vers et de romans arthuriens en prose au sein des

95 Les informations sur les manuscrits cités sont renseignées par l'article de Terry Nixon, "Catalogues of Manuscripts", art. cit., et l'ouvrage de Richard Trachsler, Les romans arthuriens en vers après Chrétien de Troyes, p. 25-31. Voir aussi l'annexe C et infra, chapitre II, «Lire le roman arthurien à la fin du Moyen Âge», p. 381-397.

96 Nous reviendrons sur la définition de ce concept au chapitre I, «Définition du canon", p. 175-230, de même que sur la distinction entre prose et vers, au chapitre II, "Choix de forme, choix de chronotope», p. 242-325.

97 Emmanuèle Baumgartner, "Les techniques narratives dans le roman en prose", art. cit., p. 171. Dès la seconde moitié du XIII ${ }^{\mathrm{e}}$ siècle, les enluminures facilitent le découpage de la lecture.

Ibid. 
manuscrits, mais ce phénomène s'explique surtout par des incompatibilités d'ordre générique.

Seuls les manuscrits Chantilly, Condé 472, et Berne, Burgerbibliothek 113 font cohabiter romans arthuriens en vers et en prose, par le biais d'un texte commun: le Perlesvaus. Il ne s'agit donc jamais du cycle du LancelotGraal. Bien que Francis Gingras lise dans le Perlesvaus une dimension édifiante qui proposerait un point de vue exégétique sur les conventions romanesques $^{99}$, il faut aussi considérer la propension talismanique que prend le Graal dans ce texte. Certes, la diégèse adopte un ton religieux, se prétend dictée par un ange, introduit la liturgie chrétienne autour du Graal et s'intègre à l'Histoire sainte. Mais elle se différencie par son idéologie du génocide joyeux ${ }^{100}$, son esthétique de la violence et sa tendance à accumuler les objets sacrés, ce qui les vide de leur portée transcendantale. Armand Strubel note également la parenté du Perlesvaus avec les continuations en vers, car son auteur renonce «à la voie ouverte par Robert de Boron, celle de l'écriture cyclique, face à laquelle il constitue une solution de rechange ${ }^{101}$. D'autres éléments, comme le recours marginal à l'hypotaxe, conduisent le critique à voir dans cette continuation en prose un texte de "l'entre-deux ${ }^{102}$, qui s'éloigne du standard en prose et se rapproche de la thématique des continuations en vers.

L'intégration du Perlesvaus au sein de recueils de romans arthuriens en vers peut se justifier alors par diverses hypothèses: l'absence de mise en cycle pour ce texte, dont la clôture facilite son insertion à côté d'autres œuvres autonomes. Ensuite, la logique de l'aventure prévaut dans ce roman construit en branches. Cette organisation crée un lien avec le Roman de Renart dans le cas du ms. Chantilly, Condé 472, voire suggère une lecture du manuscrit entier comme la réunion de branches,

99 Francis Gingras, «La triste figure des chevaliers dans un codex du XIII ${ }^{\mathrm{e}}$ siècle (Chantilly, Condé 472)", art. cit., et "Décaper les vieux romans: voisinages corrosifs", art. cit.

100 Voir Anne Berthelot, "Violence et Passion, ou le christianisme sauvage de Perlesvaus», art. cit., et Francis Dubost, "Le Perlesvaus, livre de haute violence», art. cit.

101 Armand Strubel, «Écrire le Graal en prose et en vers. Le Perlesvaus et les Continuations", in Écrire en vers, écrire en prose: une poétique de la révélation. Actes du colloque de Paris X-Nanterre, mars 2006, dir. Catherine Croizy-Naquet, Nanterre, Université Paris X-Nanterre («Littérales», 41), 2007, p. 187.

102 Ibid., p. 206. 
que constituerait chacune des œuvres ${ }^{103}$. Enfin, nous l'avons évoqué, le recueil de Chantilly semble omettre volontairement le Conte du graal et le remplacerait par une réécriture (Fergus) et une continuation (Perlesvaus) qui présente l'intérêt d'offrir un terme à l'histoire contée par Chrétien de Troyes. La forme prose n'en demeure pas moins marginalisée dans le manuscrit, par sa position en fin de volume et par la rupture matérielle qui l'introduit et que relève Francis Gingras:

Dans le manuscrit de Chantilly, la séparation entre le vers et la prose est sensible avec le passage de trois à deux colonnes. Ce changement matériel, visible au premier coup d'œil, crée un effet de rupture accentué par le fait que le texte précédent (Le Chevalier de la charrette) s'interrompt au milieu du tournoi du pire $^{104}$.

Le Perlesvaus se distingue aussi du reste des textes en ce qu'il se désigne comme "estoire» et non comme "roman». Malgré la coprésence de deux réalisations formelles du roman arthurien, la frontière est marquée matériellement et génériquement ${ }^{105}$.

La rupture générique est tout autant accentuée au début du Roman de Renart, autre texte hétérogène au sein de ce recueil de romans arthuriens en vers ${ }^{106}$. La version de Chantilly commence par la branche II, dont

103 C'est la lecture de Lori Walters, "The formation of a Gauvain cycle in Chantilly manuscript $472 »$, art. cit.

104 Francis Gingras, "La cohabitation du vers et de la prose dans deux collections médiévales (Chantilly, Condé 472 et Berne, Burgerbibliothek 113)", in Écrire en vers, écrire en prose: une poétique de la révélation. Actes du colloque de Paris $X$-Nanterre, mars 2006, dir. Catherine Croizy-Naquet, Nanterre, Université Paris X-Nanterre («Littérales», 41), 2007, p. 88.

105 Nous renvoyons à l'article de Francis Gingras au sujet de la cohabitation vers-prose dans le manuscrit de Berne: ce recueil abolit au contraire les différences entre les deux formes dans sa mise en page et traite de tous les représentants comme des «romans». "La cohabitation du vers et de la prose dans deux collections médiévales ", art. cit. On se référera à ce même article au sujet de la coprésence des deux formes dans les manuscrits médiévaux, ainsi qu’à Le Bâtard conquérant, chapitre "Roman et prose».

106 Sur sa présence dans le manuscrit de Chantilly, voir les articles de Francis Gingras, "La triste figure des chevaliers dans un codex du XIII ${ }^{\mathrm{e}}$ siècle (Chantilly, Condé 472)", art. cit., et "Décaper les vieux romans: voisinages corrosifs", art. cit. Lori Walters a perçu dans le Roman de Renart un cycle qui redouble celui que forment les romans arthuriens autour de Gauvain. L'ensemble mettrait en évidence des 
le prologue souligne les différentes catégories de récits. Nous le citions au chapitre précédent, en voici la version qu'offre le manuscrit qui nous intéresse:

Signor, oï avez maint conte,

Que maint contere vos raconte

Comment Paris ravi Helainne,

Le mal qu'il en ot et le paine,

De Tristan qui la cievre fist,

Qui ases bielement en dist,

Et fables et cançons de geste,

Romans dou leu et de la bieste,

Maint autre conte par la terre.

Mais ains n'oïste la grant guerre

De danz Renart et d'Isengrin,

Qui molt fu dure de grant fin. (Chantilly, Condé 472, folio 244)

Ce prologue marque la différence générique entre le Roman de Renart et les autres genres; il fait la transition entre les textes exclusivement arthuriens copiés plus haut et les aventures du goupil. La distinction entre les œuvres est ainsi explicitée, comme si ce prologue se référait directement aux textes qui précèdent dans la mise en recueil.

implications morales: prévenir contre les péchés terrestres et la faiblesse morale de la noblesse. Voir «Parody and moral allegory in Chantilly MS 472", MLN, 113:4, 1998, p. 937-950, «Dé-membrer pour remembrer. L’ouvre chrétienne dans le ms. Chantilly 472», in Mouvances et jointures. Du manuscrit au texte médiéval, dir. Milena Mikhaïlova, Orléans, Paradigme («Medievalia», 55), 2005, p. 253-281, "The King's Example: Arthur, Gauvain, and Lancelot in Rigomer and Chantilly, Musée Condé 472 (anc. 626) ", in De sens rassis, dir. Keith Busby et al., Amsterdam, Rodopi, 2005, p. 699-717. Nous ne suivons pas sa lecture chrétienne du manuscrit. Quant à l'appréhension du manuscrit de Chantilly comme un cycle de Gauvain par la chercheuse, elle nous semble donner trop d'importance au neveu d'Arthur, qui n'est de loin pas le héros de tous les textes du recueil. L'hypothèse de Lori Walters nous semble induite par le rôle générique de Gauvain: le personnage est un sème générique, un signal qui oriente l'appréhension générique des textes. Plus qu'un cycle de Gauvain, le ms. Condé 472 est avant tout un panorama de la littérature arthurienne en vers. Nous y reviendrons au chapitre II, "Choix de forme, choix de chronotope", p. 242-325. 


\section{Définition du concept de genre}

Le soin prêté à la mise en recueil dans Chantilly, Condé 472 témoigne d'un geste conscient du regroupement effectué. Les manuscrits organisés autour d'une forme ou d'un contenu, de même que les manuscrits cycliques, sont une preuve de plus qui confirme la pertinence de parler de "genres» pour le Moyen Âge ou, du moins, d'un point de vue générique porté sur la littérature, malgré l'absence d'un tel concept à cette époque. Encore faut-il en préciser la définition, voire l'adapter à la période qui nous occupe ${ }^{107}$, la question du genre ayant été passablement étudiée en théorie de la littérature. Considérer la généricité permet de dégager des relations textuelles ${ }^{108}$; le genre rend compte des rapports qu'entretiennent les œuvres entre elles, d'un "principe de regroupement et de différenciation " ${ }^{109}$. La relation générique est double: elle explique d'une part les rapports d'un texte à d'autres textes et d'autre part celles d'un genre aux autres genres ${ }^{110}$. Selon Antoine Compagnon, «le genre est la médiation entre l'œuvre particulière et la littérature ${ }^{111}$. Il est dès lors d'une importance capitale pour envisager les enjeux inhérents au champ littéraire. Le genre détermine avant tout une façon de

107 Nous ne détaillerons pas les questions liées à l'histoire de la notion de genre littéraire ni les points de vue adoptés au cours du $\mathrm{xx}^{\mathrm{e}}$ siècle. Nous ne confronterons pas les théories concurrentes, mais expliciterons uniquement ce qui nous paraît pertinent pour notre propos. Voir pour plus de détails Gérard Genette, «Introduction à l'architexte», art. cit., Jean-Marie Schaeffer, Qu'est-ce qu'un genre littéraire?, Karl Canvat, "Essai d'histoire de la notion de genre littéraire", Les Lettres romanes, LI, 3-4, 1997, p. 187-221, Dominique Combe, Les genres littéraires, et Marielle Macé, Le genre littéraire. La notion de genre littéraire a été dénigrée et déclarée inopérante dès les années 1960, avec l'essor des analyses stylistiques. Sa négation est également liée au surréalisme, qui refuse le souci de l'esthétisme.

108 Voir Jean-Marie Schaeffer, «Du texte au genre. Notes sur la problématique générique», in Théorie des genres, Paris, Seuil, 1986, p. 205. Le genre rend compte d'une relation transtextuelle, au sens genettien: il s'inscrit plus précisément dans le type de l'architextualité, qui désigne l'ensemble des catégories générales destinées à regrouper les textes. Gérard Genette, "Introduction à l'architexte», art. cit. et Palimpsestes.

109 Patrick Moran, "Genres médiévaux et genres médiévistes: l'exemple des termes chanson de geste et épopée", art. cit., p. 41.

110 Voir Benjamin Bouchard, "Critique des notions paragénériques», Poétique, 159, 2009, p. 358-381.

111 Voir Antoine Compagnon, La Notion de genre, cours sur fabula, https://www. fabula.org/compagnon/genre.php. 
recevoir le texte, il en assure la compréhension auprès du lecteur. C'est ce qu'exprime Wolf Dieter Stempel :

D'après l'opinion générale, le genre historique est à considérer comme un ensemble de normes ("de règles de jeu», comme on a dit aussi) qui renseignent le lecteur sur la façon dont il devra comprendre son texte; en d'autres termes: le genre est une instance qui assure la compréhensibilité du texte du point de vue de sa composition et de son contenu ${ }^{112}$.

Raphaël Baroni donne l'exemple de la nouvelle de Jorge Luis Borges, «La mort et la boussole», qui mélange les codes du roman à énigme et du roman à suspense: génériquement orienté par le roman policier, le lecteur ne s'attend pas à ce que le détective soit maintenu en échec et reste donc sourd aux indices semés par le narrateur ${ }^{113}$. Si le texte de Borges fournissait les indices d'un récit tragique, le lecteur se serait au contraire attendu à la mort du personnage: le codage générique permet en effet d'anticiper la fin.

Le genre informe ainsi l'attitude de lecture à adopter (suspicieuse pour un roman policier, amusée pour une comédie, grinçante pour une satire, etc.). À l'inverse, le lecteur influe sur la généricité du texte: les collections éditoriales, dont la gestion appartient à autant de figures de lecteurs, décident par exemple du classement en «roman de jeunesse» de textes qui pourraient aussi bien recevoir l'attention d'un public adulte. C'est ainsi qu'un genre, ou une catégorie générique, peut naître par la seule décision des lecteurs ${ }^{114}$, qui repèrent une relation d'analogie entre les œuvres.

112 Wolf Dieter Stempel, "Aspects génériques de la réception", in Théorie des genres, Paris, Seuil, 1986, p. 170.

113 Raphaël Baroni, "Genres littéraires et orientation de la lecture», Poétique, 134, 2003, p. 141-157.

114 Nous admettons ici que les lecteurs forment une communauté plus ou moins homogène du point de vue de l'appréhension du genre littéraire: on peut postuler que la plupart des lecteurs de romans policiers nommeraient les mêmes analogies entre les textes de cette classe (présence du type de l'enquêteur, de la victime, du coupable, énigme à résoudre, rebondissements de l'intrigue, etc.). Les études psychanalytiques appliquées à la théorie de la lecture supposent l'existence de faits transhistoriques, d'invariants psychologiques. Voir à ce sujet Vincent Jouve, La Lecture, Paris, Hachette ("Contours littéraires»), 1998, p. 36-37, et Alain Trouvé, Le roman de la lecture. Critique de la raison littéraire, Sprimont, Mardaga («Philosophie et langage»), 2004. 
Cette analogie peut se situer sur des niveaux différents (énonciatif, thématique, formel, etc.) selon les genres. Ce type de genre, que Jean-Marie Schaeffer nomme "classe analogique ${ }^{115}$, dépend de la généricité lectoriale, c'est-à-dire de l'attribution des lecteurs:

À l'inverse les classifications qui se fondent sur des ressemblances causalement indéterminées sont toujours des classifications rétrospectives: elles relèvent dans tous les cas en premier lieu de la généricité lectoriale ${ }^{116}$.

Dans le cadre de la littérature médiévale, différents acteurs du champ littéraire font figure de lecteurs, dont certains ont laissé des traces: en premier lieu, il s'agit des copistes, qu'ils soient contemporains à l'œuvre transcrite ou qu'ils interviennent cinquante, voire cent ans après sa composition. Les recueils manuscrits également, nous l'avons vu, opèrent des groupements générés par une instance lectoriale. Les inventaires de bibliothèques, finalement, nous renseignent parfois sur la réception des textes. Dans le cas de notre corpus, les manuscrits de Rigomer et de Claris et Laris en particulier fournissent des informations sur leur réception, le premier, nous l'avons vu, figurant exclusivement aux côtés de romans arthuriens et manifestant la formation d'une classe analogique, le second étant transmis avec une chanson de geste et un récit idyllique (infra, chapitre III, "Adoption de "patrons génériques exportables": l'épopée arthurienne», p. 572-595). L'enquête sur la généricité lectoriale médiévale n’est néanmoins pas sans limites: l'état de la transmission manuscrite ne donne que peu de pistes sur la façon dont nos romans tardifs ont été perçus génériquement. Le point de vue sera dès lors souvent celui de la généricité auctoriale, autrement dit la façon dont l'auteur inscrit son œuvre dans le paysage générique existant.

L'auteur doit être considéré comme une figure de lecteur ${ }^{117}$ : l'œuvre ne surgit pas ex nibilo, mais prend place au sein d'une production textuelle

115 Jean-Marie Schaeffer, Qu'est-ce qu'un genre littéraire?, chapitre 4.

116 Jean-Marie Schaeffer, "Genres littéraires", in Nouveau dictionnaire encyclopédique des sciences du langage, dir. O. Ducrot et J.-M. Schaeffer, Paris, Seuil, 1995, p. 520-529.

117 C'est à partir de cette donnée que Marielle Macé déroule son essai sur la pragmatique de la lecture: les lecteurs qu'elle prend pour modèle sont des grands écrivains (Proust, Sartre, Michaux, Gracq, etc.), qui ont la faculté de réfléchir de manière privilégiée sur les pratiques de lecture. Façons de lire, manières d'être, 
qui lui préexiste. L'écrivain, même s'il décide de ne pas appliquer les règles strictes et formelles qui définissent certains genres de manière prescriptive, comme c'est le cas du sonnet ou de la tragédie, doit d'abord appréhender le genre dans lequel il compte s'inscrire, ou contre lequel il veut se positionner, en comprendre les codes et l'interpréter, pour pouvoir le réactiver à sa façon. Jean-Marie Schaeffer nomme ce type de relation générique "classe généalogique»" ${ }^{118}$. La généricité auctoriale, qui parfois est différente de son homologue lectorial, interroge le rapport que l'auteur entendait créer entre son œuvre et le ou les genres - l'œuvre pouvant être polygénérique - préexistants: inscription stricte, subversion, liens ténus. En d'autres termes, "on se propose de retrouver l'ensemble des normes et des règles que l'auteur a mises en œuvre, qu'il a respectées ou violées ${ }^{119}$. L'exemple du roman policier illustre cette dynamique: initié par Edgar Allan Poe, il crée des lecteurs de fictions policières, qui, enthousiasmés, deviennent des auteurs de romans policiers en réactivant un savoir générique $^{120}$. Le genre s'engendre donc parce qu'il a touché des lecteurs, enclins à reconduire une écriture.

La même chose se passe dans le cas du roman arthurien: Chrétien de Troyes est le précurseur d'un genre bien spécifique, dans lequel les lecteurs reconnaîtront des codes idéologiques et stylistiques, et qui suscitera l'émulation des auteurs du XiII ${ }^{\mathrm{e}}$ siècle comme Renaut de Beaujeu, Raoul de Houdenc ou Guillaume le clerc. Ceux-ci n'hésiteront pas à lier leurs œuvres à la classe constituée en reconduisant les éléments qui leur

Paris, Gallimard («NRF Essais»), 2011. Voir aussi Florence Bouchet, Le Discours sur la lecture en France aux XIV et XV siècles, p. 171-186.

118 Sur les distinctions entre relations analogiques et généalogiques, voir Jean-Marie Schaeffer, Qu'est-ce qu'un genre littéraire?, p. 180-184. La classe généalogique se définit comme suit: "toute filiation plausible qu'on peut établir entre un texte et un ou plusieurs ensembles textuels antérieurs ou contemporains dont, sur la foi de traits textuels ou d'index divers, il semble licite de postuler qu'ils ont fonctionné comme modèles génériques lors de la confection du texte en question, soit qu'il les imite, soit qu'il s'en écarte, soit qu'il les mélange, soit qu'il les inverse, etc.» (p. 174) La relation analogique désigne le fait que tout texte entretient des ressemblances avec d'autres textes, reconnues a posteriori par les lecteurs.

119 Jean-Marie Schaeffer, "Genres littéraires», in Nouveau dictionnaire, p. 528.

120 Voir Raphaël Baroni, "Généricités borgésiennes", in Le Savoir des genres, dir. Raphaël Baroni et Marielle Macé, Rennes, PUR («La licorne», 79), 2006, p. 155-172. 
ont paru saillants. A posteriori, les lecteurs formeront une classe analogique avec tous les représentants de ce genre, comme le ms. Chantilly, Condé 472, en est l'exemple. Ainsi, l'œuvre s'inscrit dans le genre dès sa composition ou par un groupement fondé sur des analogies repérées par les lecteurs. Patrick Moran le résume ainsi :

La généricité, c'est le fait que tout nouveau texte ressemble à des textes antérieurs, que ce soit parce qu'il obéit aux mêmes règles, parce qu'il s'en inspire et puise dans le même fond commun, ou parce que le lecteur seul décèle une ressemblance. La littérature médiévale, qui accorde tellement d'importance à la tradition, n'a rien d'une littérature a-générique ${ }^{121}$.

Les genres littéraires dépendent donc moins des textes que de la façon dont ils sont appréhendés, par les lecteurs ou les auteurs eux-mêmes. Ils sont soumis à une part de subjectivité, liée aux compétences propres à chaque lecteur, à ses connaissances, à sa pratique des œuvres littéraires. Ceci explique la difficulté à classer celles-ci de manière exclusive, l'appréhension de la généricité étant subjective. Raphaël Baroni et Marielle Macé parlent ainsi de "sentiment du romanesque", qui ne désigne pas la capacité à définir le genre, mais décrit un condensé d'affects, qui oriente l'identification de manière cognitive et sur la base de l'expérience ${ }^{122}$. Cette appréhension intuitive des genres rejoint le concept d' "air de famille», au sens de Ludwig Wittgenstein, convoqué en théorie générique ${ }^{123}$ pour caractériser les ressemblances entre les textes des catégories qui ne reproduisent pas des règles formelles: le lecteur peut identifier des analogies textuelles sans pouvoir les expliciter, de la même manière qu'on ne peut déterminer pourquoi un frère et une sœur se ressemblent. Les membres d'une même famille ne présentent

121 Patrick Moran, Lectures cycliques, p. 644.

122 Raphaël Baroni et Marielle Macé, Le Savoir des genres, Rennes, PUR ( La licorne», 79), 2006, p. 9.

123 Antoine Compagnon, La Notion de genre, réf. cit., Marielle Macé, Le genre littéraire, p. 244-246. L'idée d'air de famille est fréquemment convoquée dans les théories du genre littéraire. Elle est développée par Ludwig Wittgenstein dans le cadre de la philosophie du langage. Ludwig Wittgenstein, Recherches philosophiques, Paris, Gallimard, 2004. L'histoire du terme "genre» encourage le parallèle avec la famille, puisqu'il désigne d'abord un groupement humain, lié au sens de «race». Le genre littéraire rend clairs les apparentements entre des textes, qui s'engendrent les uns les autres. 
pas tous les mêmes caractéristiques, mais les différents individus ont des traits communs, dont aucun n'est indispensable pour que l'on reconnaisse le lien au clan. La même chose est valable pour les textes d'une même catégorie. C'est ce qu'énonce Benjamin Bouchard:

Un genre est constitué par un ensemble de propriétés; les textes qui participent du genre en question ne possèdent jamais toutes ces propriétés à la fois, mais seulement un certain nombre; aucune des propriétés du genre n'est partagée par tous les textes à la fois ${ }^{124}$.

Ces conceptions admettent la subjectivité inhérente à toute théorie générique, ce qui n'affaiblit pas le concept, mais oblige à adopter une certaine souplesse dans son application. Ce constat permet d'esquisser déjà l'idée qu'aucun critère n'est indispensable pour qu'un texte soit inclus dans le cadre d'une réflexion sur le genre arthurien: même le personnage du roi Arthur peut être évincé, dans Blandin de Cornouailles notamment (infra, chapitre I, "Blandin de Cornouailles», p. 217-230). Quant au critère de la forme, l'étude du Conte du Papegau (infra, chapitre II, «Le Conte du Papegau entre vers et prose», p. 417-425) montrera qu'il est possible d'écrire un roman arthurien en vers dans la forme de la prose, même si cette tentative constitue un hapax; plus fréquemment, comme la considération des mises en recueil l'a prouvé, vers et prose formalisent l'univers de fiction de façon inconciliable. Cela n'empêche pas l'emprunt de techniques narratives, nous aurons l'occasion d'y revenir.

On le comprend, toute œuvre, en tant qu'elle surgit dans un champ déjà constitué, ne saurait être totalement indépendante d'un genre: dès sa composition, elle dépend des expériences de lecture de son auteur, puis des regroupements analogiques effectués par ses lecteurs successifs, ceux-là dépendant à leur tour des ouvres ultérieures - ainsi, les Confessions de Saint-Augustin s'intègrent dans la classe analogique "autobiographie» en raison du rapprochement auquel on peut procéder avec les Confessions de Rousseau, comme le roman arthurien peut apparaître comme un Bildungsroman après les œuvres de Goethe ou de Flaubert. Antoine Compagnon confirme la dépendance de l'œuvre aux genres:

Mais aucun texte n'est hors de toute norme générique, même si c'est un rêve de la littérature moderne (supprimer le genre entre l'œuvre et

124 Benjamin Bouchard, "Critique des notions paragénériques», art. cit., p. 363. 
la littérature). Un texte hors genres n'est pas concevable. Mais un texte affirme et affiche sa singularité par rapport à un horizon générique, dont il s'écarte, qu'il module, qu'il subvertit. Le genre est intermédiaire entre l'œuvre particulière et singulière et la littérature entière ${ }^{125}$.

Ainsi, si l'œuvre est toujours liée à la généricité, cela ne signifie pas pour autant qu'elle remplit forcément toutes les caractéristiques d'un genre en particulier: au contraire, elle peut s'en démarquer, le subvertir, le transformer, y participer en exposant des marques contradictoires ou externes ${ }^{126}$. En ce sens, les textes de notre corpus, même s'ils subvertissent les codes du roman arthurien et s'écartent du schéma traditionnel, n'en sont pas pour autant agénériques et n'entrent pas moins dans le cadre de la généricité arthurienne.

La subversion passe aussi par les interactions avec d'autres genres contemporains. L'œuvre singulière n'est pas influencée que par le genre dans lequel elle entre en filiation: elle prend place dans un champ plus large, qui englobe la production littéraire dans son ensemble. Il faut adopter un point de vue en synchronie, "in re», comme le propose Hans Robert Jauss ${ }^{127}$. Il existe un dialogue entre les différents genres d'une même époque, que ces relations se caractérisent par la concurrence ou l'influence mutuelle. Dès lors,

il faut aussi se débarrasser de l'idée d'une juxtaposition de genres clos sur eux-mêmes et chercher leurs interrelations, qui constituent le système littéraire à un moment historique donné ${ }^{128}$.

Ce point de vue se révélera essentiel pour la dernière partie de notre recherche; les textes tardifs semblent justement s'écarter du canon arthurien versifié, en premier lieu par l'influence qu'ils assument de la part

\footnotetext{
125 Antoine Compagnon, La Notion de genre, réf. cit.

126 Marielle Macé, Le genre littéraire, p. 214.

127 Le point de vue in re propose une perspective historique sur le genre: «une continuité, où tout ce qui est antérieur s'élargit et se complète par ce qui suit." Voir «Littérature médiévale et théorie des genres», art. cit. p. 43. Il s’oppose aux points de vue post rem et ante rem: alors que le premier est classificateur - on classe les œuvres après leur parution -, le second est normatif - le genre prescrivant des règles à respecter avant la production des œuvres.
}

128 Ibid., p. 65. 
des romans arthuriens en prose, mais aussi parce qu'ils intègrent des éléments propres à d'autres genres littéraires contemporains (chapitre III, «Confluences: un mélange des genres?», p. 554-630): ces velléités intégratives interrogent l'homogénéité d'un genre qui en absorbe d'autres. Elles construisent surtout l'esthétique tardive, dont le caractère secondaire implique l'inclusion des pratiques esthétiques variées du XIII ${ }^{\mathrm{e}}$ siècle.

La question de l'homogénéité incite à ne pas utiliser le concept de genre pour classer de manière stricte des textes ni pour fournir des règles ou prescriptions ${ }^{129}$; il doit au contraire permettre de rendre compte des relations qu'entretient une œuvre avec les autres œuvres du champ. Comme le résume Jacques Derrida,

un texte ne saurait appartenir à aucun genre. Tout texte participe d'un ou de plusieurs genres, il n'y a pas de texte sans genre, il y a toujours du genre et des genres, mais cette participation n'est jamais une appartenance ${ }^{130}$.

En d'autres termes, le genre ne sert pas à «décomposer la littérature en classes de textes mutuellement exclusives, dont chacune posséderait son essence ${ }^{131}$. L'idée de la participation évite de considérer que les genres préexistent aux textes: chaque texte participe de la définition du genre, contribue à nuancer une définition pré-construite sur la base de quelques représentants perçus comme canoniques. La généricité est un "phénomène communicationnel et non taxinomique» ${ }^{132}$. C’est en ce sens-là que

129 Ibid., c'est-à-dire adopter un point de vue post rem et ante rem.

130 Jacques Derrida, «La loi du genre», in Parages, Paris, Galilée, 1986, p. 264. Voir aussi Ute Heidmann et Jean-Michel Adam, "Six propositions pour l'étude de la généricité», art. cit., notamment p. 23. Ute Heidmann et Jean-Michel Adam proposent eux aussi de considérer la généricité comme une participation plus que comme une appartenance, les œuvres entrant fréquemment en dialogue avec plusieurs genres: «Un texte relevant généralement de plusieurs genres, il ne s'agit plus de la classer dans une catégorie - son appartenance -, mais d'observer les potentialités génériques qui le traversent - sa participation à un ou plusieurs genres - en tenant compte des points de vue tant auctorial, qu'éditorial et lectorial.» (p. 26)

131 Jean-Marie Schaeffer, Qu'est-ce qu'un genre littéraire?, p. 63.

132 Patrick Moran, «Genres médiévaux et genres médiévistes: l'exemple des termes chanson de geste et épopée», art. cit., p. 42. Patrick Moran reprend ici l'idée d'Alastair Fowler, Kinds of Literature. An Introduction to the Theory of Genres and Modes, Cambridge, Harvard University Press, 1982. 
nous parlons volontiers de "généricité arthurienne», pour évoquer l'idée d'un paradigme arthurien modulable et évolutif, et non d'une classe strictement établie.

\section{Horizon d'attente}

Si le genre ne doit pas servir à sédimenter le champ littéraire, il est en revanche opérant dans le cadre d'une réflexion sur la réception des textes et sur l'horizon d'attente des lecteurs, concept théorisé par Hans Robert Jauss:

On ne saurait imaginer une ouvre littéraire qui se placerait dans une sorte de vide d'information et ne dépendrait pas d'une situation spécifique de la compréhension. Dans cette mesure, toute œuvre littéraire appartient à un genre, ce qui revient à affirmer purement et simplement que toute ouvre suppose l'horizon d'une attente, c'est-à-dire d'un ensemble de règles préexistant pour orienter la compréhension du lecteur (du public) et lui permettre une réception appréciative ${ }^{133}$.

Comme l'exprime le critique, l'horizon d'attente désigne un ensemble de traits significatifs génériquement marqués, qui influent sur la lecture: le sous-titre "tragédie» induit par exemple pour le lecteur la mort finale des héros. Le paratexte est donc le premier niveau de l'horizon d'attente. L'écrivain sème toute une série d'autres indices, de diverses natures, qui permettent d'anticiper l'intrigue à venir. Identifier l'horizon créé suppose des compétences génériques spécifiques de la part du lecteur, construites sur la base d'expériences de lecture et de rapprochements entre les textes et les types de discours. Raphaël Baroni définit comme suit la compétence générique:

La compétence générique est, par conséquent, un amalgame de connaissances abstraites, de stéréotypes culturels, que le lecteur acquiert par sa pratique des œuvres littéraires ${ }^{134}$.

Les horizons génériques peuvent être compris comme des catégories mentales que les lecteurs construisent au fil de leur pratique et qui informent leur appréhension d'un nouveau texte. La lecture dépend ainsi de

133 Hans-Robert Jauss, "Littérature médiévale et théorie des genres», art. cit., p. 42.
134 Raphaël Baroni, "Genres littéraires et orientation de la lecture», art. cit., p. 143. 
scénarios intertextuels ${ }^{135}$ dictés par le genre, qui engendrent l'anticipation d'une suite d'actions stéréotypées.

L'auteur est libre de reconduire l'horizon ou de fourvoyer le lecteur en introduisant des traits identifiables, puis en décevant les attentes, ou en y superposant des traits d'un autre genre. Le nouveau texte se construit dès lors en rapport avec l'horizon d'attente que définit Hans Robert Jauss:

Le processus de réception peut être décrit comme l'expansion d'un système sémiologique, qui s'accomplit entre les deux pôles du développement et de la correction du système. Le rapport du texte isolé au paradigme, à la série des textes antérieurs qui constituent le genre, s'établit aussi suivant un processus analogue de création et de modification permanente d'un horizon d'attente. Le texte nouveau évoque pour le lecteur (ou l'auditeur) tout un ensemble d'attente et de règles du jeu avec lesquelles les textes antérieurs l'ont familiarisé et qui, au fil de la lecture, peuvent être modulées, corrigées, modifiées ou simplement reproduites ${ }^{136}$.

L'attente est détournée lorsque l'événement prédit par les signaux génériques n'intervient pas, comme l'illustre l'exécution de lord Eddard Stark, l'un des personnages principaux, dans la saga de George R. R. Martin, $A$ Song of Ice and Fire: le genre de la fantasy ${ }^{137}$ a pourtant habitué le lecteur à voir le triomphe des personnages auxquels il s'est attaché, comme c'est le cas dans Le Seigneur des anneaux de John R. R. Tolkien. Dans le cas de lord Stark, aucun rebondissement ne vient interrompre la mise à mort, si bien que le lecteur est déçu dans son attente, déstabilisé dans son expérience lectoriale. La perturbation peut aller jusqu'à envisager l'arrêt de la lecture de la saga, qui se voit dépourvue de héros. L'indignation du lecteur de The Song of Ice and Fire à la mort de lord Stark signale que le triomphe du héros, ou tout du moins du personnage qui véhicule des valeurs positives, est un trait du genre de la fantasy.

Dans la production arthurienne, l'usage du vers ou de la prose influe d'emblée sur l'horizon d'attente du lecteur. En ouvrant un manuscrit de

135 Voir Vincent Jouve, La lecture, p. 59-60.

136 Hans Robert Jauss, «L'Histoire de la littérature: un défi à la théorie littéraire», in Pour une esthétique de la réception, Paris, Gallimard, 1978, p. 50-51.

137 Pour une définition du genre de la fantasy, voir Jacques Baudou, "La fantasy, historique et définition du genre», Lecture Jeune, 138, 2011, p. 4-10. 
romans en vers, tel le Chantilly, Condé 472, le lecteur n'espère pas y lire la fin du monde arthurien, l'origine de l'amour de Lancelot et Guenièvre, le récit de ce qu'il se passe en amont du règne arthurien. La forme est dès lors un signal générique fort pour l'écriture arthurienne. Tout l'enjeu de l'écriture tardive repose sur la satisfaction d'une double attente: le vers impose une temporalité insouciante, circulaire, mais le lecteur est déjà familier des romans longs, construits sur l'entrelacement et offrant un certain point de vue sur les personnages. Le vers détermine aussi un mode de réception que reconduisent les romans tardifs: beaucoup plus que la prose, le vers cultive les échos intertextuels et le jeu avec la tradition antérieure. Le lecteur est invité à repérer ces allusions et à percevoir les détournements.

Le détournement de l'horizon d'attente est l'un des points d'ancrage les plus forts de la parodie ${ }^{138}$ dans le roman en vers. Le roman de Hunbaut par exemple ne cesse de détourner les épisodes traditionnels du roman arthurien en vers: Gauvain n'y est plus le héros courtois que présentait Chrétien de Troyes dans Erec et Enide. Lorsqu'un nain lui propose ainsi une tençon, défi au cours duquel les participants s'adonnent à une joute verbale, Gauvain le pourfend en deux moitiés, transgressant à la fois la règle du jeu et le code de courtoisie qui sous-tend le roman arthurien. Il s'agit dans ce cas d'un détournement des attentes: au comportement attendu de la part du chevalier, celui-ci répond par une réaction différente. L'horizon d'attente peut être déçu au lieu d'être détourné: dans ce cas, l'événement prévu par le cadre n’advient tout simplement pas. Dans Cristal et Clarie, le héros Cristal subit les affres d'une tempête dans la forêt. Dans les romans arthuriens, la tempête est un véritable motif ${ }^{139}$ narratif: le déchaînement des éléments et la peur du chevalier préparent

138 Yen-Mai Tran-Gervat donne la définition suivante de la parodie: "nous entendons donc par parodie littéraire la réécriture ludique d'un système littéraire reconnaissable (texte, style, stéréotype, norme générique...), exhibé et transformé de manière à produire un contraste comique, avec une distance ironique ou critique.» ( $\$ 37$, l'auteur souligne). Yen-Mai Tran-Gervat, "Pour une définition opérationnelle de la parodie littéraire: parcours critique et enjeux d'un corpus spécifique», Cahiers de narratologie, 13, 2006, en ligne: https://journals.openedition.org/ narratologie/?id=372. Nous développerons plus loin les enjeux de la parodie dans le roman arthurien en vers.

139 Nous définirons plus bas le concept de «motif» en littérature. Contentons-nous pour l'instant de signaler qu'il s'agit de structures narratives récurrentes. 
le surgissement de la merveille. La réactivation de ce motif que propose Cristal et Clarie ne fait toutefois intervenir aucun événement surnaturel ${ }^{140}$ pour confirmer ce que les indices, génériquement marqués, avertissaient ${ }^{141}$. L'étonnement du lecteur, sa déception à la lecture de ce passage, signale bien que ce motif est génériquement contraint et qu'il induit un certain déroulement.

Les auteurs de romans arthuriens tardifs recourent à des techniques semblables. Cela permet de maintenir l'attention du public, dont l'anticipation, génériquement construite, est mise à l'épreuve. Le merveilleux fait en particulier les frais de ces jeux sur l'horizon d'attente. Face à la manifestation surnaturelle, il arrive que le chevalier fournisse une réponse traditionnellement convenue, mais invalide dans ce nouveau contexte: dans Rigomer, on fustige Cligès d'avoir retiré l'épieu fiché dans un chevalier inconscient (Rigomer, v. 9281-9490), alors même que ce comportement était encouragé au début de la Vengeance Raguidel. Dans le roman tardif, l'empalement se révèle être un privilège qui permettait au chevalier enferré de voir Arthur en rêve, de faire partie de sa cour et de coucher avec Morgain la fée. Le monde arthurien est ainsi explicitement présenté comme un objet de fantasme, aussitôt évanoui par l'intervention ignorante de Cligès qui renvoie la victime à la réalité. Le merveilleux du roman tardif est donc à la fois une évasion plaisante et un prétexte au comique: le décalage entre le comportement effectivement attendu du

140 Nous suivons la définition du terme «surnaturel» proposée par Francis Dubost: «Si les textes en langue vulgaire n'usaient pas du terme surnaturel, ils marquaient cependant par divers procédés, dont l'emploi du mot merveille, le point de rupture entre les représentations proposées par le texte et les données de l'expérience commune. Par commodité, nous appellerons surnaturel tout événement de la fiction qui situe au-delà de ce seuil ses causes et ses modalités. " Aspects fantastiques de la littérature narrative médiévale (XII'-XIII siècle). L'Autre, l'Ailleurs, l'Autrefois, Paris, Champion, 1991, p. 79.

${ }^{141}$ Au sujet de la tempête comme motif romanesque, voir Chantal ConnochieBourgne, "L'apaisement de la tempête dans la littérature médiévale: quelques exemples", in Une Etrange constance. Les motifs merveilleux dans la littérature d'expression française du Moyen Âge à nos jours, dir. Francis Gingras, Sainte-Foy, PUL (La République des Lettres), 2006, p. 107-120. Voir notre étude sur la pratique intertextuelle de Cristal et Clarie pour une analyse du passage de la tempête, Pour une poétique de l'implicitation. Cristal et Clarie ou l'art de faire du neuf avec de l'ancien, préface de Barbara Wahlen, Lausanne, Archipel («Essais», 19), 2014, p. 71-74. 
chevalier - laisser l'épieu fiché dans le chevalier - et celui que le lecteur anticipe, préparé par la tradition - secourir le chevalier enferré -, suscite le rire en même temps que l'enchantement de l'épieu dévoile le monde arthurien comme celui du rêve et de l'imaginaire.

Plus tôt, Lancelot affronte des chats sauvages (v. 2423-2508) qui ont tout d'une manifestation merveilleuse par leur nombre impressionnant et leur agressivité. Ils sont surtout les gardiens d'une bière entourée de cierges, exposée comme le cercueil d'un saint ou d'un chevalier important. Mais cet épisode n'a rien du Cimetière Futur du Chevalier de la Charrette ni de la Douloureuse Garde du Lancelot en prose: Lancelot doit «découper» ("decolpee», v. 2488) la bière pour l'ouvrir, tandis qu'il lui suffisait de soulever les tombeaux dans les textes précédents. Le cercueil étant vide, «El fu le giete tout enmi» (v. 2492). Le chevalier rate pour toujours la potentielle inscription prophétique qui figure traditionnellement sur de tels objets. Dans Rigomer, ce sont bien souvent les chevaliers qui sont responsables du détournement de l'horizon d'attente: Lancelot n'est plus celui qu'il était chez Chrétien de Troyes ou dans le roman en prose. Il n'est plus à même de fournir la réponse attendue, car le roman de Rigomer le démythifie ${ }^{142}$. Après avoir attisé les flammes pour que la bière brûle plus vite, le narrateur commente ironiquement: "Dont ot sa bataille vaincue» (v. 2495), soulignant le décalage entre ce que l'aventure offrait en termes de potentialités narratives, et ce que Lancelot en fait ${ }^{143}$. Ces jeux sur l'horizon d'attente sont bien de l'ordre de la généricité: l'auteur joue avec les attentes de son lecteur, attentes dictées par le genre. Il renouvelle ainsi l'expérience de lecture, brise la potentielle monotonie inhérente à la reconduction d'un genre éculé.

Dans Melyador, l'horizon d'attente vis-à-vis du merveilleux est cette fois déçu et non détourné: comme l'analyse Florence Bouchet ${ }^{144}$, des

142 Les chevaliers de Rigomer sont gras et empotés; leur quête est souvent celle de la nourriture et la transformation de Lancelot en cuisinier gras dans les cuisines du château de Rigomer en est l'apogée. D'ailleurs, après le passage des chats et de la bière, Lancelot ne manque pas de s'exclamer «Ajue! Con jou ai grant fain et grant soi!» (v. 2496-2497)

143 Christine Ferlampin-Acher insiste sur la dimension déceptive des merveilles dans Rigomer, Merveilles et topique merveilleuse, p. 335-339.

144 Florence Bouchet, "Froissart et la matière de Bretagne: une écriture "déceptive" ", in Arturus Rex. Acta conventus Lovaniensis 1987, dir. Gilbert Tournoy, Willy Van Hoecke et Werner Verbeke, Louvain, Leuven University Press, t. II, 1991, p. 367-375. 
indices merveilleux sont semés, mais ils ne sont suivis qu'une seule et unique fois d'un développement proprement merveilleux - c'est l'épisode de Sagremor et de la chasse au blanc cerf. La chasse au cerf de Camel de Camois au début du roman pourrait conduire le personnage isolé à un événement surnaturel, mais il n'en est rien ${ }^{145}$. Selon la critique, la déception de l'horizon d'attente a pour fonction d' "indiquer, à travers sa disparition même, l'existence du merveilleux, au moins comme potentiel narratif devenu canonique et gardé en mémoire ${ }^{146}$. Le merveilleux se réduit à des signaux qui n'aboutissent jamais; leur mise en place remplit un rôle décoratif et joue avec l'imaginaire du lecteur. Le merveilleux devient alors un possible virtuel, un monde possible au sens où l'entend Umberto Eco, pour désigner les scénarios inférentiels qu'offre un texte à l'imagination du lecteur:

Le lecteur, en faisant ces prévisions, assume une attitude propositionnelle $[\ldots]$ quant à l'évolution des choses. Ce faisant, il configure un cours d'événements possible ou un état de choses possible - [...] il hasarde des hypothèses sur des structures de monde ${ }^{147}$.

145 Voir Laurence Harf-Lancner, "La chasse au blanc cerf dans le Méliador: Froissart et le mythe d'Actéon", Marche romane, 30, 1980, p. 143-152.

146 Florence Bouchet, "Froissart et la matière de Bretagne: une écriture "déceptive" ", art. cit., p. 374-375. Voir aussi à ce sujet Christine Ferlampin-Acher, Merveilles et topique merveilleuse, p. 519.

147 Umberto Eco, Lector in fabula, p. 149. Voir les chapitres 7 et 8. Françoise Lavocat considère plusieurs modalités du monde possible: la suite, les mondes rêvés ou souhaités par les personnages et les développements possibles de l'intrigue, laissés en suspens par le narrateur. Voir Françoise Lavocat, "L'œuvre littéraire est-elle un monde possible?", en ligne sur le site Fabula Ateliers, http://www.fabula. org/atelier.php?L\%27oeuvre_litt\%26eacute\%3Braire_est\%2Delle_un_monde_ possible\%3F. Voir aussi Marc Escola, «Mondes possibles et textes possibles», sur fabula.org, Atelier de théorie littéraire, http://www.fabula.org/atelier. php?Mondes_possibles_et_textes_possibles, qui envisage le monde possible en termes de possibles textuels, compris comme un état possible du texte: «On peut mobiliser les possibles textuels tant pour analyser rhétoriquement, avec Eco, la dynamique de la lecture et les prévisions du lecteur que pour confronter, métatextuellement, le texte tel qu'il est à ce qu'il aurait pu être. Envisager toute fabula comme un monde possible, c'est donc décrire le déroulement de l'intrigue (dramatique ou narrative) comme la succession des différents états d'un même monde possible, doublé par le(s) monde(s) projeté(s) par les attitudes propositionnelles des personnages (le cours de l'action tel qu'imaginé, espéré, craint, etc. par tel ou tel personnage), mais aussi les mondes possibles imaginés, attendus, 
Décevoir l'horizon d'attente, c'est donc aussi générer des déroulements possibles, multiplier les scénarios narratifs, convoquer en même temps une mémoire littéraire infinie. La généricité peut se manifester en creux: l'auteur compte sur la mémoire générique de son public pour mobiliser virtuellement des scénarios bien connus des lecteurs de textes arthuriens.

Ces transformations de l'horizon d'attente infléchissent nécessairement le genre: la définition d'un genre ne peut pas être établie sur la seule base d'une œuvre canonique, même s'il s'agit d'un chef-d'œuvre qui l'aurait initié, comme c'est le cas d'Erec et Enide ${ }^{148}$. Pour définir un genre, il faut donc envisager que "toute œuvre nouvelle change potentiellement la classe qu'elle vient enrichir. ${ }^{149} \mathrm{Il}$ faut en déduire que le roman arthurien en vers ne se réduit pas aux compositions de Chrétien de Troyes, même si celles-ci l'informent de manière prégnante; il faut encore considérer des représentants plus tardifs.

\section{Critères de la généricité médiévale}

En gardant à l'esprit qu'un genre est nécessairement évolutif, nous pouvons à présent définir le genre comme un concept théorique et abstrait, qui rend compte de relations textuelles fondées sur des analogies perçues parfois intuitivement par une communauté de lecteurs et réactivées par des auteurs-lecteurs. Reste à déterminer les niveaux où se manifestent ces analogies génériques. Nous aborderons dans les pages qui suivent les critères qui nous paraissent pertinents pour esquisser une relation générique dans la littérature médiévale: celui de la forme (langue, vers/prose, mètre, longueur/brièveté), la manière dont l'œuvre s'inscrit dans l'Histoire ou la fiction, le rôle du narrateur et le registre. Plutôt que de hiérarchiser ces critères les uns par rapport aux autres en affirmant que l'un est toujours surplombant, nous préférons réfléchir en termes de saillance:

craints, etc. par le lecteur empirique aux différentes disjonctions de probabilités du récit."

148 Erec et Enide est souvent considéré comme l'œuvre fondatrice du roman arthurien. Voir Francis Gingras, "Comment présenter un genre qui n'existe pas? Le prologue d'Erec et Enide et la typologie des genres vernaculaires ", Méthode!, 16, 2010, p. 29-42, et Michel Zink, "Chrétien et ses contemporains", in The Legacy of Chrétien de Troyes, éd. Norris J. Lacy, Douglas Kelly et Keith Busby, Amsterdam, Rodopi, 1987-1988, p. 5-32.

149 Marielle Macé, Le genre littéraire, p. 28. 
aucun de ces postes génériques n'est indispensable ni discriminant, malgré la saillance de certains critères, pour la définition de certains genres et à certaines périodes historiques. La forme est saillante pour opposer roman et chanson de geste, et surtout roman arthurien en vers et roman arthurien en prose. À travers quelques exemples, nous clarifierons son statut afin de penser les propriétés génériques qu'elle conditionne et son rôle dans l'attribution générique. Le dernier point considèrera l'articulation entre genre et matière; cette dernière sera envisagée non comme un équivalent médiéval du concept de genre, mais comme un critère générique saillant et déterminant pour la période médiévale, qui parfois, tout comme la forme, contraint les autres critères.

\section{Genre et forme}

L'exemple des poèmes en prose de Baudelaire cité en épigraphe a montré le caractère génériquement distinctif de la forme, tout en illustrant aussi sa réversibilité. L'application d'une forme à un genre n'est néanmoins pas sans conséquences sur le genre. C'est à ce conditionnement du genre par la forme que nous nous intéressons dans ce chapitre, en abordant trois types d'opposition formelle: celle entre vers et prose, celle des mètres, celle entre longueur et brièveté.

Nous envisageons aussi la langue comme un point de distinction formel: au Moyen Âge, un roman s'écrit exclusivement en langue vernaculaire et non en latin, réservé à des productions plus sérieuses, religieuses ou scientifiques par exemple, même si la langue vulgaire pénètre progressivement tous les domaines. L'étymologie du terme «roman", qui désigne avant tout la langue vernaculaire par opposition au latin, puis glisse vers le sens de «texte non chanté en langue romane» et finit par référer à une classe de texte en particulier ${ }^{150}$, implique nécessairement l'exclusion du latin ${ }^{151}$. Il existe néanmoins des ouvres latines, peu connues, travaillant des motifs arthuriens et s'inscrivant dans le monde arthurien: Arthur et Gorlagon, Vera Historia de morte Arthuri, l'Historia Meriadoci et De ortu

150 Oscar Bloch et Walther von Wartburg, Dictionnaire étymologique de la langue française.

151 Sur la construction du mot et du genre «roman», voir Francis Gingras, Le Bâtard conquérant, p. 49-94. 
Waluuanii nepotis Arturi - tous composés en prose ${ }^{152}$. Les deux premiers sont centrés sur le personnage d'Arthur. Dans Arthur et Gorlagon, il part en errance pour parfaire ses connaissances sur la nature de la femme et entend un récit semblable à celui du Bisclavret de Marie de France ou du Lai de Mélion, où un homme est contraint de demeurer loup-garou par la trahison de sa femme. Ce texte, véritable récit dans le récit, active des motifs typiquement arthuriens: l'ouverture sur la Pentecôte, le refus insistant d'Arthur de manger avant d'avoir obtenu la révélation qu'il attend et l'errance comme initiation. La Vera Historia de morte Arthuri donne une nouvelle version de la mort d'Arthur: après avoir été blessé mortellement, le roi est enlevé par une nuée céleste. Comme chez Geoffroy de Monmouth, le doute plane sur la mort effective ou le retour possible d'Arthur.

Les deux autres œuvres racontent chacune les aventures d'un jeune chevalier, Meriadoc ${ }^{153}$ et Gauvain. Le premier effectue ses pérégrinations aux marges de la cour d'Arthur et son errance ne l'y mène qu'une fois, au début du récit. Arthur intervient en faveur de Meriadoc pour l'aider à récupérer le royaume de Cambria - actuel pays de Galles -, usurpé par son oncle. Ce récit est parsemé de motifs empruntés à diverses traditions, la chanson de geste notamment. Quant à Gauvain dans De ortu, il évolue dans un cadre résolument arthurien, qui voit le départ du chevalier et consacre son retour, après qu'il a appris sa véritable identité. Ce texte suit donc la structure convenue du roman arthurien en vers et raconte les enfances du célèbre personnage. Peut-on pour autant considérer ces textes comme des romans arthuriens, alors que la langue romane est une condition essentielle à l'écriture en roman, qui se déclare tournée vers l'avenir et la diffusion à large spectre? L'auteur de De ortu Waluuanii explicite le choix du latin à la fin de son récit:

152 Ils sont édités et traduits ensemble dans Arthur, Gauvain et Mériadoc. Récits arthuriens latins du XIII siècle, dir. Philippe Walter, Grenoble, Ellug, 2007. On consultera à leur sujet les références suivantes: Elizabeth Archibald, "Variations on romance themes in the Historia Meriadoci», JIAS, 2/1, 2014, p. 3-19, David W. Porter, "The Historia Meriadoci and Magna Carta", Neophilologus; 76/1, 1992, p. 136-146, et Siân Echard, Arthurian Narrative in the Latin Tradition, Cambridge, University Press, 1998, p. 131-231. La datation de ces textes est très problématique et varie entre le milieu du XII ${ }^{\mathrm{e}}$ siècle, le début du XIII ${ }^{\mathrm{e}}$ siècle et le début du XIV ${ }^{\mathrm{e}}$ siècle. C'est plus souvent le XIII ${ }^{\mathrm{e}}$ siècle qui est retenu.

153 Ce personnage est vraisemblablement distinct du Meriadeuc du Chevalier aux deux épées. 
Celui qui veut connaitre la suite des hauts faits vertueux de Gauvain, qu'il tente de la demander à celui qui la connaît en le suppliant ou en le corrompant. Sachant que s'il est plus dangereux de commencer une guerre que de la raconter, il est aussi plus pénible d'écrire une histoire dans la langue de l'éloquence que de la divulguer en langue vernaculaire ${ }^{154}$.

L'adoption du latin semble consacrer le talent de l'écrivain, plus que ne le ferait la langue vulgaire. L'auteur justifie ainsi le fait qu'il ne poursuive pas le récit des aventures de Gauvain et valorise sa propre composition.

Ce premier niveau de distinction formelle, confronté aux "romans» latins, invite à relativiser le caractère indispensable de tout critère pour définir un genre: tout élément de définition peut être contredit par un exemple constituant un cas limite. Même le niveau de définition qui semble le moins problématique peut donc faire l'objet de dévoiements ou de subversions génériques.

\section{Vers et prose}

Le choix du vers ${ }^{155}$ ou de la prose doit en ce sens être problématisé: ces deux modalités relèvent d'emplois différents et se sont vu attribuer des propriétés fluctuantes au fil du temps. Déjà dans l'Antiquité tardive et au Haut Moyen Âge, les auteurs soulignent les divergences de ces deux types de discours: le vers est associé au delectare, à l'élégance, tandis que la

154 De ortu Waluuanii nepotis Arturi, trad. Philippe Walter et Claudine Marc, in Arthur, Gauvain et Mériadoc. Récits arthuriens latins du XIIt siècle, éd. cit., p. 165. "Cetera que uirtutum Waluuanii secuntur insignia qui scire desiderat a sciente prece uel precio exigat, sciens quod sicut discriminosius est bellum inire quam bellum referre sic operosius sit composito eloquencie stilo historiam exarare quam uulgari propalare sermone.» (p. 164)

155 Nous employons "vers" au sens moderne du terme. Il faut noter toutefois que le mot n'a pas toujours cette signification au Moyen Âge: il peut désigner un verset, une chanson dans son ensemble ou encore la première partie d'un texte narratif non chanté, comme c'est le cas dans Erec et Enide ("Ci fine li premerains vers", v. 1840, éd. cit.). Voir Jacqueline Cerquiglini-Toulet, «Leçon. Sentier de rime et voie de prose au Moyen Âge", Poésie, 119, 2007, p. 124-125, et Pascale Bourgain, "Qu'est-ce qu'un vers au Moyen Âge?», Bibliothèque de l'École des Chartes, t. 147, 1989, p. 231-282. Le terme "rime» est souvent préféré comme équivalent de "vers" dans les textes. 
prose résulte du prodesse et de l'éloquence ${ }^{156}$. Aucun usage ni aucune fonction prêtés à l'une ou l'autre de ces formes ne sont toutefois constants au cours du Moyen Âge ${ }^{157}$. On ne peut donc qu'esquisser quelques tendances majeures de leurs attributions au fil du temps et tâcher de dégager les enjeux de ces fluctuations.

Le vers est la forme exclusive de tout récit au XII ${ }^{\mathrm{e}}$ siècle: il offre du prestige en imposant une maîtrise technique de la part de l'écrivain. C'est ainsi qu'il donne à la langue vulgaire une légitimité, une valeur poétique ${ }^{158}$. La production littéraire est donc résolument versifiée, qu'il s'agisse de roman ou de poésie:

Sans exception, toutes les formes poétiques, même narratives ou didactiques, en langue vulgaire, jusqu'au début du XIII ${ }^{e}$ siècle, sont en vers. Celui-ci constitue l'une des modalités de leur structuration ${ }^{159}$.

156 Voir l'article d'Étienne Wolff, "Quelques remarques sur la coexistence vers-prose dans l'Antiquité tardive et le haut Moyen Âge latin", in Écrire en vers, écrire en prose: une poétique de la révélation. Actes du colloque de Paris X-Nanterre, mars 2006, dir. Catherine Croizy-Naquet, Nanterre, Université Paris X-Nanterre («Littérales», 41), 2007, p. 13-25.

157 À propos des usages du vers et de la prose, on consultera les articles de Claudio Galderisi, "Vers et prose au Moyen Âge», in Histoire de la France littéraire, vol. 1, dir. par Frank Lestringant et Michel Zink, Paris, PUF, 2006, p. 745-766, Francis Gingras, Le Bâtard conquérant, p. 353-377, les trois ouvrages collectifs dirigés par Catherine Croizy-Naquet et Michelle Szkilnik, Rencontres du vers et de la prose: conscience théorique et mise en page, Turnout, Brepols, 2015, Plus agreable a lire en prose que en rime? Vers et prose en moyen français, Le Moyen français, 76-77, Turnhout, Brepols, 2015, et Rencontres du vers et de la prose. Conscience poétique et mise en texte, Paris, PSN, 2017, Catherine Croizy-Naquet (dir.), Écrire en vers, écrire en prose: une poétique de la révélation. Actes du colloque de Paris X-Nanterre, mars 2006, Nanterre, Université Paris X-Nanterre («Littérales», 41), 2007, Christiane Marchello-Nizia, "La forme-vers et la forme-prose: leurs langues spécifiques, leurs contraintes propres", Perspectives médiévales, 3, 1977 et la discussion qui suit dans le même volume, Emmanuèle Baumgartner, "Le choix de la prose», Cahiers de recherches médiévales, 5, 1998, p. 7-13, Emmanuèle Baumgartner, "Vers, prose et fiction narrative (1150-1240)», in Shifts and Transpositions in Medieval Narrative. A Festschrift for Elspeth Kennedy, dir. Karen Pratt, Cambridge, Brewer, 1994, p. 1-9. Nous développerons plus en détails cette question pour notre corpus au chapitre II, «De la prose au vers », p. 242-339.

158 Voir Francis Gingras, Le Bâtard conquérant, p. 356-359.

159 Paul Zumthor, Essai de poétique médiévale, p. 121. 
Le vers n'est pas l'apanage des formes lyriques, au Moyen Âge et en particulier au XII ${ }^{\mathrm{e}}$ siècle: les productions narratives se réalisent également dans ce cadre. Ainsi, l'historiographie aussi bien que le roman et l'hagiographie s'écrivent en vers, tandis que la prose est réservée aux traductions, sermons, gloses, commentaires ou documents juridiques ${ }^{160}$. Le vers favorise la mémorisation grâce au rythme et à la rime ${ }^{161}$ et se propose en moyen privilégié de transmission de la tradition. Voie élective, le vers donne la mesure du talent du poète ${ }^{162}$. La prose est en revanche perçue comme le medium du vulgaire, réservé au para-littéraire ${ }^{163}$.

Les conceptions changent dès le XIII ${ }^{\mathrm{e}}$ siècle, alors que la langue vernaculaire est assez bien établie pour se passer de la caution du vers. La prose apparaît dans ce contexte comme un medium plus simple, cognitivement ${ }^{164}$ abordable: si elle s'impose comme la forme privilégiée de la

160 Catherine Croizy-Naquet et Michelle Szkilnik, "Introduction», in Rencontres du vers et de la prose, p. 2, Catherine Croizy-Naquet, "Nus contes rimés n'est verais", Revue des Sciences Humaines, Poésie en procès, dir. Claude Millet, 276, 4/2004, p. 29-44, Emmanuèle Baumgartner, "Le choix de la prose», art. cit., et Michel Zink, Littérature française du Moyen Âge, p. 173.

161 Daniel Poirion, "Romans en vers et romans en prose", in Grundriß der romanischen Literaturen des Mittelalters. Le Roman jusquà la fin du XII' siècle, IV/1, Heidelberg, Carl Winter, 1978, p. 75.

162 On trouve cette idée dans les traités poétiques latins, chez Geoffroy de Vinsauf, Matthieu de Vendôme ou Evrard l'Allemand. Voir l'article de Jean-Yves Tilliette, "Vers et prose dans la théorie littéraire médiolatine», in Écrire en vers, écrire en prose: une poétique de la révélation. Actes du colloque de Paris X-Nanterre, mars 2006, dir. Catherine Croizy-Naquet, Nanterre, Université Paris X-Nanterre («Littérales», 41), 2007, p. 27-41.

163 Voir Francis Gingras, "La part du vers dans la définition médiévale des fabliaux», art. cit.

164 La cognition désigne une assimilation particulière de la connaissance, qui englobe la perception, l'intelligence, la mémoire, le langage. Il s'agit d'un processus indépendant d'une prise de conscience, qui fonctionne sur des mécanismes psychologiques «par lesquels un organisme acquiert de l'information, la traite, la conserve, l'exploite; le mot désigne aussi le produit mental de ces mécanismes, soit envisagé de façon générale, soit à propos d'un cas particulier» (Marc Richelle, "Cognition », in Dictionnaire de Psychologie, dir. Roland Doron et al., Paris, PUF ("Quadrige»), 1991, p. 125). La cognition ne recoupe pas la simple idée de connaissance; elle remplit «un rôle à la fois modulateur et organisateur: c'est d'elle, sur la base de l'expérience passée du sujet, que dépend, par exemple, le tri attentionnel des stimulus à l'entrée, régulant, en les subordonnant à une gestion supérieure des infomations, les récepteurs sensoriels pourtant aptes à enregistrer et transmettre des 
narration, c'est qu'elle est libre de contraintes, qu'elle exprime une pensée en droite ligne, dans un ordre logique intuitif. Le discours en prose, selon Isidore de Séville dans ses Etymologies, qui influencent toujours la pensée médiévale, "ne se plie pas au nombre de la scansion, mais [...] est tout droit, [...] s'écoule avec ampleur et court sans terme fixé à l'avance» ${ }^{165}$. Le succès fulgurant de la prose au XIII ${ }^{\mathrm{e}}$ siècle est aussi justifié par une revendication de vérité de la part des auteurs ${ }^{166}$ : la prose est la langue de l'Écriture, la langue de Dieu ${ }^{167}$. Elle est donc vécue comme la seule à même de dire le vrai, et se présente comme «incarnation formelle de la vérité» ${ }^{168}$. Le vers implique au contraire une adaptation du contenu au cadre de la métrique, une distorsion du déroulement temporel, d'où l'association entre mensonge et rime dans le prologue de la Vie des Pères de Blanche de Navarre cité plus haut ("Si font les mençonges rimer», v. 25). Outre la condamnation virulente du vers que l'on trouve dans la Chronique $d u$

infomations plus nombreuses; c'est elle qui assure l'accroissement de l'information stockée en mémoire en y opérant des groupements, des indiçages, où repères perceptifs et sémantiques collaborent" (Marc Richelle, "Cognition", p. 126).

165 C'est la traduction que donne Michel Zink, Littérature française du Moyen Âge, p. 175. Voici l'extrait original: «Prosa est producta oratio et a lege metri soluta. Prosum enim antiqui productum dicebant et rectum. Unde ait Varro apud Plautum "prosis lectis" significari rectis; unde etiam quae non est perflexa numero, sed recta, prosa oratio dicitur, in rectum producendo.» (Isidori Hispalensis episcopi Etymologiarum sive originum libri XX, éd. W. M. Lindsay, Oxford, Clarendon, 1911, 2 t., t. 1, Livre I, chap. XXXVIII). La conception d'une prose simple est expliquée d'un point de vue étymologique par Isidore de Séville: selon lui, "prose» viendrait de "prosa oratio", "discours qui va en droite ligne, sans inversion". Au contraire, le "vers», "versus», vient de la famille de "vertere», c'est-à-dire "contourné». Dans la même idée, Brunet Latin parle de "voie de prose», qui "est large et pleniere», tandis que «li sentiers de risme est plus estrois et plus fors" (Livre du Trésor, éd Francis J. Carmody, Los Angeles, Berkeley, 1948, p. 327). Voir Jacqueline Cerquiglini-Toulet, «La prose et la rose: l'imaginaire spatial de la prose et du vers", in Rencontres du vers et de la prose: conscience théorique et mise en page, dir. Catherine Croizy-Naquet et Michelle Szkilnik, Turnhout, Brepols, 2015, p. 151-160. Voir aussi l'introduction à cet ouvrage collectif, p. 9-10. Nous traiterons plus en détails au chapitre II, "Choix de forme, choix de style», p. 325-339, de l'ordre de la phrase différent entre vers et prose.

166 Le succès de la prose au XIII ${ }^{\mathrm{e}}$ siècle ne signifie pas que le vers y est absent: il subsiste au contraire massivement, dans le roman ou le fabliau par exemple. Voir Francis Gingras, «La part du vers dans la définition médiévale des fabliaux», art. cit.

167 Michel Zink, Littérature française du Moyen Âge, p. 184-185.

168 Catherine Croizy-Naquet, «Nus contes rimés n’est verais», art. cit., p. 37. 
pseudo-Turpin ( Nus contes rimés n'est verais ${ }^{169}$ ), bien souvent citée, on peut mentionner celle de Pierre de Beauvais, qui associe lui aussi le vers au mensonge dans la version longue de son Bestiaire:

Et por ce que rime se velt afaitier de mos concueillis hors de verité volt li evesques que cist livres fust fait sans rime tot selonc le latin, que Phisiologes, uns bons clers d'Athenes, traita en tos sens les natures des bestes et des oiseaus a l'entendement des spiriteus $\operatorname{coses}^{170}$.

La prose respecte la "commune parleure des gens", comme le dit Brunet Latin $\left(\mathrm{XIII}^{\mathrm{e}} \text { siècle) }\right)^{171}$ : elle restituerait selon cette conception une parole authentique ${ }^{172}$. La rime et le vers sont en revanche moins naturels, et dès lors perçus comme consubstantiels à la fiction, au point de faire de celle-ci la conséquence moins d'un contenu que d'une forme, ce qui en dit long sur le pouvoir des formes sur les représentations. L'écart avec la langue quotidienne constituait l'avantage du vers français à ses débuts et en faisait une voie élective; par la suite, il fait de lui une forme par trop contrainte dans les représentations mentales.

Le lien entre vers et fiction s'explique peut-être par son utilisation dans les textes romanesques, comme le suggère Francis Gingras:

Ce serait moins le vers en tant que tel que le vers en tant que forme d'expression privilégiée des différentes manifestations romanes de la fabula qui aurait favorisé le développement d'une association du vers et du récit mensonger ${ }^{173}$.

169 Brian Woledge et Harry P. Clive, Répertoire des plus anciens textes en prose française depuis 842 jusqu'aux premières années du XIIt siècle, Genève, Droz, 1964, p. 27.

170 Pierre de Beauvais, Bestiaire, version longue, éd. Craig Baker, Paris, Champion ("CFMA»), 2010, p. 141. Jacqueline Cerquiglini-Toulet donne d'autres exemples de l'association entre prose et vérité, vers et mensonge. «Leçon. Sentier de rime et voie de prose au Moyen Âge», art. cit., p. 128-129.

171 Brunet Latin, Livre du Trésor, éd. cit., p. 327.

172 Ce qui, bien sûr, n'est qu'une conception, la prose demeurant un travail poétique éloigné de la langue parlée. L'association entre prose et langage quotidien n’est de loin pas originelle: Michel Zink signale qu'Isidore de Séville ne fait pas la confusion entre langage parlé et prose, même s'il définit la prose comme le mode qui permet l'expression directe de la pensée, extensible à l'infini. Littérature française du Moyen Âge, p. 174-176.

173 Francis Gingras, Le Bâtard conquérant, p. 365. Pour plus de détails, voir les pages 361 à 377. 
Les contraintes de la métrique sont un bon prétexte pour assimiler vers et distorsion de la vérité, que la prose ne permet pourtant pas d'éviter:

Même en prose, l'histoire n'évacue pas la part de l'improbable, voire de l'invraisemblable, mais le vers reste le principal vecteur de la fiction, le coupable tout désigné pour justifier les défis posés à l'imagination des lecteurs ${ }^{174}$.

La prose n'échappe effectivement pas à l'invention: malgré son choix de la prose, la Chronique du Pseudo-Turpin raconte les guerres fictives de Charlemagne en Espagne, tout en affirmant leur vérité. La prose est une posture destinée à attester l'authenticité du récit: sans être totalement crédules, les auteurs, probablement, n'avaient pas pour dessein de produire délibérément une fiction ni la conscience de fournir un récit tout aussi fallacieux que les contes merveilleux. La croisade narrée dans la Chronique $d u$ Pseudo-Turpin s'inscrit par exemple en continuité des conflits armés authentiques et aurait pu advenir ${ }^{175}$. Plus qu'une valeur intrinsèque, l'idée d'une vérité de la prose est le résultat d'une représentation de la part des auteurs, d'une image qu'ils veulent bien plaquer à cette forme. C'est dès lors moins un contenu véridique que l'on prête à la prose qu'un rapport à la représentation du temps, restitué dans sa complexité, dans sa continuité: elle est "la forme la plus apte à configurer le monde réel ${ }^{176}$. La prose donne à l'historiographie «l'allure d'une transmission directe/ immédiate» de l'expérience vécue, tandis que le vers "offre une vue fragmentaire et fragmentée des faits», en privilégiant l'effet sur le sens ${ }^{177}$.

C'est à partir de ce rapport entre forme et fiction que Nathalie Bragantini-Maillard envisage l'usage tardif de l'octosyllabe dans Melyador ${ }^{178}$.

174 Ibid., p. 377.

175 Cette chronique a été reçue comme une source fiable. Elle est diffusée dans les manuscrits avec d'autres textes historiographiques. Voir Marianne Ailes et Suzanne Leedham, "Le Pseudo-Turpin en Angleterre», CRMH, 25, 2013, p. 495-517.

176 Emmanuèle Baumgartner, Le Récit médiéval, XII -XIII siècles, Paris, Hachette, 1995, p. 146.

177 Catherine Croizy-Naquet, "Nus contes rimés n'est verais», art. cit., p. 35 et 36.

178 Nathalie Bragantini-Maillard, "L'octosyllabe romanesque chez Jean Froissart: une voie vers la fiction", in Poétiques de l'octosyllabe, dir. Danièle James-Raoul et Françoise Laurent, Paris, Champion, 2018, p. 259-271. Voir aussi Nathalie 
Dans ses Chroniques, Jean Froissart exprime en effet la même opposition que la Chronique du Pseudo-Turpin:

Pluiseur gongleour et enchanteour en place ont chanté et rimet lez guerres de Bretaigne et coromput, par leurs chançons et rimes controuvees, le juste et vraie histoire ${ }^{179}$.

La rime est assimilée, une fois de plus, à la corruption de la vérité historique. L'écriture de l'histoire requiert la prose, dans la conception des formes de Froissart. Ainsi, la production de cet auteur est cohérente dans ses oppositions formelles: la prose se réserve aux Chroniques, quand le vers transmet ses ouvres poétiques ou romanesques. L'octosyllabe vaudrait alors comme le signal de l'entrée en fiction et rendrait clair le statut de Melyador, lui refusant toute prétention à la véridicité.

$\mathrm{Au} \mathrm{XIII}^{\mathrm{e}}$ siècle, la revendication de vérité n'est pas le seul souci du choix de la prose: cette forme encourage l'explicite et l'exhaustivité. Elle engendre aussi le remaniement, que l'on pense aux nombreuses versions des romans arthuriens en prose, continuellement réécrits et amplifiés ${ }^{180}$. L'écriture en prose doit porter à la compréhension, quitte à allonger le texte ou à retrancher la part d'interprétation qui revient au lecteur pour résoudre les ambiguïtés ${ }^{181}$. La prose est supposément plus facile à comprendre et à composer que le vers, qui apparaît au contraire comme une coquetterie fastidieuse, comme le dira plus tard Thomas de Saluces dans le Chevalier errant (1394-1396): "Meshuy je vueil en prose en part compter / Car il m'ennuye de tant versifier. ${ }^{182}$ Cela implique des modalités de réception

Bragantini-Maillard, et Corinne Denoyelle, "Les dialogues dans Melyador", Romania, 129, 2011, p. 83-128.

179 Jean Froissart, Chroniques, éd. George T. Diller, Genève, Droz, 1992, tome 2, p. 96, $\$ 311$.

180 Michel Zink, Littérature française du Moyen Âge, p. 186-188.

181 Ibid., p. 178. Daniel Poirion souligne cette différence entre le vers et la prose: "D’un côté la suggestion poétique du sens, qui se fait par ouverture, appels, allusions, échos, de l'autre organisation démonstrative, la relation explicite, intellectuelle entre les événements.» ("Romans en vers et romans en prose», art. cit., p. 77) Voir aussi Emmanuèle Baumgartner, «Les techniques narratives dans le roman en prose", art. cit.

182 Thomas de Saluces, Il Libro del Cavaliere errante, éd. Marco Piccat, Boves, Araba Fenice, 2008, p. 159, v. 4924-4925. Voir aussi l'article de Jean-Claude Mühlethaler, "Défense et illustration du vers dans les récits du Moyen Âge tardif», art. cit. 
différentes. La prose induit une lecture plus réflexive, comme le déduit Joëlle Ducos au sujet des textes scientifiques:

Le texte en prose invite à une lecture par chapitres, peut-être silencieuse, mais en tout cas invitant à la réflexion alors que le texte en vers suppose une persuasion oratoire dans la construction d'un discours. Il s'agit ainsi de deux formes de discours savants dont la modélisation est différente sans que l'on puisse parler d'une hiérarchie des savoirs ${ }^{183}$.

Les écrits qui livrent un savoir démontrent que l'opposition entre vers et prose ne recoupe pas seulement l'opposition entre fiction et vérité: le vers n'offre pas un contenu moins véridique, mais "paraît comme une mise en scène rhétorique du savoir, voulant à la fois plaire et instruire» ${ }^{184}$.

L'idée d'une prose simple et proche du langage commun, comme l'association entre prose et vérité, n'est au fond qu'une revendication qui se vérifie peu dans les faits. La prose crée aussi un rythme et une scansion, ne serait-ce que par ses longues subordonnées ${ }^{185}$ : «la prose médiévale est une élaboration consciente, et particulièrement rigoureuse, de la langue: une forme contraignante» ${ }^{186}$. Les romans en prose présentent une écriture travaillée, stylisée, en somme, littéraire. L'écriture en prose invite elle aussi à la lecture à voix haute pour déployer ses effets et participe de la vocalité prêtée au vers. La sollicitation de l'ouïe n'est néanmoins pas du même ordre: le vers flatte l'oreille par l'harmonie de ses sonorités, dans un rapport physique au récepteur, tandis que l'oralité de la prose s'adresse

183 Joëlle Ducos, "Écrire la science en vers et en prose», in Écrire en vers, écrire en prose: une poétique de la révélation. Actes du colloque de Paris X-Nanterre, mars 2006, dir. Catherine Croizy-Naquet, Nanterre, Université Paris X-Nanterre («Littérales», 41), 2007, p. 237.

184 Ibid.

185 Voir l'article de Jean-Claude Mühlethaler, «Défense et illustration du vers dans les récits du Moyen Âge tardif", art. cit., l'étude d'Annie Combes, Le Récit en mouvement. Logiques du romanesque médiéval, Mémoire de synthèse présenté en vue de l'obtention de l'habilitation à diriger des recherches, Paris, Sorbonne nouvelle, 2007, p. 18-21, Christiane Marchello-Nizia, "La forme-vers et la forme-prose», art. cit., et Jean Rychner, L'articulation des phrases narratives dans la Mort Artu, Genève, Droz, 1970.

186 Bernard Cerquiglini, La Parole médiévale. Discours, syntaxe, texte, Paris, Éditions de Minuit, 1981, p. 18. 
à l'intellect. Michel Zink ${ }^{187}$ remarque en effet que la prose impose une lecture à voix haute pour rendre perceptibles les modulations de la phrase et de la syntaxe: il faut placer les pauses au bon endroit, distinguer l'indicatif de l'interrogatif, pour comprendre le sens du texte.

Le choix de la forme conditionne donc la réception des textes. Néanmoins, les propriétés attribuées à chaque forme, vérité et fiction, simplicité et complexité, résultent plus de l'imaginaire des auteurs, qui les perçoivent différemment et justifient leur choix diversement selon les époques. On ne peut au fond rien dégager de stable ${ }^{188}$ : la prose est tantôt le medium de la vérité, tantôt celui de la fiction. De la même manière, si la prose est souvent assimilée à l'amplification, elle peut se montrer abrégeante, en couvrant une longue période historique, mais en raccourcissant certaines sources - dans le cas de l'Histoire ancienne jusqu'à César, qui donne une version plus courte de Darès que celle du Roman de Troie en vers ${ }^{189}$, ou en retranchant les descriptions ou portraits ${ }^{190}$. Quant au vers, Jean Maillart y a recours au début du XIv ${ }^{\mathrm{e}}$ siècle dans son Roman $d u$ comte d'Anjou, ce qui ne l'empêche pas d'insister sur la vérité de son récit et d'exclure les éléments merveilleux de sa source, la Manekine: "Je vous conpte et vous devise / En lieu de mençonge et de fable, / Une aventure veritable ${ }^{191}$. Son roman s'oppose aux fables que l'on raconte sur Gauvain, Tristan, Perceval et Lancelot, lourdement décriées comme des "bourdes" (v. 3). Loin de contredire l'authenticité de la narration, le vers est employé «Pour la biauté et l'acordance / De la rime», dans laquelle ses auditeurs

187 Michel Zink, Littérature française du Moyen Âge, p. 177. Voir aussi Florence Bouchet sur les pratiques de lecture, Le Discours sur la lecture en France aux XIVe-XV siècles, p. 98 à 108 au sujet de la prose.

188 Francis Gingras nuance l'imagerie attachée à chaque forme aux pages 364-365 de Le Bâtard conquérant.

189 Au sujet de ce texte, voir Catherine Croizy-Naquet, Écrire l'histoire romaine au début du XIII siècle: L' "Histoire ancienne jusqu'à César» et les "Faits des Romains", Paris, Champion, 1999.

190 L'expansion que l'on prête aux romans en prose ne résulte pas d'un excès d'arrêts sur image et de descriptions: Emmanuèle Baumgartner souligne que les portraits et les descriptions sont rares dans le roman en prose. "Les techniques narratives dans le roman en prose», art. cit., p. 186.

191 Jean Maillart, Roman du comte d'Anjou, éd. cit., v. 36-38. Voir Jean-Claude Mühlethaler, "Défense et illustration du vers dans les récits du Moyen Âge tardif», art. cit., p. 110-112. 
«truissent plesance» (v. 57-58) - nous y reviendrons au chapitre II. Enfin, quelques chroniques composées en vers témoignent de la compatibilité de la versification avec la reproduction de documents historiques, comme la Chronique rimée de Philippe Mousket (milieu du XIII ${ }^{\mathrm{e}}$ siècle) ${ }^{192}$.

Malgré cette éternelle plasticité, le choix d'une forme demeure un parti pris générique, comme le prouvent les nombreuses justifications que l'on rencontre dans les textes ${ }^{193}$. Vérité ou fiction, simplicité ou complexité, divertissement ou exemplum, exhaustivité ou concision, mémorisation, musicalité et célébration sont autant de critères pour motiver l'usage de la prose ou du vers. Jacqueline Cerquiglini-Toulet confirme en ce sens qu'"on assiste alors à une confrontation du vers et de la prose à l'aide d'arguments dont [elle] note qu'ils sont le plus souvent parfaitement réversibles, que le critère retenu soit celui du plaisir ou de l'utilité » ${ }^{194}$. Il s'agit ainsi de préciser les enjeux de ce choix en le replaçant chaque fois en contexte.

Les tensions qui s'établissent au $\mathrm{XIII}^{\mathrm{e}}$ siècle entre ces deux formes assurent la distinction entre le roman arthurien en vers et celui en prose. Malgré leur partage des mêmes personnages et d'un univers de fiction, il s'agit bien de deux genres distincts. Leurs différences ne se réduisent pas simplement à un choix de forme: ce choix d'une forme engendre des perspectives différentes vis-à-vis de la matière, conditionne d'autres choix qui relèvent de la généricité et permettent de les envisager comme deux catégories distinctes. La prose propose un temps du récit linéaire, où chaque élément reçoit un sens et une explication - comme pour le Graal, auquel on prête toute une genèse. L'insertion du cycle arthurien dans l'histoire biblique assure sa prétention à la vérité, rendant ainsi explicite ce qui l'oppose aux textes en vers, dont l'intrigue prend place dans un

192 Voir Dominique Boutet, "De la Chronique rimée de Philippe Mousket à la prose des Grandes chroniques de France: un choix d'écriture?", in Ecrire en vers, écrire en prose: une poétique de la révélation. Actes du colloque de Paris X-Nanterre, mars 2006, dir. Catherine Croizy-Naquet, Nanterre, Université Paris X-Nanterre («Littérales», 41), 2007, p. 135-154.

193 Voir l'ouvrage collectif dirigé par Catherine Croizy-Naquet et Michelle Szkilnik, Rencontres du vers et de la prose, pour plus d'exemples.

194 "Leçon. Sentier de rime et voie de prose au Moyen Âge», art. cit., p. 129, et l'introduction de Catherine Croizy-Naquet et Michelle Szkilnik à Rencontres du vers et de la prose. 
temps profane, autonome et cyclique ${ }^{195}$. La différence de forme implique une différence idéologique entre les romans en vers et ceux en prose. Nous esquisserons tout au long de la recherche les enjeux propres à chacun, ce qui permettra de mettre en perspective nos romans tardifs et l'esthétique de la prose. Cela conduira à expliciter le choix anachronique du vers par nos auteurs, à une époque où la prose s'est déjà imposée comme medium privilégié du genre romanesque.

\section{Mètre}

Les auteurs de romans arthuriens n'adoptent pas indifféremment un type de vers: l'octosyllabe est toujours privilégié sur les autres mètres. Si le choix du vers ou de la prose est générique, il en va de même du choix d'un mètre, d'une structure formelle (laisses ou strophes) et d'une homophonie (rime ou assonance). La narration ne recourant pas au même cadre que la lyrique, il faut d'abord opposer un vers narratif et un vers lyrique, opposition qui s'ajoute à la distinction entre vers et prose. Le chant est certes un élément distinctif essentiel entre les catégories du lyrique et de la narration, mais ce n'est pas le seul; les chansons de geste s'accompagnent également d'une mélodie. Ce qui singularise la poésie lyrique, c'est peut-être la conjonction du chant et de l'expression du sentiment, d'une subjectivité, dans des formes fixes, brèves et à forte sophistication stylistique ${ }^{196}$. Le vers lyrique induit un raffinement formel: variation de la longueur des mètres au sein d'une même pièce, du schéma de rimes, de la structure strophique. Le vers narratif, s'il n'exclut bien sûr pas les effets de sonorités, l'harmonie des rythmes et des rimes, se concentre en priorité sur un contenu à restituer, qu'il soit d'ordre historiographique, diégétique, religieux ou même philosophique. Le rapport à la temporalité est donc différent: discontinu, répétitif dans le cas du mode lyrique, continu et linéaire dans celui du mode narratif. Nous entendons nous concentrer ici exclusivement sur

195 Voir Emmanuèle Baumgartner, «Temps linéaire, temps circulaire et écriture romanesque (XII ${ }^{\mathrm{e}}-\mathrm{XIII}^{\mathrm{e}}$ siècles)", in Le Temps et la durée dans la littérature au Moyen Âge et à la Renaissance, Actes du colloque organisé par le Centre de Recherche sur la Littérature du Moyen Âge et de la Renaissance de l'Université de Reims (novembre 1984), éd. Yvonne Bellenger, Paris, Nizet, 1986, p. 7-21. Nous traiterons de la temporalité plus en détail au chapitre II, "Choix de forme, choix de chronotope", p. 242-325.

196 Voir Michel Zink, Littérature française du Moyen Âge, p. 99-129. Nous définirons ce que nous attendons par «lyrique» plus loin, note 309 , page 362. 
les diverses formes du vers narratif qui permettent d'opposer le roman arthurien à d'autres genres narratifs et laissons de côté les formes du vers lyrique, en gardant toutefois à l'esprit qu'un lien de consubstantialité exclusif se noue au fil des siècles entre vers et lyrique.

La chanson de geste offre le cadre formel le plus marqué de l'écriture narrative en vers: elle privilégie le décasyllabe qu'elle couple à l'assonance et à la laisse, pour assurer sa singularité générique ${ }^{197}$. Ce mode de regroupement des vers crée un effet de statisme, d'arrêt du récit, comme si celuici ne progressait pas, ou par d'incessants retours: "l'énonciation se fait essentiellement dans l'instant du poème ${ }^{198}$, ce qui rend la forme de la chanson de geste proche de la poésie lyrique. Le roman recourt plus volontiers à l'octosyllabe à rimes plates et ne se compose jamais en décasyllabe. La prégnance de ce critère générique se signale par exemple dans l'unique manuscrit du Lai du cor, récit bref arthurien de la fin du XII ${ }^{\mathrm{e}}$ siècle qui a la particularité de mobiliser l'hexamètre au détriment de l'octosyllabe: le copiste pense d'abord à une erreur métrique et s'emploie dans les quinze premiers vers à rétablir l'octosyllabe, puis abandonne l'entreprise ${ }^{199}$. Ce témoignage illustre parfaitement à quel point le récit arthurien est attaché dans les conceptions à ce mètre en particulier.

L'octosyllabe n'est pourtant pas exclusivement destiné à la narration arthurienne et doit être considéré comme un vers génériquement non marquée ${ }^{200}$ : il est utilisé aussi bien dans l'historiographie que dans les ouvrages didactiques et hagiographiques. Comme le démontre Catherine Croizy-Naquet, il est à concevoir comme un «ferment de nouvelles

197 Il faut noter que la chanson de geste s'ouvre petit à petit à une structure formelle différente: la rime s'emploie de plus en plus fréquemment dès la fin du XII ${ }^{\mathrm{e}}$ siècle, de même que l'alexandrin. Michel Zink, Littérature française du Moyen Âge, p. 70-74. Sur l'organisation des vers en strophes, laisses ou couplet, voir Francis Gingras, Le Bâtard conquérant, p. 366-367.

198 Francis Gingras, Le Bâtard conquérant, p. 368.

199 Voir la note a) de l'édition de Nathalie Koble, Le Lai du Cor et le Manteau mal taillé. Les dessous de la Table ronde, Paris, Éditions Rue d'Ulm; ENS, 2005, p. 18, et les pages 135 à 136. L'éditrice souligne que l'hexamètre est rare et plutôt reservé aux textes didactiques.

200 Au sujet de l'octosyllabe et de ses implications génériques, voir Catherine CroizyNaquet, "L'octosyllabe dans l'Eneas, ferment de nouvelles poétiques", in Poétiques de l'octosyllabe, dir. Danièle James-Raoul et Françoise Laurent, Paris, Champion, 2018, p. 211-228. 
poétiques ", dont la souplesse est la raison de son adaptabilité à différents genres ${ }^{201}$. En tant que vers simple, le plus long des vers courts ou le plus court des vers longs, il présente une facilité cognitive qui favorise selon Benoît de Cornulier la "reconnaissance instinctive et sûre de l'égalité exacte en nombre syllabique de segments voisins $»^{202}$ par l'auditeur ou le lecteur. Il en résulte, pour le dire avec Michel Zink, que «cette forme métrique simple laisse, par une sorte de transparence du langage, l'attention se fixer presque tout entière sur le contenu du récit ${ }^{203}$. L'usage qui en est fait dans les formes narratives atténue les effets rythmiques ${ }^{204}$ : Chrétien de Troyes n'hésite par exemple pas à recourir à l'enjambement et étend la phrase sur plusieurs vers, rompant avec l'unité du couplet ${ }^{205}$. C'est aussi l'absence de césure fixe qui instaure « une sorte de transparence du langage $»^{206}$ propre à transmettre tous les genres. La rime demeure ainsi

201 Ibid. Voir aussi Danièle James-Raoul et Françoise Laurent, "Avant-propos», in Poétiques de l'octosyllabe, dir. Danièle James-Raoul et Françoise Laurent, Paris, Champion, 2018, p. 7-19, et Clothilde Dauphant, qui traite de l'octosyllabe dans la lyrique, "L'octosyllabe, un vers à tout faire? L'exemple du Jardin de Plaisance», in Poétiques de l'octosyllabe, dir. Danièle James-Raoul et Françoise Laurent, Paris, Champion, 2018, p. 153-171.

202 Benoît de Cornulier, Théorie du vers. Rimbaud, Verlaine, Mallarmé, Paris, Seuil ("Travaux linguistiques»), 1982, p. 271. Le théoricien s'appuie sur des expériences cognitives: à partir de combien de syllabes le récepteur identifie un vers à la métrique hétérogène au sein d'un poème homogène? Il tient compte à la fois de la réception auditive et visuelle d'un poème. Benoît de Cornulier relève également que jusqu'à huit syllabes, les poètes se passent de césure, tandis que celle-ci intervient dans les poèmes à plus de huit syllabes. Sa théorie se fonde sur l'idée que la versification française résulte d'un conditionnement psychologique.

203 Michel Zink, "Une mutation de la conscience littéraire: le langage romanesque à travers des exemples français du XII ${ }^{\mathrm{e}}$ siècle», art. cit., p. 6.

204 Comme le note Paul Zumthor: «il exclut absolument le chant, ainsi que les effets de rythme strophique et le découpage qu'ils imposent au récit, remplit la fonction qui plus tard sera dévolue à la prose, par opposition à tout discours lié». "Roman et histoire: aux sources d'un univers narratif", in Langue, texte, énigme, Paris, Seuil («Poétique»), 1975, p. 244.

205 Catherine Croizy-Naquet, "L'octosyllabe dans l'Eneas, ferment de nouvelles poétiques», art. cit.

206 Michel Zink, "Une mutation de la conscience littéraire: le langage romanesque à travers des exemples français du XII ${ }^{\mathrm{e}}$ siècle", art. cit., p. 6. Sur la césure de l'octosyllabe, voir Dominique Billy, «De l'octosyllabe archaïque à l'octosyllabe des troubadours", in Poétiques de l'octosyllabe, dir. Danièle James-Raoul et Françoise Laurent, Paris, Champion, 2018, p. 59-80. 
le seul élément sonore perceptible, si bien que l'octosyllabe se rapproche de la prose, pour traduire les propos de Jean-Marie Fritz:

Par sa structure continue et homogène, le couplet épouse parfaitement la linéarité de la narration et le passage à la prose s'opérera au départ par simple mise à plat du chapelet d'octosyllabes et remise en ordre des différents éléments phrastiques ${ }^{207}$.

Par sa concision, son uniformité et son absence d'éloquence, l'octosyllabe est adaptable à tous les sujets ${ }^{208}$, d'où son manque de marquage générique.

Cette linéarité inhérente à l'octosyllabe dissuade d'y associer toute structuration: le couplet d'octosyllabe échappe en principe à la circularité des laisses et se libère de leur organisation, des répétitions qu'elles permettent ou imposent. Il exploite un mode d'écriture particulier, distinct de celui de la geste, privilégiant la narration chronologique et continue sur les effets lyriques. Les rares chansons de geste composées dans ce mètre excluent d'ailleurs le plus souvent la hiérarchisation en laisses: la version octosyllabique de Lion de Bourges (milieu du XIv ${ }^{e}$ siècle) et d'Ami et Amile (fin du XII ${ }^{\mathrm{e}}$ siècle) s'extrait de ce type de structuration, alors que les copies décasyllabiques de ces mêmes textes sont composées en laisses. L'octosyllabe est donc «vecteur d'horizontalité » ${ }^{209}$ et favorise la continuité dans la narration, ce qui explique son recours dans le roman et la transition qu'il permet vers la prose.

207 Jean-Marie Fritz, "Le roman en vers au Moyen Âge», in Histoire de la France littéraire, vol. 1, dir. par Frank Lestringant et Michel Zink, Paris, PUF, 2006, p. 963. Catherine Croizy-Naquet développe également les accointances de l'octosyllabe et de la prose: "Ces propriétés de l'octosyllabe, semence d'un nouveau discours - l'histoire/mémoire (estoire/memoire) et non plus l'histoire/commémoration - et d'un nouveau type de réception - lecture plutôt que chant ou psalmodie - pourraient accélérer son absorption progressive dans la prose.» (Catherine CroizyNaquet, "L'octosyllabe dans l'Eneas, ferment de nouvelles poétiques», art. cit., p. 217)

208 Nous paraphrasons ici Danièle James-Raoul et Françoise Laurent, "Avantpropos", in Poétiques de l'octosyllabe, p. 13. Voir aussi Erich Auerbach, Le Haut Langage. Langue littéraire et public dans l'Antiquité latine tardive et au Moyen Âge, trad. Robert Kahn, Paris, Belin, 2004, p. 210.

209 Catherine Croizy-Naquet, "L'octosyllabe dans l'Eneas, ferment de nouvelles poétiques», art. cit., p. 215. 
Les cas de Lion de Bourges et d'Ami et Amile laissent percevoir la plasticité de cette forme, que l'on ne peut réduire à un seul genre. L'usage d'un tel mètre a pourtant pu être justifié par un contenu ressenti comme plus romanesque. Les éditeurs de Lion de Bourges, chanson de geste tardive, soulignent par exemple au sujet de la version en octosyllabes de ce texte qu' «il vaudrait mieux parler en ce cas du Roman de Lion de Bourges» ${ }^{210}$. $\mathrm{Vu}$ ainsi, le choix de transposer le texte de l'alexandrin à l'octosyllabe résulterait d'une perspective générique portée sur chaque forme par le remanieur, qui aurait trouvé la trame narrative de Lion de Bourges plus romanesque qu'épique. Cette explication ne fonctionne pas pour Gormont et Isembart ${ }^{211}$ : il s'agit de la seule chanson de geste écrite exclusivement en octosyllabes, sans être représentée par des versions en décasyllabes ou en alexandrins ${ }^{212}$. Cette chanson de $1130-1150$ promeut la lutte contre les Sarrasins: elle narre l'histoire d'Isembart, qui renie la foi chrétienne pour rejoindre le roi païen Gormont. L'octosyllabe ne se justifie donc pas par un contenu romanesque: il faut dès lors admettre que ce mètre était pratiqué par les premiers auteurs de chansons de geste, ce qui démontre bien sa disponibilité générique. L'utilisation en est toutefois différente de

210 Lion de Bourges. Poème épique du XIV siècle, éd. William Kibler, Jean-Louis G. Picherit, Thelma S. Fenster, t. 1, Genève, Droz, 1980, p. lvii. Voir aussi Richard Trachsler, Disjointures-Conjointures. Étude sur l'interférence des matières narratives dans la littérature française du Moyen Âge, Tübingen; Bâle, Francke ("Romanica Helvetica»), 2000, p. 165-171, qui souligne que la mise en page du manuscrit $\mathrm{BnF}$ fr. 351 est elle-même hybride: les rubriques en prose évoquent le roman tandis que les pieds de mouche suggèrent l'existence de laisses. Voir Claude Roussel, "Lion de Bourges (BnF fr. 351), une mise en prose en octosyllabes?", in Poétiques de l'octosyllabe, dir. Danièle James-Raoul et Françoise Laurent, Paris, Champion, 2018, p. 173-188.

211 Sur Gormont et Isembart et les enjeux de l'octosyllabe dans ce texte, voir Stephen Nichols, "Style and structure in Gormond et Isembard", Romania, 84, 1963, p. 500-535, et Valérie Naudet, "L'octosyllabe de Gormont et Isembart. Quelques problèmes d'arithémtique", in Poétiques de l'octosyllabe, dir. Danièle James-Raoul et Françoise Laurent, Paris, Champion, 2018, p. 125-142. Angelo Monteverdi signale que l'hagiographie en octosyllabes influence la versification de la chanson de geste dans ses débuts. "La laisse épique", in La technique littéraire des chansons de geste. Actes du colloque de Liège (septembre 1957), Paris, Les Belles Lettres ("Bibliothèque de la Faculté de philosophie et lettres de l'Université de Liège», 150), 1959, p. 139.

212 Cependant, seul un fragment nous est parvenu: on peut tout à fait imaginer qu'il existait d'autres versions en décasyllabes. 
celle qu'en fait le roman: le poème est cette fois organisé en laisses assonancées, entrecoupées parfois par un quatrain qui fait office de refrain, il n'y a pas d'enjambements, contrairement au roman courtois, et la césure 4/4 est majoritairement respectée. La chanson de geste et le roman y recourent différemment, car ils répondent à des enjeux distincts: le temps est statique dans la première, ce qui autorise une répétition stylisée des événements et la mise en ouvre de procédés comme la laisse similaire, bifurquée ou parallèle ${ }^{213}$.

Le roman, de même que l'historiographie, en revanche, entendent restituer des faits survenus sur plusieurs mois voire plusieurs années et exigent une écriture de la chronologie, qui n'empêche toutefois pas les prolepses et les jeux avec la temporalité narrative. Le choix de l'octosyllabe par certains historiographes n'est pas anodin : il apparaît comme un mètre malléable, propice à la narration, même celle qui se veut véridique. Son emploi n'est alors pas toujours le même que celui qu'en fait le roman: l'historiographie, à l'exemple des Empereors de Rome de Calendre, dépoétise l'octosyllabe, le dépouille des effets rhétoriques propres à l'écriture en vers. Le mètre est conservé pour son "caractère de performance orale, à même de diffuser un message moral et religieux à une élite» ${ }^{214}$. Exploité par la chanson de geste, l'historiographie et le roman, l'octosyllabe apparaît comme une forme neutre: il s'agit d'un mètre qui, sur le plan cognitif, semble le mieux transmettre un récit.

C'est peut-être ainsi que s'explique l'alternance entre l'octosyllabe et l'alexandrin dans le Roman de Rou de Wace. L'alexandrin se déploie principalement dans les chansons de geste et l'hagiographie ${ }^{215}:$ mis en vogue grâce au Roman d'Alexandre dans la seconde moitié du XII ${ }^{\mathrm{e}}$ siècle, il est perçu comme un vers noble voire sacré, destiné à narrer les hauts faits

213 À propos de ces procédés épiques, voir Dominique Boutet, «L'épique au Moyen Âge", in Histoire de la France littéraire, vol. 1, dir. Frank Lestringant et Michel Zink, Paris, PUF, 2006, p. 850-873.

214 Voir l'article de Catherine Croizy-Naquet, "L'histoire romaine entre vers et prose", in Écrire en vers, écrire en prose: une poétique de la révélation. Actes du colloque de Paris X-Nanterre, mars 2006, dir. Catherine Croizy-Naquet, Nanterre, Université Paris X-Nanterre ("Littérales», 41), 2007, p. 155-171; p. 171 pour la citation.

215 C'est le cas de certaines versions de La vie de Sainte Marie-Madeleine et de La vie de Saint Denis par exemple. 
des rois ${ }^{216}$. Dans le Roman de Rou, à une partie formée de 4425 alexandrins groupés en laisses monorimes en succède une autre en octosyllabes. L'exigence de l'alexandrin, tant au niveau de sa composition qu'à celui de sa réception cognitive, justifie peut-être la transition à la forme non marquée de l'octosyllabe, qui favorise le développement narratif. Plus que les raisons qui poussent l'auteur à changer de mètre en plein travail, ce qui frappe, c'est le changement de poétique concomitant au changement de forme. La section en octosyllabes commence par un prologue sur la remembrance et l'origine de la Normandie. L'auteur glorifie les figures antiques d'Alexandre et de César ${ }^{217}$, qui prouvent à quel point il est nécessaire de consigner les exploits par écrits. Il commente son statut d'écrivain, soumis à la générosité de la "riche gent» ${ }^{218}$. Rien de tel dans la partie en alexandrins, qui s'ouvre sur la mention de l'année de composition (1160) et narre les guerres auxquelles font face les ducs de Normandie. L'alexandrin semble encourager Wace à opposer le sérieux de la chronique à un contenu plus romanesque. La partie en octosyllabes est en effet plus fantaisiste: elle relate la légende du diable dans l'église et celle du sacristain noyé. Le passage où le narrateur raconte sa déception lorsqu'il cherchait les merveilles de la forêt de Brocéliande et ne les a pas trouvées se réalise aussi dans la forme de l'octosyllabe:

La alai jo merveilles querre,

Vi la forest et vi la terre

Merveilles quis, mais nes trovai,

Fol m'en revinc, fol i alai;

Fol y allai, fol m'en revinc,

Folie quis, por fol me tinc. (Wace, Roman de Rou) ${ }^{219}$

216 Au sujet de l'alexandrin, voir Jacqueline Cerquiglini-Toulet, «Littérature médiévale?", art. cit., p. 149, et Catherine Gaullier-Bougassas, Les romans d'Alexandre. Aux frontières de l'épique et du romanesque, Paris, Champion, 1998, chapitre I.A.

217 Ces figures sont évoquées ici en tant que mythes historiques (voir plus bas pour une définition du mythe, ainsi que l'article de Philippe Sellier, "Qu'est-ce qu'un mythe littéraire?», Littérature, 55, 1984, p. 112-126): il s'agit de brèves mentions destinées à expliciter un propos sans que l'on développe la vie des empereurs, ce qui explique que l'auteur n'ait pas recours à l'alexandrin.

218 Wace, Le Roman de Rou, éd. Anthony J. Holden, 3 tomes, Paris, Picard ( SATF»), 1971-1974, troisième partie, tome 1, v. 151-166.

219 Ibid., v. 6393-6398. 
La narration d'aventures se transmet mieux en octosyllabes, tandis que l'écriture de l'Histoire appelle un mètre plus exigeant et prestigieux ${ }^{220}$. L'alexandrin est donc un mètre propice à la célébration, qui convient aux sujets élevés et à une volonté de glorification. Il ne se contente pas de la simple narration, mais son utilisation signale en elle-même l'exaltation de valeurs ou de héros.

\section{Brun de la Montagne}

Le recours à l'alexandrin dans la chanson de geste est donc approprié, elle qui vise à glorifier des héros épiques et les valeurs de la nation française $^{221}$. Le texte de Brun de la Montagne (début du XIv siècle) étonne dans cette perspective: son auteur adopte une structure en laisses d'alexandrins monorimes pour narrer l'enfance de Brun de la Montagne, élevé par les fées et appelé à devenir un grand héros. L'intrigue n'a rien d'une chanson de geste; elle se concentre d'abord sur la décision controversée de Butor, père de Brun, de laisser son nouveau-né en pleine forêt pour l'exposer aux dons des fées ${ }^{222}$. Le tournoi tout à fait courtois ${ }^{223}$ donné en l'honneur de

220 Sur cette alternance métrique dans le Roman de Rou, voir Françoise Laurent, «Style et arithmétique du vers dans le Roman de Rou de Wace», Centaurus. Studia classica et mediaevalia, 7, 2010, p. 60-73, et Laurence Mathey-Maille, «De l'alexandrin à l'octosyllabe: les hésitations de Wace dans le Roman de Rou», in Poétiques de l'octosyllabe, dir. Danièle James-Raoul et Françoise Laurent, Paris, Champion, 2018, p. 141-152. Selon Laurence Mathey-Maille, Wace userait de l'alexandrin et de l'octosyllabe en alternance pour expérimenter les avantages respectifs des deux formes.

221 Sur les thèmes et motifs de la chanson de geste, voir Jean Rychner, La Chanson de geste: essai sur l'art épique des jongleurs, Genève, Droz, 1955, Jean-Pierre Martin, Les Motifs dans la chanson de geste. Définition et utilisation, Lille, Université de Lille 3, 1992, Michel Zink, Littérature française du Moyen Âge, p. 69-98, Dominique Boutet, "L'épopée», in Histoire de la France littéraire, dir. Frank Lestringant et Michel Zink, t. 1, Paris, PUF ("Quadrige»), 2006, p. 850-873, Dominique Boutet, La chanson de geste. Forme et signification d'une écriture épique du Moyen Age, Paris, PUF, 1993.

222 La coutume du don des fées est présentée comme archaïque dans le roman: les barons s'y opposent d'ailleurs en insistant sur la sénilité de Butor. Voir Lunorsola Raffalli-Grenat, Écrire des fictions en vers aux XIV et XV siècles (un problème esthétique et culturel), thèse de doctorat soutenue à l'Université de Corse, ANRT, 2008, p. 447-450.

223 Les dames y assistent depuis les tribunes et remettent le prix au vainqueur: c'est un tournoi mondain, dont on décrit peu les prouesses des participants par rapport 
son fils, qui se tire sain et sauf de sa nuit en forêt, occupe ensuite plusieurs laisses. Il laisse pour finir la place à l'errance de Brun, parti pour retrouver la fée qui l'a élevé et allaité. Seuls deux éléments peuvent être lus en lien avec la chanson de geste: d'abord, la prolepse des vers 2139 à 2142, qui annonce la guerre à venir entre Brun et Hermant, le fils de Bruiant. Ce conflit sera la conséquence de la mort de Bruiant, qui succombe aux blessures infligées pendant le tournoi par Butor: une cause est esquissée avant la description des hostilités, comme c'est souvent le cas dans la geste. La guerre n'a pas lieu dans le cadre de la version qui nous est transmise, puisque le récit se termine abruptement au premier vers d'une laisse ${ }^{224}$. Rien ne nous dit donc qu'elle sera traitée à la manière des chansons de geste. Ensuite, l'intervention des fées marraines se retrouve dans plusieurs chansons de geste $^{225}$.

à l'intérêt dont fait l'objet le dispositif courtois qui l'encadre. Lunorsola RaffalliGrenat a souligné sa dimension parodique, notamment lorsque les convives se réveillent et ne se souviennent plus des frasques de leur soirée festive. Les caroles de la fête se transforment en orgie et amants et amantes se retrouvent tous ensemble dans la prairie: "Entreusqu'ens u praël fu amis et amie, / Amours, ames, amans, tout d'une compaignie; / Es prés en plusieurs lieus toute la nuit serie, / La peüst on trouver l'amoureuse maisnie.» (v. 2516-2519) Voir Écrire des fictions en vers aux XIV et XV siècles, p. 468.

224 Notre texte se termine à la fin d'un cahier (le dixième quaternion). Aye d'Avignon, qui accompagne Brun de la Montagne, commence sur un nouveau cahier. On peut envisager l'hypothèse de cahiers manquants, égarés lors d'un démontage du recueil. Ce n'est pas seulement le texte de Brun de la Montagne qui est inachevé, mais aussi la finalisation de ce manuscrit: les neuf derniers emplacements laissés libres par le copiste pour une miniature accompagnée d'une grande initiale de quatre à six unités de réglure sont restés vides. Selon Christine FerlampinAcher, l'inachèvement de l'ornementation témoigne du "désintérêt progressif de l'enlumineur qui correspond peut-être à celui de l'auteur ou du commanditaire». Merveilles et topique merveilleuse, p. 330, note 126. Voir aussi Notices des manuscrits du département des Manuscrits et de la Bibliothèque de l'Arsenal établies par la section romane de l'IRHT, "Cote: Français 2170 ", sur Gallica: http://gallica.bnf. fr/ark:/12148/bpt6k140475p/f1.image

225 Francis Gingras donne les exemples suivants: Huon de Bordeaux, Aubéron, Garin de Monglane en prose, Les Enfances Renier. Il souligne que les fées marraines sont assez rares dans le roman alors qu'elles apparaissent fréquemment dans la chanson de geste. Le Bâtard conquérant, p. 290, et "Le roman à l'épreuve des fées", in Écriture et réécriture du merveilleux férique. Autour de Mélusine, éd. Matthew W. Morris et Jean-Jacques Vincensini, Paris, Garnier, 2015, p. 23-35. Voir aussi Laurence Harf-Lancner, «Le baptême par le feu: la survivance d'un rite 
Le thème de l'éducation par une fée fait aussi signe vers le roman arthurien, en rappelant le Lancelot en prose, d'autant que l'épisode témoigne d'un intérêt manifeste pour le merveilleux féerique ${ }^{226}$. Ce n'est pas le seul élément de parenté entre Brun de la Montagne et le genre arthurien: l'errance du héros rapproche l'œuvre de ce type de récit. Le personnage jure qu'il ne s'arrêtera jamais dans une ville plus d'une nuit et préferera l'«erbe drue» (v. 2882), répondant ainsi aux conventions de l'errance arthurienne ${ }^{227}$. Son projet est conforme à l'idéologie chevaleresque telle qu'elle est présentée dans le genre qui nous intéresse. Lorsque son père lui demande où il compte aller, sa réponse signale que c'est le hasard qui guidera ses pas:

«Sire, respondi Bruns, ma voie ert ordenee

Ainsi que l'aventure ert de moy encontree;

Mais ge chevaucherai par la forest ramee

Tant que de moy sera aventure trouvee;

Car je devieng amans, si veil trouver amee,

Car puis que l'aventure est a moy destinee

Ja mais ne sesseray si sera achevee.»

(Brun de la Montagne, v. 3025-3031)

La récurrence du mot "aventure», son surgissement au détour de la forêt et la quête de l'amour parallèle à ce cheminement ne manquent pas de signaler un dialogue établi avec le genre arthurien. De fait, les affrontements de Brun avec le Chevalier Hideux ou les gardiens de la Tour Ferrée se présentent comme des duels arthuriens, auxquels le jeune chevalier doit légitimement prendre part pour démontrer sa valeur. Ces premières épreuves l'amènent à rencontrer la cousine de Morgue, dont il s'éprend.

dans trois textes épiques tardifs", in Au carrefour des routes d'Europe: la chanson de geste. Tome II. Xe Congrès international de la Société Rencesvals pour l'étude des épopées romanes, Strasbourg, 1985, Aix-en-Provence, Publications de l'Université de Provence ("Senefiance», 21), 1987, p. 629-641. Sur les fées marraines, voir Laurence Harf-Lancner, Les fées au Moyen Âge. Morgane et Mélusine: la naissance des fées, Paris, Champion, 1984, p. 27-34.

226 Christine Ferlampin-Acher décrit le processus merveilleux qui préside à la scène du don des fées: le merveilleux est restitué à travers le point de vue particulier des barons, qui en sont troublés. Merveilles et topique merveilleuse, p. 462-466.

227 Nous développerons plus en détails ces conventions au chapitre I, "L'errance aventureuse», p. 205-216. 
C'est l'occasion de développer le topos du mal d'amour et celui de l'Orgueilleuse d'Amour qui éconduit assez rudement son soupirant.

Ce déroulement laisse entrevoir la multiplicité des influences: Brun de la Montagne emprunte au roman arthurien la structure de l'errance et de l'aventure, au folklore le motif le don des fées, à la lyrique courtoise le traitement de la relation amoureuse ${ }^{228}$, aux chastoiements la façon dont la fée marraine instruit Brun sur le comportement d'un bon amant (laisses 178-179). Son association avec le genre arthurien ne se fonde néanmoins pas que sur le modèle de l'errance: Arthur est mentionné à plusieurs reprises et le portrait que l'on en dresse est conforme à celui qu'en donnent les romans, c'est-à-dire l'image d'un roi riche, généreux, garant de la chevalerie («tout i sont retenu / Qui sevent bouhorder de lance ou d'escu. / Quiconques soit a lui il l'a tost pourveü», v. 3240-3242), à l'initiative de belles fêtes de $\operatorname{cour}^{229}$. C'est vers lui que Brun doit diriger ses pas pour être fait chevalier; le vers proleptique "Comment roys Artus fist le Brun chevalier» (v. 3085) fait entendre que la fin manquante du récit narre l'adoubement du jeune chevalier par le roi breton. À ce cadre de référence romanesque s'ajoute une liste de lieux faés dont Arthur serait le seigneur, énumérés par Butor pour introduire son projet de laisser Brun en proie au don des fées :

"Il a des lieus faés es marches de Champaigne,

Et aussi en a il en la Roche Grifaigne,

Et si croy qu'il en a ausi en Alemaigne,

Et ou bois Bersillant, par desous la Montaigne;

Et nonpourquant ausi en a il en Espaigne,

Et tout cil lieu faé sont Artu de Bretaigne.»

(Brun de la Montagne, v. 562-567)

Arthur apparaît ici comme le maître de l'espace merveilleux, en marge du monde terrestre, que celui-ci se situe en Allemagne ou en Espagne ${ }^{230}$.

228 Voir Lunorsola Raffalli-Grenat, Écrire des fictions en vers aux XIV et XV siècles, p. 357-361, sur l'exaltation de l'amour et le traitement courtois du tournoi. Sur les dons des fées, voir Laurence Harf-Lancner, Les fées au Moyen Âge, p. 27-34.

229 Nous reviendrons au chapitre I, "Voyages génériques du roi Arthur», p. 182-195, sur les apparitions génériquement différentes d'Arthur selon les genres.

230 Voir Lunorsola Raffalli-Grenat, Écrire des fictions en vers aux XIV et XV siècles, p. 324-328. Selon la critique, la géographie évoquée dans ces vers représenterait les lieux de diffusion de la légende arthurienne en Europe. 
Cette caractéristique pourrait donner lieu à un développement proche des séjours avaloniens propres aux chansons de geste - nous y reviendrons -, où le héros se rend dans le monde insituable et hors du temps régi par Arthur. On s'éloignerait alors du genre romanesque, où Arthur dirige un monde terrestre et n'évolue jamais en Avalon. Le cadre inachevé du récit qui nous est transmis ne voit pas Brun aborder aux rivages d'un Avalon: la voie qu'emprunte et annonce le texte est celle de la rencontre courtoise avec Arthur, prêt à adouber le jeune chevalier. Les discours tenus sur le roi cristallisent néanmoins les tensions génériques dont résulte Brun de la Montagne.

La filiation romanesque ne se traduit pas que dans les personnages et les motifs: Brun est surnommé «restor Tristan» (v. 1063) ou "petit Tristan» (v. 1637) par les fées. Christine Ferlampin-Acher note que le «restor» désigne le protagoniste comme un nouveau Tristan. Ce surnom est une façon de faire revivre un temps glorieux, par un «héros de seconde génération (voire de troisième ou quatrième), qui tente d'atteindre au mérite des ancêtres, de renouveler leur vaillance $»^{231}$. L'œuvre se place donc en continuité de textes arthuriens: elle s'inscrit dans une tradition qu'elle entend renouveler en proposant de nouveaux héros. Au XIv siècle, il s'agit justement de restorer le récit arthurien en vers. L'auteur reconduit les caractéristiques positives attribuées au roi Arthur mais transforme la nature de son texte en y imbriquant la forme de la chanson geste et des motifs d'origines diverses. Le restor du récit arthurien est bien à chercher du côté de l'hybridation et de la multiplication des inspirations.

La laisse d'alexandrins monorimes, justement, est moins épique qu'il n’y paraît. Christine Ferlampin-Acher démontre que, si le récit avance lentement, ce n'est pas en raison des répétitions que favorise la structure en laisse ${ }^{232}$. Les procédés épiques de redondance ne sont presque pas exploités dans cette œuvre. Seules les laisses 191 et 192 ont recours à l'enchaînement typique de la chanson de geste: la progression s'effectue en répétant la fin de la laisse précédente. L'impression de piétinement du

231 Christine Ferlampin-Acher, "Brun de la Montagne: une chançon de matiere enforciee (v. 2744)?", in Le Romanesque aux XIV et XV siècles, dir. Danièle Bohler, Bordeaux, Presses de l'Université de Bordeaux, 2009, p. 36.

232 Ibid., p. 36-38. Sur les répétitions, voir aussi Lunorsola Raffalli-Grenat, Écrire des fictions en vers aux $X I V^{e}$ et $X V^{e}$ siècles, p. 352-357, qui relève notamment que le don des fées est relaté trois fois. 
récit est plutôt liée à un développement excessif d'éléments anodins. Peu de choses se produisent mais sont pourtant déroulées sur plusieurs laisses: il faut ainsi trente-neuf laisses (737 vers) pour que l'intrigue démarre vraiment, avec le départ des chevaliers qui déposent Brun à la fontaine des fées $^{233}$. Ce retardement n'est pas dû à une surenchère d'aventures qui se succèderaient; tout se passe en fait en un jour, mais le narrateur s'attarde à raconter comment Butor prend la décision de livrer son fils à la nature, comment un messager convoque ses barons et se fait arrêter en chemin, les discussions qu'il a avec les sujets, les objections de ceux-ci envers Butor, les explications de Butor à sa femme. Le narrateur sature sa narration de détails qui freinent la progression de l'intrigue. L'ensemble, inachevé et laissant supposer un développement encore plus touffu de l'histoire de Brun, donne l'impression que l'auteur s'est prêté au jeu de l'expansion à partir d'une matière assez pauvre ${ }^{234}$. Cette tentative dit quelque chose de l'inscription du récit dans la tradition: le modèle choisi est celui de la somme, telle que l'ont élaborée les romans en prose, en racontant les enfances d'un héros et les péripéties de ses parents et en amplifiant le texte par diverses techniques que n'exploite pas l'auteur de Brun de la Montagne (l'entrelacement notamment). En conséquence, l'usage de la laisse, plutôt longue, est romanesque: elle scinde le récit en unités narratives, voire en points de vue qui divergent, notamment concernant la merveille des fées marraines (laisses 1 à 5) 235 , mais ne saurait représenter un effet d' "hypnose de la répétition $»^{236}$ propre à la chanson de geste. La diégèse progresse de

233 Sur la fontaine dans Brun et l'enluminure qui la représente dans le manuscrit, voir l'article de Dorothy L. Schrader, "L'iconographie de l'eau: la fontaine comme miroir dans Brun de la Montagne", in L'épopée romane au Moyen Âge et aux temps modernes. Actes du XIV Congrès international Rencesvals, éd. Salvatore Luongo, Napoli, Fridericiana Editrice Universitaria, 2001, t. 1, p. 97-104.

234 Roger Dubuis donne plusieurs exemples de textes longs dont la matière inviterait plutôt à la brièveté, notamment Jehan de Paris. "Les formes narratives brèves", in Grundriß der romanischen Literaturen des Mittelalters. La littérature française aux $X I V^{\vee}$ et $X V^{e}$ siècles, vol. VIII/I, Heidelberg, Carl Winter, 1988, p. 188-189.

235 C'est ce que montre Christine Ferlampin-Acher en analysant le merveilleux. "Brun de la Montagne: une chançon de matiere enforcie?", art. cit., p. 33-34. Voir aussi "Merveilles" et topique merveilleuse dans les romans médiévaux, Paris, Champion, 2003, p. 330-332 et 462-466.

236 Michel Zink, Littérature française du Moyen Âge, p. 73. Voir p. 71-73 sur les répétitions épiques. 
manière linéaire; la laisse apparaît comme un simple élément de structure, tout comme les légendes des enluminures qui ponctuent le texte et le hiérarchisent en chapitres - par exemple au folio 70r, "Comment Brun de la Montaigne / Jouste a .II. chevaliers, et en abati l'un mort / Du cheval a terre et l'autre se rendi a lui». L'exploitation de la laisse dans Brun de la Montagne correspond à celle que décrit William Kibler pour les gestes tardives: en supprimant tout effet de répétition, "la laisse a perdu son unité thématique pour devenir purement narrative ${ }^{237}$.

Que reste-t-il de la chanson de geste, si ce n'est un cadre formel qui ne remplit pas vraiment ses fonctions initiales? L'inscription générique épique est pourtant une option éclaircie par le narrateur, qui désigne son œuvre "chanson" par deux fois (v. 2744 et 3081). Cette autodésignation est concurrencée néanmoins par celle de "roman", qui figure sur le titre général de l’œuvre ( $\mathrm{Ci}$ commance li roumans de Brun / De la Montaigne, qui fu filz Butor de la Montaigne, / Qui puis fu apelez le petit Tristran le Restoré») et au vers 1128 ("Ainsi com vous ores ci apres ou roumant»). Le statut de ce texte est dès lors volontairement indécidable. Il semble pourtant que ses contemporains aient privilégié une réception épique du texte, si l'on se fie à la mise en recueil de l'unique manuscrit ayant transmis Brun de la Montagne: le BnF fr. $2170^{238}$ l'assemble avec Aye d'Avignon, chanson de geste du cycle de la Geste de Nanteuil, dont il s'agit également de l'unique témoin complet ${ }^{239}$. La forme a donc une portée générique forte, en particulier pour la chanson de geste. Alors que

237 William Kibler, «La "chanson d'aventures" ", art. cit.

238 Ce manuscrit est daté du deuxième quart du XIV ${ }^{\mathrm{e}}$ siècle selon la base de données de l'IRHT Jonas. http://jonas.irht.cnrs.fr/consulter/manuscrit/detail_manuscrit. php?projet=45671.

239 Voir l'introduction à l'édition de Samuel J. Borg, Aye d'Avignon, chanson de geste anonyme, Genève, Droz, 1967, p. 18-21. Le héros d'Aye d'Avignon, Garnier de Nanteuil, est le fils de Doon de Mayence. C'est sa femme, Aye, qui donne son nom usuel au texte. On dispose pour cette chanson de quelques autres fragments. Le BnF fr 2170 ne semble pas être un recueil factice, bien que deux copistes différents aient transcrit Brun et Aye d'Avignon et que les deux textes soient séparés par un changement de cahier. Pour Aye d'Avignon aussi, l'enluminure est inachevée, comme si l'enlumineur s'était interrompu dans son travail au milieu de Brun: seules les initiales des folios $88 \mathrm{v}$ et $89 \mathrm{r}$ ont été exécutées à l'encre rouge. Le programme initial prévoyait toutefois beaucoup moins de décoration que pour Brun: aucun espace n'est laissé pour une miniature. Pour le texte de Brun, seules les initiales et les sept premières miniatures ont été exécutées. 
la forme est le seul élément épique de Brun de la Montagne, les lecteurs l'ont visiblement reçu comme une chanson de geste.

Peut-il s'agir dans ce cas d'une chanson d'aventures? Selon la défintion de William Kibler, la chanson d'aventures respecte le cadre formel de la geste, mais s'autonomise de son organisation et de ses thèmes ${ }^{240}$. La chanson d'aventures prend ses distances par rapport à l'histoire nationale, aux conflits féodaux et à la défense de la foi pour traiter de sujets plus romanesques, le merveilleux, l'amour, le mariage, le voyage par exemple. La victoire militaire n'est plus qu'un arrière-fond, face aux motifs folkloriques (l'enfant trouvé, le don des fées) ${ }^{241}$. La fonction de la chanson d'aventures n'est donc plus l'historicité et l'instillation de la loyauté au souverain ou de la foi chrétienne, mais bien le divertissement. Christine Ferlampin-Acher renonce néanmoins à considérer Brun de la Montagne comme une chanson d'aventures: pour elle, "c'est un roman arthurien qui cherche à conjurer l'usure des années et des réécritures en puisant à la vaillance première de la chanson de geste, sans cependant y parvenir ${ }^{242}$. Le choix de la laisse d'alexandrins résulterait donc plus d'une nostalgie et d'une tentative de restaurer un idéal - chevaleresque et littéraire -, comme le fait le surnom du Restor Tristan, que d'une véritable inscription générique.

Si la chanson d'aventures, à travers les exemples qu'en donne William Kibler, maintient l'idée, même marginalement, de la commémoration et de la cohésion nationale, il n'en va pas de même de Brun de la Montagne, dont la géographie est d'ailleurs fantaisiste (Butor est seigneur de la «Montagne»; il emmène son fils à la «Roche Dormant», v. 171). Dans la chanson d'aventures, les péripéties sont réinvesties par le mode d'expression

240 William Kibler, «La "chanson d'aventures” ", art. cit.

241 William Kibler donne l'exemple de Parise la Duchesse ou de Huon de Bordeaux. "La "chanson d'aventures" ", art. cit. Voir aussi Claude Roussel, "D'armes et d'amours: l'aventure dans les dernières chansons de geste", in Le romanesque dans l'épique, éd. Dominique Boutet, Paris, Université Paris X Nanterre, 2003, p. 163-178, qui évoque les péripéties des chansons de geste tardives. Il y traite également de la réactivation de motifs folkloriques: "Peau d'Âne» et "La fille sans mains" dans La Belle Hélène de Constantinople, "la petite fille qui cherche ses frères" dans Naissance du Chevalier au Cygne, "La fiancée substituée » dans Berthe aux grands pieds.

242 Christine Ferlampin-Acher, "Brun de la Montagne: une chançon de matiere enforcie?", art. cit., p. 36. 
de la chanson de geste, poussées vers une «exploitation mélodramatique ${ }^{243}$ qui tend toujours à l'idéalisation héroïque. De même, la chanson de geste tardive que William Kibler dénomme chanson d'aventures ne met en scène l'amour que de manière anecdotique ${ }^{244}$ : ce thème ne suscite pas de débats intérieurs et n'est pas l'essence de la prouesse, contrairement à ce que l'on rencontre dans le roman et dans Brun de la Montagne. Ce texte ne s'apparente donc pas vraiment aux chansons de geste tardives. Il nous semble toutefois que l'expression "chanson d'aventures ${ }^{245}$, indépendamment de ce que William Kibler place dans cette catégorie, traduit particulièrement bien l'hybridation à l'œuvre dans Brun de la Montagne: il s'agit d'un roman d'aventures en forme de chanson. L'œuvre peut bien ne rien présenter d'épique, elle demeure tout de même une chanson, dans une forme semblable à celle de la chanson de geste. Peut-être faut-il donc voir dans cette œuvre un roman moulé dans la forme de la chanson de geste, une tentative d'hybridation qui n'a pas connu de postéritée ${ }^{246}$.

\section{Long ou bref}

L'allongement de son texte à laquelle procède l'auteur de Brun de la Montagne constitue un autre critère générique: l'allongement du récit, comme la brièveté, est un trait de genre pertinent et fait office de critère de mise en recueil. Richard Trachsler souligne en ce sens que la coprésence de fabliaux et de textes longs au sein d'un manuscrit est hiérarchisée: dans les recueils qu'il considère, il n'y pas une alternance entre long et

243 Claude Roussel, "D'armes et d'amours: l'aventure dans les dernières chansons de geste», art. cit., p. 172.

244 Ibid., p. 176-177.

245 Ibid., Claude Roussel interroge la pertinence de l'expression «chanson d'aventures", qui semble recouper la catégorie des chansons de geste tardives dans la conception de William Kibler. Il souligne la précocité de l'influence prétendument romanesque sur la chanson de geste et note que l'étiquette renvoie à une hybridation, que l'on ne peut pas toujours appliquer aux textes tardifs, ceux-ci demeurant soumis au modèle épique.

246 Claude Roussel cite l'exemple de Florent et Octavien (seconde moitié du XIv siècle), qui dérive du roman en octosyllabes Octavian (1230-1240): il s'agit d'une transposition du roman à la chanson de geste. Cependant, Octavian constitue un "gisement épique favorable», en raison de sa situation à Paris sous le règne de Dagobert. L’œuvre est amplifiée et remaniée et ne détonne donc pas dans le paysage de la chanson de geste du XIV siècle. Ibid., p. 168-169. 
bref, mais bien une opposition quantitative, organisée en deux sections ${ }^{247}$. L'autodésignation des œuvres prouve également que leur longueur est un élément signifiant, comme l'explique Francis Gingras : «Les récits brefs qui se présentent comme romans sont rares et, à l'inverse, les textes longs qui se désignent comme fables ou fabliaux sont pratiquement inexistants. " ${ }^{248}$ La brièveté distingue ainsi les lais de Lanval, du Cor ou du Mantel du roman arthurien ${ }^{249}$. Jean Frappier souligne que le lai est «au roman courtois de ce temps-là, roman breton ou roman d'aventure, exactement ce qu'est encore aujourd'hui la "nouvelle" à notre roman ${ }^{250}$.

Le choix de la brièveté implique un traitement spécifique du récit: elle exclut les longues descriptions, l'accumulation de détails et

247 Richard Trachsler, "Observations sur les "recueils de fabliaux" ", in Le Recueil au Moyen Âge. Le Moyen Âge central, dir. Yasmina Foehr-Janssens et Olivier Collet, Turnhout, Brepols («Texte, Codex, Contexte»), 2010, p. 35-46. Francis Gingras fait le même constat. Le Bâtard conquérant, p. 336-337. Voir aussi Keith Busby, Codex and Context, vol. I, p. 437-463.

248 Francis Gingras, Le Bâtard conquérant, p. 323. Au sujet de la brièveté comme critère de distinction générique, voir le chapitre «Roman et narration longue» et son article, "Pour faire court: conscience générique et formes brèves au Moyen Âge", in Faire court: l'esthétique de la brièveté dans la littérature du Moyen Âge, éd. Catherine Croizy-Naquet, Laurence Harf-Lancner et Michelle Szkilnik, Paris, PSN, 2011, p. 155-179.

249 On peut encore citer Gliglois, La Mule sans frein, Le Chevalier à l'épée, le Lai de Mélion, le lai du Trot et Tyolet. Matilda Tomaryn Bruckner et Glyn S. Burgess traitent du lai arthurien dans "Arthur in the Narrative lay", in The Arthur of the French. The Arthurian Legend in Medieval French and Occitan Literature, dir. Glyn S. Burgess et Karen Pratt, Cardiff, University of Wales Press ("Arthurian Literature in the Middle Ages", IV), 2006, p. 186-214. Voir aussi l'article de Mireille Séguy et Nathalie Koble, "Nos somes tuit enfantosmé! L'effet de (des)saisissement des lais narratifs bretons", in Faire court: l'esthétique de la brièveté dans la littérature du Moyen Âge, dir. Catherine Croizy-Naquet, Laurence Harf-Lancner et Michelle Szkilnik, Paris, PSN, 2011, p. 181-202, Emmanuèle Baumgartner, "À propos du Mantel Mautaillé», Romania, 96, 1975, p. 315-332, Nathalie Koble, Le Lai du Cor et le Manteau mal taillé. Les dessous de la Table ronde, éd. cit., et Beate Schmolke-Haßelmann, "L'intégration de quelques récits brefs arthuriens (Cor, Mantel, Espee) dans les romans arthuriens du XIII ${ }^{\mathrm{e}}$ siècle", in Le Récit bref au Moyen Âge, Acte du colloque des 27, 28, 29 avril 1979, éd. Danielle Buschinger, Université de Picardie; Paris, Centre d'Études Médiévales; Champion, 1980, p. 107-128.

250 Jean Frappier, «Remarques sur la structure du lai», art. cit., p. 23. 
de développements; au contraire, "elle appelle la rupture, le choc, la surprise ${ }^{251}$. Elle impose un rythme, entre ralentissements et action, qui suppose la maîtrise de la temporalité narrative. Les genres du comique s'accommodent particulièrement d'une narration courte, favorisant la transmission rapide de l'information et, en conséquence, l'effet de rupture qui peut susciter le rire: Roger Dubuis note que «la notion de brièveté semble, par nature, beaucoup mieux accordée au comique quau sérieux ou au grave ${ }^{252}$. Francis Gingras démontre à l'exemple du fabliau que cela va de pair avec l'adoption du vers, qui s'adapte mieux que la prose à une narration courte à visée comique ${ }^{253}$. La brièveté produit un effet différent du roman: elle touche son public de manière plus directe ${ }^{254}$. Certains genres se voient ainsi condamnés à la brièveté pour être écoutés et la revendiquent pour se démarquer de la production romanesque. Gautier de Coinci se plaint de l'enthousiasme discutable du public, qui tolère facilement les fictions longues, tandis que les sermons doivent être brefs pour être assimilés ${ }^{255}$ :

[...] chevalier, prince et haut homme

Aimment mais mielz atruperies

Risees, gas et truferies,

Sons et sonnés, fables et faintes

Que vies de sains ne de saintes.

\section{Longues fables et sermons cors}

Demandent mais aval ces cors.

Larges mençoignent, bordes amples

Aimment mais mielz que les essamples

Ne les bons dis de l'Escriture ${ }^{256}$.

251 Roger Dubuis, «Les formes narratives brèves », art. cit., p. 195.

252 Ibid., p. 194.

253 Au sujet des enjeux génériques de l'emploi du vers dans les fabliaux, voir Francis Gingras, "La part du vers dans la définition médiévale des fabliaux», art. cit.

254 Voir Francis Gingras, Le Bâtard conquérant, p. 248-250.

255 Francis Gingras traite de l'opposition entre «roman long» et «sermon court» dans son article, "Pour faire court: conscience générique et formes brèves au Moyen Âge», art. cit., et le chapitre "Roman et narration longue», in Le Bâtard conquérant. Sur la brièveté de manière générale, voir Catherine Croizy-Naquet, Laurence Harf-Lancner et Michelle Szkilnik (dir.), Faire court: l'esthétique de la brièveté dans la littérature du Moyen Âge, Paris, PSN, 2011.

256 Gautier de Coinci, Les Miracles de Nostre Dame, éd. Frederic Koenig, Genève, Droz, 1966, tome 3, II, Pr 1 (D. 52), v. 142-151. 
Ce témoignage démontre que l'opposition entre longueur et brièveté est signifiante pour le public médiéval, et recoupe en partie celle entre fiction et vérité dans des représentations telles que celle proposée par Gautier de Coinci. Bien sûr, la brièveté transmet également la fiction, mais celle-ci est «subordonnée à la vocation didactique ${ }^{257}$ et paraît donc plus recevable.

Ces «longues fables» pourraient tout à fait désigner les romans arthuriens, toujours plus longs qu'un fabliau ou qu'un sermon. L'ampleur du texte est fortement liée, au début du XIII ${ }^{\mathrm{e}}$ siècle, au choix du vers ou de la prose: l'écriture arthurienne en prose invite à l'élargissement du discours, tandis que le vers tend à la concision ${ }^{258}$. Aussi les œuvres de Chrétien de Troyes et les romans en vers du début du XIII ${ }^{\mathrm{e}}$ siècle tiennent-ils en moyenne sur 8000 à 9000 vers, alors que le Lancelot en prose s'étend sur plus de 400 folios, amplifiés encore par la mise en cycle. Ce choix correspond à des revendications différentes: l'exhaustivité pour la prose, qui entend configurer un univers dans son entier et dans une temporalité linéaire, le vers présentant au contraire un monde atemporel, où les histoires semblent se reproduire à l'infini ${ }^{259}$. Nous le verrons (chapitre III, "Structures arthuriennes: imiter la prose», p. 493-554), les textes en vers de la fin du XIII ${ }^{\mathrm{e}}$ siècle, comme Claris et Laris, Rigomer et Escanor, dérogent à cette équivalence et tendent à se rapprocher, par plusieurs aspects d'ailleurs, de l'écriture propre à la prose. Si le choix de la forme vers restreint habituellement la longueur des récits, il n'en va pas ainsi pour les romans tardifs: l'anachronisme du choix formel contraint l'écriture tardive à déroger à certains critères génériques induits par le vers. L'inverse

257 Francis Gingras, "Pour faire court: conscience générique et formes brèves», art. cit., p. 177.

258 Voir Daniel Poirion, "Sur l'écriture-prose», Perspectives médiévales, 1997, 3, p. 54-56. "Ainsi la prose nous apparaît comme ayant horreur du vide, de l'implicite et du discontinu. Elle est le lieu de l'élucidation totale. Elle cherche à tout dire, à tout expliciter.» (p. 56) Voir aussi son article, "Romans en vers et romans en prose", art. cit. Nous avons nuancé plus haut l'association trop stricte de l'allongement du récit à l'écriture en prose. Nous nuancerons plus bas l'idée encore répandue de la prétendue "horreur du vide» de la prose.

259 Wace donne d'ailleurs le canevas de cette temporalité cyclique, en décidant de ne pas raconter les douze années de paix du royaume d'Arthur, lors desquelles il se produit des aventures répétitives et hors du temps de l'Histoire. Voir au sujet de ce passage la page 122 , infra. 
est aussi valable: un texte comme le Conte du Papegau, pourtant écrit en prose, démontre plus d'accointances avec les sujets et la temporalité développés par l'écriture en vers, sa brièveté étant l'une des composantes qui l'y apparente ${ }^{260}$.

Bref ou long, vers ou prose, octosyllabe ou alexandrin, narration continue ou laisses, le choix d'un cadre formel conditionne l'appréhension générique des lecteurs, crée des horizons d'attente différents. La spécificité des romans tardifs se manifeste dès lors avec acuité: qu'advient-il de la cohérence générique de ces textes, alors qu'ils font intervenir des personnages et des modes de structuration jusque-là exclusifs à la prose? L'anachronisme de leur forme versifiée engendre ce décalage, une perturbation d'ordre générique qui les fait percevoir comme de mauvais romans arthuriens en vers - ce dont témoigne l'avis de Beate SchmolkeHaßelmann que nous citions en introduction. Le choix d'une forme, nous le notions, contraint aussi, en fonction des périodes, le rapport que chaque texte entend établir avec l'Histoire ou la fiction. En dehors des considérations formelles, instables, ce rapport est en soi un trait générique pertinent, générateur d'oppositions entre les genres.

\section{Historia et fabula}

La distinction entre historia et fabula est perçue et théorisée par les médiévaux ${ }^{261}$, notamment Jean de Garlande, dans la Parisiana Poetria: le degré de vérité du texte hiérarchise la production en trois niveaux; l'historia s'appuie sur des faits prenant place dans une époque reculée (gesta res sed ab aetatis nostrae memoria remota), la fabula raconte un événement fictif qui n'entend pas passer pour vrai (nec res veras nec verisimiles continet) et l'argumentum transmet des événements fictifs mais plausibles

260 Ainsi que le note Anne Berthelot, "Arthur, ou le Chevalier du Papegault: décadence d'une fonction, décadence d'un genre», in König Artus und der heilige Graal. Studien zum Spätarthurischen Roman und zum Graals-Roman im europäischen Mittelalter, éd. Danielle Buschinger et Wolfgang Spiewok, Greifswald, Reineke-Verlag, 1994, p. 17.

261 Au sujet de l'historiographie et de la conscience historique au Moyen Âge, voir Dominique Boutet, Formes littéraires et conscience historique. Aux origines de la littérature française (1100-1250), Paris, PUF, 1999, et Peter Ainsworth, "Conscience littéraire de l'histoire au Moyen Âge", in Histoire de la France littéraire, vol. 1, dir. Frank Lestringant et Michel Zink, Paris, PUF, 2006, p. 349-419. 
(res ficta que tamen fieri potuit) ${ }^{262}$. La dernière catégorie de l'argumentum pourrait correspondre au genre du fabliau, ainsi que le propose Francis Gingras: "Le fabliau se définirait donc, dans le discours médiéval, comme une forme intermédiaire entre fabula et historia. ${ }^{263}$ Il présente un monde inspiré de la réalité quotidienne, qui devient objet du rire. Les caricatures de types sociaux et la mise en scène de la ruse sont bienvenues et soutiennent la transposition du réel dans la fiction. Le prologue au fabliau Du Foteor de la version de Berne Burgerbibliothek 354 confirme le rapprochement avec l'argumentum:

Qui fabloier velt si fabloit,

Mais que son dit n'en affebloit

Por dire chose desresnable;

L'en puet si bel dire une fable

Qu'ele puet ainsi com voir plaire (v. 1-5) 264 .

Une fable ne doit pas être le prétexte à parler de choses "desresnables», c'est-à-dire invraisemblables. Fabloier raisonnablement, c'est proposer un récit susceptible de plaire autant que le ferait un récit véridique. Le fabliau n'a tout de même pas échappé aux condamnations des auteurs de textes didactiques et édifiants, qui le voient comme un pur tissu de mensonges, d'autant plus qu'en est absente toute revendication morale. Si la distinction entre vraisemblable et invraisemblable fait sens pour les auteurs de fictions, elle n'est perçue que comme deux modalités du récit mensonger, du point de vue des moralisateurs ${ }^{265}$. On peut ainsi élaborer un système

262 Jean de Garlande, Parisiana Poetria, éd. Traugott Lawler, New Haven; Londres, Yale University Press, 1974, V, p. 100. Au sujet de ce traité rhétorique, voir Danièle James-Raoul, «La poétique des genres dans les arts poétiques médiolatins", art. cit.

263 Francis Gingras, "La part du vers dans la définition médiévale des fabliaux», art. cit., p. 71.

264 Chevalerie et grivoiserie. Fabliaux de chevalerie, éd. Jean-Luc Leclanche, Paris, Champion ("CCMA»), 2003. Le manuscrit de la BnF, fr. 19152, offre au vers 3 l'adjectif «veritable» au lieu de «desresnable». La leçon "desresnable» n'est donc pas toujours privilégiée; elle n'en demeure pas moins tout à fait signifiante du rapport à la fiction.

265 Il faut noter que l'utilisation du terme de "fiction " pour traduire le latin fabula ne se généralise qu'au milieu du Xve siècle. Francis Gingras cite en ce sens quelques vers d'Eustache Deschamps et une phrase de Christine de Pizan, où le mot 
binaire, qui oppose d'abord Histoire ${ }^{266}$ et fiction, cette dernière se scindant encore en deux pôles: merveilleux ${ }^{267}$ ou vraisemblable.

\section{Le merveilleux}

Ces distinctions rejoignent en partie celles qu'opère Dominique Boutet pour traiter du surnaturel dans la littérature médiévale. Renonçant aux trois catégories de Jacques Le Goff - miraculosus, magicus et mirabilia ${ }^{268}$-, il s'appuie sur l'appréhension par les contemporains des phénomènes relatés et traite d'une part du merveilleux transcendantal et de l'autre du merveilleux d'altérité:

D'un côté, ce qui est susceptible d'être perçu par les médiévaux comme historiquement vrai ou vraisemblable, de l'autre ce qui relève de la fiction littéraire. Entreraient dans la première catégorie les motifs bibliques, les motifs hagiographiques (même si leur origine première est pré-chrétienne) et les motifs merveilleux attestés dans l'historiographie (les saints militaires par exemple), mais également les

"fiction» apparaît avec cette signification. "Tant con durra crestiantez. L'épreuve du temps comme épreuve de vérité dans les réécritures des romans de Chrétien de Troyes (XIII ${ }^{\mathrm{e}}$-XVIII ${ }^{\mathrm{e}}$ siècle)", in Fictions de vérité dans les réécritures européennes des romans de Chrétien de Troyes, éd. Annie Combes, Paris, Garnier, 2012, p. 82, note 3 .

266 Nous distinguons le terme "Histoire» avec une majuscule, qui désigne des événements historiques et avérés (history), et «histoire» en minuscule, employé comme synonyme de diégèse (story).

267 Nous définissons le merveilleux comme «l'événement, surnaturel ou non, par lequel le récit s'écarte des représentations inscrites dans l'horizon d'attente du lecteur. Elle marque un point de rupture dans la prévisibilité narrative et rend soudain problématique la matière de la fiction." (Francis Dubost, Aspects fantastiques de la littérature narrative médiévale, p. 63) La merveille s'accompagne de l'étonnement des personnages qui y assistent. On consultera également Christine Ferlampin-Acher, «Merveilles» et topique merveilleuse dans les romans médiévaux, pour une étude du développement du merveilleux dans la littérature médiévale. Signalons que la merveille ne se manifeste pas nécessairement de manière surnaturelle: le mot peut également renvoyer à un événement inédit, exceptionnel, insolite, qui suscite l'étonnement.

268 Jacques Le Goff, L'imaginaire médiéval: essais, Paris, Gallimard, 1991. Le miraculosus et le magicus s'opposent de manière axiologique, l'un étant le fait du divin et l'autre du malin, tandis que les mirabilia désignent les manifestations surnaturelles païennes, comme les fées ou les objets magiques. Voir aussi Francis Dubost, Aspects fantastiques de la littérature médiévale. 
merveilles attestées dans les encyclopédies et/ou héritées de l'antiquité gréco-romaine (peuples monstrueux, sirènes, centaures...). Dans la deuxième catégorie figurerait tout ce qui ressortit à la contamination arthurienne, à la féerie, au folklore et à la magie ${ }^{269}$.

Le merveilleux transcendantal n'est pas perçu comme mensonger, car il délivre une vérité morale en même temps qu'il démontre les manifestations d'un pouvoir divin sur terre. Le surnaturel de la Chanson de Roland ne transgresse par exemple pas les lois de l'écriture de l'Histoire, en raison de sa portée chrétienne et de sa propension à faire apparaître le sens providentiel des événements, Dieu apportant son soutien dans la lutte contre les Sarrasins. La magie issue de l'art sarrasin est bien plus sujette à caution, lorsqu'elle est utilisée dans le but de divertir et d'amener une touche d'exotisme ${ }^{270}$ oriental au récit; c'est le cas pour les enchantements qu'Orable fait naître afin d'éviter d'offrir son corps au Sarrasin Thiébaut dans l'épisode des jeux d'Orange des Enfances Guillaume. L'interdit qui plane sur la magie est atténué ici par le plaisir de voir les forces du mal se retourner contre l'hérésie sarrasine.

269 Dominique Boutet, "Merveilleux et interférences génériques dans la chanson de geste de Tristan de Nanteuil", in Motifs merveilleux et poétique des genres au Moyen Age, dir. Francis Gingras, Paris, Garnier, 2015, p. 23.

270 Nous définissons l'exotisme comme «ce qui provient de régions éloignées, et qui est perçu comme étrange, fascinant, excitant ou redoutable.» (Michel Tétu et Anne-Marie Busque, "Exotisme», in Dictionnaire du littéraire, Paris, PUF ("Quadrige»), 2010, p. 268). L'exotisme assure une évasion et transforme parfois la terre étrangère en lieu de fantasme, comme c'est souvent le cas pour l'Orient. L'ouverture d'esprit et la volonté de transmettre au lecteur la réalité de l'altérité (c'est la définition d'Emmanuèle Baumgartner, "L'exotisme à rebours dans la Chanson d'Antioche", in L'exotisme dans la poésie épique française, dir. Aniko Kalmar, Paris, L'Harmattan, 2003, p. 13-28) ne se rencontre que peu dans la littérature médiévale, si ce n'est chez Marco Polo, dans ses descriptions de la Chine. Le rapport à l'altérité se caractérise bien plus au Moyen Âge par le fantasme et l'imaginaire: l'Autre est rendu monstrueux, effrayant, merveilleux, cruel. On peut donc s'en tenir à la description générale que donne Jean-Marc Moura: «D'une manière générale, on entendra donc par exotisme une rêverie qui s'attache à un espace lointain et se réalise dans une écriture.» (Jean-Marc Moura, Lire l'exotisme, Paris, Dunod, 1992, p. 4). Voir, au sujet de l'exotisme dans l'épopée, Aniko Kalmar (éd.), L'exotisme dans la poésie épique française, Paris, L'Harmattan, 2003. 
Il n'est pas anodin que Dominique Boutet définisse la catégorie du merveilleux d'altéritée ${ }^{711}$ par la "contamination arthurienne»: ce type de merveilleux est en effet un élément distinctif du roman arthurien. Le miracle divin n'y intervient pas, à moins que, comme dans Escanor, il ne soit au service d'une poétique de la confluence - voir infra, chapitre III, "Imitation ponctuelle: Escanor et le miraculeux», p. 595-610. Les romans arthuriens se classent ainsi dans la catégorie des fabula, pour reprendre la hiérarchie de Jean de Garlande. Cette association entre roman arthurien et fabula est courante chez les auteurs médiévaux: nous avons déjà cité la traduction des Dialogues de saint Grégoire, qui traite les récits sur Perceval et Lancelot de "trufle et menchonge ${ }^{272}$, et le prologue du Roman du comte d'Anjou, qui qualifie les histoires de Gauvain, Tristan, Perceval et Lancelot de "bourdes", "fables», "trufles» ou "mençonge ${ }^{273}$. En ce contexte, introduire des merveilles revient à admettre le caractère fictionnel de son récit. Comme l'explique Francis Gingras, «choisir de "conter merveilles" s'apparenterait donc à une façon détournée d'assumer le statut fictif de sa narration, de l'assimiler à l'invraisemblable fabula $»^{274}$.

Le roman arthurien n'est toutefois pas le seul genre à faire intervenir du merveilleux d'altérité: la chanson de geste n'en est pas exempte, elle qui intègre des fées marraines, des objets magiques et divers monstres ${ }^{275}$. Le merveilleux y est parfois même plus explicite que dans le roman, que l'on pense aux pouvoirs des créatures merveilleuses, Auberon dans Huon de Bordeaux notamment, capable d'apparaître au son d'un cor. Dans le

271 Voir aussi Christine Ferlampin-Acher, Merveilles et topique merveilleuse, pour une définition du merveilleux et les modalités de ses manifestations littéraires.

272 «Dieu ne veut que nul homme lot / Ne Parcheval ne Lancelot, / Quar tout n'est fors trufle et menchonge. / Un coquart le trouva en songe / Qui folie fete en a / Que les menchonges ordena.", Le Dyalogue Saint Gregore: les dialogues de Saint Grégoire le Grand, v. 45-50.

273 Jean Maillart, Roman du comte d'Anjou, éd. cit., v. 1-37.

274 Francis Gingras, Le Bâtard conquérant, p. 285. Voir aussi son article, «Le roman à l'épreuve des fées", art. cit.

275 On peut citer comme exemple Tristan de Nanteuil, pour lequel Dominique Boutet recense cent quinze passages merveilleux. "Merveilleux et interférences génériques dans la chanson de geste de Tristan de Nanteuil», art. cit. Le cor merveilleux relève en particulier du merveilleux païen. On trouve de tels motifs dans Huon de Bordeaux également. Dans La Bataille Loquifer, dont nous traiterons au chapitre I, "Voyages génériques du roi Arthur», p. 182-195, les sirènes, le monstre Chapalu et les fées convoquent aussi un merveilleux d'altérité explicite. 
roman arthurien, la mise en scène de pouvoirs magiques est plus rare et bien souvent, les fées sont identifiées comme des êtres de l'Autre Monde par un processus et des indices topiques et convenus (passage d'un cours d'eau, apparition d'un animal blanc, bruit assourdissant, etc. ${ }^{276}$. Ce genre est néanmoins le prototype de la fabula, du récit mensonger, de l'affabulation, dans les représentations médiévales - si l'on en croit les divers témoignages que nous avons cités. Pour la chanson de geste, la critique est plus encline à privilégier une réception historique, le genre reposant sur le récit de guerres réelles - ou du moins vraisemblables. Ce constat démontre à quel point le genre contraint notre réception: l'association entre merveilleux et roman va de soi pour tout lecteur, probablement même médiéval, alors que d'autres genres le mettent également en scène. Le surnaturel de la geste retient donc moins l'attention que celui du roman, quelles que soient ses proportions: le public adapte sa réception du surnaturel en fonction du genre dans lequel s'inscrit le texte. Cela confirme bien que «le genre est [...] l'un des éléments - sans doute le plus important - qui composent le "pacte" passé entre destinateur et destinataire $»^{277}$.

\section{Histoire, mythe, fiction}

La réception historique dont bénéficie la chanson de geste pourrait pourtant aussi bien concerner le roman arthurien. Le roi Arthur est effectivement perçu comme une figure historique au Moyen Âge et apparaît dans plusieurs historiographies: il intervient dans les deux catégories de la fabula et de l'historia. Historiographie et roman mélangent tous deux événements réels et invention; de même, le récit historique emprunte au roman ses techniques et recourt à l'imaginaire. Dès lors, «la distinction entre narration romanesque et narration historique est ténue, car les mêmes techniques formelles, les mêmes procédés d'enchaînement, les mêmes motifs sont utilisés ${ }^{278}$. Wace, dans Le Roman de Brut, translation

\footnotetext{
276 À ce sujet, voir Christine Ferlampin-Acher, "Merveilles» et topique merveilleuse.

277 Gisèle Mathieu-Castellani, «La notion de genre», in La notion de genre à la Renaissance, dir. Guy Demerson, Genève, Slatkine, 1984, p. 29.

278 Catherine Croizy-Naquet, "Écrire l'histoire: le choix du vers ou de la prose aux $\mathrm{XII}^{\mathrm{e}}$ et XIII ${ }^{\mathrm{e}}$ siècles", in Linvention de l'histoire, éd. Christopher Lucken et Mireille Séguy, Paris, PUV («Médiévales», 38), 2000, p. 74. Voir aussi «Imaginaire et histoire. Deux historiographies à l'épreuve», in Paysages de l'imaginaire: bilans et perspectives, PRIS MA, t. XXV/1 et 2, 51-52, janv.-déc. 2010, p. 117-130.
} 
en langue romane de l'Historia Regum Britaniae, ne se prive pas d'insérer des données fictionnelles voire merveilleuses au recensement des règnes bretons, malgré la démarche d'historien qu'il adopte ${ }^{279}$; en rapportant des faits qui s'appuient sur une source qui sert d'autorité, en se référant à un passé situable dans le temps et en suivant un déroulement chronologique. Wace donne un rôle amplifié à Arthur et à son règne, en enchérissant sur les événements qui lui sont liés. Il insiste ainsi sur l'atmosphère courtoise, qui deviendra dans les romans le propre de la cour arthurienne, et invente la Table Ronde, créée au retour d'Arthur après la conquête de l'Écosse et de la Scandinavie; cette précision temporelle lui donne un surcroît de crédibilité, mais l'information demeure néanmoins une extrapolation.

Comme l'explique Dominique Boutet, «l'historien médiéval [...] avait le pouvoir de réinventer le passé» ${ }^{280}$, le public et les confrères historiens n'ayant que peu la possibilité de vérifier les affirmations. Si les ajouts d'éléments fictifs paraissent aujourd'hui transgresser les fondements de l'écriture de l'Histoire, ils servent au Moyen Âge à mieux transmettre le contenu réel: ils se font le support d'une idée à véhiculer, d'un modèle à fournir. La Table Ronde, bien que fictive, métonymise le rôle politique d'Arthur, qui ne se réduit plus, dans le Brut, à son statut de chef de guerre. Wace diffuse l'image d'un roi soucieux de la cohésion de sa cour. L'existence réelle de la Table Ronde n'a dès lors que peu d'importance,

279 Sur les ajouts de Wace par rapport à Geoffroy de Monmouth, voir Françoise Le Saux et Peter Damian-Grint, "The Arthur of the Chronicles", in The Arthur of the French: The Arthurian Legend in Medieval French and Occitan Literature, éd. Glyn S. Burgess et Karen Pratt, Cardiff, University of Wales Press, 2006, p. 93-111, Jean Frappier, "La matière de Bretagne: ses origines et son développement", in Grundriß der romanischen Literaturen des Mittelalters. Le Roman jusqu'à la fin du XIII siècle, VI/1, Heidelberg, Carl Winter, 1978, p. 183-211. Laurence MatheyMaille nuance la portée romanesque du merveilleux du Brut: Wace n'y a recours que dans une visée démonstrative, qui reste donc compatible avec le projet de l'historien. Elle note également que le clerc renonce à rapporter les merveilles liées aux douze ans de paix du règne d'Arthur, de même qu'il révèle sa déception, lorsque, dans le Roman de Rou, il raconte ne pas avoir trouvé les merveilles qu'il cherchait dans la forêt de Brocéliande (éd. Anthony J. Holden, t. 2, 1973, v. 63936395). Voir son article, "Le Roman de Brut de Wace à l'épreuve du merveilleux", in Motifs merveilleux et poétique des genres au Moyen Âge, p. 165-174. Dominique Boutet traite de l'ambiguïté générique des historiographies, et notamment du Brut dans Poétiques médiévales de l'entre-deux ou le désir d'ambiguité, p. 256-278.

280 Dominique Boutet, Formes littéraires et conscience historique, p. 26. 
l'image qu'elle construit d'Arthur étant, elle, avérée, de même que son potentiel d'idéalisation du monde féodal ${ }^{281}$. La fiction permet surtout la dramatisation du texte et favorise la réception par le public, comme le fait remarquer Catherine Croizy-Naquet au sujet des Faits des Romains:

L'important n'est pas seulement de connaître avec précision les événements relatés, mais de les percevoir, d'appréhender leur sens réel et les leçons qu'ils peuvent receler, l'œuvre historique étant conçue comme une œuvre de savoir et de sagesse. Or, comment mieux faire appréhender la réalité qu'en adaptant les faits sinon à un public, du moins à la mentalité propre à l'époque de la compilation? Pour être transmise, l'histoire est ainsi nourrie de fiction, et la fiction qui naît de l'arrière-plan littéraire occidental et médiéval est une mise en scène de l'histoire ${ }^{282}$.

La fiction permet l'actualisation de l'Histoire, sa traduction pour un public médiéval, elle

doit rendre la «dimension vécue» du passé pour un public soucieux de comprendre mais aussi de «sentir». [...] Elle sert à reconstruire la dimension "visible» d'un passé dont les vestiges sont lacunaires et à créer de la continuité dans ce lacunaire ${ }^{283}$.

Elle se présente ainsi comme un instrument de fabrication de mythes: le mythe prête à un peuple une origine prestigieuse et valorisante, mettant en scène des dieux ou des personnages merveilleux qui se transforment en héros idéaux; cela ne signifie pas que les mythes n'ont pas une base réelle ni qu'ils sont totalement admis par le public. Le but des mythes est de justifier et d'expliquer le réel par l'imaginaire. C'est ce que définit Dominique Boutet:

281 Le cinéma actuel n'hésite pas non plus à adapter les films historiques au public contemporain pour mieux l'intéresser et mieux transmettre l'Histoire, que l'on songe par exemple à la Cléopâtre de Joseph Mankiewicz (1963), qui tantôt trahit et tantôt respecte les données historiques.

282 Catherine Croizy-Naquet, «Quand la fiction se mêle à l'histoire: un combat dans les Faits de Romains", CRM, 5, 1998, p. 67-68.

283 Catherine Croizy-Naquet, "Penser l'histoire antique au XIII ${ }^{\mathrm{e}}$ siècle à la lumière de l'historiographie contemporaine", Littérature. Le Moyen Âge contemporain. Perspectives critiques, dir. Nathalie Koble et Mireille Séguy, Paris, Larousse, 148, 2007, p. 42. 
Ils retracent les angoisses d'une civilisation devant son propre destin et veulent se présenter soit comme une justification de l'essence de la société présente, soit comme un rappel de son histoire exemplaire, un récit des origines. Derrière la société se profile l'ordre du monde qui la dépasse et lui donne son sens. On pourrait, dès lors, définir le mythe comme un récit, une image, un ensemble de récits ou d'images par quoi une société exprime ses interrogations et ses terreurs, pour les remodeler en certitudes ${ }^{284}$.

Le mythe traduit l'essence d'une collectivité; il résulte de l'ethos de la société qui l'a fait naître et l'a propagé. On peut ainsi le lire comme «le miroir dans lequel une collectivité contemple son reflet [...] sur un mode imagé et symbolique ${ }^{285}$. Le mythe suppose la transposition de faits, fictifs ou historiques, dans la réalité contemporaine, destinée à susciter l'admiration du public et à illustrer une situation propre à l'époque de composition du récit mythique ${ }^{286}$. Il se situe sur un autre niveau que la réalité profane, dans «un espace privilégié et un temps cyclique, [jouissant], lui, de la plénitude ontologique ${ }^{287}$. Il se distingue de la légende en ce sens que celle-ci rapporte «des événements authentiques mais embellis et devenus invérifiables ${ }^{288}$, comme le sont à l'origine les vies de saints ou la vie de Jeanne d'Arc. La légende devient mythique lorsqu'elle revêt une

284 Dominique Boutet, "Introduction", in Pour une mythologie du Moyen Âge, dir. Laurence Harf-Lancner et Dominique Boutet, Paris, ENS, 1988, p. 95 . Voir aussi Charlemagne et Arthur ou le roi imaginaire, Paris, Champion, 1992.

285 Citation tirée d'un descriptif de l'exposition "Je suis ton père!» à la Maison d'Ailleurs à Yverdon, du 10.12.2017 au 14.10.2018. Voir le catalogue par Marc Atallah, Alain Boillat et Frédéric Jaccaud, Je suis ton père! Origines et héritages d'une saga intergalactique, Paris; Yverdon, Huginn et Muninn («Fantask»); Maison d'Ailleurs, 2017, p. 9-11.

286 Philippe Sellier distingue mythe ethno-religieux et mythe littéraire, le premier étant tenu pour vrai tandis que pas le second. Le mythe littéraire est un récit repris par plusieurs auteurs, dont l'organisation est exceptionnellement ferme. Il s'appuie sur des organisations symboliques qui font surgir des fantasmes universels chez l'homme. Le mythe suppose encore un éclairage métaphysique. Voir Philippe Sellier, "Qu'est-ce qu'un mythe littéraire?", art. cit.

287 Thomas Pavel Univers de la fiction, Paris, Seuil, 1988, p. 99.

288 Isabelle Laudouar, "Légende», in Dictionnaire du littéraire, Paris, PUF ("Quadrige»), 2010, p. 420. 
portée universelle ${ }^{289}$, évocatrice pour le public, sur le plan moral ou philosophique. La Table Ronde est un mythe, car elle prend racine dans des données pseudo-historiques tout en s'actualisant dans la contemporanéité médiévale pour symboliser une féodalité idéale. De la même manière, comme l'explique Michel Zink,

[Arthur] est un mythe, car lui-même et les récits qui s'organisent autour de lui ont été placés dans un passé lointain pour marquer l'origine et justifier l'existence d'un certain ordre et de certaines valeurs, ceux du monde chevaleresque. [...] Mais il n'est pas emprunté à la mythologie proprement dite, à peine à l'histoire, de façon douteuse au folklore. C'est une création presque complète de la littérature ${ }^{290}$.

On constate avec le personnage d'Arthur à quel point les mythes n'existent, au Moyen Âge, que par la littérature: Arthur resterait un personnage de chronique oublié, s'il n'était pas actualisé dans le roman ${ }^{291}$. La part d'embellissement due à la fiction adjointe au mythe apparaît moins comme un mensonge que comme la traduction d'une vérité signifiante, non pas la vérité des faits mais celle du symbole, dans son caractère édifiant.

Le recours à la fiction ne remet donc pas en cause l'appartenance des textes au genre de l'historiographie ${ }^{292}$. Dans ces conditions, la distinction entre les genres romanesque et historiographique paraît difficile. L'ambiguïté est encore plus étonnante dans le manuscrit BnF fr. 1450,

289 Pierre Albouy, Mythes et mythologies dans la littérature française, Paris, Armand Colin, 1981, p. 10-11.

290 Michel Zink, "Arthur", in Dictionnaire des mythes littéraires, dir. Pierre Brunel, Monaco, Éditions du Rocher, 1988, p. 193.

291 Au sujet de l'importance de la littérature pour la formation des mythes, voir Dominique Boutet, "Introduction", in Pour une mythologie du Moyen Âge.

292 Nous ne nous arrêtons pas sur les distinctions entre les genres de l'historiographie, la chronique, l'annale et l'histoire, et nous renvoyons aux travaux de Bernard Guenée sur le sujet, «Histoires, annales, chroniques. Essai sur les genres historiques au Moyen âge", Annales E.S.C., 1973, p. 997-1016, et Histoire et culture historique dans l'Occident médiéval, Paris, Aubier Montaigne, 1980, et à l'article de Paul Zumthor, "Roman et histoire», art. cit. Notons simplement que la stylisation du récit, la restitution du fait par un témoin oculaire ou contemporain, le respect de la chronologie ou l'adoption d'un point de vue critique sont des critères distinctifs de ces genres historiographiques. 
qui interrompt le Roman de Brut pour insérer les œuvres de Chrétien de Troyes au moment où Wace évoque les merveilles pruvees, mélangeant ainsi la temporalité linéaire de la chronique et la temporalité cyclique du roman, la figure d'un Arthur historique et conquérant à celle d'un roi statique:

En cele grant pais que jo di

Ne sai se vos l'avés oï

Furent les mervelles provees

Et les aventures trovees

Qui d'Artu sont tant racontees

Que a fable sont atornees

Ne tot mençonge, ne tot voir,

Tot folie ne tot savoir;

Tant ont li conteor conté

Et par la tere tant fablé

Por faire contes delitables

Que des verités ont fait fables.

Mais ce que Crestïens tesmogne

Porés ci oïr sans alogne. (folio $139 \mathrm{vc})^{293}$

Ce passage illustre la possibilité d'intégrer dans le récit du règne d'Arthur des merveilles provees, expression oxymorique qui semble désigner des événements merveilleux acceptés comme véridiques, pour autant qu’ils sortent d'une imagination agrégée: certaines merveilles sont fausses, d'autres sont vraies, selon le conteur qui les rapporte. Comme le souligne Francis Gingras, l'adversatif «mais» et le verbe "tesmogne» de l'ajout propre au BnF fr. 1450 placent en effet les œuvres du maître champenois en opposition avec les faux conteurs et la fable ${ }^{294}$. Lancrage historique

293 Les deux vers en italique sont propres au manuscrit BnF fr. 1450.

294 Francis Gingras, "Tant con durra crestiantez", art. cit., p. 73. Voir les pages 72-75 sur le manuscrit BnF fr. 1450. Michel Zink souligne que ces vers de Wace laissent aussi supposer que son propre Roman de Brut est une composition enjolivée et partiellement fictive. "Chrétien et ses contemporains", art. cit., p. 15-16. Danièle James-Raoul traite de ce passage aux pages 270-271 de Chrétien de Troyes, la griffe d'un style, Paris, Champion, 2007. Ces vers délivrent «les coordonnées spatiotemporelles, le royaume d'Arthur en temps de paix, un contenu, d'aventures et de merveilles, une essence littéraire, mixte de fiction et de vérité.» (p. 71) Autrement dit, ces douze ans de paix sont chronotopiques au sens bakhtinien du terme: le cadre spatio-temporel est générateur d'action, d'échanges entre monde réel et 
du roi Arthur, avant sa récupération romanesque, contribue à donner l'illusion de la vérité: le personnage ayant existé, les aventures auraient pu potentiellement se produire sans que les chroniques les aient restituées. C'est au roman que revient cette tâche.

Le personnage d'Arthur sert dans ce cas de caution d'authenticité. Ce rôle ne se maintient néanmoins pas à toute occasion: même s'il est présenté comme historique et référentiel dans la chronique, Arthur devient un personnage fictionnel par ses réactivations romanesques. Les auteurs de romans lui prêtent petit à petit des caractéristiques et une fonction narrative qui se pérenniseront dans le genre et qui le distingueront du personnage historique. Les fables que l'on raconte à son sujet contribuent à dissimiler ses apparitions romanesques de ses apparitions historiographiques: l'Arthur romanesque est le résultat d' "une broderie fictionnelle faite à partir d'un canevas historique ${ }^{295}$. Ce processus est explicité par Marie-Laure Ryan au sujet de Napoléon, à partir de sa théorie des mondes possibles:

Since the function of names, in a PW [possible world] model, is to pick one and only one individual in every PW [possible world] where this individual exists, the same name can refer to individuals in different worlds with different properties: in world 1, Napoleon loses the battle of Waterloo; in world 2 (perhaps created by a novelist), he wins; in world 3, he never leaves his native Corsica. All these Napoleons are linked to each other by counterpart relation ${ }^{296}$.

Napoléon, transposé dans un monde fictif, celui du roman Guerre et paix par exemple, devient la contrepartie ${ }^{297}$ du Napoléon historique, étant entendu qu'il s'agit de mondes possibles différents. Il en va de même du

monde fictionnel. Voir Mikhail Bakhtine, Esthétique et théorie du roman. Nous reviendrons plus en détails au chapitre II, "Choix de forme, choix de chronotope», p. 242-325, sur l'application du chronotope au roman arthurien.

295 Patrick Moran, Lectures cycliques, p. 115.

296 Marie-Laure Ryan, "Possible Worlds", The living handbook of narratology, dir. Peter Hühn et al., Hamburg, Hamburg University Press, en ligne: http://wikis. sub.uni-hamburg.de/lhn/index.php/Possible_Worlds, $\$ 36$.

297 On doit à David Lewis la définition de la «contrepartie» en philosophie modale, fondée sur la similarité entre des individus de mondes possibles différents, partageant des caractéristiques essentielles. Voir «Counterpart Theory and Quantified Modal Logic", The Journal of Philosophy, 65/5, 1968, p. 113-126. 
roi Arthur au Moyen Âge. Le personnage historique n'existe que dans le monde réel mais il a des contreparties dans d'autres mondes, fictionnels en l'occurrence, qui lui ressemblent mais ne sont pas lui. Même si l'on sait aujourd'hui que le personnage du roi Arthur est une construction élaborée à partir d'un possible guerrier breton, il faut envisager qu'il existe pour les médiévaux un Arthur historique, celui que présente l'Historia Regum Britanniae. L'ontologie du personnage diffère selon le type de discours, suivant qu'il prend appui sur le personnage historique ou sa contrepartie: dans un livre d'histoire, Napoléon ne sera pas traité de la même façon que dans un roman. Arthur fait lui aussi l'objet de discours concurrents qui coexistent: plusieurs historiographes reprennent le Brut, en vers ou en prose, et ne réactivent pas le modèle que le roman donne du roi Arthur $^{298}$. Le genre, en tant qu'il élabore un monde de référence textuel, dicte donc bien le comportement, les attributs et la fonction d'Arthur, différents selon le type de texte narratif, nous le verrons encore avec les épisodes avaloniens des chansons de geste. Ce constat permet d'anticiper le problème que posera l'application du concept de transfictionnalitée 299 au roman arthurien: la transfictionnalité s'applique exclusivement à la fiction. Les livres d'histoire traitant de Napoléon ne peuvent donc pas être considérés comme transfictionnels, au vu de la référentialité du personnage concerné. Nous admettrons au même titre une distinction entre un Arthur historique dans l'historiographie et un Arthur fictionnel dans le

298 François Le Saux, "The Arthur of the Chronicles», art. cit., p. 104. Voir aussi Pierre Courroux, "Le règne d'Arthur vu par des chroniqueurs de langue française aux XIV ${ }^{\mathrm{e}}-\mathrm{XV}^{\mathrm{e}}$ siècles (hors Bretagne continentale)", in Arthur après Arthur, p. 249-263, qui souligne que «bien souvent, les historiens feignirent d'ignorer les ajouts des œuvres fictionnelles» (p. 249). Michel Zink traite des échanges entre Histoire et fiction pour le personnage d'Arthur dans "Arthur", in Dictionnaire des mythes littéraires, Michelle Szkilnik problématise cette opposition entre personnage d'Histoire et personnage de roman pour César, dont elle montre qu'il résiste à la transposition romanesque et demeure un personnage historique convoqué à l'occasion pour son exemplarité. "César est-il un personnage de roman? Du Perceforest au Jouvencel", Cahiers de recherches médiévales, 13, 2006, p. 77-89.

299 Voir infra, p. 133ss. Nous renvoyons déjà à la théorie de Richard Saint-Gelais, Fictions transfuges. La transfictionnalité et ses enjeux, Paris, Seuil, 2011. Barbara Wahlen, L'Écriture à rebours. Le Roman de Méliadus du XIIT au XVIIt siècle, Genève, Droz, 2010, p. 21-38, et Noémie Chardonnens, L'Autre du même: emprunts et répétitions dans le Roman de Perceforest, Genève, Droz, 2015, p. 62-75, ont chacune donné les bases d'une application du concept à la littérature médiévale. 
roman, qui en est la contrepartie, ce qui facilite l'analyse de la transfictionnalité sur ce corpus. S’il s'agit bien du même personnage que dans la chronique, il se transforme quelque peu une fois transposé dans un autre univers.

\section{Le travail des sources}

Le rapport aux sources est un autre facteur de distinction entre historiographie et roman. L'historiographie se fonde sur une autorité présentée comme telle: que ce soit un témoignage oculaire, jugé digne de crédit, ou une source écrite, l'historien rassemble des sources fiables qu'il compile et auxquelles il réfère de temps à autre. L'usage des sources est génériquement marqué300, comme le prouve la différence que Benoît de Sainte-Maure établit lorsqu'il écrit une chronique ou un roman. Alors que dans la Chronique des ducs de Normandie, il affirme la fidélité à la source ("Tant puis bien dire sanz mentir, / Translatee ai l'estoire et dite / D'eissi cum l'ai trovee escrite / N'ai mis fauseté ne mençonge») ${ }^{301}$, dans le Roman de Troie, l'auteur admet qu'il ne se privera pas d'ajouter "aucun buen dit» (v. 142) ${ }^{302}$ à son modèle, s'il sait le faire. Le respect de la letre ( Le latin sivrai e la letre; / Niul autre rien n’i voudrai metre / S'ensi non cum jel truis escrit.», v. 139-141) se double d'un savoir-faire rhétorique, embellissant l'Histoire. La fiction est ici le moyen de mettre en forme le contenu historique, sans en trahir le fond. Lappui sur les sources fait des romans antiques un genre proche de l'historiographie: s'ils revendiquent la véracité des faits, la proportion d'éléments fictionnels voire merveilleux dépasse néanmoins celle qui agrémente les chroniques ou estoires ${ }^{303}$, si

300 Voir Emmanuèle Baumgartner, "Texte de prologue et statut du texte», in Essor et fortune de la chanson de geste dans l'Europe et l'Orient latin. Actes du IX' Congrès international de la Société Rencesvals, vol. 2, "Rapports entre chanson de geste et roman au XIII siècle», Modena, Mucchi, 1984, p. 470-471.

301 Benoît, Chronique des ducs de Normandie, éd. Carin Fahlin, Uppsala, Almqvist, 1951, tome 2, v. 42034-42037.

302 Benoît de Sainte-Maure, Le Roman de Troie, éd. Emmanuèle Baumgartner, Paris, Le Livre de Poche («Lettres gothiques»), 1998.

303 Sur ce terme et ses emplois, voir Peter Damian-Grint, "Estoire" as word and genre: meaning and literary usage in the twelfth century", Medium Aevum, 1997, 66, p. 189-206. Le mot "estoire» désigne la source et parfois le récit lui-même. Le texte qu'il caractérise est bien souvent d'ordre historiographique. 
bien que l'on peut parler de genre "para-historique», ainsi que le propose Catherine Croizy-Naquet ${ }^{304}$. Le degré de complexité de l'élaboration littéraire distingue en tous cas les romans antiques des chroniques, malgré leur rapport étroit à la source latine. La conception du temps y est différente: le roman ne suit pas le pur écoulement chronologique, mais élabore une structure apte à faire émerger le sens et à toucher les lecteurs.

Dans le roman arthurien, le renvoi à une source est fictif: dans la prose, la narration est parfois déléguée à un "conte» qui raconterait lui-même l'histoire, comme dans la formule "or dist li contes", où il se trouve en position de sujet. Le contes ne désigne pas seulement la source, mais également le récit en train de se créer et de se raconter. Les allusions au conte sont donc performatives ${ }^{305}$. Les nombreuses apparitions du conte dans le roman en prose ont été interprétées comme la marque de l'effacement du narrateur. Emmanuèle Baumgartner, Sophie Marnette et Annie Combes ont pourtant montré que le narrateur n'intervient pas moins dans la prose que dans le vers. Le renvoi au conte a pour fonction de délimiter des séquences narratives et d'organiser l'entrelacement ${ }^{306}$, tandis que le narrateur conserve ses attributions, c'est-à-dire

énoncer, garantir, modaliser la narration là où précisément elle ne coule pas de source, assurer la communication avec l'auditoire, soit sous la forme d'une simple adresse («si com vous avés oï») soit en insistant sur l'importance du message avec le recours à la formule, si fréquente dans l'ensemble du roman arthurien en prose, "et sachiés que $»^{307}$.

304 Voir son article, «Imaginaire et histoire. Deux historiographies à l'épreuve», art. cit.

305 Voir Sophie Marnette, Narrateur et points de vue dans la littérature française médiévale: une approche linguistique, Berne, Peter Lang, 1998, p. 44-46.

306 Emmanuèle Baumgartner définit l'entrelacement comme suit: «L'entrelacement consiste [...] à disposer le long d'un même segment temporel (par exemple une quête d'un an... ou de dix) les aventures de plusieurs chevaliers. Aventures que le récit relate successivement, bien entendu, mais en les interrompant chacune à des moments cruciaux et ce jusqu'au point où les différentes aventures/les différents personnages convergent/se retrouvent dans un même espace.» («Les techniques narratives dans le roman en prose», art. cit., p. 177-178.) Nous y reviendrons au chapitre III.

307 Emmanuèle Baumgartner, "Les techniques narratives dans le roman en prose», art. cit., p. 177. Voir les études du narrateur de Sophie Marnette, Narrateur et 
Le conte représente une instance narrative neutre, qui garantit la vérité et l'objectivité du récit. Malgré le caractère fictif de ce "conte», il faut admettre avec Emmanuèle Baumgartner que «tous les romans du Graal en prose se donnent à lire comme les translations d'un livre source dont le contenu est, à des titres divers, parfaitement authentifié, certifié. Leur texte est ainsi toujours un dérivé de... et non une création à part entière ${ }^{308}$. Le je du roman en prose est le relai d'une source authentifiée, et non un créateur. L'épilogue de la Queste del saint Graal est en ce sens particulièrement éloquent. Un nom d'auteur, Gautier Map, apparaît, mais son rôle est celui du translateur:

Et quant Boorz ot contees les aventures del Seint Graal telles come il les avoit veues, si furent mises en escrit et gardees en l'almiere de Salebieres, dont Mestre Gautier Map les trest a fere son livre del Seint Graal por l'amor del roi Henri son seignor, qui fist l'estoire translater de latin en françois ${ }^{309}$.

L'illusion de l'authenticité assure les distinctions entre roman en vers et roman en prose.

Chrétien de Troyes s'appuie lui aussi sur un «conte d'aventure» (Erec et Enide, v. 13) vague et jamais mieux caractérisé. Il n'est toutefois pas repris de manière significative pour structurer le roman, comme c'est le cas pour la prose. La véridicité du récit en vers repose beaucoup moins sur une source invoquée que sur l'autorité du narrateur, désigné «comme étant à l'origine du sens du récit ${ }^{310}$, ce que le narrateur de la prose n'est pas. Contrairement à ce qu'il se passe dans le roman antique, le terme «estoire» (Erec et Enide, v. 23) ne désigne plus la source, mais l'œuvre elle-même, tournée vers l'avenir, l'aventure ${ }^{311}$. L'œuvre n'est plus vouée

points de vue dans la littérature française médiévale, et d'Annie Combes, Les voies de l'aventure. Réécritures et composition romanesque dans le Lancelot en prose.

308 Emmanuèle Baumgartner, "Les techniques narratives dans le roman en prose», art. cit., p. 174. La critique exclut la Mort Artu de ce constat: l'auteur y affirme au contraire inventer une fin au monde arthurien à la demande du roi Henri.

309 La Queste del saint Graal, éd. Albert Pauphilet, Paris, Champion ("CFMA»), 2003, p. 279-280.

310 Sophie Marnette, Narrateur et points de vue dans la littérature française médiévale, p. 113.

311 Cette idée et l'importance de ce prologue dans la définition du genre romanesque sont développées par Francis Gingras, "Comment présenter un genre qui n’existe 
à rapporter des faits antérieurs, mais elle sera elle-même conservée par la mémoire et transmise à la postérité («l'estoire que toz jors mais iert en memoire», Erec, v. 23-24). Lorsque le terme "estoire» se réfère à la source, il faut plutôt comprendre un modèle rhétorique qu'un contenu à véhiculer: "Lisant trovomes en l'estoire / La descriction de la robe /Si en trai a garant Macrobe» (Erec, v. 6728-6730). D'autres versions proposent "Quinqueculce», Quinte-Curce, à la place d'"estoire», historien antique qui invoque lui-même l'autorité de Macrobe. Macrobe fournit ici à Chrétien de Troyes non pas le contenu de la description, mais la manière rhétorique de la mener. L'estoire, qui alterne avec Quinte-Curce, pourrait tout autant désigner la source d'un savoir-faire.

La fidélité à la source ne fait pas partie des revendications des romanciers. Il arrive toutefois qu'une source soit évoquée, mais celle-ci reste virtuelle, jamais intitulée ni caractérisée. Il s'agit de chevilles rhétoriques créant une illusion d'authenticité. Ainsi le substantif «estoire» qualifie à nouveau le modèle à l'origine de Floriant et Florete: "ce l'estoire ne ment" (v. 6452 et 6586), «si com l'estoire nous raconte» (v. 8008). Rien ne vient pourtant préciser la nature de cette estoire: il s'agit d'un pur effet de style, comme le sont aussi les renvois à une source écrite: "En escrit truis ci en ceste oevre / Si con li contes le descuevre (Escanor, v. 61-2), «Si com tesmoigne li escris» (Biaudouz, v. 25). Dans Biaudouz, la source est caractérisée plus nettement, par le recours au topos du manuscrit trouvé dans une abbaye ${ }^{312}$ :

Ce sachiez, n'est pas controvure,

Ainz est tot estrait d'escriture.

A Tors, ou mostier Sain-Martin,

Le trovai escrit en latin. (Biaudouz, v. 31-34)

Robert de Blois tente de donner une légitimité à son texte en le prétendant issu d'une source latine, conservée dans un monastère. L'écrit, le latin et le lieu de la trouvaille, authentifié par le nom, contribuent à rendre le

pas?", art. cit., et "Roman et translation», in Le Bâtard conquérant. Voir aussi Michel Zink, "Chrétien et ses contemporains», art. cit.

312 Emmanuèle Baumgartner, "Du manuscrit trouvé au corps retrouvé», in Le topos $d u$ manuscrit trouvé: actes $d u$ colloque international, Louvain-Gand, 22-23-24 mai 1997. Hommages à Christian Angelet, dir. Jan Herman et Fernand Hallyn, Louvain; Paris, Peeters, 1999, p. 1-14. 
présent récit digne de confiance et à favoriser l'adhésion du lecteur: ce qu'on s'apprête à lui raconter est sérieux. La suite ne le démentira pas: Biaudouz est bien destiné à délivrer un code de conduite conforme à la morale que pourrait véhiculer le «mostier Sain-Martin».

\section{Fictions assumées}

L'affirmation de vérité, garantie par une source fictive ou non, reste un lieu commun dans le roman, ce qui pourrait potentiellement mener à la confusion avec les genres de l'Histoire ${ }^{313}$. Les auteurs risquent ainsi la contradiction avec la mise en scène assumée de mirabilia, paradoxe que soulève Yasmina Foehr-Janssens:

Des «merveilles prouvées», telle pourrait bien être une définition assez roborative du roman à ses débuts, tant l'argument de la valeur historique du contenu narratif est sollicité avec insistance alors même que la volonté de produire des «merveilles» apparait comme une des raisons d'être du genre ${ }^{314}$.

Le recours à la fiction remplit néanmoins des visées différentes dans l'historiographie ou le roman: celui-ci l'utilise pour délivrer un sens. L'œuvre romanesque ne renvoie pas à une réalité extérieure à elle-même, mais la vérité doit émerger exclusivement du décryptage de la fiction, comme l'explique Paul Zumthor:

Autrement dit, dans l'épopée et dans l'historiographie, vraisemblance et vérité coïncident; dans le roman, la vraisemblance s'établit au niveau d'un enseignement, c'est-à-dire de la transmission d'un sens. «Je dis vrai» signifie ici "Je livre un sens». [...] La découverte d'un sens second exige une interprétation, et le narrateur intégrera à son texte, de quelque manière, des indices qui en suggèrent les modalités ${ }^{315}$.

313 Paul Zumthor souligne toutefois que l'affirmation de vérité est plus un effet de vraisemblance dans le roman qu'une réelle revendication. "Roman et histoire», art. cit., p. 246.

314 Yasmina Foehr-Janssens, "Une merveilleuse clergie. Pouvoirs et savoirs insolites dans le Roman des Sept Sages en vers", in Motifs merveilleux et poétique des genres au Moyen Âge, dir. Francis Gingras, Paris, Garnier, 2015, p. 407.

315 Paul Zumthor, "Roman et histoire», art. cit., p. 246-247. 
La véracité est donc perçue différemment et ne désigne pas des événements effectivement advenus dans le passé: c'est le message à transmettre et sa résonance dans le réel, son potentiel effet sur la vie humaine, qui sont véridiques, comme peuvent l'être, à un autre niveau de sens, les paraboles bibliques.

C'est en ces termes qu'il faut comprendre la conception du vraisemblable transmise par le narrateur de Rigomer: "Conter et acointier vos vuel / Une aventure si raisnable / Que bien puet estre veritable» (v. 12074-12076). L'aventure est «raisonnable, valable, légitime» («raisnable» $)^{316}$ et donc digne d'être racontée; elle est assez exemplaire pour comporter une part de vraisemblance ou de vérité, un sens que percevront les auditeurs/lecteurs. Le sens romanesque renvoie donc au texte et non à la réalité extra-textuelle: «S'il y a une vérité de l'aventure humaine, elle se réfere désormais à ce qu'en dit la poésie, non l'histoire. ${ }^{317}$ Le prologue d'Escanor laisse transparaître cette signification de la vérité:

Por coi il n'a cuer ne corage

Que mençonges i voeille atraire

Ne nule parole retraire

Qui ne soit et vraie et estable

Et a retenir pourfitable;

Car li contes est bonz et biauz

Et plainz d'armes et de cembiauz,

D'amours, de joië et de deduit. (Escanor, v. 10-17)

Girart d'Amiens renonce au mensonge, affirme la véracité de son œuvre, mais pas celle des faits: c'est la vérité des mots, de la parole, qui est mise en lumière ici, et qui rend le récit digne d'être retenu. Le contenu du conte est d'ailleurs plus propre au divertissement, ce qui n'est pas incompatible avec le profit que l'on peut en tirer, qu'à la restitution de l'Histoire. L'allégation de vérité ne constitue donc pas un mensonge aux yeux des auteurs de fictions et n’implique pas nécessairement l'adhésion du lecteur à la réalité des faits narrés.

316 C'est la définition que le dictionnaire de Frédéric Godefroy donne de ce terme. "Raisnable», in Dictionnaire de l'ancienne langue française, vol. 6, p. 565. Ce terme est aussi employé dans le prologue du Foteor cité plus haut, dans un sens proche de «vraisemblable».

317 Paul Zumthor, "Genèse et évolution du genre», Grundriß der romanischen Literaturen des Mittelalters, Heidelberg, 1978, IV/1, p. 72. Le mot "histoire» est ici compris au sens de «history». 
Chrétien de Troyes emploie justement plusieurs fois le terme «voir» pour désigner la vérité de la fiction. Dans Erec et Enide, le narrateur fait grâce à son lecteur du récit qu'Erec fait de ses propres aventures à la cour :

Cuidiez vos or que je vos die

Quex acoisons le fist movoir?

Naie; que bien savez le voir

Et de ce et de l'autre chose,

Si con je la vos ai esclose. (Erec, v. 6470-6474)

Le lecteur connaît l'histoire du personnage grâce au roman qu'il a tout juste lu/écouté. Le mot "voir" renvoie ici au fait que l'événement a déjà été raconté: le lecteur connaît la vérité, c'est-à-dire le récit que l'on vient de lui faire. Le voir est interne à l'œuvre ${ }^{318}$. C'est en ce sens que l'historiographie se distingue du roman; elle raconte des événements «qui veulent être crus ${ }^{319}$ et se réfere à une réalité extérieure. La prise de position de l'auteur est donc différente dans les deux genres.

Le roman arthurien n'a au contraire pas l'ambition d'être cru; les différences entre l'Arthur historique et sa contrepartie fictionnelle en témoignent. En témoigne aussi la revendication du recours à la fiction, dans certains romans arthuriens en vers tardifs. L'auteur de Claris et Laris renonce à élaborer un récit sur des événements contemporains, telles les prises d'Antioche et de Constantinople, le siège d'Acre et les répercussions de la politique de l'empereur Frédéric II ${ }^{320}$, car «aucun me feroient contrere» (v. 74): il risque de s'attirer les foudres des personnalités concernées et devenir «martyr» (v. 80), ce qui en dit long sur le rôle

318 Francis Gingras traite de ce passage et de la vérité de la fiction dans son article, "Tant con durra crestiantez», art. cit. Voir le recueil d'articles dirigé Annie Combes, Fictions de vérité dans les réécritures européennes des romans de Chrétien de Troyes, Paris, Garnier, 2012, au sujet de la vérité de la fiction.

319 Hans Robert Jauss, "Chanson de geste et roman courtois (analyse comparative du Fierabras et du Bel Inconnu)", in Chanson de geste und höfischer Roman, Heidelberg, Carl Winter ("Studia Romanica»), 1963, p. 65.

320 Voir les vers 40-59. Corinne Pierreville traite de ce prologue aux pages 41-42 de son introduction à l'édition et aux pages 11 à 12 de son étude, Claris et Laris, somme romanesque. Pour plus de détails sur la VIII e croisade, on consultera l'ouvrage de Jean Richard, Histoire des croisades, Paris, Fayard, 1996, en particulier p. 437-454. Voir aussi l'article de Douglas Kelly, "Tout li sens du monde dans Claris et Laris", Romance Philology, 36:3, 1982-1983, p. 406-417. 
concédé à l'écrivain, véritable acteur politique dont l'obsession de la vérité et l'opinion, susceptible d'être diffusée à plus grande échelle, peuvent nuire aux grands de ce monde. L'auteur déclare alors:

Li voir dire ne m'est pas sains,

Martyr seroie, non pas sains,

Car en voir dire apertement

N'a fors que tristece et torment.

De ceus qui or sont maintenant

Ne puis faire conte avenant

Se je vueill dire verité.

Pour ce me vient en volenté

De dire, c'on ne m'en repraigne,

Des aventures de Bretaigne. (Claris et Laris, v. 79-88)

Ce passage, en répétant l'expression "voir dire», insiste sur les implications négatives de cette modalité de récit: raconter la vérité engendre tristesse et tourment, risquerait de se retourner contre l'auteur, figure de martyr, comme si l'écriture représentait un combat équivalent à celui que l'on mène pour Dieu. La fiction, au contraire, extrait l'auteur et son texte du monde réel, les place dans un cadre rassurant, car inoffensif pour ses contemporains. L'évocation des aventures de Bretagne dans ce contexte les désigne explicitement comme des fictions par le narrateur, tandis que les personnages eux-mêmes se présentent dans Claris et Laris comme des êtres de papier: l'amie d'Yvain raconte comment elle l'a rencontré en faisant allusion à la fontaine, au perron et à la foudre et ajoute "Si con Crestïens le tesmoine» (Claris et Laris, v. 627), référant de cette manière à son propre créateur. Cette aventure et ses personnages n'existent donc pas indépendamment et sont tributaires du geste d'un auteur, Chrétien de Troyes, nommé par la jeune fille elle-même qui transcende ainsi les frontières entre les niveaux diégétique et extra-diégétique. Mentionner un nom d'écrivain au sein d'un discours direct renvoie le personnage à son statut fictionnel et met à nu les mécanismes de l'écriture romanesque. La revendication de la fiction est une donnée nouvelle au $\mathrm{XIII}^{\mathrm{e}}$ siècle: elle assume «le pouvoir artistique de l'absence de vérité » ${ }^{321}$.

321 Danièle James-Raoul, "Un curieux avatar de L'Estoire Merlin: le Roman de Silence", in Traduction, transposition, adaptation au Moyen Age, Bien dire et bien aprandre, 13, 1996, p. 147. 
En plus d'être fictives, les «aventures de Bretagne» du prologue de Claris et Laris sont également des récits plaisants (conte avenant). L'objectif de l'auteur est de plaire aux bonnes gens (v. 4) et non aux mauvais, qui se complaisent dans l'écoute de "vilain fet» (v. 9) et de médisances et ne goûteraient pas un tel récit. L'auteur suggère ainsi que ceux qui n'écouteront pas son œuvre font partie de la classe méprisable de la population ${ }^{322}$. L'idée sous-jacente est de répandre, par le biais du récit plaisant, des valeurs positives et d'éradiquer la convoitise, l'avarice,

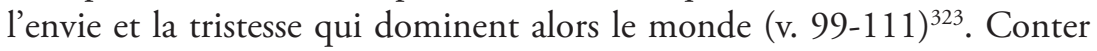
d'Arthur est ici un geste politique; l'évocation des tourments de la fin du $\mathrm{XIII}^{\mathrm{e}}$ siècle engage à penser la fiction dans son rapport avec le monde réel. Le roman dit quelque chose des comportements contemporains en valorisant les conduites exemplaires des chevaliers. Comme l'explique Olga Shscherbakova, "le roman n'obéit pas à une poétique de l'évasion, il se veut l'instrument d'une prise de conscience, pas celui d'un oubli de la

322 Olga Shscherbakova démontre cette lecture implicite qui découle de l'enthymème. Voir son article, "Lire et ré-écrire: un prologue français du XIII ${ }^{\mathrm{e}}$ siècle. De Chrétien de Troyes au roman de Claris et Laris", en ligne: http://doc.rero.ch/ record/8662/files/Lire_Ecrire_Shcherbakova.pdf, page consultée le 3.12.2013, p. 69. Elle éclaire le lien intertextuel entre ce prologue et celui du Conte du graal de Chrétien de Troyes.

323 Claris et Laris n'est pas le seul texte de notre corpus à présenter le temps d'Arthur sur le mode de la laudatio temporis acti en l'opposant au siècle contemporain: Floriant et Florete, Escanor et Biaudouz condamnent également leur époque pour ses vices et son déclin: «Ensi li siecles mesdevient, / Par force avenir le covient!» $(F F$, v. 2609-2610); "Mais ore voi en tel balance / Le mont que nuz n'a mais envie / De vivre en nule honeste vie / Car couvoitise a tel pooir / Que touz li monz en fait son oir.» (Escanor, vers déchiffrables sur le feuillet 1a, déchiré, du ms. BnF fr. 24374); "N'en seit ke faire ne ke dire, / Que li ciecles si fort empire, / mais mout en est ces cuers dolanz / Quant il empire si a son tenz." (Biaudouz, prologue, v. 51-54, transcrit par Milena Mikhaïlova-Makarius). L'insistance sur la décadence du monde doit éveiller l'attention du public sur le contraste proposé entre les comportements contemporains et arthuriens et encourager l'imitation de cet idéal fictif. La même technique est employée par Sarrasin dans le Roman $d u$ Hem: les déguisements arthuriens des participants au tournoi du Hem les idéalisent et les extraient d'un monde contemporain décadent que Largesse, Courtoisie et Prouesse ont déserté (v. 75-79). Quant à Melyador, l'éloge du temps passé se double d'une opposition géographique: l'usage était meilleur en Angleterre qu'en France (v. 9554-9568 et v. 22420-22426). Voir l'article de Nathalie BragantiniMaillard, «L'écriture des interventions narratoriales dans Melyador», art. cit. 
déviance contemporaine ${ }^{324}$. Le récit propose donc une vérité, qui n’est pas une vérité historique mais morale, la fiction illustrant par contraste les travers de la société.

Derrière l'utopie et la fiction perce ainsi une dénonciation, que le roman met au jour au fil des aventures narrées. Le compagnonnage, l'amitié, la fidélité à son seigneur, sont autant de valeurs prônées par l'œuvre qui surpassent d'ailleurs celles de l'amour et de la foi ${ }^{325}$. Le roman est tourné vers l'humain et le terrestre, ce qui confirme sa dimension réflexive sur la société contemporaine. D'autres indices de cette vision de la littérature sont semés au cours du texte. Ainsi, le roman débute sur le personnage de Claris, occupé à lire Pyrame et Tisbé et Hebé et Firamus (v. 163-164) - texte qui nous est inconnu. Le jeune homme ressent une vive émotion à la lecture («De lor mort durement li poise», v. 169) puis est frappé aussitôt par le dard d'amour ("Ainsi Claris par soi devise / Mes Amours d'un sien dart l'avise, / Au cuer le fiert a descouvert", v. 175-177). Ce n'est donc plus la vue de la femme qui fait naître le sentiment amoureux, mais la lecture de romans d'amour. Claris contracte d'abord le sentiment avant de le déporter sur un objet; la reine Lidoine, qu'il doit servir à table dans la scène suivante. Bien avant Flaubert et le bovarysme, l'auteur anonyme montre comment la lecture est génératrice de passions humaines. La littérature agit sur l'imagination du sujet, indépendamment de tout objet de projection, tout comme elle doit inviter le public à imiter un modèle sociétal.

Cette relation est explicitement exprimée au moment où est narrée la fête du mariage entre Laris et Marine, lors de laquelle se produisent des ménestrels, des conteurs et des trouvères:

Li preudome les escoutoient

Qui moult volentiers les ooient

Car il s'en cuident amender,

Et qui vos vorroit demander

S'en puet riens en romanz apprendre,

324 Olga Shscherbakova, "Lire et ré-écrire: un prologue français du XIII ${ }^{\mathrm{e}}$ siècle», art. cit., p. 75.

325 Nous nous permettons pour l'instant de ne pas développer. Corinne Pierreville et Douglas Kelly ont explicité, avant nous, l'importance du compagnonnage dans Claris et Laris : somme romanesque, et "Tout li sens du monde dans Claris et Laris», art. cit. 
Et je diroie sanz mesprendre

Qu'il i gist tout li sens du monde

Tant come il dure a la roonde

Car se les estoires ne fussent,

Les genz de droit riens ne seüssent! (Claris et Laris, v. 29623-29632)

Les récits des conteurs doivent susciter l'imitation et permettre aux auditeurs de s'améliorer ("amender»), ce qui reprend l'idée soufflée en prologue. L'auteur affirme ainsi que la lecture de romans favorise une prise de conscience sur la société et son autocorrection ${ }^{326}$. Il souligne également leur dimension didactique: le roman véhicule un savoir, est un outil d'enseignement («en romanz apprendre», «Les genz riens ne seüssent»). Il illustre "tout li sens du monde ${ }^{327}$ : capable de mimétiser les passions humaines ou de colporter un message sur la réalité, le roman est une réduction du monde réel et en livre ainsi une interprétation, un sens, en déchiffre les fonctionnements. Le terme sens est toujours ambigu: on peut deviner qu'il désigne ici les valeurs fondamentales sans quoi le monde ne pourrait prospérer. L'expression renvoie bien à la conception d'une littérature utile, qui délivre une vérité intérieure, sans recourir à la narration de faits réels ${ }^{328}$.

La même vision de la littérature transparaît dans Floriant et Florete, lors de la fête finale qui se donne à Palerme: on présente les chevaliers en train d'écouter des conteurs qui narrent les faits militaires du temps jadis. L'écoute de ces récits rend les auditeurs plus sages, pour autant qu'ils se projettent dans ces histoires:

Tout ce li conteeur contoient

Et il volentiers les ooient

Et se miroient es biaus dis,

326 L'idée du va-et-vient entre fiction et réalité est théorisée par la critique de la lecture, comme l'explique Vincent Jouve: «Lire est donc un voyage, une entrée insolite dans une dimension autre qui, le plus souvent, enrichit l'expérience: le lecteur qui, dans un premier temps, quitte la réalité pour l'univers fictif fait, dans un second temps, retour dans le réel, nourri de la fiction.» (La Lecture, p. 80)

327 Douglas Kelly traite des implications de cette expression et du mot «sens" dans "Tout li sens du monde dans Claris et Laris», art. cit.

328 Sur ce passage, voir aussi Corinne Pierreville, «De la lettre au roman. Lecture, écriture et réécriture dans Claris et Laris", in La lettre et les lettres, entre-deux, textes réunis par Claude Lachet et Laurence Richer, Lyon, C.E.D.I.C., 2006, p. 60-61. 
S'en devenoient mieux apris.
Quar qui romanz velt escouter
Et es biaus dis se vet mirer
Merveil est s'il ne s'en amende
S'il est ensi qu'il i entende. (Floriant et Florete, v. 6239-6246)

C'est bien le genre romanesque dont il est question ici: il invite par son mimétisme à se reconnaître, se mirer dans les personnages pour en reproduire les actes et les valeurs ${ }^{329}$. Le lecteur de romans corrige son comportement; il devient une meilleure personne. La résonance de la fiction dans la réalité - ou de la réalité dans la fiction - s'exprime aussi par la situation politique sicilienne qu'on déchiffre entre les lignes de l'histoire de Floriant et Florete, celui-là étant l'héritier du royaume de Sicile. Richard Trachsler et Annie Combes notent en introduction de leur édition que le roman peut être lu comme une propagande pour les Angevins, qui prétendent récupérer la Sicile et se rapprocher de l'empereur byzantin et de la Hongrie, territoires tous deux intégrés au règne du héros de Floriant et Florete par les mariages de Gauvain et Blanchandine, héritière de la Hongrie, et de Floriant et Florete, fils de l'empereur de Constantinople ${ }^{330}$.

329 Il faut noter que Floriant et Florete s'inspire peut-être du passage de Claris et Laris que nous venons de citer, étant donné qu'il s'agit d'une source claire pour l'auteur anonyme. Cela n'enlève toutefois rien à la réflexion menée sur le rôle de la littérature dans Floriant et Florete.

330 Ces constats amènent les éditeurs à situer la composition du roman dans les années 1280, hypothèse corroborée par sa postériorité à Claris et Laris. Les échos à la politique contemporaine viseraient donc non pas à glorifier les Hohenstaufen, qui règnent sur la Sicile jusqu'en 1266, mais à soutenir les revendications des Angevins sur l'île après les Vêpres siciliennes (1282) qui ont renversé la domination angevine sur l'île et l'ont placée sous la protection du roi d'Aragon Pierre III. Voir Floriant et Florete, éd. cit., p. XxIX-XxxI, ainsi que les articles de Sara SturmMaddox, "The Arthurian Romance in Sicily: Floriant et Florete", in Conjointure arthurienne. Actes de la "Classe d'excellence" de la Chaire Francqui 1998, éd. Juliette Dor, Louvain-la-Neuve, Université catholique de Louvain («Publications de l'Institut d'études médiévales. Textes, études, congrès », 20), 2000, p. 95-107, et "Arthurian Evasions: the End(s) of Fiction in Floriant et Florete", in Por le soie amisté. Essays in Honor of Norris J. Lacy, éd. Keith Busby et Catherine M. Jones, Amsterdam; Atlanta, Rodopi ("Faux Titre», 183), 2000, p. 475-489; Sara Sturm-Maddox soutient plutôt une datation entre 1250 et 1275 et une orientation normande du texte. De notre point de vue, il nous semble que l'on peut douter du parti angevin pris par l'auteur de Floriant et Florete: la mise en scène d'un héritier légitime, dont la succession est contestée et dérobée, rappelle plutôt 
Les péripéties de l'œuvre reflètent elles-mêmes la situation tourmentée de la Sicile du début du XIII ${ }^{\mathrm{e}}$ siècle, dominée alors par les Normands avant de passer aux mains angevines et tiraillée entre régences, successions contestées et sièges. Tout comme l'auteur de Claris et Laris, celui de Floriant et Florete propose une alternative aux tumultes politiques siciliens: un règne pacifié par le retour de l'héritier légitime en la personne de Floriant. Le roman tardif ne se réduit donc pas au divertissement, mais se veut le miroir fictionnel d'une réalité et le réservoir de comportements à imiter ${ }^{331}$. L'esthétique de la tardivité va de pair avec la prise en charge assumée du caractère fictionnel du roman.

l'éviction des Hohenstaufen par le pape, à la mort de Conrad IV en 1254. Même si Floriant et Florete, par sa reprise des vers de Claris et Laris, est forcément postérieur à 1268, date à laquelle le dernier prétendant Hohenstaufen, Conradin, est décapité, il peut néanmoins prendre leur parti, dans la mesure où l'insatisfaction sicilienne vis-à-vis de la politique angevine est grandissante et que l'auteur peut vouloir complaire à une noble famille italienne en dévaluant les Angevins. L'empereur byzantin, inquiet des prétentions orientales de Charles d'Anjou, se montre lui-même contre le règne en vigueur: le mariage de Floriant avec la fille de l'empereur de Constantinople peut donc être interprété diversement, soit comme l'alliance politique historique entre les opposants au régime, qui prépare les Vêpres Siciliennes (c'est notre hypothèse), soit comme la tentative de mariage entre le fils du Normand Tancred avec la fille de l'empereur en 1193 (c'est l'hypothèse de Sara Sturm-Maddox), soit comme le rêve de Charles d'Anjou d'étendre son pouvoir à l'Orient (c'est l'hypothèse de R. Trachsler et A. Combes). Quoi qu'il en soit, l'implication du roman dans la vie politique est indéniable et conforte nos remarques sur l'engagement de cette littérature. Sur l'histoire de la Sicile, voir Jean-Yves Frétigné, Histoire de la Sicile, Paris, Fayard, 2009, chapitre XI à XIII.

331 Sur la dimension spéculaire de la littérature, voir Florence Bouchet, Le discours sur la lecture en France aux XIV et XV siècles, p. 78-86. Le propagandisme des romans arthuriens en vers a été éclairci par Beate Schmolke-Haßelmann, Der arthurische Versroman. Floriant et Florete ne fait donc en ce sens pas exception parmi les autres textes du genre. Nous ne développons pas ici les implications politiques d'Escanor et de Melyador: Beate Schmolke-Haßelmann en a traité dans son étude, Der arthurische Versroman, p. 222-232 et son article "Ausklang der altfranzösischen Artusepik: Escanor und Méliador", in Spätmittelalterliche Artusliteratur ein Symposion der neusprachlichen Philologien auf der Generalversammlung der GörresGesellschaft Bonn, 25.-29. September 1982, éd. Karl Heinz, Paderborn, Schöningh, 1984, p. 41-52. Voir aussi l'introduction à l'édition de Melyador par Nathalie Bragantini-Maillard, éd. cit., p. 252-254, l'article de Gérald Brault, "Arthurian heraldry and the date of Escanor", art. cit, et celui de Richard Trachsler, "Escanor von Girart d'Amiens im Spannungsfeld von Vers und Prosa», in König Artus und der Heilige Graal. Studien zum spätarthurischen Roman und zum Graals-Roman 
L'œuvre de Robert de Blois le prouve à son tour: dans le long prologue qui précède Biaudouz dans BnF fr. 24301 - et qui figure d'ailleurs dans d'autres manuscrits compilant les œuvres de Robert de Blois -, l'auteur affirme que "cil ki vuet tot le voir dire, / Son afaire bien tost empire." (v. 167-168) ${ }^{332}$. Comme dans Claris et Laris, cette affirmation est renforcée par la comparaison du temps présent, décadent, qui «si fort empire» (v. 52), avec un passé glorieux: «Mout furent prou li ancien / Mais li novel n'en sevent rien» (v. 101-102). Introduit par un tel prologue, le roman de Biaudouz doit illustrer les vertus du temps jadis et servir d'exemplum pour les contemporains, invités à imiter le comportement des protagonistes. Cette fonction didactique conférée au roman arthurien transforme la perception du genre, jusque-là simple réservoir de récits plaisants. Pour Biaudouz, ce point de vue est approfondi par la mise en recueil, qui fait se côtoyer roman arthurien et œuvres morales. Nous y reviendrons au chapitre III, «Un récit encadrant: Biaudouz et le didactisme», p. 617-630.

Le roman tardif est donc résolument inscrit dans sa réalité contemporaine, en témoigne l'insertion de commentaires réalistes ${ }^{333}$. Au tournoi de la Garde dans Melyador, les dames ont pris la précaution d'organiser des secours pour les chevaliers tombés sur le champ de bataille:

Mais les dames pour ordener

Le tournoi mieus a sa maniere

Avoient sus la sabloniere

Fait venir grant quantité

De paÿsans pour verité

Tout a piet et pour redrecier

Aucun mesaisiet chevalier

Se cheüs estoit en peril. (Melyador, v. 6610-6617)

im europäischen Mittelalter, dir. Danielle Buschinger et Wolfgang Spiewok, Greifswald, Reineke-Verlag («Wodan», 32), 1994, p. 257-268. Ces deux exemples supplémentaires doivent prouver à quel point le roman est inscrit dans la réalité et ne se réduit pas à la fabula.

332 Nous citons ici la transcription que donne Milena Mikhaïlova-Makarius, L'École du roman, en pages 365-374.

333 Nous adoptons la définition suivante de ce terme: toute ouvre qui «semble reproduire assez fidèlement la réalité à laquelle elle se réfère» (Constanze Baethge, "Réalisme», in Paul Aron et al. (dir.), Le Dictionnaire du littéraire, Paris, PUF ("Quadrige»), p. 637). 
L'auteur tient compte du déroulement historique d'un tournoi: on peut s'y blesser, y gésir sans pouvoir se redresser et risquer sa vie, voire compromettre les autres joutes ${ }^{334}$. Les réalités du domaine guerrier sont aussi abordées dans Escanor, lorsqu'Arthur interdit à ses chevaliers de piller la population pendant la guerre contre Escanor le Bel (v. 17487-17540):

Mais ensi lor ert conmandé

Et si lour ot li rois mandé

Qu'il ne roubaissent ne tolissent

Es illes, ne ne fourfesissent,

Mais trestout ce qu'il achataissent

Autresi largement paaissent

Qu'il veïssent qu'il fust a faire. (Escanor, v. 17487-17493)

Le roman trouve par là un écho dans la vie réelle, les perturbations liées aux temps de guerre étant bien souvent le prétexte aux forfaits des armées qui se livrent au vol et au viol - comme c'est d'ailleurs le cas dans Claris et Laris, lors du déplacement armé vers Montjoie ("Li forrier vont par la contree, / Mainte riche vile ont robee, / Prennent bués, vaches et berbiz», v. 14201-14203). Plus qu'un renvoi à une réalité contemporaine, les recommandations du roi Arthur peuvent être interprétées comme un conseil prodigué aux chefs de guerre: le narrateur précise que la population, satisfaite de sa cohabitation harmonieuse avec les troupes, se fait conciliante envers l'armée arthurienne en lui fournissant des victuailles et des informations sur Escanor le Bel.

L'armée ne se réduit d'ailleurs plus au corps de la chevalerie: les derniers romans en vers ne font pas l'impasse sur l'infanterie, la piétaille ou les archers, qui accompagnent les déplacements guerriers du roi Arthur (Escanor, v. 18810-18824, Claris et Laris, v. 5232-5257 ou Biaudouz, v. 2611-2616), de même que le menu peuple («vilains del païs» dans Biaudouz, v. 2713-2716). Cette préoccupation pour d'autres corps armés va de pair avec l'intérêt croissant pour d'autres tranches sociales: le narrateur de Claris et Laris signale que la fête du mariage entre Laris et Marine est ouverte au petit peuple (v. 29594-29595), celui de Rigomer multiplie

334 Voir Michel Zink, Froissart et le temps, Paris, PUF, 1998, p. 122, et Peter F. Dembowski, "Meliador de Jean Froissart, son importance littéraire: le vrai dans la fiction", Le roman chevaleresque tardif, dir. Jean-Philippe Beaulieu, Études françaises, 32:1, 1996, p. 18-19, qui envisage les realia de Melyador. 
l'évocation de métiers manuels et en donne des précisions («Puis a vëu .iiii. maçons / Qui tinrent lor escantillons / Et lor ponçons et lor cisiaus. ", v. 9165-9167, sans parler de la liste des métiers de Rigomer, v. 63516388). Le roman tardif s'ouvre donc au monde social.

Les touches de réalisme s'étendent au domaine privé: la naissance de Froart, fils de Floriant et Florete, est l'occasion de faire allusion aux cérémonies et festivités liées à l'accouchement, comme le baptême ou les relevailles (v. 6454-6545). L'auteur introduit ainsi la possibilité d'une dynastie, qui assurera la prospérité de la Sicile à la suite de Floriant. Il démontre par là son souci de proposer un monde viable et exemplaire, et non un simple récit fictif. L'exemplarité s'applique aussi au domaine politique, l'exécution de Maragot étant présentée comme une décision royale judicieuse: «Ensi doit on felon tirant / Destruire et mener a sa fin.» (v. 5810-5811). Résolument, le roman arthurien tardif entend se démarquer par sa propension à résonner dans la vie réelle.

On a pu dire des romans en vers tardifs qu'ils rationalisaient le merveilleux, à l'instar de Corinne Pierreville, qui intitule le chapitre qu'elle consacre à la merveille dans Claris et Laris «La rationalisation de la merveille» ${ }^{335}$. Pourtant, ce que l'on perçoit comme un affaiblissement du merveilleux dans les derniers romans arthuriens en vers n'est à notre sens pas tant dû à la pauvreté des aventures surnaturelles ni à leur nature, mais bien plutôt à la proportion importante d'éléments moins fantaisites que nous venons d'évoquer. À cela s'ajoute le nombre de descriptions de combats, majoritaires par rapport à l'expérience de la merveille, et ce à plus forte raison dans les deux derniers romans du genre. On ne dénombre que quelques épisodes où le surnaturel intervient dans Escanor ${ }^{336}$, et une seule aventure merveilleuse dans Melyador.

La merveille est pourtant bien présente dans ces textes, en particulier dans Claris et Laris, Rigomer et Floriant et Florete, où se manifestent des nefs merveilleuses, des bêtes surnaturelles, des chevaliers enferrés, des illusions créées par enchantement, des métamorphoses (Calogrenant en jeune fille dans Claris et Laris) ${ }^{337}$. L'évolution concerne dès lors moins le rapport

335 Claris et Laris, somme romanesque, chapitre IV, p. 275-367.

336 Voir Christine Ferlampin-Acher, Merveilles et topique merveilleuse, p. 482-487, sur la merveille dans Escanor. La critique constate que, bien que les merveilles ne soient pas exclues, elles sont peu développées dans ce roman.

337 Nous avons traité du merveilleux dans les romans tardifs dans «Littérature arthurienne tardive en vers", in La matière arthurienne en Europe entre Moyen Âge 
à la merveille que la façon de le mettre en scène: les romans tardifs choisissent la voie de l'exotisme, en inventant des créatures étranges provenant de contrées lointaines, ils visent l'originalité en élaborant des monstres hybrides complexes, comme la guivre multicolore de Claris et Laris ${ }^{338}$, ou en créant des situations insolites, des chats sauvages gardiens d'une bière vide dans Rigomer par exemple; ils teintent également les épisodes merveilleux de comique et en profitent pour placer les chevaliers dans des postures dignes de Don Quichotte. Ainsi Cador doit-il dans Claris et Laris affronter l'aventure du moulin merveilleux, habité par un diable. Faisant fi des avertissements d'une voix menaçante, il s'avance et finit pendu à une branche. Ses compagnons le trouvent dans cette position ridicule, que le narrateur décrit non sans humour:

Et il choisirent maintenant

Kador qui a l'arbre pendoit.

Trop durement se dementoit

Car il pendoit en tel maniere:

Pou grevoit avant ne arriere

Li pendres, fors les armeüres

Qui estoient pesanz et dures

Lestraignoient parmi le cors. (Claris et Laris, v. 24913-24920)

Le chevalier pend à l'arbre tel un pantin, balloté dans son armure. La récurrence du verbe "pendre", mis en valeur par l'enjambement au vers 24918 , accentue le ridicule du chevalier. Claris et ceux qui l'accompagnent doivent alors le saisir et le dépendre. C'est ensuite au tour de Mordred de tenter sa chance. Il tombe quant à lui dans une fondrière, s'y enfonçant "Jusqu'a la gorge voirement» (v. 24938). Le narrateur, là encore, se moque gentiment: «Or gist Mordrez en la croliere!» (v. 24939), et les compagnons doivent tirer Mordred de toutes leurs forces, à plusieurs reprises, pour le sortir de là : "Tant tirerent sanz atendue, / Mordrez de la croliere traient, /

et Renaissance: diffusion et transformation en devenir, dir. Christine FerlampinAcher, Rennes, PUR, sous presses. Voir aussi Christine Ferlampin-Acher, Merveilles et topique merveilleuse, qui traite des romans arthuriens en vers tardifs au même titre que les romans plus canoniques pour son étude.

338 Il s'agit d'une créature «de mil colors» (v. 5512) qui tient du lion, du dragon et du griffon (v. 5499-5512). Voir Christine Ferlampin-Acher, Merveilles et topique merveilleuse, p. 48, et Corinne Pierreville, Claris et Laris, somme romanesque, p. 352-356. 
Mes par mainte foiz s’i ressaient.» (v. 24948-24950). Le merveilleux rend ici les chevaliers ridicules et se fait souvent le ressort privilégié du comique dans le roman tardif. Le traitement qui lui est réservé ne plaide donc pas pour une rationalisation, mais renforce au contraire les liens du roman arthurien avec la fiction.

\section{Genre et narrateur}

Le rapport du roman à la fiction ou à la vérité de la fiction est assuré par le narrateur, qui prend une importance considérable dans ce genre. C'est en effet au narrateur que revient la tâche de garantir la vraisemblance du récit - en refusant par exemple dans Erec et Enide d'exagérer le nombre de tables disposées lors de la fête finale, pour ne pas raconter «chose qui ne semble estre voire» (Erec, v. 6916, BnF fr. 1376) ${ }^{339}$. Une attestation de vérité comme "ce fu verité prouvee» encourage l'adhésion du lecteur à un contenu merveilleux, dont il admet la réalisation au sein du récit fictionnel ${ }^{340}$. Dans notre corpus, ces mentions apparaissent également; le narrateur de Rigomer ponctue son récit de tournures convenues: «Ensi cuit jou que çou fust voirs» (v. 15583), «Singnor, ço ne fu mis fable» (v. 9592), «Dont jou vos sai dire le voir» (v. 9560), «Ne vos en quier estre mentere» (v. 9140). Le narrateur de Melyador y a également recours: «il n'est mies doute» (v. 5944), «Mais par ce cop je certefi / Que Melÿador vaintera» (v. 9038-9039), «De ce me fai je tout segur / Que moult bien y trouva le voie» (v. 14275-14276), "ce puis legierement prouver» (v. 14283) $)^{341}$. Dans ces interventions, la subjectivité du narrateur

339 Ces vers sont particulièrement soumis à la mouvance: la copie Guiot (BnF fr. 794) propose "Ne vos voel pas feire acroire / mançonge sambleroit trop voire", tandis que les mss BnF fr. 1450 et 1376 remplacent «trop voire» par «trop grant». L'idée générale semble bien celle de transmettre un mensonge vraisemblable, qui implique de ne pas pousser trop loin l'exagération. À ce sujet, voir Francis Gingras, "Tan con durra crestiantez», art. cit., p. 81.

340 Francis Gingras note que ce type de formules est particulièrement fréquent dans les passages merveilleux des œuvres de Chrétien de Troyes. Voir «Comment présenter un genre qui n'existe pas?», art. cit.

341 Voir l'article de Nathalie Bragantini-Maillard, "L'écriture des interventions narratoriales dans Melyador", art. cit., qui recense les prises de parole du narrateur. Margherita Lecco recense les interventions du narrateur de Rigomer aux pages 16-20 de Le Meraviglie du Rigomer, Tradizione manoscritta e tradizione narrativa, trad. cit. 
s'exprime, en laissant apparaître un «je». La concurrence entre vérité et subjectivité est typique du roman arthurien en vers: le récit de Floriant et Florete est par exemple ponctué de formules comme "si com moi samble» $(F F$, v. 46), «mien esciant» $(F F$, v. 117), «ce m'est vis» $(F F$, v. 1192). Ce n'est pas à un contenu véridique sur le plan historique auquel adhère le public, mais à un point de vue subjectif jeté sur le monde, sur un monde possible $^{342}$. Le narrateur remplit donc un rôle spécifique dans le roman, qui le distingue du narrateur de la chronique ${ }^{343}$ : celui-ci intervient peu pour affirmer la véracité de ses dires, annoncer des événements à venir, ou fournir un commentaire omniscient ${ }^{344}$.

Cette fonction testimoniale peut se traduire par la prétention au statut de témoin direct de l'histoire par le narrateur. De telles allégations apparaissent dans Melyador: elles donnent l'impression de la contemporanéité du narrateur avec les personnages, bien que la diégèse se déroule dans la jeunesse d'Arthur. On assiste alors à un brouillage des frontières entre temps du récit et temps de l'histoire. Le narrateur justifie par exemple son incapacité à reproduire la chanson d'un chevalier lors de la fête finale par sa place reculée dans l'auditoire:

La commença uns chevaliers

a canter par bonne maniere.

Mais j'estoie adont si derriere

que sa cançon ne peus oïr. (Melyador, v. 29927-29930)

Le statut de témoin que se donne le narrateur n'est pas sans rappeler l'un des moyens utilisés par la chronique pour renforcer le caractère véridique de la narration ${ }^{345}$. Le narrateur de Melyador prend le rôle d'un chroniqueur

342 En envisageant ici que le monde dessiné par le roman est un monde possible par rapport au monde réel. Voir Marie-Laure Ryan sur les mondes possibles, «Possible Worlds", art. cit.

343 Dans son traité de rhétorique, Jean de Garlande évoque d'ailleurs la forme de la représentation comme critère distinctif: le narrateur n'intervient pas, il est seul à intervenir ou on alterne entre les deux options (mode mixte). Il s'agit donc bien d'un élément qui permet de discerner des classes de textes.

344 "La "véracité" du récit provient donc à la fois du témoignage de l'auteur et de ses limites, c'est-à-dire de l'impossibilité de reproduire le réel dans sa totalité.» (Sophie Marnette, Narrateur et points de vue dans la littérature française médiévale, p. 102)

345 Nathalie Bragantini-Maillard, «Les jeux du narrateur dans Melyador: de l'écriture en trompe-l'œil aux stratégies de l'identification ludique», in Le Moyen Âge par 
mondain, à la manière des narrateurs de reportages sportifs, comme celui du Roman du Hem ${ }^{346}$ : dans ce contexte se mêlent témoignage et procédés narratoriaux romanesques. Les procédés métaleptiques ${ }^{347}$, qui brouillent les frontières entre les niveaux extradiégétique et intradiégétique et complexifient le texte, sont permis par la toute-puissance que s'accorde le narrateur de roman. Le narrateur est libre d'esquisser le rapport de son récit à la fiction, de prétendre à l'historique tout en marquant un point de vue. Nathalie Bragantini-Maillard parle alors d'«omniscience subjectivisée ${ }^{348}$ au sujet du narrateur de Melyador: celui-ci a la maîtrise de son récit, mais laisse se dévoiler une conscience particulière, par les nombreuses formules de subjectivité, "ce me samble», "je l'imagine», «si com je pense" par exemple.

L'étude de Sophie Marnette démontre à quel point le positionnement du narrateur distingue les genres littéraires ${ }^{349}$. Elle constate notamment que la chanson de geste est un genre tourné vers le public, en raison de sa transmission orale, et recourt donc plus volontiers au vous qu'au je. Le

le Moyen Âge, même. Réception, relectures et réécritures des textes médiévaux dans la littérature française des XIV et XV siècles, éd. L. Brun, S. Menegaldo, A. Bengtsson et D. Boutet, Paris, Champion, 2012, p. 141-161, développe les liens de Melyador au genre de la chronique. On consultera aussi l'article de Jane H. M. Taylor, «The Fourteenth Century: Context, Text and Intertext", in The Legacy of Chrétien de Troyes, dir. Norris J. Lacy, Douglas Kelly et Keith Busby, Amsterdam, Rodopi, 1987-1988, vol. I, p. 288-292.

346 Nathalie Bragantini-Maillard souligne le parallèle que l'on peut faire entre Melyador et les relations de tournoi, "Les jeux du narrateur dans Melyador", art. cit., p. 158. Le narrateur du Roman du Hem est lui aussi spectateur et il commente le spectacle qui se déroule sous ses yeux. Il s'agit cependant dans ce cas d'une scénographie réelle, le ménestrel Sarrasin étant effectivement témoin du tournoi du Hem. Le texte se rapproche sur ce plan de la chronique: «Il jousterent devant le mur, / Pres des dames, que g'i estoie. [...] La rö̈ne, bien m’en souvient, / Pria pour eus de cuer entier." (Roman du Hem, v. 3548-3553)

347 Gérard Genette donne la définition suivante de la métalepse: «l'extradiégétique est peut-être toujours déjà diégétique, et le narrateur et ses narrataires, c'est-à-dire vous et moi, appartenons peut-être encore à quelque récit." (Figures III, Paris, Seuil, 2003, p. 245)

348 «Les jeux du narrateur dans Melyador», art. cit., p. 146.

349 Sophie Marnette traite de la question du genre en particulier en conclusion, mais l'ouvrage entier est construit autour de ces distinctions. L'étude du point de vue et du narrateur confirment donc la pertinence de la notion de genre pour le Moyen Âge. Narrateur et points de vue dans la littérature française médiévale. 
narrateur des chansons de geste interpelle son public et l'implique dans l'action, comme s'il était un témoin des faits qui se déroulent. Son but est explicitement de plaire aux auditeurs/lecteurs et de capter leur attention. Les vies de saint constituent quant à elles une communauté de chrétiens formée de l'auditeur/lecteur et du narrateur, et réfèrent ainsi à un nous. Dans les romans en vers et les lais, l'instance narrative est tournée vers elle-même et le je s'affirme de manière plus prégnante. Le rapport au destinataire est donc résolument différent, de même que la nature des interventions narratoriales: dans la chanson de geste, le je se positionne essentiellement en tant que conteur, qui se contente de restituer une histoire qu'il a entendue et retenue.

Au contraire, l'instance narrative du roman en vers se présente comme un compositeur, institué de pouvoirs sur la narration, la structuration du récit et le choix des épisodes racontés:

Dans les romans en vers et les lais, c'est la volonté et l'ingéniosité du je narrateur qui est soulignée, plus que le plaisir ou l'attente du public. Ce narrateur demande qu'on écoute son récit, qu'on accepte ses décisions de raconter un événement ou de passer sur un autre et qu'on lui fasse entièrement confiance ${ }^{350}$.

La composition est au centre des interventions narratoriales du roman, ce qui illustre des préoccupations différentes selon les genres. Le roman revendique la part d'invention qui revient à l'écrivain, il instaure un autre rapport à la création et assure une autre forme de vérité, garantie par le compositeur, donnant ainsi véritablement naissance à la figure de l'auteur ${ }^{351}$. Ceci explique que le narrateur tâche souvent de légitimer sa

350 Sophie Marnette, Narrateur et points de vue dans la littérature française médiévale, p. 73.

351 C'est au long des $\mathrm{XII}^{\mathrm{e}}-\mathrm{Xv}{ }^{\mathrm{e}}$ siècles que s'effectue la prise de conscience de la notion d'auteur: le mot "escrivain", apparu au $\mathrm{XII}^{\mathrm{e}}$ siècle, désigne d'abord le copiste, puis l'auteur, dont le geste de création est valorisé. Joëlle Ducos, Olivier Soutet et Jean-René Valette, Le Français médiéval par les textes, p. 52. Voir aussi Delphine Burghgraeve, Jérôme Meizoz, Jean-Claude Mühlethaler, Postures d'auteurs: du Moyen Âge à la modernité, Delphine Burghgraeve, Jean-Claude Mühlethaler, et Claire-Marie Schertz, "Introduction. Figure, posture, ethos à l'épreuve de la littérature médiévale», art. cit., Michel Zimmermann, "Ouverture», in Auctor et auctoritas. Invention et conformisme dans l'écriture médiévale, dir. Michel Zimmermann, Paris, École des chartes, 2001, p. 7-14, et Claudio Galderisi, 
prise de parole en prologue et de convaincre de la qualité de la version proposée $e^{352}$. Ce n'est donc pas la fréquence du je qui distingue le narrateur des romans en vers et celui des autres genres, mais bien le rôle qu'il s'attribue:

L'examen de la $1^{\text {ère }}$ pers. sg. permet de conclure qu'il existe bien un je narrateur explicite dans la majorité des textes du corpus. Les fonctions et la fréquence d'apparition de ce je diffèrent selon le genre des textes observés. Dans les romans en vers et les lais, on a affaire à un je narrateur qui a conscience de son rôle d'auteur et y insiste. Dans les autres textes, et particulièrement dans les chansons de geste, le je narrateur se met principalement en scène dans sa fonction de «conteur»: il dit le texte, le structure mais, apparemment, ne le compose pas ${ }^{353}$.

Cette distinction oppose également vers et prose; nous l'avons vu avec le rapport aux sources fictives, le narrateur de la prose s'affirme beaucoup moins souvent comme un créateur, un auteur, que celui du roman en vers $^{354}$. Il est plutôt un translateur: il donne accès au texte de Merlin, de Bohort, d'un ange, de Dieu, sans assumer un main-mise sur le récit.

Cet aspect ne se dédit pas dans le roman tardif. Dans Escanor, le narrateur insiste en prologue sur l'entreprise poétique nécessaire à toute composition:

"Conscience littéraire et émergence de l'individu au Moyen Âge», in Histoire de la France littéraire, vol. 1, dir. par Frank Lestringant et Michel Zink, Paris, PUF, 2006, p. 667-677.

352 Voir Emmanuèle Baumgartner, "Texte de prologue et statut du texte», art. cit., et "Sur quelques constantes et variations de l'image de l'écrivain», art. cit.

353 Sophie Marnette, Narrateur et points de vue dans la littérature narrative médiévale, p. 51. Emmanuèle Baumgartner souligne que la chanson de geste donne progressivement sa place à la figure auctoriale, par «[s]a tendance [...] à se réclamer d'abord d'une source puis à faire intervenir à côté du récitant, un auteur à part entière. Le statut de cet auteur, médiateur nécessaire entre la source et le texte produit, tend ainsi à s'aligner sur celui de l'auteur de roman et la "mise en romanz" devient le travail commun et pareillement revendiqué. Cet alignement correspond sans doute au moment où la chanson de geste n'est plus perçue ni reçue comme l'expression immédiate d'un passé et d'un idéal collectifs mais comme une forme littéraire parmi d'autres». ("Texte de prologue et statut du texte», art. cit., p. 473)

354 Le fait que Sophie Marnette isole à chaque fois romans en vers et romans en prose comme des corpus distincts pour analyser le rôle du narrateur et le point de vue démontre bien le caractère générique du choix de forme; la forme contraint les autres postes génériques. 
Et qui bel conmence et define,

L'uevre en est pluz bele et pluz fine

Et de pluz grant noblece asez:

Pour coi Gerardinz apenssez

S'est d'un bel conte en rime metre

Au miex qu'il onques entremettre

S'en saura ne pluz plaisanment. (Escanor, v. 1-7)

La bienveillance du public est encouragée par la beauté du conte et sa capacité à plaire: c'est sa valeur esthétique qui prime, engageant ainsi le talent de l'auteur. La légitimité de la prise de parole repose aussi sur l'autorité conférée à la dédicataire, Aliénor de Castille, qui dicte au poète la matière du récit, à la manière de Marie de Champagne dans Le Chevalier de la Charrette ("Car cele n'a pas le cuer duit, / De qui li contes est venus, / Qu'ele feïst rienz faire ou nuz / Peüst entendre deshonor.", Escanor, v. 18-22): l'éloge que lui dédie Girart d'Amiens doit convaincre de l'intérêt du texte qui suivra, une personne d'une telle noblesse ne pouvant qu'avoir des goûts supérieurs.

L'autorité est surtout dévolue à l'auteur lui-même, qui met en avant le geste poétique qui préside à la composition («en rime metre»). Elle est renforcée par la mention du nom de "Girart", à plusieurs reprises: au lieu de se nommer à la troisième personne comme le font ses contemporains ${ }^{355}$, Girart d'Amiens associe son nom au je du narrateur, rendant ainsi poreuse la frontière entre narrateur et auteur: "Et je, Gerars, sanz contredit, / M'otroie a son conmandement» (v. 50-51). La conjonction du je et du prénom est d'ailleurs particulièrement insistante, puisqu'on la retrouve en épilogue, au vers 25910: "Mais je, Girars, qui n’apris mie / sa mort, ne le quier metre en conte.» Cette dernière occurrence présente le je auctorial comme un témoin de l'histoire qu'il rapporte: il ne raconte que ce

355 Sophie Marnette, Narrateur et points de vue dans la littérature française médiévale, p. 216-220. "Rappelons que les romans en vers de notre corpus mentionnent tous le nom d'un auteur en l'accompagnant de la $3^{\mathrm{e}}$ pers. et non de la $1^{\text {ère }}$ pers. sg. À mon avis, cette distinction explicite entre narrateur et auteur impliqué indique à la fois que l'auteur impliqué n'est qu'une des sources du récit (face, par exemple, à la tradition orale) mais qu'il s'agit d'une source stable face aux changements qu'un interprète ou un scribe pourraient faire subir à l'œuvre.» (p. 218) L'auteur impliqué désigne l'«être non réel qui existe uniquement en tant que position textuelle, dont les opinions peuvent différer de celles de l'auteur historique, et qui est distinct du narrateur mais y est parfois amalgamé» (p. 217) 
dont il est sûr, ce qu'on lui a conté. La mort de Gifflet, sujette à caution, est donc exclue du roman. Cette posture ${ }^{356}$ garantit l'authenticité du récit et propose un narrateur-auteur ${ }^{357}$ digne de confiance. Bien que le statut de ce «je» demeure une projection fictive dont on ne saurait tirer des éléments biographiques ou historiques sur Girart d'Amiens, l'exemple d'Escanor confirme que la fin du XIII ${ }^{\mathrm{e}}$ siècle est déjà bien engagée dans la constitution et l'affermissement de la figure de l'auteur: Girart d'Amiens est un écrivain polygraphe, dont les compétences se manifestent aussi dans l'Istoire le roy Charlemaine et Meliacin. Employé aux cours d'Angleterre et de France (son Meliacin étant destiné vraisemblablement à Blanche de France, fille de saint Louis, et son Charlemagne à Charles de Valois, frère de Philippe le $\mathrm{Bel}^{358}$ ), Girart d'Amiens devait prétendre à une petite notoriété dans le milieu aristocratique qui l'autorise à se nommer en prologue et à parler en «je ${ }^{359}$.

Au contraire, le roman en prose fictionnalise son auctorialité en s'inventant de fausses attributions, celle de Gautier Map, Luce del Gat ou d'Hélie de Boron, et demeure bien souvent anonyme, ce qui n'empêche

356 Le concept de "posture» est théorisé par Jérôme Meizoz. Voir "posture d'auteur», Fabula atelier, http://www.fabula.org/atelier.php?La_posture_d\%27auteur. Delphine Burghgraeve, Jérôme Meizoz, Jean-Claude Mühlethaler, Postures d'auteurs: du Moyen Âge à la modernité. Selon Jean-Claude Mühlethaler, Delphine Burghgraeve et Claire-Marie Schertz, la posture désigne le «rôle dans lequel l'auteur se met en scène", c'est-à-dire l'image qu'il construit de lui-même dans le texte. Elle se distingue de l'ethos, «impression dominante qui se dégage au fil de la lecture quant au "caractère" de l'énonciateur» et de la figure, «individu historique, biblique ou fictif" qui sert de projection à la posture. "Introduction. Figure, posture, ethos à l'épreuve de la littérature médiévale», art. cit.

357 Sophie Marnette parle de «narrateur-auteur», pour signifier la confusion entre les deux instances désignées par je dans le roman en vers. Narrateur et points de vue dans la littérature française médiévale, p. 216-220.

358 Voir Antoinette Saly, «Écrivains mystificateurs: le cas d'Adenet le roi et de Girart d'Amiens", in Figures de l'écrivain au Moyen Âge. Actes du colloque du Centre d'Études Médiévales de l'Université de Picardie, Amiens 18-20 mars 1988, dir. Danielle Buschinger, Göppingen, Kümmerle Verlag, 1991, p. 245-253.

359 À propos des dédicataires et du statut d'auteur de Girart d'Amiens, on consultera les pages 56-67 de l'édition d'Escanor de Richard Trachsler, éd. cit. et Silvère Menegaldo, "Girart d'Amiens. Un auteur et une œuvre à la fin du XIII ${ }^{e}$ siècle", CRMH, 14, 2007, p. 145-148. 
toutefois pas la revendication d'un travail poétique ${ }^{360}$. Ces noms d'auteurs et ces identités fictifs sont repris d'un texte à l'autre, du Lancelot en prose au Roman de Guiron, comme pour masquer une auctorialité véritable qu'il faut humblement taire. À moins que ces auctorialités feintes ne soient une sorte de signal générique, comme le pense Emmanuèle Baumgartner:

Il se peut que la permanence, dans les proses du Graal, de la fiction de la translation et de la fidélité du transcripteur à sa source soit rapidement devenue un mode de repérage, une manière commode "d'annoncer la couleur» et de situer tout nouveau récit sur le Graal dans le champ narratif ${ }^{361}$.

Le nom d'auteur et la filiation revendiquée - ainsi d'Hélie de Boron qui se déclare neveu de Robert de Boron - est un signal générique fort: jamais un auteur de prose ne mentionne Chrétien de Troyes, contrairement aux auteurs de romans arthuriens en vers. L'auctorialité fictive garantit, dans la prose, une parole autorisée.

La légitimité de la prise de parole s'exprime aussi dans la confiance qu'a l'écrivain de voir son œuvre pérennisée par l'écrit et transmise à la postérité, dans Escanor: il fait acte de remembrance ${ }^{362}$. Girart d'Amiens le verbalise en s'adressant aux copistes qui reproduiront son roman: "Ainz pri Dieu qu'il gart ceuz de honte / Qui ce romant escouteront / Et qui escrire le feront" (Escanor, v. 25913-25915). Il témoigne d'une conscience que le texte se propagera par oral («escouteront») et par écrit. Cette diffusion littérarise la production de l'auteur, prouve qu'elle est digne d'être lue, entendue et reproduite, et affermit donc le statut de l'écrivain. Le texte ne se plie pas au réinvestissement de chaque jongleur, comme c'est le cas pour les gestes anciennes: il s'affiche comme le produit d'un écrivain auquel renvoie et renverra toujours le «je».

360 À ce sujet, voir les travaux d'Emmanuèle Baumgartner, "Luce del Gat et Hélie de Boron. Le chevalier et l'écriture», Romania, 106, 1985, p. 26-40, in "Masques de l'écrivain et masques de l'écriture dans les proses du Graal", in Masques et déguisements dans la littérature médiévale, dir. Marie-Louise Ollier, Montréal-Paris, Presses Universitaires de Montréal-Vrin, 1988, p. 167-175, et "Sur quelques constantes et variations de l'image de l'écrivain (XII $-\mathrm{XIII}^{\mathrm{e}}$ siècle)", art. cit.

361 «Masques de l'écrivain et masques de l'écriture dans les proses du Graal», art. cit., p. 175 .

362 Voir l'article de Valérie Fasseur, «La mémoire volontaire de l'écrivain médiéval: aspects et enjeux de la remembrance», Littérature, 175, 2014, p. 6-22. 
Dans Rigomer, la distinction entre conteur et écrivain semble de prime abord clairement établie; le "je» d'un narrateur-conteur se distingue de l'auteur Jehan ${ }^{363}$, dont il parle à la troisième personne: Jehan est celui qui a mis «en escrit» (v. 6431) son roman, en s'appuyant sur des "aventures et des lais" (v. 6433). Le narrateur se fonde sur cette source écrite pour déclamer oralement son récit, en témoignent les nombreuses références à la situation orale de la récitation que nous notions page 25. L'évocation du modèle ponctue régulièrement la narration dans des tournures convenues: « $\mathrm{Si}$ com'en escrit le trovomes» (v. 4982), "Si con li escriture dist» (v. 7629); ou moins conventionnelles: "Ce dist la laitre ou parcemin» (v. 6707), «Escrit tovons en ces quaiers» (v. 2052) qui renvoient à la matérialité du manuscrit et rend d'autant plus concrète l'existence de cette source écrite. Malgré la distinction claire entre narrateur-conteur et auteur, celui-là affirme sa subjectivité ("ço me sanle», "ce m’est avis», "je ne sai», «mien ensïentre», etc.) et son contrôle sur la narration: c'est lui qui choisit les éléments qu’il raconte, l'ordre dans lequel il les présente et surtout la quantité de détails qu'il fournit pour chaque épisode. Il insiste volontairement sur la longueur du texte de Jehan ("Mais mout i a longe carole», v. 6442) en laissant constamment penser au public qu'il synthétise $^{364}$ cette masse de contes pour lui donner l'impression que la source est encore plus longue et dense que son récit. Les interventions comme «Mais n'ai talent que tot recort» (v. 7991), "Jou ne vos voel plus aconter» (v. 12723) ou mieux encore

Or vos en ai grant ment conté

Et ne pourquant ai oblié

363 Sur le statut problématique de cet auteur, voir l'article de Francesco Carapezza, "Le fragment de Turin", art. cit., et Richard Trachsler, Les romans arthuriens en vers après Chrétien de Troyes, p. 189. Les critiques soulignent que ce Jehan peut désigner la personne qui a fourni la matière à l'auteur de Rigomer, ou qui aurait composé un roman dont s'inspire ce dernier. Selon Francesco Carapezza, l'auteur de Rigomer aurait antéposé au récit de Jehan, centré sur l'aventure de Gauvain au château de Rigomer, un roman de Lancelot et postposé l'aventure de la Quintefeuille.

364 Nous reviendrons au chapitre III, "Faire court dans un récit long", p. 519-531, sur la revendication paradoxale de la brièveté dans Rigomer, alors même que le roman est très long pour un roman en vers. Contentons-nous pour l'instant d'en donner un exemple: «Encor criem qu'il ne vos anuit / Çou que jou vos en conterai / Le moitié mains que jo ne sai.» (Rigomer, v. 7172-7174) 
Mout del millor et del plus bel,

Mais par celui qui fist Abel,

Or ai talent que me ravoie

A ço que oblié avoie;

Car sans cestui oubliement

Ne poons traire a finement

De chou que avons commencié.

Dont avon trop mal commencié. (Rigomer, v. 10583-10592)

soulignent la maîtrise du récit par le narrateur, son indépendance vis-à-vis de sa source. Elles confirment sa capacité à arranger, conjoindre la matière pour la recréer; au fond, à adopter le statut d'auteur. Quelle que soit la source écrite et quel que soit son contenu, le narrateur, qui ne se réduit pas à sa fonction de conteur, s'en autonomise et affirme sa main-mise sur la matière.

Marquer une subjectivité ou un geste conscient de création caractérise donc le narrateur du roman tardif: le lecteur est par là invité à imaginer une personne réelle derrière le récit. L'instance narrative endosse parfois une individualité encore plus prégnante: le narrateur de Floriant et Florete n'est pas seulement un récitant, qui organise la matière et choisit les passages qu'il raconte, il est aussi un individu dont les sentiments sont exposés. Il dévoile ainsi son amour pour une dame dont il requiert la bienveillance:

Mais ainçois que je plus en die

Voeil proier Amors que s'aïe

M'ostroit a ceste chose fere,

Et aussi a la debonnere

Qui a mon cuer en sa baillie

Dont ja n'en partira ma vie. (Floriant et Florete, v. 25-30)

Le narrateur, tel un personnage dans son propre récit, souffre en invoquant Amour. Son histoire évolue au fil du récit, illustrant le déroulement parallèle d'une temporalité propre au narrateur: alors que les deux couples, Floriant et Florete, Gauvain et Blanchandine, se rencontrent en secret et profitent du temps passé ensemble, le narrateur regrette de ne pas bénéficier de la même grâce. Il se croyait pourtant aimé, mais se voit à présent rejeté par son amie:

Dex! porroit il mais avenir

Que je la poïsse tenir 
Trestoute nue entre mes braz?

Nenil, voir, e mi! chaitis, laz!

J'ai veü que j'estoie amez,

Mes ore sui arrieres boutez,

Ce fet Fortune desloiaux! (Floriant et Florete, v. 4365-4371)

Ces commentaires concèdent une forme d'identité à l'instance narrative: le public est amené à imaginer une personne réelle derrière la prise de parole, qui agit, aime et existe en dehors de l'histoire qu'elle raconte. Silvère Menegaldo souligne le processus d'individualisation ${ }^{365}$ que permet la mise en scène d'un narrateur amoureux et son association avec une figure d'auteur:

Ce ne sont donc pas les longues interventions du narrateur [...] qui peuvent l'individualiser, c'est-à-dire le rapprocher de la notion moderne d'auteur, ni même lui donner une véritable importance, mais le fait que puisse lui être reconnu d'autres attributions que simplement celle de raconter une histoire ou de la traduire, et que ces attributions s'ajoutant les unes aux autres soient suffisamment nombreuses pour lui conférer une certaine épaisseur «biographique», une illusion d'existence, même si elle n'est jamais que le résultat de l'association d'un narrateur romanesque et d'un poète courtois ${ }^{366}$.

En tant qu'instance individualisée, le narrateur de roman a pour rôle d'établir un contact avec le lecteur, qu'il invite à prendre part au récit: le public doit compatir à la peine du narrateur amoureux. L'individualisation du narrateur favorise ainsi la communication avec le récepteur : le récit est vecteur d'un lien communicationnel, il est l'illusion d'un dialogue.

365 L'ouvrage collectif L'individu au Moyen Âge. Individuation et individualisation avant la modernité, dir. Brigitte Miriam Bedos-Rezak et Dominique Iogna-Prat, Paris, Aubier, 2005, distingue individuation et individualisation. Le premier désigne les marqueurs de singularité de la personne: sceau, nom, signature, portrait, blason, etc. Le second terme recoupe «toutes les formes possibles d'autoréflexion, et d'abord dans l'écriture de soi» (p. 25). Nous privilégions le second terme pour notre propos.

366 Silvère Menegaldo, «Prologues et épilogues lyriques dans le roman de chevalerie en vers aux XII ${ }^{\mathrm{e}}$ et $\mathrm{XIII}^{\mathrm{e}}$ siècles: quand le narrateur est amoureux ", Bien dire et bien aprandre, 19, 2001, p. 165. 
Dans Melyador, le lecteur/auditeur est sollicité pour donner son avis sur les pièces lyriques qui agrémentent la narration: "Pour tant vous l'orés / et puis apriés en jugerés» (v. 8468-8469), «Tele com elle est vous l'orés / et puis vostre entente en dirés» (v. 15672-15673). Il est même encouragé à produire un commentaire écrit sur un rondeau: "Je voeil bien que vous escrisiés / que moult grandement fu prisiés / cilz rondelés sur toutes riens" (v. 29161-29163). L'auteur dessine donc au fur et à mesure de l'œuvre un lecteur modèle ${ }^{367}$, qui tout à la fois se laisse impliquer dans la fiction et se prête à l'évaluation des pièces lyriques, elles-mêmes jaugées par le narrateur: "Le public de Melyador serait ainsi envisagé à l'intérieur même de la fiction comme un récepteur susceptible de produire du texte métalittéraire, du paratexte. ${ }^{368}$ La figure de lecteur que construit le texte tardif est donc spécifique, jugée capable d'adopter un point de vue critique sur

367 Tel que l'entend Umberto Eco: le lecteur modèle est «capable de coopérer à l'actualisation textuelle de la façon dont [l'auteur] le pensait, et capable d'agir interprétativement comme lui a agi générativement." (Lector in fabula, p. 71. Voir l'ensemble du chapitre 3). Il s'agit de la «figure virtuelle construite par le texte" (Vincent Jouve, La Lecture, p. 24), impliquant non seulement une posture spécifique de lecture mais aussi un certain savoir, certaines valeurs: nous parlerons en ce sens également de lecteur modèle pour évoquer les connaissances préalables supposées du public sur l'univers arthurien. Le lecteur modèle «répondrait correctement (c'est-à-dire conformément aux vœux de l'auteur) à toutes les sollicitations - explicites et implicites - d'un texte donné»(Ibid., p. 31). Vincent Jouve souligne qu'il est en partie institué par le genre auquel l'œuvre appartient. Certains critiques, notamment Wolfgang Iser, parlent de «lecteur implicite» pour désigner la même instance: "Le lecteur implicite n'a aucune existence réelle. En effet, il incorpore l'ensemble des orientations internes du texte de fiction pour que ce dernier soit tout simplement reçu.» (Wolfgang Iser, L'Acte de lecture. Théorie de l'effet esthétique, Bruxelles, Mardaga, 1985, p. 70). "Le lecteur implicite, c'est l'ensemble des stratégies textuelles par lesquelles une œuvre conditionne sa lecture." (Vincent Jouve, L'effet-personnage dans le roman, Paris, Presses Universitaires de France, 1998, p. 19)

368 Nathalie Bragantini-Maillard, "Les jeux du narrateur dans Melyador», art. cit., p. 159-160. Ce rapport au lecteur est caractéristique de la fin du Moyen Âge: les auteurs encouragent leurs lecteurs à corriger leur texte, voire à excuser leurs maladresses. Voir Florence Bouchet, Le discours sur la lecture en France aux XIV et $X V^{e}$ siècles, p. 217-224. Voir aussi les pages 224-227 et son article, "Le lecteur à l'œuvre. L'avènement du lecteur dans le discours auctorial (France, $\mathrm{XIV}^{\mathrm{e}}-\mathrm{XV}^{\mathrm{e}}$ siècles)", Poétique, 159, 2009, p. 275-285. L'implication du lecteur dans Melyador est symptomatique du nouveau rôle qu'il prend dans la littérature de la fin du Moyen Âge. 
l'œuvre. Parallèlement, l'œuvre elle-même se voit littérarisée: elle peut se soumettre à la glose, devenir l'objet d'une analyse littéraire ${ }^{369}$.

Il s'agit d'établir un lien communicationnel privilégié avec le public pour maintenir son attention. Cette tendance se dégage aussi dans Escanor: le lecteur est invoqué à plusieurs reprises par des expressions convenues ("sachiez», "si vous di bien», "conme avez oï», "com je vouz conte») ou par des questions rhétoriques ("Et savez pour coi le faisoit?», v. 6066). Le narrateur interpelle également son lecteur à travers les expressions d'hypotypose "veïssiés», "oïssiés», "evous», "regardés com», empruntées à la chanson de geste ${ }^{370}$, au vers 6120 par exemple: «Toute noblece i veïssiez». Les formules qui donnent un effet de visualisation sont particulièrement prégnantes dans la description de la chambre des merveilles de Brian des Îles, épisode qui fait écho à la Chambre des Beautés du Roman de Troie et en imite les éléments spectaculaires. Le narrateur fait en sorte de transmettre au lecteur l'effet des peintures troyennes sur le spectateur:

D'autre part Dydo de Cartage

Rert painte si tres noblement

Qu'il vous semblast visablement

Qu'ele vouz regardast des iex. (Escanor, v. 15736-15739)

Les peintures sont longuement décrites et forment une parenthèse au sein de la narration: à aucun moment on ne commente la réaction des personnages du roman face à elles. L'accent est bien plutôt mis sur la situation de la narration: le narrataire vient remplacer le personnage dans la contemplation de l'œuvre d'art. Les tableaux sont comme extraits de la diégèse pour se donner à voir dans le présent de la narration. L'appréhension de l'image concerne aussi la qualité de la représentation, puisque le narrateur précise aux vers 15740 et 15741 qu'Énée «ert encore miex painz et fais selon son endroit». Le public contemple virtuellement la prouesse artistique, par le biais de l'acte littéraire, lui-même vanté pour ses propriétés esthétiques, dans le prologue que nous citions plus haut ${ }^{371}$.

369 Comme nous le notions, les productions destinées à l'interprétation peuvent être considérées comme littéraires.

370 Les emprunts stylistiques à la geste sont d'ailleurs légion dans le roman arthurien tardif. Nous y reviendrons au chapitre III, "Adoption de "patrons génériques exportables": l'épopée arthurienne», p. 572-595.

371 Au sujet de la chambre des merveilles dans Escanor, on consultera Géraldine Toniutti, «Les peintures troyennes dans Escanor de Girart d'Amiens: un cas 
Le narrateur de roman a pour rôle d'établir un lien de communication avec le public, mais aussi d'inciter à une démarche réflexive: les pièces lyriques de Melyador, comme les peintures troyennes d'Escanor, sont soumises au jugement direct du lecteur. L'appréciation est d'ordre littéraire: même dans le cas de l'ekphrasis, c'est l'habileté du poète à reproduire de manière vivante le tableau qui est évaluée. Ce type d'interactions oblige à une réception active, typique de la tardivité, tout comme l'invitation à déceler l'exemplarité de l'histoire et à imiter ses personnages.

\section{Registre}

La mise en place d'une situation de communication traduit les fonctions que se donne la littérature: comme nous le notions plus haut, est littéraire ce qui touche un public et ne se réduit pas à la transmission d'une information. Le prologue de la Vie des Pères dédié à Blanche de Navarre, cité aux pages 44-45, souligne que le but poursuivi peut être moral ou, à l'opposé, divertissant. Ainsi, le fabliau vise à provoquer le rire, tandis que les œuvres moralisatrices espèrent générer l'édification et le changement de comportement des destinataires ${ }^{372}$. La fonction remplie par chaque texte est génériquement distinctive: didactique, morale, distrayante ou comique.

L'effet de la littérature sur le lecteur dépend du style ou du registre adopté par l'œuvre: le fabliau nourrit son comique par des jeux de mots ou un ton scabreux, tandis que l'hagiographie adopte un ton plus sérieux, volontiers moralisateur. La Roue de Virgile, élaborée à partir du commentaire de Virgile d'Aelius Donat, distingue les trois œuvres du poète en fonction des niveaux de "stylus" adoptés: humilis stylus, mediocris

d'interférence des matières au XIII ${ }^{\mathrm{e}}$ siècle», in Matières à débat. La notion de matiere littéraire dans la littérature médiévale, dir. Christine Ferlampin-Acher et Catalina Girbea, Rennes, PUR («Interférences»), 2017, p. 401-416, Mounira MezghaniManal, "L'Euvre d'art au carrefour du Monde et de l'Autre Monde: Escanor de Girart d'Amiens", in Le Monde et l'Autre Monde. Actes du colloque arthurien de Rennes, 8 et 9 mars 2001, dir. Denis Hüe et Christine Ferlampin-Acher, Orléans, Paradigme, 2002 ("Medievalia», 45), p. 267-284, et Myriam Clément-Royer, "L'Arbre aux oiseaux "automates" dans Escanor de Girart d'Amiens", in Engins et machines. L'imaginaire mécanique dans les textes médiévaux, éd. Fabienne Pomel, Rennes, PUR («Interférences»), 2015, p. 131-156.

372 Sur les fonctions du récit, voir Jean-Marie Schaeffer, Qu'est-ce qu'un genre littéraire?, p. 101-108. 
stylus, gravis stylus ${ }^{373}$. À chaque stylus correspond une classe sociale (pastor, agricola, miles dominans), un lieu, un arbre, un animal. Ce traité était connu parmi les rhétoriciens des $\mathrm{XII}^{\mathrm{e}}$ et $\mathrm{XIII}^{\mathrm{e}}$ siècles, même s'il n'apparaît finalement que peu dans leurs théories ${ }^{374}$. Dans la Roue de Virgile, c'est le style et non le genre qui régit l'organisation du champ littéraire: celui-ci s'organise alors sur la base d'une distinction sociale. Plus précisément, la manière de s'exprimer dépend du sujet dont on traite $e^{375}$.

Qu'entendait-on par «style»? Jean de Garlande le définit entre autres sens plus concrets comme "qualitas carminis uel rectitudo seruata per corpus materie» ou "officium poete ${ }^{376}$. Ces sens, assez généraux, ne recoupent que peu notre acception moderne de la notion de style, qui comprend le niveau de langage, le lexique, l'usage de figures de rhétorique, la combinaison des phrases, la syntaxe, les temps verbaux ou la richesse des structures rimiques ${ }^{377}$. La rime «Table ronde / monde» ainsi

373 Voir Edmond Faral, Les Arts poétiques du XII et du XIII siècle, p. 86-89, Danièle James-Raoul, «La théorie des trois styles dans les arts poétiques médiolatins des XII et XIII ${ }^{\mathrm{e}}$ siècles", in Effets de style au Moyen Âge, dir. Chantal Connochie-Bourgne et Sébastien Douchet, Aix-Marseille Université, Presses Universitaires de Provence ("Senefiance»), 2012, p. 17-26, et Franz Quadlbauer, Die antike Theorie der "genera dicendi» im lateinischen Mittelalter, Graz; Vienne; Cologne, Österreichische Akademie der Wissenschaften, 1962. On doit à Jean de Garlande l'exposition du détail de cette théorie au XIII ${ }^{\mathrm{e}}$ siècle, dans la Parisiana Poetria, vers 1220.

374 Danièle James-Raoul souligne que la théorie de la tripartition des styles est peu à peu laissée de côté aux XII ${ }^{\mathrm{e}}$ et XIII ${ }^{\mathrm{e}}$ siècles: plusieurs théoriciens l'ignorent, Geoffroy de Vinsauf ne lui consacre que quelques lignes, tandis que Jean de Garlande ne la développe jamais comme objet de premier intérêt. Il s'agit dès lors d'une théorie déjà désuète à l'époque qui nous intéresse. "La théorie des trois styles dans les arts poétiques médiolatins", art. cit., p. 20-23.

375 Il s'agit tout du moins de l'interprétation qu'en a fait Isidore de Séville au $\mathrm{vI}^{\mathrm{e}}$ siècle: "Ces déformations essentielles apportées par l'évêque de Séville passent au Moyen Âge: elles sont symptomatiques d'une volonté de changer une théorie qui ne répond plus aux exigences du temps. Surtout, elles témoignent en outre d'une compréhension linguistique particulière appelée à façonner les mentalités du temps: selon l'optique isidorienne, les mots sont les indices des choses (Etymologiae, I, 3).» (Danièle James-Raoul, "La théorie des trois styles dans les arts poétiques médiolatins", art. cit., p. 20)

376 Parisiana Poetria, éd. cit., V, p. 88. "qualité du poème ou [...] justesse servie par la substance du sujet traité»; "travail du poète». Traduction de Danièle James-Raoul, «La théorie des trois styles dans les arts poétiques médiolatins», art. cit., p. 25.

377 Georges Molinié, "Style», in Dictionnaire du littéraire, Paris, PUF ("Quadrige»), 2010, p. 737-740. Pour une définition de la notion de style et une histoire de sa 
que l'itération synonymique "felenesse et dure», souvent à la rime avec "aventure», sont par exemple des traits stylistiques courants dans le genre arthurien en vers ${ }^{378}$. La notion de registre en revanche pourrait s'approcher du stylus tel qu'il est développé dans la Roue de Virgile: elle désigne des procédés exprimant des émotions et des attitudes humaines ${ }^{379}$. Le registre rend compte d'affects, dicte l'attitude affective à adopter face au texte. Le style se concentre exclusivement sur la forme du discours ${ }^{380}$ et le registre sur un effet produit par le texte (comique, tragique, terrifiant, pathétique, etc.). Le registre, comme le stylus de la Roue de Virgile, peut être élevé ou bas, selon le destinataire et le sujet choisi. Ces deux notions peuvent être considérées ensemble, pour étudier les cas d'interférences génériques de notre corpus (chapitre III, "Confluences: un mélange des genres?», p. 554-630): le style ${ }^{381}$ participe de l'effet produit par le registre ${ }^{382}$.

théorie, voir Georges Molinié, La stylistique, Paris, PUF ("Que sais-je?»), 1989, et Christine Noille-Clauzade, Le style, Paris, GF ("Corpus»), 2004.

378 Emmanuèle Baumgartner, "Jeux de rimes et roman arthurien", Romania, 103, 1982 , p. 550-560, relève un certain nombre de rimes récurrentes dans les romans arthuriens en vers.

379 Alain Viala, "Des “registres” ", Pratiques, 109-110, 2001, p. 165-177.

380 "Je réserverai donc, en ce sens restreint [...], le terme de style à des propriétés formelles du discours qui se manifestent à l'échelle des microstructures proprement linguistiques, c'est-à-dire de la phrase et de ses éléments. "Gérard Genette, Fiction et diction, p. 143.

381 Cette notion est applicable à la littérature médiévale, comme le prouvent les travaux de Danièle James-Raoul, Chrétien de Troyes, la griffe d'un style. La critique fait ici l'étude du style propre à un auteur. Elle envisage aussi la pertinence d'un style de genre. Sa définition du style est cependant large; elle englobe non seulement le lexique et les figures de rhétorique, mais aussi les topoi, les motifs, l'énonciation et les figures narratives. "Questions de style à propos des romans arthuriens en vers des XII ${ }^{\mathrm{e}}$ et XIII" siècles", JIAS, 4/1, 2016, p. 25-52, "La stylistique médiévale", Perspectives médiévales, Trente ans de recherches en langues et en littératures médiévales, dir. Jean-René Valette, 2005, p. 265-284. Voir aussi Chantal Connochie-Bourgne et Sébastien Douchet (dir.), Effets de style au Moyen Âge, Aix-Marseille Université, Presses Universitaires de Provence ("Senefiance»), 2012. Séverine Abiker ("Style de genre? les rimes jumelées dans les lais narratifs", in Les Genres littéraires en question au Moyen Âge, dir. Danièle James-Raoul, Bordeaux, Presses universitaires ("Eidôlon », 97), 2011, p. 133-146) démontre quant à elle l'homogénéité stylistique du genre des lais narratifs en analysant les rimes jumelées.

382 Benjamin Bouchard problématise les différences entre genre et registre, abordé comme notion paragénérique. "Critique des notions paragénériques», art. cit. 
La pertinence de la notion de registre se vérifie lorsque l'on envisage la généricité de certains récits brefs arthuriens: les lais du Cor et du Mantel mautaillé présentent une cour arthurienne canonique - dont atteste la fête d'ouverture à la Pentecôte - en proie à des problématiques de fabliaux. Les femmes de la cour sont en effet soumises à une épreuve de chasteté à laquelle toutes échouent, sauf l'épouse de Caradoc. Agrémentés des allusions grivoises de chevaliers cocus et de leurs propos misogynes, ces textes s'éloignent du ton habituel des romans arthuriens. Keu y affectionne particulièrement les aphorismes sexuels à double sens; "Mal est couvert cui le cul pert!» (Mantel, v. 660), tandis que Gaheriet déclare que «mout poi li grieve / a lever contremont les dras, / quar ele veut isnel le pas / soit la besoingne apareillie.» (Mantel, v. 497-500). Le thème fabliesque de l'infidélité féminine couplé au style choisi, au registre du comique et à la brièveté interroge le genre auquel appartiennent ces deux récits brefs ${ }^{383}$ : Emmanuèle Baumgartner exclut le fabliau et le lai, au motif que la structure, l'idéologie et les personnages «sont trop formalisés, trop liés à un type de récit, pour pouvoir être transposés tels quels dans l'univers du fabliau » ${ }^{384}$. L'hésitation générique est néanmoins réelle: elle porte sur une question de registre, associé à un univers fictionnel connoté génériquement, celui du roi Arthur.

Le partage d'un même univers n'empêche pas les textes qui l'activent de présenter des différences d'ordre générique. Le registre est aussi conditionné par le choix de la forme et distingue le roman arthurien en vers de son homologue en prose; le vers invite à une réception ludique, fondée sur le jeu avec la tradition antérieure que l'auteur parodie,

Selon notre définition du genre et notre manière de l'aborder, nous considérons que les différences de registres sont génériques, c'est-à-dire qu'on peut les considérer comme facteur de distinction ou de regroupement de textes. Le registre est un critère générique mais ne saurait former un genre.

383 Nathalie Koble traite du rapport entre ces deux récits brefs et le fabliau aux pages 136 à 141 de Les dessous de la Table ronde, éd. cit.

384 Emmanuèle Baumgartner, "À propos du Mantel mautaillé», art. cit., p. 331, Howard R. Bloch, "Le mantel mautaillé des fabliaux. Comique et fétichisme», Poétique, 14, 1983, p. 181-198. Le contexte manuscrit du Lai du Cor montre que la réception médiévale de ce texte n'est pas celle d'un roman arthurien: il est entouré de textes qui traitent de la nature féminine. Voir Beatrice Barbieri, «Le contexte manuscrit du Lai du cor et la réception tardive des lais (avec une note sur Renart le Contrefait) ", Études françaises, 48/3, 2012, p. 115-125. 
interroge, à laquelle il fait écho. Le but est toujours le divertissement, voire le rire du spectateur. Les romans en prose du Graal, notamment la Queste del saint Graal et la Mort Arthur cultivent un ton plus sérieux, lié à l'idée de chute, de péché. Le monde arthurien ne suffit donc pas à former un ensemble générique totalement homogène, bien que le roman arthurien, comme son nom l'indique, se définisse avant tout par son univers de fiction; par sa matière.

\section{Genre et matière}

La matière est ce qui définit, en priorité, le roman arthurien. Cette notion désigne le matériau brut, en attente du travail de l'auteur qui devra le mettre en forme. Le terme est utilisé dans un sens métapoétique dans de nombreux textes, dans tous les genres et à toutes les époques ${ }^{385}$. Jacqueline Cerquiglini-Toulet en donne la définition suivante:

Selon les théories médiévales de la génération, reprises d'Aristote, la matière est ce qui est non encore organisé par une forme et à partir de quoi, grâce à quoi, dans le domaine de la création littéraire, on écrit ${ }^{386}$.

Le terme est préféré, au Moyen Âge, à «sujet», pour évoquer l'idée d'une "pâte, que vont travailler les formes " ${ }^{387}$. Il est employé en conformité avec l'étymologie établie par certains penseurs médiévaux, comme Isidore de Séville et surtout Uguccio de Pise; materia découlerait de mater, la mère, plus précisément de mater rei, "mère des choses». La matière est ce en quoi s'origine toute création ${ }^{388}$ et peut alors prendre un sens concret et abstrait. C'est à partir de son sens concret, issu de l'artisanat, "matière» renvoyant au bois par exemple, que l'usage métapoétique s'est construit sur un mode métaphorique. Le traité poétique de Geoffroy de Vinsauf à la

385 Les colloques de Poitiers, Rennes et Bucarest sur la notion de matière en 2015 ont permis de dresser un panorama des apparitions du terme et d'en dégager une définition. Ces travaux ont montré que le terme pouvait intervenir dans un contexte lyrique et ne se résume par à ses emplois narratifs. Voir les actes du colloque, Christine Ferlampin-Acher et Catalina Girbea (dir.), Matières à débat.

386 Jacqueline Cerquiglini-Toulet, «Littérature Médiévale?», art. cit., p. 111.

387 Ibid., p. 112.

388 Jean-Marie Fritz, "La matiere biblique selon Evrat", in Matières à débat, p. 515-529. C'est à Uguccio de Pise que l'on doit cette interprétation étymologique, dans son Derivationes, somme étymologique des environs de 1200. 
fin du XII ${ }^{e}$ siècle présente la matière comme une pâte, ou une cire, qu'un artiste viendrait façonner:

Formula materiae, quasi quaedam formula cerae,

Primitus est tactus duri: si sedula cura

Igniat ingenium, subito mollescit ad ignem

Ingenii sequiturque manum quocumque vocarit,

Ductilis ad quicquid ${ }^{389}$.

La métaphore de la cire malléable rejoint celle du fer que l'on forge lorsqu'il est chaud. Elle illustre le fait que la matière attend d'être façonnée, en l'occurrence par un travail poétique. L'emploi du mot "matière» dans un cadre métapoétique résulte donc d'un travail métaphorique: le terme a d'abord un sens concret et désigne le matériau brut utilisé dans l'artisanat, façonné par l'orfèvre, le charpentier, le maçon. Conrad de Mure (xIII ${ }^{e}$ siècle) l'exprime ainsi: "Vel materia est id, ex quo aliquid fit, sicut ligna et lapides materia domus construende. " ${ }^{390}$ Lorsqu'il travaille une matière, le poète exerce une opération similaire à celle de l'artisan façonnant un matériau ${ }^{391}$. C'est à l'auteur de la former, de l'allonger ou de l'abréger, comme le préconise Brunet Latin qui use de la même métaphore: "Car matire est samblable a la cire, ki se laisse mener e apeticier et croistre a la volenté du mestre. ${ }^{392}$ C'est aussi en ce sens que Jean de Garlande parle de «materiam nudam», comme «illam que non est rhetorice ampliata neque

389 Poetria nova, v. 213-217, in Edmond Faral, Les Arts poétiques du XII et du XIII siècle: "Un petit fragment de materia est comparable à un morceau de cire: d'abord, il est dur au toucher; mais si le zèle du génie le fait cuire à son feu, il mollit aussitôt à ce feu et prend la forme, quelle qu'elle soit, à laquelle le voue la main.» (trad. Jean-Yves Tilliette)

390 «Matière est ce dont quelque chose est fait, comme le bois ou les pierres utilisés pour la construction d'une maison." Conrad de Mure, Summa de arte prosanti, éd. Walter Kronblicher, in Geist und Werk der Zeiten, Zürich, Fretz und Wasmutg, 1968, p. 66. Ioana Munteanu traite de l'étymologie du mot «materia» dans son article "Matière subtile, matière non-corporelle, matière abstraire chez les auteurs latins de l'Antiquité tardive», in Matières à débat, p. 27-37.

391 Voir l'introduction aux actes du colloque Matières à débat, et l'article de Danièle James-Raoul dans ce recueil, "La materia en question dans les arts poétiques médio-latins", art. cit.

392 Brunet Latin, Li Livres dou Tresor, éd. cit., p. 330. 
ornata ${ }^{393}$. La matière est brute ou "nue» lorsqu'elle n'est pas encore mise en forme par le travail rhétorique.

Hors des traités de poétique, le mot «matière» apparaît fréquemment à l'occasion d'interventions métapoétiques dans la littérature vernaculaire. Dans la Suite du Roman de Merlin, la matière recoupe le travail littéraire, le sujet appelé à être mis en forme par l'auteur: "Messires Helyes mes compains a empris sa matiere a recorder chi et a translater en conte celle partie pour un poi alegier de ma painne. ${ }^{394}$ Entreprendre une matière semble ici synonyme de l'acte de composition, de la peine que représente le travail poétique. Travailler une matière signifie surtout suivre un canevas, transmettre une information selon un ordre précis. À partir de cette définition très générale, le mot "matière" se décline en plusieurs nuances de sens. D'abord, les vers comme "Mais or retorne la matere / A Gaherïet» (Claris, v. 21504-21505) ou «Issi com la matere conte» (La Vengeance Raguidel, v. 12) ${ }^{395}$, l'érigent en instance narrative qui performe le récit. À l'instar du "conte» ou du «livre», la matière organise et hiérarchise, dans ces occurrences, le déroulement de l'histoire. Sujet de la phrase, elle semble réciter elle-même le texte. Elle se rapproche en ce sens de la source écrite; c'est d'ailleurs un autre de ses usages, comme dans le prologue d'Escanor: "Pour coi des or voeil conmencier / A dire le conte tout outre, / Enssi con la matere moustre.» (v. 58-60)

Plus fréquemment, l'expression réfère à un sujet spécifique, principal, excluant les digressions; dans la Première Continuation, l'histoire de Joseph d'Arimathie est écartée du discours principal: «Mais n'afiert pas a ma matire» (Première Continuation du Conte du Graal, v. 7542) ${ }^{396}$. Ce vers se retrouve presque à l'identique chez Chrétien de Troyes:

Mes n'an vuel feire mancion,

Car n'afiert pas a ma matire

393 Parisiana Poetria, éd. cit., V, p. 64, 1. 143-147. "J'appelle "matière nue" celle qui n'est pas amplifiée par la rhétorique ni ornée. " (trad. de Danièle James-Raoul, "La materia en question dans les arts poétiques médio-latins des $\mathrm{XII}^{\mathrm{e}}$ et XIII ${ }^{\mathrm{e}}$ siècles ", in Matières à débat, p. 39-49.)

394 La Suite du Roman de Merlin, éd. Gilles Roussineau, Genève, Droz, 2006, $\$ 357$.

395 Raoul de Houdenc, La Vengeance Raguidel, éd. Gilles Roussineau, Genève, Droz, 2004.

396 Première Continuation du Conte du Graal, éd. William Roach et trad. Colette Van Coolput-Storms, Paris, Le Livre de Poche («Lettres Gothiques»), 1993. 
Que ci androit an doie dire,

$\mathrm{Ne}$ je ne la vuel boceier

Ne corronpre ne forceier,

Mes mener boen chemin et droit.

(Le Chevalier de la Charrette, v. 6256-6261)

La matière ne doit pas être détournée, corrompue ou altérée; elle ordonne ici les éléments et impose un droit chemin à suivre pour dérouler la narration. La matière est dotée d'une volonté propre, elle dicte le contenu du récit. Elle a dès lors un pouvoir de structuration. Elle est parfois employée en ce sens pour justifier l'ordre de composition du récit, en référant à un personnage en particulier et en prenant le sens de «ce qui concerne $X_{»}$ : «Mes or vendrons a la matere / D'Yvain, le chevalier vaillant" (Claris et Laris, v. 17707-17708). La «matière d'Yvain» signifie le contenu narratif qui concerne ce personnage en même temps qu'elle souligne le changement de perspective du récit, l'adoption d'un nouveau sujet.

La matière soumet dès lors ceux qui la travaillent. Le narrateur de Claris et Laris explicite l'autorité de la matière sur le poète:

Seingnor! Qui matere encomence,

En plusors leus met sa semence.

Toute li couvient recoillir

S'a matiere ne veult faillir,

Mes c'est trop mauvese maniere

Quant li hons faut a sa mati[e]re.

Moult l'en doit por musart tenir!

Si vueill a la moie venir. (Claris et Laris, v. 5661-5668)

Cet extrait prend la forme d'un petit prologue ${ }^{397}$ visant à capter l'attention du public que l'on interpelle. La rime "encomence» - «semence» rappelle le prologue du Conte du graal ("Crestiens seime et fait semence / D'un romanz que il encommence», v. $7-8)^{398}$, dans lequel Chrétien de Troyes compare l'écriture à la récolte agricole: il faut semer sur une terre riche

397 Voir Adeline Latimier, «Le nom et la matiere dans le roman arthurien tardif en vers", in Matières à débat, p. 273-288.

398 Chrétien de Troyes, Le Conte du graal, éd. Charles Méla, Paris, Le Livre de Poche («Lettres gothiques»), 1990. 
pour obtenir un fruit généreux. Le terme «roman» est ici remplacé par "matere»: celle-ci semble être l'équivalent de "poème», "composition". Les deux autres emplois renvoient à un contenu principal et exigeant, auquel il ne faut pas faillir: l'auteur qui ne s'en tient pas à sa matière, mais qui la trahit en digressant, est un étourdi, que l'on suppose indigne d'écrire. La métaphore de la récolte est détournée pour évoquer l'idée de dispersion: celui qui compose une "matere» ne doit pas mettre sa semence en plusieurs lieux, mais au contraire la «recoillir», la rassembler autour d'un sujet cohérent. L'auteur de Claris et Laris entend quant à lui se conformer à sa trame principale et renonce pour cela à développer certains éléments: «Si vueill ma matire tenir.» (v. 13414)

Le terme «matière» peut revêtir plus généralement le sens de "récit», "thème narratif", "sujet», comme dans Guigemar de Marie de France ("Ki de bone mateire traite, / Mult li peise si bien n'est faite», v. 1-2), le Chevalier de la Charrette ("Matiere et san li done et livre / La contesse», v. 26-27) ${ }^{399}$, Biaudouz («Por muez entendre vos dirai / La matire dont traiterai: [résumé du sujet général de l'œuvre]», v. 1-2 de l'édition Lemaire) ou Floriant et Florete ( $\mathrm{Ne}$ ja por vous ne quier laissier / $\mathrm{Ma}$ matere a encommencier.», v. 23-24). Froissart l'utilise aussi pour désigner le sujet des poèmes lyriques que composent les personnages de Melyador:

La demoiselle avoit d'usage

De dire en son parler pour vrai :

"Sans doubte ensi je le ferai.»

Briefment en sa parolle toute

Toutdis mettoit devant sans doubte.

Messires Tangis, qui ö̈

L'avoit souvent, s'en resjö̈

Entrues que sus son lit gisoit,

Et a le fois ce mot disoit.

Tant l'avoit il enamouré

Et en son coer encorporé

Et y prendoit si grant plaisir

C'a painnes en pooit issir.

399 La critique a beaucoup glosé ces vers du prologue de la Charrette. Suite à plusieurs débats, il faut admettre avec Jean Frappier que "matière" a bien le sens de «sujet» et "sens" celui d' «idée maîtresse», de "signification du roman». Voir "Le prologue du Chevalier de la Charrette et son interprétation", Romania, 93, 1972, p. 337-377. 
Dont il avint, ce termine

Qu'il gisoit dedens la courtine

Du Brun Manoir, ou .II. mois fu,

Q'il ot ordonnance et argu

De faire un jolit virelay

Sus la matere que dit ay. (Melyador, v. 18056-18074)

L'expression récurrente qu'utilise la demoiselle ravit Tangis, à tel point qu'il en compose un virelai. Cette petite aventure devient matière, contenu propre au travail poétique. Le concept s'applique ainsi aussi bien à une composition lyrique que romanesque $\mathrm{e}^{400}$.

Les usages du mot «matière» renvoient toujours à la transmission d'un contenu informatif, non encore formalisé, à un récit en train de s'élaborer, et découlent assez fidèlement des sens définis par les traités de poétique latins. On peut donc suivre en définitive Brunet Latin, qui assimile la matière à l'objet du discours:

Encore nous ensegne Tulles que nous regardons nostre matire, sor quoi nous devons parler et escrire letres, s'ele est toute simple d'une chose seulement, ou s'ele est de plusours ${ }^{401}$.

La matière est ce dont le poète ou le rhétoriqueur doit parler. Hélène Bouget le résume ainsi: "C'est donc au sens de sujet dont on parle ou bien de récit ou de l'histoire faisant l'objet du récit, que le terme est majoritairement employé. ${ }^{402}$ Cette définition est applicable à toute

400 Pour plus d'exemples de l'utilisation du mot "matière», on consultera les actes du colloque Matières à débat, notamment l'article d'Adeline Latimier, "Le nom et la matiere dans le roman arthurien tardif en vers", p. 273-288, qui signale d'autres occurrences du terme dans Claris et Laris et Melyador: il est soit employé pour caractériser le thème du poème à venir, soit il permet à l'auteur de hiérarchiser son récit. La matière structure le propos, contraint à passer d'un personnage à l'autre, à accélérer ou à commenter. Nathalie Bragantini-Maillard recense aussi dans son glossaire les emplois variés du terme dans Melyador, éd. cit., tome 2, p. 1824-1825. On consultera pour finir Pierre Gallais, L'imaginaire d'un romancier français de la fin du XII siècle. Description raisonnée, comparée et commentée de la Continuation-Gauvain, 3 tomes, Amsterdam, Rodopi, 1988, tome 2, p. 778-782, qui commente un certain nombre d'occurrences du terme dans différents genres.

401 Brunet Latin, Li Livres dou Tresor, éd. cit., p. 325.

402 Hélène Bouget, «Matière de Bretagne et source: approche historiographique et critique», in Matières à débat, p. 71. 
production artistique, indépendamment de son genre et de son époque: chaque œuvre travaille une matière, qu'elle met en forme. Montaigne donne le même sens à ce mot au début de ses Essais: "Ainsi, lecteur, je suis moy-mesme la matiere de mon livre ${ }^{403}$. L'adresse au lecteur, tel un prologue, prévient du sujet dont il sera question, le terme "matière» supposant toujours un travail poétique, tout comme la matière brute appelle le travail du forgeron, du sculpteur ou de l'orfèvre.

Les exemples que nous proposons esquissent plus précisément deux emplois conceptuels de "matière": l'un renvoie à l'idée d'un monde narratif qui préexiste au texte et dans lequel l'auteur puise ce que bon lui semble, dans les occurrences où le mot recoupe une source fictive. Dans le prologue du Roman de Meliadus, l'expression «matere du Saint Graal» réfère aussi à un thème narratif préexistant: "Et vueult que, en cestui livre que je commencerai a l'onneur de lui, soient contenues toutes les choses qui en mon livre du Bret faillent et es autres livres qui de la matere du Saint Graal furent estraites.» (Roman de Meliadus, prologue au ms. BnF fr. 338 ${ }^{404}$. La «matière du Saint Graal» semble désigner un monde virtuel réactivé dans plusieurs livres: un contenu narratif que les auteurs peuvent extraire, exploiter, un réservoir infini dans lequel puiser. Ici, le choix d'une matière suppose le choix d'un monde, qui comprend des personnages et un cadre spatio-temporel. Cet emploi est proche du concept d'univers de fiction, théorisé par Thomas Pavel dans Univers de la fiction ${ }^{405}$, puis réinvesti par les théories de la lecture, notamment par Richard Saint-Gelais, qui le définit comme la «reconstitution que les lecteurs font d'un monde élaboré par une fiction ${ }^{406}$. On feint ainsi que les mondes proposés par chaque fiction existent en dehors de la littérature et que chaque auteur peut choisir de les mobiliser pour évoquer tel élément constitutif du monde. Chaque roman construit son propre monde de fiction; Madame Bovary élabore un monde où il est vrai qu'Emma Bovary est la femme de Charles et l'amante de Rodolphe. L'univers de fiction est toujours infiniment plus exhaustif que ce que l'œuvre littéraire laisse percevoir (le lecteur

\footnotetext{
403 Montaigne, Essais, éd. Marie-Madeleine Fragonard, Paris, Pocket, 1998, p. 24.

404 Voir Roger Lathuillère, Guiron le courtois. Étude de la tradition manuscrite et analyse critique, p. 176.

405 Thomas Pavel, Univers de la fiction.

406 Richard Saint-Gelais, Fictions transfuges. Voir aussi Umberto Eco, Lector in fabula, pour une appréhension des univers de fiction du point de vue de la réception.
} 
n'apprend jamais si Emma Bovary aime le chocolat). Toutefois, la matière peut être applicable à l'historiographie et à la lyrique, tandis que l'univers de fiction désigne exclusivement, comme son nom l'indique, un monde qui prend appui sur le monde réel mais qui demeure fictionnel. Dès lors, peu importe que la matière du Saint Graal soit réelle ou fictive: l'auteur du prologue du Roman de Meliadus la nomme pour accentuer le partage d'un même monde de références entre son œuvre et celles qui lui préexistent. La matière, c'est donc un réservoir d'histoires prêtes à être actualisées, sur le mode de la transfictionalitét ${ }^{407}$ pour les romans du Graal, ou par la réécriture: Racine travaille une matière antique, la même qu'Euripide dans son Hippolyte, lorsqu'il écrit Phèdre.

Les emplois que l'on peut dégager du reste de nos exemples désignent l'œuvre en cours d'élaboration, le cadre strict du narré, indépendant de toute source qui lui préexisterait. La matière est circonscrite par l'auteur avant voire pendant l'écriture. Dans cet usage, elle se révèle proche de la notion de diégèse, au sens étymologique du mot, diegesis, chez Aristote; l'histoire racontée par le récit, les données sélectionnées par ce récit ${ }^{408}$. Alors que l'univers de fiction est autonome, la diégèse est engendrée par un auteur et ne peut être détachée du texte qui la transmet - qu'il s'agisse d'un récit oral ou d'une œuvre physique. Dans l'exemple suivant, tiré d'Escanor, le terme "matière» peut en effet être compris comme synonyme de diégèse ou d'histoire:

Mais de tel chose ne covient

En ma matere pluz parler,

Car d'aillors m'ai mout a meller

D'autres choses que je dirai

Car du tournoi vous conterai. (Escanor, v. 4892-4896)

\footnotetext{
407 Richard Saint-Gelais, Fictions transfuges.

408 Ce n'est dès lors pas le sens qu'Étienne Souriau donne au mot «diégèse» ( La structure de l'univers filmique et le vocabulaire de la filmologie", Revue internationale de filmologie, 7-8, 1951, p. 231-240) que nous entendons convoquer, ni celui que Gérard Genette précisera dans Nouveau discours du récit, Paris, Seuil, 1983: les deux critiques définissent la diégèse comme un concept proche, si ce n'est équivalent, à celui d'univers de fiction. Dans Figures III en revanche, le terme "diégèse" et surtout son adjectif «diégétique» peuvent être compris comme l'équivalent d' «histoire», c'est le sens que nous retenons pour notre confrontation à la matière.
} 
Cet usage peut bien s'interpréter dans le sens de "trame narrative», et matière désigne alors le récit compris entre les bornes du texte, sans aucune allusion à une entité externe.

Dès lors, «matière» est lié à l'affirmation d'un acte créateur de la part de l'auteur, dont le statut s'affermit petit à petit au Moyen Âge ${ }^{409}$. Elle traduit l'appropriation par l'écrivain d'un contenu narratif qu'il transpose en texte littéraire. Comme l'expriment Christine Ferlampin-Acher et Catalina Girbea, le concept ne renvoie pas «à une poétique générale, à une poétique de genre ou de corpus, mais à la poétique d'un auteur, voire d'une œuvre, plus centrée sur la production que sur la reconnaissance d'une catégorie $»^{410}$. Cela se manifeste par l'utilisation fréquente du possessif, "ma matere», dans les exemples d'Escanor, de la Première Continuation, de Floriant et Florete, de Claris et Laris, du Chevalier de la Charrette et de la Suite du Roman de Merlin cités plus haut. Avec le terme "matière», l'auteur présente son travail comme un processus et en exhibe les jalons: la matière va et vient d'un personnage à l'autre (Claris et Laris), elle force à suivre une ligne directice (Premiere Continuation, Chevalier de la charrette), fournit un sujet auquel donner du sens (Suite du Roman de Merlin). La matière désigne l'œuvre en cours d'élaboration, dans son unicité et sa spécificité et suggère "la création poétique dans ce qu'elle a d'ineffable et d'original ${ }^{411}$; un statut intermédiaire entre la source et le produit fini. Consubstantielle à la création, la matière appelle un travail poétique.

La matière impose aussi une forme $e^{412}$, ainsi que l'exprime Martin le Franc $\left(\mathrm{xv}^{\mathrm{e}}\right.$ siècle $)$ :

409 Delphine Burghgraeve, Jérôme Meizoz, Jean-Claude Mühlethaler, Postures d'auteurs: du Moyen Âge à la modernité.

410 Christine Ferlampin-Acher et Catalina Girbea, "Conclusions", in Matières à débat, p. 671.

411 Ibid., p. 671-672.

412 Richard Trachsler lie cette contrainte qu'exerce la matière au stilus de la Roue de Virgile: la matière contraint les différents paramètres du stilus. Disjointures conjointures, p. 17-19. "La materia n'est pas une "matière brute", mais [...] elle est elle-même chargée de certaines informations.» (p. 18) De sa théorisation de la matière, nous retenons la prise en considération des personnages comme critère principal d'identification d'une matière, mais nous mettons plus de réserve à l'idée d'une matière qui serait «le pivot d'une classification de la littérature narrative médiévale» (p. 20). Pour nous, la matière peut être un critère générique, mais pas un outil de classification. Voir les pages 9 à 20 de son étude. 


\begin{abstract}
Si est la matiere pesant
Plus requerant prose que rime

Et qui n'est clerc moult souffisant

A paine en entent il le disme,

Car mainte fallace ou sophisme

Et mainte auctorité obscure

Se treuvent ou parfont abisme

De la vraie et saincte Escripture.
\end{abstract}

(Martin le Franc, Champion des Dames, v. $21274-21280)^{413}$

La matière requiert le latin plus que le "commun langage» (v. 21282), car le sujet, celui des Saintes Écritures, est trop «hault et sage» (v. 21284) pour être restitué dans une langue vulgaire. Le caractère "pesant» de ce sujet implique une forme intuitive, celle de la prose, pour en percevoir plus directement les significations. La prédétermination d'une forme par la matière explique la confusion fréquente entre genre et matière. L'équivoque résulte de l'interdépendance entre les critères génériques: de même que la forme impose un traitement spécifique de la matière arthurienne, cette conjonction imposant ensuite un style, un registre, une structure $^{414}$, la laisse assonancée en décasyllabes suppose la mise en exergue de l'idéologie de croisades, la glorification de guerriers français et l'application de procédés stylistiques comme la laisse parallèle. L'exemple de Brun de la Montagne prouve que dans le cas de la chanson de geste, c'est bien le cadre formel qui fait office de critère saillant et qui influence notre appréhension générique du texte, et non sa matière. Ainsi, même si la matière demeure saillante pour la période médiévale, elle doit être considérée comme un critère générique, affecté par le choix d'autres critères, et non comme un concept équivalent à celui de genre.

413 Martin le Franc, Le Champion des dames, éd. Robert Deschaux, Paris, Champion ("CFMA»), 1999, t. V. On note, sur l'opposition entre vers et prose, que le vers est reservé à la célébration dans ce texte: l'allégorie Franc Voloir veut son «versiffiement [...] continuer pour essausser tres haultement" (v. 21269-21271) la Vierge Marie que Faux Semblant a injuriée. La prose se réserve quant à elle aux textes qui invitent à un déchiffrement, tels que la Bible.

414 L'auteur qui adopte une matière en particulier "choisit des personnages, un cadre spatio-temporel et un mode de diction (mètre, strophe etc.) qui "va avec" " (Richard Trachsler, Disjointures - conjointure, p. 16). 
La confusion entre la notion de matière et le concept théorique de genre s'explique surtout en raison de l'interprétation que la critique moderne fait du prologue de la Chanson des Saxons de Jean Bodel $\left(\mathrm{XII}^{\mathrm{e}}\right.$ siècle). À partir de ce témoignage, la critique a hiérarchisé la production littéraire médiévale en trois matières, dont la distinction avec la notion de genre littéraire est floue encore aujourd'hui. La Chanson des Saxons esquisse effectivement une relation générique pour présenter les trois matières principales:

N'en sont que trois materes a nul homme vivant:

De France et de Bretaigne et de Ronme la grant;

$\mathrm{Ne}$ de ces trois materes n'i a nule samblant.

Li conte de Bretaigne si sont vain et plaisant,

Et cil de Ronme sage et de sens aprendant,

Cil de France sont voir chascun jour aparant. (v. 6-11) 415 $^{15}$

Dans ce témoignage, la matière hiérarchise la littérature à la manière du genre; les adjectifs qui sont associés à chaque matière démontrent que chaque catégorie produit un effet différent sur son public. Selon Jean Bodel, une matière peut avoir une fonction didactique - de sens aprendant - ou distrayante - plaisant-, elle engage un rapport particulier à la fiction - vrai ou vain. Ces distinctions sont génériques. Cette conception est loin de réduire la matière au contenu et se révèle proche de notre définition du genre. Toutefois, en se penchant sur la réalité des textes, on constate bien moins d'homogénéité que ne le laisse penser Jean Bodel: très vite, les matières que l'auteur du XII ${ }^{e}$ siècle identifie se côtoient au sein d'une même ouvre ${ }^{416}$ - dans La Bataille Loquifer par exemple - et ne se privent pas de remplir d'autres fonctions que celles que leur attribuait Jean Bodel - ainsi du roman arthurien en prose de première génération, ressortissant de la matière de Bretagne, qui revendique pourtant sa portée morale bien plus que son côté divertissant. Il s'agit en fait d'un témoignage isolé: la notion de matière n'est présentée ainsi que dans ce prologue et l'attribution d'une origine géographique ${ }^{417}$ à chaque matière

415 Jean Bodel, La Chanson des Saxons, éd. cit.

416 Voir l'étude de Richard Trachsler sur les interférences de matières bodéliennes, Disjointures-conjointures.

417 Il paraît pertinent d'assimiler la matière bodélienne à la notion de chronotope bakhtinien. Nous reviendrons sur cette notion au chapitre II, "Choix de forme, 
n'apparaît nulle part ailleurs. L'expression «matière de Bretagne» constitue donc un hapax ${ }^{418}$.

Il faut alors se garder de donner trop d'importance au prologue de la Chanson des Saxons pour la théorie du genre médiéval: il s'agit d'abord d'un commentaire orienté par la volonté de promouvoir une matière, celle de France, dans laquelle s'inscrit la Chanson des Saxons. Ensuite, le champ littéraire est loin de se réduire à trois matières ${ }^{419}$. La tripartition et son exclusivité («n'en sont que trois») doivent d'ailleurs être comprises dans le sens d'un goût pour le ternaire plus que comme une ambition d'exclusivitét ${ }^{420}$. Finalement, l'interprétation moderne de ce témoignage a souvent associé les matières bodéliennes respectivement à la chanson de geste, au roman antique et au roman arthurien ${ }^{421}$, établissant des équivalences problématiques à

choix de chronotope», p. 242-325. Retenons pour l'instant que nous ne la confondons pas avec celle d'univers de fiction; le chronotope, tel que le théorise Bakhtine, ne désigne pas un monde constitué de personnages, d'un temps et d'un espace, comme on a tendance à l'employer en parlant de "chronotope arthurien ". Le chronotope désigne les relations dynamiques d'un temps et d'un espace, générateurs d'action, centres de la concrétisation figurative. Voir Esthétique et théorie $d u$ roman. En ce sens, les matières telles que les présente Jean Bodel peuvent être chronotopiques, dans la mesure où elles s'appuient avant tout sur des espaces géographiques (la France, la Bretagne et Rome), qui se couplent implicitement à un type de temporalité (temps réel, temps incertain de la merveille, temps mythologico-antique). En revanche, il nous semble que le terme "matière" tel qu'il est employé dans les usages les plus courants n'est pas chronotopique.

418 Adeline Latimier souligne que l'expression «matière de Bretagne» n'apparaît que chez Jean Bodel. Les textes arthuriens parlent quant à eux d' "aventures de Bretagne» (dans Claris et Laris par exemple, v. 88), ce qui en dit long sur le rôle définitoire de la notion d'aventure pour le genre qui nous intéresse. Voir son article "Le nom et la matiere dans le roman arthurien tardif en vers", in Matières à débat, p. 273-288. Hélène Bouget constate elle aussi la rareté du syntagme. Elle remarque que la matière n'est jamais associée à une origine géographique et que le prologue de Jean Bodel a mené la critique à confondre "matière" et «source". "Matière de Bretagne et source: approche historiographique et critique», in Matières à débat, p. 67-82.

419 Jean-Jacques Vincensini le souligne d'ailleurs lorsqu'il traite du récit idyllique. "Genres et "conscience" narrative au Moyen Âge. L'exemple du récit idyllique», Littérature, 2007, 148, p. 59-76.

420 Christine Ferlampin-Acher et Catalina Girbea, "Conclusions», in Matières à débat, p. 663.

421 Helmut Meter dresse par exemple l'équivalence entre la matière de Bretagne et le roman arthurien de Chrétien de Troyes: «Unter diesen [les contes de Bretagne] 
plusieurs égards: le plus évident est qu'on occulte de cette façon les autres genres, comme le lai breton, qui peuvent résulter d'une matière bodélienne. L'autre incohérence concerne les niveaux sur lesquels se situe chaque terme: on oppose «chanson de geste» d'une part et «roman» de l'autre, ce dernier se scindant encore en roman arthurien et roman antique. Il s'agit donc d'une opposition entre des formes métriques, problématique si on la couple aux matières bodéliennes ${ }^{422}$.

Les matières bodéliennes relèvent sans doute du cognitif: Jean Bodel entend catégoriser les grands sujets du XII ${ }^{\mathrm{e}}$ siècle pour les mettre en valeur et faciliter l'appréhension du champ littéraire par le public, ce qui ne signifie pas que le mot «matière» soit réservé aux domaines qu'il évoque. Il faut donc à notre sens abandonner totalement toute théorisation générale que l'on pourrait tirer de ce témoignage. Cela résout sa difficile articulation avec la notion de genre: la matière se manifeste dans les œuvres, mais elle n'est pas équivalente à un genre. Afin de se départir de la conception bodélienne de la matière, on doit admettre qu'il existe autant de matières qu'il y a de textes, même si certaines œuvres partagent la même matière: dans le cas du roman arthurien, la matière constitue un critère générique pertinent, lorsqu'elle prend le sens d'univers de fiction. Bien qu'elle dicte souvent le choix des autres critères, la matière n'a pas le même statut que le genre: celui-ci rend compte de l'ensemble des interactions entre les postes génériques. Il faut donc l'utiliser comme un concept surplombant, qui sert à décrire des phénomènes littéraires; la matière, malgré son statut métapoétique, n'est pas un outil théorique qui rendrait compte de relations textuelles. Elle ne sert pas à exposer des relations textuelles: elle fournit un sujet, un contenu narratif, un thème au poète, qui le contraint plus ou moins par la suite dans ses choix formels. Chaque genre peut se définir à partir d'une matière spécifique (c'est le cas du roman arthurien), mais en aucun cas la matière ne suffit à circonscrire un genre dans son ensemble.

sind aber im wesentlichen keine anderen Dichtungen zu verstehen als die arthurischen Ritterromane des Chrétien de Troyes.» («... de chevaleries d'amours et de cembiaus. Liebesthematik und Genre-Problematik in Jean Bodels Sachsenlied", in Das Epos in der Romania. Festschrift für Dieter Kremers zum 65. Geburtstag, dir. S. Kaller et E. Mara, Tübingen, G. Narr, 1986, p. 273.) «Sous cette appellation [de "contes de Bretagne"], on n'entend pratiquement pas d'autres œuvres que les romans de chevalerie arthuriens de Chrétien de Troyes.» (nous traduisons).

422 Richard Trachsler traite des problèmes liés à cette équivalence dans son article, "Genres und matières. Überlegungen zum Erbe Jean Bodels", art. cit. 
Il faut également se garder d'opposer genre et matière sur le modèle de la distinction entre forme et fond: la généricité englobe et la forme et le fond. Nous partageons en ce sens l'avis de Jacqueline Cerquiglini-Toulet:

De la combinaison de matières - grands champs identifiés par les auteurs et leur public: Dieu, les armes, l'amour -, de formes: prose et vers, chant et dit, et de modes d'action: sagesse et plaisir, fable et histoire, naît ce qu'on peut appeler les genres ${ }^{423}$.

Le genre est donc la combinaison d'une matière, d'une forme et d'un mode d'action. Cette conception donne autant d'importance à la matière qu'aux autres critères et rétablit l'application de la théorie du genre au Moyen Âge. Ainsi, les différents postes de la généricité que nous avons évoqués sont interdépendants: la matière impose une forme et un style particuliers et inversement, comme la Roue de Virgile le propose d'ailleurs, la forme contraint la façon de traiter la matière. Aussi, aucun genre ne se distingue exclusivement sur le plan thématique ou formel. La solidarité entre ces éléments crée un genre, dont chaque représentant textuel a la possibilité de moduler les traits.

Les réflexions que suscite la matière permettent l'élaboration d'une théorie plus cohérente, qui ne la présente pas comme une catégorie surplombante. Cela facilitera notre étude des romans tardifs et du jeu générique qu'ils instaurent, de même que l'abord des textes para-arthuriens dans leurs liens avec le genre arthurien - le point de contact pouvant se situer au niveau de la matière dans le cas des séjours avaloniens ou de la structure pour les romans chevaleresques sans Arthur. Cette perspective sur la matière pousse surtout à distinguer romans arthuriens en vers et romans arthuriens en prose; bien que ces deux types de production partagent la même matière, ils se différencient sur d'autres critères, comme l'esquisse Patrick Moran:

La distinction entre roman breton en vers et en prose semble d'abord purement formelle, mais elle devient aussi très vite une distinction thématique $[\ldots]$, idéologique $[\ldots]$ et référentielle ${ }^{424}$.

423 Jacqueline Cerquiglini-Toulet, "Littérature médiévale?», art. cit., p. 116. Voir aussi Christine Ferlampin-Acher, "Introduction. Après Arthur?», art. cit., p. 12.

424 Patrick Moran, "Deux questions de théorie littéraire», in Lectures cycliques, p. 645 . 
Le deuxième chapitre de notre recherche détaillera les spécificités génériques inhérentes au choix d'une forme.

Aucun des critères évoqués ci-dessus n'est forcément inclusif, c'est-à-dire que sa présence ne détermine pas de facto le genre du texte, ni universellement saillant: aucun critère ne permettrait à lui seul de rendre compte de la définition de tous les genres. Nous renonçons ainsi à considérer comme Jean Rychner que la forme prévaut sur les autres critères ${ }^{425}$. La forme ne suffit pas à elle seule à "classer» tel texte dans un genre: en revanche, la forme permet d'opposer des classes génériques, le roman de la chanson de geste, le roman arthurien en vers du roman arthurien en prose. C'est par la conjonction de critères que se forment les genres, par les interactions de postes génériques qui, associés différemment, changent la perspective générique. Toute théorie générique doit admettre une double hétérogénéité: d'abord, chaque genre définit ses critères saillants sur un niveau différent; ensuite, les textes n'appartiennent pas au genre sur la base des mêmes critères les uns par rapport aux autres: tel texte peut être qualifié d'arthurien parce qu'il présente la structure aventureuse de l'errance, tandis que tel autre n'en présentera que les personnages, la saillance du critère "personnages" pour le genre arthurien déterminant un degré de participation plus fort au genre. Pour le dire avec Marielle Macé, «tout trait de genre n'est pas une loi de genre et tout trait de genre n'est pas un signal générique ${ }^{426}$ : ce n'est pas parce qu'un critère saillant manque ou est présent que l'œuvre en question sera forcément exclue ou incluse dans le genre.

Il est dès lors important de considérer tous les paramètres évoqués pour caractériser un genre. Les associations entre un genre et un critère (par exemple: le fabliau appelle un style bas) que nous avons évoquées dans les chapitres précédents ne doivent pas être entendues comme des règles strictes. Le représentant parfait d'un genre n'existe probablement pas; les éléments de définition élaborent un canevas idéal ${ }^{427}$, présent virtuellement

\footnotetext{
425 «D’une forme appartenant à un genre défini, et d'un sujet, considéré à tort ou à raison comme propre à un autre genre, lequel doit l'emporter? Je répondrai pour ma part: la forme.» (Jean Rychner, "Les fabliaux: genre, styles, publics», art. cit., p. 46-47).

426 Marielle Macé, Le genre littéraire, p. 33.

427 Jean-Marie Schaeffer, Qu'est-ce qu'un genre littéraire?, p. 178-179.
} 
à l'esprit des médiévaux, ce qui suppose que les écarts au "canon» étaient perçus par le lecteur - ainsi le roman courtois qui adopte le ton du fabliau «déroge» explicitement au style de son genre dans l'esprit du public. Décrire un genre ne signifie pas établir une norme, mais rendre compte de «régularités", au sens où l'entend Jérôme Meizoz:

L'activité littéraire, dont le texte n'est que l'état inerte, est un dialogue ritualisé par des institutions de parole qui distribuent des rôles (auteur, lecteur, médiateurs) et codifient des genres: on y observe moins de règles que des régularités, car les acteurs sociaux y exercent des improvisations capables d'en dérégler les routines ${ }^{428}$.

Appréhender un genre implique de rendre compte d'une série de similitudes, fondées sur des critères multiples et différents selon les genres, qui ne constituent jamais des règles strictes. Le roman arthurien en vers semble s'appuyer uniquement sur les personnages, comme le reflèterait le nom que l'on donne au genre: le personnel romanesque n'est toutefois qu'une de ces régularités.

\section{LE ROMAN ARTHURIEN EN VERS}

Partant de ces constats sur les différents postes génériques, osons affirmer que le roman arthurien en vers est un genre à part entière, qui résulte de la combinaison de plusieurs éléments interdépendants. La spécificité de ce genre réside dans la saillance de la matière: le propre du roman arthurien, qu'il soit en vers ou en prose, est avant tout de prolonger un univers fictionnel construit autour de figures tutélaires, de réactiver somme toute une matière spécifique. Comme tous les genres, il est soumis à l'évolution, ce qui implique que les textes arthuriens tardifs participent différemment du genre que les premiers témoins. La vogue du roman en vers étant assez tôt remplacée par celle de la prose, grandissante jusqu'au $\mathrm{XV}^{\mathrm{e}}$ siècle, la fin du genre est assez aisément situable historiquement: alors que l'on peut considérer Erec et Enide (1170) comme le premier représentant du genre ${ }^{429}$, Melyador (1362-1369/ 1382-1383) de Jean Froissart

\footnotetext{
428 Jérôme Meizoz, "Que font aux textes les contextes (et vice versa) ?», art. cit.

429 Voir l'article de Francis Gingras «Comment présenter un genre qui n’existe pas?», art. cit., qui montre comment Chrétien de Troyes invente un nouveau genre et
} 
apparaît comme le dernier témoin qui nous a été transmis. La production s'étend donc approximativement du dernier tiers du XII ${ }^{\mathrm{e}}$ siècle à la deuxième moitié du XIV siècle. Il faut noter toutefois que cette production n'est pas constante: il est en particulier remarquable que le siècle qui sépare Melyador et Escanor (vers 1280) n'ait pas encouragé la composition d'une œuvre arthurienne en vers, pour autant que la transmission le laisse entendre. La critique définit bien souvent le genre sur la base des premiers romans, sans tenir compte de ceux de la fin du XIII ${ }^{\mathrm{e}}$ siècle et de Melyador. Nous tenterons d'abord d'élaborer une définition du genre tel qu'il est admis parmi les médiévistes en vue de la confronter au corpus du roman arthurien en vers tardif.

Certains critères de définition sont communs aux romans en prose et aux romans en vers, en premier lieu celui de l'univers de fiction. Nous distinguons, pour ce chapitre, «roman arthurien» et «roman arthurien en vers" pour éclaircir ce qui est spécifique au genre qui nous intéresse; il s'agit en particulier de la structure de l'errance et de la fin euphorique. Au vu de la saillance du critère "univers de fiction " pour ce genre, il faut envisager un regroupement général sous la dénomination "roman arthurien" qui engloberait les deux formalisations. Le choix formel engendre ensuite des distinctions qui relèvent du générique. Les différences génériques entre roman en vers et roman en prose seront abordées aux chapitres II et III, où seront aussi nuancés certains critères de définition communs. À partir de la définition du canon que nous esquisserons ici, nous tâcherons d'interroger à la suite des sous-chapitres qui viennent la dimension littéraire ou paralittéraire de notre corpus.

\section{Définition du canon}

La littérarité du corpus qui nous intéresse est guidée principalement par l'écart que les textes tardifs présentent par rapport au genre canonique. Selon une opinion souvent exprimée - par Beate Schmolke-Haßelmann que nous avons citée en page 13 par exemple - ils marquent la décadence du genre par le fait qu'ils ne respectent plus les éléments typiques du roman arthurien en vers. Ce point de vue négatif jeté sur ce corpus

pose les bases du roman arthurien. Voir sur le même sujet l'article de Michel Zink, "Chrétien et ses contemporains», art. cit. Nous ne considérons donc pas Le Roman de Brut de Wace comme le premier roman arthurien: malgré son titre, il s'agit d'une chronique historique et non d'un roman. 
résulte de l'importance donnée par la critique à Chrétien de Troyes pour conceptualiser un genre exclusif qui définirait ce qui est ou n'est pas un bon roman arthurien. Appréhender les derniers romans arthuriens en vers comme des œuvres décadentes revient à jeter un point de vue normatif sur le genre, dont les représentants tardifs seraient forcément moins bons que les précurseurs, ce que nous entendons relativiser. Les œuvres de Chrétien de Troyes jouent certes un rôle prégnant dans la définition du genre ${ }^{430}$, tant les auteurs eux-mêmes s'y réferent par le biais de la réécriture ou de la mention directe (ainsi de l'auteur d'Hunbaut ${ }^{431}$ ). Le canon fréquemment reconnu par la critique est donc fondamentalement lié aux œuvres de l'auteur champenois, érigé en norme absolue. Mais ce point de vue engendre la concentration des études sur la parenté des épigones à ses romans ${ }^{432}$. La surimportance accordée à Chrétien de Troyes favorise une lecture intertextuelle, parfois poussée à l'extrême, des romans arthuriens, qui ne rend pas compte de la spécificité du corpus tardif.

Jean-Marie Schaeffer souligne que la canonisation d'une ouvre reconnue comme exemplaire du genre est statique, car «elle ne peut que mesurer la courbe des écarts que les œuvres réelles tracent par rapport à cet étalon métatextuel qu'est l'exemplaire générique idéal » ${ }^{433}$. C'est ainsi que

430 Au sujet de l'influence de Chrétien de Troyes sur le genre dans son ensemble, voir The Legacy of Chrétien de Troyes, dir. Norris J. Lacy, Douglas Kelly et Keith Busby, 2 vol., Amsterdam, Rodopi, 1987-1988, en particulier le chapitre 3, par Keith Busby, "The Characters and the Setting», p. 57-89. Danièle James-Raoul traite du style de Chrétien de Troyes et de son rôle dans l'invention du genre dans Chrétien de Troyes, la griffe d'un style. Sa définition du style de Chrétien est applicable, jusqu'à un certain point, au genre dans son ensemble. L'étude affirme l'existence d'une rhétorique topique pour le roman arthurien. Voir aussi Michel Stanesco, D'Armes et d'amours: études de littérature arthurienne, Orléans, Paradigme («Medievalia»), 2002, en particulier le chapitre 1, qui trace la généalogie du roman et le rôle de Chrétien de Troyes.

431 «Ne dira nus hon que je robe / Les bons dis Crestïens de Troies» (v. 186-187, The Romance of Hunbaut, éd. cit.) Colette Van Coolput a dressé une liste de références à Chrétien de Troyes: "Références, adaptations et emprunts directs ", in The Legacy of Chrétien de Troyes, t. 1, p. 333-342.

432 Comme le note Richard Trachsler, «Héritiers et épigones. Les auteurs des romans arthuriens en vers après Chrétien de Troyes", art. cit. Voir aussi son article, "Chrétien de Troyes créateur ", art. cit., qui nuance le présupposé d'un corpus homogène et la hiérarchie établie entre les œuvres du Champenois et les "épigones».

433 Jean-Marie Schaeffer, Qu'est-ce qu'un genre littéraire?, p. 179. Voir aussi les enjeux qu'implique la canonisation d'une œuvre dans le Vade-mecum de Marielle Macé, Le genre littéraire, p. 222-223. 
les romans arthuriens en vers ont été jugés à l'aune de Chrétien de Troyes comme de piètres imitateurs. S'il faut nuancer l'influence de l'auteur champenois sur nos textes, il nous semble toutefois que l'appréhension des divergences que les textes particuliers présentent par rapport au canon est productive, en particulier dans le contexte médiéval, où l'écriture se fonde sur l'imitation de modèles. Ce n'est donc pas à l'idée du canon que nous souhaitons renoncer, mais nous proposons plutôt de modifier son application et sa définition: le canon n'édicte pas des règles prescriptives, mais constitue une base qui demande à être modifiée, adaptée, critiquée par les auteurs en vue de produire une composition originale. Dès lors, la définition parfaite d'un genre n'est pas celle qui englobe tous les représentants:

Es ist darum falsch, die Normen einer Gattung aus der Beschaffenheit ihrer Vertreter ableiten zu wollen, nach dem Prinzip: eine vollkommene Definition muss die Eigenschaften aller Beispiele umfassen; wenn sie ein Kunstwerk nicht deckt, taugt sie nichts ${ }^{434}$.

Il faut admettre qu'aucun critère de définition d'un genre n'est indispensable pour que l'œuvre singulière puisse participer de tel genre, mais que le canon tente d'en esquisser un représentant idéal.

Le canon représente donc un idéal qu'on ne retrouvera pas forcément dans la réalité textuelle. Il se rapproche en ce sens de la définition que donne Max Weber de l'idéal-type, catégorie abstraite visant à fournir un modèle de phénomènes sociologiques, sans prétendre que ce modèle soit réellement observable ${ }^{435}$. Comme pour l'idéal-type webérien,

434 Wolfgang Ruttkowski, Die literarischen Gattungen, p. 19. "C'est pourquoi il est faux de vouloir déduire les normes d'un genre sur la base de la perfection de ses représentants, en suivant le principe suivant: une définition parfaite doit englober toutes les propriétés de tous les exemples; si elle ne recoupe pas une propriété, elle ne vaut rien.» (nous traduisons)

435 "On obtient un idéaltype en accentuant unilatéralement un ou plusieurs points de vue et en enchaînant une multitude de phénomènes donnés isolément, diffus et discrets, que l'on trouve tantôt en grand nombre, tantôt en petit nombre et par endroits pas du tout, qu'on ordonne selon les précédents points de vue choisis unilatéralement, pour former un tableau de pensée homogène. On ne trouvera nulle part empiriquement un pareil tableau dans sa pureté conceptuelle: il est une utopie. Le travail historique aura pour tâche de déterminer dans chaque cas particulier combien la réalité se rapproche ou s'écarte de ce tableau idéal. " Max Weber, Essais sur la théorie de la science, trad. et intro. de Julien Freund, Paris, Plon, 1965, p. 181. 
le canon est un modèle virtuel appelé à être infléchi. Il est à envisager comme une catégorie mentale et virtuelle, issue d'un choix arbitraire de lecture: certains traits paraissent plus saillants au fil des lectures et des réactivations successives ${ }^{436}$. On peut dégager un "consensus, construit au fil des textes, autour de ce qui est intrinsèquement arthurien et ce qui l'est moins ${ }^{437}$. Ainsi, plus les auteurs-lecteurs réactivent un motif ${ }^{438}$ ou un groupe de personnages au sein d'une structure identique à celle du ou des textes en continuité desquels ils veulent s'inscrire, plus ce motif ou ces personnages sont perçus comme des critères génériques. La somme de ces critères forme un canon, ou un «type textuel idéal » ${ }^{439}$, qui ne constitue pas une doxa ni un absolu exclusif, mais un modèle cognitif dont les textes s'écartent tous peu ou prou, pour reprendre l'idée de Patrick Moran:

Le canon sert en quelque sorte de tamis, filtrant les éléments les plus reconnus et les plus populaires, aux dépens d'autres plus marginaux ou plus archaïques ${ }^{440}$.

Le canon ne préexiste pas aux œuvres: «ce sont elles qui, en luttant pour imposer leur version du donné arthurien, l'emportent ou non aux yeux des lecteurs et prennent le dessus dans l'imaginaire d'une époque. " ${ }^{411}$ Ainsi, aucun trait saillant du canon ne se retrouvera dans tous les représentants

436 Voir à ce sujet l'article de Patrick Moran, "Perlesvaus et le canon arthurien: la construction de l'imprévisibilité", Revue des langues romanes, 118:1, 2014, p. 53-72, qui note que la canonisation d'une œuvre est liée au contingent des lectures. Marielle Macé traite également de cet aspect lorsqu'elle évoque l'importance de la critique dans la reconnaissance d'un genre. Voir Le genre littéraire, p. 23-28.

437 Patrick Moran, Lectures cycliques, p. 130. Le consensus qu'évoque Moran est par exemple formé des données immuables de l'univers de fiction: Guenièvre est l'épouse d'Arthur, Arthur est le roi de Bretagne, les chevaliers se réunissent à la Table Ronde.

438 Nous adoptons la définition que Jean-Jacques Vincensini donne du motif: "On appelle généralement "motifs", ces micro-récits récurrents, reconnaissables grâce à une physionomie stable mais malléables selon leur migration et les œuvres sur lesquelles ils se greffent." (Motifs et thèmes du récit médiéval, Paris, Nathan, 2000, p. 2)

439 Jean-Marie Schaeffer, Qu'est-ce qu'un genre littéraire?, p. 178.

440 Patrick Moran, «Perlesvaus et le canon arthurien», art. cit., p. 60-61.

441 Patrick Moran, Lectures cycliques, p. 133. 
de la catégorie. Le genre ne se constitue pas d'éléments fixes et indispensables; un trait peut être commun à certains textes du genre, mais pas à d'autres qui présentent d'autres traits distinctifs.

Les divergences ne doivent donc pas être envisagées comme des failles, bien au contraire: le jeu avec le canon est fondamental à l'écriture arthurienne. Le lecteur prendra plaisir à reconnaître les écarts avec la norme, même si celle-ci est purement virtuelle. Jean-Marie Schaeffer signale les types d'écarts suivants: violation d'une règle, affaiblissement des règles existantes, adjonction d'une règle nouvelle, introduction d'un jeu complet de règles nouvelles ${ }^{442}$. Ces types de modulation redéfinissent petit à petit le genre, qui s'adapte aux évolutions narratives propres à son époque. Ainsi, l'entrelacement et les quêtes multiples deviennent un principe structurel important à la fin du XIII ${ }^{\mathrm{e}}$ siècle (dans Rigomer, Claris et Laris et Escanor), sous l'influence des textes en prose (voir chapitre III, "Structures arthuriennes: imiter la prose», p. 493-554).

Les écarts ressentis par rapport à une norme virtuelle dévoilent la possibilité d'un rapport plus ou moins étroit au genre, selon les œuvres. À partir de là, on peut les envisager sur le mode de l'échelle de centralité, ainsi que le propose Patrick Moran:

On pourrait représenter la canonicité arthurienne comme un cercle, les différentes œuvres se distribuant tantôt près de son centre, tantôt sur sa périphérie, le plus souvent quelque part entre les deux ${ }^{443}$.

Le public reconnaît cognitivement certains traits saillants comme arthuriens et toute transgression ou écart éloigne le texte du centre, occupé par le canon du genre arthurien. Une ouvre peut donc soit être un exemple type du genre, soit un cas limite, selon les traits qu'elle présente ou non.

${ }^{442}$ Jean-Marie Schaeffer, Qu'est-ce qu'un genre littéraire?, p. 179.

443 Patrick Moran, "Perlesvaus et le canon arthurien", art. cit., p. 60. Voir aussi Lectures cycliques, p. 229-233. Le critique s'inspire ici des théories du prototype, élaborées par Eleanor Rosch. La théorie du prototype repose sur des mécanismes cognitifs: l'exemple du manchot, moins spontanément cité comme prototype de la catégorie "oiseau» que le moineau, n'en demeure pas moins oiseau du point de vue scientifique. C'est la représentation commune que l'homme se fait d'un oiseau, fondée sur des critères fréquemment partagés par les individus (un oiseau vole), qui dicte le degré d'appartenance à la catégorie "oiseau». Le moineau se situe donc plus près du centre que le manchot, dans l'échelle de centralité de l'espèce «oiseau ». Voir Eleanor Rosch, "Natural Categories», Cognitive Psychology, 4/3, 1973, p. 328-350. 
La même chose est valable pour les éléments saillants: la communauté de lecteurs donne plus ou moins d'importance à tel trait au sein d'un genre en particulier. Pour le roman arthurien, le personnel romanesque est déterminant et engage toujours un dialogue avec le genre, même si une trame narrative originale la maintient sur les cercles extérieurs de l'échelle de centralité (ainsi du Roman du Hem). La notion de genre présente donc une double hétérogénéité: celle des critères, chaque genre se définissant sur des critères saillants différents - la forme ne devant ainsi pas être considérée comme critère surplombant dans tous les cas -, et celle des appartenances, les textes d'une même classe ne participant pas du genre de la même manière ${ }^{444}$.

Le canon du roman arthurien en vers fait l'objet d'un consensus au sein de la critique et peut être résumé comme le fait Gaston Paris ${ }^{445}$ :

Les contes anglo-normands dont il a été parlé ont pour caractère ordinaire d'être la biographie romanesque d'un des héros de la Table Ronde: un jeune chevalier inconnu, le plus souvent même sans parents, vient d'arriver à la cour d'Arthur, quand une aventure quelconque, regardée par tous comme impraticable, sollicite son courage; il quitte la cour, accomplit l'aventure et ensuite beaucoup d'autres, et finit par épouser une jeune fille qui s'y trouve mêlée et qui lui apporte en dot un royaume ${ }^{446}$.

444 Benjamin Bouchard, "Critique des notions para-génériques», art. cit., conclut en ce sens que les genres sont des catégories hétérogènes. Pour autant, le concept de genre n'en est pas inférieur aux concepts nettement circonscrits; il permet au contraire une marge d'interprétation.

445 Keith Busby dresse un état de la critique sur le roman arthurien en vers dans son article, "The Study of Post-Chrétien Verse romance», in Chrétien de Troyes et la tradition du roman arthurien en vers, dir. Annie Combes, Patrizia Serra, Richard Trachsler et Maurizio Virdis, Paris, Garnier, 2013, p. 35-50. Voir Beate SchmolkeHaßelmann, Der arthurische Versroman, p. 22. Pour établir le canon, nous nous appuyons notamment sur l'article de Paul Zumthor, "Le Roman courtois: essai de définition", Etudes littéraires, 4, 1971, p. 75-90, sur les articles tirés de The Legacy of Chrétien de Troyes, et sur l'étude de Beate Schmolke-Haßelmann, Der arthurische Versroman. Le corpus sur lequel se fondent ces constats est éclairé par ce dernier ouvrage, qui fournit également une liste de romans arthuriens en vers dont le rattachement au genre ne fait pas de doute.

446 Gaston Paris, La littérature française au Moyen Âge (XI -XIV siècle), Paris, Hachette, 1914, p. 103-104. 
Outre cette structure narrative reconnaissable, le critère le plus saillant de la généricité arthurienne, c'est l'univers fictionnel convoqué: le roman arthurien se déroule sous le règne du roi Arthur, au sein de son royaume et de ses marges. Ainsi, selon Jean Frappier, le " "roman arthurien" ou "roman de la Table Ronde" [...] ne saurait [se] concevoir sans qu'y figure, serait-ce modestement, le fameux roi Arthur de Bretagne ${ }^{447}$. L'apparition d'Arthur et des membres de sa cour ponctuent l'histoire, pour cautionner le parcours effectué par le héros. Le genre arthurien n'est alors pas envisageable sans certains personnages, notamment Gauvain, pour Beate Schmolke-Haßelmann: «Ein Versroman unserer Gattung ist ohne [Gauvain] nicht denkbar. Gauvain ist in seinem Funktionen ebensowenig austauchbar wie Artus, Keu und Guenievre » ${ }^{448}$. Colette Van Coolput fait le même constat:

L'unité du genre arthurien - vers et prose - tient d'abord à la présence remarquablement constante du trio Arthur-Gauvain-Keu, flanqué d'un nombre plus ou moins grand de personnages ${ }^{449}$.

Les critiques sous-entendent ici que le monde arthurien ne peut se passer de ces figures, car elles remplissent une fonction narrative indispensable à la cohérence: Gauvain incarne l'idéal auquel les chevaliers novices veulent se mesurer, alors que Keu valorise les héros en échouant avant eux, à moins qu'il ne lance l'aventure en stimulant leur susceptibilité par sa mauvaise langue, comme il le fait pour Perceval dans Le Conte du graal.

Quant à Arthur, son rôle est fondamental pour l'économie du récit: sa cour est un centre, à la fois centripète et centrifuge ${ }^{450}$, car les chevaliers valeureux y sont attirés puis en partent pour courir l'aventure. C'est au roi qu'il revient de distribuer les aventures, puis de consacrer la prouesse et d'établir la hiérarchie des chevaliers de la Table Ronde. Les auteurs euxmêmes ne cessent de l'affirmer: "on ne prisoit chevalerie que nus hom

447 Jean Frappier, "La matière de Bretagne: ses origines et son développement", art. cit., p. 184.

448 Der arthurische Versroman, p. 86. «Un roman en vers de notre genre n'est pas envisageable sans Gauvain. Gauvain est, dans ses fonctions, aussi peu remplaçable qu'Arthur, Keu et Guenièvre.» (nous traduisons)

449 Colette Van Coolput, "La réaction de quelques romanciers postérieurs ", in The Legacy of Chrétien de Troyes, p. 91.

450 Danièle James-Raoul, Chrétien de Troyes, la griffe d'un style, p. 297. 
faisoit, se il n'eüst ançois esté un an de la maisnie Artu ${ }^{451}$. Les apparitions d'Arthur et de sa cour organisent le récit par des moments de pauses dans l'errance du chevalier, où la valeur de celui-ci est reconnue ${ }^{452}$. La cour d'Arthur a un caractère organique: chaque élément est soudé autour du roi, selon un principe de collectivité et d'harmonie. Arthur est ainsi plus une fonction qu'un personnage: il est le représentant d'un ordre courtois, c'est pourquoi il se déplace peu sans sa cour et se trouve rarement individualisé par une aventure ou une action spécifique.

Garant d'un univers, la figure d'Arthur fonde la cohérence du genre. En ce contexte, le roman arthurien peut-il se passer de lui ? Peut-il se dérouler sous le règne d'Arthur mais hors de sa zone de domination (comme dans Floriant et Florete) ? L'univers fictionnel arthurien peut-il s'autonomiser du roman et se manifester dans d'autres genres? Enfin, qu'implique la mise en scène de personnages connus de la tradition mais qui ne se ressemblent plus tout à fait, comme le pratiquent les romans arthuriens tardifs? Ces questions méritent quelques détours par notre corpus para-arthurien, pour problématiser l'importance du personnage comme marqueur générique $^{453}$. La saillance générique de la présence du roi Arthur dans une œuvre ne suffit néanmoins pas toujours à identifier tel texte comme arthurien; le personnel arthurien ne peut fonctionner sans d'autres éléments pour que le roman soit perçu comme arthurien.

\section{Voyages génériques du roi Arthur}

Pour qu'elles soient "arthuriennes", les apparitions d'Arthur dans un texte littéraire doivent correspondre à des fonctions bien spécifiques et dominer en quelque sorte la diégèse: Arthur ne peut être un simple personnage que le protagoniste rencontre, mais doit avoir une mainmise sur le déroulement de la matière. De même, il doit agir en tant que personnage dans le récit. Ainsi, l'Enseignement des princes de Robert de

451 Version du manuscrit E, The Didot Perceval, éd. William Roach, Philadelphia, University of Pennsylvania Press, 1941, p. 139.

452 Voir Dominique Boutet, "Carrefours idéologiques de la royauté arthurienne", CCM, 28, 1985, p. 3-17, sur le rôle structurant d'Arthur.

453 Le "marqueur» est compris comme un élément qui fait signe vers un genre, vaut comme signal générique. Sur l'importance du personnage comme marqueur, on consultera l'étude d'Adeline Latimier-Ionoff, Lire le nom propre et celle de Richard Trachsler, Disjointures-conjointures. 
Blois ${ }^{454}$, où Arthur est pris comme exemple de courtoisie et de largesse, prévalant comme modèle pour le jeune prince à instruire, ne peut être considéré comme un roman arthurien. Le légendaire roi n'y remplit pas la fonction de personnage au sein du texte: il est convoqué à titre de figure exemplaire et n'a pas de rôle actanciel. On peut donc exclure du corpus arthurien les textes qui citent Arthur de manière ponctuelle et s'en servent pour illustrer un propos ou comme terme de comparaison avec le protagoniste d'une ouvre narrative.

À partir de là, il faut distinguer les cas où Arthur apparaît en tant qu'évocation ${ }^{455}$ de ceux où il a un vrai rôle dans l'économie narrative. La notion de personnage est à comprendre en lien avec la logique actancielle: est un personnage tout signe qui remplit une fonction actancielle dans la narration. Le personnage est investi d'une individualité propre, qui le singularise par rapport aux autres personnages ${ }^{456}$. Il peut être construit de toutes pièces par le texte littéraire qui le fait naître, ou faire appel à un

454 "Seveigne vos du roi Artu / Qui de si haut paraige fu / Que de lui servir fut honors / Es fiz de rois et d'emperors" (v. 1039-1042). L'épisode se prolonge jusqu'au vers 1236. Robert de Blois, L'enseignement des princes, éd. John Howard Fox, dans Robert de Blois, son cuvre didactique et narrative, p. 93-132.

455 Les renvois aux bornes d'Arthur, au temps d'Arthur ou au trésor d'Arthur consistent notamment en des évocations. Voir les exemples donnés par Richard Trachsler, Disjointures-conjointures, p. 129-133, ainsi que l'article de Claude Roussel, "Souvenirs de Bretagne dans les chansons de geste tardives", in Arthur après Arthur. La matière arthurienne tardive en dehors du roman arthurien (12701530), dir. Christine Ferlampin-Acher, Rennes, PUR («Interférences»), 2017, p. 71-89. Rigomer comporte une telle mention: "Se donc sëussent li Berton / Que Gavains fust el pavellon, / N'ëussent pas tel joie ëu / Por le tresor le roi Artu» (v. 12843-12846). Il s'agit d'un topos épique, qu'il est étonnant de retrouver au sein d'un roman arthurien: le renvoi au trésor d'Arthur n'est dans ce contexte plus topique, mais évoque plus concrètement la richesse et la largesse du roi.

456 Pour une définition de la notion de personnage et de ses niveaux d'analyse, voir l'article de Philippe Hamon, "Pour un statut sémiologique du personnage", Littérature, 6, 1972, p. 86-110. Partant du principe que c'est toujours le lecteur qui construit la représentation du personnage, Vincent Jouve propose d'étudier le personnage par rapport à ses effets: "L'effet-personnage c'est donc l'ensemble des relations qui lient le lecteur aux acteurs du récit.» (Vincent Jouve, "Pour une analyse de l'effet-personnage", Littérature, 85, 1992, p. 109) Il distingue trois postures lectoriales: le lectant (appréhension critique du texte), le lisant (l'instance séduite par l'illusion référentielle), le lu (l'inconscient du lecteur, projection fantasmatique). De là trois types d'appréhension du personnage (l'effet-personnel, l'effet-personne, l'effet-prétexte), voir L'effet-personnage dans le roman. 
modèle culturel : dans ce dernier cas, on peut parler avec Philippe Hamon de personnage référentiel, pour désigner les personnages historiques, mythologiques, allégoriques ou sociaux ${ }^{457}$. Ces figures ont la particularité de renvoyer à des réalités extralittéraires, supposées connues du lecteur. Dans le cas d'Arthur, la frontière est problématique: personnage référentiel dans la chronique, dont on présente les agissements comme des faits historiques, il acquiert dans le roman le statut de personnage fictionnel, à qui l'on prête des réactions et un caractère qui demeurent circonscrits au cadre littéraire. Le personnage est donc augmenté de caractéristiques qui le constituent presque en entité distincte de l'Arthur des chroniques: il en devient la contrepartie.

Dans des œuvres comme Floris et Lyriopé de Robert de Blois, le Tournoi de l'Antéchrist d'Huon de Méry ou encore la Bataille Loquifer, Arthur conserve l'aura courtoise ou merveilleuse qu'ont valorisée les romans arthuriens à la suite de Chrétien de Troyes. L'inspiration de ces épisodes arthuriens est donc résolument romanesque et doit peu à la chronique. La présence d'Arthur en tant que personnage-actant complexifie le statut générique de ces œuvres: l'épisode arthurien, même s'il y est ponctuel et bien délimité, interroge l'autonomie du personnage vis-à-vis du genre romanesque qui l'a popularisé. Néanmoins, dans ces textes, Arthur ne remplit pas le même rôle que dans le roman arthurien et se voit intégré au nouveau cadre de référence par quelques transformations.

Floris et Lyriopé narre les amours des parents de Narcisse et s'inscrit dans la veine des récits brefs à l'antique jouant sur le thème de la gémellité. L'Arthur proposé semble identique à celui des romans arthuriens canoniques: Floris, pour échapper au courroux du père de Lyriopé qu'il laisse enceinte, s'en va en Bretagne pour «lox et pris d'armes conquerre / A la cort lo bon roi Artu.» (v. 1191-1192) 458 , accompagné de jeunes chevaliers fraîchement adoubés. Le roi breton n'apparaît pas à proprement parler dans le récit et l'histoire reste ancrée en Grèce: jamais on ne le voit interagir avec Floris ou présidant à sa cour. Sa fonction narrative est toutefois bien celle qu'on lui reconnait habituellement: garantir la prouesse, la formation et la courtoisie des jeunes chevaliers. Le lecteur n'apprend rien du séjour en Bretagne de Floris. Il ne peut que constater que, comme

\footnotetext{
457 Philippe Hamon, "Pour un statut sémiologique du personnage», art. cit., p. 95.

458 Robert de Blois, Floris et Lyriopé, éd. Paul Barrette, Berkeley; Los Angeles, University of California Press, 1968.
} 
dans les romans arthuriens, le jeune homme en revient prêt à épouser Lyriopé, désormais héritière du duché de Thèbes. Pour autant, la présence en arrière-plan du roi Arthur, qui n'apparaît jamais sur le devant de la scène - si l'on fait en outre abstraction des problèmes de chronologie, qui signalent d'ailleurs la dimension atemporelle du roi légendaire -, n'influence pas la généricité de l'œuvre au point d'en faire un roman arthurien. Sa mention est anecdotique et ne sert que de prétexte pour exiler le héros tout en assurant son honneur et en comblant ses douze ans d'absence: les compétences génériques du lecteur suffisent à imaginer les aventures que Floris a pu vivre à la cour bretonne, sans qu'il soit besoin de les détailler.

\section{Le Tournoi de l'Antéchrist: Arthur allégorisé}

Dans le Tournoi de l'Antéchrist, ce sont aussi la prouesse, la courtoisie et la largesse légendaires de la Table Ronde qui sont exploitées: le narrateur assiste au tournoi allégorique des Vices et des Vertus. Arthur et ses compagnons figurent parmi les armées du Christ, donc des Vertus:

Entre largesce et cortoisie

Et proesce orent de mesnie

Touz ceus de la table roonde

Artu, le meillor roi du monde. (Tournoi Antéchrist, v. 1975-1978)

Arthur est accompagné de Gauvain, Yvain, Cligès, Lancelot, Gorvain Cadrus, Méraugis, le roi d'Orcanie, Perceval et Keu. Ces personnages sont promus au rang d'allégories, au même titre qu'Orgueil, Franchise ou Patience. Il s'agit donc d'une allégorisation du monde arthurien qui transforme la fonction traditionnelle de ces personnages, du narratif à la morale, du concret à l'abstrait. Plusieurs rappels intertextuels doivent convaincre que les chevaliers dont on parle sont effectivement ceux du roman arthurien : l'évocation du jeu-parti entre Gorvain et Méraugis narré dans Méraugis de Portlesguez ${ }^{459}$, la description des armes vermeilles de Perceval, gagnées sur le Chevalier Vermeil dans le Conte du graal (v. 20042007) ou l'ambiguïté de Keu, dont les armes symbolisent la calomnie, la médisance et la discourtoisie, mais qui figure tout de même parmi les

459 Raoul de Houdenc, Méraugis de Portlesguez, éd. Michelle Szkilnik, Paris, Champion ("CCMA»), 2004, v. 1994-1999. 
Vertus, comme il demeure un chevalier admis à la Table Ronde dans la littérature arthurienne. Dans ce texte se mélangent renvois historiques la campagne bretonne du roi de France Louis IX, à laquelle le narrateur aurait participé - et renvois littéraires, aux œuvres de Chrétien de Troyes et de Raoul de Houdenc en particulier. S'imbriquent ainsi expérience allégorique, récit autobiographique à prétention historique et roman arthurien.

Le récit allégorique est en effet parsemé de motifs arthuriens: le texte s'ouvre sur le passage du narrateur à la fontaine de Barenton sur le mode de l'errance aventureuse ( Sanz tenir voie ne sentier / Chevauchai IIII. jours entiers», v. 68-69), ce qui inscrit l'œuvre dans le sillage des romans arthuriens. La tempête, déclenchée par l'eau jetée par deux fois ${ }^{460}$ sur le perron, engendre un épisode merveilleux confirmant ainsi les rumeurs sur lesquelles le narrateur souhaitait apprendre la vérité (v. 62). La merveille n'est néanmoins pas celle des romans arthuriens: il s'agit de l'expérience spirituelle de la psychomachie. C'est bien la rêverie littéraire, la volonté de plonger dans la fontaine de l'Yvain romanesque, qui remplace le songe comme embrayeur vers l'allégorie ${ }^{461}$.

Le passage du narrateur à la fontaine doit contraster avec celui des personnages arthuriens, qui s'y rendent eux aussi, plus tard dans le Tournoiement Antecrist. L'aventure est cette fois vaine et explique le retard que les chevaliers prennent sur les autres Vertus, dans le cortège pour le tournoi :

Selonc lour ancien deduit,

Orent chevauchié tote nuit

Par bois et par forez oscures

460 Patrizia Serra souligne que le geste de verser deux fois de l'eau sur le perron signale l'intention de dépasser Chrétien de Troyes: Huon personnage en fait plus que Calogrenant, il entend plus d'oiseaux que lui (v. 194-195), tout comme Huon auteur fait un pas de plus que son prédécesseur et propose un renouvellement du roman arthurien par l'allégorie. "Pour ce que mors est Crestiens... La nascita dell'aventure novele nel Tornoiemenz Antecri di Huon de Méry", in Chrétien de Troyes et la tradition du roman arthurien en vers, dir. Annie Combes, Patrizia Serra, Richard Trachsler et Maurizio Virdis, Paris, Garnier, 2013, p. 147.

461 Dans le Songe d'Enfer de Raoul de Houdenc, autre intertexte du Tournoiement Antéchrist, c'est le rêve qui fait basculer le récit vers l'allégorie. Armand Strubel, "Le romanesque et l'épique: l'exemple de Huon de Méry", in Le romanesque dans l'épique, (Actes du colloque de Paris X-Nanterre 22-23 mars 2002), dir. Dominique Boutet, Nanterre, Université Paris-X («Littérales», 31), 2003, p. 208. 
Querant depors et aventures

Par Cornouaille et par Illande

Et vindrent par Broucelïande,

Ou par poi ne furent tuit mort,

Car Perceval, qui par deport

Quida arouser le perron,

L'arousa par tel desreson,

Que la foudre ocist plus de.C.

De lor mesniée et de lor gent. (Tournoi Antéchrist, v. 2019-2030)

L'errance incessante des personnages arthuriens, conjuguée à la niceté de Perceval, sert de prétexte au détournement du roman arthurien: le lecteur est invité à rire de cet égarement des chevaliers, aussi oiseux que meurtrier, puisqu'il cause plus de cent morts ${ }^{462}$. En se rendant à la fontaine de Barenton, les chevaliers "quer[e]nt deport» (v. 2022), alors que le narrateur veut apprendre la vérité sur la merveille racontée par Chrétien de Troyes (v. 62). S'ils figurent parmi les allégories positives, ils sont loin d'être dignes de Largesse, Amour et Courtoisie, vis-à-vis desquelles ils ne sont d'ailleurs que des personnages secondaires; ils ne représentent pas un concept précis et ne sont pas investis d'une individualité propre, comme les autres allégories ${ }^{463}$.

On n'assiste d'ailleurs à aucun combat des chevaliers arthuriens: seul Keu réapparaît, ou plutôt ses armes et son cheval, offerts au héraut par Courtoisie après sa victoire sur Mesdit (v. 2344-2350). Il s'agit là d'une véritable démythification de l'univers arthurien; Huon de Méry propose un projet spirituel, tentant ainsi de concurrencer Chrétien de Troyes et de donner une alternative au roman arthurien en vers, vaniteux et dénué de sens profond ${ }^{464}$. La rivalité établie avec Chrétien de Troyes et Raoul de

462 Fabienne Pomel traite de ce passage dans "Arthur en allégorie», in Arthur après Arthur. La matière arthurienne tardive en dehors du roman arthurien (1270-1530), dir. Christine Ferlampin-Acher, Rennes, PUR («Interférences»), 2017, p. 349.

463 Richard Trachsler, Disjointures-conjointures, p. 311-324.

464 Voir l'article de Patrizia Serra, "Pour ce que mors est crestïens...", art. cit., p. 155-157: "L'ancien deduit di un mondo arturiano divenuto sterile, di una tradizione destinata soltanto a soulacier, e dunque apportatrice di un mero deduit per il proprio pubblico, deve lasciare spazio alla nuova scrittura generatrice di Verità." (p. 156) "L'ancïen deduit d'un monde arthurien devenu stérile, d'une tradition destinée à l'unique soulacier, et donc importatrice d'un simple deduit pour son propre public, doit laisser sa place à la nouvelle écriture, génératrice 
Houdenc ${ }^{465}$, dont l'habileté n'a laissé que peu de sujets aux autres écrivains $^{466}$, est rendue explicite dans l'épilogue:

Car cil qui troverent avant

En ont coilli tote l'eslite,

Pour c'est ceste oevre meins eslite

Et plus fu fort a achever.

Molt mis grant peine a eschiver

Les diz Raol et Crestïen,

C'onques bouche de crestien

$\mathrm{Ne}$ dist si bien com il disoient.

Mes quant qu'il dirent il prenoient

Le bel françois trestot a plein

Si com il lor venoit a mein,

Si c'apres eus n'ont rien guerpi. (Tournoi Antéchrist, v. 3530-3541)

La figuration de personnages arthuriens, les renvois intertextuels, l'utilisation de la structure de l'aventure comme cadre narratif et la mention directe d'auteurs arthuriens sembleraient suffire à inscrire le récit dans le genre arthurien en vers. Néanmoins, comme l'exprime Stéphanie Orgeur, «s'il suit le schéma narratif du roman d'aventure, le Tornoiemenz Antecrist est avant tout une œuvre morale, la description d'une aventure spirituelle, pourrait-on dire ${ }^{467}$. À la fontaine empruntée à Chrétien de Troyes, le narrateur découvre la vérité de la foi et non une aventure chevaleresque. De la même manière, l'errance arthurienne du début du texte

de Vérité.» (nous traduisons). La critique remarque que Perceval est présenté par ses armes de chevalier nouveau (les armes vermeilles) et que l'on souligne par là son inadéquation et son incapacité à comprendre la symbolique spirituelle de la fontaine et du combat allégorique.

465 Raoul de Houdenc est surtout cité pour son œuvre allégorique (Songe d'Enfer et Roman des eles), comme le souligne Richard Trachsler (Disjointures-conjointures, p. 314-315), mais Huon de Méry connaît son œuvre narrative arthurienne, comme en témoignent ses allusions à Méraugis de Portlesguez.

466 Voir l'introduction à l'édition de Stéphanie Orgeur, Le Tournoi de l'Antéchrist, éd. cit., p. 20-21.

467 Stéphanie Orgeur, Le Tournoi de l'Antéchrist, éd. cit., p. 36. Voir aussi l'article de Fabienne Pomel, "Arthur en allégorie», art. cit., sur les manifestations d'Arthur dans les textes allégoriques et sur l'hybridité du Tournoi de l'Antéchrist. 
allégorise la déviation intérieure du moi ${ }^{468}$; le devoiement («En la forest, par aventure, / Perdi l'asens de mon sentier.», v. 74-75) est spirituel et non géographique et le narrateur ne retrouvera le droit chemin qu'après la psychomachie, en offrant sa vie à l'église de Saint-Germain-des-Prés. Si Huon de Méry joue avec les codes, la structure et les personnages du roman arthurien en vers, le modèle dominant reste celui du récit allégorique et moral ${ }^{469}$. L'auteur tout à la fois concurrence ses prédécesseurs en tâchant de montrer que son œuvre est supérieure par sa portée spirituelle tandis que le roman est vain, et renouvelle en même temps le traitement du monde arthurien en donnant aux personnages le statut d'allégories. L'univers de fiction arthurien peut donc se réaliser dans d'autres genres que le roman arthurien et la présence d'Arthur et de ses chevaliers, si elle garantit l'élaboration d'un dialogue, n'inscrit pas de facto l'œuvre dans le genre.

Les manuscrits conservant le Tournoi de l'Antéchrist ne le présentent jamais avec des œuvres arthuriennes: la lecture favorisée par la mise en recueil est bien celle de l'allégorie et de la morale, comme le prouve la présence concomitante du Songe d'Enfer de Raoul de Houdenc dans trois manuscrits (BnF fr. 1593, BnF fr. 1275 et Turin, L V.32). Les autres textes qui accompagnent la composition d'Huon de Méry dans les douze manuscrits qui l'ont transmis relèvent rarement du romanesque: les compilateurs privilégient les formes brèves, le lai, le fabliau, le dit (BnF fr. 1593, BnF fr. 24432, BnF fr. 25566), l'œuvre de poètes comme Rutebeuf, Guillaume de Machaut, Christine de Pizan, Eustache Deschamps, Alain Chartier, François Villon (BnF fr. 1593, BnF fr. 24432, Stockholm Vu 22), ou encore des œuvres religieuses ( $\mathrm{BnF}$ fr. 1275) pour environner le texte qui nous intéresse. L'entourage du Tournoi de l'Antéchrist est hétérogène, mais il témoigne de sa réception non arthurienne. Si le roi Arthur répond à un certain nombre d'invariants dans le Tournoi de l'Antéchrist, sa transposition dans un autre contexte générique éloigne ce texte du centre de la généricité arthurienne.

\footnotetext{
468 Voir Patrizia Serra, "Pour ce que mors est Creastiens...", art. cit.

469 Sur les liens du Tournoi de l'Antéchrist au genre du dit, voir l'article de Monique Léonard, "Du roman au dit: Le Chevalier au lion et Le Tournoi de l'Antéchrist», in L'ouvre de Chrétien de Troyes dans la littérature française: réminiscences, résurgences et réécritures, dir. Claude Lachet, Lyon, Université Jean Moulin, 1997, p. 87-97.
} 


\section{Arthur en Avalon: la Bataille Loquifer}

Lorsqu'Arthur apparait dans la chanson de geste, ce n'est pas tant le nouveau contexte qui empêche la généricité arthurienne de déployer ses moyens, mais la modification ontologique que subit le personnage. Arthur intervient dans les épisodes avaloniens, qui prennent place dans plusieurs textes, comme Tristan de Nanteuil, Esclarmonde, Bâtard de Bouillon, Lion de Bourges, La Bataille Loquifer, Ogier le danois dans sa version décasyllabique et sa mise en prose, Dieudonné de Hongrie ou Gaufrey ${ }^{470}$. Dans ces chansons de geste, un personnage - qui n'est pas forcément le héros de l'œuvre ou du cycle - se retrouve sur l'île d'Avalon par divers biais (le hasard, la merveille, un choix délibéré). Il y rencontre Arthur, Morgue et parfois d'autres personnages arthuriens. Avalon, situé diversement selon les textes (l'Etna, Mongibel, en Orient ou aux Antipodes), se trouve hors du temps, ce qui permet la rencontre entre ses habitants et les personnages du monde carolingien. Comme le souligne Richard Trachsler ${ }^{471}$, le séjour avalonien a souvent pour fonction de consacrer le héros épique par une

470 Cette liste est proposée par Carlos C. Carreto, "Une quête apophatique de l'originalité. Le réinvestissement de la topique arthurienne dans la chanson de geste tardive", in Original et originalité. Aspects historiques, philologiques et littéraires. Actes du IV colloque de l'Association Internationale pour l'Étude du Moyen Français, dir. Olivier Deslaux et Hélène Haug, Louvain, UCL, 2011, p. 15-31. On consultera également l'étude de Richard Trachsler pour une analyse de ces interférences entre univers arthurien et chanson de geste, Disjointures-conjointures, p. 126-209, ainsi que les articles qui concernent la chanson de geste tardive dans Arthur après Arthur, Claude Roussel, "Souvenirs de Bretagne dans les chansons de geste tardives", p. 71-89, François Suard, "Les attestations arthuriennes dans les proses épiques", p. 91-105, Dominique Boutet, "Arthur et le monde épique en Avalon (Jean d'Outremeuse, continuations et mise en prose d'Ogier)", p. 107-119, et Sarah Baudelle-Michels, "Les insertions arthuriennes dans la geste rinaldienne», p. 121-135. William W. Kibler traite également des incursions arthuriennes en contexte épique dans "Late Medieval Arthurian Literature», co-écrit avec Jane H. M. Taylor, Peter F. Ainsworth, Norris J. Lacy et Edward Donald Kennedy, in The Arthur of the French. The Arthurian Legend in Medieval French and Occitan Literature, dir. Glyn S. Burgess et Karen Pratt, Cardiff, University of Wales Press ("Arthurian Literature in the Middle Ages», IV), 2006, p. 515-518.

471 Richard Trachsler, Disjointures-conjointures, p. 126-209. Voir aussi François Suard, "La Bataille Loquifer et la pratique de l'intertextualité au début du XıII siècle", in VIII Congreso de la Société Rencesvals. Pamplona-Santiago de Compostela 15 a 25 agosto de 1978, Pamplona, Institucion Principe de Viana, 1981, p. 497-503. 
autre matière. Arthur fait office d'instance de légitimation, rôle que lui reconnaît déjà la tradition littéraire romanesque. L'admission en Avalon et la réussite de l'épreuve proposée au guerrier en font un élu à la fois chevaleresque et courtois. Le séjour transforme le héros franc et le rend parfois inadéquat à sa matière d'origine: même si l'épisode semble être une parenthèse dans le récit, il a des répercussions sur le reste de la narration. Nous prendrons comme exemple La Bataille Loquifer, en raison de sa datation au début du XIII ${ }^{\mathrm{e}}$ siècle, qui en fait un représentant précoce de l'insertion arthurienne dans la chanson de geste.

Ce texte est intégré au Cycle de Guillaume, après la chanson des Aliscans $^{472}$. Le contexte est donc résolument épique et le début narre d'ailleurs plusieurs conflits armés contre les Sarrasins. Ceux-ci parviennent à capturer le fils de Rainouart, Maillefer, pendant que Rainouart, Sarrasin converti au service de Guillaume, se battait contre l'armée de Desramé, son propre père. Rainouart s'en va chercher son fils et s'endort au bord de la mer. C'est alors que trois fées surviennent et l'emmènent avec elles sur l'île d'Avalon, où se trouvent Arthur, Yvain, Gauvain et même Roland (v. 3600ss) ${ }^{473}$. Cette fois, Arthur remplit totalement sa fonction de personnage-actant: il se réjouit d'abord de la venue de Rainouart puis commande le combat du guerrier contre Chapalu, un monstre hybride, mi-chat mi-cheval ${ }^{474}$. Le héros épique a déjà fait ses preuves dans le récit, en vainquant Loquifer et en accomplissant des prouesses contre les Sarrasins. Néanmoins, Arthur ne se contente pas des rumeurs et veut vérifier la valeur du nouvel arrivé:

Avent en vienent celle gent faerie,

Esprover volent sa grande baronie;

$S$ 'an Renoart a tel chevalerie

Con an on dit, ja sera essaïe. (Bataille Loquifer, v. 3718-3721)

L'épreuve est différente de celles qu’a accomplies Rainouart jusque-là: elle est merveilleuse, comme l'atteste la précision «celle gent faerie». Le

472 Richard Trachsler a dressé un tableau des occurrences de la Bataille Loquifer dans les manuscrits du cycle. Dans certaines versions (4 sur 10), l'épisode avalonien est supprimé. Disjointures-conjointures, p. 184.

473 La Bataille Loquifer, éd. Monica Barnett, éd. cit.

474 Sur les apparitions de Chapalu dans la geste tardive, voir l'article de Claude Roussel, "Souvenirs de Bretagne», art. cit., p. 77. 
guerrier doit être cautionné par l'Autre Monde. C'est pourquoi Arthur se montre si suspicieux, alors même que dans la tradition romanesque, il n'émet jamais d'objection à consacrer la valeur d'un chevalier sur la seule base de témoignages de tiers (le Bel Inconnu, Floriant et Biaudouz sont par exemple très attendus à la cour, car les chevaliers qu'ils ont vaincus les précèdent et rapportent leurs prouesses). Dans la chanson de geste, il exige de constater par lui-même la force du guerrier lors d'un duel dont la victoire lui ouvrira les portes d'Avalon: «An prise molt cel vasal chanpion; / Talant m'est pris c'orendroit l'esaon.» (v. 3736-3737)

Il fait même preuve d'une certaine cruauté, lorsqu'il refuse de mettre fin au combat, malgré les prières des fées, inquiètes du sort de Rainouart:

Dïent les faees: «Sire, cant vos plaira,

Et vos volrés, Chapalus s'an rira,

Et Renoars si se reposera."

"Voir, dist li rois, ancor se conbatra;

Vers Chapalu l'ostel desraisnera.» (Bataille Loquifer, v. 3786-3790)

Par deux fois, Arthur jette un rire cruel, lorsque Rainouart, en difficulté, s'étonne de l'apparence de Chapalu et le prend pour un diable: "Artus l'antent, si s'an rist et gaba.» (v. 3785). Le roi se moque sans bienveillance du chevalier, le raille sur le mode du "gab», à la manière des chansons de geste: le mot désigne généralement les propos ironiques et moqueurs tenus par le guerrier, parfois à l'encontre de son adversaire. Le gab peut faire office de défi et constitue un moyen d'humiliation ${ }^{475}$. C'est le cas

475 Sur le "gab" épique, voir Philippe Ménard, Le rire et le sourire dans le roman courtois en France au Moyen Âge (1150-1250), Genève, Droz, 1969, p. 21-28, et John L. Grigsby, The Gab as a Latent Genre in Medieval French Literature, Cambridge, The Medieval Academy of America, 2000. Le "gab" n'est pas toujours railleur: parfois, il désigne les gageures joyeuses des guerriers enivrés (dans le Voyage de Charlemagne à Jérusalem et à Constantinople en particulier, voir l'introduction d'Alain Corbellari, L'épopée pour rire. Le voyage de Charlemagne à Jérusalem et Constantinople et Audigier, éd. Alain Corbellari, Paris, Champion ("CCMA»), 2017, p. 39-49, sur le gab et la traduction par "gageure»), vise à "lowering the esteem of a threatening or playful adversary» (John L. Grigsby, p. 8) ou consiste en une simple plaisanterie sans méchanceté (ainsi quand l'équipage conduit par Bertrand est embourbé: "Voit le Guillelmes, si le prist a gaber: "Beaus niés, dist il, envers moi entendez. / De tel mestier vos estes or mellez / Dont bien i pert que gaires ne savez!" ", Le Charroi de Nîmes, v. 10111014, in Le Cycle de Guillaume d'Orange, éd. Dominique Boutet, Paris, Le Livre 
lorsque les écuyers se moquent de l'apparence de Rainouart lors de sa première apparition: "Cil escuier le prisent a gaber, / De grant torchas le prisent a ruer» (Aliscans, v. 3161-3162) ${ }^{476}$. Arthur, en recourant au gab, s'écarte du personnage que la tradition romanesque a mis en scène, généreux, miséricordieux et courtois, dont la fonction est d'assurer la précellence de la classe chevaleresque ${ }^{477}$. L'épreuve rituelle d'entrée en Avalon apparaît comme un divertissement destiné à amuser le roi des lieux. Ce n'est qu'après la fin du combat, lorsque Chapalu a repris une apparence humaine grâce au sang bu du talon de Rainouart, que l'hospitalité offerte par Arthur permet d'identifier en lui le roi courtois de la légende.

L'identification $\mathrm{du}$ roi légendaire derrière ce personnage passe surtout par sa résidence en Avalon, dont l'auteur de la Bataille Loquifer fait un lieu de la merveille. C'est bien l'atmosphère merveilleuse qui justifie l'intervention d'Arthur; la métamorphose de Chapalu, le transport onirique sur l'île, qui s'apparente à une sorte de paradis fastueux (v. 3678ss) où les habitants sont "de cest sicle venu et trespassé» (v. 3901), la présence d'être faés et celle des sirènes qui sauvent Rainouart de la noyade lorsqu'il souhaite rentrer chez lui, sont autant d'éléments propres à la merveille. Le merveilleux de l'épisode avalonien n'a toutefois rien d'arthurien: ce ne sont pas des motifs arthuriens qui sont réactivés et les faits racontés ne trouvent pas d'exemples dans le roman. L'association instinctive que le lecteur effectue entre Arthur et la merveille est exploitée pour introduire des phénomènes étonnants dans un cadre carolingien, circonscrits à l'épisode onirique en Avalon. Autrement dit, le merveilleux n'est pas arthurien, mais la figuration de personnages associés à un univers merveilleux rend légitime la présence de phénomènes surnaturels. Richard Trachsler le souligne:

de Poche («Lettres gothiques»), 1996.). Il nous semble que ce ne sont pas ces sens qui sont convoqués dans le cas d'Arthur.

476 Aliscans, in Le Cycle de Guillaume d'Orange, éd. Dominique Boutet, éd. cit.

477 D'autres attestations arthuriennes dans la chanson de geste nous convainquent qu'Arthur n'y a pas le même comportement que dans le roman. Voir les articles tirés du volume Arthur après Arthur, Claude Roussel, "Souvenirs de Bretagne dans les chansons de geste tardives", p. 71-89; François Suard, "Les attestations arthuriennes dans les proses épiques", p. 91-105; Dominique Boutet, "Arthur et le monde épique en Avalon (Jean d'Outremeuse, continuations et mise en prose d'Ogier)», p. 107-119; Sarah Baudelle-Michels, "Les insertions arthuriennes dans la geste rinaldienne», p. 121-135. 
Depuis longtemps, la lecture des chansons d'aventures à épisode avalonien nous l'a appris, ces personnages ne sont plus à proprement parler associés au cadre spatio-temporel arthurien puisque la matière de Bretagne tout entière a rejoint le merveilleux. Dans ce contexte, la présence d'Arthur et de Morgue signale précisément le merveilleux, la suspension des repères chronologiques et géographiques habituels ${ }^{478}$.

L'intervention de merveilleux d'altérité au cour de l'épopée carolingienne est encore justifiée par l'assimilation d'Avalon au monde des morts ${ }^{479}$, anhistorique et atemporel. Arthur devient dans ce contexte le roi d'un au-delà destiné aux héros littéraires de diverses matières, aussi bien Roland que Perceval. L'Arthur de la Bataille Loquifer n'est donc ni tout à fait celui de la chronique ni tout à fait celui du roman, mais un Arthur post-arthurien, retiré sur l'île de Morgane et fantasmé: son nouveau rôle est de soumettre le héros épique à l'épreuve de la merveille, dans un univers non plus courtois et policé mais cruel et morganien ${ }^{480}$, Rainouart risquant en effet de mourir après l'annonce de son départ en raison du courroux de Morgue, dont il est devenu l'amant. Dans le contexte du séjour avalonien, les personnages arthuriens s'autonomisent de leur univers romanesque: ils sont transposés dans un cadre merveilleux qui certes ne leur est pas étranger, mais qui demeure une extrapolation propre à ce type d'épisode de la chanson de geste. Le profil des autres chevaliers arthuriens reste d'ailleurs latent: les noms d'Yvain, de Gauvain et de Perceval ne sont que cités et jamais ces personnages n'agissent. Ils ne figurent que pour évoquer un monde et signifier qu'Arthur est bien le roi mythique de Logres.

478 Richard Trachsler, Disjointures-conjointures, p. 197. Yan Greub, dans son compte rendu de l'ouvage de Richard Trachsler, souligne en ce sens que tout merveilleux n'est pas forcément arthurien. Vox romanica, 63, 2004, p. 324. Voir aussi supra, p. 77.

479 Dominique Boutet traite du lien entre Avalon et l'Au-delà dans son article, "Au-delà et Autre Monde: interférences culturelles et modèles de l'imaginaire dans la littérature épique ( $\mathrm{XII}^{\mathrm{e}}-\mathrm{XV}^{\mathrm{e}}$ siècles)", in Le Monde et l'autre monde, dir. Denis Hüe et Christine Ferlampin-Acher, Orléans, Paradigme, 2002, p. 65-78. Le séjour en Avalon se double d'un voyage vers l'au-delà et l'exploration du monde.

480 Nous employons ce terme en référence à l'étude de Laurence Harf-Lancner, Les fées au Moyen Âge. La fée morganienne retient le chevalier dans son monde merveilleux, contrairement à la fée mélusinienne, qui rejoint le monde terrestre de son amant. 
L'épisode avalonien ne fait pas de la Bataille Loquifer un texte arthurien, même si Arthur y est un personnage actant et que l'on reconnait en lui le roi breton du roman et de la chronique. Le texte est d'ailleurs exclusivement transmis avec des chansons de geste dans les manuscrits, preuve que la généricité lectoriale médiévale ne l'associe pas au genre arthurien ${ }^{481}$. Le passage peut même être retranché de la chanson sans porter atteinte à son intelligibilité, comme c'est le cas dans certains manuscrits du Cycle de Guillaume $^{482}$ : une fois sauvé de la noyade causée par Chapalu sur l'ordre de Morgue, Rainouart est amené endormi sur le rivage par les sirènes. L'histoire peut ensuite reprendre là où elle en était avant l'apparition des fées et le héros peut continuer la recherche de Maillefer ${ }^{483}$. C'est bien la preuve qu'Arthur ne remplit pas le rôle structurant et central qu'il a dans le roman. C'est l'indice également que l'épisode a été perçu comme un ajout hétérogène. Dans la geste, cette parenthèse dans le récit est l'occasion d'un voyage dans un autre espace textuel, donnant lieu à une esthétique de la confluence $^{484}$. Elle ouvre la geste vers des techniques plus romanesques en approfondissant la psychologie du personnage de Rainouart et en se consacrant à une narration biographique, par le biais d'une quête et de ses détours.

481 Voir le tableau des manuscrits que donne Richard Trachsler, DisjointuresConjointures, p. 184-185, ainsi que les pages 3-4 de l'édition de Monica Barnett, éd. cit.

482 Il s'agit des mss Boulogne, BM 192, Bern, Burgerbibliothek 296, BnF fr. 2494 et Arsenal 6562. Voir Nelly Andrieux, "Arthur et Charlemagne réunis en Avalon: la Bataille Loquifer ou l'accomplissement d'une parole», in Essor et fortune de la chanson de geste dans l'Europe et l'Orient latin. Actes du IXe Congrès International de la Société Rencesvals, vol. 2 "Rapports entre chanson de geste et roman au XIII siècle», Padoue, Mucchi Editore, 1984, p. 424-434.

483 On consultera l'étude de Richard Trachsler pour comprendre l'importance de cet épisode pour le cycle entier: selon le critique, il s'agit à la fois d'une quête de l'identité, d'une mise en scène des conflits lignagers et d'une occasion de donner plus de relief au personnage de Rainouart. Disjointures-conjointures, p. 173-187.

484 Nous renvoyons encore une fois à l'étude de Richard Trachsler pour une analyse et une définition de cette esthétique dans la littérature médiévale. Disjointuresconjointures. Nelly Andrieux parle quant à elle d'une pratique «encyclopédique» pour définir la visée totalisante du cycle. "Arthur et Charlemagne réunis en Avalon ", art. cit. 


\section{Transfictionnalité et genre}

Dans la Bataille Loquifer, Arthur n'est pas simplement un personnage qui porterait ce prénom, mais le lecteur identifie en lui le roi du roman, grâce à un certain nombre d'invariants: son rapport à Avalon, lieu de son retrait à la fin du Roman de Brut, et le fait qu'il soit accompagné de chevaliers de la Table Ronde. Les variations qu'il subit - sa cruauté notamment - témoignent bien de sa transposition dans un autre cadre générique, mais l'univers de fiction reste le même. On peut dès lors affirmer que la Bataille Loquifer est une transfiction élaborée à partir de l'univers arthurien, mais ne relève pas du genre arthurien. La réappropriation de la figure d'Arthur par la geste est «transfictionnelle», au sens où l'entend Richard Saint-Gelais:

Par «transfictionnalité», j'entends le phénomène par lequel au moins deux textes, du même auteur ou non, se rapportent conjointement à une même fiction, que ce soit par reprise de personnages, prolongement d'une intrigue préalable ou partage d'univers fictionnel ${ }^{485}$.

La transfictionnalité suppose l'existence indépendante de l'univers fictionnel vis-à-vis de l'œuvre et de l'auteur qui l'ont créé. Chaque texte n'est qu'une manifestation de la donnée diégétique en question (le plus souvent un personnage $)^{486}$ : la transfiction intervient sur l'univers et non sur l'œuvre qui l'a élaboré et se distingue en ce sens de l'intertextualitée ${ }^{487}$. Chaque réactivation transfictionnelle s'appuie sur des éléments supposément déjà connus du lecteur averti auxquels s'ajoutent des caractéristiques construites par le texte. Barbara Wahlen l'exprime en ces termes:

485 Saint-Gelais, Fictions transfuges, p. 7.

486 Richard Saint-Gelais souligne toutefois que tout élément peut faire l'objet d'une transfiction et que la fréquence du personnage dans le processus transfictionnel s'explique par la simplicité de son identification: "La saillance du personnage dans les pratiques transfictionnelles ne doit donc pas nous faire oublier la reprise d'autres composantes de la fiction, par exemple des univers de référence, ou, plus modestement, des données encyclopédiques." (Fictions transfuges, p. 21-22)

487 Nous renvoyons une fois encore à Tiphaine Samoyault pour une définition et une mise au point sur l'intertextualité. L'intertextualité. Mémoire de la littérature. 
[Les personnages] s'inscrivent autant dans un jeu interne de précisions accumulées au fil du récit qu'ils se fondent sur une anaphore produite par un déjà-lu externe ${ }^{488}$.

L'univers fictionnel et virtuel est ainsi enrichi par la lecture des diverses œuvres qui le réactivent et le complètent ${ }^{489}$.

L'univers arthurien est élaboré par plusieurs textes: c'est un monde réactivable à l'envi par les auteurs, qui profitent des vides textuels, consubstantiels aux univers de fiction forcément incomplets, pour prolonger l'univers. Chaque récit contribue à construire ce monde, qui, «tentaculaire, stratifié, élaboré par plusieurs générations d'écrivains, [...] pré-existe au nouveau roman et joue le rôle d'un réservoir de personnages, de lieux, de motifs et de structures que chaque nouveau récit peut annexer et réinvestir selon ses besoins ${ }^{490}$. Les romans successifs donnent chacun une version du monde arthurien qui leur est propre, mais ils partagent un certain nombre de données universelles induites par l'univers de fiction. C'est ainsi que le narrateur de Rigomer peut faire référence à un "conte», sorte de macro-récit arthurien ou, justement, d'univers fictionnel surplombant, qui contient des invariants valables dans chaque version:

Car el conte pöés entendre,

Coustumier estoient d'atendre,

Quant on asseoir se devoit,

Qu'aucune aventure avenoit,

Qui auques fust biele et prisie. (Rigomer, v. 27-31)

L'attente de l'aventure, qui doit se manifester avant que les chevaliers puissent prendre le repas de fête, est un élément récurrent des romans arthuriens: le terme "conte» thématise ici cette donnée, devenue au fil des réactivations un invariant de l'univers de fiction arthurien. Parmi ces invariants, on peut aussi compter le lien de parenté entre Gauvain et Arthur, le fait que Guenièvre soit la femme du roi ou que Keu soit le sénéchal du royaume.

488 Barbara Wahlen, «Entre tradition et réécriture: le bon Morholt d'Irlande, chevalier de la Table Ronde", in Façonner son personnage au Moyen Âge, Aix-enProvence, CUER-MA ("Senefiance», 53), 2007, p. 352.

489 Voir Wolfgang Iser, L'acte de lecture, p. 317-352: c'est au lecteur de reconstruire l'univers que les vides textuels passent sous silence.

490 Barbara Wahlen, L'écriture à rebours, p. 23. 
L'univers de fiction englobe toutes les versions, même si elles peuvent entrer en contradiction ${ }^{491}$, comme c'est le cas de la Suite post-Vulgate par rapport à la Suite Vulgate, dont Patrick Moran étudie les relations d'un point de vue théorique ${ }^{492}$. La contradiction n'est donc pas discriminatoire pour partager un même univers de fiction, d'autant qu'elle ne pose pas problème au public médiéval: Gauvain peut se marier avec Amie dans Biaudouz, puis avec Blanchandine dans Floriant et Florete, sans que la nature de l'univers de fiction de ces deux romans soit mise en cause. Sur le plan des valeurs, nous évoquions le cas du manuscrit Chantilly, Condé 472 qui propose un Lancelot anti-courtois et un Lancelot idéal dans le même ensemble, sans que cela interfère avec la cohérence de l'univers de fiction autour duquel s'organise ce manuscrit. On peut dès lors admettre que romans en vers et romans en prose partagent un même univers de

491 Patrick Moran ("Le meilleur des mondes arthuriens possible», in Jeunesse et genèse du royaume arthurien: les "Suites» romanesques $d u$ "Merlin en prose». Actes du Colloque des 27 et 28 avril 2007, École normale supérieure, Paris, dir. Nathalie Koble, Orléans, Paradigme ("Medievalia», 65), 2007, p. 69-88) établit une hiérarchie entre un chronotope arthurien surplombant (qu'il appelle aussi méta-encyclopédie) et une multiplicité d'univers de fiction ou de versions. Nous n'employons pas «chronotope» avec la même acception, c'est pourquoi c'est l'univers de fiction qui dans notre étude est le plus englobant, à la suite de l'usage qu'en fait Richard Saint-Gelais pour la transfictionnalité (Fictions transfuges).

492 Patrick Moran, «Le meilleur des mondes arthuriens possibles», art. cit. Voir aussi sa mise au point théorique dans Lectures cycliques, p. 108-128. Patrick Moran appréhende la Suite Vulgate, la Suite post-Vulgate et le Livre d'Artus comme des mondes possibles à l'issue du Merlin en prose, c'est-à-dire des «éventualité[s] narrative[s] à un instant $t$ du récit». (Lectures cycliques, p. 113) Le monde possible est ici compris au sens d'Umberto Eco : il désigne les scénarios inférentiels qu'offre un texte à l'imagination du lecteur. Ce sens exclut la perspective modale, qui voit dans le monde fictionnel un possible du monde réel. Umberto Eco, Lector in fabula, chapitres 7 et 8 . "Le lecteur, en faisant ces prévisions, assume une attitude propositionnelle [...] quant à l'évolution des choses. Ce faisant, il configure un cours d'événements possible ou un état de choses possible - comme on l'a dit plus haut, il hasarde des hypothèses sur des structures de monde.» (p. 149) Françoise Lavocat considère plusieurs modalités du monde possible du texte: la suite, les mondes rêvés ou souhaités par les personnages et les développements possibles de l'intrigue, laissés en suspens par le narrateur. Voir Françoise Lavocat, «L'œuvre littéraire est-elle un monde possible? ", en ligne sur le site Fabula Ateliers, http://www. fabula.org/atelier.php?L\%27oeuvre_litt\%26eacute\%3Braire_est $\% 2$ Delle_un_ monde_possible\%3F 
fiction, qui respecte les invariants énoncés ci-dessus, mais les deux productions présentent des différences génériques situées sur d'autres plans.

La transfictionnalité ne se suffit pas de la simple évocation d'un personnage, mais elle doit intervenir sur le monde fictionnel en modifiant ou en ajoutant des données. Noémie Chardonnens précise le concept en ce sens, en insistant sur l'appropriation de l'univers par la transfiction:

Une transfiction non seulement reprend un univers fictionnel, mais se l'approprie en y intervenant directement. L'ambition d'un texte transfictionnel est donc de participer au monde fictif dans lequel se déroule un (ou plusieurs) récit préexistant, en le complétant ou en le corrigeant. Ce critère exclut de nombreux cas d'intertextualité de la sphère transfictionnelle. Les simples citations et les transpositions de passage ne sont pas concernées, puisqu'elles n'amènent aucune modification diégétique, pas plus que les pastiches et les parodies, qui ne reconduisent pas nécessairement l'univers fictionnel de leur source ${ }^{493}$.

Les transformations et les possibles contradictions engendrées par la transfiction ne réduisent pas l'exigence de l'identification: "Quels que soient les éléments impliqués, il doit y avoir identité ou, plus exactement, prétention à l'identité» ${ }^{494}$. Autrement dit, l'auteur doit veiller à "ne pas dépasser un écart minimal, afin que le lecteur puisse reconnaître le personnage ou le motif, l'associer à certains traits, à des caractéristiques spécifiques ${ }^{495}$. L'onomastique ou quelques traits de similitude ne suffisent pas à créer un lien transfictionnel. Les auteurs qui entendent mettre en scène Arthur dans leurs récits doivent conserver quelques caractéristiques qui permettront au lecteur de reconnaître sans ambiguïté le roi légendaire. Ainsi, même si la Bataille Loquifer construit un Arthur peu amène, il s'agit du même personnage que celui d'Erec et Enide. On en conclut que "la transfictionnalité travaille l'identité de l'intérieur, en proposant des entités qui ne sont ni tout à fait autres, ni tout à fait mêmes » ${ }^{496}$.

\footnotetext{
493 Noémie Chardonnens, L’Autre du même, p. 65. On consultera les pages 62 à 75 pour une application de la notion à la littérature médiévale.

494 Richard Saint-Gelais, Fictions transfuges, p. 22.

495 Barbara Wahlen, L'écriture à rebours, p. 29.

496 Richard Saint-Gelais, Fictions transfuges, p. 22.
} 
Reprenant nos réflexions sur la référentialité du personnage d'Arthur ${ }^{497}$, on admettra qu'il existe, aux yeux du public médiéval, un Arthur historique - celui de la chronique - et un Arthur fictionnel qui en est la contrepartie, l'équivalent fictionnalisé. Le genre est en ce sens prescripteur et oriente les propriétés ontologiques du personnage, dont le comportement répond aux attentes propres à chaque genre. L'Arthur romanesque fait l'objet de transfictions qui modulent ses aventures et son caractère au sein de plusieurs œuvres, que ce soit Claris et Laris ou le Lancelot en prose. La réactivation de la figure peut faire plus ou moins appel aux données historiques, comme celle de la guerre contre Rome dans Claris et Laris, ou demeurer dans le cadre de l'élaboration romanesque et se concentrer sur les aventures, le merveilleux, la culture courtoise qu'il implique.

La transfictionnalité suppose l'autonomie de l'univers de fiction vis-àvis des œuvres; dès lors, le personnage d'Arthur est indépendant du genre qui l'a fait naître en tant que figure fictionnelle ${ }^{498}$. L'univers arthurien

497 Voir supra, p. 123-125.

498

La même chose se produit pour le Graal : alors qu'il naît chez Chrétien de Troyes et qu'il apparaît comme un objet propre à la littérature arthurienne, Sone de Nansay (1270-1280) l'extrait de son contexte arthurien. Ce roman anonyme de la fin du XIII ${ }^{\mathrm{e}}$ siècle développe effectivemment l'histoire sacrée du Saint Vase sans pour autant mentionner une seule fois le roi Arthur ni même Perceval. Cette histoire, bien qu'augmentée et précisée par des détails nouveaux, est pourtant tirée du cycle du Lancelot-Graal: y apparaissent le récit de la vie de Joseph d'Arimathie, son prétendu fils Josephé, la lance qui saigne, et surtout le Roi Pêcheur et sa blessure. Ce dernier est identifié comme étant Joseph d'Arimathie lui-même, sa blessure aux reins étant une punition divine pour avoir épousé une princesse sarrasine (Sone de Nansay, v. 4773-4828). Le texte fait largement écho à la littérature du graal, au Conte du graal mais aussi à Perlesvaus, à la Queste, aux Continuations et à l'Estoire dou saint Graal, sources qui côtoient celle que fournissent les Évangiles. En référence à Chrétien de Troyes, le narrateur de la vie de Joseph d'Arimathie signale que celui-ci a été guéri par un chevalier ("Tant c'uns chevaliers l'ot sané», v. 4826); sans doute faut-il comprendre que l'histoire de Sone est postérieure à l'univers arthurien et l'arrivée de Galaad, mais ce serait incohérent avec la conservation du Graal comme relique, qui n'a pas disparu avec l'élu dans Sone. Cette œuvre offre sa propre interprétation du mythe; le Graal se situe en Norvège, tout comme la terre de Joseph d'Arimathie, devenu roi Pêcheur. L'objet est rendu autonome de l'univers de fiction arthurien, comme s'il s'agissait d'un objet sacré totalement indépendant, que chaque auteur peut réinvestir à sa guise. Il perd dès lors de son mystère. Pour le dire avec Christine Ferlampin-Acher, «le Graal est bien préservé, mais au prix d'une délocalisation, d'une désarthurianisation et 
peut s'insérer dans d'autres genres ${ }^{499}$, ponctuellement dans les épisodes avaloniens des chansons de geste par exemple: l'intervention arthurienne reste bien circonscrite, si bien que l'on peut parler de «bulle transfictionnelle», selon l'expression de Noémie Chardonnens, qui la définit comme «le partage et l'appropriation d'un ou de plusieurs univers fictionnel(s) préexistant(s), avant de se clore et de laisser l'intrigue revenir à la fabula qui lui est propre " ${ }^{500}$. Le personnage d'Arthur de la Bataille Loquifer, transfictionnel, est emprunté à l'univers arthurien, la matière arthurienne; la façon dont il se comporte et interagit avec les autres personnages est modulée conformément aux critères propres au genre dans lequel il est intégré - la chanson de geste. Il s'agit du même roi que chez Chrétien de Troyes, mais le genre formalise son caractère différemment. La sémiologie des personnages n'est donc pas identique d'un genre à l'autre ${ }^{501}$. Il s'agit ici d'un exemple concret de notre système générique: le genre rend compte d'une formalisation spécifique de la matière. La formalisation qu'offre la chanson de geste de la matière arthurienne place les épisodes avaloniens à la périphérie de l'échelle de centralité arthurienne.

finalement d'une banalisation qui le réduit au statut de simple relique qu'on ne sort même plus». "Interpolations et "extrapolations" : études de quelques épisodes arthuriens en contexte non arthurien", in Arthur après Arthur, p. 145. Voir aussi Sone de Nansay, éd. de Claude Lachet, Paris, Champion ("CFMA»), 2014, Claude Lachet, Sone de Nansay et le roman d'aventures en vers au XIII siècle, Paris, Champion, 1992, p. 541-578, Claude Lachet, «Un siècle après Perceval: Sone de Nansay et le Graal", in Les Personnages autour du Graal. Actes du colloque des 7 et 8 juin 2007 à l'Université de Lyon 3, Lyon, Université de Lyon 3 ("CEDIC»), 2008, p. 153-164, et Richard Trachsler, Disjointures-conjointures, p. 112-117.

499 L'autonomie de la matière vis-à-vis du genre du roman arthurien se confirme à la lecture des articles de Arthur après Arthur: la matière arthurienne peut se manifester dans des genres divers. Christine Ferlampin-Acher donne l'exemple de Laurin, du Cycle des Sept Sages: ce texte relève de la matière antique, mais le héros se rend pourtant à la cour d'Arthur. "Interpolations et "extrapolations": études de quelques épisodes arthuriens en contexte non arthurien", p. 137-155. Françoise Laurent évoque quant à elle les incursions d'Arthur dans les vies de saints. "Le roi Arthur et la composante historique des vies de saints anglonormandes", p. 157-177. Voir aussi l'annexe en fin de volume, qui recense les attestations arthuriennes, p. 561-611.

500 Noémie Chardonnens, L'Autre du même, p. 81.

501 Carlos C. Carreto l'exprime dans son article "Rainouart au pays des fées», art. cit. 
La matière arthurienne est donc, au XIII ${ }^{\mathrm{e}}$ siècle déjà, «désolidarisée du roman arthurien " ${ }^{502}$ en tant que genre; l'exemple du Roman du Hem ${ }^{503}$ le prouve également. Ce texte atypique, l'un des premiers reportages de festivitée ${ }^{504}$, raconte le tournoi réel qui a eu lieu au hameau de $\mathrm{Hem}^{505}$ en 1278. L'auteur, dénommé Sarrasin, ne se contente toutefois pas de restituer les joutes linéairement: le récit des «joutes qu'il vit molt dures» (v. 4601) alterne avec celui des «aventures» (v. 4602), inspirées de la tradition arthurienne. Sarrasin s'emploie à littérariser son compte rendu pour en faire un véritable roman, si bien que les frontières entre réalité et fiction sont brouillées. Ce sont surtout les noms des personnages qui créent un lien entre le texte et les romans de la Table Ronde: les participants historiques au tournoi du Hem se déguisent en personnages arthuriens et sont désignés par l'onomastique arthurienne. La présidente du tournoi, sœur d'Aubert de Longueval qui l'organise ("Car ses freres estoit germains", v. 1647), est dénommée exclusivement «la reine Guenièvre» et emmène avec elle au Hem le sénéchal Keu. Soredamor et un Chevalier au lion viennent également agrémenter l'histoire. Si Arthur est absent, Guenièvre

502 Christine Ferlampin-Acher, "À la mode de Bretagne: la culture arthurienne dans le Roman du Hem de Sarrasin (1278) et le Roman de Guillaume d'Orange (entre 1454 et 1456)", in Arthur après Arthur. La matière arthurienne tardive en dehors du roman arthurien (1270-1530), dir. Christine Ferlampin-Acher, Rennes, PUR ( Interférences»), 2017, p. 517.

503 Nous avons traité de ce texte en détail et à propos des mêmes problématiques dans "Imiter le roman - fictionnaliser l'Histoire: le Roman du Hem entre roman et relation de tournoi", in Don Quichotte avant Don Quichotte? Les récits de chevalerie du XIV au XVI siècle en France, Italie et Espagne: production et réception, Tirant, 22, 2019, p. 73-88, en ligne: https://ojs.uv.es/index.php/Tirant/ article/view/15294/13967. Nous nous permettons de résumer ici les principales conclusions.

504 Voir Nancy Freeman Regalado, "A contract for an early festival book: Sarrasin's Le Roman du Hem (1278)", in Acts and Texts: Performance and Ritual in the Middle Ages and the Renaissance, dir. Laurie Postlewate et Wim Hüsken, Amsterdam; New York, Rodopi ("Ludus. Medieval and Early Renaissance Theatre and Drama», 8), 2007, p. 249-267.

505 Sur le lieu où se déroule le tournoi, voir l'introduction à l'édition d'Albert Henry, éd. cit., p. ILVIII-LII. L'éditeur identifie les participants historiques aux pages LVI-CVIV. Sur les conditions historiques de ce tournoi, voir aussi Juliet Vale, Edward III and Chivalry: Chivalric Society and its Context 1270-1350, Woodbridge, Boydell, 1982, p. 4-24. Seul le témoignage de Sarrasin avec son Roman du Hem atteste l'existence de ce tournoi. 
et Keu suffisent à le remplacer pour évoquer l'univers fictionnel. On pourrait arguer que seule l'onomastique est empruntée et que le nom se réduit à une coquille vide ${ }^{506}$. Toutefois, les participants au tournoi adoptent les mêmes comportements que les personnges qu'ils incarnent et en imitent le caractère. Dans la composition de Sarrasin, ces identités ne sont jamais présentées comme fictives et le lecteur doit admettre que ce sont bien les héros arthuriens qui animent ce tournoi. Le nom propre n'est pas une coquille vide, mais exprime la tentative d'héroïser la noblesse présente à Hem et de réactiver en actes l'univers de fiction arthurien. De nouvelles aventures sont donc prêtées aux personnages fictifs et littéraires; ces nouvelles aventures ne s'élaborent pas via le medium du papier, mais via le jeu plus ou moins improvisé de participants qui mêlent identité fictive et identité réelle et créent par leurs actes une nouvelle fiction.

À la fin du Moyen Âge, l'univers arthurien est réactivé à l'intérieur d'un autre média et s'émancipe du cadre littéraire: sa réception se traduit en transfictions médiatiques, en transposition du cadre fictionnel dans la réalité d'un tournoi ${ }^{507}$. Christine Ferlampin-Acher relativise en ce sens le

506 L'exemple d'Artus de Bretagne est un cas où le nom propre est employé comme une coquille vide: le nom d' "Arthur» évoque forcément l'univers arthurien, mais le personnage ainsi nommé ne correspond pas au légendaire roi. Néanmoins, l'auteur place son intrigue en continuité du temps arthurien et exprime cette relation dès le début du texte: l'histoire se passe après le règne d'Arthur et le prestige du roi breton rejaillit sur le héros d'Artus de Bretagne par le nom qui lui est donné. On comprend avec cet exemple que l'onomastique a le pouvoir de créer des ponts avec une matière, sans qu'il y ait une transfictionnalité véritable des personnages. Voir au sujet de ce texte les travaux de Christine Ferlampin-Acher, notamment "L'écu du "petit" Artus de Bretagne: héraldique et réception arthurienne à la fin du Moyen Âge", in Marqueurs d'identité dans la littérature médiévale: mettre en signe l'individu et la famille (XIT-XIIT siècles), dir. Catalina Girbea, Laurent Hablot, Raluca Radulescu, Turnhout, Brepols, 2014, p. 93-107, ainsi que son édition, Artus de Bretagne. Roman en prose de la fin du XIII siècle, éd. cit. Elle souligne que la dénomination d'un héros tout autre d'après le roi légendaire renvoie à une réalité de la fin du Moyen Âge, quand les nobles se plaisent à porter des noms arthuriens.

507 Nous empruntons cette idée à Christine Ferlampin-Acher, "Introduction. Après Arthur?", art. cit., et Sébastien Nadot, "Arthur et ses chevaliers: un scénario pour le sport", in La Matière arthurienne tardive en Europe (1270-1530), dir. Christine Ferlampin-Acher, Rennes, PUR, 2020, p. 103-114. On peut se convaincre de la popularité de l'univers arthurien aux $\mathrm{XIV}^{\mathrm{e}}$ et $\mathrm{XV}^{\mathrm{e}}$ siècles par les évocations ou les apparitions dont les personnages arthuriens font l'objet dans des genres divers. On peut citer par exemple le Livre du Voir dit de Guillaume de Machaut: «Ne fu vaillans Lancelos pour sa dame, / Tristans, Paris et Perchevaus, qui ame / $\mathrm{Ne}$ 
déclin de la veine arthurienne aux $\mathrm{XIV}^{\mathrm{e}}$ et $\mathrm{XV}^{\mathrm{e}}$ siècles: la matière arthurienne s'affranchit non seulement du roman arthurien, mais aussi de la littérature, pour devenir un phénomène culturel. L'univers demeure résolument actuel et parle au public, même en l'absence d'une connaissance parfaite des textes:

En partie sortie du texte, «délittérarisée», lieu commun, effet de mode, la matière arthurienne se résume alors souvent à quelques noms, dont la portée est difficile à cerner si l'on s'en tient à l'intertextualité, mais qui, si on les actualise en fonction de cette dimension culturelle de la matière arthurienne, deviennent beaucoup plus parlants ${ }^{508}$.

La présence d'Arthur dans les épisodes avaloniens des chansons de geste tardives (les versions d'Ogier, Esclarmonde, Trisant de Nanteuil, Lion de Bourges par exemple), même si le personnage joue un rôle spécifique au genre et à ce type de passage, signale elle aussi la vivacité de l'univers arthurien dans les derniers siècles du Moyen Âge. C'est donc moins la matière arthurienne que le genre du roman arthurien en vers qui décline.

Les exemples du Tournoi de l'Antéchrist, de la Bataille Loquifer et du Roman du Hem dont nous venons de traiter démontrent que l'inscription générique peut être multiple: alors que le roman arthurien n'est pas le genre dominant de ces trois textes, il demeure pertinent d'engager une réflexion sur les rapports que ceux-ci entretiennent avec le genre arthurien. Cette réflexion engage les liens entre transfictionnalité et genre: à l'aune de cette confrontation, on peut déduire que la simple mise en scène du personnage d'Arthur et de son univers fictionnel ne suffit pas à affilier l'exemplaire à la classe générique, et que celle-ci se définit sur la conjonction d'autres critères, comme l'exprime Beate Schmolke-Haßelmann:

Doch macht die Verwendung einiger arthurischer Namen und Schauplätze oder eine allzu lose Verknüpfung der Romanhandlung mit dem Artushof aus einem beliebigen Abenteuerroman noch keinen

congnoissoit de bien?» (éd. Paul Imbs et Jacqueline Cerquiglini-Toulet, Paris, le Livre de Poche («Lettres gothiques»), 1999, v. 6106-6108). On consultera également l'entier du volume Arthur après Arthur.

508 Christine Ferlampin-Acher, "Introduction. Après Arthur?", art. cit., p. 21. Voir aussi «La matière arthurienne en langue d'oïl à la fin du Moyen Âge: épuisement ou renouveau, automne ou été indien?", art. cit. 
Artusroman, wenn man die einzelnen Vertreter der Gruppe unter dem Aspekt der Gattungsmerkmale betrachtet ${ }^{509}$.

La présence d'Arthur ou d'un membre constitutif du noyau de la cour arthurienne, si elle ne suffit pas à créer un roman arthurien en vers, ne manque pas de signaler l'existence d'un dialogue entre le texte et le genre qui nous intéresse ${ }^{510}$. Les trois œuvres que nous venons de considérer pourraient donc se situer à la périphérie de l'échelle de centralité arthurienne.

\section{L'errance aventureuse}

Outre un univers de fiction, le genre implique des codes esthétiques et des valeurs qui lui sont propres. Ce qui relève d'abord du contenu personnages, lieux, temps - se précise donc ensuite autour d'autres critères spécifiquement génériques, ainsi que le conçoit Annie Combes:

La persistance d'un univers fictionnel passe par la mise en place de normes narratives qui finissent par prendre une couleur générique, voire tendent à établir un genre, tel celui du roman arthurien. Ainsi, l'écriture des romans utilisant la matière de Bretagne a-t-elle très vite obéi à un ensemble de règles, dont la récurrence a fixé une généricité implicite mais confirmée par chaque nouveau récit inscrit dans cette sphère diégétique particulière. La poétique latente de ces œuvres, qu'elles soient en prose ou en vers, a pour fondement la structure narrative de l'aventure, une structure axée sur la merveille ${ }^{511}$.

L'univers de fiction contraint les autres postes génériques, induit l'adhésion à des valeurs particulières, d'où sa parenté avec la notion de matière que nous soulignions. En tant que critère générique, l'univers de fiction ou la matière est forcément interdépendant d'autres critères qui

509 Beate Schmolke-Haßelmann, Der arthurische Versroman, p. 4. «L'utilisation de quelques noms ou lieux arthuriens, ou l'établissement d'un lien ténu avec la cour arthurienne au sein de l'action d'un quelconque roman d'aventures, ne crée donc pas un roman arthurien, si l'on considère les représentants individuels du groupe sous l'aspect des critères génériques. " (nous traduisons)

510 Nous renvoyons à l'étude d'Adeline Latimier-Ionoff, sur la force définitoire de l'onomastique pour le roman arthurien. Lire le nom propre.

511 Annie Combes, "Narration et "matières". Les limites du merveilleux dans quelques romans arthuriens", in Motifs merveilleux et poétique des genres au Moyen Age, dir. Francis Gingras, Paris, Garnier, 2015, p. 359. 
définissent le genre canonique. C’est la récurrence de leurs apparitions concomitantes dans les œuvres qui permet de brosser cette "poétique latente».

Comme l'avance Annie Combes, cette poétique s'illustre principalement du point de vue de la structure ${ }^{512}$ : pour le roman arthurien en vers, celle de la quête ${ }^{513}$ et de l'errance véhicule une idéologie courtoise et idéale invitant au dépassement de soi. Paul Zumthor, dans son essai de définition du roman courtois, décrit le schéma aventureux récurrent du roman arthurien en vers comme suit:

Une situation initiale, généralement provoquée de façon imprévisible, crée ou révèle l'absence d'un objet ou d'une personne dont l'acquisition, au cours d'une errance qui suscitera les antagonismes, finit par être obtenue, pour le plus grand bien du héros et de la communauté à laquelle il appartient ${ }^{514}$.

Le roman arthurien en vers suit une structure spécifique et récurrente: il narre le parcours d'un chevalier qui chemine seul dans le but de mener à bien une quête, visant à ramener la paix dans le royaume. L'errance se fonde sur le concept d'aventure ${ }^{515}$ :

512 Précisons encore une fois qu'il s'agit ici de la structure du roman arthurien en vers canonique. Nous traiterons des rapports structurels qu'entretiennent nos romans tardifs avec ceux de la prose au chapitre III, "Structures arthuriennes: imiter la prose», p. 493-554.

513 Errance et quête sont deux concepts liés. La quête englobe le but du chevalier, ce vers quoi mènera l'errance: elle donne l'impulsion au départ du chevalier. La quête s'apparente à une recherche de la perfection, amoureuse (quête de la femme) ou spirituelle (quête de Dieu, du Graal). Dans le roman en vers, il peut s'agir plus simplement d'une mission ponctuelle, comme celle de délivrer une demoiselle victime d'un enchantement (Le Bel Inconnu) par exemple. Le but peut aussi être d'ordre abstrait: Erec doit faire ses preuves, racheter sa recreantise, pour se montrer digne d'Enide et de son statut de chevalier. La quête et l'errance sont consubstantiels: l'errance n'est pas seulement un cheminement qui conduit au but final; il s'agit d'un moyen de perfectionnement indispensable pour la réalisation de la quête. Voir Marie-Luce Chênerie, Le Chevalier errant, p. 106-125.

514 Paul Zumthor, "Le roman courtois: essai de définition", art. cit., p. 83. Danièle James-Raoul définit quant à elle le style arthurien en premier lieu sur l'épanouissement de l'aventure et les occurrences du mot. "Questions de style à propos des romans arthuriens en vers", art. cit., p. 47-50.

515 Voir l'article de Daniel Poirion, "Le Roman d'aventure au Moyen Âge: étude d'esthétique littéraire", Cahiers de l'Association internationale des études françaises, 
Chrétien de Troyes et d'autres romanciers de sa génération conférèrent au mot un sens spécifique, tel qu'il désigne, sinon une structure, du moins une règle narrative: l'aventure est une épreuve, située dans une série d'épreuves (il n'y a pas d'aventure isolée) permettant à un héros de progresser vers un état de perfection exemplaire par où sera rétabli l'ordre commun ${ }^{516}$.

L'aventure a une fonction narrative propre: c'est elle qui donne la mesure de l'évolution du héros. Elle entretient un lien organique avec le genre romanesque, comme l'expriment les premiers vers de Rigomer que nous avons déjà évoqués: "Assés briément l'a romanchié / Des aventures de Bretaigne" (v. 4-5 $)^{517}$. Le roman est perçu ici comme la forme privilégiée pour restituer les aventures de Bretagne; le terme «aventure» occupe une fonction générique $^{518}$, définitoire de la classe de récits situés en Bretagne, autour d'Arthur et de ses chevaliers ${ }^{519}$. L'emploi du syntagme «aventures de Bretagne», qui apparaît aussi dans Claris et Laris (v. 88), couplé au mot «roman», témoigne d'une perception de plus en plus claire de l'homogénéité générique de la catégorie que nous appelons « roman arthurien en vers».

1988, 40, p. 111-127, d'Annie Combes, "Le roman arthurien: un paradigme de l'aventure», in Poétique du roman d'aventure dir. Alain-Michel Boyer et Daniel Couégnas, Nantes, Éditions Cécile Défaut ("Horizons comparatistes»), 2004, p. 31-43, et Danièle James-Raoul, Chrétien de Troyes, la griffe d'un style, p. 273-314, pour une définition de l'aventure. Edina Bozoky définit quant à elle les règles de conduite que le chevalier doit adopter face à l'aventure, en les comparant à celles du conte. "Roman arthurien et conte populaire: les règles de conduite et le héros élu ", Cahiers de civilisation médiévale, 81, janvier-mars 1978, p. 31-36.

516 Paul Zumthor, «Le roman courtois: essai de définition», art. cit., p. 86.

517 Danièle James-Raoul relève que les occurrences du terme "aventure» au pluriel sont peu nombreuses dans l'œuvre de Chrétien de Troyes. Elles sont toujours en lien avec le discours: les aventures, c'est ce qu'on raconte. Chrétien de Troyes, la griffe d'un style, p. 288-289.

518 Voir notre article avec Barbara Wahlen, "La figure d'Arthur dans quelques romans en vers allemands et français", in Arthur en Europe à la fin du Moyen Âge. Approches comparées (1270-1530), dir. Christine Ferlampin-Acher, Paris, Garnier, 2020, p. 41-55, au sujet de la problématisation de la notion d'aventure dans les textes tardifs. L'exemple du roman allemand Gauriel von Muntabel, dans lequel le héros crée sa propre aventure en prenant une messagère d'Arthur en otage, est en ce sens particulièrement éclairant.

519 Voir le chapitre Francis Gingras, Le Bâtard conquérant, p. 278 à 281, qui traite du caractère structurant de l'aventure. 
Dans le roman arthurien en vers, l'aventure constitue un but en soi, au contraire de la chanson de geste où les personnages combattent ou se mettent en route parce qu'un danger menace le royaume. Les deux genres se distinguent ainsi idéologiquement: la chanson de geste propose un salut collectif, elle valorise une monarchie chrétienne et donne l'image d'une chevalerie qui soutient la royautés ${ }^{520}$, tandis que le roman arthurien s'intéresse aux questions propres à l'humaine condition, l'amour et l'accomplissement personnel, et donne à voir un destin individuel;

Action collective chantée par l'épopée; aventure individuelle contée par le roman: ici, ce qu'il advient à quelqu'un, événement complexe produit par un ensemble de facteurs; là, le sort du monde, objet d'une décision; dans l'épopée, une société, à la fois réelle et fictive; dans le «roman», la destinée d'un homme ${ }^{521}$.

Le chevalier arthurien recherche le danger de son plein gré pour se dépasser, s'éprouver. Il doit adopter un comportement particulier et stéréotypé pour correspondre à l'idéal:

La quête comporte un certain nombre de conventions: ainsi, le héros refuse de s'arrêter nulle part plus d'une nuit avant d'avoir atteint son but; il conserve l'incognito, mais répond à tout défi qu'on lui oppose; l'antagoniste vaincu a droit à la merci, mais ira rendre compte à la cour de sa défaite ${ }^{522}$.

Le chevalier part à l'aube ${ }^{523}$, chemine la journée et s'arrête la nuit pour dormir à la belle étoile ou chez un hôte hospitalier. Une fois l'errance lancée, l'aventure surgit au gré des hasards et suscite la rencontre:

520 Voir l'article de Daniel Poirion, "Chanson de geste ou épopée? Remarques sur la définition d'un genre", in Écriture poétique et composition romanesque, Orléans, Paradigme («Medievalia»), 1994, p. 21-38, qui donne une définition de la chanson de geste.

521 Paul Zumthor, Essai de poétique médiévale, p. 410.

522 Paul Zumthor, «Le roman courtois: essai de définition», art. cit., p. 83.

523 "Ces levers si matinaux renouvellent le rythme du départ initial, inaugurent celui de la journée, qui ne devrait pas non plus connaître de défaillance; ils confirment après chaque étape, l'image de santé, de vigueur ou de courage que donne la chevalerie errante." Marie-Luce Chênerie, Le Chevalier errant dans les romans arthuriens en vers des XII et XIII siècles, Genève, Droz, 1986, p. 251. 
rencontre avec des demoiselles en détresse, rencontre avec des adversaires avides de se mesurer, rencontre avec la merveille, des nains ou des géants. Ces personnages apparaissent comme autant de piliers du monde arthurien, au même titre que les figures d'Arthur, de Keu et de Gauvain. La récurrence de ces figures dans le roman arthurien depuis Chrétien de Troyes et jusqu'au roman en prose suffit à les associer au genre, même si elles interviennent ailleurs ${ }^{524}$. En s'illustrant lors des épreuves, le héros obtient une terre et une épouse ${ }^{525}$ et sa valeur est reconnue publiquement.

L'aventure a une portée thématique et structurelle: le thème de l'aventure est certes définitoire du point de vue du genre, mais c'est surtout la succession d'une série d'aventures et leur organisation qui oriente vers une lecture arthurienne de l'œuvre. L'agencement des aventures rend compte du cheminement du chevalier, à la fois progression morale et déambulation; c'est le principe de l'errance. L'errance se construit selon un principe de synergie que nourrissent les aventures: c'est au chevalier de mettre son énergie à leur surgissement, ce qui soutient l'activité du chevalier, sa saine circulation empêchant l'oisiveté ${ }^{526}$. L'aventure guide les pas du chevalier sur le mode du hasard: «Li Laiz Hardiz pas n’oblia / Sa queste, ainçois tient sa voie / La ou aventure l'avoie, / Une heure avant et l'autre arriere" (Claris, v. 12650-12653). Elle mène le héros et construit aussi le temps. De fait, dans le roman arthurien en vers, c'est moins l'espace que le fait de cheminer qui intéresse: c'est bien la valeur qu'a le mot "errer» dans cette esthétique, que celle d'exprimer un trajet hasardeux menant à des points d'achoppement ${ }^{527}$. Une précision comme «Tant ont erré, tant chevaucherent, / Qu'en la terre le roi entrerent» (Claris, v. 6205-6206) élude la géographie, volontairement incertaine, de l'itinéraire.

À partir de cette structure, Beate Schmolke-Haßelmann dégage deux types de romans arthuriens en vers, sur le modèle des textes de Chrétien de Troyes. Dans le premier type, le récit s'ouvre à la cour d'Arthur, comme dans le Chevalier au lion, où un chevalier est élu pour l'aventure. Le

524 Keith Busby, "The Characters and the Setting", art. cit., p. 73.

525 Sur l'errance comme préparation au mariage, voir Marie-Luce Chênerie, Le Chevalier errant, p. 455-472.

526 Cedric E. Pickford propose une mise au point sur le chevalier errant en particulier dans les romans en prose dans L'évolution du roman arthurien prose, p. 217-231.

527 Voir Marie-Luce Chênerie, Le Chevalier errant, p. 217 et p. 11-12 sur le mot «errer». Sur les liens entre l'aventure et le hasard, voir p. 232-233. 
deuxième type se fonde sur un schéma généalogique, comme dans Cligès: le héros est d'abord extérieur à la cour et la narration commence par présenter ses parents et son enfance. Le rattachement de Cligès au genre arthurien est pourtant problématique: sa structure est bien différente de celle des autres œuvres de Chrétien de Troyes que Beate SchmolkeHaßelmann prend pour modèle et pas tout à fait représentative de la production arthurienne versifiée qui sera engendrée à la suite de l'auteur champenois. À cela s'ajoute sa géographie orientale, bien différente de celle, incertaine et merveilleuse, de la Bretagne arthurienne. Enfin, Cligès peut être perçu comme un «étonnant bric à brac qui brasse, comme Thessala ses potions, toutes les composantes, toutes les formes, tous les styles de la littérature narrative du XII ${ }^{\mathrm{e}}$ siècle ${ }^{258}$. Ce roman fait intervenir des discours et des types de récit hétérogènes: le roman antique, le roman arthurien, Tristan et Iseut, le roman oriental.

Triplement, le deuxième roman de Chrétien de Troyes peut être considéré comme un roman de la marge, au même titre que le sont les romans tardifs. Ceux-ci entretiennent d'ailleurs un certain nombre de parentés avec Cligès. Celui-ci représente une sorte de voie inexplorée du roman arthurien en vers dont peut se nourrir l'écriture tardive; ce texte a moins fait l'objet de réécritures et a moins généré l'imitation que les autres romans de Chrétien de Troyes. La fin du XIII ${ }^{\mathrm{e}}$ siècle lui concède une sorte de retour en grâce dont participe aussi le Roman du Hem: nous en parlions au chapitre précédent, une invitée se déguise en Soredamor lors de la fête. Dans les romans tardifs, la réappropriation concerne justement ce qui fait de Cligès un roman arthurien de la marge: nous verrons que Floriant et Florete délocalise lui aussi son intrigue aux bords de la Méditerranée, ce qui a pour conséquences d'interroger son caractère arthurien (chapitre II, «Expansion géographique et référentialité de l'espace», p. 260-279).

Une preuve marquante de cette influence de Cligès sur certains romans tardifs consiste en l'apparition du personnage de Cligès dans Rigomer, Claris et Laris et Biaudouz. Il y intervient comme chevalier de la Table Ronde, prouvant par là que les auteurs ont perçu un lien fort entre cette œuvre et le genre arthurien, faisant fi de l'héritage de l'empire grec qui devrait tenir Cligès éloigné de la Bretagne à la fin du roman de Chrétien de Troyes. Dans les romans tardifs, Cligès est le héros ponctuel de petites

528 Laurence Harf-Lancner, "Introduction», in Chrétien de Troyes, Cligès, Paris, Champion («CCMA»), 2006, p. 36. 
aventures ou se range du côté des chevaliers d'Arthur lors d'un tournoi dans Biaudouz. Ces apparitions sont d'autant plus remarquables que ce personnage ne se manifeste pas dans d'autres romans arthuriens en vers, excepté dans les Continuations ${ }^{529}$. Le rôle qui lui est donné dans ces romans tardifs témoigne de la voie qu'ouvre Cligès: roman des limites, pas tout à fait arthurien, s'intéressant à plusieurs personnages, la deuxième œuvre de Chrétien de Troyes est déjà tardive, si l'on ose ce paradoxe, tout du moins recèle-t-elle quelques germes qui fleuriront dans la poétique de la tardivité.

Malgré plusieurs déviations au canon, Cligès fait intervenir la cour d'Arthur de manière assez semblable aux autres romans de Chrétien de Troyes, puisque celle-ci apparaît ponctuellement pour assurer la formation d'Alexandre, puis de Cligès. Ce roman fait donc jouer un rôle fonctionnel à ce que Beate Schmolke-Haßelmann appelle l'Artusszene. Ces scènes arthuriennes, ces retours à la cour d'Arthur, donnent l'impulsion au chevalier pour poursuivre son errance et consacrent son parcours, garantissant son exceptionnelle chevalerie ${ }^{530}$. Les Artusszenen interviennent au début, au milieu et à la fin de l'errance. Traditionnellement, l'Artusszene se caractérise par une réunion de chevaliers autour d'Arthur, lors de laquelle un messager ou le héros lui-même arrive. Quelque chose se produit, qui concerne le héros et le transforme. L'interdépendance de la cour, constituée par des personnages clés gravitant autour de la figure tutélaire d'Arthur, et de la structure globale du texte est fondamentale. Outre le début des romans, Beate Schmolke-Haßelmann dégage une structure narrative arthurienne qui concerne l'ensemble d'un récit: la «Doppelkomposition" (composition en deux parties). À une première partie progressive, lors de laquelle le héros fait ses premières preuves, succède une deuxième phase qui oblige le chevalier à réparer une faute commise (oubli du délai de Laudine, recreantise, silence au Château du Graal) et à asseoir définitivement sa valeur.

529 Un «Cligés" apparaît dans le Roman d'Yder, mais G. D. West considère qu'il s'agit d'un homonyme et que rien n'indique l'identité du fils d'Alexandre et de Soredamor. An Index of Proper Names in French Arthurian Verse Romances, 11501300, Toronto, Toronto University Press, 1969, p. 43.

530 Beate Schmolke-Haßelmann, Der arthurische Versroman, p. 35-47. Voir aussi Marie-Luce Chênerie, Le Chevalier errant, p. 125-142. 
Floriant et Florete est le seul de notre corpus à correspondre à ces critères: une première phase de conquête et d'errance s'achève sur le mariage de Floriant, puis une deuxième s'ouvre pour racheter la recreantise du héros. Le roman se construit selon les principes de "Motivdoppelung" (duplication de motif) et de "Zweiteilung" (composition en deux parties) que reconnait Beate Schmolke-Hasselmann: les aventures de la deuxième errance font écho à celles de la première, ce qui produit un effet de symétrie ${ }^{531}$. Les autres textes de notre corpus ne reconduisent quant à eux pas cette structure.

On peut discuter la pertinence de la distinction opérée par la critique allemande; elle a les défauts de prendre les œuvres du Champenois comme modèle originel et de rigidifier la structure du genre. Cette perspective pointe néanmoins le fait qu’il existe des mécanismes narratifs typiquement arthuriens, que l'on retrouve dans un certain nombre de romans, en dehors des exemples de Chrétien de Troyes. La structure peut alors fonctionner comme marqueur de genre, comme le prouvera l'exemple de Blandin de Cornouailles que nous évoquerons au chapitre suivant: cette œuvre peut être considérée comme un roman arthurien sur la base de sa structure.

La nature des aventures rencontrées au cours de l'errance est elle aussi convenue, au point que certaines sont considérées comme de véritables motifs spécifiquement arthuriens: on peut citer l'exemple de l'hôte hospitalier qui prévient le chevalier de la difficulté de l'épreuve qui l'attend et tente de l'en dissuader - le nautonier qui accueille Gauvain dans le Conte du graal, avant d'entrer dans le Château de la Merveille ${ }^{532}$. Ces motifs sont bien souvent liés à un type de merveilleux que Dominique Boutet qualifie d' "altérité», distinct de la surnature qui est théologiquement possible du point de vue médiéval ${ }^{533}$. Les blancs cerfs et autres animaux guides, les fées, les dragons cracheurs de feu sont constitutifs de cet univers. Ainsi que

531 Voir l'introduction à l'édition par Richard Trachsler et Annie Combes, p. xxxiIxxxviII, et Beate Schmolke-Hasselmann, Der arthurische Versroman, p. 41-42.

532 Voir l'index des motifs arthuriens d'Anita Guerreau-Jalabert, Index des motifs narratifs dans les romans arthuriens français en vers (XII'-XIII siècle), Genève, Droz, 1992. Norris J. Lacy distingue les motifs spécifiquement arthuriens, comme le Siège Périlleux ou l'épée fichée dans la pierre, et les motifs qui peuvent se rencontrer ailleurs. "The Typology of Arthurian Romance ", in The Legacy of Chrétien de Troyes, vol. 1, p. 33-56.

533 Dominique Boutet, «Merveilleux et interférences génériques dans la chanson de geste de Tristan de Nanteuil», art. cit. 
nous l'avons développé au chapitre I, "Historia et fabula», p. 112-142, le rapport au surnaturel est un point particulièrement sensible au Moyen Âge, mais néanmoins génériquement distinctif, malgré ses ambiguïtés. Dans le roman arthurien, la merveille est un élément déterminant pour l'errance et la transcendance du parcours chevaleresque, comme l'explique Richard Trachsler:

Dans l'univers narratif des romans de la Table Ronde, la merveille est désormais considérée non pas comme un artifice destiné à éblouir, mais comme un élément essentiel sur le plan du sens: c'est l'irruption de la Providence au sein de l'existence du protagoniste ${ }^{534}$.

Le merveilleux est partie intégrante du perfectionnement moral du héros, qui se voit confronté à l'altérité. Il a donc partie liée avec l'idéologie de l'errance.

L'errance, l'aventure et l'expérience du merveilleux font du héros un personnage accompli, fondant ainsi un idéal: le chevalier est toujours le plus preux, le plus beau et le plus courtois. Pourtant, le roman arthurien peut aussi bien véhiculer cet idéal que s'en moquer, à l'image du roi Arthur, dont on ne cesse de répéter qu'il est le roi le plus parfait mais qui est tout autant capable de comportements inadéquats à la fonction royale au sein d'une même œuvre - ainsi du début du Chevalier au lion, où Arthur est loué pour sa courtoisie et sa magnificence, mais où il se retire abruptement pour passer du bon temps avec la reine. Dès ses débuts, le roman arthurien en vers se caractérise par l'ironie ${ }^{535}$ et

534 Richard Trachsler, "En petit d'ore deus labore (Estula, v. 137), Miracles, fabliaux et la main de Dieu", in Motifs merveilleux, p. 477-478.

535 «Posture d'énonciation dédoublée, [l'ironie] est un message double, pour un public qu'elle dédouble, dédoublement qui peut aller jusqu'à la pluralisation et à l'éclatement. [...] Elle est une mise à distance et en tension, à l'intérieur d'un même texte (d'un intra-texte), d'une partie du texte avec une autre partie, disjointe, du même texte, et/ou d'un infra-texte non dit, et/ou d'un intertexte. L'ironie construit donc un lecteur particulièrement actif, qu'elle transforme en co-producteur de l'œuvre, en restaurateur d'implicite, de non-dit, d'allusion, d'ellipse, et qu'elle sollicite dans l'intégralité de ses capacités herméneutiques d'interprétation, ou culturelles de reconnaissance de référents. " Philippe Hamon, L'Ironie littéraire. Essai sur les formes de l'écriture oblique, Paris, Hachette, 1996, p. 151. Le œuvres de Chrétien de Troyes contiennent elles-mêmes cette ironie, ce qui démontre bien que cette littérature, dès ses origines, ne glorifie pas au premier degré la chevalerie. Bénédicte Milland-Bove, "Molt valt mialz, ce m’est avis / 
l'autoparodie ${ }^{536}$ : le genre se plaît à détourner dans un registre ludique sa propre matière et ses propres codes d'écriture. Par le biais de l'ironie, les auteurs ne se privent pas de moquer les chevaliers arthuriens, ainsi de Gauvain, ridiculisé par sa déconvenue lors du Pont sous l'Eau dans le Chevalier de la Charrette; le narrateur énumère ses armes, qu'il a refusé d'ôter, et qui comportent un heaume "qui des autres valoit bien dis" (v. 5116). Ce commentaire du narrateur marque une distance, qui invite à relativiser l'idéal que le chevalier représente: souligner la bonne facture des armes est un lieu commun qui contribue à glorifier la chevalerie, mais Chrétien de Troyes le détourne ici pour mettre en évidence l'attachement de Gauvain à une chevalerie courtoise hermétique aux hautes valeurs de l'amour. Il ne faut donc pas croire que les réactivations successives du genre mènent de plus en plus à la parodie d'une norme tout à fait sérieuse, qu'il s'agisse d'un Gauvain parangon de la chevalerie ou même d'une valeur comme l'amour, qui fait aussi l'objet de passages ironiques interrogeant son caractère aliénant et les excès qu'il entraîne.

La parodie est aussi tournée vers le propre genre du texte: le roman arthurien parodie les romans arthuriens ${ }^{537}$. Nous entendons donc par «autoparodie» le remploi déceptif de structures, de motifs ou de topoi reconnus comme arthuriens, dans le cadre d'un roman que l'on reconnaît

uns cortois morz c'uns vilains vis": de l'ironie et du sérieux dans le Chevalier au Lion", in "Chose qui face a escouter": études sur Le Chevalier au lion de Chrétien de Troyes. Actes de la journée d'étude organisée le 9 décembre 2017 par l'Université Paris-Diderot Paris 7 et l'Université Sorbonne Nouvelle Paris 3, dir. Amandine Mussou, Anne Paupert et Michelle Szkilnik, http://www.univ-paris3.fr/publications-de-la-silc-section-francaise--393070.kjsp?RH=1329834238527, p. 63-72, et Ana Sofia Laranjinha, "L'ironie comme principe structurant chez Chrétien de Troyes", Cahiers de civilisation médiévale, 41, 1998, p. 175-182.

536 Pour une définition de la parodie, voir Yen-Mai Tran-Gervat, «Pour une définition opérationnelle de la parodie littéraire: parcours critique et enjeux d'un corpus spécifique», art. cit., et Jean-Claude Mühlethaler, "Renversement, déplacement et irradiation parodiques. Réflexions autour du Conte du Papegau», Poétique, 57, 2009, p. 3-17. Voir aussi la définition que donne Gérard Genette: «D'abord, l'étymologie: ôdè, c'est le chant; para: "le long de", "à côté"; parôdein, d'où parôdia, ce serait (donc?) le fait de chanter à côté, donc de chanter faux, ou dans une autre voix, en contrechant - en contrepoint -, ou encore de chanter dans un autre ton: déformer, donc, ou transposer une mélodie.» (Palimpsestes, p. 17)

537 C'est toujours le cas dans le roman tardif. Isabelle Arseneau traite de la parodie dans Rigomer dans "Lancelot échevelé: la parodie dans Les Merveilles de Rigomer», Senefiance, 50, 2004, p. 9-21. 
par ailleurs comme arthurien, dans le but d'en problématiser les mécanismes d'écriture et de susciter le rire par la déception d'une attente. L'exemple du cri annonciateur de l'aventure, d'abord poussé par une jeune fille dans Erec et Enide, puis par un lion dans Le Chevalier au lion ${ }^{538}$, illustre bien l'autoparodie de l'écriture arthurienne. De manière plus évidente, le personnage de Gauvain fait l'objet du rire en manquant à sa réputation de séducteur, dans la Vengeance Raguidel par exemple, ou en adoptant les attitudes les plus discourtoises dans Hunbaut. Le roman arthurien en vers engage toujours un jeu subtil entre la variation et la tradition: d'un texte à l'autre, les manquements de Gauvain dans la littérature arthurienne ${ }^{539}$ ne lui font pas perdre sa qualité de meilleur chevalier de la cour ni de parangon de la courtoisie. Chaque nouveau texte remet en quelque sorte les compteurs à zéro et ne saurait, à sa clôture, transformer les invariants de l'univers de fiction. C'est le propre du récit arthurien en vers que d'ouvrir des parenthèses qui n'ont pas d'incidence définitive sur la conception que le lecteur se fait de l'univers.

La dérision de la courtoisie ou de certains idéaux amoureux ne contredit pas nécessairement leur promotion ${ }^{540}$. L'autocritique est donc inhérente à cette écriture, comme l'explique Beate Schmolke-Haßelmann :

Die Idealität der Artusgemeinschaft als brüchig zu durchschauen und damit Selbstkritik zu üben ist jedoch eine der Gattung grundsätzlich und seit Beginn ihrer Geschichte innewohnende Fähigkeit ${ }^{541}$.

538 Sur cet épisode du Chevalier au lion, voir Dietmar Rieger, "Il est a moi et je a lui". Le lion d'Yvain - un symbole et son champ sémantique", in Ensi firent li ancessor. Mélanges de philologie médiévale offerts à Marc-René Jung, Alessandria, Edizioni dell'Orso, 1996, vol. 1, p. 364-365.

539 Stoyan Atanassov étudie la trajectoire de la vie littéraire de Gauvain dans L'Idole inconnue. Le personnage de Gauvain dans quelques romans du XIIT siècle, Orléans, Paradigme, 2000. Le détournement des caractéristiques de Gauvain est déjà présent chez Chrétien de Troyes: c'est bien le neveu du roi qui dévoie Yvain de ses devoirs conjugaux pour lui faire courir de vains tournois, tandis que lui-même manque à l'appel de ses neveux pour les sauver du géant Harpin, et à celui de Lunete, accusée par Laudine et sur le point d'être exécutée. Voir l'étude de Keith Busby, Gauvain in Old French Literature, Amsterdam, Rodopi, 1980.

540 Heinz Klüppelholz, «Die Idealisierung und Ironisierung des Protagonisten in den altfranzösischen Gauvain-Romanen», Germanisch-Romanische Monatsschrift, 44, 1994, p. 18-36.

541 Beate Schmolke-Haßelmann, Der arthurische Versroman, p. 177. "La capacité à présenter l'idéal de la société arthurienne comme friable et à appliquer ainsi une 
L'autocritique et l'autoparodie alimentent la variation, au sein d'un genre qui peut sembler figé par son univers de fiction, le déroulement répétitif de son action et son issue, toujours heureuse. L'originalité du roman arthurien en vers réside dans les procédés littéraires qu’il expérimente, en particulier l'intertextualité:

Anspielungen, Zitate, eine durch das Dichterindividuum Chrestien geprägte Motivik und inhaltliche Rückverweise sorgen für gattungsstiftende Kontinuität besonderer Art; diese literarisierte Erzählhaltung richtet sich an ein Publikum von Kennern ${ }^{542}$.

Plus que la variété des péripéties ou la façon dont le héros parvient à ses fins, qui créent le suspense du roman d'aventures moderne, c'est bien l'élaboration du jeu littéraire qui entretient l'attente du lecteur averti. Le roman arthurien en vers comporte donc une dimension auto-réflexive, alimentée par l'usage de la parodie dont Yen-Mai Tran-Gervat précise la portée comme suit:

Le parodiste témoigne d'une distance critique à l'égard et à l'intérieur de la matière même dans laquelle s'inscrit sa réflexion, au double sens du terme: il réfléchit sur l'écriture en même temps qu'il présente à l'écriture en général un miroir déformant (parodie) ${ }^{543}$.

L'écriture arthurienne, si elle paraît redondante, engage des réflexions métatextuelles déterminantes pour l'évolution de la littérature romanesque et ses procédés narratifs.

auto-critique est fondamentalement inhérente au genre dès ses débuts.» (nous traduisons)

542 Ibid., p. 177. «Les allusions, les citations, les motifs imprégnés des œuvres de Chrétien et les renvois qui touchent le contenu produisent une continuité générique particulière; cette posture narrative littérarisée s'adresse à un public de connaisseurs." (nous traduisons). Nous définissons l'intertextualité en suivant Tiphaine Samoyault, qui préconise de parler d'intertextualité lorsque «le texte réfère directement à des textes antérieurs, selon des modes d'intégration bien visibles". L'intertextualité. Mémoire de la littérature, p. 31.

543 Yen-Mai Tran-Gervat, "Pour une définition opérationnelle de la parodie littéraire», art. cit., $\$ 26$. 


\section{Blandin de Cornouailles: errer sans Arthur, errer sans quête}

La parodie et l'intertextualité, aussi bien que la structure de l'errance, sont au cœur de Blandin de Cornouailles, composition provençale en octosyllabes à rimes plates, datée du XIv siècle $^{544}$. Ce texte pourrait être un parfait roman arthurien... si seulement Arthur y était présent. L'absence d'Arthur n'empêche néanmoins pas, du point de vue de la généricité lectoriale, de percevoir des analogies fortes avec le genre. Il présente dès lors des problématiques similaires au roman de Cristal et Clarie, roman en vers de la fin $\mathrm{du} \mathrm{XIII}^{\mathrm{e}}$ siècle, lui aussi roman arthurien sans Arthur, dont nous avons traité dans une précédente étude ${ }^{545}$.

Le roman de Blandin de Cornouailles s'ouvre sur la présentation de deux chevaliers cornouaillais ("dos cavaliers de Cornoalha», v. 5-6) désireux de partir en aventure. Leur errance se déroule dans des lieux familiers du lecteur de productions arthuriennes en vers: des vergers, jardins ou

544 Stefano Asperti propose une datation au troisième quart du XIV siècle. «Bacinetti e berrovierie. Problemi di lessico e di datazione nel Blandin di Cornovaglia", in Studia in honorem prof. M. de Riquer, Barcelone, Quaderns Crema, 1986-1991, 4 vol., vol. 1, p. 11-36. Selon Jacques de Caluwé, «il s'agit de l'œuvre d'un poète catalan, s'efforçant d'écrire en occitan, œuvre copiée ensuite par un scribe italien ", soutenant ainsi l'hypothèse de Paul Meyer. («Le roman de Blandin de Cornouaille et de Guillot Ardit de Miramar: une parodie du roman arthurien?», Cultura neolatina, 38, 1978, p. 62). On a pu douter de la provenance catalane de l'auteur: J. B. Alart y voit plutôt un occitan du Languedoc, occupé par les rois majorquais, après 1330. "Observations sur la langue du roman de Blandin de Cornouailles et Guillot Ardit de Miramar", Revue des langues romanes, 5, 1874, p. 275-304. Sabrina Galano, dernière éditrice en date du texte, situe sa composition dans le sud-ouest de la France, entre le Languedoc et la Catalogne. Lauteur se laisserait aussi influencer par le français des romans dont il s'inspire. Voir Blandin di Cornovaglia, éd. cit., p. 35-39. Les critiques s'accordent pour dire que le copiste est italien, et teinte la lange occitane de son propre idiome, dans l'unique manuscrit à être parvenu jusqu’à nous (Turin, Biblioteca nazionale, G. II. 34). Ce manuscrit transmet des textes en latin, à sujet historico-religieux. La mise en recueil renseigne donc peu sur la réception générique médiévale de ce texte. Margaret A. Burrell traite de ce manuscrit dans "The classification of Blandin de Cornouailles", Florilegium, 18.2, 2001, p. 11-19. Elle le date du début du $\mathrm{Xv}^{\mathrm{e}}$ siècle, à partir de l'écriture et du papier.

545 Géraldine Toniutti, Pour une poétique de l'implicitation. Cristal et Clarie ou l'art de faire du neuf avec de l'ancien. Voir en particulier le chapitre 2.4 .2 sur le genre. Sur le manuscrit qui conserve ce texte, voir notre article, «Mise en recueil et assemblage des contraires. Cristal et Clarie, D'Amour et le manuscrit Arsenal 3516», Le Moyen Âge, 2017/2, p. 339-349. 
châteaux se succèdent et leur offrent de quoi s'illustrer. La forêt surtout, ce «desertz» (v. 27) que l'éditrice traduit par «lieux déserts» («luoghi deserti»), c'est-à-dire inhabités ${ }^{546}$, fournit le cadre des pérégrinations de Blandin et Guilhot.

Aucune précision topographique ne vient cependant agrémenter le récit, si bien que l'on ne sait si l'errance a lieu en Cornouailles ou ailleurs. La seule certitude concerne l'origine bretonne des chevaliers, que le narrateur rappelle ponctuellement. Blandin décrit lui aussi Guilhot comme un chevalier de Cornouailles pour permettre à ses interlocuteurs de l'identifier: "Auries tu vist un cavalier / De Cornoailha, bon garrier [...] ?» (v. 1969-1970) Peut-être faut-il déduire de l'insistance des protagonistes sur leur provenance que l'intrigue se produit ailleurs que sur leur terre natale. Blandin précise plus tôt que son compagnon et lui sont "cavalliers d'Orien» (v. 515), ce qui ne manque pas d'étonner, la Cornouailles occupant la partie la plus occidentale de la Bretagne insulaire. Faut-il comprendre que les aventures se déroulent en Irlande ${ }^{54}$ ? Sans doute est-il plus sage d'insister sur la dimension incertaine de la géographie de l'errance. Toutefois, la seule mention de la Cornouailles dans un contexte aventureux et chevaleresque suffit à rappeler la Bretagne arthurienne, à suggérer tout du moins au lecteur médiéval un espace propre au surgissement d'événements qui trouveraient aisément leur place au sein d'un roman arthurien en vers.

L'identification de la Bretagne arthurienne, malgré l'absence d'Arthur, n'est activée que parce que la géographie se corrèle à la structure de l'errance ${ }^{548}$. Deux chevaliers, Blandin et Guilhot, décident de partir à l'aventure, sans but particulier. À la première manifestation aventureuse,

\footnotetext{
546 Voir l'édition de Sabrina Galano, Blandin di Cornovaglia, éd. cit., note 27, p. 45.

547 Selon Wendy Pfeffer, cette mention de l'Orient réfère à la croisade et suggère que les deux chevaliers y auraient participé. "Blandin de Cornoalha, Yet Another Look", Bulletin bibliographique de la Société internationale de littérature courtoise, 36-37, 2012-2013, p. 37-49. Voir aussi Margaret A. Burrell, "The classification of Blandin de Cornouailles", art. cit., p. 16, qui voit dans l'Orient un moyen de participer à la vogue des romans orientaux, comme Cligès.

548 Gerhard Wild démontre dans son article l'importance des traits arthuriens dans Blandin de Cornouailles. "Ausgrenzung und Integration arthurischer Themen im katalanischen Mittelalter (von Muntaners Crònica, Blandin de Cornualla und Torroellas La Faula zu Martorells Tirant lo blanc)", Zeitschrift für Katalanistik, 3, 1990, p. 67-89. Voir aussi les pages 14 à 16 de l'édition citée de Sabrina Galano.
} 
un petit braque qui les mène à une grotte, ils se séparent et Blandin s'en va seul l'explorer. Il est conduit à délivrer deux jeunes filles prisonnières d'un géant. L'errance se poursuit après qu'il a rejoint Guilhot et les aventures se succèdent, les deux amis se répartissant les combats auxquels ils sont confrontés. Les géants constituent l'adversaire principal des chevaliers (frère du premier géant, femme de celui-là, un duo père-fils), à côté des tout aussi traditionnels lions, dragons et ennemis déloyaux qu'il faut parfois affronter à dix contre un. Conformément aux conventions arthuriennes, le cheminement s'arrête chez un ermite qui soigne Guilhot et l'informe de la vengeance que lui fera subir le lignage du Noir Chevalier qu'il vient de tuer (v. 788-852). Il ne remplit donc aucun rôle spirituel mais n'use que de sa fonction d'informateur, comme si Blandin de Cornouailles s'employait à vider de leur substance les éléments signifiants du roman arthurien pour ne leur conserver que leur utilité à la progression narrative ${ }^{549}$. La nature du merveilleux, particulièrement dense dans un si court récit, invite également à une lecture arthurienne: c'est un cheval blanc, qu'une suivante de la future femme de Blandin laisse comme seule monture au chevalier, qui le mène vers la dame à secourir et fait office de guide vers l'autre monde ${ }^{550}$. Le surgissement de la merveille est souvent lié au sommeil du chevalier, qui s'endort et découvre à son réveil deux jeunes filles en détresse (v. 95-100) ou la fuite de la jeune fille au cheval blanc (v. 1059-1078) ${ }^{551}$. L'enchaînement des aventures est lui aussi typique de l'écriture arthurienne: un messager pressé ou les pleurs d'un écuyer font par exemple office d'annonces, sur un mode tout à fait convenu.

Le parcours des deux chevaliers est pourtant émaillé de quelques éléments aux résonances non arthuriennes: il s'agit d'abord du Sarrasin auquel Blandin doit prélever deux molaires pour le tuer (v. 1491-1546). Cette donnée rappelle la pénitence que doit assumer Huon de Bordeaux pour obtenir le pardon de Charlemagne: ramener quatre molaires de

549 L'intervention d'un ermite est topique dans le roman arthurien. Voir Marie-Luce Chênerie, Le Chevalier errant, p. 517-521.

550 Sur l'animal auxiliaire de la merveille, voir Marie-Luce Chênerie, Le Chevalier errant, p. 603-606, et Michel Zink, "Le monde animal et ses représentations dans la littérature du Moyen Âge", Actes des congrès de la Société des historiens médiévistes de l'enseignement supérieur public, 15, 1984, p. 68-69.

551 Sur l'endormissement comme voie d'accès à la merveille, voir Christine Ferlampin-Acher, Merveille et topique merveilleuse, p. 104-110. 
l'émir de Babylone. Dans Blandin de Cornouailles cependant, l'origine sarrasine du personnage n'est pas exploitée; l'adversaire tient plutôt du monstrueux tel qu'on le connaît dans le roman arthurien:

«Un gran sarraxin encantat,

Che es aytal comme vous diray:

El ha de golla un palm o mais,

$\mathrm{E}$ a las dens grans comme verre

[e] fort[z] e duras come ferre,

$\mathrm{E}$ a las narras ben fendudas,

E a las aurelhas ben ponchudas,

E es ben negre, veramen

E ferejos a tota gent,

El ha de barba mieya brassa,

E ten al col una gran maza.» (Blandin, v. 1410-1420)

L'altérité se manifeste par la démesure de ses organes, ses oreilles en pointes et sa couleur noire ${ }^{552}$. L'ennemi est présenté comme un opposant bestial, qui se bat à l'aide d'une massue tel un homme sauvage, et non comme un chevalier païen à exterminer ou à convertir selon l'idéologie de la croisade qui prévaut dans l'épisode de Gaudisse d'Huon de Bordeaux. L'enchantement des molaires est un signal intertextuel qui doit rappeler cette chanson de geste, mais le thème est traité comme une aventure merveilleuse $e^{53}$.

L'aventure finale est elle aussi allogène, mais elle fait l'objet de la même transposition au cadre de l'aventure arthurienne: Blandin doit délivrer Brianda d'un enchantement provoqué par son père lors d'une guerre. La demoiselle demeure figée, assise sur son lit, sans vie ("E estava se asetada, / Sobre un liech, tota encantada", v. 1381-1382). L'auteur occitan réactive le motif de la belle endormie ${ }^{554}$, rendu populaire par les contes au

552 Voir Francis Dubost, Aspects fantastiques de la littérature narrative médiévale, p. 570-575.

553 Il faut noter que Huon de Bordeaux est souvent perçu comme une œuvre à la croisée des genres romanesque et épique: le choix d'un tel intertexte confirme peut-être les intérêts romanesques de l'auteur occitan. Voir Richard Trachsler, Disjointures-conjointures, p. 187-202, et l'introduction à l'édition de William W. Kibler et François Suard, Huon de Bordeaux, Paris, Champion ("CCMA»), 2003, p. XXIII-XXXIII.

554 Jean-Charles Huchet considère que Blandin de Cornouailles folklorise le roman arthurien: il active un merveilleux qui est plus celui du conte que du roman. Le 
$\mathrm{XVII}^{\mathrm{e}}$ siècle, mais que l'on trouve déjà dans la littérature médiévale, dans Perceforest notamment ${ }^{55}$. Le développement du motif n'est pourtant pas habituel: le texte passe très rapidement sur les raisons de l'enchantement, dont il délègue l'explication au frère de Brianda, à l'arrivée de Blandin au château:

"Aquella che vos demandas

Ma sorre es, si a vos plas,

$\mathrm{E}$ e[s] dedins aquel pallais

D'aqui no pot ysir jamais,

Car nostre payre l'encantet

En aquels temps che el perdet

Tot son contat e mais sa terra;

Ayso fu per la granda gherra.

E va layssar.X. cavaliers

En garda, c'om non sa intres,

Per so suy fort merevilhat

Com tan avant n'es si entrat.» (Blandin, v. 1321-1332)

L’endormissement sert-il à protéger la fille de la guerre ou s'agit-il de la préserver des assauts de prétendants potentiels? Où se trouve le père, s'il est encore en vie, au moment de l'arrivée de Blandin? Le mystère demeure sur l'origine de l'enchantement, seule compte la manière dont on peut le

roman occitan médiéval, Paris, PUF, 1991, p. 199-200. Voir les pages 196 à 206 sur les liens de Blandin avec le roman arthurien.

555 Le thème est déjà présent dans les romans grecs antiques. Voir Emese EgediKovacs, "La "morte vivante" dans les poèmes narratifs français et occitans du Moyen Âge", in Actes du $22^{e}$ Congrès de la Société Internationale arthurienne, 2008, http://uhb.fr/alc/ias/actes/index.htm, et Giovanna Franci et Ester Zago, La bella addormentata, genesi e metamorfosi di una fiaba, Bari, Dedalo, 1984. Perceforest en serait le premier représentant au Moyen Âge. Voir Noémie Chardonnens, "D'un imaginaire à l'autre: la belle endormie du Roman de Perceforest et son fils", in Des Fata aux fées: regards croisés de l'Antiquité à nos jours, dir. Martine Hennard Dutheil de la Rochère et Véronique Dasen, Études de Lettres, 2011, 3-4, p. 191-203, Friedrich Wolfzettel, «7. La Belle endormie: le conte merveilleux populaire mis au service des idéologies courtoises", in Le Conte en palimpseste. Studien zur Funktion von Märchen und Mythos im französischen Mittelalter, Stuttgart, Franz Steiner, 2005, p. 114-135, Gilles Roussineau, "Tradition littéraire et culture populaire dans l'histoire de Troïlus et de Zellandine (Perceforest, Troisième partie), version ancienne du conte de la Belle au Bois Dormant", Arthuriana, 4.1, 1994, p. 30-45. 
briser. Point de mythe des Parques, ou des fées marraines, qui se penchent sur le berceau du bébé pour accorder des dons ou proférer une malédiction inspirée par le mauvais accueil reçu au repas ${ }^{556}$. Point non plus de quenouille à laquelle se pique la demoiselle: le roman occitan met de côté l'importance du destin, cher à la mythologie gréco-latine et central dans le motif de la belle endormie. La mort apparente est causée par le père uniquement, de même qu'il est à l'origine du confinement dans lequel se trouve le château, gardé par dix chevaliers redoutables que Blandin affronte.

Le mal est endogène et il réduit la société du château à la léthargie: le frère de Brianda, au lieu de prendre les choses en main, se délasse dans son verger et attend qu'un chevalier assume l'aventure qui délivrera sa sœur et en même temps sa société. Car la belle endormie n'est pas seule à subir les conséquences de l'enchantement: la cour entière se voit plongée dans l'inactivité et l'attente d'un sauveur. La mission relève donc d'une portée universelle $e^{55}$ : délivrer la demoiselle rétablit l'harmonie et l'ordre là où régnait une «mauvaise coutume» au sens arthurien du terme, c'est-à-dire une situation, une habitude ancestrale, contraire au bon fonctionnement du monde ${ }^{558}$. L'enlisement de la société de Brianda dans l'inaction contrevient en effet à l'idée dynamique que le roman arthurien propose d'un royaume ${ }^{559}$.

556 Sylvie Puech, "Le conte de La Belle au bois dormant et le mythe des Parques", L'information littéraire, 4, 1989, p. 19-24. La réactivation du motif retranche également l'épisode de la conception d'un enfant en la belle endormie, qui demeure inconsciente pendant l'acte sexuel et l'accouchement, comme Perrault le fera plus tard. Gilles Roussineau attribue cette omission au malaise qui peut résulter d'une concurrence sacrilège avec Marie, qui conçoit sans plaisir et vierge. "Tradition littéraire et culture populaire dans l'histoire de Troïlus et de Zellandine», art. cit., p. 39. Emese Egedi-Kovacs traite du motif de la belle endormie dans Blandin de Cornouailles: elle souligne que le motif est moins élaboré dans ce texte que dans les réactivations contemporaines et qu'il comporte quelques curiosités, comme le fait que la belle endormie soit assise. La "morte-vivante» dans le récit français et occitan du Moyen Âge, Budapest, Elte Eötvös Kiadó, 2012, p. 193 à 204.

557 Friedrich Wolfzettel, «La Belle endormie: le conte merveilleux populaire mis au service des idéologies courtoises", art. cit., p. 133-134.

558 Voir Erich Köhler, "Le rôle de la "coutume" dans les romans de Chrétien de Troyes", art. cit., et Norris J. Lacy, «On Customs in Medieval French Romance», art. cit.

559 Marie-Luce Chênerie, Le Chevalier errant, p. 106-107, exprime cette idée de vigueur compromise par l'inertie dans le roman arthurien. Le chevalier errant est 
La procédure pour réveiller la belle endormie s'inspire d'ailleurs d'aventures tout à fait topiques: outre le combat contre le monstre sarrasin, Blandin doit affronter un serpent et un dragon, lieux communs du récit arthurien. Ces adversaires gardent un oiseau, «blanc astor» (v. 1397), qui doit de son contact guérir la belle endormie. L'oiseau comme adjuvant des amants est une donnée fréquente du motif de la belle endormie: dans Perceforest, Zéphir se transforme en oiseau pour mener Troïlus auprès de la jeune fille, dans les Nibelungen, Sigfrid est conduit par un rossignol auprès de Brunehilde, dans Frère-de-Joie et Scur-de-Plaisir, c'est un geai qui porte l'herbe guérisseuse à l'endormie puis aide les amants à se retrouver ${ }^{560}$. L'oiseau choisi par l'auteur de Blandin s'inspire quant à lui de données propres au récit arthurien: il s'agit d'un autour, animal de chasse cher à l'aristocratie. Sa couleur blanche fait signe, comme pour le destrier blanc, vers la merveille ${ }^{561}$. L'autour blanc peut rappeler le motif de l'épervier de beauté que le chevalier doit conquérir pour désigner la plus belle femme, comme le représente Chrétien de Troyes dans Erec et Enide: dans les deux cas, un noble rapace est offert pour témoigner de la dévotion d'un chevalier à une dame «mot bella» (v. 1388).

Ces péripéties construisent le happy end attendu dans le roman arthurien, et conduisent au mariage de Blandin et Brianda. Guilhot n'est pas en reste: grâce à son ami, il épouse la sœur de Brianda, Yolanda. L'écart est ainsi rendu clair entre les deux amis: Blandin est toujours supérieur à Guilhot, qu'il délivre à deux reprises ${ }^{562}$. La mise en scène de deux chevaliers errants présentés comme équivalents, potentiellement problématique

celui qui circule; Mabonagrain dans l'épisode de la Joie de la Cour d'Erec et Enide est le meilleur exemple du caractère néfaste de l'inertie.

560 Sur ces exemples et le motif de l'oiseau, voir Gilles Roussineau, «Tradition littéraire et culture populaire dans l'histoire de Troïlus et de Zellandine», art. cit., et Emese Egedi-Kovacs, La "morte-vivante» dans le récit français et occitan du Moyen Âge, p. 35-36; 190-191. Les Nibelungen sont des poèmes épiques allemands du début du XIII ${ }^{\mathrm{e}}$ siècle; Frère-de-Joie et Sour-de-Plaisir est un texte catalan du XIV siècle.

561 Roger Sherman Loomis l'identifie comme une croyance celte. Arthurian Tradition and Chrétien de Troyes, New York, Octagon Books, 1982, p. 68-70.

562 Jacques de Caluwé note que la hiérarchie établie entre les deux amis est de nature parodique, car les échecs de Guilhot le ridiculisent. «Le roman de Blandin de Cornouailles: une parodie de roman arthurien?", art. cit. 
dans un genre qui valorise l'individualités63, se résout par la précellence de Blandin; encore que, nous le verrons, popularisée par les romans arthuriens tardifs, la multiplicité des héros ne pose plus vraiment problème d'un point de vue générique.

Ce happy end n'est pourtant plus celui des romans de Chrétien de Troyes: l'aventure est comme vidée de son sens et ne symbolise pas le constant dépassement de soi que doit viser le chevalier. La fin du roman précise que Blandin et Guilhot cessent de courir l'aventure pour demeurer auprès de leurs femmes:
E Blandin[et] de Cornivalha
E Guilhot, se Dieu me valha,
Van remanir an lors molhers,
E feron cum bons cavaliers;
E d'aqui non volgron partir,
$\mathrm{Ni}$ volgron plus gera segir,
Mas che feron cum bona gent
E Dieus lor donet pron de ben. (Blandin, v. 2381-2388)

La recreantise que condamnait le roman d'Erec et Enide est ici valorisée: les deux héros sont recreants, mais cet état est présenté comme un accomplissement. Faisant fi de la saine circulation des chevaliers qui fonde la société arthurienne, Blandin et Guilhot considèrent le mariage comme un but en soi. Cette fin parodie dès lors en substance le roman arthurien en vers et le sens de l'aventure ${ }^{564}$.

L'auteur occitan joue avec la signification de l'aventure et la dévoie, sans perdre pour autant de vue son rapport consubstantiel à l'errance. Le personnage de Blandin en donne une définition, élaborée, semble-t-il, à partir du récit arthurien:

"Sercan avantura veramen,

E conven la nos a sercar

Per lo desert senza tardar,

Ch'aotrament non serian preisat $[\mathrm{s}]$

Ni bons cavalies reputa[t]s.» (Blandin, v. 516-520)

\footnotetext{
563 Marie-Luce Chênerie, Le Chevalier errant, p. 122-125.

564 Voir Norris J. Lacy "Halfway to Quixote: Humor in Blandin de Cornoalha", in Risus mediaevalis. Laughter in Medieval Literature and Art, Louvain, Leuven University Press, 2003, p. 173-180.
} 
Le propre du chevalier est de chercher l'aventure inlassablement, sous peine d'être perçu comme un mauvais chevalier. Cette définition ne manque pas d'ironie et souligne la dimension convenue voire vaniteuse de l'errance ${ }^{565}$. Comme le note Keith Busby, «adventure has clearly lost its primary purpose of restoring the ordo, except on a basic narrative level, and has the sole function of contributing to the knight's reputation, of his "visibility" "566. De fait, les deux amis n'ont au départ pas de mission à accomplir: ils errent sans but, sans portée universelle ou spirituelle ${ }^{567}$. L'absence d'Arthur prive le texte d'une caution qui garantirait le sérieux de l'entreprise. Blandin et Guilhot «volgron per lo mond annar / e lur [a]vantura cerchar» (v. 7-8), sans but initial. Le parcours des chevaliers n'est donc pas une quête, bien que le hasard permette finalement la conclusion de mariages avantageux. Leur errance est plus un vagabondage qu'une démarche signifiante. Le narrateur ponctue d'ailleurs le récit d'indications temporelles qui soulignent l'absence d'aventures. Les deux amis, pourtant obsédés par celles-ci, attendent d'abord six mois avant d'en rencontrer une: «E ben miech an e[l]s cavalcheron / Che avantura non troberon" (v. 31-32). L'insistance sur le défaut d'aventures attire l'attention sur le délitement du récit chevaleresque, usé et épuisé par les auteurs précédents. La vacance des péripéties provoque le rire du public en avançant la frivolité de ce départ en errance insignifiant et orgueilleux.

Lorsqu'enfin une aventure se présente, il s'agit d'un petit braque, tout à fait anodin de prime abord. Il suscite pourtant une réaction très

565 Elle rappelle la célèbre formule de Dinadan dans le Tristan en prose, qui se définit comme "uns cevaliers errans ki cascuns jour voiz aventures querant et le sens du monde: mais point n'en puis trouver, ne point n'en puis a mon oes retenir.» (Version du ms. BnF fr. 334, f. 334rb, transcrit par Eugène Vinaver) Il s'agit là d'une manière de pointer la vanité de l'errance et son absence de sens. Voir l'article d'Eugène Vinaver, "Un chevalier errant à la recherche du sens du monde: quelques remarques sur le caractère de Dinadan dans le Tristan en prose», in Mélanges de linguistique romane et de philologie médiévale offerts à M. Maurice Delbouille, Gembloux, Duculot, vol. II, 1964, p. 677-686.

566 Keith Busby, "Blandin de Cornoalha and romance tradition", Tenso, 8:1, 1992, p. 6-7. Le critique détaille point par point la dimension comique du roman, en montrant combien chaque étape tourne à vide, des aventures aux mariages des héros.

567 Voir à ce sujet Keith Busby, "Blandin de Cornoalha and romance tradition", art. cit., et Jacques de Caluwé, «Le roman de Blandin de Cornouailles: une parodie de roman arthurien?», art. cit. 
enthousiaste de la part des chevaliers: "Aysso es avantura sen fauta!» (v. 46), s'exclame Blandin, alors que l'animal n'a pour l'instant rien fait d'autre que de croiser leur chemin. Cette excitation face à un simple chien doit prêter à sourire, tout comme le comportement que les héros, en particulier Guilhot, adoptent, notamment lors d'accès de colère qui se manifestent de manière tout à fait bestiale: "Adonc Guiloth enfla las narres / Et cruys las dens entre las beres» (v. 701-702). Les deux amis sont également enclins au sommeil et ils s'endorment plus d'une fois au cours du récit. Même le dragon que Blandin doit vaincre pour conquérir l'oiseau Astor est endormi lorsque le chevalier passe pour la première fois! Celui-ci le laisse alors tranquillement dormir pour l'affronter plus tard (v. 1483$1490)^{568}$. Tout concourt à vider l'errance de sa substance et à en moquer les mécanismes. La résolution des aventures est en ce sens vite expédiée: les géants sont vaincus sans peine, de même que les lions, le serpent et les adversaires chevaliers. Le mariage, enfin, apparaît plus comme une convention de genre, un lieu commun, que comme le résultat d'un amour profond et réciproque ${ }^{569}$.

Blandin de Cornouailles affaiblit le roman arthurien en vers en le réduisant à quelques motifs et à la structure un peu lâche de l'errance, tout comme il affaiblit le motif de la belle endormie à ses données basiques, sans lui donner de profondeur psychologique ${ }^{570}$ ni même apporter des détails sur l'origine de l'enchantement. Emese Egedi-Kovacs a en ce sens noté que les éléments constitutifs du motif sont supposés connus du public: il n'est nul besoin d'épiloguer sur les raisons de l'enfermement,

568 Norris J. Lacy, fait remarquer que les préoccupations principales des deux héros sont l'amour, la nourriture et le sommeil. "Halfway to Quixote: Humor in Blandin de Cornoalha", art. cit.

569 La dimension conventionnelle du roman est redoublée par le style répétitif choisi par l'auteur, proche du style formulaire épique: Keith Busby souligne les tournures convenues comme "tant gran colp donna», qui reviennent à plusieurs reprises. $\mathrm{Ce}$ style redondant tourne volontairement au cliché et accentue l'impression de familiarité que doit générer la lecture du roman. "Blandin de Cornoalha and romance tradition", art. cit., p. 16-18. Voir aussi les pages 22 à 29 de l'édition citée de Sabrina Galano.

570 L'absence de profondeur psychologique est valable pour le roman entier: les personnages sont plus des fonctions, des types, que de véritables individus. L'amour ne fait pas non plus l'objet d'un développement, de monologues, ou d'épanchements. Voir Jean-Charles Huchet, Le roman occitan médiéval, p. 201-202. 
le rôle du père, le remède fourni par l'animal, la magie qui le sous-tend. C'est bien une "familiarité préalable ${ }^{571}$ qui permet de saisir le sens du motif, d'en reconstruire les omissions; le constat est valable pour le genre arthurien en vers. Inutile de ré-élaborer tout l'univers associé à l'errance et à l'aventure; le petit chien croisé est identifié comme une aventure par le personnage, qui connaît bien les mécanismes du roman, sans que l'animal se doive de faire quoi que ce soit. Il est attendu du lecteur qu'il comprenne de lui-même les rouages qui sous-tendent le roman, qu'il en devine les allusions et qu'il reconvoque, en dernier lieu et virtuellement, la figure d'Arthur. Les aventures de Blandin et Guilhot, plus qu'elles ne mènent à plus haut sens ou à livrer un message, sont matière à récit, au divertissement, à la parole romancée, comme l'expriment les vers 29-30 du roman: "Tot jorn lur avanturas sercan / Et de lur novellas parlan. " ${ }^{572}$ Lerrance et la recherche d'aventures sont consubstantielles à un discours.

La vacuité des valeurs chevaleresques n'éloigne pourtant pas l'œuvre du genre arthurien en vers: le lien entre Blandin de Cornouailles et le roman arthurien en vers est d'ordre parodique. La parodie fonctionne selon un double principe d'imitation et de détournement, comme l'explique JeanClaude Mühlethaler :

Toujours, il y a mimétisme du modèle et, par conséquent, création d'un horizon d'attente que des éléments, perçus comme incompatibles par le lecteur, viennent ruiner par la suite ${ }^{573}$.

Le modèle choisi n'est pas exclusivement un texte singulier, comme l'entend Gérard Genette, mais un genre entier ${ }^{574}$. Nous admettons dès

571 Emese Egedi-Kovacs, La "morte-vivante» dans le récit français et occitan du Moyen Âge, p. 204.

572 Keith Busby, "Blandin de Cornoalha and romance tradition", art. cit., p. 5.

573 Jean-Claude Mühlethaler, «Renversement, déplacement et irradiation parodiques", art. cit., p. 6.

574 Gérard Genette, Palimpsestes, p. 164, définit la parodie comme une relation hypertextuelle: l'hypertexte parodie un hypotexte spécifique et non un groupe de textes. Il préfere parler d' "imitation" pour rendre compte de la relation d'un texte avec un genre. Voir p. 92. C'est aussi la conception de Daniel Sangsue, La Relation parodique, Paris, José Corti, 2007. La possibilité d'une parodie de genre, voire d'un type de discours ou d'un rituel est admise par Madeleine Jeay, "Polyphonies textuelles. Écritures de la parodie», in Parodies courtoises, parodies de la courtoisie, dir. Margarida Madureira, Carlos Clamote Carreto et Ana 
lors qu'il existe une parodie de genre ${ }^{575}$. Le deuxième principe, celui du détournement, ne doit pas être appréhendé comme une transgression, une dévaluation totale du modèle: celui-ci n'est jamais rabaissé. La parodie est ludique: le but visé est le jeu littéraire et non la dérision dénigrante. Le rapport parodique est de l'ordre du comique, comme le théorise Massimo Bonafin:

L'effet comique jaillit en effet d'une non-correspondance sémantique voulue entre parodié et parodiant, ou bien entre les attentes du lecteur face à l'original et leur déception/déviation déterminée par les modifications dues au parodiste ${ }^{576}$.

Le rire ${ }^{577}$ est provoqué par la rupture entre l'attente du lecteur et les données du texte. Jean-Claude Mühlethaler propose en ce sens de parler de parodie chaque fois qu'il y a un remploi déceptif, c'est-à-dire lorsque l'horizon d'attente est contredit ${ }^{578}$.

Beate Schmolke-Haßelmann tient compte de cette dimension en soulignant que «Selbstkritik zu üben ist jedoch eine der Gattung grundsätzlich

Paiva Morais, Paris, Garnier, 2016, p. 359-385. La parodie peut être appréhendée comme un phénomène intertextuel ou interdiscursif: dès lors, il peut soit concerner un texte en particulier ou un genre, un rituel, un style. Nous admettons donc que la parodie peut prendre un genre littéraire pour objet de détournement. Voir à ce sujet l'article de Jean-Claude Mühlethaler, "Renversement, déplacement et irradiation parodiques», art. cit, et celui de Yen-Mai Tran-Gervat, "Pour une définition opérationnelle de la parodie littéraire: parcours critique et enjeux d'un corpus spécifique", art. cit.

575 Nous envisageons la parodie comme une technique d'écriture et non comme un genre à part entière. Daniel Sangsue traite de la parodie comme genre dans "La parodie, une notion protéiforme", in Du pastiche, de la parodie et de quelques notions connexes, dir. Paul Aron, Québec, Nota bene, 2004, p. 79-102.

576 Massimo Bonafin, «Rire, comique et parodie médiévale à la lumière d'une théorie bio-sociale», in "Ravy me treuve en mon deduire», dir. Luca Pierdominici et Elisabeth Gaucher-Rémond, Fano, Aras Edizioni, 2011, p. 16.

577 Sur le rire au Moyen Âge, voir Philippe Ménard, Le rire et le sourire dans le roman courtois en France au Moyen Âge, et Jean-René Valette, "Le rire et le corps : éléments d'esthétique médiévale (XII ${ }^{\mathrm{e}}$-XIII ${ }^{\mathrm{e}}$ siècles) ", in Esthétique du rire, dir. Alain Vaillant, Paris, PU de Paris Ouest, 2012, p. 21-45.

578 Jean-Claude Mühlethaler, «Renversement, déplacement et irradiation parodiques", art. cit. 
und seit Beginn ihrer Geschichte innewohnende Fähigkeit » ${ }^{579}$. En modifiant point par point les éléments définitoires du roman arthurien, tout en reconduisant sa structure, l'auteur de Blandin de Cornouailles dévoile les mécanismes du genre, leur dimension convenue et leur idéalisme suranné. L'absence criante d'Arthur est elle-même déterminante pour cette lecture autoréflexive: le roi breton fait office de garant de la courtoisie et de mainteneur de la chevalerie. Ne pas le faire figurer dans le récit s'en ressent sur le déroulement de l'errance, puisqu'aucun personnage n'est habilité à confirmer la bravoure de Blandin et Guilhot. L'absence d'Arthur est fonctionnelle: elle engage la réflexion sur le roman de chevalerie et sa solidarité avec l'univers arthurien. Tout converge vers un monde arthurien qui surgit en creux, qui demeure à l'état d'attente, d'horizon jamais réalisé. Il existe un rapport générique entre d'une part la structure de l'errance, le principe dynamique de l'aventure, détourné ici, et la nature de certains motifs, et d'autre part l'univers de fiction arthurien.

L'espace de Blandin de Cornouailles et sa structure, qui entraîne deux chevaliers d'aventures en aventures jusqu'à l'obtention d'une épouse, autorisent à y voir une manifestation tardive et occitane du roman arthurien en vers: même en l'absence d'Arthur, un représentant du genre peut émerger, tout en demeurant à la périphérie du paradigme. Jacques de Caluwé souligne qu' "il est peu vraisemblable qu'un écrivain ait pu présenter "innocemment" des héros originaires de Cornouailles à une époque où la matière de Bretagne était, on le sait, très connue " ${ }^{580}$. Il faut d'ailleurs rappeler que, selon la théorie de Richard Saint-Gelais, l'univers lui-même peut être transfictionnel, le concept ne concernant pas que les personnages $^{581}$. Les univers de fiction ont une atmosphère particulière qui peut être réactivée: même si cette atmosphère est donnée en grande partie par les personnages, le monde créé peut fonctionner seul, comme c'est le cas de la forêt aventureuse, occupée par des chevaliers bretons dans Blandin de Cornouailles.

579 Beate Schmolke-Haßelmann, Der arthurische Versroman, p. 177. "L'exercice de l'autocritique est toutefois une faculté fondamentale et inhérente au genre depuis le début de son histoire." (nous traduisons)

580 Jacques de Caluwé, «Le roman de Blandin de Cornouailles: une parodie de roman arthurien?", art. cit., p. 63.

581 Voir Richard Saint-Gelais, Fictions transfuges, p. 21-22, "Personnage et transfictionnalité », art. cit. 
Cet exemple démontre que l'espace et la structure ou l'atmosphère sont des critères génériques pertinents, mais modulables. Chaque élément de définition du roman arthurien en vers a une force inclusive (son apparition dans un texte garantit une place plus ou moins périphérique au sein du paradigme) et sa subversion n'est pas exclusive (le non respect d'un critère n'exclut pas d'office le texte du genre). L'agencement de motifs traditionnels, qui forment la structure de l'errance, même en l'absence de quête spécifique, ne manque pas d'évoquer au lecteur averti le genre arthurien en vers: le roman arthurien en vers ne se fonde de loin pas exclusivement sur ses personnages, mais s'appuie aussi et surtout sur une structure narrative, réactivée, détournée, vidée de sa substance comme pour en éclaircir et en démystifier les mécanismes. La désacralisation du roman arthurien en vers à l'œuvre dans Blandin de Cornouailles, en mettant à nu une structure construite sur la juxtaposition d'aventures, fonctionne comme l' "autopsie d'un genre défunt " ${ }^{52}$, avant son extinction définitive. Sans Arthur, le genre est condamné à n'être plus qu'une structure narrative dont le sens se délite. Blandin de Cornouailles permet de tracer l'extinction $\mathrm{du}$ roman arthurien en vers: Arthur abandonne son monde, qui survit de manière autonome dans quelques textes atypiques, mais réduit à des motifs allusifs, avant que le genre ne s'éteigne complètement.

\section{Romans en "décadence »: paralittérarité du corpus tardif}

De telles entreprises marquent bien l'extinction d'un genre, dont les auteurs peuvent, après son succès, dépecer les éléments fondamentaux pour les supprimer ou les transformer. C'est ce que font aussi les auteurs des derniers romans arthuriens en vers, eux qui n'adhèrent pas totalement à tous les critères du canon et occupent ainsi un cercle périphérique de l'échelle de centralité arthurienne. D'où la perspective qu'adoptent certains critiques à leur égard, les considérant comme des "produits de décadence», comme l'exprime Gaston Paris à propos de Claris et Laris ${ }^{583}$. Alexandre Micha a le même avis à propos de Rigomer: «Cette ouvre longue et diffuse

\footnotetext{
582 Jean-Charles Huchet, Le roman occitan médiéval, p. 205.

583 "C'est un vrai produit de décadence, une perpétuelle imitation d'imitations, une interminable compilation de lieux communs." Gaston Paris, "Romans en vers du cycle de la Table Ronde», in Histoire Littéraire de la France, Paris, Imprimerie Nationale, vol. 30, 1888, p. 124.
} 
marque l'épuisement de la veine arthurienne. ${ }^{584} \mathrm{Ce}$ jugement est bien souvent appliqué aux autres romans de la fin du XIII ${ }^{\mathrm{e}}$ siècle, auxquels on reconnait des caractéristiques communes mais que l'on envisage comme des productions faibles. Les critiques du début $\mathrm{du} \mathrm{xx}^{\mathrm{e}}$ siècle s'attaquent souvent à la monotonie et au peu d'originalité dont font preuve les œuvres tardives: elles apparaissent comme des compilations sans imagination ni intérêt, construites comme une «simple succession d'aventures conventionnelles ${ }^{585}$. Le terme de "décadence» recoupe ainsi les avis sur le corpus qui nous intéresse; il désigne l'épuisement d'une forme littéraire, en raison de sa reproduction outrancière et sans innovation ${ }^{586}$. La valeur des œuvres ne peut cependant pas être parallèle à la trajectoire de leur genre: taxer les œuvres tardives de décadence, c'est envisager que le genre se termine inéluctablement sur un affaiblissement.

S'il s'agit en effet des derniers représentants du genre, il faut nuancer le préjugé de platitude qui leur est attribué: on peut d'abord soulever le paradoxe inhérent au fait de reprocher à la fois à ces textes leur irrespect de la veine arthurienne - comme le fait Beate Schmolke-Haßelmann que nous citions en introduction - et leur manque d'originalité. La redondance imputée aux romans tardifs n'est pas forcément gage de médiocrité, ces textes n'abusant d'ailleurs pas plus de la répétition que les premiers héritiers de Chrétien de Troyes. Quant à leur dimension conventionnelle, il faut sans doute la pondérer, dans la mesure où ils renouvellent les codes du roman arthurien aussi essentiels que la structure de l'errance solitaire, l'espace géographique ou le caractère des personnages, et se démarquent ainsi des premiers représentants. Les accusations résultent donc plus probablement de la longueur décourageante de ces textes tardifs, dont un lecteur moderne pressé peine à percevoir la richesse et l'originalité. Le lecteur médiéval avide de littérature, en particulier arthurienne, devait en

584 Alexandre Micha, "Merveilles de Rigomer", in Dictionnaire des lettres françaises. Le Moyen Âge, dir. Georges Grente et al., Paris, Fayard, 1964, p. 509.

585 Brian Woledge, au sujet de Claris et Laris, dans son édition de L'Âtre Périlleux, Paris, Champion ("CFMA»), 1936, p. VII.

586 Il ne s'agit donc pas du sens que le terme prend pour désigner l'esthétique qui caractérise les textes de la fin du XIX ${ }^{e}$ siècle ni celui qui renvoie au regret d'un Âge d'Or. Pour une définition de la décadence, voir Daniel Grojnowski, «Décadence», in Le Dictionnaire du littéraire, Paris, PUF, 2002, p. 176-177. 
revanche être stimulé à la fois par le plaisir de la reconnaissance ${ }^{587}$ et par la rénovation des codes d'écriture.

La disgrâce des derniers romans arthuriens en vers s'explique par des choix éditoriaux et par le jugement souvent sévère des éditeurs du début du $\mathrm{Xx}^{\mathrm{e}}$ siècle, perpétué par les histoires littéraires ${ }^{588}$. S'agit-il pour autant de textes décadents, ou paralittéraires? Le terme de "paralittérature", étymologiquement "à côté de la littérature " ${ }^{59}$, est ambigu dans la mesure où il dépend de notre acception de la littérature et de la littérarité. Notre définition du concept n'exclut pas les romans arthuriens tardifs du domaine de la littérature: il s'agit en effet de textes destinés à une diffusion et qui ne se réduisent pas à la pure transmission d'informations, mais qui entendent susciter chez le lecteur un sentiment esthétique, voire générer une interprétation $^{590}$. On peut admettre avec Danièle James-Raoul que le soin porté à la reproduction manuscrite est une preuve assez solide pour la littérarité médiévale: «Le texte médiéval qui nous est offert est forcément littéraire, parce qu'écrit et conçu comme une œuvre artistique que l'on a voulu

587 Le plaisir de la reconnaissance est un phénomène bien réel de la réception littéraire, théorisé par Umberto Eco, «Innovation et répétition: entre esthétique moderne et post-moderne", Réseaux, 68, 1994, p. 9-26. Ce plaisir est d'ailleurs loin d'être l'apanage du Moyen Âge, si l'on pense au succès que connaissent aujourd'hui les sagas, telle celle de James Bond, dont le public ne se lasse pas de voir les aventures malgré leurs déroulement et issue conventionnels.

588 La transmission de certaines œuvres au détriment d'autres à la postérité relève d'une forme de contingence. Comme le note Daniel Compère au sujet des romans populaires, la célébrité ou l'oubli des textes dépendent des conditions d'édition (dans une collection pour jeunes lecteurs par exemple), du classement en librairie ou bibliothèque, et des instances de légitimation comme la critique, les académies, les Sociétés des Gens de Lettres ou l'enseignement. Daniel Compère, Les romans populaires, Paris, PSN, 2011, en particulier le chapitre 5, "Les romans populaires et les instances littéraires». La question éditoriale concerne nos textes dans la mesure où ils paraissent pour l'instant dans des collections onéreuses et qu'ils sont rarement accompagnés d'une traduction - excepté pour Floriant et Florete, publié dans la collection "Champion Classiques». Par ailleurs, Richard Trachsler traite du phénomène éditorial qui a fixé l'hégémonie de Chrétien de Troyes dans «Héritiers et épigones. Les auteurs des romans arthuriens en vers après Chrétien de Troyes", art. cit.

589 Marc Angenot en donne la définition suivante: «ensemble des modes d'expression langagière à caractère lyrique ou narratif que des raisons idéologiques et sociologiques maintiennent en marge de la culture lettrée.» ("Qu'est-ce que la paralittérature?", Études littéraires, 7/1, 1974, p. 10)

590 Voir notre définition de la littérarité supra, p. 37-38. 
préserver d'un oubli dévolu à l'oralité. " ${ }^{591}$ Les romans arthuriens tardifs sont d'ailleurs tous conservés dans des manuscrits de bonne facture, bien qu'il s'agisse souvent de manuscrits uniques (infra, chapitre II, "Lire le roman arthurien à la fin du Moyen Âge», p. 381-397). Le fait que la haute noblesse en commande, ce qui est certain pour Escanor et Melyador, prouve aussi que ces textes suscitent l'intérêt d'un public exigeant.

Ce critère de la réception est déterminant dans la définition que donne Daniel Couégnas de la paralittérature: il dégage plusieurs critères qui la définissent à priori (contenus invraisemblables, personnages sans épaisseur psychologique, écriture négligée ou banale), pour aussitôt en montrer l'inefficience, chacun des éléments pouvant tout à fait se signaler dans des textes reconnus comme littéraires. La définition de la paralittérature qu'élabore le critique, qui s'appuie sur le domaine des romans populaires du $\mathrm{XIX}^{\mathrm{e}}$ siècle en particulier, dépend bien plutôt de la nature de la réception: le lecteur retrouve des éléments qui lui sont familiers et la part du semblable excède la part de nouveauté592. On en déduit que le roman paralittéraire reconduit souvent un genre à succès dont il se garde de travestir les codes, de manière à conforter le lecteur dans son expérience. C'est donc bien la répétition qui caractérise la paralittérature: sur le plan intertextuel, un déroulement convenu se répète, les auteurs s'imitant les uns les autres, tandis que sur le plan intratextuel, les rebondissements se multiplient et les personnages sont des types bien circonscrits. La paralittérature se distingue encore de la littérature par son absence de distanciation: l'interprétation en reste au premier degré et l'œuvre se contente de restituer une intrigue, en éclaircissant toute obscuritéf93. Il en découle que le mode narratif domine le récit et que le plan idéologique est clairement polarisé. Les personnages demeurent aisément déchiffrables et n'offrent pas de complexité psychologique ou éthique ${ }^{594}$.

591 James-Raoul, Chrétien de Troyes, la griffe d'un style, p. 13.

592 Daniel Couégnas, Introduction à la paralittérature, Paris, Seuil, 1992, p. 66-68. Alain-Michel Boyer effectue un tour d'horizon de la paralittérature dans diverses aires géographiques (de l'Europe à la Chine et à l'Afrique sub-saharienne). Il met en particulier en avant la diffusion de masse pour définir la paralittérature. $L a$ paralittérature, Paris, PUF («Que sais-je?»), 1992.

593 Cela rappelle d'ailleurs la remarque de Sarah Nancy, citée aux pages 37-38: est littéraire ce qui autorise une interprétation.

594 Au sujet des personnages paralittéraires, voir le chapitre 6 de Daniel Couégnas, Introduction à la paralittérature. On consultera les pages 181 à 182 pour une synthèse du «modèle paralittéraire». 
Ces considérations tâchent de théoriser ce qui relève plus concrètement de jugements de valeur et d'une part d'arbitraire liée à des impressions de lecture (tel texte est savant et complexe, et donc littéraire / tel texte est simple et plaisant, et donc paralittéraire). Car il faut noter à nouveau que, comme pour la littérature, c'est au critique que revient le choix de définir ce qui est paralittéraire et ce qui ne l'est pas. L'opinion des critiques du début $\mathrm{du} \mathrm{xx}^{\mathrm{e}}$ siècle à propos de nos textes est probablement guidée par des critères similaires à ceux que pointe Daniel Couégnas: on comprend en effet les liens qu'entretiennent les romans arthuriens en vers tardifs avec le modèle paralittéraire qu'il théorise. Ainsi, la répétition, tant sur le plan intertextuel qu'intratextuel, la dimension narrative et la prééminence du connu sur le nouveau sont des traits que l'on retrouve dans notre corpus. Il faut toutefois nuancer: le Moyen Âge ne valorise pas la nouveauté et le progrès, comme le démontre l'ouvrage collectif dirigé par Laurence HarfLancner et Emmanuèle Baumgartner, Progrès, réaction, décadence dans l'Occident médiéval ${ }^{95}$. L'écriture s'appuie sur des modèles qu'elle réactive, ce qui explique que la part du connu excède celle de la nouveauté, l'intérêt étant toujours, comme nous l'avons indiqué, d'infléchir quelque peu l'attente pour créer la surprise.

Il faut donc adopter un autre point de vue sur cette littérature et reconnaître la différence de valeurs qui nous sépare des $\mathrm{XII}^{\mathrm{e}}$ et $\mathrm{XIII}^{\mathrm{e}}$ siècles. Déterminer la littérarité d'une ouvre ne doit pas dépendre des goûts de l'homme du $\mathrm{Xx}^{\mathrm{e}}$ ou $\mathrm{XxI}^{\mathrm{e}}$ siècle ni de son avant-gardisme par rapport à la littérature classique que nous valorisons aujourd'hui: il convient au contraire d'historiciser les objets que nous entendons décrire ${ }^{596}$. La monotonie que l'on reproche aux romans tardifs apparaît peut-être de manière plus flagrante que dans les premiers romans arthuriens, en raison de leur longueur et de leur goût pour la surenchère, qui leur donne un caractère répétitif. Nous verrons toutefois que la longueur ne s'explique pas toujours par la redondance (dans Escanor notamment) et d'autre part que les répétitions servent un but bien précis (dans Rigomer et Claris et Laris).

595 Progrès, réaction, décadence dans l'Occident médiéval, dir. Emmanuèle Baumgartner et Laurence Harf-Lancner Genève, Droz, 2003. Voir en particulier la préface de Laurence Harf-Lancner.

596 Joëlle Ducos, Olivier Soutet et Jean-René Valette développent cette idée d'historicisation de la littérature médiévale aux pages 57 à 63 de Le français médiéval par les textes. 
Si les derniers romans arthuriens en vers ne se montrent pas originaux ${ }^{597}$ par leur choix de l'univers de fiction et de certains motifs qu'ils réactivent, ils proposent en revanche une actualisation profonde de l'écriture romanesque et du genre arthurien. Notamment, ils complexifient la psychologie des personnages (Escanor, Claris et Laris) et vont jusqu'à exclure le manichéisme (Escanor, Melyador): la polarisation idéologique et éthique des personnages commentée par Daniel Couégnas tend donc plutôt à inclure nos textes dans le domaine de la littérature. Ceux-ci ne se contentent pas non plus de reconduire le genre dans lequel ils s'inscrivent, mais en interrogent les normes et les codes, en même temps qu'ils introduisent une nouvelle esthétique. En suivant Dominique Combe ${ }^{598}$ et en admettant que la participation forte au genre et la littérarité sont inversement proportionnelles, il faut considérer que les derniers romans arthuriens en vers sont littéraires: ces textes s'éloignent effectivement du canon par leur structure, leur traitement des personnages, de l'espace et leur intégration d'éléments génériques allogènes. Quant à l'ironie et aux procédés de distanciation, nous avons noté qu'il s'agit d'une composante essentielle du genre arthurien en vers et elle n'est pas absente de notre corpus (notamment dans la présentation d'un Lancelot gras et sot dans Rigomer), de même que la réflexion sur le pouvoir d'action de l'écriture et la revendication de la fiction, que Daniel Couégnas reconnait comme des indices de littéraritée 59 . Enfin, nous avons souligné plus haut que le narrateur de Melyador encourage le public à produire une interprétation des pièces lyriques, preuve que le texte est soumis à la glose ${ }^{600}$.

Les textes de notre corpus ne sont donc pas des témoins médiocres de la veine arthurienne, et on ne peut dès lors pas les qualifier de décadents. $\mathrm{Si}$ nous adoptons le terme de «déclin» au cours de l'étude, nous n'y entendons

597 Les auteurs de l'ouvrage collectif Original et originalité. Aspects historiques, philologiques et littéraires. Actes du IV colloque de l'Association Internationale pour l'Étude du Moyen Français, dir. Olivier Deslaux et Hélène Haug, Louvain, UCL, 2011, réfléchissent à cette notion et nuancent son application au Moyen Âge. Dietmar Rieger étudie également la question de la nouveauté dans la littérature médiévale: "Tot est dit". Zum Konzept des "Neuen" in der mittelalterlichen Literatur Frankreichs", Cahiers d'Histoire des Littératures romanes, 29, 2005, p. 163-182.

598 Dominique Combe, Les genres littéraires, p. 150.

599 Daniel Couégnas, Introduction à la paralittérature, p. 182.

600 Voir supra, p. 102, et l'article de Nathalie Bragantini-Maillard, «Les jeux du narrateur dans Melyador", art. cit., p. 159-160. 
pas un jugement de valeur négatif, mais voulons signifier le fait qu'il s'agit effectivement des derniers représentants du genre: le déclin est celui de la production et de l'intérêt que ces textes suscitent, et non celui de leur valeur. Sans doute pâtissent-ils sur ce point du succès des romans en prose, largement plus diffusés que les derniers romans arthuriens en vers, Claris et Laris, Floriant et Florete et Biaudouz étant tous les trois des unica, tandis que pour Melyador, Escanor et Rigomer, il a pu exister quelques manuscrits de plus, conservés aujourd'hui à l'état de fragments ou dont la survivance ne s'exprime que dans un inventaire ${ }^{601}$. Malgré les dernières tentatives lancées par les auteurs tardifs, le roman arthurien en vers ne parvient pas à concurrencer son homologue en prose, qui finit par le supplanter. Nous le verrons, les œuvres de la fin du XIII ${ }^{\mathrm{e}}$ siècle relèvent d'une forme d'hybridation, avec d'autres genres littéraires contemporains, mais surtout avec la prose. Cet effort pour maintenir un genre qui s'épuise en empruntant les techniques narratives d'un rival à la mode ne fonctionne que quelques décennies et n'a pas dû susciter l'engouement d'un public plus désireux désormais de percevoir un terme à l'histoire de la Table Ronde, comme le proposent les romans en prose: la fin du roman arthurien en vers s'explique ainsi peut-être par la fin programmée des aventures des chevaliers et du monde fictionnel, la mort du roi Arthur et la montée au ciel du Graal ${ }^{602}$. La temporalité cyclique des textes en vers, qui présente un univers immuable et toujours jeune, peut sembler fallacieuse à qui connaît la Mort Artu.

À moins que la fin du genre ne soit à chercher du côté de sa forme, la prose offrant une simplicité cognitive pour le nouveau public que le roman arthurien s'est construit au fil du XIII ${ }^{\mathrm{e}}$ siècle. L'évolution du roman arthurien, du vers à la prose, renvoie à celle du genre romanesque dans son ensemble: la prose s'imposera comme forme privilégiée du roman du $\mathrm{XV}^{\mathrm{e}}$ siècle jusqu'à nos jours ${ }^{603}$, quand l'inverse était valable au $\mathrm{XII}^{\mathrm{e}}$ siècle.

601 Pour les cotes, voir notre annexe A.

602 C'est en tout cas l'hypothèse que formule Christine Ferlampin-Acher. "Introduction. Après Arthur?», art. cit., p. 8. Elle signale comme autre raison possible l'épuisement du merveilleux et les évolutions sociales; en matière de guerre, l'artillerie et les armes de jet rendent désuète la chevalerie.

603 Francis Gingras, Le Bâtard conquérant, chapitre "Roman et prose», Michel Zink, "XIII. Le Roman", in Grundriß der romanischen Literaturen des Mittelalters. La littérature française aux XIV et XV siècles, vol. VIII/I, Heidelberg, Carl Winter, 1988, p. 197-218. 
Considérer les derniers témoins d'un type de réalisation formelle du roman permet de comprendre comment s'opère la transition, comment le vers devient petit à petit une stylisation qui empêche les potentialités esquissées par la prose de se déployer. Ainsi, la longueur du récit est perçue de manière forte, comme un rabâchage rébarbatif dans les récits en vers, alors que les récits en prose ne cessent de s'allonger, au plus grand plaisir du public - tel le Perceforest. Ce n'est donc pas l'habileté des auteurs ni la redondance des textes qui signe la fin du roman arthurien en vers, mais

ֻั peut-être plutôt l'abandon d'une forme au profit d'une autre. 
$\frac{\tilde{U}}{\frac{1}{J}}$

음

들

(1)

五

ชับ

듬

히

듬

षृ

ฮิ

브

는 


\title{
LES DERNIERS VERS: ÉCRIRE EN VERS APRÈS LA PROSE
}

\begin{abstract}
Alors que l'adoption du vers est naturelle dans le genre romanesque au XII ${ }^{e}$ siècle, ce choix n'est plus une évidence à la fin du XIII ${ }^{\mathrm{e}}$ siècle, et à plus forte raison au XIV ${ }^{\mathrm{e}}$ siècle, la prose s'étant déjà imposée comme forme privilégiée de la narration romanesque. Dans ce contexte, les romans de notre corpus font partie des dernières manifestations d'une forme métrique désuète, toujours revendiquée d'une façon ou d'une autre dans leurs prologues. Les auteurs y valorisent le travail qu'implique la rime, comme ceux de Claris et Laris et de Floriant et Florete:
\end{abstract}

Qui en rimer velt painne metre,

Soutilment se doit entremetre

De tele matire avant trere

Qui puist toute bone gent plere (Claris et Laris, v. 1-4)

Mes molt se doit bien porpenser

Qui s'entente a rimer velt metre

Qu'il s'en sache bien entremetre

Qu'il puist rimer en tel maniere

Que par devant ne par derriere

N'en soit gabez ne escharnis. (Floriant et Florete, v. 12-17) ${ }^{1}$

1 Si le propos est similaire dans les deux cas, c'est que Floriant et Florete s'inspire de Claris et Laris, jusqu'à lui emprunter des vers sur le mode de l'implicitation. Voir l'introduction à l'édition de Richard Trachlser et Annie Combes, Floriant et Florete, p. XlIV-XLVII. Sur l'implicitation, voir notre étude, Pour une poétique de limplicitation. 
La versification demande de la peine et de l'exigence, si l'écrivain veut plaire à son public et ne pas être moqué. Le vers «n'en soit gabez ne escharnis» $(F F$, v. 17$)$ suppose que le travail de la rime est moins indulgent que celui de la prose: si la versification est mauvaise, le poète sera d'autant plus vite sujet aux critiques. Rimer exige de la subtilité («soutilment", $C L$, v. 2); ce terme métapoétique, qu'étudie Jacqueline Cerquiglini pour la poétique du XIv à l'aune de l'œuvre de Guillaume de Machaut, présente l'écriture comme «un art difficile voire orné qui fait jouer à plein toutes les ressources de l'intelligence, art de la rhétorique, mais qui est peut-être menteur $»^{2}$. Le travail rhétorique engage l'habileté de l'auteur, quitte à perdre une véracité que ne revendique pas l'auteur de Claris et Laris. L'usage de ce terme affiche un parti pris poétique et glorifie le cadre formel adopté. On retrouve la même idée dans Rigomer, lorsque le narrateur précise que Jehan, le supposé auteur, est habile dans l'art de composer des rimes:

Jehans qui en maint bien s'afaite

Et pluisor bele rime a faite,

Nos a un romanç commenchié. (Rigomer, v. 1-3)

Sans doute faut-il interpréter, par métonymie, "pluisor bele rime» comme "plusieurs compositions en vers» et non seulement comme "plusieurs rimes». Par cette expression, au détriment d'un autre syntagme qui mettrait en avant le genre choisi comme c'est le cas au vers 3, on valorise la maîtrise stylistique de l'auteur, dont la versification comporte une valeur esthétique («bele»).

Chez Girart d'Amiens et Robert de Blois, la rime est présentée comme une mise en forme qu'aurait ajoutée l'auteur à sa source:

Pour coi Gerardinz apenssez

S'est d'un bel conte en rime metre (Escanor, v. 4-5)

A Tors, ou mostier Sain-Martin,

Le trovai escrit en latin.

Or le vuel je en romanz metre

Tot ensi com conte la letre,

Que je del mien rien n'i metrai

2 Jacqueline Cerquiglini, "Un engin si soutil». Guillaume de Machaut et l'écriture au XIV siècle, Paris, Champion, 1985, p. 245. 


\section{Fors tant ke par rime dirai,}

Por ce ke ceus le vuel aprendre

Qui ne sevent latin entendre. (Biaudouz, édition Lemaire, v. 33-40)

L'expression "en rime metre», proche de celle, plus répandue, de «en roman metre $»^{3}$, révèle une transformation d'ordre formel du beau conte choisi par Girart d'Amiens. L'auteur assume son usage du vers comme un parti pris concerté. Dans ces deux prologues, le vers n'est pas le résultat d'une reproduction fidèle d'une source versifiée, mais découle bien de l'initiative de l'écrivain. Chez Robert de Blois, à une allégation de fidélité («Tot ensi com conte la letre», v. 38) succède l'affirmation que le poète transposera son modèle en vers, seule liberté qu'il s'accorde, et qui vient redoubler la traduction du latin au français ${ }^{4}$. Il faut sans doute considérer que ces sources, aussi bien le beau conte de Girart d'Amiens que le manuscrit latin trouvé dans une abbaye de Robert de Blois, sont une invention; c'est un topos bien connu de la littérature du XII ${ }^{\mathrm{e}}$ siècle $^{5}$, de même que l'ambition de rendre un texte accessible au public qui ne parle pas latin que l'on trouve bien sûr dans le Roman de Troie. La réactivation de topoi du XII ${ }^{\mathrm{e}}$ siècle va sûrement de pair avec l'exposition du choix du vers en prologue, forme en phase d'obsolescence après les romans en prose, pensée chez Robert de Blois dans un continuum avec la tradition des premiers romans arthuriens en vers. Le statut fragile de la versification narrative à la fin du XIII ${ }^{\mathrm{e}}$ siècle explique que ces auteurs la justifient au début de leurs œuvres, soit en la couplant avec des topoi anciens pour l'assimiler à une tradition à succès ${ }^{6}$, soit en valorisant la dextérité qu’elle requiert de la part de l'écrivain.

3 Dans le prologue de Biaudouz, il faut comprendre «en romanz metre» (v. 35) dans le sens de "traduire en langue vernaculaire».

4 La parenté entre mise en forme (vers ou prose) et traduction sera abordée lorsque nous envisagerons les mises en prose (chapitre II, "Les mises en prose arthuriennes", p. 398-417). Les prologues des mises en prose valorisent en effet l'idée que le changement de forme correspond à une transposition similaire à la traduction. Le prologue de Robert de Blois pourrait engager les mêmes enjeux.

5 Voir Emmanuèle Baumgartner, «Du manuscrit trouvé au corps retrouvé», art. cit.

6 L'adoption de ce parti par Robert de Blois est peut-être à mettre en lien avec le recours qu'il fait de son roman arthurien, qui encadre son œuvre didactique. L'inscription dans une tradition à succès, à l'aide de topoi privilégiés du XII ${ }^{\mathrm{e}}$ siècle, favoriserait d'autant plus l'attention du récepteur. 
En optant pour le vers, les écrivains sont soumis à des contraintes: celui du style, qui s'adapte à la forme choisie; celui d'un mode spécifique de traitement du monde arthurien, propre à chaque forme. Ces deux critères feront l'objet de notre premier chapitre et permettront de dresser un premier jalon des rapports entre vers et prose dans les textes arthuriens tardifs. L'extinction du genre arthurien en vers sera ensuite mise en parallèle avec le destin du vers à la fin du Moyen Âge, dans sa spécialisation lyrique. Dans un dernier temps, nous considèrerons deux modalités, peu exploitées dans notre corpus, de survivance du genre arthurien en vers: la mise en prose (Floriant et Florete) et la transposition des codes d'écriture du vers dans le cadre de la prose (Conte du Papegau).

\section{DE LA PROSE AU VERS}

Le choix d'une forme, nous l'avons vu, n'est jamais anodin et implique toujours des enjeux génériques. Le roman arthurien n'échappe pas à cette règle: la forme est un critère générique pertinent pour distinguer deux types de production qui chacune se définit à partir d'un cadre idéologique, temporel, structurel et stylistique spécifique, entretient un rapport différent à la fiction et varie le statut accordé au narrateur, nous y avons fait allusion au chapitre premier. Les textes de notre corpus ne peuvent ignorer de ce point de vue la direction qu'a prise le roman arthurien au début du XIII ${ }^{\mathrm{e}}$ siècle avec l'émergence des sommes en prose. Si leur étude révèle un nombre important de continuités avec la prose, elle éclaire aussi plusieurs discontinuités. Celles-ci sont ciblées sur le chronotope choisi, qui demeure celui des premiers romans arthuriens en vers, au détriment de celui des textes en prose; il s'agit aussi du style, qui, s'il évolue, prolonge des effets initiés par Chrétien de Troyes plus qu'il n'imiterait l'écriture de la prose. Les œuvres tardives apparaissent alors comme des romans intermédiaires; elles s'affirment comme des successeurs de la tradition en vers, tout en tirant profit de l'héritage de la prose.

\section{Choix de forme, choix de chronotope}

Patrick Moran, dans son étude sur les cycles, distingue le cycle de la série. Alors que le cycle propose un fil narratif englobant, la série désigne «un ensemble de textes narratifs fondé sur la récurrence mais 
sans architecture subsumante» ${ }^{7}$. Cette distinction recoupe en partie celle qui oppose romans arthuriens en vers et romans arthuriens en prose; au vers correspond le travail de la série, tandis que la prose, du moins celle du Lancelot-Graal, s'organise en cycle. Le choix d'une forme impose une lecture particulière:

Les différentes parties d'une série s'additionnent les unes aux autres de manière linéaire, tandis que celles d'un cycle construisent un ensemble complexe. On peut indifféremment lire un ou plusieurs épisodes d'une série: en lire plusieurs n'apporte rien de plus au lecteur en dehors du plaisir fondé sur la répétition et une certaine variation; en revanche la lecture d'un cycle dans sa totalité fait émerger un propos plus vaste que celui de ses parties individuelles. Le cycle est une architecture: pour cette raison il est nécessairement limité dans le nombre de ses parties, à la différence de la série, qui peut en théorie s'étendre indéfiniment ${ }^{8}$.

Ces différences de construction du propos romanesque ont une portée idéologique et révèlent les objectifs que recoupe chaque forme, d'où leur dimension générique. Écrire en prose, c'est nourrir l'ambition de circonscrire un univers dans son ensemble, de son commencement à sa fin; écrire en vers suppose la juxtaposition d'aventures qui prendraient place dans le même cadre temporel, indéfiniment recommencé.

La temporalité est en premier lieu concernée par cette distinction; d'abord parce que la narration de la prose embrasse plusieurs générations quand celle du vers couvre un ou deux ans. Ensuite, dans le roman en vers, il s'agit de donner l'impression d'un éternel recommencement, qui omet le vieillissement des personnages et du monde, quand la prose explicite cet écoulement du temps par le fait même de mentionner les âges des personnages dans la Mort Artu (Arthur y a ainsi quatre-vingtdix ans). Le cadre dans lequel prend place tout roman arthurien en vers est extensible: chaque nouvelle aventure vient augmenter l'univers fictionnel déjà constitué, y ajouter des personnages, au risque parfois de la contradiction?. Les aventures racontées en vers s'inscrivent dans un

Patrick Moran, Lectures cycliques, p. 35.

Ibid., p. 36-37.

Ce constat est aussi valable pour les romans en prose de troisième génération, dont l'intrigue s'intègre au sein de l'univers de fiction pour le prolonger en amont et y accumuler des aventures que le Lancelot-Graal n'aurait pas encore rapportées. 
temps suspendu: elles se déroulent certes individuellement de manière linéaire, mais elles occupent simultanément "un espace circulaire plutôt qu'elle[s] ne jalonne[nt] un parcours dans cette bulle matricielle, dilatable à l'infini, grosse de tous les récits existants et de tous les récits possibles que devient l'espace arthurien à partir d'Erec et Enide» ${ }^{10}$. C'est ainsi que le roman en vers ne donne pas de fin au monde arthurien, ne décrit pas la mort des personnages, et détaille rarement leur passé. Comme l'explique Emmanuèle Baumgartner,

Tout se passe alors comme si les récits de Chrétien suspendaient le temps arthurien tel que l'a déroulé, raconté Wace en un point du temps qui reste d'ailleurs non précisé, puis dilataient aux dimensions de l'œuvre, d'Erec et Enide au Conte du Graal, un moment ainsi privilégié du règne/du temps mais dont la durée comme les limites restent incertaines. Un temps toujours présent, "présentifié», qui n’a ni début ni fin, ni passé ni futur ${ }^{11}$.

Cette temporalité circulaire est accentuée par l'ouverture et la clôture du récit à la cour d'Arthur, qui demeure inchangée malgré les péripéties narrées.

Le monde arthurien du vers ne subit pas le temps, l'usure, les conflits extérieurs: il est statique. Le vers répond à une "poétique du fragment, du discontinu, au désir de capturer le temps d'instant en instant, de le construire dans son immanence devant le lecteur ${ }^{12}$. Il nie en quelque sorte "l'idée d'évolution affectant toute civilisation " ${ }^{13}$, ce qui lui permet de rester dans une atmosphère de "désinvolture joyeuse ${ }^{14}$, sans jamais

Le but visé, s'il est bien sûr lié au plaisir de réactiver un monde à succès comme c'est le cas pour les romans en vers, est toutefois proche de ce vers quoi tend toute écriture en prose: l'exhaustivité. Le Lancelot-Graal est d'ailleurs toujours à l'horizon de ces romans, ce qui comprend dès lors la fin du monde arthurien que n'envisage jamais le roman en vers.

10 Emmanuèle Baumgartner, "Temps linéaire, temps circulaire et écriture romanesque (XII ${ }^{\mathrm{e}}$-XIII ${ }^{\mathrm{e}}$ siècles)", art. cit., p. 12.

11 Ibid., p. 11.

12 Emmanuèle Baumgartner, Le Récit médiéval, p. 146.

13 Catherine Croizy-Naquet, "Nus contes rimés n'est verais», art. cit., p. 36.

14 Michelle Szkilnik, "Le chevalier "oublieux" dans le roman arthurien en vers", in Figures de l'oubli ( $V^{e}-X V I^{e}$ siècle), dir. Patrizia Romagnoli et Barbara Wahlen, Lausanne, Études de Lettres, 1-2, 2007, p. 95. 
être inquiété par la fin de son propre monde. Si ce parti pris n'exclut pas des interrogations plus profondes, les romans en vers n'ont pas, comme ceux en prose, pour ambition de problématiser la destinée humaine. L'introduction d'une chronologie touchant l'entier du règne arthurien va de pair avec «la peinture d'une humanité en proie à elle-même»" ${ }^{15}$ La prose, tout du moins celle des romans du Graal, jette un regard pessimiste sur le monde, sur l'utilité de la chevalerie ou le potentiel d'actualisation de la fin'amor ${ }^{16}$. C'est lié à la perspective diachronique qu' elle adopte sur l'univers arthurien, dont elle raconte les débuts et la fin; le travail de la chronologie $^{17}$ induit que la mort des personnages est à l'horizon, d'où les interrogations que la prose du Graal intègre et que souligne Daniel Poirion:

Ces romans, sans généralement obéir à telle ou telle idéologie cléricale, sont l'expression d'une conscience qui s'interroge, ou qui répond aux interrogations, aux soupçons, aux accusations dont l'homme mondain est l'objet. C'est que dans l'image du glissement temporel du passé vers l'avenir la prose rejoint tout naturellement les grands thèmes de la réflexion morale: elle est facilement soucieuse et obsessive; parfois même, elle étouffe l'espérance ${ }^{18}$.

Cette idéologie résulte à la fois du travail d'une temporalité linéaire et de l'ambition d'exhaustivité de la prose: cette écriture valorise l'élucidation, veut tout dire, tout expliquer, quand le vers cultive le mystère, la part réservée à l'interprétation. D’un côté, l'écriture se fait évocation poétique, de l'autre représentation dramatique ${ }^{19}$. Le monde arthurien, dans le

15 Hélène Bouget, "Chevaliers en péril: parodie et déconstruction des héros arthuriens dans Kaamelott», in Le Moyen Âge en jeu, dir. Séverine Abiker, Anne Besson et Florence Plet-Nicolas, Eidôlon, 86, 2009, p. 203.

16 Noémie Chardonnens, "Les rapports entre vers et prose», in La matière arthurienne tardive en Europe (1270-1530), dir. Christine Ferlampin-Acher, Rennes, PUR, 2020, p. 233-240. Il faut toutefois noter que les romans en prose de troisième génération, le Roman de Meliadus notamment, ne sont pas dénués d'optimisme: on tente d'y insinuer l'idée de progrès, les meilleurs chevaliers étant à l'horizon d'un futur prometteur.

17 Ferdinand Lot liste les procédés chronologiques du Lancelot en prose dans Étude sur le Lancelot en prose, Paris, Champion, 1984, p. 29-64.

18 Daniel Poirion, «Romans en vers, romans en prose», art. cit., p. 81.

19 Ibid., p. 79. 
roman en vers, "sert plus d'arrière-plan aux aventures", tandis que dans le roman en prose, il est un «sujet narratif à part entière $»^{20}$.

Ces distinctions sont chronotopiques, au sens où l'entend Mikhaï Bakhtine: ce concept n'est pas à interpréter comme un équivalent de l'univers de fiction, qui se concentrerait sur l'espace et le temps ${ }^{21}$. Il rend compte de la «corrélation essentielle des rapports spatio-temporels, telle qu'elle a été assimilée par la littérature ${ }^{22}$, et de ce que ces rapports disent de la vision du monde proposée par l'œuvre:

Le chronotope concerne donc au fond l'appréhension, sur un plan existentiel, du monde extérieur suivant la configuration et la fonction de l'espace-temps du récit. Il s'ensuit que le chronotope, plus qu'une simple somme de faits temporels et spatiaux, est une dimension du récit qui nous aide à identifier les valeurs principales de tel genre ou de telle œuvre ${ }^{23}$.

La notion n'a d'intérêt que si l'on considère les effets de sens que l'on peut tirer de la conjonction entre l'espace et le temps. La corrélation entre le temps et l'espace est perçue comme le fondement de tous les phénomènes. C'est elle qui engendre l'action:

[Les chronotopes] se présentent comme les centres organisateurs des principaux événements contenus dans le sujet du roman, dont les «nœuds» se nouent et se dénouent dans le chronotope. C'est lui, on peut l'affirmer, qui est le principal générateur du sujet ${ }^{24}$.

L'errance est par exemple chronotopique, en tant que "voie d'accès à l'espace général de l'action $»^{25}$. Dans une perspective chronotopique,

20 Patrick Moran, Lectures cycliques, p. 167.

21 Il nous paraît donc compliqué de parler de «chronotope arthurien", en tout cas lorsque cette expression désigne le monde arthurien ou l'espace-temps du règne d'Arthur. Nous préférons parler pour cela d'univers de fiction, ainsi que nous l'avons développé.

22 Mikhail Bakhtine, Esthétique et théorie du roman, p. 235.

23 Hans Färnlöf, "Chronotope romanesque et perception du monde. À propos du Tour du Monde en quatre-vingts jours", Poétique, 152, 2007/4, p. 439-456.

24 Mikhail Bakhtine, Esthétique et théorie du roman, p. 391.

25 Henri Mitterand, "Chronotopies romanesques: Germinal», Poétique, 81, 1990, p. 97. 
elle génère le récit en temps (cheminement inscrit dans une durée, bien que la temporalité soit indéfinie) et en lieu (forêt, espace merveilleux), tout en concrétisant des éléments symboliques, métaphoriques (rédemption, apprentissage, chemin de la vie). L'errance est le «centre de la concrétisation figurative», c'est-à-dire qu'elle matérialise les éléments abstraits du roman ${ }^{26}$. La notion de chronotope rend compte du fait que le traitement de la temporalité, à laquelle est soumis l'espace, pose une vision du monde.

Les distinctions que nous établissons entre vers et prose relèvent du chronotope: l'espace-temps est identique dans les deux cas (la Bretagne, sous le règne d'Arthur), mais le chronotope est différent, car le temps et l'espace entretiennent des relations différentes en contexte versifié ou prosifié. Le traitement différent de la temporalité (linéaire ou circulaire) ${ }^{27}$ dit quelque chose de la vision du monde proposée par le vers ou la prose: l'univers de fiction échappe à la chute et à l'écoulement meurtrier du temps dans le vers, il reste à l'abri dans un éternel recommencement, quand l'exploration chronologique de l'univers qu'opère la prose mène forcément à sa fin. Le chronotope engendre donc des implications symboliques; il faut aussi le considérer comme un critère générique.

Le choix d'une forme vaut alors comme avertissement au lecteur sur la version du monde qui lui est soumise et constitue un premier niveau de l'horizon d'attente. Mis en présence de personnages issus de l'univers de fiction arthurien, le lecteur mobilise un bagage textuel qu'il a acquis au fil de ses lectures. Toutes les versions du monde arthurien que le lecteur connaît sont convoquées et confirmées ou infirmées par le texte en présence. Ainsi, lorsque Lancelot apparaît dans un récit de la fin du

26 «Dans un roman tel que le Parzifal, de Wolfram von Eschenbach, le chemin réel pris par le héros pour se rendre à Monsalvat, devient insensiblement une métaphore de la route, du chemin de la vie, de l'âme, qui tantôt se rapproche de Dieu, tantôt s'en éloigne, selon les erreurs et les chutes du personnage et les occurrences survenues sur sa vraie route." (Mikhaill Bakhtine, Esthétique et théorie du roman, p. 385. Voir aussi page 391)

27 Mikhail Bakhtine donne l'exemple du chronotope de Madame Bovary pour illustrer la dimension symbolique du traitement de la temporalité: "Une telle ville ["petite ville de province", dans Madame Bovary] est le lieu du temps cyclique de la vie quotidienne. Il ne s'y passe aucun événement, rien que la répétition de l'“ordinaire”. Le temps y est privé de son cours historique progressif.» (Esthétique et théorie du roman, p. 388) 
XIII ${ }^{\mathrm{e}}$ siècle, son nom invoque tout un passé littéraire formé de son amour pour la reine, son échec partiel à la quête du Graal, sa responsabilité dans la chute du monde arthurien. Ces données définissent le personnage dans le cadre virtuel de l'univers de fiction et ne peuvent manquer d'être rappelées à la mémoire du lecteur ${ }^{28}$. Toutefois, le choix du vers ou de la prose crée un pacte de lecture: la forme versifiée signale d'emblée que certaines données n'interviendront pas dans le récit, même si elles peuvent se lire implicitement dans le caractère ontologique du personnage. Par la forme choisie, l'auteur génère un chronotope en particulier, et active chez le lecteur une vision spécifique du monde arthurien, lui intimant de placer certaines données sous narcose, pour reprendre l'expression d'Umberto $\mathrm{Eco}^{29}$.

Le choix d'une forme contraint dès lors la réception. Selon Beate Schmolke-Haßelmann, le roman en prose engage l'émotion du public et suscite la crainte et l'empathie, quand le roman en vers encourage l'émerveillement et la joie ${ }^{30}$. Bien qu'il faille se garder d'admettre de manière absolue de telles généralisations, force est de reconnaître qu'il s'agit là de tendances que l'on observe plus fréquemment dans l'une ou l'autre forme ${ }^{31}$. Les différences de traitement chronotopiques sous-tendent

28 Richard Trachsler parle en ce sens de pro-récit: le nom propre active un récit condensé, qui contient tous les éléments qui ont façonné son personnage au fil des textes. Disjointures - conjointures, p. 24-31.

29 «Quand il se trouve face à un lexème, le lecteur ne sait pas quelle propriétés ou sèmes du sémème correspondant doivent être actualisées afin de mettre en œuvre les processus d'amalgame. [...] Normalement, les propriétés du sémème restent virtuelles, c'est-à-dire qu'elles restent enregistrées par l'encyclopédie du lecteur qui tout simplement se dispose à les actualiser quand le cours textuel le lui demandera. Le lecteur n'explicite donc, de ce qui reste sémantiquement inclus ou implicité, que ce dont il a besoin. En agissant ainsi, il aimante ou privilégie certaines propriétés tandis qu'il garde les autres sous narcose." Lector in fabula, p. 112.

30 Beate Schmolke-Haßelmann, Der arthurische Versroman, p. 5.

31 Plusieurs romans en prose échappent bien sûr à l'atmosphère sérieuse et lourde d'implications morales que décrit Beate Schmolke-Haßelmann, que l'on pense à Guiron le courtois ou à Artus de Bretagne. Ce dernier se veut un prolongement optimiste du monde arthurien, en imaginant un futur au règne d'Arthur dans une sorte de continuité spirituelle entre Arthur et Artus. Les valeurs que promouvait le roi Arthur survivent après sa mort, grâce à de nouveaux personnages qui s'en montrent dignes et se placent en héritiers d'une tradition chevaleresque et littéraire. Voir les articles de Christine Ferlampin-Acher, "Le charme d'Artus de Bretagne», in Miscellanea mediaevalia. Mélanges offerts à Philippe Ménard, dir. 
effectivement une idéologie propre à chaque formalisation: les romans en prose sont régis par la mescheance ${ }^{32}$, ce malheur qui mène petit à petit à la mort par une succession de causalités. Dans la Mort Artu, la mescheance trouve son origine dans une faute sexuelle: celle de Lancelot et Guenièvre, celle du roi Arthur avec sa sœur. Dans le Tristan en prose, l'amour entre les protagonistes est aussi qualifié de mescheance par Iseut : "Tristanz, vos savez bien par quel pechié et par quel mescheance il avint que vos m'amastes et je vos. ${ }^{33}$ La faute peut aussi concerner un autre domaine que celui de l'amour: Gauvain s'accuse devant la cour des morts qu'il a engendrées, attribuant à la mescheance ses victoires, qui découlent d'un péché d'ordre moral. Loin de n'être que la victime malheureuse d'un destin funeste, le personnage a une part de responsabilité dans le malheur qui s'abat sur lui ou sur son monde, même si sa culpabilité est souvent cachée, inaccessible à sa conscience, refoulée. Pour le dire avec Servane Rayne-Michel:

La mescheance est le signe qui révèle la faute - autrement dit elle désigne le malheur comme signifiant, en fait un appel à l'examen de conscience ${ }^{34}$.

Le péché et ses conséquences pèsent dès lors sur le déroulement du récit, engendrent le temps eschatologique et le jugement de la chevalerie. C'est un monde assombri qui est présenté dans le Lancelot en prose et le Tristan en prose: il est voué à sa propre fin ${ }^{35}$.

Jean-Claude Faucon, Alain Labbé et Danielle Quéruel, Paris, Champion, 1998, t. 1., p. 513-528, et "D'un monde à l'autre: Artus de Bretagne entre mythe et littérature, de l'antiquaire à la fabrique de faux meubles bretons", in Le monde et l'autre monde, dir. Denis Hüe et Christine Ferlampin-Acher, Orléans, Paradigme, 2002, p. 129-168.

32 Sur la mescheance, voir Francis Dubost, "Mescheance”, Merveille, Mort dans la Mort le Roi Artu: recherche sur un champ associatif ", in Imprimer en cour d'homme fermeté d'espérance. Hommage au Professeur François Rouy, Nice, Association des publications de la Faculté des Lettres de Nice, 1995, p. 51-65.

33 Le Roman de Tristan en prose, éd. Renée L. Curtis, Münich, Max Hüber Verlag, 1963, tome II, p. 116.

34 Servane Rayne-Michel, La Table ronde et les deux cités: pour une lecture augustinienne des cycles arthuriens en prose du XIII siècle, Paris, Champion, 2016, p. 455. Voir les pages 455 à 465.

35 Damien de Carné traite de l'assombrissement du monde dans le Tristan en prose dans Sur l'organisation du Tristan en prose, Paris, Champion, 2010, p. 567-614. 
Le roman en vers est loin de ce type de préoccupation: la place privilégiée qu'occupent la parodie et le comique fonde la dimension ludique de ces textes. Les auteurs cultivent une esthétique du jeu; jeu avec la tradition antérieure, jeu sur les motifs, le caractère ontologique des personnages. La mort du héros ou des figures tutélaires de la cour arthurienne n'est jamais à l'horizon: le lecteur sait que l'histoire qu'on lui raconte en vers finira en apothéose, même si les personnages ou les valeurs célébrées par la chevalerie courtoise peuvent être malmenés au passage. Leur mise en cause se fait toujours sur le registre ludique et n'implique pas l'idée de culpabilité et de faute. Ce constat est encore valable pour les romans tardifs, qui demeurent hermétiques à cette direction prise par les romans arthuriens en prose de première génération. La prose peut aussi renoncer à l'occasion au ton grave de la mescheance: le Roman de Meliadus réagit à la vision eschatologique du monde arthurien en supprimant le Graal ou l'inceste d'Arthur de son horizon. Néanmoins, le chronotope reste le même que celui du LancelotGraal, puisque la diégèse s'inscrit en amont de ses aventures: la temporalité est celle de la chronologie, non de l'achronie. L'objectif est dès lors moins le jeu sur le retour des personnages et des motifs que l'ambition totalisante, la volonté d'exhaustivité36, le récit étiologique.

\section{Temps linéaire - temps circulaire}

Le roman tardif, s'il continue de s'inscrire dans le chronotope propre au vers, complexifie quelque peu ses modalités. Le roman arthurien en vers classique déroule ses aventures au cœur des douze ans de paix signalées par le Brut. Ce temps est dilatable à l'infini pour accueillir autant de péripéties que les auteurs le souhaitent. Dans le roman en prose en revanche, il est possible d'occuper un cadre temporel, circonscrit au sein de la chronologie arthurienne, selon plusieurs modalités: Jane Taylor recense le principe d'insertion contextuelle («contextual») ou extensionnelle (« extensional»), le premier qualifiant le prolongement à l'intérieur du monde arthurien et le second désignant les continuations en aval ou en amont du temps d'Arthur, celui-ci n’apparaissant pas en personne dans la diégèse ${ }^{37}$.

\footnotetext{
36 Sur la façon d'occuper les cases vides de l'univers de fiction arthurien dans le Roman de Meliadus, voir Barbara Wahlen, L'écriture à rebours, en particulier les pages 24-30.

37 Jane Taylor, "The Fourteenth Century: Context, Text, Intertext», art. cit.
} 
Dans le cas des insertions contextuelles, la diégèse choisit souvent de relater la jeunesse du monde arthurien. Cette voie a été empruntée par les romans en prose (Meliadus, Suite Vulgate, Livre d'Artus, Roman de Guiron $)^{38}$, avant de l'être par Melyador. De manière plus déroutante, il arrive aussi que le roman en vers tardif abandonne le cadre imposé par les douze ans paix pour explorer d'autres épisodes de la geste arthurienne, comme la guerre d'Arthur contre Rome, traitée comme une aventure dans Claris et Laris. L'insertion extensionnelle extrait quant à elle la diégèse du règne arthurien: c'est le cas du Perceforest, qui raconte la préhistoire d'un monde où Arthur est un roi à venir, dont la gloire est annoncée par les exploits de ses ancêtres ${ }^{39}$. Cet enjeu généalogique peut aussi bien se réaliser en aval du temps arthurien pour raconter l'histoire des descendants, comme dans Ysä̈e le Triste, centré sur les fils et petit-fils de Tristan dans un temps post-arthurien ${ }^{40}$, ou dans Artus de Bretagne, dont le héros est issu du lignage de Lancelot. Dans ces exemples, le lien tissé avec le temps d'Arthur est celui de la prédésignation: le Perceforest, s'il ne fait pas apparaître la Table Ronde en propre dans son récit, est totalement orienté vers cet avenir. Plusieurs passages se proposent alors à la lecture comme des préfigurations d'épisodes arthuriens, tandis que

38 Voir Nathalie Koble (dir.), Jeunesse et genèse du royaume arthurien. Les Suites romanesques du Merlin en prose, Orléans, Paradigme, 2007, et sur la construction du Livre d'Artus et son insertion dans le cycle du Lancelot-Graal, Noémie Chardonnens, Nathalie Koble et Patrick Moran, "L'invention du Livre d'Artus: le manuscrit PARIS, BnF, fr. 337 ", in Le manuscrit unique. Une singularité plurielle, dir. É. Burle-Errecade, V. Gontero-Lauze, Paris, PUPS, 2018, p. 115-136. Voir aussi Barbara Wahlen, L'Écriture à rebours, deuxième partie. Emmanuèle Baumgartner, "Les techniques narratives dans les romans en prose», art. cit., p. 187-190, traite de l'ambition généalogique du roman arthurien en prose, qui donne lieu à l'exploration de la vie des pères des héros arthuriens. Voir aussi Sophie Albert, "Ensemble ou par pièces». Guiron le Courtois (XIIt-XV" siècles): la cohérence en question, Paris, Champion, 2010. Le Roman de Meliadus "fait coïncider deux blancs narratifs: les guerres auxquelles Arthur est confronté après son intronisation que le Lancelot se contente de mentionner, et la petite enfance du fils de Méliadus, traitée sur le mode de l'ellipse dans le Tristan en prose.» (Sophie Albert, p. 53-54)

39 Voir Noémie Chardonnens, L'Autre du même, p. 17-23, qui interroge la portée arthurienne de ce texte, situé hors du règne arthurien.

40 Patricia Victorin, Ysaïe le triste: une esthétique de la confluence: tours, tombeaux, vergers et fontaines, Paris, Champion, 2002. 
l'ensemble suggère une progression $\mathrm{du}$ monde vers la perfection des temps arthuriens ${ }^{41}$.

L'extension du cadre temporel est une voie de renouvellement privilégiée dans les romans en prose. Le prolongement rétroactif de l'univers de fiction ${ }^{42}$, qui explore la jeunesse du monde arthurien et les événements qui précèdent les douze ans de paix, est reconduit dans Melyador. Le roman commence en précisant que le roi Arthur est «au point de sa jonece» (v. 4),

Environ ou .IX. ans ou .X.

Avant que li preus Lanselos,

Melÿadus ne li rois Los,

Guiron, Tristrans ne Galehais,

Gauwains, Yewains ne Perchevaus

Ne chil de la Table Reonde

Fuissent cogneü en ce monde

Ne que de Merlin on euist

Cognissance ne c'on seuist

Nulle riens de ses prophesies. (Melyador, v. 28-37)

À la jeunesse d'Arthur répond celle du monde arthurien: c'est l'occasion de dépeindre un temps d'insouciance, loin de l'annonce de la chute, loin des préoccupations plus sérieuses autour du Graal. "Roi passé, roi futur", pour reprendre le titre du conte de Guillaume Apollinaire ${ }^{43}$ : l'Arthur de Melyador est un personnage jeune, mais il traîne derrière lui une longue tradition littéraire. Il annonce un futur que le lecteur connaît déjà, car le roi est lourd de son passé littéraire. Comme le note Michel Zink, si "Arthur est mentionné dès le premier vers, [...] c'est pour dire que l'histoire se passe à une époque où il n'était pas encore vraiment lui-même

41 Noémie Chardonnens, L'Autre du même, p. 20-21.

42 L'expression "prolongement rétroactif» est d'Eugène Vinaver, "La Genèse de la Suite du Merlin", in Mélanges Ernest Hoepffner, Paris, Les Belles Lettres, 1949, p. 297.

43 Le Poète assassiné, Paris, l'Edition ("Bibliothèque des curieux»), 1916, p. 287-296. Ce titre renvoie à l'épitaphe d'Arthur dans La Morte d'Arthur de Thomas Malory: "Hic jacet Arthurus, rex quondam, rexque futurus" (La Morte Darthur, éd. Helen Cooper, Oxford, PU, 1998, p. 517. Barbara Wahlen étudie ce double visage d'Arthur dans la Continuation du Roman de Meliadus et intitule l'un de ses chapitres "Arthur, roi passé, roi futur", L'écriture à rebours, p. 139-174. 
et où l'univers auquel il a attaché son nom n'était pas encore structuré ${ }^{44}$. Ainsi s'expliquent peut-être les libertés que prend Froissart vis-à-vis de l'écriture arthurienne: la jeunesse du monde fictionnel est le prétexte au rôle anecdotique d'Arthur dans ce texte - nous y reviendrons -, lui qui ne maîtrise pas encore tout à fait son importance dans la gestion des aventures et dont les chevaliers les plus renommés n'ont pas eu le temps de se distinguer ${ }^{45}$.

Écrire la préhistoire arthurienne, c'est aussi inscrire ce qui a déjà été raconté en continuité. Le narrateur précise que l'on "parlera en avant / assés [des] chevaleries» (Melyador, v. 30598-30599) d'Agravain et prétend que ses aventures sont narrées "ailleurs que ci» (Melyador, v. 30634), dans un «livres» (v. 30633). Il fait aussi référence à des événements futurs mais déjà relatés concernant l'Ile de Man, future terre du roi des Cent Chevaliers ${ }^{46}$ dont parle le Lancelot en prose. Il insiste sur le rapport chronologique entre sa diégèse et les événements futurs, qu’ont racontés ses prédécesseurs, en signalant que

Mais encor de ceste ordenance

N'avoit on nulle cognissance.

Cela avint de puis ou tamps

Que Lancelos li combatans,

Messire Yewains et Perchevaus,

Tristrans, Durmas et Gallehaus

Cerkoient par tout aventures,

De quoi ailleurs les escriptures

Parollent trop plus plainnement

Qu'en ce livre presentement,

Car il avint et fu escris

En devant de ces dessus dis. (Melyador, v. 11686-11697)

On revendique ici que des escriptures sur le devenir du monde arthurien ont déjà été écrites, autre manière de rattacher le roman de Melyador à

44 Michel Zink, Froissart et le temps, p. 115.

45 Barbara Wahlen évoque cet aspect au sujet de la Continuation du Roman de Meliadus: le dysfonctionnement de la jeune cour arthurienne s'explique par le fait qu' «elle n'est pas, ou pas encore, le centre rayonnant du royaume, le lieu de la collecte et de la mise en mémoire des aventures" (L'écriture à rebours, p. 221).

46 Voir au sujet de ce personnage la note de Nathalie Bragantini-Maillard à son édition, t. 2, note 11684 , p. 1439. 
cet univers fictionnel, aussi bien celui de la prose que du vers: Durmart et Galehaut, mentionnés dans cette liste, proviennent respectivement et exclusivement du vers et de la prose, tandis que Lancelot, Yvain, Perceval et Tristan apparaissent dans les deux types de récit. Dans le prologue, Meliadus et Guiron sont des personnages exclusifs à la prose, héros de la génération des pères, dont les aventures sont aussi censées prendre place dans la jeunesse d'Arthur. Les vers 35 à 37 du prologue font quant à eux référence aux Prophéties de Merlin, qui sont tout autant un horizon futur pour l'histoire de Melyador. Les escriptures du vers 11693 désignent alors une somme de textes, du Lancelot en prose à Guiron le courtois et aux Prophéties de Merlin, qui recèlent un nombre infini de discours prononcés sur l'univers arthurien, un peu à la manière du "Livre du Bret» évoqué par le Roman de Meliadus et qui renvoie fictivement à un ensemble exhaustif et fantasmé qui épuiserait les possibilités narratives du monde arthurien ${ }^{47}$. Le monde arthurien n'est plus, dans cette perspective, une donnée historiographique, mais une réalité avant tout textuelle, littéraire, potentiellement fictionnelle - si l'on se rappelle que la dimension fictive de ces histoires est assumée par d'autres auteurs, celui de Claris et Laris en premier lieu.

Melyador se propose comme un ensemble qui s'achève sur le début des aventures arthuriennes familières au lecteur: c'est à la fin de l'histoire de Melyador et des chevaliers de sa génération qu'apparaissent Sagremor, Gauvain, Yvain et Keu (dès les vers 25000 environ) ${ }^{48}$, encore jeunes, Sagremor étant désigné comme un enfant (v. 25619). Melyador pourrait ainsi constituer la tentative de construction d'un cycle arthurien en vers, en s'intéressant à des héros différents de ceux des romans arthuriens du $\mathrm{XIII}^{\mathrm{e}}$ siècle mais dont les valeurs, les motivations et la nature de la quête trouvent un écho à l'esthétique du vers. Les noms de chevaliers célèbres servent principalement de signaux marquant le partage d'un univers de fiction et permettent de rattacher la trame narrative de Melyador au

47 Voir Barbara Wahlen, L'écriture à rebours, p. 30-35.

48 Voir les pages 269-270 de l'introduction à l'édition de Nathalie BragantiniMaillard et son article, "Pour un changement de perspective sur la construction de Melyador", art. cit, p. 166-167, où elle montre que la quête que raconte Melyador a effectivement duré neuf ans, comme l'annonce le prologue, qui situe le texte neuf ans avant le temps des aventures. 
monde arthurien, mais ils disparaissent aussitôt $\mathrm{t}^{49}$. Grâce à ces furtives apparitions et au renvoi explicite au passé littéraire, à la préexistence de récits arthuriens, rien n'empêcherait un compilateur d'apposer les romans de Chrétien de Troyes et de ses successeurs à la suite du texte de Froissart bien plus qu'il ne pourrait y apposer le Lancelot en prose.

L'inachèvement de l'histoire de Sagremor au sein de Melyador appelle quant à lui à la continuation: on laisse le personnage avec les nymphes de Diane, dans la forêt, sans connaitre la teneur de cet épisode merveilleux. Le narrateur annonce que cette aventure sera poursuivie en autre lieu:

Foy que je doy a saint Valier, ailleurs que ci en parlerons, mais nous avant parconclurons de la queste qui est emprise sur qui ceste matere ${ }^{50}$ est prise. (Melyador, v. 28827-28831)

Cette transition laisse imaginer le foisonnement d'aventures possibles et maintient l'univers ouvert ${ }^{51}$. Elle n'est pas sans rappeler les annonces que distillent la Suite du Merlin ou le Tristan en prose, qui promettent plusieurs développements ${ }^{52}$ dont l'attente n'est pourtant pas satisfaite. Il est nécessaire

49 Noémie Chardonnens parle pour ce type de cas de «marqueurs transfictionnels»: il s'agit de passages "qui ne sont pas à proprement parler transfictionnels (en particulier parce qu'ils ne présentent pas d'intervention sur une diégèse antérieure), mais qui laissent deviner le partage d'un univers de fiction». (L'autre $d u$ même, p. 186)

50 Le terme «matere» désigne ici le sujet propre au récit, ce dont le récit s'occupe principalement.

51 Voir l'édition citée de Nathalie Bragantini-Maillard, p. 41. La critique développe la question de l'inachèvement de cet épisode et de la place de Melyador dans la chronologie arthurienne dans «Pour un changement de perspective sur la construction de Melyador de Jean Froissart ", art. cit., et dans l'introduction à son édition, p. 35-43. Selon elle, le manuscrit BnF fr. 12557 est incomplet et il n'y manquerait qu'un feuillet conclusif qui narrerait seulement le tournoi proclamé par Arthur à Camaalot et non la fin de l'aventure de Sagremor. Celle-ci serait plutôt prévue pour rester en suspens de telle sorte à suggérer la continuité entre Melyador et l'univers de la Table Ronde.

52 On peut citer à titre d'exemple le meurtre annoncé de Pellinor par Gauvain dans la Suite du Merlin. Cet épisode ne se réalise jamais dans aucun texte contemporain de la Suite du Merlin, comme le souligne Nathalie Koble, «L'illusion prophétique, ou la maitrise du temps. Les prophéties dans la Suite du roman de Merlin", in 
que l'aventure de Sagremor soit inachevée, car le personnage appartient à la génération d'après, son histoire ne peut faire partie de l'univers pré-arthurien et ne peut donc s'y clore. Le roman imite les techniques temporelles de la prose: le temps n'est plus indéfini, il s'agit bien de celui des jeunes années d'Arthur. L'histoire ne se situe plus tout à fait dans un hors-temps éternel; l'apparition des jeunes Gauvain et Yvain à la fin du texte démontre l'écoulement du temps, la tendance esquissée vers la linéarité. À l'horizon de cette temporalité se trouvent néanmoins les aventures racontées en vers et non celles que déroule la prose. L'idéologie propre à ce chronotope versifié demeure, malgré l'esquisse d'une temporalité plus linéaire. Il est alors significatif que les personnages évoqués dans Melyador et qui sont propres à la prose (Guiron, Méliadus et Galehaut) ne soient pas impliqués dans la chute du royaume.

La trame d'Escanor semble elle aussi prendre ses distance avec la circularité du roman en vers: le lignage d'Escanor le Bel est détaillé et les querelles trouvent leur source dans un passé parfois générationnel. La fin du texte, surtout, laisse entrevoir la tentative d'une lecture chronologique de la diégèse: Escanor le Bel et sa femme meurent, de même que la reine des Traverses. La mort d'Escanor est décrite amplement, comme le sont aussi les honneurs qu'il reçoit - nous reviendrons sur ce passage, chapitre III, "Imitation ponctuelle: Escanor et le miraculeux», p. 595-610. Le narrateur apporte un soin particulier à mettre un terme aux aventures qui concernent les nouveaux venus dans le monde arthurien. Il précise ainsi pour Escanor le Grand qu'il «redemena tant qu'il vesqui mout bone vie» (v. 25898-25899), proposant de cette manière la perspective d'un achèvement. Il n'en va pas de même pour les personnages arthuriens connus: le lecteur n'assiste pas à leur mort et l'on évite soigneusement de narrer la fin du règne, bien que l'attardement sur le déroulement de la vie d'Escanor jusqu'à sa mort encourageât une conclusion pour les autres personnages du roman. Le narrateur s'en justifie ainsi:

Girardins d'Amiens, qui envie

N'a d'ajouster el conte fables

$\mathrm{Ne}$ mos qui ne soit veritables

Ne vouz en set avant retraire,

Fors que Giflés se prist a traire,

Jeunesse et genèse du royaume arthurien. Les Suites romanesques du Merlin en prose, dir. Nathalie Koble, Orléans, Paradigme, 2007, p. 157-178. 
Si tost qu'il perdist sa compaingne,
En la cort au roi de Bretaingne
Ou il fu puis tout son eage.
Mais lonc tans ot au cuer grant rage
De la mort de sa douce amie.
Mais je, Girars, qui n’apris mie
Sa mort, ne le quier metre en conte. (Escanor, v. 25900-25911)

Le silence sur le devenir du monde arthurien s'explique par la volonté de l'auteur de ne raconter que ce dont il est sûr, ce qui renforce l'illusion d'authenticité du récit. Tout comme celle d'Arthur, dont les Bretons n'ont de cesse d'attendre le retour, la mort de Gifflet demeure incertaine; il retourne à la cour, lieu d'où tout part et où tout revient, pour y poursuivre les aventures sans fin du monde arthurien ${ }^{53}$. Les piliers du roman arthurien en vers n'échappent donc pas au temps circulaire: l'écriture en vers les renvoie à un non-temps qui leur accorde une forme d'immortalité littéraire, la promesse d'un éternel recommencement. Quant à Escanor, qui n'appartient jamais à la Table Ronde, il peut adopter une trajectoire différente d'un personnage éprouvé de la tradition arthurienne.

L'auteur de Claris et Laris joue lui aussi de la temporalité arthurienne; les aventures semblent s'inscrire dans la même chronologie que les romans arthuriens en vers dès Chrétien de Troyes. Ainsi, les chevaliers populaires du monde fictionnel comme Yvain, Perceval, Erec ou Sagremor font plusieurs apparitions. Le passage où l'amie d'Yvain intervient pour rappeler l'aventure de la fontaine racontée par Chrétien de Troyes (v. 604-630) signale explicitement que l'histoire se passe après les faits rapportés par le Champenois. La nature des aventures les associe aisément au temps de paix, dont les douze ans semblent indéfiniment extensibles, propre aux romans arthuriens en vers. L'insertion de la guerre du roi Arthur contre Rome brouille quelque peu ces certitudes. Cette guerre est narrée par le Brut de Wace après la pacification du royaume, et après les douze ans de paix lors desquelles sont supposées prendre place les «merveilles provees» et les «aventures trovees» (Brut, v. 1059-1070) $)^{54}$ racontées dans les romans.

53 Dans La Mort Artu, c'est à Gifflet qu'il revient de jeter l'épée d'Arthur mourant dans le lac. Peut-être Girart d'Amiens se souvient-il alors que Gifflet doit rester en vie pour accomplir ce destin.

54 Voir supra, p. 122, pour l'extrait entier. 
L'épisode se situe dans le premier tiers de Claris et Laris (v. 56616897). Il présente plusieurs points communs avec le passage du Brut, dont il semble s'inspirer directement. Les conditions du conflit sont les mêmes: l'empereur romain (Luce dans un cas, Théreus dans l'autre) apprend la conquête de la France par Arthur et entend lui demander un tribut. Nous le verrons, les romans tardifs insistent peu sur les conquêtes offensives d'Arthur, contrairement au Brut. Il en résulte que dans Claris et Laris, le narrateur se garde de rappeler trop souvent que la France appartenait à Rome et qu'Arthur l'a prise de force à l'empereur. Dans la même idée, alors que dans le Brut, Arthur souhaite conquérir Rome après sa victoire sur le sol français, dans Claris et Laris, il se contente de chasser l'envahisseur. Dans les deux textes, Arthur allègue ses ancêtres pour justifier ses positions, mais il ne le fait pas dans le même but:

«Ja furent il des Trö̈ens:

Lor viel ancestres et li miens

Furent d'une seule lignie.

Romulus fu, que que nus die,

Cosins Brutus qui ceste terre

Conquist par droiture de guerre,

Ainsi conquist Romulus Ronme.

Pour ce ne vueill ge, c'est la some,

Que sor nous aient seignorage

Quant estret somes d'un lignage.» (Claris et Laris, v. 5829-5838)

"Cil [Constantin et Maximien] furent mi parent procein,

E chascun ot Rome en sa mein.

Ore pöez oïr e saveir

Que altresi devum Rome aveir

Cum il Bretaine, par raisun,

Si [a] noz anceisurs gardum.» (Brut, v. 2047-2052)

Dans le Brut, les ancêtres sont convoqués pour légitimer ses prétentions sur Rome, tandis que dans Claris et Laris, c'est la parenté entre les lignages breton et romain qui rend absurde la supériorité de l'un sur l'autre. Ici encore, l'auteur tardif véhicule une idéologie de la paix: Arthur est un roi conciliateur et pacifique, sans prétention sur d'autres royaumes que celui de Logres. Point d'apologie de la conquête; c'est bien plutôt l'harmonie, à la fois nationale et internationale, qui est valorisée. Lorsqu'Arthur passe de l'historiographie au roman, il transforme son rapport au gouvernement 
du royaume et, de roi conquérant qu'il était, devient un souverain dont le pouvoir s'impose de lui-même. Malgré ces divergences, l'écriture de ce passage dans le roman tardif démontre qu'il prend celui du texte de Wace pour modèle.

L'auteur du XIII ${ }^{\mathrm{e}}$ se départit de l'historiographie surtout dans la suite qu'il donne à la guerre romaine: jamais il n'est fait allusion à la fin du règne arthurien, alors que dans le Brut, la trahison de Mordred survient juste après la défaite des Romains, de même que, dans la Mort Artu, la longue absence d'Arthur pour sa guerre contre Lancelot puis contre les Romains laisse la place à son neveu et fils de s'emparer du pouvoir. Le récit de Claris et Laris suit au contraire son cours en narrant les péripéties topiques des chevaliers. Les aventures de Claris et Laris trouvent donc mal leur place au sein de la chronologie arthurienne habituellement retenue. Peut-être faut-il comprendre l'épisode romain comme une tentative de réécriture de la destinée arthurienne; même si Arthur doit abandonner son royaume quelque temps pour le défendre contre l'empereur romain, il le retrouve intact et évite de le confier à Mordred. À son retour en Bretagne, à la cour de Caradigan, la reine l'attend et «joie li maine» (v. 6894); elle n'a commis aucune trahison à son encontre, contrairement au personnage de l'historiographie. Les aventures et l'errance des chevaliers peuvent donc perdurer sans que les menace la chute du monde arthurien. L'insertion de la guerre contre Rome ignore ainsi la fin racontée par le Brut et prolonge indéfiniment le temps des aventures.

Le passage ne doit en tout cas pas être pris comme un épisode annexe sans grand intérêt dans le déroulement du récit: il prend place juste après les quelques vers qui définissent l'importance de suivre son sujet principal, sa «matiere», sans s'en dévoyer, «y faillir» - nous les citions en page 162. Il faut donc comprendre que le conflit armé qui oppose Arthur à l'empereur romain fait partie de la trame narrative principale et ne constitue pas une digression, puisqu'elle suit directement le vers « Si vueill a la moie [ma matière principale] venir» (v. 5668). La désignation de la guerre romaine comme la matière principale du récit corrobore l'hypothèse d'une réécriture de la destinée arthurienne: Claris et Laris intègre un événement déterminant de la chronologie du monde fictionnel et en détourne l'issue pour asseoir la temporalité cyclique propre au roman arthurien en vers.

Même s'il s'occupe parfois de la jeunesse du règne arthurien (Melyador), le roman arthurien en vers, même tardif, maintient une chronologie 
incertaine et surtout la cyclicité des aventures: la cour arthurienne n'évolue pas d'un roman à l'autre, ni au sein d'un même roman. Le temps n'est donc pas linéaire, mais cyclique, et les aventures s'engendrent à l'infini. Les exemples de la guerre romaine de Claris et Laris et la fin d'Escanor illustrent parfaitement ce travail particulier de la temporalité qui distingue romans arthuriens en vers et en prose: le monde proposé par le vers n'est pas voué à la chute et déjoue toute velléité chronologique. Il y a probablement quelque parenté avec les romans en prose tardifs, comme le cycle de Guiron le courtois, qui écarte le Graal et place ses intrigues dans un cadre mondain et insouciant ${ }^{55}$. Le choix de la prose pour ce texte oblige néanmoins à prendre pour horizon le Lancelot en prose et l'assombrissement de la Mort Artu, ce que n'impose pas le vers: Guiron le courtois s'inscrit en amont de ces textes, les prend comme point d'arrivée. Le choix du vers exclut cette perspective; le vers donne pour futur textuel à Melyador celui des romans en vers, beaucoup plus que la Mort Artu. Le critère de la temporalité demeure donc un élément de distinction entre prose et vers, même dans nos textes tardifs, et même s'il y subit quelques adaptations.

\section{Expansion géographique et référentialité de l'espace}

Dans une perspective chronotopique, au travail de la temporalité se corrèle la présentation de la géographie. Le roman arthurien est supposé prendre place en Bretagne, dont les contours ne sont pas toujours clairs et dont les noms de lieux sont bien souvent fictifs. Camaalot, Gorre, Logres, Cardeuil ou Carlion sont des toponymes fictifs, mais situables sur une carte, côte à côte avec Tintagel, Salisbury ou Londres: le roman arthurien ne construit pas un pays imaginaire, mais fictionnalise la Bretagne insulaire ${ }^{56}$.

55 Sophie Albert, "Ensemble ou par pièces". Guiron le Courtois (XIII'-XVe siècles): la cohérence en question, p. 191-402.

56 Voir Geoffrey Ashe, A Guidebook to Arthurian Britain, Londres, Longman, 1980, qui tente de situer les lieux arthuriens, ainsi que les entrées "Carduel», "Camaalot», "Carlion», "Gorre», "Logres» dans Olivier Battistini et al., Dictionnaire des lieux et pays mythiques, Paris, Robert Laffont («Bouquins»), 2011. Fritz Peter Knapp fait également une mise au point sur les lieux arthuriens, que l'on peut pour certains associer à des villes réelles, mais dont le nom est tiré de leur origine celtique: c'est le cas de Caradigan, qui correspond à Aberteifi. "Toponymie und Topographie im französischen und deutschen Artusroman", $J I A S, 4 / 1,2016$, p. 3-24. Bien que certains lieux ne soient pas identifiés (Camaalot), peut-être faut-il plutôt parler d'une volonté de donner une portée 
Malgré ces quelques noms aux résonances arthuriennes ${ }^{57}$, le chevalier évolue plus souvent dans une forêt insituable et impossible à délimiter, ce qui favorise le surgissement de la merveille et de l'inattendu. Il s'agit donc de reconduire la dimension incertaine de la géographie, tout en localisant la diégèse en Bretagne, sous le règne d'Arthur. Les romans tardifs sont loin de reproduire sans changement ces données: l'espace s'étend hors des bornes de la Bretagne, ce qui rénove le genre.

L'ouverture du roman arthurien tardif sur d'autres espaces se manifeste par la délocalisation, dans Floriant et Florete; le roman se déroule presque exclusivement en Sicile, dont on détaille la géographie par plusieurs mentions de lieux réels: la Calabre, Palerme, Monreale, le pont de Ceprano, les Pouilles, Catona, Messina ${ }^{58}$. L'espace breton demeure bien plus incertain et l'itinéraire pour s'y rendre n'est pas détaillé, contrairement aux déplacements italiens, ce qui témoigne de sa relative fictivité: ses contours ne sont pas nets et le chemin pour y pénétrer semble se suffire de l'errance d'aventure en aventure pour construire le voyage dans une durée ${ }^{59}$. En comparaison avec le cheminement italien de

mythique, étrangère, à la Bretagne, par une toponymie d'origine celtique. Cette topographie donne l'illusion d'une Bretagne originelle, d'une géographie propre à l'époque d'Arthur. Quelles que soient les identifications possibles des noms comme Cardeuil, Caradigan ou Carlion, on peut considérer avec Peter Knapp (p. 8) que le public médiéval ne les comprenait pas comme des lieux réels. Voir aussi, sur la géographie arthurienne entre réel et fiction, Danièle James-Raoul, Chrétien de Troyes, la Griffe d'un style, p. 371-394.

57 Annie Combes démontre à quel point la ville de Camaalot est fondamentalement associée au roi Arthur. "Camaalot", in Dictionnaire des lieux et pays mythiques, p. 222-224.

58 Aux vers 6728 à 6763 est déployé l'itinéraire qui mène de Sicile à Rome, en passant par la Calabre et les Pouilles. Richard Trachsler et Annie Combes commentent la géographie réelle de Floriant et Florete aux pages XXVII-XXIX et à la note 1, p. 407 de l'édition citée. Ils soulignent la différence de traitement des espaces sicilien et breton pour constater l'intérêt indéniable de l'auteur pour la Sicile, inhabituel à cette époque. Voir surtout l'article d'Arthur Långfors, «La Katone, non Lakatoué, dans le roman de Floriant et Florete", Neuphilologische Mitteilungen, 49, 1948, p. 53-55, qui a mené l'enquête pour déchiffrer les noms de lieux.

59 Marie-Luce Chênerie esquisse cette construction symbolique des itinéraires: «L'espace est bien plus encore ici d'ordre abstrait et symbolique: l'errance n'a guère besoin du support des voies et des chemins de la réalité quand elle est faite d'épreuves, d'exploits ou de mésaventures servant à vérifier les qualités chevaleresques ou l'élection du héros; ou bien quand cette errance paraît relever de la 
Floriant, le déplacement en terre bretonne est confirmé dans son statut imaginaire.

C'est également un moyen de marginaliser le cadre arthurien: le roman n'évoque la cour d'Arthur que tardivement et celui-ci n'apparait d'abord qu'en tant que frère de Morgane la fée, qui emmène et élève Floriant bébé. Elle lui intime ensuite, à l'âge de quinze ans, de se rendre à la cour d'Arthur. Celle-ci n'intervient en propre dans le récit qu'au vers 1187, au moment où Moradas, vaincu par Floriant, vient s'y rendre prisonnier: «Ce fu droit a l'Asenscion / Que roi Artus et si baron / A Carradigant cort tenoient. " (FF, v. 1187-1189). La cour de Carradigan, mentionnée dans Erec et Enide, maintient la Bretagne d'Arthur dans la géographie construite par la tradition, de même que celle de Camaalot, évoquée au vers $7673^{60}$. L'espace arthurien et breton n'est pas le lieu de l'aventure: les scènes qui s'y déroulent voient la reddition des vaincus, envoyés par Floriant en hommage au roi, un tournoi destiné à appâter Floriant (v. 2015-2495), puis la consécration du rachat de sa recreantise à la fin de son errance avec Florete (v. 7871-8011). Le roi breton remplit donc dans ce roman plus ou moins le même rôle que dans Melyador: réduit à sa fonction de garant de la chevalerie et de la courtoisie, il n'est plus l'instigateur des aventures, qui se déroulent indépendamment de sa cour et hors de son espace. Floriant ne devient pas un chevalier de la Table Ronde et ne fait appel à Arthur que lorsqu'il doit être confirmé dans son statut de chevalier ou de roi, ou pour rétablir l'équilibre rompu entre arma et amor.

Beate Schmolke-Haßelmann a pu, pour ces raisons géographiques, considérer Floriant et Florete comme un roman arthurien des limites, sortant du cadre («aus dem Rahmen fällt ») : à la situation sicilienne et au lien tardif avec le domaine arthurien s'ajoute le fait que le début raconte l'amour des parents, la naissance puis la jeunesse et les premiers exploits du héros $^{61}$. De fait, cette intrigue initiale rappelle celle de certains lais ou de

fantaisie du héros.» (Le Chevalier errant, p. 210) Le chemin suivi par le chevalier errant est en fait toujours imprécis, voire invraisemblable. Voir p. 210-241.

60 Beate Schmolke-Haßelmann étudie les lieux arthuriens et la fréquence de leur apparition à la page 37 de Der arthurische Versroman.

61 Beate Schmolke-Haßelmann, Der arthurische Versroman, p. 39. Friedrich Wolfzettel doute lui aussi de la dimension arthurienne de Floriant et Florete, "Zum Problem der Epizität im „postklassischen“ Artusroman», in Fiktionalität 
récits mettant en scène le thème de la famille décomposée (La Manekine ou le Lai de Frêne). Peut-être imite-t-elle plutôt le début de Cligès, qui s'attarde d'abord sur la jeunesse puis la mort d'Alexandre avant de se concentrer sur l'histoire de son fils, Cligès. Sous cet angle, cet intertexte devient déterminant pour rendre compte de la spécificité de Floriant et Florete: l'auteur semble s'inspirer tout autant du début de l'histoire et de la dimension généalogique que de la délocalisation de l'intrigue aux bords de la Méditerranée. Dans les deux cas, le héros provient d'une contrée orientale et ne se rend à la cour d'Arthur que pour parfaire son éducation chevaleresque. Floriant et Cligés doivent tous deux récupérer leur héritage et peuvent recevoir l'assistance militaire d'Arthur dans cette entreprise. La trame narrative de Floriant et Florete s'explique alors par une réappropriation de Cligès, dont nous soulignions aux pages 210-211 le caractère tardif avant l'heure.

L'intertexte de Floriant et Florete est enrichi encore par le Lancelot en prose; là encore, le texte commence sur les démêlés des parents de Lancelot avec le roi Claudas, la mort du père et l'enlèvement de l'enfant par la Dame du Lac, qui prend les traits de la fée Morgane dans Floriant et Florete, elle qui élève le jeune Floriant à Mongibel ${ }^{62}$. Plusieurs éléments génériquement hétérogènes se mêlent à la trame narrative d'inspiration arthurienne. Le prologue brouille l'inscription générique, en recourant à un proverbe antique:

Salemons nous dist que tant est

Li fols sages com il se test;

S'il n'est sages, si cuide l'en,

Pour ce qu'il se taist, qu'il ait sen;

Et quant au parler se deslie,

Si fet connoistre sa folie

Tant qu'il en est por fol tenuz

Et des jones et des chanuz. ( $F F$, v. 1-8)

im Artusroman des 13. bis 15. Jahrhunderts. Romanistische und germanistische Perspektiven, Wiesbaden, Reichert Verlag, 2013, p. 29-41.

62 Voir l'introduction à l'édition de Richard Trachsler et Annie Combes, éd. cit., p. xxxix, et Laurence Harf-Lancner, Les fées au Moyen Âge, p. 277-279. Cette dernière étudie le rôle de Morgue comme fée marraine et le motif du don des fées dans le roman. Morgue se départ exceptionnellement de son rôle de fée amante et géôlière, mais c'est uniquement parce qu'elle est calquée sur le modèle de la Dame du Lac dans Floriant et Florete. 
L'évocation de Salomon comme figure tutélaire du récit l'inscrit dans la lignée des romans antiques, faisant appel à une autorité dont se passent les romans arthuriens - imitant en ce sens le Roman de Troie. Aucune mention du cadre arthurien ne vient ensuite orienter le lecteur, contrairement au prologue de Melyador, l'intrigue se situant résolument en Sicile: "En Sezille ot jadis .I. roi» (FF, v. 33). La première fête de cour n'est d'ailleurs pas présidée par Arthur, mais par Elyadus, le père de Floriant: elle célèbre Noël, contrastant ainsi avec les habituelles Ascension et Pentecôte arthuriennes.

Floriant et Florete est-il toujours un roman arthurien, alors même qu'il s'applique à brouiller les pistes et à marginaliser la cour d'Arthur? La situation sicilienne du roman n'est toutefois pas incompatible avec les visées traditionnelles du genre, que Beate Schmolke-Haßelmann souligne elle-même: comme nous l'avons évoqué en note 330, page 136, Floriant et Florete peut être lu comme un roman engagé politiquement. La géographie sicilienne s'explique donc aisément par la volonté de plaire à un commanditaire italien que nous pensons défavorable à la domination angevine. Elle s'inscrit surtout dans l'expansion topographique du roman arthurien tardif, qui s'emploie à étendre l'espace de domination de la fiction arthurienne, à coloniser une Europe toujours fascinée par le mythe ${ }^{63}$. L'espace fictionnel du roman arthurien qu'est Floriant et Florete s'étend donc de la Sicile à la Bretagne arthurienne et à Byzance, hérité par Floriant grâce à son mariage avec Florete, la fille de l'empereur Philimenis. Gauvain favorise quant à lui l'annexion d'une terre à l'espace arthurien en épousant la fille du roi de Hongrie dont celui-ci lui fait cadeau. Floriant et Florete n'est pas le seul roman tardif à ouvrir les frontières de la Bretagne fictionnelle: Claris devient roi de Gascogne grâce à son mariage avec Lidaine et roi d'Espagne suite à la guerre menée conjointement avec les troupes d'Arthur. Quant à Laris, il conquiert le Danemark par les armes, en réprimant les prétentions du jeune roi danois sur Marine, la fille d'Urien ${ }^{64}$.

63 Sur la diffusion du mythe arthurien en Europe à la fin du Moyen Âge, on consultera La matière arthurienne tardive en Europe, 1270-1530, dir. Christine Ferlampin-Acher, Rennes, PUR, 2020.

64 Sur la géographie dans Claris et Laris, voir Corinne Pierreville, Claris et Laris, somme romanesque, p. 44-56. 
On le constate: la géographie du roman arthurien tardif se précise et ne se contente plus d'un espace breton incertain. La proportion de noms de lieux réels concurrence celle des lieux fictifs, et les adversaires sont présentés par leurs provenances. Dans Melyador, les participants au défi d'Hermondine se déplacent depuis la Normandie, l'Italie, Carthage, la Norvège, l'Allemagne ou la Frise ${ }^{65}$. Dans Floriant et Florete, les alliés de Maragot viennent de terres orientales, de Turquie, d'Arménie, d'Inde, d'Afrique, de Tibériade, de Libye, de Syrie. En revanche, les chevaliers de la Table Ronde se voient peu associés à une contrée, même imaginaire. De nombreuses listes de dénombrement des bataillons viennent agrémenter le récit de la guerre contre Maragot; si l'origine des ennemis ponctue la revue des troupes, il n'en est rien du côté de l'armée d'Arthur. Ainsi, "Rois Corincas qui tient Turkie / Et Jonas, rois de Taubarie, / Rois Natalons, rois Santipus / Et li dus d'Atenes» (FF, v. 3255-3258) s'opposent par exemple aux «Rois Carados et rois Cador / Et li bons rois Acecledor, / Rois Mars et rois Baudemagus» (FF, v. 3269-3271). Ces rois arthuriens gouvernent des royaumes imaginaires, relégués à la fiction, qu'il n'y a donc pas lieu de mentionner. La collision entre lieux réels et lieux fictifs dresse un clivage entre l'espace italien et tangible et l'espace breton incertain, innommable.

Cela ne signifie pas que le cadre italien réaliste n'est pas occupé par la merveille et l'aventure: Floriant ne manque pas de croiser lors de ses voyages des phénomènes tout à fait arthuriens dans leur manifestation. De la même manière, un déplacement est opéré pour l'Avalon mythique: cet au-delà arthurien, où Geoffroy de Monmouth place la retraite d'Arthur après sa blessure à la bataille de Camblan ${ }^{66}$, est situé dans Floriant et Florete à Mongibello, c'est-à-dire le mont de l'Etna ${ }^{67}$. C'est là que Morgane attend Arthur, comme elle le précise à Floriant:

65 Voir à ce sujet les pages 252 à 254 de l'édition de Nathalie Bragantini-Maillard, Melyador, éd. cit.

66 Sur l'Île d'Avalon, voir l'entrée "Avalon" dans le Dictionnaire des lieux et pays mythiques, par Jean-René Valette, p. 113-116, et Francis Dubost, L'Autre, l'Ailleurs, l'Autrefois, p. 297.

67 Plusieurs textes médiévaux assimilent Avalon à l'Etna. Voir les articles d'Arturo Graf, "Artu nell'Etna", in Miti, leggende, e superstizioni del Medio Evo, Torino, Loescher, 1893, t. 2, p. 303-325, Antonio Pioletti, "Artù, Avallon, l'Etna", Quaderni Medievali, 28, 1989, p. 6-35, et Sara Sturm-Maddox, "Arthurian Evasions: the End(s) of Fiction in Floriant et Florete», art. cit. 
Li rois Artus au defenir,

Mes freres, i ert amenez

Quant il sera a mort navrez,

Sachiés que je l'i amenrai. (FF, v. 8246-8249)

Alors qu'Avalon «représente un lieu hors de la fiction, un ailleurs où l'action n'aborde jamais ${ }^{68}-\mathrm{du}$ moins dans le genre arthurien -, sa transposition à Mongibel autorise que l'on assiste à l'intrigue qui s'y passe, en l'occurrence, l'éducation de Floriant puis son retrait du monde. L'Autre Monde appelé à accueillir le roi breton devient cartographiable: il se trouve au cœur de l'Etna. Par cette précision, le récit de Floriant et Florete s'inscrit dans l'histoire arthurienne: la fin du texte évoque explicitement la fin du royaume arthurien, la blessure mortelle du roi dont parlent le Brut et la Mort Artu. In extremis, le roman en vers renonce à la temporalité cyclique qui caractérise le genre: pour autant, la fin du monde n'est qu'un horizon qui n'est pas près de se réaliser. En faisant d'Avalon un lieu féerique idéal, protecteur et maternel, le roman présente un lieu rassurant pour accueillir Arthur; le roi breton ne mourra pas, mais ses aventures pourront se poursuivre dans l'Autre Monde, aux côtés de Floriant. Sans la raconter directement, l'auteur anonyme offre une alternative à la fin du règne arthurien, qui ne ferait que se prolonger en Avalon; s'il est possible de raconter les déambulations de Floriant dans cet espace merveilleux, il doit en aller de même pour Arthur.

La convocation de Londres est la seule incursion d'un toponyme réel en Bretagne: c'est là qu'Arthur donne rendez-vous à ses troupes en vue de la guerre contre Maragot (v. 2623), c'est là aussi qu'il retourne après la victoire (v. 6359), là enfin qu'il tient une cour pour Pâques (v. 7873). Les premières interventions de cette ville se justifient par son port, qui favorise le déplacement guerrier, par voie de mer: elles replacent le cadre arthurien dans un horizon atteignable et cartographiable. La tenue d'une fête arthurienne dans un lieu réel est plus étonnante: elle succède à l'Ascension à Caradigan (v. 1189ss) et à la Pentecôte dans ce même lieu (v. 1535). La Pâques de Londres couronne la deuxième errance de Floriant, suite à sa recreantise. Le toponyme réel réinsère la Bretagne arthurienne dans la géographie historique, après l'avoir tenue

68 Jean-René Valette, "Avalon", in Dictionnaire des lieux et pays mythiques. 
à l'écart tout le long du récit. Londres vient finalement remplacer les fictifs Caradigan et Camaalot.

La même propension à rendre tangibles certains lieux mythiques ou fictifs se traduit dans Melyador par l'explicitation de leur devenir:

Signandon si est uns chastiaus

Dedens Escoce, fors et biaus.

S'adont le fu, il est encores:

Struvelin est il nommés ores. (Melyador, v. 14762-14765)

Si appelloit on sa maison,

Qui fu et est encores grande,

Pour celi temps la Blanche Lande

Et siet ou pendant priés d'un bos.

De puis fu nommee Miauros

Et est une grande abbeÿe

De noirs monnes bien herbegie. (Melyador, v. 29015-29021)

On réfère ici à Stirling et l'abbaye de Melrose, probables souvenirs de Froissart lors de son séjour en Écosse ${ }^{69}$. Le toponyme "Blanche Lande» sonne typiquement arthurien; son évolution en "Miauros» doit convaincre que les noms de lieux périphrastiques, usuels dans le roman $\operatorname{arthurien}^{70}$, ne sont que les ancêtres de contrées connues, comme c'est encore le cas pour le château de Monchus, qui désigne l'actuelle Roxburgh

69 Voir l'édition de Nathalie Bragantini-Maillard, Melyador, éd. cit., p. 252 à 254. Voir aussi Armel Hugh Diverres, "The geography of Britain in Froissart's Meliador", in Medieval Miscellany Presented to Eugene Vinaver, Manchester, Manchester University Press, 1965, p. 97-112, qui tente de reconnaître des toponymes réels sous les lieux évoqués par Froissart. Michel Zink souligne que le voyage de Froissart en Angleterre et en Ecosse lui fournit des précisions géographiques pour compléter son roman. L'insertion de ses propres souvenirs accorde une nouvelle place à la subjectivité de l'auteur. "Les toiles d'Agamanor et les fresques de Lancelot", Littérature, 38, 1980, p. 44, et Froissart et le temps, p. 112-113. Voir encore Emmanuèle Baumgartner, «Écosse et Écossais: l'entrelacs de la fiction et de l'histoire dans les Chroniques et le Méliador de Froissart", in L'image de l'autre européen. XV'-XVIII siècles, dir. J. Dufournet, A. C. Fiorato et A. Redondo, Paris, PSN, 1992, p. 11-21.

70 Sur ces noms de lieux chez Chrétien de Troyes, voir Danièle James-Raoul, Chrétien de Troyes, la griffe d'un style, p. 387-394. 
en Écosse (Melyador, v. 28983-29008). Ces exemples ${ }^{71}$ illustrent la volonté commune des auteurs tardifs de donner une vraisemblance à l'univers arthurien, de l'inscrire dans un espace européen évocateur pour le public, et d'ainsi renforcer son adhésion au récit: l'intérêt est renouvelé par la reconnaissance de toponymes connus. Cela ne signifie pas que ces romans revendiquent une vérité historique de leurs récits: les lieux fictifs, qu'il s'agisse des cours d'Arthur (Camaalot au vers 30698 de Melyador, Carlion à maintes reprises, Logres au vers 30700) ou des jalons de l'errance (le Haut Manoir, le Manoir dou Bois, le Pas du Brun Rocier), cohabitent avec les lieux réels. L'espace arthurien demeure un ailleurs mythique; l'écriture tardive esquisse simplement la tentative de le conjoindre au réel.

L'attention pour les contrées réelles et lointaines semble s'inscrire dans un besoin plus large d'exotisme ${ }^{72}$; la Sicile, par sa situation géographique, est au Moyen Âge une terre d'échange avec l'Orient. Échanges commerciaux d'abord, qui permettent la transmission de denrées et d'étoffes, mais aussi culturels: l'île est marquée dans son architecture par les influences françaises, byzantines et arabes ${ }^{73}$. C'est également une terre qui abrite une grande variété de groupes religieux: chrétiens de langue grecque, chrétiens latins, juifs arabophones, musulmans ${ }^{74}$. La Sicile est l'image d'un lieu qui offre la possibilité de la rencontre avec un Ailleurs apprivoisé, soumis à la domination chrétienne. De là peut naître l'exotisme, une fascination exercée par la confrontation à une culture étrangère et la contemplation de ses richesses, matières premières ou architecture. L'altérité faire naître

71 On peut encore signaler l'épisode d'Escanor où Gauvain doit se rendre en Petite Bretagne pour en réprimer la rébellion. Le voyage implique de traverser la mer (v. 1743), précision inhabituelle dans le roman arthurien. Dans Biaudouz, un renvoi encore plus concret intervient: un jeune homme prévient Biaudouz que "Tamise vos covient passer» (v. 3653), s'il souhaite se rendre au tournoi d'Arthur, près de Londres.

72 Voir notre définition du concept, note 270, p. 115.

73 La cathédrale de Monreale est le meilleur exemple de cet éclectisme. Voir JeanYves Frétigné, Histoire de la Sicile, p. 180-181.

74 Sur la Sicile comme domaine interconfessionnel et la régulation politique particulière à cette situation, voir Annliese Nef, «Imaginaire impérial, empire et œcuménisme religieux: quelques réflexions depuis la Sicile des Hauteville», Cahiers de recherches médiévales et humanistes, 24, 2012, p. 227-249, et Alex Metcalfe, Muslims and Christians in Norman Sicily. Arabic speakers and the end of Islam, Londres-New York, Routledge Curzon, 2003. 
la curiosité pour l'inconnu ${ }^{75}$. La situation sicilienne de Floriant et Florete est un bon prétexte pour susciter un tel sentiment, en décrivant les odeurs et les tentures orientales de la salle des fêtes après les mariages de Floriant et Gauvain (FF, v. 6113-6124), les matériaux, marbre gris, vert, rouge, jaune et blanc, émail noir, argent massif, or, ébène et pierres précieuses, qui agrémentent la ville de l'Île des Belles Pucelles (FF, v. 1264-1314), ou encore les denrées qu'offrent ses habitantes («nois mugaites en la fin / Et gigiembras alixandrin», v. 1376-1377) ${ }^{76}$.

L'insularité est aussi l'occasion de remplacer l'errance forestière par une navigation maritime, fait assez rare dans le roman ${ }^{77}$. La mer se substitue donc à la forêt comme espace aventureux, dans Floriant et Florete, jouant ainsi audacieusement avec une condition essentielle du genre: le chevalier est un terrien, qui se déplace à cheval. La forêt constitue son

75 Voir Jean-Marc Moura, Lire l'exotisme. Catherine Gaullier-Bougassas traite de la fascination qu'exerce l'Orient sur le Moyen Âge et l'exotisme qui en résulte en particulier dans Floire et Blancheflor, Partonopeu de Blois et Cligès. La tentation de l'Orient dans le roman médiéval. Sur l'imaginaire médiéval de l'Autre, Paris, Champion, 2003, chapitre 1, "exotisme et paradis orientaux", p. 23-68.

76 Voir Megan Moore, "Hellenism, Islam, and Exoticism in French Medieval Romance", Journal of Modern Hellenism, 28, 2010-2011, p. 47-73.

77 Ainsi que le souligne Francis Gingras, qui traite des «romans maritimes», dont la structure est rythmée par la navigation, comme Apollonius de Tyr. Il note que les pérégrinations maritimes à l'antique sont remplacées au XII ${ }^{\mathrm{e}}$ siècle par l'errance chevaleresque qui fonde le roman. L'hagiographie continue quant à elle de recourir à cette voie de cheminement, ce qui peut expliquer selon le critique la prégnance de l'errance maritime dans les textes du Graal qui s'inspirent de la tradition hagiographique. "Errances maritimes et explorations romanesques dans Apollonius de Tyr et Floire et Blancheflor", in Mondes marins du Moyen Âge, dir. Chantal Connochie-Bourgne, Aix-en-Provence, Presses universitaires de Provence ("Senefiance», 52), 2006, p. 169-185. Michelle Szkilnik note également que les personnages ne traversent que très rarement la Manche pour se rendre en Petite Bretagne, pas plus qu'ils ne prennent la mer pour voyager jusqu'à Constantinople. La critique donne l'exemple de Claris et Laris, où les ambassadeurs de Rome passent par la France pour se rendre en Grande Bretagne sans que la traversée de la Manche soit évoquée. "Arthur s'en va-t-en guerre. Expéditions navales dans les romans arthuriens en vers des XII ${ }^{\mathrm{e}}$ et XIII ${ }^{\mathrm{e}}$ siècles", in Arthur, la mer et la guerre, dir. Alban Gautier, Marc Rolland et Michelle Szkilnik, Paris, Garnier, 2017, p. 97-110. Marie-Luce Chênerie précise que «la traversée maritime, vers l'Ecossee, une île, les illes, trouve encore place dans cinq romans, mais elle se réduit à quelques heures, à quelques vers». (Le Chevalier errant, p. 173) 
espace privilégié, tandis que l'eau figure plutôt un passage, une frontière $^{78}$. Ce cadre végétal a une valeur fonctionnelle: il est lié de manière consubstantielle au surgissement des aventures, qu'il paraît générer. Selon Marie-Luce Chênerie, cette association découle de la représentation symbolique médiévale de la forêt:

Dans la mentalité commune du Moyen Âge, la forêt est en effet le siège de redoutables puissances; les normes humaines y sont bouleversées. Donné sans références locales ni temporelles, le vocable devient dans sa généralité celui d'un lieu de prodiges ${ }^{79}$.

De la même manière, on n'assiste jamais à une bataille navale dans les romans arthuriens, les guerriers maîtrisant l'art de la chevalerie exclusivement ${ }^{80}$. L'évocation de la mer dans un cadre belliqueux, dans le roman arthurien, ne sert qu’à signifier le déplacement des troupes armées, qui se battent ensuite sur terre.

Floriant se rend pourtant à la cour d'Arthur à bord d'une nef merveilleuse ${ }^{81}$, et non à cheval, comme dans les romans arthuriens en vers traditionnels. L'embarcation se passe d'un équipage et répond aux désirs de son unique passager. Souvent sujet des verbes d'action ( La nef est cele part tournée», v. 971, «La nef s'en vait droit cele part», v. 1275), la nef donne l'illusion que le hasard guide son sillon, comme il dirige aussi les pas du chevalier errant dans la forêt. Dans le motif traditionnel, la nef magique emmène le personnage d'un point $A$ à un point $B$ : il en va ainsi pour Partonopeu, mené directement auprès de Mélior; il en va aussi de cette façon pour le chevalier enferré au début de la Vengeance Raguidel.

78 Voir à ce sujet Marie-Luce Chênerie, Le Chevalier errant, p. 143-160. La chercheuse s'intéresse aux lieux de l'aventure arthurienne jusqu'à la page 210 .

79 Marie-Luce Chênerie, Le Chevalier errant, p. 150. On lira les pages 143 à 150 sur cet imaginaire.

80 Voir à ce propos Michelle Szkilnik, "Arthur s'en va-t-en guerre», art. cit.

81 Au sujet de la nef merveilleuse, voir Gaël Milin, «La traversée prodigieuse dans le folklore et l'hagiographie celtique: de la merveille au miracle», Annales de Bretagne, 98, 1991, p. 1-25. Il s'agit d'un motif fréquent de la littérature arthurienne. Dans Claris et Laris, une nef merveilleuse intervient aussi lors d'une aventure de Sagremor (v. 12117-12292). À la différence de ce qu'il se passe dans Floriant et Florete, ces nefs sont le support d'aventures et ne permettent pas vraiment la déambulation du chevalier; tout au plus mènent-elles à une aventure spécifique. 
Dans Floriant et Florete, le héros chemine d'île en île, d'aventure en aventure, et remonte à chaque fois dans sa nef ${ }^{82}$, jusqu'à ce que l'embarcation juge le voyage terminé et s'en aille, laissant Floriant sur les terres d'Arthur. Ses pérégrinations se distinguent également des navigations qu'offrent les romans en prose du Graal, qui se prêtent souvent à une lecture chrétienne, en particulier dans Perlesvaus ou la Queste del saint Graal, où les nefs sont guidées par Dieu et signalent l'élection ${ }^{83}$. En revanche, l'errance par bateau est une voie privilégiée de renouvellement que l'on rencontre dans les romans en prose tardifs, notamment la Continuation du Roman de Meliadus, où les personnages ne croisent l'aventure que par ce biais. C'est à bord d'une nef qu'Arthur, Meliadus et le Bon Chevalier s'embarquent pour délivrer le Morholt. L'aventure, souvent un récit à faire ou à écouter, se manifeste ensuite sur la mer ou sur les îles auxquelles ils accostent ${ }^{84}$.

82 Michelle Szkilnik traite de la navigation de Floriant dans "Arthur s'en va-t-en guerre», art. cit. Elle souligne les passages où le héros descend de la nef, puis y remonte avec son cheval après avoir accompli l'aventure.

83 On pense notamment, pour la Queste del saint Graal, à la nef dans laquelle montent Galaad, Perceval et Bohort, accueillis par la sœur de Perceval. Cette nef a été fabriquée par Salomon et les conduit à un ennemi de Dieu. Elle embarque aussi Lancelot et le mène à une chapelle. Lancelot est nourri par la Grâce de Dieu sur le bateau. Voir Emmanuèle Baumgartner, L'arbre et le pain, p. 131-140. Sur la navigation dans les romans arthuriens en prose, voir Anne Berthelot, "Le Graal en archipel: Perlesvaus et les "illes de mer" ", in Mondes marins du Moyen Age, dir. Chantal Connochie-Bourgne, Aix-en-Provence, Presses universitaires de Provence ("Senefiance», 52), 2006, p. 57-67, Hélène Bouget, «Des rivages d'Arthur à l'Île des quatre cors: Perlesvaus au gré des flots", in Mondes marins du Moyen $\hat{A} g e$, dir. Chantal Connochie-Bourgne, Aix-en-Provence, Presses universitaires de Provence («Senefiance», 52), 2006, p. 69-78, Olivier Errecade, "Les euues qui de la mer issent vont et viennent... Présence(s) maritime(s) dans le cycle du LancelotGraal", in Mondes marins du Moyen Âge, dir. Chantal Connochie-Bourgne, Aix-en-Provence, Presses universitaires de Provence ("Senefiance», 52), 2006, p. 145-155. Dans Floriant et Florete, le voyage par mer n'a pas non plus le sens qu'il prend dans les romans de Tristan et Iseut, qui associent volontiers merlamer/ aimer. Voir Jean-Marc Pastré, "Traversées maritimes et géographie du mythe dans les romans de Tristan", in Mondes marins du Moyen Âge, dir. Chantal ConnochieBourgne, Aix-en-Provence, Presses universitaires de Provence ("Senefiance», 52), 2006, p. 367-376.

84 Voir Barbara Wahlen, L'Écriture à rebours, p. $182-184$ et 393 à 416 pour un résumé détaillé de la Continuation du Roman de Meliadus. La nef symbolise selon la critique la fracture entre la continuation et le texte premier. 
Si le déplacement guerrier par voie de mer n'est pas ignoré dans le roman arthurien en vers, la mer est présentée ici comme espace aventureux et non seulement comme canal pour un voyage. Bien que l'auteur de Floriant et Florete n'aille jamais jusqu'à proposer une aventure en pleine mer - comme le souligne Michelle Szkilnik, le personnage «n'accomplit pas ses faits d'armes sur les eaux $"{ }^{85}$-, ce moyen de transport est mis en évidence dans le texte par le surnom qu'adopte Floriant de "Chevalier qui la nef maine» (v. 1157) pour envoyer ses prisonniers à Arthur. La nef fait également l'objet d'une description détaillée: offerte par Morgane la fée, elle a la propriété de garantir de tous les périls dont menace la mer. Elle est constituée de riches matériaux: entièrement en bois d'ébène, elle est aussi garnie d'une tenture réalisée avec soin, dont la description rappelle un motif devenu topique depuis le Roman de Thèbes, celui de la description de tentes ${ }^{86}$. Enfin, on peut souligner la variété d'expressions employées pour désigner la navigation: le narrateur reprend plusieurs fois l'accumulation synonymique «ont molt bien siglé, et bien nagié et bien wacré» (v. 26932694; voir aussi v. 3085-3086). L'importance de la marine ne peut donc être négligée, d'autant moins lorsque l'on considère la rareté des évocations maritimes dans le roman. La prégnance de la mer signale bien l'intentionnalité de remplacer un espace - celui de la forêt - par un autre. Car la mer est le terrain de la rencontre aventureuse, condition sine qua non du genre: l'aventure des jeunes filles assiégées par deux géants ou celle du chevalier coupeur de tresses sont tout à fait topiques, mais sont résolument insulaires. La nef permet la jonction entre ces lieux isolés, recelant

85 "Arthur s'en va-t-en guerre», art. cit., p. 99.

86 Voir Emmanuèle Baumgartner, «Peinture et écriture: la description de la tente dans les romans antiques au XII ${ }^{\mathrm{e}}$ siècle", in De l'histoire de Troie au livre $d u$ Graal, Orléans, Paradigme, 1994, p. 179-187, ainsi que la note 2, page 59 de l'édition de Floriant et Florete par Annie Combes et Richard Trachsler. Ce type de descriptions ne manque pas dans les romans de notre corpus. Il s'agit d'un motif allogène, emprunté au roman antique et investi par le roman arthurien tardif. Voir notre article, "Les peintures troyennes dans Escanor de Girart d'Amiens: un cas d'interférence des matières au XIII ${ }^{\mathrm{e}}$ siècle", art. cit., et infra, chapitre III, "Réécriture d'un topos allogène: l'ekphrasis», p. 559-572. Dans Floriant et Florete, les quatre pans de la tenture représentent respectivement l'univers, un épisode biblique, celui d'Abel et Caïn, la guerre de Troie et l'amour, illustré par Tristan en Iseut. 
des merveilles: l'île est un Ailleurs, au sens où l'entend Francis Dubost et représente un espace lointain qui favorise le surgissement de l'inattendu ${ }^{87}$.

Précisément, la surprise de l'aventure a partie liée avec l'altérité, celle des animaux hybrides notamment, comme les sarduinas et le pellican ${ }^{88}$, qui font partie de cette poétique de la curiosité, voire d'un "fantastique des terres lointaines", comme le qualifie Francis Dubost ${ }^{89}$. Alors que le pellican, cette bête monstrueuse et hybride qui n'a de l'oiseau christique que le nom, sévit sur un espace insulaire civilisé par les Belles Pucelles qui l'occupent et auxquelles il réclame un tribut, les sarduinas ont totalement conquis leur île et y sont cantonnés, sans contact avec une quelconque présence humaine. Leur apparition est précédée par une tempête de mer des plus violentes qui tourmente Arthur embarqué avec son armée pour prêter main-forte à Floriant dans la reconquête de Monreale.

La tempête, qui peut frapper le chevalier errant en pleine forêt comme le montre la merveille de la fontaine de Barenton, éclate ici en mer, ce qui illustre bien la transposition de l'errance de la forêt à la mer. Ce qui importe dans la mise en scène du motif de la tempête, appliqué à la navigation $^{90}$, ce sont surtout ses conséquences: l'embarcation échoue près d'une île mystérieuse. Cinquante écuyers sont envoyés en éclaireurs par

87 Francis Dubost, Aspects fantastiques de la littérature narrative médiévale, p. 283-312. Christine Ferlampin-Acher traite également de l'île comme lieu privilégié du merveilleux: "Lîle est un lieu clos, accueillant à la merveille: la mythologie celtique et ses réminiscences folkloriques tout autant que l'Antiquité gréco-romaine associent insularité et merveille." Fées, bestes et luitons. Croyances et merveilles, Paris, PUPS, 2002, p. 98.

88 Les deux créatures de Floriant et Florete vivent sur terre, mais peuvent toutefois être apparentées aux monstres marins par la terreur qu'elles inspirent et leur hybridité. Elles ne sont pas répertoriées par les encyclopédies et sont une pure invention de l'auteur. Sur les monstres marins, voir Jean Arrouye, "L'en-dessous et l'en-dessus de la mer", in Mondes marins du Moyen Âge, dir. Chantal ConnochieBourgne, Aix-en-Provence, Presses universitaires de Provence ("Senefiance», 52), 2006, p. 27-41, et Marylène Possamai, "Monstres marins dans la littérature médiévale: mythologies et allégories", in Mondes marins du Moyen Âge, dir. Chantal Connochie-Bourgne, Aix-en-Provence, Presses universitaires de Provence («Senefiance», 52), 2006, p. 389-404.

89 Francis Dubost, Aspects fantastiques de la littérature narrative médiévale, p. 262.

90 Voir l'article de Danièle James-Raoul, "L'écriture de la tempête en mer dans la littérature de fiction, de pèlerinage et de voyage", in Mondes marins du Moyen $\hat{A} g e$, dir. Chantal Connochie-Bourgne, Aix-en-Provence, Presses universitaires de Provence («Senefiance», 52), 2006, p. 217-229. 
Arthur sur cette terre sauvage. C'est alors que se manifestent les «bestes Sathenas» (v. 2719):

L'en les apele sarduinas,

Granz sont et orribles et fors,

Gros et corsus orent les cors,

Les oreilles teles com vanz,

Ne doute nule arme tranchanz. (Floriant et Florete, v. 2720-2724)

Cette description ne donne pas d'information sur l'aspect des sarduinas: seul compte l'effroi qu'ils peuvent inspirer par leur taille et leur force, qui renvoie à la peur que génère l'espace maritime ${ }^{91}$. Les écuyers sont décimés, sous le regard désolé de Floriant. Rien ne sera entrepris pour venger les malheureux ni pour débarrasser ces rivages des terribles bêtes. Gauvain clôt l'affaire en rappelant leur but principal, celui de sauver la mère de Floriant:

«Sire, se Dameldieu m’aïst,

Nus ne se doit desconforter,

Laissiez les escuiers aler,

S'il sunt mort, a Dieu les commant.

Mes or pensons d'aler avant,

Tant que veignons en la contree

Ou vostre mere est enserree!» (Floriant et Florete, v. 2734-2740)

Les chevaliers de la Table Ronde, en la personne de Gauvain, pour une fois, admettent leur impuissance. En empruntant la voie maritime, les personnages font preuve de leur prouesse, mais ils sont aussi confrontés à des curiosités cantonnées à leur marginalité: les sarduinas demeurent ainsi invincibles, coupés qu'ils sont de toute forme de civilisation, et attestant par là que la mer ne s'apprivoise pas comme la forêt.

De là naît l'exotisme: l'Ailleurs maritime, l'Autre, résistent, ne se laissent pas apprivoiser et intégrer au royaume arthurien. Plus que passage vers l'Autre Monde et la merveille, la mer du roman tardif est l'espace de l'exotisme merveilleux, elle permet la mise en scène d'étrangetés

91 Les différents articles du recueil dirigé par Chantal Connochie-Bourgne, Mondes marins du Moyen Âge, Aix-en-Provence, Presses universitaires de Provence («Senefiance», 52), 2006, illustrent bien la peur qu’inspirent les profondeurs marines. 
indomptables. Il en va de même lors du tournoi de Rigomer, qui fait intervenir des peuples hybrides de l'encyclopédie antique, telles celles de Ctésias ou de Pline, réinvesties par les Romans d'Alexandre et transmises par Isidore de Séville et Gossuin de Metz ${ }^{92}$. Les chevaliers d'Arthur doivent se battre contre les Irlandais devant le château de Rigomer. Des renforts arrivent par voie maritime (v. 10249-10250), la mer étant là aussi pourvoyeuse de créatures merveilleuses et étrangères à ce que le chevalier arthurien connaît. Le premier peuple à se présenter est composé de «moine infernax» (v. 10278), comme les qualifie Keu: ils sont vêtus de noir et portent leurs armes sous leur toge. Ces moines ont la capacité de guérir instantanément de leurs blessures ("Mais on ne le pooit blechier", v. 10341), ce qui les rend d'autant plus redoutables. Yvain, Keu et Gifflet en font les frais: leur adversaire respectif toujours «Resaut [...] sus, ainc ne dit mot» (v. 10374).

Ces créatures rappellent celles des Enfances Guillaume, ainsi que le remarque Annie Combes ${ }^{93}$ : dans la chanson de geste, Orable les fait naître lors de ses enchantements pour tourmenter le Sarrasin Thibaut qu'elle doit épouser. Voici le passage:

Trois mile moines couroneiz et chantan,

Et sont plus noir ke poix nen aireman,

Et lancent flames et les grans feus ardan,

Et chacuns porte un mort honme an sa main.

Per le palais s'apardent li auquan;

Sarrasins brulent les grenons per devan ${ }^{94}$.

Leur couleur noire et leur caractère surnaturel apparentent ces deux manifestations de moines. Seulement, les moines d'Orable ne sont maléfiques que du point de vue du Sarrasin: c'est aux païens qu'ils s'en prennent

92 Nous nous permettons de ne citer que l'article suivant de Laurence Harf-Lancner au sujet des merveilles de l'Inde: "From Alexander to Marco Polo, from text to image: the marvels of India", in The Medieval French Alexander, dir. Donald et Sarah Maddox, Albany, University of New York Press, 2002, p. 235-257, ainsi que l'étude incontournable de Claude Lecouteux, Les monstres dans la pensée médiévale européenne, Paris, PUPS, 1993.

93 «Narration et "matières". Les limites du merveilleux dans quelques romans arthuriens", art. cit.

94 Enfances Guillaume, in Le Cycle de Guillaume d'Orange, éd. cit., v. 1935-1940. 
et non aux chrétiens, contrairement à ceux de Rigomer. Leur apparition dans le roman tardif est ambiguë: ces hommes de Dieu ont-ils pris la voie du diable ou leur rôle est-il plutôt de dénoncer les péchés des chevaliers arthuriens pour les avilir? Sans doute faut-il plutôt les envisager comme des manifestations d'un merveilleux inquiétant et définitivement étranger. Comme dans le cas des sarduinas, les moines d'enfer sont invaincus: alors qu'un Breton découvre qu'en leur ôtant leur caperon, ils se pâment aussitôt, une nouvelle armée maléfique survient en renfort.

Il s'agit cette fois de cynocéphales ${ }^{95}$, créatures bien connues des livres relatant les merveilles orientales:

Musiaus avoient comme cien,

Et sor le tieste sont cornu

Et par trestot le cors pelu

Ausi comme sauvages bestes.

Les cornes qu'il ont sor les tetes

Longes furent pié et demi,

Et ces cornes dont jo vos di,

Trencans estoient par deseure

Con ço fuisent cotiel a meure.

$\mathrm{Li}$ cuirs que il avoit defors,

Comme fiers ert trenchans et for

Et comme curs de cerf boli,

Qui fu redobés et trelis.

De lonc les en ont fait venir

Pour les mervelles maintenir,

Et pour enforchier les encans

I sunt venu de lontains cans. (Rigomer, v. 10410-10426)

Cette description ajoute des cornes tranchantes aux traditionnels cynocéphales: le but est bien de renchérir sur l'horreur et de varier le portrait de monstres connus. Le narrateur souligne en ce sens que les cynocéphales interviennent pour accroître le merveilleux, mais aussi pour nourrir l'exotisme, en insistant sur leur provenance lointaine. D'autres peuplades merveilleuses viennent renforcer ces effets: un peuple maritime; des

95 Voir Claude Lecouteux, "Les Cynocéphales. Étude d'une tradition tératologique de l'Antiquité au XII siècle», Cahiers de Civilisation Médiévale, 1981, p. 117-128. Christine Ferlampin-Acher traite des peuples surnaturels de Rigomer aux pages 336-337 de Merveilles et topique merveilleuse. 
créatures cannibales appelées "Chenelius» (v. 13669); des Pygmées; des "Cocu», "Torvain» et "Boncu»; des «Popelicans» (v. 13690); des hommes pourvus de becs tranchants; d'autres qui n'ont qu'un pied et qui semblent faire référence aux sciapodes antiques. Ce qui importe dans ce catalogue de races merveilleuses et diaboliques (les "cornus" "nestoient pas crestiien», v. 10409), c'est moins le déroulement narratif de la guerre menée ${ }^{96}$ que le plaisir de décrire des êtres étranges et exotiques, que le chevalier comme le lecteur ne croisent habituellement pas dans le roman arthurien. Des monstres recensés par la tradition antique côtoient ce qui semble être des inventions de Jehan. Le jeu concerne alors l'onomastique, qui doit faire sourire ( li Cocu », «li Boncu ${ }^{97}$ ), voire, peut-être, renvoyer à d'autres réalités: le "popelican" peut désigner soit le Sarrasin, l'hérétique, soit le publicain, ce percepteur d'impôts de la Rome antique ${ }^{98}$. L'effet descriptif de listage est renforcé par la scansion du vers «Li encantemens lor amaine» (v. 13664, 13689, 13697, 13717), mettant l'accent à la fois sur le caractère surnaturel de ces peuples et sur leur provenance étrangère, car ils doivent être "amenés». C'est d'ailleurs ce que souligne le vers 10426 que nous citions plus haut, renforcé par le vers 13718: «Une autre gent qui est lontaine». La fabrique de ces monstres ressemble à celle que l'on trouve dans les chansons de geste ${ }^{99}$ : à une base humaine, on ajoute des propriétés physiques animales ou on prête au peuple étranger des mœurs qui les excluent de la civilisation (ainsi des cannibales). À partir du modèle fourni par l'encyclopédie, le roman accumule de nouveaux

96 Comme l'explique Annie Combes: "L'intervention des monstres relève d'un "fantastique descriptif" davantage que narratif". "Narration et "matières". Les limites du merveilleux dans quelques romans arthuriens", art. cit., p. 373.

97 À moins que ce nom ne soit à rapprocher des «Becus» que l'on rencontre dans l'Ogier décasyllabique. Voir Dominique Boutet, "Les peuples étranges dans la chanons de geste (XII $\mathrm{XIV}^{\mathrm{e}}$ siècles), in En quête d'Utopies, dir. Claude Thomasset et Danièle James-Raoul, Paris, PUPS (“Cultures et Civilisations Médiévales», 29), 2005, p. 155-181.

98 Frédéric Godefroy, Dictionnaire de l'ancienne langue française et de tous ses dialectes $d u I X^{e}$ au $X V^{e}$ siècle.

99 Dominique Boutet, "Les peuples étranges dans la chanons de geste», art. cit. Voir aussi l'article de Chantal Connochie-Bourgne, "L'exemple des peuples d'ailleurs", in En quête d'Utopies, dir. Claude Thomasset et Danièle James-Raoul, Paris, PUPS ("Cultures et Civilisations Médiévales», 29), 2005, p. 183-194, au sujet du réinvestissement des peuples hybrides dans la littérature narrative. 
portraits fantaisistes de monstres, qui parfois ressemblent aux peuples recensés par l'encyclopédie sans en présenter toutes les caractéristiques: par exemple, les créatures à têtes de chiens sont aussi pourvues de cornes et sont appelées "cornus» et non "cynocéphales».

En dehors du plaisir que peut procurer l'accumulation de créatures menaçantes dont le potentiel comique n'est pas absent (c'est le cas pour les cocus), ce tournoi devant les portes de Rigomer n'a pas de réelle fonction dans l'économie narrative. D'abord, on ne perçoit pas bien le statut de cet affrontement: s'agit-il d'un tournoi, comme le prétend la lettre du texte (v. 13546 par exemple), ou d'une guerre, comme le laissent penser le nombre de morts et le caractère belliqueux des assaillants merveilleux? Ensuite, ce combat a un goût d'inachevé: les Bretons sont, pour une fois, déconfits et obligés de fuir (v. 13761), convaincus par le déluge tout à fait apocalyptique qui s'abat sur eux (v. 13746-13758). Le constat énoncé par les chevaliers arthuriens est amer:

«Bien sont estaintes les vertus

Que seut avoir li rois Artus.

Quant il ceste cose savra,

Sa vie et le monde hara.» (Rigomer, v. 13781-13784)

Jamais le roman ne revient sur cette déconfiture ni sur le retour de ces personnages à la cour. La merveille consacre la déchéance de cette chevalerie qu'annonçait déjà le début du texte en la personne d'une demoiselle venue reprocher leur inanité aux chevaliers ${ }^{100}$. À moins que cet échec ne vienne valoriser Gauvain, seul et unique élu dont l'armée vaincue regrette l'absence (v. 13764). Les peuples exotiques, assimilés à une Irlande mystérieuse, résistent à la conquête arthurienne; symboles de l'étranger, de l'extranéité, ils témoignent de l'ouverture du roman arthurien tardif et de sa conjonction à un registre autre. L'ouverture est géographique, mais aussi générique, en ce que les merveilles rappellent plus l'encyclopédie que le roman arthurien.

L'infléchissement de l'espace dans le roman tardif ne transforme pas l'inscription chronotopique: la corrélation entre le temps et l'espace

100 Voir Annie Combes, «Narration et "matières". Les limites du merveilleux dans quelques romans arthuriens", art. cit., p. 370-373, sur cet épisode de Rigomer. 
continue de générer des aventures insouciantes, individuelles, sans conséquences pour le monde arthurien. C'est le genre en lui-même qui est transformé par l'élargissement de la temporalité et de la géographie; la tendance à l'expansion de la géographie arthurienne est commune à plusieurs textes tardifs ${ }^{101}$, de même que le recours à l'exotisme pour agrémenter les épisodes merveilleux. La tardivité interroge les limites de l'arthurien en cessant de se borner à des lieux fictifs et incertains. Malgré cela, la Bretagne conserve son caractère central vis-à-vis de l'espace européen: il s'agit de la terre de l'épreuve et de la reconnaissance, où le héros peut se voir confirmer dans son statut d'excellent chevalier, que ce soit dans la phase du noviciat ou dans celle de la recreantise.

\section{Gauvain, emblème du vers}

L’action générée par la corrélation du temps et de l'espace est différente entre vers et prose, bien que la tardivité s'emploie à rendre ces contours plus problématiques, nous l'avons vu. En ce sens, prose et vers mettent en scène des personnages différents: le personnage a une fonction indicielle, c'est-à-dire qu'il cadre d'abord l'univers de fiction dans lequel se situe la diégèse et indique ensuite le chronotope privilégié par le récit. L'apparition de Mordred ou de Merlin oriente par exemple vers le chronotope de la prose. Les derniers romans en vers brouillent quelque peu cette typologie, en faisant apparaître des personnages spécifiques à la prose, mais aussi en intégrant des renvois intertextuels aux romans en prose, et plus seulement aux romans en vers. Ces renvois doivent se lire comme des allusions au chronotope de la prose, convoqué en creux, par le biais des souvenirs sous narcose du lecteur. Le même phénomène se produit pour le Graal, qui n'apparaît jamais en propre dans le roman en vers tardif, mais surgit au détour de signaux inférentiels. L'absence du Graal est signifiante; elle dit bien les chemins différents que prennent vers et prose dans leur traitement de l'univers de fiction arthurien. Ce sera l'objet des chapitres suivants.

101 Cette tendance se vérifie dans Artus de Bretagne, roman arthurien tardif en prose dont le héros parcourt l'Orient depuis la Bretagne. L'expansion géographique et la référentialité de l'espace pourraient bien être des caractéristiques propres à la tardivité arthurienne, en vers et en prose. Voir l'introduction à l'édition de Christine Ferlampin-Acher, Artus de Bretagne. Roman en prose de la fin du XIII siècle, éd. cit., p. CLXXXIV-CLXXXVIII. 
Ces différences sont synthétisées dans le traitement réservé au personnage de Gauvain, "parfait représentant de l'aventure circulaire » ${ }^{102}$. Le vers - dans ses premiers représentants - ne lui autorise aucune évolution, aucune progression. Malgré toutes les jeunes filles qu'il rencontre et promet d'aimer - de Lunete à Ydain -, il demeure un éternel célibataire, disponible pour l'aventure, chevaleresque et amoureuse ${ }^{103}$. Les auteurs successifs semblent oublier ses aventures ${ }^{104}$ : même si sa réputation littéraire le précède, on ignore volontairement ses actes, ses rencontres, ses victoires et ses échecs, de plus en plus nombreux d'ailleurs au cours du $\mathrm{XIII}^{\mathrm{e}}$ - que l'on pense par exemple aux péripéties de nature à le tourner en dérision dans la Vengeance Raguidel ou Le Chevalier à l'épée ${ }^{105}$. Quoi qu'il

102 Emmanuèle Baumgartner, "Retour des personnages et mise en prose de la fiction arthurienne au XIII ${ }^{\mathrm{e}}$ siècle», BBIAS, 43, 1991, p. 301.

103 Gauvain apparaît en amant notamment dans Hunbaut, La Vengeance Raguidel, Le Chevalier aux deux épées, Le Bel Inconnu, Le Conte du graal, L'Âtre Périlleux. Sur la propension séductrice de Gauvain, voir Jean Frappier, «Le personnage de Gauvain dans la Première Continuation de Perceval", in Amour courtois et Table Ronde, Genève, Droz, 1973, p. 158-163. On consultera les études suivantes sur le personnage de Gauvain: Marie-Françoise Alamichel (dir.), Le Personnage de Gauvain dans la littérature européenne du Moyen Âge. Actes du colloque international des 6, 7 et 8 mars 2014 à l'Université Paris-Est (Marne-la-Vallée), Amiens, Presses du Centre d'Études Médiévales de Picardie ("Médiévales», 58), 2015, Stoyan Atanassov, L'Idole inconnue, Keith Busby, Gauvain in Old French Literature, Keith Busby, "Diverging Tradition of Gauvain in some of the Later Old French Verse Romances", in The Legacy of Chrétien de Troyes, dir. Norris J. Lacy, Douglas Kelly et Keith Busby, Amsterdam, Rodopi, 1987-1988, vol. II, p. 93-109, Fanni Bogdanow, "The Character of Gauvain in the Thirteenth Century Prose Romances ", Medium Aevum, XXVII, 1958, p. 154-161, Jean Larmat, "Le personnage de Gauvain dans quelques romans arthuriens du XII ${ }^{\mathrm{e}}$ et du XIII ${ }^{\mathrm{e}}$ siècle», in Mélanges Lanly, Nancy, Publications de l'Université, 1980, t. II, p. 185-202, et Beate Schmolke-Haßelmann, Der arthurische Versroman, chapitre 4.

104 Michelle Szkilnik, "Le chevalier "oublieux" dans le roman arthurien en vers", art. cit. Voir aussi Keith Busby, Gauvain in Old French Literature, p. 384-387.

105 Romaine Wolf-Bonvin, "Gauvain en Écosse: vaincre ou faillir dans la Vengeance Raguidel", in L'Homme dans le texte, dir. Dina Mantchéva et Raya Kountchéva, Sofia, PU, 2008, p. 39-55, Brigitte Burrichter, «Raouls de Houdenc La Vengeance Raguidel. Komik und Parodie", in Ironie, Polemik und Provokation, dir. Cora Dietl, Christoph Schanze et Friedrich Wolfzettel, Berlin, De Gruyter, 2014, p. 287-302, et Roberta L. Krueger, "Playing to the ladies: chivalry and misogyny in Ipomedon, Le chevalier à l'épée, and La vengeance Raguidel", in Women Readers and the Ideology of Gender in Old French Verse Romance, Cambridge; New York; Melbourne, Cambridge University Press, 1993, p. 68-100. 
arrive, Gauvain demeure le parangon de la chevalerie et de la courtoisie, même s'il abandonne sa sœur à un carrefour, pourfend un nain qui lui propose un jeu parti ou embroche un chevalier en train de cuire un cerf trop alléchant (dans Hunbaut) ${ }^{106}$. À l'image du neveu d'Arthur, aucune progression n'est consignée de manière durable dans la tradition pour les personnages du roman en vers: chaque roman reprend des caractères figés, qu'il a la liberté de modifier pour le temps de son récit. Même Erec et Yvain ne réapparaissent pas dans les romans en vers successifs comme des hommes mariés ${ }^{107}$.

Gauvain peut être considéré comme le symbole de cette écriture en vers où les aventures s'effacent au fur et à mesure qu'est réactivé l'univers. Il apparaît en ce sens comme une figure d'oubli nécessaire à l'écriture du genre: "L'oubli est constitutif du personnage de Gauvain et c'est une condition nécessaire à la prolifération des romans dont il est le protagoniste. ${ }^{108}$ L'oubli exclut ainsi toute évolution du monde. Le roman en vers ne tend pas vers une fin et semble clos sur lui-même: il prend place dans un temps idéal, un âge d'or. Il en résulte une idéologie optimiste: le royaume est tout au plus menacé par des chevaliers félons, des adversaires merveilleux ou des guerres entre les sujets, mais la domination du roi Arthur est rarement mise en cause; si elle l'est, le conflit est rapidement résolu grâce au héros. Point d'un Graal sacré qui mettrait fin

106 Norris J. Lacy, "The Character of Gauvain in Hunbaut», Bulletin bibliographique de la Société Internationale Arthurienne, 38, 1986, p. 298-305, et Keith Busby, "Caractérisation par contraste dans le roman de Hunbaut», Studia Neophilologica, 52, 1980, p. 415-424.

$107 \mathrm{Du}$ moins est-ce assez rare. Beate Schmolke-Haßelmann, Der arthurische Versroman, p. 171. Le Lancelot en prose occulte également le passé littéraire versifié d'Yvain; il y devient un simple compagnon. Voir Emmanuèle Baumgartner, Chrétien de Troyes. Yvain, Lancelot, la charrette et le lion, Paris, PUF («Études littéraires»), 1992, p. 107-115, et "Le lion et sa peau ou les aventures d'Yvain dans le Lancelot en prose", in De l'histoire de Troie au livre du Graal, Orléans, Paradigme, 1994, p. 291-300. Le Lancelot en prose fait d'Yvain un chevalier de l'ancienne génération, qui certes aide Lancelot lors de son introduction à la cour d'Arthur, mais n'est attaché à aucune aventure valorisante, comme c'était le cas dans le Chevalier au lion. Le texte en prose choisit de ne pas tenir compte des données fournies par Chrétien de Troyes pour ce personnage; les mondes du vers et de la prose sont distincts.

108 Michelle Szkilnik, "Le chevalier "oublieux" dans le roman arthurien en vers", art. cit., p. 92. 
aux aventures, principe dynamique qui assure le bon fonctionnement du royaume arthurien. Point de Mordred pour trahir Arthur, qui d'ailleurs délaisse très rarement sa cour. Gauvain trouve aisément sa place dans un tel univers, lui qui se distingue par sa constante disponibilité narrative.

Comme le souligne Emmanuèle Baumgartner, il n'existe pas de Gauvain en prose $^{109}$ : le personnage apparaît dans le cycle du Lancelot-Graal uniquement en tant qu'anti-héros, représentant d'une chevalerie désuète, dénuée de but transcendantal, que ce soit l'amour ou les promesses célestes du Saint Vase. Dans la prose, il représente toutes les déviances d'une chevalerie vaniteuse tournée vers la gloire personnelle. Lancelot le surpasse constamment dans le Lancelot en prose, si bien que Gauvain fait office de faire-valoir: plus le texte progresse, plus il devient clair que Gauvain échouera à la quête du Graal ${ }^{110}$. Le neveu du roi est sans cesse en quête de Lancelot, mais ses recherches sont souvent infructueuses. S'il le cherche, c'est toujours pour le ramener à la cour, pour l'intégrer à l'univers curial; au contraire, lorsque c'est Lancelot qui cherche Gauvain, c'est pour le tirer de prison. Le personnage échoue coup sur coup lors de plusieurs aventures (les deux tronçons de l'épée brisée que lui présente Eliezer, les tombes aux épées dressées, la demoiselle de la cuve, le service du Graal ${ }^{111}$ ). Gauvain peut aussi se montrer totalement discourtois dans ce texte, par exemple lorsqu'il tente d'obtenir de force l'amour d'une jeune messagère ${ }^{112}$. Ce rapport charnel à l'amour est de nature à le déprécier par rapport à Lancelot. En revanche, il remplit un rôle positif au sein du gouvernement d'Arthur, le réprimandant lorsqu'il est besoin, l'encourageant à regagner le cœur du peuple ou plaidant la cause de Guenièvre ${ }^{113}$.

109 Emmanuèle Baumgartner, "Les techniques narratives dans le roman en prose», art. cit., p. 169.

110 Keith Busby, Gauvain in Old French Literature, p. 315-380. Voir aussi Carol J. Chase, "Remaniement et le personnage de Gauvain dans le Lancelot en prose», in Arturus rex, dir. Willy Van Hoecke, Gilbert Tournoy et Werner Verbeke, Leuven, PU, 1991, p. 278-293.

111 Ces mésaventures sont tirées du tome in de l'édition d'Alexandre Micha, Lancelot. Roman en prose du XIII siècle, éd. Alexandre Micha, Genève, Droz, 1978-1983.

112 Lancelot, éd. Alexandre Micha, t. viII, Lxiıra, 22-23 (p. 341-342).

113 Voir l'éloge qui est fait de lui dans le t. II de l'édition d'Alexandre Micha (LxIx, 2-3, p. 408-409): son dévouement pour les pauvres et les lépreux, son humilité, sa loyauté et sa courtoisie justifient son renom, mais le texte précise qu'il y a des chevaliers plus habiles dans les armes que lui. 
Dans la Queste del saint Graal, son image se ternit encore: il fait office de représentant d'une chevalerie mondaine dont les valeurs contreviennent à la quête du Graal. Il subit alors les remontrances des ermites, qui le qualifient de "mauvés serjanz et desloiax» ${ }^{114}$. Figure d'impénitent, il se vante des chevaliers qu'il tue, sans scrupules et sans velléité de mener une vie plus sainte. Il prend même le rôle de meurtrier; il tue Yvain l'Avoutre et Baudemagu, puis Pellinor, Lamorat, Erec et Palamède dans le Tristan en prose, sans ressentir aucune honte ${ }^{115}$. Enfin, dans la Mort Artu, il se comporte avec démesure, en particulier dans sa haine vengeresse envers Lancelot, qui a tué Gaheriet pour sauver la reine. Impie dans la Queste, démesuré dans la Mort Artu, discourtois et cruel dans le Tristan en prose, Gauvain peut de moins en moins prétendre au statut de parangon de la chevalerie arthurienne dans les romans en prose ${ }^{116}$. Dans les textes en vers au contraire, il fait l'objet de moqueries, mais pas de condamnations ${ }^{117}$.

À la fin du XIII ${ }^{\mathrm{e}}$ siècle, la dévaluation qu'a affrontée le chevalier aux demoiselles ne peut être ignorée par les auteurs; comment écrire sur un monde arthurien épuisé par les sommes en prose, qui ont transformé en profondeur l'appréhension des personnages clés? En adoptant le vers, les auteurs s'autorisent à poursuivre le chronotope atemporel et sans progression initié par Chrétien de Troyes. Gauvain peut donc être blanchi de ses torts. Il intervient au premier plan dans tous les textes de notre corpus - excepté Melyador, où il est trop jeune pour avoir un vrai rôle et n'apparaît que parmi les damoiseaux de la cour d'Arthur. Il accompagne ainsi plusieurs fois Claris et Laris et n'a rien perdu de sa courtoisie ni de

114 La Queste del saint Graal, p. 54.

115 Emmanuèle Baumgartner, Le Tristan en prose: essai d'interprétation d'un roman médiéval, Genève, Droz, 1975, p. 196-197, Keith Busby, "The Character of Gauvain in the Prose Tristan», Tristania, II,ii, 1977, p. 12-28, et Laurence HarfLancner, "Gauvain l'assassin: la récurrence d'un schéma narratif dans le Tristan en prose", in Tristan - Tristant. Mélanges en l'honneur de Danielle Buschinger à l'occasion de son 60'me anniversaire, dir. André Crépin et Wolfgang Spiewok, Greifswald, Reineke, 1996, p. 219-230.

116 Fanni Bogdanow, "The Character of Gauvain in the Thirteenth Century Prose Romances", art. cit. Jean Larmat oppose également dans son analyse l'image de Gauvain dans les romans en vers et dans ceux en prose. "Le personnage de Gauvain dans quelques romans arthuriens du XII ${ }^{\mathrm{e}}$ et du XIII ${ }^{\mathrm{e}}$ siècle», art. cit.

117 Du moins la condamnation reste-t-elle implicite, même s'il incarne la voie à ne pas suivre dans Le Chevalier de la Charrette et le Conte du graal. 
son habileté aux armes. Il est même désigné par une inscription magique comme le meilleur chevalier avec Claris, seuls à même de libérer le seigneur de la cité (Claris et Laris, v. 25425-25636), de même qu'il est l'un des trois meilleurs chevaliers du monde que Calogrenant doit rencontrer pour être délivré de son enchantement (Claris et Laris, v. 26149-26160). La structure de l'entrelacement l'élit finalement dans ce roman comme le deuxième meilleur chevalier après Claris, car le récit s'arrête plusieurs fois sur ses aventures alors que les autres participants aux deux quêtes de Laris ne bénéficient de cette attention qu'une fois ${ }^{118}$. Adversaire principal d'Escanor le Bel dans Escanor, il se voit défié à plusieurs reprises, en raison de sa réputation de parangon. Il y est souvent accusé à tort d'avoir tué un cousin ou d'avoir commis tel méfait pour que le rival puisse se mesurer à lui; Girart d'Amiens réactive ici un motif de la littérature arthurienne depuis le Conte du Graal et s'inscrit en continuité des textes en vers qui se concentrent sur Gauvain.

Dans Escanor, Gauvain subit le poids de la tradition sans pour autant se comporter de manière répréhensible. Si les personnages extérieurs à la cour d'Arthur tentent de remettre en cause sa suprématie en l'accusant pour l'affronter - Escanor le Bel, Escanor le Grand - ou en le traitant de «soudomites» (v. 1847), il demeure un parangon, le meilleur chevalier du monde ${ }^{119}$. Seul le doute que les membres de la cour nourrissent à son égard va à l'encontre de la valorisation du personnage: en raison de la fausse accusation d'Escanor le Bel et du fait qu'il ne connaît pas l'identité de son détracteur, Gauvain sombre dans une petite "dépression». Il s'en va "melancoliant nuit et jor» (v. 7821), se met à fréquenter assidûment l'église et se montre si anxieux et «espoentez» (v. 7845) que ses compagnons peuvent bien dire que «ainc mais si povre samblance / ne li veïsmes nul jour faire» (v. 7854-7855). Ceux-ci s'interrogent sur la vérité de l'accusation d'Escanor et doutent de la victoire de Gauvain: ce manque de confiance envers lui se manifeste pour une fois au sein même de la

118 Voir Corinne Pierreville, Claris et Laris, somme romanesque du XIIt siècle, p. 65-66.

119 Nous ne suivons ainsi pas l'avis d'Elisabeth Schulze Busacker, qui voit dans le Gauvain d'Escanor une altération du personnage. "Gauvain, li malparlier". Le rôle de Gauvain dans le roman d'Escanor", in Lancelot, Yvain et Gauvain. Colloque arthurien belge de Wégimont, Paris, Nizet («Lettres médiévales», 2), 1984, p. 113-123. 
cour arthurienne, lieu de caution des réputations ${ }^{120}$. L'image de Gauvain perd ainsi momentanément de son prestige, d'autant plus que Galantinet, un écuyer de son entourage qu'il a élevé (v. 7717-7721), commettra un attentat contre Escanor visant à empêcher le combat entre l'accusateur et l'accusé. Le mal n'émane donc pas de Gauvain lui-même: l'agression n'est pas de sa responsabilité, tout comme les soupçons dont il est l'objet sont infondés. Ces deux éléments s'inscrivent dans le projet plus vaste de Girart d'Amiens: celui de cultiver l'entre-deux, l'ambiguïté ${ }^{121}$ quant aux valeurs des personnages. Nous y reviendrons au chapitre III, "Un manichéisme relatif", p. 482-493, le personnage arthurien tardif, qu'il s'agisse de l'opposant ou du héros, n'est jamais entièrement positif ou négatif. Dans une même idée, Girart d'Amiens encourage les chevaliers de la Table Ronde, et pas seulement Keu, à douter de Gauvain, qui est leur représentant. Il montre également que le propre écuyer de Gauvain peut se comporter inconséquemment et que le neveu du roi est sujet à la faille, par procuration toutefois.

Ces suspicions passagères de culpabilité ne permettent néanmoins pas d'affirmer que Gauvain subit une dévaluation totale dans Escanor, ni même dans les romans arthuriens tardifs: au contraire, nous avons plutôt affaire à une réhabilitation, vis-à-vis de la prose d'abord, nous l'avons dit, mais aussi par rapport aux romans en vers qui le prennent pour héros - Hunbaut, La Mule sans frein, Le Chevalier à l'épée, La Vengeance Raguidel, L'Âtre Périlleux. Même si l'on souligne parfois les travers que la tradition a bien voulu lui prêter - son attrait pour les femmes ${ }^{122}$, sa trop grande courtoisie $^{123}$, les accusations constantes dont il fait l'objet -, son

120 Selon Richard Trachsler, il faut mettre le peu de foi de la cour envers Gauvain en lien avec le Tristan en prose, qui a mené à douter de l'intégrité de Gauvain. De même, Gauvain se plaint des accusations dont il est la victime dans le Tristan en prose, mais pas dans les romans en vers. Voir Escanor, éd. cit., p. 90.

121 Dominique Boutet traite de ce qu'il appelle une "poétique de l'ambiguïté» sous l'angle du mélange des genres et des registres. Ses conclusions sur la conscience médiévale de l'ambiguïté du monde, de l'obscurcissement du sens du monde, sont toutefois applicables au projet de Girart d'Amiens de proposer un univers qui n'est pas régi par le manichéisme. Voir Poétiques médiévales de l'entre-deux.

122 Ainsi, Keu rappelle l'habitude qu'il a de délaisser les jeunes filles: "Aura le pris et la pucele; / S'en fera s'amie nouvele, / Puis la laira au conmunal.» (Escanor, v. 291-293)

123 La courtoisie de Gauvain est assimilée à de l'hypocrisie par Keu, qui au contraire prétend dire la vérité par ses médisances. Escanor, v. 359-391. 
comportement est exemplaire dans les romans tardifs, à mille lieues d'un texte comme Hunbaut.

Quant à Biaudouz et Floriant et Florete, ils le présentent comme un mari ou un fiancé ${ }^{124}$. Cette forme d'engagement est inédite pour lui et pourrait bloquer ses potentialités narratives en le rendant indisponible pour l'aventure et l'amour. Pourtant, le Gauvain de Floriant et Florete se montre fidèle à son image traditionnelle de séducteur: il est le premier à reconnaître les signes de la maladie d'amour chez Floriant et, lorsqu'il apprend l'objet du désir de son ami, il s'empresse de demander si Florete a une belle jeune fille à lui présenter:

«Amis, se Dameldiex t’aïst,

A ta dame nule pucele

Qui point soit avenant ne bele?

- Öil, ele a une meschinne

Qui est nomee Blanchandine,

Fille est le roi de Honguerie,

Molt par est mignote et jolie.

- Amis, cele me saluez

Et mon anelet li portez,

Dites que Gauvains li envoie.» (Floriant et Florete, v. 4212-4221)

Ce passage suscite le rire du lecteur qui connaît la réputation de Gauvain, lui qui se montre toujours sensible à la beauté des jeunes filles "mignote et jolie». Celui-ci s'engage, par le don de son anneau, auprès d'une demoiselle qu'il n'a jamais vue. L'auteur s'amuse du motif de l'amour par ouï-dire qui touche bien souvent Gauvain (dans Hunbaut et la Première Continuation par exemple) ${ }^{125}$ en inversant les rôles de sujet et d'objet. La relation du chevalier avec Blanchandine pourrait rester une amourette sans importance, destinée à favoriser l'histoire des protagonistes. Or,

124 Dans Biaudouz, Arthur annonce que Gauvain doit épouser la dame de Galles. Il s'agit probablement de la mère de Biaudouz, bien nommée "Amie», qui vient justement de Galles (v. 3332). Elle est appelée «dame de Gales» au vers 3647. Ce roman est une œuvre morale: cela explique peut-être la volonté de mettre un terme à la vie de célibataire de Gauvain.

125 Selon Philippe Ménard, l'amour de renommée concerne toujours Gauvain dans les romans. Il permet d'atténuer la responsabilité du personnage dans l'attraction qu'il exerce sur la gent féminine. L'amoureuse de loin s'offre à lui sans qu'il l'ait séduite. Le rire et le sourire, p. 193. 
Gauvain épouse la demoiselle (v. 6105) et obtient même la Hongrie en héritage grâce à cette alliance, ce qui contrevient à la disponibilité affective qui le caractérise traditionnellement dans le roman arthurien en vers. Cet élément est peut-être à interpréter comme une contamination de l'idéologie de la prose; en prenant une épouse, Gauvain quitte pour un temps la temporalité circulaire qui le montrait à chaque fois inchangé. Ce mariage ne sera néanmoins pas retenu comme définitoire du personnage: celui-ci apparaît aussi libre de tout engagement dans les récits postérieurs. Si Gauvain se marie, ce n'est jamais après une quête laborieuse qui suscite des insomnies amoureuses, et ce n'est jamais une donnée qu'adoptent les récits postérieurs.

Le Gauvain de Rigomer synthétise aussi les visages que le personnage prend dans le vers. Il est loué par une métaphore végétale:

De la racine naist li seve

Qui le fust et l'escorce leve;

Et de le seve ist li doçors,

Dont traist li fuele et puis li flor;

Et de la flors ist for li fruis,

Dont amende li siens deduis;

Et quant li fruis est bien meürs,

Dont a l'abre tous ses [eürs].

Aussi vos di jou que Gavains

Es li abres et foille et rains,

C'est la seve, c'est li racine,

C'est li flors qui tot enlumine,

Ço est li fruis tous mëurés;

Car mesure Gavains est tes

Qu'en lui ne faloit nule rien;

Enluminés ert de tous bient. (Rigomer, v. 10597-10612)

Le narrateur file la métaphore de la "fleur de chevalerie», qualificatif souvent attribué dans la tradition à Gauvain. Ce passage exagère l'éloge: Gauvain est la fleur, la sève, l'arbre, la racine et le fruit, ce qui ne peut manquer d'être ironique. Pourvu de tous les biens, il est l'élu du château de Rigomer, quête que l'on devine moins prestigieuse que celle du Graal infra, chapitre II, "Le Graal versus la féerie», p. 313-325: il réussit maints exploits et parvient à délivrer les chevaliers victimes de l'enchantement, les merveilles se soumettant spontanément à lui à son arrivée. Il est 
également mis en avant pour ses qualités courtoises: dans l'épisode final de la Quintefeuille, il supplée au roi parti en errance dans l'exercice des fonctions royales et se fait le porte-parole de la mesure ${ }^{126}$.

Malgré les fréquentes louanges dont il fait l'objet dans ce texte et son élection pour accomplir l'aventure principale du roman, le chevalier n'échappe pas au ridicule. Gaudionés réussit à le retenir prisonnier en rusant: il envoie ses dames le flatter et le désarmer discrètement. Le séducteur invétéré ne se défend pas, puis est trahi (v. 7371-7407). Le texte se moque du personnage et de sa célèbre inconstance amoureuse ${ }^{127}$, qui le dessert dans cette aventure. Plus loin, le chevalier reste endormi et se réveille après le lever du soleil et après la fée Lorie, son amante (v. 1285912869). Il est aussi le jouet de certains mécanismes aventureux: en marchant sur la planche d'un moulin, celui-ci s'actionne et fait tomber le chevalier dans l'eau. Gauvain est heureusement rattrapé par une nef que la fée Lorie a placée sous le moulin au préalable (v. 11939-11964). Enfin, il ne se montre pas toujours d'une courtoisie sans faille: il attaque par exemple un chevalier pour récupérer son destrier volé sans pourtant défier son adversaire (v. 12057-12063) et tue les chevaux de plusieurs adversaires (v. 11351, 11420). Conformément aux romans gauviniens du début du XIII ${ }^{\mathrm{e}}$ siècle, le neveu du roi est à la fois moqué et désigné comme le meilleur chevalier du monde. La crainte que nourrit Miraudiel à son égard illustre parfaitement cette ambivalence: le chevalier, ennemi du monde arthurien, demande à Gauvain de rester dans sa prison jusqu'au jour où il devra affronter un chevalier de la Table Ronde pour avoir assiégé une dame. Gauvain y consent de bonne grâce et sympathise même avec Miraudiel, dont il accepte l'abondant festin et les caresses que lui prodiguent ses sœurs. S’il renonce à affronter Miraudiel le jour désigné,

126 Sur le personnage de Gauvain dans Rigomer, voir Adeline Latimier, "Gauvain dans les Merveilles de Rigomer: définition de la mesure dans un roman arthurien tardif", in Le Personnage de Gauvain dans la littérature européenne du Moyen Âge. Actes du colloque international des 6, 7 et 8 mars 2014 à l'Université de Paris Est (Marne-la-Vallée), dir. Marie-Françoise Alamichel, Amiens, Presses du "Centre d'Études Médiévales de Picardie» ("Médiévales», 58), 2015, p. 187-198.

127 Michelle Szkilnik a montré que cette inconstance est le résultat d'une contrainte narrative, fonctionnelle pour l'écriture du roman en vers, et non une donnée ontologique du personnage: à chaque nouveau récit, Gauvain est libre pour une nouvelle aventure et oublie ses relations précédentes. Voir «Le chevalier "oublieux" dans le roman arthurien en vers", art. cit. 
c'est aussi par modestie: bien d'autres chevaliers de la cour vengeraient mieux la dame que lui (v. 15066-15075). Malgré ces bons sentiments d'humilité, la complaisance qu'il met à endurer sa prison écorne la figure de Gauvain, sans pour autant mettre en doute son statut de parfait chevalier, redouté plus que tout autre. Cette représentation est en faveur du personnage: elle amuse le public en même temps qu'elle place Gauvain sur le devant de la scène et en fait l'objet de tous les intérêts.

Le roman arthurien en vers tardif fait donc fi des données fournies par les textes en prose. Les auteurs traitent de Gauvain comme le faisaient les successeurs de Chrétien de Troyes et renoncent à poursuivre la tendance à rabaisser le personnage, typique de la prose. La dévaluation totale qu'il a subie est réversible, à condition de choisir le cadre du vers. Le chronotope est bien distinct: dans un cas, Gauvain peut être au premier plan des aventures, dans l'autre il est l'anti-héros. Nous aurons l'occasion de voir dans les chapitres suivants l'étendue de l'emprise des techniques narratives de la prose sur l'écriture en vers tardive; les données propres à chaque chronotope ne se laissent quant à elles pas influencer, non plus que l'idéologie positive liée à la promotion d'un âge d'or arthurien.

\section{Tristan, Lancelot, Perceval: emblèmes de la prose?}

La volonté d'ignorer les contributions de la prose au monde arthurien est manifeste dans nos textes par la mise à l'écart de Tristan, de Perceval et de Lancelot, acteurs principaux des sommes en prose. Tristan est le plus occulté, malgré le succès contemporain du Tristan en prose: il n'apparaît ni dans Escanor, ni dans Melyador, ni dans Biaudouz, ni dans Claris et Laris, tandis que dans Floriant et Florete, il n'est cité que sous forme d'ornement sur une tenture de la nef merveilleuse de Floriant (v. 911), et que dans Rigomer, il n'est mentionné qu'une fois au détour d'une liste de combattants bretons (v. 10224). Perceval et Lancelot sont absents de Floriant et Florete, ne sont qu'évoqués dans des listes ou des comparaisons dans Claris et Laris et n'apparaissent dans Biaudouz que furtivement, le temps d'être désarçonnés en un coup par Biaudouz. Perceval est présenté dans ce dernier roman par un renvoi intertextuel au Conte du graal: le chevalier porte comme signe distinctif une "manche I De chainsil deliee et blanche» (v. 3896-3897), offerte par "La pucele de Bel Repaire, / Qui vout de lui son ami faire» (v. 3898-3899). Ce renvoi intertextuel choisit le cadre idéologique du récit en vers et promeut le 
versant amoureux de l'histoire de Perceval, opposé comme on le sait à sa quête spirituelle ${ }^{128}$.

Quant à Rigomer, Lancelot y occupe une place de choix, le récit se concentrant sur son errance pendant toute sa première moitié. L'œuvre peut cependant se lire comme une inversion du Chevalier de la Charrette ${ }^{129}$ : Gauvain réussit là où Lancelot échoue et se ridiculise. L'amant de la reine ne peut rivaliser avec le neveu du roi dans ce récit, qui se centre sur une présentation de l'univers arthurien propre au vers et disqualifie les personnages trop explicitement liés au monde du Graal. En se moquant de Lancelot et en le prenant ostensiblement comme héros - ainsi que l'annonce le prologue ("Or ai talent que je vos die / De Lanselot del Lac partie», v. 13-14) -, le texte de Rigomer prend volontairement le contre-pied des sommes en prose pour valoriser un comique qui n'est jamais inquiété par les prémices d'une chute du royaume arthurien: après le Lancelot-Graal, l'archétype de l'amant parfait trouve son renouvellement dans la dérision dont il fait l'objet. Cet effet est poursuivi par le recueil qui contient le roman, Chantilly, Condé 472: le manuscrit s'ouvre sur Rigomer comme pour exhiber la version qu'il entend fournir du monde arthurien ${ }^{130}$. Lancelot n'y est plus le modèle de chevalerie ni non plus de la fin'amor qu'il incarnait. Si le Chevalier de la Charrette est intégré au recueil, c'est pour se terminer après l'épisode du

128 Il faut noter que lors du tournoi final, Biaudouz vainc successivement Perceval, Keu, Lancelot, Cligès, Yvain, Calogrenant et Erec. Faut-il y lire de la part de Girart d'Amiens la volonté de dépasser Chrétien de Troyes, en faisant de son héros le vainqueur absolu de ceux du Champenois? Cet épisode fait peut-être écho à celui de Cligès, où le héros éponyme se bat contre le camp d'Arthur lors du tournoi d'Oxford et affronte son oncle Gauvain, sans que le duel puisse les départager. Le déroulement est semblable dans Biaudouz: Biaudouz affronte le camp de la Table Ronde et se retrouve face à Gauvain, qui est son père cette fois. Là encore, le combat est sans issue et donne lieu à une scène de reconnaissance entre père et fils.

129 Isabelle Arseneau évoque plusieurs allusions au texte de Chrétien de Troyes dans "Lancelot échevelé: la parodie dans Les Merveilles de Rigomer», Senefiance, 50, 2004, p. 9-21. Elle traite également des ridicules de Lancelot. Voir aussi Richard Trachsler, "Lancelot aux fourneaux: des éléments de parodie dans Les Merveilles de Rigomer?», Vox Romanica: Annales Helvetici Explorandis Linguis Romanicis Destinati, 52, 1993, p. 180-93, et Douglas Kelly, "Chretien's Lancelot Rewritten: From the Charrette to Rigomer in Manuscript and Narrative Cycle», art. cit.

130 Cette ouverture «trope» la lecture des textes suivants, comme l'exprime Douglas Kelly, "Chretien's Lancelot Rewritten: From the Charrette to Rigomer in Manuscript and Narrative Cycle», art. cit. 
tournoi au Noauz, le compilateur profitant ainsi d'une possibilité offerte par la lecture médiévale pour réinventer la réception de ce roman. Le roman de Chrétien de Troyes est donc tronqué de sa fin, si bien que le lecteur n'assiste jamais à la réhabilitation de Lancelot par le tournoi au mieux. Le personnage, dans le recueil, est démythifié, comme il l'est dans Rigomer, Jehan et l'auteur du manuscrit de Chantilly assumant ainsi leur rejet des données narratives du Lancelot en prose ${ }^{131}$.

Dans Escanor, Perceval et Lancelot s'opposent à Keu: on rappelle le piètre contraste qu'offre le sénéchal auprès d'eux et les moqueries qu'il a essuyées de leur part au cours des récits successifs, notamment lorsqu'il se jure à luimême, sur le chemin de Baubourg, que ses compagnons ne le traiteront plus jamais avec mépris («Tant fera [Keu au tournoi de Baubourg que] mesire Gavainz, / Lancelos ne mesire Yvainz, / Perchevauz ne son parenté, / Ne l'auront mais en tel viuté / Conme il ont eü longuement. ", Escanor, v. 491-495). Perceval n'agit jamais ni ne prend la parole, contrairement à Lancelot: les interventions de ce dernier sont toujours conformes à l'éthique chevaleresque et au compagnonnage. Il se propose pour défendre Gauvain et pour participer à la quête de Gifflet et se désigne également pour combattre le lion faé de la chambre des merveilles de Brian des Illes, prouvant ainsi sa hardiesse. Lancelot se présente comme un chevalier courtois, dévoué à ses amis, et non comme un amant adultère. Seuls les vers 23230 à 23231, énoncés par Gauvain, en font le meilleur chevalier du monde, mais il ne s'illustre pas autrement dans le roman et n'occupe jamais le premier plan d'un seul épisode. C'est donc en compagnon de la Table Ronde qu'il apparaît, souvent mentionné avec Yvain ou Perceval d'ailleurs. Girart d'Amiens occulte volontairement son amour adultère pour la reine, qui a généré les romans en prose et inséré le trouble au sein du monde arthurien; il choisit le chronotope propre au vers ${ }^{132}$. Ce choix est concerté, générique, et non pas le résultat d'une ignorance de la part de l'auteur, comme le prétend Gaston Paris:

131 Voir Lori Walters, "The formation of a Gauvain cycle in Chantilly manuscript 472 », art. cit. Lancelot n'est jamais vraiment réhabilité dans Rigomer: si l'on excepte l'épisode de la Quintefeuille, qui peut apparaître comme un ajout à la quête de Rigomer, on n'assiste plus à un quelconque combat de Lancelot après l'épisode qui le voit déchu aux cuisines. Miraudiel, le dernier adversaire, renonce en effet au duel en apprenant le nom de son adversaire.

132 Richard Trachsler traite de ce point dans «De la prose au vers: le cas de Dynadan dans l'Escanor», art. cit., et "Escanor von Girart d'Amiens im Spannungsfeld von Vers und Prosa", art. cit. 
Il est à remarquer que Girard ne semble pas avoir connu les divers romans en vers et en prose de Lancelot; du moins, en parlant de ce personnage, il ne le présente nullement comme épris de la reine ${ }^{133}$.

Loin d'être une lacune parmi les lectures de Girart d'Amiens, les romans en prose transparaissent au contraire de manière évidente dans son œuvre: Richard Trachsler recense plusieurs personnages exclusifs à la prose, Dinadan, Lambègue, Sinados, Fabrien et Chycoradés, qui n'apparaissent pas dans les autres romans en vers, ce qui prouve que Girart d'Amiens connaissait les romans en prose $^{134}$. Si les trois derniers jouent un rôle marginal, Dinadan ${ }^{135}$ occupe le premier plan de plusieurs épisodes. Richard Trachsler a montré à quel point son apparition dans Escanor est conforme au caractère qu'il a dans le Tristan en prose:

Dinadan refuse les joutes inutiles qui n'ont d'autre but et motif que l'honneur, [...] il n'a que faire de l'amour s'il fait souffrir ceux qui l'éprouvent, et [...] il n'a guère de respect pour les prêtres et Dieu, à qui il ne demande qu'une chose: c'est qu'il le préserve de l'amour des femmes ${ }^{136}$.

Hostile envers les femmes, Dinadan l'est dans le Tristan et dans Escanor, où ses discours s'affichent clairement misogynes ${ }^{137}$. Lorsque Girart d'Amiens

133 Gaston Paris, "Girart d'Amiens", in Histoire Littéraire de la France, Paris, Imprimerie Nationale, vol. XXXI, 1893, p. 168.

134 Richard Trachsler, "De la prose au vers: le cas de Dynadan dans l'Escanor», art. cit., p. 406-407. Le critique cite également le Perron Merlin, Perlesvaus et Brehus sans Pitié. Voir aussi Damien de Carné, "Escanor dans son roman", CRMH, 14, 2007, p. 157-158.

135 Sur le personnage de Dinadan, voir Richard Trachsler, «De la prose au vers: le cas de Dynadan dans l'Escanor", art. cit., Leslie C. Brook, "A knight with reservations: the role of Dinadan in Escanor", Studi francesi, 147, 2005, p. 477-485, Alfred Adler, "Dinadan, inquiétant ou rassurant», in Mélanges Rita Lejeune, Gembloux, Duculot, 1968, vol. II, p. 935-943, Keith Busby, "The likes of Dinadan: the role of the misfit in Arthurian Literature", Neophilologus, 67, 1983, p. 161-174, et Eugène Vinaver, "Un chevalier errant à la recherche du sens du monde», art. cit.

136 Richard Trachsler, "De la prose au vers: le cas de Dynadan dans l'Escanor», art. cit., p. 402.

137 Eugène Vinaver souligne à juste titre que le Dinadan d'Escanor est bien plus misogyne que celui du Tristan en prose. "Un chevalier errant à la recherche du sens du monde», art. cit. 
lui fait dire "Je ne quier c'Amors s'entremete / De moi ne de rienz c'a moi tiegne» (v. 11824-11825) et lui prête de longues tirades explicitant ce point de vue, il respecte l'ethos du personnage dans le roman en prose, qui tient les mêmes propos:

«Se amor est de telle maniere qe ele tolt le sens a l'ame, je ne dit pas qe ce soit amor, ainz est ragerie de teste toute droite [...] Je veille miex vivre sanz amor et estre en joie que amer de fin cuer et estre liéz et puis dolenz.» (ms. 757, f. 102v)

Cette position met en cause le rapport entre arma et amor qui fonde pourtant l'équilibre du royaume.

Ce n'est pas la seule opinion exprimée par Dinadan qui soit commune au Tristan en prose et à Escanor. Notre roman reprend effectivement à son prédécesseur en prose la critique du défi permanent en guise de salutations entre chevaliers errants:

«- Conment? Dynadan, fait li chevaliers. Ne volés vous donc maintenir la coustume du roiaume de Logres? Ja estes vous chevaliers errans! - Chertes, ce est voirs, fait Dynadans. Mais quant je voi que mout grant acoison ne me mainne a jouste ne a combatre, je m'en suefre mout volentiers, car je ne vieng mie granment en liu u je ne truise tel encontre. Tous jours truis je chevaliers ki me dient quant il m'encontrent: "Gardés vous de moi, sire cevaliers! A jouster vous couvient." Ce est orendroit une coustume si conmune par tout le roiaume de Logres que li chevalier errant ne sevent dire li un as autres fors que "Gardés vous de moi!" Je truis chestui salu en tant de lieus que, s'il m’anuie, ce n'est mie mout grant merveille. Pour coi je les refus du tout et refuserai en tous lieus a mon pooir.» (Tristan en prose, vol. IV, $\$ 118$, p. $202^{138}$ )

«Biauz sire, gardez vouz de moy!»

Dist li autres [i.e.: Dinadan]: «Merveilles oy,

Biaus sire, que me volez vouz?

Quele guerre a il entre nous?

Je ne vouz demant s'amor non:

Estre poez de grant renon,

Mais vouz n'estes mie mout sages.»

138 Le Roman de Tristan en prose, dir. Philippe Ménard, Genève, Droz, 1987-1997, tome IV, \$118, p. 202. 
Dist Espinogres: «Li usages

Est tez de moi et l'acointance.

- Biaus sire, la desacointance,

Dist li autres, voeil mix assez.

De vouz veoir sui ja lassez.

Votre acointance me desplaist:

Compaingnie point ne me plaist

Dont tel bien me doie avenir.» (Escanor, v. 11769-11783)

Dans la prose comme dans le vers, Dinadan problématise les conventions de l'errance arthurienne ${ }^{139}$ : l'usage, la coutume, du défi prononcé sans raison apparente («sanz achoison et sanz meffait», v. 12321), pour le simple plaisir de se battre, contrevient à la sagesse et à la mesure attendues du chevalier. C'est "par enfance» (v. 12345) et "pour noient» (v. 12344) que les chevaliers arthuriens s'affrontent: il ne peut en advenir que «meschiez» (v. 12347), écho possible à la Mort Artu et à la mescheance de la fin du royaume arthurien. L'importance, en termes quantitatifs, du discours que tient Dinadan dans les épisodes où il intervient doit attirer l'attention du lecteur sur ses revendications. Loin de représenter un simple personnage amusant par sa dissonance, il se fait le porte-parole d'une interrogation plus profonde sur le monde arthurien: les chevaliers sont «fol" (v. 12448) de maintenir ces usages, et "Trop sonmes plain de mescheance/ Tout ensamble conmunaument» (v. 12452-12453). Les compagnons de la Table Ronde sont tenus pour responsables de la mescheance qui peut s'abattre sur le royaume - les romans en prose en donnent la preuve.

D'autres coutumes sont pointées du doigt au début d'Escanor, lorsque Dinadan doit prendre le parti de Mordred contre Keu qui a insulté l'amie de ce dernier, alors que le texte a lourdement insisté sur le peu d'affection qu'il porte au fils incestueux du roi au début de cette aventure («Et il resavoit de tel estre / Mordret c'adonques, s’il peüst, / A son gré trové ne l'eüst, / Quar bien savoit qu'il ert estouz / Et fox et melliex deseur touz. "Escanor, v. 682-686). L'obligation à laquelle il est tenu de soutenir

139 Seule la deuxième version du Tristan en prose, la version longue, donne à voir un Dinadan qui interroge les normes arthuriennes. Dans la version courte, il se distingue surtout par sa bonne humeur. Voir Eugène Vinaver, "Un chevalier errant à la recherche du sens du monde ", art. cit., et Emmanuèle Baumgartner, Le Tristan en prose: essai d'interprétation d'un roman médiéval, p. 32-35. 
le chevalier qu'il accompagne contrevient à celle de ne pas se battre contre un chevalier de la Table Ronde, dont il est compagnon (v. 1180-1184). Le monologue que Dinadan prononce, puis le dialogue qu'il a avec Keu, celui-ci lui reprochant de l'avoir défié sans aucune raison, thématisent ce dilemme auquel il doit faire face et pointent l'absurdité des conventions. Il est également attendu de lui qu’il défende l'amie de Mordred, bien qu'il ait juré que "dame ne pucele, / Tant fust savereuse ne bele, / N'auroit en conduit a nul jor / ne ne garderoit a sejor» (v. 673-676). En refusant d'accepter sans discussion les normes du monde arthurien, Dinadan en montre le caractère irrationnel. C'est en ce sens qu'il faut comprendre la présentation qu'il fait de lui-même à Agravain dans le Tristan en prose:

Je suis un chevalier errant qui chascun jor voiz aventures querant et le sens du monde: mais point n'en puis trouver, ne point n'en puis a mon oes retenir ${ }^{140}$.

Dinadan est en quête d'un sens qui motiverait le code chevaleresque: son errance n'est plus dévolue à la recherche d'un objet ou d'une femme, mais bien à la sagesse, la mesure. En refusant le combat et l'amour, Dinadan étonne les chevaliers qu'il rencontre, mais cette attitude est le résultat d'une perspective réfléchie sur le monde, dont il rejette les folies.

Au sein du Tristan en prose, Dinadan dissone, lorsqu'il conteste le duel, l'amour, la foi, qui fondent pourtant cet univers. Les joutes, qu'elles soient pour une amie ou simplement pour le plaisir de combattre, sont dangereuses et détournent de causes justes, celle de défendre les innocents. Ce n'est donc pas la couardise ni le rejet de l'idéal chevaleresque qui l'encouragent à tenir un tel discours, mais bien sa conviction que la prouesse doit se réserver à des causes utiles et salvatrices et non se consacrer à la vaine gloire ${ }^{141}$. Cette dénonciation de la vanité de certaines

140 Version du manuscrit BnF fr. 334, f. 334r, d'après la transcription d'Eugène Vinaver, "Un chevalier errant à la recherche du sens du monde», art. cit., p. 679. Voir l'article entier sur le non-sens et la philosophie de Dinadan.

141 Dans Escanor, on en a également la preuve lorsque le lecteur apprend que Dinadan préfere s'éprouver dans l'errance que de rester statique à la cour (v. 1518-1525), et lorsqu'il poursuit Brun sans Pitié pour venger la jeune fille que celui-ci agressait. Emmanuèle Baumgartner donne plusieurs exemples attestant le courage de Dinadan dans le Tristan en prose, démontrant par là que son attitude ne résulte pas de la couardise ni d'un rejet total de l'idéal chevaleresque. Le Tristan en prose: essai d'interprétation d'un roman médiéval, p. 182-189. 
entreprises chevaleresques, qui ont construit la littérature arthurienne, au sein même d'une ouvre qui les glorifie par ailleurs, génère la complexité et l'ambiguïté de ce roman ${ }^{142}$ : les deux visions de la chevalerie peuvent coexister sur le mode de la contradiction et laissent au lecteur la liberté de se faire son propre avis, tout comme il est libre d'élire qui de Lancelot ou de Tristan est le meilleur ${ }^{143}$.

Choisir d'insérer ce personnage exclusif à la prose dans un roman en vers n'est pas anodin: l'ethos du personnage, établi par le Tristan en prose, remplit parfaitement les buts que se fixe Girart d'Amiens: cultiver l'ambiguïté d'abord, à la fois en ce qui concerne les valeurs et les personnages, qui échappent aux catégorisations manichéennes. Il s'agit d'un trait commun à plusieurs romans en vers tardifs: nous le développerons au chapitre III, «Un manichéisme relatif», p. 482-493. Ensuite, répondre aux attentes ludiques du lecteur de romans arthuriens en vers: car les épisodes dans lesquels intervient Dinadan sont toujours comiques et doivent susciter le rire et l'enthousiasme du public, comme ils génèrent celui des personnages: «Li rois prist trop forment a rire / De ce qu'il ot Dynadan dire, / Aussi firent li autre tuit.» (v. 1631-1633); "De nului / N'ert haï, ançois se rioient / De quanques dire li ooient.» (v. 11882-11884); “Car nuz hon ne fust avoec lui / Qui sa compaignie n'amast, / Conment qu'il les mesaamast» (v. 1439514397). L'humour qui accompagne Dinadan est commun à Escanor et au Tristan en prose. Dinadan s'intègre ainsi parfaitement au genre du roman en vers, alors qu'il dissone dans le roman en prose en introduisant «une tonalité plus familière et plus souriante», comme l'écrit Bénédicte MillandBove $^{144}$. Lorsqu'un personnage de la prose est choisi pour jouer un rôle dans un roman tardif, il est toujours compatible avec l'esthétique du genre,

142 Philippe Ménard, "Le Roman de Tristan en prose au cœur de la littérature arthurienne», in Mémoires arthuriennes, dir. Danielle Quéruel, Troyes, La Renaissance, 2012, et Bénédicte Milland-Bove, "Nous chantons chansons diverses et si tirom diverses cordes" Lesthétique de la dissonance dans le Tristan en prose», Cahiers de recherches médiévales, 5, 1998, en ligne: https://journals.openedition.org/crm/1402.

143 Damien de Carné analyse en détail la concurrence entre Tristan et Lancelot dans le Tristan en prose, dans Sur l'organisation du Tristan en prose, p. 177-411. Sur la cohabitation de thèses concurrentes représentée par Dinadan au sein du Tristan en prose, voir Eugène Vinaver, "Un chevalier errant à la recherche du sens du monde", art. cit., et Emmanuèle Baumgartner, Le Tristan en prose : essai d'interprétation d'un roman médiéval, p. 182-189.

144 "Nous chantons chansons diverses et si tirom diverses cordes" ", art. cit., p. 2. 
tandis que les figures tutélaires des textes en prose sont évincées pour exclure l'horizon d'une fin au monde arthurien.

L'intervention de Brun sans Pitié dans Escanor est également compatible avec l'esthétique du roman en vers tardif. Ce chevalier rappelle étrangement Brehus sans Pitié, par son surnom et les sonorités de son prénom, mais aussi parce qu'il présente des caractéristiques communes avec ce personnage issu de la prose ${ }^{145}$. Brehus «tue les vieux, viole les pucelles, apparaît et disparaît comme une ombre dans la forêt et reste généralement impuni, car il possède un cheval particulièrement rapide ${ }^{146}$. Le narrateur d'Escanor précise lui aussi que « Ne fu onques nuz teuz chevauz / Conme li sienz, ne pluz penibles, / Ne miex erranz, ne pluz paisibles, / Ne sour qui on se lassast mainz» (v. 796-799). Dans ce roman en vers, Brun demeure tout autant impuni que dans le Tristan en prose: il échappe à Dinadan et Mordret qui entendaient venger la jeune fille dont il avait tué l'ami puis qu'il avait poursuivie. Brun/Brehus incarne donc le félon, le mal que les héros doivent éradiquer. Il est pourtant chevalier de la Table Ronde, dans la prose comme dans le vers:

S'ert il de la Table Reonde

Compainz, car au conmencement

Estoit il d'autre affaitement,

Et preuz, et cortois, et raisnables.

Je ne sai conment li deables

Li ot doné tel volenté. (Escanor, v. 4026-4031)

Le narrateur d'Escanor justifie son affiliation aux chevaliers d'Arthur par les qualités courtoises dont il faisait preuve à l'origine, mais se garde de motiver son attitude hostile. Thématiser l'incongruité de ce compagnonnage, renforcée par l'enjambement des vers 4026-4027, doit encourager le lecteur à s'interroger: pourquoi faire de Brun/Brehus un chevalier de la Table Ronde? Pourquoi Girart d'Amiens choisit-il de

145 Brun sans Pitié apparaît de manière marginale dans les Continuations en vers. Le caractère qu'il a dans Escanor ne fait pas de doute sur sa provenance: il est bien inspiré des romans en prose. Outre le Tristan en prose, il figure également dans le Lancelot-Graal, Guiron le courtois et le Livre d'Artus.

146 Richard Trachsler, "De la prose au vers: le cas de Dynadan dans l'Escanor», art. cit., p. 407. Sur Brehus sans Pitié, voir aussi Emmanuèle Baumgartner, Le Tristan en prose : essai d'interprétation d'un roman médiéval, p. 197-199. 
l'insérer dans son roman? Brun/Brehus est la preuve vivante que le mal est endogène, qu'il contamine la caste arthurienne de l'intérieur, ce qui prépare la chute du royaume à l'horizon des romans en prose: sans motif spécifique à son rejet de tous les préceptes chevaleresques, Brehus incarne, dans le Tristan en prose, "la victoire des forces du mal ${ }^{147}$. Dans le roman en vers tardif, la présence de Brun sans Pitié met en cause la perfection de la Table Ronde et de la chevalerie arthurienne. Nous y reviendrons, l'esthétique tardive donne l'image d'un monde où rien n'est univoque: les personnages, qu'ils soient adversaires ou chevaliers d'Arthur, ne sont jamais ou tout blancs ou tout noirs. La présence de Brun sans Pitié dans Escanor vient accentuer l'ambiguïté des valeurs présentées, la complexité d'un monde d'où est exclu tout manichéisme.

Si Dinadan et Brun/Brehus sans Pitié peuvent être transférés de la prose au vers sans modification majeure, l'intégration de Merlin au roman en vers est plus audacieuse: l'enchanteur est en effet fortement lié au destin du monde arthurien et à ses origines. Il trouve donc difficilement sa place dans un chronotope fondé sur l'insouciance de l'achronie. L'auteur de Claris et Laris lui accorde toutefois un rôle ${ }^{148}$ : c'est d'abord Brandalis qui le rencontre sans le reconnaître. Alors qu'il erre à la recherche de Laris emprisonné chez les Danois, il suit un feu merveilleux qui semble le fuir. Lorsqu'il le rejoint enfin, il y trouve un vieil homme qui lui fournit une nourriture simple, conforme au régime alimentaire d'un ermite, de l'herbe pour son destrier et l'accueille pour la nuit à côté de son feu. Le lendemain matin, le vieux a disparu et une voix reproche à Brandalis de ne pas avoir questionné Merlin, dont le nom apparaît enfin dans le récit, au sujet de Laris; le chevalier avait pourtant eu la chance d'être hébergé par celui "Qui tout set, tout fet et tot voit» (v. 22240). Cette voix prophétique et accusatrice n'est pas sans rappeler celles qui ponctuent la Queste del Saint Graal, tout comme l'erreur de Brandalis, qui n'a pas posé de questions, rappelle le Conte du Graal. Le Graal n'est toutefois jamais mentionné, malgré les allusions à son univers. Les idées d'élection et de destinée sont en revanche reprises à ces intertextes.

147 Emmanuèle Baumgartner, Le Tristan en prose: essai d'interprétation d'un roman médiéval, p. 198.

148 Corinne Pierreville traite de cet épisode aux pages 313 à 321 de Claris et Laris, somme romanesque. 
Brandalis n'est pas l'élu de la quête de Laris, d'où son échec face à Merlin, d'où aussi sa capture dans la prison d'une dame vindicative, juste après sa rencontre avec l'enchanteur. La voix, qui se révèle être celle de Merlin, comme nous l'apprend le vers 22490, prophétise la réussite de Claris à la fois dans la quête de Laris et dans la libération de Brandalis:

«Bien set [Merlins] conment iert delivrez

Laris li biaus de la prison!

Dite t'en eüst la raison

Se li eüsses demandee.

Ore est ainsi l'uevre sonmee:

Prison tenir te couvendra

Mes Claris t'en deliverra

Par le conseill Merlin le sage.

Trop as perdu bel avantage!» (Claris et Laris, v. 22254-22262)

Brandalis remplit la fonction de faire-valoir de Claris, qui réussira l'épreuve. La voix de Merlin donne à celui-ci une destinée, l'extrait de la condition de simple chevalier. Son élection n'est toutefois pas celle qui touche Galaad, liée à la foi, mais une élection toute terrienne: Claris est le champion de l'amitié ${ }^{149}$. Lorsqu'il rencontre le vieil homme dans la forêt, il a ainsi la capacité de s'étonner de la présence de Merlin dans la forêt, de lui demander son identité, puis de se souvenir du don d'omniscience de son interlocuteur. Merlin lui annonce, avec une clarté à laquelle le lecteur est peu habitué de sa part, qu'il délivrera Brandalis puis Laris, selon le stratagème suivant: accompagné de divers chevaliers qu'il aura sortis de prison au fur et à mesure, Claris se déguisera en ermite pour pénétrer le château de Tallas. L'intervention de Merlin témoigne de la haute portée dont relève la quête de Laris, d'une importance semblable à celle du Graal ou à la conception d'Arthur, signe que le compagnonnage est une valeur essentielle dans ce roman.

Merlin est donc bien, dans Claris et Laris, le prophète que la tradition a fait connaître: il prédit l'avenir et conseille ses protégés pour mener à bien leur entreprise. La voix qui parle à Brandalis dresse d'ailleurs un portrait familier au lecteur:

149 Voir Corinne Pierreville, Claris et Laris, somme romanesque, p. 158-179. 
«Merlins est cil qui set les biens.

C'est cil qui le roy Artus fist,

C'est cil qui l'espee tramist

$\mathrm{Au}$ perron dont fu receüz

Et par Bretaingne retenuz.

Merlins fist la Roonde Table,

Merlins fu mestre connestable

Roys Pandragon veraiement,

Merlins set bien confaitement

Li roys Artus fu engendrez.» (Claris et Laris, v. 22244-22253)

Ces détails proviennent du Merlin de Robert de Boron ${ }^{150}$ : l'enchanteur est à l'initiative de la Table Ronde et «fist» Arthur, c'est-à-dire qu'il a organisé sa naissance, comme le sous-entendent également les vers 22252 et 22253. Aucune allusion n'est faite au Saint Vase, malgré la mention de la Table Ronde, qui fait pendant à celles de la Sainte Cène et du Graal chez Robert de Boron. Les références aux débuts du monde arthurien taisent le destin funeste du royaume et sa chute programmée pour se concentrer sur l'origine de sa construction.

Un deuxième discours, adressé cette fois à Claris, évoque brièvement et de manière élusive les raisons de la présence de Merlin dans la forêt:

"Ge sui Merlins par non clamez.

Du roy Pendragon fui amez.

Longuement fui ensemble o soi

Mes le monde est si plain d'anoi

Que ci ving pour espeneïr.

N'en partirai dusqu'au morir.» (Claris et Laris, v. 22935-22940)

Bien que l'expiation («espeneïr») ne soit pas clairement liée à la tradition littéraire, ce retrait du monde semble faire référence à une habitude qu'a Merlin de vivre en homme sauvage, en silvester, à intervalle régulier ${ }^{151}$.

150 Voir Richard Trachsler, Merlin l'enchanteur. Étude sur le Merlin de Robert de Boron, Paris, SEDES, 2000, pour une analyse détaillée de cette œuvre, ainsi que Irène Fabry, «De rappels en prédictions, savoir convaincre et savoir agir: le rôle ambigu de Merlin, de la naissance d'Arthur à son accès au trône de Bretagne (dans le Merlin en prose et la Suite Vulgate)", L'Esplumeoir, 6, 2007, p. 15-23.

151 Voir Richard Trachsler, Merlin l'enchanteur, p. 87-89, et Frédérique Le Nan, «Les séjours sylvestres de Merlin dans l'œuvre de Robert de Boron", in Merlin. Roman 
S'il s'agit donc bien d'un Merlin conforme à l'image qu'en donnent les romans en prose, rien n'évoque ni le Graal ni les prophéties sur le destin du royaume. Son apparition dans Claris et Laris témoigne cependant du caractère incontournable des cycles en prose à la fin du XIII ${ }^{\mathrm{e}}$ siècle et vaut comme clin d'œil à ce chronotope: l'auteur tardif signale ainsi que les thèmes qui occupent l'écriture en vers, ici l'amitié, le compagnonnage, l'amour, peuvent revêtir une dimension transcendantale et nécessiter eux aussi l'entremise du célèbre prophète.

Hormis l'œuvre de Robert de Boron, Claris et Laris est le seul texte arthurien versifié dans lequel Merlin intervient en tant que personnage ${ }^{152}$ : dans les autres romans arthuriens en vers, il n’est évoqué qu’au titre de

du XIII siècle, éd. par D. Quéruel et Chr. Ferlampin-Acher, Paris, Ellipses, 2000, p. 16-28. Merlin énonce devoir "par fine force de nature estre par foies eschis de la gent" (Robert de Boron, Merlin, éd. Alexandre Micha, Paris, GF, 1979, p. 149).

152 Merlin apparaît aussi dans le Roman de Silence, texte en vers du milieu du XIII ${ }^{\mathrm{e}}$ siècle. Son intervention rejoue une scène de la Suite Vulgate du Merlin, l'épisode de Grisandole. Dans les deux cas, une jeune fille travestie en garçon subit les tentatives de séduction d'une reine, qui l'accuse ensuite auprès de son mari, conformément au motif de la femme de Putiphar; l'héroïne doit capturer Merlin; on croit la chose impossible, car l'enchanteur ne se laisse approcher que par les jeunes filles; l'héroïne parvient à attirer Merlin; Merlin est ramené à la cour et énonce une série de vérités ou de prophéties, ponctuées par son rire mystérieux. Voir les articles d'Irène Fabry, "Le festin de l'homme sauvage dans la Suite Vulgate du Merlin et le Roman de Silence: l'attrait de la nourriture et la mise en scène paradoxale du personnage de Merlin», Questes, 12, 2007, p. 49-64, Danièle James-Raoul, «Un curieux avatar de L'Estoire Merlin: le Roman de Silence», art. cit., Sarah RocheMahdi, "A reappraisal of the Role of Merlin in the Roman de Silence", Arthuriana, 12:1, 2002, p. 6-21, et Anne Berthelot, "Merlin et Grisandole», in Actes du premier colloque de la SIAM, Amsterdam (27-28 juin 2003), Esplumeoir, janvier 2004, p. 19-25. Il s'agit d'un cas intéressant de réécriture d'un épisode arthurien dans un roman non arthurien, transfert redoublé par le passage de la prose au vers. Richard Trachsler en traite dans Disjointures-conjointures, p. 118-126. Le retour d'un personnage arthurien, aussi célèbre soit-il, et l'intertextualité ne suffisent néanmoins pas à faire de ce texte un roman arthurien en vers. Les références arthuriennes demeurent circonscrites à l'épisode de Merlin et ne sauraient prendre le pas sur les problématiques sociales et politiques qui dominent le roman (l'héritage des femmes, l'éducation d'un jeune prince, les intrigues de cour, la place des ménestrels dans la société, l'avarice, l'exercice de la justice, la révolte des comtes). Sur ces préoccupations, voir Sharon Kinoshita, «Male-Order Brides: Marriage, Patriarchy, and Monarchy in the Roman de Silence», Arthuriana, 12.1, 2002, p. 64-75. 
fondateur de certains lieux visités par l'errance des chevaliers, l'Esplumoir Merlin dans Méraugis de Portlesguez, le pilier du Mont Dolereus dans la deuxième Continuation et la Continuation de Gerbert de Montreuil, le Perron Merlin dans Escanor. Ce dernier lieu n'est, une fois encore, pas indépendant des romans en prose. Le Perron Merlin voit le premier affrontement entre Lancelot et Tristan dans le Tristan en prose: c'est là que devait se rendre Palamède pour se battre contre Tristan, mais, retenu prisonnier, il est confondu avec Lancelot par le héros. Symbole de la concurrence entre les œuvres, le Lancelot-Graal et le Tristan, le Perron Merlin est souvent rappelé au cours du roman comme lieu du rendez-vous manqué entre Tristan et Palamède et comme épisode qualifiant la prouesse et la rivalité de Tristan et Lancelot ${ }^{153}$.

Dans Escanor, il s'agit d'abord d'une aventure que Gauvain et Gifflet rencontrent au cours de leur errance. Gauvain souhaite quitter l'oisiveté de la cour et incite Gifflet à le suivre au Perron Merlin, "Car maint chevalier de haut lin / I a on trové mainte foie» (v. 12983-12984), que le lecteur ne manquera pas d'identifier, fort de ses souvenirs littéraires du Tristan. Quoique décrit comme la fontaine de Barenton, ce perron, "Lez la fontaine, souz le pin» (v. 13019), remplit une fonction similaire à celui du roman en prose. C'est là que les envoyés d'Escanor le Grand capturent Gifflet, à défaut de s'emparer de Gauvain qu'ils tiennent pour responsable de l'attentat contre Escanor le Bel. Cette capture est un tournant du récit: elle prend place au milieu de l'œuvre et mène progressivement au dénouement de tous les fils narratifs, car les membres de la Table Ronde, pour délivrer Gifflet, doivent initier une guerre contre Escanor. Le Perron Merlin cristallise alors la rivalité entre les lignages des Escanor et de Gauvain, tout comme il symbolisait celle de Tristan et Lancelot. Insérer ce lieu signifiant de la tradition arthurienne en prose dans un roman en vers, c'est aussi exhiber une rivalité avec cette écriture, signifier que le vers permet autant de construire un récit cohérent et à la structure solide sur la base du même univers.

En voyageant de la prose au vers, ce perron semble perdre le lien qu'il avait avec les prophéties de Merlin: l'enchanteur y fait graver les noms des meilleurs chevaliers, Galaad, Lancelot et Tristan au début du roman en prose, ce qui renforce la symbolique du perron comme lieu électif où

153 Voir Damien de Carné, Sur l'organisation du Tristan en prose, p. 237 et 310-313. 
se jouent les réputations ${ }^{154}$. Dans Escanor, cette lecture du Perron Merlin comme lieu de la rivalité et de l'élection ne se comprend qu'en référence au Tristan en prose: il demeure sans cela une étape de l'errance, un endroit où rencontrer à coup sûr des «aventures merveilleuses, / Bones et bien cevalereuses» (v. 12986-12987).

Les transformations que subissent les personnages lorsqu'ils sont transférés dans le chronotope du vers concernent souvent une dédramatisation, que l'on pense à ce que devient Lancelot dans Rigomer. Dodinel le Sauvage n'est lui aussi plus tout à fait le même lorsqu'il intervient dans Claris et Laris. Avant cela, il apparaît dans quelques romans en vers, où il n'est pas spécialement caractérisé et se réduit souvent à un nom au milieu d'une liste (dans Erec et Enide, Le Chevalier au lion, la Continuation de Manessier, Escanor, Rigomer). Les romans en prose lui donnent un peu plus d'épaisseur en précisant parfois son lignage (frère de Galescin, fils de la dame de Malehaut, parent de Bédoin de la Marche) ${ }^{155}$, voire en expliquant son surnom de "sauvage" par sa propension à chasser dans la forêt $(\text { Suite-Vulgate })^{156}$. Il est souvent désarçonné ou emprisonné dans le Tristan en prose, mais n'est en revanche jamais le héros d'une aventure. L'auteur de Claris et Laris répare cette injustice: toutefois, il façonne un personnage de couard, par antiphrase avec ce que le surnom de «sauvage» (v. 20394) pourrait laisser envisager et le portrait qu'en dresse la Suite-Vulgate.

L'épisode où il intervient dans Claris et Laris (v. 26743-26954) démontre son ingéniosité à éviter toute confrontation armée: il prétend, pour obtenir l'hospitalité gratuitement auprès de son premier adversaire, que son amie doit le rejoindre le lendemain. Faisant preuve d'une totale courtoisie, il souhaite donc différer le combat pour qu'elle puisse y assister. Au chevalier belliqueux suivant, il fait croire à l'arrivée imminente de son père et de son frère, qui pourraient s'immiscer dans leur duel; il vaut mieux, une fois encore, reporter l'affrontement. Enfin, en arrivant au Danemark chez Tallas, il se fait passer pour un ménestrel et échappe ainsi

154 Sur les inscriptions du Perron Merlin, voir Florence Plet, «Son non escrit par droite aventure. L'inscription du nom propre dans le Tristan en prose», Linx, 12, 2002, p. 231-235.

155 Voir G. D. West, An Index of Proper Names in French Arthurian Prose Romances, Toronto, Toronto University Press, 1978, p. 95.

156 Ernst Brugger, "Bliocadran, The Father of Perceval», in Medieval Studies in Memory of Gertrude Schoepperle Loomis, Paris, Champion, 1927, p. 166-171. 
à l'emprisonnement. Ce dernier rôle lui sied parfaitement: il remplit, dans le roman et au sein de la Table Ronde, une fonction divertissante, lui qui amuse aussi bien ses compagnons que ses adversaires. L'hôte qui l'a défié et sa demoiselle rient de bon cœur du tour que Dodinel leur a joué en s'éclipsant au matin, tandis que ses «bons moz" amusent Tallas, le mauvais roi du Danemark, et Laris, son prisonnier: "De ses bons moz souvent rioient / Li rois Talas meïsmement / Et Laris li biaux ensement.» (v. 26952-26954). Contrairement à Dinadan, ce personnage atypique ne propose pas de réflexion sur les coutumes chevaleresques: il s'assume au contraire comme un couard. Le roman lui donne néanmoins sa place, en démontrant l'importance de l'activité littéraire et du divertissement, propres à réjouir les chevaliers autant que les opposants au royaume d'Arthur, ainsi que l'exprime Corinne Pierreville:

Au milieu des tourments de la détention, la capacité à conter des histoires, à procurer de la joie, s'avère une valeur aussi essentielle que la bravoure chevaleresque, car le rire parvient même à rapprocher momentanément des ennemis aussi irréconciliables que Laris et Tallas. Par le biais de Dodinel, l'auteur prouve que l'aptitude à imaginer des fables et à divertir un auditoire est aussi louable, et aussi nécessaire, que la prouesse guerrière ${ }^{157}$.

L'auteur de Claris et Laris propose un monde joyeux et intégratif; un monde qui correspond au chronotope du roman en vers. Le nouveau visage que revêt Dodinel dans Claris et Laris témoigne bien d'un réinvestissement propre à l'écriture versifiée.

Agravain subit également une transformation ontologique lorsqu'il est récupéré par les romans arthuriens en vers tardifs; bien qu'il apparaisse beaucoup dans les continuations du Conte du graal, ce personnage a un rôle très marginal dans les premiers romans en vers. Dans la Mort Artu, il joue en revanche un rôle funeste, lorsqu'il tente par tous les moyens de prouver au roi Arthur l'amour entre Lancelot et Guenièvre. Dirigeant les hommes chargés de l'arrestation de la reine puis préposé à garder celle-ci

157 Corinne Pierreville, "Claris et Laris: les prisons du roman arthurien", in Réalités, images, écritures de la prison au Moyen Âge. Actes du colloque de Dijon des 7 et 8 octobre 2010, dir. Jean-Marie Fritz et Silvère Menegaldo, Dijon, Éditions universitaires de Dijon ("Écritures»), 2012, p. 56. Voir aussi Douglas Kelly, "Tout li sens du monde dans Claris et Laris", art. cit. 
sur le bûcher, il est tué par Lancelot. Rien d'étonnant alors à ce que les textes du Lancelot-Graal le présentent comme un personnage envieux, porté au mal ${ }^{158}$. Dans les romans en vers tardifs au contraire, il s'agit d'un compagnon de la Table Ronde tout à fait courtois, qui ne se distingue pas particulièrement parmi ses pairs. Dans Claris et Laris, il est le héros de deux petites aventures: il est d'abord défié par un chevalier à l'épervier, qui doit envoyer les adversaires qu'il parvient à vaincre à son exigeante amie (v. 10337-10450), écho à la Joie de la Cour et à l'épreuve de l'épervier dans Erec et Enide. Plus tard, il remporte un tournoi, dont le prix est un autour (v. 21318-21503). Dans Rigomer, il aide son hôte à retrouver sa femme, envolée lors d'un orage (v. 7991-8436).

Il s'agit pourtant bien du même personnage, puisque l'on précise qu'il est le frère de Gauvain à chacune de ses apparitions dans le corpus tardif (Claris et Laris, v. 13960, Rigomer, v. 8145). L'identité entre ce chevalier nommé "Agravain» ou "Engrevain» (Rigomer, v. 7994) dans le vers et celui qui dénonce Lancelot et Guenièvre dans la prose n'engendre pourtant pas un portrait négatif du personnage, contrairement à ce qu'il se passe pour Mordred. Seul l'orgueil du personnage, auquel l'allusion est si brève qu'elle passe aisément inaperçue dans Claris et Laris et Rigomer, peut assombrir très légèrement le caractère d'Agravain: "Si i fu mesire Engrevains, / Li orguellous as dures mains» (Rigomer, v. 14245-14246); "Agravains, / Li orgueilleus aus dures mains» (Claris et Laris, v. 1331513316). Le texte d'Escanor, qui par ailleurs n'octroie aucune aventure individuelle à Agravain, insiste davantage sur son orgueil: "Chevaliers ert trop merveilleuz, / S'il ne par fust tant orgueilleus" (v. 5019-5020). Le surnom d' "orgueilleux aux dures mains» et l'attribution de ce trait de caractère ne suffisent pourtant pas pour soupçonner son rôle déterminant dans la chute du royaume arthurien: Agravain est, dans le roman en vers tardif, un simple chevalier de la Table Ronde.

Nulle ombre ne plane sur son portrait; tout est affaire d'implicite. Le narrateur de Melyador n'explicite pas le rôle qu'Agravain joue dans la Mort Artu, mais fait allusion à l'importance qu'aura ce personnage dans l'histoire arthurienne:

158 La Suite-Vulgate accentue le caractère négatif du personnage. Voir Richard Trachsler, Clôtures du cycle arthurien. Étude et textes, Genève, Droz, 1996, p. 99-100. 
Agravains estoit encor jones

Sus la queste ditte devant,

Mais on parlera en avant

Assés de ses chevaleries

Qui furent moult auctorisies

Ou temps que Lancelos regna. (Melyador, v. 30597-30602)

Agravain, qui puissedi fu

Li Chevaliers au Blanch Escu

Et qui acquitta mainte cose

Ensi que li livres le glose

Ailleurs que ci qui bien le trueve. (Melyador, v. 30630-30634)

Le temps est encore à l'insouciance et la jeunesse d'Agravain dispense d'évoquer son funeste destin: un autre livre, dans une autre forme et un autre chronotope, s'en charge. Au lecteur de reconstruire virtuellement le futur de ce chevalier. Pour l'heure, dans Melyador, Agravain n'a pas l'occasion de se distinguer en bien ou en mal: on mentionne seulement à la fin du récit son mariage avec Florée, la cousine rusée d'Hermondine.

Le réinvestissement du personnage de Mordred par les romans tardifs procède d'intentions similaires. Le fils incestueux d'Arthur, dont le destin est funeste dans les textes en prose, n'apparaît que dans la Deuxième Continuation, la Continuation de Manessier, Floriant et Florete, où il ne figure qu'au sein de listes de chevaliers de la Table Ronde. Les tardifs Claris et Laris et Escanor se chargent de lui donner un rôle plus substantiel; il y devient un méchant chevalier, néanmoins intégré à la Table Ronde. Dans Claris et Laris, il tenter de violer une jeune et fait preuve d'une concupiscence que le narrateur souligne ("De chalor toz li cors li mue», v. 23904) en même temps qu'il se moque de sa précipitation à défaire son pantalon («Ses chauces deslaciés avoit», v. 23915).

Cette représentation du personnage de Mordred fait signe vers le Lancelot-Graal: l'univers de la prose intervient en creux. L'auteur prend le parti de tenir compte des données élaborées par la prose, mais il choisit de faire jouer un rôle marginal au traître de la Mort Artu, présenté comme le frère de Gauvain et non comme le fils incestueux d'Arthur dans Claris et Laris: Mordred ne détruit pas le royaume mais l'on n'oublie pas pour autant qu'il s'agit d'un mauvais chevalier. Le faire figurer sans évoquer sa trahison future, c'est revendiquer un monde atemporel qui ne tire pas vers sa fin, tout en ayant conscience que Mordred ne peut apparaître comme 
un simple chevalier de la Table Ronde après les cycles en prose. Le roman en vers tardif donne un rôle à Mordred au sein de son chronotope, mais ce rôle ne peut qu'être négatif. La dévalorisation du personnage n'a toutefois rien de celle, tragique, que le lecteur rencontre dans la prose: elle donne lieu à des épisodes comiques, comme lors de la tentative manquée de Mordred de violer Calogrenant métamorphosé en jeune fille (Claris et Laris, v. 26299-26347), ou lorsqu'il doit remonter ses chausses à la hâte pour affronter les frères de la demoiselle qu'il essaie de violer (v. 23935), ou encore quand il échoue à l'aventure du moulin et tombe pathétiquement dans une fosse, si bien que ses compagnons doivent l'en tirer de toutes leurs forces (v. 24932-24950). L'idéologie est donc fondamentalement différente, entre le vers et la prose: les mauvaises dispositions de Mordred alimentent la delectatio dans un cas, elles mènent à la chute dans l'autre. L'auteur de Claris et Laris s'efforce de transformer le traitre en un personnage ridicule qui invite à la moquerie et désamorce ainsi sa funeste incidence sur le monde arthurien. Il en fait une figure bien plus conforme aux visées de l'écriture en vers.

Mordred a un rôle identique dans Escanor: le narrateur le présente comme un personnage qui «ne fu preuz, / Car en lui n'ot que fausseté, / Felonie et desloiauté»(v. 650-652) et le compare même à Ganelon («Mordet le felon / Ou pluz ot mal qu'en Guenelon», v. 18919-18920). Sa seule intervention ne donne pas une image plus positive de lui, puisqu'il défie Keu sans se faire connaître pour venger son amie que le sénéchal n'a pas saluée. L'aversion de Dinadan à son encontre complète ce portrait négatif: le narrateur, usant de la focalisation interne, restitue les pensées du personnage qui regrette les circonstances l'ayant contraint à accompagner Mordred, car "n'amast mie tel maisnie» (v. 696). Dès qu’il peut se débarrasser du neveu du roi, d'ailleurs, il le quitte sans regret (v. 1496-1499). Pourtant, aucune prolepse qui annoncerait la trahison de Mordred envers la couronne ne vient justifier les qualificatifs «felon », «desloial» ou "faus» (v. 651-652 cités plus haut). Bien sûr, le lecteur connait les textes en prose et comprend la raison pour laquelle on dévalorise ce personnage ${ }^{159}$. Mais, dans le cadre du roman, il s'agit simplement d'un mauvais chevalier, que ses liens de parenté autorisent à siéger à la Table Ronde: il est «niez [...]

159 Richard Trachsler montre que Girart d'Amiens connaissait bien les textes en prose mais choisit délibérément de ne pas en exploiter la matière. «De la prose au vers: le cas de Dynadan dans l'Escanor", art. cit. 
au bon roi Artu» (v. 646) et "freres monseingnor Gavain, / Gaheriet et Agravain / Et Guerrehet» (v. 647-649). Cette liste de l'entier de la fratrie n'est pas si fréquente et peut faire signe, là encore, vers la Mort Artu et les conflits lignagers que cette œuvre qui clôt le cycle met en scène ${ }^{160}$. Malgré un portrait négatif, Mordred remplit néanmoins ses fonctions de compagnon de la Table Ronde en partant en quête de Gifflet et en se battant dans la campagne contre Traverses (v. 14374, 18919-20, 19751).

Le roman arthurien en vers tardif réinvestit les grands noms de l'histoire arthurienne pour les adapter à son chronotope. Le rôle de chacun des personnages secondaires n'est pas d'inscrire le monde dans une perspective eschatologique, mais de multiplier et diversifier les aventures plaisantes. C'est la fonction que remplit Sagremor dans Melyador. Ce personnage apparaît aussi bien dans le vers que dans la prose ${ }^{161}$ comme un chevalier "desreez», en raison de sa tendance à la démesure. Ce trait de caractère se traduit aussi bien en ardeur guerrière qu'en irrépressible faim, ainsi que l'exprime le Lancelot en prose:

En cele prison fu mis Saigremors et il ert de tele maniere que, quant il avoit eu chalor ou par bataille ou par aucun travail, qu'il refroidissoit aprés; et lors li prenoit une si grans fains qu'a poi qu'il n'enrajoit tos vis et aucune fois se pasmoit il d'anguoisse. Si li avint a cele hore que, quant il ot demoré jusqu'a non en la prison, qu'il li prist une si grans fains qu'il cuida iluec morir sans confession et fu si destrois qu'a paines se tenoit il de $\operatorname{crier}^{162}$.

160 Il est en ce sens notable que Gaheriet apparaisse en tant que frère de Gauvain dans plusieurs romans tardifs: Escanor, Claris et Laris, Floriant et Florete. Ce personnage intervient beaucoup moins dans le roman en vers classique. Là encore, l'influence du Lancelot-Graal est manifeste: la Mort Artu donnant un rôle important à Gaheriet, que Lancelot tue par inadvertance, ce qui engendre la vengeance de Gauvain et la guerre entre les deux clans, explique que ce personnage soit évoqué dans les romans tardifs. Dans Rigomer, il n'est pas précisé qu'il s'agit du frère de Gauvain, mais une aventure individuelle lui est attribuée.

161 William Kibler, "Sagremor in the Arthurian Verse Romances", in "Por le soie amisté»: essays in honor of Norris J. Lacy, éd. Keith Busby et Catherine M. Jones, Amsterdam, Rodopi, 2000, p. 283-292.

162 Lancelot, Roman en prose du XIII siècle, éd. Alexandre Micha, Genève, Droz, 1978, tome II, LIV, \$35, p. 297. 
Sagremor ne supporte pas le jeûne et se montre prompt à s'échauffer sur un champ de bataille, ces deux caractéristiques signalant un dérèglement que les personnages, en premier lieu la reine Guenièvre qui lui attribue son surnom dans le Livre d'Artus, regrettent: comme l'explique Claude Roussel, "son ardeur belliqueuse peut amener à négliger les qualités de mesure et de compréhension que réclame la courtoisie ${ }^{163}$. Dans le Conte du graal déjà, il tâche d'éveiller Perceval, perdu dans sa contemplation des trois gouttes de sang sur la neige, en l'attaquant rudement, conduite qui contraste avec la courtoisie des paroles amicales de Gauvain à l'encontre du jeune chevalier pensif.

Les auteurs de Claris et Laris et de Rigomer élaborent un portrait de Sagremor conforme à cette tradition : il est un chevalier apprécié à la Table Ronde, mais qui peut se montrer excessif, en violant une jeune fille par exemple. Il ne résiste en effet pas aux charmes de la jeune Orainglaie, dame d'un riche royaume, qui se prélasse seule dans sa tente, au milieu de la forêt. Ignorant le dédain évident de la jeune fille lorsqu'elle ne répond pas à ses salutations, Sagremor

Por li se desarma

Et totes ses armes osta

Et jut a li tot carnelment,

Se li escriture ne ment,

Qu'ils remest de lui ençainte (Rigomer, v. 7905-7909)

Après cette violation odieuse de la courtoisie la plus élémentaire ${ }^{164}$, Sagremor, tel un chevalier de pastourelle, se rhabille et jette un coup d'œil à celle qu'il vient de posséder: interprétant sans doute mal la tristesse d'Orainglaie, il lui jette à la poitrine une aumônière, en lui assurant qu'elle en aura bien besoin. La dimension transgressive de cet épisode, sexuelle mais aussi sociale, car Sagremor fait fi du statut de la dame en

163 Claude Roussel, "L'art de la suite: Sagremor et l'intertexte», Annales ESC, 41, 1986, p. 32.

164 Kathryn Gravdal note que le viol est soit l'apanage des adversaires dans le roman courtois, soit il remplit une visée comique dans la pastourelle ou le Roman de Renart, à moins qu'il ne permette de tester la chasteté des saintes femmes tout en les transformant en martyres dans l'hagiographie. Ravishing Maiden. Writing Rape in Medieval French Literature and Law, Philadelphie, University of Pennsylvania Press, 1991. 
lui faisant l'aumône, est finalement relativisée: en le voyant s'éloigner, la jeune fille admire la prestance de son violeur dans son armure, si bien qu'elle regrette sa propre froideur et déclare que "plus biaus de lui ne fu vëus» (v. 7982).

Les apparences sont sauves: si le roman tardif s'amuse à attribuer aux chevaliers arthuriens des pulsions sexuelles qu'ils ne maitrisent pas, l'acte est toujours relativisé. Non seulement la pucelle tombe amoureuse de son violeur, mais celui-ci est incarné par Sagremor le Desrées (Rigomer, v. 7062), déjà surnommé ainsi par Chrétien de Troyes (Conte du graal, v. 4154-4155). Cette désignation fait de lui le représentant du furor indispensable au guerrier, mais que menace l'excès de la démesure et du désordre. Cette qualité guerrière est néanmoins précieuse à la cour, ainsi que le précise Marie-Luce Chênerie:

Un roi courtois doit préserver ce capital, tout en l'épurant de ses connotations mortelles; car sans ce furor, le monde des chevaliers policés risquerait de dégénérer, et l'efficacité guerrière de disparaître; le roi lui-même n'aurait plus son rôle centralisateur et civilisateur ${ }^{165}$.

L'attribution du viol à ce personnage arthurien évite d'introduire trop franchement l'infamie dans la Table Ronde: Sagremor est un chevalier marginal dont les emportements s'expliquent par son desroi ${ }^{166}$, "qui signifie l'impossibilité où se trouve ce chevalier de garder son "roi", c'est-à-dire le sens de la juste mesure, physique et morale» ${ }^{167}$. Il est donc «incomplètement intégré à la cour bretonne ${ }^{168}$. Il est rarement le héros de sa propre aventure, avant son apparition dans Melyador, et incarne plutôt les pulsions inévitables du combattant. Sagremor permet donc de

165 Marie-Luce Chênerie, "Sagremor, encore...", in L'auvre de Chrétien de Troyes dans la littérature française: réminiscences, résurgences et réécritures, éd. Claude Lachet, Lyon, Université Jean Moulin, 1997, p. 68.

166 Jean-Charles Payen traite du desroi dans l'épique dans Le motif du repentir dans la littérature française médiévale (des origines à 1230), Genève, Droz, 1967, p. 157-180. Pour le domaine romanesque, voir Jean-Marie Fritz, Le discours du fou, p. 74-85.

167 Emmanuèle Baumgartner, "Merlin et Arthur", in La Légende arthurienne. Le Graal et la Table Ronde, Paris, Robert Laffont («Bouquins»), 1989, note 2, p. 402.

168 Claude Roussel, «L'art de la suite: Sagremor et l'intertexte», art. cit., p. 38. 
dérouler une scène de viol à la fois comique par son issue et fascinante, par l'exposition du corps nu et de la soumission de la femme ${ }^{169}$.

Froissart propose un Sagremor loin d'être aussi fougueux et impétueux que l'ont laissé entendre ses prédécesseurs. Au contraire, il se montre courtois et mesuré170, quoiqu'un peu nice en raison de son jeune âge, ce qui excuse le baiser qu'il vole à Sebille sans avoir obtenu son consentement (v. 26321-26326) ${ }^{171}$. Seule faille à son comportement, cet emportement amoureux ne suffit pas à lui voir attribuer le surnom de "desreez» au sein du roman. Jamais il ne témoigne d'une ardeur excessive lors de ses duels, mais il accepte au contraire d'interrompre celui qui l'oppose à Morenoi sur la simple demande de la sœur de celui-ci, Margadine. Lors de cet épisode, il respecte également à la lettre le code chevaleresque, lorsqu'il s'offusque de la fourberie de Morenoi, qui ne s'est pas constitué prisonnier comme il devait le faire sur ordre d'Agamanor. Il refuse de s'attribuer les mérites de la victoire sur lui et insiste pour que Morenoi annonce à Arthur que c'est bien Agamanor qui l'envoie captif.

Sagremor se montre si conforme à l'éthique chevaleresque que Nathalie Bragantini-Maillard le qualifie de héros «le plus arthurien [...] du roman ${ }^{172}$. Cette gratification se justifie par plusieurs raisons: il appartient d'abord à la génération future, celle de Gauvain, Yvain et Perceval invoquée en prologue dans ce texte qui se veut une préhistoire du monde arthurien. Sagremor reste donc extérieur à la quête d'Hermondine, matière principale de Melyador, à laquelle il ne participe d'ailleurs pas. Sa présence dans ce roman fait le lien entre ces deux générations, entre l'époque de Melyador et le temps traditionnel du roman en vers. Dès lors, il est le seul personnage connu du public à agir dans le roman, au contraire de Gauvain et Yvain qui sont simplement évoqués.

169 Kathryn Gravdal, Ravishing Maiden. Writing Rape in Medieval French Literature and Law, souligne que derrière la répulsion du viol se cache également une certaine fascination.

170 William W. Kibler, "Sagremor dans le Méliador de Froissart», in "Si a parlé par moult ruiste vertu». Mélanges de littérature médiévale offerts à Jean Subrenat, dir. Jean Dufournet, Paris, Champion, 2000, p. 307-311.

171 Nathalie Bragantini-Maillard y lit un écho au Conte du graal. Melyador, éd. cit., p. 263.

172 Nathalie Bragantini-Maillard, «Introduction», Melyador, éd. cit., p. 262. Sur Sagremor, voir en particulier les pages 261 à 279 . 
Ensuite, il est le héros de la seule aventure merveilleuse du roman (v. 28376-28831). Or, nous l'avons exprimé, le merveilleux est un critère générique pour le roman arthurien. Si la quête d'Hermondine et les péripéties des chevaliers qui s'y lancent semblent s'éloigner du canevas arthurien, la chasse au cerf de Sagremor a tout d'un épisode canonique, bien que Froissart joue avec le motif traditionnel. Ce n'est ainsi plus le chevalier qui s'écarte de son chemin pour pénétrer dans l'Autre Monde en suivant un blanc cerf, mais le blanc cerf lui-même qui poursuit le cheval effrayé de Sagremor! Le cerf invite même Sagremor à monter sur son dos pour rattraper son destrier emballé173. Il lui est alors aisé de le conduire dans un lac, où le chevalier s'endort, favorisant ainsi l'apparition de trois nymphes. L'attribution de cet unique épisode merveilleux au seul chevalier pourvu d'un passé littéraire arthurien annonce la tournure que prendront les aventures de la Table Ronde à l'époque de la génération suivante.

Futur diégétique, passé littéraire: Froissart est moins intéressé par le déploiement d'un merveilleux convenu, qu'il réinvente d'ailleurs en inversant les rôles du chasseur et de la bête chassée, que par la mise en scène des affrontements déployés lors de la quête d'Hermondine, ressemblant à ceux des tournois contemporains ${ }^{174}$. Au XIV ${ }^{e}$ siècle, l'esquisse du merveilleux, in extremis en fin de roman, suffit à faire signe vers le genre arthurien canonique. L'inachèvement ${ }^{175}$ de l'épisode fait soupçonner que l'intérêt est maintenant ailleurs: dans l'insertion lyrique (pages 361-381), dans la construction complexe de l'entrelacement (pages 495-519), dans la peinture d'un monde contrasté (pages 483-493). L'aventure merveilleuse, couplée au personnage arthurien, remplit néanmoins sa fonction indicielle en rattachant la trame narrative et le roman à l'univers et au genre

173 Sur cette chasse au cerf inversée, voir Laurence Harf-Lancner, «La chasse au blanc cerf dans le Méliador: Froissart et le mythe d'Actéon ", art. cit.

174 C'est ce que perçoit Nathalie Bragantini-Maillard, Melyador, éd. cit., p. 303-304.

175 Nathalie Bragantini-Maillard développe la question de l'inachèvement de cet épisode et de la place de Melyador dans la chronologie arthurienne dans "Pour un changement de perspective sur la construction de Melyador de Jean Froissart», Romania, 126:1-2, 2008, p. 145-173, et dans l'introduction à son édition, p. 35-43. Selon elle, le manuscrit BnF fr. 12557 est incomplet et il n'y manquerait qu'un feuillet conclusif qui narrerait seulement le tournoi proclamé par Arthur à Camaalot et non la fin de l'aventure de Sagremor. Celle-ci serait plutôt prévue pour rester en suspens de telle sorte à suggérer la continuité entre Melyador et l'univers de la Table Ronde. Nous adhérons à cette hypothèse. 
arthuriens. L'intervention de Sagremor correspond d'ailleurs à l'apparition d'autres personnages canoniques: Keu est mentionné pour la première fois lorsque Sagremor se rend à la cour d'Arthur (v. 25628), tout comme Agravain et Gauvain (respectivement v. 25636 et 25637).

\section{Le Graal versus la féerie}

Le roman arthurien en vers ne se contente pas de taire le destin des personnages qu'il emprunte à la prose: il se passe également du Graal, qui mettrait fin aux aventures. Nous l'avons vu, cette éviction est manifeste dans Claris et Laris, où l'objet de la quête n'est pas une relique de la Passion, mais un compagnon, Laris, maintes fois capturé. Malgré la présence de Merlin dans ce texte et la description de ses bienfaits, le Graal n'est pas même évoqué. Si une forme d'élection s'applique tout de même à Claris, elle le désigne comme parfait compagnon et non comme champion du christianisme. Comme dans la Queste del saint Graal et le siège périlleux, ce sont des inscriptions changeantes qui signalent l'élection du protagoniste: le roi au Cercle d'Or et Gaheriet sont retenus dans une cité gaste (v. 25051) aux résonances merveilleuses, où ils sont contraints de se nourrir exclusivement de fruits, "Tant que li vraiz compaiz venroit / Qui son vrai compaignon querroit» (v. 25085-25086), indiquent les «letres en latin» (v. 25081) sur les murs de la salle principale du château. Cet élu, sous les traits duquel le lecteur aura reconnu Claris, est décrit comme suit :

Vivre les covient en tel point
Tant que venra cil chevaliers
Qui onques n’i fu nouveliers
Ne mençongiers ne mesdisanz
Ne deslëaus ne despisanz. (Claris et Laris, v. 25092-25096)

Le chevalier appelé à mettre un terme à l'aventure doit être doté de qualités exceptionnelles, chevaleresques et morales. Ces inscriptions se transforment lorsque Claris et Gauvain pénètrent dans le château:

Les letres dient voirement

Que venuz est nouvelement

Cil qui la cité meteroit

A point et puis s'em partiroit.

Dui seront, plus n'en i convient, 
Et pour itant lor estouvient

Les deux meillors d'ax toz e[s]lire. (Claris et Laris, v. 25455-25461)

Les lettres indiquent encore que Gauvain et Claris - nommés cette fois explicitement au vers 25479 - doivent se rendre au sous-sol du château afin d'apprendre les raisons de la désolation du lieu. L'inscription dicte une marche à suivre, mais elle est également prophétique en annonçant la réussite des deux chevaliers, comme s'il s'agissait de leur destin:

Et lors iert la cité retraite

En son hennor premierement.

Estre ne le puet autrement! (Claris et Laris, v. 25488-25490)

Gauvain a d'ailleurs une totale confiance en cette prophétie et rappelle à un Claris quelque peu inquiet face aux lamentations terrifiantes de l'homme retenu au sous-sol que «aus letres poons savoir / Que ceste chose achevirons" (v. 25524-25525).

Le déroulement de cette aventure rappelle la Queste del saint Graal par la manière dont l'élu est désigné. Il rappelle aussi, comme le souligne Corinne Pierreville ${ }^{176}$, un épisode du Lancelot en prose, celui d'Escalon le Ténébreux (éd. Micha, t. 1, chapitre XVI et XX, p. 229-34 et 262-6). Dans l'un et l'autre cas, la malédiction du lieu est causée par une faute de son seigneur: celui de Claris et Laris a refusé de jeûner et de se confesser un Vendredi Saint; celui du Lancelot en prose a commis le péché de chair ce même jour de l'année. La punition plonge dans les deux cas le château dans les ténèbres et dans les deux cas, le chevalier qui met un terme à la coutume est attaqué dans le noir par des coups mystérieux. Seuls le courage et l'élection permettent à Gauvain et Claris de triompher: jamais ils n'invoquent leur foi et jamais il n'est fait mention de leur parfaite piété, qui pourrait rompre la malédiction générée par un comportement peccamineux. Il s'agit du même silence que pour Lancelot: c'est la force de son amour qui lui donne la force de poursuivre, non sa foi. Dans Claris et Laris, l'éthique n'est pas celle de la Queste ni celle de l'amour qu'incarne l'amant de la reine. Claris est désigné par les inscriptions comme celui qui «son vrai compaignon querroit» (v. 25086), non comme l'ami de Lidaine. Il ne triomphe pas seul, mais aidé d'un ami, Gauvain, lui qui était pourtant le

176 Claris et Laris, somme romanesque, p. 287-291. 
chevalier à secourir dans le Lancelot en prose. C'est donc une nouvelle idéologie que défend le roman, comme l'exprime Corinne Pierreville:

Alors que Lancelot triomphait seul de l'épreuve grâce à la force de son amour pour la reine, Claris met fin au sortilège avec l'aide de Gauvain car il est le parangon de l'amitié. Les jeux intertextuels sont ainsi mis au service de l'éthique chevaleresque fondée sur le compagnonnage guerrier que prône le romancier ${ }^{177}$.

Le Graal n'est donc jamais à l'horizon de l'aventure, même si la notion de péché affleure de temps à autre dans le récit. Nul n'est besoin de déchiffrer les signes que sèmerait une quelconque manifestation divine: le combat entre un taureau et un loup auquel assiste Bretiau (v. 2794128090) ne mène à aucune interprétation allégorique ${ }^{178}$, bien que cette scène ressemble étrangement à celles de la Queste, qui invitent toujours à être décryptées dans une perspective morale et religieuse ${ }^{179}$. Bretiau en tire au contraire un enseignement pragmatique:

Dedenz son cuer pourpense et jure

Que tors est moult aperte beste,

Bien fiert et de pié et de teste. (Claris et Laris, v. 27964-27966)

Toute lecture religieuse est écartée, en faveur d'une morale pratique ou d'une élection terrienne, tournée vers la chevalerie et l'humain.

Dans Rigomer, l'absence du Graal est plus remarquable encore: l'œuvre peut se lire comme une alternative mondaine à la quête du $\mathrm{Graal}^{180}$. L'intrigue ne cesse de croiser la route de personnages blessés à

177 Ibid., p. 291.

178 Sur cet épisode, voir Corinne Pierreville, Claris et Laris, somme romanesque, p. 358-359.

179 Ces épisodes de semblance, accompagnés d'une senefiance délivrée par un homme de dieu, sont légion dans la Queste del saint Graal et font souvent intervenir des animaux. On peut citer à titre d'exemple le songe de Perceval qui met en scène deux dames montées sur un lion et un serpent, qui représentent les deux Lois. La Queste del saint Graal, éd. cit., p. 96-104. Voir Emmanuèle Baumgartner, "The Queste del saint Graal: from semblance to veraie semblance", in A Companion to the Lancelot-Grail Cycle, éd. Carol Dover, Cambridge, Brewer, 2003, p. 107-114, et L'arbre et le pain. Essai sur la Queste del saint Graal, Paris, SEDES, 1981.

180 C'est la lecture de Neil Thomas, "The Secularisation of Myth: Les Merveilles de Rigomer as a Contrafactura of the French Grail Romances ", in Myth and Its Legacy 
Rigomer, parfois handicapés depuis plusieurs années (trente ans pour Torplain de Grineplaigne, v. 2683ss), et qui sont autant de figures de rois mehaigniez - l'expression "chevalier mahaignié» apparaît aux vers 2711 et 3141 -, tel le roi Mordrain. La merveille entoure leur rencontre avec le chevalier arthurien: le premier est un chevalier enferré, qui réveille Lancelot par la chasse ${ }^{181}$ qui précède son arrivée. Le deuxième, Torplain de Grineplaigne, paraît dans un riche lit digne du Roi Pêcheur, lors d'une scène d'hospitalité:

Un lit avoit paré selonc,

Dont li pecol furent d'argent,

Biel et massiç, bien fait et gent,

Et les espondes a esmaus

A rices pieres precïaus.

Uns chevaliers s'i gisoit sus,

De biel eage auques cenus,

Qui mout vivoit a grant meschief;

Car une plaie avoit el chief.

Cel jor avoit .XXX. ans passés,

N’en pooit iestre respassés. (Rigomer, v. 2692-2702)

Ce personnage doit attendre la fin des aventures de Rigomer pour être guéri, mais aussi pour voir s'achever la malédiction qui le frappe. S’il ne peut offrir l'hospitalité à un chevalier chaque année, il est condamné à ne vivre en jours que le nombre d'années pendant lesquelles il a porté sa plaie - c'est-à-dire trente jours. Cette merveille, comme celle à laquelle renvoie la chasse précédant l'apparition du premier blessé, n'a cependant rien à voir avec le merveilleux divin de la Queste del saint Graal: elle n'exprime

in European Literature, Durham, University of Durham, 1996, p. 159-169. Voir aussi Richard Trachsler, "Lancelot aux fourneaux: des éléments de parodie dans les Merveilles de Rigomer?", art. cit., p. 191, et Les romans arthuriens en vers après Chrétien de Troyes, p. 189-190, et Adeline Latimier, "Les Merveilles de Rigomer: un "conte ridicule"?", in Parodies courtoises, parodies de la courtoisie, dir. Margarida Madureira, Carlos Clamote Carreto et Ana Paiva Morais, Paris, Garnier («Rencontres»), 2016, p. 77-90.

181 Cette chasse rappelle celle au blanc cerf, où la proie se révèle être un guide vers l'autre monde, comme dans Erec et Enide. Dans Rigomer, ce motif est détourné de façon parodique: Lancelot tue l'animal d'un seul coup et le fait cuire dans le but de le manger. 
pas un péché moral à expier, tandis que l'attente de l'élu n’a plus rien de celle, messianique, de Galaad, dont la seule visite suffit à guérir les blessés et à rendre la vue au roi Mordrain.

Si l'élu de Rigomer doit aussi être "preus sans mavaise tece» (v. 1357), les qualités requises ne sont pas la pureté morale et la chasteté, mais bien des propriétés mondaines. Celles-ci sont décrites par les divers chevaliers mahaigniés que Lancelot croise:

«Ja ne serai respassés

De la plaie dont sui quassés

Jusqu'adont que cil ert venus,

Qui deseur tous ert conneüs

D'armes et de chevalerie

Et plus avra de cortoisie

Et miex savra dames amer

Et plus ert larges de douner.» (Rigomer, v. 1319-1326)

«Tout avant li convient avoir

Prouece, biauté et savoir

Et se li convenroit simplece,

Debounaireté et largece,

Se li convient qu'il ait amie

Biele raison et cortoisie.» (Rigomer, v. 2949-2954)

La beauté, l'amour ou la largesse ne constituent pas un idéal moral et chrétien, mais bien courtois. Un tel chevalier permettrait la guérison de tous les blessés à Rigomer, ce qui rappelle là encore l'univers graalien et la blessure du roi Pêcheur. L'attente de l'élu prend dès lors un ton prophétique, dans les vers suivants qu'adresse le premier chevalier enferré à Lancelot:

«Dont sai jou bien que li navré

Garroient et tuit li prison

Istroient fors par l'oquoison,

Li outrei d'armes par dolor

Revenroient en lor valor.» (Rigomer, v. 1362-1366)

La «profesie» (v. 6924) est d'autant plus proche de celle qui concerne le Graal que ces descriptions sont prises en charge par des personnages et non par le narrateur, comme elles le sont souvent par des ermites dans la Queste. Pour rendre le lien plus explicite avec le Graal, le chevalier blessé 
précise que "dont seroient aoviertes / Les mervelles qui sunt covertes" (v. 1369-1370), usant d'un vocabulaire qui n'est pas étranger à la Queste del saint Graal; en effet, il s'agit dans ce dernier texte de voir le Graal tout découvert, tout entièrement, à la différence des gens de la cour du Roi Mehaignié, qui «nel porent veoir apertement, ançois lor en fu coverte la vraie semblance»(Queste, p. 16). Le texte de Rigomer insiste aussi sur la nécessité d'achever l'aventure du château, d'en "assoumer les mervelles" (v. 2818). Dans la Queste, les prophéties parlent dans la même idée de l'élu comme "cil qui doit les aventures mener a chief» (p. 9), "cil qui metra a fin les aventures de la Grant Bretaigne, et par cui li Rois Mehaigniez recevra garison» (p. 10) ${ }^{182}$. Point de but eschatologique et religieux, toutefois, dans Rigomer: un hôte qui accueille Lancelot complète la prophétie par le mariage de la dame de Rigomer («Et la puciele marïee, / Qui a maudite eure fu nee», v. 1119-1120), finalité à l'opposé de celle de la Quête du Graal.

On comprend bien la direction mondaine que prend la quête de Rigomer, qui se substitue à celle du Graal; il est en ce sens légitime que Gauvain en soit l'élu, lui qui représente une morale courtoise et laïque et la parfaite incarnation des qualités exprimées par le chevalier blessé. D'ailleurs, les enchantements se soumettent à lui sans qu'il ait besoin de faire quoi que ce soit (v. 13837-13932), tout comme ils se soumettent à Galaad dans la Queste. Si Gauvain est face à quelque épreuve une fois arrivé au château de Rigomer, il s'agit de défis qui prennent très bien leur place dans un contexte curial et mondain: récupérer un autour de l'autre côté d'un pont enchanté, monter un cheval récalcitrant puis frapper une quintaine d'une lance qui s'offre naturellement à lui après la conquête du cheval. Une fois l'animal dompté, la population le qualifie de «hom

182 On pourrait multiplier les échos à la Queste: l'orage apocalyptique, suivi d'une chaleur brûlante puis d'un froid glaçant qui frappent les chevaliers à leur arrivée à Rigomer sont présentés comme "la senefiance» (v. 10078) que le château est assailli. Ces manifestations climatiques ont une résonance biblique, intertexte privilégié de la Queste. Le mot «senefiance» est quant à lui constamment employé dans ce texte en prose pour désigner l'interprétation des révélations divines. Sur le langage propre à la Queste, voir Daniel Poirion, "Semblance du Graal dans la Queste", in Mélanges de linguistique, de littérature et de philologie médiévales offerts à J.-R. Smeets, Leiden, 1962, p. 227-241. Voir aussi Jean-René Valette, La Pensée du Graal. Fiction littéraire et théologie (XIt'-XIIt siècle), Paris, Champion, 2008, p. 280-302 (senefiance) et 436-460 (covert-apert). 
saintimes» (v. 14573) et parle de «miracles» (v. 14576). L'autour, le cheval et la quintaine n'ont pourtant rien de divin, mais sont au contraire les attributs typiques du chevalier courtois, tourné vers l'exploit terrestre. Pour accentuer le parallèle avec la quête spirituelle du Graal, Gauvain entraîne même la conversion des traîtres, notamment la jeune fille trompeuse qui enchantait les chevaliers à Rigomer :

«Mais jou caitive de mal'aire,

Qui tant mal ai aidié a faire,

Sui em paor et en peril

Que m’ame ne torne a escil.» (Rigomer, v. 13929-13932)

Tout comme la fin de la quête du Graal, la réussite de l'aventure de Rigomer met fin aux merveilles: "Adont asomerent par tant / Les merveilles et li encant.» (v. 14589-14590) Le Graal est évacué des romans tardifs, mais il est remplacé par un idéal plus conforme à l'idéologie du vers. L'allusion à la Queste del saint Graal est claire, du point de vue du lexique et du déroulement; le détournement de la quête rend explicite le chronotope choisi par l'auteur, induit par le choix d'une forme. L'intertextualité est loin de se réduire à des réécritures de romans en vers, mais tire également parti de la prose par un jeu d'échos signifiants ${ }^{183}$.

Dans Biaudouz, l'allusion à la quête du Graal ne prend pas appui sur les romans en prose, mais sur le Conte du graal de Chrétien de Troyes, intertexte privilégié de ce roman tardif. Francis Gingras ${ }^{184}$ lit effectivement dans l'apparition de Beauté, la future épouse du héros, une réécriture de l'apparition du Graal par la lumière qui accompagne autant Beauté que le Graal :

Ausi com li feus ki clers art

Par nuit en chasse l'ocurté,

Tant rent entor li grant clartei,

Ausi fait cele, tant est bele:

Ja n'i covient autre chandele

183 Isabelle Arseneau signale d'autres allusions à ce texte dans «Lancelot échevelé: la parodie dans le Merveilles de Rigomer», art. cit., notamment le portrait inversé de Lancelot, aux cheveux noirs et hirsutes, au contraire de la chevelure blonde et luisante qu'il arbore dans le texte en prose.

184 Francis Gingras, "Le Biausdous de Robert de Blois: la nature du roman et l'art de la digression ", art. cit., \$33-35. 
Ou k'ele vient par nuit oscure,

Tant est sa biautez clere et pure.

Tantost com en la chanbre entra,

De sa biautei l'enlumina

Si k'ele est tote resclarcie.

Troi cierge ne rendissent mie

Tel clartei, c’il fussent empris. (Biaudouz, éd. Lemaire, v. 2203-2214)

Comme le Graal, Beauté illumine mieux la chambre que les chandelles. La quête à entreprendre pour Biaudouz n'est pas celle du Graal, mais celle, pratique, de la perfection sociale, caractérisée par l'accomplissement moral que dictent les enseignements de la mère au début du texte, et qui permettent l'enchâssement des œuvres morales et didactiques de Robert de Blois - nous y reviendrons aux pages 617-630.

Les auteurs tardifs renoncent au Graal, mais le font tout de même surgir en creux, comme pour exhiber son éviction et leur choix d'un autre système de valeurs ${ }^{185}$. Ils lui préfèrent notamment le merveilleux féerique ${ }^{186}$, dénué de toute implication morale et religieuse. Pour reprendre les catégories établies par Dominique Boutet ${ }^{187}$, l'écriture en

185 Christine Ferlampin-Acher constate la même mise à l'écart du Graal dans les romans arthuriens en prose tardifs. Elle consacre un article à l'étude des allusions au Graal dans Perceforest et Artus de Bretagne qui illustre la façon qu'ont les auteurs tardifs de renoncer au Graal tout en favorisant son souvenir dans l'esprit du lecteur attentif: "Les rémanences du Graal se font selon deux modalités, soit en laissant le vessel à l'écart et en privilégiant des éléments annexes qui lui sont associés dans la tradition, soit en mettant en scène un objet qui ne correspond que partiellement au Graal, qui retient par exemple son pouvoir de guérison, son rapport à la lumière ou au sang." "Le Graal dans les romans arthuriens de la fin du Moyen Âge: Artus de Bretagne et Perceforest", in Mémoires arthuriennes, dir. Danielle Quéruel, Troyes, Médiathèque du Grand Troyes, 2012, p. 125.

186 Si les proses du Graal (Estoire del saint Graal, Queste del saint Graal, Perlesvaus) écartent les fées de leur trame narrative, il n'en va pas de même dans le Lancelot propre. Francis Gingras analyse l'ambiguïté de Viviane et Morgane dans ce texte, qui joue de l'histoire et de la fiction. "Le roman à l'épreuve des fées», art. cit.

187 Dominique Boutet, «Merveilleux et interférences génériques dans la chanson de geste de Tristan de Nanteuil», art. cit. Jean-René Valette, qui s’interroge sur la possibilité d'établir une classe générique des "hauts livres du Graal», souligne que le Graal de la prose relève d'un merveilleux de transcendance. "Les Hauts Livres du Graal et la poétique des genres", in Motifs merveilleux et poétique des genres au Moyen Âge, dir. Francis Gingras, Paris, Garnier, 2015, p. 267-286. Mireille Séguy analyse également la transposition du surnaturel profane breton en un surnaturel 
vers s'écarte du merveilleux transcendantal et privilégie le merveilleux d'altérité, celui du surnaturel païen. Les derniers romans arthuriens en vers s'inscrivent alors dans le mouvement de retour à la féerie dont parle Christine Ferlampin-Acher et qui concerne les romans arthuriens en prose tardifs, comme Perceforest, Ysaïe le Triste ou Artus de Bretagne ${ }^{188}$. Presque chacune des œuvres ${ }^{189}$ de notre corpus met en scène des figures de fées, tantôt adjuvantes, tantôt opposantes. La critique a parfois mis en doute le caractère féerique et merveilleux de certaines figures féminines tardives: selon Peter Noble ${ }^{190}$, Lorie dans Rigomer est moins une fée dotée de pouvoirs surnaturels qu'une femme habile, usant de la psychologie pour aider Gauvain, lorsqu'elle convainc la sœur de Gaudioné, celui qui retient le neveu du roi prisonnier, de le délivrer, en aidant celle-ci à voir son propre amant. Il n'en demeure pas moins à notre sens qu'elle est désignée comme "fee» (v. 10629) et que ses interventions relèvent de la merveille: son oiseau Willeris est doué de parole, elle sauve Gauvain de la noyade

chrétien et spirituel, dans L'Estoire del Saint Graal, qui vide le merveilleux propre au Conte du graal de sa substance pour privilégier d'autres enjeux idéologiques. "La merveille du Graal à l'épreuve de la "vérité" de l'Estoire del Saint Graal", in Motifs merveilleux et poétique des genres au Moyen Âge, dir. Francis Gingras, Paris, Garnier, 2015, p. 287-300.

188 «La matière arthurienne en langue d'oïl à la fin du Moyen Âge: épuisement ou renouveau, automne ou été indien?", art. cit., p. 282-288, Merveilles et topique merveilleuse, p. 501-519, «Féerie romanesque et roman féerique ( $\mathrm{XIV}^{\mathrm{e}}-\mathrm{XVI} \mathrm{e}^{\mathrm{e}}$ siècles) : naissance et déclin annoncé d'un genre?», in Aspects du merveilleux dans les littératures médiévales, dir. Francesco Marzella, Lucilla Spetia et Franca Ella Consolino, Turnhout, Brepols, 2016, p. 159-170, Artus de Bretagne. Roman en prose de la fin $d u$ XIII siècle, éd. cit., p. CXCIV-CC, et «Le merveilleux dans la matière arthurienne (1270-1530): le recyclage, entre vacuité et prolifération du sens", in La matière arthurienne tardive en Europe, 1270-1530, dir. Christine Ferlampin-Acher, Rennes, PUR, 2020, p. 293-310. Voir les pages que Laurence Harf-Lancner consacre aux romans tardifs dans Les fées au Moyen Âge. Elle traite notamment de Claris et Laris aux pages 338-345.

189 Nous traitons exclusivement de Rigomer, Claris et Laris et Floriant et Florete. Dans Escanor, Esclarmonde est une autre figure de la fée, quoiqu'elle soit proche de l'enchanteresse maîtrisant l'art de nigremance. Voir Laurence Harf-Lancner, Les fées au Moyen Âge, p. 414. Dans Melyador, seules les trois dames qui se présentent à Sagremor après la chasse au cerf ont une résonance merveilleuse, vêtues qu'elles sont de blanc. Elles sont qualifiées de «nimphes» (v. 28824).

190 "The Role of Lorie in Les Merveilles de Rigomer", Bulletin bibliographique de la Société Internationale Arthurienne, 48, 1996, p. 283-90. Sur Lorie, voir aussi Laurence Harf-Lancner, Les fées au Moyen Âge, p. 38-39. 
en plaçant sa nef magique à l'endroit précis où il tombe (v. 11953-12001) et soigne Lancelot de ses blessures grâce à un onguent, vêtue de blanc et montée sur un destrier de la même couleur (v. 16954-17010), rappelant l'intervention de Morgue dans le Chevalier au lion.

La fée Morgane est justement présente dans deux de nos textes: dans Claris et Laris, elle préside au Val des fées dont fait partie Madoine, celle qui capture Laris à plusieurs reprises pour s'approprier son amour. Ce Val n'est pas sans évoquer le Val sans Retour du Lancelot en prose ${ }^{191}$ : celui du roman en vers est aussi présenté comme un lieu dont on ne revient pas: " "Ne porrez issir / Jamés de ceste enfermerie" (v. 3679-3680), annonce Morgane à Claris et Laris. Celle-ci, connue pour être la fée maléfique du Lancelot-Graal, bien qu'elle ne se montre pas particulièrement menaçante ici, mais au contraire "afetie» et "bien enseignie» (v. 3692 et 3693), est de nature à générer l'angoisse chez les personnages: sa magie les retient inéluctablement prisonniers, et donc loin de Lidaine, l'amie de Claris, comme les captifs du Val sans Retour. Plus que le rôle qu'elle joue dans Claris et Laris, c'est le souvenir intertextuel que le lecteur a du personnage qui signale le danger auquel les deux amis sont confrontés. Car elle ne représente pas la plus grande menace de ce val des fées, Madoine endossant cette fonction, tandis que Morgane disparaît rapidement du récit. La sœur d'Arthur n'intervient donc que pour embrayer sur une histoire de fée amoureuse et "morganienne» ${ }^{192}$, qui retient les chevaliers dans son espace merveilleux, coupé du monde social.

Madoine assume cette fonction d'opposante à la circulation des chevaliers: d'abord conciliante lorsque Laris la séduit traîtreusement pour obtenir d'elle le moyen de s'échapper du val - ce qui offre un contraste saisissant avec le Val sans Retour, dont Lancelot ne sort que grâce à sa loyauté en amour -, elle invente par la suite les stratagèmes les plus

191 Voir Corinne Pierreville, Claris et Laris, somme romanesque, p. 321-341 et Laurence Harf, Les fées au Moyen Âge, p. 338-345. Comme le note Laurence Harf-Lancner, cette capture n'a plus rien à voir avec celle que subissent les amants déloyaux du Val sans Retour: c'est par la ruse et la trahison que Laris parvient à quitter le lieu, en séduisant Madoine pour lui extorquer la façon de sortir du val. La noblesse de cour dont témoignait Lancelot n'entre pas en ligne de compte pour quitter le lieu enchanté.

192 Selon la typologie de Laurence Harf-Lancner, Les fées au Moyen Âge. La fée morganienne retient le chevalier dans son monde merveilleux, contrairement à la fée mélusinienne, qui rejoint le monde terrestre de son amant. 
perfides pour capturer son amant: capable de créer des illusions qui fourvoient Gauvain, Yvain, Claris et Laris, elle peut également déplacer la tente dans laquelle est couché Laris jusqu’à son val et concevoir de faux pavillons splendides qui transportent directement Gauvain, Yvain et Marine dans la prison des fées. Enfin, elle apparaît à Marine, l'amie de Laris, alors que celle-ci dort, et lui fait croire que Laris est mort, ce qui engendre la pâmoison de Marine. Cette entrevue fait naître le trouble fantastique en la jeune fille ${ }^{193}$ : elle croit d'abord avoir rêvé, puis découvre l'anneau, soi-disant confié par Laris pour son amie, que Madoine lui a mis au doigt (v. 28977-29098). Bien qu'elle se laisse à la fin facilement intimider par les rudes menaces de Laris (v. 29403-29425) sans opposer la moindre résistance magique, elle est qualifiée de "fee» à plusieurs reprises (v. 3994, 29428) et ses tours offrent un merveilleux d'altérité qui ne doit rien à un art de nigremance dont la maîtrise résulterait d'un apprentissage. Au fil du récit, elle n'apparaît plus comme la jeune amoureuse séduite par Laris, mais le narrateur n'a de cesse de la qualifier de «vielle sorciere» (v. 29394) et de «vielle desvee» (v. 29395), comme si le temps s'écoulait différemment dans le val et affectait ce personnage de plus en plus négatif ${ }^{194}$. L'ombre de Morgane plane sur cette fée amoureuse et maléfique: l'avilissement que subit Madoine, délaissée par Laris alors même qu'il l'a mise enceinte, toujours rappelée à sa vieillesse et vaincue finalement par le rejet de son amant, épargne ainsi la sœur d'Arthur; celleci peut demeurer la fée inquiétante et dangereuse de la tradition en prose.

La fée Morgane présente un visage bien plus positif dans Floriant et Florete, en adoptant des traits semblables à la Dame du Lac, lorsqu'elle élève Floriant dans son monde, Mongibel, le soustrayant ainsi à la menace de l'usurpateur Maragot, tout comme Lancelot est soustrait au danger que représente le roi Claudas. À l'image de la Dame du Lac, elle porte à l'enfant un amour désintéressé, digne d'une mère - et c'est ainsi que la

193 Au sens todorovien du terme: "Le fantastique, c'est l'hésitation éprouvée par un être qui ne connaît que les lois naturelles, face à un événement en apparence surnaturel. [...] Il faut que le texte oblige le lecteur à considérer le monde des personnages comme un monde de personnes vivantes et à hésiter entre une explication naturelle et une explication surnaturelle des événements évoqués. » Tzvetan Todorov, Introduction à la littérature fantastique, Paris, Seuil, 1970, p. 29.

194 Sur le personnage de Madoine dans Claris et Laris, voir Corinne Pierreville, Claris et Laris, somme romanesque, p. 330-341 et Laurence Harf, Les fées au Moyen Âge, p. 338-345. 
considère Floriant, tout comme Lancelot considère la Dame du Lac - puis le rend d'elle-même au monde des hommes dès qu'il est en âge de porter les armes et de faire ses preuves. Tout le long du roman, elle favorise le jeune homme en lui fournissant une nef merveilleuse et en lui révélant la vérité sur son lignage et sur le combat qu'il doit mener pour récupérer sa terre. À la fin du récit, elle l'intègre à son royaume, image d'Avalon où nul ne meurt jamais, et lui offre l'immortalité, le gratifiant encore de la présence de Florete envers laquelle elle ne témoigne aucune jalousie ${ }^{195}$. Morgane est un modèle de fée réutilisable dans le roman en vers, elle qui apparaît déjà furtivement dans Le Chevalier au lion pour prodiguer l'onguent guérissant Yvain. Pour ne pas être confondue avec le personnage menaçant du Lancelot en prose, elle adopte à l'occasion un visage affable malgré la captivité qu'elle impose à Claris et Laris, et prend dans l'autre cas les manières de la Dame du Lac, personnage trop assimilé à Lancelot pour élever un autre enfant.

Les auteurs tardifs s'accommodent ainsi des sommes arthuriennes en prose qui les précèdent en proposant une lecture en creux de ces récits. Le lecteur modèle doit décrypter les allusions à cet univers et comprendre la distance prise à son égard. Conter d'Arthur à la fin du XIII ${ }^{\mathrm{e}}$ siècle implique forcément de tenir compte des romans en prose, mais cette appropriation peut être de l'ordre de l'implicite, du clin d'œil ou de la concurrence, en tentant d'imposer une version divergente. Malgré les nombreux renvois intertextuels aux romans en prose, l'idéologie demeure celle du roman en vers. Le choix d'une forme n'est pas qu'une question de modalité d'écriture; c'est un choix générique. Les textes de notre corpus optent certes pour le vers par volonté de pérenniser un type de récit supplanté par la prose; mais, plus encore, il s'agit pour ces auteurs de s'inscrire dans un genre qui les autorise à échapper à la diachronie de l'univers arthurien. Même pour Melyador, qui est peut-être le moins arthurien du corpus, cette inscription générique est manifeste et assumée. L'écriture arthurienne en prose impose une temporalité chronologique, l'exploration d'un vide narratif qu'il faut inventer au sein du cadre établi par le Lancelot-Graal et étoffé, saturé, par le Tristan en prose ou Guiron le courtois. Le vers laisse au contraire l'auteur libre de dérouler à l'infini des aventures indépendantes

195 Sur Morgane dans Floriant et Florete, voir Laurence Harf-Lancner, Les fées au Moyen Âge, p. 277-279. 
de toute implication eschatologique, de renouveler l'errance des chevaliers en conjoignant tradition et innovation. Les derniers romans arthuriens en vers ne sont pas des romans en prose écrits en vers, comme le suggère Beate Schmolke-Haßelmann:

Escanor und Meliador sind, überspitzt ausgedrückt, Prosaromane in Versen, und sie stellen daher im Grunde literaturtechnische Anachronismen dar ${ }^{196}$.

Ces textes ont certes des accointances fortes avec les romans en prose, que nous mettrons en avant dans la suite de l'étude, mais le roman aventureux, placé dans une temporalité circulaire ${ }^{197}$ et une idéologie ludique, ne peut être composé en prose. C'est ainsi que l'on pourrait qualifier l'esthétique tardive: influencée par l'écriture en prose, elle reconduit les fondements du roman arthurien en vers.

\section{Choix de forme, choix de style}

Elle en reconduit aussi le style, étroitement lié au cadre formel de l'octosyllabe à rimes plates. Le style comprend des usages discursifs particuliers et se réfère, dans notre acception du terme, exclusivement à la forme du discours ${ }^{198}$. Nous n'entendons pas considérer tous les aspects stylistiques qui informent l'écriture en vers ou en prose dans le cadre de ce chapitre; d'autres chercheurs l'ont fait avant nous, en soulignant par exemple la simplicité lexicale de la prose, qui se contente d'un vocabulaire peu diversifié et formulaire, visant la clarté, l'exhaustivité et la sobriété. Le vers favorise au contraire la diversité lexicale, moins préoccupé par l'élucidation que par la stylisation et une part de mystère laissée à

196 Beate Schmolke-Haßelmann, "Ausklang der altfranzösischen Artusepik: Escanor und Méliador", art. cit., p. 51. "Escanor et Melyador sont, si l'on exagère la formulation, des romans en prose écrits en vers, et ils constituent donc en réalité des anachronismes en termes de techniques littéraires. " (nous traduisons)

197 Voir Emmanuèle Baumgartner, «Temps linéaire, temps circulaire et écriture romanesque (XII ${ }^{\mathrm{e}}-\mathrm{XIII}^{\mathrm{e}}$ siècles)", art. cit. Dans son édition d'Escanor, Richard Trachsler traite de la temporalité circulaire du roman. Voir p. 85-91.

198 Nous avons défini cette notion aux pages 155-159. Selon notre acception, le style englobe aussi bien le lexique que l'usage de figures de rhétorique, la combinaison des phrases, la syntaxe, les temps verbaux, la forme des discours rapportés ou la richesse des structures rimiques. 
l'interprétation du lecteur ${ }^{199}$. On a pu établir une autre distinction sur le plan des discours rapportés, à la suite de Bernard Cerquiglini: la prose signale explicitement les tours de parole, jusqu'à la redondance, tandis que le vers se sert d'autres moyens - le passage d'un vers ou d'un couplet à l'autre notamment - pour signifier le changement de locuteur ${ }^{200}$. Nous nous concentrerons quant à nous essentiellement sur la syntaxe, critère qui souffre le plus de différences entre vers et prose et qui nous semble suffire à engendrer une lecture différente du point de vue rythmique et à générer des identités stylistiques distinctes entre vers et prose. L'exploration d'éléments stylistiques définira si l'écriture en vers tardive est influencée par la syntaxe de la prose ou si elle conserve les spécificités du genre tel qu'il est formalisé au XII ${ }^{\mathrm{e}}$ siècle ${ }^{201}$.

Nous l'avons vu plus haut, la prose a été présentée au début du $\mathrm{XIII}^{\mathrm{e}}$ siècle comme une forme qui transcrit une idée en droite ligne, sans détour, en suivant la pensée. Le vers impose l'adaptation de la phrase à la métrique, tandis que la prose offre la liberté de dérouler la phrase à l'infini, par le moyen de coordinations ${ }^{202}$. Même si cette conception reste

199 «Dans le roman en prose médiéval, l'invention ne passe sans doute guère par le style.» (Annie Combes, Le Récit en mouvement, p. 21) Voir aussi Christiane Marchello-Nizia, "La forme-vers et la forme-prose: leurs langues spécifiques, leurs contraintes propres", art. cit., p. 37.

200 Sur les discours rapportés, on consultera Bernard Cerquiglini, La parole médiévale. Discours, syntaxe, texte, p. 21-75, Emmanuèle Baumgartner, «Les techniques narratives dans le roman en prose", art. cit., p. 186-187, Annie Bertin et Annie Combes, Écritures du Graal, Paris, PUF ("Études littéraires»), 2001, p. 117, et Daniel Poirion, "Romans en vers et romans en prose», art. cit., p. 79.

201 Ce chapitre s'appuie sur les tendances majeures que l'on peut dégager des textes de notre corpus et de l'écriture en prose telle qu'elle se présente dans les romans arthuriens. Bien sûr, chaque œuvre a ses particularités stylistiques propres, constat qu'il faut aussi élargir à chaque version qu'offre chaque manuscrit. Il ne s'agit pas dans le cadre de ce chapitre de mener une enquête statistique exhaustive, qui nécessiterait de dépouiller tous les textes en prose, tous les romans arthuriens en vers et tous les manuscrits de chacun des textes et devrait mobiliser l'appui de l'informatique. Une telle étude quantitative prouverait qu'il existe une différence réelle entre ces deux types d'écriture, constat qui se fonde pour l'instant sur des impressions de lecture intuitives. Nous demeurons néanmoins convaincue que certains choix sont liés à la forme, vers ou prose, pour laquelle optent les écrivains.

202 Cette association est présente dans les consciences médiévales: comme nous l'avons vu, Brunet Latin parle de "voie de prose», qui "est large et pleniere», 
une construction destinée à valoriser une prose pourtant assez loin de ressembler au langage commun et largement tributaire d'une stylisation ${ }^{203}$, la syntaxe plus complexe qu'exigerait le vers peut être alléguée au $\mathrm{XIII}^{\mathrm{e}}$ siècle comme argument en faveur de l'habileté du poète, à une époque où il s'agit de redéfinir cette forme et la singulariser par rapport à la prose qui s'insinue dans tous les domaines de la narration ${ }^{204}$. Cela explique l'exposition dont le vers fait l'objet en prologue dans nos textes, que nous avons présentée au début de notre deuxième partie. L'équivalence prose simple / vers complexe, au lieu de favoriser la prose comme il en va au début du XIII ${ }^{\mathrm{e}}$ siècle, peut être exploitée par les auteurs de textes en vers tardifs comme revalorisation de cette forme.

Dès lors, l'enjeu est bien d'exclure toute interpénétration formelle avec la prose: le roman arthurien tardif en vers ne mêle pas prose et vers au sein de la même ouvre, au contraire du Tristan en prose ${ }^{205}$. Il conserve également une certaine autonomie stylistique, en particulier du point de vue de la syntaxe. L'ordre des constituants de la phrase, de même que le traitement de la coordination et subordination, s'inscrivent en continuité de la tradition versifiée et ne sont pas influencés par l'écriture en prose. Les différences syntaxiques entre vers et prose ont été abondamment explorées par la critique. Nous en donnons ici une synthèse étayée par le commentaire des textes de notre corpus.

tandis que «li sentiers de risme est plus estrois et plus fors» (Livre du Trésor, éd. cit., p. 327).

203 La prose repose aussi sur des contraintes. Voir Bénédicte Milland-Bove, «Le style des romans arthuriens en prose du XIII ${ }^{\mathrm{e}}$ siècle: problèmes, méthodes, pratiques », in Effets de style au Moyen Âge, dir. Chantal Connochie-Bourgne et Sébastien Douchet, Aix-Marseille Université, Presses Universitaires de Provence ("Senefiance»), 2012, p. 47-57, Christiane Marchello-Nizia, «La forme-vers et la forme-prose: leurs langues spécifiques, leurs contraintes propres», art. cit., Emmanuèle Baumgartner, "Les techniques narratives dans le roman en prose», art. cit., Le Tristan en prose: essai d'interprétation d'un roman médiéval, p. 285-297, Daniel Poirion, "Romans en vers et romans en prose», art. cit., Bernard Cerquiglini, La parole médiévale, et Michel Zink, Littérature française du Moyen Âge, p. 174-176.

204 Voir Michel Zink, "Le Roman", in GRLMA, VIII, p. 205, et Catherine CroizyNaquet, "Écrire l'histoire: le choix du vers ou de la prose», art. cit., p. 83.

205 Nous reviendrons sur l'insertion lyrique au chapitre II, «Une spécialisation lyrique du vers: les insertions d'Escanor et Melyador", p. 361-381, qui sera aussi l'occasion de présenter un exemple où Froissart transpose une lettre prosifiée en vers pour éviter la rupture formelle. 
Le vers se satisfait de phrases courtes, composées d'une principale accompagnée éventuellement d'une subordonnée. Les subordonnées sont fréquemment juxtaposées; l'écriture en vers, bien plus que la prose, cultive la parataxe, l'absence de coordonnants et de subordonnants ${ }^{206}$. Cette observation est applicable aux textes de notre corpus:

Et tant ferai vo pais aurez (Escanor, v. 24070) ${ }^{207}$

Il nous semble / Messires Camelz vaintera (Melyador, v. 8954-8955)208

Gardez ja ne soiez lassez / De tournoiement maintenir

(Claris et Laris, v. 388-389)

Bien sai se vos m'esgardiez

Et mes mesaises saviez,

A conseill ne fauroie mie! (Claris et Laris, v. 3760-3763)

Car bien sai, se vous m'amissiez,

Ja vers moi ne vos celissiez! (Claris et Laris, v. 3938-3939)209

Et Blanchandine, l'avenant,

Gardez o vous soit acesmee (Floriant et Florete, v. 5916-5917) ${ }^{210}$

Mais miex aim la teste me trence,

Qu'il en port ma fille sans tence. (Rigomer, v. 747-748)

Ce sont les rythmes du mètre et de la rime qui marquent les frontières syntagmatiques ou phrastiques ${ }^{211}$, en l'absence de conjonction et de ponctuation: le placement des virgules dans les éditions modernes rend les phrases intelligibles au lecteur moderne.

206 Voir Philippe Ménard, Syntaxe de l'ancien français, Bordeaux, Sobodi, 1973, p. 188-191.

207 Sur la syntaxe d'Escanor, voir l'introduction à l'édition de Richard Trachsler, p. 45-48.

208 Voir l'étude de la syntaxe dans Melyador qu'effectue Nathalie Bragantini-Maillard dans l'introduction à son édition, p. 130-140.

209 Sur la syntaxe de Claris et Laris, voir l'introduction à l'édition de Corinne Pierreville, p. 85-86.

210 Voir l'introduction à l'édition de Richard Trachsler et Annie Combes p. LXXVI-LXXVII.

211 Christiane Marchello-Nizia, «La forme-vers et la forme-prose: leurs langues spécifiques, leurs contraintes propres", art. cit., p. 39. 
Les constructions paratactiques semblent propres au vers: la prose n'omet jamais une conjonction de la même manière que les exemples versifiés que nous venons de donner. Elle invite au contraire à l'allongement de la phrase et à une élaboration complexe, fondée sur la subordination et la coordination; la prose ménage son goût pour l'hypotaxe ${ }^{212}$. Les mises en prose permettent d'autant mieux de percevoir cet effort syntaxique. La comparaison de la version en vers avec celle en prose du même passage de Floriant et Florete montre parfaitement ce traitement différent de la conjonction entre l'une et l'autre forme:

Od lui avoit .i. seneschal

Qui molt estoit farcis de mal.

Maragoz estoit apelez,

Molt ert hardis et redoutez,

Mes plains ert de grant felonie.

De la roïnne a tel envie

Que bien cuide vis enragier

S'il n'a de lui son desirrier. (Floriant et Florete, v. 65-72)

Si avoit avecques lui ung seneschal appelé Maragos qui estoit moult desloyal et plain de moult grant malice. Non pourtant estoit il mout hardy et redoubté! Si eult si grant envie d'avoir la royne a son plaisir et d'en faire sa voulenté que bien pense tout vif enrager si d'elle ne fait son desir. (Le Chevalier qui la nef maine $e^{213}$, p. 82)

La version en prose réduit le nombre de propositions et les lie entre elles par des particules introductives («si»), voire des marqueurs argumentatifs («non pourtant»). Elle privilégie ainsi la conjonction, l'explicitation du rapport causal entre les propositions, "la concaténation, en une seule séquence phrastique, de plusieurs parataxes du vers ${ }^{214}$. Elle a le souci

212 Cette inclination ne fera que se renforcer au $\mathrm{XvI}^{\mathrm{e}}$ siècle, comme le montre Alexandre Lorian dans son étude, Tendances stylistiques dans la prose narrative française du XVI siècle, Paris, Klincksieck, 1973, p. 141-258.

213 Nous attribuons le titre "Le Chevalier qui la nef maine» à la mise en prose de Floriant et Florete, à la suite de Claude Lévy, qui lui donne ce sous-titre dans un souci de distinction des deux versions. Le Roman de Floriant et Florete ou le Chevalier qui la nef maine, éd. Claude M. L. Lévy, Ottawa, Éditions de l'Université d'Ottawa, 1983. Barbara Wahlen prépare une nouvelle édition de cette mise en prose.

214 Emmanuèle Baumgartner et Nelly Andrieux-Reix, Le Merlin en prose, Paris, PUF («Recto-Verso»), 2001, p. 82. Voir les exemples donnés par Nelly Andrieux-Reix 
d'établir une suture entre les constituants de la phrase. Considérée en regard de la mise en prose, l'écriture du tardif Floriant et Florete apparaît d'autant plus proche du style traditionnel propre au roman arthurien en vers: le traitement de la syntaxe est bien lié au choix d'une forme, quelle que soit l'époque à laquelle on écrit.

Ces types d'écriture offrent des expériences de lecture différentes: le lecteur du vers doit faire un effort cognitif pour reconstituer le lien logique qui associe une principale et sa subordonnée ou les phrases entre elles. La prose, au contraire, vise la cohésion des phrases, si bien qu'elles commencent très rarement sans un mot introductif qui opère la transition, «si », «lors", " et» le plus souvent, mais aussi "aprés", "meintenant», «atant $»^{215}$. Le vers juxtapose en revanche volontiers des séries de propositions. En voici deux exemples tirés de Claris et Laris:

Au tens que Bretaingne tenoit

Artus, uns gentis rois manoit

Droit en la terre de Gascoigne.

Fenme avoit nee de Coloigne;

Fille iert au bon roy d'Alemaigne,

Cousine ert au roy de Bretaigne. (Claris et Laris, v. 115-120)

aux pages 82-83. La différence entre vers et prose est aussi rendue explicite par la comparaison qu'effectue Annie Combes entre les différentes modalités de mises en prose selon leur degré de fidélité à la source en vers basée sur les trois critères du lexique, de la rime et du rythme. Si certains dérimages, ou dévers comme elle les appelle, à l'image de la version gamma du Conte de la Charrette, laissent percevoir un rythme semblable à la versification, d'autres mises en prose - les rédactions alpha et bêta de la Charrette, plus précoces - offrent une syntaxe plus hiérarchisée et complexe, libérée du rythme propre au vers et à la parataxe. Selon Annie Combes, le dévers marque un recul pris par la prose vis-à-vis de sa pratique d'écriture, caractéristique du XIV ${ }^{\mathrm{e}}$ siècle; au XIII ${ }^{\mathrm{e}}$ siècle, elle doit au contraire forger sa propre identité en concurrence avec le vers, dont elle se garde bien de reproduire les rythmes et les rimes. "L'emprise du vers dans les mises en prose romanesques (XIII- $\mathrm{XV}^{\mathrm{e}}$ siècles)", in Le Moyen Âge par le Moyen Âge, même. Réception, relectures et réécritures des textes médiévaux dans la littérature française des XIV et XV siècles, dir. par Laurent Brun, Silvère Menegaldo, Anders Bengtsson et Dominique Boutet, Paris, Champion, 2012, p. 115-140.

215 Voir l'étude de Jean Rychner, L'articulation des phrases narratives dans la Mort Artu, et Emmanuèle Baumgartner et Nelly Andrieux-Reix, Le Merlin en prose, p. 77-98. 
Li chevalier petit mengerent,

A ce qu'orent oï penserent. (Claris et Laris, v. 3708-3709)

Les propositions sont autant de phrases simples qui se succèdent, scandées par le mètre, et c'est au lecteur d'établir le lien logique, causal ou temporel, entre elles. Dans le deuxième exemple, les deux propositions sont liées de manière causale; un "car" serait attendu avant la seconde, pour figurer le lien de cause à effet entre les deux affirmations. Ce type de coordination est rétabli par la mise en prose de Floriant et Florete dans l'exemple qui suit:

Si se sont au mengier assis,

Mes n'i orent pas granment sis

Quant il les en covient lever:

La roïnne prent a crier

Cui ses maus destrain et angoisse. (Floriant et Florete, v. 527-531)

Mais ilz n'y furent pas longuement qu'il leur convint lever car la royne se print a crier comme celle qui sentoit le mal de l'enfant.

(Le Chevalier qui la nef maine, p. 89)

Escanor fait exception par rapport au reste du corpus, en recourant presque systématiquement à des coordonnants entre les propositions. Bien que les phrases n'atteignent pas le degré de complexité de celles de la prose du point de vue de la syntaxe, les propositions sont toujours au moins conjointes par «et»:

Et li rois, qui point ne vausist

Que s'emprise ne fust bien faite,

Ses genz a son pooir affaite

Conment a l'ostel serviroient

N'en quele maniere ouvreroient.

Et Kez, qui mout veoir voloit

Conment ceste besoingne aloit,

S'en fu droit a Bauborc venuz.

Si vouz di bien pour voir que nuz

$\mathrm{Ne}$ se seüst miex entremetre

D'un tel affaire n'a point metre. (Escanor, v. 3072-3082)

Girart d'Amiens use également volontiers de «lors», "car» et «mais». Le roman d'Escanor marque ici, comme pour d'autres éléments nous le 
verrons, sa forte parenté avec les textes en prose, qui influencent son écriture, comme le prouve peut-être cet état de la coordination. Il ne faut vraisemblablement pas y voir une évolution générale du roman en vers: dans Melyador, la conjonction entre les phrases est aussi lâche que dans les premiers textes du genre. L'auteur n'hésite pas à faire se succéder plusieurs propositions de deux vers sans un mot de transition:

Li cerfs s'en fuit, Camelz le cace,

Qui onques n'en perdi la trace.

Les bois passe et apriés la lande

Et les plains de Norchombrelande.

Courant s'en vient Camelz aprés

Jusques a l'estanc de Montgriés. (Melyador, v. 127-132)

Au XIV ${ }^{\mathrm{e}}$ siècle, Jean Froissart maintient la syntaxe propre au vers et ne réadapte pas ses phrases pour les rendre plus proches de celle la prose; le type d'écriture qui caractérise le vers, tout comme l'univers de fiction que nous avons défini au chapitre précédent, garde son autonomie.

Cela est d'autant plus vrai pour l'ordre des constituants de la phrase, passablement différent entre prose et vers; tous les textes du corpus conservent la structure propre à l'écriture versifiée. Le vers ne rechigne pas à inverser verbe et compléments ou les constituants du groupe verbal, voire à distordre complètement la syntaxe. Nelly Andrieux-Reix en fait l'analyse en comparant le Merlin en vers et en prose. Elle note alors dans la version en vers les ruptures du groupe verbal, entre auxiliaire et participe passé par exemple ( (fu le enfes ou lit trouvez»), l'inversion de ces deux composants ("pensive est») ou encore l'inversion de la négation («li ennemis pas ne s'oublie» $)^{216}$. La prose tend au contraire vers une organisation linéaire de la phrase. Si verbe et sujet sont encore souvent inversés ( $\mathrm{Or}$ s'en vet Galehout entre lui et son compaignon, liés et dolens.», Lancelot en prose, éd. Micha, t. I, $\$ 1$, p. 1), les compléments s'ordonnancent eux plus naturellement. On peut comparer à cet égard les deux versions de Floriant et Florete:

"Mes ains vous sera avenue

Tele aventure que je sai,

Mes ore pas nel vous dirai.» (Floriant et Florete, v. 808-810)

216 Emmanuèle Baumgartner et Nelly Andrieux-Reix, Le Merlin en prose, p. 78-82. 
"Si aurés mainte avantures avant que vous soyez a lui mais je ne les vous diray pas.» (Le Chevalier qui la nef maine, p. 94)

La syntaxe en prose établit la hiérarchie Sujet-Verbe-Complément qui prévaudra $^{217}$. Elle resoude aussi les ruptures entre les constituants d'un même groupe:

«Entendez moi, fet il, seignor,

As prisoniers. Vous vestirez

Ses robes que vous ci veez,

Je meïsmes une em penrai

Et avecques vous m'en irai.» (Floriant et Florete, v. 1174-1178)

Si dist aux prisonniers: «Seigneurs, vous vestirés les robes que vous veez ycy et moy mesmes en vestiray une et m'en yray avecques vous.» (Le Chevalier qui la nef maine, p. 99)

Fidèle à l'objectif de clarté qui l'anime, la prose résout les passages rendus obscurs par la syntaxe du vers.

Les textes de notre corpus adoptent le canevas offert par l'écriture versifiée: les inversions verbe-sujet, auxiliaire-participe passé, composants de la négation et les ruptures entre nom et complément sont fréquentes. En voici quelques exemples, où les composants d'une proposition sont séparés ou inversés:

Adont s'en torna Kez errant,

Et la bele remeist plourant

Qui durement dolente estoit. (Escanor, v. 971-973)

«Par mon senz, cis eürs me vient

De coi a jouster me covient

Ce que je mie ne vausisse;

Car eür par mon gré presisse

Meillour que de moi ci combatre.»(Escanor, v. 1211-1215)

Et li rois, qui mout noblement

De Northumberlande maintint

La feste en tant con il la tint (Escanor, v. 6364-6366)

217 Ibid., p. 87-90, et Christiane Marchello-Nizia, L'évolution du français. Ordre des mots, démonstratifs, accent tonique, Paris, Armand Colin, 1995, p. 87. 
Quant ceste chose faite eüsmes,

Vostre venir pas ne seümes (Claris et Laris, v. 3696-3697)

Une pierre li a moustree

Petite, n'estoit mie lee. (Claris et Laris, v. 4076-4077)

Dou cerf n'en voelent riens porter

Pour cose c'on seuist parler. (Melyador, v. 395-396)

La syntaxe du roman arthurien en vers tardif reste donc fidèle à celle qui est propre au vers, moins linéaire que celle de la prose, d'où sans doute le sentiment d'archaïsme qui naît de la lecture de ces romans et que soulignent certains critiques $^{218}$ aussi bien que les auteurs des mises en prose des $\mathrm{XIV}^{\mathrm{e}}$ et $\mathrm{XV}^{\mathrm{e}}$ siècles - nous y reviendrons.

Autant l'ordre de la phrase que la parataxe s'expliquent par les contraintes propres à l'écriture en vers; celle-ci oblige à adapter la phrase au cadre de la métrique. Christiane Marchello-Nizia le démontre, «l'unité syntaxique dépass[e] rarement le cadre de l'hémistiche, du vers ou du couplet de vers ${ }^{219}$. Il s'agit d'éviter les rejets et enjambements et de faire correspondre la fin d'un vers et même d'un couplet de vers avec la fin d'un syntagme. Cette correspondance est toute théorique, en particulier pour le roman arthurien: Chrétien de Troyes malmène déjà la coïncidence entre structure rythmique et structure syntaxique par la brisure du couplet d'octosyllabes et en usant à l'occasion d'enjambements. Henri Morier définit l'enjambement comme "un procédé rythmique consistant dans une non-coöncidence de l'unité de syntaxe et de l'unité du vers, la phrase ou la proposition débordant la rime et s'achevant sur l'une des premières syllabes du vers suivant $»^{220}$. L'enjambement établit une rupture entre syntaxe et mètre. Chez Chrétien de Troyes, l'enjambement se manifeste fréquemment par la séparation entre un verbe et son sujet postposé («Et par delez estoit assise / La torz sor une roche bise», Le Chevalier de la

218 Voir notamment Lunorsola Raffalli-Grenat, Écrire des fictions en vers aux XIV et XV siècles.

219 Christiane Marchello-Nizia, «La forme-vers et la forme-prose: leurs langues spécifiques, leurs contraintes propres", art. cit., p. 36. Elle note ainsi que dans les textes en octosyllabes, "le pourcentage des propositions dont les frontières (début, fin) ne coïncident pas avec les frontières métriques (coupe, rime), qui brisent donc le rythme, est, sauf dans Perceval (8\%), inférieur à 5\%" (p. 36).

220 Dictionnaire de poétique et de rhétorique, Paris, PUF, 1981, p. 412. 
Charrette, v. 425-426), liée à «la nécessité d'une phrase qui se déploie sur plus d'un vers " ${ }^{221}$, mais aussi à des effets de sens, la mise en valeur d'une fonction ou d'un personnage notamment («Lanceloz de la Lac a a non / Li chevaliers, mien esciant», v. 3666-3667) ${ }^{222}$. La rupture est plus brutale lorsqu'elle touche un syntagme: «La dameisele sist delez / Mon seignor Gauvain au mangier." (Le Chevalier de la Charrette, v. 452-453); "Si n'i a celui qui n'ait un / Baston cornu de cornillier» (Le Chevalier au lion, v. 5510-5511 ${ }^{223}$ ). Elle ne va toutefois jamais jusqu'à la brisure de la rime, où la scission s'opère sur un mot, comme le pratiquent les poètes de la fin du Moyen Âge à l'instar de Christine de Pizan ("Mais a la beaulté qu'elle a-/ Voit, toute nuit sanz cesser $")^{224}$.

Choisir à la rime un adverbe, un déterminant, une préposition ou un adjectif antéposé est de plus en plus fréquent et marqué chez les auteurs tardifs. Girart d'Amiens et Jean Froissart, les deux derniers, en sont particulièrement friands: même si on trouve des enjambements dans tous les romans arthuriens en vers tardifs, ceux d'Escanor et de Melyador sont tout à fait audacieux, preuve peut-être qu'une évolution marquée s'est dessinée. S'ils n'inventent pas le procédé qu'ils empruntent à Chrétien de Troyes, du moins l'accentuent-ils sensiblement, surtout dans le cas de Melyador ${ }^{225}$ :

Et puis se jetta en jenous

Devant le roy et dist: «Tres doulz

Peres, voelliés entendre a mi!»

221 Voir Danièle James-Raoul, Chrétien de Troyes, la griffe d'un style, p. 682.

222 Lancelot reçoit enfin un nom après avoir été dénommé «charetté» jusque-là. Le terme "chevalier" est alors mis en rejet pour souligner le changement de perception et d'identité qui intervient pour le personnage à ce moment du récit. Julia Zarankin analyse en détail les enjambements dans le Chevalier de la Charrette. "Rupture et conjointure: l'enjambement dans Le Chevalier de la Charrette», Euvres et Critiques, XXVII/1, 2002, p. 221-239.

223 Chrétien de Troyes, Le Chevalier au lion, éd. David F. Hult, Paris, Le Livre de Poche («Lettres gothiques»), 1994. Les manuscrits G et R proposent toutefois le mot «baston» à la rime avec le mot «nuiton» du vers 5509 .

${ }^{224}$ Au sujet de la rime brisée, voir Jacqueline Cerquiglini-Toulet, "Des emplois seconds de la rime et du rythme dans la poésie française des $\mathrm{XIV}^{\mathrm{e}}$ et $\mathrm{XV}^{\mathrm{e}}$ siècles ", Le Moyen Français, 29, 1991, p. 21-31. L'exemple est tiré du Livre du duc des vrais amants.

225 Voir l'introduction à l'édition de Nathalie Bragantini-Maillard, p. 79-80, et son article, «L'octosyllabe romanesque chez Jean Froissart», art. cit. 
Et quant li rois, qui l'amoit si

Que riens fors que sa fille amoit [...] (Melyador, v. 1850-1854)

A ces cops n'est il mies sans

Grant hardement et bonne emprise. (Melyador, v. 8840-8853)

Messires Tangis de Sormal

Le cheval esporonne et a le

Entente qu'il voelt tournoiier. (Melyador, v. 13003-13005)

Li chevaliers au bleu escu

Qui se brise dou soleil d'or

Les a mis en ce point. Encor

Faut il que hommage me facent

Ou trop grandement se mesfacent. (Melyador, v. 13790-13793)

Car par trop est outrageus cils

Chevaliers, qui vous voet amer. (Melyador, v. 963-964)

Quant mesire Gavains entent

Que la pucele a sa mort tent

De Nantes et le fait gaitier (Escanor, v. 1615-1617)

Ne chascunz ne puet percevanz

Pas estre toutes fois qu'il veut (Escanor, v. 2904-2905)

La rupture se fait aussi bien entre un nom et son attribut, entre les composants d'une conjonction de subordination, entre ceux de la négation, qu'entre un déterminant et son nom. Le choix de la coupe est donc particulièrement audacieux et ne manque pas de transformer le rythme attendu de la scansion versifiée.

Cet effet est redoublé par la brisure du couplet, c'est-à-dire lorsqu'une phrase s'interrompt au milieu d'un couplet au lieu de s'étendre sur un nombre pair de vers; Jean Frappier, qui l'étudie chez Chrétien de Troyes, signale qu'elle intervient souvent pour changer de locuteur lors de dialogues, ce qui facilite l'identification des voix en l'absence d'une incise («dist il»). La brisure peut également ponctuer les phases de la progression, éviter la monotonie, accentuer un vers en l'isolant ou marquer un changement de tonalité2 ${ }^{26}$. L'ensemble des romans tardifs ne se prive bien

226 Jean Frappier, "La brisure du couplet dans Erec et Enide», Romania, 341/86, 1965, p. 1-21. Voir aussi Danièle James-Raoul, Chrétien de Troyes, la griffe d'un 
sûr pas de briser les couplets, bien que la brisure alterne avec des passages où la phrase correspond au couplet, notamment les vers 127 à 132 de Melyador cités ci-dessus. Il est notable que Froissart, par ailleurs grand prosateur, fasse preuve d'une telle maîtrise de ces contraintes propres à la versification, dont témoigne aussi sa production poétique ${ }^{227}$.

La brisure du couplet, de même que les enjambements, sont donc concertés dans son œuvre et ne peuvent être appréhendés comme des facilités; l'usage qu'en fait Chrétien de Troyes le prouve d'ailleurs, en étant toujours orienté vers une signification et en imposant un nouveau rythme qui suit les infléchissements de la diégèse, ainsi que l'ont démontré Jean Frappier et Danièle James-Raoul ${ }^{228}$. Un exemple éloquent de la complémentarité entre le travail du vers et l'histoire narrée peut être tiré de Claris et Laris. Dans l'extrait suivant, la reine Lidaine, future amie de Claris, apprend l'arrivée de son frère en compagnie de celui vers lequel son cœur tend déjà :

Quant la roÿne sot de voir

Que son frere devoit veoir

Et Claris, son compaignon [bel],

De joie a esmut le cervel. (Claris et Laris, v. 7205-7208)

Le nom de Claris est reporté au vers suivant pour le mettre en valeur. Ce rejet traduit l'émotion ressentie par la reine, pour qui le retour de Claris a une valeur particulière qui dépasse la simple joie de l'amour fraternel. Le lecteur est impliqué dans ce sentiment : à la lecture, le nom de Claris est l'objet d'une sorte d'arrêt, il est emphatisé textuellement comme il l'est dans le cœur de Lidaine. Le rythme du vers influe largement sur la réception, en reproduisant et en mimant les mouvements du cœur.

style, p. 518-523 et p. 675-683. Son article, "La brisure du couplet dans le Chevalier au lion de Chrétien de Troyes», 2017, en ligne, https://revues.univ-pau. fr/opcit/index.php?176--agregation-2018, fait bien comprendre l'importance de ce procédé chez l'auteur champenois, qui le transforme en véritable poétique.

227 Jean Froissart se montre en versificateur aguerri, dans ses compositions poétiques aussi bien que dans Melyador: Nathalie Bragantini-Maillard souligne sa propension à la rime léonine de construction parfois très subtile (descouvert/Camelz couvert, v. 359-360). Voir «L'octosyllabe romanesque chez Jean Froissart», art. cit., p. 261.

Ibid. 
On a pu dire au sujet de l'enjambement et de la brisure pratiqués par Chrétien de Troyes qu'ils contribuent à faire de l'octosyllabe à rimes plates une forme proche de la prose linéaire, qu'ils annonceraient, car ils démontrent l'autonomie possible de la syntaxe vis-à-vis de la métrique ${ }^{229}$. La rime a en effet pour rôle de marquer une coupure, un souffle entre deux vers qui recoupent chacun des moments de pause. Comme l'exprime Dominique Demartini, «voilant cette articulation, [l'enjambement] fragilise le mètre, en efface partiellement les contours ${ }^{230}$, si bien que cette pratique offre une forme aux limites du vers et de la prose. De même, la brisure contribue à rapprocher la syntaxe du vers de celle de la prose: "Avec la brisure du couplet s'accomplit en somme une dernière étape dans le progressif abandon des formes strophiques de la poésie narrative » ${ }^{231}$.

La linéarisation du discours n'est toutefois pas la seule conséquence de l'enjambement et de la brisure: ceux-ci ont pour effet de retarder l'achèvement de la phrase et de créer un suspense. Lauditeur est en attente de la complétude, de la soudure entre deux éléments associés. Les enjambements audacieux travaillés par Froissart, tout comme les brisures de couplets, sollicitent l'attention du lecteur ou à plus forte raison de l'auditeur en suscitant une attente, un sentiment d'incomplétude qui modifie l'expérience réceptive; ils engendrent une "esthétique du retardement ${ }^{232}$, génératrice de rythme. Pour le dire avec Danièle James-Raoul,

229 Christiane Marchello-Nizia, «La forme-vers et la forme-prose : leurs langues spécifiques, leurs contraintes propres», art. cit., p. 42, Annie Combes, "Le dérimage du Chevalier de la Charrette: les vers de Chrétien comme ressource de la prose", in Écrire en vers, écrire en prose: une poétique de la révélation. Actes du colloque de Paris $X$-Nanterre, mars 2006, dir. Catherine Croizy-Naquet, Nanterre, Université Paris X-Nanterre («Littérales», 41), 2007, p. 173-186.

230 Dominique Demartini, «Des or est mout changiez li vers. Fictions du vers et de la prose dans Le Livre du duc des vrais amants de Christine de Pizan ", in Plus agreable a lire en prose que en rime? Vers et prose en moyen français, dir. Michelle Szkilnik et Catherine Croizy-Naquet, Le Moyen Français, vol. 76-77, 2015, Turnhout, Brepols, 2016, p. 92.

231 Jean Frappier, "La brisure du couplet dans Erec et Enide», art. cit., p. 2. Catherine Croizy-Naquet aborde l'octosyllabe dans cette perspective : en brisant le carcan du couplet d'octosyllabes, Chrétien de Troyes affaiblit le rythme de la versification en conservant la rime comme seul élément sonore perceptible. «L'octosyllabe dans l'Eneas", art. cit.

232 Danièle James-Raoul, "La poétique de l'octosyllabe dans Le Chevalier au lion", Acta LittóArts, Le laboratoire du roman. Le Chevalier au lion de Chrétien de 
chaque brisure du couplet vaut moins en elle-même que comme élément constitutif d'une dissonance musicale marquée: le texte versifié adopte momentanément une musicalité tout autre, le rythme se met à boiter avec insistance dans la durée, faisant l'effet d'être à contretemps, liant ce qui est séparé par la différence de la rime, séparant ce qui est lié rimiquement ${ }^{233}$.

Peut-être faut-il alors considérer l'accentuation des enjambements et les brisures de couplets, de plus en plus nets entre la fin du XIII ${ }^{\mathrm{e}}$ siècle et le XIV ${ }^{e}$ représenté par Melyador, comme des moyens de confirmer l'identité du vers narratif, tel qu'il a été inventé par Chrétien de Troyes; les auteurs tardifs ne semblent pas interpréter ces deux procédés en lien avec l'écriture en prose. Loin d'être des facilités, l'enjambement et la brisure du couplet peuvent être vus comme une spécificité de l'écriture arthurienne versifiée, qui singularise le rythme de l'octosyllabe propre au roman. D'Erec et Enide à Melyador, en passant par d'autres romans tardifs comme Escanor, le style du vers arthurien se distingue par des ruptures rythmiques; le vers tardif conserve son identité propre, distincte de la prose.

\section{DESTIN DU VERS}

L'identité versifiée marquée des derniers romans arthuriens tardifs et leurs interactions avec le roman en prose font de ce corpus un terrain propice à l'étude de l'abandon progressif du vers comme forme d'expression romanesque. Cette évolution peut être éclairée et étayée par trois dimensions qui occuperont ce chapitre: l'examen des derniers romans en vers non arthuriens et leur façon de revendiquer l'écriture versifiée, applicable à notre corpus; les insertions lyriques dans Escanor et Melyador, envisagées comme le symptôme de la spécialisation lyrique du vers, celui-ci concédant à la prose le privilège de la narration; enfin, la transmission manuscrite du roman arthurien en vers à la fin du Moyen Âge achèvera de traduire l'opacité que prend progressivement cette forme aux yeux des contemporains.

Troyes, 2018, \$ 6, en ligne, http://ouvroir-litt-arts.univ-grenoble-alpes.fr/revues/ actalittarts/385-la-poetique-de-l-octosyllabe-dans-le-chevalier-au-lion.

Ibid., $\$ 24$. 


\section{Le vers narratif au XIV ${ }^{e}$ siècle}

Nous avons distingué plus haut trois types de cadre formel: la prose, le vers narratif et le vers lyrique. Alors que ce dernier se développe au XIv ${ }^{\mathrm{e}}$ siècle avec de nouvelles formes - que l'on pense à la poésie d'Eustache Deschamps ou de Guillaume de Machaut ${ }^{234}$ - et se maintient jusqu'à nos jours, le vers narratif est de moins en moins employé dans le roman et se réserve à des usages génériques particuliers, bien qu'il fût, nous l'avons vu, la forme privilégiée et exclusive de la narration au $\mathrm{XII}^{\mathrm{e}}$ siècle. Les romans de notre corpus ne sont en effet pas seulement les derniers représentants du roman arthurien en vers, mais ils font également partie des derniers romans en vers. La réticence progressive à utiliser le vers narratif dans le roman $^{235}$ explique donc l'épuisement du genre puis son extinction, plus que ne le font les autres critères comme l'univers de fiction et l'idéologie choisis.

La production en vers est loin d'être marginale aux XIV et $\mathrm{XV}^{\mathrm{e}}$ siècles: Jean-Claude Mühlethaler note même une recrudescence d'œuvres narratives versifiées sous les derniers Capétiens directs, Philippe le Bel notamment ${ }^{236}$. En dehors de la poésie lyrique et du théâtre, genres qui privilégient la forme versifiée ${ }^{237}$, le vers survit aux $\mathrm{XIV}^{\mathrm{e}}$ et $\mathrm{XV}^{\mathrm{e}}$ siècles en particulier à

234 Voir Michel Zink, Littérature française du Moyen Âge, "La poésie au XIV et au Xv siècle», p. 267-300.

235 Ce mouvement est valable dans le cas de l'historiographie également: d'abord rédigée en vers, elle privilégie ensuite la prose dès le XIII ${ }^{\mathrm{e}}$ siècle, au point que les chroniques en vers se font très rares au siècle suivant, quand elles ne se confondent pas avec des chansons de geste. Nous soulignerons au chapitre suivant l'orientation presque exclusivement lyrique que prend le vers dès le XIv ${ }^{e}$ siècle; elle se vérifie aussi pour l'écriture de l'histoire. Adrian Armstrong et Sarah Kay démontrent l'essor de poèmes historiographiques, qui restituent une prise de position personnelle et subjective sur l'Histoire. Ils donnent les exemples du Ditié Jeanne d'Arc de Christine de Pizan et la Prise d'Alixandre de Guillaume de Machaut. Voir Une Muse savante? Poésie et savoir, du "Roman de la Rose" jusqu'aux grands rhétoriqueurs, Paris, Garnier, 2014, p. 71-96. Voir aussi Grundriß der romanischen Literaturen des Mittelalters, La littérature historiographique des origines à 1500, Hans Ulrich Gumbrecht et Armin Biermann, Heidelberg, Carl Winter, 1986, 4 vol.

236 Jean-Claude Mühlethaler, "Défense et illustration du vers dans les récits du Moyen Âge tardif", art. cit.

237 Adrian Armstrong et Sarah Kay, Une Muse savante?, p. 48-69. Voir les articles sur la poésie aux XIV e et $\mathrm{XV}^{\mathrm{e}}$ siècles dans Grundriß der romanischen Literaturen des Mittelalters. La littérature française aux XIV et XV siècles, vol. VIII/I, Heidelberg, 
travers le dit, en plein essor à la fin du Moyen Âge. Il s'écrit en vers, car cette forme permet un travail «sur le discontinu, sur le rythme ${ }^{238}$, qui est le propre de l'écriture du dit selon Jacqueline Cerquiglini-Toulet. Même s'il s'allonge et prend une dimension narrative au cours des derniers siècles du Moyen Âge, il s'agit d'un genre distinct du roman, caractérisé par une énonciation en je et la perspective d'un enseignement. Le dit ne se caractérise pas par une matière particulière et s'adapte à des sujets variés. Il ne s'agit pas d'un genre exclusivement narratif et sa dimension lyrique est manifeste, surtout par la subjectivité qu'introduit l'énonciateur. C'est le cas pour les dits de Jean Froissart, qui racontent les aventures amoureuses d'un narrateur et font la part belle à la composition poétique par l'insertion de pièces chantées ${ }^{239}$. Le vers du dit n'est donc pas totalement un vers narratif, mais une forme intermédiaire entre lyrique et narratif. Pour le dire avec Jacqueline Cerquiglini-Toulet, le dit «est bien un traité, mais une forme particulière de traité. Il traite en vers, de manière poétique, de matières diverses $»^{240}$.

Carl Winter, 1988: Jacqueline Cerquiglini-Toulet, "Le Rondeau», p. 45-58; Henrik Heger, "La Ballade et le Chant Royal», p. 59-69; Robert Deschaux, «Le Lai et la Complainte»; p. 70-85, et Jacqueline Cerquiglini-Toulet, "Le nouveau lyrisme (XIV -XV siècles)", in Précis de littérature française du Moyen Âge, dir. Daniel Poirion, Paris, PUF, 1983, p. 275-292. Pour le théâtre: Jelle Koopmans, "On écrit des vers - de la prose", mais que dit-on sur la scène?", in Rencontres du vers et de la prose. Conscience poétique et mise en texte, dir. Catherine Croizy-Naquet et Michelle Szkilnik, Paris, PSN, 2017, p. 127-139, Jean-Claude Aubailly, "Théâtre "populaire" et rhétorique à la fin du Moyen Âge et au début du Xvi siècle", in Aspects du théâtre populaire en Europe au XVI siècle, éd. Madeleine Lazard, Paris, SEDES, 1989, p. 17-29, Armand Strubel, Le Théâtre au Moyen Âge. Naissance d'une littérature dramatique, Paris, Bréal, 2003, Michel Rousse, "Le théâtre", in Histoire de la France littéraire. Naissances, Renaissances, dir. Frank Lestringant et Michel Zink, Paris, PUF ( Quadrige»), 2006, p. 812-849, Bernard Ribémont, Le Théâtre français du Moyen Âge au XVt siècle, Paris, Ellipse, 2003, Jean-Pierre Bordier, "Le Jeu dramatique ( $\mathrm{XIV}^{\mathrm{e}}$ et $\mathrm{XV}^{\mathrm{e}}$ siècle)", in Précis de littérature française du Moyen Âge, dir. Daniel Poirion, Paris, PUF, 1983, p. 306-335. Jean-Claude Aubailly précise que le théâtre privilégie la forme du rondeau ou de la ballade, qui favorisent respectivement le dialogue et le monologue.

238 Jacqueline Cerquiglini-Toulet, «Le dit», art. cit., p. 91.

239 Sur le caractère lyrique des dits de Froissart, voir Silvère Menegaldo, "Amateurs et professionnels: la composition poétique selon le Meliador et les dits de Jean Froissart", Perspectives médiévales, 2006, p. 179-201.

240 Jacqueline Cerquiglini-Toulet, «Le dit», art. cit., p. 92. 
Ensuite, certains traités didactiques sont encore composés en vers ${ }^{241}$. C'est le cas du traité de chasse de Gace de la Buigne pour Philippe le Hardi, Le Roman des deduis, composé de 12210 octosyllabes à rimes plates entre 1359 et $1377^{242}$. On peut également citer le Livre du Tresor de Venerie de Hardouin de Fontaines-Guérin (1390-1394)243. Henri de Ferrières (Livre du roi Modus et de la reine Ratio) mêle quant à lui vers et prose, auxquels il réserve des usages spécifiques. Le vers restitue le prologue, tandis que la partie didactique est composée en prose. Ce choix est lié à la propension pédagogique de la prose, pressentie pour mieux transmettre un enseignement, comme l'auteur l'exprime lui-même:

[Le roi Modus] nous fist un livre de deduis,

Qui sans rimer est entendu

Pour miex savoir le contenu

Des demandes qui li fesoient

Ses escoliers, qui aprenoient ${ }^{244}$.

241 Adrian Armstrong et Sarah Kay invitent à faire une distinction entre encyclopédie et textes encyclopédiques, la première ayant pour ambition l'universalité tandis que les seconds prennent un sujet pour objet. L'encyclopédie ne s'écrit plus en vers dans les derniers siècles du Moyen Âge, tandis que les textes encyclopédiques en vers sont innombrables et s'intéressent à des sujets variés, la chasse pour les exemples que nous choisissons, mais aussi la médecine, la nature ou l'ophtalmologie. Le vers apparaît ainsi comme un vecteur de savoir sur le monde. Une muse savante?, p. 133-173. Voir aussi les articles de Joëlle Ducos, qui propose d'autres exemples de textes scientifiques en vers, "Écrire la science en vers et en prose", art. cit., et "Écrire en vers après la prose: vers une poésie scientifique?", in Rencontres du vers et de la prose. Conscience poétique et mise en texte, dir. Catherine Croizy-Naquet et Michelle Szkilnik, Paris, PSN, 2017, p. 93-110. Joëlle Ducos souligne que la fonction didactique n'est pas prioritaire dans ce qu'elle dénomme le champ de la poésie scientifique: «il s'agit bien plutôt de jouer avec le savoir et avec les lecteurs, la forme poétique permettant une circulation entre les niveaux d'interprétation et les évocations figurées ou descriptives pour une vision du monde.» ("Écrire en vers après la prose», p. 110)

242 Gace de la Buigne, Le roman des deduis, éd. Åke Blomqvist, Stockholm, Almqvist och Wiksell; Paris, Thiébaud («Studia romanica Holmiensa», 3), 1951.

243 Sur les traités de chasse, on consultera Armand Strubel et Chantal de Saulnier, La poétique de la chasse au Moyen Âge, Paris, PUF, 1994, en particulier la page 71 sur le vers et la prose.

244 Henri de Ferrières, Les livres du roy Modus et de la royne Ratio, éd. Gunnar Tilander, Paris, SATF, 1932, v. 128-132. Le traité de chasse est daté entre 1354 et 1376. 
Une fois encore, on peut en déduire qu'au XIV ${ }^{\mathrm{e}}$ siècle, la prose est cognitivement plus accessible que le vers: cet exemple ne valorise pas les qualités mémorielles de la rime, contrairement à d'autres textes de la même époque $^{245}$. Le vers apparaît ici comme un ornement, qui freine potentiellement l'apprentissage, mais permet en tout cas d'introduire un propos et de capter l'attention.

Du côté de la production narrative, on peut citer la littérature religieuse, qui emprunte fréquemment le vers octosyllabique à rimes plates, propice à la conjonction d'une célébration et d'une narration. On le rencontre dans les Treize Miracles de Notre Dame ou le Tombel de Chartreuse, recueil de trente contes pieux et vies de saints. Le vers a pour fonction de rapprocher l'hagiographie du chant religieux. Quelques chroniques s'écrivent encore en vers, comme la Chronique métrique de Geoffroi de Paris, composée entre 1313 et 1317 en octosyllabes à rimes plates et relatant les crises du règne de Philippe le $\mathrm{Bel}^{246}$. Enfin ${ }^{247}$, la chanson de geste se formalise encore volontiers au cadre de la laisse d'alexandrins, tout comme les récits sur Alexandre - ainsi du Cycle du Paon. Les chansons de geste sont réadaptées, en vers, aux goûts du XIv siècle: elles sont amplifiées (Ami et Amile, Renaut de Montauban) ou prolongées en vue de former un cycle (autour d'Huon de Bordeaux par exemple) ${ }^{248}$. Plusieurs compositions nouvelles voient également le jour: Baudoin de Sebourc, le Bastard de Bouillon ou Hugues Capet. Bien que la geste prenne un tour plus narratif dans ces représentants tardifs, la survivance du cadre formel épique laisse envisager

245 Daniel Poirion, «Romans en vers et romans en prose», art. cit., p. 75, traite du lien entre vers et mémorisation.

246 Voir La Chronique métrique attribuée à Geoffroy de Paris, éd. Armel Diverrès, Strasbourg, Faculté des Lettres, 1956, et Jean-Claude Mühlethaler, «Défense et illustration du vers dans les récits du Moyen Âge tardif», art. cit., p. 113.

247 Sur d'autres formes versifiées, comme le dialogue philosophique ou le poème historiographique, voir Adrian Armstrong et Sarah Kay, Une Muse savante?

248 Les exemples sont donnés par François Suard, "L'épopée», in Grundriß der romanischen Literaturen des Mittelalters. La littérature française aux XIV et XV siècles, vol. VIII/I, Heidelberg, Carl Winter, 1988, p. 167-168. Voir aussi François Suard, "Figures du romanesque dans l'épique de la fin du Moyen Âge», in Le romanesque aux XIV et XV siècles, éd. Danielle Régnier-Bohler, Bordeaux, PU, 2009, p. 139-157. Le critique traite dans ce dernier article de l'influence des techniques romanesques sur ce corpus: multiplication des péripéties, des espaces et des personnages, éléments merveilleux. 
ses accointances avec les formes lyriques, qui survivent très bien: propice à la célébration, l'alexandrin organisé en laisses apparaît comme un artifice acceptable pour qui veut glorifier un héros, passé ou présent. En comparaison, l'octosyllabe et sa narration continue ont dû sembler faire double emploi avec une prose linéaire et plus accessible ${ }^{249}$. Pourtant, la chanson de geste s'accommode très bien de la prose: plusieurs sont mises en prose aux XIV et Xve siècles, comme Renaut de Montauban, Garin de Monglane ou encore La Belle Hélène de Constantinople par Jean Wauquelin en $1448^{250}$. Ces versions sont d'ailleurs privilégiées par l'imprimerie, qui

249 Peut-être n'est-ce en ce sens pas un hasard si Octovien de Saint-Gelais, à la fin du $\mathrm{Xv}^{\mathrm{e}}$ siècle (avant 1489), traduit l'Historia de duobus amantibus d'Eneas Silvius Piccolomini en français en huitains de décasyllabes, et non en octosyllabes: l'Ystoire de Eurialus et Lucresse, vrays amoureux n'a pourtant rien d'une chanson de geste, au niveau de son contenu. L'octosyllabe narratif est une forme définitivement abandonnée à cette époque: si le traducteur choisit le vers pour, comme le pense Frédéric Duval, inscrire son œuvre «dans la tradition de la nouvelle courtoise" (Eneas Silvius Piccolomini, Euvres érotiques, prés. et trad. Frédéric Duval, Turnhout, Brepols, 2003, p. 33), il adopte non pas le mètre qui s'accordait en son temps à la littérature courtoise, mais bien celui qui survit le plus longtemps comme forme de la célébration. Le texte n'est pas étranger au lyrique - domaine du vers à cette époque, nous y reviendrons -, surtout en ce qu'il propose un art d'aimer et exacerbe les complaintes et argumentations amoureuses (les personnages débattent en monologues intérieurs des pro et contra de l'amour, ou s'auto-analysent pour savoir s'ils sont amoureux sur le mode du pro/contra). Pierre Sala, dont nous traiterons un peu plus loin, commence aussi son remaniement du Chevalier au lion en décasyllabes; ce mètre est réservé au prologue, tandis que l'octosyllabe prend le relais pour la narration de l'histoire à proprement parler. Ce changement de forme opère une structuration du texte, une rupture entre le seuil autonome que constitue le prologue à la Renaissance et l'histoire. Peut-être ces différences métriques signalent-elles également que le décasyllabe est devenu plus naturel au début du $\mathrm{XVI}^{\mathrm{e}}$ siècle que l'octosyllabe, que Pierre Sala emploie dans un souci de fidélité à sa source qu'il souhaite moderniser. Lorsqu'il s'adresse à son roi, François I ${ }^{\text {er }}$, il est plus pratique d'adopter le décasyllabe, attaché à l'idée de célébration. C'est aussi le mètre qu'il adopte dans la dédicace du début de son Tristan. Sur le prologue du Chevalier au lion, voir l'article d'Olga Scherbakova, "Le Chevalier au lion de Pierre Sala: du prologue aux enjeux d'une récriture", Le Moyen français, 59, 2006, p. 125-137, et Corinne Deschepper, "Dédicace, prologue, résumé - Considérations sur les premières pages du Chevalier au lion de Pierre Sala", in Quant l'ung amy pour l'autre veille. Mélanges de moyen français offerts à Claude Thiry, éd. Tania Van Hemelryck et Maria Colombo Timelli, Turnhout, Brepols («Texte, codex et contexte», 5), 2008, p. 101-111.

250 Voir Maria Colombo-Timelli et al., Nouveau répertoire de mises en prose. On constate que la chanson de geste est un genre particulièrement concerné par la mise en prose. 
les diffuse mieux que les romans en prose $\mathrm{e}^{251}$. Pourquoi, dès lors, continuer à exploiter la laisse d'alexandrins, alors que la prose est au goût du jour? C'est que ces deux formes répondent à des usages différents, mais non opposés, comme le précise François Suard:

Les deux formes concourent au même but, la mise en valeur, aux fins d'imitation, des preux d'autrefois ou de ceux qui, par leur valeur, peuvent leur ressembler. Mais l'accent est différent: à la chanson de geste revient, grâce au discours lyrique et à la fiction de la transmission vivante d'un récit oral, au moment même où l'on exploite les possibilités sans limite de l'écrit, la fonction de célébration, dans le cadre d'une ouvre unique; à la prose se trouve attachée, sur le mode du récit, la mission de dire le vrai et de peindre, dans une fresque aux couleurs de la réalité, une histoire exemplaire ${ }^{252}$.

Même objectif, moyens différents; cela justifie la coexistence du vers et de la prose dans la chanson de geste lors des derniers siècles du Moyen Âge.

Cette coexistence est en revanche plus mystérieuse pour le genre romanesque qui nous intéresse plus particulièrement. En dehors du domaine arthurien ou para-arthurien, dont nous avons listé les œuvres dès la fin du $\mathrm{XIII}^{\mathrm{e}}$ siècle, peu de romans s'écrivent en vers octosyllabiques au XIV ${ }^{\mathrm{e}}$ siècle, et encore moins au $\mathrm{Xv}^{\mathrm{e}}$ siècle. Ces textes ont tous une façon particulière de revendiquer la pratique du vers, éclairant ainsi à des yeux modernes la conception attachée à cette forme à la fin du Moyen Âge. La considération de ces œuvres trace le cadre historico-littéraire des romans arthuriens tardifs, en particulier de Melyador, dans la perspective de l'usage du vers. En voici la liste chronologique, qui nous paraît exhaustive $e^{253}$ :

251 François Suard, "L'épopée», in GRLMA, VIII, p. 177. François Suard note aussi qu'il existe quelques compositions nouvelles en prose: il cite la Conqueste de Trebizonde et le Livre des troys filz le roys.

252 Ibid., p. 174.

253 Nous renonçons à considérer le Roman de Fauvel comme un roman: il s'agit plutôt d'un texte qui dénonce sur le mode satirique les manquements de la société, mais la dimension narrative y est pauvre, voire quasi inexistante. De la même manière, nous jugeons, après Michel Zink ("Le Roman», in GRLMA, VIII, p. 206), que le Chevalier errant de Thomas de Saluces est un roman du moi, plus proche du dit. L'éditeur Marco Piccat ose même le définir comme une autobiographie chevaleresque virtuelle, mêlant réel et fiction. Éd. cit., p. 5, 13-22. Ce texte emprunte 
- Le Roman du comte d'Anjou, de Jean Maillart, composé en 1316 selon le poète (v. 8154-8155) 254 . Jean Maillart est vraisemblablement un haut fonctionnaire à la cour de Philippe le Bel. Le roman est dédié à Pierre de Chambli, conseiller de ce dernier ${ }^{255}$. Ce texte est une réécriture de la Manekine; un veuf tombe amoureux de sa jolie fille, qui doit s'enfuir et vit une série de péripéties avant de trouver le bonheur. L'auteur supprime les éléments spectaculaires (l'héroïne qui se coupe une main), le merveilleux ou miraculeux (la main qui se ressoude).

- Le Roman de la Dame a la Lycorne et du Biau Chevalier au Lyon, premier tiers du XIv ${ }^{e}$ siècle, composé en décasyllabes et en octosyllabes et farci de lettres en prose ${ }^{256}$. Produit aux alentours de Beauvais et dédié à Blanche de Navarre, épouse du roi Philippe $\mathrm{VI}^{257}$, ce roman anonyme

"le versant subjectif de la narration»(p. 206). Enfin, nous nous concentrons sur le domaine strictement français et mettons de côté le texte de Belris et Machabia, en franco-italien, composé entre 1350 et 1380 . Ce roman contient de nombreuses résonances arthuriennes: le motif de la chasse au cerf, du château tournoyant ou du combat entre un lion et un serpent. Ce dernier est réécrit: Belris choisit de tuer le lion pour sauver le serpent! Pour poursuivre sur la veine intertextuelle qu'il choisit, l'auteur fait de ce serpent une guivre, qui embrasse le chevalier, puis retourne précipitamment se cacher avant de réapparaître en belle dame. On aura reconnu le $\mathrm{Bel}$ Inconnu. Le choix du vers dans Belris et Machabia s'explique peut-être par une volonté d'expliciter le lien qu'il tisse avec les romans arthuriens, quoique le reste de l'intrigue en demeure autonome. Il s'agit avant tout d'un roman qui fait se succéder les aventures merveilleuses, sans prétention historique ni morale ou religieuse. Voir l'édition de Jacques Monfrin, "Le roman de Belris», Romania, 83, 1962, p. 493-519, et son étude, "Le roman de Belris, Le bel inconnu, Carduino", in Testi, cotesti e contesti del franco-italiano. Atti del $1^{\circ}$ simposio franco-italiano (Bad Homburg, 13-16 aprile 1987). In memoriam Alberto Limentani, éd. Günter Holtus, Henning Krauß et Peter Wunderli, Tübingen, Niemeyer, 1989, p. 161-176.

254 Nous nous appuyons sur l'édition de Mario Roques de 1921, éd. cit.

255 Voir l'étude de Catherine Rollier-Paulian, L'esthétique de Jean Maillart. De la courtoisie au souci de l'humaine condition dans Le Roman du Comte d'Anjou, Orléans, Paradigme, 2007, p. 8-12.

256 Le Romans de la Dame a la Lycorne et du Biau Chevalier au Lyon, éd. Friedrich Gennrich, Dresde, Max Niemeyer, ("Gesellschaft für romanische Literatur»), 1908. Nathalie Koble prépare une traduction de ce texte, à paraître chez Librio.

257 Selon Anthime Fourrier, "La destinataire de La Dame à la licorne», in Mélanges de langue et de littérature médiévales offerts à Pierre Le Gentil, Paris, Société d'édition d'enseignement supérieur et Centre de documentation universitaire, 1973, p. 265-276. 
narre les amours de la Dame à la licorne, mal-mariée à Privé Dangier, avec le Beau Chevalier, dont les noms sont allégoriques ${ }^{258}$. Alors que le soupçon pèse sur eux, le Beau Chevalier doit s'éloigner de la cour, partir en errance, et vit des épreuves chevaleresques avant de pouvoir retrouver sa Dame. Cette œuvre tire son inspiration de divers modèles: celui de la lyrique courtoise, bien sûr, et de la relation triangulaire qui implique un mari jaloux, un amant et une dame, ainsi que des adjuvants et des losengiers. Le Roman de la Dame a la Lycorne fait également écho à la tradition arthurienne, par les modalités de l'errance et la nature topique des aventures, comme le combat contre un géant, le sauvetage d'une demoiselle prisonnière d'une source d'eau, celui d'une autre jeune fille malmenée par un nain et métamorphosée en cerf. Le roman renvoie plus spécifiquement au Chevalier au lion de Chrétien de Troyes; le héros sauve un lion qui se bat contre un dragon ${ }^{259}$, devient fou lorsqu'il croit sa dame morte et guérit grâce à un onguent.

- Le Roman d'Eledus et Serene, fin du XIv ${ }^{e}$ siècle, inachevé260. Ce roman raconte l'histoire d'amour entre Eledus, filleul du roi de Tubie Gemenis, et Serene, la fille de ce dernier, promise à sa naissance au fils du duc d'Alide, Maugrier, alors que le duc expirait son dernier soupir. L'histoire tourne autour des péripéties des héros éponymes pour être réunis. L'un des éléments marquants de l'histoire est la ruse qu'imagine la suivante de Serene, Sébille, qui consiste à faire croire à Gemenas que Maugrier s'est marié, ce qui libère le roi de son serment et le mène à

258 Michel Zink souligne que les derniers romans en vers tendent à «donner à l'aventure amoureuse l'expression intériorisée de l'allégorie» ("Le Roman», in GRLMA, VIII, p. 205-206).

259 Le surnom de «Beau Chevalier au lion» n'est toutefois pas dû à cette réécriture du lion reconnaissant : c'est lorsque le héros sauve le Chevalier Faé en tuant le lion sur lequel celui-là est attaché qu'il est ainsi baptisé. Au sujet des noms et de la symbolique du lion et de la licorne dans le roman, voir Alice Planche, «Les plus beaux, le plus fort, la plus belle. Les extrêmes du rêve courtois dans le Roman de la Dame à la Licorne et du Beau Chevalier au Lion (composé vers 1350)", in Medieval and Renaissance Monographs. Serie VI: Courtly Romance. A Collection of Essays, éd. Guy R. Mermier, Michigan Consortium for Medieval and Early Modern Studies, 1984, p. 177-202.

260 Nous nous référons à l'édition suivante: Le Roman d'Eledus et Serene. Edited for the first time from the unique manuscript of the Bibliothèque nationale, éd. John Revell Reinhard, Texas, University of Texas Press, 1923. 
marier Eledus et Serene. Les amants subissent les attaques de Maugrier, prévenu de leur mariage: le duc enlève plusieurs fois Serene et Sebille, mais les jeunes filles sont sauvées à chaque fois par Eledus. Le couple engendre une fille, Brande, ravie par deux fées qui l'emmènent en Bretagne, et un fils, Arthur ${ }^{261}$. Comme il manque la fin du texte, on n'assiste jamais à la vengeance attendue d'Eledus envers Maugrier, qui a tout de même piétiné Serene de ses pieds garnis d'éperons.

- Mélusine de Coudrette, version en vers, à la suite du roman de Jean d'Arras, de l'histoire de la fée Mélusine, ancêtre des Lusignan. Commandé par Guillaume Larchevêque, seigneur de Parthenay ${ }^{262}$, le roman est achevé en $1401^{263}$.

- Pierre Sala, Le Chevalier au Lion, composé en $1522^{264}$. Il s'agit d'une réécriture du roman de Chrétien de Troyes, mais l'on peut s'étonner que l'auteur ne choisisse pas, comme ses contemporains, de transposer la matière en prose, d'autant plus que son Roman de Tristan de Leonnois et de la belle reine Yseulte (1525-1529)265 est rédigé en prose.

261 Christine Ferlampin-Acher traite des liens entre Eledus et Serene et le genre arthurien dans "Interpolations et "extrapolations" : études de quelques épisodes arthuriens en contexte non arthurien", in Arthur après Arthur, p. 153.

262 Sur la famille des Parthenay, voir l'introduction à l'édition d'Eleanor Roach, Coudrette, Le Roman de Mélusine ou Histoire de Lusignan, Paris, Klincksieck, 1982, p. 21-77. Le choix du vers dans le contexte romanesque ne semble pas devoir être attribué à une cour ou un milieu en particulier: pour autant que l'on puisse le savoir, ces derniers romans en vers sont issus de contextes et de régions différents.

263 Sur les accointances entre le Roman de Mélusine et le genre arthurien, voir Barbara Wahlen et Jean-Claude Mühlethaler, «Dépasser le modèle arthurien: Geoffroy la Grand'Dent, chevalier de la fin des temps?", in 550 Jahre deutsche MelusineCoudrette und Thüring von Ringoltingen/550 ans de Mélusine allemande-Coudrette et Thüring von Ringoltingen, dir. André Schnyder, et Jean-Claude Mühlethaler, Bern, Peter Lang, 2008, p. 343-362, et Joanna Pavlesvski-Malingre, "Avalon, "L'ille perdue" : la fin du temps arthurien dans les romans de Mélusine», in Arthur après Arthur, p. 41-70.

264 Pierre Sala, Le chevalier au lion, éd. Pierre Servet, Paris, Champion («Bibliothèque du Xv siècle», 56), 1996.

265 Pierre Sala, Tristan, éd. Chantal Verchère, Paris, Champion ("Textes de la Renaissance», 135), 2008. Voir en particulier la riche introduction de cette édition. Si l'on suppose que la source principale de ce texte est le Tristan en prose, Pierre Sala prend beaucoup de liberté vis-à-vis de la tradition, si bien qu'il s'agit 
Pierre Sala aurait également écrit un Roman de Messire Herec en vers, remaniement perdu aujourd'hui ${ }^{266}$. Comme l'explique Jean-Claude Mühlethaler ${ }^{267}$, la posture qu'adopte l'auteur est celle de conserver la forme originale de sa source, que ce soit pour Le Chevalier au lion, Tristan ou Herec, et d'agir, en quelque sorte, en philologue: son but est de rendre les textes accessibles à son roi, François I ${ }^{\text {er }}$, du point de vue linguistique. Il l'exprime aux vers 11 à 13 du Chevalier au lion: «D’y travailler je fis tant quë ung comp[te] / En extrahy, dont nul ne tenoit co[mpte], / Car trop estoit difficil a le lire ${ }^{268}$.

La démarche de Pierre Sala est donc bien différente de celle des textes que nous avons listés précédemment. Elle justifie que nous nous intéressions plus à ceux-ci qu'au Chevalier au lion, d'autant que le recours à la rime est l'objet d'une problématisation dans ces romans. Jean Maillart veut transmettre un message moral en réactivant le motif de la jeune fille

plus de sa propre version de l'univers de fiction, agencée à partir de la tradition, que d'une réécriture explicite d'une seule source. D'autres textes interviennent dans la composition: le Lancelot en prose, les Prophéties de Merlin, la Suite du Merlin, etc. La démarche est donc quelque peu différente que pour le Chevalier au lion. Voir les pages 40 à 47.

266 Maria Colombo Timelli, “On ne prête qu'aux riches”. Sur l'attribution de quelques ouvres à Pierre Sala", in "Pour vous donner ung peu de passetens..." Autour de Pierre Sala, lyonnais (ca. 1457-1529), Studi francesi, 156, 2008, p. 550. Ce remaniement serait semblable à celui pratiqué à partir du Chevalier au lion. La seule preuve de l'existence d'une telle version se trouve dans la Bibliothèque françoise d'Antoine du Verdier au XVI ${ }^{\mathrm{e}}$ siècle.

267 Jean-Claude Mühlethaler, "Défense et illustration du vers dans les récits du Moyen Âge tardif ", art. cit., p. 121-122. Sergio Cappello s'interroge sur le remaniement du vers dans les imprimés du Xvi ${ }^{\mathrm{e}}$ siècle et propose l'hypothèse qu'il peut s'agir d'une influence des modèles italiens renaissants, Boccaccio, Pulci et Boiardo par exemple. «L'édition des romans médiévaux à Lyon dans la première moitié du XVI ${ }^{\mathrm{e}}$ siècle», Réforme, Humanisme, Renaissance, 71, 2011, p. 55-71.

268 La simplification n'est pas seulement linguistique: Pierre Sala «clarifie, explique, ampute l'histoire quand elle lui paraît obscure, invraisemblable ou redondante" (Pierre Servet, Le Chevalier au lion, éd. cit., p. 75). Son remaniement est donc une véritable transposition du roman de Chrétien de Troyes dans le contexte de la Renaissance. Voir les pages 24 à 75 de l'édition de Pierre Servet et l'article de Jane H. M. Taylor, "Hungrie shadows: Pierre Sala and his Yvain», Arthuriana, 19:1, 2009, p. 7-19. Dans son Tristan, Pierre Sala évoque aussi la difficulté à déchiffrer le parchemin source: il s'est beaucoup fatigué à lire le "vieil Tristan», "Car les lectres estoient effacees / Et les marges du parchemin cassees» (p. 135). 
dont le père tombe amoureux (Peau d'Âne) ${ }^{269}$. Il se place, comme nous l'avons vu plus haut, en opposition avec les romans traitant de Lancelot, Perceval ou Cligès qui sont vains, "Fors que l'anui des cuers enchacent / Par leurs contes et par leurs fables» (v. 24-25). Le seul intérêt des récits arthuriens, fictifs, serait leur caractère divertissant, trompant ainsi l'ennui. La supériorité du Roman du comte d'Anjou sur les récits arthuriens dont il se démarque réside dans sa conjonction de l'exemplarité qu'il revendique et le plaisir qu'il suscite chez le public: l'emploi du vers a partie liée avec cette prétention, car "cil qui l'orront retraire [le conte]» (v. 56), "Pour la biauté et l'acordance / De la rime, i truissent plesance» (v. 57-58). C'est ici la dimension esthétique du vers qui est mise en avant; cette plesance n'est pas seulement induite par une histoire distrayante, mais surtout par la beauté du vers et de la rime, par la jouissance d'ordre esthétique qu'elle éveille. C'est pourquoi le roman doit être entendu plutôt que lu. L'auteur met en scène une réception auditive ("orront retraire», v. 56, "Seingneurs, or veilliéz tous taire: / A ma matiere m'en repaire, / Un po me doingniéz d'audiance», v. 61-63) et non visuelle, condition à l'appréciation de l' «acordance», de l'harmonie du rythme et des sonorités de l'octosyllabe ${ }^{270}$. L'auditeur doit néanmoins être considéré comme fictionnel: Catherine Rollier-Paulian propose d'établir une distinction entre l'auditeur inscrit dans le texte, aussi fictif que les personnages, et le lecteur réel ${ }^{271}$. L'épilogue occulte la situation orale de réception et s'adresse à «ceus qui cest oevre / Verront, quant en leur mains charra» (v. 80768077). Peut-être faut-il en ce sens admettre que, si le texte n'était pas effectivement récité oralement, du moins était-il attendu que le lecteur le lise à voix haute pour profiter des beautés de la rime.

269 Voir les pages 27 à 41 de Catherine Rollier-Paulian, L'esthétique de Jean Maillart.

270 La propension du vers à favoriser l'oralité est confirmée par la justification que donne Nicolò da Verona de son choix formel dans la Pharsale (1343): il choisit la rime car "home civauçant auroit trou destorbance / A lire por zamin le feit en comunance» (v. 32-33). Ainsi, "cil qe por ma rime l'aura en remembrance / le pora dire sens livre e sens nulle pesance / E de falir l'istoire ja non aura dotance» (v. 35-37). Die Pharsale des Nicolas von Verona, éd. Hermann Wahle, Marburg, Elwert, 1888. Même pour un texte de nature épique, le vers ne va pas de soi à l'époque des mises en prose. Voir Michel Zink, "Le Roman», in GRLMA, VIII, p. 207, et les pages 54 à 69 d'Adrian Armstrong et Sarah Kay, Une Muse savante?

271 Catherine Rollier-Paulian, L'esthétique de Jean Maillart, p. 246-248. 
Le vers favorise également les jeux et énigmes, comme celle que lance Jean Maillart en signature de son épilogue. On trouvera son nom en lisant attentivement, "soutilment», les deux vers qui suivent le mot "decevance», ce dernier terme traduisant bien l'intentionnalitée ${ }^{72}$ ludique de l'auteur en cette fin de roman:

Veil qu'en puist en ce meismes dit

Trouver mon non sanz contredit,

Qui avoir en veult connoissance,

Et mon seurnon, sanz decevance. [...]

(Roman du comte d'Anjou, v. 8065-8068)

Qui voudra son senz esprouver

A mon non en ce di trouver

Et mon seurnon, prengne avisance,

Puis le vers ou est "decevance",

En deus verséz qui après viennent

Asséz tost et si s'entretiennent,

Car illecques les trouvera

Qui soutilment i gardera.

(Roman du comte d'Anjou, v. 8105-8112)

La critique a établi qu’il fallait déchiffrer les vers en question ainsi: «JE n'ai pas molt HANté tel chose, / Ainz pesche au MAIL ART qui enclose» (v. 8069-8070 ${ }^{273}$. C'est bien le cadre formel qui favorise de tels jeux de piste, car l'énigme implique de compter deux vers, d'être attentif au mot à la rime et de décomposer la phrase en question en syllabes. Le mot qui doit attirer l'attention, "decevance", la tromperie, illustre les possibilités de sens cachés qu'offre le vers, et qui trompent quelque peu la vigilance du lecteur. Le plaisir du lecteur n'est donc pas qu'esthétique: il s'agit aussi de

272 Nous utilisons ce terme à la suite de Algirdas J. Greimas et Joseph Courtès : «Pour rendre compte de la communication en tant qu'acte, on introduit généralement le concept d'intention qui est censé la motiver et la justifier. Cette notion nous paraît critiquable, dans la mesure où la communication est alors envisagée à la fois comme un acte volontaire - ce qu'elle n'est certainement pas toujours - et comme un acte conscient - ce qui relève d'une conception psychologique par trop simpliste de l'homme [...]. Nous lui préférons le concept d'intentionnalité $[\ldots]$ : il permet de concevoir l'acte comme une tension qui s'inscrit entre deux modes d'existence: la virtualité et la réalisation». Sémiotique. Dictionnaire raisonné de la théorie du langage, Paris, Hachette, 1979, p. 190.

273 Voir les pages 8 à 23 de Catherine Rollier-Paulian, L'esthétique de Jean Maillart. 
le divertir en se servant de la forme versifiée, de mettre au défi son intelligence et d'instaurer une connivence entre auteur et lecteur ${ }^{274}$. Le terme "soutilment», habituellement réservé dans un usage métapoétique à l'art rhétorique de l'auteur ${ }^{275}$ concerne ici le lecteur: le vers mobilise autant l'acuité du récepteur que de l'écrivain.

Les textes contemporains, en particulier les mises en prose, revendiquent pourtant une jouissance plus grande du récit lorsqu'il est en prose, à l'instar de Florent et Lyon, mise en prose de la version octosyllabique de Florent et Octavien:

Lequel livre [Florent et Lyon] a este translate a Paris de latin en françoys et extraict des croniques des roys de France. Et pource que lystoire est moult belle et plaisante et que plusieurs gens preignent plus grant plaisir a lyre romans en prose que en rime a esté cestuy present livre translaté de ryme en prose en la maniere qui sensyut ${ }^{276}$.

Le plaisir du texte qu'évoque le prosateur renvoie aux goûts de l'époque, probablement liés à la facilité cognitive qu'offre la prose. Jean Maillart prend le parti d'exalter une autre satisfaction, celle de l'harmonie des sonorités et de la métrique, qui se savoure à l'écoute ${ }^{277}$. C'est aussi le cas de Coudrette ${ }^{278}$, qui espère que son destinataire préfèrera sa version à l'ancienne:

Maiz a mon pouoir je feray,

Se Dieu plaist, tant que le metray

D'aultre forme, se j'ay loisir,

Qui mieulx vous vendra a plaisir. (v. 93-96)

274 Florence Bouchet traite des jeux sur les signatures par l'anagramme ou l'acrostiche dans Le discours sur la lecture en France aux XIV et XV siècles, p. 293-303. Voir la page 299 sur le cas de Jehan Maillart.

275 Jacqueline Cerquiglini, "Un engin si soutil».

276 Florent et Lyon. Wilhelm Salzmann: Kaiser Octavianus, éd. Xenja von Ertzdorff et Ulrich Seelbach, Amsterdam, Rodopi, 1993, p. 8.

277 Florence Bouchet, Le discours sur la lecture en France aux XIV et XVe siècles, p. 103-104, donne aussi l'exemple du Tombel de Chartrose, qui exalte les rythmes plaisants du vers: "Quar le vulgal les rimes prise: / La mesure dedens enclose / Leur delite plus que la prose." (v. 44-46) Voir les pages 103 à 106 sur le plaisir auditif qu'offre l'harmonie du vers.

278 Voir Jean-Claude Mühlethaler, «Défense et illustration du vers dans les récits du Moyen Âge tardif», art. cit., sur le vers dans la Mélusine de Coudrette. 
Coudrette assume s'appuyer sur des sources écrites, «selon les livres que on trouva» (v. 99): il ne s'agit pas d'une histoire nouvelle, s'inscrivant dans un genre anciennement formalisé par l'octosyllabe. L'auteur signale en prologue que l'histoire a déjà été écrite en vers ("car autreffoiz / Elle a esté mise en françoys / Et rimee si comme en conte», v. 87-89); l'objectif pour Coudrette est dès lors de proposer une autre forme métrique, qui plaira mieux à son commanditaire - peut-être faut-il comprendre ici que la version antérieure en vers n'était pas rédigée en octosyllabes. Le récit en vers précédant celui de Coudrette pourrait aussi recouper le modèle de Jean d'Arras; malgré les similitudes entre la version de Coudrette et celle du prosateur, rien ne permet toutefois d'affirmer que le premier a pris exemple sur le texte du second qu'il aurait mis en vers: les points de convergence s'expliquent aussi bien par le recours à une source commune $^{279}$. Le choix du vers n'est donc pas forcément le résultat d'une volonté de distanciation par rapport à la prose préexistante, que l'auteur aurait voulu archaïser.

Il exprime avant tout le goût très spécifique du commanditaire, Guillaume Larchevêque. Cette requête est mise en scène en prologue et l'auteur restitue en discours direct les désirs du destinataire, comme si Coudrette n'assumait pas le choix de la versification. Guillaume Larchevêque valorise la réception auditive que favorise le vers: "Je vueil qu'elle soit rimoÿe, / Elle en sera plus tost ouye.” (v. 81-82). Le commanditaire établit un lien entre la transmission orale et le vers: l'histoire sera diffusée plus efficacement au public sous cette forme ${ }^{280}$. Le texte signale plusieurs fois que l'œuvre doit être écoutée, notamment par des formules comme "Ainsi com vous m’orrez compter» (v. 1432). L'oralité et la réception auditive sont donc des arguments qui justifient le choix du vers, comme dans le roman de Jean Maillart.

279 C'est l'hypothèse d'Eléanor Roach, introduction à l'édition citée, p. 15, et de Laurence Harf-Lancner, Coudrette, Le Roman de Mélusine, trad. Laurence HarfLancner, Paris, GF, 1993, p. 24-25. Matthew W. Morris traite des différences entre ces deux œuvres, "Les deux Mélusines. Une comparaison des œuvres de Jean d'Arras et de Coudrette", in Écriture et réécriture du merveilleux féerique. Autour de Mélusine, dir. Matthew W. Morris et Jean-Jacques Vincensini, Paris, Garnier, 2012, p. 107-120.

280 Francis Gingras précise que l'adverbe «tost» évoque la facilité de la transmission par le vers, plus que le sens de «rapidement». Le Bâtard conquérant, p. 354. 
Le commanditaire énonce également la propension mémorielle $\mathrm{du}$ vers, qui permet au public de mieux retenir l'histoire. Guillaume Larchevêque la donne comme qualité en faveur de la rime: "affin qu'il en soit memoire, / Vous mettrez en rime l'istoire» (v. 79-80). La rime «memoire - istoire» intervient d'ailleurs à plusieurs reprises dans le prologue (v. 37-38, 45-46): elle exprime de manière topique le rôle fondamental de l'écriture dans la transmission de l'Histoire ${ }^{281}$. L'utilisation de cette rime bien connue renforce l'exaltation du vers, moyen le plus à même d'assurer la conservation d'un récit dans la postérité, de pérenniser le souvenir d'un passé lignager ${ }^{282}$. La commémoration se couple à la célébration du lignage ${ }^{283}$; le vers a partie liée avec l'exaltation, comme dans la chanson de geste.

Mélusine ou Histoire des Lusignan n'est pourtant pas seulement à interpréter comme la commande un peu excentrique d'un mécène aux inclinations désuètes. Le roman a eu assez de succès pour être reproduit dans vingt manuscrits, dont deux sont enluminés ${ }^{284}$. La version de Coudrette

281 Cette rime est topique: on la trouve notamment chez Geffrei Gaimar, Wace, Benoît de Sainte-Maure et Chrétien de Troyes. Dans le Roman de Rou, Wace élabore une véritable réflexion sur les pouvoirs de l'écriture dans la sauvegarde du passé en lui donnant sens. Cette idée est chapeautée par la rime "estoire/ memoire»: "Pur mettre lus nuns en estoire, / Que tuz tens mais fust de eus memoire» (3 ${ }^{\text {ème }}$ partie, v. 149-150). Voir Laurence Mathey-Maille, Écritures $d u$ passé. Histoire des ducs de Normandie, Paris, Champion, 2007, p. 252-253.

282 Matthew W. Morris et Jean-Jacques Vincensini traitent du prologue de Coudrette et de son évocation d'Aristote en rapport avec la revendication du passé et de la nostalgie dans l'introduction à leur édition, Couldrette, Mélusine (Roman de Parthenay ou Roman de Lusignan), New York, Lewiston Edwin Mellen Press, 2009, p. 23-28.

283 Voir Jean-Claude Mühlethaler, «Défense et illustration du vers dans les récits du Moyen Âge tardif», art. cit., p. 117-118. Le critique insiste sur la force persuasive du vers. Michelle Szkilnik relève quant à elle l'introduction de formules poétiques, dans l'épisode de l'incendie de Maillezais; les jeux de mots et de sonorités favorisent la célébration et la commémoration. «Maillezais, un lieu de mémoire dans les romans français de Mélusine", in L'Abbaye de Maillezais: Des moines du marais aux soldats huguenots, dir. Mathias Tranchant et Cécile Treffort, Rennes, PUR, 2005, p. 29-47.

284 Voir Laurence Harf-Lancner, «La serpente et le sanglier. Les manuscrits enluminés des deux romans français de Mélusine", Le Moyen Âge, 101, 1995, p. 65-97, et Eléanor Roach, "La tradition manuscrite du Roman de Mélusine par Coudrette», Revue d'Histoire des textes, 7, 1977, p. 185-233. Il faut noter que les imprimés 
fait également l'objet d'une traduction en allemand par Thüring von Ringoltingen - en prose toutefois, preuve de plus, s'il est besoin, de la prééminence de la prose sur le vers ${ }^{285}$. En comparaison, les autres romans en vers de notre liste sont transmis par un manuscrit (Eledus et Serene $e^{286}$ et La Dame à la licorne), voire trois pour le Roman du Comte d'Anjou. Cette diffusion est peut-être à chercher du côté de la postériorité de la Mélusine en vers par rapport au roman de Jean d'Arras: les lecteurs ont pu être interpellés par la forme versifiée d'une histoire connue par ailleurs dans une prose plus abordable. Ce qui apparaît comme une résurgence archaïque dans le cas d'une composition initiale en vers est appréhendé comme un remaniement digne d'intérêt pour la Mélusine de Coudrette.

Le rapport au passé, par le recours à une forme inusitée, est au cour de ce corpus. Une forme de nostalgie anime les auteurs qui font le choix $\mathrm{du}$ vers aux $\mathrm{XIV}^{\mathrm{e}}$ et $\mathrm{Xv}^{\mathrm{e}}$ siècles: le vers transcrit l'exaltation des mœurs passées ${ }^{287}$. On trouve peu de parodie dans ces romans: l'héroïne du Roman du Comte d'Anjou est un modèle de vertu, que le narrateur regrette de ne pas voir imité dans sa société contemporaine (v. 8043-8047) ${ }^{288}$, tandis que la Dame à la licorne et le Beau Chevalier au Lion se portent un amour

du $\mathrm{XVI}^{\mathrm{e}}$ siècle prennent la version de Jean d'Arras pour modèle, et non celle de Coudrette. Cela confirme bien le désintérêt progressif pour les romans en vers.

285 Jean-Claude Mühlethaler, André Schnyder, 550 ans de Mélusine allemande Coudrette et Thüring von Ringoltingen. Actes du colloque organisé par les Universités de Berne et de Lausanne en août 2006, Berne, Peter Lang, 2008.

${ }^{286}$ Jean-Jacques Vincensini attire toutefois l'attention sur les allusions à Eledus et Serene dans quelques œuvres contemporaines: les amants sont cités à titre d'exemple dans le Breviari d'Amor de Matfré Ermengau et dans la Faula de Guilhem de Torroella, et sont représentés sur un dessin qui orne le manuscrit de Guillaume de la Barre, avec pour légende "Eledus et Cerena». Ce roman était donc lu et jugé connu d'un certain nombre de lecteurs. «De l'alliance à l'hostilité. Dons contraints et troubles de l'idylle dans le Roman d'Eledus et Serene", in Plaist vos ö̈r bone cançon vallant. Mélanges offerts à François Suard, dir. Dominique Boutet, Marie-Madeleine Castellani, Françoise Ferrand et Aimé Petit, Villeneuve d'Ascq, Université Charles-De-Gaulle-Lille 3, 1999, p. 975-991.

${ }^{287}$ Voir l'introduction de l'édition de Mélusine de Jean-Jacques Vincensini et Matthew W. Morris, éd. cit., p. 24-26.

288 Catherine Rollier-Paulian analyse la temporalité du Roman du comte d'Anjou en la situant dans un jadis proche du temps de l'écriture: le temps glorifié est celui de la génération qui précède, celle des grands-parents, de l'hier ou avant-hier. L'esthétique de Jean Maillart, p. 128-130. 
sincère et fidèle, tout comme Eledus et Serene. La relation amoureuse n'a point de commune mesure avec celle, subversive, proposée dans Jean de Saintré d'Antoine de la Sale, composé un peu plus tard (1456-1460) ${ }^{289}$. Le vers est employé comme la forme privilégiée d'un type de récit qui s'évanouit, celui d'une histoire qui divertit et ne saurait s'inscrire dans un cycle.

Si nostalgie il y a, elle concerne donc aussi bien l'exaltation de mœurs révolues que le regret d'un type de production littéraire ${ }^{290}$ : Eledus et Serene comporte de longs monologues amoureux ${ }^{291}$ dans la tradition des récits $\mathrm{du} \mathrm{XIII}^{\mathrm{e}}$ siècle et réactive le thème des amours contrariées par une décision paternelle, histoire qui se formalise particulièrement bien au cadre du vers, lui aussi désuet. Le choix et le traitement du sujet placent le roman dans une tradition littéraire qui n'est plus celle du XIV siècle. D'ailleurs, ce texte se présente comme une réécriture d'une "geste ancienne»:

Et j'en diray bien la maniere

Sy com le treuve en l'istoyre

De l'aulte geste ancienne

Que on escript en rime plaine;

Et moult grant en fu l'ystoyre.

Mes j'aberge l'essamplaire,

Car trop lonc seroit a dir,

Et s'il vous plaist, veullés ouïr. (Eledus et Serene, v. 11-18)

Si le terme "geste» se traduit par le sens général de "faits mémorables» et «récit de ces hauts faits», l'expression "chanson de geste» existe bel

289 Voir Michelle Szkilnik, Jean de Saintré: une carrière chevaleresque au XVe siècle, Genève, Droz, 2003, et Helmut Hatzfeld, "La décadence de l'amour courtois dans le Saintré, l'Amadis et le Tirant lo Blanc", in Mélanges de littérature du Moyen $\hat{A} g e$ au XX offerts à Mademoiselle Jeanne Lods, professeur honoraire de littérature médiévale à l'École normale supérieure de jeunes filles, par ses collègues, ses élèves et ses amis, Paris, École normale supérieure de jeunes filles ("Collection de l'École normale supérieure de jeunes filles», 10), 1978, t. 1, p. 339-350.

290 Voir Michel Zink, "Le Roman», in GRLMA, VIII, p. 206.

291 L'auteur imagine même un dialogue entre Eledus et son écuyer Sapyne, qui reproduisent de manière fictive la déclaration d'amour du héros à Serene; Eledus joue le rôle de la jeune fille, qui protesterait contre cet amour, et Sapyne élabore des arguments destinés à la convaincre, qu'Eledus devra réutiliser. Ce dialogue est destiné à vaincre les réticences du héros à se déclarer. 
et bien au Moyen Âge dans un sens générique. Partant de ce constat, il n'est pas impossible que cette source ancienne renvoie à une chanson de geste, hypothèse corroborée par l'évocation de «rime plaine» ${ }^{292}$, qui pourrait désigner les laisses de décasyllabes monorimes propres au genre. Enfin, le siège de Maugrier à Tubie occupe une grande partie du récit d'Eledus et Serene, rendant ainsi envisageable la portée épique de la source du roman, bien que le thème principal des amours contrariées, sur le modèle de Pyrame et Thisbe $e^{293}$, ne soit pas d'inspiration épique. Eledus et Serene pourrait donc être le résultat d'une transposition romanesque d'une chanson de geste. Si cette hypothèse manque de preuves concrètes, il n'en demeure pas moins que l'auteur revendique le recours à un modèle ancien, archaïque, d'une longueur qui pourrait rebuter. L'abrégement qu'il dit entreprendre semble être lié au choix du mètre, d'une "rime»: la réécriture passerait avant tout par la brièveté de l'octosyllabe. Le projet de l'auteur anonyme est bien de proposer une vieille histoire, réactualisée pour le lecteur du XIV ${ }^{\mathrm{e}}$ siècle ${ }^{294}$.

Comme Michel Zink l'exprime au sujet de Melyador, ces textes sont «une entreprise de conservation littéraire ${ }^{295}$. Pour autant, le vers narratif

292 Nous n'avons pas trouvé d'autres témoignages d'une telle expression. Le mot «rime» peut aussi bien désigner le vers que la rime elle-même. L'adjectif «plein» peut donc soit être interprété comme la longueur, la plénitude, du décasyllabe, soit comme l'extension d'une rime unique sur toute une laisse.

293 L'intrigue se concentre en effet sur l'amour de deux jeunes gens, dont la jeune fille est d'origine plus noble, et qui se trouvent encore sous l'autorité de leurs parents. L'auteur réactive également le motif de la fausse mort: on pense Eledus mort, si bien que Serene est en proie au désespoir. Elle ne se suicide pourtant pas, mais décide plutôt de se rendre chez Cuizelot, le prétendu meurtrier de son ami, pour le frapper puis mourir à son tour. Eledus revient à la cour avant la réalisation de ce projet. Cet épisode, contrairement à ce qu'il se passe dans Pyrame et Thisbé, ne conduit pas à la fin du récit et la mort des amants, mais renforce l'amour encore inavoué des protagonistes.

294 L'hypothèse d'une réactualisation d'une histoire ancienne est confortée par les allusions à l'histoire d'amour entre Eledus et Serene dans des textes du XIII ${ }^{\mathrm{e}}$ siècle. Voir Jean-Jacques Vincensini, "De l'alliance à l'hostilité. Dons contraints et troubles de l'idylle dans le Roman d'Eledus et Serene", art. cit., et l'introduction à l'édition citée de John R. Reinhard, p. XIII-XVI.

295 Michel Zink, "Le Roman», in GRLMA, VIII, p. 206. Le critique a souligné la propension de Froissart à la nostalgie, son rapport au passé, qu'il réactualise et problématise aussi dans ses œuvres poétiques. Voir Michel Zink, Froissart et le 
ne nous semble pas nécessairement ressortir d'une volonté d'archaïsme ${ }^{296}$ chez les auteurs de notre liste: la langue est par exemple bien celle du $\mathrm{Xv}^{\mathrm{e}}$ siècle pour la Mélusine de Coudrette ${ }^{297}$, un français marqué par la transition vers le moyen français. L'effet d'archaïsme résulte plutôt de l'adaptation de la langue à la syntaxe particulière du vers, de l'ajustement des phrases et des mots aux exigences de la métrique. C'est ainsi que la modernité de la langue concurrence un conservatisme induit par la construction de la phrase propre à la versification. Le constat est valable pour Melyador: à plusieurs phénomènes archaïques (certains mots, le respect fréquent de la déclinaison, l'ordre des mots, la parataxe) s'associent l'abondance des nouveautés lexicales et les traits du français du XIv siècle $^{298}$. Ce sentiment d'archaïsme est la conséquence de l'écriture propre au vers, qui autorise la distorsion de la syntaxe ou le choix de certains mots qui conviennent aux exigences de la métrique. Ces facteurs rendent le vers de moins en moins abordable et propice à la transmission d'un récit narratif. Si la prose s'impose, c'est parce qu'elle offre une facilité cognitive pour les récepteurs.

La prééminence de la prose n'est dès lors plus justifiée par le lien que les auteurs établissaient au début du XIII ${ }^{\mathrm{e}}$ entre prose et vérité, bien que le vers $\mathrm{du} \mathrm{XIV}{ }^{\mathrm{e}}$ siècle se conjugue parfois avec une certaine revendication de fiction. Francis Gingras note que la Mélusine de Coudrette «s'inscrit clairement dans l'univers fictionnel en évoquant les chevaliers de la Table Ronde» et se place "moins exclusivement du côté de "l'histoire vraie" que de l'histoire mémorable» ${ }^{299}$. Malgré la portée historique que revêt la composante lignagère du récit, Mélusine étant présentée comme l'ancêtre des Lusignan et des Parthenay ${ }^{300}$, le versificateur n’hésite pas à qualifier

temps, et Jacqueline Cerquiglini-Toulet, «Un paradoxe mélancolique ou le lyrisme selon Jean Froissart ", Perspectives médiévales, 2006, p. 53-62.

296 Lunorsola Raffalli-Grenat lit Le Roman de la Dame a la Lycorne, Eledus et Serene et Mélusine à la lumière d'une "esthétique de l'archaïsme». Voir Écrire des fictions en vers aux $X I V^{e}$ et $X V^{e}$ siècles. Nous ne suivons pas son hypothèse.

297 Voir l'analyse linguistique d'Eleanor Roach, p. 87 à 99 de l'édition citée. Les quelques formes anciennes auxquelles a recours Coudrette s'expliquent selon la critique par le modèle ancien sur lequel l'auteur s'appuie.

298 On se convaincra de l'étendue de la modernité linguistique de Froissart en consultant l'introduction linguistique de Nathalie Bragantini-Maillard, éd. cit., p. 112-187.

299 Francis Gingras, Le Bâtard conquérant, p. 354-355.

300 Voir l'introduction à l'édition d'Eleanor Roach, p. 21-61. 
son œuvre de «roman", là où Jean d'Arras préférait éviter le terme en vue d'historiciser son récit. Dans le Roman de la Dame a la Lycorne également, l'auteur souffle l'idée que son roman est fictionnel, lorsqu'il affirme la piètre qualité de sa source:

Car de Coulongne sur le Rin

La matere en vint trouvee

Et si vous di que compassee

Fu la sans cause en latin

Et l'aporta .i. pelerin;

Et si estoit si mal escripte

Que je ne vus puis avoir dite

La verité entirement. (Dame a la Lycorne, v. 8551-8558)

Le soupçon de la fiction n'est pas du ressort de l'auteur et de sa propre imagination: si mensonge il y a, il résulte de l'impossibilité de lire clairement la source du roman. Cette façon de se disculper équivaut implicitement à affirmer la dimension fictionnelle de son texte, dont le but est essentiellement de fournir un modèle idéal d'amour et «moustrer ensengnement» (v. 8564) aux amants.

Bien sûr, le choix du vers ne saurait se réduire à une intentionnalité fictionnelle; nous avons déjà insisté sur le caractère approximatif et subjectif de l'association entre prose et véridicité d'une part et vers et fiction de l'autre. Le Roman du comte d'Anjou est d'ailleurs là pour réfuter la tentative de justification du vers tardif par la portée fictionnelle du récit: à partir de son modèle, la Manekine, Jean Maillart écarte les éléments surnaturels qui contreviennent à la logique, comme le miracle de la main qui se ressoude à la fin du roman de Philippe de Rémi ${ }^{301}$. Dans la version du XIv ${ }^{e}$ siècle, le vers n'est pas à mettre en rapport avec une revendication de la fiction, comme c'est le cas dans le Roman de la Dame a la Lycorne ou Claris et Laris. L'auteur s'efforce de placer sa diégèse dans un cadre familier, entre le Maine-Anjou, le Berry et Chartres.

301 Catherine Rollier-Paulian consacre un chapitre à discuter la dimension «réaliste» du Roman du comte d'Anjou qu'a mise en évidence Rita Lejeune. Voir L'esthétique de Jean Maillart, p. 114-232. Elle note que malgré la mise à l'écart du merveilleux et l'intérêt pour les realia, le roman travaille également des éléments spectaculaires, fascinants voire fabuleux, comme la beauté surnaturelle, la rencontre dans la forêt, le silence sur les origines et la fausse accusation de naissance monstrueuse (p. 122-123). 
Les constantes que l'on dégage des derniers romans en vers au sujet de leur choix formel sont plutôt à chercher du côté de ce plaisir qu'évoque le prologue du Roman du comte d'Anjou, de la transmission auditive à laquelle est voué le texte, enfin, de la propension mémorielle du vers, que l'on retrouve aussi dans le Roman de la Dame a la Lycorne, qui fait rimer «recorder» et «rimer» (v. 8562-8563) ${ }^{302}$. Par sa musicalité, le vers est la forme de la célébration ${ }^{303}$, en même temps qu'il donne une structure au poème, comme le résume Jean-Claude Mühlethaler:

Instrument de la gloire, la musique de la rime et du rythme donne un ordre aux événements narrés, les inscrivant dans la mémoire lors d'une lecture (individuelle ou publique) à voix haute. La delectatio ne nuit pas à la vérité du discours; au contraire, le vers lui sert de caisse de résonance, insufflant à la vérité la forme nécessaire pour qu'elle emporte l'adhésion du public ${ }^{304}$.

Ces enjeux cristallisent petit à petit la spécialisation lyrique à laquelle est soumis le vers. Cet usage se manifeste aussi dans le jeu formel que pratiquent certains romans; Coudrette ajoute à la fin de son récit un lai de louanges religieux formé de vers de huit ou quatre syllabes. Le vers se signale par là comme la forme propice à la célébration de valeurs éternelles, ainsi que l'a montré Jean-Claude Mühlethaler ${ }^{305}$. Le Roman de la Dame

302 "Et pour leur vie recorder / Me prist talent de le rimer", Le Roman de la Dame a la Lycorne, v. 8562-8563. Jean-Claude Mühlethaler traite de ces trois aspects liés au vers au XIV ${ }^{\mathrm{e}}$ siècle dans «Défense et illustration du vers dans les récits du Moyen Âge tardif", art. cit., p. 110-114. On peut encore citer le prologue de Dame Guile, court texte du XIII ${ }^{\mathrm{e}}$ siècle qui décrit la nature de Dame Guile: «L'en met ce c'on voit avenir / En rime por resouvenir, / Et si plest miex a escouter / Ce c'on ot par rime conter / Que ne fet chose desrimée. / Por ce doit estre miex amée / Quant ele est ordenée a droit.» Dame Guile, éd. Achille Jubinal, Jongleurs et trouvères, Paris, Librairie J. Albert Merklein, 1835, v. 1-7.

303 Daniel Poirion traite de la désolidarisation progressive entre écriture et musique au $\mathrm{XIV}^{\mathrm{e}}$ siècle. "L'épanouissement d'un style: le gothique littéraire à la fin du Moyen Âge", in Grundriß der romanischen Literaturen des Mittelalters. La littérature française aux XIV et XV siècles, vol. VIII/I, Heidelberg, Carl Winter, 1988, p. 29-44.

304 Jean-Claude Mühlethaler, "Défense et illustration du vers dans les récits du Moyen Âge", art. cit., p. 120.

305 Ibid., p. 119-120. Sur les liens de la Mélusine de Coudrette avec le sacré et le discours religieux, voir Jean-Claude Mühlethaler et Barbara Wahlen, "Geoffroy la Grand'Dent, chevalier de la fin des temps?», art. cit. 
a la Lycorne mêle quant à lui d'autres formes métriques à l'octosyllabe: le décasyllabe à rimes plates intervient au début du texte, dans la partie qui équivaut à une sorte d'introduction narrant les premières déceptions amoureuses de la Dame (jusqu'au vers 589). Dès que le roman se concentre sur son histoire avec le Beau Chevalier, le roman adopte l'octosyllabe et signale de cette façon la transition vers le véritable roman d'amour. Le récit est aussi parsemé d'insertions lyriques en décasyllabes, en alexandrins, en heptasyllabes (sept rondeaux, quinze ballades et un dit). La multiplication des formes renforce la disposition lyrique du roman en vers, invite à sa déclamation, même solitaire, et rapproche l'œuvre de la poésie subjective.

\section{Une spécialisation lyrique du vers: les insertions d'Escanor et Melyador}

Le mélange de formes que l'on rencontre dans le Roman de la Dame a la Lycorne n'est pas nouveau: les trois termes formels, vers narratif, vers lyrique et prose, se côtoient fréquemment au sein d'une même œuvre, et ce avant le XIv ${ }^{\mathrm{e}}$ siècle. Jean Renart en lance la mode, au début du XIII ${ }^{\mathrm{e}}$ siècle, en insérant des poèmes dans son Roman de la Rose $e^{306}$. Le texte juxtapose ici vers narratif et vers lyrique, mais toutes les combinaisons sont envisageables: l'insertion du vers lyrique au sein d'une œuvre en prose bien sûr (le Tristan en prose), l'alternance, dans le cadre de la narration, d'une prose narrative et de passages chantés en vers dans Aucassin et Nicolette $^{307}$, l'insertion à la fois de la prose - sous forme de lettres - et

306 Les références sur le sujet sont pléthoriques. On consultera en particulier les pages XXII-XXIX de l'édition de Felix Lecoy, Jean Renart, Le Roman de la Rose ou Guillaume de Dole, Paris, Champion ("CFMA»), 1962, Michel Zink, "Suspension and Fall. The Fragmentation and Linkage of Lyric Insertions in Le Roman de la Rose and Le Roman de la Violette", in Jean Renart and the Art of Romance, éd. Nancy Vine Durling, Gainesville, University of Florida Press, 1997, p. 105-121, Emmanuèle Baumgartner, «Les citations lyriques dans le Roman de la Rose de Jean Renart", Romance Philology, 35, 1981, p. 260-266, Marc-René Jung, "L'empereur Conrad, chanteur de poésie lyrique - Fiction et vérité dans le Roman de la rose de Jean Renart", Romania, 101, 1980, p. 35-50.

Michel Zink traite de l'alternance entre vers et prose dans Aucassin et Nicolette dans "Le premier type: de l'alternance à l'insertion", Perspectives médiévales, 3, 1977, p. 15-20. Le critique y distingue l'alternance de l'insertion: "dans Aucassin et Nicolette, les passages lyriques n'interrompent pas la narration, qui poursuit de vers en prose et de prose en vers.» (p. 15) 
du vers lyrique au sein d'un roman en vers narratif, dans le Roman de la Dame a la Lycorne ${ }^{308}$. Le processus de l'insertion va de pair avec une confrontation des modes de discours, ceux de la narration et du lyrique ${ }^{309}$. Ces jeux sur les formes n'ont néanmoins pas tous la même fréquence et dessinent petit à petit des usages spécifiques à chaque forme, jusqu'à exclure in fine le vers narratif. Le vers, plus souvent en position d'insertion lyrique que de forme d'accueil pour une prose lyrique, se réserve dès lors plus volontiers à l'expression de la subjectivité. Le maintien du vers dans le dit et la poésie au XIV ${ }^{\mathrm{e}}$ siècle est donc cohérent en ce qu'il traduit les états d'âme et impressions d'un «je», ainsi que l'explique Michel Zink:

Or le vers, objet de la notion nouvelle de poésie, est associé - implicitement, mais de plus en plus nettement à mesure que chansons de geste et romans en vers se font plus rares jusqu'à n'être plus que des survivances - à l'expression de l'affectivité et à la peinture du moi, qui caractérisent, bien que de façon différente et presque opposée, aussi bien le lyrisme au sens propre du terme que le $\mathrm{dit}^{310}$.

308 Voir à ce sujet Jacqueline Cerquiglini-Toulet, "La prose et la rose: l'imaginaire spatial de la prose et du vers", art. cit.

309 Nous définissons le lyrique par deux qualités: la musicalité et/ou l'expression du moi. Le lyrique rend compte des émotions d'un sujet, qu'il traduit dans un langage poétique. Dès le XIv ${ }^{e}$ siècle, le lien entre chant et poésie est rompu, notamment par Eustache Deschamps dans son Art de dictier, qui distingue musique naturelle de la poésie et musique artificielle des instruments. Néanmoins, l'idée d'harmonie et de musicalité demeure constitutive de la poésie lyrique: si l'on ne met plus les poèmes en chanson, leurs sons, habilement agencés, offrent à entendre une mélodie. Voir Michèle Gally, "Lyrisme», in Le dictionnaire du littéraire, p. 445-446. Le lyrique est un mode - c'est-à-dire une catégorie de l'architextualité - axé sur les rapports émotionnels : il engage une implication de la part du récepteur, de l'ordre de l'empathique. Cette dimension se traduit dans sa mise en forme du discours, fondée sur le rythme et l'harmonie, qui "transforme le texte en une incarnation textuelle de la vie affective: la forme elle-même exemplifie les émotions désignées par le texte». (Antonio Rodriguez, "Lyrique», in Arts et émotions, dir. Mathilde Bernard, Alexandre Gefen et Carole Talon-Hugon, Paris, Armand Colin, 2015, p. 254). Antonio Rodriguez établit une distinction entre «lyrisme» et "lyrique», le premier référant à un ethos, celui de l'affectation romantique, et le second à un mode de discours. En suivant sa démarche, nous utiliserons donc exclusivement en substantif le terme "lyrique». Voir Le pacte lyrique. Configuration discursive et interaction affective, Sprimont, Pierre Mardaga, 2003. Voir aussi Paul Zumthor, Essai de poétique médiévale, p. 213-214, qui le définit comme une personnalisation du discours.

310 Michel Zink, «Le Roman », in GRLMA, VIII, p. 267-268. 
La spécialisation lyrique du vers est manifeste dans la distinction établie entre prose narrative et poésie lyrique dans un roman comme le Tristan en prose. Les insertions lyriques y donnent libre cours aux émotions des personnages et révèlent le vers comme «lieu électif où se disent la vérité d'un être et de sa passion et ce qu'elle recèle d'indicible ${ }^{311}$, alors que la prose demeure l'espace de la narration. La poésie est le moyen privilégié pour transmettre les sentiments des personnages, ainsi que Kahédin le verbalise lui-même dans son Lai mortel: "Je laisse la prosse pour vers. I D'amours que je truis si pervers / me lo et plaing et fais en vers" (éd. Ménard, t. I, $\$ 163$, p. 238 $)^{312}$. Le vers offre une forme, un rythme différents, propice à la transmission des inexprimables mouvements du cœur. La rupture formelle, et visuelle sur la page du manuscrit, traduit le passage au registre de l'émotion ${ }^{313}$.

L'insertion lyrique ${ }^{314}$ en contexte narratif prosifié marque d'autant plus clairement les propriétés attribuées à chaque forme; la narration pour la

311 Catherine Croizy-Naquet, "Du vers à la prose ou les aléas du changement de forme», in Des "Tristan" en vers au "Tristan» en prose. Hommage à Emmanuèle Baumgartner, dir. Laurence Harf-Lancner, Laurence Mathey-Maille, Bénédicte Milland-Bove et Michelle Szkilnik, Paris, Champion, 2009, p. 174.

312 Sur le Lai mortel, voir Emmanuèle Baumgartner, La Harpe et l'épée. Tradition et renouvellement dans le Tristan en prose, Paris, SEDES, 1990, p. 157-159. "Tout se passe donc comme si dans cet univers du Tristan où les mots et les choses sont depuis toujours manipulés, où les évidences les plus palpables [...] peuvent être questionnées ou occultés, où la ruse et l'amour ont sans cesse partie liée, la parole lyrique échappait seule à toute perversion du sens.» (p. 116-117)

313 Sur l'insertion lyrique dans le Tristan en prose, voir les articles d'Emmanuèle Baumgartner, "Sur les pièces lyriques du Tristan en prose», in Études de langue et de littérature du Moyen Âge offertes à Félix Lecoy, Paris, Champion, 1973, p. 19-25, Dominique Boutet, "Le lyrique comme moyen du romanesque aux XII et XIII siècles ", in Le romanesque, dir. Gilles Declercq et Michel Murat, Paris, PSN, 2004, t. 1, p. 49-62, et Philippe Ménard, "Les pièces lyriques du Tristan en prose», in Les Genres insérés dans le roman, éd. Claude Lachet, Lyon, Université de Lyon III ("Publications du CEDIC», 9), 1994, p. 35-46, et l'ouvrage de Dominique Demartini, Miroir d'amour, miroir du roman. Le discours amoureux dans le Tristan en prose, Paris, Champion, 2006.

314 Sur l'insertion lyrique, on consultera le numéro de Perspectives médiévales, 3, 1977 , p. 3-32, en particulier l'article de Jacqueline Cerquiglini-Toulet qui propose trois catégories d'insertion (collage, montage, collage/montage), "Pour une typologie de l'insertion», p. 9-14, Daniel W. Lacroix, "L'insertion poétique dans les œuvres narratives du XIII ${ }^{\mathrm{e}}$ siècle. Le domaine roman", Littératures, 35, 1996, p. 189-216. 
prose, l'expression de la subjectivité, voire des passions pour le vers. Elle permet l'exploration du déploiement du vers dans le domaine poétique que la prose n'a pas investi ${ }^{315}$. La spécialisation lyrique du vers se dessine alors dès le XIII ${ }^{\mathrm{e}}$ siècle. Elle résulte de l'essor de la prose, dont l'extension à tous les types de narration (Histoire, fiction, épopée) exclut progressivement le vers de ce domaine, ainsi que l'explique Michel Zink:

La fusion de tous les types de narration dans l'uniformité de la prose donne par contraste au vers une unité qu'il n'avait jamais eue. Il trouve cette unité dans la coloration affective et subjective qui commence à le marquer en tant que tel et qui annonce la naissance de la notion, jusqu'alors inexistante, de poésie ${ }^{316}$.

D’universel qu'il était, le vers se spécialise, s'unifie autour d'une sphère particulière d'expression: la poésie, les passions, les sentiments ${ }^{317}$. L'appropriation du domaine narratif par la prose entraîne également l'abolition de différences génériques: la distinction formelle entre chanson de geste et roman s'affaiblit dans le moule uniforme de la prose, donnant ainsi lieu à un syncrétisme des thèmes et des visions du monde que décrit Michel Zink:

La résolution des différents genres littéraires et des modes d'utilisation variés qui leur sont liés en une forme unique, celle de la narration en prose divisée en chapitre, dont les règles, sinon absentes, du moins souples, ne sont sans doute pas analysées consciemment comme telles par l'auteur et par son public, a pour conséquence que l'attente de ce dernier est la même quelle que soit l'histoire racontée, et qu'elle dérive d'une chanson de geste, d'un roman antique ou breton, d'un récit hagiographique. La vision du monde propre à chacun de ces genres perd dès lors de sa spécificité aux yeux du lecteur et se fond

315 Adrian Armstrong et Sarah Kay, Une Muse savante? envisagent la conception d'une prose poétique, notamment dans l'essor du prosimètre: l'alternance entre vers et prose conçoit cette dernière comme une forme dépourvue de rimes et de mètres, mais dont le potentiel poétique est semblable. Voir p. 207-211.

316 Michel Zink, «Le Roman», in GRLMA, VIII, p. 205.

317 Le dit a peut-être partie liée avec cette évolution: prenant une dimension narrative, il se caractérise aussi et surtout par sa dimension lyrique, par l'expression d'un moi. Ce n'est donc pas un hasard si ce genre est en plein essor à la fin du Moyen Âge: il synthétise le statut du vers, entre lyrique et narratif, en passe de devenir exclusivement lyrique. 
dans une sorte de syncrétisme idéologique commun à toute la littérature narrative $e^{318}$.

D'un côté la prose narrative, de l'autre le vers lyrique. C'est vers cette distinction que tend la littérature au $X{ }^{e}$ siècle; elle contribue à la conscientisation de la poésie ${ }^{319}$. Par le recours à l'insertion lyrique, nos textes tracent cette évolution.

Dans notre corpus, deux ouvres l'exploitent: il s'agit des deux derniers représentants du genre arthurien en vers, Escanor et, de manière bien plus importante, Melyador. Cette pratique est pourtant inédite dans le roman arthurien en vers et se réserve en principe à la prose - le Tristan en prose en chef de file -, à l'exception de ces deux textes. La pratique de l'insertion ne donne pas lieu à une confrontation entre les formes, contrairement à ce qu'il se passe dans le roman arthurien en prose. Froissart évite soigneusement d'immiscer de la prose dans son texte; son narrateur précise qu'il a mis en vers une lettre initialement en prose, afin de ne pas perturber l'harmonie formelle:

Or vous dirai, il m'en souvient,

Quel cose avoit dedens la lettre

C'on peut au chevalier tramettre.

Elle estoit assés bien dittee

A l'usage de leur contree,

Selonc ce qu'encor j'en exprime,

Mais elle n'estoit point en rime.

Je l'i ay mis de mon voloir

Pour le livre son cours avoir: (Melyador, v. 23279-23287)

318 Ibid., p. 203-204. Emmanuèle Baumgartner fait le même constat au sujet du syncrétisme de la prose. Le Récit médiéval, p. 147. Voir aussi Claude Roussel, "Mise en prose ou mise en roman?", in Du roman courtois au roman baroque. Actes du colloque des 2-5 juillet 2002, dir. Emmanuel Bury et Francine Mora, Paris, Les Belles Lettres, 2004, p. 339-352.

319 Sur la notion de "poetrie" à la fin du Moyen Âge, voir Adrian Armstrong et Sarah Kay, Une Muse savante?, p. 21-26. En moyen français, le terme "poète" désigne un compositeur de textes en vers ou en prose dont la teneur est édifiante. On le trouve semble-t-il pour la première fois sous la plume d'Eustache Deschamps parlant de Guillaume de Machaut. Voir Jacqueline Cerquiglini-Toulet, "Le nouveau lyrisme (XIV $-\mathrm{XV}^{\mathrm{e}}$ siècles)", art. cit., p. 288. 
Le dernier vers exprime la volonté d'éviter la discontinuité dans la composition, la rupture ${ }^{320}$. La lettre en prose est pourtant un prétexte courant au mixage des formes, dans Aucassin et Nicolette ou Le Roman de la Dame a la lycorne. Point de mélange entre vers et prose dans le roman arthurien en vers, même tardif: le choix du vers est exclusif dans ce genre, et ne tolère que la transition de vers narratif à vers lyrique.

Cet usage illustre non seulement la vogue littéraire de l'insertion lyrique et l'influence du Tristan en prose sur notre corpus, mais il trace également la propension subjective que prend le vers: celui-ci affiche son caractère lyrique et ne se satisfait plus, à plus forte raison à la fin du XIV $^{\mathrm{e}}$ siècle, de la simple narration. Car Escanor et Melyador se distinguent par la proportion d'insertions qu'ils égrènent: alors que Froissart insère cinquante-deux rondeaux, seize virelais et onze ballades tout au long de son roman, Girart d'Amiens concentre les quatre courts refrains choisis dans un épisode du récit. Dans Melyador, l'insertion lyrique est structurante et possède une vraie fonction narrative; dans Escanor, elle sert un but bien précis, propre au passage où elle intervient.

Il s'agit plus précisément du moment où Galantinet, l'écuyer de Gauvain, tend une embuscade à Escanor le Bel qui se rend à la cour d'Arthur pour le jugement qui l'oppose à Gauvain, suite aux accusations qu'il a proférées à l'encontre du neveu du roi. Le passage s'emploie à décrire longuement la cour d'Escanor qui l'escorte et le précède. Galantinet est chaque fois plus émerveillé en découvrant le défilé. Nous aurons l'occasion de le repréciser, l'ampleur de cette mise en scène produit un contraste entre la beauté et l'enchantement que représente ce cortège et l'attentat que projette Galantinet. Les pièces lyriques font partie de cet effet: elles accompagnent chaque nouveau groupe, comme pour scander cette procession destinée à introduire petit à petit Escanor et son amie, qui ferment la marche. Les pièces lyriques soulignent la progression du cortège et contribuent à la tension narrative, créant un effet de suspense, car l'arrivée d'Escanor est sans cesse repoussée ${ }^{321}$. Ce sont tour à tour

320 Voir la note du vers 23287 de l'édition de Nathalie Bragantini-Maillard, t. 2, p. 1533-1534.

321 Voir Raphaël Baroni, La tension narrative. Suspense, curiosité et surprise, Paris, Seuil («Poétique»), 2007 et «Passion et narration», Protée, 34/2-3, 2006, p. 163-175. Le suspense repose sur un double principe d'incertitude et d'incomplétude: l'information attendue par le lecteur est retardée, favorisant l'intérêt et le plaisir 
des damoiseaux, des pucelles, de jeunes dames accompagnées de jeunes hommes et le couple royal qui se montrent face à Galantinet, formant ainsi quatre ensembles. Le déroulement est similaire pour chacune des troupes: on commence par une présentation de la suite, sa composition, sa beauté, ses atours. On souligne en particulier la joie que les suivants manifestent («mout liement», v. 7929, «demener joie et feste», v. 8130, "chantant de cuer gai", v. 8132, «joie faire et en deduit», v. 8140 , «joie et deduis», v. 8335, «joie et revel», v. 8349). C'est surtout par le chant que cette gaieté s'extériorise: chaque groupe entonne un refrain. S'ensuit à chaque fois une discussion entre Galantinet et les membres de la cour de la Blanche Montagne, qui présentent Escanor et le portent aux nues.

Les chansons font donc office, justement, de refrains aux quatre tableaux (damoiseaux, pucelles, dames et jeunes hommes, couple royal) dont la structure est répétitive ${ }^{322}$. Elles renforcent le caractère idyllique du spectacle qui s'offre aux yeux de Galantinet. En effet, en plus d'être beaux et richement parés, les jeunes gens donnent également à contempler un idéal d'harmonie et d'amour mutuel. Les membres de chaque groupe se tiennent par les mains (v. 7926, v. 7992, v. 8215), se témoignent "grant amistié» (v. 7992) et se montrent sensibles à l'amour, ce que reflète leur envie de chanter:

Chascunz, el chief le vert chapel,

Chantoit et faisoit contenance

C'Amors, qui les finz cuers avance,

Avoit lor cuers en sa baillie. (Escanor, v. 8101-8104)

De fait, le contenu des refrains renvoie à l'amour, la mort qu'il peut engendrer et la sincérité à observer dans la démarche amoureuse. En voici la teneur:

de lecture en l'invitant à pronostiquer de la suite. La description de la procession est même interrompue au vers 8234 pour revenir brièvement à la mélancolie de Gauvain, accusé à tort. Ce retardement éveille bien l'attention du lecteur, qui attend de rencontrer enfin Escanor, dont le roman n'a eu de cesse de parler sans pourtant le mettre véritablement en scène: il manque d'ailleurs également au tournoi de Baubourg alors qu'il y est attendu (v. 3276).

322 Bien sûr, le dernier tableau est différent et se termine sur l'attentat perpétré par Galantinet. Il nous manque néanmoins la fin, comme le cahier qui suit le neuvième est perdu. Dans le manuscrit BnF fr. 24374, incomplet, l'épisode se termine donc sur le portrait détaillé d'Escanor. 
Mal amendement preingnent

Cil qui font samblant d'amer,

Si n'en ont talent. (chant des damoiseaux, v. 7930-7932)

Diex, je muir d'amouretes,

Jolie mort a ci. (chant des pucelles, v. 7994-7995)

Cha que ferai? je muir

D'amouretes, conment

En garray? (chant des dames et jeunes hommes, v. 8133-8135)

Ainsi doit entrer en vile

Qui Amours maine. (chant d'Escanor et la reine de la Blanche Montagne, v. 8341-8342)

On peut supposer qu'il s'agit de refrains connus des contemporains du XIII ${ }^{\mathrm{e}}$ siècle: on les rencontre ailleurs, dans Renart le Nouvel et Méliacin par exemple, en ce qui concerne le dernier ${ }^{323}$. La célébration de l'amour qu'ils proposent correspond parfaitement à l'atmosphère du cortège: les membres de la cour d'Escanor sont courtois et glorifient un amour sincère, en même temps qu'ils se manifestent de l'affection les uns aux autres. Ils sont véritablement menés par Amour, comme l'exprime d'ailleurs le dernier refrain, chanté par Escanor.

Le chant accompagne donc l'amour mutuel que se portent les sujets d'Escanor et celui qu'ils ressentent pour leur seigneur, qu'ils n'ont de cesse de louer pour sa courtoisie, sa beauté, sa prouesse, son couple si bien assorti ${ }^{324}$. L'amour chanté dans les pièces lyriques fait écho à celui qui transparaît dans les paroles élogieuses des jeunes hommes et femmes. Les chansons illustrent à la fois l'amour, l'harmonie curiale et la joie: on chante ensemble, d'une même voix, inspiré par des sentiments conjoints. C'est ainsi qu'elles participent de l'atmosphère merveilleuse du cortège, que Galantinet décrit comme un "grant enchantement» (v. 8144), comme s’il était entré «en la faerie» (v. 8146). Elles contribuent à «ménager une

323 Voir les pages 51 à 52 de l'introduction à l'édition de Richard Trachsler, qui s'appuie sur Nico H. J. Van Den Boogaard, Rondeaux et Refrains du XIt au début du XIV siècle, Paris, Klincksieck, 1969.

324 Voir François Laurent, Les insertions lyriques dans les romans en vers du XIII siècle, Thèse de doctorat sous la direction de Jacques Fontanille, Université de Limoges, 2007, https://halshs.archives-ouvertes.fr/tel-00925877/document, p. 277-282 et 501-501. 
rupture entre le domaine de la réalité et celui du merveilleux» ${ }^{325}$, elles créent une «separation between the everyday character of the rest of the world, and the better world of Escanor's court ${ }^{326}$.

Le passage au vers lyrique engendre aussi une rupture métrique. Comme le remarque Richard Trachsler, les refrains sont intégrés au texte par la rime ${ }^{327}$; le vers introductif rime toujours avec le dernier vers de la chanson et ne se trouve jamais orphelin:

Chantoient clerement ensi:

«Diex, je muir d'amouretes,

Jolie mort a ci.» (v. 7993-7995)

L'intention est bien d'intégrer les refrains au récit, de les rendre constitutifs du roman. Il y a une fusion harmonieuse entre le vers narratif et le vers lyrique. Du côté de la mise en page, les refrains commencent chacun par une initiale dorée. Une place a été réservée au-dessus de chaque vers pour une partition qui n'a jamais été transcrite ${ }^{328}$. Il était donc envisagé que chaque chanson soit accompagnée de musique. Cela laisserait penser que le texte était prévu pour une récitation orale, mais il est aussi admissible que la musique contribue simplement à l'atmosphère du passage et remplisse tout autant cette fonction dans le cadre d'une lecture solitaire à voix haute.

La même hésitation se dessine pour la réception de Melyador: Froissart indique dans deux de ses autres productions qu'il lisait son roman au comte de Foix Gaston Fébus, pendant l'hiver 1388. L'auteur se vante dans ses Chroniques et dans le Dit dou Florin du plaisir pris par l'auditeur:

L'accointance de li a moy pour ce temps fu telle, que je avoie avecques moy apporté un livre, le quel je avoie fait a la requeste et contemplacion du Monseigneur Wincelaus de Boesme, duc de Lucembourc et de Braibant, et sont contenus ou dit livre, qui s'appelle de Meliador, toutes les chançons, balades, rondeaulx, virelaiz que le gentil duc fist en son temps, lesquelles choses, parmi l'ymaginacion que je avoie en

\footnotetext{
325 Richard Trachsler, Escanor, éd. cit., p. 54.

326 Ann Ladd, "Attitude towards Lyric in the Lai d'Aristote and some Later Fictional Narratives", Romania, 96, 1975, p. 205.

327 Escanor, éd. cit., p. 53.

328 Voir l'annexe B et ibid., p. 52.
} 
dicter et ordonner le livre, le conte de Fois vit moult volentiers; et toutes les nuis aprés son soupper je lui en lisoie. Mais en lisant, nul n'osoit parler ne mot dire, car il vouloit que je feusse bien entendu, et aussi il prenoit grant solas au bien entendre. (Troisième Livre, $\$ 13$ ) $^{329}$

Car toutes les nuis je lisoie

Devant lui et le solaçoie

D'un livre de Melyador,

Le chevalier au soleil d'or,

Le quel il ooit volentiers

Et me dit: "C'est uns beaus mestiers,

Beaus maistres, de faire telz choses. "

Ces passages laissent penser à une diffusion orale du texte, c'est-à-dire que celui-ci était lu à voix haute dans un cercle restreint. Cette hypothèse serait renforcée par l'abondance des interventions communicatives du narrateur ${ }^{331}$. Enfin, Beate Schmolke-Haßelmann voit dans la succession de petites aventures un moyen pratique de fractionner la récitation sur plusieurs soirées ${ }^{332}$. Pour autant, ce roman n'est pas dédié à une réception exclusivement auditive ${ }^{333}$ : Froissart s'attend en effet à ce que le livre soit

329 Jean Froissart, Chroniques, éd. Peter Ainsworth et Alberto Varvaro, Paris, Le Livre de Poche («Lettres gothiques»), 2001-2004, t. 2, p. 173-174. Sur la vie et les mécènes de Froissart, voir Michel Zink, Froissart et le temps, p. 1-18, Godfried Croenen, "Froissart et ses mécènes: quelques problèmes biographiques», in Froissart dans sa forge, éd. Odile Bombarde, Paris, Académie des inscriptions et belles-lettres - Collège de France, 2006, p. 9-32, et l'introduction à l'édition de Nathalie Bragantini-Maillard, éd. cit., p. 15-25.

330 Jean Froissart, «Le Dit dou Florin», in «Dits» et "Débats», éd. Anthime Fourrier, Genève, Droz, 1979, v. 293-299.

331 Nathalie Bragantini-Maillard a étudié l'importance des interventions du narrateur dans Melyador, en particulier celles qui remplissent une fonction communicative et s'adressent au public - «le quel rondiel je vous lirai» (v. 20803) par exemple. "L'écriture des interventions narratoriales dans Melyador", art. cit., et "Les jeux du narrateur dans Melyador: de l'écriture en trompe-l'œil aux stratégies de l'identification ludique", art. cit. Sur la récitation de Melyador au comte de Foix, voir les pages 50 à 69 de l'édition citée et Florence Bouchet, Le Discours sur la lecture en France aux XIV et XV siècles, p. 34-35.

332 Beate Schmolke-Haßelmann, «Ausklang der altfranzösischen Artusepik: Escanor und Méliador", art. cit., p. 51.

333 La question de la réception auditive ou visuelle des textes est complexe: Florence Bouchet a montré que les deux modalités étaient en vigueur à la fin du Moyen 
acheté et déploie des effets narratifs encourageant les retours en arrière, la lecture des pièces lyriques notamment, que le public est invité à évaluer.

Les poèmes insérés, qui sont la plupart du temps chantés par les personnages ${ }^{334}$, agrémenteraient la transmission du roman par leur mise en musique. Néanmoins, contrairement à celui d'Escanor, le manuscrit de Melyador ne prévoit pas d'espace pour une portée musicale qui mettrait les insertions lyriques en chanson. Si celles-ci étaient chantées face au comte de Foix, la mélodie devait être improvisée par Froissart. Le narrateur précise d'ailleurs pour un rondeau de Floree qu'il en a oublié la mélodie:

Le dit orés, non pas le chant,

Ce poise moy, que ne le say.

Mais le dit mieus retenu ay

Que le chant. Pour tant vous l'orés

Et puis apriés en jugerés. (Melyador, v. 8465-8469)

Cette façon de s'excuser suppose que les autres rondeaux sont accompagnés de musique dans la déclamation du texte; tout du moins scénographie-t-on une réception auditive et musicale du roman. Les personnages regrettent aussi parfois l'absence de mise en musique: Lansonnet recommande par exemple à Melyador de "mettre en chant" (v. 17814) son rondeau, car celui-ci lui plaît beaucoup, puis insiste sur la valorisation des mots par la musique. Quoi qu'il en soit de la diffusion de Melyador, l'insertion lyrique est liée à la vocalité par la performance orale des personnages et invite à dire le texte à haute voix. Le vers, associé au chant, a un lien corporel avec celui qui le déclame: il mobilise les sens, l'ouïe, la voix $^{335}$ et la vue. Les tendances que nous dégagions au sujet des romans

Âge, vraisemblablement indépendamment de la forme, vers ou prose. Le Discours sur la lecture en France aux XIV et XV siècles, p. 23-55.

334 En voici un exemple parmi tant d'autres: «Or est çou raison qu'il souviegne / a Melÿador de canter.» (v. 4348-4349)

335 Avec la prose en revanche, "l'oreille n'est plus si impérieusement sollicitée par le mètre et la rime, ou plutôt elle l'est différemment, non par ce qui l'émeut physiquement, mais par ce qui permet la compréhension du texte» (Michel Zink, Littérature française du Moyen Âge, p. 177, nous soulignons). La lecture de la prose implique de moduler sa voix en fonction de la syntaxe de la phrase, de son mode, indicatif, interrogatif, exclamatif. D'où une «exigence intellectuelle qui s'oppose à la séduction affective du vers" (ibid.). 
en vers du XIV ${ }^{e}$ siècle sont donc applicables à nos deux textes: l'idée que le vers est attaché à l'oralité, la déclamation.

Les insertions lyriques remplissent plusieurs fonctions dans Melyador $^{36}$ : d'abord, une fonction pratique, celle de flatter un mécène, Wenceslas de Brabant, qui aurait commandé à Froissart d'intégrer tous ses poèmes. L'auteur aurait remanié en profondeur une première version du roman, composée à la cour d'Édouard III et de Philippa de Hainaut, en vue d'insérer les compositions du duc ${ }^{337}$. Le but visé est bien de mettre en valeur les poésies de Wenceslas et de former ainsi une sorte d'édition ${ }^{338}$, travail qui attend d'être récompensé par une rémunération pécuniaire. Mais cette entreprise n'est pas que d'ordre financier: il s'agit d'un travail poétique qui fait de Melyador «l'œuvre de deux co-auteurs ${ }^{339}$, une entreprise collaborative qui impose un réaménagement subtil de la part de Froissart. Mettre en valeur les compositions poétiques de son mécène implique de les accueillir dans un contexte, de les donner à lire dans le cadre du roman. Le travail est conséquent, car Froissart parvient à rendre

336 Jeanne Lods et Jane Taylor ont traité des insertions lyriques dans Melyador. Jeanne Lods, "Les poésies de Wenceslas et le Méliador de Froissart", in Mélanges de langue et littérature françaises du Moyen Âge et de la Renaissance offerts à Monsieur Charles Foulon, professeur de langue et littérature françaises du Moyen Âge et de la Renaissance, par ses collègues, ses élèves et ses amis. Tome I, Rennes, Institut de français, Université de Haute-Bretagne, 1980, p. 205-216, Jane H. M. Taylor, «The lyric insertion: towards a functional model", in Courtly Literature: Culture and Context. Selected Papers from the 5th Triennial Congress of the International Courtly Literature Society, Dalfsen, The Netherlands, 9-16 August, 1986, dir. Keith Busby et Erik Kooper, Amsterdam; Philadelphia, Benjamins ( Utrecht Publications in General and Comparative Literature», 25), 1990, p. 539-548.

337 Introduction à l'édition citée, p. 50-69 et 304-311. Nathalie Bragantini-Maillard n'affirme toutefois pas avec certitude que les poèmes soient bien de la plume de Wenceslas de Brabant. Il paraît en revanche sûr que ce n'est pas Froissart leur auteur. Voir la note 315 , t. I, p. 194, et note 12550, t. II, p. 1448. Sylvère Menegaldo note que ces poèmes donnent des indices précieux sur les pratiques poétiques de la noblesse à la fin du Moyen Âge. "Amateurs et professionnels: la composition poétique selon le Meliador et les dits de Jean Froissart», art. cit.

338 C'est l'effet que Jacqueline Cerquiglini-Toulet dégage de ce «montage/collage» à l'œuvre dans Melyador: les pièces lyriques forment un corpus qui, pour être intégré, impose une modification conséquente de la trame narrative. "Pour une typologie de l'insertion", art. cit.

339 Nathalie Bragantini-Maillard, Melyador, éd. cit., p. 305. 
les pièces lyriques indispensables à la trame narrative, si bien qu'elles transforment l'appréhension générique du texte, entre lyrique et narratif.

Au sein de la diégèse, leur intervention sert parfois des enjeux narratifs: les personnages chantent pour tromper l'ennui (on chante «a le fin que mains nous anuie la voie», v. 10095-10096), pour arrêter et attirer un chevalier (Melyador aux vers 26597-26639, Sagremor aux vers 2739527404) ou pour «resvillier courtoisement» (v. 7846-7847) un dormeur ${ }^{340}$. Elles ont donc partie liée avec l'intrigue, ce qui témoigne de leur bonne intégration. Le plus souvent, les pièces lyriques ont pour fonction d'exprimer les sentiments des personnages; c'est un enjeu que l'œuvre a en commun avec les autres textes qui pratiquent l'insertion lyrique. Le but des poèmes en contexte narratif est bien souvent de traduire les états d'âme des personnages, qui chantent en guise de consolation face à une situation douloureuse $\mathrm{e}^{341}$. Dans le Tristan en prose, «le texte lyrique n'est autre que la mise en forme immédiate d'une méditation, d'un appel ou d'un regret, [et] devient même, à l'occasion, fragment de biographie $»^{342}$. La composition de poèmes par les personnages sert donc d'exutoire et découle d'un état psychologique particulier. Sylvère Menegaldo remarque en ce sens que les termes "penser», "sentement», "ymagination» et "souvenir» ${ }^{343}$ accompagnent souvent la composition dans Melyador. Ils traduisent une introspection liée au sentiment amoureux, condition indispensable au chant. L'amour va de pair avec l'art poétique, si bien que c'est lui qui pousse les personnages à y souscrire, ainsi que l'exprime Meylador dans cet extrait:

340 Ibid., p. 306-310.

341 C'est ce que Daniel Poirion dénomme la consolation philosophique et religieuse. Cette fonction côtoie selon lui celle d'instruire et la fonction esthétique. Voir "Conclusion" au volume sur l'insertion lyrique de Perspectives médiévales, 3, 1977, p. 31. Noémie Chardonnens souligne aussi que la composition des lais du Perceforest est un acte d'introspection, lors duquel, par leurs silences, les personnages opèrent un retour sur soi. "Mémoire de la prose, destin du vers. Les lais du Perceforest $\mathrm{du} \mathrm{Xv}^{\mathrm{e}}$ au $\mathrm{XVI}^{\mathrm{e}}$ siècle", in Plus agreable a lire en prose que en rime? Vers et prose en moyen français, dir. Michelle Szkilnik et Catherine Croizy-Naquet, Le Moyen Français, vol. 76-77, 2015, Turnhout, Brepols, 2016, p. 65-84.

342 Emmanuèle Baumgartner, "Sur les pièces lyriques du Tristan», art. cit., p. 23.

343 Sylvère Menegaldo, «Amateurs et professionnels: la composition poétique selon le Meliador et les dits de Jean Froissart», art. cit. Voir page 185 pour un relevé de ces termes dans le roman. 
«Amours m'a mis et met en voie
Et chi le sentement m'envoie
De faire un rondelet joli
Et tout pour l'amour de celi
Que tu me dis et si m'afferme
Que je verai dedens brief terme.» (Melyador, v. 11972-11977)

C'est bien Amour qui, de manière récurrente par la formule «Amours voelt», commande à l'amoureux de faire un rondeau. Le chant extériorise ici clairement un sentiment indicible et le traduit, par la musique, par le rythme et les rimes du vers. Il plaît "a toutes gens / qui ont les biens d'Amours senti» (v. 19047-19048).

Cependant, le chant est rarement une complainte: le personnage s'y adonne toujours dans des moments de gaieté, dans des sursauts de bonne humeur, lorsqu'il a «joieuse et lie pensee» (au sujet de Floree, v. 8463). Chanter exprime alors à chaque fois la joie de l'amour ${ }^{344}$. L'amour n'est pas une souffrance, tel qu'il est présenté dans les pièces lyriques de Melyador, mais au contraire une source de joie. Si les chansons découlent d'un «sentement», celui-ci est "gais et jolis» (v. 6537). On chante ou on compose «de coer liet, amoureus et gay» (v. 11989) et les chants sont toujours «joli», «gay», «joieus» ou "plaisant». L'expression «ensi s'esbat» (v. 5628 par exemple) suit de manière récurrente la transcription des chansons; tout comme celles d'Escanor, les insertions lyriques s'inscrivent toujours dans une atmosphère positive. Même Camel, pourtant l'infortuné amoureux d'Hermondine, ne chante que dans la joie.

Non seulement le compositeur se trouve dans de bonnes dispositions lorsqu'il chante son virelai, sa ballade ou son rondeau, mais ceux-ci ont également un effet euphorisant sur le personnage qui les écoute. Lorsque Melyador demande à Lansonnet si son rondeau lui a plu, l'écuyer répond: «Toutes ytels coses me font / resjö̈r bien et grandement!» (v. 9813-9814). Le verbe «resjoïr» traduit à plusieurs reprises l'effet des chansons sur les

344 Deux exceptions dérogent à ce principe: Melyador compose une ballade dans le chagrin (v. 12549-12566). La ballade numéro 9 est quant à elle élaborée alors que le héros est "moiiennement lié et malade» (v. 17445), c'est-à-dire mi-heureux, mi-tourmenté. On peut supposer dans ce cas que l'angoisse qu'il ressent à l'idée de rencontrer Hermondine est atténuée par la ballade. Enfin, Sagremor compose aussi un poème lors de sa maladie d'amour. Toutefois, la ballade lui fait oublier sa mélancolie (v. 26145-26151). 
auditeurs. Melyador précise ce sentiment en ajoutant que la chanson de la dame de Montrose lui a fait "grant bien et [...] grant solas» (v. 10139). Le pouvoir réconfortant des poèmes est particulièrement exploité lors de la maladie d'amour de Phénonée; sa cousine Lucienne l'apaise en lui chantant deux rondeaux, qui parviennent à rendre son entrain à Phénonée. Elle «se resjö̈» (v. 19655), «se tient reconfortee» (v. 19674). Les chants fonctionnent comme une initiation à l'amour: ils ouvrent le cœur de l'amoureuse au bonheur que procure l'amour et sont la promesse d'une connivence entre Lucienne et la jeune fille. Sa cousine l'invite à chanter dans la joie:

«Moi et vous ferons, je m'en vant,

Des rondelés et des cançons

Et des jolies pareçons

Pour nous resjoïr et esbatre.» (Melyador, v. 19592-19595)

"Ançois que li ans soit passés,

Nous esbaterons vous et moy.

Ostés vos cuer de tout anoy

Et de grosse merancolie

Vous devés estre gaie et lie,

Nulle aultre riens ne vous besongne.» (Melyador, v. 19664-19669)

Chanter, se réjouir et aimer vont de pair: il s'agit d'un même élan du cœur. La capacité de composer des pièces poétiques est en ce sens le signe des dispositions amoureuses du poète: celui-ci démontre par là qu'il est apte à aimer sincèrement - c'est la conclusion à laquelle parvient Sagremor en entendant Margadine: en chantant, "vous moustrés bien c'amourous / avés le cuer» (v. 27443-27444).

$\mathrm{Si}$, comme dans le Tristan en prose, il existe un «lien nécessaire et suffisant, un rapport direct, de cause à effet, entre la sensation brute et sa transposition en discours poétique $»^{345}$, contrairement au roman en prose, le poème lyrique dans Melyador n'est pas une complainte; il n'est pas non plus solitaire. L'invitation de Lucienne à se divertir à deux, elle et Phénonée («moi et vous», "vous et moy»), exprime la dimension collective du chant, qui renforce son caractère optimiste. Le chant est presque

345 Emmanuèle Baumgartner, «Sur les pièces lyriques du Tristan», art. cit., p. 24. 
toujours partagé ${ }^{346}$, soumis à l'appréciation d'un tiers, proposé comme une déclaration. Les écuyers jouent en ce sens un rôle important: Lansonnet manifeste par exemple souvent son goût pour les chansons de Melyador, il l'incite à composer ou à ajouter une mélodie à ses productions. Flori est quant à lui l'élève d'Hermondine, qui lui apprend ses chansons (v. 2367323695). Il peut ensuite les transmettre à Melyador, qui en ressent une joie immense et désire les retenir à son tour (v. 23825-23836), comme Agamanor en entendant le rondeau de Phénonée un peu plus tôt ( $\mathrm{En}$ cantant volt les mos haper, / car pas a oublier ne fait, / car il touchent moult a son fait», v. 23011-23014). Les poèmes circulent, s'échangent, s'offrent; ils accroissent le sentiment amoureux et la communion entre les hommes.

Comme dans ce dernier passage, où Melyador s'efforce de retenir les compositions de sa bien-aimée, les pièces lyriques sont liées à la mémoire; les personnages en ont conscience. Melyador déclare alors au vers 7557: «Il m'en souvenra tout ce mois»; ou au vers 16656: «Jamais jour ne l'oublierai». C'est d'abord le narrateur ${ }^{347}$ qui les retient («si com retenu de lui l'ay», v. 4356, par exemple) et qui s'excuse parfois de ne pas se souvenir de tout. Tantôt, il oublie la mélodie qui accompagne le poème, comme dans les vers que nous avons cités plus haut, tantôt, c'est une pièce entière qu'il ne peut restituer, comme le rondeau de Lucienne:

Mais ceste je ne sçai pas bien,

Car mon argu sur toute rien

Mis a un virelai oïr

Qui me fist forment resjoïr

Le quel Aghamanor chanta.

Si grant plaisir y pris droit la

A l'oïr et au retenir

Que puis ne me peut souvenir

De la cançon de Luciienne. (Melyador, v. 22882-22890)

346 Daisy Delogu a souligné cette dimension collective des chansons dans Melyador. "Armes, amours, écriture. Figures de l'écrivain dans le Méliador de Jean Froissart», Médiévales, 41, 2001, p. 133-148.

347 Sur les interventions du narrateur, qui problématisent les frontières entre les niveaux diégétique et extradiégétique puisqu'il se pose en contemporain de l'action, voir Nathalie Bragantini-Maillard, "L'écriture des interventions narratoriales dans Melyador», art. cit., et "Les jeux du narrateur dans Melyador: de l'écriture en trompe-l'œil aux stratégies de l'identification ludique», art. cit., et Jane H. M. Taylor, "The Fourteenth Century», art. cit., p. 287-292. 
La chanson de la jeune fille est éclipsée par un virelai plus intéressant et plus joli; une façon habile de flatter le mécène Wenceslas de Brabant. En brouillant les frontières entre niveaux diégétique et extradiégétique - le narrateur a entendu les chansons des personnages alors qu'il se situe en prologue à l'époque contemporaine de ses auditeurs -, Froissart scénographie sa propre réception des chansons de son mécène: par la voix - ou l'oreille - du narrateur, il restitue son appréhension des poèmes. Une fois encore, c'est le plaisir que l'on retire des chansons qui est mis en avant, plaisir des personnages, mais aussi du narrateur, qui concentre ses efforts à retenir les meilleurs morceaux. Il ne fait au fond pas autre chose que ses personnages, eux qui chantent rarement seuls: le but est bien de partager les poèmes de Wenceslas, de les léguer à la postérité, de les conserver en mémoire. Il n'hésite pas pour cela à convoquer l'écriture:

Cilz rondelés moult me plaisi

Lors que l'ö̈, je l'escrisi

a fin qu'il fust mis en memore. (Melyador, v. 30510-30512)

Le narrateur met ici en scène l'activité de l'auteur, fondée sur l'écrit, sur la conservation d'un contenu destiné à l'oralité. Les chansons sont néanmoins plus souvent retenues sans le recours à l'écriture ${ }^{348}$, surtout parmi les personnages, comme c'est le cas de Melyador, qui se souvient si parfaitement de son rondeau "que il le canta sans escrire" (v. 23221). C'est au narrateur que revient la tâche de les coucher sur papier, tandis que les figures intradiégétiques les conservent en mémoire, car elles sont conformes aux mouvements de leur cour ${ }^{349}$.

Des personnages au public du roman, les enjeux des pièces lyriques sont semblables: elles doivent être retenues et elles doivent réjouir. Leur fonction au sein du roman n'est pas seulement de traduire un état psychologique des actants, mais aussi d'agrémenter le récit. Source de divertissement autant que plus-value esthétique, les chansons, par les changements de métriques qu'elles imposent, évitent la monotonie de la longue narration linéaire. En commentant sa transcription du rondeau qu'Agamanor a

348 Daisy Delogu traite des évocations de l'écriture des pièces lyriques. "Armes, amours, écriture. Figures de l'écrivain dans le Méliador de Jean Froissart ", art. cit.

349 Voir à ce sujet l'article de Sylvère Menegaldo, "Amateurs et professionnels: la composition poétique selon le Meliador et les dits de Jean Froissart", art. cit, p. 186-187. 
écrit sur la toile qu’il offre à Phénonée, le narrateur éclaire ce rapport des chansons à son œuvre:

Encores pour mon livre acroistre

en tous solas et tous reviaus

ens ou cas que cilz [le rondeau] est nouviaus,

je le dirai sans nul detri. (Melyador, v. 20340-20343)

Les poèmes lyriques se savourent donc à tous les niveaux narratifs. Leur caractère divertissant est également soulevé par Sébille, qui parle à Sagremor en songe:

"On doit, de tant vous voel ja apprendre, toutes cançons en bon gré prendre, car on les fait seul pour esbatre, non pour argüer ne debatre.» (Melyador, v. 28657-28660)

Les chansons accompagnent la détente, elles ne sont pas toujours à prendre au sérieux et ne doivent pas mener au débat, au conflit. Ici encore, l'insertion lyrique sert une apologie de la joie, du divertissement.

Les enjeux majeurs de l'insertion lyrique dans Melyador rejoignent ceux que nous dégagions au sujet du vers dans les romans en vers du $\mathrm{XIV}^{\mathrm{e}}$ siècle: l'importance de l'oralité, de la mémoire et du plaisir, esthétique ou ludique. La lyrique est surtout liée à l'amour et à une forme d'introspection, à tel point que, selon Michel Zink, elle prend le pas sur l'œuvre narrative chevaleresque et présente Melyador comme une succession de dits, genre dans lequel Froissart excelle:

À l'inverse des recueils lyriques où la succession des poèmes s'organise en récit, ce roman se déguise en roman mais est en réalité une succession des poèmes. Non pas un roman analogue aux romans arthuriens $\mathrm{du} \mathrm{XII}^{\mathrm{e}}$ et du XIII ${ }^{\mathrm{e}}$ siècle, mais un roman dans l'esprit des récits en vers du XIV siècle, une narration sentimentale dont le fil léger coud un peu lâchement les effusions et les scènes de genre successives. Une œuvre, en un mot, qui sous son apparent anachronisme est parfaitement de son temps ${ }^{350}$.

L'impression d'œuvre poétique résulte à la fois des insertions lyriques et du ton général du texte, selon Michel Zink: l'intrigue initiale, qui

350 Michel Zink, Froissart et le temps, p. 123-124. 
narre les déconvenues de Camel, tourmenté par les jeunes filles, et pour lequel le lecteur éprouve de l'empathie, rappelle les poèmes de Froissart comme La prison amoureuse, L'espinette amoureuse ou Le paradis d'amour, qui mettent aussi en scène les taquineries amoureuses dont le poète est la victime ${ }^{351}$. C'est ainsi que les demoiselles du roman vont toujours par deux (Phénonée et Lucienne, Hermondine et Floree), reproduisant l'effet de groupe des dits. À cela s'ajoute le style que Michel Zink qualifie d'élégiaque en citant les vers suivants: «En .I. bois desous le chastiel / Ou vert faisoit, ombru et biel» (v. 6565-6566).

À l'aune de ces considérations, les insertions lyriques dans Melyador mènent à porter un autre regard sur l'emploi du vers dans ce texte: elles invitent à voir dans cette forme moins le medium du récit chevaleresque que de l'expression du moi ${ }^{352}$. Les poèmes participent aussi de l'hésitation générique autour de l'œuvre: faut-il la classer du côté du roman de chevalerie ou plutôt du poème sentimental, du "dit à "farcissure" lyrique "353 comme le juge Michel Zink? Sans doute n'est-il pas besoin de trancher. Froissart, dans Melyador, se veut l'héritier du roman arthurien en vers, héritage qu'il revendique dans son prologue, autant qu'il valorise cette poésie qui cadre si bien avec la vogue de son temps. Il en résulte un texte de la transition, entre résurgence anachronique et actualisation contemporaine, dont le vers est autant lyrique que narratif. Le titre du chapitre que Michel Zink consacre à Melyador dans Froissart et le temps est alors particulièrement éloquent: «Roman ancien ou poème moderne». Il nous semble que Melyador tient à la fois de l'un et de l'autre.

351 Michel Zink, "Meliador and the inception of a new poetic sensibility", in Froissart Across the Genres, dir. Donald Maddox et Sara Sturm-Maddox, Gainesville, University Press of Florida, 1998, p. 155-175.

352 Selon Didier Lechat, les chansons dans Melyador reconfigurent l'ethos du chevalier, qui s'illustre à la fois par ses faits d'armes et par son chant, nouvel attribut de sa caste. "Les chevaliers-poètes dans Meliador de Froissart", in Poètes et poétesses dans le roman médiéval. Journée d'étude du 8 décembre 2005, dir. Catherine Gaullier-Bougassas, Lille, PU, 2007, p. 73-85.

353 Michel Zink, Froissart et le temps, p. 126. Sur cette question, voir les pages 111-130, "Chapitre VII, Roman ancien ou poème moderne", où Michel Zink étudie en détail les tensions entre l'héritage du roman breton et la modernité de son recours au lyrique. 
Les deux derniers romans arthuriens en vers ${ }^{354}$ dessinent le destin du vers: à une centaine d'années d'intervalle, ils permettent de suivre les proportions grandissantes que prennent les pièces lyriques et la spécialisation lyrique du vers. D'ailleurs, Girart d'Amiens, conscient des potentialités d'un vers qui s'adapte au lyrique et au narratif au sein d'un même texte, développe le procédé de l'insertion lyrique dans Meliacin, composé peu après 1285 . Ce ne sont plus quatre refrains qui parsèment l'œuvre, mais bien vingt-quatre rondeaux, motets, refrains et couplets, certains tirés de chansons célèbres, comme pour Escanor. Les chants n'accompagnent plus la joie d'un cortège, ni même d'une fête ou d'une danse: ils traduisent les états d'âme des personnages qui les déclament et sont "l'expression exemplaire d'une expérience intime ${ }^{355}$, le fruit d'une émotion. Girart d'Amiens donne à l'insertion lyrique une profondeur psychologique qu'elle avait sans doute moins dans Escanor. Ces textes laissent voir les dernières hésitations du vers, entre narration et lyrique, et le primat de celui-ci sur celle-là dans le recours à la forme versifiée. L'engouement pour la prose, au début du XIII ${ }^{\mathrm{e}}$ siècle, a pour conséquence la particularisation du vers, qui passe de forme non marquée à forme marquée de l'expression du moi, comme l'explique Catherine Croizy-Naquet:

Son émergence [à la prose] provoque une prise de conscience aiguë des virtualités du vers, dont elle dégage et dynamise les vertus intrinsèques, et gouverne une fracture, non plus conjoncturelle ni déontologique, mais ontologique entre les deux formes, la dichotomie initiale fausseté/vérité évoluant vers une problématique annexée à la dialectique présence/absence du je. Le vers est à part entière l'écrin où s'enclôt le je, où se noue une réflexion sur le je aimant doublée peu à peu d'une réflexion sur le je écrivant, les auteurs retrouvant de ce point de vue mais dans un cadre nouveau - le cœur des chansons lyriques ${ }^{356}$.

354 Les similitudes que l'on peut dégager entre Escanor et Melyador sur le plan de l'histoire littéraire ont été soulignées par Beate Schmolke-Haßelmann, "Ausklang der altfranzösischen Artusepik: Escanor und Méliador», art. cit., et Michel Zink, Froissart et le temps, p. 127-128.

355 Antoinette Saly, "La chanson dans le Meliacin de Girart d'Amiens", Travaux de linguistique et de littérature, 23.2, 1985, p. 13. L'article transcrit toutes les pièces lyriques.

356 Catherine Croizy-Naquet, "Nus contes rimés n'est verais», art. cit., p. 42. 
Alors que la prose se fait le support de tous les genres ${ }^{357}$, le vers affiche sa spécificité comme support de la poésie, en pleine mutation au XIV ${ }^{\mathrm{e}}$ siècle $^{358}$. Â cette époque, le vers est assimilé au lyrique dans les conceptions. Dans les rares romans qui exploitent encore l'octosyllabe narratif, le lyrique contamine la trame narrative ${ }^{359}$, que ce soit par l'insertion lyrique Melyador, Dame à la licorne - ou par la revendication de l'oralité et du plaisir que l'on retire du rythme et des sonorités - Le Roman du comte d'Anjou, Mélusine de Coudrette.

\section{Lire le roman arthurien à la fin du Moyen Âge}

Les interpénétrations entre vers et prose qu'offrent les insertions lyriques semblent avoir posé difficulté, à une époque plus tardive où la distinction entre vers et prose est consommée: l'insertion lyrique en contexte romanesque ne survit pas toujours à son passage à l'imprimerie. Ainsi, plusieurs textes en prose voient leurs insertions en vers supprimées dans les imprimés (Ysä̈e le Triste) ${ }^{360}$ ou transcrites en longues lignes (Meliadus ${ }^{361}$,

357 C'est l'idée du syncrétisme de la prose que nous évoquions plus haut. Pour la prose, le XIV siècle est aussi celui de la mutation: Annie Combes démontre dans son article "L'emprise du vers dans les mises en prose romanesques ( $\mathrm{XIII}^{\mathrm{e}}-\mathrm{Xv}^{\mathrm{e}}$ siècles) », art. cit., que le dévers, c'est-à-dire une transposition en prose qui conserve le lexique, les rimes et le rythme de l'original en vers, "témoigne d'une époque où l'écriture en prose n'est plus de l'ordre d'une simple impulsion mais donne place à une pluralité de choix» (p. 138). Si, au XIII ${ }^{\mathrm{e}}$ siècle, elle doit s'imposer en forgeant son propre style, au XIV ${ }^{e}$ siècle, elle peut se renouveler et s'essayer à l'homéotéleute.

358 Voir Jacqueline Cerquiglini-Toulet, «Le nouveau lyrisme (XIV ${ }^{\mathrm{e}}-\mathrm{XV}^{\mathrm{e}}$ siècles)», art. cit., qui traite de l'orientation que prend la poésie lyrique à la fin du Moyen Âge.

359 Michel Zink ajoute que l'on ressent cette évolution dans les derniers romans en vers, car ceux-ci donnent à l'aventure amoureuse l'«expression intériorisée de l'allégorie». "Le Roman», in GRLMA, VIII, p. 205.

360 Anne-Cécile Le Ribeuz, «Des manuscrits aux imprimés d'Ysä̈e le Triste: le romanesque à l'épreuve de la mise en page et des images", in Le romanesque aux XIV" et $X V^{*}$ siècles, éd. Danielle Régnier-Bohler, Bordeaux, PU, 2009, p. 243-256. La fonction de rappel, d'écho et de résumé remplie par les insertions lyriques est remplacée par les titres de chapitre.

361 Barbara Wahlen, L'écriture à rebours, p. 335-339, et «Du manuscrit à l'imprimé: le cas de Guiron le Courtois", in Du roman courtois au roman baroque. Actes du colloque des 2-5 juillet 2002, dir. Emmanuel Bury et Francine Mora, Paris, Les Belles Lettres, 2004, p. 233-249. L'hétérogénéité de la mise en page pour les vers des épitaphes et des lettres est en revanche conservée. 
le Tristan en prose ${ }^{362}$ ). Le roman doit s'écrire en prose exclusivement, à l'époque de l'imprimerie; les vers sont devenus étrangers au genre, à tel point que l'imprimé de Meliadus comporte plusieurs fautes, contre la métrique ou même la rime ${ }^{363}$. Il n'est dès lors pas étonnant que l'on ne dispose d'aucun imprimé pour les romans arthuriens en vers, que ce soit ceux de Chrétien de Troyes, ses successeurs du début du XIII ${ }^{\mathrm{e}}$ siècle ou les derniers représentants tardifs. Le genre ne survit à l'imprimerie que dans les mises en prose: celle du Conte du graal de Chrétien de Troyes, couplée aux Continuations, et celle du Bel Inconnu par Claude Platin, que l'éditeur entrelace à Jaufre ${ }^{364}$.

Le rejet du vers comme forme d'expression romanesque se traduit dès le XIV ${ }^{e}$ siècle, ainsi que le laisse penser la transmission manuscrite de la fin

362 Emmanuèle Baumgartner, "Du manuscrit BnF fr. 103 du Tristan en prose à l'imprimé du Tristan par Jehan le Bourgoys (1489)", Ateliers, 30, 2003, p. 17. Sur la mise en page différente entre vers et prose, voir Florence Bouchet Le discours sur la lecture en France aux XIV et XV siècles, p. 284-292, Jacqueline CerquigliniToulet, "La prose et la rose: l'imaginaire spatial de la prose et du vers", art. cit., et Emmanuèle Baumgartner, "Remarques sur la prose du Lancelot», 105:417, 1984, p. 4: "La forme prose substitue une mise en page compacte, où la ligne d'écriture n'est que par le plus grand des hasards une "unité de lecture", où les points de repère et les signes diacritiques (alinéas, majuscules, ponctuation etc.) sont rares. Elle propose un texte dont la durée n'est plus étalonnée, donnée a priori, mais dépend, en fait, du champ de vision, du souffle, du rythme interne, de la compréhension propre du lecteur. Bref un texte livré tout entier ou presque à l'inventio de la lecture."

363 Comme le remarque Barbara Wahlen, L'écriture à rebours, p. 338. C'est également une contrainte de l'impression, qui valorise la régularité et la justification des colonnes. Voir Emmanuèle Baumgartner, «Du manuscrit BnF fr. 103 du Tristan en prose à l'imprimé", art. cit., note 12, p. 25.

364 Giglan s'inspire aussi pour quelques épisodes du Roman de Laurin. Il s'agit plus d'intertextualité, d'emprunt, pour cette source, et non d'entrelacement et de réécriture, comme sont traités le Bel Inconnu et Jaufré. Voir Cédric Pickford, «Les éditions imprimées de romans arthuriens en prose antérieures à 1600 ", BBIAS, 13, 1961, p. 99-109, Jane H. M. Taylor, "Imperious Seductions". Giglan and Perceval", in Rewriting Arthurian Romance in Renaissance France. From Manuscript to Printed Book, Cambridge, Brewer, 2014, p. 119-146 et p. 232-239 pour un tableau de la structure de Giglan, et Laurence Harf-Lancner, "Le Bel Inconnu et sa mise en prose au Xvi ${ }^{\mathrm{e}}$ siècle, L'Histoire de Giglan: d'une esthétique à l'autre", in Le Chevalier et la merveille dans le Bel Inconnu ou le beau jeu de Renaut, dir. Jean Dufournet, Paris, Champion, 1996, p. 69-89. Voir aussi notre annexe C.2 pour un tableau des mises en prose arthuriennes. Nous y reviendrons au chapitre suivant. 
du Moyen Âge, qui fonctionne comme indice des lectures et des goûts de l'époque ${ }^{365}$. Les manuscrits qui conservent des romans arthuriens en vers $^{366}$, en dehors des œuvres de Chrétien de Troyes, et que l'on peut dater postérieurement au XIII ${ }^{\text {e }}$ siècle se font assez rares: Jaufré, d'abord, profite d'une diffusion plutôt importante par rapport aux textes du domaine d'oïl, puisqu'il est transmis par quatre manuscrits datés des alentours de 1300 , voire de la fin du XIV ${ }^{e}$ siècle $^{367}$. Du côté des recueils de romans français, on hésite pour les plus tardifs entre une datation à la fin du XIII ${ }^{\mathrm{e}}$ siècle ou au début du XIv siècle (BnF fr. 12603 pour Le Chevalier aux deux épées, qui contient aussi Yvain, BnF nouv. acqu. fr. 5386, Vatican, Reginensi latini 1725, Vienne, ÖNB 2599 pour Méraugis, BnF fr. 1447 pour Claris et Laris, New York, Public Library, De Ricci 122 pour Floriant et Florete, BnF fr. 1433 pour L'Âtre Périlleux, qui contient aussi Yvain) ${ }^{368}$.

365 Dans sa thèse inédite, "La produzione manoscritta del romanzo francese in versi: modelli materiali e modelli di cultura», Piero Andrea Martina mène une étude statistique sur la production de romans en vers qu'il confronte à la production de manuscrits conservant des textes en vers. Ses travaux permettent de retracer l'intérêt que suscite le vers à la fin du Moyen Âge.

366 Sur les manuscrits arthuriens, toute date confondue et en vers et en prose, voir Roger Middleton, "The Manuscripts", in The Arthur of the French. The Arthurian Legend in Medieval French and Occitan Literature, dir. Glyn S. Burgess et Karen Pratt, Cardiff, University of Wales Press ("Arthurian Literature in the Middle Ages», IV), 2006, p. 8-92. Voir aussi les pages 178 à 183 de Beate SchmolkeHaßelmann, Der arthurische Versroman, qui étudie la diffusion du roman arthurien.

367 Voir Jaufré. Roman arthurien du XIII siècle en vers provençaux, éd. Clovis Brunel, Paris, SATF, 1943, tome 1, p. Xx-Xxx, et Charmaine Lee, "La tradition "indirecte" dans l'édition d'un roman: l'exemple de Jaufre", in Actes du XXIV Congrès International de Linguistique et de Philologie Romanes. Aberystwyth 2004, Congrès International de Linguistique et de Philologie Romanes, 24, Tübingen, Niemeyer, 2007, t. II, p. 199-210. Cette diffusion s'explique peut-être par la rareté du roman arthurien occitan: les œuvres de Chrétien de Troyes occupent largement l'espace culturel du domaine d'oïl et occultent ainsi les œuvres ultérieures aux yeux des commanditaires des $\mathrm{XIV}^{\mathrm{e}}$ et $\mathrm{XV}^{\mathrm{e}}$ siècles, tandis que Jaufré est le seul à rendre l'univers arthurien accessible à des locuteurs du Sud. Il est toujours transmis dans des recueils de textes en langue d'oc ou figure seul.

Voir notre annexe C.1. Sur les manuscrits des romans arthuriens en vers après Chrétien de Troyes, on consultera Richard Trachsler, Les romans arthuriens en vers après Chrétien de Troyes, et Keith Busby, Codex and Context, 2 tomes. Pour une description détaillée des manuscrits de Méraugis, voir Meraugis von Portlesguez. Altfranzösischer Abenteuerroman, éd. Mathias Friedwagner, Halle, Niemeyer, 
Le BnF fr. 353, daté de la fin du XIv siècle, marque bien cette forme de rejet des textes arthuriens en vers à cette époque, car il transmet le Mautel Mautaillé en longues lignes, comme pour donner l'illusion d'un texte en prose par la mise en page ${ }^{369}$. Enfin, le manuscrit Turin, L. IV. 33 est le seul recueil de romans arthuriens en vers daté d'après 1350 , si l'on exclut les exemplaires des œuvres de Chrétien de Troyes et les manuscrits de Melyador: ce manuscrit sur papier de la fin du XIV ou du début du $\mathrm{XV}^{\mathrm{e}}$ siècle transmet un fragment de Rigomer, titré «D'une aventure du roi Artu ", Gliglois et Méraugis, à côté d'œuvres d'autres genres, les romans de Thèbes et de Troie en prose ou le Lai de Mélion notamment ${ }^{370}$.

Le tardif Melyador apparaît dès lors comme une exception: composé et remanié dans la deuxième moitié du XIv ${ }^{\mathrm{e}}$ siècle, il a dû plaire à un public aristocrate contemporain: le duc Wenceslas de Brabant demande la recomposition du roman, dans lequel s'insèreront ses propres poèmes, nous l'avons vu. Plus tard, en hiver 1388, le comte de Foix Gaston Fébus semble apprécier la lecture de Melyador, comme nous l'avons évoqué plus haut. Toutefois, s'il laisse quatre-vingts florins à Froissart, il ne fait pas l'acquisition du livre ( «li bons contes / Me fist par la chambre des contes / Delivrer quatre vins florins / D’Arragon [...] Et mon livre qu'il m'ot laissié, / (Ne sçai se ce fu de coer lié,) / Mis en Avignon sans damage.») ${ }^{371}$.

1897. On consultera aussi Keith Busby et al. (dir.), Les manuscrits de Chrétien de Troyes, tome 2, p. 62-63 pour le manuscrit du Vatican, tome 2, p. 73-75 pour BnF fr. 1433 et tome 2, p. 69-70 pour le BnF fr. 12603. Sur ce dernier manuscrit et sa datation au début du XIV ${ }^{\mathrm{e}}$ siècle, voir l'article de Richard Trachsler, "Le recueil Paris, BN fr. 12603», Cultura neo-latina, 54, 1994, p. 189-211. Sur BnF fr. 1433, voir Lori Walters, "The creation of a "super romance": Paris, Bibliothèque nationale, fonds français, MS 1433", in The Arthurian Yearbook, dir. Keith Busby, New York, Garland, 1991, p. 3-35.

369 Voir Nathalie Koble, Les dessous de la Table ronde, p. 93. Il faut souligner que Florimont, qui accompagne le Mantel mautaillé dans ce manuscrit, est aussi transcrit en longues lignes. Il faut peut-être considérer que ce choix de présentation est lié à un souci d'économie, ce que corroboreraient la pauvreté de l'enluminure et la coprésence de la fin de Florimont et du début du Mantel sur la même page, sans espace ni titre. Voir la reproduction en ligne, http://gallica.bnf.fr/ark:/12148/ btv1b9007612r/f1.item

370 Francesco Carapezza, «Le fragment de Turin», art. cit.

371 «Le Dit dou Florin», éd. cit., v. 381-389. Voir les pages 23 à 24 et 50 à 57 de l'édition citée de Nathalie Bragantini-Maillard. 
Ce dernier roman arthurien ne nous est transmis que par un manuscrit incomplet de la fin ${ }^{372}$ et un fragment, datés de la fin du XIV ${ }^{e}$ siècle ${ }^{373}$.

Les œuvres du maître champenois ont à peine plus de succès au XIV ${ }^{e}$ siècle: neuf manuscrits de ses quatre ouvres arthuriennes datent de la fin du XIII ${ }^{e}$ siècle ou du XIV siècle $-\mathrm{y}$ compris BnF fr. 12603, Vatican 1725 et BnF fr. 1433 que nous avons déjà cités pour les autres romans arthuriens qui y sont contenus ${ }^{374}$. Nous ne disposons d'aucun témoin du $\mathrm{XV}^{\mathrm{e}}$ siècle ${ }^{375}$, preuve sans doute de la difficulté que posent ces textes au public; en raison de leur langue d'abord, ce qui encourage Pierre Sala à «traduire ${ }^{376}$ le Chevalier au lion en 1522, mais aussi en raison de leur forme versifiée.

Le traitement du roman arthurien en vers en contexte manuscrit varie, dans les exemplaires que nous retenons: le texte «épigonal» figure souvent avec une ouvre de Chrétien de Troyes, dans BnF fr. 12603 (Chevalier aux deux épées et Yvain), Vatican, lat. 1725 (Méraugis, Charrette et Yvain) et BnF fr. 1433 (L'Âtre Périlleux et Yvain). C'est l'occasion d'un dialogue

372 Nathalie Bragantini-Maillard a traité de la question de l'inachèvement de Melyador aux pages 35 à 43 de son édition, éd. cit. Selon elle, il ne manquerait qu'un feuillet découpé, et donc que quelques vers, au texte. L'œuvre se terminerait ainsi sur le tournoi conclusif de Camelot et laisserait inachevée l'aventure amorcée de Sagremor.

373 Voir l'édition de Nathalie Bragantini-Maillard, éd. cit., p. 26-35. Selon Nathalie Bragantini-Maillard, les cours d'Édouard III, de Wenceslas de Brabant et de Gaston Fébus, qui ont toutes accueilli le roman de Froissart, se caractérisent par «un goût ancien pour la culture et les valeurs chevaleresques et courtoises véhiculées par la littérature.» («L'octosyllabe romanesque chez Jean Froissart», art. cit., p. 264.

374 Terry Nixon, "Catalogue of Manuscripts», art. cit. Le Chevalier au lion est représenté dans quatre de ces manuscrits tardifs, Erec et Enide dans deux, Le Chevalier de la Charrette dans un seul et le Conte du graal dans trois manuscrits, dont deux sont des compilations qui contiennent les Continuations.

375 Il faut néanmoins insister sur le fait que la pauvreté de la transmission des romans arthuriens en vers pour la fin du Moyen Âge s'explique aussi par des pertes: Richard Trachsler souligne notamment que l'exemplaire d'Escanor que mentionne l'inventaire de la bibliothèque de Charles $\mathrm{V}$ est perdu. Ce manuscrit circulait à la fin du XIV siècle, comme en témoigne une note dans l'inventaire qui signale le prêt de l'ouvrage à la reine, le 29 août 1390. Voir Richard Trachsler, Escanor, éd. cit., p. 20-21.

376 Nous employons les guillemets en raison des rapports étroits entre mise en prose et traduction. Voir infra, chapitre II, "Les mises en prose arthuriennes», p. 398-417. 
intéressant entre les textes: Lori Walters voit dans le BnF fr. 1433 un "super romance», qui conjoindrait deux romans en un, sur le mode de l'entrelacement ${ }^{377}$. L'assemblage de ces deux romans propose deux portraits concurrents de Gauvain: dans l'un, le chevalier est réhabilité et fonctionne comme héros, dans l'autre, il est surpassé en valeurs par Yvain. Francis Gingras, dans le même esprit, considère le Vatican, lat. 1725 comme un ensemble de jeux d'échos entre les quatre textes qui le composent ${ }^{378}$.

Le reste des manuscrits de la période retenue offre trois autres types de regroupement: le premier cas concerne le Conte du graal, qui forme deux fois une collection avec les Continuations (BnF fr. 1453 et BnF fr. 12577). Ensuite, le texte arthurien est parfois seul, sans un quelconque entourage (Vienne, ÖNB 2599, New York, De Ricci 122, BnF fr. 12557), mais le plus souvent, il figure dans des recueils hétérogènes, accompagné de romans d'Antiquité, de chroniques ou de textes relatifs à l'histoire sainte. Le rendu est soit la compilation des genres variés et représentatifs des $\mathrm{XII}^{\mathrm{e}}$ et XIII ${ }^{\mathrm{e}}$ siècles, qui fournit une véritable bibliothèque ${ }^{379}$ comme c'est le cas de BnF fr. 12603, recueil contenant des récrits brefs - fables, fabliaux, songe, texte renardien -, deux romans arthuriens, l'Eneas suivi du Brut et des chansons de geste; soit la conjonction de l'histoire et de la légende, dans Londres, Arundel XIV et Turin, L. IV $33^{380}$.

Seul le manuscrit de Turin, L. IV 33 justement, pourtant de la fin du $\mathrm{XIV}^{\mathrm{e}}$ siècle, propose encore une petite collection de romans arthuriens en

377 Lori Walters, "The creation of a "super romance" ", Paris, Bibliothèque nationale, fonds français, MS 1433 », art. cit.

378 «Roman contre roman dans l'organisation du manuscrit du Vatican, Regina Latina 1725 ", art. cit.

379 C'est ainsi que Keith Busby présente le BnF fr. 12603, acquis par Charles de Croy (1460-1527). Codex and Context, vol. II., p. 802-803. Voir aussi vol. I, p. 434-436: le copiste manifeste un intérêt particulier à conjoindre les œuvres, notamment en supprimant le prologue du Brut pour le présenter comme une continuation d'Eneas. La conjonction de l'univers arthurien et breton avec l'histoire antique renforce sa légitimité. Voir aussi Keith Busby, "Post-Chrétien Verse Romance. The Manuscript Context", art. cit., p. 22-23. Florence Bouchet note aussi la tendance à l'hétérogène dans les recueils pour former de véritables anthologies. Le discours sur la lecture en France aux XIV et XV siècles, p. 167.

380 Francis Gingras, «Roman contre roman dans l'organisation du manuscrit du Vatican, Regina Latina 1725», art. cit., p. 64. 
vers. Il transmet des textes du XIII ${ }^{\mathrm{e}}$ siècle, aussi bien en vers qu'en prose, mêlant la chronique au roman antique et au dit. En voici le contenu ${ }^{381}$ :

- Le Roman de Troie en prose $e^{382}$

- La chronique du Pseudo-Turpin, prose, version pour Mathieu de Harnes

- Clerc de Vaudoy, Le dit des droitz, vers

- Chroniques d'outremer, prose

- D'une aventure du roi Artu (Rigomer), fragment

- Mélion

- Gliglois

- Raoul de Houdenc, Méraugis de Portlesguez

- Le Roman de Thèbes en prose

Ainsi, quatre textes arthuriens se suivent à la fin du recueil, si l'on considère Mélion comme un lai arthurien. Il s'agit pour le fragment de Rigomer, Mélion et Gliglois de récits brefs: le manuscrit ne transmet que l'épisode final, dit de la Quintefeuille, de Rigomer, tandis que Mélion et Gliglois comportent respectivement 592 et 2942 vers. Ce choix priorise une lecture par épisodes, tirés d'œuvres différentes. La section s'ouvre sur le seul passage de la littérature en vers où Arthur part en errance - nous y reviendrons: une bonne façon de présenter les textes suivants comme des petits épisodes de sa vie, le tout étant bien circonscrit dans l'univers placé sous sa tutelle. Le manuscrit propose ainsi au lecteur, non pas l'entier du roman de Rigomer, mais bien un seul épisode jugé intéressant et facilement détachable de son contexte. Le dernier recueil manuscrit de romans arthuriens en vers suggère une consommation fragmentaire, par épisodes brefs, comme autant de captures efficaces du monde arthurien, sorti de toute causalité, de toute complexification. C'est le constat que fait Francesco Carapezza:

381 Ce manuscrit a été endommagé lors de l'incendie de la bibliothèque en 1904. S'il n'a pas été détruit, la lecture est devenue très laborieuse. Les informations nous proviennent de l'édition de Marie-Luce Chênerie, Le Roman de Gliglois, Paris, Champion ("CCMA»), 2003, p. 9-15, qui reprend les indications de Charles H. Livingstion, Gliglois. A French Arthurian Romance of the Thirteenth Century, Cambridge, Harvard University Press, 1932.

382 Il s'agit plus précisément de la traduction de Darès par Jean de Flixecourt. Voir Marc-René Jung, La légende de Troie en France au moyen âge. Analyse des versions françaises et bibliographie raisonnée des manuscrits, Bâle, Francke, 1996, p. 437. 
$\mathrm{Au}$ contraire, cette attestation tardive et épisodique de Rigomer témoigne d'une diffusion particulière, propre aux romans d'aventures vers la fin du Moyen Âge. Ces longs récits se prêtent effectivement à une "décomposition" en de plus courts fragments qui gardent pourtant une suffisante cohésion narrative: la copie de Turin serait donc - du point de vue de la réception - une très intéressante et caractéristique "preuve» de la survivance de ce type de récits à une époque postérieure de plus d'un siècle à celle de leur composition ${ }^{383}$.

La lecture fragmentaire, inspirée de la lecture cléricale, se répand au XIv siècle pour les ouvres profanes. C'est le constat que propose Daniel Poirion à partir des annotations dans les marges des manuscrits au sujet des œuvres didactiques: "La plupart des grandes œuvres, et l'on peut dire la totalité des œuvres de vulgarisation, sont destinées à la lecture fragmentaire $»^{384}$.

Justement, les derniers romans arthuriens en vers qui constituent notre corpus cultivent dans une certaine mesure cette "poétique de la vignette" que dénomme Patricia Victorin au sujet du Conte du Papegau, où les aventures se succèdent sans lien de progression, selon une logique de la parataxe $e^{385}$. La succession de petits épisodes plaisants, comme celui de la transformation de Calogrenant en jeune fille dans Claris et Laris (v. 26093-26397), sont décomposables pour une lecture telle que celle soumise par le manuscrit de Turin. Peut-être peut-on en déduire que le

383 Francesco Carapezza, "Le fragment de Turin», art. cit., p. 101. Richard Trachsler regrette quant à lui la dépendance du manuscrit de Turin vis-à-vis de celui de Chantilly: "L'indépendance du manuscrit de Turin aurait pour ainsi dire apporté la preuve tangible d'une composition par "agglutination", où le roman épisodique devient recueil de contes, avec une trame principale suffisamment souple pour accueillir des récits brefs de toutes sortes." (Les romans arthuriens en vers après Chrétien de Troyes, p. 189) Il nous semble que ce constat reste applicable même si Turin dérive de Chantilly: le copiste n'en isole pas moins un épisode d'un roman plus étendu.

384 Daniel Poirion, "L'épanouissement d'un style: le gothique littéraire à la fin du Moyen Âge", art. cit., p. 38. Voir aussi Florence Bouchet, Le discours sur la lecture en France aux XIV et XV siècles, p. 156-166. Florence Bouchet n'exclut pas le roman de cette lecture sélective: «La lecture du roman est certes orientée vers l'accomplissement de l'intrigue mais peut, guidée par les rubriques, s'arrêter à un récit de combat ou à un autre morceau de bravoure.» (p. 161)

385 Le Conte du Papegau, éd. cit., p. 20. Voir aussi Danielle Régnier-Bohler, «Arthur en enfances dans Le Chevalier du Papegau», PRIS-MA, 13/1, 1997, p. 91-106. 
roman arthurien en vers survit sous forme de brefs épisodes rapidement consommés, car il n'est plus besoin, à cette époque, de dérouler en détail l'entier de l'univers de fiction arthurien, trop bien connu.

Il s'agit néanmoins du seul recueil de textes en vers que l'on peut soumettre à une telle interprétation; la diffusion du roman arthurien en vers se fait de plus en plus pauvre au XIv ${ }^{e}$ siècle, jusqu'à disparaître au $\mathrm{XV}^{\mathrm{e}}$ siècle, même pour la transmission d'épisodes isolés. Les romans arthuriens en prose bénéficient en revanche de plus d'attention. On compte ainsi soixante-cinq manuscrits du cycle du Lancelot-Graal - tous textes confondus - depuis 1300 et jusqu'à la fin du Xv $\mathrm{xv}^{\mathrm{e}}$ siècle ${ }^{386}$, ce qui dépasse largement la production de romans en vers, en nombre et en date ${ }^{387}$. L'intérêt pour les textes en prose se manifeste aussi par les manipulations auxquelles les soumettent les copistes, qui compilent des épisodes choisis sous forme de patchwork. L'exemple de la compilation de Rusticien de Pise à la fin du XIII ${ }^{\mathrm{e}}$ siècle en est un cas particulièrement représentatif: l'auteur assemble des morceaux qu'il sélectionne à partir du Lancelot en prose, du Tristan en prose et de Guiron le courtois ${ }^{388}$. On peut également citer le BnF fr. 112 par Michel Gonnot en 1470, qui déstructure ses sources (Suite post-Vulgate, Lancelot en prose, Tristan en prose, Guiron, Queste, Mort $A r t u)$, les raccourcit, les combine et les amplifie par des interpolations

386 Voir le site entretenu par Alison Stones, http://www.lancelot-project.pitt.edu/ LG-web/Arthur-LG-ChronGeog.html, qui recense les manuscrits du cycle.

387 D'autant que la diffusion des romans arthuriens en prose se poursuit au $\mathrm{XVI}^{\mathrm{e}}$ siècle dans l'imprimerie. Cedric E. Pickford recense un nombre considérable d'imprimés pour cette production. Voir «Les éditions imprimées de romans arthuriens en prose antérieures à 1600 ", art. cit. Le critique souligne néanmoins que les romans de la Table Ronde sont beaucoup moins imprimés que les mises en prose des chansons de geste, qui bénéficient d'un nombre énorme d'impression. Il conclut que «la popularité du roman arthurien fut assez modeste en France» (p. 104). Ce constat s'applique d'autant plus aux romans en vers qu'à ceux en prose. Voir aussi Claude Roussel, "Mise en prose ou mise en roman?», art. cit., sur les imprimés des chansons de geste, et l'étude de Jane H. M. Taylor, Rewriting Arthurian Romance in Renaissance France. From Manuscript to Printed Book, Cambridge, Brewer, 2014, sur la transposition des romans arthuriens en prose dans les imprimés.

388 Marina Brownlee, «Des usages politiques d'un prequel arthurien: Rustichello, Palamède et Byzance", in Sens, rhétorique et musique. Études réunies en hommage à Jacqueline Cerquiglini-Toulet, éd. Sophie Albert et al., Paris, Champion 2015, p. 77-92, Roger Lathuillère, Guiron le courtois. Étude de la tradition manuscrite et analyse critique, Genève, Droz, 1966. 
pour donner une nouvelle expérience de lecture, soucieuse de grouper des textes voisins ${ }^{389}$. Le cycle de Guiron le courtois est souvent l'objet de combinaisons variées, typiques de la transmission des sommes en prose à la fin du Moyen Âge ${ }^{390}$ : Roger Lathuillère signale que les manuscrits de Florence (Biblioteca Medicea-Laurenziana, Ashburnham 123) et de Turin (Biblioteca nazionale universitaria, L. I. 7-L. I. 9) juxtaposent les narrations secondaires "comme des éléments épars ou indépendants " ${ }^{391}$. Ce type de présentation traite ces récits brefs comme des nouvelles isolables de leur contexte d'origine ${ }^{392}$.

La richesse des décors de certains exemplaires est un critère de plus pour témoigner de l'intérêt dont les romans en prose font encore l'objet: les recueils des ducs de Berry et de Bourgogne (BnF fr. 117-120 et Arsenal 3479-3480) contiennent cent trente miniatures chacun, le BnF fr. 112 pour Jacques d'Armagnac deux cent cinquante-huit ${ }^{393}$. Il s'agit de véritables

389 Cedric E. Pickford, L'évolution du roman arthurien en prose, sur le manuscrit BnF fr. 112.

390 Voir les travaux de Barbara Wahlen, "Adjoindre, disjoindre, conjoindre. Le recyclage d'Alixandre l'Orphelin et de l'Histoire d'Erec dans Guiron le Courtois (Paris, BnF, français 358-363)", in Le Texte dans le texte. L'interpolation médiévale, dir. Annie Combes, Michelle Szkilnik et Anne-Catherine Werner, Paris, Classiques Garnier, 2013, p. 235-248, «Du recueil à la compilation: le manuscrit de Guiron le Courtois, Paris, BNF fr. 358-363", Ateliers, 30, 2003, p. 89-100. Sur les combinaisons et interpolations dans les manuscrits de romans en prose, voir Roger Middleton, "The Manuscripts», art. cit., p. 37-84. Patrick Moran étudie aussi les combinaisons variées que les compilateurs opèrent sur les textes en prose, Lectures cycliques, en particulier les pages 543-589. On peut encore citer le manuscrit de l'Arsenal 5229: Nathalie Koble, «Un nouveau Ségurant Le Brun en prose? Le manuscrit de Paris, Arsenal 5229, un roman arthurien monté de toutes pièces", in Le Romanesque aux XIV et XVe siècles, dir. Danielle Bohler, Eidôlon, 83, 2009, p. 69-94.

391 Roger Lathuillère, "L'évolution de la technique narrative dans le roman arthurien en prose de la deuxième moitié du XIII ${ }^{\mathrm{e}}$ siècle", Études de langue et de littérature françaises offertes à André Lanly, Nancy, 1980, p. 210.

392 Roger Lathuillère, "Un exemple de l'évolution du roman arthurien en prose dans la deuxième moitié du XIII ${ }^{\mathrm{e}}$ siècle", in Mélanges de langue et littérature françaises $d u$ Moyen Âge offerts à Pierre Jonin, Senefiance, 7, 1979, p. 387-401.

393 Voir le site d'Alison Stones, lancelot-project.pitt.edu. Le tableau de cette page web permet de constater l'importance des enluminures dans les manuscrits du Lancelot-Graal. Roger Middleton rappelle toutefois qu'il ne faudrait pas en déduire que le public des romans arthuriens en prose serait exclusivement aristocratique: il est probable que les manuscrits moins richement décorés se soient 
programmes iconographiques faisant appel à un atelier réputé. De tels volumes supposent une aisance financière et un bagage culturel obtenu dans les cours: Sarah Fourcade note que la littérature arthurienne en prose fait partie de la culture nobiliaire de la fin du Moyen Âge; ses lecteurs appartiennent à la haute noblesse, à l'entourage du roi. Leur engouement pour les romans arthuriens en prose s'explique par les valeurs positives qu'encourage cette littérature: loyauté au seigneur, honneur, défense de la foi, exploit chevaleresque sont autant de mérites qui touchent un lectorat aristocrate ${ }^{394}$.

En comparaison, les manuscrits de romans arthuriens en vers sont beaucoup moins richement décorés. En nous concentrant toujours sur les manuscrits de la fin du Moyen Âge, seuls le BnF fr. 1453, le BnF fr. 12577, le BnF fr. 1433 et le Vienne, ÖNB 2599 offrent un programme iconographique avec plusieurs miniatures ${ }^{395}$. Le reste des recueils comporte tout au plus une miniature par texte et des enluminures plus ou moins élaborées. C'est le cas pour les textes suivants de notre corpus: Claris et Laris (BnF fr. 1447) ${ }^{396}$, Floriant et Florete (New York, De Ricci 122) ${ }^{397}$ et

plus facilement perdus au fil du temps que les volumes de luxe, d'où le nombre important de ceux-ci. "The Manuscripts", art. cit., p. 47. Voir l'entier de l'article pour une analyse détaillée des manuscrits arthuriens en prose. Giulio Bertoni montre aussi qu'un lectorat plus humble avait accès à ces textes en les empruntant: il donne en exemple les registres de la cour des ducs d'Este au $\mathrm{Xv}^{\mathrm{e}}$ siècle, qui mentionnent le prêt de romans arthuriens en prose français à des notaires ou des tapissiers. "Lettori di romanzi francesi nel quattrocento alla corte estense», Romania, 45, 1918, p. 117-122.

394 Sarah Fourcade, "Les lecteurs nobles de la littérature arthurienne à la fin du Moyen Âge", in Arthur après Arthur, p. 429-442. En annexe, la critique liste les manuscrits arthuriens dont on connaît les possesseurs. Voir p. 605-609. L'article tient aussi compte de la circulation des volumes, qui renforce leur diffusion. Voir aussi Cedric E. Pickford, L'évolution du roman arthurien en prose, p. 272-290.

395 Keith Busby, "Mise en texte and Mise en image: Méraugis de Portlesguez in Vienna, ÖNB 2599", in "Por le soie amisté». Essays in honor of Norris J. Lacy, dir. Keith Busby et Catherine M. Jones, Amsterdam, Rodopi, 2000, p. 95-116. Voir notamment les descriptions de Terry Nixon, "Catalogue of Manuscripts», art. cit. et Roger Middleton, "The Manuscripts», art. cit., p. 20-21.

396 Il s'agit d'un repas à la table du roi Ladon et de Lidaine. Chaque œuvre de ce recueil (Floire et Blanchefleur et Berte aux grands pieds) commence par une miniature. Voir l'édition citée de Corinne Pierreville, p. 56-59. Nous reviendrons sur la mise en recueil de cette copie.

397 La miniature représente les parents de Floriant, Elyadus et la reine accolés. Les visages ont été grattés par un pudique lecteur ultérieur. Floriant et Florete a toujours 
Melyador (BnF fr. 12557) ${ }^{398}$ présentent chacun une miniature au début du texte. Ces images illustrent toutes la scène initiale de chaque roman. Le manuscrit d'Escanor (BnF fr. 24374) devait lui aussi, selon son premier éditeur Henri Michelant ${ }^{399}$, être orné d'une grande miniature au début du texte, mais elle a été déchirée, si bien qu'il ne nous reste que le bas de la première page. Si l'on se fie à la mise en page de ce morceau, cette hypothèse est tout à fait raisonnable: on y devine une initiale - peut-être une grande initiale ornée comme celle du folio 2 -, elle aussi déchirée, sept vers avant la fin de la colonne. Elle se prolonge jusqu'à la marge de queue, décor assez typique pour la première lettre d'un texte. Cela laisse envisager que l'image occupait la moitié supérieure de la page, ou tout du moins la moitié de la première colonne.

Si le nombre d'illustrations de nos textes ne saurait concurrencer celui des volumes du Lancelot-Graal, il serait faux d'en déduire que leur décor est pauvre: il s'agit toujours de copies soignées, agrémentées de lettrines à l'encre (Rigomer, Biaudouz), voire de dorures (Floriant et Florete, Escanor, Claris et Laris, Melyador). Même si ces romans ne semblent visiblement pas assez importants aux yeux des commanditaires pour y investir des moyens semblables aux textes en prose, ils demeurent conservés dans des manuscrits de bonne facture. Celui de Claris et Laris (BnF fr. 1447) en est l'exemple le plus remarquable; par la qualité de son parchemin, la proportion de ses dorures et de ses initiales ornées et dorées, l'importance des bandes d'I filigranées à l'or et le soin apporté aux illustrations qui ornent chaque début d'œuvre, que ce soit les miniatures ou les scènes de chasse

figuré seul dans ce manuscrit: la numérotation des cahiers est contemporaine de la copie, et le premier cahier commence par «I». Quant au dernier cahier, qui ne comporte que trois bifeuillets, il se termine par un feuillet en grande partie déchiré sur lequel ne figure pas de texte au verso. On peut donc en déduire que rien ne suivait notre roman. Voir Jonathan J. G. Alexander, James H. Marrow, Lucy Sandler Freeman (dir.), "Floriant et Florete", in The Splendor of the Word. Medieval and Renaissance illuminated manuscripts at the New York Public Library, Turnhout, Brepols, 2005, p. 389-391, et l'édition citée de Richard Trachsler et Annie Combes, p. xv-xxir.

398 La grande image qui orne la première page représente la chasse au cerf au cours de laquelle Camel rencontre Hermondine. Voir l'édition citée de Nathalie Bragantini-Maillard, p. 30-48.

399 Gerard von Amiens, Roman von Escanor, éd. Henri-Victor Michelant, Tübingen, Literarischen Verein in Stuttgart, 1886, p. xxv. Voir aussi l'édition citée de Richard Trachsler, p. 11-21. 
de la marge de queue. L'exemplaire de Floriant et Florete (New York, De Ricci 122) témoigne quant à lui d'un souci d'harmonie visuelle: les lettrines, successivement dorées et bleues et prolongées de bande d'I, n'ont pas de fonction organisatrice au sein du récit, mais sont toujours placées au milieu de chaque colonne. Chaque double page offre ainsi une rangée de quatre lettrines, flattant l'œil du lecteur par la symétrie de la mise en page. Le soin apporté au décor et à la présentation du manuscrit prouve qu'il existe toujours un public pour ces textes au XIV siècle, même s'il se restreint à quelques amateurs.

Ces amateurs sont principalement français: la grande majorité des manuscrits arthuriens versifiés tardifs sont issus de Paris, de Normandie, du Hainaut, du nord-est et de l'est de la France. Un manuscrit tardif provient d'Angleterre et seuls les manuscrits de Jaufré ont été réalisés en Italie, qui privilégie nettement les chansons de geste et les romans arthuriens en prose ${ }^{400}$. Bien que les informations soient maigres sur les lecteurs de ces textes, Roger Middleton ${ }^{401}$ fournit tout de même quelques indications sur les possesseurs de manuscrits arthuriens versifiés aux XIV et $\mathrm{XV}^{\mathrm{e}}$ siècles: le BnF fr. 12576 (Conte du graal et ses continuations) a vraisemblablement appartenu à un bourgeois prospère de la fin du XIII ${ }^{\mathrm{e}}$ siècle, puis à une famille noble du XvI siècle; le BnF fr. 12560 (Yvain, Charrette) appartenait à Marguerite de Flandres en 1405; Vienne, ÖNB 2599 (Méraugis) figurait quant à lui dans la bibliothèque du Louvre en 1373, puis dans la bibliothèque des ducs de Bourgogne en 1467 et aurait pu être une commande pour Jeanne de Bourgogne, femme de Philippe de Valois morte en $1348^{402}$; le BnF fr. 12603 (Yvain, Chevalier aux deux épées) appartenait à Charles de Croy, Prince de Chimay en 1486. Selon Roger Middleton, Charles de Croy ne devait pas goûter particulièrement les romans arthuriens en vers, mais a pu faire l'acquisition de ce manuscrit en vue de fournir de la matière pour une mise en prose. Enfin, le

400 Voir Ilaria Molteni, I romanzi arturiani in Italia: tradizione narrative, strategie delle immagini, geografia artistica, Thèse de doctorat sous la direction de la Professeure Serena Romano, Université de Lausanne, 2017, à paraître, et Roger Middleton, "The Manuscripts», art. cit., p. 29-30. Voir aussi notre annexe C.1 pour les lieux de provenance de chaque manuscrit arthurien tardif.

401 Roger Middleton, "The Manuscripts», art. cit., p. 31-37.

402 Keith Busby, "Mise en texte and Mise en image: Méraugis de Portlesguez in Vienna, ÖNB 2599", art. cit. 
BnF fr. 1453 (Conte du graal et continuations) a pu appartenir aux ducs de Bourbon au $\mathrm{Xv}^{\mathrm{e}}$ siècle. Ce lectorat est donc socialement varié, de la haute noblesse à la riche bourgeoisie ${ }^{403}$.

Il faut compter bien sûr avec plusieurs manuscrits perdus au cours des siècles et dont l'existence est parfois attestée par des mentions dans des inventaires. Celui de la bibliothèque du Louvre (inventaires de 1373 à 1424) mentionne trois Conte du graal, un Atre Périlleux et un Escanor ${ }^{404}$. Un «Torrez chevalier au Cercle d'or, rymé» pourrait aussi contenir un roman arthurien, peut-être la source française du roman arthurien hollandais Torec ${ }^{405}$. Un Melyador figurait dans celle de Charles d'Orléans ${ }^{406}$, un «Beaudoux» et un Conte du graal dans celle de Jean de Saffres, chanoine de Langres mort en $1365^{407}$. Roger Middleton signale encore la mention des items «Floret et Florete» et "Le livre de Florent» dans l'inventaire de 1474 de la bibliothèque de la comtesse de Montpensier à Aigueperse sous la rubrique des livres en papier. En 1507 en revanche, le premier est «en pappier» et le second en "parchemyn». Peut-être s'agit-il dans le cas du manuscrit sur papier de la version en prose de Floriant et Florete, conservée dans deux exemplaires sur papier. Le «Floriant de Sécille» de Tours,

403 La vogue des pas d'armes et des jeux guerriers à thème arthurien témoigne bien d'un engouement qui transcende les classes: le peuple participe aussi à ces manifestations en y assistant. Voir Catherine Daniel, «La légende arthurienne, un lien social politique et culturel européen", in Regards croisés sur le lien social, dir. Denis Bouget et Serge Karsenty, Nantes, Ange-Guépin, 2003, p. 41.

404 Roger Middleton, "The Manuscripts», art. cit., p. 33, et Leopold Delisle, Recherches sur la librairie de Charles V, roi de France (1337-1380), n 1163, 1103, 1151, 1152, 1153. Voir l'édition citée de Richard Trachsler, p. 20.

405 Roger Middleton, "The Manuscripts", art. cit., p. 34 et Leopold Delisle, Recherches sur la librairie de Charles V, roi de France (1337-1380), n 1195 . Cet ouvrage, dans lequel figure aussi un "Perceval le Galois", est prêté à la reine Isabel de Bavière en 1392. Le roman de Torec est titré "Torrez chevalier au Cercle d'or, rymé, bien historié et escript".

406 Voir l'éd. cit. de Nathalie Bragantini-Maillard, p. 43-48.

407 L'inventaire de la bibliothèque de Jean de Saffres est un rouleau conservé aux Archives départementales de la Haute-Marne. Les deux romans arthuriens en vers sont mentionnés sous les numéros 4 et 6 . D'autres romans arthuriens, probablement en prose, figurent dans cet inventaire. Voir J. Carnandet, "Bibliothèques de deux chanoines de Langres au XIv ${ }^{e}$ siècle», Bulletin du bibliophile, 13, 1857, p. 463-477, qui transcrit l'inventaire. 
recensé à la fin du $\mathrm{Xv}^{\mathrm{e}}$ siècle, pourrait aussi être un Floriant et Florete ${ }^{408}$. Dans ces mêmes inventaires sont mentionnés un Perceval et un Durmart. Enfin, l'«Inventaire du Trésor des comtes d'Artois» signale l'achat par la comtesse d'un "Perceval le Galoys» à Arras en novembre 1308, marquant un intérêt encore vivace pour les romans arthuriens au début du XIV ${ }^{\mathrm{e}}$ siècle $^{409}$.

Ces informations confirment l'accueil plus favorable que reçoit le roman arthurien en vers en France par rapport à d'autres pays. On compte très peu d'œuvres recensées dans les inventaires italiens ou anglais: celui de la librairie de Mantoue en 1407 et celui de l'abbaye de Canterbury au $\mathrm{XV}^{\mathrm{e}}$ siècle comprennent chacun un Perceval. Là encore, on peut souligner l'intérêt supérieur que suscite le roman en prose: «English bequests and catalogues include a good number of Arthurian titles but most are likely to be in prose $»^{410}$. La cour anglaise fait pourtant naitre les deux derniers romans arthuriens en vers, Escanor et Melyador: le premier est commandité par la reine d'Angleterre Alienor de Castille ${ }^{411}$, femme d'Édouard Ir dont on connaît l'inclination pour le roi Arthur ${ }^{412}$, tandis que le second est composé dans sa première version à la cour d'Édouard III et Philippa de Hainaut ${ }^{413}$. Il ne faudrait pas en conclure que le roman arthurien en vers trouve son public de prédilection en Angleterre, comme c'était le cas aux

408 Roger Middleton, "The Manuscripts», art. cit., p. 26-27. Voir aussi Richard Trachsler, "Floriant et Florete», in Nouveau répertoire des mises en prose (XIV"-XVI siècle), dir. Maria Colombo-Timelli et al., Paris, Garnier, 2014, p. 253-258, et l'introduction à l'édition de Claude Lévy, Le Chevalier qui la nef maine, éd. cit., p. 53-57.

409 M. le Chanoine Dehaisnes, Documents et extraits divers concernant l'histoire de l'art dans la Flandre, l'Artois et le Hainaut avant le XV siècle, Lille, L. Danel, 1886, et Roger Middleton, "The Manuscripts», art. cit., p. 35.

410 Roger Middleton, "The Manuscripts», art. cit., p. 36. Voir aussi p. 49-57.

411 Voir l'introduction à l'édition citée de Richard Trachsler, p. 56-67.

412 Roger Sherman Loomis, Roger Sherman Loomis, «Edward I, Arthurian Enthusiast», Speculum, 28/1, 1953, p. 114-127.

413 Pour les autres textes, nous ne disposons pas d'informations sur les commanditaires et sommes réduits à des suppositions, comme celle que nous formulions sur la possibilité d'une commande par la noblesse sicilienne de Floriant et Florete. Robert de Blois est le seul autre auteur de notre corpus dont on connaît les mécènes, qui sont quant à eux français; il dédie certaines de ses œuvres - mais pas Biaudouz, dont on ignore le destinataire - au seigneur de Poix Hue Tyrel et à son fils Guillaume, au parlementaire Geoffroy de la Chapelle et à Thierry, comte de Forbach. John Howard Fox, Robert de Blois, son ceuvre didactique et narrative. 
$\mathrm{XII}^{\mathrm{e}}$ et XIII ${ }^{\mathrm{e}}$ siècles: la situation a changée $\mathrm{e}^{414}$. La provenance des manuscrits tardifs, y compris ceux d'Escanor ${ }^{415}$ et Melyador, de même que les possesseurs de copies arthuriennes versifiées à la fin du Moyen Âge prouvent bien que le genre est lu presque exclusivement en France à cette période. Peut-être faut-il l'expliquer par la difficulté de lecture que posent ces textes versifiés, à plus forte raison pour un public dont le français n'est pas la langue première, et plus probablement rompu à la lecture d'un français parlé ou prosifié. Quelle que soit l'aire géographique considérée, le roman arthurien en vers est supplanté par son homologue en prose.

La présence d'annotations postérieures à la rédaction signale aussi l'existence d'un lectorat plus tardiff ${ }^{416}$, même s'il ne ressent pas le besoin de produire de nouvelles copies. Il ne faut pas négliger non plus l'importance de la transmission des ouvres par d'autres biais que la reproduction manuscrite: un manuscrit d'Escanor est encore prêté à la reine Isabel de Bavière en 1390, comme le mentionne l'inventaire de la bibliothèque de Charles $\mathrm{VI}^{417}$. Enfin, bien sûr, il faut considérer la diffusion orale des textes en vers qui s'y prêtent particulièrement bien, sur le modèle de la lecture à voix haute qu'effectue Froissart pour Gaston Fébus ${ }^{418}$. Le genre

414 Beate Schmolke-Haßelmann, Der arthurische Versroman.

415 Le manuscrit d'Escanor provient vraisemblablement d'un atelier parisien et peut être daté de la fin du XIII ${ }^{\mathrm{e}}$ siècle. Il faut également tenir compte du fait que Girart d'Amiens travaille pour la cour de France, pour Blanche de France, fille de saint Louis, et Charles de Valois, respectivement pour son Meliacin et son Charlemagne. Voir à ce sujet Richard Trachsler, «Escanor von Girart d'Amiens im Spannungsfeld von Vers und Prosa», art. cit. et Antoinette Saly, "Écrivains mystificateurs: le cas d'Adenet le roi et de Girart d'Amiens", art. cit.

416 On trouve plusieurs annotations dans le ms. Chantilly, Condé 472, par exemple au folio 8v. Certaines inscriptions sont grattées. Le manuscrit BnF fr. 12557 comporte également plusieurs annotations d'une écriture $\mathrm{du} \mathrm{Xv}^{\mathrm{e}}$ siècle. Voir l'édition de Melyador de Nathalie Bragantini-Maillard, éd. cit., p. 33-34.

417 L'inventaire mentionne la date du 29 août 1390. Voir Richard Trachsler, Escanor, éd. cit., p. 20-21.

418 Et ce même si la fin du Moyen Âge voit aussi la généralisation de la lecture visuelle, par opposition à une réception auditive. Le prologue de la mise en prose de Floriant et Florete invoque ainsi les «lisants": "Or pry je aux lisans qu'en ce qu'ilz trouveront a amender en cestuy traictié que benignement ilz amendent ou corrigent." (Le Chevalier qui la nef maine, p. 81) Tania Van Hemelryck explique d'ailleurs que le geste de mise en prose vise à la fois la simplification des ouvres et l'adaptation aux nouvelles conditions de lecture: "On sait combien, pour les mises en prose, la dynamique de la lecture est importante puisque l'existence 
n'est donc pas totalement oublié à cette période, même si le XIV siècle est indéniablement celui du déclin. Son importance se manifeste également en creux dans les phénomènes d' "enromancement " ${ }^{419}$ de la société à la fin du Moyen Âge: les ordres de chevalerie, de même que les fêtes que sont les tournois et les pas d'armes, témoignent d'une influence générale du roman arthurien tel qu'il est présenté par les textes en vers sur la culture courtoise $^{420}$.

\section{... DU VERS À LA PROSE: SURVIVANCE DU GENRE}

Le genre du roman arthurien en vers survit également à la fin du Moyen Âge par la pratique de la mise en prose. Cet usage est à la fois un moyen pour le genre d'être lu par un public pour qui le vers est devenu inaccessible, et il est aussi le signe de l'extinction du vers narratif: le contenu a toujours des chances de plaire, mais plus la forme qui le transmet. Le chapitre suivant se penchera sur l'ensemble des mises en prose arthuriennes produites à partir du XIV siècle, dans le but d'explorer le devenir du genre arthurien en vers en cette fin du Moyen Âge. Si les

même de ces textes a été motivée, d'une part par la nécessité de rendre intelligibles et accessibles des textes qui étaient devenus incompréhensibles pour le lecteur moyen $\mathrm{du} \mathrm{Xv}^{\mathrm{e}}$ siècle, et d'autre part, par les changements des pratiques de lecture, dues aux mutations des usages livresques.» ("Le livre mis en prose à la cour de Bourgogne. Réflexions pour une approche codicologique d'un phénomène littéraire", in Mettre en prose aux XIVe-XVI siècles, dir. Maria Colombo-Timelli et al., Turnhout, Brepols, 2010, p. 252). Sur les mutations de la réception de la littérature au Moyen Âge et les mutations qui touchent les $\mathrm{XIV}^{\mathrm{e}}$ et $\mathrm{XV}^{\mathrm{e}}$ siècles, voir Florence Bouchet, Le Discours sur la lecture en France aux XIV et XV siècles.

419 Nous utilisons ce terme, à la suite de Michel Pastoureau, "L'“enromancement” du nom. Étude sur la diffusion des noms de héros arthuriens à la fin du Moyen Âge", in Couleurs, images, symboles. Études d'histoire et d'anthropologie, Paris, Le Léopard d'or, 1989, p. 111-124, au sens de transposition de l'idéal romanesque dans les comportements réels. Le mot «enromancer» existe au Moyen Âge, mais désigne le fait de traduire en langue vernaculaire.

420 Sur les pas d'armes comme témoins de réception, voir l'article de Michel Stanesco, "Sous le masque de Lancelot: du comportement romanesque au Moyen Âge», in Actes du XIV Congrès International Arthurien, Rennes, 16-21 août 1984, Rennes, PUR, 1984, t. II, p. 569-583, Michelle Szkilnik, "Que lisaient les chevaliers du $\mathrm{Xv}^{\mathrm{e}}$ siècle? Le témoignage du Pas du Perron Fée», Le Moyen Français, 2010, 68, p. 103-114, et Christine Ferlampin-Acher "À la mode de Bretagne», art. cit. 
romans arthuriens peuvent être mis en prose jusqu'au $\mathrm{XVI}^{\mathrm{e}}$ siècle, c'est que des exemplaires en vers circulent encore à cette période pour servir de base à la transposition en prose, et qu'un intérêt est encore manifesté à cette époque. Cette pratique est toutefois marginale pour le genre qui nous occupe, par rapport à l'ampleur du phénomène contemporain qui concerne la chanson de geste ${ }^{421}$. Il faut donc plutôt y voir une tentative de pérennisation du genre par la transposition dans une forme plus au goût du jour, qui a néanmoins suscité peu d'engouement au vu du peu de textes transposés en prose. On peut considérer au même titre l'entreprise qui préside au Conte du Papegau: cette œuvre rédigée en prose ressemble au niveau de son contenu et de sa structure à un roman arthurien en vers. Le caractère exceptionnel d'une telle démarche donnera une autre portée à notre étude de l'extinction du genre: s'agit-il de l'extinction d'une forme ou d'un type de récit?

\section{Les mises en prose arthuriennes}

Les mises en prose signalent que c'est avant tout une forme qui s'éteint, puisqu'un effort est fourni pour actualiser une source en vers. L'intérêt se concentre sur le contenu des narrations: la démarche est bien celle de rendre les anciens textes accessibles à un public pour qui la syntaxe du vers et l'ancien français sont devenus opaques. Le recours à la prose répond dans ce contexte à des enjeux différents de ceux qui animent les premiers romanciers prosateurs: au début du XIII ${ }^{\mathrm{e}}$ siècle, on développe une nouvelle poétique plus conforme à de nouvelles potentialités narratives. Plus tard, la prose étant érigée en medium principal de la narration, le projet est plutôt celui de traduire les œuvres en vers en vue de les simplifier. Comme l'explique Claude Roussel, la mise en prose a pour but de

rendre palpable, en prétendant la combler, la distance qui sépare l'œuvre source de son nouveau public. Il s'agit en effet de moderniser

421 Voir François Suard, "Les mises en prose épiques et romanesques: les enjeux littéraires", in Mettre en prose aux XIV -XVI siècles, dir. Maria Colombo-Timelli et al., Turnhout, Brepols, 2010, p. 33-52, et Claude Thiry, "Les mises en prose épiques", in Cinquante ans d'études épiques. Actes du colloque anniversaire de la Société Rencesvals (Liège, 19-20 août 2005), dir. Nadine Henrard, Genève, Droz, 2008, p. 353-364. On consultera aussi le Nouveau Répertoire des mises en prose dirigé par Maria Colombo-Timelli et al., pour comparer la proportion de textes épiques et romanesques mis en prose. 
la langue devenue peu intelligible, perçue comme corrompue, et d'opter pour le «bon vulgaire françois» selon la formule de Wauquelin (La Manekine) ou du dérimeur de Mabrien, de "translater» telle «memorable histoire, de la dicte ancienne rime et obscur langaige, en prose et langaige françois cler et entendible ${ }^{422}$.

L'idée de traduction est prégnante dans les mises en prose ${ }^{423}$, ce qui implique que la part de modernisation de la langue est importante. La mise en prose du Conte du Graal au Xvi ${ }^{\mathrm{e}}$ siècle démontre par certains aspects les difficultés de lecture que pose un texte ancien comme celui de Chrétien de Troyes à un lecteur renaissant: Jean Frappier ${ }^{424}$ a montré la confusion du prosateur face au terme "noif», la neige, qu'il interprète comme «noix», lors de l'épisode des trois gouttes de sang sur la neige. Cet exemple démontre à quel point la langue est une difficulté pour aborder ces textes à la fin du Moyen Âge. Cette difficulté est d'ailleurs reconnue par l'auteur de la réécriture lui-même:

Et parce que le langaige dudict Mennessier ne de son predecesseur n'est en usaige en nostre vulgaire françoys, mais fort non acoustumé et estrange, je $[\ldots]$ ay bien voulu m'employer a traduire et mectre de rithme en prose familiere les faictz et vie dudict vertueux chevallier Perceval ${ }^{425}$.

422 Claude Roussel, "Mise en prose ou mise en roman?», art. cit., p. 340.

423 Voir Dorothea Kullmann, "Le métadiscours sur la récriture dans les prologues épiques", in Réécritures. Regards nouveaux sur la reprise et le remaniement de textes, dans la littérature française et au-delà, du Moyen Âge à la Renaissance, dir. Dorothea Kullmann et Schaun Lalonde, Toronto, Pontifical Institute of Mediaeval Studies, 2015, p. 126-131, Sabine Lehman, "Les prologues dans les textes en prose (XIV $\mathrm{XV}^{\mathrm{e}}$ siècles): modèles et déviances", in Mettre en prose aux XIV'-XVI siècles, dir. Maria Colombo-Timelli et al., Turnhout, Brepols, 2010, p. 177-186, Florence Bouchet, Le discours sur la lecture en France aux XIV et XV siècles, p. 98-115, et Annie Combes, "L'athanor de la prose (l'atelier de Jean de Wavrin)», in Plus agreable a lire en prose que en rime? Vers et prose en moyen français, dir. Michelle Szkilnik et Catherine Croizy-Naquet, Le Moyen Français, vol. 76-77, 2015, Turnhout, Brepols, 2016, p. 39-64.

424 Jean Frappier, "Sur le Perceval en prose de 1530», in Jean Frappier, Autour du Graal, Genève, Droz, 1977, p. 211-224.

425 Cité d'après le Nouveau répertoire des mises en prose, Maria Colombo Timelli, "Perceval le Gallois», p. 683. 
Les velléités traductives sont consubsantielles à la transposition en prose.

Transposition formelle et traduction vont de pair avec le transfert d'un contexte culturel à un autre; chaque forme offre au public un rapport différent à l'œuvre. Les prologues des mises en prose revendiquent alors le choix de la prose comme conforme aux goûts des contemporains; ils valorisent aussi, et c'est lié, l'intelligibilité de la prose par rapport au vers. L'Histoire de Charles Martel synthétise ces ambitions:

M'efforcheray d'ensieuvir la matiere, laquelle j'ay prinse et translattee d'anchiennes histoires rymees jadiz et reduitte en ceste prose, pour ce que au jourd'huy les grans princes et autres seigneurs appetent plus la prose que la ryme, pour le langaige quy est plus entier et n'est mie tant constraint ${ }^{426}$.

L'auteur assume l'entreprise de traduction («translattee») d'un conte ancien, car rimé; l'ancienneté est liée à la forme versifiée et celle-ci apparaît comme un archaïsme ${ }^{427}$. Il affirme la préférence accordée par la noblesse à la prose, dont l'écriture est moins contrainte et correspond mieux au récit que le vers, trop astreint à la rhétorique. Même conception chez Evrart de Conty, qui écrit :

aussi come pour declairier aucunes choses que la rime contient qui semblent estre obscures et estranges de prime face. Et pour ce fut il fait et ordené en prose pour ce que prose est plus clere a entendre que n'est rime ${ }^{428}$.

426 Histoire de Charles Martel, vol. I, Bruxelle, KBR, ms. 6, f. 9v-10r. Cité d'après Anne Schoysman, "Voix d'auteur, voix de copiste dans la mise en prose: le cas de David Aubert ", in Rencontres du vers et de la prose, p. 49-60.

427 L'association entre ancienneté/vers et modernité/prose est courante: Maria Colombo-Timelli en donne plusieurs exemples dans «Les prologues des mises en prose, lieu d'une réflexion sur les formes entre $\mathrm{Xv}^{\mathrm{e}}$ et $\mathrm{XVI}^{\mathrm{e}}$ siècle», in Rencontres $d u$ vers et de la prose, p. 43-44. Michelle Szkilnik discute de la traduction qu'offrent les mises en prose dans "Hoster la contraincte de retoricque": notes de lecture sur le "Nouveau Répertoire de mises en prose (XIV ${ }^{\mathrm{e}} \mathrm{XVI} \mathrm{e}^{\mathrm{e}}$ siècle)" ", Studi Francesi, 179, 2016, p. 273-277.

428 Le Livre des eschez amoureux moralisés, éd. Françoise Guichard-Tesson et Bruno Roy, Montréal, Ceres («Bibliothèque du Moyen Français»), 1993, p. 2. Voir l'article d'Amandine Mussou, "A l'instance d'un autre, fait en rime nagueres. Fiction et commentaire chez Evrart de Conty, des Eschés amoureux en vers au 
L'obscurité du vers ressentie par les auteurs et le public semble résulter du style que nous évoquions aux pages 325-339, si l'on en croit Jean Wauquelin, qui met la Belle Hélène de Constantinople en prose "pour retrenchier et sincoper les prolongacions et motz inutiles qui souvent sont mis et boutez en telles rimes ${ }^{429}$. Le mètre et la rime nécessitent parfois des aménagements, l'insertion de chevilles qui favorisent le respect de la métrique et dont peut se passer la prose pour alléger le récit ${ }^{430}$. La mise en prose et la façon qu'ont les auteurs de la présenter montrent bien à quel point cette forme touche des mécanismes cognitifs qui en facilitent la réception.

Seules sept œuvres arthuriennes en vers font l'objet d'une transposition en prose ${ }^{431}$. Sans vouloir proposer une étude individuelle et détaillée de chacune, nous souhaitons considérer le phénomène dans son ensemble, dégager les tendances majeures des mises en prose arthuriennes et les enjeux d'une telle pratique pour l'histoire du genre. Les mises en prose arthuriennes sont en effet assez rares pour témoigner du désintérêt progressif qui touche le roman arthurien en vers à la fin du Moyen Âge. Des sept mises en prose qui nous sont parvenues, quatre sont issues de romans de Chrétien de Troyes: Erec et Enide, Cligès, Le Chevalier de la Charrette, Le Conte du graal ${ }^{432}$. On pourrait croire pour Le Chevalier au lion

Livre des eschez amoureux moralisés en prose», Le Moyen Français, 76-77, 2015, p. 159-184. Il faut relever que la source en vers est probablement du fait d'Evart de Conty lui-même.

429 Jehan Wauquelin, La belle Hélène de Constantinople: mise en prose d'une chanson de geste, éd. Marie-Claude de Crécy, Genève, Droz, 2002, p. 14.

430 Sur les topoi des prologues de mises en prose, voir Maria Colombo-Timelli, «Les prologues des mises en prose, lieu d'une réflexion sur les formes entre $\mathrm{Xv}^{\mathrm{e}}$ et $\mathrm{XVI}^{\mathrm{e}}$ siècle", in Rencontres du vers et de la prose, p. 35-48.

431 Voir notre annexe C.2 pour la liste complète.

432 Le Conte de la Charrette est en fait un dérimage interpolé aux cycles en prose. Annie Combes, «Le dérimage du Chevalier de la Charrette: les vers de Chrétien comme ressource de la prose», art. cit., Annie Combes, «Fiction de vérité et vérité de la fiction dans les mises en prose du Chevalier de la Charretten, in Fictions de vérité dans les réécritures européennes des romans de Chrétien de Troyes, Paris, Garnier, 2012, p. 33-57, David F. Hult, «Pour ou contre une esthétique de la compilation? La mise en prose du Chevalier de la Charrette dans deux manuscrits du Lancelot-Graal de la fin du XIV siècle", in Le romanesque aux XIV et XV siècles, dir. Danielle Bohler, Bordeaux, Presses de l'Université de Bordeaux, 2009, p. 57-67. La version gamma qu'étudie Annie Combes est très fidèle au texte de 
que le manuscrit d'Aberystwyth, National Library 444D en est une mise en prose, car il commence par le titre "Cest livres est le livre de monseigneur Yvain et parole de maint buen chevaliers». Ce manuscrit juxtapose en réalité sept épisodes arthuriens tirés à la fois de sources en prose (le Lancelot en prose, le Tristan en prose, la Queste) et de sources en vers. Le Chevalier au lion est le modèle du premier épisode, qui narre le combat entre un lion et un dragon auquel assiste Yvain. Le deuxième texte en vers mobilisé est le Chevalier aux deux épées; le passage choisi se concentre sur Gauvain, qui doit combattre Burian (Brian), celui-ci étant amoureux d'une ennemie de Gauvain. Ce manuscrit fournit un témoignage intéressant de la réception de textes arthuriens au XIV $v^{\mathrm{e}}$ siècle: comme nous l'avions noté pour le manuscrit de Turin, L. IV. 33, c'est une lecture épisodique et fragmentée qui est proposée. Une série de courtes scènes arthuriennes se suivent sans lien entre elles, bien qu'une voix conteuse s'emploie à les souder par des formules d'entrelacement, en indiquant qu'un sujet est délaissé pour se concentrer sur le suivant. La logique de composition est celle de l'accumulation; l'auteur du manuscrit compte sur la bonne connaissance qu'a son lectorat du monde arthurien pour extraire de leurs

Chrétien de Troyes, si bien qu'elle permet de démontrer la proximité de la versification du Champenois avec l'écriture en prose; le passage du vers à la prose se satisfait de peu de transformations. Erec et Enide fait l'objet d'une mise en prose bourguignonne: L'Histoire d'Erec en prose. Roman du XV siècle, éd. Maria ColomboTimelli, Genève, Droz, 2000. La mise en prose de Cligès, Le livre de Alixandre empereur de Constantinoble et de Cligès son filz, est elle aussi bourguignonne et date d'avant 1455. Voir l'édition de Maria Colombo Timelli, Genève, Droz, 2004, et ses articles, notamment «Le Cligés en prose (1455), ou l'actualisation d'un ancien conte en vers", L'Analisi Linguistica e Letteraria, 8/1-2, 2000, p. 329-342. Le Conte du graal n'est mis en prose que plus tard par l'imprimerie du XVI ${ }^{\mathrm{e}}$ siècle. Voir Pierre Servet, "D'un Perceval l'autre. La mise en prose du Conte du Graal (1530)", in L'ouvre de Chrétien de Troyes dans la littérature française - Réminiscences, résurgences et réércritures, Lyon, CEDIC, 1997, p. 197-201, Maria Colombo-Timelli, "La Tresplaisante et recreative hystoire du trespreulx et vaillant chevallier Perceval le Galloys... (1530), mise en prose tardive du "cycle" du Graal», Le Moyen Âge, 64, 2009, p. 13-54, Jane H. M. Taylor, "Imperious Seductions": Giglan and Perceval", art. cit. Maria Colombo-Timelli a publié une édition de ce texte: Perceval le Galloys en prose (Paris, 1530), Paris, Garnier, 2017. Voir surtout les bibliographies relatives à ces textes dans Maria Colombo-Timelli et al., Nouveau répertoire des mises en prose. 
contextes des épisodes remarquables ${ }^{433}$. Le geste de mise en prose est anecdotique et ne concerne que deux épisodes de l'ensemble.

Le succès de l'œuvre du Champenois suffit à expliquer la volonté de la mettre en prose ${ }^{434}$. En dehors de ses textes, seuls Floriant et Florete, le Mantel mautaillé et Le Bel Inconnu ont l'honneur d'être mis en prose ${ }^{435}$. Encore ce dernier est-il entrelacé à l'histoire de Jaufré et à Laurin par l'imprimeur Claude Platin, comme pour créer un roman conforme à l'esthétique de l'entrelacement propre à la prose: au lieu de simplement choisir un texte en vers pour le mettre en prose, le remanieur combine deux œuvres qu'il décompose et recompose ${ }^{436}$. L'écriture en prose ne se satisfait pas d'une histoire simple; il en résulte une sorte de petite somme, L'hystoire de Giglan, dont les deux trames narratives ont de la peine à se conjoindre véritablement ${ }^{437}$. Le choix du Bel Inconnu pour cette entreprise paraît cohérent, si l'on considère le nombre de traductions ou réécritures étrangères dont ce roman a fait l'objet: on compte ainsi une version en allemand, Wigalois (1210-1220), une en anglais, Lybeaus Desconus (deuxième quart du XIV siècle) et une en italien, Carduino (deuxième moitié du XIV ${ }^{\mathrm{e}}$ siècle ${ }^{438}$. La composition de Renaut de Beaujeu a donc

433 Voir Norris J. Lacy, "The Enigma of the Prose Yvain", in Arthurian Studies in honor of P. J. C. Field, dir. Bonnie Wheeler, New York, Brewer, 2004, p. 65-71.

434 Michelle Szkilnik note toutefois que le nom de Chrétien de Troyes n'apparaît pas dans les mises en prose de ses œuvres: le passage à la prose est favorisé par l'effacement du nom des auteurs. "Hoster la contraincte de retoricque": notes de lecture sur le "Nouveau Répertoire de mises en prose (XIV -XVI ${ }^{\mathrm{e}}$ siècle)" ", art. cit.

435 Voir notre annexe C.2. Voir aussi Noémie Chardonnens, «Les rapports entre vers et prose", art. cit. et Maria Colombo-Timelli, Barbara Ferrari, Anne Schoysman et François Suard (dir.), Nouveau répertoire des mises en prose (XIV $V^{e} X V I^{e}$ siècle), Paris, Garnier, 2014.

436 Laurence Harf-Lancner explique la fusion de Jaufré et du Bel Inconnu dans Giglan par la parenté de ces textes sur le plan des thèmes, des personnages et des structures. "Le Bel Inconnu et sa mise en prose», art. cit.

437 D'où la scission qu'opère entre les deux intrigues le comte de Tressan dans la Bibliothèque universelle des romans en 1777: selon lui, les deux histoires n'ont rien à faire ensemble. Voir l'article de Laurence Harf-Lancner, "Le Bel Inconnu et sa mise en prose", art. cit.

438 Madeleine Tyssens, "Chrétien de Troyes et les versions étrangères du Bel inconnu», Bulletin bibliographique de la Société internationale arthurienne, 18, 1966, p. 174-175, Jacques Monfrin, "Le roman de Belris, Le bel inconnu, Carduino", 
été considérablement diffusée ${ }^{439}$, ce qui explique qu'elle survive dans l'imprimerie aux côtés des classiques de Chrétien de Troyes.

Ladaptation en prose des textes en vers, "transmuer de rime en prose ${ }^{440}$ comme le disent volontiers les prosateurs, va souvent de pair avec une tentative d'élucidation des obscurités originelles, l'introduction «de la continuité, de la cohérence et de la causalité dans une intrigue qui ne s'en souciait pas systématiquement ${ }^{441}$. Cette ambition est d'ailleurs cohérente avec l'esprit des premiers textes en prose du XIII ${ }^{\mathrm{e}}$ siècle, qui ont le souci d'expliciter chaque point du déroulement de l'histoire - nous y reviendrons. Dans L'hystoire de Giglan, la suppression du mystère propre à l'écriture en vers touche le rapport au lignage, la filiation du héros avec Gauvain et son nom: ceux-ci sont donnés d'emblée dans la prose, en annonce de ce qui va suivre, alors que le roman de Renaut de Beaujeu maintenait le mystère sur l'identité de Guinglain jusqu'à l'épreuve qualifiante. Dans la même perspective, les deux héroïnes du roman en vers, la Pucelle aux Blanches Mains et Blonde Esmérée, désignées par des périphrases, sont rebaptisées Helayne et Emerie dans la version en prose, dans un souci de rationalisation. Plus qu'une question de forme, la mise en prose est donc aussi la transposition d'une esthétique à une autre, comme l'exprime Laurence Harf-Lancner : «Le roman en vers joue constamment d'un mystère dévoilé peu à peu et incomplètement; la prose place le lecteur dans l'attente d'un triomphe annoncé. ${ }^{442}$ Les titres-résumés des

art. cit., et Albert Mennung, Der "Bel inconnu» des Renaut de Beaujeu in seinem Verhältnis zum "Lybeaus Disconus", "Carduino" und "Wigalois». Eine litterarhistorische Studie, Halle, Kandler, 1890, qui résume en détails le contenu des quatre œuvres.

439 Et ce malgré le manuscrit unique dans lequel le roman est transmis en France. Il faut supposer que le Bel Inconnu circulait oralement ou qu'un certain nombre de versions nous sont perdues aujourd'hui. Voir Roger Middleton, "The Manuscripts», art. cit., p. 24-25. L'intervention du personnage du Bel Inconnu dans la deuxième Continuation, tantôt sous ce surnom, tantôt sous le nom de Guinglain, en est une preuve de plus. Le Bel Inconnu y est bien le même personnage que celui de Renaut de Beaujeu: il est bien le fils de Gauvain.

440 La formulation apparaît dans plusieurs prologues, par exemple celui de l'Erec en prose ou du Livre de Alixandre et de Cliges son filz. Voir Sabine Lehman, «Les prologues dans les textes en prose", art. cit.

441 Annie Combes, "Le dérimage du Chevalier de la Charrette», art. cit., p. 174.

442 Laurence Harf-Lancner, "Le Bel Inconnu et sa mise en prose», art. cit., p. 84. 
chapitres $^{443}$ qui caractérisent le roman de chevalerie aux $\mathrm{XV}^{\mathrm{e}}$ et $\mathrm{XVI}^{\mathrm{e}}$ siècles jouent de cette attente: le lecteur connaît le contenu de la suite et en guette la réalisation.

Ce mouvement est similaire dans les mises en prose de Chrétien de Troyes. Dans l'Erec bourguignon en prose (vers 1468), le narrateur intervient pour affirmer explicitement qu'Erec part en aventures pour éprouver l'amour et la loyauté d'Enide suite aux reproches qu'elle lui a faits: «et devés savoir que la joie ne fu pas petitte ad ceste nouvelle acointance, et que tout ce que Erec avoit fait n'estoit que pour esprouver Enide ${ }^{444}$. Les aventures sont réaménagées, moyennant quelques changements, pour les présenter comme autant de tests destinés à Enide et non comme des preuves de la bravoure d'Erec. Le héros contrefait par exemple volontairement le mort au château du comte de Limor. On supprime alors la complexité des rapports humains: l'errance doit rétablir l'autorité d'Erec sur ses sujets et sur sa femme, mais l'on occulte la réciprocité des torts des époux. La faute incombe explicitement à Enide, qu'il s'agit de tester ${ }^{445}$.

Dans la mise en prose de la Charrette, intégrée au Lancelot en prose, ce phénomène se traduit par exemple lorsque la Dame du Lac envoie Lancelot à Camaalot le jour de l'Ascension, si bien qu'il croise la reine qu’emmène Keu pour répondre au défi de Méléagant, fournissant ainsi une justification à sa présence qui manque dans le texte en vers. Même chose pour l'épisode de la demoiselle au carrefour dont traite Annie Combes $^{446}$ : Chrétien de Troyes pose comme une donnée acquise le

443 Maria Colombo Timelli, "Syntaxe et technique narrative: titres et attaques de chapitre dans l'Erec bourguignon", Fifteenth Century Studies, 24, 1998, p. 208-230. Les titres de l'Erec en prose démontrent également un parti-pris quant à l'interprétation de l'histoire en occultant la plupart du temps Enide. Sur les titres au Xvi ${ }^{\mathrm{e}}$ siècle, voir aussi Alexandre Lorian, Tendances stylistiques dans la prose narrative française du XVI siècle, p. 275-278.

444 L'Histoire d'Erec en prose, éd. cit. de Maria Colombo Timelli, p. 200. Voir Martha Wallen, "Significant Variations in the Burgundian Prose Version of Erec et Enide», Medium Aevum, LI, 1982, p. 187-196, et Maria Colombo-Timelli, "L'Erec en prose, ou les traces de l'implication du lecteur dans un roman du $\mathrm{xv}^{\mathrm{e}}$ siècle», Le goût du lecteur à la fin du Moyen Âge, éd. Danielle Bohler, Cahiers du Léopard d'Or, 11, 2006, p. 121.

445 Martha Wallen, «Significant Variations in the Burgundian Prose Version of Erec et Enide», art. cit.

446 Annie Combes, "Le dérimage du Chevalier de la Charrette», art. cit., p. 179. La chercheuse s'attarde en particulier sur la version gamma de ce dérimage: dans cette copie, qui se montre très proche du texte en vers en particulier du point 
savoir de la demoiselle sur la direction prise par la reine et les chemins qui y mènent, le Pont de l'Épée ou le Pont sous l'Eau. La mise en prose insère un scénario qui justifie sa présence au carrefour aussi bien que ses connaissances: elle est envoyée par la dame qui a accueilli Lancelot et Gauvain la veille. Les mêmes tendances se retrouvent dans la mise en prose du Conte du graal (1530): le Graal perd quelque peu de son mystère en étant nommé d'emblée le «saint graal». Mais c'est surtout le personnage de Perceval qui est touché, comme le montre Pierre Servet ${ }^{447}$ : le héros n'est jamais un nice dans la mise en prose et se montre preux dès le début, si bien que le remaniement éclipse les implications de la progression du personnage, liée au graal, que développait Chrétien de Troyes. L'un des enjeux de la prose est donc aussi d'élucider les passages obscurs des romans en vers en ajoutant des liens de causalité ${ }^{448}$.

$\mathrm{Au} \mathrm{XVI}{ }^{\mathrm{e}}$ siècle, cette tendance se vérifie toujours dans la mise en prose du Mantel mautaille ${ }^{449}$ : le prosateur ajoute des noms qui rendent claire

de vue des rythmes et de la conservation de certains octosyllabes tels quels, la proximité avec le roman de Chrétien de Troyes engendre aussi la conservation du mystère propre au texte en vers. On a alors affaire à une "prose intermédiaire" (p. 185), ou plutôt un "dévers", comme Annie Combes préférera le caractériser dans un article ultérieur, désignant de cette manière la fusion du vers et de la prose par la conservation du lexique, de certains mots à la rime et du rythme de l'original en vers. Elle établit ainsi une distinction entre dérimage, où l'adaptation s'emploie à ne supprimer que les rimes, dérythmage, où c'est le rythme seul qui est rompu, et dévers, où rime et rythme sont tous les deux conservés. Dérimage, dérythmage et dévers sont cependant des concepts applicables à des portions de texte et non forcément à des textes entiers. "L'emprise du vers dans les mises en prose romanesques ( $\mathrm{XIII}^{\mathrm{e}}-\mathrm{XV}^{\mathrm{e}}$ siècles)», art. cit.

447 Pierre Servet, "D'un Perceval l'autre. La mise en prose du Conte du Graal (1530) », art. cit.

448 Walter Haug a montré que cette tendance à éclaircir le propos des œuvres de Chrétien de Troyes se trouve aussi dans les romans en vers. Les modalités en sont toutefois différentes: il ne s'agit pas de donner une cause et une explication logique à chaque événement, mais de proposer des héros sans crise. Le protagoniste n'a pas, comme Yvain, Erec et Perceval, une faute à expier, mais doit simplement affronter le mal qui sévit en dehors de la cour. Walter Haug cite Wigalois, Daniel der Stricker et Diu Crône; Biaudouz pourrait être, pour le domaine français, un autre exemple. "Über die Schwierigkeiten des Erzählens in "nachklassischer Zeit" ", in Positionen des Romans im späten Mittelalter, dir. Walter Haug et Burghart Wachinger, Tübingen, Max Niemeyer, 1991, p. 338-365.

449 Voir l'article de Stefania Marzano, "Une mise en prose inédite du XVI ${ }^{\mathrm{e}}$ siècle. Le Compte du mantheau maltaillé (Paris, BnF, fr. 2153)", in Pour un nouveau 
l'identité des personnages, nommés seulement par leur fonction dans la version en vers. La reine est Guenièvre, la fée, Morgane. Ce parti-pris démontre bien l'importance de l'onomastique dans le genre: même à cette époque, l'univers de fiction trouve sa cohérence dans la permanence de ses personnages. On ne peut alors imaginer que la reine anonyme du conte soit quelqu'un d'autre que Guenièvre. L'introduction de ces personnages permet aussi le rappel d'une trame devenue constitutive de l'univers de fiction: celle de l'amour de Morgane pour Lancelot. C'est la fée qui envoie le manteau à Arthur pour rendre publique la tromperie des femmes de la cour, en particulier de Guenièvre, dont elle est jalouse :

Pour abreger, il feit presens et a grans et a petitz tant que chescun se disposa de mener joye plus que en feste ou ils eussent jamais esté. Ce que l'on eust fait si ne fust Mourguein la fee qui par son enchantement deslibera de troubler la Reine et toute sa belle compaignye pour ce que elle estoit ennuieuse de sa grant beaulté et jalouse de messire Lancelot $\mathrm{du}$ Lac que elle aimoit mais il ne la vouloit aimer, qui fut cause la faire conspirer sur la Reine et toutes ses dames. (BnF fr. 2153, f. 4)

La publicité de la tromperie de Guenièvre renvoie bien sûr à l'épisode de la salle aux images dans la Mort Artu, lorsque Morgane ouvre les yeux d'Arthur sur l'adultère de la reine. La version en prose du Mantel mautaillé propose une causalité et motive l'envoi du manteau ${ }^{450}$. Elle s'inspire d'un épisode du Tristan en prose, lors duquel Lamorat détourne le messager qui porte le cor - et non le manteau cette fois - à la cour d'Arthur, pour l'envoyer à celle de Marc et révéler l'infidélité d'Iseut. Ce messager est envoyé par Morgane, qui souhaite bien sûr dénoncer Guenièvre ${ }^{451}$. La mise en prose du Mantel mautaillé tire donc parti à la fois de l'original en vers et de données qu'ont élaborées les textes en prose.

répertoire des mises en prose. Roman, chanson de geste, autres genres, dir. Maria Colombo Timelli, Barbara Ferrari et Anne Schoysman, Paris, Garnier, 2014, p. 212-227.

450 Sergio Cappello, "Décalages contre-textuels: la mise en prose du Manteau mal taillé au XVI ${ }^{\mathrm{e}}$ siècle», in Etudes romanes. I. Hommages offerts à Florica Dimitrescu et Alexandru Niculescu, éd. Dan Octavian Cepraga et al., Bucarest, Editura Universitatii din Bucuresti, 2013, t. 1, p. 135-144.

451 Lucy Allen Paton, Studies in the Fairy Mythology of Arthurian Romance, New York, Burt Franklin, 1903, p. 104-123. 
La transposition en prose est bien différente dans le cas du Chevalier qui la nef maine, adaptation de Floriant et Florete. Il s'agit du seul texte de notre corpus à être mis en prose, d'où le fait que nous le traitions plus en détail que les autres mises en prose arthuriennes. Cette version, qui date de la fin du $\mathrm{Xv}^{\mathrm{e}}$ siècle, est conservée dans deux manuscrits sur papier contemporains (BnF fr. 1492 et $\mathrm{BnF}$ fr. $1493^{452}$ ). Elle a mieux survécu au passage du temps que sa source en vers, qui n'est conservée, rappelons-le, que dans un manuscrit. L'auteur de la mise en prose traduit bien un sentiment partagé par ses contemporains lorsqu'il affirme dans un prologue original par rapport au modèle versifié que "pour ce que la matiere du present livret m'est plus agreable a lire en prose que en rime, me vueil pener de le transporter de rime en prose» (Le Chevalier qui la nef maine, p. 81$)^{453}$.

Le choix ${ }^{454}$ de Floriant et Florete pour la mise en prose s'explique peutêtre par les accointances de ce texte avec l'idéologie des mises en prose. Barbara Wahlen l'a montré, les quelques transformations qu'opère la prose sur la source en vers

ne sont pas pour autant synonyme de resémantisation, comme ce fut le cas pour les mises en prose d'Erec et Enide ou de Cligès. Cette resémantisation était inutile, tant Floriant et Florete s'intègre, dès le départ, parfaitement dans les canons littéraires des mises en prose ${ }^{455}$.

452 Claude Lévy les décrit dans son édition, Le Chevalier qui la nef maine, p. 45-51. Ils semblent tous deux provenir de Tours.

453 Voir l'article de Barbara Wahlen pour une analyse complète de ce prologue, " "Transporter de rime en prose". L'exemple de Floriant et Florete», in Plus agreable a lire en prose que en rime? Vers et prose en moyen français, dir. Michelle Szkilnik et Catherine Croizy-Naquet, Le Moyen Français, vol. 76-77, 2015, Turnhout, Brepols, 2016, p. 213-230. Voir aussi Richard Trachsler, "Floriant et Florete», in Nouveau répertoire des mises en prose (XIV-XVI siècle), art. cit., pour la présentation de cette mise en prose.

454 Michel Zink explique certains choix de textes pour les mises en prose par leur ambiguïté thématique ou idéologique: il donne l'exemple de Berinus et de la Belle Hélène de Constantinople, qui tous deux trouvent mal leur place au sein des genres des $\mathrm{XII}^{\mathrm{e}}$ et $\mathrm{XIII}^{\mathrm{e}}$ siècles. Le mélange des genres dans ces textes aurait déconcerté les lecteurs de la première version en vers, tandis qu’à la fin du Moyen Âge, l'uniformité de la prose englobait tous les genres dans un syncrétisme qui plaisait au public. "Le Roman», in GRLMA, VIII, p. 204-205.

455 Barbara Wahlen, " "Transporter de rime en prose". L'exemple de Floriant et Florete», art. cit., p. 229. 
L'œuvre en vers a en effet pour ambition de réécrire certains passages fameux de la littérature arthurienne en vers. L'épisode de recreantise d'Erec et Enide est réinvesti en ce sens par l'auteur de Floriant et Florete pour en supprimer les conflits psychologiques, notamment la potentielle culpabilité de la femme ${ }^{456}$. C'est une vieille femme, et non Florete, qui dénonce l'oubli des armes de Floriant:

«Je voi la mon seignor le roi

Qui est le mieudre chevalier

Du mont et mius fait a prisier,

Et l'a la roïne si pris

Et si torné a son devis

Qu' ne fet mes chevalerie.» (Floriant et Florete, v. 6618-6623)

Ces paroles sont perçues par Floriant, qui décide de partir en quête pour recouvrer son autorité, mais il ne force à aucun moment Florete à l'accompagner, contrairement à Erec: c'est la jeune femme qui insiste pour se joindre à lui. Nous n'avons donc plus affaire à une crise conjugale, ainsi que l'explique Keith Busby:

This "crisis», if such it be, has none of the complexity and existential implications of its source in Erec et Enide, and the events generated in its wake have little of the enigmatic significance of the couple's aventures in Chrétien's text ${ }^{457}$.

Les deux époux sont d'ailleurs en harmonie et se démontrent des signes d'affection lors du départ, évacuant ainsi toute trace d'un conflit: «Florete et Floriant s'en vait, / l'un l'autre grant joie fait» (FF, v. 68196820). L'entente est telle que Floriant consulte souvent Florete sur le parti à adopter («Dame, fet il, quel la ferons?», v. 7035) et la remercie chaleureusement lorsqu'elle a la bonne idée de suggérer l'incognito, pour que les adversaires potentiels soient plus enclins à se battre contre

456 Cet épisode est une réécriture explicite d'Erec et Enide. L'allusion à la beauté du harnachement et du cheval de Florete ne manque pas de rappeler la description de la monture d'Enide (v. 6794-6808). Voir Keith Busby, "The Intertextual Coordinates of Floriant et Florete», French Forum, 20:3, 1995, p. 261-277.

457 Keith Busby, "The intertextual coordinates of Floriant et Florete», art. cit. p. 271. On lira également cet article pour un relevé des allusions aux romans de Chrétien de Troyes. 
lui ("Quant Floriant ot la parole, / Floriant la baise et acole», v. 68616862). Les surnoms que se donnent Floriant et Florete (le Beau Sauvage et la Plaisante de l'Île) sont eux-mêmes exempts de toute forme de problématisation: ils sont destinés à garantir l'anonymat des personnages et ne sauraient s'inscrire dans la même configuration symbolique que les surnoms adoptés par Yvain ou Lancelot ${ }^{458}$. Floriant loue même explicitement sa femme pour sa loyauté:
«Certes, fet il, or voi je bien
Qu'el monde n'a si loial rien
Com preude fame, bien le sai,
Bien en sui venus a l'essai.
Fox est cil qui d'eles mesdist!» (Floriant et Florete, v. 7001-7005)

Floriant ne teste pas sa femme au cours de l'errance, contrairement à l'Erec de la version en prose; sa loyauté se manifeste spontanément et aucun conflit n'est esquissé entre les époux. Enfin, le retrait des protagonistes à Mongibel auprès de Morgane, sorte d'équivalent d'Avalon, résout définitivement la question de la recreantise et de l'équilibre entre arma et amor: le couple échappe pour toujours aux regards du monde terrestre et l'image qui demeure de Floriant est celle d'un excellent chevalier. Cette esthétique ne saurait pourtant être attribuée à l'ensemble des romans tardifs: nous aurons l'occasion de le montrer au chapitre suivant, il s'agit de textes qui privilégient au contraire la complexité psychologique et le refus de polariser le monde entre Bien et Mal. Floriant et Florete détonne parmi ce corpus, lui dont l'auteur vise plutôt à proposer un monde clairement polarisé et sans ambiguïté. Il apparait pour cette raison comme un candidat idéal à la mise en prose $\mathrm{du} \mathrm{Xv}$ siècle, pratique portée sur l'explicite.

Le prosateur trouve donc en Floriant et Florete un roman dont la causalité est déjà claire: nul besoin de lever les mystères, comme le demandaient les œuvres de Chrétien de Troyes. Le travail de transposition se réduit alors à la suppression des vers et à l'adaptation de la syntaxe au cadre de la prose. De manière générale, le passage à la prose s'accompagne d'une modernisation de la langue ${ }^{459}$, de la transformation

\footnotetext{
458 Ibid., p. 272.

459 Voir le bilan que dresse Claude Lévy de l'étude de la langue dans son édition, p. 78.
} 
de l'ordre des mots, d'une reformulation et de changements de certaines expressions. La transposition fluidifie parfois le fil discursif en liant certaines phrases que rompait l'écriture paratactique du vers, comme dans l'exemple suivant:

Lors a main a l'espee mis,

Car molt estoit amanevis.

En la bataille s'est ferus,

Em poi d'eure fu conneüs:

Li plus vaillant voie li font

Et il les depart et desront

Quel part qu'il velt a son plaisir,

Nus ne li puet contretenir.

(Floriant et Florete, v. 4637-4644)
Lors met la main a l'espee et se fiert en la bataille et donne telz coups qu'en peu d'heure qu'il est congneu si lui font les plus vaillans voye, et les despart et esparpille la ou il vieult si n'y a celui qui ose son coup actendre. (Le Chevalier qui la nef maine, p. 154)

Plusieurs propositions sont soudées par des coordonnants «et», «si», dont la proportion est bien supérieure par rapport à la version en vers. Le contenu, tout comme une majeure partie du lexique, est conservé. Les transformations peuvent aussi concerner la suppression d'expressions convenues et de chevilles, comme "se Diex me gart ${ }^{460}$ dans l'exemple suivant:

Mes Gauvains entent autre part

Et Florianz, se Diex me gart.

(Floriant et Florete, v. 4437-4438)
Mais Floriant et Gauvain entendent autre part.

(Le Chevalier qui la nef maine, p. 151)

La prose se débarrasse des tournures inutiles, tout comme elle se soucie de clarifier certaines phrases. Ainsi dans l'exemple suivant:

[Floriant dit qu'il faut rendre publique la trahison de Maragot envers ses parents]

"Quant l'emperere le savra

«Si ne cuide mye que quant l'empereur Jamais ne li vorra aidier.

Et s'il le vouloit denoier en saura la verité qu'il lui vueille plus aider et, se Maragos vouloit la chose

460 Barbara Wahlen traite du sort des interventions narratoriales dans la mise en prose: le prosateur supprime les interventions modalisantes et les passages qui ont trait à l'histoire d'amour du narrateur. Ces transformations vont dans le sens d'un affaiblissement de la subjectivité du narrateur. Voir Barbara Wahlen, " "Transporter de rime en prose”. L'exemple de Floriant et Florete», art. cit., p. 219-221. 
Je sui qui li esproveroie

Et a lui m'en combateroie.»

(Floriant et Florete, v. 4998-5002) nyer, je sui celui qui lui prouveray par mon corps contre le sien.

(Le Chevalier qui la nef maine, p. 160)

L'ambiguïté du référent de «il» au vers 5000 est levée dans la prose: c'est bien de Maragot que l'on parle. Le remanieur transpose aussi «le» en «la chose" pour rendre clair le renvoi à la trahison, et non à l'empereur.

La précision qu'introduit la prose peut aussi concerner le contenu, au moment où Floriant interroge sa mère sur les raisons pour lesquelles elle souhaite entrer en religion par exemple:

«Dame, fet il, nel me celez,

Mes dites moi, se vous avez

Corrous ne maltalent ne ire.

Il n'a home en tot cest empire,

Se vers vous a de riens mesfait

Qui ne soit pendus ou desfait.

(Floriant et Florete, v. 6555-6560)
«Dame, est ce par ire ou par talent que vous voulez rendre religieuse? Dictes moy si on vous a nul mal fait et s'il y a homme en ceste terre qui vous ai mesdit ou mesfait qu'il ne soit incontinant pendu. (Le Chevalier qui la nef maine, p. 182)

La prose rend claire la question que pose Floriant et le lien direct qu'il établit entre la volonté de prendre le voile et une rancœur que la mère pourrait encore nourrir.

Malgré ces quelques adaptations minimes, la mise en prose est très fidèle au texte d'origine; Barbara Wahlen ${ }^{461}$ a démontré qu'elle correspondait majoritairement à du dévers, modalité de mise en prose catégorisée par Annie Combes ${ }^{462}$ comme une transposition fidèle à l'intrigue, au lexique, au rythme et à la rime de la source en vers. Dans Le Chevalier qui la nef maine, le prosateur maintient une grande partie du lexique et reproduit un rythme semblable au vers, qui permet une forme de scansion par la répartition en périodes de sept à dix syllabes. Il maintient également certaines rimes et certains octosyllabes. En voici un court exemple ${ }^{463}$ :

461 Barbara Wahlen, "Transporter de rime en prose". L'exemple de Floriant et Florete", art. cit.

462 Annie Combes, «L'emprise du vers dans les mises en prose romanesques $\left(\mathrm{XIII}^{\mathrm{e}}-\mathrm{XV}^{\mathrm{e}}\right.$ siècles)", art. cit.

463 Dans l'introduction à son édition, Claude Lévy donne une liste conséquente de vers isolés conservés tels quels, ainsi que trois cas de distiques reproduits aussi à l'identique. Voir les pages 31-32. 
Quant l'ot la roïnne escoutee,

Si chiet a la terre pasmee.

Et quant ele fu revenue,

Si s'escrie com esperdue:

(Floriant et Florete, v. 393-396)
Quant la royne entend la damoiselle, si cheut a terre toute pasmee, et quant elle fut revenue, si s'escrie comme toute esperdue et dist: (Le Chevalier qui la nef maine, p. 87)

Les transformations concernent ici uniquement l'ordre des constituants de la phrase, pour le premier vers / la première ligne retranscrits, et l'ajout de quelques particules comme l'adverbe «tout». Le passage à la prose donne bien lieu à une forme intermédiaire, une prose rythmée, rimée ${ }^{464}$ même, malgré l'irrégularité des syllabes qui séparent chaque rime. Cette forme peut se développer à une période où la prose s'est déjà imposée: selon Annie Combes, la pratique d'une écriture qui se définit par le "caractère non réglé des retours rimiques et des récurrences rythmiques" peut émerger après le XIII ${ }^{\mathrm{e}}$ siècle et l'individualisation de la prose par

464 La possibilité d'une prose rimée est envisagée par Jacques Legrand vers 1400, qui préconise dans l'Archiloge Sophie l'usage de rimes à intervalles irréguliers au sein de la prose: «Si doiz sçavoir que ryme aucunesfois se fait en prose et aucunesfois en vers, et quant elle se fait en prose, il ne convient point regarder au nombre de ses sillabes, ne mais il suffit que en la prose soyen aucunes diccions d'une mesme ou de semblable terminaison, et lors langaige est plus bel, et singulierement quant les sentences de la prose se finent es diccions semblablement terminees. Exemple de ce que nous pouvons donner en disant: "Tu es celluy a qui je doy fere plaisir, tu es ma joye, mon cuer et mon desir; en tous cas je te vouldroye servir, et si suys prest, come raison le veult, de toujours toy obeir." Par cest exemple tu peulz apercevoir comment ceste prose est plus belle pour tant que les sentences sont semblablement terminees, c'est assavoir en ir, come tu peulz appercevoir.» (Ernest Langlois, Recueil d'Arts de Seconde Rhétorique, Paris, Imprimerie nationale, 1900, p. 1) Selon Annie Combes («L'emprise du vers dans les mises en prose romanesques (XIII- $\mathrm{XV}^{\mathrm{e}}$ siècles)», art. cit.), ce témoignage illustre une pratique bien différente du dévers et réfère à l'homéotéleute antique. On peut cependant apparenter le concept de prose rimée à celui de dévers: bien que la fréquence de la rime dans le dévers soit loin d'être aussi systématique et se contente en général d'un couplet de rime, il s'agit aussi d'une façon de donner à la prose un rythme qui la rapproche de la scansion. Jean-Claude Mühlethaler s'emploie à étudier l'utilisation du vers dans la prose, destinée à la rythmer et lui donner la couleur du lyrique. "La prose au rythme de l'octosyllabe. Réflexions autour de la "couleur de mesure", de Guillaume de Machaut à Jean Molinet", in Poétiques de l'octosyllabe, dir. Danièle James-Raoul et Françoise Laurent, Paris, Champion, 2018, p. 189-207. 
rapport au vers ${ }^{465}$. À cette époque, la prose est en construction et doit se démarquer du vers en inventant ses propres modalités d'écriture. Elle doit «forger son identité de forme romanesque [...] en opposition avec la forme précédente ${ }^{466}$. Dès le XIV e siècle, la prose peut se réinventer et prendre le parti de rester fidèle à sa source en vers en adaptant aussi ses spécificités rythmiques.

Le Chevalier qui la nef maine n'adopte toutefois pas le régime du dévers tout le long du texte. Certains passages témoignent d'une liberté plus grande, notamment les épisodes épiques, comme l'a montré Barbara Wahlen: la prose ajoute des détails macabres («Lors recommance l'estour moult oultrageux car vous eussiez veu courir le ruisseau de sang comme ung ruisseau d'eaue et si n'eussiez veu que gens mors sur le rivage de la mer et en estoit toute la grieve couverte", p. 130-131), des discours directs ou quelques éléments de description ${ }^{467}$. Dans le passage suivant, le fond reste le même et la prose est fidèle au contenu que véhicule le vers, mais le lexique change du tout au tout:

Mesire Yvains grans cols i donne

A la trenchant espee bonne.

Molt i fiert bien Kaheriés

Et Agravains et Gaherés;

Mordrés i fiert par grant entente,

Molt en ocit, molt en cravente.

Bien i refiert li Lais Hardis,

Autretel refait Brandalis.

Mesire Gauvains s’i aiue

A la trenchant espee nue.

Mes Floriant si les enchace,

Si les ocit, si les dechace,

Si les ocit, si les confont,

Si les desparpeille et deront. (Floriant et Florete, v. 3167-3180)

465 Annie Combes, «L'emprise du vers dans les mises en prose romanesques (XIII ${ }^{\mathrm{e}}-$ $\mathrm{xV}^{\mathrm{e}}$ siècles)», art. cit., p. 138 pour la citation. Selon la critique, on trouve peu de dévers au $\mathrm{Xv}^{\mathrm{e}}$ siècle; Le Chevalier qui la nef maine, daté de la fin du $\mathrm{Xv}^{\mathrm{e}}$ siècle, pourrait en être un exemple.

466 Ibid., p. 139.

467 Voir Barbara Wahlen, "“Transporter de rime en prose”. L'exemple de Floriant et Florete», art. cit. 
Messire Yvain est yssu hors qui fiert moult merveilleux coups de son espee et aussi fait Gaheriez et Agravains et Gaherretz et aussi fait Mordret et Lislés le Hardy ${ }^{468}$ et le roy Brandalis. Si frappent moult merveilleux coups et font de leur prouesse vuyder les rencs devant eulx et n'y a celui qui ne soit espoventé de veoir leurs coups ferir. Mais messire Gauvain et Floriant sont tout devant qui donnent si grans horions qu'il n'y a celui qui ne s'enfuye devant eulx.

(Chevalier qui la nef maine, p. 130)

Les acteurs de ce passage sont conservés; la principale modification concerne l'anaphore épique qui scande les actions de Floriant. La traduction de l'anaphore en une phrase en prose qui restitue le même contenu est fréquente dans ce texte. Même si la prose du Chevalier qui la nef maine se plaît à adopter le rythme du vers, elle renonce à ce type de présentation et "dérythme» les anaphores épiques. Il semble alors que la mise en prose écarte tout passage qui serait trop explicitement marqué par l'esthétique du vers: reproduire une anaphore épique en dévers, en conservant le rythme voire la rime, ce serait affaiblir l'individualité de la prose, assumer une transposition automatique du vers à la prose qui ne se conforme pas à la démarche de l'auteur. Car, si les changements sont souvent minimes, c'est que, comme nous l'avons dit, Floriant et Florete correspond déjà à l'esthétique d'élucidation que favorise la mise en prose.

Le traitement du passage de l'Île aux Pucelles ${ }^{469}$ confirme cette tendance des mises en prose; il s'agit du seul extrait véritablement transformé, au point que cela affecte le déroulement de l'épisode. Le remanieur ne se prive donc pas de modifier sa source comme bon lui semble; sans doute cette aventure et la façon dont elle est amenée sont jugées trop mystérieuses pour correspondre à l'esthétique propre à la prose. Dans la version en vers, Floriant accoste sur une île que gouverne une reine très belle. Celle-ci, dénommée Alemandine, accueille Floriant avec amabilité et luxe. Le lendemain, le héros souhaite repartir, mais il entend un cri mystérieux. Lorsqu'il en demande la nature, la reine répond qu'il s'agit d'une bête effroyable, le Pellican, qui terrorise la contrée et dévore chaque jour une

468 Le prosateur lit mal le nom du Laid Hardi et invente un personnage dénommé Lislet le Hardi. Sur les autres confusions qui concernent les noms arthuriens, voir l'introduction à l'édition citée de Claude Lévy, p. 38-40.

469 Voir Barbara Wahlen, "Transporter de rime en prose". L'exemple de Floriant et Florete», art. cit., p. 227-229 sur ce passage. 
jeune fille en tribut. Floriant, après quelques résistances d'Alemandine qui tente de le dissuader, relève le défi et terrasse le monstre. Il refuse d'épouser en récompense la reine, au motif qu'il ne se mariera pas avant de connaître le nom de son père. Dans la version en prose, l'ordre de présentation est bien différent: Floriant est accueilli par des hommes, des barons, des chevaliers, des écuyers, accompagnés de dames et de demoiselles. Le texte annonce dès le départ l'aventure qui habite ces lieux:

Si estoient les portes de la cité fermees pour doubte d'une beste sauvage qui devouroit et mengeoit les gens quant elle les povoit rancontrer.

(Le Chevalier qui la nef maine, p. 101)

Loin de faire un accueil chaleureux à Floriant, les gens de la cité l'avertissent du danger et l'exhortent à faire demi-tour, sous peine d'être dévoré:

Sire, reboutez vous en vostre nef car il y a une beste sauvaige moult diverse et cruelle laquelle, si elle vous apparçoit, elle vous devourera tout incontinant. (Le Chevalier qui la nef maine, p. 101)

Cette entrée en matière a des conséquences sur l'appréhension de l'épisode: d'abord, ce ne sont plus seulement des jeunes filles qui sont la cible des appétits du Pellican, mais bien tout être humain, indépendamment semble-t-il de son âge et de son sexe. Ensuite, on supprime la nuit d'hospitalité que reçoit Floriant au château et l'insistance sur la beauté et la sensualité des occupantes de l'île, transformées en une société masculine, même si elle est toujours gouvernée par une reine. La séduction que peut opérer un lieu exclusivement occupé par de belles femmes, auxquelles il faut apporter son secours, est écartée dans la version en prose. C'est en même temps le mystère de cet être monstrueux, nourri exclusivement de corps féminins, qui se voit élucidé: le Pellican devient une bête féroce assoiffée de chair humaine, et non plus une créature à laquelle on devrait payer un tribut énigmatique, jamais explicité dans la version en vers.

Enfin, annoncer d'emblée la nature de l'aventure qui attend le chevalier, aussi bien au lecteur qu'au personnage lui-même, supprime l'effet de mystère. À aucun moment, l'île, transformée d'ailleurs en «cité» dans le même esprit, n'est ambiguë. Point de questionnement sur le nom du lieu et de la reine dans la version en prose ( Comment vous estes 
apelee / Et ceste citez est noumee», FF, v. 1345-1346), qui sous-entend l'interrogation sur les raisons de cette présence féminine sur l'île, liée à la mauvaise coutume ${ }^{470}$ qui sévit, c'est-à-dire une situation contraire au bon fonctionnement du monde. La réécriture de ce passage entend bien élucider les zones d'incertitude, par la suppression de la féminisation du lieu et par l'annonce précoce de l'aventure. La fidélité habituelle de cette mise en prose à sa source tient donc plus à ce que celle-ci correspond aux visées des transpositions en prose qu'à la paresse d'un auteur qui se contenterait de rompre servilement la forme du vers.

\section{Le Conte du Papegau entre vers et prose}

Même si Floriant et Florete s'adapte particulièrement bien à la prose par sa réécriture d'Erec et Enide en particulier, qui écarte toute crise psychologique dans le couple, il n'en demeure pas moins que le Chevalier qui la nef maine est passablement différent de textes comme le Lancelot en prose; la mise en prose est loin d'adopter tous les codes d'écriture de la prose et de partager sa vision du monde. Elle maintient par exemple la structure de l'errance aventureuse et l'idée d'initiation, de même que le figement de la cour arthurienne dans une achronie. Il en résulte un texte hybride, écrit en prose, mais choisissant le chronotope du roman arthurien en vers. L'impression qui découle de la lecture du Chevalier qui la nef maine, si on le lit indépendamment de sa source en vers, est semblable à celle que procure le Conte du Papegau. Ce roman, daté de la fin du XIv ou du début $\mathrm{du} \mathrm{Xv}^{\mathrm{e}}$ siècle, est en effet un hapax de la littérature médiévale tardive: composé en prose, il présente plusieurs caractéristiques du roman arthurien en vers. Il s'emploie en effet à raconter l'errance aventureuse du jeune roi Arthur, au début de son règne, «quant il porta coronne premierement» $(\$ 1)$. La narration suit le personnage, qui prend l'anonymat en se faisant appeler «Le Chevalier au Papegau», au fil des aventures rencontrées.

\footnotetext{
${ }^{470} \mathrm{Au}$ sens arthurien du terme. Erich Köhler définit la coutume arthurienne et ses enjeux, "Le rôle de la "coutume" dans les romans de Chrétien de Troyes", Romania, 81/323, 1960, p. 386-397. Voir aussi Beate-Schmolke Haßelmann, Der arthurische Versroman, p. 73-75, Donald Maddox, "Yvain et le sens de la coutume", Romania, 1988, 109, p. 1-17, et Norris J. Lacy, "On Customs in Medieval French Romance», Revue belge de philologie et d'histoire, 83/3, 2005, p. 977-986.
} 
Les accointances du Conte du Papegau avec le roman en vers sont nombreuses; Patricia Victorin et Hélène Charpentier renoncent pourtant à le considérer comme une mise en prose et préfèrent l'hypothèse que l'auteur a imaginé son récit en puisant dans divers textes en vers. L'inspiration est indéniablement versifiée: les éditrices mettent en avant les réécritures de Chrétien de Troyes, du Bel Inconnu et surtout de la réécriture allemande de ce dernier, Wigalois de Wirnt von Grafenberg (1210-1220 $)^{471}$. La conjonction de ces sources pour créer une œuvre originale suffit en effet à expliquer la genèse du Conte $d u$ Papegau, sans devoir imaginer une composition en vers qui ferait déjà ce travail.

La critique a montré à quel point ce texte met en avant la parole conteuse, voire le psittacisme, à travers le symbole du perroquet dont la mission est de raconter les exploits d'Arthur, tout comme la littérature arthurienne répète inlassablement ceux des chevaliers arthuriens ${ }^{472}$. La redondance se manifeste dès l'ouverture du roman; une demoiselle vient annoncer l'aventure le jour de Pentecôte, alors qu'Arthur est couronné pour la première fois, l'auteur réactivant un déroulement éculé de la tradition. La diffusion de cette tradition s'exprime dans la scène finale du roman, qui illustre la séduction qu'opèrent les aventures arthuriennes et en même temps le primat du récit sur l'aventure elle-même:

Et entredeux qu'on seoit a table, si chanta le papegau si doulcement toutes les aventures qui estoient avenues au roy Artus, si que tous ceulx qui la furent s'esmerveillerent plus que de rien qu'ilz oÿssent oncques, et en laisserent le boire et le mangier. (\$82)

Le conte vient remplacer la nourriture, alimenter l'auditoire. Une telle mise en scène de la parole arthurienne, par le rôle central que joue le papegau au cours du récit, à la fois chanteur, conteur omniscient et

471 Voir les pages 12 à 20 de leur introduction, éd. cit.

472 Danielle Régnier-Bohler, "Arthur en enfances (Le Chevalier au Papegau)», art. cit., l'introduction à l'édition d'Hélène Charpentier et Patricia Victorin, et Lori Walters, "Parody and the Parrot: Lancelot References in th Chevalier au Papegau", in Translatio studii. Essays by his Students in Honor of Karl D. Uitti for his sixty-fifth Birthday, Amsterdam, Rodopi, 2000, p. 331-344. Sur le perroquet, voir Bruce Thomas Boehrer, Parrot Culture. Our 2500-Year-Long Fascination with the World's Most Talkative Bird, Philadelphia, University of Pennsylvania Press, 2004, en particulier les pages 44 à 47, qui parlent également de Willeris, le perroquet de Rigomer. 
dispensateur de divertissement, se combine à une esthétique de la réécriture et de l'écho intertextuel.

L'œuvre de Chrétien de Troyes est effectivement convoquée à plusieurs reprises: le chevalier errant doit se battre pour obtenir un oiseau, prix d'un concours de beauté, qui n'est plus un épervier, comme dans Erec, mais un perroquet. L'oiseau est enlevé des mains de Lion sans Merci, pendant négatif $\mathrm{du}$ Chevalier au Lion, qui opprime son peuple; une fois vaincu, l'adversaire doit se rendre en charrette à la cour. Ces éléments sont toutefois vidés du sens qu'ils avaient chez le Champenois: l'oiseau est un prix que remporte le chevalier et n'est plus le symbole d'un amour à naître, tandis que la charrette se réduit à un simple moyen de transport à «qui ne puet chevaucher» (\$7). Ces échos sont circonscrits lors de la première aventure d'Arthur; après ce rapide panorama de la littérature arthurienne, le héros embrasse l'incognito en adoptant le surnom de "Chevalier au Papegau», en référence au perroquet qu'il vient de gagner, à défaut d'endosser des implications symboliquement plus fortes, comme c'est le cas pour ses prédécesseurs littéraires, le Chevalier de la Charrette et le Chevalier au lion. Le surnom n'exprime en effet pas un changement ontologique qui signifierait l'éveil à l'empathie du chevalier ou l'humilité consentie d'un amoureux: la référence au papegau illustre plutôt la redondance des aventures arthuriennes et de cet univers, dont Arthur est justement le garant, et le primat du divertissement sur les enjeux plus profonds que sont l'amour et la morale ${ }^{473}$.

Un autre passage, celui de la Dame aux Cheveux Blonds, réécrit explicitement le tournoi de Noauz du Chevalier de la Charrette: cette dame demande à Arthur de combattre au pire pour lui prouver son amour et obtenir ses faveurs. Si le roi obéit, c'est pour mieux se venger le soir venu, en se comportant aussi mal dans la chambre à coucher que sur le champ de bataille. Plus de soumission volontaire de la part de l'amant; la scène est réécrite sur le mode du fabliau et encourage le rire par le décalage entre la version de Chrétien de Troyes et celle du $\mathrm{Xv}^{\mathrm{e}}$ siècle ${ }^{474}$.

473 L'introduction de Patricia Victorin analyse en détail ces réécritures et leurs enjeux. Voir p. 20-30.

474 Jane Taylor, "The Parrot, the Knight and the Decline of Chivalry", in Conjunctures. Medieval Studies in Honor of Douglas Kelly, dir. Keith Busby et Norris J. Lacy, Amsterdam, Rodopi, 1994, p. 529-44, et "The Fourteenth Century: Context, Text and Intertext", art. cit., p. 322-323. 
Les échos à Wigalois ${ }^{475}$, qui lui-même s'appuie sur le Bel Inconnu, sont encore plus nombreux, non seulement dans les motifs exploités, mais également dans la succession des aventures. Le prix du concours de beauté est un perroquet, un cheval et un nain dans le roman allemand; dans le Conte du Papegau, il s'agit principalement d'un perroquet, transporté par un cheval et dont s'occupe un nain. Lauteur français donne donc une place privilégiée au papegau qu'il n'avait pas chez Wirnt von Grafenberg. Arthur conserve d'ailleurs l'oiseau pour lui-même, quand Wigalois le laisse à la messagère venue chercher de l'aide à la cour d'Arthur au début du texte.

L'épisode de Fleur de Mont dans le Papegau, qui contient l'aventure du tournoi fantôme, fait quant à lui l'objet d'une véritable réécriture: les deux héros de chacun des textes sont guidés par un animal fabuleux, métamorphose du roi dont il faut secourir la fille et la femme, puis assistent au tournoi fantôme, sauvent un couple d'un dragon, sont trouvés évanouis par des pêcheurs, sont attaqués par une femme sauvage et doivent affronter plusieurs périls, dont une roue tranchante, pour passer un pont périlleux. Dans le récit $\mathrm{du} \mathrm{Xv}^{\mathrm{e}}$ siècle, le tournoi fantôme perd toutefois le sens religieux qu'il avait dans le roman allemand; celui de représenter la pénitence des âmes du Purgatoire. Wigalois est en effet l'élu de Dieu, dont le destin est de combattre les forces du mal, le diable, allié du Sarrasin Roaz qui tourmente la jeune fille qu'il est venu secourir. Il convertit même les sujets de Roaz à la foi chrétienne.

Rien de tout cela dans le Conte du Papegau, où le tournoi fantôme n'est qu'une aventure mystérieuse parmi d'autres dont Arthur est tout au plus l'élu, sans que cet exploit ait une quelconque conséquence eschatologique ni un quelconque lien avec l'histoire du roi Bel Nain dont il doit sauver la fille et la femme. L'arrêt de la roue du pont est d'ailleurs éloquent sur les ambitions de chacun des textes: la roue tranchante est mise hors d'état de nuire par un miracle dans Wigalois, tandis que le Chevalier au Papegau la stoppe en brisant son mécanisme. Les aventures de Fleur de Mont et de Korntin - du nom de la contrée - se distinguent aussi par leur place dans l'errance du héros: dans Wigalois, la messagère du début du texte, Nereja, vient chercher de l'aide pour Laris, la jeune fille déshéritée, renommée Fleur de Mont dans le Papegau. Il s'agit de l'aventure principale du roman,

475 Wirnt von Grafenberg, Wigalois. Text, Übersetzung, Stellenkommentar, éd. Sabine Seelbach et Ulrich Seelbach, Berlin, De Gruyter, 2014. 
celle qui qualifiera le héros et lui offrira l'amour et la reconnaissance chevaleresque. C'est aussi à ce moment-là que Wigalois apprend ses origines et le nom de son père, Gauvain. Dans le roman français en revanche, la messagère est envoyée par la Dame aux Cheveux Blonds pour trouver un chevalier à même de terrasser le Chevalier-Poisson. L'aventure de Fleur de Mont et du roi Bel Nain se présente dans un deuxième temps, sur un plan équivalent à celle du Chevalier-Poisson ou de l'épisode de la licorne maternelle ${ }^{476}$. Les aventures se succèdent sans gradation ni véritable relation entre elles.

Le Conte du papegau ressemble à une balade plaisante à travers des souvenirs littéraires ${ }^{477}$, tirés de romans en vers, allemands et français: Arthur erre à travers les récits de son propre monde. L'originalité de ce texte réside alors dans le choix de son héros: c'est au tour d'Arthur de jouer au chevalier errant et d'occuper le rôle principal. Nous reviendrons sur les enjeux qu'implique le départ en aventures du roi Arthur pour la stabilité du monde; notons pour l'instant que le Conte du papegau est le seul à se concentrer uniquement sur un Arthur aventureux, quand l'errance du roi n'est dans les autres textes que l'un des points de focale parmi d'autres. En quelque sorte, ce roman réactive le principe diégétique du roman arthurien en vers en prenant audacieusement pour héros le seul personnage de la cour à ne pas être parti en errance. Ce parcours reste toutefois sans conséquence, contrairement à ce qu'il se passe pour les héros de Chrétien de Troyes et de ses successeurs: Arthur ne conquiert ni terre ni femme et ne subit pas de changement ontologique. Il retrouve même sa cour comme il l'a laissée; l'absence du souverain pendant un an n'a mené à aucune dissension politique, comme cela se produisait dans la Mort Artu. L'absence d'un garant à la cour n'empêche pas le jeune héros d'envoyer les chevaliers vaincus à sa propre cour; là encore,

476 Voir l'introduction à l'édition citée de Patricia Victorin et Hélène Charpentier, p. 12-20, qui détaille les points de convergence entre le Papegau et Wigalois, Christoph Cormeau, "Wigalois» und "Diu Crône»: Zwei Kapitel zur Gattungsgeschichte des nachklassischen Aventureromans, Münich, Beck, 1976, et l'introduction à la traduction de Danielle Buschinger, qui traite du passage du tournoi fantôme comme d'une épreuve de purification, Wirt von Grafenberg, Wigalois, le Chevalier à la roue, Paris, Champion ("Traduction des classiques du Moyen Âge»), 2004, p. 18-25.

477 Danielle Régnier-Bohler développe cette idée dans "Arthur en enfances (Le Chevalier au Papegau)", art. cit. 
la démarche est vidée de son sens car Arthur n'est pas là pour sanctionner la prouesse ni recevoir l'hommage manifesté par cette reddition.

C'est qu'il n'a rien à prouver: l'Arthur du Papegau est certes jeune et fraîchement couronné, l'auteur entendant s'intéresser aux premières années de son règne, mais il traîne avec lui le poids de la tradition littéraire. L'auteur associe, sans crainte de la contradiction, l'image traditionnelle d'Arthur, forgée par plus de deux siècles d'écriture arthurienne, et l'inscription de la diégèse dans le passé de la Table de Ronde: il réussit le coup de force d'inscrire son ouvre à la fois dans la jeunesse du monde arthurien (temporalité de la diégèse) et dans la tradition finissante de l'écriture arthurienne (temporalité réelle de l'histoire littéraire). Cette interférence temporelle est assumée lorsque le nain de l'île inconnue, dans le dernier épisode du roman, raconte au jeune Arthur que son seigneur devait se rendre à la cour du roi Arthur, il y a de cela soixante ans ( $\$ 75$ $76)^{478}$. Le choix de ce personnage comme héros prend tout son sens: les incohérences démontrent l'importance du rôle d'Arthur dans le genre, rôle centralisateur et statique sur lequel nous aurons à revenir, garant d'une temporalité cyclique et toujours renouvelée. Le Conte du Papegau met en scène un roi Arthur autant concept que personnage, figure tutélaire sans âge et jeune chevalier errant.

L'inscription de la diégèse en amont du règne implique que le devenir du monde arthurien est déjà construit; l'auteur ne peut que proposer une errance parenthétique, en prenant le parti de ne rien modifier de ce que le lecteur connait déjà, si bien que "Arthur's court is abstracted from the "historical" process ${ }^{479}$. D'où l'absence de sens des aventures, qui

478 À la fin de cet épisode, Arthur abandonne son surnom de "Chevalier au papegau» et redevient le roi civilisateur que la tradition connaît en intégrant le nain, le géant et la licorne à sa société. Voir à ce sujet notre article, "De l'encyclopédie au Conte du Papegau: la licorne entre vérité et fiction", in Mondes animaliers au Moyen Âge et à la Renaissance, Amiens, Presses du Centre d'Études Médiévales de Picardie ("Médiévales», 62), 2016, p. 458-470. Voir aussi Elisabeth Gaucher, "Le Chevalier au Papegau: "Enfances" ou déclin de la littérature arthurienne?", in Enfances arthuriennes. Actes du $2^{e}$ colloque arthurien de Rennes, 6-7 mars 2003, dir. Denis Hüe et Christine Ferlampin-Acher, Orléans, Paradigme, 2006, p. 255-266.

479 Jane H. M. Taylor, "The Fourteenth Century: Context, Text and Intertext», art. cit., p. 272. 
s'accumulent sans mener à un but commun ${ }^{480}$. La brièveté du prologue traduit elle-même cette vacuité:

Cil qui se delite a oÿr les aventures et proesses de chevaleries entende et oye les premieres aventures qui avindrent au bon roy Artus quant il porta coronne premierement, qui comencent en telle maniere. $(\$ 1)$

Le récit des aventures d'Arthur semble gratuit et l'auteur ne thématise pas son importance pour la compréhension du monde arthurien en devenir ${ }^{481}$. Le Conte du papegau engage un point de vue surplombant sur la littérature arthurienne et en propose une synthèse par les pérégrinations de son personnage principal, qui montreraient que l'aventure arthurienne est avant tout matière à récit, fonction qu'assume le papegau.

Plus qu'un parcours initiatique, c'est un voyage touristique qu'effectue Arthur: il déambule dans son propre univers de fiction, sa propre littérature, et en rapporte des curiosités - une licorne ${ }^{482}$, un géant, un papegau-, comme pour souligner la dimension ludique du genre qui a façonné son mythe. Le primat du divertissement sur la lecture symbolique, morale ou eschatologique s'insinue partout: dans le choix du papegau comme oiseau emblématique - au détriment de l'épervier courtois ou du rossignol de la lyrique -, dans les réécritures parfois comiques, dans la juxtaposition de petites aventures plaisantes. Le Conte du papegau réactive bien tous les

480 Patricia Victorin et Hélène Charpentier parlent de "poétique de la vignette», éd. cit., p. 20. Elles mettent cette esthétique de la fragmentation en lien avec l'essor de la nouvelle à la même époque (p. 39-40). Voir aussi Danielle RégnierBohler, "Arthur en enfances", art. cit., Norris J. Lacy, "Convention and Innovation in Le Chevalier du Papegau", in Studies in Honor of Hans-Erich Keller. Medieval French and Occitan Literature and Romance Linguistics, dir. Rupert T. Pickens, Kalamazoo, Western Michigan University, 1993, p. 237-246, et Jane H. M. Taylor, "The Fourteenth Century: Context, Text and Intertext», art. cit., p. 322-324.

481 Voir Anne Berthelot, "Arthur, ou le Chevalier du Papegault: décadence d'une fonction, décadence d'un genre», art. cit., p. 20.

482 Voir notre article, "De l'encyclopédie au Conte du Papegau: la licorne entre vérité et fiction", art. cit., et Lidia Amor, "Entre las "maravillas de Bretaña” y el saber "enciclopédico": aspectos de los maravilloso en el Conte du Papegau", in $V$ Jornadas de Estudios Clásicos y Medievales, 5 al 7 de octubre de 2011, La Plata. Juventud y vejez en la Antigüedad y el Medioevo: Diálogo entre culturas: de lo antiguo a lo contemporáneo, en ligne: http://www.memoria.fahce.unlp.edu.ar/ trab_eventos/ev.1214/ev.1214.pdf 
critères du genre du roman arthurien en vers: la temporalité circulaire, qui se traduit dans le statisme de la cour, inchangée malgré l'errance d'Arthur; l'adoption de la structure de l'errance, qui se concentre sur un seul chevalier cheminant d'aventures en aventures; la brièveté et la clôture de l'aventure racontée, bien loin des longs développements propres à la prose; l'idéologie, détachée de toute idée de fatalité, de destinée, mais qui exalte au contraire le comique, la narration plaisante, le jeu intertextuel. Bien qu'il se compose dans la forme prose, le Conte du papegau ne doit rien aux romans arthuriens en prose, contrairement aux romans tardifs qui constituent notre corpus; c'est bien aux romans en vers qu'il emprunte le chronotope.

La gêne que la critique éprouve par rapport à ce roman tardif ${ }^{483}$, que seule la forme rattache aux romans en prose, illustre bien la distinction qu'il est légitime d'opérer entre ces deux types de productions, différences dont la nature est générique. Le Conte du papegau apparaît dès lors comme un hapax, une "tentative sans lendemain pour renouveler [le genre en décadence] ${ }^{484}$. Ce que fait en effet l'auteur anonyme, c'est mobiliser le genre du roman arthurien en vers en le composant en prose, pour susciter l'intérêt des contemporains qui, nous l'avons dit, goûtent plus la prose que le vers. La démarche n'est pas si éloignée de celle de la mise en prose: dans les deux cas, il s'agit d'accommoder formellement le genre aux préférences du public, de transposer un canevas narratif dans une autre forme que celle qui le formalise habituellement. Cette tentative de faire perdurer le genre est un échec: on ne compte qu'un manuscrit du Conte du papegau (BnF fr. 2154) et l'entreprise n'a pas connu d'imitateurs.

L'étude conjointe des rares mises en prose arthuriennes et du Conte $d u$ Papegau comme deux modalités de pérennisation l'a montré: si la forme versifiée a largement contribué à faire tomber le roman arthurien en vers dans l'oubli, il faut admettre que sa conjonction à un type d'aventures et à une idéologie spécifiques précipite la fin du genre. L'extinction du roman arthurien en vers est donc imputable à la fois à sa forme et au

483 "L'ennui, c'est que tout ça ne fait pas un roman arthurien. De façon faussement paradoxale, le choix d'Arthur comme héros de l'aventure entérine le fait que le texte ne correspond plus aux normes (d'ailleurs assez souples) d'un "genre" préexistant qui serait le roman arthurien - et encore moins le roman arthurien en prose.» Anne Berthelot, "Arthur, ou le Chevalier du Papegault: décadence d'une fonction, décadence d'un genre», art. cit., p. 23-24.

Ibid., p. 18. 
type de récit choisi. Les romans arthuriens tardifs font en effet partie des derniers romans en vers et témoignent de l'extinction du vers narratif dans la littérature française. Bien que le genre du dit travaille au XIv siècle un vers que l'on pourrait appeler mi-narratif, mi-lyrique, il faut admettre que cette forme s'éteint progressivement; du moins cesse-t-on complètement de l'employer dans le genre romanesque après les œuvres dont nous avons traité plus haut. Tout comme la prose infléchit la définition même de poésie avec l'avènement du poème en prose, l'application du vers dans le roman contraint l'appréhension du genre. Nous l'avons vu, le résultat de cette conjonction est différent de ce qu'entraîne la prose dans le roman arthurien, malgré le partage d'un même univers de fiction; la forme contraint le chronotope et le style. En cette période de mutations qu'est la fin du XIII et à plus forte raison le XIv siècle, l'emploi du vers dans le roman appelle au lyrique, en vertu d'une spécialisation des formes déjà bien amorcée. Inévitablement, la définition du roman arthurien en vers s'en voit transformée. 
$\frac{\tilde{U}}{\frac{1}{J}}$

음

들

(1)

五

ชับ

듬

히

듬

षृ

ฮิ

브

는 


\section{TRAJECTOIRE DU ROMAN TARDIF}

Choisir le vers pour écrire un roman arthurien est programmatique; cela annonce au lecteur qu'est racontée une tranche de vie isolée sans conséquence pour le monde arthurien dans son ensemble. La matière à traiter n'est dès lors pas la même que celle de la prose et le lecteur est supposé l'admettre. Néanmoins, en connaisseur des cycles en prose, il ne peut totalement effacer de sa mémoire ce qu'il sait du devenir des personnages et de l'univers lorsqu'il ouvre un nouveau roman arthurien en vers. Le défi des romans en vers tardifs est bien de jouer de cette double tradition, de respecter le chronotope du vers tout en tenant compte des nouvelles voies ouvertes par la prose, en termes de destin des personnages et en termes de poétique. Nous aborderons dans ce chapitre la trajectoire que le roman tardif suit, lorsqu'il infléchit le genre dans lequel il s'inscrit. Cette trajectoire, nourrie des traditions en vers et en prose, concerne la modulation des personnages, les figures tutélaires étant soumises à la variation jusqu'à trahir les codes habituels du genre; elle concerne aussi la structure de l'errance, enrichie de nouvelles perspectives; enfin, elle explore des types de narration différents, puisés dans la littérature des $\mathrm{XII}^{\mathrm{e}}$ et $\mathrm{XIII}^{\mathrm{e}}$ siècles dont $\mathrm{s}^{\prime}$ inspirent les auteurs. À partir de ces modulations, c'est une véritable esthétique de la tardivité qui s'élabore, commune à ces textes et inhérente à la fin d'un genre, dont il devient possible de transformer en profondeur les composantes.

\section{TRANSFICTIONS TARDIVES}

Contrairement à Blandin de Cornouailles, les romans arthuriens tardifs font figurer le personnel romanesque habituel à l'univers de fiction 
arthurien. Il s'agit donc bien de transfictions. Le travail transfictionnel est particulièrement poussé dans ces textes, dans la mesure où les variations qui touchent les données de l'univers de fiction sont audacieuses, sans pour autant qu'elles entravent l'identification du personnage dont il est question. Les figures tutélaires d'Arthur et de Keu sont en particulier affectées par ce travail de variation, mais c'est aussi la typologie du personnage arthurien qui se voit transformée: le chevalier arthurien est loin d'être irréprochable et se voit concurrencé par plusieurs adversaires, valorisés par leur portrait ou par la proportion de leur intervention dans le récit.

\section{Arthur chef de guerre, Arthur errant}

\section{Dux bellorum ${ }^{1}$}

En premier lieu, le personnage d'Arthur reprend ponctuellement le statut de chef que lui ont donné les chroniques, alors que le roman en vers traditionnel privilégie l'image d'un "roi fainéant»". Arthur peut être statique chez les premiers auteurs de romans arthuriens en vers, car les aventures s'insèrent au cœur des douze années de paix qui suivent la pacification de la Bretagne par Arthur ${ }^{3}$. La paix explique à elle seule le faste de la cour et l'inaction d'Arthur; il s'agit d'une contrainte chronotopique, liée à la temporalité choisie par les romans en vers. Ce rôle de pilier, qui ne se déplace qu'avec une grande suite et représente un point d'ancrage pour tout chevalier errant, nous l'avons vu, donne sa cohérence au monde fictionnel et assure l'équilibre du royaume aussi bien que du roman. Claude Thomasset précise le rôle de l'immobilisme du roi:

1 Nennius, dans l'Historia Britonum, qualifie Arthur de "dux bellorum». Ferdinand Lot, Nennius et l'Historia Brittonum. Étude critique suivie d'une édition des diverses versions de ce texte, Paris, Champion, 1934, chapitre 56, p. 94.

2 Le titre de l'article de Barbara N. Sargent-Baur illustre bien les multiples visages d'Arthur: "Dux bellorum / rex militum / roi fainéant. La transformation d'Arthur au XII ${ }^{\mathrm{e}}$ siècle", Le Moyen Âge, 1984, 3-4, p. 357-373. Elle donne l'exemple du rôle tenu par Arthur au début du Conte du graal; son comportement déçoit totalement les attentes de Perceval.

3 Il s'agit des vers 1057 à 1070 de l'édition d'Emmanuèle Baumgartner et Ian Short, La geste du roi Arthur selon le Roman de Brut de Wace et l Historia Regum Britanniae de Geoffroy de Monmouth, Paris, 10/18 ("Bibliothèque médiévale»), 1993. 
On s'est souvent étonné de la passivité d'Arthur, mais elle est fonctionnelle. Le combat qui établit le pouvoir royal ne peut être accompli qu'une fois par le héros fondateur. La fonction royale se caractérise donc par l'inaction, l'impuissance et l'attente. Le roi est contraint de déléguer au héros la mission de renouveler l'acte fondamental ${ }^{4}$.

Cela explique l'importance dévolue à l'attente de l'aventure à la cour, au retardement du repas lorsque l'aventure ne s'est pas présentée. La cour, et le roi en son centre, est témoin de la perturbation et «le lieu primordial de l'impulsion tout en restant elle-même passive $»^{5}$.

Le statisme du roi encourage la prouesse des chevaliers. Ce n'est pas à lui d'affronter l'aventure; il doit plutôt la susciter, la stimuler. Cette stimulation est engendrée soit par son inaction ${ }^{6}$, soit par son penser, ces moments lors desquels Arthur intériorise un sentiment négatif, pousse un soupir de tristesse. Le penser du roi signale une faille dans l'harmonie de la cour, un manquement, que les chevaliers sont appelés à réparer. Arthur a pour fonction de dynamiser sa cour tout en demeurant en son centre, de réguler les va-et-vient des chevaliers et d'ainsi mettre en marche la fiction romanesque. Une fois l'aventure accomplie, c'est à lui qu'il revient de consacrer les exploits, ainsi que l'explique Emmanuèle Baumgartner :

Provoquer l'aventure, en attiser le désir au cour des chevaliers, en assurer la relance (c'est la fonction du motif du penser du roi) puis, lorsqu'elle est achevée, en prendre acte et, éventuellement, la mettre en forme, telle est, me semble-t-il, la fonction essentiellement «scripturaire» dévolue par Chrétien au roi Arthur?

L'émulation autour de la renommée est un autre moyen de relance: Arthur est garant de la prouesse et tient à jour «le grand catalogue de la

4 Claude Thomasset, «Du Pont de l'épée au pouvoir royal», La Figure du roi, Bien dire et bien aprandre, 18/2, 2000, p. 176. Voir aussi Marie-Luce Chênerie, Le Chevalier errant, p. 88.

5 Dominique Boutet, Charlemagne et Arthur ou le roi imaginaire, p. 539. Voir les pages 537 à 543 .

6 Voir à ce sujet Philippe Ménard, Le rire et le sourire dans le roman courtois en France au Moyen Âge, p. 311-314.

7 Emmanuèle Baumgartner, «Rois et chevaliers: du "Lancelot en prose" au "Tristan en prose" ", in Tristan et Yseut, mythe européen et mondial, dir. Danielle Buschinger, Göppingen, Kümmerle Verlag, 1987, p. 20. 
chevalerie arthurienne ${ }^{8}$, il proclame le classement des meilleurs chevaliers, sans cesse renouvelé par l'errance et les rencontres des uns et des autres. Cette fonction est déterminante dans un cadre littéraire qui valorise la remembrance:

Cil ont lor nouveles contees

Tieux con les orent aportees.

Li rois les oï volentiers

Et fist escrire endementiers. (Claris et Laris, v. 11370-11373)

L'aventure est racontée puis couchée sur le papier, sous la tutelle d'Arthur, pour être léguée à la postérité.

Y a-t-il dès lors des conséquences génériques à la mise en scène d'un Arthur guerrier, conquérant, voire chevalier errant? C'est le rôle qu'il prend dans les romans tardifs: dans Escanor, lors de la campagne guerrière qu'il mène contre Escanor pour récupérer Gifflet, retenu captif, le roi reprend son statut de chef de guerre. On le voit élaborer des stratégies, comme l'embuscade:

Mais li rois Artuz ja seü

Avoit que fors venu estoient

Et que mout grant paine metoient

Conment le peüssent sozprendre.

Si fist celeement aprendre

Quel part devoient chevauchier

Et fist de se gent embuschier

En un pas ou passer devoient. (Escanor, v. 18796-18803)

Il envoie des espions ( «Si fist celeement apprendre») et se tient informé des déplacements de l'ennemi («seü avoit»). Il organise les bataillons avec conscience et savoir-faire:

Li rois Artuz endementiers,

Si tost conme il les ot veüz,

Vaut encore estre porveüz

$\mathrm{Li}$ quel ançois assambleroient

Ne li quel au costé ferroient

Por pluz faire as autres damage.

8 Florence Plet-Nicolas, La création du monde. Les noms propres dans le roman de Tristan en prose, Paris, Champion, 2007, p. 243. 
Mout regarda son avantage

Conme cil qui bien l'ot apris. (Escanor, v. 18814-18821)

Les deux derniers vers insistent sur la formation guerrière d'Arthur et sur son acuité à tirer le meilleur profit de ses combattants. Il est véritablement maitre de ses troupes et des mouvements de chacun: autour de lui se forme une collectivité qui lui est soumise, ce qui n'est pas sans rappeler l'esthétique de la chanson de geste, à laquelle le roman emprunte d'ailleurs plusieurs techniques, celle du dénombrement des bataillons ${ }^{9}$ notamment, liée à l'organisation des troupes par le roi.

En véritable chef de guerre, Arthur s'emploie aussi à haranguer ses hommes pour les remotiver, ce qui rappelle, là encore, les techniques narratives de la chanson de geste ${ }^{10}$ :

Si dist lors mout ireement

A pluiseurs de ses compaignonz:

"Seigneur, dist il, nouz nouz faignonz,

Ce m'est avis, trop laidement,

Car trop nouz tienent longuement

Un poi de gent qui auques sont

Au dos tourner, car le pluz ont

De lour meillors honmes perduz,

Dont li remananz esperduz,

Est si forment et entrepris

Qu'il seront tantost mort ou pris,

S’il vouz plaist, et mis a la voie.

9 Nous reviendrons au chapitre III, "Adoption de "patrons génériques exportables": l'épopée arthurienne», p. 572-595 sur l'esthétique épique des romans tardifs. Signalons pour l'instant l'étude de Madeleine Jeay, Le commerce des mots. L'usage des listes dans la littérature médiévale (XII-XVe siècles), Genève, Droz, 2006, p. 45-53. Voir aussi Jean-Pierre Martin, Les motifs dans la chanson de geste. Définition et utilisation, p. 360, "Revue des troupes». L'énumération des combattants et des bataillons est reconnue comme un motif de la chanson de geste.

10 On peut donner l'exemple de la dernière harangue de Charlemagne à ses vassaux dans la Chanson de Roland, lors de la bataille finale contre Baligant: "Barons franceis, vos estes bons vassals, / Tantes batailles avez faites en camps; / Vëez paien: felun sunt e cuart! Tute lor leis un dener ne lur valt. / S'il unt grant gent, d'iço, seignurs, qui calt? / Ki or ne voelt a mei venir, s'en alt!" " (La Chanson de Roland, éd. Ian Short, Paris, le Livre de Poche («Lettres gothiques»), 1990, v. 3335-3340). 


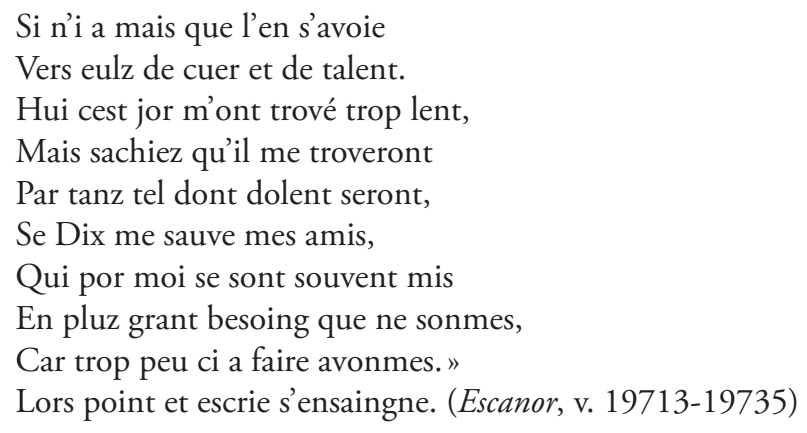

Arthur provoque d'abord ses chevaliers en pointant leur manque de courage ("nouz nouz faignonz») alors même que l'ennemi est affaibli et privé de ses meilleurs combattants. En piquant ainsi la fierté de ses troupes, il suscite un surcroît d'énergie, mais il ne refuse pas pour autant la responsabilité du recul de ses troupes et prend sur lui la pusillanimité de son camp («m'ont trové trop lent», v. 19728). Le pronom personnel $m$ ' établit un rapport de synecdoque entre Arthur et ses armées, le roi étant partie aussi bien que représentant de celles-ci. Ce rapport militaire entre le roi et ses sujets et la longueur de ce développement esquissent un autre portrait de la figure royale, loin du roi fainéant du roman arthurien en vers.

C'est d'autant plus vrai qu'Arthur ne dirige pas seulement les troupes, mais se bat aux côtés de ses guerriers et ne se contente plus de les envoyer à sa place pacifier son royaume ou conquérir de nouvelles terres, comme c'est généralement le cas dans les romans arthuriens en vers (dans Hunbaut par exemple, Gauvain est dépêché pour soumettre le roi des Îles à la domination d'Arthur; dans le Chevalier de la Charrette, Arthur ne se déplace pas lui-même pour secourir Guenièvre; dans Le Conte du Graal, il attend passivement un secours contre le Chevalier Vermeil). Dans Escanor, il accomplit des prouesses contre le roi d'Écosse ( $\mathrm{Li}$ rois Artuz, qui pluz querant / Ne raloit que de lui la jouste, / Ne fist mie samblant que dote / Eüst adont du roi d'Escoce», Escanor, v. 19428-19431). Ces propriétés guerrières d'Arthur sont communes à d'autres romans tardifs: dans Claris et Laris et Floriant et Florete, il organise les bataillons (FF, v. 3697-3698), prend conseil (FF, v. 4394-4400), encourage ses troupes et se bat. Lors de la guerre contre le Danemark, c'est même lui qui achève le conflit en tuant le roi Tallas d'un coup d'épée (Claris et Laris, v. 28851-28858) ${ }^{11}$.

11 Sur le statut d'Arthur dans Claris et Laris, voir Corinne Pierreville, Claris et Laris, somme romanesque, p. 216-265. 
Son ardeur au combat est favorisée dans Escanor par l'ire qu'il ressent, lorsque ses combattants sont en difficulté face à Escanor:

Mais li rois Artuz trambloit d'ire,

Quant ses neveuz vit a meschief

Et li greva, quant derechief

Vit la bataille maintenir

A ses anemis et tenir

Encontre lui si fierement. (Escanor, v. 19708-19712)

L'ire est positive dans l'esthétique épique: même si elle peut faire basculer dans le péché d'orgueil, cette colère aiguillonne assez le héros pour donner un nouveau souffle au combat ${ }^{12}$. Le motif est lié au furor antique $^{13}$, qui traduit l'idée de démesure, d'hybris: le furor pousse le héros au-delà de ses propres limites et décuple sa prouesse. Il habite par exemple Roland, capable de dépasser la mesure humaine grâce à sa fougue, qui l'oppose au raisonnable Olivier: "Rollant est proz et Oliver est sage» (v. $\left.1093^{14}\right)$. Cette colère est bien souvent salvatrice dans l'esthétique épique; elle intervient lorsque le guerrier voit son propre camp en difficulté. Roland est ainsi "maltalentifs" (v. 2056) après la mort d'Olivier, ce qui l'entraîne à tuer vingt Espagnols. L'application du furor au roi Arthur dément la passivité qu'il a traditionnellement dans

12 Bruno Méniel souligne que la colère motive souvent l'intrigue de la chanson de geste au début du récit, de même qu'elle désigne un protagoniste temporaire lors des descriptions de combats. "La colère dans la poésie épique, du Moyen Âge à la fin du xvi ${ }^{\text {e }}$ siècle», $C R M H, 11,2004$, p. 1-11.

13 Le furor relève de la fortitudo, de la bravoure épique. Elle s'allie à la sapientia pour ne pas mener à la démesure. Voir Ernst Robert Curtius, European Literature and the Latin Middle Ages, Londres et Henley, Routledge \& Kegan Paul, 1979, p. 170-178.

14 Sur le furor, voir Janique Perrin, Le furor du héros épique médiéval. Essai de lecture comparative de quatre chansons de geste françaises, Mémoire de licence sous le direction de G. Eckard, Université de Neuchâtel, 1989, Marie-Luce Chênerie, Le Chevalier errant, p. 288-299, et Jean-Marie Fritz, Le discours du fou au Moyen Âge, $X I I^{e}$-XIII siècles, Paris, PUF, 1992. Voir aussi sur le couple Olivier / Roland l'étude de Micheline de Combarieu du Grès, L'idéal humain et l'expérience morale chez les héros des chansons de geste des origines à 1250, Aix-en-Provence, Publications Université de Provence, 1979, p. 296-316. 
le roman arthurien en vers: il remplit pour une fois pleinement sa fonction guerrière ${ }^{15}$.

Bien que l'exercice des armes entre dans les fonctions royales, la guerre étant l'activité principale de la société féodale ${ }^{16}$, cet Arthur dux bellorum est surprenant, lorsque l'on connaît son statisme fonctionnel dans le roman en vers. Le roman tardif renoue avec la tradition historiographique en présentant un roi dans le plein exercice de ses fonctions: Arthur se comporte en chef de guerre dans tout le Brut, en particulier lors du passage de la guerre contre les Saxons. Arthur «Sa gent parti e ordena / e il mesme se arma» (v. 657), puis «le petit pas les fist errer» (v. 685), avant d'haranguer son armée («Vengiez voz amis, voz parenz / Vengiez les granz destruiemenz!», v. 699-700). L'historiographie le montre comme un chef actif, maitre de ses troupes et présent sur le champ de bataille. C'est aussi le rôle qu'il prend dans Cligès, dont nous soulignions l'influence sur certains romans tardifs. Dans la guerre contre Angrès, Arthur rassemble ses armées, prend des décisions militaires, ordonne de tuer tous les prisonniers. Ce roman ne privilégie donc pas son statut de roi statique, marquant là encore un distinction avec ce qu'est devenu le roman arthurien en vers depuis Erec et Enide.

Tout comme Cligès, le roman tardif offre un personnage intermédiaire entre le roi courtois et le roi belliqueux, à l'instar du manuscrit BnF fr. 1450, dans lequel les œuvres de Chrétien de Troyes sont enchâssées dans le Brut: si ce recueil alterne entre l'Arthur conquérant de la chronique et l'Arthur statique voire fainéant du roman (au début du Chevalier au lion par exemple), Escanor, Claris et Laris et Floriant et Florete conjoignent les deux visages du personnage. Les douze ans de paix ne sont plus le prétexte à l'inactivité: Arthur doit prouver qu'il mérite sa réputation et doit montrer

15 Nous nous référons ici au système trifonctionnel théorisé par Georges Dumézil, Jupiter, Mars, Quirinus. 1. Essai sur la conception indo-européenne de la société et sur les origines de Rome, Paris, Gallimard, 1941. Au Moyen Âge, chaque roi réunit en lui les trois fonctions sacrée (application de la justice, exercice du pouvoir avec sagesse), guerrière (direction des armées) et nourricière (distribution de biens et de fiefs, largesse). Voir Jacques Le Goff, «Note sur la société tripartite, idéologie monarchique et renouveau économique dans la Chrétienté du IX ${ }^{\mathrm{e}}$ au XII ${ }^{\mathrm{e}}$ siècle», in Pour un autre Moyen Âge, Paris, Gallimard, 1999, p. 80-90.

16 «La conduite de la guerre était une réalité royale, et toutes les traditions qui pouvaient servir de base à l'image de la royauté convergeaient en ce sens.» Dominique Boutet, Charlemagne et Arthur, p. 102. 
l'exemple en se battant. L'Arthur tardif concilie donc les qualités attendues d'un souverain et se départ quelque peu de son rôle de pilier narratif. La conjonction de ces deux visages est déjà à l'œuvre dans les romans en prose, qui activent les images du roi guerrier et du roi mainteneur: dans le Lancelot en prose ${ }^{17}$, la Suite-Vulgate, Le Livre d'Artus ${ }^{18}$, le Roman de Meliadus ${ }^{19}$ ou le Tristan en prose $^{20}$, Arthur défend son royaume d'attaques variées, celle du roi Marc par exemple; sa vaillance, son autorité et sa stratégie le désignent comme figure idéalisée, même si sa défaite contre le roi cornouaillais dans la mêlée est le signe que sa puissance est étroitement liée aux chevaliers de la Table Ronde, qui l'ont quitté pour quêter le Graal ${ }^{21}$.

La résurgence de la figure du dux bellorum ne date donc pas des romans en vers tardifs: la prouesse royale est déjà problématisée dans les romans en prose. Elle soulève des questions d'ordre politique et donne une image contrastée et problématique du roi: à la fois, celui-ci est le symbole de la chevalerie et se doit d'encourager par son exemple la ferveur guerrière; mais son rôle est aussi de gouverner et d'assurer la cohésion de sa cour, en prenant soin en particulier de ne pas mettre sa personne en danger. L'organisation sociale proposée par Jean de Salisbury en 1159 dans le Policraticus cloisonne les rôles dévolus à chaque membre de la société, appréhendée comme un corps: «Princeps vero capitis in re publica optinet locum $»^{22}$. Le roi occupe la tête du corps social et non les

17 Elspeth Kennedy, "King Arthur in the first part of the Prose Lancelot», in Medieval Miscellany Presented to Eugene Vinaver by Pupils, Colleagues and Friends, éd. Frederick Whitehead, Armel Hugh Diverrès et Franck Edmund Sutcliffe, Manchester, Manchester University Press; New York, Barnes and Noble, 1965, p. 186-195. Voir aussi Dominique Boutet, Charlemagne et Arthur, p. 543-545, 573-574. Dans le Lancelot en prose, le roi est à la fois un chef de guerre exemplaire et un monarque statique, inutile et parfois pathétique lorsqu'il pleure à sa table de n’avoir pas pu protéger Ban.

18 Voir Michelle Szkilnik, "La jeunesse guerrière d'Arthur", in Jeunesse et genèse du royaume arthurien. Les Suites romanesques du Merlin en prose, dir. Nathalie Koble, Orléans, Paradigme, 2007, p. 17-32.

19 Barbara Wahlen, L'Écriture à rebours, p. 139-174.

20 Voir le chapitre 2 de Mario Botero García, Les Rois dans le Tristan en prose. (Ré) écritures du personnage arthurien, Paris, Champion, 2011.

21 Ibid., p. 301-305.

22 Jean de Salisbury, Policratici sive De nugis curialium et vestigiis philosophorum libri VIII, éd. Clemens C. J. Webb, Oxford, Clarendon, 1909, tome 1, Livre V, chap. 2. "Le prince occupe la place de la tête dans cette res publica.» Traduit par 
membres: son rôle est d'utiliser ses armées avec sagesse et justice, et donc d'avoir l'expérience de la guerre sans forcément la pratiquer (Livre VI, chapitre 2). Dans la littérature, la fonction de représentant de la res publica l'oblige à demeurer passif, comme c'est le cas chez Chrétien de Troyes, où son immobilisme est aussi narrativement fonctionnel dans la mesure où il se veut le moteur et le réceptacle des aventures. Ce statisme va néanmoins à l'encontre de la saine circulation propre au chevalier: dans le Lancelot en prose, Bohort refuse par exemple la couronne de Gaunes pour ne pas devenir «riches rois recreanz $»^{23}$. Le roi se voit condamné à coiffer «simplement un système dont [il] ne peut incarner pleinement les valeurs ${ }^{24}$. Dominique Boutet précise ainsi le paradoxe du statut de roi:

Il est, à cette date, impensable qu'un roi demeure extérieur au monde chevaleresque, il n'est pas pensable non plus que sa position officielle au sein de la chevalerie ne soit pas la première, mais, en même temps, il n'est pas admissible que le seul statut de roi l'emporte sur les exigences morales qui définissent l'idéal chevaleresque au point que ce statut suffise à faire entrer le roi dans l'élite de la chevalerie ${ }^{25}$.

Les fonctions du roi l'empêchent d'être un chevalier pleinement accompli, car il doit avant tout «maintenir, réguler les flux bénéfiques qui parcourent la société, et donc se préserver lui-même des risques de la condition chevaleresque ${ }^{26}$; en même temps, il n'est pas admissible que le roi ne soit pas le meilleur des chevaliers ${ }^{27}$. Les romans tardifs que nous

Joseph Canning, Histoire de la pensée politique médiévale, trad. Jacques Ménard, Fribourg, Éditions universitaires Fribourg Suisse; Paris, Éditions du Cerf, 2003, p. 151. Sur l'organisation sociale préconisée par Jean de Salisbury, voir Tilman Struve, "The Importance of the Organism in the Political Theory of John of Salisbury", in The World of John of Salisbury. Studies in Church History, éd. Michael Wilks, Oxford, B. Blackwell, 1984, p. 303-317.

23 Lancelot en prose, éd. Alexandre Micha, t. VI, \$28, p. 170. Voir Dominique Boutet, Charlemagne et Arthur, p. 40-41, et Barbara Wahlen, L'Écriture à rebours, p. 142-143.

24 Dominique Boutet, Charlemagne et Arthur, p. 41.

25 Ibid., p. 44.

26 Ibid., p. 604-605.

27 Nous renvoyons encore une fois à l'étude de Barbara Wahlen, L'écriture à rebours, p. 139-174, qui problématise la figure royale d'Arthur et la conjonction que ses divers visages dans le Roman de Meliadus. 
avons cités résolvent le paradoxe en dynamisant la figure royale, voire en proposant une éthique de la royauté, telle que la formule Mario Botero García :

Le statut royal implique donc l'exercice de la chevalerie qui en constitue une autre dimension dans la mesure où la prouesse chevaleresque se présente comme une conséquence du pouvoir royal; autrement dit, la manifestation du statut royal, du pouvoir, se fait à travers la prouesse du roi ${ }^{28}$.

L'ethos du dux bellorum est conforme aux fonctions royales: il assure la cohésion du royaume, puisque le roi est au milieu de ses hommes. Girart d'Amiens propose un programme de bon roi; est un bon souverain celui qui peut à la fois remplir son rôle de mainteneur et redevenir ponctuellement un excellent guerrier.

L'éthique de la royauté se caractérise aussi par la sagesse dont fait preuve Arthur: il préserve par exemple les chevaliers valeureux, même s'ils sont dans le camp adverse. Alors qu'Escanor a le dessous, Arthur a pitié et rappelle ses chevaliers, percevant comme une félonie le fait de mettre un tel preux à mort. Le narrateur souligne que ses ennemis "point de pitié n'eüssent" (Escanor, v. 19827) s’ils avaient été à sa place, rendant ainsi la conduite du roi d'autant plus admirable. Celui-ci apparaît comme un souverain juste et charitable, guerrier mais dénué de convoitise, capable de prendre des décisions politiques et guerrières judicieuses et d'écouter l'avis et les conseils de ses barons. L'Arthur du roman tardif fournit un miroir des princes: le roman adopte une perspective didactique, il propose une réflexion sur le pouvoir et son exercice. Le roi se doit de gouverner, rendre la justice ${ }^{29}$ et prendre de sages décisions; mais il est aussi nécessaire qu'il fasse la démonstration de sa prouesse guerrière de temps à autre, en particulier

28 Mario Botero García, Les Rois dans le Tristan en prose, p. 59.

29 Arthur jure de retrouver le coupable de l'attentat contre Escanor le Bel dans Escanor. Il échoue à cette promesse pour des raisons que nous évoquerons plus loin. L'intention manifestée de rendre la justice est néanmoins conforme à l'éthique royale. Dominique Boutet développe cette idée de justice dans les romans arthuriens, en particulier en prose, en lien avec l'augustinisme politique et la foi en un rapport transcendant entre Dieu et le roi: Charlemagne et Arthur, p. $167-210$; p. 583 . L'augustinisme politique ne touche que peu les romans en vers, même tardifs. 
lorsqu'il s'agit de défendre son royaume. Le roi ne se résume donc pas à la tête du corps social: il s'investit dans tous les domaines d'activité.

L'exercice des armes n'est pourtant pas synonyme de conquêtes belliqueuses dans le roman tardif: là encore, nos auteurs donnent l'image d'un roi idéal, preux mais non avide. Arthur n'y est pas totalement identique au personnage de la chronique de Wace ou de Geoffroi : l'esprit de conquête anime le roi du Brut, elle le pousse à envahir l'Irlande et le Gothland, puis la France occupée par Rome ${ }^{30}$. Dans les romans tardifs, l'expansion territoriale n'est que la conséquence de conflits générés par les ennemis extérieurs et dont le camp arthurien sort victorieux; elle ne résulte pas d'une volonté conquérante d'Arthur, qui critique d'ailleurs les prétentions orgueilleuses des conquérants dans Claris et Laris:

«Mauvés fait a tieux genz amordre,

Que tout le mont vuelent avoir

Et ja n'avront assez avoir

Car Avarice les pormainne

Qui touz jours les conduit et mainne.» (Claris et Laris, v. 5820-5824)

Cette politique défensive et non offensive donne l'image positive d'un roi pacificateur, dont la domination sur l'Europe s'impose tout naturellement par la soumission volontaire des sujets, qui reconnaissent la supériorité et la légitimité du gouvernement d'Arthur. Celui-ci n'apparaît pas comme un nouvel Alexandre, dont la soif de conquêtes territoriales trahit un orgueil démesuré3 ${ }^{31}$ : si l'espace arthurien ne cesse d'augmenter, c'est que les régions annexées sont dans la nécessité d'un nouveau souverain, après avoir subi une mauvaise gestion. Sans aller jusqu'à dire que nos auteurs récusent la conquête militaire ${ }^{32}$, il semble bien que ce soit l'attitude pacifique d'Arthur qui est valorisée.

30 Voir le chapitre "Le temps des conquêtes" de La geste du roi Arthur, éd. cit., p. 79-99.

31 Voir les articles de Hans Höllander, "Alexander: Hybris und Curiositas», in Kontinuität und Transformation des Antike im Mittelalter, Sigmaringen, Jan Thorbecke, 1989, p. 65-79, Catherine Gaullier-Bougassas, "Alexandre face aux révoltes des siens: recompositions médiévales du passé historique ", Bien dire, bien aprandre, 25, 2007, p. 209-225, et Laurence Harf-Lancner, «Héroïsme et démesure: Alexandre et la Tour de Babel», in Romans d'Antiquité et littérature du Nord, Paris, Champion, 2007, p. 405-422.

32 Nos auteurs ne seraient pas les seuls à condamner la conquête: Étienne de Fougères ne se prive pas de blâmer les velléités conquérantes des rois: "N'eit 
Seule la conquête de l'Espagne fait l'objet d'un projet manifeste d'annexion en faveur de Claris:

Artus fet ses barons venir

A son tref por conseil tenir:

«Seingnor, fet il, mandé vous ai!

Savez por quoi? Jel vous dirai :

En ceste terre venu somes,

Monjardin conquesté avonmes

Qui est la clef de ceste terre.

Petit $i$ a mes a conquerre

Et se nous a raison fesons,

Legierement la conquerrons

Puis la donromes a Claris.» (Claris et Laris, v. 14569-14579)

Certes, la Table Ronde s'est d'abord rendue à Montjardin pour récupérer Lidaine, retenue prisonnière par le roi Savaris qui la convoitait; la mort du roi d'Espagne laisse le siège royal vacant et oblige Arthur à rétablir l'ordre en désignant un suppléant. Néanmoins, c'est plutôt la tentation d'obtenir facilement un nouveau territoire qui est soulignée ici, que la nécessité de pacifier la contrée. Tout comme celui de la prose, l'Arthur tardif profite des divers visages qui lui ont été attribués: roi courtois, sage et large dans le roman en vers de première génération, roi conquérant et guerrier dans la chronique.

\section{Arthur facétieux}

Les pratiques armées se manifestent également dans le cadre du tournoi. Il s'agit là d'un divertissement qui réunit les trois fonctions royales: la sagesse, car le roi doit assortir adéquatement les concurrents et désigner un vainqueur, la prouesse pour l'exercice chevaleresque et surtout la largesse, le roi distribuant ses richesses à profusion à la fois en ce qui concerne les présents et l'organisation en elle-même ${ }^{33}$. Dans Claris

pas envie d'autrui terre / esgaugrinier ne a tort conquerre, / quar por itant mout sovent guerre / qui gent essille et gent enterre." (Le Livre des Manières, éd. Anthony Lodge, Genève, Droz, 1979, strophe 24); "qui plus i a, et plus i pert.» (v. 118)

33 Michel Parisse indique que «le tournoi est une manifestation guerrière, il est dangereux, il coûte cher, il comporte un prix, il impose d'avoir les moyens de 
et Laris, Arthur ne se contente pas de proclamer un tournoi pour le retour de Laris à la Pentecôte, après sa capture par la fée Madoine: il y devient aussi tournoyeur, tel un compagnon de la Table Ronde. Sa participation en tant que concurrent se déroule dans des conditions particulièrement originales:

Mes trop a grant bachelerie

En la compaignie le roy

Artus qui vient a grant derroy

Car le jour veult armes porter

Et pour son cors plus deporter,

Avoit ses armes remüees

Et autreteles endossees

Con Gauvains les souloit porter

Pour sa gent mielz reconforter. (Claris et Laris, v. 13142-13150)

Le personnage démontre ici qu'il est aussi impétueux que ses chevaliers et refuse le rôle statique qu'il joue habituellement lors des tournois qu'il organise dans les romans en vers, où il occupe plutôt la présidence. Il se montre également audacieux, en adoptant les armes de son neveu, par amusement: prétexter que les armes de Gauvain encouragent ses tournoyeurs est surprenant, dans la mesure où c'est le roi qui constitue le pilier, censé donner l'ardeur aux combattants. L'adoption des armes de Gauvain par Arthur est facétieuse, aussi bien de la part du roi, qui manifeste par là sa volonté d'égaler son neveu aux armes, que de celle de l'auteur: Gauvain supplée bien souvent son oncle dans l'exercice de ses fonctions ${ }^{34}$, la première occurrence étant celle de la chasse au blanc cerf dans Erec et Enide, lorsqu'il fait remarquer à son oncle l'inconvenance de cette

recevoir une grande foule de combattants et de spectateurs. Ce sont les souverains et les hauts barons qui semblent pouvoir seuls l'organiser». "Le tournoi en France des origines à la fin du XIII ${ }^{\mathrm{e}}$ siècle», in Das ritterliche Turnier im Mittelalter, dir. Josef Fleckenstein, Göttingen, Vandenhoeck \& Ruprecht, 1986, p. 178. Sur la largesse du roi Arthur, voir Dominique Boutet, Charlemagne et Arthur, ou le roi imaginaire, notamment p. 260-263, 331-333.

34 Marie-Luce Chênerie note qu'il incarne la part guerrière du roi, absente des romans arthuriens traditionnels. Le Chevalier errant, p. 94-98. "Il double la générosité royale ou la remplace quand elle est en crise.» (p. 95) Voir aussi William Nitze, "The Character of Gauvain in the Romances of Chrétien de Troyes", Modern Philology, 50/4, 1953, p. 219-225. 
tradition. Le travestissement est dès lors symbolique et propose un rappel comique des manquements du roi $^{35}$. Arthur regrette d'ailleurs l'absence de son neveu lorsque ses chevaliers ont le dessous contre Gauvain, Laris et Claris incognito: le travestissement ne suffit pas à remplacer Gauvain. Malgré la défaite de son camp, Arthur ne se ridiculise pas lors du tournoi: il joute contre son neveu, sans le reconnaître, et tous deux tombent à terre, ce qui prouve bien la valeur du roi, presque égale à celle du chevalier aux demoiselles. L'épisode s'inscrit bien en continuité des romans de première génération en convoquant le motif de la suppléance d'Arthur par Gauvain, mais contribue à construire l'image d'un roi proactif, qui viendrait remplacer celle qu'a élaborée la tradition versifiée.

La mise en scène d'un Arthur tournoyeur n'est pas étrangère, une fois encore, aux romans en prose: le Trisan en prose propose également un Arthur concurrent aux tournois du Château des Pucelles et de Louveserp ${ }^{36}$. Le roi intervient en dernier recours et s'emploie surtout à encourager la prouesse de ses hommes par sa présence. Si sa royauté prime sur ses exploits chevaleresques, il ne manque pas de faire montre d'exploits face à Tristan au tournoi du Château des Pucelles ou dans la mêlée à Louveserp. De la même manière, dans Claris et Laris, il fait le poids face à Gauvain. Son rôle de tournoyeur déroge néanmoins bien plus à ses fonctions royales que dans le Tristan en prose, car il doit se déguiser pour assurer la cohésion de son camp. Le roi s'amuse à jouer au chevalier, conscient du paradoxe inhérent à la royauté que nous évoquions plus haut: le roi ne doit pas se mettre en danger mais reste tout de même le meilleur des chevaliers. L'Arthur de Claris et Laris résout ce paradoxe par le déguisement, le changement temporaire d'identité par l'adoption d'autres armes.

Ce déguisement est facétieux: par les souvenirs littéraires qu'il appelle chez le lecteur - celui du rôle de Gauvain dans le gouvernement - et par l'intention du personnage, qui endosse d'autres armes «pour son cors plus deporter» (v. 13146). C’est le rire et le plaisir qui sont favorisés par cet épisode et qui motivent Arthur. Le roi breton fait preuve d'autres facéties dans Escanor, lorsqu'il taquine plus ou moins gentiment Keu à propos

35 Thérèse Bouché évoque ces manquements chez Chrétien de Troyes dans «De Chrétien de Troyes à la Mort le Roi Artu: le personnage d'Arthur ou la désagrégation progressive d'un mythe», Op. cit. Revue de littératures françaises et comparée, 3, 1994, p. 5-13.

36 Mario Botero García, Les Rois dans le Tristan en prose, p. 88-97 et 305-316. 
d'Andrivete: le sénéchal a en effet blâmé son amie de son prétendu mariage avec un autre, rumeur propagée par le méchant Aiglin. Maintenant que la vérité est rétablie, Andrivete pourrait être fâchée du manque de confiance et des propos de Keu. Pour se moquer de lui, Arthur insiste sur l'erreur de ce dernier, «car trop l'amoit a courechier» (Escanor, v. 22441):

«Neporquant par vo nonsavoir

Et par vo langue mesdisanz

Vouz est la bele, la plaisanz

Que tant amiez, des mainz volee.» (Escanor, v. 22484-22487)

Arthur énonce clairement la médisance de Keu et sa responsabilité dans la perte potentielle de son amie. Dans les romans de première génération, le roi ne reproche malgré tout jamais leur conduite à ses chevaliers et fait preuve d'une patience surprenante à l'égard de Keu; il se contente de le remettre en place une seule fois, dans le Conte du Graal. Dans Escanor, il s'amuse de la colère du sénéchal et le pousse dans ses retranchements, fût-ce au mépris des règles de la courtoisie et de la sagesse, fonction royale pourtant essentielle. Malgré le tourment de Keu, il continue de le blâmer (Escanor, v. 22642-22661) puis exige des excuses pour s'être montré impoli envers sa royale personne. Il exprime ensuite le souhait de retarder la rencontre entre les amants ("Cel jor alongié li eüsse», v. 22724); par jeu, il propose à Keu de lui donner une grande terre, s'il accepte d'attendre trois jours d'ici les retrouvailles:

Et li rois pour Ké fourssener

Li voloit grant terre doner

Pour qu'il se tenist seulement

.iii. jours sanz veoir nulement

Monseingnor Gavain et s'amie. (Escanor, v. 22737-22741)

Ce comportement taquin écorne la figure royale: quel roi distribue ses terres sans considération pour le simple plaisir de voir se languir son chevalier? Le narrateur insiste surtout sur les intentions du roi: il veut «Ké fourssener» et aime le «courechier» (22441). Arthur s'amuse du pouvoir qu'il a sur ses chevaliers, par caprice, mais aussi, peut-être, pour entretenir le rire consubstantiel au roman arthurien en vers; le personnage régit le bon fonctionnement du genre.

Ce passage subvertit les valeurs arthuriennes et contrebalance l'image positive d'Arthur en chef de guerre: le roi peut se montrer inconséquent 
dans le cadre restreint de sa cour, même s'il remplit totalement sa fonction guerrière ${ }^{37}$. De tels épisodes parodient la propension courtoise du roi légendaire: alors qu'Arthur est bien souvent le garant de la courtoisie, même dans les textes les plus tardifs et hors du roman arthurien ${ }^{38}$, ses agissements ne correspondent pas toujours à sa réputation. Arthur s'éloigne tellement de l'attitude attendue d'un monarque que Gauvain doit apaiser Keu et résoudre la querelle. Il s'impose comme arbitre et supplée une fois de plus son oncle (Escanor, v. 22574-22621). Keu le prend même à témoin, pour qu'il constate qu'Arthur poursuit ses paroles outrageuses, quand lui a tenté d'être plus poli :

«Biaus sire, or me poez reprendre,

Dist Kez a monseingnor Gavain,

Se je di bien, ce est en vain.

Mal fait li rois qu'enssi parole,

Car sanz raison a poi m'afole.» (Escanor, v. 22646-22650)

La situation est inédite: c'est Keu le malparlier qui a raison contre Arthur et qui tente de le ramener sur la voie de la courtoisie. Le jugement en incombe à Gauvain, qui reproche en effet au roi ses intentions querelleuses: "Sire, ce dist Gavainz, mal dites / Qui le seneschal contredites / Que s'amie veoir ne viengne»(Escanor, v. 22747-22749). Dans cet épisode, le roi affiche un caractère taquin outre la raison, dispendieux, obstiné dans sa conduite alors que Keu fait profil bas, son senz est donc «bestorné» (v. 22551) comme le conclut le sénéchal.

L'exemplarité d'Arthur en tant que chef de guerre ne l'empêche pas de se montrer déraisonnable et de manquer parfois à ses fonctions. Girart d'Amiens propose dans cet épisode un Arthur plus familier, capable de s'amuser au détriment de ses chevaliers et de provoquer le rire du lecteur. En ce sens, le personnage ne se réduit plus à sa fonction, comme dans

37 Dans le passage que nous évoquons, c'est la fonction nourricière qui fait défaut au roi, lui qui distribue des largesses pour un mauvais motif.

38 Voir les divers articles de Arthur après Arthur, qui citent plusieurs exemples où le personnage n'est que mentionné comme modèle à suivre. Arthur figure par exemple parmi les Neuf Preux. Voir à ce sujet Richard Trachsler, Clôtures du cycle arthurien, p. 294-313. Silvère Menegaldo traite de ces évocations chevaleresques dans les dits de Jean Froissart dans "L'exemple chevaleresque dans la poésie de Jean Froissart», CRM, 6, 1999, en ligne: https://journals.openedition.org/ crm/941 ?lang=en. 
les premiers romans arthuriens en vers, où il a longtemps pris un rôle archétypal, celui d'une figure symbolique idéale, peu évolutive, haute en valeurs mais faible en actions. Dominique Boutet définit le rôle organique d'Arthur au sein de la collectivité, dont il est le reflet, l'expression éminente, le symbole:

Le roi n'est pas autre chose que l'expression consciente, la conscience d'un ordre qui s'impose à tous, d'un ordre du monde avec lequel coïncide miraculeusement, anhistoriquement, l'ordre socio-politique ${ }^{39}$.

La cour est "le centre d'un monde en train de s'ordonner ${ }^{40}$, elle trouve son harmonie autour de la figure du roi. Arthur peut être considéré comme un archétype du roi souverain: l'"archétype" se définit, en littérature, comme l'image représentative forte, caractérisée et reconnaissable d'un sujet donné (Don Juan est l'archétype du séducteur) ${ }^{41}$. La notion d'archétype s'accompagne d'une dimension symbolique: le personnage archétypal représente une abstraction, en est le symbole.

Dans le cas d'Arthur, son rôle d'archétype est lié à sa fonction narrative et structurelle: il est le pilier essentiel de la cour et il remplit une fonction de surplomb sur l'univers et ses personnages, s'imposant finalement peu au sein de la diégèse à proprement parler. Philippe Ménard précise les implications de ce rôle:

Il ne peut partir sans que son royaume soit bouleversé et sans que la cour dont il est l'âme et où prennent naissance et aboutissent les aventures soit gravement perturbée. Arthur doit rester au milieu de sa cour qui suscite, enregistre et consacre les prouesses, qui est le centre de la vie courtoise et du compagnonnage guerrier. Dans ces conditions, le roi Arthur joue forcément un rôle un peu ingrat ${ }^{42}$.

39 Dominique Boutet, "Carrefours idéologiques de la royauté arthurienne», art. cit., p. 9.

$40 \quad$ Ibid., p. 11.

41 Chez Carl Gustav Jung, l'archétype «est reconnu comme une figure dynamique, porteuse des représentations symboliques siégeant dans l'inconscient collectif dont dépend, selon lui, la nature psychique de l'individu, en deçà même de ses déterminations culturelles» (Florence de Chalonge, "Archétype», in Le Dictionnaire du littéraire, Paris, PUF ("Quadrige»), 2010, p. 26). On doit en particulier à Gaston Bachelard l'entrée en littérature de cette notion. Lautréamont, Paris, Corti, 1939.

42 Philippe Ménard, Le rire et le sourire dans le roman courtois en France au Moyen Âge, p. 314. 
Sa dimension archétypale se traduit dans la portée universelle de ses bienfaits, exprimée dans le Lancelot en prose par l'écuyer du roi Claudas, qu'il tente de dissuader de tuer Arthur:

Car se cil sels hom estoit mors, je ne voi que jamais soustenist chevalerie ne gentillece la ou ele est; et moult seroit mix que vous, qui n'estes c'uns sels hom, estiés mors ou vous fuissiés ariere boutés de vostre fole emprise, que tous li mondes fust tornés a povreté et a dolour. Car bien seroit mors tous li mondes se cil estoit desiretés qui tout le monde bee a soustenir ${ }^{43}$.

Arthur est le représentant de l'éthique chevaleresque: son importance dépasse la vie du seul individu, car elle garantit la bonne marche du monde, sur lequel son aura rayonne. Lorsqu'Arthur se montre facétieux en taquinant Keu, il reçoit une individualité plus forte qui infléchit quelque peu son rôle archétypal.

\section{Égarements de la figure royale: l'univers en perte de maîtrise}

Si Arthur devient un personnage parmi d'autres et quitte son rôle d'archétype, qu'en résulte-t-il pour la stabilité de l'univers arthurien? Au contraire de Claris et Laris et de Floriant et Florete, où le royaume arthurien conserve son fonctionnement idéal, dans Escanor, des failles s'immiscent: Arthur semble perdre parfois la maitrise de son monde, notamment par l'irrésolution de plusieurs fils narratifs. Alors que le roman arthurien en vers canonique se caractérise par sa clôture et le dénouement de toutes les aventures, Girart d'Amiens n'hésite pas à laisser certaines données en suspens. L'exemple le plus remarquable concerne l'attentat perpétré par Galantinet contre Escanor le Bel (Escanor, v. 7860-8488, le feuillet qui narre le moment de l'attaque manque) pour éviter une défaite à Gauvain, que l'on croit coupable de l'accusation proférée contre lui en raison de la mélancolie dont il fait preuve. Escanor le Bel est au seuil de la mort et sa suite, éplorée, reproche à Arthur cette attaque: leur seigneur bénéficiait d'un sauf-conduit pour se rendre à la cour et se battre contre Gauvain pour prouver ses dires. Le roi se voit investi de la responsabilité de l'événement: «Or l'a on mort en ton conduit» (Escanor, v. 8633), lui

43 Le Livre du Graal, éd. Daniel Poirion et al., Paris, Gallimard («Pléiade»), 2003, t. II, p. 65. 
lancent deux pucelles de la maisonnée d'Escanor. Il s'agit en effet d'une faille très grave, qui dévoile le manque d'autorité du roi sur ses sujets. Le responsable de ce lâche attentat, Galantinet, se trouve en effet faire partie de la cour d'Arthur: l'évolution d'Arthur s'accompagne donc de celle de son entourage, dont la loyauté décline comme par mimétisme. Pire encore, l'auteur du méfait ne sera jamais démasqué, malgré les promesses de vengeance d'Arthur (Escanor, v. 8714-8744), si bien que le souverain impose à la cour un deuil de plusieurs mois, une saison entière ( «de toute cele saison", v. 8873). C’est Keu - qui jette souvent un regard lourd de sens sur la cour - qui fait voir au roi l'inconvenance d'un deuil si long. Girart d'Amiens réactive ici une caractéristique traditionnelle du sénéchal - son point de vue méprisant sur la cour, qui fait souvent allusion aux manquements de celle-ci - pour la transformer en qualité. Nous reviendrons au chapitre suivant sur la mutation de ce personnage dans Escanor.

L'intensité et la durée de la mélancolie de la cour, thématisées sur un long passage, alors que l'individu lésé est un ennemi qui n'est même pas mort, se justifient par l'incapacité d'Arthur à réparer le tort causé: la cour et son autorité ont failli. Le roi échoue à garantir la sécurité de ses hôtes et à appliquer une justice. C'est ce constat qui le place dans l'état de léthargie déploré par Keu. L'aveu d'échec se cristallise dans la longue justification que donne Arthur à Keu, dont voici un extrait :

«Mais en lieu ou on ait esté

N'en poi ainc chose el mont apprendre

Dont je m'en seüsse a qui prendre.

N'en sai de qui prendre venjance.

Si vouz di bien, si grant pesance

Ai de ce qu'il ainsi m'est pris

C'onques en ma vie n'apris

Dolour qui a ceste tornast

$\mathrm{Ne}$ qui ainsi me destornast

A mener joie ne revel.» (Escanor, v. 10434-10443)

La longueur du débat sur le deuil, qui s'étale sur plus de cent cinquante vers (Escanor, v. 10381-10536), n'exprime pas l'importance de la victime mais bien une perte de maîtrise, la rupture de l'équilibre curial, la décadence de l'univers. Alors que l'endormissement de la cour arthurienne est souvent souligné dans la tradition arthurienne en vers, en particulier en raison de l'absence d'aventures (ainsi du début de La Vengeance Raguidel), 
il s'agit ici d'un cas plus grave: ce n'est pas l'absence d'aventures qui est la cause de l'enlisement des chevaliers, mais bien la propre décision du roi. Le deuil, tout comme le manque de quêtes, les condamne à l'immobilisme et contrevient au processus dynamique qui fonde le monde arthurien.

L'attentat d'Escanor le Bel n'est pas le seul fil narratif qui demeure irrésolu, bien qu'il s'agisse du plus développé. Les chevaliers arthuriens n'apprennent jamais non plus que c'est Brian des Îles qui défie Gauvain devant son château (Escanor, v. 15183-15579): Brian souhaite se mesurer au neveu du roi, car son amie Esclarmonde a un jour évoqué la rumeur qui fait de celui-ci le meilleur chevalier du monde (Escanor, v. 15779-15833). Il adopte des armes de novice, affronte Gauvain incognito, échoue, mais ne révèle jamais sa véritable identité (Escanor, v. 15548-15555). Brian ment sur son nom et contrefait sa voix pour cacher sa défaite. Les chevaliers arthuriens sont ensuite accueillis au château sans se rendre compte que le seigneur des lieux est également le challenger de Gauvain. La conduite de Brian des Îles est bien peu courtoise, d'autant plus qu'il tait aussi le combat à Esclarmonde. Ce personnage a un statut ambigu; il est à la fois l'adversaire privilégié du roman arthurien, qui traine derrière lui un passé littéraire d'opposant ${ }^{44}$, et un personnage positif, compagnon de Keu, puis hôte hospitalier et courtois. S'il prend le rôle de l'opposant à la cour arthurienne, la tradition voudrait que son identité et sa défaite soient révélées au grand jour pour qu'il fasse amende honorable et se convertisse aux valeurs arthuriennes. C'est le propre de l'écriture de l'entrelacement - voir chapitre III, «Entrelacer les aventures», p. 495-519 - que de laisser des fils narratifs en suspens, pour les résoudre plus tard: l'identité du challenger n'est pourtant jamais éclaircie, preuve que la structure s'étiole; Arthur ne remplit plus désormais sa fonction régisseuse, il n'est plus le point focal qui garantit et cautionne l'achèvement des aventures et leur bonne marche. L'univers arthurien est en déclin.

44 Brian des Îles est par exemple l'ennemi dans le Chevalier aux deux épées: la dame dont il est amoureux lui impose de vaincre Gauvain pour mériter son amour, car elle n'aimera que le meilleur et le plus beau chevalier du monde. Ce personnage est donc construit intertextuellement: on réactive son passé d'opposant, sa rivalité avec Gauvain et sa volonté de complaire à son amie - la Reine des Îles dans un cas, Esclarmonde dans l'autre. On rend toutefois Brian plus sympathique, plus courtois, plus conforme à l'idéal arthurien. Cette façon de réhabiliter l'adversaire du monde arthurien est typique des romans tardifs. Nous y reviendrons aux pages 474-493. Damien de Carné traite de Brian des Îles dans «Escanor dans son roman", art. cit. 
Arthur, devenu personnage, peut se comporter en roi exemplaire, redevenir un dux bellorum, mais il délaisse pour cela ses fonctions narratives et structurantes. Si le roi est un personnage, soumis à l'évolution, aux modulations transfictionnelles, et non plus un archétype, nécessairement plus abstrait et plus universel pour être un modèle, le monde proposé n'est plus le même que celui des romans de Chrétien de Troyes: il se délite ${ }^{45}$.

La décadence diégétique se manifeste d'autant plus clairement dans Rigomer: l'aventure se fait souvent attendre à la cour d'Arthur, tandis que les chevaliers se comportent de manière peu orthodoxe, adoptant des armes peu chevaleresques, se battant à mains nues (Rigomer, v. 5711ss), refusant l'hospitalité d'un vieillard pourtant désireux d'aider le chevalier (Rigomer, v. 2319-2408) ou exprimant des sentiments répréhensibles, comme la convoitise de Lancelot envers le bel écu d'un chevalier (Rigomer, v. 4854-4966). Le déclin des valeurs et les velléités négatives des chevaliers, souvent concupiscents ${ }^{46}$, ne sont que la conséquence du propre comportement du roi Arthur.

Dans Rigomer, il semble dans un premier temps remplir son rôle d'archétype: il préside à la cour, se montre généreux, ne prend pas part à l'aventure de Rigomer. Néanmoins, certains aspects moins glorieux de sa personnalité surgissent ponctuellement: il refuse d'abord d'envoyer trop de chevaliers à Rigomer pour sauver Lancelot et se met en colère, allusion à un épisode similaire dans le Lancelot en prose. En voici les deux extraits:

[Quarante chevaliers se proposent pour la quête de Lancelot. Gauvain promet qu'ils ne reviendront pas à la cour avant de l'avoir trouvé,

45 Peut-être peut-on évoquer la même dialectique dans les romans en prose: encore archétype au début du Lancelot en prose, Arthur devient un homme doté de passions individuelles, il tombe amoureux de Camille l'enchanteresse et de la Fausse Guenièvre par la suite. Voir Thérèse Bouché, «De Chrétien de Troyes à la Mort le Roi Artu», art. cit. et Dominique Boutet, Charlemagne et Arthur ou le roi imaginaire, p. 545.

46 Il faut d'abord mentionner le viol d'une jeune fille par Sagremor, puis la façon dont Lancelot profite d'une héritière amoureuse de lui, qu'il laisse enceinte, alors qu'il l'avait précisément sauvée du déshonneur en combattant son violeur. Gauvain n'est pas en reste: il est retenu captif à deux reprises et à chaque fois jouit d'une présence féminine: d'abord chez Gaudioné (Rigomer, v. 7371-7384), puis Miraudiaus engage ses sœurs à ne rien refuser à Gauvain, même s'il «veut deduit de pucele» (Rigomer, v. 15117). La prison de Gauvain est donc «biele et amourouse» (Rigomer, v. 15127). 
risquant ainsi de manquer le rendez-vous fixé pour la guerre contre Galehaut.] De chest serement furent tout esbahi li chevalier qui en la queste devoient aler, mais li rois en fu esbahis sor tous, car il li menbra del jour de l'assamblee qui entre lui et Galaholt devoit estre. «Biax niés, fait li rois, mal avés fait quant vous l'essoine de m'assamblee n'avés mis fors de vostre sairement. (Lancelot en prose, éd. Micha, t. 8 , LIa $\$ 7$, p. 38)

[500 chevaliers se proposent pour quêter Lancelot]

Quant çou veoit li rois Artus,

Par grant ire et par mautalent

En a juré un sairement,

Se nus oltre son gré i va,

Que jamais ne repaiera

En son païs et en sa terre,

Bien voist aillors son esploi querre;

Car s'il le puet tenir u prendre,

Il le fera ardoir u pendre.

"Comment, diauble! por un cors

Esvuidera tote ma cors

De ma millor chevalerie!

Autant ne m'en demore mie.

Se jou [Lancelot tant n'amaise,]

Nesun aller n'en i laisaise;

Car çou est tot paine pierdue:

Ja ne venrés sans revenue.» (Rigomer, v. 7112-7128)

[Gauvain propose de réduire le nombre de quêteurs à quarante; Arthur en octroie soixante. Finalement, ce sont cinquante-huit chevaliers qui partent.]

Dans Rigomer, Arthur menace ses chevaliers de ne plus les reprendre à son service, pire, de les brûler ou de les pendre, il jure et s'agace, avise que s'il s'agissait d'un autre que de Lancelot, il n'enverrait même personne. Ce comportement résulte peut-être d'une exagération de son attitude pensive lorsqu'un de ses chevaliers manque à la cour. Dans la Première Continuation par exemple, il manifeste son inquiétude face à un siège vide; celui de Girflet, retenu prisonnier au Château Orgueilleux. Ses pleurs et ses soupirs sont le signe d'une intuition critique; celle d'un affaiblissement du dynamisme de la Table Ronde, d'une incomplétude, d'une 
humiliation ${ }^{47}$. Dans Rigomer en revanche, ses réactions ne servent qu’à le désigner comme un roi exempt de sagesse et de mesure. Il entre en contraste avec l'Arthur de la prose, auquel il réfère en faisant allusion au nombre de quarante; dans le Lancelot en prose, Arthur proteste mais ne se fâche pas. Et il proteste à juste titre: le serment de Gauvain est inconsidéré et contrevient à l'obligation qu'il a envers son seigneur de l'aider militairement dans sa guerre contre Galehaut. L'inconvenance de la promesse de Gauvain est d'ailleurs soulignée par le narrateur et la suite de l'histoire: les quêteurs rentreront bredouille et parjures avant le terme fixé ${ }^{48}$. L'Arthur de Rigomer ne dispose pas de l'argument de la guerre contre Galehaut pour retenir ses chevaliers. Sa réaction conjoint cet épisode du Lancelot en prose, qui doit faire contraste, et celui de la Queste del saint Graal, où il fond en larmes au départ de ses chevaliers, car «ja mes ne seront a [sa] table rasemblé einsi come il ont esté». Sa cour perdra en prestige et en gloire et Arthur, hermétique à l'idéologie cistercienne de ce texte, se montre incapable de percevoir qu'il n'y a pas "graindes honors " ${ }^{49}$ que de mourir en cette quête spirituelle, comme le fait remarquer Lancelot. L'auteur du texte tardif recourt à plusieurs intertextes en prose pour donner une image négative, ridicule, du roi.

L'Arthur traditionnel n'est pourtant pas non plus exemplaire: il est assez fréquent que le roi manque à ses fonctions même dans les premiers récits arthuriens. Il oublie ainsi Lanval dans la distribution de ses largesses dans le lai du même nom et ne remplit pas sa fonction guerrière dans les cas nombreux où ses chevaliers se substituent à lui pour défendre ses intérêts (nous avons mentionné plus haut Le Chevalier de la Charrette et Le Conte du Graal). Nous l'avons vu, cette passivité est fonctionnelle: elle laisse l'occasion aux chevaliers de sa cour de s'illustrer et de démontrer leur valeur ou crée un espace vide qui permet à la merveille, à la fée, de se manifester dans le cas de Lanval. La conduite qu'Arthur tient dans

47 Marie-Luce Chênerie, Le Chevalier errant, p. 86. Voir aussi Dominique Boutet, Charlemagne et Arthur ou le roi imaginaire, p. 343-345.

48 "Mais onques n'i ot si preu ne si hardi qui puis ne se tenist pour fol, car puis en furent apelé tout parjure par la bouce le roi meisme, car il errerent tout l'an jusc'a l'assamblee et lors les ramena tous mesire Gauvain. " (Lancelot en prose, éd. Micha, t. 8, LIa, \$9, p. 39)

49 La Queste del Saint Graal. Roman du XII siècle, éd. Albert Pauphilet, Paris, Champion ("CFMA»), 2003, p. 17. 
Rigomer semble toutefois plus problématique que la simple passivité et faiblesse dont il fait preuve dans ces exemples. Le Roman d'Yder (fin $\mathrm{XII}^{\mathrm{e}}$ ou début $\mathrm{XIII}^{\mathrm{e}}$ siècle) est le seul autre texte, à notre connaissance, où le roi se comporte de manière aussi problématique. Il se montre orgueilleux, jaloux et avare, à tel point qu'Yder est déçu de sa première visite à la Table Ronde. La jalousie d'Arthur est telle à l'encontre de celui-ci, qui suscite la sympathie platonique de la reine Guenièvre, qu'il projette même de le tuer $^{50}$. Toutefois, même dans ce roman, le discours que les personnages tiennent sur le roi reste élogieux, à l'instar de la présentation qu'en fait un chasseur à Yder:

Li preus, li sages, li cortois,

Qui d'ennor ad passé les rois,

Cels qui furent e cels qui sunt:

De cels qui emprés lui vendront

N'en sera nuls ne vaille meins.

N'en di pas trop, ke tant est pleins

De valur e de corteisie

Ke nus n'en ment qui bien en die. (éd. Lemaire, v. 36-44)

Jamais l'attitude d'Arthur n'influe sur sa réputation. Dans Rigomer, il fait tout autant l'objet d'un discours élogieux de la part de Sagremor: «Et sui de la maisnie Artu, / Le millor roi qui sor Div fu / Ne qui jamais corone port.» (v. 7709-7711) Ce portrait est renforcé par la récurrence de l'expression "maisnie Artu»: Lancelot puis d'autres chevaliers se revendiquent de sa cour, garante de la prouesse.

L'écart entre ce que l'on dit d'Arthur et son comportement réel est manifeste: il y a toujours un décalage entre le discours tenu sur le roi et

50 Il s'agit des vers 5233 à 5244 dans l'édition de Jacques Lemaire, Le Romanz $d u$ reis Yder, Fernelmont, E.M.E., 2010. Le narrateur accentue l'ignominie du projet en commentant: "Ha, las! por dreit nïent le het, / A tort li voelt tolir la vie. Cruele chose a en gelosie.» (v. 5242-5244) Johanna Bagnoud a traité de la colère d'Arthur dans ce texte: De la gelosie d'Arthur à lire d'Yder: les émotions négatives au service de la nouvelle chevalerie dans le Romanz du reis Yder, mémoire de Maîtrise, sous la direction de Barbara Wahlen, Université de Lausanne, 2014, en ligne: https://serval.unil.ch/resource/serval:BIB_65F5BDCCE401.P001/REF. Voir aussi l'article de Beate Schmolke Haßelmann, "King Arthur as villain in the thirteenth-century romance Yder", Reading Medieval Studies, 6, 1980, p. 31-44, et celui de Norris J. Lacy, "Arthur's Character and Reputation in Yder", Cahiers de recherches médiévales et humanistes, 14, 2007, p. 40-48. 
les faits. Barbara Wahlen convoque en ce sens la théorie des «deux corps du roi» conceptualisée par Ernst Kantorowicz" ${ }^{51}$ : "Arthur, en tant que chevalier, autrement dit en tant qu'individu, est faillible; en tant que roi, il est le parangon de toutes les vertus, le "meilleur homme du monde", comme n'ont de cesse de le répéter les personnages. " ${ }^{52}$ C'est cette distinction entre une fonction royale archétypale, idéale et statique, et la manifestation d'une individualité, perfectible. La disparité entre la réputation et les actions d'Arthur peut être fonctionnelle sur le plan narratif et favoriser l'accomplissement des chevaliers ou servir la parodie, comme c'est le cas dans Rigomer, où l'inconséquence d'Arthur prête à sourire. Dans Yder, l'orgueil et la jalousie du roi dévoilent plutôt la dégradation d'un monde et la nécessité de changer de valeurs: Johanna Bagnoud a souligné qu'ils ne relevaient que peu du comique, au contraire de la jalousie manifestée par Cligès et Nuc dans le même roman ${ }^{53}$. Si le Roman d'Yder constitue un hapax parmi la littérature arthurienne du tournant des $\mathrm{XII}^{\mathrm{e}}$-XIII ${ }^{\mathrm{e}}$ siècles, dans le roman tardif, l'individualisation du personnage d'Arthur est plutôt la règle: à l'exemple de Rigomer, il est capable de se singulariser par des comportements indignes de la figure royale.

\section{Égarements de la figure royale: errance d'Arthur}

Ce processus d'individualisation s'accentue encore dans l'épisode de la Quintefeuille: il s'agit de la scène finale du roman, ou tout du moins celle qui termine le manuscrit qui nous a été conservé - qui demeure inachevé $e^{54}$. Cette aventure ne s'inscrit pas dans le cadre de la quête pour Rigomer et forme un ensemble autonome, introduit d'ailleurs par une interpellation au public, qui suit la clôture de l'aventure de Rigomer. Une messagère demande de l'aide pour la dame de Quintefeuille, dont

51 Ernst Kantorowicz, Les Deux corps du Roi, in Euvres, Paris, Gallimard, 2000, p. 643-1222.

52 Barbara Wahlen, L'Écriture à rebours, p. 172. Voir aussi Dominique Boutet, Charlemagne et Arthur, note 1, p. 53.

53 Voir Johanna Bagnoud, De la gelosie d'Arthur à lire d'Yder, partie 3.

54 Deux folios manquent à la fin de Rigomer dans Chantilly, Condé 472. Peut-être ont-ils été découpés ultérieurement. Le manuscrit de Turin ne donne pas plus d'indices sur la fin du roman, car il semble reproduire la version de Chantilly et s'arrête au milieu d'une colonne, sur le même vers que le manuscrit de Chantilly. Voir Franceso Carapezza, «Le Fragment de Turin de Rigomer», art. cit. 
l'héritage est disputé par son cousin. Celui-ci accepte de résoudre le conflit par un combat singulier, mais uniquement contre Arthur en personne. C'est l'occasion pour le roi de devenir à son tour un chevalier errant, et non plus un roi statique ou un dux bellorum:

«Lors me convient, fait il, aller

Ausi bien aventure querre

Con les autres fors de ma terre.» (Rigomer, v. 16036-16038)

Arthur part en errance comme pour imiter ses chevaliers. Si l'Arthur guerrier surprenait, il ne mettait pas nécessairement à mal l'équilibre du royaume; la guerre maintient la cohésion curiale, le roi combat à côté de ses sujets et les encourage. Il n'en va pas de même de son rôle de chevalier errant: absent de sa cour, il ne peut plus recevoir les plaintes de ses sujets ni y pourvoir, et c'est Gauvain qui le supplée, encore une fois, dans ce rôle (Rigomer, v. 16079-16086). Arthur serait donc remplaçable? Si sa fonction peut être assumée par un autre, son univers n'a plus rien de particulier et perd de sa singularité.

L'inconvenance de son départ en errance est explicitée par les protestations des chevaliers: "Sire, çou dist se baronie, / Par no consel n'irés vos mie! / Por vos i voist li uns de nos." (Rigomer, v. 16039-16041). De fait, «le roi ne doit pas mettre sa vie en péril si un chevalier peut le faire à sa place ${ }^{55}$. Le roi ne s'appartient pas, mais dédie sa personne au royaume: s'il lui arrive malheur, la vacance du pouvoir laisse place à des dissensions. Le souverain doit veiller à la "res publica " et non à sa "privata voluntas»: le bien commun prime sur les velléités personnelles du roi, «et in omnibus aliorum commoda privatae praeferat voluntati $"{ }^{56}$, selon Jean de Salisbury. Étienne de Fougères l'exprime également dans le Livre des Manières (-1174-1178):

55 Mario Botero García, Les Rois dans le Tristan en prose, p. 69.

56 Jean de Salisbury, Policratici sive De nugis curialium et vestigiis philosophorum libri VIII, éd. Clemens C. J. Webb, Oxford, Clarendon, 1909, tome 1, Livre IV, chap. 2, p. 515. "[the prince] prefers the advantage of others to his private will." trad. de Cary J. Nederman, in John of Salisbury, Policraticus. Of the Frivolities of Courtiers and the Footprints of Philosophers, Cambridge, Cambridge University Press, 1990, p. 30. Ernst Kantorowicz détaille l'implication de cette dualité entre persona publica et privata voluntas dans Les Deux corps du Roi, p. 94-97. 
Reis n'est pas son, ainz est a toz,

S’il por sei vit, si ne est proz.

Obeïr deit les conmons voz

Se il sunt bon tot a lor moz.

Si de bien vout aveir reison,

A toz sera, si n'iert pas son.

Oblier deit tot li son bon

Por le comun, s'il est prodom ${ }^{57}$.

Si la prouesse chevaleresque est inhérente à la fonction royale, il faut distinguer les statuts de chef de guerre et de chevalier errant: celui-ci se déplace seul et n'a pas pour fonction d'harmoniser l'ensemble d'une société. Lorsque le roi se prête au jeu de l'errance, il ne fait pas «oevres de roi mes de garchon ${ }^{58}$, ainsi que l'exprime le roi Urien dans le Roman de Meliadus.

Rigomer n'est pas le premier roman à proposer un Arthur en chevalier errant: l'ont fait avant lui le Perlesvaus, le Tristan en prose, la Suite du Merlin, La Continuation du Roman de Meliadus et Le Livre d'Artus ${ }^{59}$. Postérieurement à Rigomer, seul le Conte du Papegau donne de tels épisodes, justifiés par la jeunesse d'Arthur, tout comme dans Meliadus d'ailleurs: le jeune âge du roi explique son attrait pour l'errance, qui n'est qu'un prélude au plein investissement de ses fonctions royales. Un constat s'impose: notre roman est le seul texte en vers de cette liste. L'errance d'Arthur se signale bien comme une donnée élaborée par la prose; elle désigne encore une fois les romans tardifs en vers comme des dérivés de leurs homologues en prose.

Dans les romans en prose, Arthur ne brille pas toujours par sa prouesse lors de ces épisodes d'itinérance: il est vaincu par Tristan dans l'épisode de la Fontaine des Merveilles du Tristan en prose et subit plusieurs déconvenues dans Meliadus. Pour autant, il n'y perd pas sa réputation de preux combattant. Le Tristan en prose résout ce paradoxe:

57 Etienne de Fougères, Le Livre des Manières, éd. cit., strophes 41-42.

58 Le Roman de Meliadus, BnF fr. 350 f. 36c, cité par Barbara Wahlen, L'Écriture à rebours, p. 173. Voir p. 158-174 sur l'Arthur errant dans ce roman.

59 Cette liste est dressée par Barbara Wahlen, L'Écriture à rebours, p. 160-161. Pour une analyse des épisodes d'errance dans le Tristan en prose, voir Mario Botero García, Les Rois dans le Tristan en prose, p. 316-326. Voir aussi sur le sujet les pages 39 à 45 de Dominique Boutet, Charlemagne et Arthur. 
Li rois Artus, ki de grant force estoit et de grant pooir (et bien disoient vraiment chil ki sa forche avoient esprouvee k'il estoit bien uns des plus fors chevaliers du monde et uns des mieudres, et disoient aucune fois li preudome de son ostel que, se li rois Artus fust uns povres cevaliers errans, bien fust de haute renommee; mais pour ce que rois estoit et si grans sires com Diex l'avoit fait, ne li laissoient si home porter armes; et por ce disoient li auquant que sa boine cevalerie estoit en lui perdue et que c'estoi ausi com damages de cevalerie k'il avoit esté rois), li rois Artus, ki de tel forche estoit comme je vous cont... (éd. Ménard, t. II, $\$ 175$, p. 324-325) ${ }^{60}$

La fonction royale empêche le roi de faire preuve de toute sa puissance chevaleresque: c'est bien l'incompatibilité de la royauté avec l'errance qui explique les déconvenues d'Arthur. Sans sa fonction de roi, il est le meilleur chevalier du monde.

L'auteur de Rigomer va plus loin: c'est moins sa fonction royale et sacrée qui serait à l'origine du peu de vaillance dont il fait preuve que la volonté de donner une image comique et ridicule d'Arthur. S'il gagne effectivement le combat contre l'usurpateur et restitue ses terres à la dame de Quintefeuille, il ne s'illustre pas pendant l'errance qui l'y mène et se montre plutôt en retrait par rapport à Lancelot, qui lui sert d'écuyer. C'est ainsi Lancelot qui vainc cinq voleurs croisés au détour d'un chemin, alors même qu'Arthur s'était avancé, prêt à jouter (Rigomer, v. 16391-16440). Lancelot s'interpose entre les combattants, démontrant de cette manière le peu de confiance qu'il témoigne envers son roi, qui subit cette humiliation sans aucun commentaire: au lieu de s'offenser, Arthur "grant ris en ot» (Rigomer, v. 16431), exprimant par là sa gaîté, sa bonne humeur, sans l'ombre d'un ressentiment ${ }^{61}$. C'est également Lancelot qui mène le combat contre une panthère terrorisant la forêt: il prend l'initiative de terrasser l'animal, fait fi des avertissements des personnages croisés à l'orée de la forêt et assume l'affrontement. On oublie même la présence d'Arthur pendant deux cents vers, à tel point que le narrateur doit le réintroduire: «Dont a parlé li rois Artus, / Qui longement s'estoit tëus» (Rigomer, v. 16729-16730). Lancelot est bien le héros de cette aventure: il demande

\footnotetext{
60 Voir Barbara Wahlen, L'Écriture à rebours, p. 173-174, sur ce passage.

61 Philippe Ménard traite de l'expression «jeter un ris» aux pages 31-34 de Le rire et le sourire dans le roman courtois en France au Moyen Âge.
} 
même au roi de s'écarter, lorsque celui-ci tente de le dissuader d'affronter la "pante»: "Tornés vous fors de cele voie, / Et si verés que j’en ferai" (Rigomer, v. 16772-16773).

Arthur n'incarne donc pas un idéal chevaleresque lors de son errance - qui n'est d'ailleurs pas solitaire. Dans l'ombre de Lancelot, il peine à s'illustrer et même à faire preuve de courtoisie: c'est le souvenir de la loyauté de Gauvain et Lancelot qui le pousse à descendre de cheval pour affronter à pied son adversaire démonté (Rigomer, v. 17143-17148), et non ses propres valeurs. Son comportement à la cour avant le départ en aventure est également particulièrement inconvenant, lorsqu'il lance un rire énigmatique (v. 16138), qui n'est pas l'expression de sa bonne humeur, comme dans le cas évoqué ci-dessus; ce rire ne s'explique pas non plus par un événement comique et risible. Il se révèle d'autant plus déplacé que la reine pleure simultanément, à la perspective de son départ ${ }^{62}$. L'explication que fournit Arthur pour justifier son rire n'est pas sans rappeler les rires de Merlin dans le Merlin en prose ${ }^{63}$ : les rires du prophète révèlent les choses cachées du passé, du présent et de l'avenir. Ils délivrent également une interprétation exégétique de faits quotidiens. Quant à Arthur, il a ri car il fera sa volonté des rois sarrasins et chrétiens - rire prophétique -, car il possède le meilleur destrier - rire au présent - et finalement parce que le meilleur des chevaliers (Gauvain) lui a tenu l'étrier - rire sur le passé (Rigomer, v. 16151-16206). Le rire est souvent assimilé à la folie dans l'imaginaire médiéval : il est un substitut à la parole des fous, qui s'amusent de ce qui précisément n'est pas risible. Il y a donc une discordance entre le rire de Merlin et la situation de laquelle il rit, qui le rapproche de son origine diabolique. Le décalage se situe également entre les apparences, la logique et le savoir du prophète. Howard R. Bloch le décrit en ces termes:

62 Francesco Carapezza compare cet épisode au début du Pèlerinage Charlemagne. "Le Fragment de Turin de Rigomer», art. cit., p. 102-106.

63 Merlin rit par exemple devant la peur de sa mère d'être exécutée, il rit des émissaires de Vertigier qui viennent pourtant le tuer, ou encore d'un paysan qui mourra avant d'avoir réparé ses chaussures. Voir Alexandre Micha, Étude sur le Merlin de Robert de Boron, roman du XIII siècle, Genève, Droz ( Publications romanes et françaises»151), 1980, p. 184, qui liste les rires de Merlin. Voir aussi Lewis Thorpe, "Merlin's sardonic laughter", in Studies in Medieval Literature and Languages in Memory of Frederick Whitehead, Manchester, Manchester University Press, 1973, p. 323-339. 
Dans chaque cas, le rire n'est pas une question de substance, de sujet ou de thème, mais provient d'une distance illusoire entre deux manières de savoir - entre précepte déductif et certitude proleptique, entre croyance et démonstration, entre mode conceptuel et mode perceptif ${ }^{64}$.

Comme le précise Jean-Marie Fritz, «le rire du fou peut [...] avoir partie liée avec le discours du vrai» ${ }^{65}$. Le rire paradoxal de Merlin le rapproche de la folie, mais il est surtout le signe d'un savoir et d'un discours infinis. Il exprime le triomphe de la connaissance, l'affirmation d'un pouvoir sur l'avenir et la mort.

Dans le cas d'Arthur, le rire est inopportun et ne révèle rien de déterminant: la conquête de tous les rois apparaît plutôt comme une vantardise de la part d'Arthur, tandis que le reste des informations est connu de l'assemblée. Le rire paradoxal du roi ne cache pas une sagesse plus subtile, comme celle de Merlin; au contraire, il le ridiculise et le présente comme un insensé, dont on peut se moquer. Il est en plus à l'origine d'une querelle entre le roi et la reine, cette dernière affirmant connaître un chevalier meilleur que Gauvain, l'auteur faisant ainsi allusion à sa liaison adultère avec Lancelot ${ }^{66}$. Arthur menace alors de lui couper la tête en l'attrapant par les tresses, symbole de sa féminité et de sa beauté. Il entre dans une colère peu séante pour le représentant de l'harmonie curiale et qui n’a cette fois rien à voir avec le furor épique:

64 Howard R. Bloch, "Le rire de Merlin", Cahiers de l'Association internationale des études françaises, 37, 1985, p. 9. On consultera l'article entier au sujet du rire de Merlin. Voir aussi Philippe Ménard, Le rire et le sourire dans le roman courtois en France au Moyen Âge.

65 Jean-Marie Fritz, Le discours du fou au Moyen Âge, p. 345.

66 L'amour entre Lancelot et Guenièvre n'apparaît qu'à titre d'allusion dans Rigomer: la reine se montre d'abord triste que son chevalier parte en errance, puis celuici lui envoie les chevaliers vaincus. Dans l'épisode de la Quintefeuille, Arthur se fâche contre Guenièvre car elle soutient que Lancelot est meilleur que Gauvain, puis il affirme que si Lancelot meurt, on l'accusera de l'avoir tué, phrase incompréhensible sans l'allusion aux relations adultères. L'adultère reste toutefois implicite: après le Lancelot-Graal, insinuer une telle transgression impliquerait un déroulement narratif qui mènerait à la chute du royaume. Les simples allusions doivent entretenir la connivence du lecteur sans mener jusqu'à expliciter les implications funestes de l'amour entre Guenièvre et Lancelot. Voir Francesco Carapezza, «Le fragment de Turin de Rigomer», art. cit., p. 97-98. 
Li rois la roïne manace
Et a talent que mal li face.
Tout a ceval vers li s'adrece,
Ja l'evust prise par le trece
Et si l'eüst vers lui tiree
Et de son cors mal atiree,
Se ne fusent li haut baron
Qui sont entor et environ. (Rigomer, v. 16247-16254)

Cette réaction est à l'opposé de la mesure attendue du souverain: l'adultère de Guenièvre et Lancelot est idéalisé comme le désir nécessaire à l'émulation du meilleur chevalier, dans le Lancelot en prose aussi bien que dans le Tristan en prose ${ }^{67}$. L'amour que peut susciter la reine est profitable au roi dans l'idéologie courtoise, car il permet de fidéliser les chevaliers. Ici, la jalousie du roi ne fait que le ridiculiser. C'est Gauvain qui ramène le silence à la cour après l'indignation des chevaliers et s'engage à réconcilier les époux, remplissant ainsi le rôle dévolu au monarque. Alors qu'il interpelle le roi, celui-ci l'ignore, marquant un mépris que Gauvain relève: Arthur ne lui a jamais rendu ses services ni témoigné de reconnaissance (Rigomer, v. 16295-16307). Insensé, jaloux, colérique, ingrat, vindicatif, Arthur est loin de véhiculer un idéal de royauté dans cet épisode: il apparaît comme un personnage démesuré, que symbolise la fréquence de la rime «roi/desroi ${ }^{68}$. L'insertion de l'aventure de la Quintefeuille à la suite de celle de Rigomer donne à voir un roi qui s'éloigne de l'idéal mais qui encourage surtout le rire du public et son divertissement.

Nous l'avons souligné en évoquant le Roman d'Yder, il serait néanmoins faux d'opposer un Arthur exemplaire dans les romans du $\mathrm{XII}^{\mathrm{e}}$ et du début du XIII ${ }^{\mathrm{e}}$ siècle à un Arthur tardif et négatif: il y a toujours une tension entre la réputation du roi, parfaite, et ses véritables agissements, de même que les moments où il fait l'objet de la dérision sont contrebalancés par ceux qui le valorisent. C'est le cas dans Rigomer: il se montre preux dans le combat final de l'épisode de Quintefeuille. Il en va d'ailleurs de

67 Voir Mario G. Botero, Les rois dans le Tristan en prose, p. 286-298, et Emmanuèle Baumgartner, "Rois et chevaliers: du "Lancelot en prose" au "Tristan en prose" ", art. cit.

68 Aux vers 9-10 par exemple. Voir Adeline Latimier, "Gauvain dans les Merveilles de Rigomer", art. cit. Sur l'épisode de la Quintefeuille, voir l'article de Francesco Carapezza, "Le fragment de Turin Rigomer», art. cit. 
même pour Gauvain: moqué dans plusieurs romans du début du XIII ${ }^{\mathrm{e}}$ siècle, il demeure le parangon de la chevalerie et de la courtoisie, comme si sa réputation était inaltérable ${ }^{69}$. À la fin du siècle, salir l'image du neveu du roi a un goût de déjà vu: il faut dès lors s'attaquer à un personnage plus haut placé dans la hiérarchie. C'est naturellement Arthur qui fait les frais de cette subversion.

L'individualité du roi, sa jalousie, n'a pas la chute du royaume pour horizon, dans Rigomer, contrairement à ce qu'il se passe dans la Mort Artu et dans d'autres parties du Lancelot-Graal. Devenu personnage, l'Arthur de la prose induit le déroulement linéaire du temps; le délitement de son règne est le résultat de volontés individuelles, de l'abandon de la fonction royale et du bien commun au profit d'affaires privées. De même, raconter son enfance l'individualise forcément plus que ne le faisait le roman en vers de première génération. Dans le vers tardif, l'individualité du roi n'a pas de conséquences sur le destin du royaume; seul le rire du public semble visé. Les conséquences de ce changement de statut concernent bien plus les mécanismes du genre que le déroulement de la diégèse.

\section{De l'archétype au personnage}

N'étant plus un archétype, le symbole de la stabilité de la cour, Arthur n'est plus indispensable au roman arthurien: dans Melyador, son rôle est plus anecdotique que structurel. Il apparaît peu en personne dans le roman et demeure statique, cantonné à sa cour de Carlion ${ }^{70}$, n'intervenant que pour adouber Melyador ou présider de manière un peu artificielle au tournoi final. Le roi Arthur est surtout évoqué pour sa réputation glorieuse et a moins une fonction organique au sein du roman. Il n'est jamais à l'initiative des projets: on lui demande son concours pour élire le chevalier digne d'Hermondine, en qualité de tiers externe dont on reconnaît la probité. Il ne remplit donc pas un rôle centralisateur, ne lance pas l'aventure, mais se contente d'y présider et d'apporter un jugement neutre et qualifié.

\footnotetext{
69 Voir Stoyan Atanassov, L'Idole inconnue.

70 Robert Deschaux fait un relevé des apparitions statiques d'Arthur. "Le monde arthurien dans le Meliador de Froissart», Marche romane, 30, 1980, p. 63-67.
} 
Si l'onomastique suffit à donner à l'œuvre une coloration arthurienne ${ }^{71}$, il n'en demeure pas moins que Melyador s'éloigne du canon du genre en rendant la présence de la cour arthurienne accessoire. "L'arthurianité» du texte se justifie alors moins par sa structure que par la dissémination de l'onomastique arthurienne ${ }^{72}$, à tel point que Michel Zink a pu douter de son appartenance au genre:

On ne peut nier que Méliador soit en vers. Mais est-ce un roman arthurien? Rien n'est moins sûr. À tout le moins, l'œuvre est de telle nature qu'il n'y a pas lieu d'y voir une résurrection anachronique du roman arthurien en vers ${ }^{73}$.

Il nous semble tout de même pouvoir parler de résurgence, si ce n'est de résurrection: Froissart stimule l'horizon d'attente de ses lecteurs en générant un univers familier aux amateurs de romans arthuriens en vers comme en prose. Le prologue, qui situe la diégèse «En ce temps que li rois Artus, [...] regnoit au point de sa jonece»(Melyador, v. 1 et 4), établit un lien clair avec le monde arthurien. Peut-être peut-on dire que "Meliador se veut donc un roman arthurien sans aucun personnage arthurien ${ }^{74}$; mais l'intention de se positionner d'une façon ou d'une autre par rapport au genre demeure et prévaut sur les distances qu'il prend avec les autres critères du genre pour créer une esthétique qui lui est propre. À l'horizon des chevaliers de Melyador se trouvent Gauvain, Lancelot, Guiron, Tristan, Galehaut, Yvain et Perceval (v. 29-32), dont les noms doivent évoquer des exploits et des aventures que le lecteur est en droit d'attendre chez les nouveaux héros qui lui sont proposés. Dans son Paradis d'Amour d'ailleurs, Froissart - à moins que ce ne soit un interpolateur? mentionne Melyador, Tangis et Camel au sein d'une liste de chevaliers arthuriens présents dans le Paradis ${ }^{75}$ :

71 Voir l'introduction à l'édition de Nathalie Bragantini-Maillard, Melyador, éd. cit., p. 268-269.

72 Voir Adeline Latimier, Lire le nom propre.

73 Michel Zink, Froissart et le temps, p. 113.

74 Ibid., p. 115.

75 Voir Silvère Menegaldo, "L'exemple chevaleresque dans la poésie de Jean Froissart", art. cit., et les pages 61 à 62 de l'édition de Melyador par Nathalie Bragantini-Maillard. 
Il y sont Tristrans et Yseus,

Drumas et Perchevaus li preus,

Guirons et Los et Galehaus,

Mordrés, Melyadus, Erbaus.

Et chils a che biel Solel d'Or,

On l'appelle Melyador,

Tanghis et Camels de Camois

Sont la ensus dedens ce bois,

Agravains et Bruns et Yeuwains

Et li bons chevaliers Gauwains ${ }^{76}$.

Cette référence témoigne de la volonté d'intégrer les nouveaux personnages créés par Froissart à l'univers arthurien, en même temps qu'elle fait d'eux des héros exemplaires et renommés, au même titre qu'Yvain et Gauvain. Les liens ténus que Froissart tisse entre la trame de Melyador et le monde arthurien suffisent à inscrire le roman dans une continuité, à le considérer comme un récit sur cet univers de fiction. La présence même marginale d'Arthur demeure donc un marqueur fort de genre.

On perçoit ainsi que la fonction d'Arthur est modulable, ce qui n'exclut pas tel roman du genre; Rigomer demeure par exemple un roman arthurien, bien que le roi y devienne un personnage faillible et doté d'une conscience individuelle. La dévaluation progressive de sa cour, l'insertion de failles au sein de l'univers, ressort privilégié du comique chez les auteurs $\mathrm{du} \mathrm{XIII}^{\mathrm{e}}$ siècle, mène toutefois à l'autonomisation du personnel arthurien vis-à-vis du genre: si Arthur est un individu, il est remplaçable et ne remplit plus un rôle génériquement déterminant. Son évanouissement progressif du genre se traduit par sa difficile identification, dans Floriant et Florete, lorsque Floriant ne le reconnait pas et doit lui demander son nom, alors qu'il se trouve à sa propre cour ("Comment estes vous apelez, / Fait Floriant, qui m’araisniez? / - Le roi Artus, bien le sachiez!», v. 23722374), et dans Claris et Laris, lors de la première rencontre des deux protagonistes avec le roi («Puis demandent: "Qui estes, sire?” », v. 6085). Arthur est d'ailleurs absent de Cristal et Clarie et Blandin de Cornouailles alors qu'on l'y attendrait, tant l'univers et la structure prennent la forme d'aventures arthuriennes. Les réactivations successives de l'univers ont

76 Jean Froissart, Le Paradis d'Amour. L'orloge amoureus, éd. Peter Florian Dembowski, Genève, Droz, 1986, v. 981-990. 
construit un canevas, reconnaissable pour tout lecteur de romans arthuriens: le genre peut dès lors se passer du roi légendaire, qui reste toujours en creux de la lecture, comme si les auteurs s'amusaient parfois de ne pas le nommer alors que tous les éléments y convergent - ainsi de Sone de Nansay qui met en scène le Graal mais n'évoque jamais Arthur ${ }^{77}$.

Le phénomène est moins marqué dans le roman en prose: les œuvres que l'on hésite à rattacher au genre - que l'on pense par exemple au Perceforest et à Artus de Bretagne - établissent toujours un lien clair avec Arthur, qu'il soit généalogique ou temporel ${ }^{78}$. Les aventures racontées se situent alors en amont du temps arthurien et s'attardent sur les générations qui précèdent la Table Ronde. Malgré les failles introduites dans la Mort Artu notamment, la présence d'Arthur demeure partie prenante du roman arthurien en prose. Peut-être peut-on en déduire que la structure propre au genre du roman arthurien en vers est plus remarquable et plus stable que celle de son homologue en prose, et que le genre peut donc plus aisément s'autonomiser des personnages inhérents à l'univers de fiction. L'impulsion créatrice à la base des deux esthétiques est différente: la prose est fondamentalement animée par l'idée de complétude et les textes découlent du prolongement, des précisions apportées à l'univers fictionnel. L'auteur de prose brode autour de données fictionnelles préexistantes. Dans le cas du vers, l'ajout de nouvelles aventures au temps des douze ans de paix se double d'un exercice de réactivation de données génériques: les écrivains tissent leurs trames autant autour d'un univers de fiction que d'un schéma structurel éprouvé. Moduler la fonction de mainteneur du monde arthurien qu'endosse le roi Arthur, c'est se livrer

77 Il est d'ailleurs significatif que le nom d'Arthur subsiste dans les textes de la fin du Moyen Âge majoritairement comme point de comparaison laudatif et exemplaire. Sa figuration au rang des Neuf Preux est en ce sens éloquente. Plusieurs contributions au volume Arthur après Arthur, en témoignent, réunies dans un chapitre intitulé "Modèles arthuriens", que commente Christine FerlampinAcher aux pages 267-268: "Si Arthur n'est plus, on peut être comme Arthur.» (p. 267)

78 Alors que Perceforest explore les origines du monde arthurien et les ancêtres des héros, Artus de Bretagne place son intrigue dans une Bretagne post-arthurienne et exprime d'emblée un lien clair entre le règne du roi Arthur et l'histoire d'Artus de Bretagne. Celui-ci serait issu du lignage de Lancelot et la continuité temporelle avec l'époque arthurienne est évoquée dès l'incipit. Voir l'édition de Christine Ferlampin-Acher et son introduction, Artus de Bretagne. Roman en prose de la fin du XIII siècle, éd. cit. 
à un exercice de style qui précipite malgré tout l'extinction du genre, par l'étiolement d'un ensemble générique stable.

\section{Keu courtois, preux et amant: décalage transfictionnel}

La transformation ontologique d'Arthur affecte la généricité de l'œuvre de même qu'elle interroge l'importance de sa présence comme critère générique pertinent. Elle rejaillit aussi sur les autres personnages du monde, inévitablement, les membres de la cour étant interdépendants. La version que propose Girart d'Amiens de Keu dans Escanor en est l'exemple le plus évident: le sénéchal n'est jamais le héros d'une aventure, dans les romans arthuriens en vers. Soit il n'intervient que pour déverser sa médisance, caractère qui lui est rattaché, et raille ouvertement le héros - dans Le Conte du graal par exemple -; soit il est l'anti-héros d'une petite aventure à laquelle il échoue, laissant ensuite sa place au protagoniste et lui servant ainsi de faire-valoir - lors de l'aventure contre Méléagant dans Le Chevalier de la Charrette ${ }^{79}$. Au-delà de la portée comique de ses interventions, Keu catalyse bien souvent l'action, en piquant l'orgueil des chevaliers et en pointant les travers de la société courtoise. Sa langue bien pendue l'autorise à proférer des vérités amères qui interrogent les valeurs du monde arthurien. Sa présence au sein de l'univers est, comme pour celle d'Arthur, fonctionnelle, en raison du rapport qu'il entretient avec les chevaliers que décrit Marie-Luce Chênerie:

\footnotetext{
79 Sur le personnage de Keu, voir entre autres l'étude de Linda Gowans, Cei and the Arthurian Legend, Cambridge, Boydell and Brewer ("Arthurian Studies»), 1988, l'article de Jacques Merceron, «De la "mauvaise humeur” du sénéchal Keu: Chrétien de Troyes, littérature et physiologie», Cahiers de civilisation médiévale, 1998, 41, p. 17-34, et Marie-Luce Chênerie, Le Chevalier errant, p. 99-103, 129, 132-133. Cette dernière souligne que Keu est bien souvent un héros malheureux, désarçonné plus d'une fois. Keu n'est néanmoins pas un personnage foncièrement méchant et se caractérise par sa fidélité à Arthur. Seul le Perslesvaus le présente comme un traître qui tue le fils d'Arthur, Lohot. Voir Keith Busby, "The Enigma of Loholt", in An Arthurian Tapestry. Essays in Memory of Lewis Thorpe, dir. Kenneth Varty, Glasgow, French Department of the University of Glasgow, 1981, p. 28-36. Peter Noble traite du personnage de Keu dans Escanor dans son article, "The Unexpected Hero - The Role of Kay in Escanor", in Courtly Romance: A collection of Essays, par Guy R. Mermier et Edelgard E. Du Bruck, Detroit, Fifteenth Century Symposium, 1984, p. 161-168.
} 
Il les gêne, il les trouble, et empêche ainsi la vigueur aristocratique de s'amollir dans les dérobades ou les hypocrisies courtoises. [...] Le monde arthurien particulièrement ne saurait se passer de lui, à cause d'une double ouverture, à la courtoisie, mais aussi à toutes les sources vives de la vocation guerrière, fussent-elles celles de la petite noblesse ${ }^{80}$.

Traditionnellement, il remplit donc un rôle important et figé, rarement soumis à la variation. Ceci lui vaut de fonctionner comme pilier du monde arthurien et comme marqueur d'univers de fiction: ses caractéristiques sont assez bien ancrées dans la tradition pour que le lecteur identifie par sa présence le monde fictionnel auquel il a affaire.

L'originalité d'Escanor réside en ce sens dans la promotion de Keu au rang de héros: le récit s'intéresse à son histoire d'amour avec Andrivete, à ses aventures et ses prouesses. Il occupe dès lors le devant de la scène. Girart d'Amiens conserve cependant plusieurs éléments traditionnellement constitutifs du personnage, comme sa propension à médire et se moquer de ses compagnons. Tout comme dans les romans arthuriens de première génération, ses interventions encouragent le rire du public. Le comique repose d'abord dans la grossièreté des propos, lors de son altercation avec l'amie de Mordred par exemple, qui l'a accusé vertement de ne pas l'avoir saluée:

«Mais vouz, orde garce chetive,

Estes de sifaite maniere

Et du cors fole et garçoniere!

Et vouz et vostre orde faiture,

Vostre despit creature,

Vostre nain qu'avoec vouz menez,

Dont vo luxure maintenez.» (Escanor, v. 934-940)

L'allusion à une possible aventure entre l'amie de Mordred et le nain ne manque pas d'audace. Le lecteur, qui se souvient du rôle funeste de Mordred dans la Mort Artu, est d'autant plus enclin à rire de son potentiel cocufiage. Les qualificatifs fleuris adressés à la jeune fille («orde garce chetive») renforcent quant à eux le côté cocasse de la scène.

80 Marie-Luce Chênerie, Le Chevalier errant, p. 101. Voir aussi Joan Tasker Grimbert, Yvain dans le miroir: une poétique de la réflexion dans le Chevalier au lion de Chrétien de Troyes, Amsterdam, Benjamins, 1988, p. 26-34, et Richard Trachsler, Escanor, éd. cit., p. 70-71. 
Girart d'Amiens réactive également l'ironie légendaire de Keu: il dénonce la galanterie excessive de Gauvain en sous-entendant que celui-ci n'hésiterait pas à séduire Andrivete, la jeune fille à marier, puis la laisserait tomber:

«Maugré qui qu'en parolt derriere,

Aura le pris et la pucele;

S'en fera s'amie nouvele,

Puis le laira au conmunal.» (Escanor, v. 290-293)

Le sénéchal résume ici le rôle que joue Gauvain dans la tradition: reconnu comme le parangon de la chevalerie, il peut largement prétendre à l'obtention du prix du tournoi et de la pucelle dont il fera son amie. L'adjectif «nouvele» accentue les intérêts versatiles du neveu du roi, qui change bien souvent de compagne d'un roman arthurien en vers à l'autre. Lallusion est métalittéraire et ne fait pas appel au passé diégétique du personnage: comme l'a montré Michelle Szkilnik, Gauvain n'est pas un Don Juan, mais se doit d'être disponible pour l'aventure amoureuse en raison de l'éternel recommencement qu'impose le genre ${ }^{81}$. L'ironie de Keu met en lumière cette caractéristique du personnage, fait la synthèse de ce que la tradition a fait connaître au lecteur.

Le comique ne réside donc pas seulement dans la grossièreté du vocabulaire, mais aussi dans l'expression des ridicules qui fondent certains personnages arthuriens. Keu remplit en fait sa fonction structurante au sein de la cour: dès la scène inaugurale, ses sarcasmes à l'encontre des chevaliers posent le cadre de l'univers. Chaque personnage a l'occasion de manifester son caractère en réagissant aux propos du sénéchal, ce qui permet au lecteur de reconnaître le monde arthurien dont il est familier. Son ironie envers Perceval convoque notamment l'histoire du Gallois:

"Vo raisonz est un peu sauvage,

Si la covient un autre espondre

Ainz c'on i puisse bien respondre,

Car trop parlez obscurement.» (Escanor, v. 338-341)

81 Michelle Szkilnik, "Le chevalier "oublieux" dans le roman arthurien en vers», art. cit. 
L'allusion à sa sauvagerie et à ses paroles obscures renvoient au Conte $d u$ graal et en particulier au cortège du Graal: Keu convoque ici des références intertextuelles qui favorisent l'identification de l'univers fictionnel.

En exacerbant son malparlier, l'auteur inscrit bien Keu en continuité de la tradition littéraire, ainsi que les personnages l'expriment à plusieurs reprises:

«Mesire Ké, vous dites mal!

Ce dist li rois, mais cest usage

Avez usé tout vostre eage,

Si ne vouz en porriez tenir.» (Escanor, v. 294-297)

Alors que, traditionnellement, les médisances de Keu n'occupent que quelques vers, elles font ici l'objet de véritables développements ${ }^{82}$, où chacun met en avant ce trait de caractère. L' «eage» évoqué renvoie bien à l'existence littéraire du sénéchal, qui pèse sur ses réactivations transfictionnelles. L'auteur ne cherche donc pas à gommer ses défauts: mieux, il les transforme pour en faire des qualités et valoriser Keu. Nous l'avons dit, la médisance du personnage permet souvent aux auteurs de romans arthuriens de première génération de mettre le doigt sur les déviances du monde arthurien. Cette caractéristique se confirme dans Escanor: Keu n'hésite pas à dire ses vérités au roi Arthur, lorsqu'il estime que celui-ci manque à ses fonctions:

«Sire, or voi bien que devenue

Est vo courtoisie la merde.» (Escanor, v. 22538-22539)

82 À tel point que le thème se diffuse dans tout le récit, indépendamment des apparitions de Keu. On s'en convainc en se rendant attentif au nombre d'occurrences du verbe «mesdire». Albert Gier souligne l'importance dévolue à la parole dans l'entier du roman: "Die paradigmatische Struktur des Escanor wird, so scheint es, durch die Grundopposition Schweigen und Schwätzen mit den Spielarten Rühmen, Lästern und Lügen (bzw. Verleumden) geprägt. » Albert Gier, "Lästern, Lügen, Schweigen: Syntagmatische und paradigmatische Strukturen im Escanor des Girart d'Amiens", in Erzählstrukturen der Artusliteratur: Forschungsgeschichte und neue Ansätze, éd. Friedrich Wolfzettel, Peter Ihring, Tübingen, Max Niemeyer Verlag, 1999, p. 230. "Il semble que la structure paradigmatique d'Escanor soit conditionnée par l'opposition fondamentale entre le silence et le bavardage, par l'intermédiaire de la flatterie, de la médisance et du mensonge (ou plutôt de la calomnie).» (nous traduisons) 
Le malparlier, dont on voit ici encore une manifestation par le vocabulaire ordurier, sert une mise en cause de la courtoisie telle qu' elle est pratiquée à la cour d'Arthur. Les vérités proférées par Keu dénoncent ainsi les manquements de cette société et doivent encourager une meilleure conduite.

Plus encore, l'auteur propose autour du thème de la parole une véritable réflexion, esquissée dès la scène d'ouverture à la cour: le dire est évoqué sous toutes ses formes, entendre dire, dire la vérité, médire, ne savoir que dire, dire sens et raison (v. 359-381). Le personnage de Keu permet d'embrayer sur ces modalités de la parole et d'insinuer un questionnement profond, anticipant ainsi la thématique du Misanthrope: faut-il être médisant et dire la vérité ou être courtois au risque de l'hypocrisie? Le péché de langue qui caractérise Keu dans la tradition est en ce sens relativisé: il est présenté comme un moyen d'éviter la flatterie et l'hypocrisie, postures représentées par Gauvain. Le neveu du roi suggère ainsi au sénéchal de préférer la courtoisie à la vérité: "Ne dites pas quanque pensez, / Mais dites chose qui pluz siece.” " (v. 320-321). Et Keu de répondre qu'il n'y a pas de mal à dire les choses lorsqu' elles sont vraies:

«Et pour ce que voir en ai dit,

Ai, biauz sire, ore tant mesdit

Que m'en doiez enssi reprendre?

Certes, ne quit de rienz mesprendre,

Se je ne voeil estre flaterres;

Et j'ameroie estre miex lerres

Que ja flaterres devenisse.» (Escanor, v. 379-385)

Keu insiste ici sur l'association problématique que fait Gauvain entre vérité et médisance tout en condamnant la flatterie comme un crime pire que le vol. Le personnage de Keu, placé au centre de l'attention du récit, permet non seulement l'insertion de scènes comiques, constituées de répliques cinglantes qui amusent les personnages aussi bien que le lecteur ( S’en estoient laienz si duit / Qu’il tornoient tot a deduit», v. 427-428), mais il problématise surtout la courtoisie. La société courtoise est invitée à s'interroger sur les vertus qu'elle prône: les mœurs policées de la cour sont-elles compatibles avec l'honnêteté? L'hypocrisie n'est-elle pas un vice plus condamnable? Sur l'échelle des péchés, il semble bien que cette dernière soit moins tolérable que la dénonciation honnête des apories de la société que Keu se charge de révéler. Une interversion de la hiérarchie 
s'opère: Keu, par certains aspects, surpasse Gauvain et bouscule les valeurs dont celui-ci se faisait le porte-parole ${ }^{83}$. La mise en cause des coutumes et valeurs de la chevalerie arthurienne qu'énonce Dinadan et que nous évoquions précédemment joue le même rôle: Escanor interroge les normes et les conventions du roman arthurien en se servant de ces deux personnages bien connus de la tradition arthurienne, en vers et en prose. Il adopte, sur le modèle du Tristan en prose, une "esthétique du contraste " ${ }^{84}$, qui favorise la multiplicité des interprétations et pousse au débat en esquissant des jeux partis.

Girart d'Amiens invite à relire différemment la tradition: de répréhensible qu'il était, le péché de langue de Keu devient le support positif de l'honnêteté tandis que Gauvain se mue en représentant négatif de l'hypocrisie, de la dissimulation et des faux-semblants. Les interventions du sénéchal ne sont plus malveillantes, injustes et rabaissantes: elles trahissent les torts de ses interlocuteurs - l'amie de Mordred, orgueilleuse-, ou les déviances de la cour - l'absence de courtoisie du roi dans l'épisode où il se montre taquin avec son sénéchal, traité plus haut. Le rapport de Keu à la parole n'est donc plus présenté selon les mêmes modalités que dans les romans arthuriens précédents: si les personnages ne cessent d'insister sur cet aspect, celui-ci est rendu tolérable par sa conjonction à l'idée de vérité.

La complexification du rapport de Keu à la parole, qui l'éloigne peu ou prou du péché de langue, s'accompagne de la revalorisation du personnage sur plusieurs plans: celui de la prouesse et celui de l'amour. Le narrateur en fait à maintes reprises un éloge qui vient contrebalancer sa mauvaise langue:

Se ses paroles anieuses

Ne fuissent, conme avez ö̈,

83 Elisabeth Schulze-Busacker propose de voir dans Escanor une interversion entre les caractères de Keu et de Gauvain, le premier devenant fin'amant et le deuxième voyant sa réputation bafouée à plusieurs reprises. Même si les valeurs représentées par Gauvain sont parfois mises en cause, il nous semble que le personnage n'est jamais dévalué à la manière du Tristan en prose, mais parvient à conserver son statut de parangon. "Gauvain, li malparlier". Le rôle de Gauvain dans le roman d'Escanor", art. cit.

84 Bénédicte Milland-Bove, "Nous chantons chansons diverses et si tirom diverses cordes" ", p. 13. 
Tuit li compaignon esbahi

Fussent du bien qu'en lui avoit,

Car nuz hom si bien ne savoit

A son seingnor faire une honor,

Ne si le grant ne le menor

Servir, se ne fust sa parole. (Escanor, v. 14308-14315)

Le récit s'efforce de donner une image positive du personnage, qui dispose de toutes les qualités requises du parfait chevalier. Keu gagne en crédibilité et se départ de la mauvaise réputation que lui ont faite les premiers romans arthuriens. En plus d'être un bon compagnon et un loyal sujet comme la citation précédente le propose, il s'illustre au tournoi de Baubourc revêtu d'armes vermeilles et suscite l'admiration des spectateurs:

Tout ensi de Ké devisoient

Cil qui ses joutes avisoient,

Car trop venoit hardiement.

Si fu loez mout durement

De ce que Gorvain abati,

Car si roidement le flati

A terre que ce fu merveilles.

Tuit crient: «Les armes vermeilles

Au jor d'ui honor conquerront,

Car les joustes forjousteront.» (Escanor, v. 3745-3754)

Il s'illustre à chacune de ses apparitions dans les tournois et conflits armés et dément la lâcheté et la médiocrité que lui ont attribuées Chrétien de Troyes et ses successeurs en faisant de lui le faire-valoir des héros.

Ses prouesses engendrent inéluctablement l'attirance des demoiselles qui observent le tournoi de Bauborc. De manière inédite, il est l'objet de toutes les convoitises, comme l'exprime Onorete:

«Et tant a en lui d'autres bienz

Que, foi que je vouz doi, pucele,

Il n'a dame ne damoisele

Çaienz, tant ait grande biauté

$\mathrm{Ne}$ tant soit de grant parenté

$\mathrm{Ne}$ tant ait en li bones mors,

Que, se Kez l'amoit par amours,

Pour tant c'aillors son cuer n'eüst, 
C'a païe ne s'en deüst

Tenir et bien et richement.» (Escanor, v. 3922-3931)

Sa mauvaise langue ne l'empêche pas de susciter de tels commentaires: la discourtoisie traditionnelle de Keu se voit remise en question. En se montrant preux sur le champ de bataille et en justifiant habilement ses paroles parfois excessives, Keu parvient à bouleverser sa réputation jusqu’à devenir l'amant parfait dont rêvent les dames de la cour. Il se mue même en représentant du lien organique entre arma et $a m o r^{85}$ : l'habileté de Keu sur le terrain suscite l'intérêt des femmes, comme, en amont, l'amour engendre sa vaillance, puisque celui qu'il nourrit pour Andrivete ${ }^{86}$ est bien la cause de sa prouesse. Le sénéchal reconnaît lui-même l'importance du sentiment amoureux dans son succès:

Et dist: «Par moi puis bien prover

Que c'est voirs, et bien le conois,

Car ainc mais ne valui .ii. nois.

Mais ore m’a Amors presté

Essience et force et bonté

Tant qu'il ne puet estre a nul fuer,

Se, par faute de mauvais cuer,

Ne remaint qu'encore ne vaille.» (Escanor, v. 4272-4279)

S'il est surprenant pour le lecteur de voir Keu tomber profondément amoureux, lui dont les propos misogynes sont bien connus, et tenir un discours empreint de la plus pure courtoisie, l'image que le roman offre du personnage n'est pas forcément contradictoire avec la tradition arthurienne: Keu reconnaît lui-même avoir été un piètre chevalier (v. 4274), avant qu'Amour ne l'aiguillonne. De cette manière, Girart d'Amiens

85 Il est surprenant que le sénéchal soit le représentant de ces valeurs, si l'on se rappelle par exemple le jeu-parti du Lai du Mantel: en débattant de l'infidélité féminine, Gauvain défend la doxa courtoise; les femmes sont infidèles, car la chevalerie est en déclin. Keu en revanche propose un point de vue plus grinçant et misogyne, en rejetant la faute sur les femmes et en niant l'importance du rapport dialectique entre arma et amor. Le Manteau mal taillé, éd. Nathalie Koble, éd. cit., v. 662-731.

86 Les relations amoureuses de Keu sont également évoquées dans le Cort Mantel, le Perceval en prose et le Tournoiement du Blanc Castel. Voir l'article de Damien de Carné, «Escanor dans son roman», art. cit. 
présente un personnage en évolution, capable d'amendements malgré son passé littéraire, pour devenir à son tour un chevalier errant, un fin'amant. Lauteur respecte alors la juste proportion d'invariants et de variations propre à l'écriture transfictionnelle.

La courtoisie de Keu passe aussi par un comportement différent selon le milieu dans lequel il évolue. Le sénéchal n’est jamais médisant en dehors du cercle de la Table Ronde, comme le souligne Brian des Îles:

Et li dist, «Ké, en vo parole

Ne voi rienz ore a amender.» (Escanor, v. 15090-15091)

Si sa mauvaise langue ne s'exprime qu'à la cour d'Arthur, c'est bien que Girart d'Amiens souhaite en démontrer le rôle structurant et fédérateur, par le rire qu'elle suscite auprès des chevaliers:

Quant li rois ot bien entendu

Ce que Kez li ot despondu

De ses oevres et de ses fais,

Il fu si de rires refais

C'a grant paines se sostenoit.

Nuz qui la fust ne s'en tenoit,

Au mainz cil qui le conte oïrent. (Escanor, v. 6891-6807)

C'est donc en subvertissant les éléments de la tradition que l'auteur revalorise le personnage pour en montrer le caractère organique. Le Keu d'Escanor demeure fidèle à ce qu'il était dans les romans arthuriens antérieurs et les variations sur son caractère n'empêchent pas son identification $^{87}$. Seule l'adjonction d'une origine noble contredit quelque peu les données fournies par les romans antérieurs: Keu est de "grant lignage» (v. 6697) dans Escanor, propriété commode pour qui souhaite épouser

87 Voir en ce sens l'article de Richard Saint-Gelais, "Personnage et transfictionnalité», in La fabrique du personnage, dir. Françoise Lavocat, Claude Murcia et Régis Salado, Paris, Champion, 2007, p. 269-286. Le critique y traite du retour des personnages et de leurs variations au sein des diverses transfictions. La question se complique en littérature moderne par l'hégémonie de l'auteur qui crée le premier le personnage: le lecteur établit une hiérarchie entre le personnage d'Emma Bovary tel que le présente Flaubert et ses contreparties transfictionnelles, perçues comme des fausses représentations. Dans le cas de la littérature médiévale, la question se résout plus facilement en raison de la dimension participative de l'écriture: nul ne peut revendiquer l'invention du personnage de Keu. 
l'héritière de Northumberland. La tradition fait pourtant de lui un homme aux origines obscures, fils d'un vavasseur et nourri au sein d'une servante pour laisser sa place à Arthur ${ }^{88}$. La reprise d'un univers de fiction autorise la variation: en l'absence de propriété littéraire, le romancier peut, même après Chrétien de Troyes, «réemployer des personnages sans (leur) garder la mémoire des aventures qu'ils ont vécues ${ }^{89}$. L'écriture médiévale, par sa dimension participative, suppose qu'il n'y a pas une version canonique parmi les récits qui impliquent le sénéchal; il n'est pas besoin d'élire un portrait de Keu qui serait son image immuable.

La transformation qu'opère le roman sur le sénéchal n'est pas anodine et bouleverse les convictions préalables du lecteur: la transfictionnalité de l'univers arthurien permet de convoquer des personnages déjà conceptualisés par les lecteurs, qui en ont une idée précise, en l'occurrence celle d'un piètre combattant et médiocre compagnon insensible à l'amour dans le cas de Keu. Le lecteur modèle ${ }^{90}$ d'Escanor, celui que le récit conceptualise comme récepteur idéal, en tant que connaisseur du roman arthurien, doit réviser ses présupposés sur le personnage du sénéchal et en construire une nouvelle image sur la base des données diégétiques supplémentaires voire contradictoires que fournit le roman de Girart d'Amiens ${ }^{91}$. La cour arthurienne est ainsi privée d'un faire-valoir aussi bien que d'un élément qui structurait l'errance des chevaliers en les obligeant à prouver leur bravoure. Beate Schmolke-Haßelmann a jugé en ce sens que

so negiert der Verfasser in mehrfacher Hinsicht die herkömmlichen Aspekte des arthurischen Versromans. Ist es Verständnislosigkeit oder der bewusste Versuch, ein Gegenmodell aufzubauen ??2

L'auteur n'aurait-il pas perçu le rôle structurant de Keu dans la logique narrative arthurienne, comme le pense la critique? Il faut à notre avis

\footnotetext{
88 Voir Marie-Luce Chênerie, Le Chevalier errant, p. 99-103.

89 Annie Combes, Le Récit en mouvement, p. 39.

90 Voir note 367, page 153 pour une définition du lecteur modèle.

91 Elisabeth Schulze-Busacker traite du renouveau opéré sur Keu dans «"Gauvain, li malparlier". Le rôle de Gauvain dans le roman d'Escanor», art. cit.

92 Beate Schmolke-Haßelmann, Der arthurische Versroman, p. 69. "Ainsi, l'auteur nie en plusieurs points les aspects traditionnels du roman arthurien en vers. S'agit-il d'un défaut de compréhension ou de la tentative consciente de construire un contre-modèle?" (nous traduisons)
} 
plutôt y voir une tentative de transformer le déroulement habituel du roman arthurien en vers: au lieu d'intégrer un jeune chevalier à la Table Ronde ou de prêter de nouvelles aventures à Gauvain, Girart d'Amiens donne un rôle actanciel à une figure tutélaire du monde arthurien pourtant toujours reléguée au second plan. Il ne s'agit plus, dans Escanor, d'augmenter le personnel arthurien, mais plutôt de valoriser l'univers déjà construit au fil du temps pour le réinventer de l'intérieur. La nouveauté du roman ne réside pas dans ses aventures ou ses personnages, mais dans les techniques narratives qu'il explore. Revisiter un personnage si célèbre donne un autre point de vue sur Keu, le réhabilite en proposant au lecteur un caractère non dénué de défauts mais dont le courage et la sensibilité ne demandaient que l'occasion de s'exprimer.

Retravailler l'univers en transformant les interactions entre les personnages et la fonction dévolue aux figures clés n'est pas une technique étrangère au roman arthurien en prose: cette écriture met aussi en scène des actants dont le passé littéraire est bien attesté, en approfondissant leur enfance, leur caractère, leurs motivations ou leur destin. Ce processus est appliqué au Morholt d'Irlande, personnage réduit à un opposant dévastateur dans les romans en vers du XII ${ }^{\mathrm{e}}$ siècle. Sa biographie est donc lacunaire, jusqu'à ce que La Suite du Roman de Merlin et le Roman de Meliadus comblent le vide en narrant les aventures qui l'ont mené à devenir un chevalier redouté ${ }^{93}$. La même continuation paraleptique ${ }^{94}$ s'applique $^{\prime}$ pour Bréhus sans Pitié, dont le Roman de Meliadus explicite la haine des femmes par la trahison de l'amie du Morholt ${ }^{95}$. Reproduire en vers cette façon d'étendre l'univers de fiction a bien sûr d'autres implications: ce n'est ni le destin du personnage ni ses enfances qui sont reconstruits, mais son caractère qui se voit approfondi et problématisé. Là encore, l'univers de fiction n'est pas envisagé dans sa linéarité chronologique, mais dans son immanence.

93 Barbara Wahlen étudie l'évolution du personnage du Morholt dans «Entre tradition et réécriture: le bon Morholt d'Irlande, chevalier de la Table Ronde», art. cit.

94 L'expression désigne l'opération qui consiste à combler les lacunes, les vides laissés par les textes antérieurs. Gérard Genette, Palimpsestes. La littérature au second degré, Paris, Le Seuil, 1982, p. 242-243. Cette notion est particulièrement féconde dans l'écriture en prose.

95 Voir Barbara Wahlen, L'Écriture à rebours, p. 328. 


\section{Typologie du personnage arthurien tardif}

\section{Le héros: problèmes de désignation}

La réactivation transfictionnelle qui concerne Keu ferait-elle enfin de lui le héros d'un roman arthurien? Cette question pose le problème de la difficile assignation d'un héros aux romans arthuriens tardifs, qui multiplient les protagonistes potentiels, au contraire des romans arthuriens de première génération. Vincent Jouve ${ }^{96}$ constate une évolution dans la typologie du héros au cours des siècles: ainsi le héros classique est un demidieu qui se distingue par des exploits, tandis que le héros médiéval est un individu qui fait preuve de courage et de prouesse dans l'exercice des armes. L'application du terme "héros" n'est donc pas identique à toutes les époques littéraires. Le critique dégage deux constantes inhérentes à la notion, dans une acception littéraire: la singularité et l'exemplarité. Le héros désigne en ce sens le personnage sur lequel se concentre l'attention du récit et celui qui par son exemple - positif ou négatif - délivre un enseignement. À partir de là, chaque période mais aussi chaque genre privilégie un type de héros: Philippe Hamon ${ }^{97}$ souligne que celui-ci se définit par une prédésignation conventionnelle liée au genre, c'est-à-dire que le héros de tragédie n’aura par exemple pas les mêmes propriétés intrinsèques que le héros de romans policiers.

Dans le roman arthurien en vers, le héros est un chevalier, remarquable autant pour sa valeur guerrière hors norme que pour sa courtoisie. Il est le meilleur chevalier. La démonstration de ses capacités à l'épée et à la lance, qu'il met au service du bien commun, de même que la découverte de l'amour, couronnent son itinérance ${ }^{98}$. Alors qu'un protagoniste se détachait assez nettement chez Chrétien de Troyes - malgré l'entrelacement naissant dans le Conte du graal -, dans les romans tardifs, plusieurs personnages répondent aux caractéristiques de la prédésignation conventionnelle. Dans Escanor, Keu remplit les critères du héros singulier: le récit se focalise très souvent sur son personnage et donne une motivation à ses actes.

\footnotetext{
96 Vincent Jouve, «Le héros et ses masques», in Le Personnage romanesque, Cahiers de narratologie 6, Presses de l'université de Nice, 1995, p. 253-254.

${ }^{77}$ Philippe Hamon, «Pour un statut sémiologique du personnage», art. cit., p. 91-93.

98 Voir Marie-Luce Chênerie pour une définition du héros de roman de chevalerie, Le Chevalier errant, en particulier le chapitre I.
} 
La diégèse est jalonnée par la prouesse du sénéchal et se termine par sa conquête d'une femme. Si Keu apparaît comme un excellent chevalier, le roman ne laisse néanmoins pas l'impression qu'il est le meilleur, mais bien plutôt que l'amour accroît son potentiel, comme nous l'avons signalé au chapitre précédent. Il est pourtant indéniable que le sénéchal suscite un intérêt particulier dans ce roman.

Girart d'Amiens ne prend pas le parti de proposer une figure exemplaire à tous points de vue, il renonce à mettre en scène un "meilleur chevalier du monde» en plus. Au contraire, il élit un personnage digne d'intérêt par l'image contrastée qu'il donne de la chevalerie. Le héros n'est dans ce cas pas un exemple de perfection, mais un individu dont les qualités viennent excuser les défauts. Ce choix ne va pas sans évoquer les héros modernes, promus au rang de protagonistes pour la complexité de leurs caractères et de leurs passions - que l'on pense à Frédéric Moreau ou Emma Bovary. Vincent Jouve établit en ce sens une distinction entre classicisme et modernité:

Alors qu'à l'époque classique, le héros attirait d'abord l'attention par ses exploits, à l'époque moderne, c'est surtout par la façon dont le texte le présente qu'il suscite l'intérêt ${ }^{99}$.

Keu se situe à mi-chemin entre ces deux états: la volonté de redorer le blason d'un personnage décrié de la tradition implique de raconter ses prouesses pour légitimer qu'il occupe le devant de la scène. Le but n'est pas de faire du sénéchal un nouveau "biaus desconneüz», mais bien d'approfondir son caractère et de motiver voire justifier son comportement.

Ce déroulement de potentialités narratives se traduit aussi par un jeu sur les focalisations. Une large place est accordée aux tourments amoureux de Keu, que le narrateur laisse monologuer (Escanor, v. 9207-9244), voire dont il transcrit les pensées en discours indirect libre ${ }^{100}$ :

\footnotetext{
99 Vincent Jouve, "Le héros et ses masques», art. cit., p. 252.

100 Si certains critiques considèrent que le narrateur de la littérature médiévale n'est pas assez subtil pour opérer la distinction, nécessaire au discours indirect libre, entre son point de vue et celui du personnage, il faut admettre que dans cet exemple, comme dans d'autres passages d'Escanor, ce sont bien les ambitions et les pensées de Keu qui sont restituées, sans qu'apparaisse un verbe introducteur de parole. Au sujet de la possibilité pour le discours indirect libre de se manifester
} 
Tant fera mesire Gavainz,

Lancelos ne mesire Yvainz,

Perchevauz ne son parenté,

Ne l'auront mais en tel viuté

Conme il ont eü longuement.

Car il ert au tornoiement

De si tres aspre vasselage

Qu'il en fera crever de rage

Touz les mesdisanz de la cort

Qui ore l'ont tenu si court.

Mais il s'en vengera, s'il puet:

De rienz plus li cuers ne li duet

Que de ce qu'il ne voit le point

Qu'il s'en puist bien venchier a point.

En tel maniere chemina

Kez ce soir, qui ainz ne fina

D'ainsi pensser a lui meïsmes. (Escanor, v 491-507)

Ce passage est une promesse de vengeance formulée par Keu, qui entend démontrer sa prouesse et démentir sa réputation littéraire. Les trois derniers vers signalent la clôture du discours indirect libre: c'est ainsi «en tel maniere»- que Keu est en train de penser «a lui meïsmes», ce sont ses propres paroles qui sont restituées. Le narrateur d'Escanor varie particulièrement les points de vue adoptés et multiplie les focalisations internes, ce qui brouille la désignation d'un héros unique au roman. Keu n'est ainsi pas le seul à remplir les critères qui l'éliraient comme protagoniste: le même développement des amours et insomnies de Gifflet et la reine de Traverses agrémente le récit, si bien que l'on ne peut se fonder sur l'intrigue amoureuse pour désigner le héros d'Escanor. On

dans la littérature médiévale, on consultera l'article de Caroline Pernot, "Le discours indirect libre médiéval: épistémologie et enjeux méthodologiques», Atelier Reverdie, 22 février 2008, en ligne: http://reverdie.free.fr/site/spip. php?article32 et celui de Sophie Marnette, "Réflexions sur le discours indirect libre en français médiéval», Romania, 114, 1996, p. 1-49, qui présente les spécificités du discours indirect libre médiéval en proposant plusieurs exemples qui attestent bien son existence. Elle souligne notamment que les temps verbaux ne marquent pas spécifiquement le DIL et que celui-ci est très souvent précédé d'un discours indirect ou d'un discours direct qui rattache explicitement le passage au point de vue d'un personnage particulier. 
ne peut non plus se fier à la fréquence des apparitions: Escanor le Bel ${ }^{101}$ intervient à intervalles réguliers, puis devient le personnage central à la fin du roman, lorsqu'il se retire dans un ermitage et meurt en odeur de sainteté. L'inventaire de la bibliothèque du roi Charles $\mathrm{V}^{102}$ donne d'ailleurs la faveur à ce personnage en dénommant l'œuvre «Escanor ", tout comme le font aussi les éditeurs modernes.

La difficulté à désigner un héros est une spécificité du roman arthurien tardif: les auteurs jouent volontairement avec les attentes du lecteur et avec la structure traditionnelle du genre. Nous évoquions le cas de Keu protagoniste, problématique, car son rôle de faire-valoir est fonctionnel dans le monde arthurien; c'est en fait bien la notion même de héros qui devient l'objet des subversions des auteurs. Dans les derniers représentants du roman arthurien, le héros n'est plus nécessairement le chevalier qui est singularisé en premier dans le récit. La remarque est valable pour les romans en prose. Le Roman de Meliadus commence par s'attarder sur les péripéties romaines d'Esclabor, père de Palamède, avant que le récit dirige son attention vers la cour d'Arthur et les aventures du Bon Chevalier Sans Peur et de Meliadus. Ce début annonce que le roman s'intéresse aux pères des héros arthuriens. Dans Floriant et Florete, l'histoire des parents de Floriant, qui occupe les 732 premiers vers, trompe de la même manière le lecteur sur le sujet principal du récit, à tel point que la reliure du manuscrit, datée du XVII ${ }^{\mathrm{e}}$ siècle, porte le titre de «Roman de Elyadus», du nom du père de Floriant ${ }^{103}$.

Le brouillage de l'objet d'attention principal est fréquent dans nos romans: Melyador met d'abord en scène le personnage de Camel de

101 Le personnage d'Escanor apparaît dans des textes antérieurs, notamment L'Âtre Périlleux, la Continuation de Gerbert de Montreuil et Guiron le courtois. On consultera à ce sujet l'article de Damien de Carné, «Escanor dans son roman ", art. cit. Le critique traite également de la promotion de l'opposant à la cour arthurienne en protagoniste du roman.

102 Le manuscrit, sans doute perdu, y était en effet désigné par le titre «Du Bel Escanor de la Montangne et de Witasse le Moine, avecques tres grans truffes». Voir l'introduction à l'édition de Richard Trachsler, éd. cit., p. 20, et son article, "Escanor von Girart d'Amiens im Spannungsfeld von Vers und Prosa", art. cit., p. 262-263. Cette entrée dans l'inventaire laisse penser qu'Escanor figurait côte à côte avec le court roman de piraterie Wistasse le moine.

103 Voir les pages XIX-Xx de l'édition d'Annie Combes et Richard Trachsler, éd. cit. 
Camois ${ }^{104}$, qui tombe amoureux de la jeune Hermondine et lui compose des rondeaux dans la plus pure tradition courtoise. Il est le premier à être présenté:

Chils castiaus fu nomé Camois

Et li sire qui le tenoit

Messires Camelz se nommoit. (v. 14-16)

L'énamourement respecte la tradition ovidienne: «En ce regart li vient la darde / d'Amours, c'onques senti n'avoit.» (v. 226-227). Camel, en parfait fin'amant, est touché par le dard d'Amour, qui traverse ses yeux. Le narrateur se concentre ensuite sur son point de vue: il traduit ses hésitations, son chagrin, ses stratégies, comme lorsque le personnage se rend pour la deuxième fois à Montgriés dans le but de se déclarer, mais qu'il n'ose pas le moment venu:

Mais, quant la est, il le crient si,

Ou le voit aler et venir,

Que brief il ne poet revenir

A son pourpos, ançois le pert. (Melyador, v. 504-507)

Cette pénétration dans l'intériorité du personnage semble lui réserver une place primordiale et valorisante dans l'économie du récit. De fait, le narrateur en offre un portrait élogieux:

On ne trouvast parel a li, plus preu, plus fier ne plus hardi, fust a la guerre ou au tournoi, car riens ne duroit devant soi. (Melyador, v. 323-326)

Camel de Camois est surtout le premier personnage à composer des rondeaux et prend dès lors le rôle du chevalier poète, sur le modèle de Tristan: il chante son premier rondeau au retour de Montgriés, près d'une fontaine, puis envoie une lettre contenant une nouvelle pièce lyrique à

104 Au sujet du personnage de Camel de Camois, on consultera les pages 254-256 de l'introduction à l'édition de Nathalie Bragantini-Maillard et l'article de Florence Bouchet, "Camel de Camois, anti-héros problématique", in Façonner son personnage au Moyen Âge. Actes du 31 Colloque du CUER-MA, 9, 10 et 11 mars 2006, dir. Chantal Connochie-Bourgne, Aix-en-Provence, Publications de l'Université de Provence, («Senefiance», 53), 2007, p. 67-75. 
Hermondine, dans la plus pure tradition de la finamor (insomnies de l'amant, yeux séduisants de l'amie, vocabulaire féodal et guerrier comme métaphore de l'amour, etc., v. 871-935). La focalisation du récit sur le personnage de Camel de Camois dure plus de 1150 vers; hormis la faille du somnambulisme explicitée par l'auteur après le portrait élogieux (Melyador, v. 327-350), le personnage présente jusque-là toutes les qualités d'un potentiel héros qui pourrait supporter des valeurs positives.

En concentrant le début du récit sur cette figure, le narrateur fourvoie son lecteur: lorsque Floree commence à mettre «empecement et detrïance» aux velléités de Camel (Melyador, v. 541-544), le lecteur peut penser qu'elle occupe le rôle de l'opposant, jalouse d'un amour qu'elle ne suscite pas. Le narrateur semble d'ailleurs soutenir Camel, lorsque celui-ci repart bredouille, après qu'Hermondine s'est cachée lors de sa visite, sur ordre de Floree:

\section{Li chevaliers dont je devis}

Se departi a celle fois

Tous courouciés, et ce fu drois,

Car point n'avoit veü sa dame. (Melyador, v. 692-695)

Aux yeux du narrateur, il est normal que Camel soit chagriné de ce rejet. Il fait donc peser sur Floree le soupçon de la calomnie. À ce stade du récit, le lecteur ne peut présager avec certitude la suite de l'histoire et n'anticipe pas forcément les mesquineries auxquelles se livrera Camel de Camois; l'horizon d'attente est perturbé. Seules quelques discordances disqualifient le potentiel héros: la chasse au cerf, qui n'a plus rien de merveilleux, l'animal étant tué sans états d'âme ${ }^{105}$, et le somnambulisme, qui justifie à lui seul l'éviction du personnage auprès d'Hermondine. Il faut attendre le retour d'Hermondine en Écosse pour que Camel révèle sa vraie nature et se montre sans pitié envers Lot, l'oncle de sa bien-aimée, qu'il attaque et emprisonne. Le lecteur se rend compte alors que Camel, loin d'être le héros, est en réalité l'opposant de l'histoire, que les personnages positifs vont s'employer à combattre et qui finira vaincu par Melyador. Ce dernier n'apparaît qu'après 2500 vers, et l'on doute sans cesse qu'il soit le

105 Au sujet des chasses au cerf dans Melyador, voir l'article de Laurence Harf-Lancner, "La chasse au blanc cerf dans le Méliador: Froissart et le mythe d'Actéon ", art. cit, et l'introduction à l'édition de Nathalie Bragantini-Maillard, éd. cit., p. 275-278. 
vrai héros, concurrencé qu'il est par les nombreux chevaliers ${ }^{106}$ embarqués dans le défi d'Hermondine.

L'auteur de Rigomer déçoit lui aussi les attentes, en repoussant sans cesse le début de l'errance chevaleresque et la désignation d'un héros à l'histoire: Yvain puis Sagremor se lancent d'abord à la poursuite de la messagère venue à la cour pour reprocher leur avachissement aux chevaliers, puis échouent, le premier ayant oublié son épée, le second abandonnant le combat après l'interruption de la demoiselle. Lancelot montre plus de persévérance et décide de poursuivre son errance malgré son incapacité à répondre à la demande de la demoiselle, mais il échoue tout autant au château de Rigomer. Dans la deuxième partie du roman, c'est à Gauvain, l'élu de Rigomer, que revient la réussite de l'aventure. Peut-on néanmoins affirmer qu'il s'agit du héros de l'histoire? L'élection suffit-elle à réduire les autres chevaliers à des rôles secondaires, quand bien même on narre leurs aventures pendant plus de 10000 vers? Lancelot, s'il est tourné en ridicule à maintes reprises et échoue au château, réapparaît tout de même en héros à la cour puis se distingue lors de l'errance qui précède la Quintefeuille. Quant aux autres chevaliers, ils font chacun l'objet d'un petit épisode lors duquel ils s'illustrent.

À la multiplicité des héros répond la multiplicité des héroönes: dans Melyador, si Hermondine est présentée comme l'amie à conquérir, aussi belle que courtoise, c'est bien plutôt Floree qui occupe le premier plan et détient les ficelles de l'histoire. Adeline Latimier note qu'Hermondine est souvent désignée comme "sa cousine» en référence à Floree et se définit donc dans son lien avec cette dernière ${ }^{107}$ : " "Et ou est sa cousine, / ceste que on nomme Hermondine?” "(Melyador, v. 773-774). À côté de Floree, dont l'esprit vif se manifeste dans ses ruses, Hermondine est peu individualisée et se singularise uniquement par sa parenté: en tant que fille du grand roi d'Écosse, elle représente un bon parti que le narrateur souligne à plusieurs reprises en la nommant par la périphrase «la fille au roy Hermont» (v. 1208). La jeune fille se soumet d'ailleurs bien souvent

\footnotetext{
106 Cette multiplication des chevaliers est présente également dans Claris et Laris, Escanor et Rigomer: elle est liée à l'entrelacement, que nous développerons aux pages 495-519.

107 Adeline Latimier, Lire le nom propre.
} 
à l'avis de sa cousine et n'émet que rarement une opinion ${ }^{108}$. Dans le roman tardif, ce n'est plus forcément l'amante ni la plus belle jeune fille qui focalise l'attention du narrateur et attire la sympathie ou l'admiration du lecteur: l'intelligence pratique de Floree et son dévouement pour sa cousine assurent au personnage l'adhésion du lecteur ${ }^{109}$.

Cette multiplicité des héros n'est pas étrangère aux romans en prose: déjà le Lancelot-Graal impose une distinction entre élection et héroïcité, en mettant en scène dans la Queste un élu, Galaad, dont on ne peut affirmer qu'il soit le héros du cycle, ni même de l'œuvre, si l'on peut considérer la Queste comme telle ${ }^{110}$. Dans les romans de troisième génération comme dans les romans en vers tardifs, il est bien difficile de distinguer un seul héros parmi la quantité de bons chevaliers qui interviennent. Roger Lathuillère commente cette impossibilité à désigner un personnage qui surpasserait tous les autres dans le cycle de Guiron le courtois:

Le lecteur moderne se tromperait s'il essayait de discerner qui est le protagoniste de Lac ou d'Yvain, du Bon Chevalier sans peur ou de Leodagan, de Danain ou du roi Hoël. Tous représentent un aspect du chevalier idéal, reflètent tel ou tel trait de son visage, aucun ne l'incarne tout entier ${ }^{111}$.

L'esthétique des romans tardifs, en vers ou en prose, adopte donc des tendances communes, liées au travail de l'accumulation de courtes

108 Jeanne Lods, "Amour de regard et amour de renommée dans le Méliador de Froissart", Bulletin bibliographique de la Société internationale arthurienne, 32, 1980, p. 240-243.

109 Nathalie Bragantini-Maillard souligne la maîtrise de l'art rhétorique dont fait preuve Floree, qui fait d'elle un double de la figure du clerc-poète. Elle légitime la fiction en rendant le mensonge acceptable, voire positif ( Il fault mentir pour un moiien / trouver quant le requiert li cas", v. 2173-2174). Voir Melyador, éd. cit., p. 259-261 et "Il faut mentir pour un moiien trouver quant le requiert li cas." Melyador: une courtoisie entre ombre et lumière", in Cultures courtoises en mouvement, dir. Isabelle Arseneau et Francis Gingras, Montréal, Presses de l'Université de Montréal, 2011, p. 64-73.

110 La question des bornes de l'œuvre au sein d'un cycle complexifie celle de l'héroïcité: faut-il chercher un héros par œuvre du cycle ou un héros pour le cycle entier? Dans les deux cas, la question est sans issue. Sur les bornes de l'œuvre dans l'architecture cyclique, voir Patrick Moran, Lectures cycliques.

111 Roger Lathuillère, "L'évolution de la technique narrative dans le roman arthurien en prose de la deuxième moitié du XIII ${ }^{\mathrm{e}}$ siècle», art. cit., p. 205. 
aventures et de l'entrelacement, sur lesquels nous aurons à revenir. L'élection d'un héros unique relève déjà du passé, d'un mode de narration propre aux premiers romans en vers.

La mise en scène de plusieurs protagonistes potentiels complexifie le monde fictionnel, le présente comme multiple. Les auteurs jouent avec l'horizon d'attente du lectorat, habitué au héros unique dès lors qu'il était mis en présence d'un texte en vers. Bouleversé dans ses codes génériques d'appréhension du texte, le lecteur est invité à considérer la Table Ronde comme un ensemble, dont chacun des membres a ses failles, même si un élu se distingue le temps d'une aventure. Cet état de faits contribue à la démythification de l'univers arthurien, où même le roi ne remplit plus son rôle: les chevaliers sont têtes en l'air (Yvain part en aventures sans son épée, Rigomer, v. 169-170), discourtois (ainsi de Lancelot qui gagne à la course en tuant le cheval de son adversaire, Rigomer, v. 5153-5154) et affamés (Cligès s'inquiète d'abord de manger, alors que ses hôtes lui annoncent qu'il va mourir, Rigomer, v. 9227-9232), ils suscitent le rire du public (comme celui de Gauvain devant la transformation de Lancelot: "Quant Gavains l'ot, si en sousrist», Rigomer, v. 14053) et rapprochent le roman arthurien des genres comiques ${ }^{112}$.

\section{Un manichéisme relatif}

L'insinuation de failles au sein de la chevalerie arthurienne a pour conséquence l'engendrement d'un monde où l'entre-deux est envisageable: les auteurs tardifs renoncent au manichéisme, à une polarisation claire des personnages. Cela vaut pour les personnages principaux, faillibles $^{113}$, mais également pour les opposants au monde arthurien, qui ne

112 Sur le comique dans Rigomer, voir l'article de Peter Noble, «Le Comique dans Les Merveilles de Rigomer et Hunbaut», Arthurian Literature, 19, 2003, p. 77-86, et celui de Richard Trachsler, "Lancelot aux fourneaux: des éléments de parodie dans Les Merveilles de Rigomer?», art. cit.

113 On peut encore signaler à cet égard que Laris engendre un bâtard avec la fée Madoine qu'il rejette sans scrupules par la suite, sans aucune considération pour son fils, et que les chevaliers de la Table Ronde font preuve d'une envie peu conforme à l'idéal chevaleresque à l'encontre de Gauvain, qu'ils ne reconnaissent pas, au tournoi de Rigomer: "Tout sont a lui abandoné / Et se li ont le pris doné, / For Breton qui'n ont tel envie, / Qu'il jurent le mort et le vie: / Si il revienent au lundi, / Ains en seront .c. cuer parti, / Que il ensi le pris en port." (Rigomer, v. 13293-13299) L'envie des Bretons paraît d'autant plus condamnable 
sont pas aussi foncièrement mauvais que dans le roman arthurien canonique. Camel de Camois aime Hermondine pour elle-même, et non pour son statut ni sa réputation. Son amour sincère pour elle suffit à interroger les limites de celui de Melyador, qui n’a jamais rencontré la demoiselle, comme le lui rappelle Camel:

"Je vous dirai raison pour quoi:

Pour ce que la belle Hermondine

Ay aimé tous jours d'amour fine

Et vous l'amés par oïr dire.

On en doit bien truffer et rire!» (Melyador, v. 8944-8948)

Camel exprime ici une opposition effective entre leurs deux types d'amour: l'amour de visu pour lui-même, l'amour par ouï-dire pour Melyador ${ }^{114}$. Si le personnage de Camel est condamné pour sa démesure, la nature de ses sentiments est cautionnée par le narrateur, qui compare sa mort à celle des martyres d'amour, Narcisse, Tristan ou encore Achille (Melyador, v. 9126-9135). Ce n'est donc pas sa traîtrise qui le mène à la mort, mais bien l'amour qu'il porte à Hermondine, ce qui relativise la condamnation dont il fait l'objet. Camel ne fonctionne pas entièrement comme anti-héros, d'autant moins qu'après sa mort, Hermondine semble éprouver des regrets, peut-être celui de ne pas s'être montrée assez indulgente envers cet amant éploré, dont on loue sans cesse la prouesse:

que les autres chevaliers du tournoi reconnaissent la suprématie de Gauvain avec admiration. On pourrait multiplier les exemples tirés des romans tardifs. Il faut encore noter que les prose attribue aussi des comportements répréhensibles à ses héros, Bohort ou Lancelot par exemple, qui tuent violemment et sans scrupules. Voir Cedric E. Pickford, L'évolution du roman arthurien en prose, p. 230-231.

114 La légitimité de l'amour par ouï-dire est plusieurs fois interrogée, notamment du point de vue de sa vraisemblance psychologique. Agamanor en problématise également la portée, en signifiant à Phénonée qu'il n'aimait Hermondine que par ouï-dire, ce sentiment n'égalant de loin pas l'amour de visu qu'il ressent pour son interlocutrice. Voir l'introduction à l'édition de Nathalie BragantiniMaillard, éd. cit., p. 314-321. Le roman interroge donc l'amour et ses fondements et propose une réflexion sur la connaissance de l'autre en amour, question qui concerne tous les couples mis en scène. Voir l'article de Nathalie BragantiniMaillard, "Une courtoisie entre ombre et lumière», art. cit. Sur l'amour par ouïdire, voir aussi Jeanne Lods, "Amour de regard et amour de renommée», art. cit. 
«Il m'est vis que cilz chevaliers

Qui mors est, c'est ou nom de moy.

C'est une raison ou je doy

Bien penser, qui sui une femme,

Car en conscience et en ame

Je m'en tieng grandement cargie

Et si plaing la chevalerie

De ce Camel, qui fu si grande.» (Melyador, v. 14371-14378)

Cette empathie exprimée doit encourager le lecteur à considérer positivement le personnage de Camel. Celui-ci est en quelque sorte racheté par son amour et sa chevalerie, qui en font un personnage plus contrasté que les habituels opposants du roman arthurien ${ }^{115}$.

L'intérêt porté au type de l'opposant rend ambiguë la polarisation axiologique des personnages: la compassion que le lecteur peut ressentir pour les adversaires des chevaliers arthuriens dans les représentants tardifs est liée à la focalisation interne dont ils font l'objet. C'est le cas pour Camel de Camois, mais aussi pour d'autres personnages: Aiglinz, l'oncle qui trahit Andrivete dans Escanor, Madoine, le roi qui assiège Beauté pour obtenir son amour dans Biaudouz, ou encore Maragot, le sénéchal amoureux de la mère de Floriant, qui se plaint de sa douleur d'amour (Floriant, v. 75-90). On suit ainsi le cheminement réflexif précédant l'élaboration de la ruse d'Aiglinz, qui craint que Keu ne lui nuise et lui fait croire qu'Andrivete a épousé un autre homme (Escanor, v. 11504-11635). À la fin du roman, lorsqu'Aiglinz constate la supériorité des troupes arthuriennes et que ses propres hommes menacent de se retourner contre lui, le récit s'arrête sur ses doutes et ses pensées:

Et pour ce que tez genz creoit

Et les preudonmes mescreoit,

Fu il tout ainssi triboulés,

Dont il par fu si adolez

115 Voir l'article de Douglas Kelly, "Analogie et anomalie dans la description de chevaliers: la diverse ordenance de Camel de Camois", in Façonner son personnage au Moyen Âge, éd. Chantal Connochie-Bourgne, Aix-en-Provence, Presses universitaires de Provence («Senefiance», 53), 2007, p. 145-155, et celui de Florence Bouchet, "Camel de Camois, anti-héros problématique», art. cit., pour qui Camel n'est jamais un anti-héros, mais attire au contraire la sympathie ou la compassion du narrateur. 
Que mot ne dist d'une grant piece.

Ainz pensoit adez a sa niece,

Ou point n'avoit fait son devoir. (Escanor, v. 24005-24011)

Alors que la reddition et la conversion des personnages malveillants sont habituellement expédiées en quelques lignes dans le roman arthurien canonique, elles font l'objet ici de plusieurs vers (plus de cent), donnant de cette manière une importance particulière à la psychologie de l'adversaire qui contribue à l'amender aux yeux du lecteur.

Cette perspective proposée sur l'adversaire et ses pensées s'exprime d'abord par la transcription des stratégies guerrières du camp ennemi. Le roman arthurien n'adopte en général pas un mode de focalisation interne centré sur l'opposant: cette pratique est empruntée à la chanson de geste, qui transcrit souvent la perspective du roi sarrasin et en restitue les stratégies et les conseils de guerre ${ }^{116}$. Le but est d'en démontrer la perfidie et de justifier la guerre menée contre un chef déloyal. Dans le roman arthurien en vers tardif, la restitution du point de vue ennemi brouille plutôt le sens et brise le manichéisme. Dans Escanor, le narrateur ne se contente pas de s'attarder sur l'organisation des bataillons d'Escanor le Bel (Escanor, v. 19043-19182), en parallèle au dénombrement de ceux d'Arthur ${ }^{117}$; il exprime également les pensées d'Escanor lors de son combat singulier contre Gauvain:

\author{
Mais dolenz ert en son corage \\ De ce qu'il ne pooit mener \\ A fin, tant s'en seüst pener, \\ Cest affaire qu'il ot empris; \\ Car il avoit ja bien apris \\ Qu'il n'estoit pas a son voloir \\ Et ce le faisoit mout doloir. (Escanor, v. 21056-21062)
}

116 On peut citer les laisses 32 à 52 de la Chanson de Roland, qui narrent le complot de Marsile contre Roland. Sur la symétrie des conseils du Sarrasin et de Charlemagne, voir Alain Labbé, L'architecture des palais et des jardins dans les chansons de geste: essai sur le thème du roi en majesté, Paris, Champion, 1987, p. 20ss.

117 L'effet de symétrie entre Arthur et Escanor le Grand est accentué par leurs sentiments pour leurs neveux respectifs. Tous deux s'inquiètent pour Gauvain et Escanor le Bel lors du combat qui les oppose, et veulent "deffaire ceste bataille», expression reprise presque à l'identique dans les vers 20975 et 20993. 
L'expression du point de vue d'Escanor le Bel $^{118}$ tout au long du récit permet au lecteur d'éprouver une certaine empathie pour lui et de comprendre les raisons qui le poussent à affronter Gauvain: le vœu exprimé lors de son mariage d'affronter le meilleur chevalier de la cour d'Arthur (Escanor, v. 13704-13736) semble résulter de l'obligation de se soumettre à la coutume pour ne pas être déclaré recreant et magnifier la fête plus que de velléités belliqueuses ${ }^{119}$. Il subit également l'influence de son oncle, qui, en tentant de le dissuader d'affronter Gauvain et en laissant entendre qu'il ne sera pas à la hauteur, éveille en lui cette rivalité (v. 13786-13807). Le texte souligne d'ailleurs, pour l'excuser, qu'Escanor le Bel n'a proféré une fausse accusation qu'en raison de «la melancolie / Qu'il avoit prise en la parole / De son oncle qu'il tint a fole» (v. 1382013822), ce qui responsabilise l'oncle plus que le neveu et signale que les erreurs d'Escanor le Bel sont affaires de de lignage ${ }^{120}$.

Sont également transcrites les interactions d'Escanor avec sa femme malade, qui le pousse à secourir Andrivete même s'il doit pour cela la laisser seule (Escanor, v. 23467-23526). Le narrateur insiste d'ailleurs régulièrement sur l'amour mutuel «fine» (v. 8208, v. 25221) et sincère que se portent les époux, dont ont dit que «onques iii. creatures / $\mathrm{Ne}$

118 On pourrait faire les mêmes constats sur le personnage d'Escanor le Grand, oncle d'Escanor le Bel, dont on motive les actes par le récit des conditions de sa haine envers Gauvain (Escanor, v. 13479-13676). L'homonymie des personnages participe de la confusion volontaire qui règne sur le lignage des opposants à la cour d'Arthur, qui sont tous plus ou moins apparentés.

119 Ce vœu rappelle le gab épique, en particulier ceux prononcés par les chevaliers ivres du Voyage de Charlemagne à Jérusalem et à Constantinople. John L. Grigsby, The Gab as a Latent Genre. La coutume des vœux exprimés lors d'une célébration est mise en cause dans Escanor, comme le sont d'ailleurs plusieurs autres conventions romanesques: l'incognito et le code de l'honneur, qui oblige Dinadan à prendre le parti de Mordred qu'il accompagne contre Keu. On relira en ce sens ses lamentations qui explicitent l'absurdité des conventions chevaleresques, Escanor, v. 1185-1229. Albert Gier traite de la mise en cause du code de l'honneur dans son article, "Lästern, Lügen, Schweigen », art. cit. Sur l'épisode de Dinadan - Mordred - Keu, voir aussi Leslie C. Brook, "A knight with reservations: the role of Dinadan in Escanor", art. cit.

120 Nous y reviendrons. Joanna Treboux en déduit que «tous les traits négatifs sont rattachés à Escanor le Grand». Escanor: la Montagne qui voulait éclipser le Soleil, mémoire de maîtrise soutenu en 2018 à l'Université de Lausanne, sous la direction de Barbara Wahlen, p. 46. 
furent assamblé si bien» (v. 8049-8050). Ecanor est donc capable d'un amour conforme à l'idéal arthurien, pour une femme extrêmement belle et noble ${ }^{121}$. La narration s'intéresse à la sphère privée du personnage et ne se contente pas de le présenter comme un nouvel opposant converti et intégré à la cour d'Arthur. Escanor a une histoire lignagère, un passé qui motive ses actions: sa rivalité avec Gauvain d'abord, et l'attentat perpétré par Galantinet ensuite, ponctuellement rappelé au cours du récit, notamment pour resituer le personnage d'Escanor comme

Celui qui par tel fausseté

Fu navrez si vilainement,

Dont li escuiers faussement

Ouvra, si conme avez ö̈. (Escanor, v. 13550-13553)

Le rappel de cet attentat, commis par l'écuyer du prétendu parangon de la courtoisie, n'est pas destiné qu'à faire ressurgir les souvenirs d'un lecteur oublieux: il s'agit également de susciter sa compassion pour Escanor et de lui permettre de comprendre ses motivations, si bien qu'il ne sait plus bien quel combattant soutenir lors du duel contre Gauvain. L'interruption de la demoiselle, qui sauve Escanor, tombe à point nommé pour éviter au lecteur la frustration de voir mourir un personnage qui lui est sympathique.

Escanor le Bel est d'autant moins négatif que l'on ne cesse de louer sa beauté (Escanor, v. 8042-8068), sa prouesse (Escanor, v. 20408-20464), ses beaux atours et l'amour qu'il suscite parmi ses sujets ${ }^{122}$, comme l'exprime à Galantinet une demoiselle de la suite qui précède son arrivée à la cour:

«Or sachiez bien, biax amis chiers,

Que touz li plus gentix princiers,

Li pluz franz, li pluz couvenables

Qui soit, nouz a a gouverner

Et nouz puet en touz liex mener

Conme les soies puceletes.» (Escanor, v. 8026-8032)

121 Le portrait de la femme d'Escanor intervient aux vers 8389-8464. La longueur de l'extrait traduit bien l'importance donnée à ce personnage, en tant que faire-valoir d'Escanor le Bel.

122 Voir Damien de Carné, «Escanor dans son roman», art. cit., p. 154. 
Les commentaires de ses gens, qui se répètent au fur et à mesure de la procession pour renforcer le portrait positif du personnage ${ }^{123}$, font d'Escanor le modèle du bon seigneur, tandis que la magnificence de son cortège, décrit longuement comme un "grant enchantement» (v. 8144) et une "faerie» (v. 8146), démontrent sa noblesse et le caractère merveilleux de sa cour. Ces éléments d'éloge doivent rendre l'attentat de Galantinet d'autant plus odieux aux yeux du lecteur. Tout mène à le blâmer: la longue description d'Escanor et sa suite, qui dépeint un tableau idéal de gaieté, de beauté et d'amour mutuel entre époux et entre sujets et seigneur, devrait inciter l'écuyer à renoncer à son projet. Il n'en fait rien, lui qui pourtant a entendu le plus grand bien d'Escanor. Il regrette plutôt d'entendre louer son ennemi :

L'escuiers prist a maudire

Pour ce que deseur touz looit

Celui que si forment haoit. (Escanor, v. 8382-8384)

Cette réaction offre un contraste saisissant avec la courtoisie et la beauté de ce cortège. Ce passage démontre bien que l'adversaire de Gauvain n'est pas si haïssable, mais qu'il vient au contraire bouleverser la tradition du genre: l'ennemi de la cour peut aussi être sincèrement apprécié de ses sujets, tout comme il peut apparaître comme un chanteur charmant et sympathique, lui qui entonne un refrain lors de cette procession.

Galantinet l'attaque néanmoins lâchement ("par guile», v. 7879) en s'embusquant («s'ala embuschier», v. 7912, «se mist reconduement / El bois en cel lieu droitement / Ou li Biauz Escanors devoit / Passer, qui ne s'en percevoit.", v. 8385-8388), vêtu d'une armure rouillée et noire (v. 7875-7892), dont la couleur et l'état contrastent avec l'éclat, la joie et la dimension merveilleuse du cortège. L'armure rouillée est destinée à le faire passer pour fou, de telle sorte à obtenir des informations sur Escanor en demeurant incognito. Cet accoutrement a cependant surtout une fonction symbolique: il est dans un tel état de délabrement qu'on prend l'écuyer pour un "deable» (v. 8013) et on pourrait croire "qu'il venist d'enfer» (v. 7905). Voilà de quoi clarifier la façon dont le lecteur

123 Le narrateur ne manque pas de louer Escanor le Bel non plus: «Et vouz di c'ainc pluz franche rienz / Ne vit nuz ne mix affaitie, / Pluz debonaire, pluz haitie / A ses amis en toz endrois." (Escanor, v. 13680-13683) 
doit considérer le personnage, face au seigneur de la Blanche Montagne valorisé positivement ${ }^{124}$.

Escanor le Bel n'est pas, dans ce roman, un simple adversaire trop bien converti aux valeurs courtoises: il est dès le début un personnage courtois, vaillant, amoureux et policé. Pour créer ce personnage ambigu, Girart d'Amiens puise dans la tradition arthurienne: Escanor apparaît dans la Continuation de Gerbert de Montreuil, Guiron le courtois et surtout L'Âtre Périlleux. Damien de Carné a montré l'influence indubitable de ce dernier texte sur Escanor ${ }^{125}$. L'auteur y reprend en particulier la rivalité d'Escanor avec Gauvain, voire son fonctionnement comme double du neveu d'Arthur. Girart d'Amiens joue habilement de cette intertextualité: son roman dédouble la figure d'Escanor en un oncle semi-géant, orgueilleux et porté au mal (v. 13532-13535) et un neveu qui réhabilite son lignage. L'homonymie d'Escanor le Grand et d'Escanor le Bel ${ }^{126}$ est volontaire: elle fait écho à cet adversaire dangereux dans L'Âtre Périlleux - que Gauvain se verra dans la nécessité d'éliminer malgré sa demande de merci, trop menaçant qu'il est - et permet la rédemption du personnage par sa partition en deux pendants positif et négatif.

La stratégie de Girart d'Amiens pour façonner son personnage est la même pour construire celui de Brian des Îles, l'adversaire du Chevalier aux deux épées: il choisit un opposant de la tradition littéraire, un rival de Gauvain, dont il reconduit la concurrence avec celui-ci mais qu'il réhabilite en montrant ses qualités courtoises, lors des passages qui narrent son amitié avec Keu, et en motivant ses différends - Brian est jaloux de l'admiration que son amie Esclarmonde porte à Gauvain. L'enjeu est bien celui d'adopter une autre perspective sur l'opposant arthurien dans le but de complexifier un monde trop polarisé par le Bien et le Mal, d'où le choix de deux ennemis connus de la tradition. Car Brian des Îles a un

124 Voir Joanna Treboux, Escanor: la Montagne qui voulait éclipser le Soleil, p. 43-45 et l'introduction à l'édition de Richard Trachsler, éd. cit., p. 54.

125 Damien de Carné, «Escanor dans son roman», art. cit.

126 Ibid., Damien de Carné souligne que le surnom «le Bel» évoque une qualité courtoise, tandis que «le Grant» renvoie à l'altérité, à ses origines gigantales. Il développe également la rivalité d'Escanor et de Gauvain dans la tradition littéraire. L'homonymie accentue la parenté des deux personnages et l'idée de prédestination: quoique différents, ils sont tous deux contraints par un passé familial. Nous y reviendrons. 
statut tout aussi ambigu qu'Escanor : il commande le meurtre de Gauvain au début du texte et le défie devant les portes de son château, mais est sans cesse loué pour sa prouesse lors du tournoi de Baubourc, se fait l'ami indéfectible et compréhensif de Keu et se montre très courtois lorsqu'il reçoit Arthur chez lui. On apprend ensuite qu'un commentaire de son amie Esclarmonde sur la renommée et la prouesse de Gauvain a motivé sa jalousie et sa rivalité. Apparaissant à plusieurs reprises tout au long du roman, il n'y est ni totalement positif ni totalement négatif ${ }^{127}$.

Du point de vue des valeurs, les chevaliers de la Table Ronde et leurs opposants sont interchangeables, comme l'exprime Albert Gier :

Durch die Veränderungen, die Girart d'Amiens am Strukturmodell des Artusromans vorgenommen hat, werden die Aktanten Held und Gegenspieler (Aggressor), die bei seinen Vorgängern in scharfen Gegensatz stehen, einander bis zur Austauschbarkeit angenähert ${ }^{128}$.

Girart d'Amiens propose un monde qui n'est pas polarisé par le Bien et le $\mathrm{Mal}$, mais où l'entre-deux est bien plutôt la norme. Il s'inscrit en ce sens en continuité de la "culture de l'équivoque» ${ }^{129}$ qui se développe petit à petit au Moyen Âge; Jacqueline Cerquiglini-Toulet souligne que «dès la fin du douzième siècle, se met en place, progressivement, un mode de pensée plus complexe, qui brouille les oppositions frontales au profit d'une pensée du paradoxe ${ }^{130}$. Progressivement, l'homme se départit du binarisme pour considérer le statut des états intermédiaires, comme l'est la dorveille, entre le sommeil et la veille, la mélancolie, entre la joie et la douleur, comme l'est aussi la fiction, entre la vérité et le mensonge: «On

127 Le roman de Floriant et Florete fournit lui aussi un personnage qui n'est pas clairement polarisé: l'empereur Philimenis appartient au camp ennemi, parce que Maragot lui a promis sa vassalité. Il n'est pourtant pas un personnage négatif, malgré ses alliances douteuses.

128 Albert Gier, «Lästern, Lügen, Schweigen», art. cit., p. 227. "À travers les modifications que Girart d'Amiens entreprend sur la structure canonique du roman arthurien, les actants que sont le héros et l'opposant (l'agresseur), en total antagonisme chez ses prédécesseurs, deviennent presque interchangeables.» (nous traduisons)

129 Selon l'expression de Bruno Roy, Une culture de l'équivoque, Montréal; Paris, Presses de l'Université de Montréal, 1992.

130 Jacqueline Cerquiglini-Toulet, «Penser la littérature médiévale: par-delà le binarisme», French Studies, 64/1, 2010, p. 3. 
passe ainsi d'un monde où le blanc se distinguait sans ambages du noir à un monde où blanc et noir se mêlent dans une couleur qui reçoit de plus en plus d'attention: le gris ${ }^{131}$.

Ce goût pour l'équivoque et l'ambiguïté se manifeste de manière particulièrement forte dans Escanor; il s'agit d'une caractéristique qu'il a en commun avec d'autres romans arthuriens en vers tardifs. Nous l'avons souligné pour Camel de Camois dans Melyador, on peut encore citer Miraudiaus dans Rigomer, personnage négatif dont on adopte néanmoins le point de vue pour assister à sa crainte maladive d'affronter Gauvain, qui devient d'ailleurs son ami (Rigomer, v. 14953-15138). L'absence de manichéisme n'est pas étrangère non plus à certains romans en prose de deuxième génération: le Morholt devient dès le Tristan en prose un chevalier de la Table Ronde. Son passé n'est pas pour autant occulté: il ne cesse d'être désigné comme l'ennemi de Tristan, mais cela n'empêche pas sa valorisation comme un chevalier courtois et preux, ni même son amitié avec Arthur, dans Le Roman de Meliadus ${ }^{132}$. Meliadus lui-même entre en guerre contre Arthur après sa capture de la reine d'Écosse, mais demeure un héros positif. Brehus sans Pitié, le traître du Tristan en prose, apparaît lui aussi comme un chevalier arthurien, suscitant les rires de ses compagnons alors même qu'il bafoue l'un des fondements de l'idéologie arthurienne en affichant sa haine des femmes. À l'inverse, les héros font preuve de vices, que l'aventure ne vient pas amender: c'est le cas de Meliadus et du Bon Chevalier, dont la rivalité et l'émulation mènent aux péchés d'orgueil et d'envie ${ }^{133}$.

Dans la prose comme dans le vers tardif, les personnages sont contrastés et font preuve d'une psychologie qui leur est propre, que l'on pense à Kahédin et Palamède, qui suggèrent dans le Tristan en prose deux modes différents de vivre l'impossibilité amoureuse ${ }^{134}$. En désamorçant le manichéisme et en multipliant les focales, le roman arthurien en vers tardif s'autorise à donner une plus grande épaisseur psychologique aux personnages: pas seulement celle qu'impliquent l'introspection et le

131 Jacqueline Cerquiglini-Toulet, «Littérature médiévale?», art. cit., p. 180.

132 Voir Barbara Wahlen, «Entre tradition et réécriture: le bon Morholt d'Irlande, chevalier de la Table Ronde», art. cit.

133 Voir Barbara Wahlen, L'Écriture à rebours, p. 230-233.

134 Voir Philippe Ménard, "Le Roman de Tristan en prose au cœur de la littérature arthurienne», art. cit, p. 175-176. 
monologue intérieur, mais bien plutôt celle de la complexité éthique et ontologique. Par la multiplicité des quêtes, plusieurs personnages sont individualisés et reçoivent des propriétés inédites dans le roman arthurien. Laris se montre ainsi volontiers impulsif et irréfléchi, en proposant à Tallas une joute au lieu de la guerre qui se prépare, encourant le courroux de Marine, choquée des risques que son ami a pris. Laris se lance plus tard tout seul à la poursuite des ennemis, dont il est d'ailleurs fait prisonnier (Claris et Laris, v. 19483-20273), ignorant l'esprit de camaraderie et la solidarité qui animent le roman ${ }^{135}$. Le développement de caractères plus fins aboutit dans Melyador, au XIv siècle, à une véritable plongée «dans le cœur humain [dont on sonde] les mouvements de l'âme en s'appliquant à rendre compte de leur complexité » ${ }^{136}$. L'intérêt pour la psychologie est particulièrement clair dans la scène où Melyador fait part de sa jalousie envers Camel à Lansonnet et analyse ses propres sentiments:

"Quant cë oÿ, telz et si fais

En fui et si tres fort jalous

Et si tres merancolious,

Si pensieus et si debatus,

Se je me fuisse combatus

Ce soir, je n'euisse riens fait

Et tant seulement pour ce fait.

Est dont jalousie tel cose?» (Melyador, v. 9831-9838)

Lansonnet répond que la jalousie est un mauvais vice qui enflamme les amants; toutefois, Melyador ayant le cour noble, ces pensées ne devraient pas le hanter trop longtemps. Ce n'est donc pas seulement le narrateur qui rend compte des sentiments des personnages, mais les personnages euxmêmes qui s'auto-analysent et livrent les mystères du cœur ${ }^{137}$.

Les derniers romans en vers s'inscrivent dans un climat littéraire cohérent, à la suite des romans arthuriens en prose de troisième génération comme Meliadus et le Roman de Guiron. Lambiguïté des personnages

135 Corinne Pierreville développe les caractères opposés de Claris et de Laris dans son étude, Claris et Laris, somme romanesque, chapitre «Le renouveau de la Table Ronde».

136 Nathalie Bragantini-Maillard, intoduction à l'édition de Melyador, éd. cit., p. 323.

137 Sur le réalisme psychologique dans Melyador, on consultera les pages 320 à 327 de l'édition de Nathalie Bragantini-Maillard, éd. cit. 
n'est pas à appréhender, en ce sens-là, comme une faiblesse de l'écrivain qui ne comprend pas l'importance de la polarisation dans l'idéologie arthurienne: au contraire, il s'agit d'une complexification du monde qui ouvre des perspectives narratives. La répartition axiologique équivoque des personnages, en s'appuyant sur la multiplicité des points de vue, affermit le statut du narrateur omniscient et la maitrise qu'il a sur son monde.

Le traitement des personnages est en mutation, dans le roman arthurien en vers tardif. Au lieu de reconduire simplement le personnel romanesque propre au genre, les auteurs en modulent le comportement et la psychologie: sans montrer un seul personnage dans son évolution et son apprentissage, comme le faisait Chrétien de Troyes, ils privilégient la mise en scène de caractères kaléidoscopiques, jamais parfaits ni univoques. La même chose est valable pour le personnage d'Arthur. Les variations autour de sa fonction n'entravent toutefois pas l'appartenance des textes au genre: l'œuvre demeure rattachée de manière privilégiée au roman arthurien, même si les scènes arthuriennes sont marginales et anecdotiques (Melyador) et même si Arthur ne remplit pas toujours sa fonction royale (Rigomer, Escanor). Bien que chaque écart par rapport aux critères canoniques du roman en vers entraîne la relative marginalisation du texte à la périphérie de l'échelle de centralité du point de vue du lecteur moderne, le critère des personnages demeure déterminant, à tel point que le recours à l'onomastique arthurienne engage toujours une réflexion sur la participation du texte au genre arthurien. Comme nous l'avons vu au chapitre I, "Définition du canon", c'est aussi la corrélation entre un univers de fiction et la structure de l'errance qui permet de rattacher tel roman au genre. Ce critère est, là encore, transformé par les auteurs de romans arthuriens en vers tardifs, qui tirent parti des techniques narratives popularisées par la prose.

\section{STRUCTURES ARTHURIENNES : IMITER LA PROSE}

Dans les romans tardifs, la démarche d'autonomie prise vis-à-vis du genre arthurien canonique est symétrique à celle de Blandin de Cornouailles que nous évoquions au premier chapitre; les romans arthuriens en vers tardifs font tous apparaître le roi Arthur et ses chevaliers, mais s'émancipent de la structure fondée sur l'errance aventureuse et 
solitaire. La modulation de ce critère générique affecte moins la généricité que l'absence d'Arthur, si bien que ces textes sont presque toujours rangés dans la catégorie des romans arthuriens, avec cette réserve toutefois qu'il s'agit d'œuvres qui s'éloignent du genre, auquel elles n'appartiennent plus tout à fait. Beate Schmolke-Haßelmann, qui insiste particulièrement sur l'importance des différentes structures arthuriennes qu'elle présente comme autant de cadres fixes, émet du reste de lourdes réserves à l'encontre de la réactivation arthurienne dans Escanor:

Das Werk [Escanor] ist unzusammenhängend und unübersichtlich konstruiert. Der Autor Girart d'Amiens hat, anders als Froissart, die latente strukturbildende Kraft der Artusszenen nicht erkannt, obwohl sein Werk dem Chretiens zeitlich etwa 100 Jahre näher liegt als Meliador. Dasselbe darf auch über die Dichter von Floriant et Florete und Claris et Laris gesagt werden ${ }^{138}$.

Ces affirmations sont portées par une conception cloisonnée du genre arthurien, qui devrait se plaquer exclusivement sur le modèle de Chrétien de Troyes, quitte à ce que les auteurs supportent malgré tout l'étiquette d' "épigone». La qualité d'un auteur arthurien se définirait, selon cette idée, par sa faculté à comprendre l'importance de la structure figée qu'impliquent les retours à la cour et surtout par sa capacité à la reproduire. Girart d'Amiens faillirait à ces qualités :

Girart d'Amiens gehört nicht zu den grossen Dichtern arthurischer Werke. Deshalb hat er es auch weniger gut als Guillaume le clerc [auteur de Fergus] verstanden, sich auf ein zentrales Anliegen zu beschränken und dieses klar herauszuarbeiten ${ }^{139}$.

138 Beate Schmolke-Haßelmann, Der arthurische Versroman, p. 45. "L'œuvre d'Escanor est construite de manière incohérente et obscure. L'auteur Girart d'Amiens, contrairement à Froissart, n'a pas reconnu la force structurelle latente des "Artusszenen" [i.e. les scènes de relance de l'aventure qui se déroulent à la cour d'Arthur, celles qui ouvrent les romans par exemple], bien que son œuvre soit plus proche de celle de Chrétien de 100 ans par rapport à Melyador. On peut dire la même chose des poètes de Floriant et Florete et Claris et Laris." (nous traduisons)

139 Beate Schmolke-Haßelmann, Der arthurische Versroman, p. 226. "Girart d'Amiens n'appartient pas aux grands poètes d'œuvres arthuriennes. C'est pourquoi il a aussi moins bien compris que Guillaume le clerc [auteur de Fergus] comment se limiter à une intrigue centrale et l'élaborer clairement.» (nous traduisons) 
On comprend bien ce que cette vision a de problématique, si l'on adopte la théorie générique que nous proposons au chapitre I; il n'est pas nécessaire que tous les critères d'un genre soient représentés dans l'œuvre pour que celle-ci y participe. Plus encore, les auteurs ont bien la faculté de transformer les critères canoniques du genre pour le dynamiser. C'est ce qui se produit pour celui de la structure, dans les derniers romans arthuriens en vers.

Loin de suivre l'errance linéaire d'un héros unique sur moins de 10000 vers, les auteurs de romans tardifs imbriquent les aventures de plusieurs personnages tout en allongeant considérablement leur récit. La pratique de l'entrelacement soutient le foisonnement et la longueur impressionnante des textes, en même temps qu'elle induit la multiplication des personnages que nous étudiions au chapitre précédent. L'allongement du récit est manifeste dans Rigomer (17271 vers), Claris et Laris (30372 vers), Escanor (25938 vers) et Melyador (30771 vers); l'entrelacement fonde leur architecture. Ces deux éléments structuraux résultent d'un souci d'exhaustivité et d'explicite; nous développerons ces trois aspects dans les chapitres qui suivent, en gardant à l'esprit la dette qu'ont les textes de notre corpus envers les sommes en prose du XIII ${ }^{\mathrm{e}}$ siècle.

\section{Entrelacer les aventures}

Les romans tardifs usent différemment de l'entrelacement par rapport au Lancelot en prose: le récit tardif suit un déroulement linéaire en dehors de certains passages spécifiques, ceux que l'on appellera de quêtes multiples ${ }^{140}$, tandis que le Lancelot se construit presque exclusivement par entrelacement. On lit par exemple de manière suivie l'errance entière de Lancelot dans Rigomer, de même que les aventures de jeunesse de Claris et Laris et les multiples guerres qui parsèment ce roman éponyme. En revanche, les passages de quêtes multiples, où plusieurs chevaliers cheminent chacun de son côté mais dans un même but, se fondent sur une structure entrelacée. Il n'est pas inutile de rappeler les principaux moments où les quatre œuvres que nous étudierons dans ce chapitre ont recours à l'entrelacement:

140 Emmanuèle Baumgartner fait le même constat au sujet du Tristan en prose: Le Tristan en prose: essai d'interprétation d'un roman médiéval, p. 269. 
- Claris et Laris narre deux moments de quête, celle de Laris, capturé une fois par la fée Madoine et une seconde par les Danois. D'abord onze puis trente chevaliers se lancent à la recherche de leur ami, chacun vivant des aventures individuelles dont il est le héros pour un temps du récit. L'entrelacement est manifeste une troisième fois, lorsque Gauvain, Yvain, Claris et Laris, victimes d'un enchantement, se dispersent (v. 16964-18840) puis se rejoignent après quelques péripéties $^{141}$.

- Rigomer fait usage de la quête multiple lorsque cinquante-huit chevaliers de la Table Ronde décident de se rendre à Rigomer pour délivrer Lancelot qui y demeure prisonnier. Le fil narratif qui concerne ce dernier dépend de l'arrivée de Gauvain, l'élu, et reste donc en suspens.

- Escanor ne propose pas de quêtes multiples, mais imbrique plusieurs intrigues: celle de l'amour entre Keu et Andrivete, qui touche de près au conflit du Northumberland entre Aiglinz et Andrivete; celle de la rivalité entre Gauvain et Escanor, liée là aussi étroitement à l'attentat de Galentinet à l'encontre de celui-ci. Chaque trame s'interrompt pour un temps, laissant le récit se focaliser sur un autre fil narratif ${ }^{42}$. Ce type de construction, contrairement à la quête multiple, ne restitue pas l'impression de simultanéité propre à l'entrelacement.

- Melyador, enfin, fait alterner l'errance des divers chevaliers prétendant à la main d'Hermondine. La quête multiple se substitue rapidement à l'intrigue linéaire des interactions entre Camel de Camois et Hermondine, qui pose le cadre du roman ${ }^{143}$.

L'entrelacement n'est pas à proprement parler une invention de l'écriture en prose; on en trouve les prémices dans le Conte du graal, qui fait alterner les aventures de Perceval et celles de Gauvain, dans la

141 Corinne Pierreville a analysé la structure du roman, Claris et Laris, somme romanesque du XIII siècle, p. 61 à 98.

142 Sur l'entrelacement dans Escanor, voir l'édition citée de Richard Trachsler, p. 91-95.

143 Voir Nathalie Bragantini-Maillard, "Pour un changement de perspective sur la construction de Melyador de Jean Froissart», art. cit., sur la structure générale du roman. 
deuxième moitié du roman ${ }^{144}$. La formule de transition de l'un à l'autre personnage qu'emploie l'auteur champenois sera reprise dans le Lancelot en prose:

De mon seignor Gauvain se taist

Atant li contes dou Graal,

Si commence de Perceval. (Conte du graal, v. 6140-6142)

Le procédé est en germe dès la fin du XII ${ }^{\mathrm{e}}$ siècle. La prose ${ }^{145}$ amplifie cette structure en intégrant de plus en plus de personnages, vivant des aventures parallèles sur un même axe temporel. C'est en termes de temporalité qu'Emmanuèle Baumgartner définit l'entrelacement:

L'entrelacement consiste en effet à disposer le long d'un même segment temporel (par exemple une quête d'un an... ou de dix) les aventures de plusieurs chevaliers. Aventures que le récit relate successivement, bien entendu, mais en les interrompant chacune à des moments cruciaux et ce jusqu'au point où les différentes aventures / les différents personnages convergent / se retrouvent dans un même espace ${ }^{146}$.

L'entrelacement se construit sur la saturation du récit, le foisonnement d'intrigues, en même temps que sur l'attente et l'interruption ${ }^{147}$. Il fonde la multiplication d'aventures et de personnages et se présente comme un ressort privilégié de l'allongement du récit et de la surenchère, autres composantes du roman tardif aussi bien que du roman en prose. Même si le procédé est en quelque sorte lancé par Chrétien de Troyes, il s'agit

144 Voir Danièle James-Raoul, Chrétien de Troyes, la Griffe d'un style, p. 543-550. Annie Combes traite également de l'entrelacement dans les autres œuvres de Chrétien de Troyes, aux pages 403 à 417 en particulier de Les voies de l'aventure.

145 Annie Combes souligne aussi l'influence de l'historiographie sur les techniques d'entrelacement. Voir Les voies de l'aventures, p. 418-423.

146 "Les techniques narratives dans le roman en prose», art. cit., p. 177-178. Ferdinand Lot, Étude sur le Lancelot en prose, et Eugène Vinaver, À la Recherche d'une poétique médiévale, Paris, Nizet, 1980, ont posé les bases de l'étude de l'entrelacement.

147 Damien de Carné, Sur l'organisation du Tristan en prose, p. 35. Voir aussi Elspeth Kennedy, "Rupture de la linéarité temporelle dans la technique narrative du cycle Lancelot-Graal», in Ensi firent li ancessor. Mélanges de philologie médiévale offerts à Marc-René Jung, éd. Luciano Rossi, Alessandria, Edizioni dell'Orso, vol. 1, 1996, p. 387-398. 
d'une structure narrative que développe l'écriture en prose et permet de distinguer les deux modalités d'écriture et qui permet de distinguer les deux modalités d'écriture, comme le confirme Catherine Croizy-Naquet:

Structurellement, vers et prose se prêtent à des modes de représentation divergents. Tandis que la prose invente une esthétique de l'ordonnancement et travaille à l'entrecroisement sur un même fil narratif de la chronologie et de la logique des faits, le vers ménage à dessein la focalisation sur un personnage et le resserrement de l'action, en cultivant vivacité des enchaînements et rebondissements ${ }^{148}$.

L'agencement de la temporalité est complexe dans la prose, par le recours à l'entrelacement et à ses va-et-vient; il est suivi dans le vers, du moins dans ses représentants classiques.

L'entrelacement tente de donner l'illusion de la simultanéité: par des analepses, il devient possible de raconter les aventures simultanées de chevaliers différents et isolés ${ }^{149}$. Le retour se fait à la fois sur la temporalité de la diégèse et celle du récit: le récit remonte le temps diégétique et revient au point de la narration où il avait abandonné tel personnage. Il en résulte plusieurs difficultés: celle d'abord de la mémoire potentiellement défaillante du lecteur, à qui il est souvent nécessaire de faire un petit résumé de la trame laissée en suspens, et celle de reconstruire la chronologie des événements, complexifiée par l'entrelacement. Annie Combes distingue trois concepts destinés à définir les étapes propres à l'entrelacement: par le terme de "voie», elle désigne «le trajet que suit un acteur, depuis son entrée dans le récit jusqu’à sa sortie [...] qui correspond à la série discontinue des segments narratifs où figure le personnage».

148 Catherine Croizy-Naquet, "Nus contes rimés n’est verais», art. cit., p. 41.

149 Annie Combes distingue trois types de travail de la temporalité: la prolongation, le chevauchement et le recouvrement, selon que le récit prolonge la durée en changeant de lieu et de personnages, qu'il effectue une analepse de durée indéterminée pour raconter les aventures simultanées d'un autre personnage, ou que cette analepse soit clairement déterminée. Voir Les voies de l'aventure, p. 409-414. "Ou bien le récit, lorsqu'il change d'acteur, enchaîne des actions distinctes dans une temporalité linéaire; ou bien, il articule au sein d'une même temporalité des théâtres d'action séparés; ou enfin, il remonte dans le temps de la diégèse pour poser, à partir d'un point précis, le cadre d'une simultanéité qui se dévide.» (p. 409) 
Ce terme de "segment " ${ }^{150}$ réfère à "l'unité narrative encadrée par deux formules codées, une d'ouverture et une de fermeture». Les formules en question sont appelées «seuil» ${ }^{151}$.

Les seuils sont nécessaires pour suspendre le temps et signaler les distorsions de la temporalité narrative, faite d'analepses. Le verbe "retorner $»^{152}$ est en particulier un indice fort de retour à un point de départ, duquel s'est éloigné le personnage dont on vient de traiter. On le rencontre plusieurs fois dans Claris et Laris, à côté d'autres expressions qui signifient la régression temporelle du récit:

Or vueil a Claris retorner (v. 8566)

Or revenrai a la matiere

Des autres compaignons arriere. (v. 8875-8876)

Or revendrai au paveillon

Dont partirent li compaignon. (v. 9026-9027)

Or m'estuet a ceus revenir

Qui doivent lor chemin tenir

Et qui se doivent esprouver

De Laris le vaillant trover. (v. 10067-10072)

Ore est li contes ravertiz

A Bedoier le connestable (v. 10226-10227)

Or revendrons a la matiere

Dont vous parlames ci arriere. (v. 23515-23516)

Le récit retourne ou revient à un acteur, voire un lieu, mis de côté pour un temps, le terme «arriere» venant redoubler l'idée d'antériorité. Le dernier exemple est explicite: le retour se fait certes au niveau du temps diégétique, mais renvoie aussi à la façon d'organiser le récit, le narrateur

150 Dans Claris et Laris, on trouve parfois le mot «laisse» : "Ore est droiz que de ceus vous laisse, / Si vous redirai une laisse / Des compaginons qui chevauchoient.» (Claris, v. 4999-5001) Employé ainsi, ce terme semble recouper le sens de «segment» tel qu'il est théorisé par Annie Combes.

151 Annie Combes, Les voies de l'aventure, p. 430. Les seuils du Tristan en prose ont été analysés par Danièle James-Raoul, «Rhétorique de l'entrelacement et art de régir la fin: le cas du Tristan en prose (ms. Vienne 2542) ", PRIS-MA, XV/1, 1999, p. 85-111, et Damien de Carné, Sur l'organisation du Tristan en prose, p. 46-173.

152 Annie Combes, Les voies de l'aventure, p. 468. 
reprenant un fil qu'il a mis en attente, désigné ici par le terme "matiere» qui prend le sens de thème narratif, voire recoupe le concept de "voie» théorisé par Annie Combes ${ }^{153}$.

Ce type d'articulation n'est pas sans rappeler les formules de transition de la prose, quoique celle-ci privilégie les tournures ayant pour sujet le conte qui semble assumer la narration. Le fameux " or dist li contes" prend en charge le narré, mais n'est pas un substitut de l'instance narrative, comme l'ont montré Emmanuèle Baumgartner et Annie Combes ${ }^{154}$ : le narrateur conserve ses fonctions, bien qu'il délègue au conte l'organisation de la narration. Le conte articule les segments narratifs et marque les transitions, mais n'éclipse pas le narrateur. Les romans tardifs n'exploitent pas cette formule stéréotypée de transition mais privilégient largement la prise de parole d'un «je» ou d'un "nous» narrant, dans des expressions comme "Or vous redirons aparmain / De ceus qi sont dela le pont." (Rigomer, v. 14304-14305). Le concept d'un conte qui assumerait la narration de l'histoire est abandonné au profit d'une présence forte de l'instance narrative qui affirme sa maîtrise de l'organisation du récit. De manière éloquente en ce sens, dans Claris et Laris, le conte se transforme en verbe d'action dont le narrateur est le sujet:

Mes d'euls ici vous laisserai,

Des trois fees vous conterai (v. 8335-8336)

Or conteronmes de Claris (v. 18093)

Les romans tardifs redonnent la parole au "je» du narrateur, alors que la prose, bien que le narrateur y conserve ses fonctions communicative, modélisante et testimoniale, fait du conte "le sujet abstrait de la narration, le conte se disant à mesure qu'avance le roman ${ }^{155}$.

Le narrateur de Melyador fait preuve de la même présence, Froissart s’employant à développer une véritable individualité pour cette instance,

153 Adeline Latimier a montré comment le terme "matière» organise la narration entrelacée de Claris et Laris: il est très souvent présent dans les seuils et indique que le narrateur suit une ligne directrice. "Le nom et la matiere dans le roman arthurien tardif en vers", in Matières à débat, p. 273-288.

154 Annie Combes, Les voies de l'aventure, p. 431-444, Emmanuèle Baumgartner, "Les techniques narratives dans le roman en prose», art. cit., p. 175-176. Voir aussi Annie Combes et Annie Bertin, Écritures du Graal, p. 120.

155 Annie Combes, Les voies de l'aventure, p. 417. 
ainsi que l'a montré Nathalie Bragantini-Maillard ${ }^{156}$. Il est à la fois témoin des faits qu'il raconte, mais aussi commentateur, jugement qu'il transmet à son public avec lequel il communique par plusieurs interpellations. Il assume également une fonction métanarrative, notamment lors des transitions, encore assurées par un «je» et non un conte ${ }^{157}$. L'instance narrative laisse même transparaître son affect vis-à-vis de son récit : «Or parlerai, c’est mes plaisirs, / de sa serour la renommee» (v. 7569-7570). Les transitions d'un personnage à un autre sont construites sur le même mode que celui de Claris et Laris et des romans en prose entrelacés: le commentaire métanarratif signale l'abandon du personnage dont on parlait pour annoncer celui dont on parlera. Ce passage peut être un retour en arrière ( Nous revendrons a Graciien », v. 5810) qui exhibe le processus d'analepse propre à l'entrelacement et exprime la reprise d'une voie mise de côté. Parfois, le récit change de perspective et de fil narratif par un jeu temporel et spatial, comme dans l'exemple suivant:

De Melÿador laisserons

A parler, car bien nous savons

Qu'i ne se poet ores armer.

Entrues poons nous bien parler

D'autres aventures nouvelles. [...]

Et toutes fois une moult grande

Aventure y avint ce terme

Que Melÿador ens ou ferme

De Montgriés illuec reposoit,

Et me samble que ce fu droit

A .III. liewes dou chastiel

Dessus dit et fu de nouviel,

Quatre jours apriés ce pour voir

Que Melÿador son devoir

Eut fait, ensi c'on puet escrire,

De ce dit Camel desconfire. (Melyador, v. 9367-9384)

156 "L'écriture des interventions narratoriales dans Melyador», art. cit.

157 La mention d'un conte, comme dans Claris et Laris et Rigomer, est rare. Dans Melyador, on la trouve par exemple au vers 28828: «Li contes se taist a present / De Saigremor a celle fois». Plus souvent, on lui substitue "l'écriture», au vers 4370 par exemple: «Or nous dient les escriptures.» Ce renvoi est fréquent aussi dans Rigomer. 
Melyador vient de vaincre Camel. À partir de là, la focale se déplace à trois lieues et quatre jours plus tard pour se concentrer sur les frères Savare et Feughin, comme s'il fallait situer le nouveau point d'intérêt par rapport au précédent pour introduire de nouveaux personnages.

La transition n'effectue donc pas toujours de saut en arrière mais peut aussi procéder par ellipses. Il arrive que la temporalité soit brouillée par les seuils: on s'attend à ce que chaque segment qui concerne un même personnage, mis bout à bout, reforme sa trajectoire chronologiquement. Or, il semble que la temporalité soit plus complexe que cela dans Melyador. Le narrateur raconte que Melyador croise Gerpin, qu'il vainc. Le récit quitte ensuite un moment son héros éponyme pour narrer les faits de Florée, qui accueille Gerpin blessé, et d'Hermondine. Il retourne à Melyador pour raconter son entrevue avec Lyonnel, envoyé par Phénonée qui cherche son frère. Melyador se garde bien de révéler son identité. On le quitte pour se concentrer sur Lyonnel et sa rencontre avec Agamanor, puis, lorsque le narrateur se réintéresse à Melyador, il annonce:

\author{
Nous lairons ci d'Agamanor \\ Et au vaillant Melÿador \\ Retournerons, car c'est bien drois, \\ Et conterons a ceste fois \\ Qu'il li avint de puissedi \\ Que dou chevalier se parti \\ Monsigneur Gerpin, qu'il bleça. (Melyador, v. 15412-15418)
}

Or, la voie dédiée à Melyador avait déjà progressé depuis son affrontement contre Gerpin, puisqu'on l'a vu interagir depuis avec Lyonnel. Peutêtre faut-il comprendre alors que ce dernier moment est une analepse par rapport à l'épisode de Gerpin, destinée à raconter la trajectoire de Lyonnel plus que celle de Melyador, pour qui il s'agit d'un événement passé. Le narrateur se donne pour tâche d'agencer cette temporalité éclatée, d'en montrer aussi la complexité.

Dans Rigomer, le passage d'un segment à un autre est ponctué d'un décompte qui recense le nombre de chevaliers ne s'étant pas encore désolidarisés du groupe qui quitte la cour pour sauver Lancelot prisonnier à Rigomer. S’ils sont cinquante-huit à partir initialement (v. 7162-7163) ${ }^{158}$,

158 Voir Christine Ferlampin-Acher, "La Table Ronde dans Les Merveilles de Rigomer», CRM, 14, 2007, p. 49-59. 
la troupe s'étiole petit à petit, donnant lieu à une forme de scansion de la part du narrateur :

Lor s'en vont li .l. .vii. (v. 7469)

Des .ii. ne vos vel jo plus dire,

Si averai parlé premiers

Des .lvi. chevaliers

Qui sont errant vers Rigomer. (v. 7984-7987)

De lui ne vel jo plus parler.

Des .lv. compaignons

Dont nos avons oï les nons

Vos aconteromes ançois. (v. 8436-8439)

Or dirons des .1. trois

Qui chevaucent par grans detrois. (v. 8861-8862)

Encor furent .l. et doi. (v. 9107)

Et dirons des .l. et un. (v. 9493)

Qui duque a .1. sunt. (v. 9834) 159

Ce décompte fait office de formule de transition entre les segments ${ }^{160}$. Il accentue la multiplicité que l'entrelacement met justement en lumière: même si chaque chevalier vit une aventure destinée à lui seul, il appartient à un groupe qui le subsume et définit son identité, car il est un chevalier de la Table Ronde avant d'être un personnage dont l'individualité est marquée. Ce mode de progression du récit exhibe de manière parodique l'entrelacement des romans en prose: par la récurrence de la formule, l'auteur souligne "le caractère mécanique, artificiel du procédé» ${ }^{161}$. La redondance qui se dégage de cette structure est donc aussi le résultat d'un réinvestissement parodique des techniques narratives du roman en prose. L'entrelacement, dans Rigomer, suggère l'incessant recommencement d'un

159 L'éditeur transcrit «[.l. et] .i.», mais c'est bien un «.l.» et non un «.i.» qu'il faut lire, comme le fait remarquer Richard Trachsler, "Lancelot aux fourneaux: des éléments de parodie dans les Merveilles de Rigomes?», art. cit., p. 191.

160 Adeline Latimier lit dans ce décompte négatif le progressif délitement de la cour arthurienne. "Les Merveilles de Rigomer: un "conte ridicule" ?", art. cit.

161 Richard Trachsler, "Lancelot aux fourneaux: des éléments de parodie dans les Merveilles de Rigomes?», art. cit., p. 191. 
monde indéfiniment stimulé par le surgissement de l'aventure et jamais mené à terme par la chute que racontent les romans en prose.

L'obsession du décompte structure également l'errance de Lancelot. Son parcours est ponctué d'informations relatives au nombre de jours de marche qui le séparent de Rigomer. Là encore, le récit progresse sur un mode numéral qui rapproche petit à petit le lecteur de l'issue. Ce sont à chaque fois des hôtes qui informent Lancelot du temps qu'il lui reste:

«Sis jornees i a tout droit

A houme qui haitiés seroit.» (v. 3129-3130)

«.v. jornees, dist il, i a.» (v. 3240)

«En .ii. jors i venrés sans hui.» (v. 3820)

Ce décompte est l'occasion d'amusants jeux sur le retard que prend le chevalier. Après avoir secouru une jeune fille du viol, il demande au père de celle-ci la distance qu'il y a jusqu'à Rigomer:

«A Rigomer m’en irai gié,

Si me dites combien i a?

- .iii. jornees a jusques la,

Ço dist li rois, biax dous amis,

Qui au droit chemin seroit mis.»

Dist Lanselos: «A i dont tant?

Jou cuidoie iestre plus avant.»

Et dist li rois: «Biax amis dous,

Ce sachiés bien, si fustes vos.

Hier, quant vos fustes es foriés,

A .ii. jornees fustes priés,

Mais bien sachiés c'onques tres hier

$\mathrm{Ne}$ finastes de repairier.

Por ma tres biele fille chiere

Iestes une jornee ariere.» (Rigomer, v. 4538-4552)

Le chevalier ne peut s'adonner à des quêtes secondaires sans prendre du retard sur l'aventure principale: il se dévoie. Le savoir supérieur du père de Marte sur le parcours du chevalier prête à sourire: il est à même d'expliquer le cheminement de Lancelot et ses détours, matérialisés par le décompte temporel. En plus de hiérarchiser les aventures auxquelles participe Lancelot, ce dialogue dévoile le principe de structuration choisi par 
l'auteur: celui du retardement. En repoussant l'aventure de Rigomer, le narrateur crée un suspense ${ }^{162}$, redoublé par les informations que Lancelot reçoit régulièrement au sujet du château : Rigomer est une aventure dont on parle avant de la vivre. L'auteur de Rigomer se joue de l'entrelacement de la prose qu'il parodie: le lecteur des romans en vers tardifs est aussi celui des romans en prose et reconnaît cette structure. Le plaisir vient bien d'un détournement, d'un lien établi avec la prose dont l'imitation, formalisée dans le cadre du vers, est comique.

Le détournement provient aussi du fait que le trajet qui conduit à Rigomer ne constitue pas vraiment une chaîne logique qui mènerait le chevalier à la perfection et le rendrait digne de Rigomer: il s'agit plutôt d'une juxtaposition de petites aventures pas toujours au service de la pax arturiana, qui prépare le terrain, allèche le lecteur jusqu'à le lasser. L'issue est sans cesse reportée, que ce soit par le dévoiement de Lancelot ou l'insertion des aventures individuelles des chevaliers. Ces retards pris sur l'aventure principale servent le plaisir de l'accumulation, du prolongement du récit et de l'univers de fiction, semblable à la volonté qui anime les auteurs des romans en prose du Tristan en prose ou du cycle de Guiron le courtois ${ }^{163}$. Cette esthétique est particulièrement évidente dans Rigomer: non seulement l'arrivée de l'élu, Gauvain, à Rigomer est toujours différée, mais le narrateur n'a de cesse de relancer l'aventure par une succession de captationes benevolentiae: régulièrement, il annonce le début du roman véritable, de ce qui doit retenir l'attention du lecteur, comme si ce qui précédait n'était que prélude. C'est ainsi que se présente la partie consacrée à Gauvain, qui suit celle de Lancelot:

162 Sur la notion de suspense en lien avec les théories cognitives, voir Raphaël Baroni, La tension narrative. Suspense, curiosité et surprise. Face à certains phénomènes textuels, le lecteur se demande "Que va-t-il se passer?" et établit des pronostics qui anticipent la fin du récit. Le suspense implique une attente, une incertitude, que vient combler la suite du texte. Christine Ferlampin-Acher étudie ce suspense dans Rigomer à l'aune du merveilleux: celui-ci passe par l'attente, mais l'auteur «reste paralysé lorsqu'il s'agit d'atteindre la merveille, de la percevoir, et de mettre en œuvre la polyphonie et la polysémie» (Merveille et topique merveilleuse, p. 339).

163 Emmanuèle Baumgartner traite de plusieurs points qui épuisent la matière dans le Tristan en prose: "Compiler / accomplir", in Nouvelles recherches sur le Tristan en prose, dir. Jean Dufournet, Paris, Champion, 1990, p. 33-49. 
Ains nos convient prendre conroi

De Gavain, le neveu le roi,

Qui mout ert dolans et plains d'ire,

Quant la noviele en ora dire.

Se il par lui n'est jetés fors,

N'en istera desq'il ert mors.

Chi commence nostre romans,

Qui mout est riches et vaillans

Des aventures qi avinrent

A chiaus qui a Rigomer vinrent. (Rigomer, v. 6415-6424)

Ces quelques vers de transition, qui abandonnent un personnage pour se consacrer à un autre, investissent Gauvain de son statut d'élu, ce qui explique pourquoi le roman commence véritablement à cet endroit. S'ensuit un passage qui a tout d'un prologue:

Or entendés, et roi et conte,

Çou que Jehans nos dist et conte

D'un romans que en escrit mist

Au tans que il s'en entremist,

Des aventures et des lais

Biaus et plaisans, et le plus lais;

Mais sour tout ço son sens i mist

Cil Jehans qui s'en entremist;

Car il nos dist tante aventure,

Qui bien i meteroit sa cure

En escouter et en entendre,

Mout grant sens i poroit aprendre. (Rigomer, v. 6429-6440)

Tous les topoi de prologue sont convoqués: l'invitation à écouter, destinée à un public aristocratique, le nom de l'auteur, la valorisation de son travail et du présent roman en particulier et finalement le profit que l'on retire à écouter son ouvre. Les constants retards pris sur l'aventure principale créent une attente, captent à nouveau l'attention d'un lecteur endormi par la redondance des aventures. Les formules d'entrelacement sont transformées ici en petits prologues intermédiaires, qui dévoilent au lecteur le rôle fonctionnel de l'entrelacement dans la prose: celui d'insuffler une nouvelle impulsion au récit.

Car ce type de prologue interne dans Rigomer ne sert pas qu'à marquer les grandes articulations du roman: sa fonction est surtout de redonner 
un souffle au récit, de donner l'illusion que l'action est relancée, quand bien souvent elle ne fait que suivre son cours. Le cas se présente alors que le récit se concentre sur le parcours de Gauvain. Le narrateur interrompt l'action pour annoncer la narration d'une petite aventure:

Lors vos vel dire et acointier

Une aventure sans tencier,

Qui mout est plaisans et mignote.

Cançonete, fabliau ne note

N'est si plaisans, si con jo cuide,

Qui bien meteroit s'estuide. (Rigomer, v. 10957-10962)

Le récit se poursuit en fait sur l'errance de Gauvain, qui se sépare de la fée Lorie puis affronte plusieurs chevaliers dans un jardin. On ne change donc pas réellement de sujet après cette intervention narratoriale. Cependant, ces quelques vers accentuent l'accumulation de petites aventures autonomes au sein du roman, comme si chacune pouvait être isolable et figurer seule dans un manuscrit - nous en parlions aux pages 381-397. La multiplication des prologues prend sens de ce point de vue: elle souligne l'éclatement de l'histoire racontée, que l'on pense à l'aventure de la Quintefeuille qui clôt le manuscrit de Chantilly et n'a que peu de rapport avec la quête de Rigomer. Alors que, dans la Queste del saint Graal par exemple, les aventures individuelles des chevaliers ne peuvent être extraites d'un contexte qui leur donne leur cohérence, celle d'une quête spirituelle dont certains sont petit à petit exclus ${ }^{164}$, le roman en vers tardif cultive une poétique de la vignette ${ }^{165}$. Chaque séquence est achevée et pourrait être détachée de la quête plus globale de Rigomer ou de celle de Laris pour former un récit bref autonome, rappelant en cela les romans en prose tardifs comme le cycle de Guiron le courtois, propices à

164 Ferdinand Lot souligne au sujet du Lancelot propre qu' "aucune aventure ne forme un tout se suffisant à lui-même», affirmation qui ne s'applique pas à la majorité des segments du roman tardif entrelacé, qu'il soit en vers ou en prose d'ailleurs. Étude sur le Lancelot en prose, p. 426.

165 Sur cette expression, voir l'édition citée du Conte du Papegau par Patricia Victorin, p. 20, et Danielle Régnier-Bohler, "Arthur en enfances dans Le Chevalier $d u$ Papegau», PRIS-MA, 13/1, 1997, p. 91-106. 
la déstructuration qu'a d'ailleurs opérée la tradition manuscrite ${ }^{166}$. C'est ainsi que Francesco Carapezza décrit le roman arthurien en vers tardif: «éclosions hypertrophiques des contes octosyllabiques du $\mathrm{XII}^{\mathrm{e}}$ siècle, composées par une suite interminable d'aventures enchaînées par de faibles liens narratifs» ${ }^{167}$.

L'entrelacement, dans Rigomer et Claris et Laris, est donc majoritairement distinct de celui du Lancelot en prose, qui se définit par la discontinuité des segments, "chaque épisode étant tenu en suspens et laissant place à un autre, qui lui-même est à son tour interrompu pour permettre la continuation de l'épisode antérieur ${ }^{168}$. Les passages de quêtes multiples, comme celui des cinquante-huit chevaliers de Rigomer, racontent successivement les aventures de divers chevaliers qui n'ont droit qu'à un seul segment chacun. S'ils réapparaissent dans le récit, c'est parce qu'ils ont atteint leur but et reformé une multitude. Ainsi, seule l'intrigue principale demeure en suspens: le narrateur abandonne Lancelot aux cuisines de Rigomer le temps qu’il soit délivré par Gauvain. Il exprime explicitement que son récit ne gagnerait rien à poursuivre sur ce personnage:

Or le laisons de lui ester,

Que n'i poons rien conquester,

Ains nos convient prendre conroi

De Gavain, le neveu le roi. (Rigomer, v. 6413-6416)

Gauvain bénéficie d'une voie discontinue: on le laisse momentanément en prison chez Gaudionés avant qu'il ne soit secouru quelques segments plus tard par la fée Lorie. L'auteur de Claris et Laris fait quelqu'effort pour lier des segments les uns aux autres par la réapparition des quêteurs, quoique dans la première quête de Laris seulement, où les chevaliers secondaires sont les héros de deux aventures chacun. Lors de la deuxième quête de Laris en revanche, les aventures individuelles se succèdent linéairement, et les personnages ne reparaissent pas, si ce n'est à la fin de la quête; après avoir été chacun les héros d'une petite aventure achevée, les

\footnotetext{
166 Voir Roger Lathuillère, «Un exemple de l'évolution du roman arthurien en prose dans la deuxième moitié du XIII ${ }^{\mathrm{e}}$ siècle», art. cit. et l'étude de Sophie Albert, "Ensemble ou par pieces». Guiron le courtois (XIII-XV siècles): la cohérence en question.

167 Francesco Carapezza, «Le fragment de Turin de Rigomer», art. cit., p. 101.

168 Jean Frappier, Étude sur la Mort le Roi Artu, Genève, Droz, 1972, p. 348.
} 
quêteurs tombent les uns après les autres dans la prison de Toas puis de Tallas ${ }^{169}$ et attendent le temps de quelques segments d'être délivrés par Claris et Laris, ce qui permet ainsi de reconstituer la multitude.

Créer une continuité entre les segments pallie le sentiment d'une juxtaposition gratuite menaçant la cohérence de ces récits. D’autres moyens sont exploités: le narrateur de Claris et Laris respecte scrupuleusement la structure qu'il s'impose, lorsqu'il annonce qu'il racontera l'errance de tous les chevaliers qui prennent part aux quêtes de Laris («mes ja n’i seront mesconté / Leur fet ne lor demenement», v. 23160-23161) ${ }^{170}$. Le souci est à la fois celui de l'exhaustivité, chaque participant dont le nom est mentionné à la quête étant le héros d'une petite aventure, mais aussi celui de fournir une trame narrative savamment ficelée. Corinne Pierreville ${ }^{171}$ l'a montré, les aventures se répondent entre elles: en se ressemblant, elles se font écho les unes aux autres. Pour n'en donner qu'un exemple, le récit aborde par deux fois une jeune fille en proie au diable: la première a été livrée au Malin par sa propre mère, car la pucelle, refusant de se faire nonne selon le vœu de son beau-père, s'est donnée à un chevalier de bonne origine. La seconde, au contraire, a refusé d'épouser le meunier à qui son père voulait la marier et a elle-même invoqué le diable qui tourmente le moulin depuis lors. Ces effets de symétrie ${ }^{172}$ affichent le travail sur la

169 Ces multiples prisons dont il faut tirer les chevaliers arthuriens ne sont pas sans rappeler celles du Lancelot en prose: la Douloureuse Garde, le Val sans Retour ou la prison de Caradoc par exemple.

170 La structure bien ficelée de Claris et Laris n'est cependant pas exempte de petites incohérences, qui concernent souvent une confusion sur les noms: Toas est par exemple pendu au vers 11340 puis réapparaît plus loin, tandis que Brandalis tombe une deuxième fois dans sa prison, alors qu'il est censé avoir déjà été capturé. Voir l'article de Douglas Kelly, "Multiple quests in French verse romance: Merveilles de Rigomer and Claris et Laris", L'Esprit créateur, 9, 1969, p. 257-266.

171 Voir les pages 61 à 98 de Corinne Pierreville, Claris et Laris, somme romanesque du XIII siècle.

172 Annie Combes et Richard Trachsler ont montré dans leur introduction la construction symétrique de Floriant et Florete: les aventures se font écho. Voir Floriant et Florete, éd. cit., p. XxxII-XxxviII. Helen L. M. Neat s'y intéresse également: "Depictions of Violence in Floriant et Florete: Inter- and Intratextual Patterns", in Battle and Bloodshed. The Medieval World at War, dir. par Lorna Bleach et Keira Borrill, Cambridge, Cambridge Scholars Publishing, 2013, p. 177-197. Voir aussi Norris J. Lacy, "Les Merveilles de Rigomer and the Esthetics of "Post-Chrétien" Romance", Arthurian Yearbook, 1993, 3, p. 77-90, sur la 
variation: à partir d'un même motif (celui de la jeune fille tourmentée par un diable, que l'on rencontre dans l'Atre Périlleux par exemple), on démontre les diverses modulations que permet la dextérité de l'auteur. La variation, sur les types d'aventures proposés, sur les caractères des personnages, sur les modalités de présentation du récit, découle du foisonnement d'aventures que les auteurs s'emploient à structurer: nos longs romans tardifs, en accumulant les lieux communs de l'errance, illustrent le fondement de l'écriture arthurienne en vers; reprendre et varier. La juxtaposition des aventures n'empêche donc pas l'élaboration d'une structure cohérente et signifiante.

Le défi est dès lors aussi d'insérer des rappels à l'intention du lecteur, qui peut avoir oublié le contenu de segments, en raison de leur multitude et de leur ressemblance. Lorsque le narrateur reprend la voie de Gauvain, que le récit a abandonné dans la prison de Gaudionés dans Rigomer, il présente cette mise en suspens du fil narratif comme un oubli :

Or vos en ai grant ment conté

Et ne pourquant ai oblié

Mout del millor et del plus bel,

Mais par celui qui fist Abel,

Or ai talent que me ravoie

A ço que oblié avoie;

Car sans cestui oubliement

Ne poons traire a finement

De chou que avons commencié. (Rigomer, v. 10583-10592)

L'oubli est consubstantiel à la narration entrelacée: le narrateur, et surtout le lecteur, oublient momentanément un personnage pour se focaliser sur d'autres acteurs. L'entrelacement implique donc une distorsion temporelle (le récit se "ravoit» à une voie narrative ouverte) et impose un effort de mémoire en jouant sur l'inachèvement des fils narratifs. L'auteur met ainsi en évidence le fonctionnement de cette technique narrative propre à la prose.

Les auteurs, toutefois, ont le souci de ne pas laisser leur lecteur amnésique: des rappels ponctuels des aventures précédentes permettent de faire ressurgir le souvenir. Le moyen privilégié est celui du récit fait à la cour

composition en analogie de Rigomer: les mêmes thèmes parsèment le roman, comme l'importance de révéler son nom. 
d'Arthur par les chevaliers ${ }^{173}$, qui résument ce dont le lecteur a déjà été témoin au cours de sa lecture. La cour apparaît bien souvent, déjà chez Chrétien de Troyes, comme le lieu privilégié de la «réunion d'un cercle conteur propice à l'échange des récits brefs ${ }^{174}$. Dans nos textes, cette technique permet de rappeler les événements passés en même temps que de structurer le récit. Dans Claris et Laris, la première apparition de la cour d'Arthur dans le roman correspond à une première articulation de la narration: les jeunes héros ont fait leurs preuves au cours de plusieurs aventures, lors desquelles sont intervenus des personnages secondaires que le récit avait mis de côté pour un temps. On les retrouve à la cour, racontant leurs histoires au roi. En discours indirect, le narrateur donne un bref résumé du rapport que chacun des chevaliers ou demoiselles (Gauvain, Yvain, la Blanche Roÿne, Karadoc, l'enchanteur, Matidas de la Roche Perdue, le roi Loth) fait devant l'assemblée (v. 4576-4674) ${ }^{175}$. Ce passage

173 Le roman en prose de troisième génération, Meliadus et Guiron le courtois, développe l'insertion de récits métadiégétiques qu'assument les personnages rencontrés au détour de l'aventure par les chevaliers errants: chacun peut devenir une figure de conteur et tenir un discours qui occupe plusieurs folios pour raconter son histoire. Ces récits seconds peuvent faire l'objet d'un jeu sur les points de vue: le même événement est raconté deux fois par des personnages différents qui se complètent l'un l'autre. On ne trouve pas une telle ampleur du phénomène dans nos textes: tout au plus le narrateur restitue l'aventure racontée par le personnage dans ses grandes lignes et en discours indirect. Barbara Wahlen traite des récits métadiégétiques dans la Continuation du Roman de Meliadus et montre que le texte se construit sur la parole des personnages, qui racontent à Arthur diverses histoires: "Questa curiosità [celle d'Arthur dans la Continuation] è l'espressione di un desiderio narrativo, di un desiderio di ascoltare storie." / "Cette curiosité est l'expression d'un désir narratif, d'un désir d'écouter des histoires." (nous traduisons). "La parola raccontata dai cavalieri-narratori nella Continuation du Roman de Meliadus (ms. Ferrell 5)", Versants, 59/2 (fascicolo italiano), 2012, p. 18. Voir aussi Roger Lathuillère, "L'évolution de la technique narrative dans le roman arthurien en prose de la deuxième moitié du XIII ${ }^{\mathrm{e}}$ siècle", art. cit., et Richard Trachsler, "Il racconto del racconto. La parola del cavaliere nel "Guiron le courtois" ", in "D'un parlare ne l'altro" Aspetti dell'enunciazione dal romanzo arturiano alla Gerusalemme liberata, dir. Annalisa Izzo, Pise, ETS, 2013, p. 11-22.

174 Madeleine Jeay, "Por conter a le cort le roi” Le plaisir du récit enchâssé dans les romans de Raoul de Houdenc", Cahiers de recherches médiévales et humanistes, 29, 2015, p. 94.

175 Raconter ses aventures à la cour d'Arthur est très fréquemment mis en scène. On peut encore citer un passage d'Escanor: «Et Dynadanz li fist savoir / De son estre 
consacre la prouesse de Claris et Laris et indique que les aventures de jeunesse sont terminées, comme si un premier chapitre venait de se clore. Cet artifice est un ressort particulièrement apprécié des auteurs tardifs pour asseoir leur maitrise du foisonnement des aventures et signaler que chaque épisode a son importance dans l'économie narrative. En fonctionnant comme rappel au lecteur oublieux, le récit second a aussi pour effet d'accentuer la redondance: dans Rigomer, Joran li Febles, le Chevalier aux Armes Triples, raconte certes son affrontement avec Lancelot ${ }^{176}$, mais il répète une fois encore le mystère du château de Rigomer, les qualités que doit avoir l'élu, la nature des enchantements dont a été victime Lancelot. $\mathrm{Si}$, pour l'auditoire du personnage, ces éléments sont nouveaux, le lecteur en a déjà pris connaissance à plusieurs reprises au cours du récit.

Girart d'Amiens, en revanche, a moins le souci de résumer des éléments précédents: il arrive pour certains fils narratifs qu'ils soient rappelés voire racontés plusieurs fois par le narrateur ou des personnages - ainsi de la rencontre belliqueuse entre Keu, Mordred, son amie et Dinadan (v. 67846890) -, mais cela concerne des données importantes du récit, comme la capture de Gifflet ou l'attentat perpétré par Galantinet. Bien plus souvent, le roman vise un lectorat attentif aux détails et dont la mémoire est sans failles, à moins qu'il n'invite à sa relecture. Pour exemple, on peut évoquer la mort du roi des Traverses lors du premier tournoi de Baubourg, au début du texte. Cette mort peut paraître sans grandes conséquences, noyée qu'elle est au milieu des descriptions de joutes. Cependant, elle rend la reine des Traverses disponible pour tomber amoureuse de son captif, Gifflet, à la fin de l'œuvre. Le narrateur se garde d'anticiper sur la suite et ne rend même pas son lecteur attentif à cet événement qui a pourtant son importance. Loin d'insérer une quelconque prolepse à cet égard, il se contente de dire que le défunt roi «si restoit nouvelement / Mariez, bien et hautement / Et en grant liu et a pucele / Qui mout estoit et bone et bele» (v. 5055-5059). Plus qu'un signe de désinvolture envers le lecteur,

trestot le voir, / Conme li compaingnon faisoient / Qui lor aventures disoient, / Tout lour fust ou honors ou hontes. / Et selonc c'on ooit lour contes, / Lor donoit on et los et pris.» (v. 1531-1537) Le récit devant la cour va de pair avec la consécration de la prouesse.

176 Ce récit semble particulièrement vivant: loin de se contenter de raconter verbalement la joute, le chevalier mime vraisemblablement les coups: «Ainc n'i ot cop qu'i ne mostrast / [Ne ne leissa qu'il ne contast,] / Con faitement il s'abatirent / Et com'a pié se conbatirent.» (Rigomer, v. 6861-6864). 
ce procédé prévoit une lecture attentive: le lecteur modèle d'Escanor est celui qui se concentre pour se souvenir des moindres détails, voire qui relit plusieurs fois le texte pour en comprendre les mécanismes.

Les mêmes personnages vont et viennent, sans que leur futur rôle dans l'intrigue ne soit préalablement explicité177. La même chose est valable pour Brian des Îles: ce personnage est l'instigateur de l'embuscade dont est victime Gauvain au début de l'œuvre, lors de l'errance qu'il entreprend pour échapper à l'oisiveté. Le neveu du roi est victime d'un autour maléfique qui le confronte à cinq puis huit chevaliers. Après avoir défait leur chef, Gauvain apprend de la bouche de celui-ci qu'il est envoyé par Brian des Îles. Le chevalier, surnommé le Bel Inconnu, précise:

«Mais se trop meillor n’eüst ci

De moi, mal vous fust covenant,

Car rienz ne het tant maintenant

Briant des Illes que vos cors.

Ne sai conment vint cis descors,

Mais trop vouz het moltelment.» (Escanor, v. 2514-2519)

Le lecteur n'apprendra que plus tard, lorsque la Table Ronde en route pour délivrer Gifflet fait halte à son château, les raisons de la haine de Brian pour Gauvain: il est jaloux de son renom (v. 15513-15555) et de l'admiration que lui voue Esclarmonde, son amie (v. 15779-15833). Là encore, le narrateur ne guide pas son lecteur pour le rendre attentif à la haine de Brian lors de sa première intervention dans le texte: il s'agit

177 Lorsqu'ils réapparaissent, ce rôle est explicité et l'explication définit les caractères ontologiques du personnage plus précisément. Brun sans Pitié, qui intervient au début d'Escanor en train de poursuivre traîtreusement une jeune fille, sème Mordred et Dinadan. Il réapparaît plus tard dans le récit, lors du tournoi de Baubourg où il est vaincu par Keu, puis il est mentionné pour être le frère de Colivre l'Orgueilleux. Dans les deux cas, le narrateur le présente plus en détail comme un chevalier déloyal et traître. Il précise que ces traits de caractère se sont déjà manifestés plus tôt dans le récit: "Brunz ert preus, s’il fust de tel estre / Conme chevaliers devroit estre, / Mais poi i ot de loiauté, / Si con j'ai autre fois conté / Et si con raconte nos livres.» (v. 9027-9031) Le narrateur fait vraisemblablement référence à l'épisode qui implique Mordred et Dinadan et dont le lecteur a pris connaissance auparavant, tandis que le «livre» renvoie à la prétendue source du roman. Le caractère négatif du personnage est supposé connu du lecteur modèle, lui qui a lu les textes en prose, par exemple le Roman de Meliadus qui explique les raisons de sa méchanceté. 
en fait d'un fil narratif inachevé appelé à reparaître, mais qui n'est pas non plus rappelé lors de l'affrontement entre Gauvain et Brian devant le château de celui-ci. L'instance narrative feint donc d'ignorer la suite des événements; son omniscience se cantonne au passé, contrairement à celui du Lancelot en prose, porté à la prolepse pour annoncer les événements qui surviendront dans des œuvres ultérieures du cycle ${ }^{178}$. Ainsi, son rôle est celui de transmettre une série de faits, en explicitant leurs causes en temps voulu.

Le lecteur oublieux de la première querelle entre Brian et Gauvain et de l'épisode de l'autour maléfique ne réagira alors pas spécialement, lorsque Brian fait grise mine et baisse la tête au moment d'accueillir Gauvain dans son château avec les autres chevaliers arthuriens: "Mais quant monseingnor Gavain ot / Nonmer, le chief baissa en terre» (v. 1514415145). Le narrateur ne donne pas l'interprétation de cette morosité: c'est au lecteur attentif de reconstruire la rivalité des deux personnages, bien que Brian soit apparu dans l'intervalle comme une figure positive, ami et allié de Keu dans ses aventures en Northumberland. C'est surtout cette amitié et le visage aimable dont Brian des Îles fait preuve, qui font oublier au lecteur l'hostilité que ce personnage montre envers le monde arthurien: si le lecteur connaît le Chevalier aux deux épées, il est au courant de la rivalité entre Gauvain et Brian, celui-ci étant contraint de battre celui-là pour obtenir la main de la Dame des Îles.

Désamorcer le manichéisme renforce la curiosité ${ }^{179}$ du lecteur: après avoir constaté sa bienveillance envers Keu, il oublie d'autant plus

178 Voir Annie Combes, Les voies de l'aventure, p. 58-62.

179 Raphaël Baroni distingue suspense, surprise et curiosité dans la constitution de la tension narrative: "[L] e suspense dépend fondamentalement de la transgression d'une routine (exprimée sous forme de script) et de l'anticipation, teintée d'incertitude, que rend possible la maîtrise de séquences actionnelles sous-déterminées (plan-acte, conflit, matrices, etc.); la surprise s'appuie quant à elle sur le détournement d'un intertexte ou de régularités génériques ou actionnelles; enfin la curiosité résulte d'une représentation incomplète du réseau conceptuel de l'action." (La tension narrative. Suspense, curiosité et surprise, p. 165). Pour synthétiser, on pourrait présenter ces trois notions par des questions que se pose le lecteur face à l'incertitude que lui soumet une œuvre; pour le suspense: "Que va-t-il arriver?»; pour la curiosité: "Que se passe-t-il?»; pour la surprise: "Que s'est-il passé?». La curiosité du lecteur au sujet de Brian concerne les qualités ontologiques du personnage: est-il un personnage positif ou un ennemi de la cour? Pourquoi déteste-t-il Gauvain? 
facilement le rôle que Brian joue dans l'épisode de l'autour maléfique et s'étonne de le voir défier Gauvain incognito devant son propre château. Le fil narratif de l'autour maléfique est dès lors achevé: Gauvain a pu prendre sa revanche sur le personnage à l'origine de l'embuscade, même s'il n'en est lui-même pas conscient, Brian demeurant anonyme. Cette écriture qui tait le futur et n'explicite pas les liens entre les fils narratifs pousse le lecteur à effectuer une lecture active, qui convoque aussi bien des souvenirs intertextuels qu'intratextuels. C'est donc un lecteur savant qui se dessine en creux comme récepteur modèle, appelé à tisser les liens qui s'imposent entre les intrigues, et non un simple consommateur de récits divertissants.

Le monde que propose Girart d'Amiens est finement construit: les personnages reparaissent avec une grande cohérence, sans pourtant que l'ensemble imite véritablement l'entrelacement et surtout les transitions propres au roman en prose. Dans Escanor, le narrateur se garde de marquer les seuils signalant le passage d'un fil narratif à un autre. Au contraire, il s'emploie à fluidifier les transitions, les changements de lieux et de focales et exclut toute formule métanarrative. Le passage d'un fil narratif à un autre se fait ainsi souvent par le cheminement du personnage que l'on suivait au préalable. Pour n'en donner qu'un exemple, la narration se sert du retour de Keu à la cour d'Arthur pour passer du récit de ses amours avec Andrivete à l'intrigue qui concerne Escanor, en l'occurrence le deuil que les chevaliers portent sur ordre du roi pour l'attentat qu'Escanor a subi :

Lors prist congié et s'en ala

Et ne torna ne ça ne la

Tant qu'a la cort fu repairiez. [...]

En tel manierre repaira

Kez a la court et demora

Avoec le roi, qui mout l'ot chier.

Mais nel pooit elleechier

Pour le chevalier nuz hom nez.

Le quel? Cel qu'enssi maumenez

Fu en son conduit laidement. (Escanor, v. 10361-10377)

À la segmentation, l'auteur préfère imbriquer ses fils narratifs les uns aux autres, les rendre interdépendants pour que les transitions ne soient jamais abruptes, mais toujours guidées par les pas d'un personnage. 
L'entrelacement, dans Escanor, n'a donc rien de la quête multiple de Claris et Laris ou Rigomer: non seulement le roman ne se construit pas sur l'errance de plusieurs chevaliers animés par un même but, mais encore l'entrelacement ne se produit jamais par une distorsion temporelle qui donnerait l'idée de la simultanéité des segments. La progression du récit n'est pas faite d'analepses; elle est au contraire linéaire et les intrigues s'alternent heureusement selon un principe chronologique ${ }^{180}$. Le roman échappe ainsi à la fragmentation qui peut caractériser Claris et Laris et Rigomer: son architecture est au contraire solide, de même que ses soudures empêcheraient le retranchement d'un épisode sans briser la cohérence de l'ensemble. Les deux intrigues se rejoignent d'ailleurs par les doubles mariages de Keu et Andrivete et de Gifflet et la reine des Traverses $^{181}$.

Le constat s'applique à Melyador, qui réussit à conjoindre structure entrelacée à quêtes multiples et organisation d'un monde d'où rien ne peut être retranché. À côté des commentaires métanarratifs annonçant la transition d'un personnage à l'autre, majoritaires, on trouve également des transitions fluides, rendant inaperçu le changement de focale. Ainsi, des vers 3734 à 3766, on passe de Melyador à Camel sans formule explicite. Le héros chevauche en direction de Carmelin pour secourir une dame. Son cheminement est un prétexte pour élargir le propos aux chevaliers errants lancés dans la quête d'Hermondine, puis pour resserrer le point de vue sur Camel:

Pluiseur bon chevalier y [à Hermondine] pensent,

Qui de leurs terres s'en absensent

Et viennent en la Grant Bretagne.

Mais pour privet ne pour estragne

Messires Camelz de Camois

N'a point laissiet a ceste fois

Sa contree ne son paÿs. (Melyador, v. 3754-3760)

180 Cela correspond au premier cas d'alternance entre les acteurs et les lieux repéré par Annie Combes: "Les premiers événements liés à $\mathrm{Y}$ se situent au point $b$, c'est-à-dire que le récit poursuit la durée $\delta$ en introduisant seulement un changement d'acteur et de lieu; on peut parler dans ce cas de prolongation temporelle. Cette forme de transition, on va le voir, peut s'effectuer sans intervention du narrateur." (Les voies de l'aventures, p. 409)

181 Richard Trachsler souligne ce dernier point dans son édition citée d'Escanor, p. 93-94. 
Imperceptiblement, on est passé d'une voie à une autre, car les chevaliers sont tous, méchants comme gentils, animés d'un même désir.

Ils appartiennent tous au même monde, qui fonctionne sans le concours du récit: bien souvent, le lecteur apprend que Melyador a déjà affronté au cours de la quête tel chevalier sur lequel le récit s'arrête pour un temps, sans que ledit combat lui ait été rapporté. Il en va ainsi pour Begot, le chevalier parjure que vainc Gratien: il avoue à celui-ci que le Chevalier Bleu - c'est-à-dire Melyador - s'est battu contre lui et lui a enjoint de se rendre à la cour d'Arthur, ce à quoi Begot a désobéi (v. 5002-5065). La même histoire se reproduit pour Morenoi, vaincu par Agamanor, envoyé auprès d'Arthur puis vaincu une fois de plus par Sagremor, à qui il doit avouer son parjure. Dans les deux cas, le lecteur découvre de nouveaux adversaires aux héros du roman et constate l'autonomie du monde présenté: le récit n'a pas la prétention de se concentrer sur tous les combats ni toutes les aventures rencontrées par chacun des chevaliers. L'évocation de plusieurs éléments passés mais néanmoins absents du texte suggère une infinité d'affrontements, un monde encore plus foisonnant que ce que le récit laisse percevoir.

Ce type de scènes permet aussi de lier les trajectoires entre elles: les chevaliers errants n'effectuent pas des parcours isolés sans conséquence sur le reste de la trame narrative, mais leurs cheminements s'imbriquent, se croisent et s'influencent. Agamanor rencontre par exemple la dame de Montrose accompagnée de ses prisonniers, vaincus par Melyador pour avoir assiégé la dame (v. 13759-13822). Ce fil narratif avait été laissé pour achevé à l'issue heureuse du combat; on le retrouve pour assurer le lecteur que les personnages poursuivent bien leur route de manière autonome, que la dame de Montrose continue en quelque sorte à vivre, bien que le récit ne la suive plus nécessairement. Elle reparaît encore à la fin du récit, car elle se marie à Gratien, le troisième meilleur chevalier de la quête. Cette dame en détresse n'est donc pas qu'un personnage à sauver: elle apparaît certes lors d'un segment qui pourrait faire l'objet d'une aventure rapidement expédiée, mais elle occupe un rôle important dans la quête générale, en vantant également les mérites du Chevalier Bleu auprès d'Hermondine et Florée. La trame narrative est dès lors indéchirable, sous peine de perte de sens.

Par la pratique de l'entrelacement et de la quête multiple, les romans arthuriens en vers tardifs assument leurs accointances avec les romans en prose, quitte à perdre un peu de ce qui faisait d'eux des romans 
arthuriens en vers. En adoptant une telle structure, en effet, le sens de l'œuvre change: on ne valorise plus l'accomplissement individuel, à la manière d'un roman d'apprentissage, comme cela pouvait être le cas chez Chrétien de Troyes. C'est plutôt l'idée de communauté qui est valorisée: communauté de la quête, communauté de l'appartenance à un même ordre chevaleresque. C'est ce compagnonnage qu'illustre l'entrelacement dans Claris et Laris, par les errances des chevaliers, leurs séparations et leurs retrouvailles. Corinne Pierreville ${ }^{182}$ a analysé en détail la composition du roman en montrant que la structure en quêtes multiples donne son importance à tous les personnages: chacun contribue, à son échelle, à la magnificence de la Table Ronde en prenant part à une quête collective qui renforce les liens entre les membres de la cour. L'entrelacement participe donc des perspectives que nous esquissions au chapitre précédent sur le devenir du personnage dans le roman tardif. L'éthique prônée par le roman est celle de l'amitié virile, à travers celle de Claris et Laris, décrite en des termes proches d'une relation amoureuse, de l'entraide, de l'union entre les hommes. S'il y a un idéal dans ce texte, c'est plutôt celui du compagnonnage masculin que de l'amour ou de la foi. Telle qu'elle est présentée, la structure entrelacée en quêtes multiples rappelle celle de la Queste del saint Graal, qui raconte l'errance de plusieurs chevaliers animés par un même but. Les motivations de la quête sont pourtant bien différentes: aux promesses célestes du Graal, on substitue la détermination à sauver un ami en danger et à réconforter Claris, éperdu de la disparition de son meilleur ami (v. 8301-8328). L'auteur anonyme privilégie les réalités terrestres, les combats à mener ici-bas, sur le mysticisme de la religion: le genre du roman arthurien en vers permet d'autant mieux d'occulter la veine chrétienne qu'a prise la matière arthurienne ${ }^{183}$.

La quête multiple autorise aussi, dans ce roman, à varier les registres: le récit fait alterner moments comiques et moments sérieux. Les maladies d'amour des protagonistes côtoient ainsi le ridicule des personnages;

182 Voir les pages 61 à 98 de Corinne Pierreville, Claris et Laris, somme romanesque du XIII siècle. L'étude entière s'emploie à montrer cette idéologie du compagnonnage.

183 Guiron le courtois prouve néanmoins que la prose n'empêche pas l'évacuation du Graal et du message chrétien. Sophie Albert, «Ensemble ou par pièces». Guiron le Courtois (XIII-XV siècles): la cohérence en question, p. 191-402. Sur le parallèle entre la Queste del saint Graal et Claris et Laris, voir Corinne Pierreville, Claris et Laris, somme romanesque du XIII siècle, p. 95-96. 
Keu se cache dans un fourré pour échapper à la fée Madoine (v. 1007310225), Cador reste pendu à un arbre jusqu'à ce que ses compagnons viennent l'aider (v. 24908-24925), Lidaine tombe à l'eau en raison de sa vanité, jetée à bas d'une nef merveilleuse ${ }^{184}$ (v. 16096-16195). Les auteurs de ces romans se servent de la multiplicité des personnages et des situations pour offrir une fresque contrastée du monde arthurien. La structure permet alors le développement d'une somme, qui concerne aussi la variété générique: l'influence de différents genres sur nos textes, dont nous traiterons plus loin, est organisée par cette esthétique de la variation. Dans le même mouvement, l'imitation d'une architecture narrative qui définit l'écriture en prose signale la volonté de concurrencer cette dernière, dans l'espoir peut-être de donner un second souffle au roman en vers.

\section{Faire court dans un récit long}

Cette concurrence s'exprime aussi par l'allongement du récit, en particulier dans Rigomer, Claris et Laris, Escanor et Melyador, qui doublent voire triplent le nombre de vers que les auteurs de romans arthuriens classiques réservaient à leurs textes. La longueur de nos œuvres résulte à la fois de la multiplication des personnages et de la structure entrelacée, qui fonctionne selon une logique de l'accumulation, comme nous l'avons montré, et n'a de cesse de reporter l'achèvement du roman. Deux ambitions en apparence contradictoires s'affrontent dans ces textes: d'abord, la fin est différée par une constante relance du récit, surtout dans Rigomer, qui multiplie les prologues réveillant l'attention du lecteur et que nous évoquions au chapitre précédent; ensuite, le narrateur répète inlassablement son envie de raccourcir son récit, d'aller à l'essentiel pour ne pas alourdir son propos. Cette combinaison entre allongement du récit ${ }^{185}$ et

184 Sur les liens entre merveilleux et comique, voir Christine Ferlampin-Acher, "Merveilleux et comique dans les romans arthuriens français (XII $-\mathrm{XV}^{\mathrm{e}}$ siècles)", Arthuriant Literature, XIX, 2003, p. 17-47.

185 Nous adoptons le terme "allongement" pour désigner l'amplification quantitative du récit. Stéphane Macé précise que l'amplificatio antique concerne le plan qualitatif plus que quantitatif; c'est selon lui le Traité du sublime qui a popularisé l'interprétation de l'amplification comme un procédé quantitatif, mais que chez les auteurs antiques, il s'agit de "souligner l'importance de quelque chose, que cela entraîne ou non un développement quantitatif» («L'amplification, ou l'âme de la rhétorique. Présentation générale», Exercices de rhétorique, 4, 2014, en ligne: https://journals.openedition.org/ rhetorique/364, p. 9). L'enjeu est donc moins de faire long que de faire grand. 
brièveté est fréquente dans la production médiévale, ainsi que l'a montré Madeleine Jeay ${ }^{186}$ : elle sert des buts divers selon les genres, le jeu entre le bref et le long permettant aux auteurs de profiter des avantages de chaque forme. Dans nos textes, la brièveté se manifeste dans les segments que l'on peut isoler du récit et qui forment autant de vignettes; l'allongement réside dans leur multitude et leur accumulation. Faut-il alors croire les narrateurs qui prétendent aller à l'essentiel?

Le roman de Rigomer associe de manière remarquable long et bref. Le narrateur est particulièrement pressé et parsème son récit de nombreuses formules d'abréviation:

Lanselos li conte et descuevre [à son hôte comment il a tué Savaris],

Mais n'ai cure de raconter,

Car le conte m'estuet haster. (v. 2784-2786)

Ne vos aroie hui aconté

Les aventures de cascun,

Ançois venroit li blans au brun,

Ançois venroit li jors al nuit.

Encor criem qu'il ne vos anuit

Çou que jou vos en conterai

Le moitié mains que jo ne sai. (v. 7168-7174)

Lor mes que vos aconteroie?

De nient mon conte alongeroie. (v. 9267-9268)

Qui or vauroit tot aconter

Le commenchier et le finer,

Trop i averoit a descrire,

Mais plus briment le vaurai dire. (v. 9393-9396)

Que jo vel mon conte haster (v. 9677)

Or acorcerai le parole,

Que trop i a longe parole. (v. 13331-13332)

Ci commence longe carole,

Mais n'en ferai longe parole. (v. 15909-15910)

186 Madeleine Jeay, "Pour cause de briefté: les formules d'abrègement dans la narration longue", in Faire court, p. 105-120. 
Le narrateur emploie particulièrement l'adverbe "briment" (v. 9396, $9676,11489)^{187}$, le verbe «haster » (v. 2786, 11281) ${ }^{188}$ et répète à plusieurs reprises le vers «De nient mon conte alongeroie» (v. 9268, 11280, $12172)^{189}$. Ce procédé rhétorique, qui consiste à expliciter une réticence à décrire un objet en détail, est déjà défini par les arts poétiques et se trouve chez Chrétien de Troyes ${ }^{190}$. Chez l'auteur champenois, l'abbreviatio ${ }^{191}$ intervient lors de descriptions, écourtées parce que la magnificence de telle fête ou la beauté de telle femme dépassent le dicible. Dans Rigomer, il ne s'agit pas d'éluder une description de repas, de portrait, de combat ou de lieu, mais bien de signifier l'abrègement du récit lui-même, dans sa dimension actancielle. Au lieu de suggérer l'ineffable, la prétendue concision vise à donner l'illusion du foisonnement, d'une quantité infinie d'aventures et de faits à raconter, que le texte ne peut épuiser : au fond, elle sous-entend l'infini de l'univers de fiction qu'elle convoque. L'abbreviatio est alors une forme d'hyperbole: en dire moins pour suggérer plus. Elle stimule l'imagination du lecteur, amené à concevoir une infinité de digressions, de voies narratives possibles que le récit pourrait multiplier.

187 Alors même que le genre romanesque emploie généralement peu l'adverbe «brièvement", selon l'étude de Francis Gingras, Le Bâtard conquérant, p. 342.

188 Le texte de Biaudouz est aussi parsemé d'allégation de brièveté: «Mais je ne vuel plus deviser / Lor armes por le plus haster» (v. 2595-2596); "Bien devisaisse queles sont / Ses armes et quel valor ont, / Mais ce ceroit oisouse chose [...] Arme, tant soit de bon ascier, / Ne les puet de rien empirier. / Por ce vos di briement la some: / Tez sont com covient a tel home.» (v. 3142-3151) Lauteur de Floriant et Florete fait également l'économie de quelques passages narratifs, par exemple: «Ne me voil pas ci demorer / Ne lor jornees raconter, / Por tant m'en passerai briement. " (v. 8081-8083)

189 Margherita Lecco donne un relevé des interventions narratoriales insistant sur la brièveté. Voir Le Meraviglie du Rigomer. Tradizione manoscritta et tradizione narrativa, p. 18.

190 Danièle James-Raoul, Chrétien de Troyes, la griffe d'un style, p. 586-603.

191 La rhétorique antique reconnaît deux formes de brevitas: l'une qualitative, l'autre quantitative. Dans sa première modalité, elle peut être soit un moyen de minorer soit un moyen de célébrer. Nous nous occupons exclusivement de la brevitas quantitative. Voir Catherine Croizy-Naquet, Laurence Harf-Lancner et Michelle Szkilnik, "Préface», in Faire court, p. 10, et l'article de Pierre-Yves Badel dans le même recueil, «La brièveté au risque de l'obscurité. Poétique médio-latine et comique», p. 19-33. 
Elle soulève aussi la redondance de certains passages incontournables du roman arthurien, comme le combat, au déroulement convenu. En ne le racontant pas en détail, le narrateur peut suggérer que le motif est supposé connu et souligne la dimension stéréotypée de l'issue:

Assés en poriés escoter,

Mais trop est lonc a aconter.

Tant vos en di que en le fin

Le lait Yvains mort ou cemin. (Rigomer, v. 8837-8840)

Le narrateur feint l'économie, comme s'il échappait à la redondance et aux longueurs par le simple fait de dire qu'il les évite. Chaque fois qu'il prétend ne pas vouloir ennuyer son lecteur ou alourdir son récit («Mais jel vos raconte briément, / Por qu'il ne vos anuit d'atendre», v. 39143915, "Trop en seroit pesans li fais», v. 7990), il se montre conscient des mécanismes d'engendrement du récit arthurien et de la répétitivité de son propre récit: au lieu d'amenuiser cet effet, les expressions renvoyant à la brièveté et à l'ennui ne font que l'accentuer, démontrant ainsi que l'auteur assume cette esthétique de la redondance, du retour du même. Au delà du lieu commun, les formules annonçant la brièveté témoignent de la conscience qu'ont les écrivains de l'ampleur parfois rébarbative de leurs textes.

L'auteur de Rigomer joue beaucoup de cette association entre long et bref et se plaît à abréger parfois des passages importants sur le plan actantiel après s'être étendu longuement sur une scène au caractère déceptif. Il arrive fréquemment que l'action qu'il choisit de raconter ne présente pas de combat; l'errance de Lancelot donne plus souvent lieu à des scènes d'hospitalité ou à des mésaventures du héros, dont on vole les armes ou le cheval, qu'à des affrontements véritablement chevaleresques. L'épisode de la vieille laide n'aboutit par exemple à rien d'autre qu'à un portrait de la laideur (v. 3461-3558) ${ }^{192}$ : aucune aventure merveilleuse ne se manifeste ni aucune occasion de faire montre de prouesse ${ }^{193}$. Dans ce roman, l'enjeu

192 Francis Gingras traite de cet épisode et du qualificatif «vielle desfaee» (v. 3566) attribué au personnage: la vieille n'est pas une fée, contrairement à ce que l'atmosphère de la scène laissait attendre, mais une "desfaee", un personnage désenchanté. Voir «Le roman à l'épreuve des fées", art. cit., p. 33-34.

193 La lenteur qu'a l'action à démarrer va dans le même sens: le héros pressenti n'est pas le bon (Yvain, Sagremor, puis Lancelot, supplanté par Gauvain). La déception 
est avant tout rhétorique: l'auteur cultive l'exercice de style et joue volontairement des attentes de son lecteur en modulant la longueur de son récit.

La clôture de l'aventure de Rigomer est en ce sens particulièrement éloquente: elle se termine sur le mariage entre Midomidas et Dionise, la dame de Rigomer. La conclusion de cette union est racontée très succinctement, malgré l'importance de l'événement qui représentait l'enjeu de l'aventure de Rigomer, paradoxe soulevé par les vers suivants: «Ci commence longe carole, / Mais n'en ferai longe parole» (v. 15909-15910). L'introduction du personnage de Midomidas est pourtant fastidieuse et détournée: il s'agit d'un jeune homme fraîchement arrivé à la cour, qui demande un don contraignant. Il réclame ensuite de défendre une pucelle qui vient obtenir l'aide d'Arthur contre Miraudiaus, un chevalier qui veut l'épouser de force et gagner sa terre. Finalement, personne n'affrontera Miraudiaus: Midomidas est désigné, mais il laisse sa place à Lancelot, qui arrive à la cour méconnaissable, tel un homme sauvage. Miraudiaus renonce au combat, car il redoute trop Lancelot. C'est donc un récit fort détourné et déceptif qui mène au mariage de Dionise, dont on ne connaît d'ailleurs pas la réaction. Une fois encore, c'est une poétique du retardement qui prévaut dans ce roman: le narrateur concentre ses efforts à accumuler les détours et les rebondissements, repoussant une issue qui, pour avoir été trop longtemps attendue, se révèle finalement assez peu intéressante pour faire l'objet d'un développement. Il en résulte une lecture au rythme varié: le lecteur attend constamment que le récit démarre réellement, qu'il cesse de s'allonger en rapportant des éléments sans substance. Cette expérience de lecture illustre peut-être ce que cherche réellement le public de romans arthuriens en vers: le pur divertissement, fondé sur la connivence avec l'auteur, sans implication idéologique, morale ou religieuse. La lecture sérieuse est fournie par les romans en prose; lorsqu'il reçoit un roman en vers, le lecteur n'attend pas de moralisation ni de plus haut sens, mais entend probablement être diverti par la parodie qui touche les personnages et les techniques narratives, ici celle de l'allongement du récit.

des attentes se traduit aussi par l'origine de beaucoup d'opposants à Lancelot: celui-ci se bat plus fréquemment contre des larrons de bas étage, voire des vilains, que contre des chevaliers. Là encore, l'honneur chevaleresque semble déchu, car il s'attaque à de petites causes. On est loin du rétablissement de la justice par l'extermination d'un géant maléfique qui tourmente une contrée entière. 
Dans les autres romans du corpus, c'est moins le retardement que l'ambition d'exhaustivité qui justifie l'association du long et du court. Fréquemment, les auteurs ont recours à une formule de prétérition, annonçant d'abord qu'ils ne s'attarderont pas à décrire les combats ou aventures de chaque chevalier, mais enchérissent tout de même. En voici un exemple tiré d'Escanor, lors de la guerre contre Escanor:

Mais ne puis pas de chascun conte

Tenir conment se maintenoit

Ne conment chascunz se tenoit

Devant ou arriere ou encoste,

Car trop seroit longue riote.

Por coi ne m'en quier pluz debatre,

Fors que du roi d'Escossuatre

Vouz puis dire hardiement

Qu'il le fist bien et vassaument. (Escanor, v. 19626-19634)

Le narrateur poursuit encore quelques vers l'énumération des chevaliers qui se défendent admirablement sur le champ de bataille. L'ambition de brièveté, le rejet des "longes riotes", font croire au caractère indispensable de chaque élément évoqué, comme si l'instance narrative se contentait du strict minimum, mais ne pouvait faire l'impasse de certaines données fondamentales, laissant envisager l'infini du monde narratif qui sous-tend son récit. Cette stratégie est similaire à celle qui fonde l'écriture en prose: suggérer l'existence, fictive, d'un grand livre de l'histoire arthurienne, dont la matière serait inépuisable ${ }^{194}$.

Le fait est encore plus explicite dans Melyador ${ }^{195}$, lorsque, à la fête finale des mariages, le narrateur tâche de faire l'économie de plusieurs chansons («De ce ne me reprende nulz, / des cançons, je n'en retins plus / que cesti, il vous doit souffire!», v. 30662-30664) et d'abréger sa description des réjouissances ( Trop seroit lontains li recors / se de tout parler je voloie», v. 30095-30096). Cette volonté de faire court est contrariée par

194 Emmanuèle Baumgartner, «Robert de Boron et l'imaginaire du livre du Graal», in De l'Histoire de Troie au Livre du Graal, Orléans, Paradigme, 1994, p. 487-496.

195 Sur l'abrègement de la narration dans Melyador et les interventions du narrateur en ce sens, voir Nathalie Bragantini-Maillard, "L'écriture des interventions narratoriales dans Melyador», art. cit., p. 437-438. 
la nécessité d'évoquer certains faits importants, comme les mariages de Lucienne et Florée. Cette contradiction entre le long et le bref est thématisée ainsi :

Se de tout voloie parler,

De leur venir, de leur aler,

De leurs joies, de leurs solas,

Trop seroit prolongiés li cas.

Mais encores j'en parlerai

Un petit, car matere en ay. (Melyador, v. 30574-30579)

Cette conscience d'une association entre allongement et brièveté dévoile une intentionnalité ludique: avec ironie, ces vers renvoient à la tentation de la surenchère qui anime le narrateur. La poursuite du récit, l'accumulation de détails supplémentaires sur la fête - notamment l'ajout d'un nouveau et dernier rondeau -, ont pour but de plaire à l'auditoire. Mais il ne s'agit pas que de détails insignifiants: "avoir matere» désigne ici le compte-rendu indispensable du sort réservé aux deux cousines d'Hermondine et de Phénonée, la matière imposant de raconter ce qui est essentiel au récit.

Les prétentions à la brièveté ont donc partie liée avec l'ambition d'exhaustivité qui caractérise les romans tardifs autant que les romans en prose. Les auteurs sont animés par cette volonté d'épuiser le monde de fiction tout en étant conscients de cette impossibilité. Dès lors, la longueur impressionnante de ces textes est due à la multiplication des aventures et à la digression. Catherine Croizy-Naquet le décrit ainsi :

[Les romans en prose] divertissent leurs lecteurs; ils leur font prendre des chemins de traverse alors que les formes brèves, l'exemplum par exemple, suivent la droite voie, pour atteindre d'emblée leur but ${ }^{196}$.

Ces chemins de traverse sont constitués, dans Claris et Laris et Rigomer, de petites historiettes, autant de récits brefs que l'on pourrait isoler ${ }^{197}$.

196 Catherine Croizy-Naquet, Laurence Harf-Lancner et Michelle Szkilnik, «Préface», in Faire court, p. 12.

197 Le degré d'autonomie du récit, c'est-à-dire sa capacité à être extrait de son contexte d'origine, est un critère d'identification d'un récit bref, d'après Emmanuèle Baumgartner, "Récits brefs et romans en prose: l'exemple du Tristan", in Le récit bref au Moyen Âge. Actes du colloque des 8 et 9 mai 1988, Amiens/Paris, éd. Danielle 
Cette fragmentation du récit est favorisée par l'entrelacement, qui mène à la constitution d'unités autonomes. La présence de récits brefs dans les romans arthuriens, en prose comme en vers, a déjà retenu l'attention de la critique: Beate Schmolke-Haßelmann et Emmanuèle Baumgartner ont analysé l'insertion de contes brefs arthuriens, ceux du Mantel et du Cor en particulier, dans les romans en vers et dans le Tristan en prose ${ }^{198}$. Il s'agit là d'intégration d'histoires par ailleurs connues du public, quand nos textes créent des séquences inédites mais néanmoins exploitables sans le cadre plus large qui les englobe. L'ambition de brièveté s'imbrique alors avec la prétention à l'exhaustivité: le récit est une structure extensible à l'infini et fragmentée, à l'instar, mutatis mutandis, d'un recueil de nouvelles ${ }^{199}$. D'où la multiplication, dans Rigomer, de ce qui ressemble à des prologues, des appels à l'attention, qui annoncent une nouvelle histoire liée parfois artificiellement à l'aventure du château.

Par exemple, le rattachement de l'aventure finale de la Quintefeuille à la matière de Rigomer est moins régi par un fil narratif logique et continu que par la tentation de surenchérir: le narrateur introduit simplement une nouvelle aventure appartenant au même univers de fiction, bien qu'elle

Buschinger et Wolgang Spiewok, Amiens, Publications du Centre d'Études Médiévales, 1989, p. 27-38, et Bénédicte Milland-Bove, "Les nouvelles des romans arthuriens du XIII ${ }^{\mathrm{e}}$ siècle: narration longues, narrations brèves?», in Faire court, p. 249-267. Voici la définition d'Emmanuèle Baumgartner: "une histoire autonome, découpée à l'emporte-pièce dans le devenir du temps, bouclant rapidement - même si tout est toujours un peu long dans l'univers de la prose - la boucle d'une aventure unique et qui peut fonctionner comme "exemple", que la leçon à tirer soit ou non explicitée.» (p. 29)

198 Beate Schmolke-Haßelmann, "L'intégration de quelques récits brefs arthuriens (Cor, Mantel, Espee) dans les romans arthuriens du XIII ${ }^{\mathrm{e}}$ siècle», art. cit., Emmanuèle Baumgartner, "Récits brefs et romans en prose: l'exemple du Tristan», art. cit.

199 Le rapprochement entre le récit bref, contenu à l'intérieur d'un roman plus vaste, et l'avènement de la nouvelle a été envisagé par plusieurs critiques, dont Alexandre Micha, qui conçoit les récits rétrospectifs du Lancelot en prose comme autant de nouvelles, "qui pourraient prendre place dans un Heptaméron, dont elles sont les lointains ancêtres» (Essais sur le cycle du Lancelot Graal, Genève, Droz, 1987, p. 140). Ce parallèle est d'autant plus pertinent que dans le récit fragmenté aussi bien que dans le recueil de nouvelles, l'ordre de présentation des récits brefs a son importance et que l'ensemble forme un tout signifiant, même si certaines portions sont lisibles pour elles-mêmes. Voir l'article de Bénédicte Milland-Bove, "Les nouvelles des romans arthuriens du XIII ${ }^{\mathrm{e}}$ siècle: narration longues, narrations brèves?», in Faire court, p. 249-267. 
n'ait rien à voir avec ce qui précède. La transition entre la fin de Rigomer et l'aventure de la Quintefeuille donne lieu à un nouveau prologue:

Ciste aventure est a fin traite,

Qui de Miraudiel fu estraite.

Mais or me samble en mon mimore

Qu'el cief de l'an, en cel tempore

Avint une aventure grans

Dont jou vos conterai par tans.

Segnor, oiiés que dire voel:

.i. jour estoit a Estriguel

Li rois Artus et ses barnages. (Rigomer, v. 15917-15925)

Cet épisode est autonome: seuls le rôle prépondérant de Lancelot et l'apparition de la fée Lorie le rattachent à la trame narrative de Rigomer ${ }^{200}$. Les quelques vers qui officient comme petit prologue établissent un lien temporel entre les deux aventures: elles surviennent «en cel tempore». Plus encore, la Quintefeuille surgit à la mémoire du conteur («en mon mimore») juste après qu'il a terminé Rigomer. Peu importe dès lors le rapport logique entre les deux histoires: ce qui compte surtout, c'est de continuer le récit d' "aventures grans" autour du roi Arthur et de poursuivre le lien établi entre un conteur et son public. Le retardement, l'association du bref - dans les formules d'abbreviatio et la brièveté des segments - et du long - dans l'ampleur de l'ensemble -, sont fonctionnels dans Rigomer: ils mettent en scène l'inlassable recommencement de l'univers arthurien.

L'épisode de la Quintefeuille s'étend sur environ 1300 vers, longueur parfaite pour constituer un récit bref arthurien, tel qu'il apparaît d'ailleurs dans le manuscrit de Turin - nous en parlions aux pages 381-397. La lettrine «s» à «segnor» signale la rupture avec ce qui précède et renforce le commencement d'une nouvelle histoire. Celle-ci s'ouvre traditionnellement sur la cour d'Arthur et se clôt sur la victoire d'Arthur à la Quintefeuille, une fête qui la célèbre, le coucher puis le départ des deux chevaliers. Le manuscrit étant incomplet, il manque le retour d'Arthur et Lancelot à la cour et les péripéties qui devaient animer ce cheminement.

200 Francesco Carapezza montre que cet épisode fait partie intégrante du roman de Rigomer et qu'il ne s'agit pas d'un ajout postérieur d'un interpolateur. "Le fragment de Turin de Rigomer", art. cit. 
Une fontaine merveilleuse agrémentait notamment le récit d'une nouvelle petite aventure, mais le manuscrit n'en fournit que le tout début. Si l'on se fie aux deux morceaux découpés au dernier cahier de Rigomer dans Chantilly, Condé 472 et à la numérotation en chiffre arabe, qui tient compte de la lacune, il ne doit manquer que deux feuillets au maximum ${ }^{201}$. Cela représente un espace suffisant pour conclure, à moins que l'inachèvement soit constitutif de l'esthétique que met en place l'auteur de Rigomer, et que ces deux feuillets relançassent une fois de plus l'action ${ }^{202}$.

Ce n'est pas le seul passage isolable du roman. Les aventures individuelles que vivent les chevaliers en chemin pour le château de Rigomer sont toutes plus ou moins autonomes, à l'exception peut-être de celles de Gauvain. L'aventure d'Agravain n'amène par exemple rien de substantiel à la quête de Rigomer: le chevalier reçoit l'hospitalité du châtelain Robert, qui lui raconte avoir perdu sa femme mystérieusement, lors d'un orage (v. 8086-8135). Vraisemblablement, il faut croire qu' " avec cel vent en fu ravie» (v. 8115). Agravain s'en va sans exprimer l'envie d'aider son hôte et rencontre quatre chevaliers qui attendent une aventure. Celle-ci ne tarde pas à se manifester: une ouverture se crée par enchantement dans la montagne devant laquelle ils guettent, laissant apercevoir une somptueuse fête, célébrant un mariage. Agravain convoite la mariée, non pour lui-même mais pour Robert, en consolation de son épouse envolée. Les quatre chevaliers déclarent justement faire partie de sa maison et ont le projet de récupérer la dame, qui se révèle être celle de Robert. Après un affrontement avec les gens de la montagne, ils récupèrent la dame, qui pourtant «se desconforte» (v. 8416), pour la ramener à son mari ${ }^{203}$.

201 La numérotation passe de 55 à 57 . Du dernier cahier de Rigomer, il ne reste que trois feuillets de texte. La tranche de deux feuillets découpés est encore visible, mais on peut supposer que le cahier devait comporter initialement six feuillets pour former un ternion. Au vu de la numérotation, on peut émettre l'hypothèse que seul un de ces feuillets manquants était copié, tandis que l'autre, vierge, a été supprimé dès la copie. Pour une description codicologique de Chantilly, Condé 472, voir Keith Busby et al., Les manuscrits de Chrétien de Troyes, vol. I, p. 98-102.

202 Sur ces questions codicologiques, voir Francesco Carapezza, «Le fragment de Turin de Rigomer», art. cit. Selon le critique, le modèle de notre copie était luimême inachevé et les trois feuillets manquants ne transmettaient que la suite de l'épisode et non la conclusion du roman.

203 Marie-Luce Chênerie traite de cet épisode dans son étude sur les sources folkloriques et mythologiques de Rigomer, "Un Recueil arthurien de contes populaires 
Le mystère entoure cette aventure: par quel événement merveilleux la dame s'est-elle retrouvée dans la montagne? Qui sont les gens qui l'accompagnent et en particulier ce nouveau mari? Pourquoi ne se réjouit-elle pas d'être délivrée? Alors que le roman s'allonge sans cesse par l'ajout de nouvelles aventures et de détours, les historiettes ne sont pas toujours développées et les personnages secondaires qui y interviennent ne reçoivent pas un portrait moral et des motivations explicites - ainsi de la vieille laide, dont on ne sait rien si ce n'est son aspect physique repoussant. Ces vignettes adoptent donc la concision des récits brefs, pour lesquels le lecteur doit faire un effort interprétatif ${ }^{204}$ : dans le cas de l'aventure de Robert, son imagination est stimulée et il est invité à inventer lui-même le contexte de cette histoire. Dans cette perspective, la dame peut avoir été ravie par un être merveilleux semblable à ceux des lais de Tydorel et de Yonec. L'intervention du chevalier arthurien apparait selon cette interprétation comme une perturbation digne d'un losengiers qui mettrait un terme à une idylle merveilleuse. La première réaction d'Agravain, qui souhaite littéralement voler la belle épousée pour la donner à son hôte sans rien savoir d'elle, contrevient d'ailleurs totalement à l'éthique chevaleresque et conforte l'hypothèse de l'inadéquation entre ce chevalier et le monde auquel il est confronté.

Ce petit récit ne constitue pas une narration seconde, un récit dans le récit, comme c'est le cas pour les récits seconds du Lancelot en prose dont traite Bénédicte Milland-Bove ${ }^{205}$, qui rendent clair le parallèle avec un recueil comme l'Heptameron. Le récit bref n'instaure pas nécessairement dans Rigomer un narrateur intradiégétique ni un retour temporel. Cependant, il s'agit bien de petites histoires que l'on pourrait extraire sans porter préjudice à l'intrigue de base et sans que le récit bref perde

au XIII ${ }^{\mathrm{e}}$ siècle: les Merveilles de Rigomer", in Réception et identification du conte depuis le Moyen Âge. Actes du colloque de Toulouse, janvier 1986, dir. Michel Zink et Xavier Ravier, Toulouse, Université de Toulouse-Le Mirail («Travaux de l'Université de Toulouse-Le Mirail, série A», 41), 1987, p. 43-44.

204 Voir Nathalie Koble et Mireille Séguy, "Nos somes tuit enfantosmé! L'effet de (des)saisissement des lais narratifs bretons", in Faire court, p. 181-202.

205 "Les nouvelles des romans arthuriens en prose du XIII ${ }^{\mathrm{e}}$ siècle: narrations longues, narrations brèves?", in Faire court, p. 249-268. 
de sa cohérence ${ }^{206}$. À ceci près, toutefois, que l'hôte Robert s'est rendu à Rigomer et donne quelques informations à Agravain sur ce sujet, sans pour autant beaucoup avancer le lecteur qui est quant à lui déjà au fait de ces éléments. L'évocation de Rigomer dans la discussion de Robert et Agravain, qui se présente en tant que chevalier participant à cette quête, n'apporte rien de substantiel à la trame principale. L'aventure de la femme emportée par le vent peut donc tout à fait fonctionner seule, tout comme celle de la Quintefeuille.

L'association entre le bref et le long esquisse la tentative de concurrence que nourrissent les romans qui nous intéressent vis-à-vis de l'esthétique des romans en prose. La longueur de ces textes pense répondre à de nouvelles attentes du public que n'ont pas lassé les longues aventures de Lancelot et de Tristan. Si «l'abandon du vers permet d'allonger les textes et de développer des récits plus fournis, à l'ambition totalisante ${ }^{207}$, le nouveau souffle que les versificateurs tardifs donnent à ce même vers à la fin du XIII ${ }^{\mathrm{e}}$ siècle joue de cette évolution du récit arthurien et tâche d'imiter ce format long. La juxtaposition d'historiettes, ressort privilégié de l'allongement du récit dans Rigomer et Claris et Laris, donne les clés de cette ambition tout en respectant les fondements du genre en vers: l'errance, qui progresse d'aventure en aventure, sans le dessin d'un futur au monde arthurien. L'autonomisation des aventures par rapport au reste du récit, que l'on rencontre moins dans le roman arthurien classique, se place dans une évolution parallèle à celle des romans en prose: c'est cette idée que le roman somme ${ }^{208}$, aux proportions énormes, mène à la nouvelle

206 Il nous semble que l'exemple de l'aventure d'Agravain dans Rigomer est un épisode bien plus autonome que le passage de la demoiselle entreprenante du Chevalier de la Charrette que donne Roger Dubuis pour illustrer le travail de la brièveté dans le roman. Ce dernier passage s'inscrit dans le parcours spécifique de Lancelot et se révèle signifiant pour le roman entier, car il dit quelque chose de l'amour pur dont le héros est habité. Le traitement des aventures est donc différent dans le roman tardif. D’ailleurs Roger Dubuis précise que ce passage est un de ces épisodes «dont le roman peut difficilement se passer mais qui se passent, eux, très facilement du roman». Roger Dubuis, Les Cent nouvelles Nouvelles et la tradition de la nouvelle en France au Moyen Âge, Grenoble, PU, 1973, p. 509. Dans Rigomer, le passage et le roman entier se passent réciproquement l'un de l'autre.

207 Patrick Moran, Lectures cycliques, p. 37.

208 Voir Patrick Moran, Lectures cycliques, p. 38-39, pour une distinction entre cycle et somme. La somme désigne un récit long et totalisant mais sans la fragmentation qui permet de moduler la présentation de plusieurs œuvres au sein d'un même cycle. 
par une autonomisation des épisodes, et ce dès le Tristan en prose ${ }^{209}$. Les auteurs de romans en vers répondent alors tant bien que mal à un besoin qui se dessine progressivement et qui conduira au recueil de nouvelles, celui d'une lecture fragmentée, sélective, qui peut être aussi bien longue que brève ${ }^{210}$.

\section{Prétendre à l'explicite et à l'exhaustivité}

L'extension du récit est en accord avec l'ambition d'exhaustivité des romans de notre corpus, nous l'avons évoqué. Là encore, ce souci n'est pas étranger à l'écriture en prose, elle qui a le dessein de «tout expliquer, de fournir une lecture absolument cohérente, de verrouiller de tous les côtés, les lignages, les noms, les épisodes parallèles, les événements antérieurs ou ultérieurs, les coïncidences ${ }^{211}$. Entrelacement, allongement, exhaustivité et explicite sont autant de tendances interdépendantes que l'on peut attribuer à cette forme, ainsi que l'exprime Michel Zink:

[La prose] ne fait confiance ni au contexte ni au lecteur pour résoudre ce qui lui paraît ambigu et son système de repérage est serré jusqu’à la redondance. C'est pourquoi le texte en prose est toujours plus long que le texte en vers, alors même qu'il supprime ce qui lui apparaît comme des chevilles dues aux contraintes de la versification. [...] Cette prose ne connaît ni les raccourcis ni les syncopes. Elle a horreur du vide ${ }^{212}$.

La longueur des textes s'explique alors autant par l'accumulation d'aventures parallèles que par la volonté, illusoire, d'élucider tout ce qui

209 Bénédicte Milland-Bove, "Les nouvelles des romans arthuriens en prose du XIII ${ }^{\mathrm{e}}$ siècle: narrations longues, narrations brèves?», in Faire court, p. 249-268.

210 Nous n'irons toutefois pas jusqu'à dire que nos romans engendrent naturellement le recueil de nouvelles: la naissance de ce genre découle d'une évolution lente à partir de plusieurs genres différents, dont fait partie le roman sans en être l'inspirateur exclusif. Voir Roger Dubuis, Les Cent nouvelles Nouvelles et la tradition de la nouvelle en France au Moyen Âge.

211 Anne Berthelot, "Les "Enfances Tristan" dans le roman en prose: comment apprivoiser un mythe?», Tristania, 15, 1994, p. 104.

212 Michel Zink, Littérature française du Moyen Âge, p. 178. La dernière formule de cette citation, "Elle a horreur du vide», est reprise à Daniel Poirion, "Sur l'écriture-prose», art. cit, p. 56: la prose a «horreur du vide, de l'implicite et du discontinu ". 
peut paraître obscur au lecteur. Le caractère illusoire de l'épuisement de la matière est probablement conscient chez les auteurs: la prose s'étale, mais crée en même temps paradoxalement de nouveaux vides, de nouveaux espaces à combler. En développant parfois démesurément son discours, elle pose de nouvelles questions, d'où sa capacité à s'imposer dans le genre romanesque; l'écriture en prose élargit les perspectives à interroger. Il convient dès lors de nuancer l'horreur du vide qui pourrait aller de pair avec l'écriture en prose: le vide, comblé ou créé, est constitutif du roman en prose.

De même, il faut quelque peu nuancer et hiérarchiser les velléités explicatives attribuées à la prose par la critique. Le Tristan en prose maintient certaines ambiguïtés et ne cultive pas particulièrement l'explicite: le lecteur est par exemple invité à choisir qui est le couple le plus parfait, de Lancelot et Guenièvre ou de Tristan et Iseut, sans que le texte fournisse une hiérarchie, tandis que le personnage de Dinadan introduit un point de vue dissonant sur la chevalerie. L'explicite dont nous entendons traiter dans ce chapitre concerne ainsi plus les faits du récit, l'introduction de liens de causalité - on explique l'origine d'une aventure - que la nature précise des valeurs prônées par l'œuvre, qui peuvent demeurer ambiguës dans certains romans en prose, ceux des deuxième et troisième générations en particulier. La prose n'est donc pas que simplificatrice: elle problématise différemment le monde que ne le fait le roman arthurien en vers canonique de Chrétien de Troyes, en élucidant la logique des événements, mais en obscurcissant les valeurs, la répartition axiologique des personnages entre le Bien et le Mal. Le roman en vers classique est quant à lui souvent elliptique voire mystérieux sur certains éléments de logique actancielle ${ }^{213}$ : le savoir des personnages secondaires, les demoiselles par exemple, n'a jamais d'origine claire, de même que les nouvelles circulent de manière énigmatique, que l'on pense à la reine Guenièvre, informée on ne sait comment de la brève hésitation de Lancelot face à la charrette dans le roman de Chrétien de Troyes ${ }^{214}$.

213 Voir l'étude d'Hélène Bouget, Écritures de l'énigme et fiction romanesque. Poétiques arthuriennes (XII'-XIIT siècles), Paris, Champion, 2011.

214 Voir l'introduction à l'édition de Catherine Croizy-Naquet, Chrétien de Troyes, Le Chevalier de la Charrette, éd. cit., p. 22-25. 
Cette différence entre vers et prose est particulièrement claire dans les mises en prose. Annie Combes ${ }^{215}$ démontre que les dérimages de la Charrette ont le souci de lever les incertitudes du récit ou ses incohérences, notamment lorsque Gauvain ne reconnaît pas Lancelot au château où ils sont hébergés: le dérimage le justifie par le souci qu'a Lancelot de s'envelopper la tête dans un manteau pour ne pas être reconnu, quand le vers n'explicite pas l'aveuglement de Gauvain. Ce type d'étrangeté est constitutif du roman en vers et fait partie de l'esthétique fondatrice du genre, qui «réclame[...] du lecteur une attention toujours renouvelée ${ }^{216}$. La prose introduit quant à elle une causalité et motive chaque élément: le Lancelot en prose a bien pour ambition d'éclairer le Chevalier de la Charrette, l'énamourement de Lancelot pour Guenièvre, son enfance auprès de la Dame du Lac notamment. Vers et prose proposent donc deux façons différentes de capter l'intérêt du lecteur, d' "attirer [son] attention, par défaut d'information dans le vers, par excès dans la prose ${ }^{217}$.

Cela touche également le développement du merveilleux: selon Christine Ferlampin-Acher, la prose a le souci d'expliciter le caractère merveilleux de certains éléments, en ajoutant un terme de la famille de «merveille» ou en fournissant une digression explicative sur l'origine de

215 Annie Combes, «Fiction de vérité et vérité de la fiction dans les mises en prose du Chevalier de la Charrette», art. cit., et "Le dérimage du Chevalier de la Charrette: les vers de Chrétien comme ressource de la prose», art. cit., qui se penche notamment sur le savoir des demoiselles, éclairci par certaines versions du dérimage. Voir aussi Le récit en mouvement. Logiques du romanesque médiéval, p. 51: "La récriture semble détourner le goût affirmé de la prose pour les récits étiologiques, un penchant qui la porte à dévoiler l'origine de toponymes, d'édifices, de créatures particulières, telles les fées, ou de coïncidences (pourquoi Lancelot, dans Le Chevalier de la charrette, est-il justement à l'endroit où passent Méléagant et la reine captive? La réponse est dans le Lancelot en prose!).» La mise en prose du Conte du graal mène à des constats similaires: Pierre Servet, "D’un Perceval à l'autre. La mise en prose du Conte du graal», art. cit.

216 Pierre Servet, "D'un Perceval à l'autre. La mise en prose du Conte du graal», art. cit., p. 201.

217 Nathalie Koble, «L'autre monde de la prose: reliure et relecture du roman arthurien en vers dans le Livre d'Artus", in Rencontres du vers et de la prose: conscience théorique et mise en page, dir. Catherine Croizy-Naquet et Michelle Szkilnik, Turnhout, Brepols, 2015, p. 80. Elle montre également comment le Livre d'Artus élucide des passages obscurs du Chevalier au lion de Chrétien de Troyes. 
la merveille, ce que ne fait pas le roman en vers classique ${ }^{218}$. Le Lancelot en prose donne par exemple une origine à la carole magique de la Forêt Perdue, qui retient ceux qui aiment et ont aimé et dans laquelle est embarqué Lancelot: il s'agit de l'œuvre d'un enchanteur, cousin du roi Ban, qui l'a offerte en divertissement à son amie (éd. Micha, t. V, LXXIX, $\$ 33-36$, p. 234-236 et LXXXIII, \$1-4, p. 286-291) 219. Par comparaison, la carole magique de Mérangis de Portlesguez ne fait l'objet d'aucune explication sur ses raisons d'être. En revanche, le tardif Claris et Laris réinvestit ce motif en mettant au centre de la fascination et de l'oubli non pas une carole, mais un conteur. Plus de deux mille dames et chevaliers sont contraints d'écouter «Un conteor qui lor contoit / Une chançon et si notoit / Ses refrez en une viele» (v. 9945-9947) ${ }^{220}$. Il s'agit d'un «desleal enchantement» (v. 10757) qui empêche la saine circulation des chevaliers, si bien que le Laid Hardi, qui s'y est laissé prendre, se tient "por fol» (v. 10802). Tout en soulignant malicieusement la fascination que peuvent exercer les récits, cette scène désigne une fois encore Claris comme un élu: le conteur s'enfuit à sa seule vue. C'est alors qu'un vieux chevalier peut raconter au héros l'origine de l'enchantement: la fée Brunehout en est responsable, là encore par amour. Afin d'empêcher les amis de son amant qu'elle retient auprès d'elle de le retrouver, elle les a immobilisés dans cette carole conteuse. L'intervention de Claris, «li compainz plus lëaus / Vers autre[s] et li plus fëaus» (v. 10781-10782), seul à même de mettre un terme au conte, sert donc l'amitié, comme dans le reste du roman.

218 Merveilles et topique merveilleuse, p. 460-462.

219 Voir Antoinette Saly, "L'épisode du Pré aux Jeux dans le Chevalier de la Charrette", in Image, structure et sens. Études arthuriennes, Aix-en-Provence, CUERMA («Senefiance», 34), 1994, p. 49-54, Emmanuèle Baumgartner, "La musique pervertit les mœurs", in Miscellanea Mediaevalia. Mélanges offerts à Philippe Ménard, Paris, Champion, 1998, t. 1, p. 75-89, Margit Sahlin, Étude sur la carole médiévale: l'origine du mot et ses rapports avec l'église, Uppsala, Almqvist \& Wiksells, 1940, et, sur la carole dans Méraugis de Portlesguez, Carine Giovénal, «Essart et caroles: la problématique du cercle dans Mérangis de Portlesguez de Raoul de Houdenc", PRIS-MA, XXVII/1-2, 2011, p. 65-84.

220 Cet épisode est évoqué par Christine Ferlampin-Acher, Merveilles et topique merveilleuse, p. 359-360 et 507, et par Corinne Pierreville, Claris et Laris, somme romanesques, p. 335-336. 
Ainsi, redondance, longueur, tentative d'exhaustivité et saturation d'explications se retrouvent dans les romans en vers tardifs ${ }^{221}$. Le début de Melyador s'attarde sur l'amour déçu de Camel de Camois pour Hermondine, qui conduit à la proclamation d'une quête de cinq ans pour les chevaliers qui convoiteraient la jeune héritière. Cette quête doit être cautionnée par Arthur, c'est pourquoi six chevaliers écossais se rendent à sa cour pour l'annoncer. Ces messagers, comme tout émissaire du monde arthurien, interrompent une fête («Evous, droitement sus le point / C’on servi dou darrain més, / Un moult grant et noble entremés, / Car .VI. chevalier sont entré / En la sale», v. 2731-2735). Le récit ne s'ouvre donc pas sur la cour d'Arthur et l'arrivée de l'aventure; le lecteur suit l'origine même de cette aventure offerte à la caution du monde arthurien. Il en connaît les enjeux, qui ne se résument pas à la simple conclusion d'un mariage, mais implique bien l'éviction d'un prétendant indésirable. Il en résulte une mise à distance du monde arthurien, présenté comme un garant plus vraiment indispensable: c'est montrer que l'auteur a compris les codes du genre arthurien en vers et qu'il s'en joue. Arthur remplit en effet sa fonction de pilier statique, mais en déplaçant la focale de sa cour à l'origine écossaise de l'aventure, son univers perd de son caractère absolu. Son intervention devient artificielle, dès lors que Florée élabore d'elle-même une stratégie, sans nul recours à l'aide d'un chevalier arthurien. Melyador, en tuant Camel et en se montrant à la hauteur d'Hermondine, ne fait qu'accomplir un plan déjà ficelé à l'avance par la jeune fille.

L'ouverture d'Escanor est en revanche topique et reconduit la fête de cour et l'arrivée d'un messager qui lance l'action. Ce sont surtout les circonstances présidant à la rencontre sur le chemin de l'errance qui s'éloignent du modèle véhiculé par le roman arthurien en vers classique. Une fois parti de la cour, Keu croise par exemple une jeune fille près d'une fontaine, occupée à se regarder dans un miroir et accompagnée d'un nain. Malgré le caractère convenu de cette rencontre, qui se passerait aisément de motivation dans un roman en vers classique, le narrateur met un point d'honneur à raconter en détail les raisons de sa présence à cet endroit, par le biais d'un récit analeptique. Il s'agit en fait de l'amie de Mordred;

221 Ce n'est pas le cas de tous nos romans: Rigomer, nous l'avons vu avec l'épisode d'Agravain, renonce parfois à lever les mystères constitutifs du roman en vers. L'ambition d'exhaustivité que nourrit l'auteur de Rigomer n'implique pas forcément d'être explicite en tout temps. 
accompagné d'un Dinadan fort peu enthousiaste de cette compagnie, le couple s'est rendu quelque temps plus tôt à la fontaine pour se reposer, «pour ce que la fontaine ert bele» (v. 713). Mais un cri est venu brusquement troubler cette quiétude: une jeune fille est poursuivie par Brun sans Pitié, qui a également tué son ami un peu plus tôt. Mordred et Dinadan se sont mis aux trousses de Brun, permettant à la demoiselle de s'échapper chez sa mère - ainsi sait-on ce qu'il advient de cette pucelle. L'amie de Mordred demeure donc seule, disponible pour rencontrer Keu qui l'offense en ne la saluant pas. Soucieux de fluidifier les transitions, le narrateur revient habilement du récit analeptique à Keu et la jeune fille, en signalant que Mordred et Dinadan, semés par le rapide cheval de Brun sans Pitié, retournent à la fontaine,

En icel lieu meïsmement

Ou la pucele orent laissie

Qui mout fu ançois courecie

Qu'il venissent, car il avint

Que Kez a la fontaine vint

Quant Mordrés fu au cri alez. (Escanor, v. 830-835)

Une fois la situation éclaircie, la narration peut poursuivre l'altercation entre Keu et la jeune fille. Le narrateur fait l'économie de raconter à nouveau le début de leur rencontre: "Vouz avez bien la chose oÿe» (v. 845), dit-il à son public.

Girart d'Amiens hérite de la prose cette propension à tout motiver et à attribuer une origine aux aventures et aux personnages rencontrés. Le vers "Si vouz en dirai l'achoison» (v. 1812), qui précède l'explication de la haine que nourrit l'enchanteresse à l'initiative de l'autour maléfique envoyé sur Gauvain, traduit bien cette ambition. Le roman se construit sur ces analepses explicatives, qui ouvrent une nouvelle histoire, nécessaire à la pleine compréhension du récit premier. Ces récits, que l'on peut qualifier d' "étiologiques» à la suite de Richard Trachsler ${ }^{222}$, répondent à la question "pourquoi?», selon Donald Maddox, qui utilise la notion au

222 Richard Trachsler, "Qui a donné le Gringalet à Gauvain? À propos d'un épisode d'Escanor de Girart d'Amiens", in Le cheval dans le monde médiéval, Aix-en-Provence, CUER-MA ("Senefiance» 32), 1992, p. 527-542. Voir aussi l'introduction à son édition d'Escanor, éd. cit., p. 85-91, et son article, «De la prose au vers: le cas de Dynadan dans l'Escanor de Girart d'Amiens », art. cit. 
sujet du Tristan en prose - c'est dire à quel point l'esthétique tardive versifiée est proche de ce roman en prose:

Létiologie révèle l'origine d'un nom propre, d'un toponyme, ou d'un objet remarquable, l'instance originaire d'une situation ou d'une institution; elle sert à situer un phénomène, une pratique, ou un état par rapport à une instance dans le passé censée en être la cause, à partir de laquelle une tradition peut être tracée directement «jusqu'à ce jour», c'est-à-dire jusqu'à l'actualité diégétique signifiée dans le discours ${ }^{223}$.

On peut distinguer deux types d'étiologie: soit la narration procède par analepse pour expliquer un fait qui survient dans la trame de base et trace les causes d'un événement jusqu'au présent diégétique. Nous l'appellerons «type analeptique» ou récit rétrospectif. Soit la trame de base constitue elle-même un récit étiologique qui explique un fait présenté comme chronologiquement ultérieur, par exemple pour donner une origine à une donnée par ailleurs bien connue de l'univers de fiction arthurien. C'est le type "prospectif». Dans ce cas, le lien à effectuer entre l'action racontée et sa conséquence dans le futur diégétique - ou le passé littéraire - peut être explicité ou non.

L'exemple le plus éloquent de la première modalité concerne la haine des deux Escanor envers Gauvain, qui fait remonter le récit aux lignages respectifs de ces chevaliers et à leur enfance et signale ainsi la "volonté d'embrasser la totalité du temps "224, à l'image des romans en prose. C'est l'enlèvement de Gifflet, longuement raconté aux vers 13011 à 13478, qui appelle l'explication du narrateur. Celui-ci commence par dire que c'est Escanor le Grand qui l'a orchestré, par haine de Gauvain: ce personnage, très brièvement évoqué jusque-là, prend de l'épaisseur et éclaire les raisons de la rivalité d'Escanor le Bel, son neveu, avec Gauvain. Dans le roman arthurien en vers classique, le neveu du roi génère beaucoup de jalousies qui n'ont pas besoin d'être justifiées: étant le chevalier le plus renommé

223 Donald Maddox, "Fictions étiologiques dans le Roman de Tristan en prose", in Des "Tristan" en vers au "Tristan" en prose. Hommage à Emmanuèle Baumgartner, dir. Laurence Harf-Lancner, Laurence Mathey-Maille, Bénédicte Milland-Bove et Michelle Szkilnik, Paris, Champion, 2009, p. 132. Donald Maddox distingue récit, motif ou note étiologique selon la longueur du retour au passé. Soit on développe l'événement avec l'idée que "c'est à partir de là que...", soit on évoque brièvement une cause, en une phrase du type "appelé ainsi parce que XY".

224 Richard Trachsler, Escanor, éd. cit., p. 87. 
de la cour, il est naturel que des adversaires orgueilleux soient tentés de se mesurer à lui et de le surpasser (dans le Conte du graal ou l'Âtre Périlleux par exemple). Girart d'Amiens entend quant à lui donner une raison explicite au réinvestissement de ce motif. Escanor le Grand est fils d'un géant et d'une «sorchiere» (v. 13507). Ses parents sont portés au mal et à la cruauté, ce qui explique que leur enfant soit «fel et estouz» (v. 13534). Cette histoire prend place en dehors de la temporalité diégétique et relève de la prédestination ${ }^{225}$ : sous l'influence de son lignage, Escanor le Grand est appelé au mal, tout comme le sera son neveu par son influence. C'est d'ailleurs sa propre mère qui alimente le conflit avec Gauvain, en apprenant à Escanor le Grand que les astres ont révélé la future supériorité de ce chevalier sur lui. C'est ce qui décide Escanor à démentir la prophétie en affrontant le neveu du roi, celui-ci lui laissant la vie sauve in extremis sans pour autant apaiser sa rancœur.

Ce récit s'imbrique à celui qui concerne Escanor le Bel, neveu d'Escanor le Grand, et opposant le plus prégnant jusque-là. C'est bien son lignage, en l'occurrence sa parenté avec Escanor le Grand, qui le pousse à rivaliser orgueilleusement avec Gauvain: l'homonymie des personnages accentue ce même besoin de se mesurer au meilleur chevalier arthurien, de rivaliser avec le représentant de la prouesse mondaine. Lambiguïté de la dénomination est voulue et affermie par l'auteur: le nom de leurs domaines n'est pas non plus de nature à lever la confusion, l'oncle étant seigneur de la Grande Montagne quand le neveu a hérité grâce à sa femme de la Blanche Montagne. De quoi stimuler l'attention du lecteur modèle, dont il est attendu qu'il reste concentré pour identifier le personnage en question, en ayant retenu notamment lequel était l'oncle, lequel le neveu, lequel le Bel, lequel le Grand. Pour n'en donner qu'un exemple, le récit étiologique se concentre sur Escanor le Bel puis réintroduit Escanor le Grand sans véritable transition:

Ore avint qu'Escanors aprist

Que ses niez cele voie emprist

Dont il ne le tint pas a sage. (Escanor, v. 13737-13739)

Il est alors nécessaire d'être bien au fait du rapport avunculaire pour savoir qu'on ne parle plus d'Escanor le Bel, mais de son oncle, grâce au vers 13738.

225 Richard Trachsler, Les romans arthuriens en vers après Chrétien de Troyes, p. 137. Le chercheur souligne la parenté de ce point avec l'esthétique de la prose. 
À nouveau, le texte appelle un lecteur modèle actif, attentif à chaque détail, voire qui relit et déchiffre les allusions pour détricoter les références à tel des Escanor. Faire la distinction entre ces deux personnages est d'ailleurs fondamental: l'homonymie est là pour représenter les deux facettes d'un même personnage ${ }^{226}$, c'est-à-dire l'archétype de l'opposant à la cour. Escanor le Grand en est le pendant négatif, tandis qu'Escanor le Bel laisse entrevoir une rédemption (voir chapitre III, "Imitation ponctuelle: Escanor et le miraculeux", p. 595-610) et montre que l'adversaire n'est pas nécessairement un être entièrement noir. Cela se traduit, comme on pouvait s'y attendre au vu de l'importance du lignage dans ce texte, par les parents du personnage: sa mère, sœur d'Escanor le Grand, est belle et sage (v. 13584), contrairement à la mère de son oncle. Le texte insiste sur les qualités du neveu, sa beauté et sa douceur, qui font de lui le meilleur des hommes: «Et vouz di c'ainc pluz franche rienz / $\mathrm{Ne}$ vit nuz ne mix affaitie» (v. 13680-13681), précise le narrateur. Ainsi, ce ne sont pas tant les dispositions intérieures du personnage qui le poussent à accuser mensongèrement Gauvain; le lien familial et onomastique unissant Escanor le Bel à son oncle le prédestine à une telle rivalité.

La destinée contraint la vie du personnage ${ }^{227}$. Pour autant, cette concurrence n'est pas laissée sans explication ni origine: lors de son mariage, chacun prononce des vœux guerriers et Escanor le Bel fait celui de se battre contre le meilleur de la cour de Bretagne (v. 13720-13730). Ainsi, il accuse Gauvain à tort pour se mesurer à lui :

Et sachiez, por rienz pluz n'ala

A la court quant il apela

Monseingnor Gavain de lait fait,

Car mesires Gavainz jor fait

N'avoit une si vilaine oevre

Enssi con li contes descoevre. (Escanor, v. 13731-13736)

L'accusation fallacieuse contre le neveu du roi est topique: on la retrouve dans plusieurs romans arthuriens en vers, le Conte du graal en chef de file. Girart d'Amiens donne à son personnage une raison de plus que la simple

\footnotetext{
226 Voir l'article de Damien de Carné, «Escanor en son roman», art. cit.

227 Richard Trachsler, Escanor, éd. cit., p. 88. Cette destinée est même inscrite dans les astres, puisque la mère d'Escanor le Grand y lit l'avenir de Gauvain et de son fils (v. 13520-13535).
} 
émulation pour se battre contre le meilleur chevalier: il s'agit de ne pas paraître « recreanz» (v. 13712) à son propre mariage et de formuler le défi le plus impressionnant possible.

Cette raison ne saurait toutefois suffire: il faut qu'Escanor le Grand provoque la fierté de son neveu pour que celui-ci parte à la cour. L'oncle lui demande en effet un don contraignant et lui interdit par la suite de se mesurer à Gauvain, sous prétexte qu'il ne sera jamais à la hauteur:

«Et bien est drois que le connoisse,

Car tant m'a fait ire et angoisse

Qu'encore en ai duel et anui,

N'onques rienz el mont ne connui

Que tant haïsse mortelment.

Je te di bien certainement:

Tu ne t'en porroies deffendre."

Li Biax Escanors de duel fendre

Cuida de ce c'adont ö̈.

Son oncle forment en haï

Et ala a cort sanz atendre. (Escanor, v. 13801-13811)

La peur que son neveu se révèle plus fort que lui transparaît dans le discours d'Escanor le Grand. Il n'en fallait pas plus pour affermir la détermination d'Escanor le Bel, que le narrateur excuse en ces termes:

Et sachiez bien, de ceste alee

Fist li Biauz Escanors folie.

Mais ce fist la melancolie

Qu'il avoit prise en la parole

De son oncle qu'il tint a fole

Et la la felonie prist. (Escanor, v. 13818-13823)

La responsabilité du lignage dans la conduite d'Escanor le Bel est dès lors claire: le récit achève de dresser un portrait positif du personnage en élucidant les mystères tus jusque-là. Remonter à la généalogie du personnage imite les romans en prose en transformant le conflit entre individus en conflit lignager, tel celui qui oppose la famille de Gauvain à celle de Lancelot dans la Mort Artu ${ }^{228}$.

228 Richard Trachsler, Escanor, éd. cit., p. 88-89. Cela est d'autant plus vrai que le récit évoque ici et là plusieurs membres de la famille d'Escanor. Richard Trachsler tente de reconstruire cette généalogie embrouillée à la page 1083 de son édition. 
Le récit étiologique se poursuit en rappelant le vil attentat perpétré contre Escanor par Galantinet, qui l'a empêché ainsi d'affronter Gauvain. Les vides laissés jusque-là par le récit sont alors comblés: Escanor n'est pas mort de cette attaque, mais récupère de ses blessures; Escanor le Grand a souhaité venger son neveu et a tendu une embuscade à Gauvain, que l'on prend pour l'auteur de l'attentat; le chevalier aux demoiselles a montré toutefois une résistance trop importante, si bien que Gifflet a été emmené en échange, dans l'espoir que Gauvain vienne le libérer ${ }^{229}$. La narration rejoint la temporalité diégétique en revenant à l'embuscade: le récit étiologique se clôt. La capture de Gifflet est racontée à nouveau, du point de vue de l'adversaire cette fois, ce qui donne une autre perspective au récit. Adopter le point de vue des assaillants relativise le caractère mesquin de la capture, car il est précisé que «Escanors ne son parenté / Grant mal mie ne li [à Gifflet] voloient» (v. 13936-13937). La superposition d'une autre focalisation sur cette attaque fournit également de nouvelles informations au lecteur: il apprend notamment que Gifflet est emmené à Traverses où il est emprisonné sans être maltraité. Les données de l'événement une fois complétées, le récit peut continuer là où le narrateur l'avait laissé, au moment où les chevaliers d'Arthur s'en vont en quête de Gifflet.

Ce long retour en arrière de près de cinq cents vers (v. 13479-13930) résout ainsi toutes les situations obscures que le roman a laissées en suspens et que n'aurait pas résolues un roman arthurien en vers classique, le genre cultivant plutôt une part de mystère laissée à l'imagination du lecteur. Le roman de Girart d'Amiens imite la prose explicative qui vise la complétude et l'exhaustivité des informations fournies, même s'il faut pour cela patienter plusieurs pages. Comme c'est le cas dans la prose $e^{230}$, le

229 Ces informations sont ré-énoncées plus tard par Escanor le Bel à Arthur (v. 17319-17432). Il explique que Gifflet a été capturé à juste titre par ses amis pour le venger de l'attentat de Galantinet.

230 Elspeth Kennedy analyse les formules d'introduction des digressions explicatives dans le Tristan en prose, "Les structures narratives et les allusions intertextuelles dans le Tristan en prose", in Nouvelles recherches sur le Tristan en prose, dir. Jean Dufournet, Paris, Champion, 1990, p. 123-147. Voir aussi Alexandre Micha, qui dénombre les récits rétrospectifs du Lancelot en prose, pour se convaincre de la fréquence de ce procédé dans l'écriture en prose: "Sur un procédé de composition du Lancelot: les récits rétrospectifs", in Approches du Lancelot en prose, dir. Jean Dufournet, Paris, Champion, 1984, p. 7-23. 
récit étiologique est introduit par des interventions narratoriales qui expriment la dimension explicative de la digression:

Si vouz vaudrai dire conment

Vint la haïne et la descorde,

Si con li contes le recorde

Qu'en no livre fait mention

De lui et de sa nation. (Escanor, v. 13492-13496)

$\mathrm{Si}$ est bien raisonz que l'en oie

Conment la besoingne en ala

Ne par quel raison l'apela. (Escanor, v. 13674-13676)

L'enjeu est bien celui de ne rien laisser en suspens, de traiter toutes les facettes de l'histoire et pas seulement ce qui est directement accessible aux personnages. Ces digressions explicatives établissent une connivence avec le lecteur, qui en sait ainsi plus que les chevaliers arthuriens. Il est d'ailleurs remarquable que les interventions du narrateur sont plus nombreuses dans ces vers que lorsque la narration se poursuit linéairement. Le narrateur multiplie les injonctions à son public comme "sachiez", "si vouz di", «que volez?», ou «si conme avez ö̈» (v. 13815 et 13925), qui rappelle que l'événement a déjà été raconté.

La complicité avec le lecteur est plus manifeste encore dans un autre récit étiologique analeptique: celui qui concerne la rivalité de Brian des Îles avec Gauvain. Là encore, ce personnage sert à varier le motif de l'émulation que suscite Gauvain et celui de la fausse accusation. Alors que la cour se rend à Traverses pour délivrer Gifflet, elle fait escale au château de Brian des Îles. Keu est envoyé auprès de lui pour demander l'hospitalité que Brian accorde bien volontiers. Mais au nom de Gauvain, «le chief baissa en terre» (v. 15145) puis il endosse des armes blanches de novice, après avoir donné les instructions pour le repas. Son projet n'est pas explicité, mais le lecteur devine ses intentions. Dès lors, lorsque la focale se recentre sur les chevaliers arthuriens, le public n'est pas étonné de voir un chevalier anonyme défier Gauvain et ne manque pas de reconnaittre en lui l'hôte qui s'apprête à accueillir l'armée d'Arthur :

Trestot ensi qu'il devisoient

De Gifflet et qu'il s'avisoient

Qu'il porroient faire ne dire,

Virent venir par mout grant ire, 
Ce lour sambla, un baceler,

Car ses chevauz estinceler

Faisoit les pierres au venir. (Escanor, v. 15235-15241)

Les verbes de perception («virent», «lour sambla») montrent bien que l'on adopte une conscience au savoir restreint, de même que le mot «baceler» pour désigner l'attaquant signale que la supercherie de Brian a fonctionné: on le prend réellement pour un jeune chevalier.

Comme nous l'avons exprimé plus haut, le lecteur attentif sait que Brian des Îles en veut à Gauvain et a déjà tenté de lui nuire en lançant l'autour maléfique à ses trousses. Brian se sert cette fois-ci d'un faux prétexte pour réclamer un duel: Gauvain aurait assassiné traîtreusement son cousin germain. Le récit étiologique intervient plus tard, après la défaite de Brian et alors que le narrateur décrit les merveilles du château: la fée qui est à l'origine de celles-ci, Esclarmonde, son amie, a osé dire un jour que Gauvain était le chevalier le plus courtois et le plus habile et que l'on devrait blâmer toute femme qui, aimée de lui, dédaignerait son amour (v. 15779-15793). Le désir de complétude qui anime Girart d'Amiens est ainsi rempli: chaque adversaire de Gauvain voit sa haine justifiée par une digression explicative qui contente le lecteur, sans pour autant instruire les personnages auxquels Brian cache son identité jusqu'au bout, tout comme Galantinet n'est jamais reconnu comme l'auteur de l'attaque envers Escanor le Bel.

À l'inverse, le récit rétrospectif peut, lorsqu'il comble des vides narratifs, instruire le lecteur en même temps que les personnages. Dans Melyador, Agamanor raconte à Phénonée et Lucienne ce qui l'a poussé à se déguiser en peintre pour rencontrer Phénonée (v. 21250-21453). En discours direct, il remonte à l'époque de son enfance, lorsqu'à neuf ans, il demeurait fasciné devant les peintres qui décoraient le salon du manoir paternel de fresques représentant la guerre de Troie. Ces peintures symbolisent l'alliance de l'art pictural et de l'art chevaleresque, qui définissent tous deux le personnage d'Agamanor ${ }^{231}$. La transition entre sa vie d'artiste et sa vie chevaleresque se fait alors tout naturellement: «Ensi, dame, je vous approce / La matere dont parler voel» (v. 21311-21312). La contemplation des fresques troyennes mène bien aux armes, comme si Agamanor avait d'abord tenté de les atteindre par le geste pictural,

231 Voir Michel Zink, «Les toiles d'Agamanor et les fresques de Lancelot», art. cit. 
puis de les imiter en devenant à son tour un combattant, matière à peinture. Il explique alors la décision qu'il prend de se lancer dans la quête d'Hermondine, puis les grandes étapes de son errance, le tournoi de la Garde, où le Chevalier au Soleil d'Or s'est illustré notamment. Deux informations inédites pour le lecteur interviennent: d'abord, Agamanor raconte son affrontement contre Melyador juste avant le tournoi de Tarbonne. Ce duel n'est pas rapporté par le narrateur: le lecteur apprend en même temps que les deux jeunes filles que Melyador et Agamanor se sont battus en dehors des tournois ${ }^{232}$. Il est également informé à ce moment-là que Phénonée a chanté un rondeau lors de la fête qui a suivi le tournoi de Tarbonne, pièce lyrique qu'Agamanor transmet à la suite du récit de sa vie ${ }^{233}$.

Plus qu'une parenthèse explicative nécessaire à la pleine compréhension de l'histoire ${ }^{234}$, le récit rétrospectif multiplie les points de vue sur l'univers présenté. Ce que ne peut rapporter le narrateur, parfois occupé à un autre plan de la scène qu'il narre - il le thématise d'ailleurs lors de la fête finale, lorsqu'il s'excuse: "j'estoie adont si derriere / Que sa cançon ne peus oïr» (v. 29929-29930) -, un autre personnage plus préoccupé du chant de son amie le peut. Le but visé est le même que l'accumulation des aventures: suggérer que l'univers de fiction est multiple et bien plus infini que ce que le texte laisse percevoir. Peut-être plus que l'exhaustivité, ce que recherche Froissart serait l'esquisse d'un monde ouvert dont il capte une parcelle, prolongeable - par la poursuite de l'aventure de Sagremor - et extensible - par le récit d'affrontements occultés dans le cadre du roman. Pour le lecteur, de multiples mondes possibles éclosent: le texte pousse son imagination à inventer une infinité de scénarios inférentiels, pour le dire avec Umberto $\mathrm{Eco}^{235}$. Le roman de Froissart génère alors dans l'esprit des lecteurs l'augmentation du monde fictionnel.

232 Voir la note du vers 21359 de l'édition de Nathalie Bragantini-Maillard, Melyador, éd. cit. p. 1517-8.

233 Voir la note du vers 21404 de l'édition de Nathalie Bragantini-Maillard, Melyador, éd. cit. p. 1519.

234 Il ne s'agit alors pas à proprement parler d'un récit étiologique, dans la mesure où il n'élucide aucun mystère du récit, mais y ajoute des données. D'où une distinction que l'on peut établir entre récit étiologique analeptique et récit rétrospectif.

235 Pour une définition du monde possible sur le plan théorique, voir Umberto Eco, Lector in fabula, chapitres 7 et 8 . 
Ces cas de retours dans le passé concernent la trame narrative propre au roman dans lequel ils s'insèrent. Dans d'autres cas, les auteurs jouent à donner une origine à un élément bien établi de la tradition arthurienne. Il en va ainsi de la célèbre qualité qu’a Gauvain de voir ses forces croître à midi. La nature de ce phénomène n'est jamais explicitée dans les romans arthuriens, en vers comme en prose. Girart d'Amiens prend alors la liberté de lier cette propriété au motif du don des fées: les deux fées marraines qui se penchent sur le berceau de Gauvain à sa naissance lui attribuent, en plus de la prouesse et de la beauté, le don de voir ses forces se décupler selon l'heure de la journée. La première fait le vœu qu'il soit de plus en plus fort de l'heure de prime jusqu'à midi (v. 2793-2798), tandis que la deuxième redouble ce vœu en prophétisant que, aussitôt midi sonné, il sera encore plus hardi et redoutable quauparavant (v. 2804-2814). Comme pour l'explication du conflit contre Escanor, c'est le destin qui fait de Gauvain le meilleur chevalier de la cour.

Les velléités explicatives de nos auteurs ne prennent pas toujours la forme d'un retour dans le passé. Il arrive également que le narrateur désigne l'événement relaté comme l'origine d'une coutume en vigueur dans son présent de narration. L'auteur de Rigomer présente par exemple l'avilissement des chevaliers en travailleurs manuels à Rigomer comme l'origine du surnom de "chevalier» que l'on donne aux tisserands $s^{236}$ («telier», v. 6381). Le récit étiologique s'ouvre comme souvent sur un appel à l'auditoire, signe qu'une connivence est tissée entre narrateur et narrataire:

Or escoutés, signor baron, Par tel fait et par tel raison Claime l'on encor les teliers Soventes fies chevaliers.

Mais li telier ne sevent mie, Que çou soit par tel signorie, Ains sont si fol qu'il s'en corocent,

Qant aucun musart lor reprocent;

Mais s'il le vreté en savoient,

Sachiés, grant joie en averoient. (Rigomer, v. 6379-6388)

236 C'est la traduction que donnent Wendelin Foerster et Hermann Breuer dans le glossaire de leur édition. 
Les interpellations au public et l'évocation élusive de ce surnom donnent l'illusion que la référence est supposée connue du lecteur modèle, ce sur quoi insiste la notion de "vreté», de vérité, attribuée à cette origine. Néanmoins, nous n'avons pas trouvé de traces historiques de ce surnom, qui paraît au demeurant bien fantaisiste: il faut plutôt envisager ces quelques vers explicatifs comme une tentative d'imiter l'étiologie que pratique la prose en donnant une résonance réelle à son récit.

Escanor contient d'ailleurs un passage qui n'est pas sans rappeler directement un récit étiologique du Tristan en prose $e^{237}$ : Arthur impose à sa cour de porter le deuil pour Escanor le Bel, que l'on croit mort. Le texte précise que tout le monde, y compris le roi et la reine, doit porter les «roubes noires» (v. 8876), en signe de «ramembrance du duel et de la mescheance ${ }^{238}$ (v. 8877-8878). Le narrateur n'explicite pas que c'est Arthur qui a instauré cette habitude de porter un habit noir lors d'un deuil, comme le veut une coutume encore en vigueur au présent de la narration. Et pour cause: ce n'est pas la première fois, du point de vue de la littérature, qu'Arthur porte le noir pour un personnage. Voici le passage dans le Tristan en prose:

Et si sachiez que chacun jour qu'ilz faisoient le dueil de monseigneur Tristan, y estoient les laiz recordez. Et tout celui an, le roy Artu e ceulx de sa court porterent robes noires, si vous di bien que monseignour Tristan fut le premier par qui robes noires furent premier treuvees. (éd. Ménard, t. IX, \$141, p. 281-282)

Girart d'Amiens ne peut donc attribuer au deuil d'Escanor l'introduction de la coutume des robes noires: le lecteur féru de littérature arthurienne sait qu'elle a été instaurée pour Tristan, dans un passé littéraire proche et prégnant. L'allusion est claire: ce passage ne saurait se passer de l'intertexte tristanien pour être compris comme un récit étiologique.

237 Voir Richard Trachsler, notamment son article «De la Prose au Vers. Le cas de Dynadan dans l'Escanor de Girart d'Amiens", art. cit., p. 408.

238 Le terme de "mescheance", quoiqu'il ne soit bien sûr par exclusif à la Mort Artu, est néanmoins un concept clé de la dernière œuvre du Lancelot-Graal, exprimant l'idée de fatalité, la succession de concours de circonstances qui mènent à la chute. De fait, l'attentat contre Escanor le Bel dans Escanor est une mescheance qui pourrait potentiellement conduire à une guerre mortelle et à la décadence des valeurs arthuriennes. Il n'en sera rien: le vers garantit la pérennité du monde arthurien. 
Fait d'échos et de clins d'œil, le récit étiologique convoque les connaissances arthuriennes que possède un lectorat modèle. Il en va ainsi pour les robes noires comme pour l'épisode de Sagremor dans Melyador, dont nous avons déjà traité: Froissart raconte la jeunesse de ce chevalier, son intégration à la cour d'Arthur et la façon dont il s'éprend de Sebille. Ce personnage est connu du monde arthurien: il apparaît furtivement dans quelques romans en vers, dans le Lancelot-Graal et surtout dans les Suites $d u$ Merlin, qui fournissent des indications contradictoires sur son origine byzantine notamment ${ }^{239}$. Melyador ne reconduit pas les liens familiaux qu'entretiendrait Sagremor avec l'empereur de Constantinople, et fait de ce personnage le fils du roi d'Irlande. De son côté, le Livre d'Artus raconte aussi son histoire d'amour avec Sebille ${ }^{240}$. Celle-ci est veuve depuis l'assassinat de son mari par le Noir Chevalier Faez. Elle attend l'aide d'un chevalier hardi pour la soustraire aux ardeurs de ce soupirant. Sagremor, qui erre dans la région, est tout désigné pour cette entreprise: il libère la dame de l'emprise du Chevalier Faez et convainc Sebille, alors païenne, de se convertir au christianisme pour pouvoir vivre leur amour. Le nom de son amante n'est dès lors pas une invention de la part de Froissart, mais circule vraisemblablement dans certains textes arthuriens. Le passage de Melyador consacré à Sagremor est donc peut-être une tentative concurrente du Livre d'Artus de donner une origine à l'amour de Sagremor et Sebille, qui est chrétienne dès l'origine dans le roman en vers.

À ceci près que cet amour n'est pas réalisé dans les bornes du récit qui nous a été transmis: Sagremor avoue son amour à son amie, mais celle-ci ne semble pas s'y intéresser et le fuit. Le roman ne transmet jamais par la suite l'issue de cet amour ni celle de l'errance qu'entreprend le jeune homme dans l'espoir de mériter la main de Sebille. Le narrateur annonce

239 Claude Roussel, "L'art de la suite: Sagremor et l'intertexte», art. cit.

240 Le Livre d'Artus, in The Vulgate Version of the Arthurian Romances edited from manuscripts in the British Museum, éd. H. Oskar Sommer, Washington, The Carnegie Institution of Washington, 1908-1916, t. 7, p. 280-288. La SuiteVulgate raconte également l'enfance de Sagremor et son origine. Voir Richard Trachsler, "Quand Gauvainet rencontre Sagremoret ou le charme de la première fois dans la Suite-Vulgate du Merlin", in Enfances arthuriennes. Actes du $2^{e}$ colloque arthurien de Rennes, 6-7 mars 2003, dir. Denis Hüe et Christine Ferlampin-Acher, Orléans, Paradigme, 2006, p. 203-215. Voir aussi Claude Roussel, «L'art de la suite: Sagremor et l'intertexte», art. cit., sur les origines généalogique et onomastique que les romans en prose prêtent à Sagremor. 
que "ailleurs que ci en parlerons»(Melyador, v. 28828) 241 $^{24}$ se servant de l'entrelacement pour interrompre l'aventure et laisser le destin de ce chevalier ouvert. Nathalie Bragantini-Maillard juge que cette histoire était volontairement inaboutie, laissant la place à d'éventuelles continuations de l'univers de fiction ${ }^{242}$. L'amour de Sagremor et Sebille n'en est qu'à ses premiers balbutiements, la jeune fille n'étant pas en âge de se marier, de même que la formation chevaleresque de Sagremor demeure imparfaite. Conditionnée par le genre, l'errance qu'il entreprend appelle l'obtention d'une femme et d'une terre, en l'occurrence celle d'Irlande, qu'il doit reconquérir sur l'usurpateur Bondigal. Le narrateur esquisse d'ailleurs le futur qui attend Sagremor:

Or li couvenra reconquerre

Par armes s'il le [sa terre] voet ravoir.

Je croi moult bien que son devoir

En fera ou temps a venir. (Melyador, v. 26589-26592)

Rien d'inattendu donc, pour qui est familier des trames narratives arthuriennes, au point que l'imagination du lecteur suffit à reconstruire la suite des aventures de Sagremor.

Le récit étiologique prospectif, qui explique l'amour entre Sagremor et Sébille, est ici un horizon, il demeure à l'état d'intention jamais réalisée. Plutôt que de saturer l'univers, Froissart tente des ouvertures, comme pour encourager les auteurs potentiels à perpétuer les récits arthuriens. Les suites rétrospectives du Lancelot en prose, la Suite Vulgate, le Livre d'Artus ou les Prophéties de Merlin, ont toutes un horizon déjà tracé qu'elles annoncent

241 Les renvois sont fréquents dans la prose, qu'ils soient intratextuels (ou intracycliques si l'on veut) ou intertextuels. Pour le premier cas, on peut donner un exemple du Lancelot propre qui fait référence à la fin de la Mort Artu: "Einsinc com Lanceloz ot dites ses aventures furent eles mises en escrit, et pour ce que li fet estoient greingnor que nus de çaux de laienz, les fist li rois mestre par lui seul si que des fez et des ovres trova l'an .I. grant livre en l'aumaire le roi Artu aprés ce qu'il fu navrez a mort en la bataille Mordret, si com li contes vos devisera apertement.» (éd. Micha, t. 5, LxxxIv, \$72, p. 396-397). Le même texte invite à consulter une œuvre fictive - ou aujourd'hui perdue - qui raconterait les prouesses de Galehaut: «Et si retesmoigne li livres Tardamides de Vergials, qui plus parole des proesces Galehout que nus des autres, que neis li rois Artus ne fu mie de gaires plus vaillans. » éd. Micha, t. 1, I, \$1, p. 1 .

242 Melyador, éd. cit., p. 29-43. 
explicitement sur un ton proleptique ${ }^{243}$, ou dont elles tracent l'origine, par exemple l'arrivée de Morgane au Val sans Retour dans le Livre d'Artus ${ }^{244}$, la conception de Mordred dans la Suite-Vulgate ${ }^{245}$. Ces procédés sont autant de moyens de créer des ligatures avec le reste du cycle. Mais il arrive aussi que les annonces, qu'elles prennent ou non la forme de prophéties de Merlin, ne se réalisent jamais dans le cadre d'un récit qui nous serait parvenu. Nathalie Koble parle alors de "mirage prophétique», pendant au «mirage des sources» qui fait croire à un grand livre qui fournirait aux romans leur matière. L'ouverture sur un avenir textuel participe d'un "effet de cycle», qui "serait une façon de donner le change à l'exigence de totalisation sans pour autant se soumettre intégralement aux contraintes de la structure d'accueil» ${ }^{246}$. L'annonce d'une suite à l'histoire de Sagremor dans Melyador fonctionne selon le même principe, bien que le roman ne se greffe pas sur une structure préexistante: que Froissart ait réellement eu l'intention d'écrire cette suite ou non, cette promesse ouvre l'œuvre à une élaboration cyclique et se veut une invitation lancée à de futurs continuateurs. Énoncer que l'histoire se poursuit "ailleurs que ci", c'est inscrire le texte "dans un devenir cyclique ${ }^{247}$ et renforcer l'ouverture de l'inépuisable livre arthurien.

243 Ainsi Merlin résume-t-il dans un récit proleptique - ou prophétique - le contenu de la Queste dans le Livre d'Artus (p. 147-148). Voir Nathalie Koble, «Les romans arthuriens en prose au XIII ${ }^{\mathrm{e}}$ siècle: des cycles en série?», in Cycle et collection, dir. Anne Besson, Vincent Ferré et Christophe Pradeau, Paris, L'Harmattan, 2008, p. 179-198. Ces liens tissés entre la suite et le récit qu'elle augmente en amont sont autant de marques de cyclicité. Voir aussi Patrick Moran, Lectures cycliques.

244 Voir Keith Busby, "L'intertextualité du Livre d'Artus», Arturus Rex, Leuven, Leuven University Press, 1991, p. 306-319. Il est fréquent de trouver dans le roman en prose des promesses de suites semblables à celle qui concerne Sagremor dans Melyador. En voici un exemple dans l'Estoire Merlin: "Et devant la riche vile del gaut destroit qui tant fist a proisier tant que Gaudin le conquist par sa proece si comme li contes devisera encore s'il est qui le vous die mais li lieus n'i est pas ore mie." L'Estoire de Merlin, in The Vulgate Version of the Arthurian Romances edited from manuscripts in the British Museum, éd. H. Oskar Sommer, Washington, The Carnegie Institution of Washington, 1908-1916, t. 2, p. 164.

245 L'étiologie fonde particulièrement l'esthétique de la Suite-Vulgate, qui raconte l'enfance de personnages célèbres, dont le prénom est affublé du suffixe -et. Voir Richard Trachsler, "Quand Gauvainet rencontre Sagremoret ou le charme de la première fois dans la Suite-Vulgate du Merlin", art. cit.

246 Nathalie Koble, "Les romans arthuriens en prose au XIII ${ }^{\mathrm{e}}$ siècle: des cycles en série?", art. cit., p. 192.

247 Ibid. 
En appelant à la continuation et en multipliant les références à l'encyclopédie arthurienne, le roman tardif vise à établir un lien entre le roman qui s'offre au lecteur et l'ensemble des ouvres arthuriennes existantes et même à venir. Le poids des cycles et sommes en prose encourage l'esthétique tardive à inscrire les textes en vers en réseau, c'est-à-dire à former un ensemble d'œuvres autonomes qui se font écho, d'où l'idée de cycle. L'avant-dernier roman arthurien en vers, Escanor, fait preuve de la même volonté: le roman raconte les circonstances présidant à la conquête du Gringalet par Gauvain, donnant ainsi une origine au lien que ce personnage entretient avec son cheval, qui apparait dans Erec et Enide, La Vengeance Raguidel, L'Âtre Périlleux, la Suite-Vulgate ou encore le Livre d'Artus. Richard Trachsler a déjà analysé en détail cet épisode et ses sources potentielles ${ }^{248}$, c'est pourquoi nous nous bornons à traiter les enjeux de ce passage pour l'esthétique globale. Le Gringalet est, dans Escanor, le cheval d'Escanor le Bel, reçu en présent par la fée Esclarmonde. Son oncle, qui emprunte la monture sans prévenir son propriétaire lors de la guerre qui oppose leur camp à celui d'Arthur, est désarçonné par Gauvain qui s'empare du beau cheval. Constatant que le Gringalet refuse de se nourrir et de s'abreuver, Gauvain est cependant bien malheureux, trop sans doute pour un cheval ("Ainz d'un cheval si courechiez / Ne fui mais ne si esmeüs», v. 20056-20057), ce qui en dit long sur la relation littéraire qu'il entretient avec cette bête. Une jeune fille de la parenté d'Escanor, Felinete, lui apprend qu'une poudre glissée dans l'oreille du destrier empêche quiconque de chevaucher l'animal vivant. Elle espère, par ce service, recevoir un guerredon en échange; elle l'obtiendra au moment où, lors du duel qui oppose Escanor le Bel et Gauvain, celui-ci a le dessus sur celui-là, et qu'il accepte pour elle d'interrompre le combat. L'histoire du Gringalet ne

248 "Qui a donné le Gringalet à Gauvain?», art. cit. Richard Trachsler souligne notamment l'influence de la chanson de geste sur cet épisode, qui lui emprunte le motif épique du don du cheval, son origine merveilleuse et le nom d' "Esclarmonde», qui renvoie bien sûr au cycle d'Huon de Bordeaux que Girart d'Amiens devait connaître. Cette hypothèse anticipe sur les constats que nous ferons dans le chapitre suivant: les romans tardifs puisent volontiers une partie de leurs thèmes et motifs dans d'autres genres littéraires, en particulier celui de la chanson de geste. L'épisode du Gringalet renforce ce constat. Il faut également noter que la version de la rencontre entre Gauvain et le Gringalet proposée par Girart d'Amiens concurrence celle de la Suite-Vulgate: dans ce texte en prose, le cheval est dérobé à Clarion, un roi saxon. 
constitue donc pas un épisode isolé, mais elle s'insère parfaitement dans la trame narrative générale et permet la progression de l'intrigue.

Ce récit étiologique reproduit bien ce qui fait la saveur de ce rapport entre le personnage et sa monture dans les romans arthuriens précédents: le Gringalet est souvent dérobé à Gauvain, comme il l'est à Escanor le Bel par Escanor le Grand, puis à celui-ci par le neveu du roi Arthur. L'animal est un cheval merveilleux, don d'une fée dans Escanor: ainsi s'explique le prodigieux hennissement qu'il pousse dans le Livre d'Artus, résonnant à deux lieues à la ronde ${ }^{249}$. Pour savourer cet épisode, le lecteur modèle doit, là encore, se montrer connaisseur de la tradition arthurienne. À travers cet épisode, Girart d'Amiens emprunte la voie de la préhistoire arthurienne, bien qu'il ne l'explicite pas comme Froissart dans Melyador. Raconter l'origine d'éléments connus de la tradition est déjà une voie éprouvée par les suites rétrospectives du Lancelot en prose: le Livre d'Artus s'intéresse à la construction des lieux emblématiques du roman arthurien, le Pont de l'Épée, le Pont sous l'eau, Le Val sans Retour, le royaume du roi Pécheur ${ }^{250}$. Chose rare pour le roman en prose, l'horizon de ce texte ne se cantonne pas au Lancelot en prose, au cycle dans lequel il s'insère, mais s'ouvre aussi aux œuvres en vers, la Vengeance Raguidel par exemple, dont on raconte les causes de la haine que voue la dame de Gaudestroit à Gauvain, puis dont on réécrit le passage de la fenêtre-guillotine que la dame invente ${ }^{251}$. Il semble alors que le récit arthurien tardif, d'abord en prose puis à plus forte raison en vers, prenne de plus en plus appui sur l'ensemble de la tradition arthurienne, qui forme un univers de fiction encore plus vaste que celui que parcourt le Lancelot en prose $e^{252}$. Keith Busby envisage cette vision

249 Voir à ce sujet Richard Trachsler, "Qui a donné le Gringalet à Gauvain?», art. cit.

250 Voir Noémie Chardonnens, Nathalie Koble et Patrick Moran, "L'invention du Livre d'Artus: le manuscrit Paris, BnF, fr. 337 », art. cit.

251 Voir Keith Busby, "L'intertextualité du Livre d'Artus", art. cit., Noémie Chardonnens, Nathalie Koble et Patrick Moran, "L'invention du Livre d'Artus: le manuscrit PARIS, BnF, fr. 337 ", art. cit., et Nathalie Koble, "L'autre monde de la prose: reliure et relecture du roman arthurien en vers dans le Livre d'Artus", art. cit. L'intertextualité avec la Vengeance Raguidel est même assez forte pour qu'on puisse identifier des passages transposés de vers en prose.

252 Les romans en vers ne sont jamais un horizon diégétique pour le Lancelot en prose: le personnage d'Yvain, par exemple, n'a plus aucun lien avec la Fontaine qui bout, ni avec une fée Laudine, ni même avec un lion reconnaissant. Au contraire, la prose réécrit l'origine de son surnom de "Chevalier au lion» en prétendant 
globale du monde arthurien comme une caractéristique de l'écriture tardive:

La tendance à tout vouloir rassembler dans un roman, un cycle, une compilation, caractérise les dernières phases dans l'évolution du roman $\operatorname{arthurien}^{253}$.

Romans en vers et romans en prose partagent alors clairement le même univers de fiction: nous en traitions au chapitre II, le roman en vers tardif insère des personnages exclusifs à la prose dans sa trame narrative. Ils partagent aussi les mêmes aspirations structurelles: entrelacement, allongement, exhaustivité.

Pour le vers néanmoins, la constitution d'un cycle ${ }^{254}$ demeure un possible jamais réalisé: aucun manuscrit ne crée des coutures qui feraient se succéder plusieurs romans en vers chronologiquement ${ }^{255}$. Le propre du

qu'Yvain a revêtu la peau d'un lion tué par Lionnel sur son écu. L'intertexte de Chrétien de Troyes est nécessaire pour engendrer le sourire du lecteur face à ce nouveau rapport entre Yvain et le lion, tant elle dessert le chevalier. Toutefois, le Chevalier au lion n'est pas indispensable à l'intelligibilité de la diégèse ni ne représente son futur; au contraire, il s'agit d'une version que l'auteur tente de supplanter. Voir Emmanuèle Baumgartner, "Le lion et sa peau ou les aventures d'Yvain dans le Lancelot en prose", in De l'histoire de Troie au livre du Graal, Orléans, Paradigme, 1994, p. 291-300.

253 Keith Busby, «L'intertextualité du Livre d'Artus», art. cit., p. 319.

254 Nous définissions le cycle, avec Patrick Moran (Lectures cycliques), comme une architecture qui crée un lien entre ses membres, tandis que la série, à laquelle nous apparentions les romans en vers, comprend des œuvres juxtaposées, potentiellement infinies.

255 L'absence de construction cyclique au sein des manuscrits est un trait que les romans arthuriens en vers tardifs partagent avec les romans arthuriens en prose tardifs (Perceforest, Ysaïe le Triste, Artus de Bretagne). Noémie Chardonnens parle d' "effet de cycle" au sujet du Perceforest, reprenant la terminologie de Nathalie Koble («Les romans arthuriens en prose au XIII ${ }^{\mathrm{e}}$ siècle: des cycles en série?», art. cit.) pour désigner les liens thématiques, le partage d'éléments entre Perceforest et d'autres textes, notamment lorsque ces éléments annoncent un futur que racontent d'autres textes (le Tristan en prose, le Cycle Vulgate par exemple). L'effet de cycle laisse voir le monde arthurien comme l'horizon du Perceforest, mais se distingue néanmoins de la véritable cyclicité, qui construit un rapport de dépendance thématique et chronologique entre les textes. Voir L'autre du même, p. 275-283. 
vers est de créer cet effet d'ensemble, de suggérer l'appartenance du roman individuel à une collection, à une encyclopédie, qui n'apparaît toutefois jamais physiquement dans les alentours textuels. Les deux derniers romans arthuriens en vers thématisent ce lien consubstantiel entre les textes, en proposant des récits étiologiques prospectifs qui rendent visible la transition avec les œuvres précédentes. Celui du Gringalet n'est pourtant pas suivi d'un passage où l'animal serait volé à Gauvain, comme c'est le cas dans la tradition littéraire établie jusque-là: c'est au lecteur de savoir, de se rappeler, à la lecture d'Escanor, que ce destrier est promis à un avenir signifiant. La tardivité jette un nouveau point de vue sur le genre et peut convoquer en creux des scénarios inférentiels, en comptant sur la compétence générique de son lecteur. Même si la construction cyclique demeure incompatible avec l'esthétique du roman arthurien en vers ${ }^{256}$, les romans tardifs ont l'ambition d'élargir l'horizon de ce chronotope pour suivre la mode qu'ont lancée les romans en prose.

Seul le manuscrit Chantilly, Condé 472 crée un effet d'ensemble à partir de romans arthuriens en vers: ce recueil se lit comme un condensé du chronotope versifié. Il peut être considéré comme une réduction du processus d'écriture en vers: nous l'avons vu, les personnages reviennent d'un texte à l'autre, parfois de manière contradictoire et sans chronologie particulière. Les données d'une ouvre s'effacent lorsque l'on sort de son cadre et les compteurs repartent à zéro à chaque début de récit. Gauvain peut être le meilleur chevalier dans Rigomer et un novice accompagné de Hunbaut dans Hunbaut. Ce recueil n'est pas un cycle, comme a pu l'affirmer Lori Walters ${ }^{257}$ : il n'y a pas de chronologie entre les textes ni de lien généalogique ${ }^{258}$, les récits se passant tous dans un non-temps et

256 La résistance du genre vis-à-vis de la mise en cycle n'est pas liée à l'écriture en vers: la chanson de geste s'organise volontiers en cycle, que l'on pense au Cycle de Guillaume. Voir Michael Heintze, "Les techniques de la formation de cycles dans les chansons de geste", in Cyclification. The development of narrative Cycles in the Chanson de Geste and the Arthurian Romances, dir. B. Besamusca et al., Amsterdam; Oxford, North-Holland, 1994, p. 21-58, et Nelly Andrieux-Reix, «Écriture d'un cycle, écriture de geste. L'exemplarité d'un corpus», Romania, 108, 1987, p. 145-164.

257 Lori Walters, "The formation of a Gauvain cycle in Chantilly manuscript 472 ", art. cit., et "Chantilly Ms. 472 as a cyclic work», art. cit.

258 La définition que donne Annie Combes du cycle englobe ces deux aspects. Les Voies de l'aventures, p. 55. 
échappant à tout ordonnancement temporel. Dans la même idée, s'il figure tout de même dans le recueil un texte en prose traitant du Graal, le Perlesvaus, l'œuvre n'est pas transmise dans sa totalité: seules les huit premières branches figurent, le roman s'achevant avant la découverte du Saint Vase par Perlesvaus et maintenant le temps des aventures ouvert. Plutôt que de cycle, on peut qualifier le ms. Chantilly, Condé 472 de florilège de romans arthuriens en vers, de capture de l'univers de fiction proposé par l'écriture versifiée.

L'étiologie, comme l'entrelacement et l'allongement, influent structurellement l'écriture tardive et font davantage de ces œuvres des héritiers de la prose que des romans de Chrétien de Troyes. Contemporains des romans-sommes ${ }^{259}$ comme le Tristan en prose, nos textes s'inspirent des pratiques fondatrices de cette esthétique, qui a tracé la voie de productions longues, digressives, multipliant les aventures. Sans atteindre les dimensions d'un roman-somme en prose, ils se présentent comme des sommes en vers, mêlant la narration d'un court laps de temps, propre au vers, à l'esquisse, peut-être timide par rapport à celle de la prose, d'une généalogie (Escanor), à la multiplication des lieux d'action simultanée (Claris et Laris, Melyador), à l'adoption d'une perspective globale sur le monde arthurien.

\section{CONFLUENCES : UN MÉLANGE DES GENRES?}

L'esthétique de la somme ne se réduit pas à l'ambition de tout dire ni à celle d'inscrire l'histoire dans la durée: ce sont aussi les capacités d'absorption du roman arthurien tardif qui le rapprochent d'une "somme romanesque», selon le titre que Corinne Pierreville donne à son étude sur Claris et Laris. La généricité arthurienne de ces textes est en effet interrogée par leur propension à intégrer des éléments tirés d'autres genres littéraires, à tel point que les composants allogènes concurrencent parfois

259 Patrick Moran distingue cycle et somme, l'un succédant à l'autre: «Les romanssommes poussent simplement cette logique à sa conclusion: puisque la prose a révélé la possibilité d'une narration de longue haleine, capable de dépasser les dimensions traditionnellement acceptées dans le cadre d'une production en vers, rien n'empêche à partir de là de débarrasser la forme-cycle de ses coutures superflues, et de composer des romans d'un seul tenant." (Lectures cycliques, p. 546) 
la proportion de données arthuriennes. À la fin du XIV siècle, Melyador en est l'aboutissement. Jeanne Lods voit en Melyador une somme de différents genres, roman de chevalerie, roman d'amour, roman lyrique, roman breton $^{260}$. La structure entrelacée contribue à ces interactions entre différents genres, qui peuvent expliquer l'écart de ces textes avec le canon du genre arthurien en vers. L'ouverture sur les rencontres entre Camel de Camois et Florée et Hermondine n'ont en effet rien d'arthurien, ni même d'ailleurs la quête en elle-même, qui, selon Michel Zink,

au lieu d'être un engagement collectif mettant en cause, à travers les aventures individuelles, les valeurs fondamentales du monde arthurien et son sens, débouchant sur une révélation lourde de conséquence pour ce monde entier, devient une chasse au beau parti sous forme de compétition sportive ${ }^{261}$.

Le roman s'éloigne du genre arthurien en vers, car il renonce à sa portée métaphysique, à la conception d'une quête qui bénéficierait à toute une communauté dont le héros serait le représentant et le défenseur. Point de nuit à la belle étoile ni de véritable péril de mort, excepté pour Camel de Camois, seul adversaire à abattre ${ }^{262}$.

L'aventure dans Melyador valorise au contraire un bonheur individuel, atteignable par tout un chacun; l'errance des personnages ressemble à celle des chevaliers réels du XIv siècle dont on tire des biographies qui rencontrent un grand succès en France ${ }^{263}$. Nathalie Bragantini-Maillard

260 Jeanne Lods, "Amour de regard et amour de renommée dans le Méliador de Froissart», art. cit., p. 248-249.

261 Michel Zink, «Le Roman», art. cit., p. 212-213. Voir aussi l'article "Meliador and the inception of a new poetic sensibility", art. cit.: "While it would indeed be difficult to deny that Meliador is a verse romance, I would like to suggest here that it is not an Arthurian romance. At the very least, the nature of this work is such that we cannot perceive it as an anachronistic resurrection of the Arthurian verse romance.» (p. 156), et Froissart et le temps, p. 121-123. Didier Lechat voit également dans la quête de Melyador une manifestation proche de la compétition sportive: "l'héroïsme ne consiste pas en l'acquisition d'une meilleure connaissance de soi ou en la résolution d'un conflit intérieur, mais en l'obtention d'un palmarès. " ( Les chevaliers-poètes dans Meliador de Froissart», art. cit., p. 77)

262 C'est le constat de Jeanne Lods, «Les poésies de Wenceslas et le Méliador de Froissart", art. cit., p. 207.

263 Elisabeth Gaucher, La biographie chevaleresque. Typologie d'un genre (XIII -XV'), Paris, Champion, 1994, et Michelle Szkilnik, "À quoi se résume une vie? Du 
perçoit une parenté entre Melyador et les romans de tournoi comme le Roman du Hem, en ce que tous deux narrent des fêtes de cour ludiques entrecoupées d'interactions courtoises:

Lalternance du fait chevaleresque et de l'intrigue amoureuse, l'esthétique de spectacle et d'exaltation de la chevalerie, ce plaisir pris à exhiber le jeu fictionnel en exploitant à plein la thématique de la simulation, et à brouiller les pistes pour confondre fiction et réalité relèvent assurément de cette dimension qui caractérise les festivités arthuriennes dès le XIII ${ }^{\mathrm{e}}$ siècle, où participants et spectateurs se glissent dans la peau de leurs héros romanesques ${ }^{264}$.

Les affrontements sont souvent cantonnés au cœur des quatre tournois organisés par diverses cours, présentant la chevalerie comme un jeu plus que comme un moyen de rendre la justice ou de défendre ou étendre le territoire politique:

À l'instar des romans de tournois et des festivités arthuriennes dont ceux-ci s'inspirent, le monde ordené de Melyador correspond, en réalité, à un espace de jeu, aux aspirations ludiques de l'aristocratie, plus qu’à un idéal politique ou social à atteindre ${ }^{265}$.

Si le roman de tournoi s'inspire de l'écriture romanesque, Froissart nourrit réciproquement son Melyador de caractéristiques propres aux jeux guerriers réels.

D'où les explications que fournit le héraut d'armes avant le début de la quête: ce héraut proclame l'ouverture de la quête sur deux cents vers (v. 2780-2935) et fait ainsi écho aux programmes des événements sportifs réels, qui détaillent les règles du jeu. Le contenu de ces recommandations renvoie aux conventions du roman arthurien, d'abord par le rôle centralisateur que l'on essaie de donner de manière un peu artificielle à la cour

souci de la brefté dans les biographies du $\mathrm{xv}^{\mathrm{e}}$ siècle», in Faire court: l'esthétique de la brièveté dans la littérature du Moyen Âge, dir. Catherine Croizy-Naquet, Laurence Harf-Lancner et Michelle Szkilnik, Paris, PSN, 2011, p. 137-152.

264 Melyador, éd. cit., p. 303-304. Voir aussi Nathalie Bragantini-Maillard, «Les tournois de Melyador, ou l'originalité d'une stéréotypie stylisée", Le Moyen Français, 68, 2011, p. 1-22, et "Les jeux du narrateur dans Melyador», art. cit., au sujet du brouillage entre réel et fiction.

265 Melyador, éd. cit., p. 288. 
d'Arthur: les participants sont amenés à vivre des aventures puis à revenir à la cour d'Arthur pour les y raconter, tout comme dans les romans arthuriens classiques. Le héraut précise encore que chaque chevalier ne peut emmener avec lui qu'un seul écuyer et qu'il doit maintenir l'incognito:

«Uns chevaliers ne poet sans doubte

Mener c'un seul varlet de route,

Et garde ossi qu'il ne se nomme

Pour aventure ne pour homme

Qui li puist nestre ne venir

En la cace parmaintenir.» (Melyador, v. 2896-2901)

L'errance n'est donc pas totalement solitaire, contrairement à celle des œuvres plus canoniques. Cette situation rappelle ainsi d'autant mieux les errances réelles de chevaliers qui imitent les héros de romans ${ }^{266}$. Thématiser, par l'intermédiaire d'un héraut d'armes, des conventions implicites dans le roman arthurien classique, c'est apparenter l'histoire de Melyador aux divertissements de la noblesse chevaleresque et rapprocher Melyador du reportage de tournoi, le tout dans un "climat arthurien ${ }^{267}$.

Faut-il parler en ce cas de "mélange des genres »? Les types d'interactions avec d'autres genres sont multiples dans notre corpus. Jean Froissart fait un travail de confluence dans son roman, en intégrant des genres variés au sein d'un canevas arthurien. Ces différents genres (le lyrique et l'imitation de relations de tournoi en particulier) se diffusent dans tout le récit et ne sont pas cloisonnés dans des passages ponctuels. La confluence désigne selon Patricia Victorin, qui l'applique pour Ysä̈e le Triste, «le mélange des voix et des discours littéraires ${ }^{268}$. L'esthétique de la confluence emprunte des tons, des registres à d'autres genres; elle emprunte aussi des canevas narratifs. Nous l'employons pour signifier toute collision entre un genre dominant, le roman arthurien pour le corpus qui nous intéresse, et un autre genre. Dans Melyador, cette collision s'opère harmonieusement et se

266 Ainsi d'Ulrich von Liechtenstein qui joue au roi Arthur sur le chemin d'un tournoi. Voir Roger Sherman Loomis, "Chivalric and Dramatic Imitations of Arthurian Romance", in Medieval Studies in Memory of A. Kingsley Porter, dir. Wilhelm R. W. Koehler, vol. 1, Cambridge, Harvard University Press, 1939, p. 79-97.

267 Richard Trachsler, Les Romans Arthuriens en vers après Chrétien de Troyes, p. 15.

268 Ysaïe le Triste: une esthétique de la confluence, p. 21. 
diffuse dans l'entier du roman. Il s'agit donc d'une esthétique différente de celle que Richard Trachsler dénomme «interférence des matières», qu'il définit comme le côtoiement de plusieurs matières bodéliennes au sein d'un même texte ${ }^{269}$. Il l'applique en particulier au transfert d'un personnage d'une matière narrative bodélienne à une autre. Ainsi, les épisodes avaloniens des chansons de geste présentent des cas typiques de telles interférences.

Le transfert qui nous occupe, celui de la confluence générique, concerne plutôt des développements rhétoriques qui font signe vers un genre autre que le roman arthurien. Nous traiterons de cinq relations entretenues par le roman arthurien tardif avec d'autres genres. Elles touchent d'abord la reprise de structures narratives ou rhétoriques propres à des genres allogènes: la réécriture ponctuelle de l'ekphrasis travaillée par le roman antique et actualisée dans notre corpus; la réécriture de motifs épiques dans les romans tardifs. Dans ce dernier cas, la confluence ne se concentre pas à un seul endroit du texte, mais en influence aussi la diégèse, si bien que l'esthétique de la guerre prend une importance considérable dans ce corpus. L'actualisation de l'épique rejoint donc une autre modalité de la confluence, celle de l'emprunt d'un registre. Cette pratique se manifeste par l'imitation circonscrite de la littérature liturgique, dans la fin miraculeuse d'Escanor, et par l'adoption d'un registre proche de celui des récits narratifs comiques, les fabliaux ou le Roman de Renart, dans Rigomer en particulier. Enfin, la confluence générique informe matériellement Biaudouz, qui accueille au sein de sa trame narrative les œuvres didactiques de son auteur. Le mélange des genres affecte ici à la fois la transmission matérielle du roman arthurien et la fonction remplie par le genre, utilisé pour dispenser un enseignement: le roman arthurien se mue en genre de l'utilitas. Nous envisageons ces phénomènes comme autant de moyens de pratiquer la confluence générique: la construction du genre arthurien tardif ne se fonde plus sur des renvois intragénériques, c'est-à-dire internes à la littérature arthurienne et qui permettaient d'identifier les relations privilégiées de nos textes avec ce genre, mais s'ouvre à d'autres cadres rhétoriques. Ainsi, la réécriture de motifs provenant de genres allogènes comporte d'autres implications que celle de motifs arthuriens: elle

269 Richard Trachsler, Disjointures-conjointures, p. 10. 
modifie l'horizon d'attente et introduit un écart esthétique entre le texte et l'attente que son genre crée ${ }^{270}$.

\section{Réécriture d'un topos allogène: l'ekphrasis}

L'ekphrasis ${ }^{271}$ ne fait a priori pas partie de l'horizon d'attente d'un lecteur arthurien. Elle est pourtant travaillée par quatre de nos romans: Floriant et Florete, avec les tentures de la nef merveilleuse du héros (v. 842-921), décrites à la manière de la tente d'Adraste du Roman de Thèbes; Claris et Laris (v. 29189-29226), dans lequel sont décrits les pavillons enchantés de Madoine; Escanor et la chambre de Brian, ressemblant étrangement à la Chambre des Beautés du Roman de Troie; Rigomer (v. 12789-12816), qui imite lui aussi ces deux romans antiques pour décrire la tente que Lorie dresse pour Gauvain.

La description de tentures est un topos ${ }^{272}$ génériquement marqué, c'est-à-dire qu'il est élaboré et exploité par et dans un genre particulier; le roman antique ${ }^{273}$. Marc Angenot précise que le topos correspond à "certaines images-thèmes qui constituent les invariants obligés et conventionnels de genres littéraires particuliers. Il s'agit d'un répertoire

270 Nous reprenons ici le concept théorique d'Hans Robert Jauss («L'Histoire de la littérature: un défi à la théorie littéraire», art. cit., p. 51). L'écart esthétique se définit comme la différence entre l'attente du lecteur et l'œuvre elle-même.

271 L'ekphrasis entend «rendre visible, sous les yeux, un élément artistique qui, en fait, n'est ni à portée de main ni sous les yeux». (Giuseppina Brunetti, "L'Antiquité partagée; la tente historiée du païen Agolant», in In Limine Romaniae. Chanson de geste et épopée européenne, dir. Carlos Alvar et Constance Carta, Berlin, Peter Lang, 2012, p. 153.) C'est par ce concept que nous désignons la description littéraire d'un objet d'art.

272 Nous faisons le choix d'opérer une distinction entre motif et topos: le motif implique la récurrence d'un déroulement narratif, quand le topos désigne un canevas rhétorique convenu. L'ekphrasis est un lieu commun de la littérature narrative; il suppose une manière particulière et récurrente de décrire, mais n'engendre pas un déroulement narratif qui lui serait propre. Le motif est narratif, le topos est rhétorique. Ces deux notions sont toutefois souvent employées en synonymes dans la critique. Voir Marc Angenot, La parole pamphlétaire. Typologie des discours modernes, Paris, Payot, 1982, et Roland Barthes, "L'ancienne rhétorique», Communications, 16, 1970, p. 172-223.

273 Voir Emmanuèle Baumgartner, «Peinture et écriture: la description de la tente dans les romans antiques au XII ${ }^{\mathrm{e}}$ siècle», art. cit. Elle traite notamment du motif dans le Roman d'Alexandre et Athis et Prophilias. 
de conventions, de développements-types et d'images, ensemble qui n'est pas relié à une fonction persuasive ${ }^{274}$. Activer un topos allogène n'est pas anodin et perturbe l'horizon d'attente du lecteur: intégrer des descriptions de tentes, c'est faire signe vers un autre genre, c'est revendiquer une multitude de sources rhétoriques. L'ekphrasis, la description d'objets dont on souligne la dimension artistique, se manifeste effectivement en premier lieu dans le roman antique. Aimé Petit a montré que la description de la tente d'Adraste dans le Roman de Thèbes «représente le texte fondateur d'une typologie ${ }^{275}$, c'est-à-dire qu'il est à l'origine d'un déroulement rhétorique que l'on rencontre dans d'autres textes, notamment dans le Roman d'Alexandre. Même si l'on pourrait trouver des exemples de descriptions de tentes ailleurs que dans le roman antique, il faut admettre avec Norris J. Lacy que "motifs are repeatedly "rewritten", but a trace of prior developments always remains ${ }^{276}$. L'ekphrasis de la tente est donc toujours rattachée au genre qui l'a fait naître, d'autant qu'elle est plutôt rare dans le roman arthurien ${ }^{277}$.

Celles que l'on trouve dans Claris et Laris et Floriant et Florete suivent ainsi le modèle fourni par le Roman de Thèbes. La tente d'Adraste ${ }^{278}$ se

274 Marc Angenot, La parole pamphlétaire. Typologie des discours modernes, p. 165.

275 Aimé Petit, «Les premières descriptions de tentes: la tente d'Adrastus dans le Roman de Thèbes", Bien dire et bien aprandre, 11, 1993, p 311.

276 Norris J. Lacy, "Motif Transfert in Arthurian Romance», in The Medieval Opus: Imitation, rewriting and transmission in the French tradition: proceedings of the Symposium held at the Institue for research in humanities, October 5-7 1995, dir. Douglas Kelly, Amsterdam; Atlanta, Rodopi, 1996, p. 163.

277 On la trouve toutefois dans le premier représentant du genre, Erec et Enide, dans le passage qui décrit la robe d'Enide. Ce vêtement est l'œuvre de quatre fées qui y représentent la géométrie, l'arithmétique, la musique et l'astronomie, proposant ainsi une association entre chevalerie et clergie. Le caractère antique de ce topos rhétorique est thématisé par Chrétien de Troyes: "Lisant trovomes en l'estoire / La descriction de la robe, / Si en trai a garant Macrobe / Qui ou descrire mist s'entente.» (v. 6728-6731). Comme le souligne l'éditeur Jean-Marie Fritz, «Macrobe semble ici transmettre à Chrétien l'art de décrire plutôt que le contenu même de cette description" (éd. cit., p. 509). C'est bien une rhétorique à l'antique que retravaille Chrétien de Troyes, aussi bien que les auteurs de romans antiques. L'ekphrasis ne s'est pourtant pas vraiment imposée comme topos de la littérature arthurienne.

278 Sur la tente d'Adraste, voir Aimé Petit, «Les premières descriptions de tentes: la tente d'Adrastus dans le Roman de Thèbes", art. cit., et Catherine Croizy-Naquet, Thèbes, Troie et Carthage, p. 313-315. 
caractérise d'abord par la richesse de ses matériaux: étoffes de prix, or et pierres précieuses en font un objet exceptionnel. Le caractère extraordinaire de cet habitacle vient surtout du soin porté aux peintures qui ornent les pans de la tente et qui représentent une mappemonde, les mois et les saisons, les lois antiques et les animaux. La tente se mue en imago mundi; l'ensemble des composantes du monde est peint sur ses tentures, si bien qu'elle fait figure de "cité au centre du monde» ${ }^{279}$. La mappemonde est notamment décrite avec de nombreux détails et représente bien l'ambition de faire de cette tente une réduction de l'univers. Comme l'exprime Catherine Croizy-Naquet,

le macrocosme est ainsi reproduit dans un microcosme qui brise l'étroitesse et la clôture du lieu et qui s'impose alors comme une exploration fidèle et exhaustive du monde ${ }^{280}$.

Une «compulsion encyclopédique ${ }^{281}$ fait de cette tente un vecteur de connaissances. La tente d'Adraste, comme d'ailleurs toute ekphrasis dans les romans antiques, est un lieu de configuration du savoir ${ }^{282}$ : l'objet décrit dispense un savoir cosmologique, temporel, naturaliste ou historique. Ces objets sont aussi bien souvent l'expression du pouvoir royal: la tente d'Adraste est une tente royale, ce qu'exhibe la richesse de ses matériaux. Elle symbolise ainsi l'association entre pouvoir et savoir et ne remplit pas qu'un rôle ornemental: dans le Roman d'Alexandre, la description de la tente signale le désir de plus en plus affirmé d'Alexandre d'une conquête, d'une prise de possession de l'univers et du Temps ${ }^{283}$.

L'auteur de Floriant et Florete reprend la description en quatre temps qu'initie le Roman de Thèbes. La tenture qui recouvre la nef merveilleuse

279 Aimé Petit, "Le pavillon d'Alexandre dans le Roman d'Alexandre (ms. B. Venise, Museo Civico VI, 665)", Bien dire et bien aprandre, 6, 1988, p. 92.

280 Catherine Croizy-Naquet, Thèbes, Troie, Carthage, p. 320.

281 Jean R. Scheidegger, "Les automates dans le roman antique (Roman de Thèbes et Roman de Troie)", in Le Roman antique au Moyen Âge, dir. Danielle Buschinger, Göppingen, Kümmerle Verlag, 1992, p. 179. Jean Scheidegger souligne que la compulsion encyclopédique anime d'autres objets que les tentes: elle régit aussi le char de guerre d'Amphiaraüs dans le Roman de Thèbes.

282 Catherine Croizy-Naquet, Thèbes, Troie, Carthage, p. 302-322.

283 Emmanuèle Baumgartner, «Peinture et écriture: la description de la tente dans les romans antiques au XII ${ }^{\mathrm{e}}$ siècle», art. cit. 
qu'offre Morgane à Floriant est faite de quatre couleurs, dont chacune illustre un aspect du monde: la première partie dépeint l'univers, la terre, le ciel, l'eau, le feu et les planètes; la deuxième l'histoire d'Adam et Ėve et la naissance d'Abel et Caïn; la troisième la guerre de Troie; la quatrième l'Amour. L'ambition d'universalité est bien au fondement de cette description. Les trois premiers pans sont assez classiques dans les ekphraseis médiévales: le premier correspond à l'élaboration d'un microcosme similaire à la mappemonde du Roman de Thèbes, le deuxième représente l'Histoire à travers l'histoire biblique et le troisième suit une tendance convenue d'illustrer la guerre de Troie sous forme de peinture ou de sculpture. La guerre de Troie est fréquemment exploitée pour les peintures: elle renvoie aux origines de l'humanité284. Le Roman d'Alexandre fait déjà figurer ce récit sur la tente d'Alexandre; Floriant et Florete ne ferait en ce sens que s'inspirer d'une autre description de tente antique. La figuration de l'Amour est plus atypique: le dieu Amour est parfaitement "portrais" (v. 901), entouré de sa compagnie dans un cadre de reverdie que vient compléter l'énumération des instruments de musique (v. 914-916). De son arc, il vise Tristan en Yseult, emblèmes de l'amour romanesque. L'amour, la matière romanesque, est dès lors digne de figurer côte à côte avec la matière antique, la matière biblique et l'univers, comme autant de composantes de la vie humaine.

Cette tenture est certes le symbole de l'alliance entre savoir et pouvoir: le jeune Floriant est au début de son parcours, il est tout juste adoubé et doit encore reconquérir son trône usurpé. La tente présage bien son futur couronnement, non seulement royal mais aussi impérial. Mais il y a plus: en intégrant Amour au microcosme de l'ekphrasis, l'auteur signale l'importance du roman dans le champ littéraire. L'ekphrasis ne se concentre plus seulement sur les divers domaines du savoir, comme dans le Roman de Thèbes, ni seulement sur la guerre emblématique des romans antiques: l'amour est en ce contexte présenté comme un sujet de réflexion

284 Sur ce mythe des origines associé aux Troyens, voir Colette Beaune, Naissance de la nation France, Paris, Gallimard, 1985. Colette Van Coolput-Storms souligne que la guerre de Troie est figurée sur 8 chambres peintes, 3 tentes, 2 robes brodées, 1 courtine, 1 selle, 1 coupe. "Performance au château", in Lire, danser et chanter au château. La culture châtelaine, XIII'-XVII siècles. Actes du $4^{e}$ colloque international organisé au château fort d'Ecaussinnes-Lalaing, les 22, 23 et 24 mai 2013, dir. JeanMarie Cauchies, Marie Henrion et Philippe Bragard, Turnhout, Brepols, 2016, p. 185-189. 
et d'enseignement, valorisant ainsi les romans d'armes et d'amour que sont les romans arthuriens.

La tente est symbole, dans Floriant et Florete: symbole d'un pouvoir à saisir, autant pour Floriant que pour l'écriture romanesque. L'ekphrasis est l'occasion d'une "démonstration d'un savoir-faire rhétorique». Comme l'explique Francine Mora, c'est le «lieu privilégié d'une réflexion sur la création poétique où le clerc-adaptateur se met en scène à travers la figure d'autres artistes, dans un mouvement de mise en abyme ${ }^{285}$. D'où l'importance de décrire l'objet comme un microcosme: l'artiste de la tente, comme l'auteur de la description, ont le pouvoir de créer un monde à l'imitation de l'univers réel. En réactivant le topos de l'ekphrasis propre au roman antique, l'auteur de Floriant et Florete revendique son rôle de créateur tout en affirmant la légitimité poétique du roman arthurien. Faire intervenir la rhétorique d'un autre genre, c'est donc à la fois inscrire son propre genre en filiation d'une tradition et manifester sa faculté de manier le langage aussi bien que ses prédécesseurs, même au sein d'un genre réputé pour être dépourvu de sens profond.

Cela explique que, bien souvent, la qualité de l'œuvre décrite soit soulignée avec insistance, accordant un relief particulier au travail de l'artiste. Dans Floriant et Florete, le narrateur précise plusieurs fois que "onc mius ovree ne fu» (v. 844-845; 903; 921), formule tout à fait convenue dans ce contexte, qui témoigne bien de l'appropriation d'une rhétorique spécifique ${ }^{286}$. Dans Claris et Laris, la facture est au centre de la description des dix pavillons que la fée Madoine dresse sur le chemin d'Yvain, Gauvain et Marine. Cette ekphrasis est bien plus courte que celle de la nef de Floriant ou de la tente d'Adraste, mais sa construction n'en rappelle pas moins le topos antique. Le narrateur insiste d'abord sur la richesse et la beauté de ces pavillons, couverts de soie, d'or et de cyprès. Y figurent toutes les recettes de médecine en hébreu, une représentation des trois grandes

285 Francine Mora-Lebrun, "Metre en romanz". Les romans d'antiquité du XII siècle et leur postérité (XIII-XIV siècle), Paris, Champion, 2008, p. 417. Cette idée est déjà évoquée par Emmanuèle Baumgartner, notamment dans «Peinture et écriture: la description de la tente dans les romans antiques au XII ${ }^{\mathrm{e}}$ siècle", art. cit., et par Catherine Croizy-Naquet, Thèbes, Troie, Carthage, p. 293: «Derrière la figure de l'artiste se dessine en filigrane celle de l'écrivain; derrière l'hommage implicite rendu au fabricant de pierre se profile l'hommage au fabricant des mots. "

286 On peut comparer cette formule à celles qui interviennent dans le Roman de Troie, "molt bien ovré» (v. 14935) par exemple. 
religions monothéistes, l'univers, avec les planètes et le firmament, et enfin la manière dont la foudre s'abat sur la terre. L'ambition est donc aussi celle de proposer un imago mundi qui tienne compte des divers aspects de la vie humaine dans une perspective didactique.

L'intégration des recettes de médecine en hébreu («Toutes les vraies medecines / I sont escrites en ebrieu », v. 29206-29207) prend particulièrement part à cette ambition: loin d'être typique, cette mention dit bien l'ouverture du roman sur les différents domaines du savoir, la précision sur la langue de transmission des potions accentuant encore un point de vue particulier porté sur les sciences, le retour à un texte authentique qui transmettrait directement ce savoir. La place réservée aux trois religions monothéistes, pour le moins surprenante dans le contexte chrétien du Moyen Âge, fait partie du même projet: présenter le monde sous tous ses aspects, en adoptant une forme de neutralité toute scientifique. La description se termine sur l'émerveillement des spectateurs face à l'œuvre:

Trop sont li baron esbahis

De regarder la grant richece,

La grant euvre, la grant noblece

Qui ert el paveillon pourtrete

Et par trop grant mestrie faite. (Claris et Laris, v. 29222-29226)

Ces vers assimilent l'ébahissement des chevaliers face à la beauté des tentes et le geste à l'origine de leur création ("par trop grant mestrie faite»). L'évocation du Beau n'engendre pas que le plaisir d'une contemplation esthétique, mais le déplacement opéré met l'accent sur le pouvoir mystificateur de cette contemplation.

Les personnages sont en effet trompés par la splendeur des pavillons, ils y prennent place pour manger et dormir, mais sont téléportés par l'enchantement de Madoine vers la vallée des fées où elle les retient prisonniers. Le lecteur apprend à ce moment-là que l'auteur de ces magnifiques tentes n'est autre que la méchante fée Madoine, amoureuse éperdue de Laris qui l'a abandonnée avec son enfant:

Ancontre mie nuit avint

Que Madoine la fee vint

Qui par son fier enchantement

Avoit fet ainsifaitement

Les paveillons en la forest 
Car mener vouloit sanz arrest

Touz ceus d'iluec en lor valee. (Claris et Laris, v. 29271-29277)

La création artistique, sur laquelle le texte a d'abord insisté par une hyperbole ("trop grant mestrie»), est le résultat d'un enchantement destiné à fourvoyer les contemplateurs. Les tentes ne sont donc pas le symbole du pouvoir, mais peut-être l'illustration de la force qu'exerce l'art, plastique ou poétique, sur le sujet, comme l'illustre le passage où le Laid Hardi est retenu pour écouter un conteur à la manière des caroles magiques (v. 9929-9956).

La fabrication des artefacts littéraires du roman antique est bien souvent le résultat d'un enchantement. Catherine Croizy-Naquet souligne que le fabricant d'objets d'art "s'apparente davantage à un démiurge qu'à un artisan. Comme tel, il semble doté de pouvoirs occultes. Le constructeur n'est pas loin du magicien ou de l'enchanteur ${ }^{287}$. L'art est surtout le résultat du savoir et de la sagesse de l'artiste, dans ce contexte. Dans le roman arthurien en vers, cette magie est plus proche de la féerie celtique que d'un enchantement savant. Le terme "sage» qui intervient dans les romans antiques pour qualifier le travail de l'artiste (ainsi des «trei sage» qui firent le tombeau d'Hector dans le Roman de Troie, v. 16660) n'est jamais employé dans les ekphraseis de nos textes. En revanche, l'artiste à l'origine de l'artefact digne d'éloges est toujours une fée: Morgane dans Floriant et Florete, Madoine dans Claris et Laris, Lorie dans Rigomer, Esclarmonde dans Escanor. Emblème du merveilleux romanesque, la fée endosse naturellement le rôle du créateur, dont la magie recrée un microcosme à l'image du macrocosme.

Dans Rigomer, la tente que dresse Lorie est d'ailleurs observée "a grant mervelles» (v. 12761) par les passants, le substantif insinue ainsi l'origine potentiellement surnaturelle de l'habitacle. Ce pavillon s'inspire à la fois de la tente d'Adraste et de la Chambre des Beautés : la tente de Gauvain est elle aussi richement ornée d'argent, d'or et de soie et le narrateur précise qu'elle est carrée, suggérant la possible description de quatre tentures. Cette tente signale l'élection de Gauvain dans l'aventure de Rigomer; chacun prétend en la contemplant que celui à qui elle est destinée "Sera sor tox li bons eslis» (v. 12832). Le lien entre pouvoir et artefact propre au

287 Catherine Croizy-Naquet, Thèbes, Troie, Carthage, p. 293. La critique parle ici des figures de constructeurs élaborées par le Roman de Troie. 
motif antique est donc bien tissé, même s'il ne s'agit pas, dans le contexte du roman arthurien, d'un pouvoir royal mais de la maitrise d'une aventure ponctuelle. C'est surtout l'aigle d'or ornant le faite de la tente qui rappelle le Roman de Thèbes. En voici la description:

Sor le plus maistre avoit asis

Une aigle d'or, qi tant valoit,

Li plus rices qi le veoit,

Ne le pëust mie eligier

Sans se garisons engagier.

Segnor, li oisiaus Wileris

Estoit sor l'agle d'or asis,

Qui tous tans doucement cantoit. (Rigomer, v. 12778-12785)

La principale caractéristique de cet aigle est sa richesse et sa valeur inestimable, tout comme celui de la tente d'Adraste, qui «est tant beals [...] que onc nul homme ne vit tant cler» (v. 3261-3263) ${ }^{288}$. Le rapace est associé à Wileris, l'oiseau parlant de Lorie qui guide Gauvain. Bien que l'espèce de ce volatile ne soit jamais explicite, sa description correspond à celle du perroquet, réputé pour parler et pour être doté d'un plumage très coloré («Colors avoit de tante guise», v. 11635). Wileris est perché sur l'objet inanimé; l'auteur reconduit le couple constitué de l'aigle d'or et de la colombe dans le Roman de Thèbes, qui symbolisaient ensemble la guerre et la paix, deux valeurs qu'incarne le roi Adraste ${ }^{289}$. Dans Rigomer toutefois, la colombe est remplacée par un perroquet, qui fait souvent office de figure conteuse, que l'on pense en particulier au papegau du Conte $d u$ Papegau ${ }^{290}$.

288 Le Roman de Thèbes, éd. Francine Mora-Lebrun, Paris, Le Livre de Poche («Lettres gothiques"), 1995.

289 Sur l'aigle de la tente d'Adraste, voir Catherine Croizy-Naquet, Thèbes, Troie, Carthage, p. 130-131.

290 À ce sujet, on consultera Danielle Régnier-Bohler, "Arthur en enfances (Le Chevalier au Papegau)", art. cit., et l'introduction au Conte du Papegau par Hélène Charpentier et Patricia Victorin, éd. cit. Sur le perroquet, voir Bruce Thomas Boehrer, Parrot Culture. Our 2500-Year-Long Fascination with the World's Most Talkative Bird, en particulier les pages 44 à 47 pour le roman arthurien. Selon Christine Ferlampin-Acher, le chant de Wileris associe merveilleux et parole poétique: les merveilles de la tente trouvent leur fondement dans la parole poétique. Voir Merveilles et topique merveilleuse, p. 335. 
Souvent retenu comme figure de l'éloquence, dans les bestiaires et encyclopédies des $\mathrm{XII}^{\mathrm{e}}$ et $\mathrm{XIII}^{\mathrm{e}}$ siècles ${ }^{291}$, le perroquet glorifie ici la toutepuissance de la parole conteuse, d'autant mieux qu'il est associé au topos de l'ekphrasis. Cette interprétation est favorisée par la présentation que Jehan donne de l'oiseau: c'est le plus sage du monde, doué de la faculté de parler plusieurs langues («N’ot bieste ne oisiel si sage. / Parler savoit plusor langage.», v. 11651-11652). Le roman arthurien réinvestit un lieu commun du roman antique pour en infléchir les codes et les rendre plus proches de ses préoccupations: l'association entre guerre et paix est remplacée par deux symboles de la réécriture. L'aigle d'or est une figure figée, empruntée à la tradition, et fait signe vers les textes dont s'inspire explicitement l'auteur; le perroquet, par son psittacisme ${ }^{292}$, symbolise la reprise de voies rhétoriques éculées, redynamisées par une parole vive et sage. Il n'est pas figé, mais bien vivant; c'est à lui qu'il revient de donner vie à l'artefact de la tente, objet de l'ekphrasis antique, tout comme il revient à l'auteur d'en réactiver la description. C'est en effet un animal en chair et en os qui remplace la colombe inanimée, quoique ce dernier terme ne soit pas si bien adapté, les oiseaux qui ornent les objets d'art des romans antiques étant souvent des automates ${ }^{293}$. Dans le Roman de Thèbes, l'aigle crache du feu quand le soleil brille sur ses innombrables pierres précieuses ${ }^{294}$, tandis que celui de la tente d'Alexandre chante au

291 Lori Walters, «Parody and the Parrot: Lancelot References in the Chevalier au Papegau", art. cit., p. 334 et surtout l'étude de Bruce Thomas Boehrer, Parrot Culture. Our 2500-Year-Long Fascination with the World's Most Talkative Bird, p. 23-49, et l'introduction à l'édition du Conte du Papegau par Patricia Victorin et Hélène Charpentier, éd. cit., p. 40-56.

292 Voir l'introduction à l'édition du Conte du Papegau par Patricia Victorin et Hélène Charpentier, éd. cit., p. 50-56 et Patricia Victorin, «Psittacisme et captivité dans le Chevalier du Papegau et Tirant le Blanc", in Du Roman courtois au roman baroque, dir. Emmanuel Bury et Francine Mora, Paris, Les Belles Lettres, 2004, en particulier p. 150-157. Patricia Victorin trace dans cet article l'ambiguïté de la figure du perroquet, à la fois animal courtois capable d'entonner un chant lyrique et figure du psittacisme, incarnation potentielle du losengier qui vient répéter publiquement l'amour des amants.

293 Catherine Croizy-Naquet rappelle que les oiseaux factices et autres automates sont inspirés des merveilles de l'Orient, observée notamment à Constantinople. Voir Thèbes, Troie et Carthage, p. 298-300.

294 "Des que soleils ne venz le touche, / Feu ardant jette par la bouche», Roman de Thèbes, v. 3271-3272. 
contact du vent ${ }^{295}$. Wileris n'est quant à lui régi par aucun mécanisme; son chant est le produit de la nature, à moins qu'il ne soit, lui aussi, le fruit de la magie de Lorie. L'écho aux romans antiques est en tous les cas clair: Jehan réécrit le topos rhétorique de la description de tente et en transforme certaines modalités pour les rendre plus proches de l'esthétique des romans arthuriens.

Les automates ne sont pour autant pas absents de la tente de Lorie: chaque porte des trente chambres de ce pavillon comporte un anneau qui libère une mélodie délicieuse dès lors que l'on y passe le doigt. Cette musique s'entend ensuite à une lieue et demie à la ronde. Elle est commune à la Chambre des Beautés du Roman de Troie, pour laquelle le narrateur décrit les instruments qui produisent un doux son. L'intérieur de la tente de Gauvain fait encore signe vers ce passage du roman antique lorsque sont présentés les pouvoirs curatifs des épices et de l'encens qui agrémentent les pièces: "Se uns malades i entrast, / Esrant morust ou respasast.»(Rigomer, v. 12813-12815). Dans la Chambre des Beautés, plusieurs éléments disposent de cette vertu guérisseuse ou régénérante: le fauteuil en obsidienne, la musique et l'odeur des épices qui remplissent l'encensoir de la quatrième statue. L'allusion de Rigomer au Roman de Troie est donc tout à fait évidente.

Plusieurs éléments de la chambre de Brian des Îles dans Escanor ${ }^{296}$ offrent tout autant un écho intertextuel à la Chambre des Beautés, c'est-à-dire une référence directe au texte du Roman de Troie en particulier, en premier lieu la présence d'automate ${ }^{297}$ : un ange qui trompette, des oiseaux qui chantent et qui rappellent l'automate de l'oiseau dont le souffle dessèche les fleurs (Troie, v. 14820-14862), des lions, à mi-chemin entre des automates et des consciences animées, qui s'apprivoisent par

295 «Ens el bec dedevant avoit un chalemel; / Qant li vens se fiert ens, donques chante si bel / Que mieus vaut a oïr que flagol ne frestel", Le Roman d'Alexandre, éd. Laurence Harf-Lancner, Paris, Le Livre de Poche ("Lettres gothiques»), 1994, branche I, v. 2005-2007.

296 Ces paragraphes reprennent en partie notre article, «Les peintures troyennes dans Escanor de Girart d'Amiens: un cas d'interférence des matières au XIII ${ }^{\mathrm{e}}$ siècle", art. cit.

297 Sur les automates de la Chambre des Beautés, voir Catherine Croizy-Naquet, Thèbes, Troie et Carthage, p. 132-136 et Emmanuèle Baumgartner, "Le temps des automates ", in De l'Histoire de Troie au Livre du Graal, Orléans, Paradigme, 1994, p. $171-177$. 
le son d'une vielle. Parmi les autres points communs, on note encore l'abondance des pierres précieuses et la lumière qu'elles répandent, comme en plein jour, le faste de l'or et de l'argent, les formules laudatives sur les merveilles et les considérations financières: "Noble et riche et costeuse a ffaire, / Car Brianz fu de grant affaire, / Si n'i garda nul costement» (Escanor, v. 15751-15753), "Bien met son aveir e enpleie / Qui en tiel ovre le despent!», «Plus valeit de cent mile livre.» (Troie, v. 14932-14933, v. 14957). Comme dans toute bonne chambre soumise à l'ekphrasis, dont la tente de Rigomer d'ailleurs, il y a dans la chambre de Brian un dispositif thérapeutique: le visiteur guérit de ses maux en respirant les plumes d'oiseaux exotiques qui remplissent le matelas et la couverture. L'auteur se complaît ici dans les précisions sur la nature de ces oiseaux: l'alphä̈s, venu d'Arménie, se nourrit d'une épice qui lui confère cette vertu guérisseuse. Quant à l'osterain, il habite les rives du fleuve de Paradis et l'odeur de son plumage rend heureux, selon le narrateur. L'insistance sur les senteurs est destinée à flatter les sens du visiteur: la vue, par le faste de la pièce, le toucher, par la finesse des draps ("c'estoit merveille a sentir», v. 16163), l'ouie, enchantée par le chant des oiseaux et la trompette de l'ange, et enfin l'odorat, intermédiaire qui transmet la santé et le bonheur.

Comme dans le roman antique, la chambre agit sur le visiteur, mais l'on perd ici la dimension directive qui caractérisait les automates de la Chambre des Beautés: les acrobaties et autres tours qu'effectue la deuxième statue dans le Roman de Troie fascinent le spectateur au point de l'empêcher de quitter les lieux, tandis que la quatrième commande son comportement et que la première l'oblige à avoir une mise correcte. Alors que ces statues se meuvent sans impulsion apparente, commandent les occupants de la pièce et semblent dotées d'une réelle conscience autonome, les hôtes de Brian disposent de moyens de contrôle sur les merveilles. Ils peuvent tourner l'ange à leur guise pour faire taire la musique et dompter les lions en effleurant une vielle ${ }^{298}$, bien que ceux-ci semblent doués d'une certaine intelligence, puisqu'ils sont capables de reconnaitre ceux qui ont joué de la vielle "par semblant»(v. 15889). Les visiteurs ne sont donc

298 On notera que dans Floire et Blancheflor, ce sont des oiseaux factices qui ont le pouvoir de calmer n'importe quelle bête sauvage de leur chant, déclenché par le vent. Ils font partie du jardin merveilleux de l'émir de Babylone et désignent aussi la vierge qu'il doit épouser chaque année. 
pas passifs et soumis aux farces que jouaient volontiers les automates du $\mathrm{XII}^{\mathrm{e}}$ siècle ${ }^{299}$ : au contraire, l'homme a ici le pouvoir sur le monde factice.

Le texte de Girart insiste d'ailleurs beaucoup sur le savoir-faire qui préside à la fabrication des merveilles: on rappelle constamment que c'est bien la fée Esclarmonde qui est à l'origine de la chambre. L'édification des automates résulte d'un savoir féerique, mais néanmoins rationalisé: «Et ceste fee longuement / Regarda et pourvit conment / Peüst s'uevre estre bone et bele» (v. 15933-15935), "Mais la fee, qui compasser / Savoit bien un sifait ovrage» (v. 16002-16003). Il s'agit bien de produits de l'«engien» (v. 16004): Esclarmonde, comme les sages des romans antiques, est une figure de démiurge aux pouvoirs et aux connaissances occultes. Savoir et création s'imbriquent dans de tels artefacts, selon Catherine Croizy-Naquet :

Les automates ont l'extraordinaire pouvoir de figurer et de mimer les connaissances qu'ils incarnent. Le clerc insuffle vie au savoir, créant dans l'espace clos qu'est la Chambre un théâtre en abrégé de l'univers ${ }^{300}$.

Les automates incarnent aussi un savoir encyclopédique par les actions qui les caractérisent: la musique, le divertissement, les animaux. D'où l'importance des ekphraseis dans les romans antiques, qui revendiquent leur dimension didactique. C'est à l'écrivain qu'il revient en dernier lieu d'animer ces objets, de les inventer et de les représenter avec éloquence.

Sans doute le rapport au didactisme motive-t-il l'emploi de tels topoi du roman antique dans le roman arthurien en vers tardif - nous reviendrons sur cette perspective aux pages 617-630. Cela n'est toutefois pas la seule raison qu'ont les auteurs d'intégrer des ekphraseis: l'hétérogénéité générique de ces passages est assumée, en témoignent les allusions claires à la tente d'Adraste et à la Chambre des Beautés. En ce sens, il s'agit à la fois de réécritures directes d'un hypotexte et de réactivations d'un topos récurrent du roman antique. Intégrer une ekphrasis, c'est exhiber l'habileté de l'écrivain, non seulement par la maîtrise de techniques rhétoriques

\footnotetext{
299 Voir l'article de Myriam Clément-Royer, "L'Arbre aux oiseaux "automates" ", art. cit., au sujet des automates farceurs qui animaient notamment les jardins.

300 Thèbes, Troie et Carthage, p. 320.
} 
issues d'autres genres ${ }^{301}$, mais aussi parce que l'ekphrasis en elle-même est un morceau de bravoure qui valorise, comme nous l'avons vu, la puissance créatrice. L'hétérogénéité générique contribue donc à construire une figure d'écrivain polyvalent et démiurgique.

L'hétérogénéité est redoublée dans Escanor par les peintures murales qui ornent la chambre ${ }^{302}$ et représentent la guerre de Troie: le motif en lui-même de la chambre aux merveilles et aux peintures est antique, tandis que le contenu figuré resémantise l'histoire antique par excellence. L'appropriation d'un autre genre se produit donc à deux niveaux: d'un côté est emprunté un topos génériquement marqué, celui de l'ekphrasis, de l'autre est représentée l'histoire, la matière, d'une ouvre antique ${ }^{303}$. Il s'agit selon Richard Trachsler d'un cas simple d'interférence des matières, fréquent dans la littérature médiévale, notamment arthurienne $e^{304}$, où les peintures troyennes fonctionnent souvent comme avertissement d'une catastrophe. Le critique parle d'interférence, car les peintures troyennes sont plus fréquemment des narrations que des descriptions figées; c'est le cas aussi dans Escanor, où les images sont un prétexte pour raconter la guerre de Troie. Les personnages agissent alors directement au sein d'une matière allogène. L'objectif est de prouver que l'auteur connaît cette histoire et sait la conter ${ }^{305}$ : il est capable de rivaliser avec les auteurs du $\mathrm{XII}^{\mathrm{e}}$ siècle. Bien plus que de rappeler une histoire, le roman traduit ici un

301 «L'écrivain affirme surtout que sa compétence est égale à celle des auteurs qui écrivent des romans antiques et que son sujet vaut autant que le leur." Richard Trachsler, Disjointures-conjointures, p. 96.

302 À propos du topos de la chambre peinte, voir Colette Van Coolput-Storms, "Narration médiévale et ecphrasis. Le topos de la chambre peinte dans la littérature narrative d'imagination en ancien français", in Texte, image, imaginaire, dir. Jean-Louis Tilleuil et Myriam Watthee-Delmotte, Paris, L'Harmattan, 2007, p. $57-73$.

303 Comme nous l'avons montré dans un article précédent, les images de la chambre de Brian prennent appui sur le roman de Benoît de Sainte-Maure et s'élaborent donc dans un cadre strictement littéraire, et non historique. Voir «Les peintures troyennes dans Escanor de Girart d'Amiens: un cas d'interférence des matières au $\mathrm{XIII}^{\mathrm{e}}$ siècle», art. cit., dans lequel nous traitons des peintures troyennes plus en détail.

304 Ainsi de Lancelot dans le Lancelot en prose, qui peint sa propre histoire en imitant les représentations d'Énée s'enfuyant de Troie. Voir Richard Trachsler, Disjointuresconjointures, p. 93-99.

305 Richard Trachsler, Disjointures-conjointures, p. 97. 
enthousiasme pour la littérature et une volonté d'en faire la synthèse. Il vise un savoir totalisant, symbolisé par les ekphraseis.

La notion d'interférence telle que la définit Richard Trachsler ne s'applique toutefois qu'à ce passage où l'histoire de Pâris et Hélène contamine la trame narrative d'Escanor, puisqu'une pause dans le récit arthurien permet le développement d'un résumé de la guerre de Troie où les personnages interviennent presque en propre. Les réécritures de la Chambre des Beautés ou du topos de la tente ornée sont quant à elles le résultat de ce que nous appelons la confluence générique: le croisement de plusieurs genres ne concerne pas l'intervention de personnages issus d'une matière bodélienne autre, mais se réalise par l'adoption d'une rhétorique étrangère au roman arthurien et par l'intertextualité manifeste avec certains romans antiques. En ce sens, la solidarité entre les diverses relations transtextuelles dégagées par Gérard Genette est signifiante: l'intertextualité - ou hypertextualité chez Genette - soutient une réflexion architextuelle, c'est-à-dire générique, car la dérivation d'une œuvre à l'autre influence la généricité de cette dernière. La rhétorique, respectivement le motif, allogène n'est néanmoins pas incompatible avec le genre dominant dans le cas qui nous occupe: le topos du roman antique est infléchi pour correspondre à l'idéologie arthurienne, comme en témoigne l'intervention du perroquet à la place d'une colombe au faîte de la tente de Gauvain. Il modifie également l'horizon d'attente: le roman arthurien s'arroge une profondeur scientifique et didactique qu'il avait moins dans les premiers représentants du genre.

\section{Adoption de "patrons génériques exportables $»^{306}$ : l'épopée arthurienne}

Tout comme celle de l'ekphrasis, la réécriture de motifs épiques est harmonieusement intégrée à la trame narrative arthurienne et ne rélève pas d'une quelconque impossibilité: le lecteur n'est pas perturbé par ce transfert, ce qui démontre la compatibilité de tels développements avec le roman arthurien en vers. Les romans tardifs se caractérisent par leur intérêt pour la guerre et son développement rhétorique, notamment par

306 L'expression est de Patrick Moran, «La guerre comme marqueur générique dans la littérature narrative des XII -XIII $^{\mathrm{e}}$ siècles ", Le Moyen Âge, CXXV, 2019/1, p. 21-35, en ligne: https://www.cairn.info/revue-le-moyen-age-2019-1-page-21.htm. 
l'intégration du motif du conseil de guerre, de l'élaboration de stratégies militaires, de la harangue ou encore du butin de guerre; d'où l'appellation d' "épopée arthurienne» que nous adoptons en sous-titre. L'épopée n'est pas à confondre avec la chanson de geste, dont il ne s'agit que d'une des actualisations: Patrick Moran problématise l'emploi de ces termes en signalant que la chanson de geste est un genre généalogique, c'est-à-dire que l'auteur s'inscrit dans la continuité d'un genre donné. L'épopée relève en revanche de la classe analogique: le lecteur seul apparente la chanson de geste aux textes antiques, comme l'Énéide, ou renaissants, comme la Franciade, sur la base de ressemblances entre ces textes, en l'occurrence, le thème de la guerre. La chanson de geste serait alors une manifestation romane de l'épopée ${ }^{307}$. Notre emploi du substantif «épopée» ne désigne donc pas la chanson de geste, mais un genre analogique dont le critère commun est le développement d'une thématique guerrière. Quant à l'adjectif "épique», il en qualifie l'écriture. Une "esthétique épique» renvoie à un style ou des motifs propres au récit de guerre.

L'adoption de motifs est le premier niveau de confluence entre le roman arthurien en vers et la chanson de geste. Un motif se reconnaît à l'horizon d'attente qu'il crée: le lecteur conçoit mentalement un développement narratif lié à l'élément évoqué, suggéré par ses connaissances antérieures. Il peut donc se définir comme une structure narrative récurrente, soit au sein d'un même texte, le plus souvent à travers plusieurs textes:

On appelle généralement «motifs», ces micro-récits récurrents, reconnaissables grâce à une physionomie stable mais malléables selon leur migration et les œuvres sur lesquelles ils se greffen $\mathrm{t}^{308}$.

307 "Genres médiévaux et genres médiévistes: l'exemple des termes chanson de geste et épopée», art. cit., p. 38-60. Voir aussi Daniel Poirion, "Chanson de geste ou épopée? Remarques sur la définition d'un genre», art. cit., qui préconise de réserver l'appellation "épopée» pour les œuvres qui imitent la poésie grecque de l'epos, comme Virgile. Il propose d'appliquer l'adjectif "héroïque» au type de discours que l'on rencontre dans la chanson de geste.

308 Jean-Jacques Vincensini, Motifs et thèmes du récit médiéval, Paris, Nathan, 2000, p. 2. Jean-Jacques Vincensini traite également des méthodes pour identifier un motif: il parle d' "invariant figuratif», identifiable pour chaque motif. Cet invariant est solidaire d'un thème. À thèmes différents, il s'agit de motifs différents (p. 59). 
Le motif se caractérise par sa capacité d'itération et sa narrativité: il ne se réduit pas à un élément (la fontaine), mais englobe un déroulement ${ }^{309}$. En ce sens, on peut le qualifier de "matière», entendue comme thème narratif en attente d'actualisation ou de réactualisation; le motif recoupe l'idée d'un développement narratif qui appelle à la réactivation. Ce type de portions minimales de matière est génériquement marqué: le don contraignant, l'arrivée à la cour, le jeu du décapité sont autant de motifs que l'on rencontre dans le roman arthurien, tandis que la transmission de la couronne, le dénombrement des échelles ou l'assaut épique se réalisent plus volontiers dans la chanson de geste ${ }^{310}$. L'horizon d'attente anticipe donc pour chaque genre la présence de motifs spécifiques, d'où la propension générique du motif.

L'adoption d'un motif épique ne fait pas forcément signe vers la seule chanson de geste: la rhétorique épique se diffuse tôt dans toute la littérature et singularise de moins en moins ce genre, comme l'ont montré Omer Jodogne et Alexandre Micha en traitant du style épique dans les romans antiques $^{311}$. Patrick Moran parle de «patron générique exportable ${ }^{312}$ pour

309 Francis Gingras, «L'anneau merveilleux et les deux versants du désir. Présentation du Thesaurus informatisé des motifs merveilleux de la littérature médiévale", Revue des langues romanes, 1997, t. CI/2, 163-183.

310 Voir Anita Guerreau-Jalabert, Index des motifs narratifs dans les romans arthuriens français en vers, et l'article de Jean-Pierre Martin, "Les motifs dans la chanson de geste. Définition et utilisation", Cahiers de civilisation médiévale, 120, 1987, p. 315-329. Sur la distinction entre thème et motif, voir Jean-Jacques Vincensini, Motifs et thèmes, p. 68-74. Le thème est un "contenu sémantique minimal de nature conceptuelle» (p. 70).

311 Omer Jodogne, "Le caractère des œuvres antiques dans la littérature du XII et du XIII ${ }^{\mathrm{e}}$ siècle", in L'humanisme médiéval dans les littératures romanes du XII au XIV siècle, dir. Anthime Fourrier, Paris, Klincksieck, 1964, p. 55-83, Alexandre Micha, "Couleur épique dans le Roman de Thèbes", Romania, 91/362, 1970. p. 145-160. Selon ces critiques, on doit au Roman de Thèbes l'introduction du style épique dans le genre romanesque.

312 «La guerre comme marqueur générique dans la littérature narrative des $\mathrm{XII}^{\mathrm{e}}-\mathrm{XIII}{ }^{\mathrm{e}}$ siècles ", art. cit. Patrick Moran a montré que la manière de présenter la chose militaire est bien de l'ordre du genre et non d'une représentation culturelle commune de la guerre: en comparant l'Histora regum Britanniae et le Roman de Brut, il montre que Wace déroule le motif de l'assaut guerrier à partir de mentions brèves chez Geoffroy. On peut en déduire que l'auteur français s'inspire du modèle esthétique fourni par la chanson de geste pour décrire la bataille. Ces patrons sont donc génériques et ne résultent pas d'un imaginaire cognitif commun. 
désigner ces transferts de canevas narratifs d'un genre à l'autre, en prenant notamment l'exemple de l'assaut épique. Ce motif est exploité dans la Suite Vulgate, la Mort Artu ou encore le Lancelot propre, sans toutefois affecter la généricité de ces textes, qui demeurent des romans arthuriens et ne peuvent être considérés comme des chansons de geste. Pour autant, ces séquences sont génériquement marquées et probablement reconnues comme allogènes par le public médiéval: leur intégration influence la lecture et la perspective engagée sur l'œuvre.

Les travaux de Patrick Moran poussent à envisager que l'influence de l'épique est déjà manifeste dans les romans arthuriens en prose, ce que confirme également Marion Bonansea dans un article qu'elle consacre à la guerre dans la Mort $A_{r t u}{ }^{313}$. La collision entre éléments épiques et roman arthurien n'est donc pas nouvelle lorsqu' elle intervient dans notre corpus, surtout si l'on considère qu'on en trouve les prémices dans les textes en vers du début du XIII ${ }^{\mathrm{e}}$ siècle et surtout dans les romans antiques du XII ${ }^{\mathrm{e}}$ siècle, dans Cligès et dans l'historiographie, le Brut en particulier, sur lequel plusieurs romans arthuriens tardifs prennent appui. L’originalité de nos textes réside dans l'importation massive de ces éléments dans le genre arthurien en vers et dans l'importance de l'adoption de vers formulaires ${ }^{314}$ ou de procédés rhétoriques épiques comme l'anaphore ou les formules épiques de visualisation ${ }^{315}$ du type "veïssiez». Autour de ces éléments

313 Marion Bonansea, «La guerre dans la Mort Artu: hybridation générique et clôture romanesque", in Les genres au Moyen Âge: la question de l'hétérogénéité, dir. Hélène Charpentier et Valérie Fasseur, Bandol, Vallongues, 2010, p. 123-131.

314 Pour se convaincre de l'importance du style épique dans le roman arthurien, on consultera l'article d'Aurora Aragon Fernandez et José Fernandez Cardo, «Les traces des formules épiques dans le roman français du XIII ${ }^{\mathrm{e}}$ siècle: le combat individuel", in Essor et fortune de la chanson de geste dans l'Europe et l'Orient latin. Actes du IX Congrès international de la Société Rencesvals, vol. 2, "Rapports entre chanson de geste et roman au XIII ${ }^{\mathrm{e}}$ siècle», Modena, Mucchi, 1984, p. 435-463, qui compare la formularité de l'écriture du combat entre roman arthurien et chanson de geste. Notre but n'est pas d'observer les formules épiques dans notre corpus ni de constater que la structure convenue du combat est respectée. Corinne Pierreville a fait ce relevé pour Claris et Laris: Claris et Laris, somme romanesque $d u$ XIII siècle, p. 379-386, et Helen L. M. Neat pour Floriant et Florete: «Depictions of Violence in Floriant et Florete: Inter- and Intratextual Patterns ", art. cit.

315 Nous empruntons cette appellation à Aimé Petit, Naissances du roman: les techniques littéraires dans les romans antiques du XII siècle, Lille, Atelier national reproduction des thèses Université Lille III, 1985, t. 1, p. 305. 
rhétoriques se déploie une esthétique de la guerre qui occupe une grande partie des romans tardifs.

Les motifs du conseil de guerre et de l'élaboration d'une stratégie militaire sont largement exploités dans notre corpus. La scène de conseil concerne aussi bien les ennemis d'Arthur que le camp des chevaliers arthuriens, ce qui correspond au motif tel qu'il apparaît dans la chanson de geste, que l'on pense aux conseils de guerre de Marsile et de Charlemagne dans la Chanson de Roland, ou dans le roman antique, lors du discours qu'adresse Turnus à ses barons à propos du conflit qui l'oppose à Eneas et qui suscite des réactions divergentes de la part de ceux-ci dans le Roman $d^{\prime}$ nneas $^{316}$. La même structure narrative, le patron générique exportable, est récurrente dans notre corpus: le chef de guerre demande conseil à ses gens; ceux-ci donnent leur avis tour à tour, proposant éventuellement des points de vue divergents; un parti est adopté. Dans Floriant et Florete, Arthur prend notamment conseil auprès de ses barons à propos de la guerre contre Maragot et l'empereur de Constantinople (" "Or dites que nous en ferons / S'en cest jor d'ui les asaudrons.” ", v. 4399-4400). Sagremor le Desreez répond en premier d'attaquer directement. Cet avis est contesté par Yvain:
«Nous n'avons berfroi ne perriere
Ne chaut dont nos puissons covrir.
Trop verriez voz gens laidir
S'en tel maniere assailliens,
Ce ne me samble mie biens,
Nous ferïons trop grant outrage.» (Floriant et Florete, v. 4416-4421)

Le conseil permet d'opposer les points de vue à l'intérieur même du camp d'Arthur, et non seulement entre celui-ci et l'ennemi. L'avis d'Yvain intègre également une dimension peu prise en considération dans les romans arthuriens: celle des engins de siège ${ }^{317}$, que le chevalier propose ici

316 Voir Le Roman d'Eneas, éd. Aimé Petit, Paris, Le Livre de Poche («Lettres gothiques»), 1997, v. 4194-4325. Dans le Roman de Brut, on trouve un tel épisode par exemple après la provocation des Romains. Les barons d'Arthur offrent diverses réactions face à la menace et la discussion se prolonge pendant plus de trois cents vers.

317 Dans Claris et Laris, les engins de siège sont aussi évoqués: Arthur commande d'aller chercher du bois en forêt pour fabriquer des "mangonniax" et des "berfroiz» (v. 14873-14885). 
de construire en allant chercher du bois en forêt (v. 4423-4436), insérant ainsi dans le roman des considérations très pratiques ${ }^{318}$.

Ces conseils de guerre sont l'occasion de dérouler parfois longuement de véritables stratégies militaires, peu communes dans le roman arthurien. Une vraie réflexion sur l'art de la guerre se déroule à travers les discussions des personnages, tandis que les ruses des uns et des autres donnent de la profondeur aux affrontements. Biaudouz imagine exhiber les chevaliers de l'arrière-garde afin de faire croire à l'ennemi que les chevaliers sont en grand nombre et qu'ils sont tous aussi frais que ceux de l'arrière (v. 25522561). Escanor le Bel fait espionner Arthur pour savoir si ses troupes sont nombreuses (v. 18784-18790). Celui-ci sait déjà que son ennemi tente de le surprendre et fait embusquer ses soldats, que repèrent alors les espions d'Escanor. Les tentatives de prendre l'armée adverse par surprise constituent une stratégie souvent investie par les personnages des romans $\operatorname{tardifs}^{319}$. Le roi Ladon, mari de Lidoine, propose par exemple dans Claris et Laris d'attaquer avant que l'ennemi ne soit armé (v. 7660-7674). Cette recommandation ne plaît toutefois pas à ses barons: l'honneur condamne une telle attaque, qui ne garantit pas l'égalité des chances des opposants. Ainsi, bien que des échos à la réalité de la guerre affleurent, l'idéal littéraire fondé sur le code chevaleresque reste tenace. Le roman arthurien en vers s'en voit ainsi renouvelé: l'adoption de patrons génériques épiques met l'honneur chevaleresque en perspective avec une vision plus prosaïque de la guerre.

En ce sens, l'attaque par surprise est une tactique militaire souvent exclusive aux ennemis d'Arthur. Si le camp arthurien en esquisse la possibilité, elle est souvent avortée: le roi Ladon renonce finalement à son projet, et dans Escanor, l'embuscade d'Arthur ne sert à rien, car elle est repérée par les espions. En revanche, le projet de Maragot, dans Floriant et Florete, d'attaquer l'armée d'Arthur à peine débarquée de ses navires aboutit. L'empereur Philimenis demande conseil à ses barons: faut-il

318 Sur l'influence épique dans Floriant et Florete, voir Florence Bouchet, «Les éléments épiques dans Floriant et Florete», in "Plaist vos ö̈r bone cançon vallant?" Mélanges de langue et de littérature médiévales offerts à François Suard, dir. Dominique Boutet, Marie-Madeleine Castellani, Françoise Ferrand et Aimé Petit, Lille, Éditions du Conseil scientifique de l'Université Charles-de-Gaulle-Lille III, 1999, t. 1, p. 87-99.

319 Jean-Pierre Martin traite de ce motif épique dans Les motifs dans la chanson de geste, p. 100-104. 
laisser débarquer Arthur ou lui interdire l'accès? L'un des conseillers, le duc d'Athènes, énonce clairement le déshonneur inhérent à la seconde solution:

«Sire, se croire me voulez,

Ja nul anui ne lor ferez

Quar point d'onor n'i avriez

S'adonc seure lor couriez.

Mes quant il seront arrivé

Et tuit rengié et ordrené

Et lor banieres desploiees

Et toutes lor gens arrengies,

S'adonc conquerre les poons

Grans loenges en averons!» (Floriant et Florete, v. 2991-3000)

Ce sage avis, conforme à l'idéal chevaleresque valorisant la gloire méritée et non la victoire à armes inégales, n'est pourtant pas suivi: Maragot préconise d'affaiblir l'ennemi dès que l'occasion se présente. Son armée procède ainsi et attaque Arthur à l'aide de flèches et de lances ${ }^{320}$. L'élaboration de stratégies guerrières permet donc aussi de distinguer les bons des mauvais, les rois faibles - Ladon est vieux et appelé à être remplacé par Claris - des rois courtois.

Ce type de développement ne résulte pas que d'un intérêt pour la guerre: le recours à l'esthétique épique est manifeste dans nos textes et témoigne d'une volonté de conjoindre différents genres, afin de nourrir le roman arthurien de nouveaux souffles. Le motif du dénombrement des eschelles ${ }^{321}$ est particulièrement exploité dans notre corpus dans cet

320 Michelle Szkilnik aborde ce passage comme l'esquisse d'une bataille navale. "Arthur s'en va-t-en guerre», art. cit., p. 106-108. La critique montre que cette scène est inspirée du Brut, lors du retour d'Arthur en Grande-Bretagne, accueilli par le traître Mordred.

321 Ce motif rhétorique est recensé par Jean-Pierre Martin, Les motifs dans la chanson de geste, p. 360. On le trouve aussi dans l'historiographie de Wace, notamment lors de la guerre contre Rome. Le narrateur liste la provenance des alliés de l'armée romaine (Le Roman de Brut, éd. cit. d'E. Baumgartner et I. Short, v. 2267-2290) et procède aussi au dénombrement des bataillons d'Arthur (v. 3530-3564). Ce motif est exploité par le roman antique également, par exemple au moment des premiers affrontements entre Grecs et Troyens dans le Roman de Troie; sont catalogués les quarante-neuf navires grecs puis les alliés de Priam. Il ne s'agit donc pas d'une exclusivité de la chanson de geste. 
objectif: il donne lieu à des listes ${ }^{322}$ de noms de guerriers, à la fois dans le camp ennemi et ami. La guerre contre Rome dans Claris et Laris est notamment agrémentée de l'énumération des guerriers qui s'affrontent:

Li empereres par devis

Les a trestoz en conroy mis.

Li roys de Grece Celidon

Et cil de Sezile Calon

Et Ditas, li roys de Hongrie,

Madon, li roys de Bouguerie

Firent la premiere bataille. [...]

Li roys Artus de l'autre part

Ne fait pas chiere de cöart,

Ainz a ses batailles rengiees,

Pour combatre bien atiriees.

L'avant garde conduist Claris,

Gauvains li preuz, Yveins, Laris,

Lucans et Keus li seneschaux,

Gaherïez, Gales li Chaux. (Claris et Laris, v. 6257-6308)

Ce type d'énumération se poursuit tout le long de la description et scande le récit. Le caractère répétitif de telles séquences correspond à un rythme qu'a instauré la chanson de geste ${ }^{323}$ et qu'ont adapté au cadre de l'octosyllabe l'historiographie et le roman antique, fondant alors un style épique activable dans des genres différents: la reprise, dans différents genres, de patrons génériques donne lieu à la codification de la description de guerre, fondée sur la répétition. On peut faire le même constat pour Floriant et Florete, où l'armée de l'empereur Philimenis fait l'objet d'une description sous forme de liste qui énumère pour chaque eschelle les chefs de guerre:

322 Sur la liste et ses effets rhétoriques, voir Madeleine Jeay, Le commerce des mots. L'usage des listes dans la littérature médiévale (XII-XV siècles), p. 45-53 au sujet du dénombrement épique des combattants. La critique donne pour exemple Girart de Roussillon, la Conquête de Jérusalem, la Chanson de Roland, celle de Guillaume ou la Chevalerie Vivien. Le but est souvent de signifier le nombre important des forces en présence. Les listes soulignent aussi l'habileté du poète, par le jeu sur les sonorités que les noms propres introduisent.

323 Voir à ce sujet l'étude de Joseph J. Duggan, The Song of Roland: Formulaic Style and Poetic Craft, Berkeley; Los Angeles; Londres, University of California Press, 1973. 
Li rois Jonas de Taubarie

Ra la quarte et sa gent fornie.

La sinquiesme fist Santipus,

Et li dus d'Atenes, Porus.

Filitoé fist la sissieme

Et Geremie la septieme. (Floriant et Florete, v. 3747-3752)

L'organisation des bataillons de Constantinople est récurrente et intervient à plusieurs reprises dans le roman ${ }^{324}$, d'où l'effet de scansion.

Dans Biaudouz, le dénombrement des eschelles est l'occasion d'intégrer d'autres types de renforts aux rangs de l'armée:

Ez vos les autres par de la

Venuz, trois escheles i a;

Bien sont de chevaliers cinc cent.

En chascune a bien d'autre gens:

Prés de deus mile atornee

Et de combatre entalentee.

La premerainne eschiele guie

Li quens Ludis. Mout est hardie

Sa rote: c'il dussent morir,

$\mathrm{Ne}$ voustrent de l'estor fuïr.

Vilains del païs i a mout,

Qui sont de duel fier et estout. (Biandouz, v. 2703-2714)

Les chevaliers ne sont pas les seuls à agrandir ces bataillons: paysans et gens du peuple se battent aussi contre Madoine, ainsi que des arbalétriers (v. 2611). Girart d'Amiens ${ }^{325}$ prend également en considération d'autres combattants que les seuls nobles chevaliers: les eschieles sont composées de la piétaille, des archers et des arbalétriers (v. 18810-18813). En parallèle au développement de l'idéal chevaleresque, les realia viennent compléter le portrait de la guerre dressé dans le roman tardif ${ }^{226}$.

324 Voir le relevé de Florence Bouchet, "Les éléments épiques dans Floriant et Florete», art. cit., p. 89-90.

325 Le roman d'Escanor présente également plusieurs passages de dénombrement des eschelles. Voir par exemple les vers 18810 à 18936.

326 L'adoption de perspectives réalistes est envisagée par Daniel Poirion comme composante de ce qu'il appelle le "style gothique», c'est-à-dire les tendances 
En ce sens, l'évocation du butin de guerre contribue à ce renvoi à la réalité contemporaine en même temps qu'au motif épique ${ }^{327}$. Respectant l'honneur chevaleresque, Biaudouz recommande à ses troupes de ne pas s'emparer du butin avant la victoire: "Mais bien vos gardez d'avoir prendre / Tant ke nos avrons tot l'estor / Vaincu.» (v. 2646-2648). Les armées d'Arthur conquièrent également un trésor après leur victoire contre les Romains dans Claris et Laris: de la nourriture, du bétail, de l'or, de l'argent, des soieries (v. 6866-6888). La distribution des richesses par le roi et le partage entre les combattants sont toujours soulignés, comme dans Floriant et Florete: "[Floriant] Tout le commence a departir / Onques n'en volt riens retenir» (v. 7579-7580). Personne, «ne petit ne grant» (Biaudouz, v. 2982), ne ressort pauvre de l'affrontement; la guerre est ainsi valorisée dans les romans comme instrument de gloire et de richesse $\mathrm{e}^{328}$.

L'esthétique épique ne va pas sans l'adoption d'un style formulaire ${ }^{329}$, nous l'avons vu au sujet du dénombrement des combattants. Les descriptions de guerre font alors très souvent intervenir des anaphores:

littéraires des XIV e et $\mathrm{XV}^{\mathrm{e}}$ siècles. "L'épanouissement d'un style: le gothique littéraire à la fin du Moyen Âge», art. cit., p. 39-41.

327 Jean-Pierre Martin, Les motifs dans la chanson de geste, p. 363. D'autres motifs épiques interviennent encore dans notre corpus. En voici une liste qui est loin d'être exhaustive: la prière à Dieu («Et prist adont Diu a requerre, / De qui tout son secors espoire, / Qu'il li vausist prester victoire», Escanor, v. 18960-18962); l'encouragement des troupes («Prenez en vos mismes confort / Et pensez hui de vos vengier!», Biaudouz, v. 2523-2524); l'assaut épique («Lors point Floriant le destrier / Des esperons tranchanz d'acier. [...]», Floriant et Florete, v. 53135314); l'armement des chevaux et chevaliers ("Atant sunt as armes courus, / Vestent hauberc mailliez menus, / Prenent escus, lances et dars", Floriant et Florete, v. 3023-3025). Richard Trachsler mentionne encore le motif du don du cheval, repris dans Escanor avec le récit étiologique concernant le Gringalet. "Qui a donné le Gringalet à Gauvain? À propos d'un épisode d'Escanor de Girart d'Amiens", art. cit.

328 Corinne Pierreville constate que les tournois sont démythifiés au profit de la guerre, dans Claris et Laris. Les tournois sont ainsi décrits avec le vocabulaire guerrier ("batailles», "conrois», "eschieles») et les figures de style propres à la description de guerres. "Plaisance et outrance, les tournois dans Claris et Laris", in Le tournoi au Moyen Âge, Actes du colloque des 25 et 26 janvier 2002, dir. Nicole Gonthier, Lyon, Université Jean Moulin ("Cahiers du Centre d'Histoire Médiévale», 2), 2003, p. 31-43.

329 La formularité de l'écriture se retrouve dans Melyador et ses descriptions de tournois. Nathalie Bragantini-Maillard analyse le style répétitif de ce texte et son 
La rot merveilleuse envahie,

La rot trop grant charpenterie,

La rot douloureuse criee,

La rot perilleuse mellee,

La sont li cöart en error,

La s'espreuvent li fereor! (Claris et Laris, v. 6507-6512) $)^{330}$

L'anaphore est parfois couplée à un autre motif rhétorique, celui de l'hypotypose ou figure épique de visualisation:

Dont oïssiez tant cor soner,

Grailes et busines soner,

Tant boin cheval vissiez covert,

Tant escu point d'azur, de vert,

Tante sele, tant garniment, [...] (Biaudouz, v. 2619-2623)

Ces usages sont courants ${ }^{331}$, déjà chez Chrétien de Troyes et ses successeurs du début du XIII ${ }^{\mathrm{e}}$ siècle. Les auteurs tardifs poussent toutefois plus loin leur usage d'une écriture formulaire et répétitive, par la fréquence de cette rhétorique et la longueur des passages en question, plus proche de ce que l'on rencontre dans les romans antiques, l'historiographie ou la chanson de geste que dans les premiers romans arthuriens en vers.

En plus de valoriser en proportion ces descriptions épiques, les textes de notre corpus renchérissent sur l'esthétique de la répétition à l'aide d'autres techniques. Le sénéchal du roi Ladon dans Claris et Laris conseille la retraite d'une guerre perdue d'avance contre l'Espagne. Sa rhétorique est empreinte d'un effet de répétition qui donne plus de force à son discours et accentue la folie contre laquelle il tente de prévenir son seigneur:

«Sire, fet il, en ceste terre

Venismes la folie querre!

usage de procédés de célébration propres à la geste. «Les tournois de Melyador, ou l'originalité d'une stéréotypie stylisée ", art. cit.

330 Voir Corinne Pierreville, Claris et Laris, somme romanesque du XIII siècle, p. 182-216, pour le relevé de quelques anaphores, nombreuses dans le roman, et surtout des différents motifs épiques.

331 Les exemples sont innombrables dans notre corpus. On peut encore citer un passage tiré d'Escanor: «La veïssiez a souhaidier / Et bel meller et bel venir, / Et bel le chaple maintenir, / Et bel jouster et bel aerdre / Et bel gaaingnier et bel perdre, / Et bel encontrer et abatre, / Et bel relever touz ces .iiii. ", v. 4846-4852. 
Querre venimes la folie

Si n'i devonmes faillir mie!» (Claris et Laris, v. 7697-7700)

La répétition du même vers, avec une syntaxe inversée, crée un chiasme qui rapproche le texte du style épique par la redondance de la formule et cause un effet de ralentissement ${ }^{332}$. Cet effet est justement le propre de l'écriture épique, qui exalte les faits d'armes en décrivant longuement une guerre s'étendant sur un court laps de temps. Il s'agit d'amplifier l'événement par la répétition en recourant notamment aux laisses similaires et enchainnées. Le roman de Claris et Laris imite parfois la laisse enchaînée, ainsi que le suggère Corinne Pierreville au sujet de la guerre contre Nabon: Laris abat Elyadas mort deux fois au cours de vingt vers ${ }^{333}$. Cette répétition favorise la progression du récit épique, présenté comme une succession de combats mêlés les uns aux autres ${ }^{334}$.

L'utilisation de formules et de la répétition dans Floriant et Florete est particulièrement remarquable: Richard Trachsler et Annie Combes ont analysé dans l'introduction à leur édition le caractère formulaire de l'écriture dans ce roman ${ }^{335}$. Ils relèvent que les mêmes vers se répètent plusieurs fois. Il s'agit parfois de vers qui adoptent l'inversion épique et rappellent ainsi le fameux "Halt sunt li pui et li val tenebrus»" ${ }^{336}$ de la Chanson de Roland:

Grant sunt li cri, grant sont li plors

Des navrez, et li mort s'acoisent. (v. 3224-3225)

332 Alexandre Micha, "Couleur épique dans le Roman de Thèbes», art. cit., p. 147-148, donne des exemples similaires de telles répétitions dans le Roman de Thèbes.

333 «Erïadas fu au jouster; / Tuit troi au cheval s'adrecerent, / Mort contre terre le verserent, / Mes Laris tost rest sus sailliz, / Ne fu mie de cuer failliz. / De fuerre trait sa bone espee / Et l'en a donné tel colee / Que la teste li a tolue.» (v. 31883195) «Laris raba Elÿadas» (v. 3206).

334 Sur la laisse enchaînée, voir Jean Rychner, La Chanson de geste : essai sur l'art épique des jongleurs, p. 74.

335 Floriant et Florete, éd. cit., p. XLVII-LXVII. Voir aussi Richard Trachsler, «Formulas, Orality and Arthurian Romance: A short Note on a Long Story", Romanic Review, 100, 2009, p. 415-429. La répétition s'étend aussi à la structure symétrique du roman. Les éditeurs l'ont montré, ainsi que Helen L. M. Neat, "Depictions of Violence in Floriant et Florete: Inter- and Intratextual Patterns", art. cit.

336 La Chanson de Roland, éd. cit., v. 814. On retrouve cette même formule aux vers 2271 et 1830 . 
Grant sunt li cri desor la mer. (v. 3206)

Grant sunt li cris, grant sunt li hus. (v. 3164 et 3286)

L'inversion épique et la répétition de ce vers, par trois fois, ne manquent pas de faire signe vers la chanson de geste, la Chanson de Roland en particulier $^{337}$. Ce vers provient en fait non pas de la Chanson de Roland, mais de Claris et Laris (v. 6687), auquel l'auteur de Floriant et Florete emprunte un certain nombre de passages.

La critique ${ }^{338}$ a montré à quel point l'auteur de Floriant et Florete s'inspire de la tradition pour élaborer son récit: il copie en particulier plus ou moins fidèlement des vers à ses prédécesseurs. Nous avons dénommé ailleurs cette pratique "implicitation ${ }^{339}$ au sujet de Cristal et Clarie, qui

337 Sur ce vers d'intonation récurrent, voir Jean-Pierre Martin et Marielle Lignereux, La Chanson de Roland, Neuilly, Atlande, 2003, p. 159. Voir aussi Florence Bouchet, "Les éléments épiques dans Floriant et Florete», art. cit., p. 91-92.

338 Voir Keith Busby, "The intertextual coordinates of Floriant et Florete», art. cit., Annie Combes et Richard Trachsler, introduction à l'édition citée, Richard Trachsler, «Formulas, Orality and Arthurian Romance: A short Note on a Long Story", art. cit., et Laura Endress, "Orality and Textual Reworking in Floriant et Florete: Another Note on a "Patchwork Romance" ", art. cit. Les critiques se sont pour l'instant concentrés sur les emprunts aux romans arthuriens. Sans doute pourrait-on trouver des citations tirées d'autres genres. Seule Laura Endress identifie des vers provenant de la Vie des Pères ou des Arts d'amour.

339 C'est en référence à la notion que nous proposons dans Pour une poétique de l'implicitation, que nous employons le mot «implicitation» et ses dérivés dans les pages qui suivront. Nous la définissons comme un mode d'écriture fondé sur l'intégration de citations non déclarées tirées d'autres romans. Le gommage de tout élément qui permettrait d'identifier directement le texte de provenance de la citation en garantit le caractère implicite. Il nous semble que cette poétique est un véritable phénomène qui se développe dès la fin du XIII ${ }^{\mathrm{e}}$ siècle. D’autres exemples viennent s'ajouter à Cristal et Clarie pour démontrer l'importance de cette pratique, qu'il faut appréhender comme une technique d'écriture productive et ludique: le Roman de Laurin emprunte des passages à la Queste del saint Graal (Christine Ferlampin-Acher, "Laurin: li contes de Bretaigne sont sage et de sens aprendant?", in Matières à débat, p. 441-462). Pour Floriant et Florete, Richard Trachsler et Annie Combes donnent le relevé des vers repris au début de leur édition cité, p. XXVI-XXVII. Voir aussi les pages XLIV-LII. Corinne Pierreville propose un relevé des vers que l'on rencontre dans Claris et Laris et Floriant et Florete dans sa traduction de Claris, Paris, Champion (“CFMA»), 2007, p. 691-710. La formularité des vers "implicités» par Floriant et Florete, qui permettent peu au lecteur d'identifier leur provenance contrairement à ce qu'il se passe pour Cristal 
copie massivement ses hypotextes, jusqu'à fonder une nouvelle poétique à partir de ces collages. Dans Floriant et Florete, les vers repris sont de l'ordre de la formularité: les passages tirés du Conte du graal ou d'Erec et Enide ne concernent souvent que quelques vers et sont loin d'atteindre l'emprunt considérable auquel s'adonne l'auteur de Cristal et Clarie. En voici quelques exemples ${ }^{340}$ :

Lors dist: «Vassal, ci qui t’envoie? Et dit: «Vallez, qui ça t’anvoie?

Di moi l'ochoison de ta voie, Di moi l'ochoison de ta voie.

Viens tu pais ou bataille querre? Viens tu paiz ou bataille querre?

Dont es tu nez et de quel terre?" - Mais que faiz tu en cele terre?»

(Floriant et Florete, v. 985-988) (Conte du graal, v. 2132-2136)

[...] Me poïst vaincre, or ai trové Me peüst veincre; or ai trové

Meillor de moi, bien l'air prové! Meillor de moi : bien l'ai prové.

(Floriant et Florete, v. 1119-1120) (Erec et Enide, v. 1049-1050)

Les vers empruntés par Floriant et Florete sont liés à la rime: ceux qu'ont repérés la critique présentent toujours les mêmes mots en fin de vers, preuve sans doute que ce qui prévaut dans ce procédé, c'est la mémoire. Pour le dire avec Richard Trachsler,

the poet has in mind a whole stock of lines coming from romances he has read, heard or copied and has retained for some reason or another. I think we must admit that medieval romance works in this respect like medieval epic. In other words, just as we believe that the chanson de geste is made up of formulas and is transmitted by professionals who know by heart great quantities of text, we should probably consider medieval romance as being the result of a poet who has memorized an

et Clarie, pourrait être un indice de la façon dont sont composées les œuvres à cette époque. Il est d'ailleurs significatif que les vers choisis concernent très majoritairement des scènces de bataille, dont on connaît le caractère convenu. D'autres exemples démontrent que la reprise de quelques vers est fréquente, sans qu'elle soit forcément développée en poétique dans tous les textes. On citera à cet égard les vers 1425-1426 (Philippe de Rémi, La Manekine, éd. Marie-Madeleine Castellani, Paris, Champion («CCMA»), 2012) de la Manekine, repris au Conte du graal: "Et tuit oel se sont par nature / Plus fol que bestes en pasture» // "Que Galois sont tuit par nature / plus fol que bestes en pasture» (Conte du graal, v. 237-238).

340 Tirés de Richard Trachsler, «Formulas, Orality and Arthurian Romance: A short Note on a Long Story», art. cit. 
enormous amount of other romances which he did not hesitate to use for his own creation ${ }^{341}$.

La parenté de Floriant et Florete avec la chanson de geste concernerait donc aussi la façon dont le roman a été composé, c'est-à-dire sur la base de formules, qui se trouvent peut-être incidemment dans le roman.

Si les implicitations tirées des romans de Chrétien de Troyes sont courtes, celles empruntées à Claris et Laris sont bien plus importantes: il s'agit de l'hypotexte privilégié par le nombre de vers copiés (environ 330 vers). Certains passages sont également réécrits, notamment le prologue et les vers 6228 à 6248 de Floriant et Florete, qui font l'apologie des ménestrels. Corinne Pierreville a recensé les vers identiques ${ }^{342}$; à partir du classement thématique qu'elle établit, on peut affirmer que la grande majorité des implicitations concerne la guerre et sa description. Les implicitations reprennent les récits de bataille en eux-mêmes et les motifs épiques comme le dénombrement des eschelles, les conseils de guerre ou les menaces. À côté de cela se trouvent aussi des passages qui rapportent des combats tout à fait arthuriens, celui contre un monstre par exemple - la guivre dans Claris et Laris, le pellican dans Floriant et Florete -, celui contre un géant ou encore le tournoi incognito. Laris et Floriant affrontent tous deux en une telle occasion Keu, qui se rend ridicule dans des conditions identiques:

Keus le fiert en l'escu premiers

Keus le fiert en l'escu amont

Si qu'il ne remest mie entiers:

La lance est parmi trespassee,

Sus le hauberc est arrestee.

Maintenant est volee en piece!

Or crien ge que Keus ne meschiece

Car Laris ruiste coup li donne

Sa lance a parmi trespassee,

Sus le hauberc est arrestee,

Maintenant est volee em piece.

Or crien ge qu'a Keu ne meschiece,

Car Floriant tel cop li donne

341 Richard Trachsler, «Formulas, Orality and Arthurian Romance: A short Note on a Long Story», art. cit., p. 426-427. Laura Endress considère aussi la dimension formulaire des vers implicités et propose d'y voir le résultat de la transmission orale des textes et de la mémorisation des auteurs. Elle invite en outre à distinguer les citations verbatim des simples formules orales. Laura Endress, "Orality and Textual Reworking in Floriant et Florete: Another Note on a "Patchwork Romance" ", Neophilologus, 2015, p. 1-18.

342 Claris et Laris, trad. cit., p. 691-710. 
En la gorge que tout l'estonne. La lance fu courte et poignal, Parmi la croupe du cheval L'en porte a terre tretot plat $\mathrm{A}[\mathrm{in}] \mathrm{si}$ estendu conme un chat! (Claris et Laris, v. 13307-13218)
En la gorge que tout l'estone. La lance fu courte et poignal, Parmi la croupe du cheval Le porte a terre trestout plat Aussi estendu comme .I. chat. (Floriant et Florete, v. 2234-2244)

La comparaison avilissante de Keu à un chat étendu à plat ventre est assez atypique pour que l'hypotexte soit identifié sans hésitation. D’autres vers sont toutefois moins proches de l'hypotexte et plus formulaires. Il peut paraître étonnant d'emprunter des passages guerriers à un roman arthurien plutôt qu'à d'autres textes plus épiques, comme l'historiographie ou le roman antique. Il est étonnant aussi de convoquer à tel point un texte tardif plutôt qu'un classique de Chrétien de Troyes ou de Renaut de Beaujeu. Il faut donc en déduire d'une part que le roman arthurien tardif, tout du moins Claris et Laris, se diffuse assez bien pour que l'auteur de Floriant et Florete en ait les vers en tête pour les reproduire. D'autre part, ces implicitations s'inscrivent dans un mouvement plus large qui englobe l'esthétique tardive dans son ensemble: le fait d'impliciter un texte quasi contemporain prouve bien le dessin d'une écriture commune à ces textes, que nous nous sommes employée à éclaircir. Le roman arthurien en vers tardif tend donc à créer une esthétique commune et cohérente, qui subsume divers contenus narratifs et développements rhétoriques; en l'occurrence, par l'adoption de patrons génériques épiques.

La notion théorique de patrons génériques exportables permet de rendre compte de la diffusion de certains canevas narratifs ou rhétoriques dans l'ensemble de la production littéraire: ce qui identifiait initialement la chanson de geste est exploité dans d'autres genres, si bien que le dénombrement des eschelles peut provenir du roman antique, de l'historiographie ou de la chanson de geste. Le traitement de la guerre dans notre corpus peut d'ailleurs très bien s'expliquer par un détour par le Brut de Wace, en particulier pour la guerre contre Rome narrée par Claris et Laris. Ce passage concentre tous les motifs épiques usuels: la description du harnachement, la provocation, la liste de combattants venus d'Orient, l'organisation des bataillons ennemis et d'alliés d'Arthur, les encouragements du roi. La stylisation épique fait l'objet d'un processus d'enromancement depuis le roman antique, qui a rendu de tels développements compatibles avec le genre romanesque et exportables dès lors dans le roman arthurien en vers. 
Qu'il soit attaché ou non à un genre en particulier, le patron générique se distingue par sa fonction propre, en l'occurrence épique, et son caractère allogène au sein du roman arthurien en vers, peu enclin à développer des guerres collectives.

Parallèment à l'adoption de patrons génériques et du style épique, Claris et Laris offre plusieurs allusions à des chansons de geste en particulier, ce qui vient renforcer la généricité épique de ce texte et cette orientation commune aux autres romans arthuriens en vers tardifs. À l'issue du combat contre la guivre et ses sept petits, Claris sonne désespérément du cor, afin d'être entendu du prévôt qui les a hébergés et leur a parlé de l'aventure:

Lors s'est Claris aperceüz

Qui moult iert las et estonnez

Du bon cor qui li fu donnez,

Que li bons prevoz li donna

Qui belement li sermonna

Du sonner s'il avoit victoire.

Bien s'en sovint en sa memoire.

A grant destrece l'a sonné

Mes tant ot le chief estonné

Et le cors chargié de venim,

Lez (C)Laris chaï ou chemin

Paumez, pres li cuers ne li ment. (Claris et Laris, v. 5582-5593)

La détresse du chevalier puis sa pâmoison ne manquent pas de rappeler au lecteur le passage où Roland sonne du cor pour appeler Charlemagne en renfort, et se pâme à plusieurs reprises avant de mourir d'avoir soufflé trop fort ${ }^{343}$. Les lamentations du prévôt, lorsqu'il découvre les deux corps évanouis, font également échos au planctus de Charlemagne. Ce passage

343 Olga Shcherbakova établit cette comparaison avec la Chanson de Roland. Elle dresse également un parallèle entre le combat contre la guivre et ses sept petits et le combat contre le Sathanas de la Chanson des Chetifs, qui nous paraît intéressant, quoique moins convainquant. "La question des sources multiples: le cas de Claris et Laris, roman arthurien du XIII ${ }^{\mathrm{e}}$ siècle", in Lieux de mémoire antiques et médiévaux. Texte, image, histoire: la question des sources, dir. Bernard Andenmatten, Panayota Badinou, Michel E. Fuchs et Jean-Claude Mühlethaler, Lausanne, BSN Press, ("a contrario Campus»), 2012, p. 293-317. 
s'accommode d'autant mieux d'une lecture épique que l'auteur emploie une répétition proche du procédé de la laisse enchainée:

Mes Laris fu si esblöez

Du feu et du venim ensemble

Que paumez chaï, ce me semble.

Ore est Laris paumez cheüz. (Claris et Laris, v. 5578-5581)

La reprise de la pâmoison de Laris permet d'enchaîner sur les éléments qui concernent Claris, comme si l'on commençait une nouvelle unité narrative, une nouvelle laisse.

Cette allusion intertextuelle ${ }^{344}$ invite dès lors à lire les motifs épiques à la lumière de la chanson de geste. L'auteur de Claris et Laris a encore recours à un motif propre à ce genre lorsque Claris et ses compagnons se déguisent en ermites pour délivrer Laris du roi Tallas. Cette séquence narrative se retrouve dans plusieurs chansons de geste ${ }^{345}$; la plus connue est sans doute Le Charroi de Nîmes, où Guillaume se déguise en marchand pour conquérir la ville de Nîmes. Dans la chanson de geste comme dans Claris et Laris, le but est bien de tromper l'ennemi afin de l'attaquer par surprise. Ce motif a une double visée stratégique et comique ${ }^{346}$ : le chevalier parvient à ses fins et ridiculise en même temps son ennemi. Dans le roman arthurien, Tallas est ainsi obligé de prendre la fuite, lui dont seule l'avarice a fait recevoir les ermites qui se présentaient à sa porte. Le comique intervient également au moment où les chevaliers de Claris, parmi lesquels se trouvent des rois, doivent marcher pieds nus et s'en plaignent. Le narrateur souligne ironiquement:

.VIII. rois ot en lor compaignie

Qui deschauz va par la chaucie!

Taint se sont c'on ne les connoise.

$\mathrm{N}^{\prime} \mathrm{i}$ a celui qui point ne s'envoise

344 On peut encore citer comme exemple d'allusion intertextuelle le châtiment infligé à Maragot dans Floriant et Florete: tout comme Ganelon, il est écartelé à la suite d'un conseil où chaque baron a donné son avis sur le supplice à infliger au traître. Voir Florence Bouchet, "Les éléments épiques dans Floriant et Florete», art. cit., p. 92-93.

345 Voir François Suard, "Le Motif du déguisement dans quelques chansons du cycle de Guillaume d'Orange», Olifant, 7, 1980, p. 343-358.

346 Selon François Suard, ibid. 
Car les pierres grant mal lor font

Qui parmi la chauciee sont. (Claris et Laris, v. 27655-27660)

La mise en avant du comique et le déroulement de la scène du déguisement correspondent à l'épisode que l'on trouve dans le Charroi de Nîmes. Le lecteur ne peut manquer d'y lire une allusion à la chanson de geste, genre privilégié de l'épopée au XIII ${ }^{\mathrm{e}}$ siècle.

En plus des motifs, de formules rhétoriques et des allusions intertextuelles, c'est aussi en termes de proportions qu'il vaut la peine de considérer le roman arthurien tardif comme une épopée: la guerre collective prend dans ce corpus une ampleur qu'elle n'avait pas dans les représentants précédents du genre, qui privilégient plutôt le combat individuel. Corinne Pierreville note par exemple que Claris et Laris est consacré pour plus d'un tiers au récit d'affrontements, en multipliant les épisodes de guerres collectives ${ }^{347}$. Ce pourcentage est semblable dans d'autres textes de notre corpus, Escanor, Biaudouz et Floriant et Florete en particulier. Dans Escanor, la guerre contre Escanor le Bel est décrite très longuement (4000 vers), de même que le tournoi de Baubourc, qui occupe 3000 vers. Dans Biaudouz, c'est également une guerre en particulier qui se révèle centrale et fait l'objet d'une attention tout épique; celle contre Madoine, l'amoureux malheureux de Beauté, l'amie de Biaudouz. Quant à Floriant et Florete, la guerre contre Maragot occupe le centre du récit, puis c'est au tour de celle contre l'invasion sarrasine à Rome de faire l'objet d'une description épique.

Ce dernier thème différencie là encore notre corpus des autres romans arthuriens en vers: la lutte contre les païens, thème clé de la chanson de geste, est exploitée dans Floriant et Florete. Florence Bouchet voit par exemple en Florete une manifestation du motif de la Sarrasine amoureuse, si ce n'est qu'elle est déjà chrétienne ${ }^{348}$. La jeune fille appartient effectivement au camp adverse de celui de Floriant; il s'agit de la fille de l'empereur de Constantinople, venu soutenir le traître Maragot qui s'est emparé du royaume de Sicile, héritage de Floriant. L'amour entre Floriant et Florete est donc d'abord un amour interdit. Le recensement des alliés de Maragot n'est d'ailleurs pas sans évoquer un ennemi oriental, proche dès

\footnotetext{
347 Corinne Pierreville, Claris et Laris, somme romanesque du XIII siècle, p. 201. Elle dénombre douze guerres collectives (p. 387-388).

348 Florence Bouchet, "Les éléments épiques dans Floriant et Florete», art. cit., p. 93.
} 
lors du Sarrasin affronté dans les chansons de geste: les troupes viennent de Tibériade, de Syrie, d'Arménie, de Turquie ou encore de Libye (v. 3181-3262). Le rapprochement avec la guerre sainte est encore plus manifeste lors de la deuxième guerre du roman, celle qui vise à protéger Rome, victime de l'incompétence de son souverain, de l'invasion sarrasine. Sous les ordres du sultan, Turcs et Persans envahissent Rome (v. 7278-7285). Grâce à Floriant, l'attaque païenne est repoussée et les Sarrasins fuient. Le jeune homme apparaît alors comme un héros de la chrétienté, aux yeux de la cour arthurienne qui entend rapporter ses exploits par le roi Julien qu'il a fait prisonnier avant la guerre: «La li vi .M. paiens tuer / Et le soudanc le chief coper!» (v. 7701-7702).

Peut-être trouve-t-on ici une voie d'explication à l'importance de la guerre dans le roman tardif: l'idéologie de la croisade est encore vive au $\mathrm{XIII}^{\mathrm{e}}$ siècle, après le règne de saint Louis. Le prologue de Claris et Laris déplore d'ailleurs le siège d'Acre, qui devait tomber en 1291 aux mains des Musulmans ( Nous savons bien par verité / Que Grece et Acre et Antioche, / L'une en chiet et li autre en cloche / Et la tierce en est ja ploïe / Ce n'est pas nouvele joïe. ", v. 40-44). La préoccupation de l'auteur anonyme de ce roman pour le destin de la Terre sainte témoigne d'un regard positif jeté sur la guerre ${ }^{349}$. Glorifier la guerre collective dans la littérature narrative ne peut qu'encourager les auditeurs à soutenir les entreprises belliqueuses de leurs seigneurs, en besoins matériels ou en hommes. Relire l'esthétique épique à l'aune du roman arthurien en vers diffuse l'idéologique guerrière dans un genre qui n'en faisait pas sa priorité et renforce ainsi le caractère indispensable de la guerre dans la société de la fin du XIII ${ }^{\mathrm{e}}$ siècle.

L'esthétique épique n'est toutefois pas reprise sans transformations dans le roman arthurien. De tels passages ne vont pas sans l'exacerbation de la dimension courtoise, qui fonde la différence de l'actualisation épique dans le roman arthurien tardif par rapport à ses autres manifestations dans le roman antique, l'historiographie et la chanson de geste. Dans Escanor,

349 Les croisades cessent avec saint Louis, instigateur de la huitième croisade à Tunis. On a pu dire que Philippe III le Hardi et Philippe Le Bel étaient moins impliqués dans le destin de la Terre sainte; Xavier Hélary prouve toutefois que les rois de France de la fin du XIII ${ }^{\mathrm{e}}$ siècle ont tout de même entrepris des projets d'expédition en Terre sainte, projets inaboutis. "Les rois de France et la guerre sainte de la croisade de Tunis à la chute d'Acre (1270-1291)», Annales - Bulletin de la Société de l'histoire de France, 2005, p. 21-104. 
les affrontements du tournoi de Baubourc alternent avec les discussions des demoiselles et les considérations sur l'amour de Keu et d'Andrivete, tandis que lors de la guerre contre Escanor, ce sont les tourments amoureux de Gifflet et de la reine des Traverses qui interrompent les descriptions. L'amour contraint aussi la guerre dans Floriant et Florete: c'est à cette occasion que les deux protagonistes se rencontrent et que la demoiselle tombe amoureuse, en observant le chevalier se démener dans les rangs ${ }^{350}$. Les batailles sont donc entrecoupées de scènes amoureuses qui narrent les entrevues des personnages, leurs stratégies pour se voir en secret et leur badinage. Un contraste s'établit entre registres épique et courtois: l'épique se voit enromancé, comme si la dominante arthurienne et courtoise ne pouvait manquer de reprendre le dessus sur les combats.

L'intégration de l'épique ne modifie donc pas le genre du texte, mais demeure une rhétorique qui enrichit le roman arthurien. Malgré la forte proportion de passages épiques, les romans arthuriens tardifs demeurent des romans arthuriens ${ }^{351}$. Le mélange des genres peut toutefois influencer la réception, notamment la mise en recueil. Ainsi, Claris et Laris figure dans l'unique manuscrit qui le transmet côte à côte avec une chanson de geste, Berthe aux grands pieds, et un roman de clergie ${ }^{352}$, Floire et Blanchefleur. Ce recueil, le BnF fr. 1447, offre une grande cohérence dans son organisation. C'est d'abord sur le plan visuel que cela se manifeste: chacun des trois romans commence par une miniature qui occupe le tiers de la première colonne et illustre une des scènes initiales de chaque texte. L'initiale champie sur fond d'or qui ouvre le premier vers est prolongée dans la marge de queue par des scènes de chasse. Celles-ci n'ont pas pour objectif d'illustrer l'une ou l'autre œuvre en particulier; elles créent un

350 Au sujet de la dimension courtoise de la guerre dans Floriant et Florete, voir Florence Bouchet, "Les éléments épiques dans Floriant et Florete», art. cit., p. 87-99.

351 Selon Friedrich Wolfzettel, l'univers arthurien est tout de même marginalisé par l'importance de la dimension épique. Cet avis renforce l'idée que les romans tardifs sont des œuvres marginales par rapport aux textes canoniques. "Zum Problem der Epizität im „postklassischen“ Artusroman", in Fiktionalität im Artusroman des 13. bis 15. Jahrhunderts. Romanistische und germanistische Perspektiven, Wiesbaden, Reichert Verlag, 2013, p. 38-39.

352 Cette étiquette est donnée par Jean-Luc Leclanche dans son édition, Conte de Floire et Blanchefleur, Paris, Champion ("CCMA»), 2003, p. xx. 
effet de recueil et établissent une continuité entre les trois textes. Tel un fil rouge, la chasse des marginalia annonce un rapport étroit entre ceux-ci ${ }^{353}$.

Le lien entre Floire et Blanchefleur et Berthe aux grands pieds, les deux premiers textes, est flagrant: Floire et Blanchefleur sont les parents de Berthe. La naissance de la mère de Charlemagne est annoncée dans le prologue de Floire et Blanchefleur ${ }^{354}$; cette filiation apparaît sans cesse dans le récit de Berthe aux grands pieds, Blanchefleur se rendant à Paris pour voir sa fille et mettant au jour la disparition de Berthe, évincée par la serve Aliste et sa mère Margiste. Arrivé au terme de cette chanson de geste, le lecteur s'attend naturellement à lire l'histoire de la descendance de Berthe elle-même, c'est-à-dire qu'il attend l'intégration d'une chanson de geste traitant de Charlemagne. C'est pourtant Claris et Laris qui intervient. Jean-Luc Leclanche explique ce choix par le personnage de Gloris, appelée Claris dans le ms. BnF fr. 1447: il s'agit de l'amie de Blanchefleur dans la Tour des Vierges de l'émir de Babylone ${ }^{355}$. Il faudrait alors imaginer que le recueil aurait pour but d'élargir l'univers de fiction de Floire et Blanchefleur, en racontant la descendance des personnages principaux et le destin des personnages secondaires. Cette hypothèse est rendue difficile par le fait que Claris est un jeune homme dans Claris et Laris. Il faut sans doute concevoir une autre raison à l'intégration de ce roman dans BnF fr. 1447, qui, potentiellement, contraint le copiste à transformer le nom de la suivante de Blanchefleur en guise de clin d'œil au roman arthurien.

La cohérence se dégage donc des personnages, tout du moins des noms reparaissant d'un texte à l'autre. D'un point de vue générique, le recueil est déceptif: la chanson de geste est un horizon jamais vraiment réalisé. Si Berthe aux grands pieds peut bien être considéré comme tel, par sa forme en laisses d'alexandrins assonancées et par sa matière, aucune bataille ne vient satisfaire les attentes d'un lecteur intéressé par la chanson de geste

353 Voir la première page de chaque début de texte sur https://gallica.bnf.fr/ ark:/12148/btv1b9059914m/f3.image.r=fr

354 «Ce est du roi Flore l'enfant / Et de Blancheflor la vaillant, / De cui Berte aus granz piez fu nee; / Puis fu en France coronnee. / Fame fu au gentill baron, / Pepin le roy, pere Charlon. / Berte fu mere Charlemaigne / Qui puis tint (et) France et [A]lemaingne.» Floire et Blanchefleur, BnF fr. 1447, f. 1 ra.

355 Conte de Floire et Blanchefleur, éd. cit., note 1, p. vir. 
pour sa dimension épique ${ }^{356}$. Quant à Claris et Laris, l'inverse se produit: il ne s'agit nullement d'une chanson de geste, mais l'importance de la guerre dans ce roman convoque ce genre en creux. Le caractère déceptif de cette mise en recueil par rapport à la chanson de geste se manifeste également par l'expectative d'un récit sur Charlemagne, à la suite de l'histoire de sa mère.

Il est difficile de tirer des conclusions définitives sur l'intention qui préside à la mise en recueil du $\mathrm{BnF}$ fr. 1447. Il semble néanmoins clair qu'elle n'est pas due au hasard: l'organisation chronologique des textes, les échos entre les personnages et les scènes de chasse des marginalia attestent la tentative de créer un ensemble cohérent, constitué, peut-être, à partir de variations autour de la chanson de geste ${ }^{357}$. Ainsi, la lecture épique des romans arthuriens en vers est-elle une potentialité, mais elle n'est jamais actualisée: Claris et Laris est le seul roman de notre corpus à figurer côte à côte avec une chanson de geste, qui n'en est pas vraiment une du point de vue de sa diégèse. Le registre épique, par son intégration harmonieuse aux romans, infléchit néanmoins la généricité du texte sans pour autant en transformer complètement la réception.

Le caractère épique de certains romans tardifs devient dès lors une composante de cette nouvelle esthétique ${ }^{358}$. Destinée peut-être à favoriser les entreprises guerrières dans la réalité contemporaine, l'esthétique épique est aussi un moyen de contraster avec les premiers romans arthuriens en vers qui privilégient le duel sur la guerre collective. En tendant vers l'épopée, le roman arthurien en vers rejoint en quelque sorte le Brut dans sa manière de présenter l'histoire arthurienne, constituée de guerres menées par un dux bellorum. Le roman tardif enrichit alors la présentation du monde arthurien, habituellement statique dans le vers, pour le

356 Voir Anne Berthelot, "Berte as grans piés et l'abolition des frontières génériques chez Adenet le Roi», Cahiers de recherches médiévales, 18, 2009, en ligne: https:// journals.openedition.org/crm/11718?lang=it.

357 À la fin du recueil, une inscription d'une main légèrement plus tardive donnait le nom d'un propriétaire. Ce nom a été gratté. Il n’en reste que: "Ce livre est [...] demourant a Rouen en la paroisse Saint [...]». Voir Claris et Laris, éd. cit., p. 59.

358 Cet aspect rapproche le roman tardif, une fois encore, des romans en prose, qui introduisent eux aussi l'esthétique épique. Voir par exemple Marion Bonansea, "La guerre dans la Mort Artu: hybridation générique et clôture romanesque», art. cit. 
dynamiser et lui donner une dimension historique en le montrant dans ses interactions avec les pays voisins ou sarrasins.

\section{Imitation ponctuelle: Escanor et le miraculeux}

La fin d'Escanor offre une confluence générique moins diffuse que celle qui concerne l'esthétique épique, ce qui témoigne peut-être de l'incompatibilité du registre miraculeux auquel elle recourt avec le roman arthurien. L'épisode final (v. 24501-25938) se désolidarise en effet totalement et brusquement du registre du début du roman, c'est pourquoi Alexandre Micha la qualifie de "postiche» ${ }^{359}$, avis que rejoint Richard Trachsler, pour qui «elle n'est pas préparée, rien ne l'amène, et par conséquent elle sonne faux ${ }^{360}$. Il y a bien une rupture de registre dans ces pages, plus proche de l'hagiographie ${ }^{361}$ et d'écrits d'obédience religieuse que de la littérature courtoise. Le registre miraculeux ${ }^{362}$ est en effet inhabituel dans le roman arthurien en vers: le surnaturel est païen et, bien que Dieu ne soit pas absent, il est rare qu'il se manifeste réellement autrement qu'en donnant un surcroît de force au chevalier au moment opportun.

On quitte alors le domaine de l'aventure chevaleresque: cette fin de roman est une "sainte aventure» (v. 25217), comme l'exprime le narrateur au moment où l'ermite enterre Escanor le Bel, recadrant ainsi l'aventure arthurienne conventionnelle. On pense bien sûr à la Queste del saint Graal, qui reconfigure également les fondements de l'errance arthurienne en ce

359 Alexandre Micha, "Escanor", in Grundriß der romanischen Literaturen des Mittelalters. Le Roman jusqu’à la fin du XIII siècle, IV/1, Heidelberg, Carl Winter, 1978, p. 397.

360 "De la prose au vers: le cas de Dynadan dans l'Escanor de Girart d'Amiens", art. cit., p. 409.

361 Pour une définition du genre hagiographique, voir Françoise Laurent, Plaire et édifier. Les récits hagiographiques composés en Angleterre aux XII et XIII siècles, Paris, Champion, 1998.

362 Nous distinguons le miraculeux, que nous percevons comme un registre, et le miracle au sens générique, qui désigne un genre théâtral particulier. Michelle Szkilnik problématise la question du miracle, entendu comme genre narratif bref issu de la dilatation d'un scénario ponctuel - ce que nous appelons registre. Voir "Conclusion", in Miracles d'un autre genre. Récritures médiévales en dehors de l'hagiographie, dir. Olivier Biaggini et Bénédicte Milland-Bove, Madrid, Casa de Velázquez, 2012, p. 309-314. 
$\operatorname{sen}^{363}$. On pense aussi à l'hagiographie, par l'invocation du vocabulaire lié à la sainteté. Enfin, les conditions dans lesquelles le registre miraculeux est introduit dans le roman tardif, c'est-à-dire la décision d'Escanor de se faire ermite pour expier ses péchés et prier pour sa femme, rappellent les moniages des chansons de geste. Ces influences littéraires diverses se manifestent du point de vue structurel, thématique rhétorique et idéologique; c'est ainsi que l'arrière-plan religieux d'Escanor se construit.

Les moniages, ces moments où le guerrier se retire dans une abbaye après une vie de combat, informent structurellement cette fin de roman. Le parallèle se justifie surtout lorsque l'on considère le début de la séquence dans Escanor: le guerrier épique se retire souvent suite à la mort de son épouse, tel Guillaume qui se fait ermite après la mort de Guibourc dans le Moniage Guillaume, modèle en ce genre ${ }^{364}$. Escanor est quant à lui éploré de la perte de sa femme, que le texte n'a eu de cesse de louer de même que l'amour réciproque qu'ils se portaient. Le moniage est une manière de clore le cycle autour de Guillaume, de donner une fin à la carrière chevaleresque du guerrier, tout comme l'ermitage d'Escanor met un terme à son histoire et à ses interactions avec le monde arthurien.

Le moniage d'Escanor se distingue toutefois de ceux des chansons de geste, où le héros a souvent de la peine à s'intégrer à l'univers monastique: Guillaume aussi bien que Rainouart adoptent des comportements inadéquats en gardant leurs armes et sont rejetés par les autres moines, ce qui donne lieu à des passages comiques qui ridiculisent quelque peu le guer$\operatorname{rier}^{365}$. Les moniages ne sont pas l'occasion de glorifier la vie contemplative,

363 Jean-René Valette, "La Queste del Saint Graal, une hagiographie en semblance: défi laïque et spiritualité décléricalisée ", Les Dossiers du Gribl [En ligne], 01, 2015, mis en ligne le 03 décembre 2015, consulté le 17 janvier 2019. URL: http://journals.openedition.org/dossiersgrihl/6324, et La Pensée du Graal. Fiction littéraire et théologie (XII-XIII siècle). Selon le critique, les Hauts Livres du Graal se présentent comme des fictions théologiques, c'est-à-dire «des récits fictifs qui font intervenir, pour se constituer, une part de théologie» (p. 35).

364 Comme pour Escanor, les visions font partie de l'atmosphère de ce texte, puisqu'un ange apparaît au chevalier et lui ordonne de rejoindre un cloître, puis un autre lui commande de quitter ce lieu pour rejoindre un ermitage.

365 Voir David P. Schenck, "Le comique et le sérieux dans le Moniage Guillaume et le Moniage Rainouart», in Les chansons de geste du cycle de Guillaume d'Orange. Hommage à Jean Frappier. Tome III: Les moniages Guibourc, dir. Philippe Ménard et Jean-Charles Payen, Paris, Société d'édition d'enseignement supérieur, 1983, p. 239-259, et Jean Frappier, "Le Moniage Guillaume», in Les chansons de geste du 
mais ils sont plutôt le lieu de la bouffonnerie et d'une opposition entre moine et ermite au profit de celui-ci ${ }^{366}$. La vie érémitique, contrairement à la vie monastique, est compatible avec la lutte contre les Sarrasins et ne se réduit pas à la prière. Le parallèle que l'on peut faire entre Escanor et les moniages a donc ses limites, et concerne surtout la structure de cette fin.

Escanor cesse effectivement toute activité chevaleresque. Il ne devient pas un miles christi comme l'est Galaad, ni un ermite qui continue à combattre le Sarrasin comme Guillaume, mais se dédie entièrement à la prière. Alors qu' «aucun moniage n'est attendu des héros" dans la Queste del saint Graal et que du début à la fin, Galaad y reste un chevalier ${ }^{367}$, dans Escanor, le personnage accomplit un moniage complet, abandonne son état de chevalier pour devenir exclusivement un ermite. Dans ce roman tardif intervient la même collision entre chevalerie et religieux que l'on trouve dans la Queste del saint Gral $^{368}$, à cette différence près que les deux dimensions alternent et ne se mêlent pas: la quasi totalité du roman est un roman de chevalerie et seule la fin rompt avec la laïcité. L'intertexte privilégié est peut-être alors moins la Queste que la Mort Artu, où Lancelot abandonne finalement les armes, devient prêtre, expie ses péchés, puis est emmené au Ciel par des anges ${ }^{369}$. Toutefois, Escanor n'imite pas l'atmosphère de fin du monde inhérente au retrait de Lancelot: aucun arrière-fond d'apocalypse ne sous-tend la mort d'Escanor. Il est le seul à mourir de cette façon et, ainsi que nous l'avons montré aux pages 250-260, seule la temporalité qui

cycle de Guillaume d'Orange. Hommage à Jean Frappier. Tome III: Les moniages Guibourc, dir. Philippe Ménard et Jean-Charles Payen, Paris, Société d'édition d'enseignement supérieur, 1983, p. 19-83. Ce dernier article présente les deux versions divergentes du Moniage Guillaume.

366 Micheline de Combarieu, "Ermitages" épiques (de Guillaume et de quelques autres)", in Les chansons de geste du cycle de Guillaume d'Orange. Hommage à Jean Frappier. Tome III: Les moniages Guibourc, dir. Philippe Ménard et Jean-Charles Payen, Paris, Société d'édition d'enseignement supérieur, 1983, p. 143-180.

367 Nous citons puis paraphrasons ici Jean-René Valette, "La Queste del Saint Graal, une hagiographie en semblance: défi laïque et spiritualité décléricalisée », art. cit., $\$ 13$.

368 Jean Frappier, "Le Graal et la chevalerie», in Jean Frappier, Autour du Graal, Genève, Droz, 1977, p. 89-128.

369 Voir Francis Dubost, "Fin de partie: les dénouements dans La Mort le roi Artu», in La Mort du roi Arthur ou le crépuscule de la chevalerie, dir. Jean Dufournet, Paris, Champion ("Unichamp»), 1994, p. 85-111, et Jean Frappier, Étude sur la Mort le Roi Artu, p. 240-246. 
affecte ce personnage devient linéaire, ce qui l'extrait de la temporalité cyclique propre au chronotope du roman en vers.

Celle-ci continue d'affecter les personnages arthuriens de ce roman, au sujet desquels le narrateur préfère ne rien ajouter, car il n'a pas appris leur mort (v. 25910-25912). L'entourage d'Escanor ne cesse donc pas de porter les armes et échappe au destin érémitique. Néanmoins, en cherchant Escanor, son oncle se bat dans des conditions semblables à celles auxquelles sont confrontés les chevaliers christiques de la Queste. Il reçoit de Dieu la force de vaincre les bêtes féroces qui peuplent la forêt alentour:

Et ainsi le consenti Diex,

Qui sens et force l'en livra

Que le bois si en delivra

C’on i ala bien asseür. (Escanor, v. 25526-25529)

Le combat est soutenu par la grâce divine et s'apparente ainsi à une victoire contre les forces du mal. Affronter des bêtes sauvages ressemble moins ici aux combats contre les fauves des romans arthuriens en vers classiques qu'à une épreuve d'origine diabolique issue d'une idéologie religieuse $\mathrm{e}^{370}$.

Escanor le Grand n'est toutefois pas un élu, jugé digne de recevoir ce type de gratification: c'est avant tout la mission qu'il s'est donnée de trouver Escanor le Bel qui lui donne ce surcroît de force. L'irradiation d'Escanor, qui transmet sa grâce à son entourage mais aussi et surtout au lieu qu'il occupe, est une caractéristique propre aux saints des hagiographies, ainsi que l'expriment Jean-René Valette et Patrick Henriet:

Le discours hagiographique valorise classiquement des lieux associés à des saints qui y ont vécu ou/et y sont enterrés ou/et y accomplissent des miracles. Ces lieux polarisent un espace sacré que l'on peut

370 L'ermitage du saint dans la Vie de Saint Gilles est aussi placé dans une forêt peuplée de bêtes sauvages: ours, lions, cerfs, daims, sangliers, éléphants, bêtes cornues, tigres, serpents et sagittaires (Guillaume de Berneville, La Vie de saint Gilles, éd. Françoise Laurent, Paris, Champion ("CCMA»), 2003, v. 1229-1238). Ce bestiaire réel et fantaisiste invite à rêver à des terres lointaines, exotiques. Sans doute faut-il aussi y lire l'isolement du lieu et la protection divine qui entoure le saint. Voir à ce sujet Françoise Laurent, Plaire et édifier. Les récits hagiographiques composés en Angleterre aux XII et XIIT siècles, p. 499-508. 
considérer comme hétérogène et sont gérés par des communautés qui ont construit leur identité autour de la personne du saint patron ${ }^{371}$.

L'ermitage où est enterré Escanor est désigné comme un "saint lieu» (v. 25607) et devient le théâtre de miracles, touché qu'il est par la grâce qu'offre la présence du saint Escanor, dont le cadavre est qualifié plusieurs fois de "saint cors» (v. 25215 et 25766). Parmi ces miracles, un cercueil apparaît miraculeusement pour y recevoir le corps du saint, ce que l'ermite présent qualifie de "miracle de Dieu» (v. 25197). Ce même ermite, pourtant déjà âgé, voit ensuite ses forces s'accroître miraculeusement pour lui permettre d'enterrer Escanor, puis c'est au tour de l'abbé qu'Escanor le Grand vient consulter d'avoir une vision lui indiquant l'endroit où se trouve le saint. Le lieu est si saint que la quête d'Escanor le Grand pour le retrouver est qualifiée de "pelerinage» (v. 25428) et de "saint voiage» (v. 24642). On ne pourrait faire une plus claire allusion au culte des saints, et donc au registre hagiographique.

L'intégration de ce registre affecte le statut du merveilleux, qui n'est plus le merveilleux d'altérité habituellement travaillé par le roman arthurien en vers, mais un merveilleux transcendantal ${ }^{372}$. Ce type de merveilleux, inspiré de l'hagiographie, est déjà celui que favorise la Queste del saint Graal; Girart d'Amiens transforme alors in extremis le rapport au surnaturel, plus proche, dans la fin du roman, de celui des proses du Graal que du vers. La façon de présenter les divers miracles qui se manifestent depuis le moniage d'Escanor respecte la rhétorique propre à l'hagiographie ${ }^{373}$. Ainsi, les bêtes sauvages n'inquiètent pas l'abbé, protégé qu'il est par sa foi, comparée à une armure:

Et si ert nus et desgarnis,

Mais de la foi estoit garnis,

371 "Perlesvaus et le discours hagiographique», Revue des Langues Romanes, 118/1, 2014, p. 75.

372 Selon la distinction de Dominique Boutet, "Merveilleux et interférences génériques dans la chanson de geste de Tristan de Nanteuil», art. cit. Jean-René Valette applique cette distinction à la littérature du Graal dans «Les Hauts Livres du Graal et la poétique des genres", art. cit.

373 D'autres commentaires illustrent l'adoption de tournures d'inspiration biblique par le narrateur: «Dieu, qui l'ot formé a s'ymage» (v. 24929), "Dieu le Pere / Et sa tres glorieuse mere» (v. 25189-25190). 
Une armeüre si seüre

Que mal ne crient ne bleceüre

Que male beste li puist faire. (Escanor, v. 25541-25545)

La métaphore guerrière, associée à la foi, est courante dans l'hagiographie. On la trouve par exemple dans la Vie de Saint Alban:

Martir glorius! jo vus quier e demant

Ke ceus k'en cest mund vus sunt honurant,

Servant e ami e vostre bienvoillant,

Soiez cuntre diable lur escu e guarant

Ke sauf soium; si en dient «amen!» veil e enfant ${ }^{374}$.

L’emprunt de la rhétorique hagiographique et du miraculeux va de pair avec celui de son idéologie. La métaphore de l'écu ou de l'armure illustre l'idée que le croyant est récompensé de sa foi, protégé des dangers extérieurs, ici les bêtes sauvages, symboles des forces diaboliques. C'est aussi le message que transmettent les anges à Escanor, lorsqu'ils viennent chercher le corps du premier ermite:

Et li sambla qu'il vit entor

Le preudome grant plenté d'angles

Et par deseure les archangles

Qui compaingnie li faisoient

Et souventes fois li disoient

Que de riens ne s'espoentast

Et en avant ne se doutast

D'issir de ceste mortel vie,

Car Diex avoit de s'ame envie. (Escanor, v. 24844-24852)

L'évocation de la "mortel vie», l'invitation à ne pas craindre la mort et l'assurance que Dieu désire recevoir son âme rappellent les passages hagiographiques qui appellent l'auditeur à se préoccuper de la vie après la mort. Le saint dont on raconte la vie doit valoir comme modèle en ce sens, lui qui s'est employé à prier pour ses péchés et à mener une bonne vie; Escanor en est un autre exemple, tel qu'il est présenté dans son roman.

374 La Vie de seint Auban. An anglo-norman poem of the thirteenth century, éd. Arthur R. Harden, Londres, ANTS, 1968, v. 1762-1766. 
L'exemplarité est un autre trait définitoire de l'hagiographie que reconnaissent Jean-René Valette et Patrick Henriet:

Le discours hagiographique a toujours une dimension exemplarisante, ou si l'on préfère parénétique. Que le saint soit admirable et imitable, ou seulement admirable, le texte hagiographique est pédagogique et vise à modeler les comportements ${ }^{375}$.

Les interventions narratoriales sont en ce contexte particulièrement importantes pour accentuer l'exemplarité du personnage mis en scène ${ }^{376}$. Le narrateur d'Escanor ne manque pas de commenter sa diégèse en respectant la rhétorique hagiographique et en renforçant le caractère exemplaire de son récit:

Par coi chascuns doit avoir fin

Le cuer de deservir tel don,

Car si grassieus guerredon

$\mathrm{Ne}$ puet nus rendre que Dieus fait

A celui qu'il prent sanz meffait. (Escanor, v. 24912-24916)

L'instance narrative parle ici de la mort du premier ermite, dont l'âme est accueillie au ciel. Il délivre un message moral qui s'adresse aussi au lecteur, appelé à imiter le saint homme et à se préoccuper de son âme pour recevoir le guerredon de Dieu, terme que l'on retrouve dans certaines hagiographies, la Vie de Saint Alban de Matthieu Paris par exemple ${ }^{377}$. La sanctification d'Escanor est aussi qualifiée en termes de gratification accordée: Dieu le récompense de son service, «Car il li fist si noble don / C'avoec ses sains le corona» (v. 25164-25165).

Comme dans l'hagiographie, l'exemplarité des personnages permet de transmettre un message moral: celui de mener une bonne vie sur terre afin d'en être recompensé au ciel, d'où la mention de la «mortel vie».

375 "Perlesvaus et le discours hagiographique», art. cit., p. 75. Les critiques relèvent cinq critères qui, ensemble, créent un discours hagiographique. Ils distinguent «discours» et «motifs» hagiographiques, ces derniers pouvant se manifester hors de la combinatoire, dans des textes d'autres genres. C'est ce dernier cas qui se produit dans Escanor.

376 Au sujet du narrateur dans l'hagiographie, voir Françoise Laurent, Plaire et édifier. Les récits hagiographiques composés en Angleterre aux XII et XIII siècles, p. 41-166.

377 "Ki seisiz estes ja du guerdun desirable [...]», La Vie de seint Auban, éd. cit., v. 1046. 
L'épilogue d'Escanor imite ces exhortations hagiographiques, fréquentes à la fin des textes:

La bone vie est li hauteche

Et la noblece de ce monde,

Car qui rent l'ame nete et monde

A Dieu, cil est fins eüreus,

Riches et bons aventureus;

Car je puis bien dire en apert

Que cil n'est pas riches qui pert

La digne glore au roi celestre

Por ce mauvais siecle terrestre.

Et Diex nouz doinst tous si ouvrer

Que ce que li devons livrer

A son doutable jugement

Li puissons rendre dignement! (Escanor, v. 25926-25938)

Cet épilogue ne ressemble en rien à ceux des romans arthuriens en vers: il adopte au contraire les traits d'une moralisation, qui encourage les lecteurs à imiter le saint dont on a raconté la vie et à se préoccuper du salut de l'âme et de la vie après la mort. La distinction entre vie terrestre et vie céleste est très forte dans ce texte: le narrateur et les personnages parlent de «cest vil siecle» (v. 240878), disent que «ceste vie n'est c'ordure / Et dampnemens de cors et d'ame» (v. 25042-25043). L'épilogue de la Vie de saint Gilles peut en ce sens être comparé à celui d'Escanor:

Or voil finir icest escrit:

Deus, si lui pleist, ne nus oblit,

Ke al jur de la grant juise,

Quant nus serrum al cele assise,

Ke nus i seiuns, si li pleist,

E k'il tut di iloc nus leist

$\mathrm{U}$ ses amis erent enclin,

La u joie n'avera fin,

Si nus defent de la dolur

$\mathrm{U}$ il plurent e nuit e jur,

Ceo est enfern; gardez vus i:

Iloc n'avra fors plur e cri;

Deus nus desfent ke nus n'entrum!

Amen dites tut envirun. (Vie de saint Gilles, v. 3781-3794) 
Dans Escanor comme dans la Vie de saint Gilles, le narrateur évoque le jugement de Dieu et la vie après la mort. Le cadre de ce discours est aussi commun aux deux textes: l'hagiographie se termine souvent sur une prière. Dans Escanor, elle commence par une formule convenue: "Ainz pri Dieu qu'il gart ceuz de honte / Qui ce romant escouteront. (v. 25912-25913), formule que l'on trouve aussi dans l'Estoire de seint Aedward le Rei: "Pri Deu k'après ceste vie / Eu regne celestïen / Regner pusse of vu. Amen. »"

La prédication est renforcée par l'ajout d'un «amen» à la fin d'Escanor ${ }^{379}$. Ce mot signifiant «ainsi soit-il» peut désigner la fin d'un récit ou d'un discours doxologique: il est en tous les cas fortement connoté religieusement ${ }^{380}$. Prononcer un «amen » à la fin de son récit n’est pas si rare dans la littérature narrative des $\mathrm{XII}^{\mathrm{e}}$ et $\mathrm{XIII}^{\mathrm{e}}$ siècles: ce prêche est encouragé par un épilogue fournissant une moralisation religieuse. Amen couronne en particulier les épilogues de vies de saint, comme l'illustrent les exemples cités ci-dessus ${ }^{381}$. Bien que le mot «amen » caractérise surtout l'hagiographie, la littérature profane en fait aussi usage: l'épilogue de la Manekine propose une harangue chrétienne, qui présente l'histoire de la Manekine comme un exemplum et invite les lecteurs à garder foi en Dieu pendant plus de cinquante vers. Les dernières phrases incitent à prier Dieu et à dire «amen» :

Et vous, priiés Dieu qui tout voit

Que Il celui grant joie otroi

378 La Estoire de seint Aedward le Rei, éd. Kathryn Y. Wallace, Londres, ANTS, 1983, v. 3972-3974. Sur les prières dans les hagiographies, voir Françoise Laurent, Plaire et édifier. Les récits hagiographiques composés en Angleterre aux XII et XIII siècles, p. 221-231.

379 Ce mot est transcrit après la dernière ligne de la dernière colonne du manuscrit BnF fr. 24374. Il n'apparaît pas sur le microfilm, car une feuille a été colée pardessus. On ne le déchiffre donc qu'en transparence, par une consultation directe du manuscrit.

380 Walther von Watburg, FEW, Bâle, Zbinden, 1968, t. 20, p. 24.

381 On peut encore citer la Vie de Saint Thomas: "Amen, amen verraiment" (La vie de saint Thomas Becket par Beneit, poème anglo-normand du XII siècle, éd. Borje Schlyter, Lund, Études romanes de Lund, 1941, v. 2125), ou celle de Sainte Foi: "Amen, amen, trestuz dium» (Alfred T. Baker, "La Vie anglo-normande de sainte Foi par Simon de Walsingham", Romania, 66, 1931, p. 49-94, v. 1242). Françoise Laurent donne de nombreux autres exemples aux pages 221 à 231 de Plaire et édifier. Les récits hagiographiques composés en Angleterre aux XII et XIII siècles. 
Qui de penser se vaut limer

Pour la Manequine rimer.

Dix li doinst joie et bone vie!

Amen cascuns de vous en die.

Ici endroit Phelippes fine

Le rommant de la Manekine ${ }^{382}$.

Le «amen» est intégré dans cet exemple comme dans celui de la Vie de saint Gilles cité plus haut et dans plusieurs vies de saints à une phrase d'adresse au public, qui l'encourage à prononcer collectivement un "amen". Le mot peut ainsi faire office, selon Françoise Laurent, de "signe de ralliement» qui participe à une identité communautaire et renforce le sentiment de communion ${ }^{383}$. Le registre religieux est largement exploité tout le long de la Manekine ${ }^{384}$, ce qui rend cette conclusion moins étonnante qu'elle ne l'est dans Escanor.

On peut en dire autant du "amen" qui termine l'Estoire de la guerre sainte: le contexte historiographique de la croisade est indissociable d'un arrière-fond religieux, qui se prête dès lors parfaitement à une conclusion en "amen». Le mot "amen" clôt néanmoins d'autres textes laïcs, Galeran de Bretagne, Huon de Bordeaux et Blandin de Cornouailles par exemple. Dans ces deux derniers cas, le terme intervient isolément après quelques phrases d'exhortation religieuse:

Li Roy dou cielz, per sa sainte piteit,

Nous dont sa graice, se il li vient en grey.

(Huon de Bordeaux, v. 10796-10797)

E pregas Dieus che ayssi vos prenna

E che ve don la bonna strenna. (Blandin, v. 2393-2394)

Il semble donc bien qu'en recourant au mot "amen» au lieu de "explicit» pour terminer son roman, Girart d'Amiens recadre la lecture d'Escanor dans une perspective religieuse.

382 Philippe de Rémi, La Manekine, éd. cit., v. 8583-8590.

383 Françoise Laurent, Plaire et édifier. Les récits hagiographiques composés en Angleterre aux XII et XIII siècles, p. 221.

384 Marie-Madeleine Castellani, "Philippe de Remi ou la tentation du sermon», in La volonté didactique dans la littérature médiévale, dir. Sarah Baudelle-Michels et Marie-Madeleine Castellani, Bien dire et bien aprandre, 29, 2014, p. 139-149. 
Le contexte courtois qui prévalait jusque-là est en effet reconfiguré, sans pour autant disparaître. Certains développements convenus dans le roman arthurien sont alors explicitement désignés comme inadéquats. Lorsqu'elle apprend la mort d'Escanor, la reine des Traverses est si triste que "de duel faisoit desmesure» (v. 25817). La représentation d'une douleur extrême est courante dans le roman arthurien, sur le modèle ovidien antique; le lecteur se souvient d'ailleurs de celle que manifestent les sujets d'Escanor le Bel lorsqu'ils le croient mort après l'attaque de Galantinet («la grande destrece / De lour duel et lor grant tristrece», v. 8493-8494). Ici, la réponse convenue qu'offre la reine des Traverses à l'annonce de la mort d'Escanor n'est pas adaptée à la situation, comme le lui reproche Gifflet:

Mais Giflés, ou mout ot mesure,

Mout tres durement l'en blasma

Et droite fole l'en clama,

Quant tel duel faisoit sanz raison;

Car s'il i eüst achoison,

N'en fust mie tant courechiez. (Escanor, v. 25818-25823)

Ces remontrances se justifient par la nouvelle atmosphère mise en place en cette fin de roman: la reine apparait comme une impie de se plaindre de la mort d'Escanor, alors que celle-ci s'accompagne de miracles et de la sanctification du personnage. Cette mort est donc "si eüreuse, si douce [et] si pressieuse» (v. 25829-25830) qu'il est indécent de la pleurer, "Car ceste mors doit a toz plaire, / C'est mireoirs d'examplaire / A tous ceuz qui croient en Dieu" (v. 25832-25833). Sa fonction d'exemple, explicitement évoquée, sert à témoigner de la manifestation de la miséricorde divine et doit encourager la foi des autres personnages.

La fin'amor fait elle aussi l'objet d'un réinvestissement religieux. Escanor ne se fait pas ermite par simple conviction chrétienne, mais surtout en raison du deuil qu'il mène pour sa femme. C'est donc d'abord un mal d'amour qui conduit au moniage. La consolation que lui propose Gifflet exprime l'inéluctabilité de la mort et l'exhorte à penser à son salut, à expier ses péchés au lieu de pleurer ses morts:

«A endurer ceste bataille

Nous covient dont vencu seromes;

Et selonc que nouz fait aronmes,

Nous en rendra Dix la deserte.» (Escanor, v. 24614-24617) 
L'idéologie d'une vie après la mort qui récompense ou punit toute «creature humaine» (v. 24621) est constante dans la fin d'Escanor, comme nous l'avons vu, de même que la doctrine chrétienne qui présente l'être humain comme une créature imparfaite dont le corps est éphémère, mais l'âme éternelle. Ce discours est d'autant plus remarquable que dans le roman arthurien traditionnel, la souffrance due à l'amour encourage l'amélioration du chevalier, prêt à se dépasser pour son amie, et n'appelle pas une consolation divine.

L'amour terrestre mène donc naturellement et sans contradiction à la grâce, et vient compléter l'amour de Dieu, donnant lieu à plusieurs collisions. À la place d'anges ou de la Vierge, c'est sa femme qu'Escanor voit au cours d'une "avision» (v. 25141) miraculeuse. L'imitation de l'hagiographie ne va pas sans quelques distorsions concédées à l'idéal courtois, qui dévoient quelque peu l'idéal religieux. L'emprunt du registre hagiographique et du thème des visions n'est donc pas une copie sèche, mais une tentative de conciliation avec les codes clés du roman arthurien. L'épitaphe d'Escanor met alors l'accent autant sur son amour que sur sa foi exceptionnelle:

Sor le cors saint letres escrist [l'ermite],

Le non du roi et l'amor fine

Qu'il ot vers la douce roïne. (Escanor, v. 25220-25222)

Cette inscription valorise l'amour pur qu'il éprouvait pour sa reine, la rime «fine-roïne» accentuant encore cette dimension. Elle est complétée plus loin par la piété du personnage:

[Escanor le Grand] Vit un escrit qui devisoit

Son non et dont il estoit nez

Et conment il s'estoit menez

El service le roi celestre.

Sa vie vit et tout son estre,

Conment Diex l'avoit espiré

Et en la fin tant honeré

Qu'en ses douces mains reçut l'ame

Dou saint cors qui ert soz le lame. (Escanor, v. 25656-25664)

L'épitaphe est chargée symboliquement: elle détermine ce qui restera dans la postérité, la trace que laissera Escanor sur terre. Il peut s'agir d'une réminiscence de la Mort Artu, où les épitaphes sont nombreuses et donnent un 
point de vue sur le défunt, appellent à la vengeance ou réunissent deux personnages. Être enterré avec un autre personnage oriente également la perspective qu'il faut poser sur celui dont parle l'épitaphe: Lancelot est enterré avec Galehaut et non avec Guenièvre, pour souligner sa chevalerie - il est «li mieldres chevaliers qui onques entrast el roiaume de Logres» $\left(\$ 252^{385}\right)$ - plus que son amour adultère, cause de la chute du royaume. Gauvain et Gaheriet sont réunis dans la tombe pour traduire l'importance du lignage dans la prose et surtout celle des vengeances familiales, celle due ici à la démesure de Gauvain ${ }^{386}$. Escanor est quant à lui enterré avec sa femme, dont on déplace le corps pour qu'il rejoigne le lieu rendu saint par son époux: dans ce cas aussi, cette réunion dans un même tombeau traduit l'amour parfait qu'éprouvait le héros éponyme et sa compatibilité avec la doctrine chrétienne. L'épitaphe achève de consacrer la perfection d'Escanor, amoureuse, religieuse, mais aussi chevaleresque et royale.

Les échos transtextuels ${ }^{387}$ sont nombreux dans cette fin de roman; l'imitation du registre religieux s'inspire à la fois de la Mort Artu pour les épitaphes, de l'hagiographie et des proses du Graal, la Queste del saint Graal ${ }^{388}$ et l'Estoire del saint Graal, qui se hisse à la hauteur d'un écrit

385 La Mort du Roi Arthur, éd. Emmanuèle Baumgartner et Marie-Thérèse de Medeiros, Paris, Champion ("CCMA»), 2007.

386 Voir Philip E. Bennett, «Once and Future Monuments: Knights' and Lovers' Tombs in Medieval French Romance», in "Moult a sans et vallour». Studies in Medieval French Literature in Honor of William W. Kibler, dir. Monica L. Wright, Norris J. Lacy et Rupert T. Pickens, Amsterdam; New York, Rodopi, 2012, p. 1-19, et Régine Colliot, "Les Épitaphes arthuriennes», Bulletin bibliographique de la Société internationale arthurienne, 25, 1973, p. 155-175.

387 Au sens où l'entend Gérard Genette: tout ce qui met un texte en relation avec d'autres textes. Palimpsestes.

388 Le parallèle que l'on peut faire entre Escanor et la Queste a été souligné par Alexandre Micha, "Escanor", in Grundriß der romanischen Literaturen des Mittelalters, art. cit. On peut encore mentionner l'inscription qui détaille les événements qui se sont produits dans l'ermitage d'Escanor: la mort des deux ermites, les miracles, la mort d'Escanor, etc. Cette inscription rappelle celles qui parsèment la Queste del saint Graal, qui ont toujours une fonction exégétique. De même, l'importance du personnage de l'ermite dans la Queste est manifeste. La présence d'ermites dans la fin d'Escanor est dès lors là aussi liée au roman en prose. Escanor rejoint un ermitage, enterre l'ermite qui l'occupe, est rejoint par deux autres ermites, puis est enterré par l'un de ces derniers. Au sujet des ermites dans la Queste, voir Robert Deschaux, "Le personnage de l'ermite dans la Queste del saint Graal et dans Le Haut Livre du Graal: Perlesvaus", in Actes du $14^{e}$ congrès 
apocryphe ${ }^{389}$. Le lien que l'on peut établir avec la Queste concerne également le déroulement rhétorique. Le narrateur emploie la dyade demostrance - senefiance lorsqu'il évoque la faveur en laquelle est tenu Escanor auprès de Dieu :

[...] Diex pas perdre ne voloit

Le Bel Escanor, quant l'aloit

Visitant par tel demostrance,

Ançois estoit senefiance

Qu'il avoit grant partie en lui. (Escanor, v. 25051-25055)

Le couple demostrance - senefiance fait partie de l'exégèse chrétienne arthurienne depuis la Queste del saint Graal ${ }^{390}$. Il désigne la manifestation divine à un élu, toujours accompagnée d'une interprétation, d'une signification, à caractère souvent moral. Ainsi que l'exprime Jean-René Valette, «ce qui scelle donc fondamentalement le lien qui unit la senefiance et la demostrance, c'est la notion de révélation, l'idée d'un Dieu dont la puissance réside notamment dans le demoustrement»" ${ }^{391}$. Ici, la senefiance

international arthurien, Rennes, PUR, 1985, p. 172-183, et Pierre Jonin, «Des premiers ermites à ceux de La Queste del Saint Graal», Annales de la Faculté des Lettres et Sciences Humaines d'Aix, 44, 1968, p. 326-350.

389 Voir Marie-Christine Bracconi-Giordano, «Le merveilleux chrétien dans les écrits apocryphes chrétiens et dans l'Estoire del Saint Graal: éléments de comparaison ", in "Furent les merveilles pruvees et les aventures truvees". Hommage à Francis Dubost, dir. Francis Gingras, Françoise Laurent, Frédérique Le Nan et Jean-René Valette, Paris, Champion ("Colloques, congrès et conférences sur la Renaissance», 6), 2005, p. 83-100, Michelle Szkilnik, Archipel du Graal. Étude de lEstoire del Saint Graal, Genève, Droz, 1991, Mireille Séguy, Le livre monde. L'Estoire del Saint Graal et le cycle du Lancelot-Graal, Paris, Champion, 2017, et «La merveille du Graal à l'épreuve de la "vérité" de l'Estoire del Saint Graal”, art. cit.

390 Voir Emmanuèle Baumgartner, "The Queste del saint Graal: from semblance to veraie semblance», art. cit., L'arbre et le pain. Essai sur la Queste del saint Graal, Daniel Poirion, "Semblance du Graal dans la Queste», art. cit., et Jean-René Valette, La Pensée du Graal. Fiction littéraire et théologie (XII-XIII siècle), p. 280-302. Les aventures qui surviennent sont ainsi «les senefiances et les demostrances dou Saint Graal» (Queste del saint Graal, éd. cit., p. 160-161). Divers personnages habilités à interpréter les signes divins fournissent autant de senefiances: "Cele qui sor le lyon estoit montee senefie la Novele Loi”" (p. 101), dit à Perceval l'homme de religion qui interprète son rêve.

391 Jean-René Valette, La Pensée du Graal. Fiction littéraire et théologie (XII'-XIII siècle), p. 286. 
concerne la pureté d'Escanor, qu'a démontrée la vision des anges dont il a été gratifié. La fin du roman présente en effet l'opposant à la cour d'Arthur comme un homme dénué de tout péché. L’ermite qui le confesse ne perçoit ainsi aucune once de vice, il «le vit net durement / Et si pur que certainement / Connut qu'il amoit Dieu le Pere / Et sa glorieuse mere" (Escanor, v. 25081-25084). La confession ne fait aucune allusion aux forfaits du personnage lors de son conflit contre Gauvain. Le lecteur en oublie presque qu'Escanor le Bel a calomnié Gauvain en l'accusant à tort et qu'il a fait emprisonner Gifflet pour affronter le neveu du roi. La conversion de l'opposant à la cour d'Arthur est donc totale: il ne s'agit pas seulement d'une réconciliation entre lui et les membres de la cour arthurienne, mais d'une véritable caution accordée par la grâce divine.

La relation que l'on peut établir entre Escanor et les textes en prose est cohérente, par rapport à l'influence du roman en prose sur le roman en vers tardif que l'on a soulignée au cours de l'étude. Toutefois, il s'agit cette fois d'un registre étranger au roman arthurien, qui traduit déjà la christianisation d'un univers dans le roman en prose. Intégrer ce registre in extremis n'exprime donc pas seulement la volonté d'imiter les prosateurs de la part de Girart d'Amiens, mais celle surtout de travailler l'hétérogénéité afin de christianiser à son tour le chronotope du roman en vers. Comme l'écrit Richard Trachsler, Girart semble avoir tenté «durch den Einbau einer religiösen Perspektive seinem Roman etwas von der Tiefe eines Prosaromans in der Art der Queste zu verleihen " 392 . Cette perspective religieuse et sérieuse induit nécessairement la temporalité linéaire adoptée par le roman, d'où le caractère postiche de l'épisode: la linéarité et la profondeur d'un message chrétien sont incompatibles avec le roman en vers. C'est ce que déduit Richard Trachsler:

Mais nous avons aussi vu que sa façon [celle de Girart d'Amiens] de réemployer des éléments repris aux cycles en prose traduisait en même temps une grande incompréhension à l'égard du fonctionnement de

392 "Escanor von Girart d'Amiens im Spannungsfeld von Vers und Prosa", art. cit., p. 267. Girart a tenté «de prêter à son roman la profondeur des romans en prose du type de la Queste, en y intégrant une perspective religieuse» (nous traduisons). Cette fin illustre aussi, selon Richard Trachsler, l'opposition entre terrien et celestiel qu'a introduite la Queste: Escanor vaudrait comme pendant celestiel tandis que Gifflet et les autres membres de la cour arthurienne rejoignent la temporalité circulaire. Voir l'introduction à l'édition citée, p. 94-95. 
ces éléments: Girart les utilise comme des artifices, il n'arrive pas à les intégrer dans la structure de son roman (peut-être, précisément, parce qu'il y a des incompatibilités entre les romans en vers et ceux en prose) $)^{393}$.

L'artificialité de cette fin hagiographique résulte de la rupture brutale entre deux registres; la doxa religieuse paraît dès lors incohérente. Sans

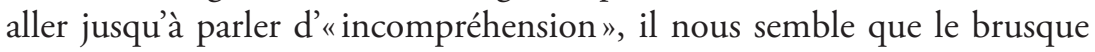
changement d'idéologie ne peut manquer d'être volontaire de la part de l'auteur, tant il frappe le lecteur. Le happy end des mariages de Keu et Andrivete, et de Gifflet et de la reine des Traverses aurait pourtant suffi à achever le roman dans une perspective plus conforme au roman arthurien en vers. Dès lors, il faut admettre que cette adjonction n'est pas le fruit de l'incompétence d'un auteur embarrassé pour finir son roman, mais procède d'une forme d'expérimentation: celle de l'hétérogénéité générique, pour renouveler le roman arthurien en vers en perte de vitesse et tenter de l'adapter à plusieurs registres différents. La nécessité d'introduire une rupture entre la fin et le reste du récit témoigne du caractère relatif de cette adaptabilité. Le roman arthurien en vers est fermement attaché au ludisme, à une perspective positive jetée sur le monde et le destin, dénuée de toute implication d'ordre eschatologique et de toute doxa religieuse. Le point d'achoppement que constitue la fin d'Escanor illustre à quel point roman en vers et roman en prose proposent des chronotopes différents.

\section{L'effet-fabliau}

Le registre propre aux textes à visée comique, comme les fabliaux et le Roman de Renart, est beaucoup plus compatible avec le roman arthurien en vers et ne donne donc pas lieu à une rupture avec le reste des aventures chevaleresques, lorsqu'il est intégré dans un roman tardif. Le comique est effectivement consubstantiel à l'écriture en vers, si bien que l'intégration d'un discours proche de celui des fabliaux ne constitue pas une entrave au genre. Annie Combes traite de cette intégration ponctuelle dans les romans en prose. Elle dénomme le phénomène "effet-fabliau» et le définit ainsi: "l'intrigue globale d'un roman adopte de manière

393 «De la prose au vers: le cas de Dynadan dans l'Escanor de Girart d'Amiens", art. cit., p. 409. 
ponctuelle une structure et une tonalité fabliesque, mais sans recourir à un enchâssement. " ${ }^{394}$ L'effet-fabliau conjugue une intrigue typique de fabliau et un registre bas. Ni réécriture de motifs, ni exportation de patrons génériques, il se manifeste surtout en tant que potentialité: tel passage trouverait sa place dans un fabliau ou "ouvre des perspectives fabliesques " ${ }^{395}$. Annie Combes relève ainsi que le recours au style bas ${ }^{396}$ crée un effet-fabliau. Cela peut concerner la mise en scène de vilains ou de bourgeois, du bas corporel et de la luxure, de la couardise, d'actions triviales, l'utilisation d'insultes ou de gros mots. Le comique, bien sûr, est toujours à l'horizon.

Jeter un regard comique sur la chevalerie arthurienne n'est pas une nouveauté de notre corpus; déjà Chrétien de Troyes émaille ses textes d'ironie, tandis que les auteurs du début du XIII ${ }^{\mathrm{e}}$ siècle placent les personnages arthuriens dans des situations cocasses, Fergus qui se bat à l'aide d'une broche à chapons par exemple ${ }^{397}$. L'avilissement des chevaliers ainsi de Gauvain dans la Mule sans frein - est une voie déjà explorée: elle atteint son paroxysme avec Rigomer. Nous avons déjà traité de la vacuité de l'aventure dans Rigomer et des comportements souvent discourtois des chevaliers dans ce texte. On peut maintenant élargir la problématique aux passages où le comique repose aussi sur l'emploi d'un registre bas qui crée un effet-fabliau, c'est-à-dire ouvre des potentialités narratives dignes d'un fabliau. Ce registre n'est bien sûr pas le propre des seuls fabliaux: le Roman de Renart en fait également usage. L'effet-fabliau pourrait aussi bien, dans Rigomer, être un "effet-Renart", à plus forte raison lorsque l'on considère l'intégration de quelques branches du Roman de Renart à la fin du manuscrit qui transmet Rigomer, Chantilly, Condé 472. Cette

394 Annie Combes, "Des fabliaux dans le Lancelot-Graal?», Romania, 2008, 126, p. 419.

395 Ibid., p. 431.

396 Le style bas est en effet un critère déterminant du genre du fabliau, comme l'exprime Dominique Boutet: «Le fabliau est un genre narratif bref, non animalier, en octosyllabes, dans lequel les caractères, la trame narrative, le registre sociologique et le ton relèvent, les uns et/ou les autres et à des degrés divers, du style bas tel qu'il ressort de l'esprit général des Arts poétiques contemporains. " Les fabliaux, Paris, PUF, 1985, p. 28.

397 Guillaume le Clerc, The Romance of Fergus, éd. cit., v. 3362-3367. 
proximité manuscrite soutient ainsi la potentielle contamination registrale de l'un sur l'autre.

L’omniprésence de la nourriture dans le roman est d'ailleurs commune aux deux textes: les chevaliers de Rigomer sont empâtés, ainsi que le leur reproche la messagère du début du texte ( $N$ 'avés mais cure de proueche / Fors seul que de vos encraissier. », v. 80-81). La faim est au cœur des préoccupations des chevaliers, si bien que les premières errances de Lancelot concernent bien souvent la quête d'une pitance. Au lieu de commenter la bravoure du chevalier, le narrateur souligne à plusieurs reprises que "sueffre grant faim et grant soi» (v. 419). L'aventure merveilleuse est de la même manière détournée vers les plaisirs du ventre: Lancelot entend d'abord des cors de chasse et des aboiements de chiens qui ont tout d'une manifestation merveilleuse - si bien qu'il se demande s'il s'agit de "gent faé / U crestieen u vif maufé» (v. 1207-1208). Lorsqu'une bête - un cerf? - apparaît, Lancelot la tue sur le coup au lieu de la suivre, conformément au motif de la chasse au blanc cerf. Loin de percevoir l'animal comme un guide vers l'aventure, Lancelot «Rostir cuida sor les carbons / Et des lardés et des braons» (v. 1229-1230), mais l'arrivée des chasseurs interrompt ce dessein.

L'insistance constante du texte sur la faim et la nourriture rappelle l'«épopée de la faim» que constitue le Roman de Renart selon Jacques Le Goff ${ }^{398}$. Cette intrusion du bas corporel avilit la chevalerie de manière plus insidieuse que la ridiculisation ponctuelle à laquelle on assiste dans les autres romans arthuriens en vers. L'épisode central, celui du château de Rigomer, voit la déchéance de Lancelot en cuisinier gras et renforce dès lors cette dimension. Richard Trachsler a montré à quel point cette condition est avilissante pour un guerrier, bien qu'elle renvoie à un comique semblable dans les chansons de geste, à travers le personnage de Rainouart notamment ${ }^{399}$. Les

398 Jacques Le Goff, La Civilisation de l'Occident médiéval, Paris, Arthaud, 1965, p. 292.

399 Richard Trachsler, «Lancelot aux fourneaux: des éléments de parodie dans Les Merveilles de Rigomer?», art. cit. Voir aussi Peter Ihring, "Wunder zum Lachen. Die komische Entzauberung des arthurischen merveilleux in zwei altfranzösischen Versromanen des 13. Jahrhunderts: Meraugis de Portlesguez und Les merveilles de Rigomer", in Das Wunderbare in der arthurischen Literatur: Probleme und Perspektiven, dir. Friedrich Wolfzettel, Tübingen, Max Niemeyer Verlag, 2003, p. 175-191, à propos de la relation entre comique et merveilleux dans ce texte. Peter Ihring traite notamment de l'épisode des cuisines. Sur cette association, 
allusions de cet épisode sont multiples ${ }^{400}$ - Lancelot devient nice et pose les mêmes questions que Perceval -, mais son thème principal concerne la faim du chevalier, préparée depuis le début du roman.

Le traitement de la nourriture est similaire dans les fabliaux, où les personnages cherchent constamment à assouvir leur appétit - que l'on pense au fabliau Le Dit des Perdrix. L'importance donnée au ventre dans Rigomer n'est pas le seul élément qui le rapproche de ce genre: Lancelot n'est pas toujours - voire rarement - accueilli par des nobles lorsqu'il demande l'hospitalité. Il est par exemple hébergé par des bergers, qui sont attaqués de nuit par quatre voleurs. Roy J. Pearcy souligne à propos de cet épisode que les voleurs ne sont pas rares dans les romans arthuriens en vers, mais ils y sont toujours à cheval, dans la forêt, et le héros les affronte de jour ${ }^{401}$. Il s'agit plutôt de chevaliers félons que de brigands, contrairement à ceux qui attaquent les hôtes de Lancelot dans le roman tardif. Le texte de Rigomer s'attarde sur le moment où la femme du berger repère les larrons alors qu'elle et son mari sont au lit. Le berger, «tos nus» (v. 3378), réveille Lancelot qui peut alors défendre la maison. Cette pénétration dans la sphère domestique du bas peuple n'est pas fréquente dans le roman arthurien: l'intrusion dans la chambre coucher, la nudité du berger et enfin la facilité avec laquelle les voleurs percent les murs de l'humble demeure signalent bien un changement de registre: on quitte l'élévation de la noblesse et de la courtoisie pour côtoyer le bas peuple et le bas corporel, deux dimensions très présentes dans Renart aussi bien que dans les fabliaux. C'est tout nu que le couple de bergers se bat contre les voleurs, armé d'une hache et d'une massue. Lancelot ne dispose pas d'une arme plus noble: il doit se servir d'un pieu de bois que le berger venait de ramener le jour même pour réparer la porte. De ce «tinel» (v. 3439), il tue les quatre intrus, dont l'un se cachait lâchement dans les buissons, mais qu'une toux trahit. Tous ces éléments convergent vers un comique fabliesque: il ne s'agit pas seulement, à l'instar des textes comme la Mule

voir encore Christine Ferlampin-Acher, "Merveilleux et comique dans les romans arthuriens français (XII $-\mathrm{XV}^{\mathrm{e}}$ siècles)", Arthurian Literature, XIX, 2003, p. 17-47. Voir Isabelle Arseneau,, "Lancelot échevelé: la parodie dans Les Merveilles de Rigomer", art. cit., sur la parodie de diverses sources arthuriennes, en vers et en prose, dans Rigomer.

401 Roy J. Pearcy, «Fabliau Intervention in some Mid-Thirteenth-Century Arthurian Verse Romances", Arthurian Yearbook, 1, 1991, p. 63-89. 
sans frein ou Hunbaut, de se moquer des chevaliers, mais de transposer l'univers chevaleresque dans une autre sphère, celle du peuple, où peuvent se déployer la nudité, la faim et une manifestation corporelle telle que la toux.

Une violence sauvage et animale également; l'épisode du berger hospitalier n'est pas le seul lors duquel Lancelot abandonne son épée. Lorsque des voleurs veulent s'emparer de son cheval, le héros lutte à mains nues à deux contre un:

Seure li keurent ambedoi,

$\mathrm{Li}$ uns desous, l'autres deseure,

Si commenchierent a cele eure

Une luite qui mout dura.

Cascuns grant paine i endura,

Car il savoient mout de tours

Et perilleus fu li estours. (Rigomer, v. 2032-2038)

Ils tombent ensuite à terre et Lancelot parvient à les tuer. Ce combat n'a plus rien de l'affrontement chevaleresque, mais ressemble plus à la lutte au corps à corps qui oppose Renart et Ysengrin dans la branche VI. Dans ce texte, les deux animaux s'affrontent d'abord à l'écu et au bâton, puis jettent ces semblants d'armes chevaleresques pour se saisir à bras le corps l'un de l'autre ("Andui ont leurs escus gerpiz, / Si s'aerdent parmi les piz [...] Renars l'estraint, pas ne se faint: / Jambet li fait, de lui l'enpaint", v. 1239-1260) ${ }^{402}$. Dans Rigomer, un effet de décalage est produit par le recours à ce registre, qui n'est plus tout à fait celui du roman arthurien.

La composition du manuscrit Chantilly, Condé 472 est donc cohérente; l'intégration du Roman de Renart à la fin du recueil fait écho au texte qui l'ouvre, c'est-à-dire Rigomer, dont le registre est semblable. Un épisode du tronc primitif - qui ne figure toutefois pas dans Chantilly, Condé 472 - rappelle d'ailleurs la course qu'entreprennent Renart et Tibert le chat: Lancelot est défié par un chevalier d'atteindre avant lui une lance placée plus loin. Pour être sûr de gagner, il retient son adversaire puis coupe la tête de son cheval («Si fiert le cheval par devant, / La tieste en fait voler avant", v. 5153-5154). La ruse est bien plus brutale et moins subtile que celle de Renart, qui tente d'attirer Tibert dans un piège à loup

402 Le Roman de Renart, éd. Jean Dufournet et Andrée Méline, Paris, GF, 1985, tome 1 . 
en prétendant que son cheval court de travers. Les conditions sont bien différentes et nous ne prétendons pas qu'il existe un rapport hypertextuel, c'est-à-dire de dérivation directe entre ces deux textes ${ }^{403}$. Ce qui nous semble remarquable, c'est que le système de valeurs est semblable: le héros tente de s'arroger la victoire par tous les moyens, aussi déloyaux soient-ils.

Parfois, ce n'est pas tant le comportement du chevalier qui fait signe vers le registre bas que la situation à laquelle il est confronté. Lancelot sauve une fille de roi, Marte, des mains d'un de ses prétendants qui tente de la violer. Le roi apprend que sa fille a été enlevée et lance ses hommes à leur suite. Lorsque les chevaliers rejoignent la demoiselle, elle est déjà sauve et c'est Lancelot qui l'accompagne, si bien que c'est lui que les hommes du roi attaquent. Le héros se garde bien de résoudre le quiproquo, mais coupe au contraire la main d'un adversaire et gagne dans ces affrontements deux chevaux, dont un beau destrier noir. Lancelot est si content de cette acquisition que le narrateur précise qu'il monte tout de suite dessus pour l'essayer. Un tel butin vaut bien d'avoir combattu contre des chevaliers amis de Marte, si bien que Lancelot ne regrette rien: «Mout fu biele cele encontree, / Car mout estoit de grans bontés [le cheval].» (v. 4328-4329). Si Lancelot ne révèle pas aux chevaliers qu'il a sauvé la jeune fille, c'est peut-être parce qu'il s'agit potentiellement de nouveaux prétendants avides, le roi ayant promis la main de sa fille et la moitié de son royaume à qui la ramènerait saine et sauve. Mais le texte n'invite pas à cette lecture: il insiste bien plus sur la cruauté de Lancelot, qui tranche le poing d'un chevalier à peine celui-ci s'avance-t-il vers Marte, et sa convoitise envers le cheval noir. Traité ainsi, le quiproquo n'est là encore pas l'intrigue privilégiée par le roman arthurien et offre un portrait avilissant de la chevalerie: Lancelot est convoiteux et ne rechigne pas devant la violence gratuite, caractéristiques parfaitement attribuables au personnage de Renart. Structurellement, le quiproquo est un ressort privilégié du comique de fabliau ${ }^{404}$, à l'exemple du fabliau Estula, dans lequel le fils d'un berger pense que son chien lui parle lorsqu'il l'appelle «Estula», alors qu'il s'agit de voleurs ayant entendu «es-tu là?».

\footnotetext{
403 Le sens d' "hypertextualité» que nous convoquons est celui de Gérard Genette, Palimpsestes.

404 Jean-Claude Aubailly, "Le fabliau et les sources inconscientes du rire médiéval», Cahiers de civilisation médiévale, 118, 1987, p. 105-117.
} 
Ce type d'actualisation d'un registre allogène se retrouve dans d'autres textes tardifs. Nous avons mentionné le vocabulaire trivial employé par certains personnages d'Escanor. On accuse par exemple Gauvain d'être «soudomites» (v. 1847); Keu traite l'amie de Mordred de "Garce despite, fole et baude» (v. 924) et l'encourage à poursuivre ses interactions luxurieuses avec son nain ( Vostre nain qu'avoec vouz menez, / Dont vo luxure maintenez.», v. 939-940). Dans Claris et Laris, le lecteur assiste à un combat entre Brandalis et un couple de vieux laids et difformes, dont le portrait rappelle le vilain du Chevalier au lion: l'affrontement, quoiqu'il respecte les règles chevaleresques du combat à cheval puis à l'épée, est cocasse, par l'intervention de la vieille qui jette des pierres à Brandalis. Le contraste entre l'apparence repoussante de la vieille et les propositions indécentes qu'elle fait au chevalier arthurien frappe aussi le lecteur par le décalage de registre que l'épisode instaure avec le registre courtois habituel au roman arthurien: "Ge ferai vostre volenté, / G’en ai le cuer entalenté. / Descendez si nos deduisons!» (v. 11779-11781) Cette aventure n'a rien de bien effrayant et ne glorifie pas vraiment la prouesse du chevalier. Il s'agit d'un épisode plaisant destiné à agrémenter le récit et à susciter le rire, d'autant plus que Brandalis lui-même rit face au vieux et à sa laideur: «De rire ne pot tenir.» (v. 11816)

Le comique de ces textes tardifs repose sur l'emploi d'un registre bas, qui s'inspire du fabliau et du Roman de Renart. L'effet-fabliau que décrit Annie Combes nous paraît probant pour rendre compte de ce phénomène: c'est en termes d'effet que se traduit l'intégration de ce ton trivial, roturier, voire grossier, rappelant autant le fabliau que le Roman de Renart, productions qui partagent toutes deux le même registre. Ponctuel dans Escanor et Claris et Laris, l'effet-fabliau informe la trame entière de Rigomer et fonde la vision que ce roman donne de la chevalerie, décadente, dénuée de toute courtoisie, et dont le représentant le plus parfait qu'était jusque-là Lancelot se comporte lui-même en personnage vil et glouton. Plutôt que d'un réel rapport de dérivation, d'échos hypertextuels bien définis - les rapprochements que l'on peut faire entre les épisodes de Rigomer et ceux de Renart étant ténus du point de vue de leur contenu -, c'est sous un angle générique qu'il faut penser la relation entre Rigomer et Renart et l'intervention de la trivialité dans le roman arthurien en vers tardif. Il ne s'agit pas de la réécriture de passages particuliers auxquels le roman renverrait directement ou s'inspirerait manifestement, mais plutôt de l'emprunt d'un registre, dont l'effet est de 
convoquer chez le lecteur un horizon générique, celui du fabliau, celui du Roman de Renart.

\section{Un récit encadrant: Biaudouz et le didactisme}

C'est moins en termes d'effet que de fonction qu'il faut envisager le changement de registre qu'opère Robert de Blois lorsqu'il écrit Biaudouz et organise surtout le recueil de la BnF, fr. 24301. Ce manuscrit est un œuvre complet du trouvère. D'autres manuscrits regroupent déjà ses textes pour former des recueils d'auteur: Arsenal 5201, BnF fr. 2236 et Arsenal 3516. Les critiques ont montré que Robert de Blois présidait à l'organisation de ses œuvres dans les compilations, dans Arsenal 3516 et Arsenal 5201 notamment. Selon Milena Mikhaïlova-Makarius, la collection du manuscrit BnF fr. 24301 est également conçue par l'auteur, bien que les traits lorrains du manuscrit et quelques maladresses lui fassent privilégier l'hypothèse d'un manuscrit apographe ${ }^{405}$. Ce recueil, le seul à transmettre Biaudouz, a ceci de particulier par rapport aux autres manuscrits d'auteur de Robert de Blois qu'il ne présente pas chaque texte individuellement, mais les enchâsse au milieu du roman de Biaudouz. Le roman arthurien s'interrompt au moment où la mère du héros prodigue un enseignement à son fils, le chastoie. Ce discours maternel est l'occasion d'insérer successivement le texte religieux De la Trinité, puis les traités l'Enseignement des princes, l'Honneur des Dames, deux autres compositions religieuses intitulées "Sermon» et "Création du monde» par Milena MikhaïlovaMakarius, le roman Floris et Lyriopé, le Chastoiement des dames et enfin D’amour, un art d'aimer ${ }^{406}$. Ce n'est qu'une fois tous ces textes déroulés que le roman arthurien reprend, avec l'errance de Biaudouz, sa rencontre avec son amie, puis son arrivée finale à la cour d'Arthur.

L'ensemble est si bien agencé, les transitions entre les textes si bien harmonisées, qu'il est difficile d'établir des bornes au roman de Biaudouz.

405 Milena Mikhaïlova-Makarius, L'École du roman, p. 352-354. Concernant les autres recueils d'auteur présidés par Robert de Blois, voir Claudia Guggenbühl, Recherches sur la composition et la structure du ms. Arsenal 3516, et Paul Meyer, "Notice du ms. de l'Arsenal 5201 ", Romania, 46, 1887, p. 24-72.

406 Voir notre annexe D sur l'ordre d'apparition des textes dans le ms. BnF fr. 24301. Voir aussi le tableau de Milena Mikhaillova-Makarius, L'École du roman, p. 376, et Lori Walters, "Manuscript Context of the Beaudous of Robert de Blois», art. cit., qui détaille le contenu des textes intégrés à Biaudouz. 
Le prologue général de l'œuvre complet, commun à d'autres manuscrits de Robert de Blois, se poursuit naturellement par le prologue propre à Biaudouz, qui adopte certains topoi du genre romanesque ${ }^{407}$. Les frontières du roman ne sont pas non plus claires; aucun titre, ni changement de colonne ou de page n'informe la transition d'un texte à l'autre. Matériellement, seules des lettrines de taille plus importante renseignent le passage entre les œuvres ${ }^{408}$. Les textes enchâssés subissent même quelques menus ajouts ou modifications pour s'intégrer parfaitement au discours de la mère de Biaudouz.

Dans ce contexte, Biaudouz fait office de récit encadrant: la mère de Biaudouz lui prodigue un enseignement, à la manière de la mère de Perceval ${ }^{409}$, et assume donc le discours narratorial dans les œuvres enchâssées. Celles-ci sont placées sous l'autorité d'un personnage, qui les véhicule à son fils en discours direct. Comme dans le Conte du graal, la mère ponctue son exhortation de l'apostrophe "Biaus fiz", à chaque nouveau conseil prodigué. Cette appellation se manifeste d'abord au sein du roman de Biaudouz:

«Biaus fiz, fait elle, ce Dé plait,

Nel contredirai : [...]» (éd. Lemaire, v. 179-810) ${ }^{410}$

«Biaus fiz, fait ele, encor entent,

Qu'apprendre te vuel un bel sens.» (éd. Lemaire, v. 219-220)

«Biaus fiz, fait ele, encor te vuel

Un bel sen dire: [...]» (éd. Lemaire, v. 251-225)

«Biaus fiz, ce tu sez consillier

Preudomes, n'en faire jai dongier

Adés, kant requis en seras.» (éd. Lemaire, v. 391-393)

407 Cette transition a lieu au vers 253, selon Milena Mikhaïlova-Makarius, L'École du roman, p. 42. Elle se fonde sur sa transcription du prologue général, p. 365-374. C'est aussi à partir de ce vers que Jacques Lemaire fait débuter son édition de Biaudouz.

408 Notre annexe D indique la taille des lettrines.

409 Sur la réécriture du Conte du graal dans Biaudouz, voir Francis Gingras, "Le Biausdous de Robert de Blois: la nature du roman et l'art de la digression", art. cit., et Le Bâtard conquérant, p. 398-404.

410 Pour ce chapitre, nous précisons à chaque fois si la référence provient de l'édition de Jacques Lemaire ou du prologue édité par Milena Mikhaïlova-Makarius, L'École du roman, p. 365-374. 
Le contexte du chastoiement est rappelé lorsque l'on passe au texte de l'Enseignement des princes: le prologue original de cette œuvre est modifié pour y insérer l'interpellation «Biaus fiz» et garantir que l'énonciation de ce texte est bien celle de la mère de Biaudouz. La comparaison entre la version de $\mathrm{BnF}$ fr. 24301 et celle des autres manuscrits de l'Enseignement des princes prouve l'effort fourni pour ne pas simplement juxtaposer les écrits de Robert de Blois, mais les présenter comme une composante du récit encadrant:

Des princes vos reconterai, Et por ce que je lor dirai, Se porront bien tuit chastoier Dames et clercs et chevaliers. (Arsenal 5201, f. 19a)
Biaus fiz, entent .i. bel savoir Qui molt puet a prince valoir. De tous senz nul plus bel ne sai Et par ce ke je te dirai Ce poront bien tuit chastoier, Dames et clers et chevaliers. (BnF fr. 24301, p. 487b) $)^{411}$

Les œuvres enchâssées sont donc adaptées à leur nouveau contexte. Le texte religieux De la Trinité est particulièrement remanié, comme l'étudie Milena Mikhaïlova-Makarius ${ }^{412}$ : des passages sont ajoutés ou déplacés. Ainsi, il est difficile de dire où commence véritablement ce texte, tant il diffère de ses autres versions et tant le début s'inscrit parfaitement dans la continuité de Biaudouz: "Biaus fiz, sor tout te vuel louer: / Met tout ton cuer en Deu amer." " (éd. Lemaire, v. 439-440). "Biaus fiz» indique là encore la recherche d'une cohérence d'ensemble, d'une jointure entre les éléments disparates.

Le statut du narrateur est dès lors problématique: Robert de Blois se nomme à plusieurs reprises dans le prologue général, mais ce n’est plus lui que représente le je dans L'Enseignement des princes ou L'Honneur des dames. La narration est déléguée au discours direct de la mère, nommée Amie et présentée comme une figure exemplaire, aussi belle que sage. C'est elle qui assume l'enseignement moral, qu'elle déclare profitable à tous :

411 Nous nous fondons ici sur les transcriptions de Milena Mikhaïlova-Makarius, L'École du roman, p. 97. Voir aussi Francis Gingras, "Le Biausdous de Robert de Blois: la nature du roman et l'art de la digression", art. cit. Nous parlons pour ce manuscrit de "page» plutôt que de «folio" car la numérotation qui y figure correspond à l'unité de la page et non du folio.

412 Milena Mikhaïlova-Makarius, L'École du roman, p. 71-78. 
«Pense, biauz fiz, del retenir:

Grans honors t'en puet avenir.

Je nel dis pas sanz plus por toi,

Mais por touz autres, car je doi

Voloir a chascun ke cil sens

Puist profitier a toute gens:

Sor toutes choses vos penés

D’avoir honor et d'estre amés.» (Biaudouz, éd. Lemaire, v. 255-262)

Le passage soudain du tutoiement au vouvoiement après la déclaration d'Amie de vouloir faire profiter chacun de ses conseils confirme la portée large que doit avoir son discours ${ }^{413}$. Ces vers font écho aux déclarations répétées sur l'universalité du discours didactique, dans les prologues de Robert de Blois :

Mais tel dit doit on bien oïr

Dont tuit ce pueent esjoïr (prologue général, v. 21-22)

Ainz vuet dire comunement

Por chastoier toute la gent. (prologue général, v. 33-34)

Car je vuel por toz chastoier

Un novial dit encomencier. (prologue général, v. 209-210)

Cette idée est aussi évoquée au début de L'Enseignement des princes que nous citions plus haut. Dans le contexte du manuscrit BmF fr. 24301, ce type de commentaires, tout comme le vouvoiement, insiste sur le fait que le destinataire du discours ne se réduit pas au seul Biaudouz, interlocuteur diégétique de la prise de parole: l'auditeur/lecteur du texte doit se sentir concerné.

La mère de Biaudouz se confond donc avec l'auteur moralisateur en visant le même objectif: chastoier «toute gens» (v. 260). L'universalité du discours a pour conséquence l'insertion de conseils qui concernent difficilement Biaudouz: le Chastoiement des dames étant un traité moral à destination des femmes, à qui l'on conseille par exemple de ne pas trop manger, de ne pas montrer sa chair à d'autres que des intimes ou encore de couper leurs ongles à $\operatorname{ras}^{414}$, on comprend mal ce qu'il vient faire au

\footnotetext{
413 Ibid., p. 97.

414 Lori Walters traite de cette adresse à un public mixte: le discours profite aux hommes et aux femmes. "Manuscript Context of the Beaudous of Robert de Blois", art. cit.
} 
milieu du chastoiement d'une mère à son jeune garçon. La confusion entre les figures narratoriales est dès lors totale. Le je renvoie à nouveau à Robert de Blois au début de D'Amour, ou du moins au narrateur qu'il délègue:

En la fin de mon livre vuel

Parler d'amors ou dairien fuel. [...]

Robers de Blois i fist escrire

Ce k'il i pout penser ne dire. (BnF fr 24301, page 560b)

Lévocation d'un livre et le nom du poète écartent le cadre narratif initialement posé, que plus rien ne vient rappeler, contrairement au début de L'Enseignement des princes, où Biaudouz est interpellé. Selon Milena Mikhaïlova, cette incohérence résulte de l'élargissement de l'auditoire $v^{\text {viséf }}{ }^{415}$ : la compilation vise un savoir complet, elle constitue un guide à l'usage de tous. Les mondes extradiégétique et intradiégétique se confondent, si bien que le discours moral se destine autant au personnage de Biaudouz qu'au dédicataire, que Robert de Blois mentionne dans le prologue général:

A un de mes millors amis

Qui bien est conus de tel pris

C'on doit por lui mout bien rimer,

Vuel je cest livre presenter. [...]

En la fin del livre savrez

Par kel nom il est apelez. (prologue général, v. 219-222; 251-252)

Le manuscrit étant incomplet, le lecteur contemporain n'apprend jamais le nom de ce dédicataire, qui pourrait être un futur souverain selon Milena Mikhaïlova-Makarius ${ }^{416}$ : le contenu du manuscrit serait alors particulièrement approprié à l'éducation d'un futur prince.

L'œuvre complet de Robert de Blois n'est d'ailleurs pas le seul contenu moral du manuscrit BnF fr. 24301. Avant cette collection figure aussi une

415 Milena Mikhaïlova-Makarius, L'École du roman, p. 201.

416 «Ainsi, le destinataire le plus probable du codex, l'élève à qui s'adresse le maitre, a toutes les chances d'être un futur souverain. Le codex BnF fr. 24301 est conçu comme un miroir où le prince peut acquérir tout ce qui est nécessaire à son éducation: la morale s'exprimant dans les textes, les genres de la rhétorique que doit connaître l'homme idéal et la pose faussement naturelle de l'orateur que met en scène le Beaudous garni. » Milena Mikhaïlova-Makarius, L'École du roman, p. 351. 
Vie des Pères, une liste des rois défunts, un récit de la Passion de Jésus et le Dolopathos d'Herbert ${ }^{417}$. Ce dernier roman qui fait partie du Cycle des Sept Sages de Rome intègre lui aussi des textes à sa trame narrative: il s'agit de fables destinées à mettre en garde contre la perfidie des femmes. Elles sont énoncées par des sages romains pour défendre le fils du roi de Sicile, Dolopathos, accusé à tort par sa belle-mère d'avoir essayé de la séduire, conformément au motif de la femme de Putiphar. L'histoire de Dolopathos et de son fils, comme celle de Biaudouz, servent de récitcadre à un discours moral et didactique, puisqu'elles enchâssent d'autres textes; en même temps, elles sont elles-mêmes des exempla, des exemples de bons comportements à suivre. C'est ainsi qu'est présentée l'histoire de Biaudouz dans le prologue spécifique à Biaudouz:

Et ci dis est mout bel et gens,

C'ancor i poront mainte gens

Example prendre et demander,

C'il i volent a droit penser.

Li malvais s'en chastieront

Et li boen s'en amenderont.

Et mout doit on prisier tel dit

Qui fait solas et grant profit

Et dont li cors et l'arme amende:

Bien est raisons c'om i entende.

As saiges soit li solaciers

Et as fous soit li proficiers!

(prologue exclusif à Biaudouz, éd. Lemaire, v. 41-52)

Le récit arthurien qui suivra, dont l'univers est d'emblée posé avant ces vers par l'évocation du roi Arthur et de Gauvain, est exemplaire et doit permettre à ses lecteurs de s'amender tout en éprouvant du plaisir à cette lecture. En convoquant le topos de l'utilitas et delectatio ${ }^{418}$, l'auteur transforme la fonction généralement attribuée aux romans arthuriens: le roman de Robert de Blois ne vise plus le simple divertissement mais se veut

${ }_{417}$ Milena Mikhaïlova-Makarius traite du recueil entier aux pages 337 à 363 de L'École du roman.

418 Sur le "plaisir et le profit» de la lecture, voir Florence Bouchet, Le discours sur la lecture en France aux XIV et XV' siècles: pratiques, poétique, imaginaire, p. 57-95. 
semblable à un roman de clergie comme le Dolopathos qui l'accompagne dans le recueil ${ }^{419}$.

L'exemplarité de l'histoire de Biaudouz est rappelée à la fin du roman, après les textes enchâssés et après les tribulations du personnage. C'est à Arthur qu'il revient d'énoncer le profit que l'on peut tirer en imitant les hommes honorables, lorsque toute la cour attend impatiemment la venue de Biaudouz:

\author{
«Hé Deus! com sont li malvais vil \\ Qui ne ce voelent chastoier \\ Qant oient louer et prisier \\ Les vaillans ke par lor bonté \\ Et vif et mort sont honorei!» (Biaudouz, éd. Lemaire, v. 3517-3521)
}

Biaudouz est un personnage exemplaire que les chevaliers de la cour autant que les lecteurs du roman doivent tenter d'imiter. La perfection morale et physique du chevalier est mise en lien direct avec le chastoiement: Biaudouz a été bien éduqué et en devient lui-même un modèle. L'enseignement de la mère a donc des conséquences positives sur le personnage, contrairement à ce qu'il se passe dans le Conte du graal, où Perceval écoute à peine les conseils. Alors que Perceval "entant molt petit / A ce que sa mere li dit» (v. 453-454), Biaudouz «Dedens son cuer met en escrit / Tout ce ke la mere li dit» (éd. Lemaire, v. 483-484) ${ }^{420}$. L'inversion est manifeste, et renforcée par la reprise presque telle quelle du deuxième vers. L'image de l'inscription gravée sur le cœur rappelle peut-être le prologue énoncé par Calogrenant dans le Chevalier au lion, lui qui exhorte à entendre avec son cœur et non avec ses seules oreilles ("Car parole oïe est perdue / S'ele n'est de cuer entendue», v. 151-152). Le roman arthurien encadrant illustre alors les vertus d'une bonne éducation, en conjoignant deux textes bien connus de la tradition arthurienne $e^{421}$.

419 Le rapprochement entre Biaudouz et les romans de clergie est renforcé par les allusions aux romans antiques que liste Francis Gingras, «Le Biaudous de Robert de Blois: la nature du roman et l'art de la digression», art. cit., \$19-20.

420 Francis Gingras lit dans Biaudouz un "anti-Perceval». Voir «Le Biaudous de Robert de Blois: la nature du roman et l'art de la digression", art. cit.

421 Voir à ce sujet Lori Walters, "Manuscript Context of the Beaudous of Robert de Blois", art. cit. 
Le roman remplit d'autant mieux sa fonction d'exemplum qu'il adopte certains traits du roman allégorique. Les personnages se muent en allégories, par les noms qui leur sont donnés: Biaudouz (ou Beaudoux), le héros, Beauté, son amie, Amie, sa mère, qui deviendra l'épouse de Gauvain, d'où ce prénom, Clairette, la demoiselle dotée de clairvoyance ${ }^{422}$, qui sert de guide à Biaudouz. Celui-ci représente un idéal de perfection, l'incarnation allégorique des vertus positives du chastoiement de Robert de Blois. Cette dimension valorise l'enseignement prodigué: si le lecteur le suit, il peut atteindre l'accomplissement de Biaudouz. L'orientation nouvelle du roman arthurien que propose Robert de Blois procède donc aussi à un détour par le roman allégorique, en vogue à la fin du XIII ${ }^{\mathrm{e}}$ siècle grâce au succès du Roman de la Rose ${ }^{423}$.

Se servir de genres à la mode, aussi bien que le fait de déléguer la narration à un personnage, permet de donner plus de relief à l'enseignement véhiculé. Le roman arthurien étonne dans un recueil qui contient exclusivement des œuvres à portée morale, mais il y trouve sa place par la réorientation que donne Robert de Blois au genre. L'auteur utilise la dimension plaisante du genre, sa faculté de capter l'attention du public, pour ensuite le ramener vers le droit chemin de la morale. L'idéologie n'est plus tout à fait celle que promeuvent Chrétien de Troyes et les autres auteurs de romans arthuriens en vers, mais plutôt celle des romans de clergie, comme le note Francis Gingras:

Car à travers son jeu subtil avec le roman arthurien, Robert de Blois propose de renouveler le genre, moins en faisant la promotion de la chevalerie célestielle que de ce qu'on pourrait appeler, en assumant l'oxymore, une chevalerie cléricale capable de mettre fin à un débat qui aurait trop duré entre clercs et chevaliers ${ }^{424}$.

Sans emprunter la voie de la chevalerie celestielle qu'ont déjà exploitée les romans en prose, Robert de Blois réinvestit le roman arthurien en vers pour en faire un genre de l'utilitas. Alors que le genre n'a pas bonne presse chez les moralisateurs - comme en témoigne le prologue de la Vie des Pères

422 C'est la lecture que fait Milena Mikhaïlova-Makarius de ce personnage, L'École du roman, p. 298-299.

423 À propos du parallèle avec le Roman de la Rose, voir Milena Mikhaïlova-Makarius, L'École du roman, p. 326-328.

424 Le Bâtard conquérant, p. 402. 
dédiée à Blanche de Navarre, que nous citions aux pages 44-45 - il est ici rendu acceptable de ce point de vue.

Le roman arthurien de Robert de Blois relève alors d'une poétique de l'ambiguïté, telle que la théorise Dominique Boutet ${ }^{425}$. Cette poétique se caractérise par l'impossible distinction d'un genre ou d'un message dominant: "elle contraint le lecteur-auditeur à un perpétuel mouvement de va-et-vient, la cause de ce mouvement étant une incertitude non résolue. " ${ }^{426} \mathrm{La}$ Queste del saint Graal est par exemple un texte ambigu, car il relève d'une inspiration biblique et arthurienne. L'idéologie religieuse y est confrontée au monde romanesque sans que l'un ou l'autre ait plus d'importance. De la même manière, Biaudouz recourt au caractère plaisant du roman arthurien en respectant les codes d'écriture du genre tardif, comme nous l'avons vu, tout en véhiculant en même temps un message moral et un enseignement didactique. Robert de Blois, en procédant à un mélange matériel des genres au sein du recueil manuscrit BnF fr. 24301, transforme génériquement le roman arthurien en vers: à la fois miroir ${ }^{427}$, roman allégorique et chastoiement, Biaudouz n'est pas seulement un roman d'armes et d'amour ancré dans le cadre de la cour d'Arthur.

Peut-on dès lors envisager que cette œuvre a d'abord existé de manière autonome, comme le fait Milena Mikhaïlova-Makarius ?428 Étant donné que nous ne disposons que du seul BnF fr. 24301 comme témoin manuscrit de ce texte, rien ne prouve qu'il ait eu une existence indépendante. L'inventaire de Jean de Saffres, chanoine de Langres, daté de 1365, est la seule autre attestation de ce roman. Parmi plusieurs autres textes narratifs dont des romans arthuriens, cet inventaire mentionne un «Beaudoux»: "Item, romancium dicti de Beaudoux, taxatum

\footnotetext{
425 Voir Poétiques médiévales de l'entre-deux, ou le désir d'ambiguïté.

426 Ibid., p. 461.

427 C'est-à-dire le genre lié à la moralisation : la métaphore du miroir présente l'œuvre comme un reflet exemplaire du monde réel. De nombreux textes didactiques se nomment "Miroir des princes", "Miroir de l'âme", "Miroir des dames". Voir à ce sujet Florence Bouchet, Le discours sur la lecture en France aux XIV et XV siècles, p. 78-86.

428 "Il est probable que Beaudous ait existé de manière indépendante, car par sa structure aussi bien que par sa matière, le roman n'est pas isolé, mais s'inscrit dans la lignée des romans arthuriens en vers en vogue au XIII ${ }^{\mathrm{e}}$ siècle. " (L'École du roman, p. 208)
} 
precio dodecim grossorum ${ }^{429}$. Il ne s'agit sans doute pas du manuscrit $\mathrm{BnF}$ fr. 24301, qui aurait plutôt été titré après le texte liminaire, c'est-à-dire la Vie des Pères. Cette recension nous permet peu d'estimer la taille du volume et donc l'autonomie possible du roman. Seul le prix de l'article peut servir en ce sens: Biaudouz y coûte douze gros, monnaie constituée de pièces d'argent, tandis que Cligès en coûte trois. Un «Mellini», titre sous lequel nous identifions le Roman de Merlin, coûte quinze gros. D'autres productions arthuriennes, un "de Percevaux le Galoix» et un "Galaad», valent un peu plus cher, c'est-à-dire quatre florins, sans doute en raison d'enluminures. La décoration de "Beaudoux" pourrait expliquer la différence de prix entre cet item et Cligès, mais celle-ci pourrait aussi se justifier par la taille des volumes. En ce cas, ce «Beaudoux» ne peut qu'être le récit encadrant qu'il constitue déjà dans $\mathrm{BnF}$ fr. 24301, puisque sa longueur, sans les textes didactiques, c'est-à-dire tel qu'il apparait dans l'édition de Jacques Lemaire, n'est que d'environ 4500 et n'excède donc de loin pas celle de Cligès $^{430}$.

Probablement ne connaîtrons-nous jamais le contenu de cet item titré "Beaudoux», ni même s'il s'agit véritablement du roman de Robert de Blois ${ }^{431}$. Quoi qu'il en soit, la possibilité d'une existence autonome de Biaudouz nous paraît douteuse: du point de vue d'un moraliste, pour quelle raison conter d'Arthur, si ce n'est en guise de captatio benevolentiae, comme l'emploie l'abbé Gevardus dans le Dialogus Miraculorum de Césaire de Heisterbach, réduit à mentionner Arthur pour réveiller son auditoire endormi lors des sermons? ${ }^{432}$ L'inscription du roman dans le

429 L'inventaire de Jean de Saffres est édité par J. Carnandet, «Bibliothèques de deux chanoines de Langres au XIV ${ }^{\mathrm{e}}$ siècle», art. cit., p. 471 pour la citation.

430 Une autre hypothèse pourrait être que Biaudouz est simplement le texte liminaire du recueil et que son prix se justifie par la présence de plusieurs autres textes non listés par cet inventaire, qui ne donne pour chaque item qu'un seul titre d'œuvre.

431 Il faut noter que l'inventaire ne donne aucun nom d'auteur, si bien que l'absence du nom de Robert de Blois n'est pas un critère pour dire que l'item "Beaudoux" n'est pas celui de ce trouvère.

432 L'abbé Gevard prêche dans la salle du chapître et s'aperçoit que les moines convers dorment et même ronflent. "Il s'exclame: "Écoutez, frères, écoutez, je vais vous raconter une histoire grande et originale! Il était une fois un roi, qui s'appelait Arthur." Après avoir dit cela, il ne poursuivit pas son récit, mais dit: "Voyez, frères, votre grande misère. Lorsque je parlais de Dieu, vous dormiez; dès que j'ai prononcé des paroles futiles, vous vous êtes réveillés et avez tendu des oreilles 
genre arthurien nous semble confirmer que l'auteur se sert de la vogue des contes d'Arthur pour remplir ses visées didactiques et non dans un but de pur divertissement. Sans les digressions, Biaudouz n'est plus vraiment un roman moral ou didactique et perdrait de sa substance, celle qu'énonce pourtant le prologue qui l'introduit.

L'uniformité qui se dégage de la partie consacrée à Robert de Blois dans le manuscrit BnF fr. 24301 et que démontre l'étude de Milena Mikhaïlova-Makarius nous paraît favoriser notre hypothèse que Biaudouz a été composé dès le départ comme un récit encadrant ${ }^{433}$. L'ajournement du nom du dédicataire dans le prologue encourage par exemple le lecteur à aller au bout de la lecture de l'ensemble, tout comme l'interruption du récit qui concerne Biaudouz, censé capter le lecteur. Le terme de «doctrine», employé en prologue pour désigner l'enseignement de la mère que le narrateur s'apprête à raconter ("Coment li damoisiaus retint / La doctrine», éd. Lemaire, v. 13-14), ne peut se comprendre que si l'on considère les textes enchâssés comme constitutifs du roman: sans eux, l'enseignement maternel se réduit à quelques conseils de comportement assez brefs. Milena Mikhaïlova-Makarius souligne la difficile adéquation entre le terme «doctrine» et l'enseignement effectivement véhiculé par la mère dans le cadre exclusif - problématique d'ailleurs - de Biaudouz, mais elle l'interprète comme une tentative de jointure entre le roman et les textes encadrés ${ }^{434}$. Nous y voyons plutôt une preuve que Biaudouz est conçu dès le début comme un récit-cadre. La question des bornes de l'œuvre, qui se pose avec acuité pour ce texte et rend compliquée son édition sans la digression morale qui occupe la majorité de cet ensemble ${ }^{435}$, démontre bien que ce roman fonctionnerait difficilement en autonomie. L'insertion

attentives"." (notre traduction) Césaire d'Heisterbach, Dialogus miraculorum, éd. et trad. Nikolaus Nösges et Horst Schneider, Turnhout, Brepols, 2009, t. 2, chap. 36, p. 761-762.

433 Cela n'empêche pas que des copistes postérieurs aient pu l'extraire de son contexte didactique pour le faire figurer de manière autonome. Mais il nous semble que cela ne devait pas être la démarche de l'auteur.

434 L'École du roman, p. 44-45.

435 C'est pourtant le parti qu'adopte Jacques Lemaire. Son édition a le mérite de donner un accès direct au roman de Biaudouz, mais ne rend pas compte de la complexité de sa transmission manuscrite. Milena Mikhaïlova-Makarius prépare une édition entière de la version que donne le manuscrit BnF fr. 24301, projet qui démontre en soi la difficulté que pose la possible autonomie de Biaudouz. 
du premier texte, De la Trinité, prouve bien aussi la solidarité constitutive de Biaudouz et des œuvres qu'il enchâsse, car le début du texte religieux est tant modifié qu'il ne se distingue pas de la partie romanesque qui l'englobe.

Enfin, on peut donner l'argument de la longueur de ce texte sans les digressions: elle demeure avec 4564 vers en deçà de celle des romans arthuriens en vers, qui, de surcroît, ne cessent de s'allonger à la même époque, comme nous l'avons montré. Ce roman est certes inachevé et l'on pourrait spéculer l'existence d'un prolongement monumental, mais la constitution du manuscrit n'y invite pas. Seuls deux folios manquent au dernier senion du texte de Biaudouz qui clôt le recueil ${ }^{436}$. Le dernier verso s'achève au milieu d'une phrase, à la fin d'une colonne d'un verso. Il s'agit donc vraisemblablement d'une perte. Le manuscrit semble dès lors incomplet - et non inachevé. Selon Lori Walters ${ }^{437}$, le roman touchait cependant à sa fin: après le tournoi final qui voyait la reconnaissance entre Biaudouz et Gauvain, le double mariage de Gauvain avec Amie et Biaudouz avec Beauté est annoncé. Ce double mariage constitue une fin tout à fait acceptable pour un roman arthurien en vers, et pourrait clore ainsi l'histoire. Si l'on admet cette hypothèse sur la fin du roman, il faut reconnaitre qu'en substance, l'histoire de Biaudouz est plus courte que la moyenne des romans arthuriens contemporains; son autonomie paraît alors peu vraisemblable. Envisager que Biaudouz est composé pour fonctionner comme récit encadrant correspond en revanche à la propension digressive des romans arthuriens tardifs: tout comme Rigomer ou Claris et Laris, Biaudouz n'a de cesse de s'allonger, cette fois par la multiplication des textes intégrés, génériquement allogènes ${ }^{438}$.

Le projet de Robert de Blois semble donc bien de réinvestir le roman arthurien pour en exploiter le potentiel moral et l'exemplarité. La composition du roman de Biaudouz n'est d'ailleurs pas le seul endroit où

436 Voir la base de données de l'IRHT, Jonas, http://jonas.irht.cnrs.fr/consulter/ manuscrit/detail_manuscrit.php?projet=45906

437 Lori Walters, «A Love That Knows No Falsehood: Moral Instruction and Narrative Closure in the Bel Inconnu and The Beaudous", South Atlantic Review, 58:2, 1993, note 8, p. 37-38.

438 Sur la digression dans Biaudouz, voir Francis Gingras, «Le Biausdous de Robert de Blois: la nature du roman et l'art de la digression", art. cit., et Milena MikhaïlovaMakarius, L'École du roman, p. 287-288. 
le trouvère s'emploie à traiter ainsi le cadre arthurien: dans L'Enseignement des princes, une série de personnages littéraires est proposée au destinataire en exemple de comportements vertueux ou de trahison (Roland et Ganelon par exemple). Arthur y figure et constitue l'exemplum le plus développé. Il illustre la vertu de la largesse, par opposition à celle de l'avarice, dans la liste de vices et vertus que l'auteur dresse. L'éloge au roi Arthur, qui commence par «Soveigne vos del roi Artu / Qi de si grant hautesce fu» (BnF. fr. 24301, p. 503a) est consciencieusement développé. La perfection du souverain justifie l'intérêt que l'on porte aux récits qu'il inspire:

Si sont en maintes cors oï

Volentiers et bon conjoï

Cil ki de lui seivent conter,

S'avons veü en pris monter

Aucuns de sens et de richesse

Qui sourent conter la prouesse. (BnF fr. 24301, p. 505a) $)^{439}$

Dans L'Enseignement des princes, Robert de Blois présente les romans arthuriens comme des textes exemplaires, regard inédit jeté sur une tradition plutôt décriée par les moralistes, Philippe de Mézières notamment, dont nous citions l'enseignement à Charles VI à la page 45. Dans le contexte du manuscrit BnF fr. 24301, ce passage vient justifier la pertinence de l'entreprise de composition de Biaudouz, en tant que récit encadrant d'œuvres didactiques. Le genre s'en voit dès lors infléchi.

À l'exception de Biaudouz qui, considéré dans le recueil BnF fr. 24301, est une œuvre ambiguë du point de vue générique, les autres textes de notre corpus demeurent des romans arthuriens, malgré les différents genres qui les nourrissent. On peut donc difficilement parler de «mélange des genres", le genre dominant étant toujours clair. Pourtant, il y a bien une esthétique commune à ces textes qui tient de la confluence des genres. Les romans arthuriens tardifs ne sont pas des hybrides ${ }^{440}$, terme qui dési-

439 Il s'agit de la transcription de Milena Mikhaïlova-Makarius, L'École du roman, p. 94 . Voir les pages 90 à 94 au sujet des exempla de souverains donnés dans L'Enseignement des princes.

440 Selon Keith Busby, Floriant et Florete "generically speaking, therefore, [...] is something of a hybrid». "The Intertextual coordinate of Floriant et Florete», art. cit., p. 262. 
gnerait plutôt des œuvres mixtes, à la croisée de plusieurs genres dont aucun n'aurait l'avantage. En revanche, ils relèvent d'un processus de confluence, entendu comme procédé dynamique qui modifie insidieusement le genre dominant en y intégrant des registres ou des éléments allogènes. L'esthétique de la confluence transforme génériquement le roman arthurien, d'où le regard parfois sceptique de la critique sur les romans tardifs, impliqués dans la nécessaire évolution du genre.

Le renouvellement du roman arthurien en vers fait intervenir des contenus rhétoriques variés, qui subvertissent parfois le genre par leur incompatibilité avec l'idéologie ou les codes que celui-ci avait jusque-là privilégiés. C'est pourquoi la fin miraculeuse d'Escanor crée une rupture nette avec le reste du texte: le merveilleux transcendantal n'est pas celui auquel l'écriture en vers recourt et ne peut s'harmoniser avec le récit chevaleresque sans introduire un changement brutal. Dans d'autres cas, la rhétorique allogène procède à un infléchissement de la trame narrative arthurienne qui en redéfinit les contours: l'influence de l'épique sur le roman tardif conduit à une apologie de la guerre et une esthétisation des combats collectifs plus prégnante que dans le roman arthurien classique. Quand il s'agit du registre fabliesque, c'est le texte entier qui se voit contaminé par une atmosphère de parodie qui encourage le rire plus qu'une lecture sérieuse. L'écart esthétique que la pratique de la confluence opère suffit à perturber l'horizon d'attente et à redéfinir le genre: la nouvelle esthétique créée est propre à la tardivité. 


\title{
CONCLUSION
}

\section{AUTOPSIE D'UNE FORME}

\begin{abstract}
"Cette aventure, contemporaine du Livre I de la série télévisée, s’inscrit dans la grande épopée de Kaamelott, alors qu'Arthur vient de construire sa forteresse et d'instituer les réunions de la Table Ronde. ${ }^{1}$
\end{abstract}

Lorsqu’il commercialise une bande dessinée dérivée de la série télévisée Kaamelott dont il est le scénariste, Alexandre Astier ressent le besoin de préciser que l'aventure à suivre s'inscrit dans le même chronotope que le Livre (ou saison) I: Arthur vient de réunir ses chevaliers à la Table Ronde et chaque épisode de la série déroule une courte intrigue unique, à visée comique, sans s'intégrer dans un déroulement chronologique. Cette façon de circonscrire un temps en particulier est surtout un moyen d'exclure les aventures bédéesques de la tournure chronologique et tragique que prend la série dès le Livre $\mathrm{IV}^{2}$. La fin de la série raconte en effet le séparatisme de Lancelot, sa fuite avec Guenièvre dans la forêt et la tentative de suicide du roi Arthur. Éclaircir ce cadre spatio-temporel au début de chaque tome de la bande dessinée revient à signaler au lecteur que le temps est à l'insouciance et qu'il doit mettre sous narcose ce qu'il sait du Lancelot intégriste et du Arthur stérile et dépressif qui lui ont été présentés au Livre VI.

Alexandre Astier et Steven Dupré, Kaamelott: L'armée du nécromant, Tournai, Casterman, 2006, p. 1. Cette mention est présente dans toutes les bandes dessinées de Kaamelott.

2 Sur Kaamelott, voir Hélène Bouget, «Chevaliers en péril: parodie et déconstruction des héros arthuriens dans Kaamelott», art. cit., et Florian Besson et Justine Breton (dir.), Kaamelott, un livre d'histoire, Paris, Vendémiaire, 2018. 
Le choix du vers dans la littérature du XIII ${ }^{\mathrm{e}}$ siècle fonctionne de la même manière que cet avertissement: il annonce le récit d'une aventure unique, sans grande conséquence pour le devenir du monde fictionnel. Sans qu'il soit besoin de l'expliciter, l'intégration dans un chronotope circulaire est rendue claire pour le lecteur par la forme. Néanmoins, celui-ci ne peut manquer d'être influencé dans sa lecture par ce qu'il sait déjà du monde fictionnel: le caractère d'un Lancelot intégriste dans Kaamelott est sous narcose et sous narcose seulement pour le lecteur de la BD, c'est-à-dire que ces informations sont accessibles à sa conscience et qu'il ne peut s'empêcher de chercher les manifestations de la discorde entre Lancelot et Arthur et les propriétés séparatistes naissantes de celui-là.

Il faut imaginer qu'un phénomène similaire se produit pour le lecteur de romans arthuriens tardifs. En connaisseur des cycles en prose, il cherchera inévitablement les prémices de la chute, les personnages qui y sont à l'origine et dont ne parlaient pas les premiers romans arthuriens en vers. Même si le vers est programmatique du point de vue chronotopique, la narcose n'opère pas intégralement: il revient aux auteurs de s'accommoder des cycles en prose en semant des indices, toujours soumis à l'idéologie du vers. Le défi que doit relever un auteur de roman arthurien en vers dès le dernier tiers du XIII ${ }^{\mathrm{e}}$ siècle est de composer avec une tradition qui comprend non seulement Chrétien de Troyes et ses «épigones», mais également les textes en prose, en supposant à leurs lecteurs une mémoire des versions en prose. Ainsi, les personnages clés du roman en prose font leur apparition dans le roman tardif, mais ils sont conditionnés par l'idéologie propre au vers qui exclut tout pathos: Gaheriet et Agravain sont de simples chevaliers, Merlin est un homme sauvage omniscient que les chevaliers croisent ponctuellement au détour d'une aventure unique, Morgane est une fée maternelle qui élève Floriant puis l'accueille dans un Avalon dans lequel le récit peut s'immiscer et qui accueillera un jour indéterminé le roi Arthur blessé. Plus que des anticipations, le roman tardif adresse des clins d'œil à l'attention du lecteur averti, mais jamais il n'invite directement à penser une continuité chronologique et tragique avec les parties du cycle du LancelotGraal. De même, Mordred, dans Claris et Laris, se singularise au sein de la Table Ronde par ses mesquineries, anticipant en cela sa trahison dans la Mort Artu, mais ses actions sont toujours l'objet de la dérision : il ne devient pas un chevalier sympathique dans les romans tardifs, mais la désapprobation des valeurs qu'il incarne se manifeste par le ridicule, la moquerie, l'avilissement comique, et non par la réprobation moralisante de ses méfaits. 
L'univers de fiction est forcément affecté par ces transferts: en plus de l'intervention de personnages exclusifs à la prose ou du moins à l'historiographie, Arthur reprend ponctuellement son rôle de dux bellorum et les personnages ne se scindent plus entre les bons et les méchants. L'effet en est transformé: c'est un monde contrasté qui est proposé au lecteur, nourri des divers visages que prend le roi Arthur dans les différentes productions qui le mettent en scène, ce qui infléchit nécessairement la fonction qu'il remplit au sein des textes et explique ses apparitions marginales dans l'œuvre la plus tardive - Melyador -, voire son absence dans certains textes des limites, Cristal et Clarie et Blandin de Cornouailles. Seule demeure inchangée l'atmosphère joyeuse propre au vers.

Il en résulte des textes à la croisée de deux esthétiques, celle du vers et celle de la prose. Nous écartions à la fin du chapitre précédent la notion d'hybridité pour aborder l'intervention de genres allogènes à divers niveaux (réécriture ponctuelle, diffusion de motifs, adoption d'un registre étranger). Cette notion est en revanche pertinente pour qualifier les interactions entre vers et prose. Si le roman arthurien en vers tardif est hybride, c'est bien plutôt parce qu'il croise le roman arthurien en prose, dont il tente d'imiter les mécanismes, que parce qu'il intègre çà et là des motifs ou registres issus d'autres genres. De l'écriture en vers, les romans tardifs conservent la forme et surtout l'idéologie insouciante. Le chronotope demeure inchangé, mais l'esquisse d'une temporalité linéaire, par la mort d'Escanor, par l'évocation du retrait d'Arthur en Avalon dans Floriant et Florete, par la description de la guerre contre les Romains dans Claris et Laris, démontre la tentation que représente la linéarité de la prose.

De la prose, ces romans héritent aussi une façon particulière de construire le récit et de suggérer l'existence d'un monde de fiction foisonnant et infini: ainsi de Melyador, qui donne les prémices d'un cycle en se référant à d'autres romans arthuriens et en invitant à la continuation par l'inachèvement de l'histoire de Sagremor. L'influence de la prose se manifeste surtout par la structure et les techniques narratives adoptées, l'entrelacement, la surenchère, la tendance à l'explicite. Imiter l'écriture de la prose, c'est tenter de redynamiser un genre et une forme en perte de vitesse, en flattant les goûts du lecteur par des stratégies narratives qui ont déjà porté leurs fruits, ont su toucher le public. La notion de tardivité traduit particulièrement bien le rapport du vers tardif à la prose, opposé à toute forme de réaction: il ne s'agit pas pour les auteurs tardifs de contrer l'esthétique introduite par la prose et d'en montrer l'invalidité, comme 
l'ont fait les premiers écrivains en prose vis-à-vis du vers, mais au contraire de faire profiter le vers des innovations de la prose. L'usage du vers dès la fin $\mathrm{du} \mathrm{XIII}^{\mathrm{e}}$ siècle n'est donc pas réactionnaire et ne revendique pas non plus une restauration: il prolonge et infléchit une esthétique déjà épuisée avec la conscience du caractère irréversible de l'avènement de la prose.

La réception moderne des textes tardifs, que même Beate SchmolkeHaßelmann accuse de ne pas avoir compris les codes du genre ${ }^{3}$, éclaire une appréhension différente de l'écriture en vers par rapport à celle de la prose et, partant, le caractère générique du choix de la forme. En qualifiant Claris et Laris d' "interminable compilation de lieux communs", Gaston Paris condamne la longueur du texte, amplifié par le retour de motifs narratifs. Nous l'avons vu, cette structure s'inspire de l'écriture en prose, et ces éléments ne sauraient déranger le lecteur moderne lorsqu'ils apparaissent sous cette forme. L'usage du vers est assigné à des codes spécifiques qui excluent le syncrétisme qu'offre la prose, ainsi que l'exprime Michel Zink: l'avènement de la prose réduit les différences génériques entre les œuvres narratives et subsume tous les contenus 4 . Dans les conceptions mentales, le vers est au contraire voué à la stabilité des structures et de la matière ${ }^{5}$, ce dernier terme étant compris comme synonyme de diégèse

3 «Der Autor Girart d'Amiens hat, anders als Froissart, die latente strukturbildende Kraft der Artusszenen nicht erkannt, obwohl sein Werk dem Chretiens zeitlich etwa 100 Jahre näher liegt als Meliador. Dasselbe darf auch über die Dichter von Floriant et Florete und Claris et Laris gesagt werden." Beate SchmolkeHaßelmann, Der arthurische Versroman, p. 45.

4 Michel Zink, «Le Roman», in GRLMA, VIII, p. 203-205. "La vision du monde propre à chacun de ces genres perd dès lors de sa spécificité aux yeux du lecteur et se fond dans une sorte de syncrétisme idéologique commun à toute la littérature narrative.»(p. 204). Il donne notamment l'exemple de Berinus: ce texte hybride commence sur les modalités du conte oriental, dont il développe les rebondissements propres à la navigation et au merveilleux marin, puis déroule une deuxième partie imitée de l'errance arthurienne. Cette œuvre a eu un grand succès en prose, mais pas dans sa première version en vers. Michel Zink l'explique par le syncrétisme naturel de la prose.

5 Ainsi que l'exprime Norris J. Lacy: «A related problem, and one that similarly merits correction, is our tendency to recognize the emergence of a new esthetic in the long cyclical works (Vulgate and Post-Vulgate, Prose Tristan) but to assume that other romances, especially the episodic verse texts known collectively as Gauvain romances, continue to be formed - or should continue to be formed in accordance with earlier compositional principles.» ("Les Merveilles de Rigomer and the Esthetics of "Post-Chrétien" Romance», p. 87) 
ou d'univers de fiction et ne devant pas être confondu avec la notion de genre. La matière, comme le style, le registre ou le statut du narrateur, est un critère générique qui contraint ou est contraint par les autres postes. La conservation du vers, par le traitement de la matière qu'il impose, assure une distinction de type générique avec les romans en prose; ce constat montre que la forme peut contraindre les autres choix qui relèvent de la généricité et renforce l'idée que les postes génériques sont interdépendants et s'influencent mutuellement. De la conjonction de différents choix naît un genre littéraire, ce qui permet d'opposer roman arthurien en vers et roman arthurien en prose, malgré le partage d'un même univers de fiction.

Bien que la réception soit affectée par le choix d'une forme, l'état de la transmission n'invite pas à envisager des lecteurs différents entre vers et prose aux XIII ${ }^{\mathrm{e}}$ et XIV ${ }^{\mathrm{e}}$ siècles. À ce sujet, la dichotomie tracée par Beate Schmolke-Haßelmann ${ }^{6}$ entre couronne anglaise/roman arthurien en vers et couronne française/roman arthurien en prose ne nous semble pas suffire à expliquer le choix anachronique du vers dans les textes tardifs. Escanor et Melyador sont certes tous deux composés pour la cour d'Angleterre qu'ils promeuvent. Ils s'inscrivent dans un contexte littéraire qui favorise la production en vers; la prose intervient en effet plus tard dans la littérature anglaise et il faut attendre Thomas Malory et sa Morte Darthur pour lire un roman sur Arthur en prose anglaise ${ }^{7}$. Néanmoins, il fait peu de doute que la production arthurienne française en prose circulait en Angleterre et exerçait une influence, d'autant plus pour les écrivains de culture française venus trouver des mécènes insulaires; en écrivant en vers, Girart d'Amiens

6 Beate Schmolke-Haßelmann, Der arthurische Versroman. Richard Trachsler discute l'hypothèse de la critique allemande dans son édition d'Escanor, éd. cit., p. 61-67. Sur le contexte de composition d'Escanor, on consultera aussi son article, "Escanor von Girart d'Amiens im Spannungsfeld von Vers und Prosa», art. cit. Sur Édouard Ir et l'identité nationale anglaise autour de la figure d'Arthur, voir Catherine Daniel, «Édouard I Ir et l'identité arthurienne», in Marqueurs d'identité dans la littérature médiévale: mettre en signe l'individu et la famille (XII-XV siècles). Actes du colloque tenu à Poitiers les 17 et 18 novembre 2011, éd. Catalina Girbea, Laurent Hablot et Raluca Radulescu, Turnhout, Brepols ("Histoires de famille. La parenté au Moyen Âge», 17), 2014, p. 75-89.

7 Voir Derek Brewer, "Secular prose. Malory and Caxton", in English Gothic Literature, Londres, Macmillan Press, 1983, p. 262-279, et Michelle Szkilnik, "Arthur parle en vers anglais mais en prose française", in Arthur en Europe à la fin du Moyen Âge. Approches comparées (1270-1530), dir. Christine Ferlampin-Acher, Paris, Garnier, 2020, p. 234-251. 
et Jean Froissart confortent autant une habitude du lectorat anglais qu'ils s'appliquent à retravailler, réactiver, un chronotope particulier, à réinventer un type d'écriture dans un contexte qui favorise la versification.

Le choix du vers est donc moins un choix politique qu'un choix littéraire, encouragé certes par le contexte littéraire anglais, mais surtout par cette volonté de résurgence que nous décrivions. Il ne faut d'ailleurs pas oublier que Melyador est recomposé pour accueillir les poèmes de Wenceslas de Brabant et lu au comte Fébus de Foix; le roman en vers est tout aussi bien accueilli en France, si ce n'est plus. La conclusion de l'article de Richard Trachsler synthétise parfaitement cette hypothèse:

Es wurden auf dem Kontinent das ganze 13. Jhd hindurch Versromane geschrieben, sodaß es vielleicht nicht nötig ist, die Wahl des Verses (und nicht der Prosa) als rein gattungsbedingt zu betrachten, d. h. als Medium für pro-englische Dichtunge. Statt nur für Propaganda für König Edward könnte man somit Escanor für ein literarisches Produkt seiner Zeit nehmen, das versucht, in das traditionelle Genre des Versromans Elemente aus dem Prosaroman einzuarbeiten ${ }^{8}$.

Dès lors, ce n'est pas en termes sociologiques qu'il faut qualifier la réception du roman arthurien en vers par rapport à celui en prose, mais bien en termes littéraires.

Ce sont sans doute des goûts spécifiques, liés aux représentations attachées à la forme du vers ou au chronotope privilégié par le genre qui expliquent ce choix chez les commanditaires. Quoique l'état actuel de la transmission manuscrite ne signale pas une diffusion large des œuvres en vers tardives, plusieurs indices permettent de constater les bonnes grâces dans lesquelles ils ont été reçus. Nous l'avons vu, lorsque l'on connaît le nom d'un commanditaire, il s'agit toujours de la haute noblesse française ou anglaise, la reine d'Angleterre pour Escanor, Édouard III puis Wenceslas de Brabant pour Melyador. Quant à Claris et Laris, il est

8 Richard Trachsler, "Escanor von Girart d'Amiens im Spannungsfeld von Vers und Prosa», art. cit., p. 268. "On a écrit des romans en vers sur le continent pendant tout le $\mathrm{XIII}^{\mathrm{e}}$ siècle, si bien qu'il n'est peut-être pas besoin de considérer le choix du vers (et non de la prose) comme une condition du genre, c'est-à-dire comme medium privilégié des compositions pro-anglaises. Au lieu de le voir seulement en tant que propagande pour le roi Édouard, on peut aussi prendre Escanor pour un produit littéraire de son temps, qui tente d'intégrer des éléments du roman en prose au sein du genre traditionnel du roman en vers. » (nous traduisons) 
conservé dans un manuscrit d'assez bonne facture pour laisser envisager un possesseur fortuné, potentiellement amateur de littérature de genres variés. Il est en plus diffusé assez largement pour être connu de l'auteur de Floriant et Florete, que nous imaginons au service de la noblesse italienne. Ces textes ne proviennent sans doute pas d'un même milieu de production, mais dessinent tous une esthétique commune, qui est le résultat de leur tardivité.

La reconnaissance d'une esthétique de la tardivité commune à ces textes les inscrit dans la trajectoire historique du roman arthurien en les opposant au caractère précurseur des œuvres de Chrétien de Troyes, dont nous avons décrit le canon pour le confronter à la tardivité. Cette opposition donne paradoxalement un statut primordial aux œuvres tardives, car elle les présente comme un corpus symétrique et dès lors fondamental du point de vue de l'histoire littéraire. Leur étude rend compte d'une extinction, elle autopsie un genre dont on peut dater le dernier représentant. Cette autopsie est enrichie par la diversité qu'offrent les textes tardifs au cours de la période étudiée. Les derniers romans arthuriens en vers partagent un certain nombre de traits communs que le présent travail a dégagés, mais ils se scindent en deux catégories qui traduisent un rapport particulier à la tradition versifiée. L'écriture tardive se décline en deux modalités: la secondarité 9 ou la résurgence. À la première catégorie appartiennent Claris et Laris, Floriant et Florete et Rigomer, qui sont aussi les plus anciens textes du corpus. Les innovations de ces textes sont incontestables, de même que le parti qu'ils tirent des romans en prose. Néanmoins, ils se montrent plus attachés à l'écriture précurseur qu'Escanor et Melyador. Pour Claris et Laris et Rigomer, cela se manifeste par la propension des auteurs à manier la parodie et à poursuivre la veine anti-romanesque que décrit Isabelle Arseneau à propos de Méraugis de Portlesguez: "Sur le plan de la forme, l'antiroman semble s'amuser à faire dérailler la mécanique du genre et à jeter du sable dans les rouages trop

9 Cette notion est développée par Judith Schlanger pour penser l'influence des œuvres précédentes, le rapport entre l'ancien et le nouveau. Toute œuvre naît seconde, au sein d'un champ littéraire déjà constitué et qu'elle doit réinventer. L'œuvre tardive serait à la fois mémoire d'un passé littéraire sur lequel elle se fonde et construction d'une mémoire qui lui est propre. Le neuf, le différent et le déjà-là. Une exploration de l'influence, Paris, Hermann, 2014, et La mémoire des ouvres, Paris, Verdier, 1992. 
bien huilés du roman ${ }^{10}$. Comme l'écrit Francis Gingras, «le roman se pense très tôt en termes de contraste et d'opposition avec les romans antérieurs ${ }^{11}$. C'est ce que font les auteurs de Claris et Laris et Rigomer, en reconduisant la distance critique qu'instauraient déjà Raoul de Houdenc, Renaut de Beaujeu ou l'auteur de Hunbaut ${ }^{12}$ dans la première moitié du $\mathrm{XIII}^{\mathrm{e}}$ siècle. Le rire nourrit ces romans et rend patente la dette de Claris et Laris et Rigomer envers ces "antiromans». Quant à Floriant et Florete, sa secondarité s'exprime par l'importance de l'intertextualité dans ce texte: l'auteur pratique la citation d'œuvres antérieures et la réécriture, celle de l'épisode de la recreantise d'Erec et Enide mettant particulièrement en évidence cette filiation, de même que sa parenté avec Cligès. Le rapport au genre de ces trois textes, envisagé dans sa dimension historique, est celui de la survivance.

Les compositions de Girart d'Amiens et de Jean Froissart instaurent une rupture plus nette. La parodie intervient très peu et le rire n'est pas ce qui définit en premier lieu l'effet que produisent Escanor et Melyador. Plus que des survivances, ces deux romans se présentent comme des résurgences d'un genre et d'une forme dont la fin est déjà irrémédiablement consacrée. À presque un siècle d'intervalle l'un de l'autre, ces auteurs font renaître ponctuellement une façon de raconter l'univers arthurien, contrainte par la forme, avec la conscience du caractère irréversible de l'avènement de la prose au détriment du vers dans le roman. Les deux derniers romans arthuriens en vers prennent acte du destin du vers narratif et rendent compte de la mutation des représentations.

Le roman de Biaudouz se distingue au sein de cette production: composé pour accueillir les œuvres morales de Robert de Blois, il est une sorte d'hapax. Plus survivance que résurgence, Biaudouz profite de

10 Isabelle Arseneau, "Méraugis de Portlesguez ou l'art de railler et de faire dérailler la mécanique du roman", Études françaises, 47/2, 2011, p. 37.

11 Francis Gingras, "Roman contre roman dans l'organisation du manuscrit du Vatican, Regina Latina 1725», art. cit., p. 11.

12 Ce court roman rend fort bien compte d'un rapport paradoxal à Chrétien de Troyes: il en mentionne le nom en prologue pour aussitôt s'en distancier et se placer en opposition du maître champenois, par des phénomènes de reprise et de détournement. L'auteur se présente ainsi non comme un clerc, mais comme un ménestrel, classe que condamnait Chrétien de Troyes dans son prologue à Erec et Enide. Voir à ce sujet l'article de Michelle Szkilnik, "Un exercice de style au XIII siècle: Hunbaut», Romance Philology, 54, 2000, p. 29-42. 
plusieurs esthétiques. Il peut paraître étonnant que son auteur choisisse une forme anachronique dans le but de promouvoir sa propre production. Outre le plaisir évident qu'apporte encore ce type de récit à cette époque, ce choix s'explique sans doute, là encore, par la forme, et les incompatibilités entre vers et prose au sein du manuscrit: les œuvres morales de Robert de Blois sont en vers et ne pourraient donc être intégrées dans un cadre en prose sans voir leur statut générique se transformer, sans passer pour des insertions lyriques, étant établi que la forme affecte toujours d'une façon ou d'une autre le genre littéraire. Le chronotope du roman arthurien en vers garantit en plus une atmosphère joyeuse et le récit d'une aventure unique qui favorise la transmission d'un enseignement, ce que ne pourrait offrir le chronotope de la prose. Biaudouz est bien marginal par rapport aux autres romans tardifs. Néanmoins, son étude élargit la restitution de l'esthétique tardive avec profit: c'est par son statut second, par sa position tardive, que le roman arthurien en vers peut se prêter à un tel exercice de récit encadrant et remplir d'autres objectifs.

Si le roman arthurien en vers peut servir de telles ambitions et se réinventer à tel point, c'est qu'il est jugé éculé et que Biaudouz intervient bien au crépuscule de la trajectoire du genre. Cette œuvre atypique a donc tout à fait sa place au sein du corpus des romans tardifs. La fin du XIII ${ }^{\mathrm{e}}$ siècle nous semble bien représenter un moment charnière dans l'histoire littéraire. Toutes les œuvres composées à partir de cette période - pour autant que l'on puisse se fier aux datations que nous avons retenues - font corpus, sont marquées par une cohérence qui est celle de la tardivité. L'inscription des textes tardifs dans l'histoire littéraire est double: esthétique d'abord, puisqu'ils donnent l'occasion de tracer la trajectoire d'un genre finissant; formelle ensuite, puisqu'ils permettent de réfléchir à l'histoire des formes et de leurs usages.

En tant qu'elle est symétrique à l'esthétique précurseur de Chrétien de Troyes, l'esthétique tardive n'est pas une décadence. Probablement n'est-elle pas ressentie comme telle par les lecteurs contemporains de ces textes. Le mauvais accueil qu'ils ont reçu chez la critique du début du $\mathrm{Xx}^{\mathrm{e}}$ siècle n'est alors que le fait des critères génériques choisis pour les décrire. Abordés d'un point de vue normatif en comparaison - et non en symétrie - des œuvres de Chrétien de Troyes, que l'on considère comme des textes canoniques, les romans tardifs ne peuvent qu'être des "produits 
de la décadence $»^{13}$. Tout critère générique, nous l'avons détaillé au chapitre 1, est pourtant appelé à être modulé par les auteurs, quitte à ce que leur texte occupe la périphérie de l'échelle de centralité, à l'instar des œuvres que nous avons appelées para-arthuriennes. Les derniers romans arthuriens en vers ne sont donc pas de mauvais romans arthuriens; au contraire, ils ont le mérite de proposer une synthèse de la littérature arthurienne qui les précède et leur est quasi contemporaine, puisqu'ils entrent aussi en résonance avec les romans en prose de deuxième et de troisième générations, le Tristan en prose et le cycle de Guiron le courtois. Cette perspective globale sur l'univers de fiction dans son ensemble fait de ces textes des romans de leur temps, qui permettent d'envisager la trajectoire que prend un genre au cours des siècles, dans ses continuités et ses discontinuités ${ }^{14}$. Engagés dans le nécessaire renouvellement d'un genre éculé, les romans tardifs disent quelque chose de ce que le lecteur espère trouver dans un roman arthurien après une tradition foisonnante: la surenchère autour de l'aventure et des personnages, des jeux d'échos à l'ensemble de la production arthurienne - en vers, en prose, romanesque et historiographique -, la peinture d'un monde sans Graal, sans fin surtout.

Que la poétique tardive plaise ou ait plu est finalement secondaire. L'intérêt de ces romans est quant à lui indéniable pour rendre compte de l'influence de la forme sur la réception. Il nous semble que ces textes permettent de tracer plus largement un changement qui touche le genre romanesque français dans son ensemble: celui de l'abandon du vers narratif. Cognitivement plus accessible, la prose peut élaborer une poétique plus complexe, sur le plan structurel - entrelacement, longueur, démultiplication des intrigues et des personnages, cycle - et sur le plan idéologique - ambiguïté des valeurs et neutralisation du manichéisme dans le Tristan en prose et le cycle de Guiron le courtois par exemple. C'est comme

13 «C'est un vrai produit de décadence, une perpétuelle imitation d'imitations, une interminable compilation de lieux communs.» Gaston Paris, "Romans en vers du cycle de la Table Ronde», art. cit.

14 Il faut en ce sens suivre l'avis de Daniel Poirion et replacer les chefs-d'œuvres dans un contexte: "s'il est vrai que le style s'affirme dans les chefs-d'œuvre, encore faut-il situer ces modèles à l'intérieur de l'ensemble de la tradition dont ils émanent et qu'ils orientent." "L'épanouissement d'un style: le gothique littéraire à la fin du Moyen Âge», art. cit., p. 30. C'est adopter sur eux un point de vue in re, selon l'expression d'Hans Robert Jauss, "Littérature médiévale et théorie des genres", art. cit. p. 43. 
si la difficulté imposée par la forme versifiée faisait obstruction au déroulement de la complexité sur le plan narratif et éthique. L'épuisement de cette production s'exprime alors surtout par le déclin du vers comme forme de la narration. Le vers se spécialise pour la production lyrique, construisant une opposition qui mêle genre et forme, populaire aujourd'hui: prose d'un côté, poésie de l'autre, opposition que viendra relativiser l'avènement $\mathrm{du}$ poème en prose au XIX ${ }^{\mathrm{e}}$ siècle. L'étude de notre corpus mène à penser les contingences qui créent des liens de consubstantialité entre une forme et un genre et leur réversibilité.

Dans le roman arthurien tardif, l'exploration du lyrique qui s'attache de plus en plus au vers à cette époque se manifeste par les insertions lyriques d'Escanor et de Melyador. Dans le dernier roman arthurien en vers, cette pratique prend une ampleur considérable allant de pair avec une réflexion psychologique, qui concerne la jalousie ou l'amour par ouï-dire. Cette introspection, l'intégration d'une subjectivité marquée, est peut-être favorisée par la temporalité circulaire du chronotope du vers. La suspension du temps arthurien, dans la paix du royaume, extrait de toute problématique eschatologique, laisse la place à l'autoréflexivité: celle du lyrique, qui explore les passions humaines; celle aussi qui concerne le genre. L'emploi du vers dans le roman arthurien alimente une perspective métalittéraire qui mène à la refonte de ses propres moyens d'engendrement.

Au terme de l'étude, force est de constater que le roman arthurien en vers n'est pas conservateur ${ }^{15}$, mais que l'appréhension du genre dans son ensemble, de son début à sa fin, de ses représentants les plus canoniques aux œuvres les plus marginales, offre une palette variée des modulations auxquelles ce corpus se soumet. Les derniers vers du roman arthurien ne sont pas ceux qui suscitent l'intérêt des imprimeurs du XvI siècle, ni ceux qui nourrissent la culture populaire contemporaine dont

15 Contrairement à ce qu’affirme Beate Schmolke-Haßelmann: «Denn verglichen mit den Prosaromanen stellt sich die Gattung des arthurischen Versromans als weitgehend konservativ dar. Die Texte schreiben eine Zustand des Arthurischen fest, wie er sich bei Chrestien (in seinen frühen Werken) manifestierte und sich seit jener Zeit zwar in Detail, jedoch nicht im wesentlichen verändert hat.» Der arthurische Versroman, p. 182. "Comparé aux romans en prose, le genre des romans arthuriens en vers se représente comme étant largement conservateur. Les textes fixent un état de l'arthurien tel qu'il se manifeste chez Chrétien (dans ses premières œuvres) et qui n'a pas fondamentalement changé depuis ce temps, si ce n'est dans le détail.» (nous traduisons) 
ressortit Kaamelott. Pourtant, les œuvres dont ils sont issus contribuent à construire nos représentations modernes de la littérature romanesque et invitent à penser la concurrence entre vers narratif et vers lyrique, entre vers et prose. Le genre romanesque élit la prose au détriment du vers comme forme privilégiée, marquant un tournant auquel le vers narratif ne pourra survivre, à moins d'imiter dans un dernier élan les techniques de son rival à la mode. 


\section{ANNEXES}

\section{ANNEXE A: ROMANS ARTHURIENS EN VERS TARDIFS}

Les informations sont tirées des éditions de référence de chaque texte.

\begin{tabular}{|l|l|l|l|}
\hline Titre courant & Datation & Localisation & $\begin{array}{l}\text { Contexte manuscrit et } \\
\text { diffusion }\end{array}$ \\
\hline Claris et Laris & $\begin{array}{l}\text { Vers 1270 (après } \\
1268)\end{array}$ & Est de la France & $\begin{array}{l}\text { BnF fr. 1447 } \\
\text { Contient Floire et } \\
\text { Blancheflor et Berte aux } \\
\text { grans piés. } \\
\text { Copiste francien de l'Île } \\
\text { de France. } \\
\text { Date: début XIv } \\
\text { 3 miniatures au début } \\
\text { de chaque texte }\end{array}$ \\
\hline $\begin{array}{l}\text { Floriant et } \\
\text { Florete }\end{array}$ & Vers 1280 & Est de la France & $\begin{array}{l}\text { New York, Public } \\
\text { Library, De Ricci 122 } \\
\text { Contient uniquement } \\
\text { Floriant. } \\
\text { Scripta du Nord-Est. } \\
\text { Date: } \text { xIII }{ }^{\mathrm{e}} \text {-XIV }{ }^{\mathrm{e}} \text { siècle } \\
\text { Probablement } \\
\text { produit pour la } \\
\text { noblesse sicilienne }\end{array}$ \\
& & & \\
\hline
\end{tabular}




\begin{tabular}{|c|c|c|c|}
\hline Titre courant & Datation & Localisation & $\begin{array}{l}\text { Contexte manuscrit et } \\
\text { diffusion }\end{array}$ \\
\hline Jehan, Rigomer & $1268-1275$ & $\begin{array}{l}\text { Est, Cambrai ou } \\
\text { Tournai }\end{array}$ & $\begin{array}{l}\text { Chantilly, Condé } 472 \\
\text { Contient plusieurs } \\
\text { romans arthuriens en } \\
\text { vers, quelques branches } \\
\text { du Perlesvaus et du } \\
\text { Roman de Renart. } \\
\text { Flandres, Hainaut. } \\
\text { Date: fin du XIII } \\
\text { Pas de miniatures } \\
\\
\text { Fragment de Turin, } \\
\text { L. IV. } 33 \\
\text { Diverses ouvres } \\
\text { hétérogènes. } \\
\text { Fin XIve-début Xv } \\
\text { Transmet uniquement } \\
\text { l'épisode de la } \\
\text { Quintefeuille }\end{array}$ \\
\hline $\begin{array}{l}\text { Girart } \\
\text { d'Amiens, } \\
\text { Escanor }\end{array}$ & Vers 1280 & $\begin{array}{l}\text { Entourage de la cour } \\
\text { d'Angleterre, dédié à } \\
\text { Eleonore de Castille, } \\
\text { épouse d'Édouard I'r. } \\
\text { Langue franco- } \\
\text { picarde }\end{array}$ & $\begin{array}{l}\text { BnF fr, } 24374 \\
\text { Ne contient qu'Escanor } \\
\text { Scripta franco-picarde. } \\
\text { Atelier parisien } \\
\text { Date: fin XIII } \\
\text { Pas de miniatures } \\
2 \text { Fragments perdus } \\
\text { servant de reliure } \\
\text { Mention dans } \\
\text { l'inventaire de la biblio } \\
\text { de Charles V. Envoyé à } \\
\text { la reine en } 1390 \text {, avec } \\
\text { Charlemagne }\end{array}$ \\
\hline $\begin{array}{l}\text { Robert de Blois, } \\
\text { Biaudouz }\end{array}$ & Après 1272 & $\begin{array}{l}\text { Dialecte francien. } \\
\text { Robert de Blois } \\
\text { écrit pour plusieurs } \\
\text { petits seigneurs } \\
\text { français, dont Hue } \\
\text { Tyrel de Poix et } \\
\text { Thierry, comte de } \\
\text { Forbach. Biaudouz } \\
\text { et son manuscrit ne } \\
\text { comportent pas de } \\
\text { nom de dédicataire. }\end{array}$ & $\begin{array}{l}\text { BnF fr. } 24301 \\
\text { Plusieurs œuvres } \\
\text { morales, dont une Vie } \\
\text { des Pères - cf. annexe D. } \\
\text { Fin des années } 1260 . \\
\text { Est de la France } \\
\text { Pas de miniatures }\end{array}$ \\
\hline
\end{tabular}




\begin{tabular}{|c|c|c|c|}
\hline Titre courant & Datation & Localisation & $\begin{array}{l}\text { Contexte manuscrit et } \\
\text { diffusion }\end{array}$ \\
\hline $\begin{array}{l}\text { Jean Froissart, } \\
\text { Melyador }\end{array}$ & $\begin{array}{l}\text { 1362-1369: } \\
\text { première version } \\
\text { 1381-1383: } \\
\text { deuxième version }\end{array}$ & $\begin{array}{l}\text { Froissart est } \\
\text { originaire du } \\
\text { Hainaut. } \\
\text { - Cour d'Angleterre, } \\
\text { pour Édouard III et } \\
\text { Philippa de Hainaut } \\
\text { (1'ere version) } \\
\text { - Wenceslas de } \\
\text { Brabant (2 } \\
\text { versione }\end{array}$ & $\begin{array}{l}\text { BnF fr. } 12557 . \\
\text { Ne contient que } \\
\text { Melyador dans sa } 2^{\text {ème }} \\
\text { version } \\
\text { Date: fin du XIv } \\
\text { Picardie } \\
1 \text { miniature } \\
\text { BnF nouv. acqu. lat. } \\
2374 \text { (4 fragments de la } \\
\text { première version) } \\
\text { Date: Fin XIv } \\
\text { Nord-Est } \\
\text { Mention dans un } \\
\text { inventaire du Château } \\
\text { de Blois de Charles } \\
\text { d'Orléans en } 1466 \\
\text { Lecture à Gaston Fébus } \\
\text { en } 1388 \text { (rapporté dans } \\
\text { Le Dit dou Florin et les } \\
\text { Chroniques) }\end{array}$ \\
\hline
\end{tabular}




\section{ANNEXE B: INSERTION LYRIQUE DANS ESCANOR}

Source: https://gallica.bnf.fr/ark:/12148/btv1b9063126g.r=escanor?rk=21459;2

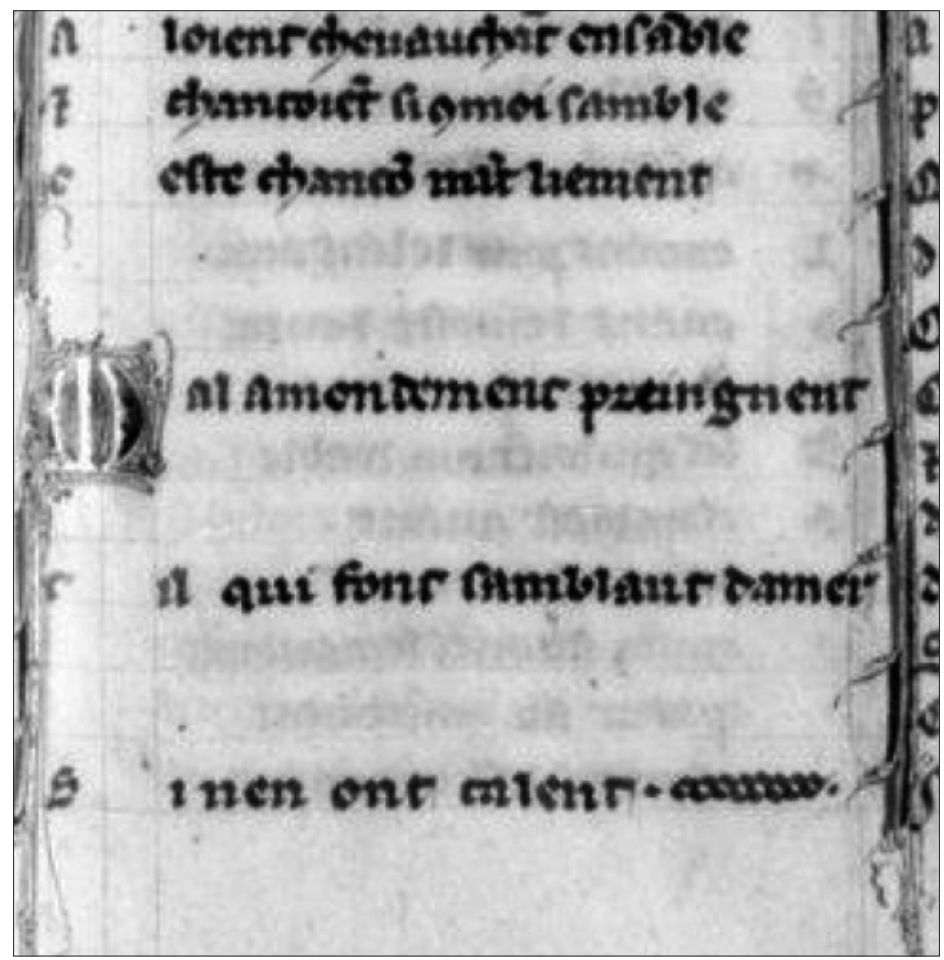




\section{ANNEXE C: DIFFUSION DU ROMAN ARTHURIEN EN VERS APRÈS LE XIIIe SIÈCLE}

\section{Manuscrits conservant des romans arthuriens en vers après 1300}

\begin{tabular}{|c|c|c|}
\hline Cote & Contenu & Date et lieu \\
\hline $\begin{array}{l}\text { BnF fr. } 2164 \\
\text { Informations: Charmaine Lee, } \\
\text { "La tradition "indirecte" ", } \\
\text { art. cit. }\end{array}$ & - Jaufré & $\begin{array}{l}\text { Fin XIII }{ }^{\mathrm{e}} \text {, début } \\
\mathrm{XIV}^{\mathrm{e}} \\
\text { Nîmes }\end{array}$ \\
\hline $\begin{array}{l}\text { BnF fr. } 12571 \\
\text { Informations: Charmaine Lee, } \\
\text { "La tradition "indirecte" ", } \\
\text { art. cit. }\end{array}$ & - Jaufré & $\begin{array}{l}\text { Fin XIII }{ }^{\mathrm{e}} \text {, début } \\
\mathrm{XIV}^{\mathrm{e}} \\
\text { Italie }\end{array}$ \\
\hline $\begin{array}{l}\text { BnF fr. } 12603 \\
\text { Informations: Terry Nixon, } \\
\text { "Catalogue of Manuscripts», } \\
\text { in Les Manuscrits de Chrétien } \\
\text { de Troyes, tome 2, p. 18-85, } \\
\text { Richard Trachsler, "Le recueil } \\
\text { Paris, BN fr. 12603», art. cit., } \\
\text { et Sarah Fourcade, "Les } \\
\text { lecteurs nobles de la littérature } \\
\text { arthurienne à la fin du Moyen } \\
\text { Âge», in Arthur après Arthur, } \\
\text { p. } 429-442 .\end{array}$ & $\begin{array}{l}\text { - Le chevalier aux deux épées } \\
\text { - Chrétien de Troyes, Le Chevalier } \\
\text { au lion } \\
\text { - Le roman d'Enéas } \\
\text { - Wace, Le roman de Brut } \\
\text { - Adenet le roi, Les enfances Ogier } \\
\text { le Danois } \\
\text { - Fierabras } \\
\text { - } 18 \text { fabliaux et récits en vers, } \\
\text { dont le Songe d'Enfer de Raoul } \\
\text { de Houdenc et La Compagnie } \\
\text { Renard } \\
\text { - Marie de France, Les Fables } \\
\text { - Fabliau «De la femme qui cun- } \\
\text { quie sen baron» }\end{array}$ & $\begin{array}{l}\text { Fin XIII }{ }^{\mathrm{e}} \text {, début } \\
\text { XIV }^{\mathrm{e}} \\
\text { A appartenu } \\
\text { à Charles de } \\
\text { Croÿ, comte de } \\
\text { Chimay, au XV } \\
\text { siècle } \\
\text { Arras }\end{array}$ \\
\hline $\begin{array}{l}\text { BnF nouv. acqu. fr. } 5386 \\
\text { Informations: arlima.net }\end{array}$ & $\begin{array}{l}\text { - Fragments d'une traduction } \\
\text { français de la Bible } \\
\text { - Épître de Saint Paul aux Romains } \\
\text { - Nicole Oresme, Ethiques, frag- } \\
\text { ment } \\
\text { - Histoire universelle depuis } \\
\text { Adam jusqu’à Louis XI, dauphin } \\
\text { - Raoul de Houdenc, Méraugis de } \\
\text { Portlesguez, fragment } \\
\text { - Évangiles selon saint Matthieu } \\
\text { (et saint Marc en provençal) }\end{array}$ & $\begin{array}{l}\text { Fin XIII }{ }^{\mathrm{e}} \text {, début } \\
\mathrm{XIV}^{\mathrm{e}} \\
\text { Picardie }\end{array}$ \\
\hline
\end{tabular}

1 Voir Richard Trachsler, «Le recueil Paris, BN fr. 12603», art. cit., pour le détail des fabliaux et récits brefs en vers contenu dans ce manuscrit. 


\begin{tabular}{|c|c|c|}
\hline Cote & Contenu & Date et lieu \\
\hline $\begin{array}{l}\text { Vatican, lat. } 1725 \\
\text { Informations: Terry Nixon, } \\
\text { "Catalogue of Manuscripts», } \\
\text { art. cit., Francis Gingras, } \\
\text { «Roman contre roman dans } \\
\text { l'organisation du manuscrit du } \\
\text { Vatican, Regina Latina } 1725 », \\
\text { art. cit. }\end{array}$ & $\begin{array}{l}\text { - Chrétien de Troyes, Chevalier de } \\
\text { la Charrette } \\
\text { - Chrétien de Troyes, Chevalier au } \\
\text { - Lion } \\
\text { - Jean Renart, Guillaume de Dôle } \\
\text { Raoul de Houdenc, Méraugis de } \\
\text { Portlesguez }\end{array}$ & $\begin{array}{l}\text { Fin XIII', début } \\
\text { XIV }^{e} \\
\text { Nord-est de la } \\
\text { France }\end{array}$ \\
\hline $\begin{array}{l}\text { Vienne, Nationalbibliothek } \\
2599 \\
\text { Informations: Keith Busby, } \\
\text { "Mise en texte and Mise en } \\
\text { image: Méraugis de Portlesguez } \\
\text { in Vienna, ÖNB 2599", } \\
\text { art. cit. }\end{array}$ & $\begin{array}{l}\text { - Raoul de Houdenc, Méraugis de } \\
\text { Portlesguez }\end{array}$ & $\begin{array}{l}\begin{array}{l}\text { Deuxième quart } \\
\text { du XIV }\end{array} \\
\text { Paris }\end{array}$ \\
\hline $\begin{array}{l}\text { BnF fr. } 375 \\
\text { Informations: Terry Nixon, } \\
\text { "Catalogue of Manuscripts", } \\
\text { art. cit. }\end{array}$ & $\begin{array}{l}27 \text { textes, parmi lesquels Erec et } \\
\text { Enide }\end{array}$ & $\begin{array}{l}\text { Fin } \mathrm{XIII}^{\mathrm{e}} \text {, début } \\
\mathrm{XIV}^{\mathrm{e}} \\
\text { Arras }\end{array}$ \\
\hline $\begin{array}{l}\text { BnF fr. } 1376 \\
\text { Informations: Terry Nixon, } \\
\text { "Catalogue of Manuscripts", } \\
\text { art. cit. }\end{array}$ & $\begin{array}{l}\text { - Aimon de Varennes, Florimont } \\
\text { - Chrétien de Troyes, Erec et Enide }\end{array}$ & $\begin{array}{l}\text { Fin } \mathrm{XIII}^{\mathrm{e}} \text {, début } \\
\mathrm{XIV}^{\mathrm{e}} \\
\text { Bourgogne }\end{array}$ \\
\hline $\begin{array}{l}\text { BnF fr. } 1447 \\
\text { Informations: édition de } \\
\text { Corinne Pierreville, p. 56-59. }\end{array}$ & $\begin{array}{l}\text { - Floire et Blancheflor } \\
\text { - Berte aux grands pieds } \\
\text { - Claris et Laris }\end{array}$ & $\begin{array}{l}\text { Début XIv } \\
\text { Île-de-France }\end{array}$ \\
\hline $\begin{array}{l}\text { New York, Public Library, De } \\
\text { Ricci } 122 \\
\text { Informations: édition de } \\
\text { Richard Trachsler et Annie } \\
\text { Combes. } \\
\text { Jonathan J. G. Alexander et } \\
\text { al., The Splendor of the Word, } \\
\text { p. 389-391. }\end{array}$ & - Floriant et Florete & $\begin{array}{l}\text { Fin XIII', début } \\
\text { XIV }^{\mathrm{e}} \\
\text { ou premier } \\
\text { quart du XIV } \\
\text { Nord - Nord- } \\
\text { Est de la France }\end{array}$ \\
\hline
\end{tabular}




\begin{tabular}{|c|c|c|}
\hline Cote & Contenu & Date et lieu \\
\hline $\begin{array}{l}\text { BnF fr. } 1433 \\
\text { Informations: Terry Nixon, } \\
\text { "Catalogue of Manuscripts", } \\
\text { art. cit. } \\
\text { Lori Walters, "The Creation of } \\
\text { a "Super Romance" ", art. cit. }\end{array}$ & $\begin{array}{l}\text { - L'Âtre Périlleux } \\
\text { - Chrétien de Troyes, Le Chevalier } \\
\text { au lion }\end{array}$ & $\begin{array}{l}\text { Premier quart } \\
\text { du XIV }(1315- \\
1330) \\
\text { Nord-est de la } \\
\text { France }\end{array}$ \\
\hline $\begin{array}{l}\text { New York, Morgan Library, } \\
\text { M. } 819 \\
\text { Chansonnier provençal N } \\
\text { Informations: Charmaine Lee, } \\
\text { "La tradition "indirecte" ", } \\
\text { art. cit. }\end{array}$ & $\begin{array}{l}\text { - Ensenhamens } \\
\text { - Jaufré, fragment de } 280 \text { vers } \\
\text { - Raimon Vidal, Judici d'Amor } \\
\text { - Le roman du comte de Toulouse, } \\
\text { fragment } \\
\text { - La cort d'amor } \\
\text { - Énigme, en occitan }\end{array}$ & $\begin{array}{l}\text { XIV } \\
\text { Vénétie, Italie }\end{array}$ \\
\hline $\begin{array}{l}\text { Paris, BnF fr. } 1453 \\
\text { Informations: Terry Nixon, } \\
\text { "Catalogue of Manuscripts", } \\
\text { art. cit. }\end{array}$ & $\begin{array}{l}\text { - Chrétien de Troyes, Le Conte du } \\
\text { Graal } \\
\text { - Première Continuation } \\
\text { - Deuxième Continuation } \\
\text { - Continuation Manessier } \\
\end{array}$ & $\begin{array}{l}2^{\mathrm{e}} \text { quart du XIV } \\
\text { Paris }\end{array}$ \\
\hline $\begin{array}{l}\text { Paris, BnF fr. } 12577 \\
\text { Informations: Terry Nixon, } \\
\text { "Catalogue of Manuscripts", } \\
\text { art. cit. }\end{array}$ & $\begin{array}{l}\text { - Chrétien de Troyes, Le Conte du } \\
\text { Graal } \\
\text { - Première Continuation } \\
\text { - Deuxième Continuation } \\
\text { - Continuation Manessier }\end{array}$ & $\begin{array}{l}2^{\mathrm{e}} \text { quart du XIV } \\
\text { Paris }\end{array}$ \\
\hline $\begin{array}{l}\text { Montpellier, Bibliothèque } \\
\text { interuniversitaire, section } \\
\text { Médecine, H252 } \\
\text { Informations: Terry Nixon, } \\
\text { "Catalogue of Manuscripts", } \\
\text { art. cit. }\end{array}$ & $\begin{array}{l}\text { - Chrétien de Troyes, Le Chevalier } \\
\text { au lion } \\
\text { - Aimon de Varennes, Florimont } \\
\text { Il s'agit d'un recueil factice. Les } \\
\text { textes sont fragmentaires }\end{array}$ & $\begin{array}{l}\text { Milieu du XIv } \\
\text { Nord de la } \\
\text { France }\end{array}$ \\
\hline $\begin{array}{l}\text { Londres, College of Arms, } \\
\text { Arundel XIV } \\
\text { Informations: Terry Nixon, } \\
\text { "Catalogue of Manuscripts", } \\
\text { art. cit. }\end{array}$ & $\begin{array}{l}\text { - Wace, Le roman de Brut } \\
\text { - Gaimar, L'Histoire des Engleis } \\
\text { - Le lai d'Haveloc } \\
\text { - Peter Langtoft, Chronicle, partie } 3 \\
\text { - La lignée des Bretons et des Engleis } \\
\text { - Chrétien de Troyes, Le Conte du } \\
\text { graal } \\
\text { - Walter of Henley, The Husban- } \\
\text { dry } \\
\text { - Art d'aimer }\end{array}$ & $\begin{array}{l}\begin{array}{l}\text { Deuxième } \\
\text { moitié du XIV }\end{array} \\
\text { Angleterre }\end{array}$ \\
\hline
\end{tabular}




\begin{tabular}{|c|c|c|}
\hline Cote & Contenu & Date et lieu \\
\hline $\begin{array}{l}\text { Vatican, lat. } 3206 \\
\text { Chansonnier provençal L } \\
\text { Informations: Charmaine Lee, } \\
\text { "La tradition "indirecte" ", } \\
\text { art. cit. }\end{array}$ & $\begin{array}{l}\text { - Chastel d'Amors } \\
\text { - Raimon Vidal, En aquel tems } \\
\text { - Jaufré, fragment } \\
\text { - Peire de Corbian, Thesaur }\end{array}$ & $\begin{array}{l}\text { Fin } \mathrm{XIV}^{\mathrm{e}} \\
\text { Italie }\end{array}$ \\
\hline $\begin{array}{l}\text { BnF fr. } 353 \\
\text { Informations: jonas.irht.cnrs.fr }\end{array}$ & $\begin{array}{l}\text { - Aimon de Varennes, Florimont } \\
\text { - Le Mantel mautaillé (en longues } \\
\text { lignes) }\end{array}$ & $\begin{array}{l}\text { Fin XIV } \\
\\
\text { A appartenu } \\
\text { à Nicolas } \\
\text { Moreau, Sieur } \\
\text { d'Auteuil au } \\
\text { XVII }{ }^{\mathrm{e}} \text { siècle } \\
\end{array}$ \\
\hline $\begin{array}{l}\text { Turin, L. IV. } 33 \\
\text { Informations: Francesco } \\
\text { Carapezza, «Le fragment } \\
\text { de Turin", art. cit., } \\
\text { Roger Middleton, "The } \\
\text { Manuscripts», art. cit., p. 36, et } \\
\text { jonas.irht.cnrs.fr }\end{array}$ & $\begin{array}{l}\text { - Le Roman de Troie en prose } \\
\text { - La chronique du Pseudo-Turpin } \\
\text { - Clerc de Vaudoy, Le dit des droitz } \\
\text { - Chroniques d'outremer } \\
\text { - D'une aventure du roi Artu (Rigo- } \\
\text { mer) } \\
\text { - Mélion } \\
\text { - Gliglois } \\
\text { - Raoul de Houdenc, Méraugis de } \\
\text { Portlesguez } \\
\text { - Le Roman de Thèbes en prose }\end{array}$ & $\begin{array}{l}\text { Fin } \mathrm{XIV}^{\mathrm{e}} \text {, début } \\
\mathrm{XV}^{\mathrm{e}} \\
\text { Savoy? }\end{array}$ \\
\hline $\begin{array}{l}\text { BnF fr. } 12557 \\
\text { Informations: édition de } \\
\text { Nathalie Bragantini-Maillard }\end{array}$ & - Melyador & $\begin{array}{l}\text { Tournant du } \\
\text { XIV }^{\mathrm{e}} \\
\text { Picardie }\end{array}$ \\
\hline $\begin{array}{l}\text { BnF, nouv. acq. lat. } 2374 \\
\text { Informations: édition de } \\
\text { Nathalie Bragantini-Maillard }\end{array}$ & $\begin{array}{l}\text { Fragments de Melyador, parmi } \\
\text { d'autres fragments de textes latins } \\
\text { et français }\end{array}$ & 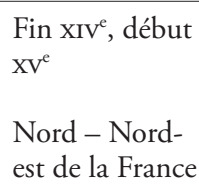 \\
\hline
\end{tabular}




\section{Mises en prose de romans arthuriens aux $\mathrm{XIV}^{\mathrm{e}}$ et $\mathrm{XV}^{e}$ siècles}

Informations tirées du Nouveau répertoire des mises en prose, dir. Maria Colombo Timelli et al.

\begin{tabular}{|l|l|l|}
\hline Source & Nom et cote de la MP & $\begin{array}{l}\text { Date de la } \\
\text { MP }\end{array}$ \\
\hline $\begin{array}{l}\text { Chrétien de Troyes, Le } \\
\text { Chevalier de la Charrette }\end{array}$ & $\begin{array}{l}\text { Le Conte de la Charrette } \\
\text { Paris, BnF, Arsenal 3480. vers 1400. A } \\
\text { appartenu à la famille de Croÿ } \\
\text { Paris, BnF fr. 119. vers 1400 } \\
\text { Paris, BnF fr. 122. 1345. A appartenu à } \\
\text { Louis de Bruges }\end{array}$ & $\begin{array}{l}\text { Le Conte de la Charrette est mis en recueil } \\
\text { Le Coc diverses parties du Lancelot en } \\
\text { prose. Cette mise en prose n'a donc pas } \\
\text { d'autonomie et fait office d'épisode du } \\
\text { Lancelot. }\end{array}$ \\
\hline $\begin{array}{l}\text { Chrétien de Troyes, } \\
\text { Cligès }\end{array}$ & $\begin{array}{l}\text { Le livre de Alixandre empereur de } \\
\text { Constantinoble et de Cligés son filz } \\
\text { Leipzig, UB, Rep-II-108. A appartenu à } \\
\text { Philippe le Bon }\end{array}$ & Avant 1455 \\
\hline $\begin{array}{l}\text { Chrétien de Troyes, Erec } \\
\text { et Enide }\end{array}$ & $\begin{array}{l}\text { Erec } \\
\text { Bruxelles, KBR, 7235. 1450-1460. A } \\
\text { appartenu à Philippe le Bon }\end{array}$ & Avant 1468 \\
\hline
\end{tabular}

2 Il s'agit ici de la version bourguignonne. Il existe un autre «Erec en prose», interpolé au manuscrit $\mathrm{BnF}$ fr. 112 daté de 1470, mais l'histoire d'Erec n'est pas une mise en prose du roman de Chrétien de Troyes dans ce cas. Voir Gilles Susong, "À propos de deux récits arthuriens du XIve siècle: Erec, Perceforest", Le Moyen Français, 30, 1992, p. 19-25, Friedrich Wolfzettel, «Le Roman d'Erec en prose du XIII ' siècle: un anti-Erec et Enide?», in The Legacy of Chrétien de Troyes, dir. Norris J. Lacy, Douglas Kelly et Keith Busby, Amsterdam, Rodopi, 1987-1988, vol. II, p. 215-228, et Cédric Pickford, Lévolution du roman arthurien en prose vers la fin du Moyen Âge: d'après le manuscrit 112 du fonds français de la Bibliothèque nationale, Paris, A. G. Nizet, 1960. 


\begin{tabular}{|c|c|c|}
\hline Source & Nom et cote de la MP & $\begin{array}{l}\text { Date de la } \\
\text { MP }\end{array}$ \\
\hline & $\begin{array}{l}\text { Fragment interpolé: } \\
\text { Paris, BnF fr. 363. A appartenu à Louis de } \\
\text { Bruges }^{3} \\
\text { Regroupement de folios illustrés: } \\
\text { Oxford, Bodl. Libr., Douce 383. A } \\
\text { appartenu à Engelbert de Nassau }\end{array}$ & \\
\hline $\begin{array}{l}\text { Différents textes, dont } \\
\text { Chrétien de Troyes, Le } \\
\text { Chevalier au lion, le } \\
\text { Chevalier aux deux épées. } \\
\text { Ces épisodes } \\
\text { s'entremêlent à d'autres } \\
\text { tirés de la Queste, du } \\
\text { Lancelot en prose, du } \\
\text { Tristan en prose }\end{array}$ & $\begin{array}{l}\text { Aberystwyth, National Library } 444 \mathrm{D} \\
\text { Plusieurs épisodes juxtaposés dans ce } \\
\text { manuscrit: } \\
\text { 1. Yvain face au combat d'un dragon et } \\
\text { d'un lion } \\
\text { 2. La sœur de Perceval donne son sang } \\
\text { pour sauver une lépreuse } \\
\text { 3. Une aventure de Lancelot et Palamède, } \\
\text { qui sauvent Gaheriet } \\
\text { 4. Gauvain attaqué par Burian, dont l'amie } \\
\text { le déteste (Le Chevalier aux deux épées) } \\
\text { 5. Gaheriet puis Yvain sauvés par le Cheva- } \\
\text { lier à la cotte mal taillée } \\
\text { 6. Lancelot libère Tristan puis tous deux } \\
\text { vainquent deux géants } \\
\text { 7. Tristant, Yseut aux blanches mains et } \\
\text { Kahedin emprisonnés par un géant. } \\
\text { Bataille entre les chevaliers de Logres et } \\
\text { de Norgales }\end{array}$ & $\begin{array}{l}\text { XIV }{ }^{e} \text { siècle } \\
\text { Voir l'article } \\
\text { de Norris J. } \\
\text { Lacy, "The } \\
\text { enigma of } \\
\text { the prose } \\
\text { Yvain», } \\
\text { art. cit. }\end{array}$ \\
\hline Floriant et Florete & $\begin{array}{l}\text { Rouman de Floriant et Florete } \\
\text { Paris, BnF fr. } 1492.1480-1490 \\
\text { Paris, BnF fr. } 1493.1480-1490\end{array}$ & Vers 1480 \\
\hline $\begin{array}{l}\text { Composition entrelacée } \\
\text { à partir de: } \\
\text { Jaufré } \\
\text { Renaut de Beaujeu, Le } \\
\text { Bel Inconnu } \\
\text { Roman de Laurin }\end{array}$ & $\begin{array}{l}\text { Claude Platin, Giglan: L'hystoire de Giglan } \\
\text { fllz de messire Gauvain qui fut roy de Galles. } \\
\text { Et de Geoffroy de Maience son compaignon: } \\
\text { tous deux chevaliers de la table Ronde. } \\
\text { Imprimés: } \\
\text { Lyon, Claude Nourry. } 1520 \\
\text { Lyon, Olivier Arnoullet. Environ } 1525 \\
\text { Lyon, Frères Gilles et Jacques Huguetan. } 1539\end{array}$ & $\begin{array}{l}\text { Autour de } \\
1520\end{array}$ \\
\hline
\end{tabular}

3 Sur cette interpolation, voir l'article de Barbara Wahlen, "Adjoindre, disjoindre, conjoindre. Le recyclage d'Alixandre l'Orphelin et de l'Histoire d'Erec dans Guiron le Courtois (Paris, BnF, français 358-363)", art. cit. 


\begin{tabular}{|c|c|c|}
\hline Source & Nom et cote de la MP & $\begin{array}{l}\text { Date de la } \\
\text { MP }\end{array}$ \\
\hline $\begin{array}{l}\text { Chrétien de Troyes, Le } \\
\text { Conte du Graal } \\
\text { Première Continuation } \\
\text { Deuxième Continuation } \\
\text { de Wauchier de Denain } \\
\text { Continuation de } \\
\text { Manessier } \\
\text { Prologues de Elucidation } \\
\text { et Bliocadran }\end{array}$ & $\begin{array}{l}\text { La Tresplaisante et recreative Hystoire du } \\
\text { Trespreulx et vaillant Chevallier Perceval le } \\
\text { Galloys } \\
\text { Imprimé: } \\
\text { Paris, Bernard Aubry. } 1530\end{array}$ & Avant 1530 \\
\hline Le Mantel Mautaillé & $\begin{array}{l}\text { Le compte du mantheau mal taillé. Dédié à la } \\
\text { cousine de l'auteur. } \\
\text { Manuscrit: BnF fr. } 2153 \text {. Porte l'inscription } \\
\text { "Ce livre est a moy Henry de Tournon»". } \\
\text { Imprimé: } \\
\text { Lyon, François Didier, } 1577 \text { ou } 1578^{5}\end{array}$ & $\mathrm{XVI}^{\mathrm{e}}$ siècle \\
\hline
\end{tabular}

4 Frederik-Amadeus Wulff, "Le conte du Mantel, texte français des dernières années du XIII ${ }^{\mathrm{e}}$ siècle", Romania, 55-56, 1885, p. 343-380.

5 Cet imprimé est perdu. 


\section{ANNEXE D: LE MANUSCRIT BNF FR. 24301}

5

\begin{tabular}{|c|c|}
\hline \multicolumn{2}{|c|}{$\begin{array}{l}\text { Les œuvres de Robert de Blois dans le ms. BnF fr. } \mathbf{2 4 3 0 1} \\
\text { Le présent découpage est souvent guidé par les initiales du manuscrit }{ }^{6} \text {. Aucun blanc ou } \\
\text { rubrique ne donne plus d'indices }\end{array}$} \\
\hline Prologue général & $\begin{array}{l}\text { Pages } 475 \mathrm{a}-478 \mathrm{a} \\
\text { Commence par une grande initiale ornée de } 8 \text { UR } \\
4 \text { petites initiales de } 2 \text { UR structurent le reste du texte } \\
\text { Ce prologue, quelque peu modifié, se trouve aussi dans } \\
\text { Arsenal } 4201 \text { et BnF fr. } 2236\end{array}$ \\
\hline Prologue de Biaudouz & $\begin{array}{l}\text { Pages } 478 \mathrm{~b}-479 \mathrm{~b} \\
\text { Commence par une initiale de } 3 \text { UR, qui se prolonge dans la } \\
\text { marge et se termine en bande d'I. }\end{array}$ \\
\hline Début de Biaudouz & $\begin{array}{l}\text { Pages } 479 \mathrm{~b}-480 \mathrm{~b} \\
\text { Commence par une initiale de } 4 \mathrm{UR} \\
2 \text { petites initiales structurent le reste du texte }\end{array}$ \\
\hline $\begin{array}{l}\text { Début du discours de } \\
\text { la mère }\end{array}$ & $\begin{array}{l}\text { Pages } 480 \mathrm{~b}-484 \mathrm{~b} \\
\text { Commence par une initiale de } 5 \text { UR prolongée en bande d'I } \\
6 \text { petites initiales structurent le reste du texte }\end{array}$ \\
\hline $\begin{array}{l}\text { De la Trinité } \\
\text { Texte religieux }\end{array}$ & $\begin{array}{l}\text { Pages } 484 \mathrm{~b}-487 \mathrm{a} \\
\text { Commence par une petite initiale de } 2 \text { UR } \\
1 \text { petite initiale structure le reste du texte } \\
\text { Ce texte se trouve aussi dans Arsenal } 5201, \mathrm{BnF} \text { fr. } 2236 \text { et } \\
\text { Arsenal } 3516\end{array}$ \\
\hline $\begin{array}{l}\text { Enseignement des princes } \\
\text { début } \\
\text { Miroir des princes, } \\
\text { conseils prodigués } \\
\text { sur le plan } \\
\text { religieux, politique, } \\
\text { chevaleresque. Mise } \\
\text { en garde contre les } \\
\text { mauvaises personnes et } \\
\text { les vices }\end{array}$ & $\begin{array}{l}\text { Pages } 487 \mathrm{~b}-491 \mathrm{a} \\
\text { Commence par une petite initiale de } 2 \text { UR. La transition } \\
\text { rappelle qu'il s'agit du discours de la mère («Biaus fiz») } \\
22 \text { petites initiales structurent le reste du texte } \\
\text { Ce texte - et sa suite - se trouve aussi dans Arsenal } 5201 \text {, } \\
\text { BnF fr. } 2236 \text { et Arsenal } 3516\end{array}$ \\
\hline $\begin{array}{l}\text { Honneur des dames } \\
\text { Texte didactique } \\
\text { invitant les hommes à } \\
\text { honorer les femmes }\end{array}$ & $\begin{array}{l}\text { Pages } 491 \mathrm{a}-493 \mathrm{a} \\
3 \text { petites initiales structurent le reste du texte } \\
\text { Ce texte se trouve aussi dans Arsenal } 5201, \mathrm{BnF} \text { fr. } 2236 \text { et } \\
\text { Arsenal } 3516\end{array}$ \\
\hline
\end{tabular}

6 On consultera les tableaux de Milena Mikhaïlova-Makarius pour plus de détails sur les correspondances entre les manuscrits des œuvres de Robert de Blois et la structuration des lettrines dans le recueil entier. L'École du roman, p. 340-346; 363-376. 


\begin{tabular}{|c|c|}
\hline $\begin{array}{l}\text { Enseignement des princes } \\
\text { suite }\end{array}$ & $\begin{array}{l}\text { Pages } 493 \mathrm{a}-508 \mathrm{a} \\
\text { Commence par une initiale de } 3 \text { UR } \\
21 \text { petites initiales de } 2 \text { à } 3 \text { UR structurent le reste du texte }\end{array}$ \\
\hline Sermon & $\begin{array}{l}\text { Pages } 508 \mathrm{a}-520 \mathrm{~b} \\
\text { Commence par une initiale de } 4 \text { UR } \\
7 \text { petites initiales }-1 \text { initiale de } 5 \text { UR }-22 \text { petites initiales } \\
\text { Ce texte se trouve aussi dans Arsenal } 5201 \text {, BnF fr. } 2236 \text { et } \\
\text { partiellement dans Arsenal } 3516\end{array}$ \\
\hline Création du monde & $\begin{array}{l}\text { Pages } 520 \mathrm{~b}-527 \mathrm{a} \\
\text { Commence par une initiale de } 6 \text { UR } \\
\text { Ce texte se trouve aussi dans Arsenal } 5201\end{array}$ \\
\hline $\begin{array}{l}\text { Floris et Lyriopé } \\
\text { Roman qui raconte } \\
\text { l'amour entre les } \\
\text { parents de Narcisse et } \\
\text { présente le malheur } \\
\text { de celui-ci comme } \\
\text { une conséquence du } \\
\text { comportement de sa } \\
\text { mère, une orgueilleuse } \\
\text { d'amour. Le prologue } \\
\text { de Floris et Lyriopé } \\
\text { blâme l'orgueil. }\end{array}$ & $\begin{array}{l}\text { Pages } 527 \mathrm{a}-550 \mathrm{~b} \\
\text { Commence par une initiale de } 7 \text { UR } \\
15 \text { petites initiales structurent le reste du texte } \\
\text { Ce texte se trouve aussi dans Arsenal } 5201\end{array}$ \\
\hline $\begin{array}{l}\text { Chastoiement des dames } \\
\text { Conseils de bon } \\
\text { comportement à } \\
\text { destination des } \\
\text { femmes. Il donne des } \\
\text { conseils sur l'amour } \\
\text { également. }\end{array}$ & $\begin{array}{l}\text { Pages } 550 \mathrm{~b}-560 \mathrm{~b} \\
\text { Commence par une initiale de } 7 \text { UR } \\
\text { Une initiale de } 4 \text { UR marque le début de l'enseignement } \\
25 \text { petites initiales structurent le reste du texte } \\
\text { Ce texte se trouve aussi dans Arsenal 5201, Arsenal } 3516 \text { et } \\
\text { BnF fr. } 837 \text {. }\end{array}$ \\
\hline $\begin{array}{l}\text { D'Amour } \\
\text { Art d'aimer, description } \\
\text { des manifestations de } \\
\text { l'amour. }\end{array}$ & $\begin{array}{l}\text { Pages } 560 \mathrm{~b}-565 \mathrm{~b} \\
\text { Commence par une petite initiale de } 2 \text { UR } \\
1 \text { petite initiale structure le reste du texte } \\
\text { Ce texte se trouve aussi dans Arsenal } 5201, \mathrm{BnF} \text { fr. } 2236 \text {, } \\
\text { Arsenal } 3516, \mathrm{BnF} \text { fr. } 837 \text { et London Add. } 10289\end{array}$ \\
\hline Biaudouz suite et fin & $\begin{array}{l}\text { Pages } 565 \text { b- } 620 \text { b } \\
\text { Commence par une initiale de } 5 \text { UR } \\
57 \text { petites lettrines structurent le reste du texte } \\
\text { Le texte s'achève au milieu d'une phrase, à la fin de la } \\
\text { colonne b. Selon la base de données de l'IRHT Jonas, il } \\
\text { manque deux folios au dernier senion. }\end{array}$ \\
\hline
\end{tabular}


$\frac{\tilde{N}}{\frac{0}{J}}$

ᄃ

픅

픔

들

(1)

풀

ฮํ

(1)

다

ข)

듬

이

ฮิ

브

능 


\section{BIBLIOGRAPHIE}

\section{Sources}

Arthur, Gauvain et Mériadoc. Récits arthuriens latins du XIIt siècle, dir. Philippe Walter, Grenoble, Ellug, 2007.

Artus de Bretagne. Roman en prose de la fin du XIII siècle, éd. Christine FerlampinAcher, Paris, Champion ("CFMA»), 2017.

L'Âtre Périlleux, éd. Brian Woledge, Paris, Champion («CFMA»), 1936.

Aye d'Avignon, chanson de geste anonyme, éd. Samuel J. Borg, Genève, Droz, 1967. Baudelaire Charles, Euvres complètes, Paris, Gallimard («Pléiade»), 1975 [1869, posthume].

Beneit, La vie de saint Thomas Becket, poème anglo-normand du xiie siècle, éd. Borje Schlyter, Lund, Études romanes de Lund, 1941.

Benoît, Chronique des ducs de Normandie, éd. Carin Fahlin, Uppsala, Almqvist, 1951, 3 tomes.

Benoît de Sainte-Maure, Le Roman de Troie, éd. Emmanuèle Baumgartner, Paris, Le Livre de Poche («Lettres gothiques»), 1998.

Bertrand de Bar-sur-Aube, Girart de Vienne, éd. Wolfgang van Emden, Paris, SATF, 1970.

La Bataille Loquifer, éd Monica Barnett, Oxford, Society for the Study of Medieval Languages and Literature («Medium Aevum»), 1975.

Blandin di Cornovaglia, éd. Sabrina Galano, Alessandria, Edizioni dell'Orso, 2004.

An Annotated Edition of Brun de la Montaigne, éd. Charles Louis Janssens, thèse de l'Université d'Arizona, 1967.

Brunet Latin, Livre du Trésor, éd Francis J. Carmody, Los Angeles, Berkeley, 1948.

Cartulaire général de l'Ordre des Hospitaliers de Saint-Jean de Jérusalem, éd. Joseph Delaville, Paris, Leroux, 1894, 3 vol.

La Chanson de Roland, éd. Ian Short, Paris, le Livre de Poche («Lettres gothiques»), 1990.

Le Chevalier à l'épée, éd. Ronald C. Johnston et Douglas D. R. Owen, in Two Old French Gauvain Romances, Edinburgh, Scottish Academic Press, 1972, p. 30-60. 
Chrétien de Troyes, Le Chevalier de la Charrette, éd. Catherine Croizy-Naquet, Paris, Champion ("CCMA»), 2006.

Chrétien de Troyes, Le Chevalier au lion, éd. David F. Hult, Paris, Le Livre de Poche («Lettres gothiques»), 1994.

Chrétien de Troyes, Cligès, éd. Laurence Harf-Lancner, Paris, Champion («CCMA»), 2006.

Chrétien de Troyes, Erec et Enide, éd. Jean-Marie Fritz, Paris, Le Livre de Poche («Lettres gothiques»), 2013.

Chrétien de Troyes, Le Conte du graal, éd. Charles Méla, Paris, Le Livre de Poche («Lettres gothiques»), 1990.

La Chronique métrique attribuée à Geoffroy de Paris, éd. Armel Diverrès, Strasbourg, Faculté des Lettres, 1956.

Claris et Laris, éd. Corinne Pierreville, Paris, Champion («CFMA»), 2008.

Claris et Laris, trad. Corinne Pierreville, Paris, Champion ("CFMA»), 2007.

Conte de Floire et Blanchefleur, éd. Jean-Luc Leclanche, Paris, Champion («CCMA»), 2003.

Le Conte du Papegau, éd. Hélène Charpentier et Patricia Victorin, Paris, Champion, («CCMA»), 2004.

Coudrette, Le Roman de Mélusine ou Histoire de Lusignan, éd. Eleanor Roach, Paris, Klincksieck, 1982.

Coudrette, Le Roman de Mélusine, trad. Laurence Harf-Lancner, Paris, GF, 1993.

Couldrette, Mélusine (Roman de Parthenay ou Roman de Lusignan), éd. Matthew W. Morris et Jean-Jacques Vincensini, New York, Lewiston Edwin Mellen Press, 2009.

Cristal und Clarie, altfranzösischer Abenteurerroman des XIII. Jahrhunderts, éd. Hermann Breuer, Dresden, Gesellschaft für romanische Literatur, 1915.

Le Cycle de Guillaume d'Orange, éd. Dominique Boutet, Paris, Le Livre de Poche ("Lettres gothiques»), 1996.

Dame Guile, éd. Achille Jubinal, Jongleurs et trouvères, Paris, Librairie J. Albert Merklein, 1835.

The Didot Perceval, éd. William Roach, Philadelphia, University of Pennsylvania Press, 1941.

Durmart le Galois, roman arthurien du treizième siècle, éd. Joseph Gildea, Villanova, Villanova Press, 1965-1966.

Le Dyalogue Saint Gregore: les dialogues de Saint Grégoire le Grand traduits en vers français à rimes léonines par un Normand anonyme du XIV siècle, éd. et trad. Sven Sandqvist, Lund, Lund University Press ("Études romanes de Lund», 42), 1989. 
La Estoire de seint Aedward le Rei, éd. Kathryn Y. Wallace, Londres, ANTS, 1983.

Eneas Silvius Piccolomini, Euvres érotiques, prés. et trad. Frédéric Duval, Turnhout, Brepols, 2003.

L'épopée pour rire. Le voyage de Charlemagne à Jérusalem et Constantinople et Audigier, éd. Alain Corbellari, Paris, Champion ("CCMA»), 2017.

L'Estoire de Merlin, in The Vulgate Version of the Arthurian Romances edited from manuscripts in the British Museum, éd. H. Oskar Sommer, Washington, The Carnegie Institution of Washington, 1908-1916, t. 2.

Etienne de Fougères, Le Liure des Manières, éd. Anthony Lodge, Genève, Droz, 1979.

The old French Évangile de l'Enfance, éd. Maureen Barry McCann Boulton, Toronto, Pontifical Institute of Mediaeval Studies, 1984.

Evrart de Conty, Le Livre des eschez amoureux moralisés, éd. Françoise GuichardTesson et Bruno Roy, Montréal, Ceres («Bibliothèque du Moyen Français»), 1993.

Floriant et Florete: a metrical romance of the fourteenth century edited from a unique manuscript at Newcastle Abbey by Francisque-Michel, Edinburgh, Clark for the Roxburghe Club, 1873.

Floriant et Florete, éd. Harry F. Williams, Ann Arbor, University of Michigan Press; London, Oxford University Press («University of Michigan Publication in Language and Literature», 23), 1947.

Floriant et Florete, éd. et trad. Richard Trachsler et Annie Combes, Paris, Champion («CCMA»), 2003.

Le Roman de Floriant et Florete ou le Chevalier qui la nef maine, éd. Claude M. L. Lévy, Ottawa, Éditions de l'Université d'Ottawa, 1983.

Gace De la Buigne, Le roman des deduis, éd. Åke Blomqvist, Stockholm, Almqvist och Wiksell; Paris, Thiébaud («Studia romanica Holmiensa», 3), 1951.

Gautier de Coinci, Les Miracles de Nostre Dame, éd. Frederic Koenig, Genève, Droz, 1966.

Gerard von Amiens, Roman von Escanor, éd. Henri-Victor Michelant, Tübingen, Litterarischen Verein in Stuttgart, 1886.

Girart D’Amiens, Escanor, éd. Richard Trachsler, Genève, Droz («Textes littéraires français»), 1994.

Girart d'Amiens, Meliacin ou le Cheval de fust, éd. Antoinette Saly, Aix-enProvence, Publications du CUER-MA («Senefiance», 27), 1990.

Critical Edition of Girart d'Amiens' "L'Istoire le roy Charlemaine», poème épique $d u X I V^{e}$ siècle, éd. Daniel Métraux, Lewiston, Queenston et Lampeter, Edwin Mellen Press («Studies in French Literature», 72), 2003. 
La geste du roi Arthur selon le Roman de Brut de Wace et PHistoria Regum Britanniae de Geoffroy de Monmouth, prés. et éd. par Emmanuèle Baumgartner et Ian Short, Paris, 10/18 ("Bibliothèque médiévale»), 1993.

Guillaume le Clerc, The Romance of Fergus, éd. Wilson Frescoln, Philadelphia, Allen, 1983.

Guillaume de Berneville, La Vie de saint Gilles, éd. Françoise Laurent, Paris, Champion ("CCMA»), 2003.

Guillaume de Machaut, Le Livre du Voir Dit, éd. Paul Imbs et Jacqueline Cerquiglini-Toulet, Paris, le Livre de Poche («Lettres gothiques»), 1999.

Guillem de Torroella, La Faula, http://www.rialc.unina.it/179.1.htm, édition de Anna Maria Compagna, Palma de Mallorca, 2007.

Le Roman de Gliglois, éd. Marie-Luce Chênerie, Paris, Champion ( CCMA»), 2003.

Le Haut Livre du Graal, éd. Armand Strubel, Paris, Le Livre de Poche («Lettres gothiques»), 2007.

Heldris de Cornuälle, Le Roman de Silence, éd. Lewis Thorpe, Cambridge, 1972.

Henri de Ferrières, Les livres du roy Modus et de la royne Ratio, éd. Gunnar Tilander, Paris, SATF, 1932.

L'Histoire d'Erec en prose. Roman du $X V^{e}$ siècle, éd. Maria Colombo-Timelli, Genève, Droz, 2000.

The Romance of Hunbaut: An Arthurian Poem of the Thirteenth Century, éd. par Margaret Winters, Leiden, Brill (Davis Medieval Texts and Studies, 4), 1984.

Huon de Bordeaux, éd. William W. Kibler et François Suard, Paris, Champion ( СCMA»), 2003.

Huon de Méry, Le Tournoi de l'Antéchrist, éd. Georg Wimmer, prés. Stéphanie Orgeur, Orléans, Paradigme ("Medievalia», 13), 1995.

Inventaire de la bibliothèque du roi Charles VI fait au Louvre en 1432, éd. Louis Douët-D’Arcq, Paris, Imprimerie Charles Lahure, Société des Bibliophiles, 1867.

Isidori Hispalensis episCopi, Etymologiarum sive originum libri XX, éd. W. M. Lindsay, Oxford, Clarendon, 1911, 2 t.

Јасов Max, Le Cornet à dés, Paris, Gallimard («Poésie»), 2003.

Jaufré. Roman arthurien du XIII siècle en vers provençaux, éd. Clovis Brunel, Paris, SATF, 1943, 2 tomes.

Jehan, Les Merveilles de Rigomer, éd. Wendelin Foerster et Hermann Breuer, Dresde, Gesellschaft für romanische Literatur, 1908 et 1915, 2 volumes.

Le Meraviglie di Rigomer (Les Merveilles de Rigomer). Tradizione manoscritta et tradizione narrativa, éd. Margherita Lecco, Alessandria, Edizioni dell'Orso, 2013. 
Jean Bodel, La Chanson des Saxons, éd. Annette Brasseur, Genève, Droz («Textes littéraires français»), 1989.

Jean Froissart, Melyador, éd. Nathalie Bragantini-Maillard, Genève, Droz ("Textes littéraires français»), 2 tomes, 2012.

Méliador par Jean Froissart, roman comprenant les poésies lyriques de Wenceslas de Bohême, duc de Luxembourg et de Brabant, éd. Auguste Longnon, Paris, Firmin Didot («Société des anciens textes français», 35), 1895-1899, 3 t.

Jean Froissart, Chroniques, éd. Peter Ainsworth et Alberto Varvaro, Paris, Le Livre de Poche («Lettres gothiques»), 2001-2004, 2 tomes.

Jean Froissart, Chroniques, éd. George T. Diller, Genève, Droz, 1992, 3 tomes.

Jean Froissart, "Le Dit dou Florin", in "Dits» et "Débats", éd. Anthime Fourrier, Genève, Droz, 1979.

Jean Froissart, Le Paradis d'Amour. L'orloge amoureus, éd. Peter Florian Dembowski, Genève, Droz, 1986.

Jean de Garlande, Parisiana Poetria, éd. Traugott Lawler, New Haven; Londres, Yale University Press, 1974.

Jean Maillart, Roman du comte d'Anjou, éd. Mario Roques, Paris, Champion, 1931.

Jean de Salisbury, Policratici sive De nugis curialium et vestigiis philosophorum libri VIII, éd. Clemens C. J. Webb, Oxford, Clarendon, 1909, 2 t.

John of Salisbury, Policraticus. Of the Frivolities of Courtiers and the Footprints of Philosophers, trad. Cary J. Nederman Cambridge, Cambridge University Press, 1990.

Jean Renart, Le Roman de la Rose ou Guillaume de Dole, éd. Felix Lecoy, Paris, Champion («CFMA»), 1962.

Le Lai du Cor et le Manteau mal taillé. Les dessous de la Table ronde, éd. et prés. Nathalie Koble, Paris, Éditions Rue d'Ulm; ENS, 2005.

Lais bretons (XII-XIIt siècles): Marie de France et ses contemporains, éd. Nathalie Koble et Mireille Séguy, Paris, Champion, ("CCMA»), 2011.

La Légende arthurienne. Le Graal et la Table Ronde, Paris, Robert Laffont («Bouquins»), 1989.

Lancelot. Roman en prose du XIIf siècle, éd. Alexandre Micha, Genève, Droz, 19781983, 9 t.

Lion de Bourges. Poème épique du XIV siècle, éd. William Kibler, Jean-Louis G. Picherit, Thelma S. Fenster, t. 1, Genève, Droz, 1980.

Le livre de Alixandre empereur de Constantinoble et de Cligès son filz, éd. Maria Colombo Timelli, Genève, Droz, 2004.

Le Livre d'Artus, in The Vulgate Version of the Arthurian Romances edited from manuscripts in the British Museum, éd. H. Oskar Sommer, Washington, The Carnegie Institution of Washington, 1908-1916, t. 7. 
Le Livre du Graal, dir. Philippe Walter, Paris, Gallimard, («Pléiade»), 2003, 3 tomes.

Montaigne Michel (de), Essais, éd. Marie-Madeleine Fragonard, Paris, Pocket, 1998.

Die Pharsale des Nicolas von Verona, éd. Hermann Wahle, Marburg, Elwert, 1888.

La Mort du Roi Arthur, éd. Emmanuèle Baumgartner et Marie-Thérèse de Medeiros, Paris, Champion ("CCMA»), 2007.

Nouveau Recueil complet des fabliaux, éd. Willem Noomen et Nico Van den Boogaard, Assen, Van Gorcum, 1983-1998, 10 tomes.

Perceval le Galloys en prose (Paris, 1530), éd. Maria Colombo-Timelli, Paris, Garnier, 2017.

Philippe de Mézı̀̀res, Songe du viel pelerin, éd. Joël Blanchard, Genève, Droz, 2015.

Philippe De RÉmi, La Manekine, éd. Marie-Madeleine Castellani, Paris, Champion ("CCMA»), 2012.

Pierre de Beauvais, Bestiaire, version longue, éd. Craig Baker, Paris, Champion («CFMA»), 2010.

Première Continuation du Conte du Graal, éd. William Roach et trad. Colette Van Coolput-Storms, Paris, Le Livre de Poche («Lettres Gothiques»), 1993.

La Queste del Saint Graal. Roman du XIII siècle, éd. Albert Pauphilet, Paris, Champion ("CFMA»), 2003.

Raoul de Houdenc, Méraugis de Portlesguez, éd. Michelle Szkilnik, Paris, Champion («CCMA»), 2004.

Raoul de Houdenc, Meraugis von Portlesguez. Altfranzösischer Abenteuerroman, éd. Mathias Friedwagner, Halle, Niemeyer, 1897.

Raoul de Houdenc, La Vengeance Raguidel, éd. Gilles Roussineau, Genève, Droz, 2004.

Renaut de Beaujeu, Le Bel Inconnu, éd. Michèle Perret et Isabelle Weil, Paris, Champion («CCMA»), 2003.

Robert De Blois, Floris et Lyriopé, éd. Paul Barrette, Berkeley; Los Angeles, University of California Press, 1968.

Robert de Blois, Biaudouz, éd. Jacques Lemaire, Liège, Éditions de l'Université de Liège, 2008.

Robert de Boron, Merlin, éd. Alexandre Micha, Paris, GF, 1979.

Le Roman d'Alexandre, éd. Laurence Harf-Lancner, Paris, Le Livre de Poche ("Lettres gothiques»), 1994.

Le Romans de la Dame a la Lycorne et du Biau Chevalier au Lyon, éd. Friedrich Gennrich, Dresdes, Max Niemeyer, ("Gesellschaft für romanische Literatur»), 1908. 
Le Roman d'Eledus et Serene. Edited for the first time from the unique manuscript of the Bibliothèque nationale, éd. John Revell Reinhard, Texas, University of Texas Press, 1923.

Le Roman d'Eneas, éd. Aimé Petit, Paris, Le Livre de Poche («Lettres gothiques»), 1997.

Le Roman de Renart, éd. Jean Dufournet et Andrée Méline, Paris, GF, 1985.

Le Roman de Renart, éd. dirigée par Armand Strubel, Paris, Gallimard ("Pléiade»), 1998.

Le Romanz du reis Yder, éd. Jacques Lemaire, Fernelmont, E.M.E., 2010.

Le Roman de Thèbes, éd. Francine Mora-Lebrun, Paris, Le Livre de Poche («Lettres gothiques»), 1995.

Sarrasin, Le roman du Hem, éd. Albert Henry, Bruxelles, Éditions de la Revue de l'Université de Bruxelles; Paris, Belles Lettres («Travaux de la Faculté de philosophie et lettres de l'Université de Bruxelles », 9), 1939.

Sone de Nansay, trad. Claude Lachet, Paris, Champion ("TCFMA»), 2012.

Sone de Nansay, éd. Claude Lachet, Paris, Champion (“CFMA»), 2014.

Le Roman de Tristan en prose, éd. Renée L. Curtis, Münich, Max Hüber Verlag, 1963, 2 tomes.

Le Roman de Tristan en prose, dir. Philippe Ménard, Genève, Droz, 1987-1997, 9 tomes.

La Vie des pères, éd. Félix Lecoy, Paris, Société des anciens textes français, 19871999, 3 tomes.

La Vie de seint Auban. An anglo-norman poem of the thirteenth century, éd. Arthur R. Harden, Londres, ANTS, 1968.

Wace, Le Roman de Rou, éd. Anthony J. Holden, 3 tomes, Paris, Picard («SATF $), 1971-1974$.

Wirnt von Grafenberg, Wigalois. Text, Übersetzung, Stellenkommentar, éd. Sabine Seelbach et Ulrich Seelbach, Berlin, De Gruyter, 2014.

Wirt von Gravenberg, Wigalois, le Chevalier à la roue, trad. Danielle Buschinger, Paris, Champion («Traduction des classiques du Moyen Âge»), 2004.

\section{Dictionnaires}

Aron Paul, Saint-Jacques Denis, Viala Alain (dir.), Le dictionnaire du littéraire, Paris, PUF («Quadrige»), 2010.

Battistini Olivier et al., Dictionnaire des lieux et pays mythiques, Paris, Robert Laffont («Bouquins»), 2011.

Bloch Oscar et Von Wartburg Walther (dir.), Dictionnaire étymologique de la langue française, Paris, PUF ("Quadrige»), 1994. [1932] 
Godefroy Frédéric, Dictionnaire de l'ancienne langue française et de tous ses dialectes $d u I X X^{e}$ au $X V^{e}$ siècle, Paris, Librairie des sciences et des arts, 1937-1938.

Greimas Algirdas J. et Courtès Joseph, Sémiotique. Dictionnaire raisonné de la théorie du langage, Paris, Hachette, 1979.

Neiva Saulo et Montandon Alain (dir.), Dictionnaire raisonné de la caducité des genres littéraires, Genève, Droz, 2014.

REY Alain (dir.), Dictionnaire historique de la langue française, Paris, le Robert, 1992, 2 tomes.

Von Wartburg Walther, Französisches etymologisches Wörterbuch: eine Darstellung des galloromanischen Sprachschatzes, Basel, Zbinden, 1922-1967.

\section{Études théoriques}

Adam Jean-Michel et Heidmann Ute, «Six propositions pour l'étude de la généricité», in Le Savoir des genres, dir. Raphaël Baroni et Marielle Macé, Rennes, PUR («La licorne», 79), 2006, p. 21-34.

Angenot Marc, "Qu'est-ce que la paralittérature?», Études littéraires, 7/1, 1974, p. 9-22.

Angenot Marc, La parole pamphlétaire. Typologie des discours modernes, Paris, Payot, 1982.

Bakhtine Mikhaïl, Esthétique et théorie du roman, Paris, Gallimard, 1978.

Baroni Raphaël, "Genres littéraires et orientation de la lecture», Poétique, 134, 2003, p. 141-157.

Baroni Raphaël et Macé Marielle (dir.), Le Savoir des genres, Rennes, PUR ( La licorne», 79), 2006.

Baroni Raphaël, «Passion et narration», Protée, 34/2-3, 2006, p. 163-175.

BARONi Raphaël, "Généricités borgésiennes", in Le Savoir des genres, dir. Raphaël Baroni et Marielle Macé, Rennes, PUR («La licorne», 79), 2006, p. 155-172.

BARoni Raphaël, La tension narrative. Suspense, curiosité et surprise, Paris, Seuil («Poétique»), 2007.

Barthes Roland, «L'ancienne rhétorique», Communications, 16, 1970, p. $172-223$.

Bouchard Benjamin, "Critique des notions paragénériques», Poétique, 159, 2009, p. 358-381.

Boyer Alain-Michel, La paralittérature, Paris, PUF («Que sais-je?»), 1992.

Combe Dominique, Les Genres littéraires, Paris, Hachette, 1992.

Compagnon Antoine, La Notion de genre, cours sur Fabula, 2001, https:/www. fabula.org/compagnon/genre.php.

CouÉGnas Daniel, Introduction à la paralittérature, Paris, Seuil, 1992. 
Cornilliat François et Merlin-Kajman Hélène, "Littérature” : où allons-nous, du 3 au 5 octobre 2012 », Paris, en ligne : http://www.mouvement-transitions.fr/ index.php/litterarite/colloques/3-5-octobre-2012-litterature-ou-allons-nous.

Cornulier Benoît (de), Théorie du vers. Rimbaud, Verlaine, Mallarmé, Paris, Seuil («Travaux linguistiques»), 1982.

Derrida Jean, «La loi du genre», in Parages, Paris, Galilée, 1986, p. 251-287.

Eco Umberto, Lector in fabula, Paris, Grasset, 1985.

Eco Umberto, "Innovation et répétition: entre esthétique moderne et postmoderne», Réseaux, 68, 1994, p. 9-26.

Escola Marc, «Mondes possibles et textes possibles», sur Fabula, Atelier de théorie littéraire, 2006, http://www.fabula.org/atelier.php?Mondes_possibles_et_ textes_possibles.

FLeCK Frédérique, "Anachroni(sm)e: mise au point sur les notions d'anachronisme et d'anachronie", Fabula, Atelier de théorie littéraire, 2011, http://www.fabula.org/atelier.php?Anachronisme_et_anachronie.

FärnlöF Hans, "Chronotope romanesque et perception du monde. À propos du Tour du Monde en quatre-vingts jours", Poétique, 152, 2007/4, p. 439-456.

Genette Gérard, Palimpsestes. La littérature au second degré, Paris, Le Seuil, 1982.

Genette Gérard, Nouveau discours du récit, Paris, Seuil, 1983.

Genette Gérard et al., Théorie des genres, Paris, Seuil, 1986.

Genette Gérard, «Introduction à l'architexte», in Théorie des genres, dir. Gérard Genette et al. Paris, Seuil, 1986, p. 89-159.

Genette Gérard, Fiction et diction, Paris, Seuil, 1991.

Genette Gérard, Figures III, Paris, Seuil, 2003.

IsER Wolfgang, L'Acte de lecture. Théorie de l'effet esthétique, Bruxelles, Mardaga, 1985.

Jauss Hans Robert, Pour une esthétique de la réception, Paris, Gallimard, 1978.

Jauss Hans Robert, "Littérature médiévale et théorie des genres", in Théorie des genres, Paris, Seuil, 1986, p. 37-76.

Jouve Vincent, La Lecture, Paris, Hachette (“Contours littéraires»), 1998.

Jouve Vincent, "Pour une analyse de l'effet-personnage», Littérature, 85, 1992, p. 103-111.

Jouve Vincent, L'effet-personnage dans le roman, Paris, Presses Universitaires de France, 1998.

Macé Marielle, Le genre littéraire, Paris, Flammarion ("GF corpus»), 2004.

Macé Marielle, "Connaître et reconnaître un genre littéraire», Fabula, Atelier de théorie littéraire, 2005, http://www.fabula.org/atelier.php?Conna\%26 icirc\%3Btre_et_reconna\%26icirc\%3Btre_un_genre_litt $\% 26$ eacute $\% 3$ Braire. 
Mathieu-Castellani Gisèle, "La notion de genre», in La notion de genre à la Renaissance, dir. Guy Demerson, Genève, Slatkine, 1984, p. 17-34.

Meizoz Jérôme, "Que font aux textes les contextes (et vice versa) ?», En ligne: http://www.mouvement-transitions.fr/intensites/contexte/n-1-j-meizoz-quefont-aux-textes-les-contextes-et-vice-versa2.html?highlight=WyJjb250ZXh0 ZSJd, page consultée le 11.05.2016.

Meizoz Jérôme, "La posture d'auteur», Fabula, Ateliers de théorie littéraire, 2017, http://www.fabula.org/atelier.php?La_posture_d\%27auteur.

Merlin-Kajman Hélène et Cornilliat François (organisateurs), "Littérature": où allons-nous?", colloque international tenu du 3 au 5 octobre 2012 à Paris, synthèse en ligne: http://www.mouvement-transitions.fr/index. php?option=com_content $\&$ view=article $\&$ id $=175 \&$ Itemid $=168$.

Merlin-Kajman Hélène, «Retour sur le colloque "Littérature: où allons-nous?": synthèse et débat», Versants, 62, 2015, p. 171-194.

Mitterand Henri, "Chronotopies romanesques: Germinal», Poétique, 81, 1990, p. $89-104$.

Murat Michel, «Le dernier livre de la bibliothèque. Une histoire du poème en prose», Fabula, Atelier de théorie littéraire, https://www.fabula.org/atelier. php?Histoire_du_poeme_en_prose\#_ednref27.

PAvel Thomas, Univers de la fiction, Paris, Seuil («Poétique»), 1988.

Rodriguez Antonio, Le pacte lyrique. Configuration discursive et interaction affective, Sprimont, Pierre Mardaga, 2003.

Ryan Marie-Laure, "Possible Worlds", The living handbook of narratology, dir. Peter Hühn et al., Hamburg, Hamburg University Press, en ligne: http:// wikis.sub.uni-hamburg.de/lhn/index.php/Possible_Worlds.

SAINT-Gelais Richard, "Personnage et transfictionnalité", in La fabrique du personnage, dir. Françoise Lavocat, Claude Murcia et Régis Salado, Paris, Champion, 2007, p. 269-286.

SaInT-Gelais Richard, Fictions transfuges. La transfictionnalité et ses enjeux, Paris, Seuil, 2011.

Samoyault Tiphaine, L'intertextualité. Mémoire de la littérature, Paris, Armand Colin, 2005.

SANGsue Daniel, "La parodie, une notion protéiforme», in Du pastiche, de la parodie et de quelques notions connexes, dir. Paul Aron, Québec, Nota bene, 2004, p. 79-102.

SAngsue Daniel, La Relation parodique, Paris, José Corti, 2007.

Schaeffer Jean-Marie, «Du texte au genre. Notes sur la problématique générique», in Théorie des genres, Paris, Seuil, 1986, p. 179-205.

Schaeffer Jean-Marie, Qu'est-ce qu'un genre littéraire?, Paris, Seuil, 1989. 
SChaEffer Jean-Marie, "Genres littéraires", in Nouveau dictionnaire encyclopédique des sciences du langage, dir. O. Ducrot et J.-M. Schaeffer, Paris, Seuil, 1995, p. 520-529.

Schaeffer Jean-Marie, Adieu à l'esthétique, Paris, PUF, 2000.

Schlanger Judith, La mémoire des auvres, Paris, Verdier, 1992.

Schlanger Judith, "Le précurseur", in Le Temps des auvres. Mémoire et préfiguration, dir. Jacques Neefs, Saint-Denis, PUV, 2001, p. 13-26.

Schlanger Judith, Le neuf, le différent et le déjà-là. Une exploration de l'influence, Paris, Hermann, 2014.

SOURIAU Étienne, "La structure de l'univers filmique et le vocabulaire de la filmologie", Revue internationale de filmologie, 7-8, 1951, p. 231-240.

Trouvé Alain, Le roman de la lecture. Critique de la raison littéraire, Sprimont, Mardaga ("Philosophie et langage»), 2004.

Viala Alain, "Des “registres”", Pratiques, 109-110, 2001, p. 165-177.

Weber Max, Essais sur la théorie de la science, trad. et intro. de Julien Freund, Paris, Plon, 1965.

\section{Études critiques}

Abiker Séverine, "Style de genre? les rimes jumelées dans les lais narratifs", in Les Genres littéraires en question au Moyen Âge, dir. Danièle James-Raoul, Bordeaux, Presses universitaires («Eidôlon», 97), 2011, p. 133-146.

Adler Alfred, "Dinadan, inquiétant ou rassurant», in Mélanges Rita Lejeune, Gembloux, Duculot, 1968, vol. II, p. 935-943.

Agamben Giorgio, L'Aventure, Paris, Payot et Rivages, 2016.

Ainsworth Peter F., Kennedy Edward Donald, Kibler William W., Lacy Norris J., TAYLOR Jane H. M., "Late Medieval Arthurian Literature», in The Arthur of the French. The Arthurian Legend in Medieval French and Occitan Literature dir. Glyn S. Burgess et Karen Pratt, Cardiff, University of Wales Press, ("Arthurian Literature in the Middle Ages», IV), 2006, p. 488-527.

Ailes Marianne et Leedham Suzanne, "Le Pseudo-Turpin en Angleterre», CRMH, 25, 2013, p. 495-517.

Alexander Jonathan J. G., Marrow James H., Sandler Freeman Lucy, The Splendor of the Word. Medieval and Renaissance illuminated manuscripts at the New York Public Library, Turnhout, Brepols, 2005.

Alamichel Marie-Françoise (dir.), Le Personnage de Gauvain dans la littérature européenne du Moyen Âge. Actes du colloque international des 6, 7 et 8 mars 2014 à l'Université Paris-Est (Marne-la-Vallée), Amiens, Presses du Centre d'Études Médiévales de Picardie ("Médiévales», 58), 2015.

Albert Sophie, "Ensemble ou par pièces». Guiron le Courtois (XIII'-XV siècles): la cohérence en question, Paris, Champion, 2010. 
Albouy Pierre, Mythes et mythologies dans la littérature française, Paris, Armand Colin, 1981.

Allen Judson Boyce, The Ethical Poetic of the Later Middle Ages: a decorum of convenient distinction, Toronto, University of Toronto Press, 1982.

Amor Lidia, "Entre las "maravillas de Bretaña" y el saber "enciclopédico": aspectos de los maravilloso en el Conte du Papegau", in V Jornadas de Estudios Clásicos y Medievales, 5 al 7 de octubre de 2011, La Plata. Juventud y vejez en la Antigüedad y el Medioevo: Diálogo entre culturas: de lo antiguo a lo contemporáneo, en ligne: http://www.memoria.fahce.unlp.edu.ar/trab_ eventos/ev.1214/ev.1214.pdf.

ANDrieux Nelly, "Arthur et Charlemagne réunis en Avalon: la Bataille Loquifer ou l'accomplissement d'une parole", in Essor et fortune de la chanson de geste dans l'Europe et l'Orient latin. Actes du IXe Congrès International de la Société Rencesvals, vol. 2, "Rapports entre chanson de geste et roman au XIII" siècle", Padoue, Mucchi, 1984, p. 424-434.

Andrieux-Reix Nelly, "Écriture d'un cycle, écriture de geste. L'exemplarité d'un corpus», Romania, 108, 1987, p. 145-164.

Aragon Fernandez Aurora, Fernandez Cardo José, «Les traces des formules épiques dans le roman français du XIII ${ }^{\mathrm{e}}$ siècle: le combat individuel ", in Essor et fortune de la chanson de geste dans l'Europe et l'Orient latin. Actes du IXe Congrès international de la Société Rencesvals, vol. 2, "Rapports entre chanson de geste et roman au XIII ${ }^{\mathrm{e}}$ siècle», Modena, Mucchi, 1984, p. 435-463.

Archibald Elizabeth, "Variations on romance themes in the Historia Meriadoci», JIAS, 2/1, 2014, p. 3-19.

Armstrong Adrian et Kay Sarah, Une Muse savante? Poésie et savoir, du "Roman de la Rose" jusqu'aux grands rhétoriqueurs, Paris, Garnier, 2014.

Arrouye Jean, "L'en-dessous et l'en-dessus de la mer", in Mondes marins du Moyen Âge, dir. Chantal Connochie-Bourgne, Aix-en-Provence, Presses universitaires de Provence ("Senefiance», 52), 2006, p. 27-41, en ligne: https://books.openedition.org/pup/3824.

Arseneau Isabelle, "Méraugis de Portlesguez ou l'art de railler et de faire dérailler la mécanique du roman ", Études françaises, 47/2, 2011, p. 21-37.

Ashe Geoffrey, A Guidebook to Arthurian Britain, Londres, Longman, 1980.

Atallah Marc, Boillat Alain et Jaccaud Frédéric, Je suis ton père! Origines et héritages d'une saga intergalactique, Paris; Yverdon, Huginn et Muninn («Fantask»); Maison d'Ailleurs, 2017.

Atanassov Stoyan, L'Idole inconnue. Le personnage de Gauvain dans quelques romans du XIIt siècle, Orléans, Paradigme, 2000.

Aubailly Jean-Claude, "Le fabliau et les sources inconscientes du rire médiéval», Cabiers de civilisation médiévale, 118, 1987, p. 105-117. 
Aubailly Jean-Claude, "Théâtre "populaire" et rhétorique à la fin du Moyen Âge et au début du XVI ${ }^{\mathrm{e}}$ siècle", in Aspects du théâtre populaire en Europe au XVI siècle, éd. Madeleine Lazard, Paris, SEDES, 1989, p. 17-29.

Auerbach Erich, Le Haut. Langage. Langue littéraire et public dans l'Antiquité latine tardive et au Moyen Âge, trad. Robert Kahn, Paris, Belin, 2004.

Bachelard Gaston, Lautréamont, Paris, Corti, 1939.

Baethge Constanze, "Réalisme», in Le Dictionnaire du littéraire, Paris, PUF ("Quadrige»), 2010, p. 637-639.

Bagnoud Johanna, De la gelosie d'Arthur à lire d'Yder: les émotions négatives au service de la nouvelle chevalerie dans le Romanz du reis Yder, mémoire de Maîtrise, sous la direction de Barbara Wahlen, Université de Lausanne, 2014, en ligne: https://serval.unil.ch/resource/serval:BIB_65F5BDCCE401.P001/ REF.

BAKer Alfred T., «La Vie anglo-normande de sainte Foi par Simon de Walsingham ", Romania, 66, 1931, p. 49-94.

BARBIERI Beatrice, "Le contexte manuscrit du Lai du cor et la réception tardive des lais (avec une note sur Renart le Contrefait) ", Études françaises, 48/3, 2012, p. $115-125$.

BAudou Jacques, "La fantasy, historique et définition du genre», Lecture Jeune, 138, 2011, p. 4-10.

BAUmgartner Emmanuèle, "Sur les pièces lyriques du Tristan en prose», in Études de langue et de littérature du Moyen Âge offertes à Félix Lecoy, Paris, Champion, 1973, p. 19-25.

BAumgartner Emmanuèle, Le Tristan en prose: essai d'interprétation d'un roman médiéval, Genève, Droz, 1975.

Baumgartner Emmanuèle, "À propos du Mantel Mautaillé», Romania, 96, 1975, p. 315-332.

Baumgartner Emmanuèle, "Les citations lyriques dans le Roman de la Rose de Jean Renart», Romance Philology, 35, 1981, p. 260-266.

Baumgartner Emmanuèle, L'arbre et le pain. Essai sur la Queste del saint Graal, Paris, SEDES, 1981.

Baumgartner Emmanuèle et Méla Charles, "Mise en roman", in Précis de littérature française du Moyen Âge, dir. Daniel Poirion, Paris, PUF, 1982, p. $83-127$.

BAumgartner Emmanuèle, "Jeux de rimes et roman arthurien ", Romania, 103, 1982, p. 550-560.

Baumgartner Emmanuèle, "Texte de prologue et statut du texte», in Essor et fortune de la chanson de geste dans l'Europe et l'Orient latin. Actes du IXé Congrès international de la Société Rencesvals, vol. 2, "Rapports entre chanson de geste et roman au XIII ${ }^{\mathrm{e}}$ siècle», Modena, Mucchi, 1984, p. 465-473. 
Baumgartner Emmanuèle, "Remarques sur la prose du Lancelot», Romania, $105: 417,1984$. p. $1-15$.

Baumgartner Emmanuèle, "Luce del Gat et Hélie de Boron. Le chevalier et l'écriture", Romania, 106, 1985, p. 26-40.

BAumgartner Emmanuèle, "Temps linéaire, temps circulaire et écriture romanesque (XII-XIII ${ }^{\mathrm{e}}$ siècles)", in Le Temps et la durée dans la littérature au Moyen Âge et à la Renaissance, Actes du colloque organisé par le Centre de Recherche sur la Littérature du Moyen Âge et de la Renaissance de l'Université de Reims (novembre 1984), dir. Yvonne Bellenger, Paris, Nizet, 1986, p. 7-21.

BAumgartner Emmanuèle, "Rois et chevaliers: du "Lancelot en prose" au "Tristan en prose" ", in Tristan et Yseut, mythe européen et mondial, dir. Danielle Buschinger, Göppingen, Kümmerle Verlag, 1987, p. 19-31.

BAUMgartner Emmanuèle, "Les techniques narratives dans le roman en prose», in The Legacy of Chrétien de Troyes, dir. Norris J. Lacy, Douglas Kelly et Keith Busby, Amsterdam, Rodopi, 1987-1988, vol. 1, p. 167-190.

Baumgartner Emmanuèle, "L'Orient d'Alexandre", Bien dire, bien aprandre, 6, 1988, p. 7-15.

BAumgartner Emmanuèle, "Masques de l'écrivain et masques de l'écriture dans les proses du Graal», in Masques et déguisements dans la littérature médiévale, dir. Marie-Louise Ollier, Montréal-Paris, Presses Universitaires de MontréalVrin, 1988, p. 167-175.

BAumgartner Emmanuèle, "Récits brefs et romans en prose: l'exemple du Tristan", in Le récit bref au Moyen Age. Actes du colloque des 8 et 9 mai 1988, Amiens/Paris, éd. Danielle Buschinger et Wolgang Spiewok, Amiens, Publications du Centre d'Études Médiévales, 1989, p. 27-38.

BAumgartner Emmanuèle, La Harpe et l'épée: tradition et renouvellement dans le Tristan en prose, Paris, SEDES, 1990.

Baumgartner Emmanuèle, "Compiler / accomplir", in Nouvelles recherches sur le Tristan en prose, dir. Jean Dufournet, Paris, Champion, 1990, p. 33-49.

BAumgartner Emmanuèle, "Retour des personnages et mise en prose de la fiction arthurienne au XIII' siècle», BBIAS, 43, 1991, p. 297-314.

Baumgartner Emmanuèle, Chrétien de Troyes. Yvain, Lancelot, la charrette et le lion, Paris, PUF («Études littéraires»), 1992.

BAumgartner Emmanuèle, "Peinture et écriture: la description de la tente dans les romans antiques au XII ${ }^{\mathrm{e}}$ siècle", in De l'histoire de Troie au livre du Graal, Orléans, Paradigme, 1994, p. 179-187.

Baumgartner Emmanuèle, "Le temps des automates", in De l'Histoire de Troie au Livre du Graal, Orléans, Paradigme, 1994, p. 171-177.

Baumgartner Emmanuèle, "Le lion et sa peau ou les aventures d'Yvain dans le Lancelot en prose", in De l'histoire de Troie au livre du Graal, Orléans, Paradigme, 1994, p. 291-300. 
Baumgartner Emmanuèle, "Robert de Boron et l'imaginaire du livre du Graal», in De l'Histoire de Troie au Livre du Graal, Orléans, Paradigme, 1994, p. 487-496.

BAUMgarTNER Emmanuèle, "Vers, prose et fiction narrative (1150-1240)», in Shifts and Transpositions in Medieval Narrative. A Festschrift for Elspeth Kennedy, dir. Karen Pratt, Cambridge, Brewer, 1994, p. 1-9.

Baumgartner Emmanuèle, Le Récit médiéval, XII -XIIt siècles, Paris, Hachette, 1995.

Baumgartner Emmanuèle, "Le choix de la prose», Cahiers de recherches médiévales, 5, 1998, p. 7-13.

Baumgartner Emmanuèle, "La musique pervertit les mours», in Miscellanea Mediaevalia. Mélanges offerts à Philippe Ménard, Paris, Champion, 1998, t. 1, p. 75-89.

BAUMgarTner Emmanuèle, "Du manuscrit trouvé au corps retrouvé», in Le topos du manuscrit trouvé: actes du colloque international, Louvain - Gand, 22-23-24 mai 1997. Hommages à Christian Angelet, dir. Jan Herman et Fernand Hallyn, Louvain; Paris, Peeters, 1999, p. 1-14.

BAUMgartner Emmanuèle, «Sur quelques constantes et variations de l'image de l'écrivain (XII ${ }^{\mathrm{e}}-\mathrm{XIII}^{\mathrm{e}}$ siècle)", in Auctor et auctoritas. Invention et conformisme dans l'écriture médiévale. Actes du colloque de Versailles-Saint-Quentin-enYvelines (14-16 juin 1999), dir. Michel Zimmermann, Paris, École des Chartes, 2001, p. 391-400.

Baumgartner Emmanuèle et Andrieux-Reix Nelly, Le Merlin en prose, Paris, PUF ( Recto-Verso»), 2001.

Baumgartner Emmanuèle et Harf-Lancner Laurence (dir.), Progrès, réaction, décadence dans l'Occident médiéval, Genève, Droz, 2003.

Baumgartner Emmanuèle, «Du manuscrit BnF fr. 103 du Tristan en prose à l'imprimé du Tristan par Jehan le Bourgoys (1489)", Ateliers, 30, 2003, p. 11-25.

Baumgartner Emmanuèle, "L'exotisme à rebours dans la Chanson d'Antioche", in L'exotisme dans la poésie épique française, dir. Aniko Kalmar, Paris, L'Harmattan, 2003, p. 13-28.

BAUMgarTner Emmanuèle, "The Queste del saint Graal: from semblance to veraie semblance", in A Companion to the Lancelot-Grail Cycle, éd. Carol Dover, Cambridge, Brewer, 2003, p. 107-114.

Beaune Colette, Naissance de la nation France, Paris, Gallimard, 1985.

BÉDIER Joseph, Les Fabliaux, Paris, E. Bouillon, 1895.

Bedos-Rezak Brigitte Miriam et Iogna-Prat Dominique (dir.), L’individu au Moyen Age. Individuation et individualisation avant la modernité, Paris, Aubier, 2005. 
Bennett Philip E., «Once and Future Monuments: Knights' and Lovers' Tombs in Medieval French Romance», in "Moult a sans et vallour». Studies in Medieval French Literature in Honor of William W. Kibler, dir. Monica L. Wright, Norris J. Lacy et Rupert T. Pickens, Amsterdam; New York, Rodopi, 2012, p. 1-19.

BÉRIER François, «Étude rhétorique et stylistique du prologue de la branche II-Va du Roman de Renart», Bulletin de la Faculté des Lettres de Mulhouse, IX, 1978, p. 9-14.

Bernard Suzanne, Le Poème en prose de Baudelaire jusqu'à nos jours, Paris, Nizet, 1959.

Berthelot Anne, "Les "Enfances Tristan" dans le roman en prose: comment apprivoiser un mythe?», Tristania, 15, 1994, p. 99-111.

Berthelot Anne, "Violence et passion, ou le christianisme sauvage de Perlesvaus: Le Haut Livre du Graal", in La Violence dans le monde médiéval, Aix-enProvence, CUERMA ("Senefiance», 36), 1994, p. 21-36.

Berthelot Anne, "Arthur, ou le Chevalier du Papegault: décadence d'une fonction, décadence d'un genre», in König Artus und der heilige Graal, dir. Danielle Buschinger et Wolfgang Spiewok, Greifswald, Reineke Verlag, 1994, p. 17-25.

Berthelot Anne, "Merlin et Grisandole», in Actes du premier colloque de la SIAM, Amsterdam (27-28 juin 2003), Esplumeoir, janvier 2004, p. 19-25.

Berthelot Anne, "Le Graal en archipel: Perlesvaus et les "illes de mer" ", in Mondes marins du Moyen Âge, dir. Chantal Connochie-Bourgne, Aix-enProvence, Presses universitaires de Provence («Senefiance», 52), 2006, p. 57-67, en ligne: https://books.openedition.org/pup/3827.

Berthelot Anne, "Berte as grans piés et l'abolition des frontières génériques chez Adenet le Roi", Cahiers de recherches médiévales, 18, 2009, en ligne: https:// journals.openedition.org/crm/11718?lang=it.

Bertin Annie et Combes Annie, Écritures du Graal, Paris, PUF («Études littéraires»), 2001.

Bertoni Giulio, «Lettori di romanzi francesi nel quattrocento alla corte estense», Romania, 45, 1918, p. 117-122.

Besson Florian et Breton Justine (dir.), Kaamelott, un livre d'histoire, Paris, Vendémiaire, 2018.

Billy Dominique, "De l'octosyllabe archaïque à l'octosyllabe des troubadours", in Poétiques de l'octosyllabe, dir. Danièle James-Raoul et Françoise Laurent, Paris, Champion, 2018, p. 59-80.

Bloch Howard R., "Le mantel mautaillé des fabliaux. Comique et fétichisme», Poétique, 14, 1983, p. 181-198.

Bloch Howard, R. «Le rire de Merlin», Cahiers de l'Association internationale des études françaises, 37, 1985, p. 7-21. 
Boenrer Bruce Thomas, Parrot Culture. Our 2500-Year-Long Fascination with the World's Most Talkative Bird, Philadelphia, University of Pennsylvania Press, 2004.

Bogdanow Fanni, "The Character of Gauvain in the Thirteenth Century Prose Romances", Medium Aevum, XXVII, 1958, p. 154-161.

BonAfin Massimo, «Rire, comique et parodie médiévale à la lumière d'une théorie bio-sociale", in "Ravy me treuve en mon deduire", dir. Luca Pierdominici et Elisabeth Gaucher-Rémond, Fano, Aras Edizioni, 2011, p. 13-35.

Bonansea Marion, "La guerre dans la Mort Artu: hybridation générique et clôture romanesque", in Les genres au Moyen Âge: la question de l'hétérogénéité, dir. Hélène Charpentier et Valérie Fasseur, Bandol, Vallongues, 2010, p. 123-131.

Bordier Jean-Pierre, "Le Jeu dramatique ( $\mathrm{XIV}^{\mathrm{e}}$ et $\mathrm{XV}^{\mathrm{e}}$ siècle)", in Précis de littérature française du Moyen Âge, dir. Daniel Poirion, Paris, PUF, 1983, p. 306-335.

Botero García Mario, Les Rois dans le Tristan en prose. (Ré)écritures du personnage arthurien, Paris, Champion, 2011.

Bouché Thérèse, "De Chrétien de Troyes à la Mort le Roi Artu: le personnage d'Arthur ou la désagrégation progressive d'un mythe", Op. cit. Revue de littératures françaises et comparée, 3, 1994, p. 5-13.

Bouchet Florence, Le Discours sur la lecture en France aux XIV et XV siècles: pratique, poétique, imaginaire, Paris, Champion, 2008.

Bouchet Florence, «Le lecteur à l'œuvre. L'avènement du lecteur dans le discours auctorial (France, XIve-Xve siècles)», Poétique, 159, 2009, p. 275-285.

Bouget Hélène, "Des rivages d'Arthur à l'île des quatre cors: Perlesvaus au gré des flots", in Mondes marins du Moyen Âge, dir. Chantal Connochie-Bourgne, Aix-en-Provence, Presses universitaires de Provence («Senefiance», 52), 2006, p. 69-78, en ligne: https://books.openedition.org/pup/3828.

Bouget Hélène, "Chevaliers en péril: parodie et déconstruction des héros arthuriens dans Kaamelott», in Le Moyen Âge en jeu, dir. Séverine Abiker, Anne Besson et Florence Plet-Nicolas, Eidôlon, 86, 2009, p. 193-204.

Bouget Hélène, Écritures de l'énigme et fiction romanesque. Poétiques arthuriennes (XII-XIII siècles), Paris, Champion, 2011.

Bourgain Pascale, "Qu'est-ce qu'un vers au Moyen Âge?", Bibliothèque de l'École des Chartes, t. 147, 1989, p. 231-282.

Boutet Dominique, "Carrefours idéologiques de la royauté arthurienne», CCM, 28, 1985, p. 3-17.

Boutet Dominique, Les fabliaux, Paris, PUF, 1985.

Boutet Dominique, "Introduction", in Pour une mythologie du Moyen Âge, dir. Laurence Harf-Lancner et Dominique Boutet, Paris, ENS, 1988, p. 89-97. 
Boutet Dominique, Charlemagne et Arthur ou le roi imaginaire, Paris, Champion, 1992.

Boutet Dominique, La chanson de geste. Forme et signification d'une écriture épique du Moyen Âge, Paris, PUF, 1993.

Boutet Dominique, Formes littéraires et conscience historique. Aux origines de la littérature française (1100-1250), Paris, PUF, 1999.

Boutet Dominique, «Au-delà et Autre Monde: interférences culturelles et modèles de l'imaginaire dans la littérature épique ( $\mathrm{XIII}^{\mathrm{e}}-\mathrm{XV}^{\mathrm{e}}$ siècles)", in Le Monde et l'autre monde, dir. Denis Hüe et Christine Ferlampin-Acher, Orléans, Paradigme, 2002, p. 65-78.

Boutet Dominique (dir.), Le romanesque dans l'épique, (Actes du colloque de Paris $X$-Nanterre 22-23 mars 2002), Nanterre, Université Paris-X ("Littérales », 31), 2003.

Boutet Dominique, "Les peuples étranges dans les chansons de geste $\left(\mathrm{XII}^{\mathrm{e}}-\mathrm{XIV}^{\mathrm{e}}\right.$ siècles)», in En Quête d'Utopies, dir. Claude Thomasset et Danièle JamesRaoul, Paris, PUPS ("Cultures et Civilisations Médiévales», 29), 2005, p. 155-181.

Boutet Dominique, "La voix: mirages et présence de l'oralité au Moyen Âge», in Histoire de la France littéraire, vol. 1, dir. Frank Lestringant et Michel Zink, Paris, PUF, 2006, p. 193-212.

Boutet Dominique, "L'épique au Moyen Âge», in Histoire de la France littéraire, vol. 1, dir. Frank Lestringant et Michel Zink, Paris, PUF, 2006, p. 850-873.

Boutet Dominique, "Les formes de la dérision: le fabliau", in Histoire de la France littéraire, vol. 1, dir. Frank Lestringant et Michel Zink, Paris, PUF, 2006, p. 501-505.

Boutet Dominique, "L'épopée», in Histoire de la France littéraire, dir. Frank Lestringant et Michel Zink, vol. 1, Paris, PUF ("Quadrige»), 2006, p. 850-873.

Boutet Dominique, «De la Chronique rimée de Philippe Mousket à la prose des Grandes chroniques de France: un choix d'écriture?", in Écrire en vers, écrire en prose: une poétique de la révélation. Actes du colloque de Paris X-Nanterre, mars 2006, dir. Catherine Croizy-Naquet, Nanterre, Université Paris X-Nanterre («Littérales», 41), 2007, p. 135-154.

Boutet Dominique, "Merveilleux et interférences génériques dans la chanson de geste de Tristan de Nanteuil», in Motifs merveilleux et poétique des genres au Moyen Âge, dir. Francis Gingras, Paris, Garnier, 2015, p. 21-38.

Boutet Dominique, Poétiques médiévales de l'entre-deux, ou le désir d'ambiguïté, Paris, Champion, 2017.

Bоzокy Edina, "Roman arthurien et conte populaire: les règles de conduite et le héros élu», Cahiers de civilisation médiévale, 81, 1978, p. 31-36.

Bracconi-Giordano Marie-Christine, «Le merveilleux chrétien dans les écrits apocryphes chrétiens et dans L'Estoire del Saint Graal: éléments de 
comparaison", in "Furent les merveilles pruvees et les aventures truvees". Hommage à Francis Dubost, dir. Francis Gingras, Françoise Laurent, Frédérique Le Nan et Jean-René Valette, Paris, Champion, 2005, p. 83-100.

Brewer Derek, "Secular prose. Malory and Caxton ", in English Gothic Literature, Londres, Macmillan Press, 1983, p. 262-279.

Brownlee Marina, «Des usages politiques d'un prequel arthurien: Rustichello, Palamède et Byzance", in Sens, rhétorique et musique. Études réunies en hommage à Jacqueline Cerquiglini-Toulet, éd. Sophie Albert et al., Paris, Champion 2015, p. 77-92.

Bruckner Tomaryn Matilda et Burgess Glyn S., "Arthur in the Narrative lay», in The Arthur of the French. The Arthurian Legend in Medieval French and Occitan Literature, dir. Glyn S. Burgess et Karen Pratt, Cardiff, University of Wales Press ("Arthurian Literature in the Middle Ages», IV), 2006, p. 186-214.

Brugger Ernst, "Bliocadran, The Father of Perceval», in Medieval Studies in Memory of Gertrude Schoepperle Loomis, Paris, Champion, 1927, p. 147-174.

Brunetti Giuseppina, "L'Antiquité partagée; la tente historiée du païen Agolant", in In Limine Romaniae. Chanson de geste et épopée européenne, dir. Carlos Alvar et Constance Carta, Berlin, Peter Lang, 2012, p. 151-174.

Burgess Glyn S. et Pratt Karen (dir.), The Arthur of the French. The Arthurian Legend in Medieval French and Occitan Literature, dir. Glyn S. Burgess et Karen Pratt, Cardiff, University of Wales Press ("Arthurian Literature in the Middle Ages ", IV), 2006.

Burghgraeve Delphine, Meizoz Jérôme, Mühlethaler Jean-Claude, Postures d'auteurs: du Moyen Âge à la modernité, Fabula / Les colloques, 2014, http:// www.fabula.org/colloques/sommaire2341.php.

Burghgraeve Delphine, Mühlethaler Jean-Claude, et Schertz Claire-Marie, «Introduction. Figure, posture, ethos à l'épreuve de la littérature médiévale», in Un territoire à géographie variable. La communication littéraire au temps de Charles VI, Paris, Garnier («Classiques Garnier»), 2017, p. 9-51.

Burin Elizabeth, "Pierre Sala's Manuscript of Le Chevalier au lion», in Les manuscrits de Chrétien de Troyes, éd. Keith Busby, Terry Nixon, Alison Stones et Lori Walters, Amsterdam; Atlanta, Rodopi, 1993, tome 2, p. 323-330.

Burrichter Brigitte, "Raouls de Houdenc La Vengeance Raguidel. Komik und Parodie", in Ironie, Polemik und Provokation, dir. Cora Dietl, Christoph Schanze et Friedrich Wolfzettel, Berlin, De Gruyter, 2014, p. 287-302.

Busby Keith, "The Character of Gauvain in the Prose Tristan", Tristania, II, ii, 1977, p. 12-28.

Busby Keith, "Caractérisation par contraste dans le Roman de Hunbaut», Studia Neophilologica, 52, 1980, p. 415-424.

Busby Keith, Gauvain in Old French Literature, Amsterdam, Rodopi, 1980. 
Busby Keith, "The Enigma of Loholt", in An Arthurian Tapestry. Essays in Memory of Lewis Thorpe, dir. Kenneth Varty, Glasgow, French Department of the University of Glasgow, 1981, p. 28-36.

BusBy Keith, "The likes of Dinadan: the role of the misfit in Arthurian Literature», Neophilologus, 67, 1983, p. 161-174.

Busby Keith, "Diverging Tradition of Gauvain in some of the Later Old French Verse Romances", in The Legacy of Chrétien de Troyes, dir. Norris J. Lacy, Douglas Kelly et Keith Busby, Amsterdam, Rodopi, 1987-1988, vol. II, p. 93-109.

Busby Keith, "L'intertextualité du Livre d'Artus», Arturus Rex, Leuven, Leuven University Press, 1991, p. 306-319.

Busby Keith, Nixon Terry, Stones Alison et Walters Lori (dir.), Les Manuscrits de Chrétien de Troyes, Amsterdam; Atlanta, Rodopi, 1993, 2 tomes.

Busby Keith, "Mise en texte and Mise en image: Méraugis de Portlesguez in Vienna, ÖNB 2599", in "Por le soie amisté». Essays in honor of Norris J. Lacy, dir. Keith Busby et Catherine M. Jones, Amsterdam, Rodopi, 2000, p. 95-116.

Busby Keith, Codex and Context. Reading Old French Narrative in Manuscript, Amsterdam, Rodopi, 2002, 2 vol.

Busby Keith, "Narrative genres", in The Cambridge Companion to Medieval French Literature, dir. S. Gaunt et S. Kay, Cambridge, Cambridge University Press, 2008, p. 139-152.

Busby Keith, "Du livre arthurien au "Livre d'Arthur” ", 303, Arts, recherches, création. Le Roi Arthur, 114, novembre 2010, p. 110-119.

Busby Keith, "The Study of Post-Chrétien Verse romance», in Chrétien de Troyes et la tradition du roman arthurien en vers, dir. Annie Combes, Patrizia Serra, Richard Trachsler et Maurizio Virdis, Paris, Garnier, 2013, p. 35-50.

Busque Anne-Marie et TETu Michel, "Exotisme», in Dictionnaire du littéraire, Paris, PUF ("Quadrige»), 2010 p. 268-269.

Calin William, "Rapport introductif», in Essor et fortune de la chanson de geste dans l'Europe et l'Orient latin. Actes du IX Congrès international de la Société Rencesvals, vol. 2, "Rapports entre chanson de geste et roman au XIII siècle", Modena, Mucchi, 1984, p. 407-424.

Canning Joseph, Histoire de la pensée politique médiévale, trad. Jacques Ménard, Fribourg, Éditions universitaires Fribourg Suisse; Paris, Éditions du Cerf, 2003.

Canvat Karl, "Essai d'histoire de la notion de genre littéraire», Les Lettres romanes, LI, 3-4, 1997, p. 187-221.

Cappello Sergio, "L'édition des romans médiévaux à Lyon dans la première moitié du XVI siècle», Réforme, Humanisme, Renaissance, 71, 2011, p. 55-71.

Cappello Sergio, "Décalages contre-textuels: la mise en prose du Manteau mal taillé au $\mathrm{XVI}^{\mathrm{e}}$ siècle", in Études romanes. I. Hommages offerts à Florica 
Dimitrescu et Alexandru Niculescu, éd. Dan Octavian Cepraga et al., Bucarest, Editura Universitatii din Bucuresti, 2013, t. 1, p. 135-144.

Carnandet J., "Bibliothèques de deux chanoines de Langres au XIV siècle", Bulletin du bibliophile, 13, 1857, p. 463-477.

Carreto Carlos F. Clamote, "Rainouart au pays des fées. Interchangeabilité des personnages et dialogisme dans La Bataille Loquifer", in Façonner son personnage au Moyen Âge, dir. Chantal Connochie-Bourgne, Aix-en Provence, Presses universitaires de Provence, 2007, p. 99-122.

Carreto Carlos F. Clamote, "Une quête apophatique de l'originalité. Le réinvestissement de la topique arthurienne dans la chanson de geste tardive", in Original et originalité. Aspects historiques, philologiques et littéraires. Actes du $I V^{E}$ colloque de l'Association Internationale pour l'Etude du Moyen Français, dir. Olivier Deslaux et Hélène Haug, Louvain, UCL, 2011, p. 15-31.

Castellani Marie-Madeleine, "Philippe de Remi ou la tentation du sermon", in La volonté didactique dans la littérature médiévales, dir. Sarah BaudelleMichels et Marie-Madeleine Castellani, Bien dire et bien aprandre, 29, 2014, p. 139-149.

Catalogue des manuscrits en écriture latine portant des indications de date, de lieux ou de copistes, dir. Charles Samaran et Robert Marichal, Paris, Éditions CNRS, t. 3, en ligne: http://gallica.bnf.fr/ark:/12148/bpt6k4830j/f2.item.zoom.

Cavallo Guglielmo et Chartier Roger, "Introduction», in Histoire de la lecture dans le monde occidental, dir. Guglielmo Cavallo et Roger Chartier, Paris, Seuil, 1995, p. 7-49.

Cerquiglini Bernard, La Parole médiévale. Discours, syntaxe, texte, Paris, Éditions de Minuit, 1981.

Cerquiglini-Toulet Jacqueline, "Pour une typologie de l'insertion », Perspectives médiévales, 3, 1977, p. 9-14.

Cerquiglini-Toulet Jacqueline, «Le clerc et l'écriture: le Voir dit de Guillaume de Machaut et la définition du dit», in Grundriß der romanischen Literaturen des Mittelalters, "Literatur in der Gesellschaft des Spätmittelalters, I, dir. Hans Robert Jauss, Heidelberg, Carl Winter, 1980, p. 151-168.

Cerquiglini-Toulet Jacqueline, "Le nouveau lyrisme ( $\mathrm{XIV}^{\mathrm{e}}-\mathrm{XV}^{\mathrm{e}}$ siècles)", in Précis de littérature française du Moyen Âge, dir. Daniel Poirion, Paris, PUF, 1983, p. 275-292.

Cerquiglini Jacqueline, "Un engin si soutil». Guillaume de Machaut et l'écriture au XIV siècle, Paris, Champion, 1985.

Cerquiglini-Toulet Jacqueline, "Le dit», in Grundriß der romanischen Literaturen des Mittelalters. La littérature française aux XIV et $X V^{e}$ siècles, vol. VIII/I, Heidelberg, Carl Winter, 1988, p. 86-94.

Cerquiglini-Toulet Jacqueline, "Des emplois seconds de la rime et du rythme dans la poésie française des $\mathrm{XIV}^{\mathrm{e}}$ et $\mathrm{Xv}^{\mathrm{e}}$ siècles", Le Moyen Français, 29, 1991, p. 21-31. 
Cerquiglini-Toulet Jacqueline, "Littérature médiévale?», in La Littérature française: dynamique et histoire, dir. Jean-Yves Tadié, Paris, Gallimard ("Folio essais»), 2007, p. 27-232.

Cerquiglini-Toulet Jacqueline, «Leçon. Sentier de rime et voie de prose au Moyen Âge», Poésie, 119, 2007, p. 123-131.

Cerquiglini-Toulet Jacqueline, «Penser la littérature médiévale: par-delà le binarisme», French Studies, 64/1, 2010, p. 1-12.

Cerquiglini-Toulet Jacqueline, «Littérature», conférence au colloque " "Littérature" : où allons-nous, du 3 au 5 octobre 2012 », dir. François Cornilliat et Hélène Merlin-Kajman, Paris, en ligne : http://www.mouvement-transitions. fr/index.php/litterarite/colloques/3-5-octobre-2012-litterature-ou-allonsnous.

Cerquiglini-Toulet Jacqueline, «La prose et la rose: l'imaginaire spatial de la prose et du vers", in Rencontres du vers et de la prose: conscience théorique et mise en page, dir. Catherine Croizy-Naquet et Michelle Szkilnik, Turnhout, Brepols, 2015, p. 151-160.

De Chalonge Florence, "Archétype», in Le Dictionnaire du littéraire, Paris, PUF ("Quadrige»), 2010, p. 25-26.

Chalumeau Chloé, "La scatologie dans Audigier: de la chanson de geste au fabliau", Grivoiserie, pornographie, scatologie, Questes, 21, 2011, p. 55-71.

Chardonnens Noémie, "D’un imaginaire à l'autre: la belle endormie du Roman de Perceforest et son fils", in Des Fata aux fées: regards croisés de l'Antiquité à nos jours, dir. Martine Hennard Dutheil de la Rochère et Véronique Dasen, Études de Lettres, 2011, 3-4, p. 191-203.

Chardonnens Noémie, L'Autre du même: emprunts et répétitions dans le Roman de Perceforest, Genève, Droz, 2015.

Chardonnens Noémie, "Mémoire de la prose, destin du vers. Les lais du Perceforest $\mathrm{du} \mathrm{Xv}^{\mathrm{e}}$ au $\mathrm{XvI}^{\mathrm{e}}$ siècle", in Plus agreable a lire en prose que en rime? Vers et prose en moyen français, dir. Michelle Szkilnik et Catherine CroizyNaquet, Le Moyen Français, vol. 76-77, 2015, Turnhout, Brepols, 2016, p. 65-84.

Chardonnens Noémie, "Les rapports entre vers et prose", in La matière arthurienne tardive en Europe (1270-1530), dir. Christine Ferlampin-Acher, Rennes, PUR, 2020, p. 233-240.

Chardonnens Noémie, Koble Nathalie et Moran Patrick, "L'invention du Livre d'Artus: le manuscrit PARIS, BnF, fr. 337 ", in Le manuscrit unique. Une singularité plurielle, dir. É. Burle-Errecade, V. Gontero-Lauze, Paris, PUPS, 2018, p. 115-136.

Chase Carol J., «Remaniement et le personnage de Gauvain dans le Lancelot en prose", in Arturus rex, dir. Willy Van Hoecke, Gilbert Tournoy et Werner Verbeke, Leuven, PU, 1991, p. 278-293. 
ChÊNERIE Marie-Luce, Le Chevalier errant dans les romans arthuriens en vers des XII et XIII siècles, Genève, Droz, 1986.

ChÊNerie Marie-Luce, "Sagremor, encore...", in L'ouvre de Chrétien de Troyes dans la littérature française: réminiscences, résurgences et réécritures, dir. Claude Lachet, Lyon, Université Jean Moulin, 1997, p. 59-72.

Colliot Régine, "Les Épitaphes arthuriennes", Bulletin bibliographique de la Société internationale arthurienne, 25, 1973, p. 155-175.

Содомво Timelli Maria, "Syntaxe et technique narrative: titres et attaques de chapitre dans l'Erec bourguignon", Fifteenth Century Studies, 24, 1998, p. 208-230.

Содомво Timelli Maria, «Le Cligés en prose (1455), ou l'actualisation d'un ancien conte en vers", L'Analisi Linguistica e Letteraria, 8/1-2, 2000, p. 329-342.

Colombo Timelli Maria, «L'Erec en prose, ou les traces de l'implication du lecteur dans un roman du $\mathrm{Xv}^{\mathrm{e}}$ siècle", in Le goût du lecteur à la fin du Moyen Âge, éd. Danielle Bohler, Cahiers du Léopard d'Or, 11, 2006, p. 117-132.

Содомво Timelli Maria, "On ne prête qu'aux riches”. Sur l'attribution de quelques œuvres à Pierre Sala", in "Pour vous donner ung peu de passetens..." Autour de Pierre Sala, lyonnais (ca. 1457-1529), Studi francesi, 156, 2008, p. 542-553.

Colombo Timelli Maria, Ferrari Barbara, Schoysman Anne et Suard François (dir.), Nouveau répertoire des mises en prose (XIV-XVI siècle), Paris, Garnier, 2014.

Combarieu du Grès Micheline (de), L'idéal humain et l'expérience morale chez les héros des chansons de geste des origines à 1250, Aix-en-Provence, Publications Université de Provence, 1979.

Combarieu Micheline de, "Ermitages" épiques (de Guillaume et de quelques autres)", in Les chansons de geste du cycle de Guillaume d'Orange. Hommage à Jean Frappier. Tome III: Les moniages Guibourc, dir. Philippe Ménard et Jean-Charles Payen, Paris, Société d'édition d'enseignement supérieur, 1983, p. 143-180.

Combes Annie, Les voies de l'aventure. Réécritures et composition romanesque dans le Lancelot en prose, Paris, Champion, 2001.

Combes Annie, "Le roman arthurien: un paradigme de l'aventure», in Poétique du roman d'aventure, dir. Alain-Michel Boyer et Daniel Couégnas, Nantes, Éditions Cécile Défaut, («Horizons comparatistes»), 2004, p. 31-43.

Combes Annie, Le Récit en mouvement. Logiques du romanesque médiéval, Mémoire de synthèse présenté en vue de l'obtention de l'habilitation à diriger des recherches, Paris, Sorbonne nouvelle, 2007.

Combes Annie, "Le dérimage du Chevalier de la Charrette: les vers de Chrétien comme ressource de la prose", in Ecrire en vers, écrire en prose: une poétique de 
la révélation. Actes du colloque de Paris X-Nanterre, mars 2006, dir. Catherine Croizy-Naquet, Nanterre, Université Paris X-Nanterre («Littérales», 41), 2007, p. 173-186.

Combes Annie, «Des fabliaux dans le Lancelot-Graal?», Romania, 2008, 126, p. 418-434.

Combes Annie (dir.), Fictions de vérité dans les réécritures européennes des romans de Chrétien de Troyes, Paris, Garnier, 2012.

Combes Annie, "L'emprise du vers dans les mises en prose romanesques (XIII ${ }^{\mathrm{e}}$ $\mathrm{xv}^{\mathrm{e}}$ siècles)", in Le Moyen Âge par le Moyen Âge, même. Réception, relectures et réécritures des textes médiévaux dans la littérature française des XIV et XV siècles, dir. par Laurent Brun, Silvère Menegaldo, Anders Bengtsson et Dominique Boutet, Paris, Champion, 2012, p. 115-140.

Combes Annie, «Fiction de vérité et vérité de la fiction dans les mises en prose du Chevalier de la Charrette", in Fictions de vérité dans les réécritures européennes des romans de Chrétien de Troyes, Paris, Garnier, 2012, p. 33-57.

Combes Annie, Serra Patrizia, Trachsler Richard et Virdis Maurizio (dir.), Chrétien de Troyes et la tradition du roman arthurien en vers, Paris, Garnier, 2013.

Combes Annie, "Narration et "matières". Les limites du merveilleux dans quelques romans arthuriens", in Motifs merveilleux et poétique des genres au Moyen Âge, dir. Francis Gingras, Paris, Garnier, 2015, p. 359-374.

Combes Annie, "L'athanor de la prose (l'atelier de Jean de Wavrin)», in Plus agreable a lire en prose que en rime? Vers et prose en moyen français, dir. Catherine Croizy-Naquet et Michelle Szkilnik, Le Moyen Français, vol. 76-77, 2015, Turnhout, Brepols, 2016, p. 39-64.

Compère Daniel, Les romans populaires, Paris, PSN, 2011.

Connochie-Bourgne Chantal, "L'exemple des peuples d'ailleurs", in En quête d'Utopies, dir. Claude Thomasset et Danièle James-Raoul, Paris, PUPS ("Cultures et Civilisations Médiévales», 29), 2005, p. 183-194.

Connochie-Bourgne Chantal, "L'apaisement de la tempête dans la littérature médiévale: quelques exemples", in Une Étrange constance. Les motifs merveilleux dans la littérature d'expression française du Moyen Âge à nos jours, dir. Francis Gingras, Sainte-Foy, PUL (La République des Lettres), 2006, p. $107-120$.

Connochie-Bourgne Chantal, Mondes marins du Moyen Âge, Aix-en-Provence, Presses universitaires de Provence («Senefiance», 52), 2006.

Connochie-Bourgne Chantal et Douchet Sébastien (dir.), Effets de style au Moyen Âge, Aix-Marseille Université, Presses Universitaires de Provence ("Senefiance»), 2012.

Corbellari Alain, Des fabliaux et des hommes. Narration brève et matérialisme au Moyen Âge, Genève, Droz, 2015. 
Cormeau Christoph, "Wigalois» und "Diu Crône»: Zwei Kapitel zur Gattungsgeschichte des nachklassischen Aventureromans, Münich, Beck, 1976.

Croizy-Naquet Catherine, Thèbes, Troie et Carthage: poétique de la ville dans le roman antique au XII siècle, Paris, Champion ("Nouvelle bibliothèque du Moyen Âge», 30), 1994.

Croizy-Naquet Catherine, "Quand la fiction se mêle à l'histoire: un combat dans les Faits de Romains", CRM, 5, 1998, p. 55-68.

Croizy-Naquet Catherine, Écrire l'histoire romaine au début du XIII siècle: L' "Histoire ancienne jusqu'à César» et les "Faits des Romains», Paris, Honoré Champion, 1999.

Croizy-Naquet Catherine, "Écrire l'histoire: le choix du vers ou de la prose aux XII ${ }^{\mathrm{e}}$ et XIII" siècles", in L'invention de l'histoire, dir. Christopher Lucken et Mireille Séguy, Paris, PUV («Médiévales», 38), 2000, p. 71-85.

Croizy-Naquet Catherine, "Nus contes rimés n'est verais", Revue des Sciences Humaines, Poésie en procès, dir. Claude Millet, 276, 4/2004, p. 29-44.

Croizy-Naquet Catherine, "Penser l'histoire antique au XIII ${ }^{\mathrm{e}}$ siècle à la lumière de l'historiographie contemporaine", Littérature. Le Moyen Âge contemporain. Perspectives critiques, dir. Nathalie Koble et Mireille Séguy, Paris, Larousse, 148,2007 , p. 28-43.

Croizy-Naquet Catherine (dir.), Écrire en vers, écrire en prose: une poétique de la révélation. Actes du colloque de Paris X-Nanterre, mars 2006, Nanterre, Université Paris X-Nanterre («Littérales», 41), 2007.

Croizy-Naquet Catherine, "L'histoire romaine entre vers et prose», in Écrire en vers, écrire en prose: une poétique de la révélation. Actes du colloque de Paris $X$-Nanterre, mars 2006, dir. Catherine Croizy-Naquet, Nanterre, Université Paris X-Nanterre («Littérales», 41), 2007, p. 155-171.

Croizy-Naquet Catherine, "Du vers à la prose ou les aléas du changement de forme", in Des "Tristan" en vers au "Tristan" en prose. Hommage à Emmanuèle Baumgartner, dir. Laurence Harf-Lancner, Laurence MatheyMaille, Bénédicte Milland-Bove et Michelle Szkilnik, Paris, Champion, 2009, p. 161-176.

Croizy-Naquet Catherine, "Imaginaire et histoire. Deux historiographies à l'épreuve", in Paysages de l'imaginaire: bilans et perspectives, PRIS MA, t. XXV/1 et 2, 51-52, janv.-déc. 2010, p. 117-130.

Croizy-Naquet Catherine, "Dislocation de la discipline "Littérature" ?", conférence au colloque "Littérature": où allons-nous, du 3 au 5 octobre 2012», dir. François Cornilliat et Hélène Merlin-Kajman, Paris, http://www. mouvement-transitions.fr/index.php?option $=$ com_content $\&$ view=article \&id=565:civilites-qlitterature-ou-allons-nousq-dislocation-de-la-discipline \&catid=29\&Itemid=101. 
Croizy-Naquet Catherine et Szkilnik Michelle (dir.), Rencontres du vers et de la prose: conscience théorique et mise en page, Turnout, Brepols, 2015.

Croizy-Naquet Catherine, Harf-Lancner Laurence et Szkilnik Michelle (dir.), Les manuscrits médiévaux témoins de lectures, Paris, PSN, 2015.

Croizy-Naquet Catherine et Szkilnik Michelle (dir.), Plus agreable a lire en prose que en rime? Vers et prose en moyen français, Le Moyen français, 76-77, Turnhout, Brepols, 2015.

Croizy-Naquet Catherine et Szkilnik Michelle (dir.), Rencontres du vers et de la prose. Conscience poétique et mise en texte, Paris, PSN, 2017.

Croizy-Naquet Catherine, Harf-Lancner Laurence et Szkilnik Michelle (dir.), Faire court: l'esthétique de la brièveté dans la littérature du Moyen Âge, Paris, PSN, 2011.

Croizy-Naquet Catherine, "L'octosyllabe dans l'Eneas, ferment de nouvelles poétiques ", in Poétiques de l'octosyllabe, dir. Danièle James-Raoul et Françoise Laurent, Paris, Champion, 2018, p. 211-228.

Curtius Ernst Robert, European Literature and the Latin Middle Ages, Londres et Henley, Routledge \& Kegan Paul, 1979.

DAMIAN-Grint Peter, "Estoire” as word and genre: meaning and literary usage in the twelfth century", Medium Aevum, 1997, 66, p. 189-206.

DANiel Catherine, "La légende arthurienne, un lien social politique et culturel européen", in Regards croisés sur le lien social, dir. Denis Bouget et Serge Karsenty, Nantes, Ange-Guépin, 2003, p. 41-51.

DANIEL Catherine, «Édouard I ${ }^{\text {er }}$ et l'identité arthurienne», in Marqueurs d'identité dans la littérature médiévale: mettre en signe l'individu et la famille (XII-XV siècles). Actes du colloque tenu à Poitiers les 17 et 18 novembre 2011, éd. Catalina Girbea, Laurent Hablot et Raluca Radulescu, Turnhout, Brepols ( Histoires de famille. La parenté au Moyen Âge», 17), 2014, p. 75-89.

Dauphant Clothilde, «L'octosyllabe, un vers à tout faire? L'exemple du Jardin de Plaisance», in Poétiques de l'octosyllabe, dir. Danièle James-Raoul et Françoise Laurent, Paris, Champion, p. 153-171.

De Carné Damien, Sur l'organisation du Tristan en prose, Paris, Champion, 2010.

Dehaisnes M. le Chanoine, Documents et extraits divers concernant l'histoire de l'art dans la Flandre, l'Artois et le Hainaut avant le XV siècle, Lille, L. Danel, 1886.

Delisle Leopold, Recherches sur la librairie de Charles V, roi de France (13371380), Paris, Champion, 1907, 2 vol.

Demartini Dominique, Miroir d'amour, miroir du roman. Le discours amoureux dans le Tristan en prose, Paris, Champion, 2006.

Demartini Dominique, "Des or est mout changiez li vers. Fictions du vers et de la prose dans Le Livre du duc des vrais amants de Christine de Pizan ", in 
Plus agreable a lire en prose que en rime? Vers et prose en moyen français, dir. Michelle Szkilnik et Catherine Croizy-Naquet, Le Moyen Français, vol. 76-77, 2015, Turnhout, Brepols, 2016, p. 85-109.

Deschaux Robert, "Le personnage de l'ermite dans la Queste del saint Graal et dans Le Haut Livre du Graal: Perlesvaus", in Actes du $14^{e}$ congrès international arthurien, Rennes, PUR, 1985, p. 172-183.

Deschepper Corinne, «Dédicace, prologue, résumé - Considérations sur les premières pages du Chevalier au lion de Pierre Sala", Quant l'ung amy pour l'autre veille. Mélanges de moyen français offerts à Claude Thiry, éd. Tania Van Hemelryck et Maria Colombo Timelli, Turnhout, Brepols («Texte, codex et contexte», 5), 2008, p. 101-111.

Deslaux Olivier et Haug Hélène (dir.), Original et originalité. Aspects historiques, philologiques et littéraires. Actes du IVE colloque de l'Association Internationale pour l'Étude du Moyen Français, Louvain, UCL, 2011.

Duвоsт Francis, Aspects fantastiques de la littérature narrative médiévale (XII'-XIII siècle). L'Autre, l'Ailleurs, l'Autrefois, Paris, Champion, 1991.

Duвost Francis, "Le Perlesvaus, livre de haute violence», in La Violence dans le monde médiéval, Aix-en-Provence, CUERMA ("Senefiance», 36), 1994, p. 181-199.

Dubost Francis, "Fin de partie: les dénouements dans La Mort le roi Artu», in La Mort du roi Arthur ou le crépuscule de la chevalerie, dir. Jean Dufournet, Paris, Champion («Unichamp»), 1994, p. 85-111.

Dubuis Roger, Les Cent nouvelles Nouvelles et la tradition de la nouvelle en France au Moyen Âge, Grenoble, PU, 1973.

Dubuis Roger, "Les formes narratives brèves", in Grundriß der romanischen Literaturen des Mittelalters. La littérature française aux XIV et XV siècles, vol. VIII/I, Heidelberg, Carl Winter, 1988, p. 178-196.

Ducos Joëlle, "Écrire la science en vers et en prose", in Écrire en vers, écrire en prose: une poétique de la révélation. Actes du colloque de Paris X-Nanterre, mars 2006, dir. Catherine Croizy-Naquet, Nanterre, Université Paris X-Nanterre ("Littérales», 41), 2007, p. 229-244.

Ducos Joëlle, Soutet Olivier et VALetTe Jean-René, Le français médiéval par les textes: anthologie commentée, Paris, Champion ("Références et Dictionnaires»), 2015.

Ducos Joëlle, "Écrire en vers après la prose: vers une poésie scientifique?», in Rencontres du vers et de la prose. Conscience poétique et mise en texte, dir. Catherine Croizy-Naquet et Michelle Szkilnik, Paris, PSN, 2017, p. 93-110.

Duggan Joseph J., The Song of Roland: Formulaic Style and Poetic Craft, Berkeley; Los Angeles; Londres, University of California Press, 1973.

DumézIL Georges, Jupiter, Mars, Quirinus. 1. Essai sur la conception indo-européenne de la société et sur les origines de Rome, Paris, Gallimard, 1941. 
ECHARD Siân, Arthurian Narrative in the Latin Tradition, Cambridge, University Press, 1998.

EGEDI-Kovacs Emese, "La "morte vivante" dans les poèmes narratifs français et occitans du Moyen Âge", in Actes du $22^{e}$ Congrès de la Société Internationale arthurienne, 2008, http://uhb.fr/alc/ias/actes/index.htm.

EGEDI-Kovacs Emese, Le "morte-vivante" dans le récit français et occitan du Moyen Âge, Budapest, Elte Eötvös Kiadó, 2012.

ERrecade Ollivier, "Les euues qui de la mer issent vont et viennent... Présence(s) maritime(s) dans le cycle du Lancelot-Graal", in Mondes marins du Moyen Age, dir. Chantal Connochie-Bourgne, Aix-en-Provence, Presses universitaires de Provence ("Senefiance», 52), 2006, p. 145-155.

Essor et fortune de la chanson de geste dans l'Europe et l'Orient latin. Actes du IXe Congrès international de la Société Rencesvals, Modena, Mucchi, 1984, 2 vol.

FABRY Irène, «De rappels en prédictions, savoir convaincre et savoir agir: le rôle ambigu de Merlin, de la naissance d'Arthur à son accès au trône de Bretagne (dans le Merlin en prose et la Suite Vulgate) ", L'Esplumeoir, 6, 2007, p. 15-23.

FABRY Irène, "Le festin de l'homme sauvage dans la Suite Vulgate du Merlin et le Roman de Silence: l'attrait de la nourriture et la mise en scène paradoxale du personnage de Merlin", Questes, 12, 2007, p. 49-64.

FARAL Edmond, Les Arts poétiques du XII et du XIII siècle: recherches et documents sur la technique littéraire du Moyen Âge, Paris, Champion, 1924.

FAsSEur Valérie, "La mémoire volontaire de l'écrivain médiéval: aspects et enjeux de la remembrance», Littérature, 175, 2014, p. 6-22.

Ferlampin-Acher Christine, "Le charme d'Artus de Bretagne», in Miscellanea mediaevalia. Mélanges offerts à Philippe Ménard, dir. Jean-Claude Faucon, Alain Labbé et Danielle Quéruel, Paris, Champion, 1998, t. 1, p. 513-528.

Ferlampin-Acher Christine, Fées, bestes et luitons. Croyances et merveilles, Paris, PUPS, 2002.

Ferlampin-Acher Christine, «D'un monde à l'autre: Artus de Bretagne entre mythe et littérature, de l'antiquaire à la fabrique de faux meubles bretons", in Le monde et l'autre monde, dir. Denis Hüe et Christine Ferlampin-Acher, Orléans, Paradigme, 2002, p. 129-168.

Ferlampin-ACHer Christine, "Merveilles» et topique merveilleuse dans les romans médiévaux, Paris, Champion, 2003.

Ferlampin-Acher Christine, "Merveilleux et comique dans les romans arthuriens français (XII $-\mathrm{XV}^{\mathrm{e}}$ siècles)», Arthurian Literature, XIX, 2003, p. 17-47.

Ferlampin-Acher Christine, "Brun de la Montagne: une chançon de matiere enforciee (v. 2744)?", in Le Romanesque aux XIV et XV siècles, dir. Danièle Bohler, Bordeaux, Presses de l'Université de Bordeaux, 2009, p. 29-40.

Ferlampin-Acher Christine, Perceforest et Zéphir. Propositions autour d'un récit arthurien bourguignon, Genève, Droz, 2010. 
Ferlampin-Acher Christine, «La matière arthurienne en langue d'oïl à la fin du Moyen Âge: épuisement ou renouveau, automne ou été indien?», Bulletin bibliographique de la Société Internationale Arthurienne, vol. LXIII, 2011, p. 258-294.

Ferlampin-Acher Christine, «Le Graal dans les romans arthuriens de la fin du Moyen Âge: Artus de Bretagne et Perceforest», in Mémoires arthuriennes, dir. Danielle Quéruel, Troyes, Médiathèque du Grand Troyes, 2012, p. 123-142.

Ferlampin-ACHer Christine, "Féerie romanesque et roman féerique $\left(\mathrm{XIV}^{\mathrm{e}}-\mathrm{XVI}^{\mathrm{e}}\right.$ siècles) : naissance et déclin annoncé d'un genre?", in Aspects du merveilleux dans les littératures médiévales, dir. Francesco Marzella, Lucilla Spetia et Franca Ella Consolino, Turnhout, Brepols, 2016, p. 159-170.

Ferlampin-Acher Christine et Girbea Catalina (dir.), Matières à débat. La notion de matiere littéraire dans la littérature médiévale, Rennes, PUR («Interférences»), 2017.

FERLAMPIN-ACHer Christine, Arthur après Arthur. La matière arthurienne tardive en dehors du roman arthurien (1270-1530), Rennes, PUR ("Interférences»), 2017.

FERlampin-Acher Christine, "À la mode de Bretagne: la culture arthurienne dans le Roman du Hem de Sarrasin (1278) et le Roman de Guillaume d'Orange (entre 1454 et 1456)", in Arthur après Arthur. La matière arthurienne tardive en dehors du roman arthurien (1270-1530), dir. Christine Ferlampin-Acher, Rennes, PUR («Interférences»), 2017, p. 517-538.

Ferlampin-Acher Christine, "Introduction. Après Arthur?", in Arthur après Arthur. La matière arthurienne tardive en dehors du roman arthurien (12701530), dir. Christine Ferlampin-Acher, Rennes, PUR («Interférences»), 2017, p. 7-21.

FERLAmpin-Acher Christine, "Interpolations et "extrapolations»: études de quelques épisodes arthuriens en contexte non arthurien", in Arthur après Arthur. La matière arthurienne tardive en dehors du roman arthurien (12701530), dir. Christine Ferlampin-Acher, Rennes, PUR («Interférences»), 2017, p. 137-155.

FERLAMPIN-ACHER Christine (dir.), Littérature arthurienne tardive en Europe (LATE), Rennes, PUR, 2019, 10 vol.

Foehr-Janssens Yasmina, «Une merveilleuse clergie. Pouvoirs et savoirs insolites dans le Roman des Sept Sages en vers", in Motifs merveilleux et poétique des genres au Moyen Âge, dir. Francis Gingras, Paris, Garnier, 2015, p. 403-419.

Fourrier Anthime, "La destinataire de La Dame à la licorne», in Mélanges de langue et de littérature médiévales offerts à Pierre Le Gentil, Paris, Société d'édition d'enseignement supérieur et Centre de documentation universitaire, 1973, p. 265-276.

Fowler Alastair, Kinds of Literature. An Introduction to the Theory of Genres and Modes, Cambridge, Harvard University Press, 1982. 
FrANCI Giovanna et ZAGO Ester, La bella addormentata, genesi e metamorfosi di una fiaba, Bari, Dedalo, 1984.

Frappier Jean, «Remarques sur la structure du lai. Essai de définition et de classement", in La Littérature narrative d'imagination, Paris, PUF, 1961, p. 23-39.

Frappier Jean, «La brisure du couplet dans Erec et Enide», Romania, 341/86, 1965 , p. $1-21$.

Frappier Jean, Étude sur la Mort le Roi Artu, Genève, Droz, 1972.

Frappier Jean, "Le prologue du Chevalier de la Charrette et son interprétation ", Romania, 93, 1972, p. 337-377.

Frappier Jean, «Le personnage de Gauvain dans la Première Continuation de Perceval", in Amour courtois et Table Ronde, Genève, Droz, 1973, p. 158-163. 153-167.

Frappier Jean, "Sur le Perceval en prose de 1530», in Jean Frappier, Autour du Graal, Genève, Droz, 1977, p. 211-224.

Frappier Jean, «Le Graal et la chevalerie», in Jean Frappier, Autour du Graal, Genève, Droz, 1977, p. 89-128.

Frappier Jean, "La matière de Bretagne: ses origines et son développement", in Grundriß der romanischen Literaturen des Mittelalters. Le Roman jusqu'à la fin du XIII siècle, VI/1, Heidelberg, Carl Winter, 1978, p. 183-211.

Frappier Jean, "Le Moniage Guillaume», in Les chansons de geste du cycle de Guillaume d'Orange. Hommage à Jean Frappier. Tome III: Les moniages Guibourc, dir. Philippe Ménard et Jean-Charles Payen, Paris, Société d'édition d'enseignement supérieur, 1983, p. 19-83.

Freeman Regalado Nancy, "A contract for an early festival book: Sarrasin's Le Roman du Hem (1278)", in Acts and Texts: Performance and Ritual in the Middle Ages and the Renaissance, dir. Laurie Postlewate et Wim Hüsken, Amsterdam; New York, Rodopi («Ludus. Medieval and Early Renaissance Theatre and Drama», 8), 2007, p. 249-267.

Frétigné Jean-Yves, Histoire de la Sicile, Paris, Fayard, 2009.

Fritz Jean-Marie, Le discours du fou au Moyen Âge, XIe-XIII siècles, Paris, PUF, 1992.

Fritz Jean-Marie, "Le roman en vers au Moyen Âge», in Histoire de la France littéraire, vol. 1, dir. par Frank Lestringant et Michel Zink, Paris, PUF, 2006, p. 957-969.

Galderisi Claudio, "Conscience littéraire et émergence de l'individu au Moyen Âge", in Histoire de la France littéraire, vol. 1, dir. par Frank Lestringant et Michel Zink, Paris, PUF, 2006, p. 667-677.

Galderisi Claudio, "Vers et prose au Moyen Âge», in Histoire de la France littéraire, vol. 1, dir. par Frank Lestringant et Michel Zink, Paris, PUF, 2006, p. 745-766. 
GallaIs Pierre, L'imaginaire d'un romancier français de la fin du XIr siècle. Description raisonnée, comparée et commentée de la Continuation-Gauvain, Amsterdam, Rodopi, 1988, 3 tomes.

GAUCHER Elisabeth, La biographie chevaleresque. Typologie d'un genre (XIIt -XV'), Paris, Champion, 1994.

Gaucher Elisabeth, "Le Chevalier au Papegau: "Enfances" ou déclin de la littérature arthurienne?", in Enfances arthuriennes. Actes $d u 2^{e}$ colloque arthurien de Rennes, 6-7 mars 2003, dir. Denis Hüe et Christine Ferlampin-Acher, Orléans, Paradigme, 2006, p. 255-266.

Gaullier-Bougassas Catherine, Les Romans d'Alexandre. Aux frontières de l'épique et du romanesque, Paris, Champion, 1998.

Gaullier-Bougassas Catherine, La tentation de l'Orient dans le roman médiéval. Sur l'imaginaire médiéval de l'Autre, Paris, Champion, 2003.

Gaullier-Bougassas Catherine, "Alexandre face aux révoltes des siens: recompositions médiévales du passé historique», Bien dire, bien aprandre, 25, 2007, p. 209-225.

Gingras Francis, «L'anneau merveilleux et les deux versants du désir. Présentation du Thesaurus informatisé des motifs merveilleux de la littérature médiévale», Revue des langues romanes, 1997, t. CI/2, 163-183.

Gingras Francis, "La triste figure des chevaliers dans un codex du XIII siècle (Chantilly, Condé 472)», Revue des langues romanes, 110:1, 2006, p. 77-97.

Gingras Francis, «Décaper les vieux romans: voisinages corrosifs dans un manuscrit du XIII ${ }^{e}$ siècle (Chantilly, Condé 472)», Etudes françaises, 42:1, 2006, p. 13-38.

GINGRAS Francis, "Errances maritimes et explorations romanesques dans Apollonius de Tyr et Floire et Blancheflor", in Mondes marins du Moyen Âge, dir. Chantal Connochie-Bourgne, Aix-en-Provence, Presses universitaires de Provence («Senefiance», 52), 2006, p. 169-185, en ligne: https://books. openedition.org/pup/3838.

GINGRAS Francis, "Roman contre roman dans l'organisation du manuscrit du Vatican, Regina Latina 1725", in La mise en recueil des textes médiévaux, dir. Xavier Leroux, La Garde, Université du Sud Toulon-Var («Babel», 16), 2007, p. 61-80.

Gingras Francis, "La cohabitation du vers et de la prose dans deux collections médiévales (Chantilly, Condé 472 et Berne, Burgerbibliothek 113)», in Écrire en vers, écrire en prose: une poétique de la révélation. Actes du colloque de Paris $X$-Nanterre, mars 2006, dir. Catherine Croizy-Naquet, Nanterre, Université Paris X-Nanterre ("Littérales», 41), 2007, p. 85-99.

Gingras Francis, "Comment présenter un genre qui n'existe pas? Le prologue d'Erec et Enide et la typologie des genres vernaculaires ", Méthode!, 16, 2010, p. $29-41$. 
GINGRAS Francis, Le bâtard conquérant: essor et expansion du genre romanesque au Moyen Âge, Paris, Champion, 2011.

GiNGRAs Francis, "Pour faire court: conscience générique et formes brèves au Moyen Âge", in Faire court: l'esthétique de la brièveté dans la littérature du Moyen Age, dir. Catherine Croizy-Naquet, Laurence Harf-Lancner et Michelle Szkilnik, Paris, PSN, 2011, p. 155-179.

Gingras Francis, "Tant con durra crestiantez. L'épreuve du temps comme épreuve de vérité dans les réécritures des romans de Chrétien de Troyes (XIII ${ }^{\mathrm{e}}$-XVIII ${ }^{\mathrm{e}}$ siècle)", in Fictions de vérité dans les réécritures européennes des romans de Chrétien de Troyes, dir. Annie Combes, Paris, Garnier, 2012, p. 71-88.

Gingras Francis, "La part du vers dans la définition médiévale des fabliaux», in Rencontres du vers et de la prose: conscience théorique et mise en page, dir. Catherine Croizy-Naquet et Michelle Szkilnik, Turnout, Brepols, 2015, p. 61-74.

Gingras Francis (dir.), Motifs merveilleux et poétique des genres au Moyen Âge, Paris, Garnier, 2015.

Gingras Francis, "Le roman à l'épreuve des fées", in Écriture et réécriture du merveilleux féérique. Autour de Mélusine, dir. Matthew W. Morris et JeanJacques Vincensini, Paris, Garnier, 2015, p. 23-35.

Giovénal Carine, "Essart et caroles: la problématique du cercle dans Méraugis de Portlesguez de Raoul de Houdenc», PRIS-MA, XXVII/1-2, 2011, p. 65-84.

Grimbert Joan Tasker, Yvain dans le miroir: une poétique de la réflexion dans le Chevalier au lion de Chrétien de Troyes, Amsterdam, Benjamins, 1988.

Gowans Linda, Cei and the Arthurian Legend, Cambridge, Boydell and Brewer ("Arthurian Studies»), 1988.

Gravdal Kathryn, Ravishing Maiden. Writing Rape in Medieval French Literature and Law, Philadelphie, University of Pennsylvania Press, 1991.

Grigsby John L., The Gab as a Latent Genre in Medieval French Literature, Cambridge, The Medieval Academy of America, 2000.

Grojnowski Daniel, "Décadence», in Le Dictionnaire du littéraire, Paris, PUF, 2002, p. 176-177.

GuenÉE Bernard «Histoires, annales, chroniques. Essai sur les genres historiques au Moyen âge", Annales E.S.C., 1973, p. 997-1016.

GuenéE Bernard, Histoire et culture historique dans l'Occident médiéval, Paris, Aubier Montaigne, 1980.

Guerreau-Jalabert Anita, Index des motifs narratifs dans les romans arthuriens français en vers (XII'-XIII siècle), Genève, Droz, 1992.

GuggenbüHL Claudia, Recherches sur la composition et la structure du ms. Arsenal 3516, Bâle et Tübingen, Francke, 1998.

GuietTe Robert, "Baudelaire et le poème en prose», Revue belge de philologie et d'histoire, 42/3, 1964, p. 843-852. 
Gumbrecht Hans Ulrich et Biermann Armin (dir.), Grundriß der romanischen Literaturen des Mittelalters, La littérature historiographique des origines à 1500, Heidelberg, Carl Winter, 1986.

Gumy Chloé, Lancelot dans les Merveilles de Rigomer: un héros aux prises avec son appétit, mémoire de maîtrise sous la direction de Barbara Wahlen, Université de Lausanne, 2018.

Hamon Philippe, «Pour un statut sémiologique du personnage», Littérature, 6, 1972, p. 86-110.

Hamon Philippe, L'Ironie littéraire. Essai sur les formes de l'écriture oblique, Paris, Hachette, 1996.

Harf-Lancner Laurence, Les fées au Moyen Âge. Morgane et Mélusine: la naissance des fées, Genève, Slatkine, 1984.

HARF-LANCNER Laurence, "Le baptême par le feu: la survivance d'un rite dans trois textes épiques tardifs", in Au carrefour des routes d'Europe: la chanson de geste. Tome II. Xe Congrès international de la Société Rencesvals pour l'étude des épopées romanes, Strasbourg, 1985, Aix-en-Provence, Publications de l'Université de Provence («Senefiance», 21), 1987, p. 629-641.

HARF-LANCNER Laurence, "La serpente et le sanglier. Les manuscrits enluminés des deux romans français de Mélusine», Le Moyen Âge, 101, 1995, p. 65-97.

HARF-LANCNer Laurence, "Le Bel Inconnu et sa mise en prose au XVI ${ }^{\mathrm{e}}$ siècle, L'Histoire de Giglan: d'une esthétique à l'autre", in Le Chevalier et la merveille dans le Bel Inconnu ou le beau jeu de Renaut, dir. Jean Dufournet, Paris, Champion, 1996, p. 69-89.

Harf-LANCNER Laurence, "Gauvain l'assassin: la récurrence d'un schéma narratif dans le Tristan en prose", in Tristan - Tristant. Mélanges en l'honneur de Danielle Buschinger à l'occasion de son $60^{\text {ime }}$ anniversaire, dir. André Crépin et Wolfgang Spiewok, Greifswald, Reineke, 1996, p. 219-230.

Harf-Lancner Laurence, "From Alexander to Marco Polo, from text to image: the marvels of India", in The Medieval French Alexander, dir. Donald et Sarah Maddox, Albany, University of New York Press, 2002, p. 235-257.

Harf-LAnCNer Laurence, "Héroïsme et démesure: Alexandre et la Tour de Babel ", in Romans d'Antiquité et littérature du Nord, Paris, Champion, 2007, p. 405-422.

HatzFeld Helmut, "La décadence de l'amour courtois dans le Saintré, l'Amadis et le Tirant lo Blanc", in Mélanges de littérature du Moyen Âge au XX offerts à Mademoiselle Jeanne Lods, professeur honoraire de littérature médiévale à l'École normale supérieure de jeunes filles, par ses collègues, ses élèves et ses amis, Paris, École normale supérieure de jeunes filles ("Collection de l'École normale supérieure de jeunes filles», 10), 1978, t. 1, p. 339-350.

HAug Walter, "Über die Schwierigkeiten des Erzählens in "nachklassischer Zeit" ", in Positionen des Romans im späten Mittelalter, dir. Walter Haug et Burghart Wachinger, Tübingen, Max Niemeyer, 1991, p. 338-365. 
Heintze Michael, «Les techniques de la formation de cycles dans les chansons de geste", in Cyclification. The development of narrative Cycles in the Chanson de Geste and the Arthurian Romances, dir. B. Besamusca et al., Amsterdam; Oxford, North-Holland, 1994, p. 21-58.

HÉLARY Xavier, "Les rois de France et la guerre sainte de la croisade de Tunis à la chute d'Acre (1270-1291)", Annales - Bulletin de la Société de l'histoire de France, 2005, p. 21-104.

Henriet Patrick et Valette Jean-René, «Perlesvaus et le discours hagiographique», Revue des Langues Romanes, 118/1, 2014, p. 73-93.

Henry Albert, Les aeuvres d'Adenet le roi, Brugge, De Tempel, 1951.

Höllander Hans, "Alexander: Hybris und Curiositas», in Kontinuität und Transformation des Antike im Mittelalter, Sigmaringen, Jan Thorbecke, 1989, p. 65-79.

Huchet Jean-Charles, Le roman occitan médiéval, Paris, PUF, 1991.

Hüe Denis et Gallé Hélène, Rutebeuf, Neuilly, Atlande ("Clefs concours Lettres médiévales»), 2006.

Hult David F., «Pour ou contre une esthétique de la compilation? La mise en prose du Chevalier de la Charrette dans deux manuscrits du Lancelot-Graal de la fin du XIV siècle", in Le romanesque aux XIV et XV siècles, dir. Danielle Bohler, Bordeaux, Presses de l'Université de Bordeaux, 2009, p. 57-67.

James-Raoul Danièle, "Un curieux avatar de L'Estoire Merlin: le Roman de Silence", in Traduction, transposition, adaptation au Moyen Age, Bien dire et bien aprandre, 13, 1996, p. 145-157.

James-Raoul Danièle, «Rhétorique de l'entrelacement et art de régir la fin: le cas du Tristan en prose (ms. Vienne 2542)", PRIS-MA, XV/1, 1999, p. 85-111.

James-Raoul Danièle, «La stylistique médiévale», Perspectives médiévales, Trente ans de recherches en langues et en littératures médiévales, dir. Jean-René Valette, 2005, p. 265-284.

James-Raoul Danièle, «L'écriture de la tempête en mer dans la littérature de fiction, de pèlerinage et de voyage", in Mondes marins du Moyen Agge, dir. Chantal Connochie-Bourgne, Aix-en-Provence, Presses universitaires de Provence («Senefiance», 52), 2006, p. 217-229), en ligne: https://books. openedition.org/pup/3841.

James-Raoul Danièle, Chrétien de Troyes, la griffe d'un style, Paris, Champion, 2007.

James-Raoul Danièle (dir.), Les Genres littéraires en question au Moyen Âge, Bordeaux, Presses universitaires («Eidôlon», 97), 2011.

James-Raoul Danièle, «La poétique des genres dans les arts poétiques médiolatins (XII ${ }^{\mathrm{e}}$-XIII ${ }^{\mathrm{e}}$ siècles)", in Les Genres littéraires en question au Moyen Âge, dir. Danièle James-Raoul, Bordeaux, Presses universitaires («Eidôlon», 97), 2011, p. 169-186. 
James-Raoul Danièle, "La théorie des trois styles dans les arts poétiques médiolatins des $\mathrm{XII}^{\mathrm{e}}$ et $\mathrm{XIII}^{\mathrm{e}}$ siècles", in Effets de style au Moyen Âge, dir. Chantal Connochie-Bourgne et Sébastien Douchet, Aix-Marseille Université, Presses Universitaires de Provence ("Senefiance»), 2012, p. 17-26.

James-Raoul Danièle, "Questions de style à propos des romans arthuriens en vers des XII ${ }^{\mathrm{e}}$ et XIII ${ }^{\mathrm{e}}$ siècles", JIAS, 4/1, 2016, p. 25-52.

James-Raoul Danièle, "La brisure du couplet dans le Chevalier au lion de Chrétien de Troyes", Op. cit. Revue des littératures et des arts, CRPHLL, Université de Pau, 2017, en ligne: https://revues.univ-pau.fr/opcit/index. php?176--agregation-2018.

James-Raoul Danièle, "La poétique de l'octosyllabe dans Le Chevalier au lion", Acta Litt\&Arts, Acta Litt\&Arts, Le laboratoire du roman. Le Chevalier au lion de Chrétien de Troyes, 2018, http://ouvroir-litt-arts.univ-grenoble-alpes.fr/ revues/actalittarts/385-la-poetique-de-l-octosyllabe-dans-le-chevalier-au-lion.

James-Raoul Danièle et Laurent Françoise (dir.), Poétiques de l'octosyllabe, dir., Paris, Champion, 2018.

Jauss Hans Robert, "Chanson de geste et roman courtois (analyse comparative du Fierabras et du Bel Inconnu)", in Chanson de geste und höfischer Roman, Heidelberg, Carl Winter («Studia Romanica»), 1963, p. 61-77.

JEAY Madeleine, Le commerce des mots. L'usage des listes dans la littérature médiévale (XIt $-X V^{e}$ siècles), Genève, Droz, 2006.

JEAY Madeleine, "Por conter a le cort le roi” Le plaisir du récit enchâssé dans les romans de Raoul de Houdenc", Cahiers de recherches médiévales et humanistes, 29, 2015, p. 91-109.

JEAY Madeleine, "Polyphonies textuelles. Écritures de la parodie», in Parodies courtoises, parodies de la courtoisie, dir. Margarida Madureira, Carlos Clamote Carreto et Ana Paiva Morais, Paris, Garnier, 2016, p. 359-385.

Jodogne Omer, "Le caractère des œuvres antiques dans la littérature du XII et du XIII ${ }^{\mathrm{e}}$ siècle", in L’humanisme médiéval dans les littératures romanes du XII au $X I V^{e}$ siècle, dir. Anthime Fourrier, Paris, Klincksieck, 1964, p. 55-83.

Jouve Vincent, "Le héros et ses masques", in Le Personnage romanesque, Cahiers de narratologie 6, Presses de l'université de Nice, 1995, p. 253-254.

Jung Marc-René, "L’empereur Conrad, chanteur de poésie lyrique - Fiction et vérité dans le Roman de la rose de Jean Renart", Romania, 101, 1980, p. 35-50.

Jung Marc-René, La légende de Troie en France au moyen âge. Analyse des versions françaises et bibliographie raisonnée des manuscrits, Bâle, Francke, 1996.

Kalmar Aniko (dir.), L'exotisme dans la poésie épique française, Paris, L'Harmattan, 2003.

Kantorowicz Ernst, Les Deux corps du Roi, in Euvres, Paris, Gallimard, 2000, p. 643-1222. 
Kennedy Elspeth, "King Arthur in the first part of the Prose Lancelot», in Medieval Miscellany Presented to Eugene Vinaver by Pupils, Colleagues and Friends, éd. Frederick Whitehead, Armel Hugh Diverrès et Franck Edmund Sutcliffe, Manchester, Manchester University Press; New York, Barnes and Noble, 1965, p. 186-195.

KeNNEDY Elspeth, «Les structures narratives et les allusions intertextuelles dans le Tristan en prose», in Nouvelles recherches sur le Tristan en prose, dir. Jean Dufournet, Paris, Champion, 1990, p. 123-147.

KibleR William, "La "chanson d'aventures"”, in Essor et fortune de la chanson de geste dans l'Europe et l'Orient latin. Actes du IXe Congrès international de la Société Rencesvals, vol. 2 «Rapports entre chanson de geste et roman au XIII ${ }^{e}$ siècle», Modena, Mucchi, 1984, p. 509-515.

Kiblen William, «Sagremor in the Arthurian Verse Romances», in "Por le soie amisté»: essays in honor of Norris J. Lacy, dir. Keith Busby et Catherine M. Jones, Amsterdam, Rodopi, 2000, p. 283-292.

Kinoshita Sharon, «Male-Order Brides: Marriage, Patriarchy, and Monarchy in the Roman de Silence", Arthuriana, 12.1, 2002, p. 64-75.

KuÜppelholz Heinz, "Die Idealisierung und Ironisierung des Protagonisten in den altfranzösischen Gauvain-Romanen", Germanisch-Romanische Monatsschrift, 44, 1994, p. 18-36.

Koвle Nathalie (dir.), Jeunesse et genèse du royaume arthurien. Les Suites romanesques du Merlin en prose, Orléans, Paradigme, 2007.

KовLE Nathalie, «L'illusion prophétique, ou la maîtrise du temps. Les prophéties dans la Suite du roman de Merlin", in Jeunesse et genèse du royaume arthurien. Les Suites romanesques du Merlin en prose, dir. Nathalie Koble, Orléans, Paradigme, 2007, p. 157-178.

Koвle Nathalie, «Les romans arthuriens en prose au XIII ${ }^{\mathrm{e}}$ siècle: des cycles en série?», in Cycle et collection, dir. Anne Besson, Vincent Ferré et Christophe Pradeau, Paris, L'Harmattan, 2008, p. 179-198.

Koble Nathalie, «Un nouveau Ségurant Le Brun en prose? Le manuscrit de Paris, Arsenal 5229, un roman arthurien monté de toutes pièces", in Le Romanesque aux XIV et XV siècles, dir. Danielle Bohler, Eidôlon, 83, 2009, p. 69-94, en ligne: https://books.openedition.org/pub/25201?lang=fr.

Koвle Nathalie, "L'autre monde de la prose: reliure et relecture du roman arthurien en vers dans le Livre d'Artus", in Rencontres du vers et de la prose: conscience théorique et mise en page, dir. Catherine Croizy-Naquet et Michelle Szkilnik, Turnhout, Brepols, 2015, p. 75-90.

KöHLER Erich, "Le rôle de la "coutume" dans les romans de Chrétien de Troyes», Romania, 81/323, 1960, p. 386-397.

Koopmans Jelle, " "On écrit des vers - de la prose”, mais que dit-on sur la scène?», in Rencontres du vers et de la prose. Conscience poétique et mise en texte, dir. Catherine Croizy-Naquet et Michelle Szkilnik, Paris, PSN, 2017, p. 127-139. 
Krueger Roberta L., "Playing to the ladies: chivalry and misogyny in Ipomedon, Le chevalier à l'épée, and La vengeance Raguidel", in Women Readers and the Ideology of Gender in Old French Verse Romance, Cambridge; New York; Melbourne, Cambridge University Press, 1993, p. 68-100.

Kullmann Dorothea, "Le métadiscours sur la réécriture dans les prologues épiques", in Réécritures. Regards nouveaux sur la reprise et le remaniement de textes, dans la littérature française et au-delà, du Moyen Âge à la Renaissance, dir. Dorothea Kullmann et Shaun Lalonde, Toronto, Pontifical Institute of Medieval Studies, 2015, p. 97-133.

LaCHaud Magali, "Fabliau», in Dictionnaire raisonné de la caducité des genres littéraires, dir. Saulo Neiva et Alain Montandon, Genève, Droz, 2014, p. 307-325.

LACHet Claude, Sone de Nansay et le roman d'aventures en vers au XIIt siècle, Paris, Champion, 1992.

LACHet Claude, "Un siècle après Perceval: Sone de Nansay et le Graal», in Les Personnages autour du Graal. Actes du colloque des 7 et 8 juin 2007 à l'Université de Lyon 3, Lyon, Université de Lyon 3 («CEDIC»), 2008, p. 153-164.

LACY Norris J., "The Character of Gauvain in Hunbaut», Bulletin bibliographique de la Société Internationale Arthurienne, 38, 1986, p. 298-305.

Lacy Norris J., Kelly Douglas et Busby Keith (dir.), The Legacy of Chrétien de Troyes, 2 vol., Amsterdam, Rodopi, 1987-1988.

LaCY Norris J., "Convention and Innovation in Le Chevalier du Papegau», in Studies in Honor of Hans-Erich Keller. Medieval French and Occitan Literature and Romance Linguistics, dir. Rupert T. Pickens, Kalamazoo, Western Michigan University, 1993, p. 237-246.

LACY Norris J., "Motif Transfert in Arthurian Romance», in The Medieval Opus: Imitation, rewriting and transmission in the French tradition: proceedings of the Symposium held at the Institue for research in humanities, October 5-7 1995, dir. Douglas Kelly, Amsterdam; Atlanta, Rodopi, 1996, p. 157-168.

LaCy Norris J., "The Enigma of the Prose Yvain", in Arthurian Studies in honor of P. J. C. Field, dir. Bonnie Wheeler, New York, Brewer, 2004, p. 65-71.

LaCy Norris J., "On Customs in Medieval French Romance», Revue belge de philologie et d'histoire, 83/3, 2005, p. 977-986.

LACY Norris J., "Arthur's Character and Reputation in Yder", Cahiers de recherches médiévales et humanistes, 14, 2007, p. 40-48.

Lacroix Daniel W., "L'insertion poétique dans les œuvres narratives du XIII ${ }^{\mathrm{e}}$ siècle. Le domaine roman", Littératures, 35, 1996, p. 189-216.

LADD Ann, "Attitude towards Lyric in the Lai d'Aristote and some Later Fictional Narratives", Romania, 96, 1975, p. 194-208.

Langlois Ernest, Recueil d'Arts de Seconde Rhétorique, Paris, Imprimerie nationale, 1900 . 
LaRanjinha Ana Sofia, «L'ironie comme principe structurant chez Chrétien de Troyes", Cahiers de civilisation médiévale, 41, 1998, p. 175-182.

LARMAT Jean, «Le personnage de Gauvain dans quelques romans arthuriens du $\mathrm{XII}^{\mathrm{e}}$ et du XIII ${ }^{\mathrm{e}}$ siècle», in Mélanges Lanly, Nancy, Publications de l'Université, 1980 , t. II, p. 185-202.

LATHUILlÈRe Roger, Guiron le courtois. Étude de la tradition manuscrite et analyse critique, Genève, Droz, 1966.

Lathuillère Roger, "Un exemple de l'évolution du roman arthurien en prose dans la deuxième moitié du XIII ${ }^{\mathrm{e}}$ siècle", in Mélanges de langue et littérature françaises du Moyen Âge offerts à Pierre Jonin, Senefiance, 7, 1979, p. 387-401.

LATHuilLÈre Roger, «L'évolution de la technique narrative dans le roman arthurien en prose de la deuxième moitié du XIII ${ }^{e}$ siècle», Étude de langue et de littérature françaises offertes à André Lanly, Nancy, 1980, p. 203-213.

Latimier-Ionoff Adeline, Lire le nom propre dans le roman médiéval, Paris, Classiques Garnier («Recherches littéraires médiévales»), 2019.

LAURENT François, Les insertions lyriques dans les romans en vers du XIII siècle, Thèse de doctorat sous la direction de Jacques Fontanille, Université de Limoges, 2007, https://halshs.archives-ouvertes.fr/tel-00925877/document.

Laurent Françoise, Plaire et édifier. Les récits hagiographiques composés en Angleterre aux XII et XIII siècles, Paris, Champion, 1998.

Laurent Françoise, "Style et arithmétique du vers dans le Roman de Rou de Wace», Centaurus. Studia classica et mediaevalia, 7, 2010, p. 60-73.

Lavocat Françoise, "L'œuvre littéraire est-elle un monde possible?», Fabula, Atelier de théorie littéraire, 2009, http://www.fabula.org/atelier.php?L\% 27oeuvre_litt\%26eacute\%3Braire_est\%2Delle_un_monde_possible\%3F.

Le Briz-Orgeur Stéphanie, "Le Narcisse anonyme du XII siècle: une histoire de roman", in Fiction narrative et hybridation générique dans la littérature française, dir. Hélène Baby, Paris, L’Harmattan, 2006, p. 19-33.

Lechat Didier, "Les chevaliers-poètes dans Meliador de Froissart", in Poètes et poétesses dans le roman médiéval. Journée d'étude du 8 décembre 2005, dir. Catherine Gaullier-Bougassas, Lille, PU, 2007, p. 73-85.

Lecouteux Claude, «Les Cynocéphales. Étude d'une tradition tératologique de l'Antiquité au XII èècle", Cahiers de Civilisation Médiévale, 1981, p. 117-128.

Lecouteux Claude, Les monstres dans la pensée médiévale européenne, Paris, PUPS, 1993.

LeE Charmaine, "La tradition "indirecte" dans l'édition d'un roman: l'exemple de Jaufre", in Actes du XXIV Congrès International de Linguistique et de Philologie Romanes. Aberystwyth 2004, Congrès International de Linguistique et de Philologie Romanes, 24, Tübingen, Niemeyer, 2007, t. II, p. 199-210.

Le Goff Jacques, La Civilisation de l'Occident médiéval, Paris, Arthaud, 1965. 
Le Goff Jacques, L’imaginaire médiéval: essais, Paris, Gallimard, 1991.

LE Goff Jacques, «Note sur la société tripartite, idéologie monarchique et renouveau économique dans la Chrétienté du $\mathrm{IX}^{\mathrm{e}}$ au XII ${ }^{\mathrm{e}}$ siècle", in Pour un autre Moyen Âge, Paris, Gallimard, 1999, p. 80-90.

Lehman Sabine, "Les prologues dans les textes en prose ( $\mathrm{XIV}^{\mathrm{e}}-\mathrm{XV}^{\mathrm{e}}$ siècles): modèles et déviances",", in Mettre en prose aux XIV -XVI siècles, dir. Maria Colombo-Timelli et al., Turnhout, Brepols, 2010, p. 177-186.

LE NAN Frédérique, "Les séjours sylvestres de Merlin dans l'œuvre de Robert de Boron", in Merlin. Roman du XIII siècle, éd. par D. Quéruel et Chr. Ferlampin-Acher, Paris, Ellipses, 2000, p. 16-28.

LÉONARD Monique, Le "dit» et sa technique narrative des origines à 1340, Paris, Champion, 1996.

LÉOnARD Monique, "Du roman au dit: Le Chevalier au lion et Le Tournoi de l'Antéchrist", in L'ouvre de Chrétien de Troyes dans la littérature française: réminiscences, résurgences et réécritures, dir. Claude Lachet, Lyon, Université Jean Moulin, 1997, p. 87-97.

LÉONARD Monique, "L'hybridation générique dans le domaine du dit narratif: le cas du Lai de l'Oiselet", in Fiction narrative et hybridation générique dans la littérature française, dir. Hélène Baby, Paris, L'Harmattan, 2006, p. 35-48.

Le Ribeuz Anne-Cécile, «Des manuscrits aux imprimés d'Ysaïe le Triste: le romanesque à l'épreuve de la mise en page et des images ", in Le romanesque aux XIV et $X V^{e}$ siècles, éd. Danielle Régnier-Bohler, Bordeaux, PU, 2009, p. 243-256.

Le Saux Françoise, Damian-Grint Peter, "The Arthur of the Chronicles", in The Arthur of the French. The Arthurian Legend in Medieval French and Occitan Literature, dir. Glyn S. Burgess et Karen Pratt, Cardiff, University of Wales Press, ("Arthurian Literature in the Middle Ages», IV), 2006, p. 93-111.

LEwis David, "Counterpart Theory and Quantified Modal Logic», The Journal of Philosophy, 65/5, 1968, p. 113-126.

Lodge Anthony, "De Tristan que la chievre fist», Romania, CIV, 1983, p. 524-533.

Loomis Roger Sherman, "Chivalric and Dramatic Imitations of Arthurian Romance", in Medieval Studies in Memory of A. Kingsley Porter, dir. Wilhelm R. W. Koehler, Cambridge, Harvard University Press, 1939, vol. 1, p. 79-97.

Loomis Roger Sherman, "Edward I, Arthurian Enthusiast», Speculum, 28/1, 1953, p. 114-127.

Loomis Roger Sherman, Arthurian Tradition and Chrétien de Troyes, New York, Octagon Books, 1982.

Lorcin Marie-Thérèse, Façons de sentir et de penser: les fabliaux français, Paris, Champion («Essais sur le Moyen Âge», 6), 1979.

LORIAN Alexandre, Tendances stylistiques dans la prose narrative française $d u$ XVI siècle, Paris, Klincksieck, 1973. 
Lот Ferdinand, Nennius et l'Historia Brittonum. Étude critique suivie d'une édition des diverses versions de ce texte, Paris, Champion, 1934.

Lот Ferdinand, Étude sur le Lancelot en prose, Paris, Champion, 1984.

Macé Stéphane, "L'amplification, ou l'âme de la rhétorique. Présentation générale», Exercices de rhétorique, 4, 2014, en ligne: https://journals.openedition. org/rhetorique/364.

Maddox Donald, "Yvain et le sens de la coutume», Romania, 1988, 109, p. 1-17.

Maddox Donald, "Fictions étiologiques dans le Roman de Tristan en prose», in Des "Tristan" en vers au "Tristan" en prose. Hommage à Emmanuèle Baumgartner, dir. Laurence Harf-Lancner, Laurence Mathey-Maille, Bénédicte MillandBove et Michelle Szkilnik, Paris, Champion, 2009, p. 131-144.

Madureira Margarida, "Le Recueil d'auteur au XIII ${ }^{\mathrm{e}}$ siècle: Guillaume de Machaut et la compilation de ses œuvres", in Le Recueil au Moyen Age. La fin du Moyen Âge, dir. Tania Van Hemelryck et Stefania Marzano, Turnhout, Brepols ("Texte, Codex, Contexte»), 2010, p. 199-211.

Marchello-Nizia Christiane, «La forme-vers et la forme-prose: leurs langues spécifiques, leurs contraintes propres», Perspectives médiévales, 3, 1977, p. 35-42.

Marchello-Nizia Christiane, L'évolution du français. Ordre des mots, démonstratifs, accent tonique, Paris, Armand Colin, 1995.

Marnette Sophie, "Réflexions sur le discours indirect libre en français médiéval», Romania, 114, 1996, p. 1-49.

MarnetTe Sophie, Narrateur et points de vue dans la littérature française médiévale: une approche linguistique, Berne, Peter Lang, 1998.

Martin Jean-Pierre, "Les motifs dans la chanson de geste. Définition et utilisation", Cahiers de civilisation médiévale, 120, 1987, p. 315-329.

Martin Jean-Pierre, Les Motifs dans la chanson de geste. Définition et utilisation, Lille, Université de Lille 3, 1992.

Martin Jean-Pierre et Lignereux Marielle, La Chanson de Roland, Neuilly, Atlande, 2003.

Marzano Stefania et Van Hemelryck Tania (dir.), Le recueil au Moyen Âge. La fin du Moyen Âge, Turnhout, Brepols («Texte, Codex, Contexte»), 2010.

Marzano Stefania, "Une mise en prose inédite du xvi ${ }^{\mathrm{e}}$ siècle. Le Compte $d u$ mantheau maltaillé (Paris, BnF, fr. 2153)", in Pour un nouveau répertoire des mises en prose. Roman, chanson de geste, autres genres, dir. Maria Colombo Timelli, Barbara Ferrari et Anne Schoysman, Paris, Garnier, 2014, p. 212-227.

Mathey-Maille Laurence, Écritures du passé. Histoire des ducs de Normandie, Paris, Champion, 2007.

Mathey-Maille Laurence, "Le Roman de Brut de Wace à l'épreuve du merveilleux", in Motifs merveilleux et poétique des genres au Moyen Âge, dir. Francis Gingras, Paris, Garnier, 2015, p. 165-174. 
Mathey-Maille Laurence, « «De l'alexandrin à l'octosyllabe: les hésitations de Wace dans le Roman de Rou», in Poétiques de l'octosyllabe, dir. Danièle JamesRaoul et Françoise Laurent, Paris, Champion, 2018, p. 141-152.

MÉnARd Philippe, Le rire et le sourire dans le roman courtois en France au Moyen Âge (1150-1250), Genève, Droz, 1969.

MÉnARD Philippe, Syntaxe de l'ancien français, Bordeaux, Sobodi, 1973.

Ménard Philippe, "Les pièces lyriques du Tristan en prose», in Les Genres insérés dans le roman, éd. Claude Lachet, Lyon, Université de Lyon III («Publications du CEDIC», 9), 1994, p. 35-46.

MÉnARD Philippe, "Le Roman de Tristan en prose au cour de la littérature arthurienne", in Mémoires arthuriennes, dir. Danielle Quéruel, Troyes, La Renaissance, 2012, p. 159-183.

Méniel Bruno, "La colère dans la poésie épique, du Moyen Âge à la fin du Xvi siècle», $C R M H, 11,2004$, p. 1-11.

Mennung Albert, Der "Bel inconnu" des Renaut de Beaujeu in seinem Verhältnis zum "Lybeaus Disconus", "Carduino" und "Wigalois». Eine litterar-historische Studie, Halle, Kandler, 1890.

Merceron Jacques, «De la "mauvaise humeur" du sénéchal Keu: Chrétien de Troyes, littérature et physiologie», Cahiers de civilisation médiévale, 1998, 41, p. 17-34.

Meter Helmut, "... de chevaleries d'amours et de cembiaus. Liebesthematik und Genre-Problematik in Jean Bodels Sachsenlied", in Das Epos in der Romania. Festschrift für Dieter Kremers zum 65. Geburtstag, dir. S. Kaller et E. Mara, Tübingen, G. Narr, 1986, p. 271-297.

Meyer Paul, "Notice du ms. de l'Arsenal 5201», Romania, 46, 1887, p. 24-72.

Micha Alexandre, "Couleur épique dans le Roman de Thèbes", Romania, 91/362, 1970. p. 145-160.

Micha Alexandre, Étude sur le Merlin de Robert de Boron, roman du XIII siècle, Genève, Droz («Publications romanes et françaises» 151), 1980.

Micha Alexandre, "Sur un procédé de composition du Lancelot: les récits rétrospectifs", in Approches du Lancelot en prose, dir. Jean Dufournet, Paris, Champion, 1984, p. 7-23.

Micha Alexandre, Essais sur le cycle du Lancelot Graal, Genève, Droz, 1987.

Middleton Roger, "The Manuscripts", in The Arthur of the French. The Arthurian Legend in Medieval French and Occitan Literature, dir. Glyn S. Burgess et Karen Pratt, Cardiff, University of Wales Press, ("Arthurian Literature in the Middle Ages», IV), 2006, p. 8-92.

Mikhaïlova-Makarius Milena, L'École du roman. Robert de Blois dans le manuscrit BNF fr. 24301, Paris, Champion, 2010. 
Misın Gaël, «La traversée prodigieuse dans le folklore et l'hagiographie celtique: de la merveille au miracle", in Annales de Bretagne, 98, 1991, p. 1-25.

Milland-Bove Bénédicte, "Nous chantons chansons diverses et si tirom diverses cordes" L'esthétique de la dissonance dans le Tristan en prose», Cabiers de recherches médiévales, 5, 1998, en ligne: https://journals.openedition.org/ $\mathrm{crm} / 1402$.

Milland-Bove Bénédicte, "Le style des romans arthuriens en prose du XIII ${ }^{\mathrm{e}}$ siècle: problèmes, méthodes, pratiques", in Effets de style au Moyen Âge, dir. Chantal Connochie-Bourgne et Sébastien Douchet, Aix-Marseille Université, Presses Universitaires de Provence ("Senefiance»), 2012, p. 47-57.

Milland-Bove Bénédicte, "Molt valt mialz, ce m’est avis / uns cortois morz c'uns vilains vis": de l'ironie et du sérieux dans le Chevalier au Lion", in "Chose qui face a escouter": études sur Le Chevalier au lion de Chrétien de Troyes. Actes de la journée d'étude organisée le 9 décembre 2017 par l'Université Paris-Diderot Paris 7 et l'Université Sorbonne Nouvelle Paris 3, dir. Amandine Mussou, Anne Paupert et Michelle Szkilnik, http://www.univ-paris3.fr/ publications-de-la-silc-section-francaise--393070.kjsp?RH=1329834238527, p. 63-72.

Molinié Georges, La stylistique, Paris, PUF («Que sais-je?»), 1989.

MoliniÉ Georges, «Style», in Dictionnaire du littéraire, Paris, PUF ("Quadrige»), 2010, p. 737-740.

Monfrin Jacques, «Le roman de Belris», Romania, 83, 1962, p. 493-519.

Monfrin Jacques, "Le roman de Belris, Le bel inconnu, Carduino", in Testi, cotesti e contesti del franco-italiano. Atti del $1^{\circ}$ simposio franco-italiano (Bad Homburg, 13-16 aprile 1987). In memoriam Alberto Limentani, éd. Günter Holtus, Henning Krauß et Peter Wunderli, Tübingen, Niemeyer, 1989, p. 161-176.

Monteverdi, Angelo, "La laisse épique», in La technique littéraire des chansons de geste. Actes du colloque de Liège (septembre 1957), Paris, Les Belles Lettres («Bibliothèque de la Faculté de philosophie et lettres de l'Université de Liège», 150), 1959, p. 128-140.

Mora-Lebrun Francine, "Metre en romanz»: les romans d'antiquité du XII siècle et leur postérité, XIII-XIV siècle, Paris, Champion, 2008.

Moran, Patrick, "Le meilleur des mondes arthuriens possible», in Jeunesse et genèse du royaume arthurien: les Suites romanesques du Merlin en prose, dir. Nathalie Koble, Orléans, Paradigme, 2007, p. 69-88.

Moran Patrick, "Perlesvaus et le canon arthurien: la construction de l'imprévisibilité», Revue des langues romanes, 118:1, 2014, p. 53-72.

Moran Patrick, Lectures cycliques. Le réseau inter-romanesque dans les cycles du Graal du XIII siècle, Paris, Champion, 2014.

Moran Patrick, "Genres médiévaux et genres médiévistes: l'exemple des termes chanson de geste et épopée», Romania, 541-542, 2018, p. 38-60. 
Moran Patrick, "La guerre comme marqueur générique dans la littérature narrative des XII ${ }^{\mathrm{e}}$-XIII ${ }^{\mathrm{e}}$ siècles", Le Moyen Âge, CXXV, 2019/1, p. 21-35, en ligne: https://www.cairn.info/revue-le-moyen-age-2019-1-page-21.htm.

Morato Nicola, "Formation et fortune du cycle de Guiron le courtois», in Le Cycle de Guiron le courtois. Prolégomènes à l'édition intégrale du corpus, dir. Lino Leonardi et Richard Trachsler, Paris, Garnier, 2018, p. 179-247.

Moreau Pierre, La Tradition française du poème en prose avant Baudelaire, Paris, Lettres modernes ("Archives des Lettres modernes», 19-20), 1959.

Morier Henri, Dictionnaire de poétique et de rhétorique, Paris, PUF, 1981.

Morris Matthew W., «Les deux Mélusines. Une comparaison des œuvres de Jean d'Arras et de Coudrette", in Ecriture et réécriture du merveilleux féerique. Autour de Mélusine, dir. Matthew W. Morris et Jean-Jacques Vincensini, Paris, Garnier, 2012, p. 107-120.

Morrisson Cécile, Les croisades, Paris, PUF («Que sais-je?»), 2006, en ligne: https://www.cairn.info/les-croisades--9782130554790.htm.

Moura Jean-Marc, Lire l'exotisme, Paris, Dunod, 1992.

MüHlEthaler Jean-Claude, Schnyder André, 550 ans de Mélusine allemande - Coudrette et Thüring von Ringoltingen. Actes du colloque organisé par les Universités de Berne et de Lausanne en août 2006, Berne, Peter Lang, 2008.

MüHLETHALER Jean-Claude, «Renversement, déplacement et irradiation parodiques. Réflexions autour du Conte du Papegau», Poétique, 57, 2009, p. 3-17.

MüHLETHALER Jean-Claude, "Défense et illustration du vers dans les récits du Moyen Âge tardif: du règne de Philippe e Bel au règne de Charles VI", in Rencontres du vers et de la prose: conscience théorique et mise en page, dir. Catherine Croizy-Naquet et Michelle Szkilnik, Turnout, Brepols, 2015, p. 105-122.

MüHlethaler Jean-Claude, «La prose au rythme de l'octosyllabe. Réflexions autour de la "couleur de mesure", de Guillaume de Machaut à Jean Molinet", in Poétiques de l'octosyllabe, dir. Danièle James-Raoul et Françoise Laurent, Paris, Champion, 2018, p. 189-207.

Mussou Amandine, "A l'instance d'un autre, fait en rime nagueres. Fiction et commentaire chez Evrart de Conty, des Eschés amoureux en vers au Livre des eschez amoureux moralisés en prose", Le Moyen Français, 76-77, 2015, p. 159-184.

NADOT Sébastien, "Arthur et ses chevaliers: un scénario pour le sport», in $L a$ Matière arthurienne tardive en Europe (1270-1530), dir. Christine FerlampinAcher, Rennes, PUR, 2020, p. 103-114.

NAïs Hélène, "La notion de genre en poésie au XvI ${ }^{\mathrm{e}}$ siècle: étude lexicologique et sémantique", in La notion de genre à la Renaissance, dir. Guy Demerson, Genève, Slatkine, 1984, p. 103-127.

NAUdET Valérie, "L’octosyllabe de Gormont et Isembart. Quelques problèmes d'arithémtique", in Poétiques de l'octosyllabe, dir. Danièle James-Raoul et Françoise Laurent, Paris, Champion, 2018, p. 125-142. 
Nichols Stephen, "Style and structure in Gormond et Isembard», Romania, 84, 1963 , p. 500-535.

Nitze William, "The Character of Gauvain in the Romances of Chrétien de Troyes", Modern Philology, 50/4, 1953, p. 219-225.

Nixon Terry, "Catalogue of Manuscripts ", in Les Manuscrits de Chrétien de Troyes, dir. Keith Busby, Terry Nixon, Alison Stones et Lori Walters, Amsterdam; Atlanta, Rodopi, 1993, tome 2, p. 17-85.

Noille-Clauzade Christine, Le style, Paris, GF («Corpus»), 2004.

Nykrog Per, Les fabliaux, Copenhague, Ejnar Munksgaard, 1957.

PARIs Gaston, La littérature française au Moyen Âge (XI'-XIV siècle), Paris, Hachette, 1914.

PARISSE Michel, "Le tournoi en France des origines à la fin du XIII ${ }^{\mathrm{e}}$ siècle», in Das ritterliche Turnier im Mittelalter, dir. Josef Fleckenstein, Göttingen, Vandenhoeck \& Ruprecht, 1986, p. 175-211.

Pastoureau Michel, «L'"enromancement” du nom. Étude sur la diffusion des noms de héros arthuriens à la fin du Moyen Âge", in Couleurs, images, symboles. Études d'histoire et d'anthropologie, Paris, Le Léopard d'or, 1989, p. 111-124.

PAstré Jean-Marc, "Traversées maritimes et géographie du mythe dans les romans de Tristan ", in Mondes marins du Moyen Âge, dir. Chantal ConnochieBourgne, Aix-en-Provence, Presses universitaires de Provence («Senefiance», 52), 2006, p. 367-376, en ligne: https://books.openedition.org/pup/3855.

PAton Lucy Allen, Studies in the Fairy Mythology of Arthurian Romance, New York, Burt Franklin, 1903.

Pearcy Roy J., «Fabliau Intervention in some Mid-Thirteenth-Century Arthurian Verse Romances", Arthurian Yearbook, 1, 1991, p. 63-89.

Pernot Caroline, «Le discours indirect libre médiéval: épistémologie et enjeux méthodologiques", Atelier Reverdie, 22 février 2008, en ligne: http://reverdie. free.fr/site/spip.php?article32.

Petit Aimé, Naissances du roman: les techniques littéraires dans les romans antiques $d u$ XII siècle, Lille, Atelier national reproduction des thèses Université Lille III, 1985.

Petit Aimé, «Le pavillon d'Alexandre dans le Roman d'Alexandre (ms. B. Venise, Museo Civico VI, 665)», Bien dire et bien aprandre, 6, 1988, p. 77-95.

Petit Aimé, «Les premières descriptions de tentes: la tente d'Adrastus dans le Roman de Thèbes", Bien dire et bien aprandre, 11, 1993, p. 303-315.

Pickford Cédric E., L'évolution du roman arthurien en prose vers la fin du Moyen Agge: d'après le manuscrit 112 du fonds français de la Bibliothèque nationale, Paris, Nizet, 1960. 
Pickford Cédric E., "Les éditions imprimées de romans arthuriens en prose antérieures à 1600», BBIAS, 13, 1961, p. 99-109.

Planche Alice, "Les plus beaux, le plus fort, la plus belle. Les extrêmes du rêve courtois dans le Roman de la Dame à la Licorne et du Beau Chevalier au Lion (composé vers 1350)", in Medieval and Renaissance Monographs. Serie VI: Courtly Romance. A Collection of Essays, éd. Guy R. Mermier, Michigan Consortium for Medieval and Early Modern Studies, 1984, p. 177-202.

PLeT Florence, "Son non escrit par droite aventure. L'inscription du nom propre dans le Tristan en prose», Linx, 12, 2002, p. 231-235.

Plet-Nicolas Florence, La création du monde. Les noms propres dans le roman de Tristan en prose, Paris, Champion, 2007.

POIRION Daniel, "Romans en vers et romans en prose», in Grundriß der romanischen Literaturen des Mittelalters. Le Roman jusqu'à la fin du XIII siècle, IV/1, Heidelberg, Carl Winter, 1978, p. 74-81.

Poirion Daniel, "Semblance du Graal dans la Queste», in Mélanges de linguistique, de littérature et de philologie médiévales offerts à J.-R. Smeets, Leiden, 1982, p. 227-241.

PoIrion Daniel (dir.), Précis de littérature française du Moyen Âge, Paris, PUF, 1983.

Poirion Daniel, "Théorie et pratique du style au Moyen Âge: le sublime et la merveille», Revue d'Histoire littéraire de la France, 1986/1, p. 15-32.

PoIrion Daniel, «Le Roman d'aventure au Moyen Âge: étude d'esthétique littéraire", Cahiers de l'Association internationale des études françaises, 1988, 40, p. 111-127.

PoIRION Daniel (dir.), Grundriß der romanischen Literaturen des Mittelalters. La littérature française aux XIV et XV siècles, vol. VIII/I, Heidelberg, Carl Winter, 1988.

PoIrion Daniel, "L'épanouissement d'un style: le gothique littéraire à la fin du Moyen Âge", in Grundriß der romanischen Literaturen des Mittelalters. La littérature française aux XIV et XV siècles, vol. VIII/I, Heidelberg, Carl Winter, 1988, p. 29-44.

Poirion Daniel, "Chanson de geste ou épopée? Remarques sur la définition d'un genre», in Écriture poétique et composition romanesque, Orléans, Paradigme («Medievalia»), 1994, p. 21-38.

Poirion Daniel, «Sur l'écriture-prose», Perspectives médiévales, 1997, 3, p. 54-56.

Pomel Fabienne, "Arthur en allégorie», in Arthur après Arthur. La matière arthurienne tardive en dehors du roman arthurien (1270-1530), dir. Christine Ferlampin-Acher, Rennes, PUR («Interférences»), 2017, p. 341-362.

Possamai Marylène, "Monstres marins dans la littérature médiévale: mythologies et allégories", in Mondes marins du Moyen Âge, dir. Chantal 
Connochie-Bourgne, Aix-en-Provence, Presses universitaires de Provence («Senefiance», 52), 2006, p. 389-404, en ligne: https://books.openedition. org/pup/3858.

Porter David W., "The Historia Meriadoci and Magna Carta», Neophilologus; 76/1, 1992, p. 136-146.

Puech Sylvie, "Le conte de La Belle au bois dormant et le mythe des Parques", L'information littéraire, 4, 1989, p. 19-24.

Quadlbauer Franz, Die antike Theorie der "genera dicendi" im lateinischen Mittelalter, Graz; Vienne; Cologne, Österreichische Akademie der Wissenschaften, 1962.

RaFFALLI-Grenat Lunorsola, Écrire des fictions en vers aux XIV et XV siècles (un problème esthétique et culturel), thèse de doctorat soutenue à l'Université de Corse, ANRT, 2008.

RaYne-Michel Servane, La Table ronde et les deux cités: pour une lecture augustinienne des cycles arthuriens en prose du XIII siècle, Paris, Champion, 2016.

RÉGNier-Bohler Danielle, "Arthur en enfances dans Le Chevalier du Papegau", PRIS-MA, 13/1, 1997, p. 91-106.

RıвÉmont Bernard, Le Théâtre français du Moyen Âge au XVI siècle, Paris, Ellipse, 2003.

Richelle Marc, "Cognition», in Dictionnaire de Psychologie, dir. Roland Doron et al., Paris, PUF ("Quadrige»), 1991, p. 125-126.

RIEGER Dietmar, "“Il est a moi et je a lui". Le lion d'Yvain - un symbole et son champ sémantique", in Ensi firent li ancessor. Mélanges de philologie médiévale offerts à Marc-René Jung, Alessandria, Edizioni dell'Orso, 1996, vol. 1, p. 349-369.

Rieger Dietmar, "Tot est dit". Zum Konzept des "Neuen" in der mittelalterlichen Literatur Frankreichs", Cahiers d'Histoire des Littératures romanes, 29, 2005, p. 163-182.

ROACH Eléanor, «La tradition manuscrite du Roman de Mélusine par Coudrette», Revue d'Histoire des texte, 7, 1977, p. 185-233.

Roche-Mandi Sarah, "A reappraisal of the Role of Merlin in the Roman de Silence», Arthuriana, 12:1, 2002, p. 6-21.

Rodriguez Antonio, "Lyrique», in Arts et émotions, dir. Mathilde Bernard, Alexandre Gefen et Carole Talon-Hugon, Paris, Armand Colin, 2015, p. 253-254.

Rollier-Paulian Catherine, L'esthétique de Jean Maillart. De la courtoisie au souci de l'humaine condition dans Le Roman du Comte d'Anjou, Orléans, Paradigme, 2007.

Rosch Eleanor, "Natural Categories», Cognitive Pychology, 4/3, 1973, p. 328-350. 
Rousse Michel, "Le théâtre", in Histoire de la France littéraire. Naissances, Renaissances, dir. Frank Lestringant et Michel Zink, Paris, PUF ("Quadrige»), 2006, p. 812-849.

Roussel Claude, "L'art de la suite: Sagremor et l'intertexte", Annales ESC, 41, 1986, p. 27-42.

Roussel Claude, "D'armes et d'amours: l'aventure dans les dernières chansons de geste", in Le romanesque dans l'épique, éd. Dominique Boutet, Paris, Université Paris X Nanterre, 2003, p. 163-178.

Roussel Claude, "Mise en prose ou mise en roman?", in Du roman courtois au roman baroque. Actes du colloque des 2-5 juillet 2002, dir. Emmanuel Bury et Francine Mora, Paris. Les Belles Lettres, 2004, p. 339-352.

Roussel Claude, "Souvenirs de Bretagne dans les chansons de geste tardives", in Arthur après Arthur. La matière arthurienne tardive en dehors du roman arthurien (1270-1530), dir. Christine Ferlampin-Acher, Rennes, PUR («Interférences»), 2017, p. 71-89.

Roussel Claude, "Lion de Bourges (BnF fr. 351), une mise en prose en octosyllabes?", in Poétiques de l'octosyllabe, dir. Danièle James-Raoul et Françoise Laurent, Paris, Champion, 2018, p. 173-188.

Roussineau Gilles, "Tradition littéraire et culture populaire dans l'histoire de Troïlus et de Zellandine (Perceforest, Troisième partie), version ancienne du conte de la Belle au Bois Dormant", Arthuriana, 4.1, 1994, p. 30-45.

Roussineau Gilles, "Réflexions sur la genèse du Perceforest», in Perceforest. Un roman arthurien et sa réception, dir. Christine Ferlampin-Acher, Rennes, PUR, 2012, p. 255-267.

Roy Bruno, Une culture de l'équivoque, Montréal; Paris, Presses de l'Université de Montréal, 1992.

Ruff Marcel A., "Baudelaire et le poème en prose», Zeitschrift für französische Sprache und Literatur, 77, 1967, p. 116-123.

Rutткоwsкi, Wolfgang V., Die literarischen Gattungen, Bern-München, Francke, 1968.

Rychner Jean, La Chanson de geste: essai sur l'art épique des jongleurs, Genève, Droz, 1955.

RyCHNER Jean, «Les fabliaux: genre, styles, publics ", in La Littérature narrative d'imagination, Paris, PUF, 1961, p. 41-54.

Rychner Jean, L'articulation des phrases narratives dans la Mort Artu, Genève, Droz, 1970.

SAHLin Margit, Étude sur la carole médiévale: l'origine du mot et ses rapports avec l'église, Uppsala, Almqvist \&Wiksells, 1940.

Saly Antoinette, "La chanson dans le Meliacin de Girart d'Amiens", Travaux de linguistique et de littérature, 23.2, 1985, p. 7-23. 
Saly Antoinette, "L'épisode du Pré aux Jeux dans le Chevalier de la Charrette", in Image, structure et sens. Études arthuriennes, Aix-en-Provence, CUERMA («Senefiance», 34), 1994, p. 49-54.

SARgent-BAur Barbara N., "Dux bellorum / rex militum / roi fainéant. La transformation d'Arthur au xiı siècle», Le Moyen Âge, 1984, 3-4, p. 357-373.

Scheidegger Jean R., "Les automates dans le roman antique (Roman de Thèbes et Roman de Troie)", in Le Roman antique au Moyen Agge, dir. Danielle Buschinger, Göppingen, Kümmerle Verlag, 1992, p. 177-186.

Schenck David P., «Le comique et le sérieux dans le Moniage Guillaume et le Moniage Rainouart», in Les chansons de geste du cycle de Guillaume d'Orange. Hommage à Jean Frappier. Tome III: Les moniages Guibourc, dir. Philippe Ménard et Jean-Charles Payen, Paris, Société d'édition d'enseignement supérieur, 1983, p. 239-259.

Scherbakova Olga, "Le Chevalier au lion de Pierre Sala: du prologue aux enjeux d'une récriture", Le Moyen français, 59, 2006, p. 125-137.

Schmolke-Hasselmann Beate, Der arthurische Versroman, von Chrestien bis Froissart: Zur Geschichte einer Gattung, Tübingen, Max Niemeyer Verlag, 1980.

Schmolke-Hasselmann Beate, "King Arthur as Villain in the ThirteenthCentury Romance Yder", Reading Medieval Studies, 6, 1980, p. 31-43.

Schmolke-Hasselmann Beate, "L'intégration de quelques récits brefs arthuriens (Cor, Mantel, Espee) dans les romans arthuriens du XIII siècle", in Le Récit bref au Moyen Âge, Acte du colloque des 27, 28, 29 avril 1979, dir. Danielle Buschinger, Université de Picardie; Paris, Centre d'Études Médiévales; Champion, 1980, p. 107-128.

Schrader Dorothy L., "L'iconographie de l'eau: la fontaine comme miroir dans Brun de la Montagne", in L'épopée romane au Moyen Âge et aux temps modernes. Actes du XIV Congrès international Rencesvals, éd. Salvatore Luongo, Napoli, Fridericiana Editrice Universitaria, 2001, t. 1, p. 97-104.

SÉGuY Mireille, "La merveille du Graal à l'épreuve de la "vérité" de l'Estoire del Saint Graal", in Motifs merveilleux et poétique des genres au Moyen Âge, dir. Francis Gingras, Paris, Garnier, 2015, p. 287-300.

SÉgur Mireille, Le livre monde. L'Estoire del Saint Graal et le cycle du LancelotGraal, Paris, Champion, 2017.

Sellier Philippe, "Qu'est-ce qu'un mythe littéraire?», Littérature, 55, 1984, p. 112-126.

SERra Patrizia, "Pour ce que mors est Crestïens... La nascita dell'aventure novele nel Tornoiemenz Antecri di Huon de Méry", in Chrétien de Troyes et la tradition du roman arthurien en vers, dir. Annie Combes, Patrizia Serra, Richard Trachsler et Maurizio Virdis, Paris, Garnier, 2013, p. 129-166. 
Stanesco Michel, "Sous le masque de Lancelot: du comportement romanesque au Moyen Âge", in Actes du XIVE Congrès International Arthurien, Rennes, 16-21 août 1984, Rennes, PUR, 1984, t. II, p. 569-583.

Stanesco Michel et Zink Michel, "Critiques du roman", in Histoire européenne du roman médiéval, dir. Michel Stanesco et Michel Zink, Paris, PUF, 1992, p. 175-189.

Stanesco Michel, D’Armes et d'amours: études de littérature arthurienne, Orléans, Paradigme («Medievalia»), 2002.

Stempel Wolf Dieter, "Aspects génériques de la réception", in Théorie des genres, Paris, Seuil, 1986, p. 161-178.

Stones Alison, "The Manuscript, Paris BnF fr. 1588, and its illustrations", in Philippe de Remi, Le Roman de la Manekine, edited from Paris BnF fr. 1588 and Translated, with contributions by Alison Stones and Roger Middleton, éd. Barbara Sargent-Baur, Amsterdam, Rodopi, GA, 1999, p. 1-39.

Strubel Armand et Saulnier Chantal (de), La poétique de la chasse au Moyen Âge, Paris, PUF, 1994.

Strubel Armand, "Le romanesque et l'épique: l'exemple de Huon de Méry", in Le romanesque dans l'épique, (Actes du colloque de Paris X-Nanterre 22-23 mars 2002), dir. Dominique Boutet, Nanterre, Université Paris-X («Littérales», 31), 2003, p. 199-213.

Strubel Armand, Le Théâtre au Moyen Âge. Naissance d'une littérature dramatique, Paris, Bréal, 2003.

Strubel Armand, "Écrire le Graal en prose et en vers. Le Perlesvaus et les Continuations", in Écrire en vers, écrire en prose: une poétique de la révélation. Actes du colloque de Paris X-Nanterre, mars 2006, dir. Catherine CroizyNaquet, Nanterre, Université Paris X-Nanterre («Littérales», 41), 2007, p. 187-207.

STruve Tilman, "The Importance of the Organism in the Political Theory of John of Salisbury", in The World of John of Salisbury. Studies in Church History, éd. Michael Wilks, Oxford, B. Blackwell, 1984, p. 303-317.

SuARD François, "Le Motif du déguisement dans quelques chansons du cycle de Guillaume d'Orange», Olifant, 7, 1980, p. 343-358.

SuARD François, «La Bataille Loquifer et la pratique de l'intertextualité au début du XIII ${ }^{\mathrm{e}}$ siècle", in VIII Congresso de la Société Rencesvals. Pamplona-Santiago de Compostela 15 a 25 agosto de 1978, Pamplona, Institucion Principe de Viana, 1981, p. 497-503.

SuARD François, "L'épopée», in Grundriß der romanischen Literaturen des Mittelalters. La littérature française aux XIV et XV siècles, vol. VIII/I, Heidelberg, Carl Winter, 1988, p. 161-177.

SuARD François, «Le passage à la prose», CRMH, 12, 2005, p. 29-43. 
SuARD François, «Figures du romanesque dans l'épique de la fin du Moyen Âge», in Le romanesque aux XIV et XV siècles, éd. Danielle Régnier-Bohler, Bordeaux, PU, 2009, p. 139-157.

SuARD François, "Les mises en prose épiques et romanesques: les enjeux littéraires", in Mettre en prose aux XIV-XVte siècles, dir. Maria Colombo-Timelli et al., Turnhout, Brepols, 2010, p. 33-52.

SuARD François, "La chanson de geste française: une forme littéraire évolutive», in Épopées du monde. Pour un panorama (presque) général, dir. Ėve FeuilleboisPierunek, Paris, Garnier, 2011, p. 331-350.

Susong Gilles, "À propos de deux récits arthuriens du xIv siècle: Erec, Perceforest", Le Moyen Français, 30, 1992, p. 19-25.

Szkilnik Michelle, Archipel du Graal. Étude de lEstoire del Saint Graal, Genève, Droz, 1991.

Szkilnik Michelle, "Un exercice de style au XIII ${ }^{\mathrm{e}}$ siècle: Hunbaut", Romance Philology, 54, 2000, p. 29-42.

Szkilnik Michelle, Jean de Saintré: une carrière chevaleresque au XV siècle, Genève, Droz, 2003.

Szkilnik Michelle, "Sommes romanesques du Moyen Âge: cycles ou compilations?", in Chemins tournants. Cycles et recueils en littérature des romans du Graal à la poésie contemporaine, dir. Stéphane Michaud, Paris, PSN, 2004, p. 21-50.

Szkilnik Michelle, «Maillezais, un lieu de mémoire dans les romans français de Mélusine", in L'Abbaye de Maillezais: Des moines du marais aux soldats huguenots, dir. Mathias Tranchant et Cécile Treffort, Rennes, PUR, 2005, p. 29-47.

Szkilnik Michelle, "César est-il un personnage de roman? Du Perceforest au Jouvencel", Cahiers de recherches médiévales, 13, 2006, p. 77-89.

Szkilnik Michelle, "La jeunesse guerrière d'Arthur", in Jeunesse et genèse du royaume arthurien. Les Suites romanesques du Merlin en prose, dir. Nathalie Koble, Orléans, Paradigme, 2007, p. 17-32.

SzKILNIK Michelle, "Le chevalier "oublieux" dans le roman arthurien en vers", in Figures de l'oubli (IV'-XVI siècle), dir. Patrizia Romagnoli et Barbara Wahlen, Lausanne, Études de Lettres, 1-2, 2007, p. 77-97.

Szkilnik Michelle, "Que lisaient les chevaliers du xve siècle? Le témoignage du Pas du Perron Fée», Le Moyen Français, 2010, 68, p. 103-114.

Szkilnik Michelle, "À quoi se résume une vie? Du souci de la brefté dans les biographies du Xve siècle", in Faire court: l'esthétique de la brièveté dans la littérature du Moyen Âge, dir. Catherine Croizy-Naquet, Laurence Harf-Lancner et Michelle Szkilnik, Paris, PSN, 2011, p. 137-152.

Szkılnıк Michelle, "Conclusion", in Miracles d'un autre genre. Récritures médiévales en dehors de l'hagiographie, dir. Olivier Biaggini et Bénédicte MillandBove, Madrid, Casa de Velázquez, 2012, p. 309-314. 
Szkilnik Michelle, "Hoster la contraincte de retoricque" : notes de lecture sur le "Nouveau Répertoire de mises en prose (XIV -XVI siècle)" ", Studi Francesi, 179, 2016, p. 273-277.

SzKilnik Michelle, "Arthur s'en va-t-en guerre. Expéditions navales dans les romans arthuriens en vers des $\mathrm{XII}^{\mathrm{e}}$ et XIII ${ }^{\mathrm{e}}$ siècles", in Arthur, la mer et la guerre, dir. Alban Gautier, Marc Rolland et Michelle Szkilnik, Paris, Garnier, 2017, p. 97-110.

Szkilnik Michelle, "Arthur parle en vers anglais mais en prose française», in Arthur en Europe à la fin du Moyen Âge. Approches comparées (1270-1530), dir. Christine Ferlampin-Acher, Paris, Garnier, 2020, p. 234-251.

Taylor Jane H. M., "The Fourteenth Century: Context, Text and Intertext», in The Legacy of Chrétien de Troyes, dir. Norris J. Lacy, Douglas Kelly et Keith Busby, Amsterdam, Rodopi, 1987-1988, vol. I, p. 267-332.

Taylor Jane H. M., "The Parrot, the Knight and the Decline of Chivalry», in Conjunctures. Medieval Studies in Honor of Douglas Kelly, dir. Keith Busby et Norris J. Lacy, Amsterdam, Rodopi, 1994, p. 529-44.

TAylor Jane H. M., "Hungrie shadows: Pierre Sala and his Yvain», Arthuriana, 19:1, 2009, p. 7-19.

TAylor Jane H. M., "Pierre Sala, poacher», in Rewriting Arthurian Romance in Renaissance France. From Manuscript to Printed Book, Cambridge, Brewer, 2014, p. 11-37.

TAYlor Jane H. M., "Imperious Seductions". Giglan and Perceval», in Rewriting Arthurian Romance in Renaissance France. From Manuscript to Printed Book, Cambridge, Brewer, 2014, p. 119-146.

Taylor Jane H. M., Rewriting Arthurian Romance in Renaissance France. From Manuscript to Printed Book, Cambridge, Brewer, 2014.

Tesnière Marie-Hélène, «Les romans de la Table Ronde dans la Librairie royale de Charles V et Charles VI», in La Légende du Roi Arthur, dir. Thierry Delcourt, Paris, BnF; Seuil, 2009, p. 51.

Thiry Claude, "Les mises en prose épiques», in Cinquante ans d'études épiques. Actes du colloque anniversaire de la Société Rencesvals (Liège, 19-20 août 2005), dir. Nadine Henrard, Genève, Droz, 2008, p. 353-364.

Thomasset Claude, "Du Pont de l'épée au pouvoir royal», La Figure du roi, Bien dire et bien aprandre, 18/2, 2000, p. 171-183.

Thorpe Lewis, "Raoul de Houdenc: a possible new poem», The Modern Language Review, 47/4, 1952, p. 512-515.

Tilliette Jean-Yves, "Vers et prose dans la théorie littéraire médiolatine», in Écrire en vers, écrire en prose: une poétique de la révélation. Actes du colloque de Paris X-Nanterre, mars 2006, dir. Catherine Croizy-Naquet, Nanterre, Université Paris X-Nanterre («Littérales», 41), 2007, p. 27-41. 
Thorpe Lewis, "Merlin's sardonic laughter", in Studies in Medieval Literature and Languages in Memory of Frederick Whitehead, Manchester, Manchester University Press, 1973, p. 323-339.

Todorov Tzvetan, Introduction à la littérature fantastique, Paris, Seuil, 1970.

Toniutti Géraldine, Pour une poétique de limplicitation. Cristal et Clarie ou l'art de faire du neuf avec de l'ancien, préface de Barbara Wahlen, Lausanne, Archipel («Essais», 19), 2014.

Toniutti Géraldine, "De l'encyclopédie au Conte du Papegau: la licorne entre vérité et fiction", in Mondes animaliers au Moyen Age et à la Renaissance, Amiens, Presses du Centre d'Études Médiévales de Picardie ("Médiévales», 62), 2016, p. 458-470.

Toniutti Géraldine, "Mise en recueil et assemblage des contraires. Cristal et Clarie, D'Amour et le manuscrit Arsenal 3516", Le Moyen Agge, 2017/2, p. 339-349.

Toniutti Géraldine, «Imiter le roman - fictionnaliser l'Histoire: le Roman du Hem entre roman et relation de tournoi», in Don Quichotte avant Don Quichotte? Les récits de chevalerie du XIV au XVI siècle en France, Italie et Espagne: production et réception, Tirant, 22, 2019, p. 73-88, en ligne: https:// ojs.uv.es/index.php/Tirant/article/view/15294/13967.

Toniutti Géraldine et Wahlen Barbara, «La figure d'Arthur dans quelques romans en vers allemands et français", in Arthur en Europe à la fin du Moyen Âge. Approches comparées (1270-1530), dir. Christine Ferlampin-Acher, Paris, Garnier, 2020, p. 41-55.

Trachsler Richard, "Le recueil Paris, BN fr. 12603», Cultura neo-latina, 54, 1994, p. 189-211.

Trachsler Richard, Clôtures du cycle arthurien, Genève, Droz, 1996.

Trachsler Richard, Les Romans Arthuriens en vers après Chrétien de Troyes, Paris; Roma, Memini («Bibliographie des Ecrivains Français» 11), 1997.

TRACHSLER Richard, «Genres und matières. Überlegungen zum Erbe Jean Bodels», in Gattungen mittelalterlicher Schriftlichkeit, dir. Barbara Frank, Thomas Haye et Doris Tophinke, Tübingen, Narr, 1997, p. 201-219.

Trachsler Richard, Disjointures-Conjointures. Étude sur l'interférence des matières narratives dans la littérature française du Moyen Âge, Tübingen; Bâle, Francke («Romanica Helvetica»), 2000. Compte rendu par Yan Greub, Vox romanica, 63, 2004, p. 322-326.

Trachsler Richard, Merlin l'enchanteur. Étude sur le Merlin de Robert de Boron, Paris, SEDES, 2000.

TRACHSLer Richard, "Quand Gauvainet rencontre Sagremoret ou le charme de la première fois dans la Suite-Vulgate du Merlin", in Enfances arthuriennes. Actes du $2^{e}$ colloque arthurien de Rennes, 6-7 mars 2003, dir. Denis Hüe et Christine Ferlampin-Acher, Orléans, Paradigme, 2006, p. 203-215. 
Trachsler Richard, "Observations sur les "recueils de fabliaux" ", in Le Recueil au Moyen Âge. Le Moyen Âge central, dir. Yasmina Foehr-Janssens et Olivier Collet, Turnhout, Brepols ("Texte, Codex, Contexte»), 2010, p. 35-46.

Trachsler Richard, "Chrétien de Troyes, créateur. De l'inventeur d'un genre au statut de maître", in Chrétien de Troyes et la tradition du roman arthurien en vers, dir. Annie Combes, Patrizia Serra, Richard Trachsler, Maurizio Virdis, Paris, Garnier, 2013, p. 13-25.

Trachsler Richard, "Il racconto del racconto. La parola del cavaliere nel "Guiron le courtois" ", in "D'un parlare ne l'altro" Aspetti dell'enunciazione dal romanzo arturiano alla Gerusalemme liberata, dir. Annalisa Izzo, Pise, ETS, 2013, p. 11-22.

TraChSLER Richard, "Héritiers et épigones. Les auteurs des romans arthuriens en vers après Chrétien de Troyes", in Les Héritiers littéraires dans la littérature française $\left(X V I^{e}-X X^{e}\right.$ siècle), dir. Franziska Meier, Brigitte Diaz et Francine Wild, Paris, Garnier, 2014, p. 181-196.

Tran-Gervat Yen-Mai, «Pour une définition opérationnelle de la parodie littéraire: parcours critique et enjeux d'un corpus spécifique", Cahiers de narratologie, 13, 2006, en ligne: https://journals.openedition.org/ narratologie/?id=372.

Treboux Joanna, Escanor: la Montagne qui voulait éclipser le Soleil, mémoire de maîtrise soutenu en 2018 à l'Université de Lausanne, sous la direction de Barbara Wahlen.

Tyssens Madeleine, "Chrétien de Troyes et les versions étrangères du Bel inconnu», Bulletin bibliographique de la Société internationale arthurienne, 18, 1966, p. 174-175.

Vale Juliet, Edward III and Chivalry: Chivalric Society and its Context 12701350, Woodbridge, Boydell, 1982.

Valette Jean-René, La Pensée du Graal. Fiction littéraire et théologie (XII $-X I I{ }^{e}$ siècle), Paris, Champion, 2008.

VAlETte Jean-René, "Le rire et le corps: éléments d'esthétique médiévale (XII ${ }^{\mathrm{e}}$ $\mathrm{XIII}^{\mathrm{e}}$ siècles)", in Esthétique du rire, dir. Alain Vaillant, Paris, PU de Paris Ouest, 2012, p. 21-45.

VAlette Jean-René, "Les Hauts Livres du Graal et la poétique des genres", in Motifs merveilleux et poétique des genres au Moyen Age, dir. Francis Gingras, Paris, Garnier, 2015, p. 267-286.

VAlette Jean-René, "La Queste del Saint Graal, une hagiographie en semblance: défi laïque et spiritualité décléricalisée», Les Dossiers du Gribl [En ligne], 01, 2015, mis en ligne le 03 décembre 2015, consulté le 17 janvier 2019. URL: http://journals.openedition.org/dossiersgrihl/6324.

Van Coolput Colette-Anne, "Appendice: Références, adaptations et emprunts directs", in The Legacy of Chrétien de Troyes, dir. Norris J. Lacy, Douglas Kelly et Keith Busby, Amsterdam, Rodopi, 1987-1988, vol. 1, p. 333-342. 
Van Den Boogaard Nico H. J., Rondeaux et Refrains du XII au début du XIV siècle, Paris, Klincksieck, 1969.

VAnder Elst Stefan, "Literature and chivalric education in Philippe de Mézières' Le Songe du Vieil Pelerin", in Philippe de Mézières and His Age. Piety and Politics in the Fourteenth Century, dir. Renate Blumenfeld-Kosinski et Kiril Petkov, Leiden; Boston, Brill, 2012, p. 189-206.

Van Hemelryck Tania, «Le livre mis en prose à la cour de Bourgogne. Réflexions pour une approche codicologique d'un phénomène littéraire», in Mettre en prose aux $X I V^{e}-X V I^{e}$ siècles, dir. Maria Colombo-Timelli et al., Turnhout, Brepols, 2010, p. 245-254.

Victorin Patricia, Ysaïe le Triste: une esthétique de la confluence: tours, tombeaux, vergers et fontaines, Paris, Champion, 2002.

Victorin Patricia, "Psittacisme et captivité dans le Chevalier du Papegau et Tirant le Blanc", in Du Roman courtois au roman baroque, dir. Emmanuel Bury et Francine Mora, Paris, Les Belles Lettres, 2004, p. 135-159.

Vinaver Eugène, "La Genèse de la Suite du Merlin», in Mélanges Ernest Hoepffner, Paris, Les Belles Lettres, 1949, p. 295-300.

VINAVER Eugène, «Un chevalier errant à la recherche du sens du monde: quelques remarques sur le caractère de Dinadan dans le Tristan en prose», in Mélanges de linguistique romane et de philologie médiévale offerts à M. Maurice Delbouille, Gembloux, Duculot, vol. II, 1964, p. 677-686.

Vinaver Eugène, À la Recherche d'une poétique médiévale, Paris, Nizet, 1980.

Vincensini Jean-Jacques, "De l'alliance à l'hostilité. Dons contraints et troubles de l'idylle dans le Roman d'Eledus et Serene», in Plaist vos oïr bone cançon vallant. Mélanges offerts à François Suard, dir. Dominique Boutet, MarieMadeleine Castellani, Françoise Ferrand et Aimé Petit, Villeneuve d'Ascq, Université Charles-De-Gaulle-Lille 3, 1999, p. 975-991.

VInCENsini Jean-Jacques, Motifs et thèmes du récit médiéval, Paris, Nathan, 2000.

Vincensini Jean-Jacques, "Genres et "conscience" narrative au Moyen Âge. L'exemple du récit idyllique», Littérature, 2007, 148, p. 59-76.

WAhlen Barbara, "Du recueil à la compilation: le manuscrit de Guiron le Courtois, Paris, BNF fr. 358-363", Ateliers, 30, 2003, p. 89-100.

Wahlen Barbara, "Du manuscrit à l'imprimé: le cas de Guiron le Courtois», in Du roman courtois au roman baroque. Actes du colloque des 2-5 juillet 2002, dir. Emmanuel Bury et Francine Mora, Paris, Les Belles Lettres, 2004, p. 233-249.

WAHLEN Barbara, «Entre tradition et réécriture: le bon Morholt d'Irlande, chevalier de la Table Ronde", in Façonner son personnage au Moyen Âge, Aix-enProvence, CUER-MA («Senefiance», 53), 2007, p. 351-360.

Wahlen Barbara et MüHlethaler Jean-Claude, «Dépasser le modèle arthurien: Geoffroy la Grand' Dent, chevalier de la fin des temps?», in 550 Jahre 
deutsche Melusine-Coudrette und Thüring von Ringoltingen/550 ans de Mélusine allemande-Coudrette et Thüring von Ringoltingen, dir. André Schnyder, et JeanClaude Mühlethaler, Bern, Peter Lang, 2008, p. 343-362.

WAHLEN Barbara, L'Écriture à rebours. Le Roman de Méliadus du XIII au XVIII siècle, Genève, Droz, 2010.

WAHLEN Barbara, "La parola raccontata dai cavalieri-narratori nella Continuation du Roman de Meliadus (ms. Ferrell 5)», Versants, 59/2 (fascicolo italiano), 2012, p. 9-25.

WAHLEN Barbara, "Adjoindre, disjoindre, conjoindre. Le recyclage d'Alixandre l'Orphelin et de l'Histoire d'Erec dans Guiron le Courtois (Paris, BnF, français 358-363)", in Le Texte dans le texte. L'interpolation médiévale, dir. Annie Combes, Michelle Szkilnik et Anne-Catherine Werner, Paris, Classiques Garnier, 2013, p. 235-248.

Wallen Martha, "Significant Variations in the Burgundian Prose Version of Erec et Enide», Medium Aevum, LI, 1982, p. 187-196.

WALTers Lori, "The creation of a "super romance" : Paris, Bibliothèque nationale, fonds français, MS 1433", in The Arthurian Yearbook, dir. Keith Busby, New York, Garland, 1991, p. 3-35.

Walters Lori, "Parody and the Parrot: Lancelot References in the Chevalier au Papegau", in Translatio studii. Essays by his Students in Honor of Karl D. Uitti for his sixty-fifth Birthday, Amsterdam, Rodopi, 2000, p. 331-344.

West G. D., An Index of Proper Names in French Arthurian Verse Romances, 11501300, Toronto, Toronto University Press, 1969.

West G. D., An Index of Proper Names in French Arthurian Prose Romances, Toronto, Toronto University Press, 1978.

Wittgenstein Ludwig, Recherches philosophiques, Paris, Gallimard, 2004.

Woledge Brian et Clive Harry P., Répertoire des plus anciens textes en prose française depuis 842 jusqu'aux premières années du XIII siècle, Genève, Droz, 1964.

Wolf-Bonvin Romaine, "Gauvain en Écosse: vaincre ou faillir dans la Vengeance Raguidel», in L'Homme dans le texte, dir. Dina Mantchéva et Raya Kountchéva, Sofia, PU, 2008, p. 39-55.

WolfF Étienne, "Quelques remarques sur la coexistence vers-prose dans l'Antiquité tardive et le haut Moyen Âge latin", in Écrire en vers, écrire en prose: une poétique de la révélation. Actes du colloque de Paris X-Nanterre, mars 2006, dir. Catherine Croizy-Naquet, Nanterre, Université Paris X-Nanterre («Littérales», 41), 2007, p. 13-25.

Wolfzettel Friedrich, "Le Roman d'Erec en prose du XIII ${ }^{\mathrm{e}}$ siècle: un anti-Erec et Enide?", in The Legacy of Chrétien de Troyes, dir. Norris J. Lacy, Douglas Kelly et Keith Busby, Amsterdam, Rodopi, 1987-1988, vol. II, p. 215-228.

Wolfzettel Friedrich, "Doppelweg und Biographie», in Erzählstrukturen der Artusliteratur, dir. Friedrich Wolfzettel, Tübingen, Max Niemeyer Verlag, 1999, p. 119-141. 
Wolfzettel Friedrich, "7. La Belle endormie: le conte merveilleux populaire mis au service des idéologies courtoises", in Le Conte en palimpseste. Studien zur Funktion von Märchen und Mythos im französischen Mittelalter, Stuttgart, Franz Steiner, 2005, p. 114-135.

Wolfzettel Friedrich, "Zum Problem der Epizität im „postklassischen“Artusroman", in Fiktionalität im Artusroman des 13. bis 15. Jahrhunderts. Romanistische und germanistische Perspektiven, Wiesbaden, Reichert Verlag, 2013, p. 29-41.

WulfF Frederik-Amadeus, "Le conte du Mantel, texte français des dernières années du XIII ${ }^{\mathrm{e}}$ siècle», Romania, 55-56, 1885, p. 343-380.

ZaRANKIn Julia, "Rupture et conjointure: l'enjambement dans Le Chevalier de la Charrette», Euvres et Critiques, XXVII/1, 2002, p. 221-239.

ZimmermanN Michel, "Ouverture", in Auctor et auctoritas. Invention et conformisme dans l'écriture médiévale, dir. Michel Zimmermann, Paris, École des chartes, 2001, p. 7-14.

ZINK Michel, "Une mutation de la conscience littéraire: le langage romanesque à travers des exemples français du XII ${ }^{\mathrm{e}}$ siècle», Cahiers de Civilisation Médiévale, 24, 1981, p. 3-27.

ZINK Michel, "Le monde animal et ses représentations dans la littérature du Moyen Âge», Actes des congrès de la Société des historiens médiévistes de l'enseignement supérieur public, 15, 1984, p. 47-71.

ZINK Michel, "Chrétien et ses contemporains", in The Legacy of Chrétien de Troyes, dir. Norris J. Lacy, Douglas Kelly et Keith Busby, Amsterdam, Rodopi, 1987-1988, vol. I, p. 5-32.

ZINk Michel, "Arthur", in Dictionnaire des mythes littéraires, dir. Pierre Brunel, Monaco, Éditions du Rocher, 1988, p. 180-194.

ZINK Michel, "XIII. Le Roman", in Grundriß der romanischen Literaturen des Mittelalters. La littérature française aux XIV et XV siècles, vol. VIII/I, Heidelberg, Carl Winter, 1988, p. 197-218.

ZINk Michel, Littérature française du Moyen Âge, Paris, PUF («Quadrige»), 1992.

ZINK Michel, "Suspension and Fall. The Fragmentation and Linkage of lyric Insertions in Le Roman de la Rose and Le Roman de la Violette", in Jean Renart and the Art of Romance, éd. Nancy Vine Durling, Gainesville, University of Florida Press, 1997, p. 105-121.

ZINK Michel, "Littérature(s)», in Dictionnaire raisonné de l'Occident médiéval, dir. Jacques Le Goff et Jean-Claude Schmitt, Paris, Fayard («Pluriel»), 1999, p. 610-624.

Zumthor Paul, «Le Roman courtois: essai de définition», Études littéraires, 4, 1971, p. 75-90.

Zumthor Paul, "Roman et histoire: aux sources d'un univers narratif», in Langue, texte, énigme, Paris, Seuil («Poétique»), 1975. 
Zumthor Paul, "Genèse et évolution du genre», in Grundriß der romanischen Literaturen des Mittelalters. Le Roman jusqu'à la fin du XIII siècle, IV/1, Heidelberg, Carl Winter, 1978, p. 60-73.

Zumthor Paul, La lettre et la voix: de la "littérature" médiévale, Paris, Seuil («Poétique»), 1987.

Zumthor Paul, Essai de poétique médiévale, Paris, Seuil, 2000.

\section{Ressources en ligne}

Arlima, bibliographie en ligne:

http://arlimat.net

Base de données $C l e r c 6$, recensant les termes liés à la communication littéraire à

l'époque du roi Charles VI:

http://wp.unil.ch/clerc6/

Fabula, La recherche en littérature:

http://www.fabula.org/

Gallica, numérisation de manuscrits :

http://gallica.bnf.fr/

«La décoration du manuscrit», ressource du site de l'IRHT:

https://irht.hypotheses.org/751

Base de données Jonas, catalogue des manuscrits médiévaux d'oc et d'oïl :

http://jonas.irht.cnrs.fr/consulter/manuscrit/recherche_manuscrit.php

Projet Lancelot-Graal:

http://www.lancelot-project.pitt.edu/LG-web/Arthur-LG-ChronGeog.html

\section{Sur Biaudouz et Robert de Blois}

Fox John Howard, Robert de Blois, son ouvre didactique et narrative : étude linguistique et littéraire, suivie d'une édition critique avec commentaire et glossaire de l'Enseignement des princes" et du "Chastoiement des dames", Paris, Nizet, 1950.

Gingras Francis, "Le Biausdous de Robert de Blois: la nature du roman et l'art de la digression", in La digression dans la littérature et l'art du Moyen Âge. Actes du $29^{\circ}$ colloque du CUER-MA, février 2004, dir. Chantal Connochie-Bourgne, Aix-en-Provence, Publications de l'Université de Provence, 2005, p. 187-199.

Gingras Francis, "Mise en recueil et typologie des genres aux XIII ${ }^{\mathrm{e}}$ et XIV ${ }^{\mathrm{e}}$ siècles: romans atypiques et recueils polygénériques (Biaudous, Cristal et Clarie, Durmart le Gallois et Mériadeuc)", in Le Recueil au Moyen Âge, dir. Yasmina Foehr-Janssens et Olivier Collet, Turnhout, Brepols, 2010, vol. 1, p. 91-111.

Gingras Francis, "Récriture, collages et bricolages dans Cristal et Clarie et Biausdous de Robert de Blois", in Chrétien de Troyes et la tradition du roman 
arthurien en vers, dir. Annie Combes, Patrizia Serra, Richard Trachsler et Maurizio Virdis, Paris, Garnier, 2013, p. 93-106.

Gingras Francis, "La polygraphie à l'œuvre. Du recueil médiéval au roman recyclé», in Polygraphies. Les frontières du littéraire, dir. J.-P. Dufiet, E. Nardout-Lafarge, Paris, Garnier, 2015, p. 29-40.

LefÈvre Sylvie, "Prologues de recueils et mise en œuvre des textes. Robert de Blois, Christine de Pizan et Antoine de la Sale», in Seuils de l'œuvre dans le texte médiéval, dir. Emmanuèle Baumgartner et Laurence Harf-Lancner, Paris, Presses de la Sorbonne, 2002, p. 89-125.

Walters Lori, "A Love That Knows No Falsehood: Moral Instruction and Narrative Closure in the Bel Inconnu and The Beaudous», South Atlantic Review, 58:2, 1993, p. 21-39.

Walters Lori, "Manuscript Context of the Beaudous of Robert de Blois", Manuscripta, $37: 2$, 1993, p. 179-192.

\section{Sur Blandin de Cornouailles}

Alart J. B., "Observations sur la langue du roman de Blandin de Cornouailles et Guillot Ardit de Miramar", Revue des langues romanes, 5, 1874, p. 275-304.

Asperti Stefano, "Bacinetti e berrovierie. Problemi di lessico e di datazione nel Blandin di Cornovaglia", in Studia in honorem prof. M. de Riquer, Barcelone, Quaderns Crema, 1986-1991, 4 vol., vol. 1, p. 11-36.

Burrell Margaret A., "The classification of Blandin de Cornouailles», Florilegium, 18.2, 2001, p. 11-19.

Busby Keith, "Blandin de Cornoalha and romance tradition", Tenso, 8:1, 1992, p. $1-25$.

De Caluwé Jacques, «Le roman de Blandin de Cornouaille et de Guillot Ardit de Miramar: une parodie du roman arthurien?", Cultura neo-latina, 38, 1978 , p. 55-66.

LACY Norris J., "Halfway to Quixote: Humor in Blandin de Cornoalha", in Risus mediaevalis. Laughter in Medieval Literature and Art, Louvain, Leuven University Press, 2003, p. 173-180.

WILD Gerhard, "Ausgrenzung und Integration arthurischer Themen im katalanischen Mittelalter (von Muntaners Crònica, Blandin de Cornualla und Torroellas La Faula zu Martorells Tirant lo blanc) ", Zeitschrift für Katalanistik, 3, 1990, p. 67-89.

\section{Sur le manuscrit Chantilly, Condé 472}

Busby Keith, "Epigonal Arthurian Romance and its Manuscripts", in Codex and Context. Reading Old French Verse Narrative in Manuscript, Amsterdam, Rodopi, 2002, p. 405-437. 
Busby, Keith, "Post-Chrétien verse romance: the manuscript context», CRM, 14, 2007, p. 11-24.

Carroll Carleton W., "Tentative de réhabilitation d'un manuscrit mal famé d'Erec et Enide: Chantilly, Musée Condé 472 (A)», in "Moult a sens et vallour». Studies in Medieval French Literature in Honor of William W. Kibler, dir. par Monica L. Wright et al., Amsterdam, Rodopi, 2012, p. 99-110.

Gingras Francis, "La triste figure des chevaliers dans un codex du XIII ${ }^{\mathrm{e}}$ siècle (Chantilly, Condé 472)», Revue des langues romanes, $110: 1,2006$, p. 77-97.

Gingras Francis, «Décaper les vieux romans: voisinages corrosifs dans un manuscrit du XIII ${ }^{\mathrm{e}}$ siècle (Chantilly, Condé 472)", in De l'usage des vieux romans, dir. Ugo Dionne et Francis Gingras, Études françaises, 42:1, 2006, p. 13-38.

Kelly Douglas, "Chretien's Lancelot Rewritten: From the Charrette to Rigomer in Manuscript and Narrative Cycle", in Dame Philology's Charrette. Approaching Medieval Textuality through Chrétien's Lancelot. Essays in Memory of Karl D. Uitti, dir. Gina L. Greco et Ellen M. Thorington, Tempe, ACMRS, 2012, p. 77-96.

Ruby, Christine, "5. Chantilly, Musée Condé 472 (626)", in Album de manuscrits français du XIII siècle. Mise en page et mise en texte, dir. Maria Careri, Françoise Fery-Hue et al., Roma, Viella, 2001, p. 19-22.

Walters Lori, "Chantilly Ms. 472 as a cyclic work", in Cyclification: The Development of Narrative Cycles in the Chansons de Geste and the Arthurian Romances, dir. Bart Besamusca, Willem P. Gerritsen, Corry Hogetoorn et Orlanda S. H. Lie, Amsterdam, Royal Academy of Arts and Sciences, 1992, p. 135-139.

WALTERs Lori, "The formation of a Gauvain cycle in Chantilly manuscript 472 ", Neophilologus, $78: 1,1994$, p. 29-43 ; réimpr. dans Raymond H. Thompson et Keith Busby, New York et London: Routledge ("Arthurian Characters and Themes»), 2006, p. 157-172.

WALTERS Lori J., "Parody and moral allegory in Chantilly MS 472», MLN, $113: 4,1998$, p. 937-950.

Walters Lori J., "The King's Example: Arthur, Gauvain, and Lancelot in Rigomer and Chantilly, Musée Condé 472 (anc. 626)", in De sens rassis, dir. Keith Busby et al., Amsterdam, Rodopi, 2005, p. 699-717.

Walters, Lori J., «Dé-membrer pour remembrer. L’œuvre chrétienne dans le ms. Chantilly 472», in Mouvances et jointures. Du manuscrit au texte médiéval, dir. Milena Mikhaïlova, Orléansm, Paradigme («Medievalia», 55), 2005, p. 253-281.

Walters Lori, "Manuscript compilations of verse romances", in The Arthur of the French. The Arthurian Legend in Medieval French and Occitan Literature, dir. Glyn S. Burgess et Karen Pratt, Cardiff, University of Wales Press ("Arthurian Literature in the Middle Ages », IV), 2006, p. 461-487. 


\section{Sur Claris et Laris}

Busby Keith, "Plus acesmez qu'une popine”. Male cross-dressing in medieval French Narrative", in Gender Transgressions. Crossing the Normative Barrier in Old French Literature, dir. Karen J. Taylor, New York; Londres, Garland, 1998, p. 45-59.

Jordan Leo, «Der Roman von Claris und Laris, ein Sprachdenkmal des oberen Mosestals aus dem Jahr 1268», Archivum Romanicum, 9, 1925, p. 5-33.

Kelly Douglas, "Multiple quests in French verse romance: Merveilles de Rigomer and Claris et Laris", L'Esprit créateur, 9, 1969, p. 257-266.

Kelly Douglas, "Tout li sens du monde dans Claris et Laris", Romance Philology, 36:3, 1982-1983, p. 406-417.

KLose Martin, Der Roman von Claris und Laris in seinen Beziehungen zur altfranzösischen Artusepik des XII. und XIII. Jahrhunderts, Max Niemeyer Verlag, 1916.

Micha Alexandra, "Claris et Laris", in Dictionnaire des lettres françaises. Le Moyen Âge, dir. Georges Grente et al., Paris, Fayard, 1964, p. 203.

PARIs Gaston, "Romans en vers du cycle de la Table Ronde», in Histoire Littéraire de la France, Paris, Imprimerie Nationale, vol. 30, 1888, p. 124-136.

Pierreville Corinne, "Plaisance et outrance, les tournois dans Claris et Laris", in Le tournoi au Moyen Age, Actes du colloque des 25 et 26 janvier 2002, dir. Nicole Gonthier, Lyon, Université Jean Moulin ("Cahiers du Centre d'Histoire Médiévale», 2), 2003, p. 31-43.

Pierreville Corinne, «De la lettre au roman. Lecture, écriture et réécriture dans Claris et Laris", in La lettre et les lettres, entre-deux, textes réunis par Claude Lachet et Laurence Richer, Lyon, C.E.D.I.C., 2006, p. 37-63.

Pierreville Corinne, Claris et Laris, somme romanesque du XIII siècle, Paris, Champion, 2008.

Pierreville Corinne, "Claris et Laris: les prisons du roman arthurien", in Réalités, images, écritures de la prison au Moyen Âge. Actes du colloque de Dijon des 7 et 8 octobre 2010, dir. Jean-Marie Fritz et Silvère Menegaldo, Dijon, Éditions universitaires de Dijon ("Écritures»), 2012, p. 49-57.

Shcherbakova Olga, "Lire et ré-écrire: un prologue français du XIII ${ }^{\mathrm{e}}$ siècle. De Chrétien de Troyes au roman de Claris et Laris", en ligne: http://doc. rero.ch/record/8662/files/Lire_Ecrire_Shcherbakova.pdf, page consultée le 3.12.2013.

ShCherbakova Olga, "La question des sources multiples: le cas de Claris et Laris, roman arthurien du XIII ${ }^{\mathrm{e}}$ siècle", in Lieux de mémoire antiques et médiévaux. Texte, image, histoire: la question des sources, dir. Bernard Andenmatten, Panayota Badinou, Michel E. Fuchs et Jean-Claude Mühlethaler, Lausanne, BSN Press, («a contrario Campus»), 2012, p. 293-317.

Shcherbakova Olga, "De la courtoisie à la pédagogie: Gauvain dans Claris et Laris, roman arthurien du XIII ${ }^{\mathrm{e}}$ siècle", in Le Personnage de Gauvain dans la 
littérature européenne du Moyen Âge. Actes du colloque international des 6, 7 et 8 mars 2014 à l'Université de Paris Est (Marne-la-Vallée), dir. M-F. Alamichel, Amiens, Presses du "Centre d'Études Médiévales de Picardie» ("Médiévales», 58), 2015, p. 137-152.

\section{Sur Escanor et Girart d'Amiens}

Brault, Gérald J., A Study of the Works of Girart d'Amiens, thèse de Ph.D., sous la direction de William Roach, University of Pennsylvania, 1958.

Brault Gérald, "Les Manuscrits des oeuvres de Girart d'Amiens ", Romania, 80, 1959, p. 433-445.

Brault Gérald, "Arthurian heraldry and the date of Escanor", Bulletin bibliographique de la Société internationale arthurienne, 11, 1959, p. 81-88.

Brault Gérald, "Girart d'Amiens ", in Dictionnaire des lettres françaises. Le Moyen Âge, dir. Georges Grente et al., Paris, Fayard, 1964, p. 321-322.

Brook, Leslie C., "Demons and angels: female portrayal in Escanor», Reading Medieval Studies, 28, 2002, p. 23-38.

Brook Leslie C., "A knight with reservations: the role of Dinadan in Escanor", Studi francesi, 147, 2005, p. 477-485.

CARnÉ Damien (de), «Escanor dans son roman », CRMH, 14, 2007, p. 153-175.

Clément-Royer Myriam, "L'arbre aux oiseaux "automates" dans Escanor de Girart d'Amiens", in Engins et machines. L'imaginaire mécanique dans les textes médiévaux, dir. Fabienne Pomel, Rennes, PUR («Interférences»), 2015, p. 131-156.

GiER Albert, "Lästern, Lügen, Schweigen: Syntagmatische und paradigmatische Strukturen im Escanor des Girart d'Amiens", in Erzählstrukturen der Artusliteratur: Forschungsgeschichte und neue Ansätze, dir. Friedrich Wolfzettel, Peter Ihring, Tübingen, Max Niemeyer Verlag, 1999, p. 219-231.

Menegaldo Silvère, "Girart d'Amiens. Un auteur et une œuvre à la fin du XIII ${ }^{\mathrm{e}}$ siècle», CRMH, 14, 2007, p. 145-148.

Mezghani-Manal Mounira, "L'œuvre d'art au carrefour du Monde et de l'Autre Monde: Escanor de Girart d'Amiens", in Le Monde et l'Autre Monde. Actes du colloque arthurien de Rennes, 8 et 9 mars 2001, dir. Denis Hüe et Christine Ferlampin-Acher, Orléans, Paradigme («Medievalia» 45), 2002, p. 267-284.

MichA Alexandre, "Escanor», in Grundriß der romanischen Literaturen des Mittelalters. Le Roman jusqu'à la fin du XIII siècle, IV/1, Heidelberg, Carl Winter, 1978, p. 397-398.

Noble Peter, "The Unexpected Hero - The Role of Kay in Escanor", in Courtly Romance: A collection of Essays, par Guy R. Mermier et Edelgard E. Du Bruck, Detroit, Fifteenth Century Symposium, 1984, p. 161-168. 
Noble Peter "Chrétien de Troyes and Girart d'Amiens ", in The Legagy of Chrétien de Troyes, par Norris J. Lacy, Douglas Kelly et Keith Busby, Amsterdam; Atlanta, Rodopi, vol. II, 1988, p. 143-150.

PARIs Gaston "Girart d'Amiens», in Histoire Littéraire de la France, Paris, Imprimerie Nationale, vol. XXXI, 1893, p. 151-205.

SALY Antoinette, "Écrivains mystificateurs: le cas d'Adenet le roi et de Girart d'Amiens", in Figures de l'écrivain au Moyen Âge. Actes du colloque du Centre d'Études Médiévales de l'Université de Picardie, Amiens 18-20 mars 1988, dir. Danielle Buschinger, Göppingen, Kümmerle Verlag, 1991, p. 245-253.

Schmolke-Hasselmann Beate, "Ausklang der altfranzösischen Artusepik: Escanor und Méliador", in Spätmittelalterliche Artusliteratur ein Symposion der neusprachlichen Philologien auf der Generalversammlung der Görres-Gesellschaft Bonn, 25.-29. September 1982, dir. Karl Heinz, Paderborn, Schöningh, 1984, p. $41-52$.

Schulze-Busacker Elisabeth, "Gauvain, li malparlier". Le rôle de Gauvain dans le roman d'Escanor", in Lancelot, Yvain et Gauvain. Colloque arthurien belge de Wégimont, Paris, Nizet («Lettres médiévales», 2), 1984, p. 113-123.

ToniutTi Géraldine, «Les peintures troyennes dans Escanor de Girart d'Amiens: un cas d'interférence des matières au XIII" siècle», in Matières à débat. La notion de matiere littéraire dans la littérature médiévale, dir. Christine FerlampinAcher et Catalina Girbea, Rennes, PUR («Interférences»), 2017, p. 401-416.

Trachsler Richard, "Qui a donné le Gringalet à Gauvain? À propos d'un épisode d'Escanor de Girart d'Amiens", in Le cheval dans le monde médiéval, Aix-en-Provence, CUER-MA («Senefiance» 32), 1992, p. 527-542.

Trachsler Richard, "De la Prose au Vers. Le cas de Dynadan dans l'Escanor de Girart d'Amiens", in Actes du XX Congrès de la Société Internationale de Linguistique et Philologie Romanes, Université de Zurich, 6-11 avril 1992, Tübingen; Basel, Francke, 1993, p. 401-412.

Trachsler Richard, "Escanor von Girart d'Amiens im Spannungsfeld von Vers und Prosa", in König Artus und der Heilige Graal. Studien zum spätarthurischen Roman und zum Graals-Roman im europäischen Mittelalter, dir. Danielle Buschinger et Wolfgang Spiewok, Greifswald, Reineke-Verlag («Wodan», 32), 1994, p. 257-268.

VAn Coolput-Storms Colette, "Performance au château", in Lire, danser et chanter au château. La culture châtelaine, XIII'-XVII siècles. Actes du $4^{e}$ colloque international organisé au château fort d'Ecaussinnes-Lalaing, les 22, 23 et 24 mai 2013, dir. Jean-Marie Cauchies, Marie Henrion et Philippe Bragard, Turnhout, Brepols, 2016, p. 185-189. 


\section{Sur Floriant et Florete}

Bouchet Florence, "Les éléments épiques dans Floriant et Florete», in "Plaist vos oür bone cançon vallant?" Mélanges de langue et de littérature médiévales offerts à François Suard, dir. Dominique Boutet, Marie-Madeleine Castellani, Françoise Ferrand et Aimé Petit, Lille, Éditions du Conseil scientifique de l'Université Charles-de-Gaulle-Lille III, 1999, t. 1, p. 87-99.

Busby Keith, "The intertextual coordinates of Floriant et Florete», French Forum, $20: 3,1995$, p. 261-277.

ENDREss Laura, "Orality and Textual Reworking in Floriant et Florete: Another Note on a "Patchwork Romance" ", Neophilologus, 2015, p. 1-18.

Graf Arturo, "Artu nell'Etna", in Miti, leggende, e superstizioni del Medio Evo, Torino, Loescher, 1893, t. 2, p. 303-325.

LÅNGFORs Arthur, "La Katone, non Lakatoué, dans le roman de Floriant et Florete», Neuphilologische Mitteilungen, 49, 1948, p. 53-55.

Menegaldo Silvère, "Prologues et épilogues lyriques dans le roman de chevalerie en vers aux $\mathrm{XII}^{\mathrm{e}}$ et XIII ${ }^{\mathrm{e}}$ siècles: quand le narrateur est amoureux", Bien dire et bien aprandre, 19, 2001, p. 149-165.

Moore Megan, «Hellenism, Islam, and Exoticism in French Medieval Romance", Journal of Modern Hellenism, 28, 2010-2011, p. 47-73.

Neat Helen L. M., "Depictions of Violence in Floriant et Florete: Inter- and Intratextual Patterns", in Battle and Bloodshed. The Medieval World at War, dir. par Lorna Bleach et Keira Borrill, Cambridge, Cambridge Scholars Publishing, 2013, p. 177-197.

Pioletti Antonio, "Artù, Avallon, l'Etna", Quaderni Medievali, 28, 1989, p. 6-35.

Sturm-Maddox Sara, "The Arthurian Romance in Sicily: Floriant et Florete», in Conjointure arthurienne. Actes de la "Classe d'excellence» de la Chaire Francqui 1998, dir. Juliette Dor, Louvain-la-Neuve, Université catholique de Louvain («Publications de l'Institut d'études médiévales. Textes, études, congrès», 20), 2000, p. 95-107.

Sturm-Maddox Sara, "Arthurian Evasions: the End(s) of Fiction in Floriant et Florete», in Por le soie amisté. Essays in Honor of Norris J. Lacy, dir. Keith Busby et Catherine M. Jones, Amsterdam; Atlanta, Rodopi («Faux Titre», 183), 2000, p. 475-489.

Trachsler Richard, "Floriant et Florete", in The Arthur of the French. The Arthurian Legend in Medieval French and Occitan Literature, dir. Glyn S. Burgess et Karen Pratt, Cardiff, University of Wales Press, («Arthurian Literature in the Middle Ages», IV), 2006, p. 432-434.

TrachSLER Richard, «Formulas, Orality and Arthurian Romance: A short Note on a Long Story", Romanic Review, 100, 2009, p. 415-429. 
TRACHSLER Richard, "Floriant et Florete", in Nouveau répertoire des mises en prose (XIV $V^{e} X V I^{e}$ siècle), dir. Maria Colombo-Timelli et al., Paris, Garnier, 2014, p. 253-258.

Wahlen Barbara, "Transporter de rime en prose”. L'exemple de Floriant et Florete", in Plus agreable a lire en prose que en rime? Vers et prose en moyen français, dir. Michelle Szkilnik et Catherine Croizy-Naquet, Le Moyen Français, vol. 76-77, 2015, Turnhout, Brepols, 2016, p. 213-230.

Williams Harry F., "Prose Versions of Floriant et Florete», Modern Philology, 48/4, 1951, p. 217-220.

\section{Sur Melyador et Jean Froissart}

Baumgartner Emmanuèle, "Écosse et Écossais: l'entrelacs de la fiction et de l'histoire dans les Chroniques et le Méliador de Froissart", in L'image de l'autre européen. XV'-XVIII siècles, dir. J. Dufournet, A. C. Fiorato et A. Redondo, Paris, PSN, 1992, p. 11-21.

Bouchet Florence, "Froissart et la matière de Bretagne: une écriture "déceptive" ", in Arturus Rex. Acta conventus Lovaniensis 1987, dir. Gilbert Tournoy, Willy Van Hoecke et Werner Verbeke, Louvain, Leuven University Press, t. II, 1991, p. 367-375.

Bouchet Florence, «Les “signes” de l'amour: stratégies sémiotiques de la déclaration amoureuse dans le Meliador de Froissart", Bien dire et bien aprandre, 15, 1997, p. 167-178.

Bouchet Florence, "Rhétorique de l'héraldique dans le roman arthurien tardif. Le Meliador de Froissart et le Livre du Cuer d'Amours espris de René d'Anjou ", Romania, 116, 1998, p. 239-255.

Bouchet Florence, "Camel de Camois, anti-héros problématique», in Façonner son personnage au Moyen Âge. Actes du 31 Colloque du CUER-MA, 9, 10 et 11 mars 2006, dir. Chantal Connochie-Bourgne, Aix-en-Provence, Publications de l'Université de Provence, («Senefiance», 53), 2007, p. 67-75.

Bragantini-Maillard Nathalie, "Pour un changement de perspective sur la construction de Melyador de Jean Froissart», Romania, 126:1-2, 2008, p. $145-173$.

BRAgANTINI-MaILlaRD Nathalie, "L'écriture des interventions narratoriales dans Melyador», CRMH, 19, 2010, p. 423-464.

Bragantini-Maillard Nathalie, et Denoyelle Corinne, "Les dialogues dans Melyador", Romania, 129, 2011, p. 83-128.

Bragantini-Maillard Nathalie, "Les tournois de Melyador, ou l'originalité d'une stéréotypie stylisée", Le Moyen Français, 68, 2011, p. 1-22.

Bragantini-Maillard Nathalie, "Il faut mentir pour un moiien trouver quant le requiert li cas." Melyador: une courtoisie entre ombre et lumière», in 
Cultures courtoises en mouvement, dir. Isabelle Arseneau et Francis Gingras, Montréal, Presses de l'Université de Montréal, 2011, p. 64-73.

Bragantini-Maillard Nathalie, «Les jeux du narrateur dans Melyador: de l'écriture en trompe-l'œil aux stratégies de l'identification ludique", in Le Moyen Âge par le Moyen Âge, même. Réception, relectures et réécritures des textes médiévaux dans la littérature française des XIV et XV siècles, dir. L. Brun, S. Menegaldo, Anders Bengtsson et D. Boutet, Paris, Champion, 2012, p. 141-161.

Bragantini-Maillard Nathalie, «L'octosyllabe romanesque chez Jean Froissart: une voie vers la fiction ", in Poétiques de l'octosyllabe, dir. Danièle James-Raoul et Françoise Laurent, Paris, Champion, 2018, p. 259-271.

Cerquiglini-Toulet Jacqueline, «Un paradoxe mélancolique ou le lyrisme selon Jean Froissart», Perspectives médiévales, 2006, p. 53-62.

Croennen Godfried, "Froissart et ses mécènes: quelques problèmes biographiques", in Froissart dans sa forge, éd. Odile Bombarde, Paris Académie des inscriptions et belles-lettres - Collège de France, 2006, p. 9-32.

Delogu Daisy, «Armes, amours, écriture. Figures de l'écrivain dans le Méliador de Jean Froissart", Médiévales, 41, 2001, p. 133-148.

Dемвожsкi Peter F., "Meliador de Jean Froissart, son importance littéraire: le vrai dans la fiction ", Le roman chevaleresque tardif, dir. Jean-Philippe Beaulieu, Études françaises, 32:1, 1996, p. 7-19.

Dembowsкi Peter F., "Considérations sur Meliador", in Etudes de philologie romane et d'histoire littéraire offertes à Jules Horrent, dir. Jean-Marie d'Heur et Nicoletta Cherubini, Liège, 1980, p. 123-131.

Dembowski Peter F., Jean Froissart and his Meliador. Context, Craft, and Sense, Lexington, French Forum Publishers ( $"$ The Edward C. Armstrong Monographs on Medieval Literature», 2), 1983.

Deschaux Robert, «Le monde arthurien dans le Meliador de Froissart», Marche romane, 30, 1980, p. 63-67.

Diverres Armel Hugh, "The geography of Britain in Froissart's Meliador", in Medieval Miscellany Presented to Eugene Vinaver, Manchester, Manchester University Press, 1965, p. 97-112.

Diverres Armel Hugh, «Froissart's Meliador and Edward III's Policy towards Scotland», in Mélanges offerts à Rita Lejeune, Gembloux, Duculot, t. 2, 1969, p. 1399-1409.

Diverres Armel Hugh, "The Irish adventures in Froissart's Meliador», in Mélanges de langue et de littérature du Moyen Âge et de la Renaissance offerts à Jean Frappier, Genève, Droz, 1970, t. 1, p. 235-251.

Diverres Armel Hugh, "Les aventures galloises dans Meliador de Froissart», Marche romane, 30, 1980, p. 73-79.

Diverres Armel Hugh, "The two versions of Froissart's Meliador», in Studies in Medieval French Language and Literature presented to Brian Woledge in honour of his 80th Birthday, dir. Sally Burch North, Genève, Droz, 1988, p. 37-48. 
Harf-LAnCNer Laurence, "La chasse au blanc cerf dans le Méliador: Froissart et le mythe d'Actéon ", Marche romane, 30, 1980, p. 143-152.

Нuoт Sylvia, "Unruly bodies, unspeakable acts: Pierre de Béarn, Camel de Camois, and Actaeon in the writings of Jean Froissart", Exemplaria, 14:1, 2002, p. 79-98.

JoRDAN Leo, "Wallonismen und Franzismen im Méliador», Zeitschrift für romanische Philologie, 52, 1932, p. 732-757.

Kelly Douglas, "Analogie et anomalie dans la description de chevaliers: la diverse ordenance de Camel de Camois", in Façonner son personnage au Moyen Âge, dir. Chantal Connochie-Bourgne, Aix-en-Provence, Presses universitaires de Provence («Senefiance», 53), 2007, p. 145-155.

Kibler William W., "Sagremor dans le Méliador de Froissart», in "Si a parlé par moult ruiste vertu». Mélanges de littérature médiévale offerts à Jean Subrenat, dir. Jean Dufournet, Paris, Champion, 2000, p. 307-311.

LoDs Jeanne, "Amour de regard et amour de renommée dans le Méliador de Froissart", Bulletin bibliographique de la Société internationale arthurienne, 32, 1980, p. 231-249.

Lods Jeanne, "Les poésies de Wenceslas et le Méliador de Froissart», in Mélanges de langue et littérature françaises du Moyen Âge et de la Renaissance offerts à Monsieur Charles Foulon, professeur de langue et littérature françaises du Moyen Âge et de la Renaissance, par ses collègues, ses élèves et ses amis. Tome I, Rennes, Institut de français, Université de Haute-Bretagne, 1980, p. 205-216.

Malfait-Dohet Monique, "Biel et grant esploit d'armes" (v. 12770) dans le Meliador de Froissart", in Le monde des héros dans la culture médiévale, dir. Danielle Buschinger et Wolfgang Spiewok, Greifswald, Reineke-Verlag ( Wodan», 20), 1994, p. 171-180.

Menegaldo Silvère, "Amateurs et professionnels: la composition poétique selon le Meliador et les dits de Jean Froissart", Perspectives médiévales, 2006, p. 179-201.

Menegaldo Silvère, "L'exemple chevaleresque dans la poésie de Jean Froissart», $C R M, 6,1999$, en ligne: https://journals.openedition.org/crm/941?lang=en.

Schwarze Michael, "Vom Artushof nach Arkadien: das merveilleux in Jean Froissarts Meliador", in Das Wunderbare in der arthurischen Literatur. Probleme und Perspektiven, dir. Friedrich Wolfzettel, Tübingen, Max Niemeyer Verlag, 2003, p. 113-125.

Schwarze Michael, «L'anthropologie médiévale en transition. À propos du Méliador de Froissart", in Froissart dans sa forge. Actes du colloque réuni à Paris du 4 au 6 novembre 2004, dir. Odile Bombarde, Paris, Académie des inscriptions et belles-lettres; Collège de France, Diffusion De Boccard, 2006, p. 147-171.

TAYlor Jane H. M., "The lyric insertion : towards a functional model», in Courtly Literature: Culture and Context. Selected Papers from the 5th Triennial Congress 
of the International Courtly Literature Society, Dalfsen, The Netherlands, 9-16 August, 1986, dir. Keith Busby et Erik Kooper, Amsterdam; Philadelphia, Benjamins ("Utrecht Publications in General and Comparative Literature», 25), 1990, p. 539-548.

Victorin Patricia, "La rétro-écriture ou l'écriture de la nostalgie dans le roman arthurien tardif: Ysaïe le Triste, Le Conte du Papegau et Mélyador de Froissart", Arthurian Literature, 2013, p. 158-181.

Wolfzettel Friedrich, "La "modernité" du Meliador de Froissart: plaidoyer pour une revalorisation historique du dernier roman arthurien en vers", in Arturus Rex. Acta conventus Lovaniensis 1987, dir. Gilbert Tournoy, Willy Van Hoecke et Werner Verbeke, Louvain, Leuven University Press, t. 2, 1991, p. 376-387.

Zink Michel, "Agamanor peintre dans Meliador de Froissart», Bulletin bibliographique de la Société internationale arthurienne, 31, 1979, p. 316-317.

Zink Michel, «Les toiles d'Agamanor et les fresques de Lancelot », Littérature, 38, 1980 , p. 43-61.

ZInk Michel, Froissart et le temps, Paris, PUF («Moyen Âge»), 1998.

ZINK Michel, "Meliador and the Inception of a New Poetic Sensibility", in Froissart Across the Genres, dir. Donald Maddox et Sara Sturm-Maddox, Gainesville, University Press of Florida, 1998, p. 155-175.

\section{Sur Rigomer}

ArseneAu Isabelle, "Lancelot échevelé: la parodie dans Les Merveilles de Rigomer», Senefiance, 50, 2004, p. 9-21.

Boyd Matthieu William, The Source of Enchantment: 'The Marvels of Rigomer' ('Les Merveilles de Rigomer') and the Evolution of Celtic Influence on Medieval Francophone Storytelling, PhD thesis, Harvard University, 2011.

Carapezza Francesco, "Le Fragment de Turin de Rigomer: Nouvelles perspectives", Romania, 119:1-2 [473-474], 2001, p. 76-112.

Chênerie Marie-Luce, "Un Recueil arthurien de contes populaires au XIII $^{\mathrm{e}}$ siècle: les Merveilles de Rigomer", in Réception et identification du conte depuis le Moyen Âge. Actes du colloque de Toulouse, janvier 1986, dir. Michel Zink et Xavier Ravier, Toulouse, Université de Toulouse-Le Mirail («Travaux de l'Université de Toulouse-Le Mirail, série A», 41), 1987, p. 39-49.

Ferlampin-Acher Christine, "La Table Ronde dans Les Merveilles de Rigomer», CRM, 14, 2007, p. 49-59.

Grossel Marie-Geneviève, "Entre féérie et magie: la merveille dans Rigomer», in Die Welt der Feen im Mittelalter, dir. Danielle Buschinger et Wolfgang Spiewok, Greifswald, Reineke-Verlag, 1994, p. 81-100. 
InrING Peter, "Wunder zum Lachen. Die komische Entzauberung des arthurischen merveilleux in zwei altfranzösischen Versromanen des 13. Jahrhunderts: Meraugis de Portlesguez und Les merveilles de Rigomer", in Das Wunderbare in der arthurischen Literatur: Probleme und Perspektiven, dir. Friedrich Wolfzettel, Tübingen, Max Niemeyer Verlag, 2003, p. 175-191.

James-Raoul Danièle, "Monts et merveilles romanesques", in La Montagne dans le texte médiéval: entre mythe et réalité, dir. Danièle James-Raoul et Claude Thomasset, Paris, PUPS, 2000, p. 255-283.

Kelly Douglas, "Multiple quests in French verse romance: Merveilles de Rigomer and Claris et Laris», L'esprit créateur, 9, 1969, p. 257-266.

LACY Norris J., "Les Merveilles de Rigomer and the Esthetics of "Post-Chrétien" Romance», Arthurian Yearbook, 1993, 3, p. 77-90.

LAtimier Adeline, "Gauvain dans les Merveilles de Rigomer: définition de la mesure dans un roman arthurien tardif", in Le Personnage de Gauvain dans la littérature européenne du Moyen Âge. Actes du colloque international des 6, 7 et 8 mars 2014 à l'Université de Paris Est (Marne-la-Vallée), dir. Marie-Françoise Alamichel, Amiens, Presses du "Centre d'Études Médiévales de Picardie" ("Médiévales», 58), 2015, p. 187-198.

Latimier Adeline, «Les Merveilles de Rigomer: un "conte ridicule" ?», in Parodies courtoises, parodies de la courtoisie, dir. Margarida Madureira, Carlos Clamote Carreto et Ana Paiva Morais, Paris, Garnier («Rencontres»), 2016, p. 77-90.

Lecco Margherita, Saggi sul romanzo del XIII secolo (Jaufré, Merveilles de Rigomer, Joufroi de Poitiers, Wistasse le Moine, Sir Orfeo, Lai du Trot), Alessandria, Edizioni dell'Orso ("Studi e ricerche», 37), 2003.

Lecco Margherita, Le meraviglie di Rigomer. Tradizione manoscritta e tradizione narrativa, Alessandria, Edizione dell'Orso, 2013.

Lecco Margherita, «L'avventura prima di mangiare. Una convenzione del romanzo arturiano ", Medievalia, 46, 2014, p. 43-52.

López Martínez-Morás Santiago, "Los tres héroes de Les Merveilles de Rigomer", in Iucundi acti labores. Estudios en Homenaje a Dulce Estefanía Álvarez, dir. Teresa Amado Rodríguez et al., Santiago de Compostela, 2004, p. 328-334.

Micha Alexandra, "Merveilles de Rigomer», in Dictionnaire des lettres françaises. Le Moyen Age, dir. Georges Grente et al., Paris, Fayard, 1964, p. 509-510.

Noble Peter S., "Le Comique dans Les Merveilles de Rigomer et Hunbaut», Arthurian Literature, 19, 2003, p. 77-86.

Noble Peter, "The Role of Lorie in Les Merveilles de Rigomer", Bulletin bibliographique de la Société Internationale Arthurienne, 48, 1996, p. 283-90.

O'Sullivan Daniel E., "Les Merveilles de Rigomer's Apocalyptic Geography», Medieval Perspectives, 12, 1997, p. 110-22. 
Rupp, Theodore Hanna, The Influence of Chrétien de Troyes on Jehan's "Les Mervelles de Rigomer", Ph.D., University of Pennsylvania, Philadelphia, 1954.

Thomas Neil, "The Secularisation of Myth: Les Merveilles de Rigomer as a Contrafactura of the French Grail Romances", in Myth and Its Legacy in European Literature, Durham, University of Durham, 1996, p. 159-169.

Trachsler Richard, "Lancelot aux fourneaux: des éléments de parodie dans Les Merveilles de Rigomer?", Vox Romanica: Annales Helvetici Explorandis Linguis Romanicis Destinati, 52, 1993, p. 180-93.

Vesce Thomas Eugene, "Les Merveilles de Rigomer", Chantilly, Musée Condé Manuscript 472 (626), Ph.D., Fordham University, New York, 1967.

Vesce, Thomas Eugene, "Celtic material in Les Merveilles de Rigomer", Romance Notes, $11: 3,1970$, p. 640-646.

Walters Lori, "Rigomer", in The Arthur of the French. The Arthurian Legend in Medieval French and Occitan Literature, dir. Glyn S. Burgess et Karen Pratt, Cardiff, University of Wales Press, ("Arthurian Literature in the Middle Ages", IV), 2006, p. 437-439. 
$\frac{\tilde{N}}{\frac{0}{J}}$

ᄃ

픅

픔

들

(1)

풀

ฮํ

(1)

다

ข)

듬

이

ฮิ

브

능 


\section{INDEX}

Cet index n'est pas exhaustif, mais recense uniquement les passages significatifs qui concernent les œuvres ou les personnages, et non l'ensemble de ces mentions.

\section{INDEX NOMINUM}

Aliénor de Castille 23, 147, 395 Benoît de Sainte-Maure 125, 354 Blanche de Navarre 44-45, 47, 86, 155,346

Chrétien de Troyes 12-15, 25, 35, $58,60,61,64,69,76,78,80$, $95,111,122,127-128,131,132$ 149, 161-162, 176-177, 184, 186-188, 201, 209-212, 214, 223 224, 231, 242, 244, 255, 257 , 281, 283, 289, 291, 310, 319, 334-339, 347, 348, 382-385, 399, 401-402, 404, 405-406, 410, 418419, 421, 434, 436, 448, 469, 472, 474, 493-494, 497, 511, 518, 521, 532, 554, 560, 582, 586-587, 611, 624, 632, 637-639

Gautier Map 127, 148

Gerbert de Montreuil 44, 302, 477, 489

Girart d'Amiens 23-24, 130, 147-149, 240-241, 284-285, 291-292, 297. $331,335,366,380,396,437$, 443, 445, 463-465, 468, 470-473, 475, 489-490, 494, 512, 515, 536, 538-539, 541, 543, 545-546, 551, 570, 580, 599, 604, 609-610, 635-636, 638
Guillaume de Machaut 189, 240, 340

Guillaume le clerc 42, 69

Hélie de Boron 148-149

Huon de Méry 28, 184-189

Jean Bodel 50, 169-171, 558, 572

Jean de Garlande 41, 112, 116, 156$157,160-161$

Jean Froissart 24, 39, 89, 163, 174$175,253,255,267,311,312$, 332, 335, 337, 338, 341, 365-366, 369-372, 377-379, 384-385, 396, 460-461, 494, 500, 544, 547-549, $551,556-557,634,636,638$

Luce del Gat 148

Marie de Champagne 147

Marie de France 62, 82, 163

Philippe de Mézières 45-46, 629

Pierre Sala 17, 344, 348-349, 385

Raoul de Houdenc 14, 53-54, 69, 186, 189, 387, 638

Renaut de Beaujeu 14, 69, 403$404,587,638$

Robert de Blois 20-23, 55-57, 128, 138, 184, 240-241, 320, 617629, 638-639

Sarrasin 28, 35, 202-203

Thomas de Saluces 89, 345

Wace 98-99, 111, 117-118, 122, 244, 257, 259, 438, 587 


\section{GUVRES}

N. B.: les ceuvres du corpus principal (Biaudouz, Claris et Laris, Floriant et Florete, Escanor, Melyador, Rigomer) étant traitées par l'ensemble de l'étude, elles ne figurent pas dans cet index.

Ami et Amile 96-97, 343, Arthur et Gorlagon 81-83

Artus de Bretagne 27, 203, 248-249, 251, 279, 320-321, 462, 552 Atre Périlleux 14, 58-61, 285, 383, 385, 394, 489, 510, 538, 550, Bataille Loquifer 28, 116, 169, 184, 190-195

Benoît de Sainte-Maure, Roman de Troie 61, 91, 125, 154, 241, 264, 559, 565, 568-569

Blandin de Cornonailles 28, 217-230, 461-462, 604

Brun de la Montagne 28, 100-108

Chanson de Roland 115, 191, 431, 433, 485, 576, 583-584, 588, 629

Chevalier à l'épée 109, 280, 285

Chevalier qui la nef maine 329-331, 333, 396, 408-417

Chrétien de Troyes, Cligès 210-211, 262-263, 290, 401-402, 434, 575, 626, 638

Chrétien de Troyes, Erec et Enide 48, 58, 60, 76, 80, 83, 127-128, 131, 142, 174, 199, 215, 223-224, 244, 262, 303, 305, 339, 401, 402, 405, 408-410, 417, 419, 434, 440, 550, 585, 638

Chronique du Pseudo-Turpin 86-89, 387

Conte du Papegau 417-425, 454, 566567

Continuations du Conte du graal 58, 63, 161, 167, 211, 286, 302-303, 304, 306, 382, 386, 393-394, 449-450, 489

Coudrette, Mélusine 348-361
Cristal et Clarie 11, 76-77, 217, 584585

Dame a la lycorne 346-361

De ortu Walunanii, nepotis Arturi 81-83

Eledus et Serene 347-361

Gormont et Isembart 97

Guiron le courtois 17, 26, 251, 254, 260, 389-390, 481, 505, $507-$ 508,511

Historia Meriadoci 81-83

Hunbaut 14, 58-60, 76, 176, 215, 280-281, 285-286, 432, 553, 614, 638

Huon de Méry, Tournoi de l'Antéchrist 185-189

Jaufré 382-383, 393

Jean Bodel, Chanson des Saxons 50, 169-171

Jean Froissart, Chroniques 88-89, 369-370

Jean Froissart, Dit dou Florin 369370, 384

Jean Maillart, Roman du Comte d'Anjou 47, 91-92, 116, 346-361

Jean Renart, Roman de la Rose 61, 361, 624

Lai d'A ristote 52, 57

Lai de Mélion 61, 82, 109, 384, 387

Lai de Narcisse 52-53

Lai du Cor 94, 109, 158

Lai du Mantel 109, 158, 403, 406-407

Lancelot en prose 25, 46, 78, 102, 111, 148-149, 200, 249, 253-255, 260, 263, 281-282, 291, 308, 314-315, 322, 324, 332, 389, 402, 405, 417, 435-436, 445, 448-450, 458, 495, 497, 508, $514,529,533-534,548-549,551$

Lion de Bourges 96-97, 190, 204

Livre d'Artus 26, 198, 251, 309, 435, $454,547-551$

Meliadus 26, 165-166, 250-251, 254 , 271, 381-382, 435, 454, 473, $477,491-492,511$ 
Mort Artu 26, 236, 243, 249, 259260, 266, 283, 294, 304-308, 389, 407, 421, 459, 462, 464, $540,546,548,575,597,606-$ 607,632

Mule sans frein 109, 285, 611

Perceforest 27, 221, 223, 237, 251, 321, 462, 552

Philippe Mousket, Chronique rimée 92

Pierre de Beauvais, Bestiaire 87

Pierre Sala, Le Chevalier au lion 17, 344, 348-349, 385

Prophéties de Merlin 254, 548

Pyrame et Tisbé 134, 357

Queste del Saint Graal 26, 58, 127, 159, 271, 283, 298, 313-319, 389, 402, 450, 481, 507, 518, 595, 597-599, 607-609, 625

Raoul de Houdenc, Mérangis de Portlesguez 61, 185, 302, 383, 384, 385, 387, 393, 534, 637

Raoul de Houdenc, Vengeance Raguidel 58, 59, 60, 77, 161, 215, 270, 280, 285, 446, 550-551

Robert de Blois, Floris et Lyriopé 184185,617

Roman de Renart 50, 58, 63-65, 558, 610-617

Roman de Silence 301

Roman de Thèbes 61, 272, 384, 387, 559, 560-562, 566-567

Roman du Hem 28, 133, 144, 202-203

Sone de Nansay 200-201, 462

Tristan en prose 17, 26, 46, 225, 249, 255, 283, 289, 292-298, 302$303,324,327,361,363,365-$ 366, 373, 375, 382, 389-390, 402, 407, 435, 441, 454-455, 458, 468, 491, 505, 526, 531532, 537, 546, 554, 640

Vera historia de morte Arturi 81-83

Wace, Roman de Brut 62, 117-118, 121-122, 124, 196, 250, 257259, 266, 386, 434, 438, 575, $578,587,594$
Wace, Roman de Rou 98-100, 118, 354

Wirnt von Grafenberg, Wigalois 403 , 418, 420-421

Ysaïe le Triste 27, 251, 321, 381, 552, 557

\section{MANUSCRITS}

Les annexes fournissent également des renseignements sur certains manuscrits, en particulier l'annexe $C$.

Aberystwyth, National Library 444D : 402

Bern, Burgerbibliothek 113: 58, 63

BnF fr. 112: 389, 390

BnF fr. 353: 384

BnF fr. 794: 58, 61

BnF fr. 1433: 61, 383-386, 391

BnF fr. 1447 : 18, 383, 391-392, 592594

BnF fr. 1450: 58, 61, 121-122, 434

BnF fr. 1492: 408

BnF fr. 1493: 408

BnF fr. 2170: 106

BnF fr. 2236: 23, 617

BnF fr. 12557: 24, 255, 386, 392, 396

BnF fr. $12560: 61,393$

BnF fr. 12576: 58, 393

BnF fr. 12603: 61, 383-386, 393

BnF fr. 24301 : 21-23, 55, 138, $617-$ 629, Annexe D

BnF fr. 24374: 23, 61, 367, 392, 603

BnF nouv. acq. fr. 1104: 57

BnF nouv. acq. fr. 5386: 383

Chantilly, Condé 472: 19-20, 58, 60, 63-65, 70, 76, 198, 290, 396, 452, 528, 553-554, 611, 614

New York, Public Library, De Ricci 122: 19, 383, 386, 391, 393

Turin, L IV 33 : 20, 61, 189, 384, 386-389, 402, 452, 527 
Vatican, Regina Latina 1725: 61, 383, 385-386

Vienne, ÖNB 2599: 383, 386, 391, 393

\section{PERSONNAGES}

Agravain 253, 304-306, 313, 528530

Arthur 11, 45, 49, 71, 77, 82, 103104, 117-118, 121-124, 139, 172, 181-185, 189, 190-195, 199-200, 202, 213, 217, 230, 236, 243, 249, 251-252, $257-$ 259, 262, 264, 265-266, 272, 273-274, 281-282, 300, 304, $311,387,407,417-423,428-$ 463, 466, 490, 491, 493, 527, $535,546,551,576-578,622-$ 623, 626, 629

Brun sans Pitié /Brehus sans Pitié 297-298, 473, 491, 513, 536

Camel de Camois 79, 374, 379, 460-461, 477-480, 483-484, 491492, 496, 501-502, 516, 535, 555

Cligès 45-46, 77-78, 185, 210-211, 263, 290, 350, 452, 482

Dinadan 225, 292-298, 304, 307, $468,486,512-513,532,535-536$

Dodinel 303-304

Erec 59, 206, 257, 281, 283, 290, 405

Galaad 200, 271, 299, 302, 317, 318, $481,597,626$

Galantinet 284-285, 366-368, 445446, 487-489, 512, 541, 543, 605

Gauvain 64-65, 76-77, 82-83, 181, 198, 214-215, 249, 264, 274, 279-291, 302, 313-315, 317-319, 366-367, 440-441, 443, 445-447, 449-450, 453, 458-459, 460, 465, 467-468, 480, 482-483, 485-490,
505-509, 513-515, 533, 537-543, $545,550-551,565-566,607$

Gifflet 147-148, 257, 275, 291, 302, 308, 430, 476, 512-513, 516, 537, 541-542, 592, 605, 609-610

Guenièvre 11, 76, 181, 197, 202-203, 249, 282, 304-305, 309, 407, 432, $451,457,458,532-533,607,631$

Keu 158, 181, 185-187, 197, 202203, 209, 254, 275, 285, 291, 294-295, 307, 313, 405, 428, 441-447, 463-477, 484, 489, 490, $512,514-519,535-536,542,586-$ $587,592,610,616$

Lancelot 47, 59, 78, 198, 203, 247 248, 254, 263, 271, 282, 289-292, 302, 304-305, 316-318, 322-324, 335, 405-407, 448-451, 455-458, 460, 480, 482, 504-505, 508, 522-523, 527, 532-534, 597, 607, 612-617, 631-632

Merlin 146, 252, 279, 298-303, 313, 456-457, 548-549, 632

Mordred 141-142, 259, 279, 282, 294-295, 297, 305-308, 464, 512, 535-536, 549, 632

Morgane 190-195, 262-263, 265266, 272, 322-324, 406-407, $410,549,561-562,565,632$

Perceval 35, 45-47, 58, 91, 116, 181, 185, 187, 194, 203, 254, 257, 289-291, 309, 311, 350, 395, 406, 460, 465-466, 496497, 613, 618, 623

Sagremor 79, 254-256, 257, 308313, 321, 373-375, 378, 448, 451, 480, 517, 544, 547-549, 576,633

Soredamor 202, 210

Tristan 47, 50, 91, 116, 203, 249, 251, 254, 289, 296, 302, 441, 454, 460, 478, 483, 491, 530, 532, 546, 562 
NOTIONS THÉORIQUES Littérarité 34-38

Lyrique 362

Les numéros de page signalent le lieu de l'étude où est définie la notion théorique.

Anachronisme 15-16

Archétype 444-445, 459-463

Canon 175-180

Chronotope 169-170, 246-247

Confluence 557-558

Contrepartie 123-125

Ekphrasis 559-561

Entrelacement 496-500

Exotisme 115

Fiction 112-114

Genre littéraire 66-80

Horizon d'attente 74-80

Implicitation 584-585

Insertion lyrique 361-365

Intertextualité 19
Matière 159-173

Mise en prose 398-401

Monde possible 79

Narcose 248

Paralittérature 232-234

Parodie 76

Patron générique exportable 574-575

Poème en prose 7-9

Précurseur 14-15

Récit étiologique 536-537

Registre 157-158

Style 156-157

Tardivité /tardif 14-16

Tension narrative 366-367, 505, 514

Transfictionnalité 196-199

Univers de fiction 165-166, 170, 197 198, 246-248 
$\frac{\tilde{N}}{\frac{0}{J}}$

음

들

(1)

五

ํㅗ

ย

बั

등

이

ฮิ

브

는 


\section{TABLE DES MATIÈRES}

INTRODUCTION. ..................... 7

Chapitre premier

CHOIX DE FORME, CONSÉQUENCES GÉNÉRIQUES. . 31

Une théorie des genres pour le Moyen Âge?.......... . 32

Pertinence de la notion de genre . . . . . . . . . . . 32

Témoignages individuels et traités latins. . . . . . . . 40

Désignations - Autodésignations . . . . . . . . 42

Mises en recueil ..................... 57

Définition du concept de genre. . . . . . . . . . . 66

Horizon d'attente ....................... 74

Critères de la généricité médiévale. . . . . . . . . . 80

Genre et forme. . . . . . . . . . . . . . . . 81

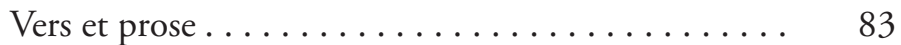

Mètre ....................... 93

Brun de la Montagne. . . . . . . . . . . . . . . 100

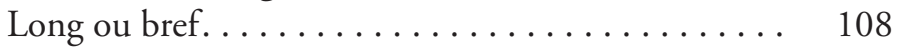

Historia et fabula ....................... 112

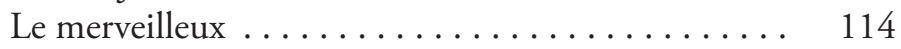

Histoire, mythe, fiction. . . . . . . . . . . . . 117

Le travail des sources. . . . . . . . . . . . . . . . 125

Fictions assumées . . . . . . . . . . . . . . . . . . . . . 129

Genre et narrateur . . . . . . . . . . . . . . . . . 142

Registre . . . . . . . . . . . . . . . . . . . . 155

Genre et matière ... . . . . . . . . . . . . . . . . 159

Le roman arthurien en vers. . . . . . . . . . . . . . . 174

Définition du canon . . . . . . . . . . . . . . . . . . . . . . 175

Voyages génériques du roi Arthur. . . . . . . . . . 182

Le Tournoi de l'Antéchris: Arthur allégorisé . ...... 185

Arthur en Avalon: la Bataille Loquifer. . . . . . . . . . . 190

Transfictionnalité et genre ................. 196 
L'errance aventureuse . . . . . . . . . . . . . . . . 205

Blandin de Cornouailles: errer sans Arthur, errer

sans quête..................... 217

Romans en «décadence»: paralittérarité du corpus tardif . . 230

Chapitre II

LES DERNIERS VERS : ÉCRIRE EN VERS

APRÈS LA PROSE ......................... 239

De la prose au vers..................... 242

Choix de forme, choix de chronotope............ 242

Temps linéaire - temps circulaire ........... 250

Expansion géographique et référentialité de l'espace. . . . 260

Gauvain, emblème du vers. . . . . . . . . . . . . . . 279

Tristan, Lancelot, Perceval: emblèmes de la prose?. . . . 289

Le Graal versus la féerie . . . . . . . . . . . . . . 313

Choix de forme, choix de style . . . . . . . . . . . 325

Destin du vers .......................... 339

Le vers narratif au XIv siècle . . . . . . . . . . . . 340

Une spécialisation lyrique du vers: les insertions

d'Escanor et Melyador ..................... 361

Lire le roman arthurien à la fin du Moyen Âge . . . . . . . . 381

... du vers à la prose: survivance du genre . . . . . . . . . . . . . 397

Les mises en prose arthuriennes. . . . . . . . . . . . . . 398

Le Conte du Papegau entre vers et prose. . . . . . . . . . . . 417

Chapitre III

TRAJECTOIRE DU ROMAN TARDIF . . . . . . . . . 427

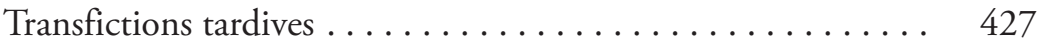

Arthur chef de guerre, Arthur errant . . . . . . . . . 428

Dux bellorum .................... 428

Arthur facétieux. . . . . . . . . . . . . . . . . 439

Égarements de la figure royale: l'univers en perte

de maitrise. . . . . . . . . . . . . . . . . . . . 445

Égarements de la figure royale: errance d'Arthur .... . . 452

De l'archétype au personnage. . . . . . . . . . . . . 459

Keu courtois, preux et amant: décalage transfictionnel .... 463

Typologie du personnage arthurien tardif . . . . . . . . 474

Le héros : problèmes de désignation ............ 474

Un manichéisme relatif . . . . . . . . . . . . . 482 
Structures arthuriennes: imiter la prose ........... 493

Entrelacer les aventures . . . . . . . . . . . . . . . 495

Faire court dans un récit long . . . . . . . . . . . 519

Prétendre à l'explicite et à l'exhaustivité. . . . . . . . . . . . 531

Confluences: un mélange des genres? .............. 554

Réécriture d'un topos allogène: l'ekphrasis........... . 559

Adoption de "patrons génériques exportables»:

l'épopée arthurienne ................... 572

Imitation ponctuelle: Escanor et le miraculeux ....... 595

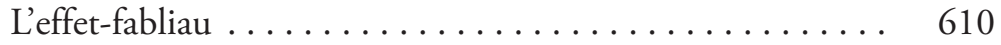

Un récit encadrant: Biaudouz et le didactisme. ........ 617

Conclusion

AUTOPSIE D'UNE FORME $\ldots \ldots \ldots \ldots \ldots \ldots \ldots \ldots . \ldots 31$

\section{ANNEXES}

Annexe A: romans arthuriens en vers tardifs. . . . . . . . 643

Annexe B: insertion lyrique dans Escanor ........... 646

Annexe $\mathrm{C}$ : diffusion du roman arthurien en vers après le XIII ${ }^{\mathrm{e}}$ siècle . . . . . . . . . . . . . . . . . . . . . 647

Annexe D: le manuscrit BnF fr. $24301 \ldots \ldots \ldots \ldots \ldots 64$

BIBLIOGRAPHIE. . . . . . . . . . . . . . . . . . . 657

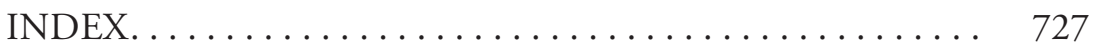


Mise en pages:

Atelier Perrin

CH-2014 Bôle (NE)

Mai 2021 